\title{
Basalt - fluid interactions at subcritical and supercritical conditions: An experimental study
}

\author{
By \\ Mauro Passarella
}

\begin{abstract}
A thesis
submitted to the Victoria University of Wellington

in partial fulfillment of the requirements for the degree of

Doctor of Philosophy
\end{abstract}

School of Geography, Environment and Earth Sciences

Victoria University of Wellington

Wellington, New Zealand 


\section{Abstract}

To investigate the interaction between fluids and basalt at subcritical, near-supercritical, and supercritical hydrothermal conditions $\left(350-400^{\circ} \mathrm{C} / 500 \mathrm{bar}\right)$, eight experiments have been conducted. These used a continuous-flow, high temperature and pressure hydrothermal apparatus. The basalt was reacted with three fluids: distilled water; geothermal brine; and natural seawater. Two further experiments used only seawater as a control to determine its behaviour without the influence of basalt.

With distilled water, the fluid chemistry results show elevated $\mathrm{SiO}_{2}, \mathrm{~K}, \mathrm{Cl}, \mathrm{SO}_{4}$, and $\mathrm{H}_{2} \mathrm{~S}$ in solution for the first 12 days of both experiments. This is due to volcanic glass dissolution. After glass was removed, fluid composition was controlled by the remaining rock minerals. At $400^{\circ} \mathrm{C}$, the secondary mineral assemblage at the bottom of the Reactor (fluid entry point) is composed of grossular, wollastonite, anorthite, and chlorite. These results show the effectiveness of distilled water, which lacks any alkali cations, at removing $\mathrm{Na}$ and $\mathrm{K}$ rapidly from the rock. At the top of the Reactor (fluid exit point) the secondary minerals are anorthite and celadonite. At $350^{\circ} \mathrm{C}$, the secondary mineral assemblage at the bottom is anorthite and chlorite, while celadonite is the dominant secondary mineral at the top. In both experiments, celadonite replaces solely olivine. The formation of celadonite through reaction with distilled water shows that it can be formed by the interaction of deuteric water and basalt without addition of other components.

The geothermal brine contains high concentrations of $\mathrm{SiO}_{2}, \mathrm{~K}, \mathrm{SO}_{4}, \mathrm{Na}, \mathrm{Cl}$ and has an acidic $\mathrm{pH}$. At $400^{\circ} \mathrm{C}$, fluid chemistry displays elevated $\mathrm{SiO}_{2}$ concentrations for approximately two weeks due to glass dissolution. At $350^{\circ} \mathrm{C}, \mathrm{SiO}_{2}$ concentration is initially high after temperature increase, but decreases gradually over the remainder of the experiment. At $400^{\circ} \mathrm{C}$, the secondary mineral assemblage at the bottom of the Reactor is composed of anhydrite and biotite, while at the top of the Reactor, smectite is the only secondary mineral. At $350^{\circ} \mathrm{C}$, anhydrite and smectite are found at the bottom, while only smectite is found at the top. The lack of biotite at $350^{\circ} \mathrm{C}$ suggests this mineral's precipitation kinetics are too slow to outcompete chlorite precipitation.

The seawater-only experiments were conducted as controls to determine its behaviour during heat-up and provide the input solution composition for the seawater-basalt experiments. Both seawater-only experiments $\left(377^{\circ} \mathrm{C}\right.$ and $\left.342^{\circ} \mathrm{C}\right)$ show the precipitation of anhydrite, caminite and brucite due to their retrograde solubilities. The effluent solutions are greatly depleted in $\mathrm{Ca}$, 
$\mathrm{Mg}$ and $\mathrm{SO}_{4}$.

In the seawater-basalt experiments at near-supercritical $\left(400^{\circ} \mathrm{C}\right)$ and subcritical conditions $\left(350^{\circ} \mathrm{C}\right)$, elevated $\mathrm{SiO}_{2}$ concentrations due to glass dissolution are not observed. This is attributed to rapid secondary mineral precipitation. Fluid chemistry and mass balance calculations show almost complete removal of $\mathrm{SO}_{4}$, and in particular, $\mathrm{Mg}$, from the seawater while Ca shows a considerable loss from the rock. Three mineralization fronts were identified: (1) glass dissolution; (2) chloritization; and (3) anhydrite precipitation. In both experiments, there is a switch from chloritization to smectitization. This is accompanied by a decrease in $\mathrm{Mg} / \mathrm{Fe}$ ratio in smectite. This mineral was also found at the top of both experiments, but its composition was more reflective of the rock.

In terms of reactivity, the order of phases from most to least reactive is glass - olivine clinopyroxene - plagioclase - Fe-Ti oxide. For the aluminosilicate phases this is attributed their respective $\mathrm{Al}$ contents. The seawater-basalt experiments also emphasise the fast rate of reaction at which $\mathrm{Mg}$ is fixed by the rock, which is conjectured to take less than a few hours.

Considering all experiments, the distilled water results show a rock control on fluid chemistry while in the remaining basalt experiments, the chemistry is largely controlled by the fluid.

Temperatures calculated using standard $\mathrm{Na} / \mathrm{K}$ geothermometer did not estimate, in most cases, values close to the experimental temperature. This is due to the inability of the rock to sufficiently adjust the $\mathrm{Na} / \mathrm{K}$ ratio given the secondary mineral assemblages that form. 


\section{Dedication}

This thesis is dedicated to my parents and sister. My father, Riccardo, passed away on February $11^{\text {th }} 2019$ during the last year of my Doctoral studies. He cannot physically enjoy this special moment with us, but I am sure he is rejoicing next to me. My mother, Enrichetta, is the best and strongest woman that I know. She is my example of strength, courage and initiative. And my sister, Martina, one of the most intelligent and thoughtful persons, with whom I grew up. 


\section{Acknowledgements}

I want to express my greatest thanks to my supervisor Dr. Bruce W. Mountain who during my PhD has intellectually formed the person I am now. Thank you, Bruce, for believing in me from the beginning despite the long and hard path that I had before me. Thanks for your support in completing this thesis and for the extraordinary facilities you made available to me at the Department of Geothermal Science, GNS.

I also want to say thanks to Dr. Greg Bignall, Head of Department when I arrived at GNS Science. Greg you invested time and money on me during my first eight months in New Zealand while I was preparing for my English exam. Thanks for having believed so much in me. Also, a warm thanks to your wife, Aki, for her support and information on English instruction.

A special thanks to Prof. Terry Seward for being extremely supportive and encouraging during my doctorate. Thank you so much Terry for taking care of my situation at the University after leaving New Zealand. Without your help many things would have been much more difficult.

Thanks to Dr. Isabelle Chambefort who gave me a great support and advice regarding petrological studies. Thanks, Isabelle, for all the time spent with me on the SEM but especially for making EMPA analyses possible at Oregon State University, USA.

Thanks to Stefan and Dr. Ed Mroczek whom invested a considerable amount of their working time in developing the EqSolvR program for my data interpretation. Thanks, Ed, for your availability at GNS and valuable advice during my entire Ph.D.

A heartfelt thanks to Andrea (Andy) Blair. Andrea you have been my rock when I first arrived in New Zealand. You provided me with a place to live for the first three years of my Ph.D. Thanks to you, your mom Catherine and your father Tony, as well as to your sister Melanie and her husband, for all the help and support I received during my time in New Zealand. Thanks to all of you guys. I felt part of a big KIWI family.

An enormous thanks to all those people at GNS whom helped me "behind the scenes". These are the laboratory, IT, and operation technicians who assisted me and were an essential resource during my stay at the Department of Geothermal Sciences. These include: Moya Appleby; Chris Ferguson; Dr. Debra Chappell; Ann Noddings; Judy Gillespie; Lea Henderson; Dr. Worku Gobeze; Manoj Kesavan; the laboratory manager, Stuart Sanderson; the unforgettable Colette 
Dedual; senior systems engineer, Steve Lawson; IT support analysts, Absalom Ander and Duncan White; operations technician, Cameron Asher; geothermal field technician, Thomas Brakenrig; and the supervisor of mechanical and electric workshops, Stephen Mawdesley. Stephen built the special equipment hydrothermal pressure vessel that I used during my laboratory work, without which I would not have been able to complete the most interesting experiment of my doctorate. Thanks, Stephen, for your patience and support in adjusting, developing and providing material for the Experimental Geochemistry Laboratory. Thanks to my italian colleague and Analytical Facility Manager at Edith Cowan University in Perth, Australia, Dr. Francesco Busetti, for the trace elements analyses.

Obviously, a special thanks to Natalie and Stuart, my neighbours and owners of my last home in New Zealand. Thanks, guys, for your hospitality and fun with your lovely daughter Hazel during my last year and a half in Acacia Bay. But especially thanks guys for having been so understanding and extremely generous with me during my difficult family issues.

Finally, I want to express my most important thanks to all of my colleagues and friends in New Zealand whom have supported me with loving words and thoughts during the difficult times for me and my family. Your support means a lot to us. I hope one day of being able to express personally my most sincere gratitude to all of you. 


\section{Table of contents}

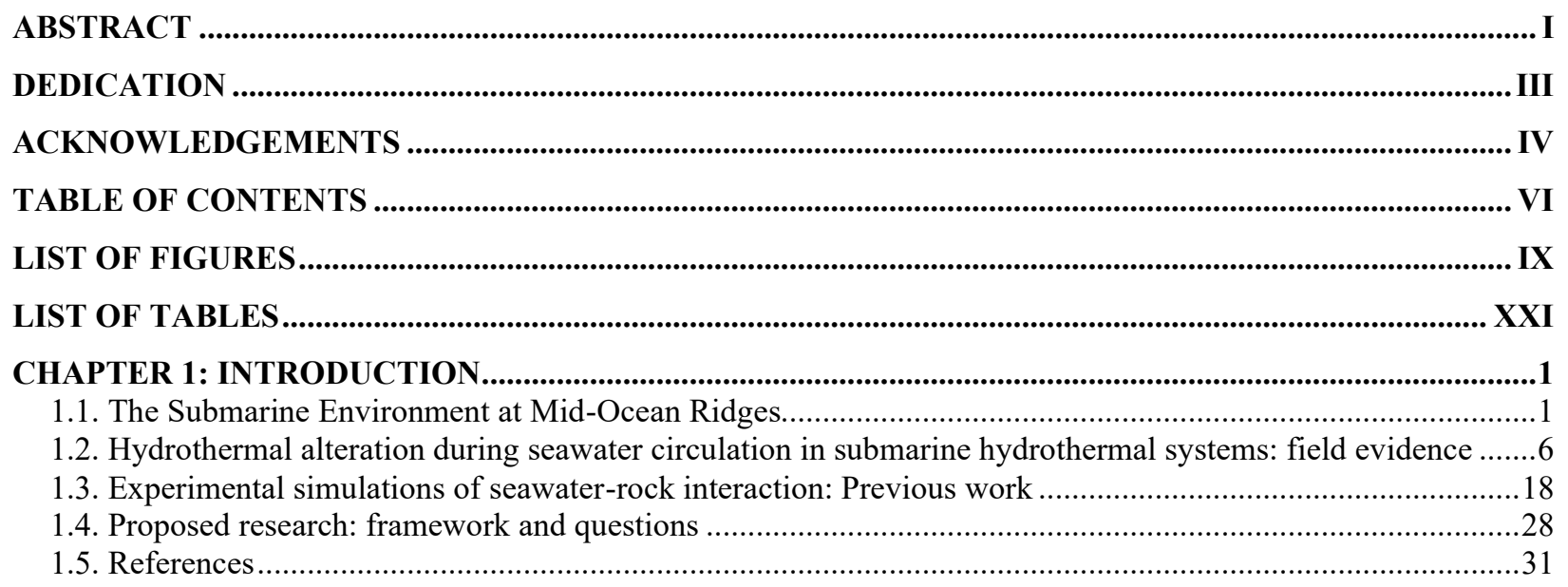

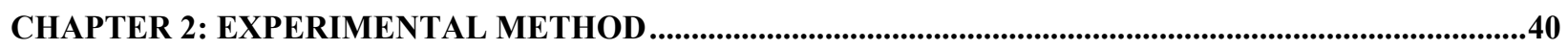

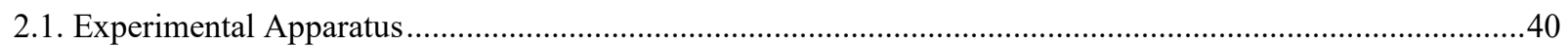

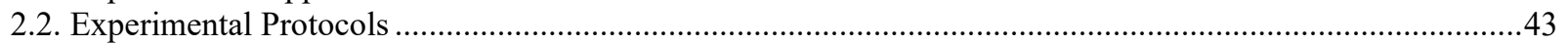

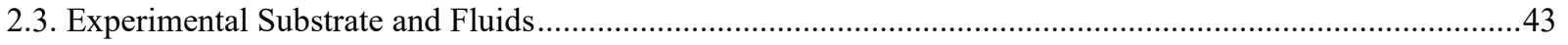

2.3.1. Unreacted basalt: mineralogy, texture and mineral chemistry ................................................................ 43

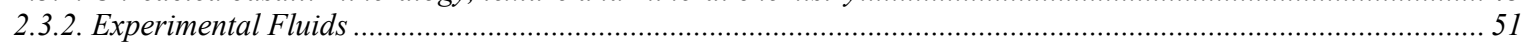

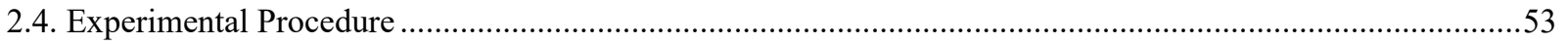

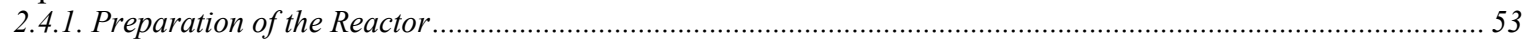

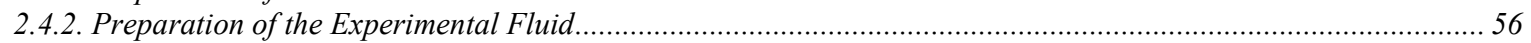

2.4.3. The Back-pressure Regulator and Temperature Control............................................................................. 59

2.4.4. Experimental Set-up: Water and Geothermal Brine.............................................................................. 60

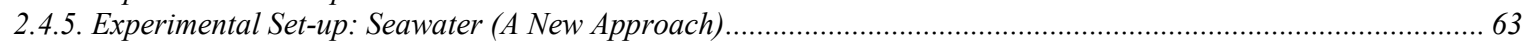

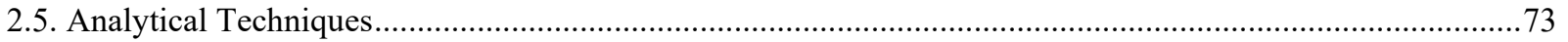

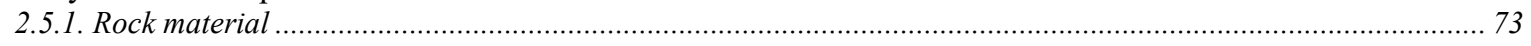

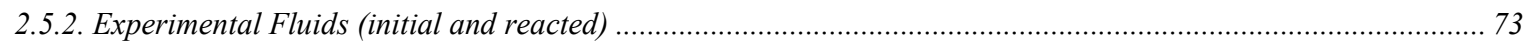

2.6. Determination of experimental $\mathrm{pH}$ and solute speciation at high temperature and pressure conditions (325-

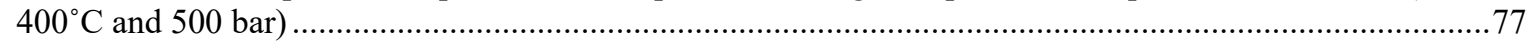

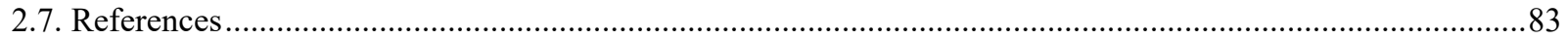

CHAPTER 3: BASALT - WATER INTERACTIONS UNDER HYDROTHERMAL CONDITIONS .............85

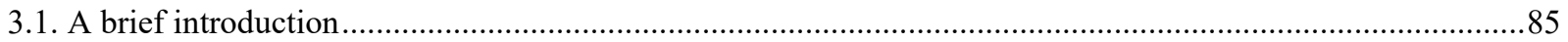

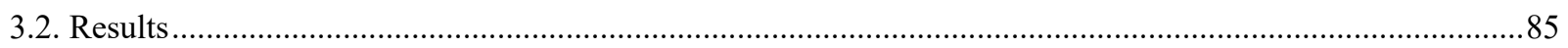

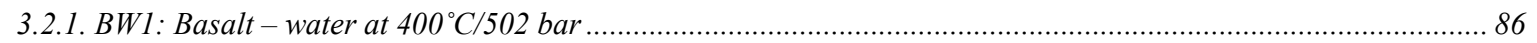

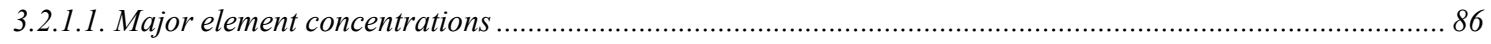

3.2.1.2. Trace element concentrations ............................................................................................................. 90

3.2.1.3. Mineralogy and Texture of Reacted Basalt: Bottom of the Reactor (Portion 1) ............................................ 93

3.2.1.4. Mineralogy and Texture of Reacted Basalt: Top of the Reactor (Portion 2) ............................................. 101

3.2.1.5. Mineralogy and Texture of Reacted Basalt: Basalt Block ...................................................................... 106

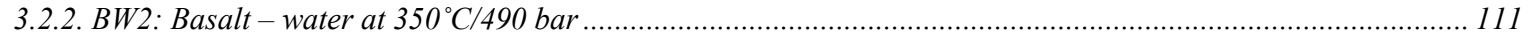

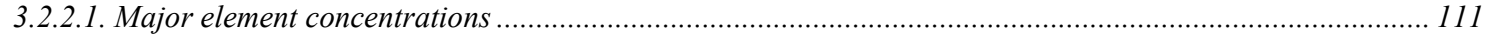

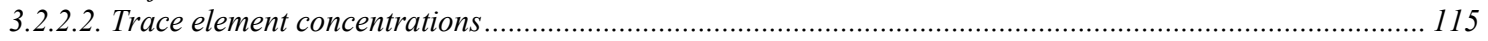

3.2.2.3. Mineralogy and Texture of Reacted Basalt: Bottom of the Reactor (Portion 1) ……................................. 118

3.2.2.4. Mineralogy and Texture of Reacted Basalt: Top of the Reactor (Portion 2) ............................................ 122

3.2.2.5. Mineralogy and Texture of Reacted Basalt: Basalt Block .................................................................... 126

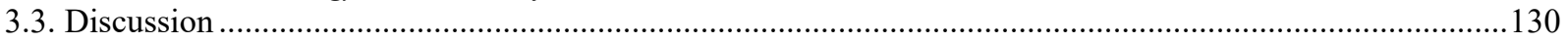

3.3.1. Major and trace element exchange during water - rock interaction ……………...................................... 130

3.3.2. The path of fluid-rock interaction .................................................................................................... 141

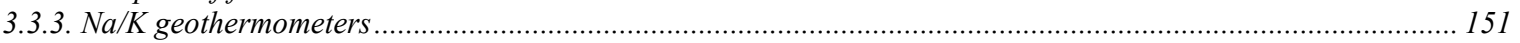

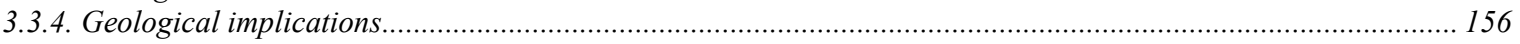

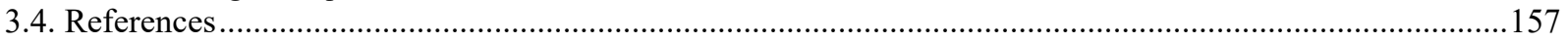


CHAPTER 4: BASALT - GEOTHERMAL BRINE INTERACTIONS UNDER HYDROTHERMAL

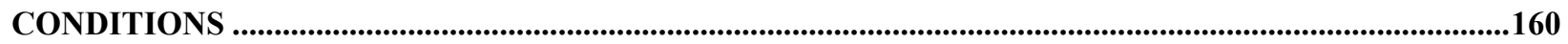

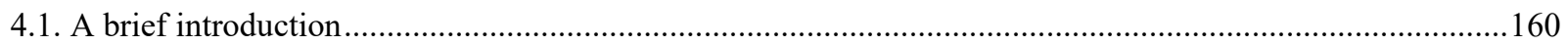

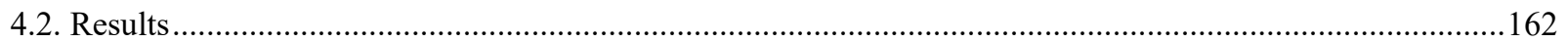

4.2.1. BGB1: Basalt - Geothermal brine at $400^{\circ} \mathrm{C} / 483$ bar …………………………................................. 162

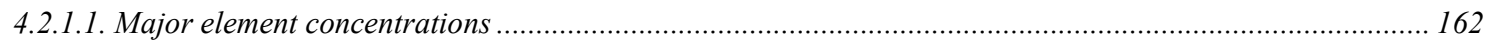

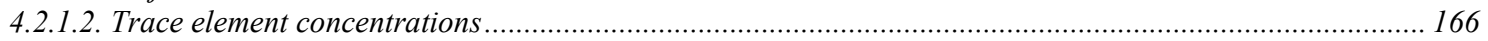

4.2.1.3. Mineralogy and texture of reacted basalt: Bottom of Reactor (Portion 1) .............................................. 169

4.2.1.4. Mineralogy and texture of reacted basalt: Top of Reactor (Portion 2) ……………………………….... 173

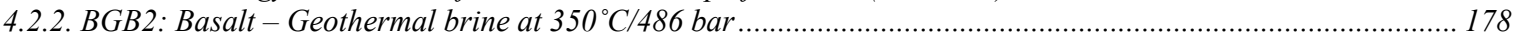

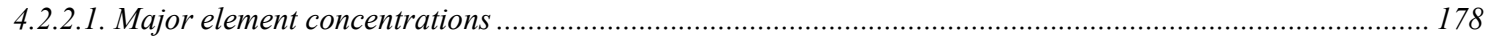

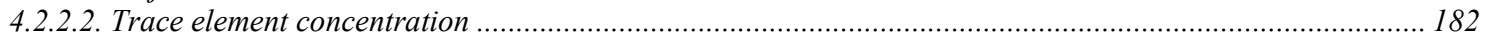

4.2.2.3. Mineralogy and Texture of Reacted Basalt: Bottom of Reactor (Portion 1)............................................ 185

4.2.2.4. Mineralogy and Texture of Reacted Basalt: Top of Reactor (Portion 2) ................................................191

4.2.2.5 Mineralogy and Texture of Reacted Basalt: Basalt Block ................................................................... 194

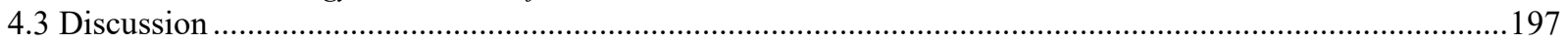

4.3.1. Major and trace element exchange during water - rock interaction ........................................................... 197

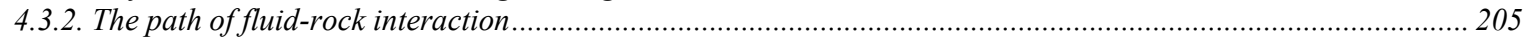

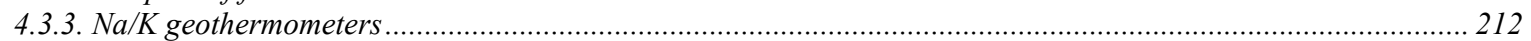

4.3.4. Comparison of Distilled Water and Brine Experiments ........................................................................ 216

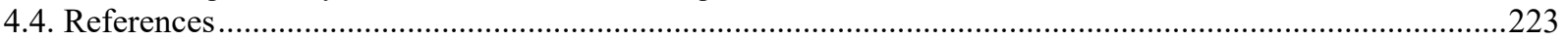

CHAPTER 5: THE EXPERIMENTAL BEHAVIOUR OF SEAWATER ........................................................226

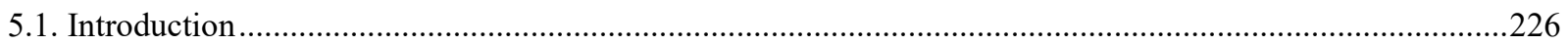

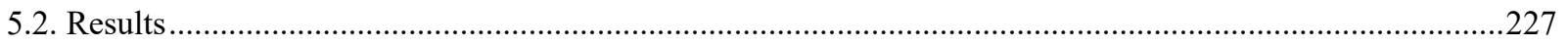

5.2.1. Method development test $\left(377^{\circ} \mathrm{C} / 490\right.$ bar $)$ : Mineralogy of precipitated phases.............................................. 228

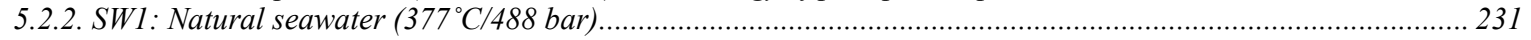

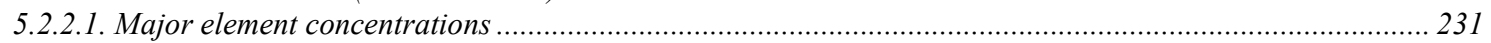

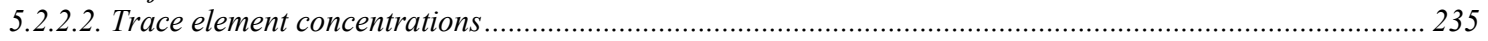

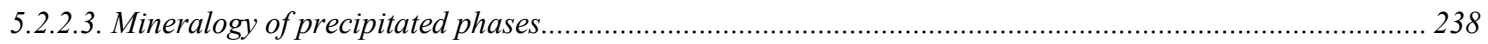

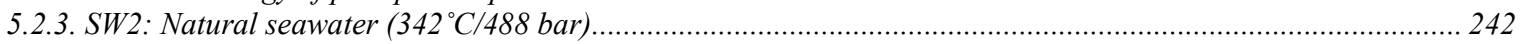

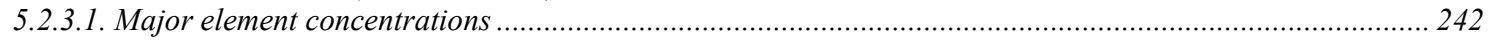

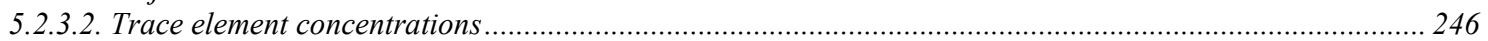

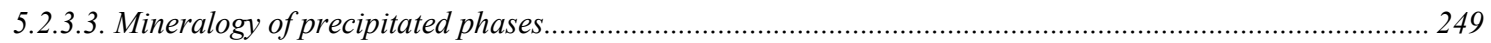

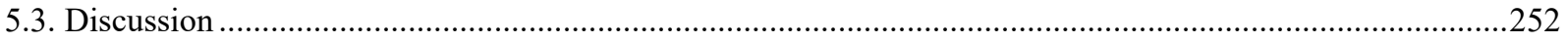

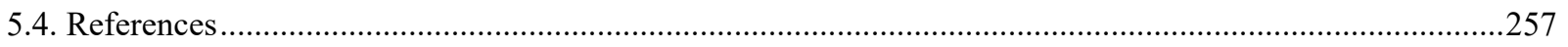

CHAPTER 6: BASALT - SEAWATER INTERACTIONS UNDER HYDROTHERMAL CONDITIONS ..259

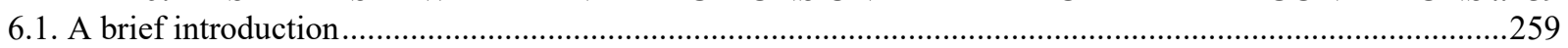

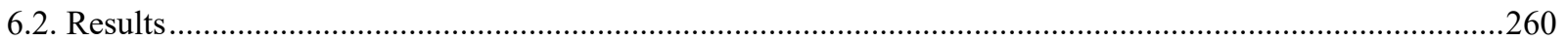

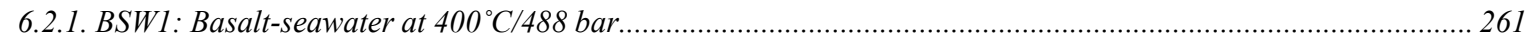

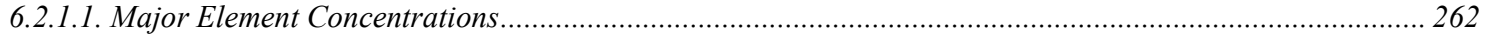

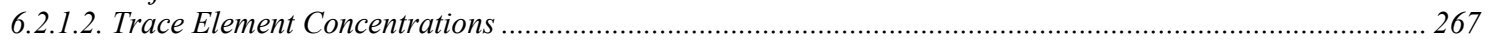

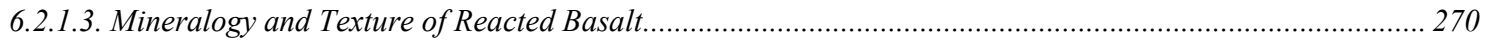

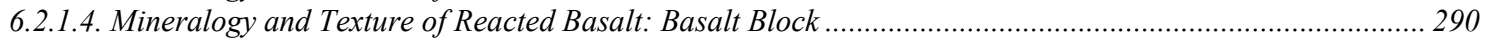

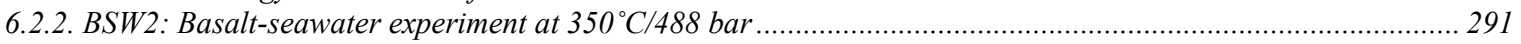

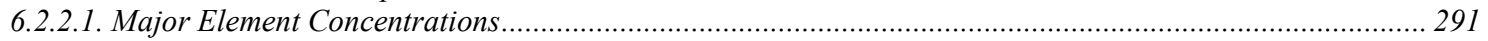

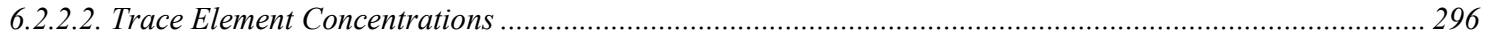

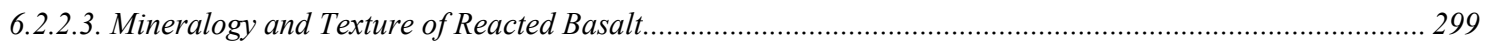

6.2.2.4. Mineralogy and Texture of Reacted Basalt: Basalt Block ………………............................................... 314

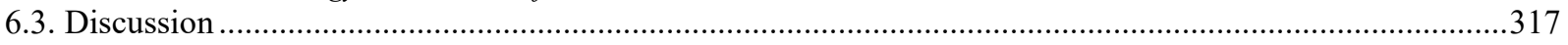

6.3.1. Major and trace element exchange during seawater - basalt interaction........................................................ 317

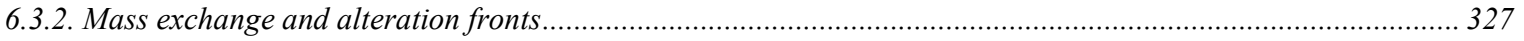

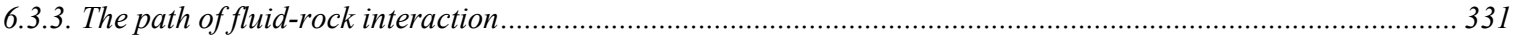

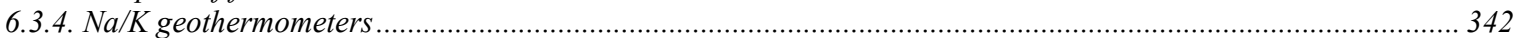

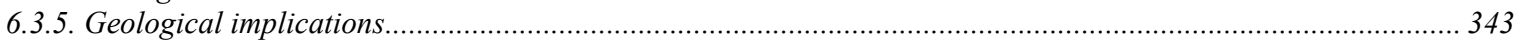

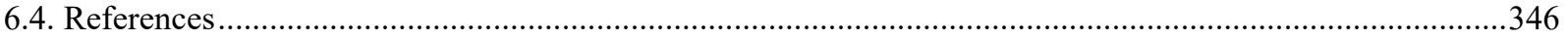




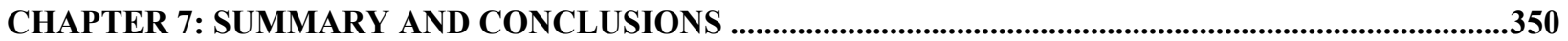

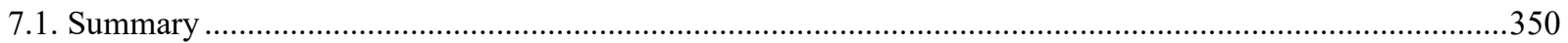

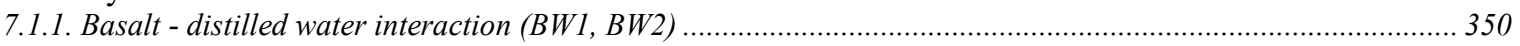

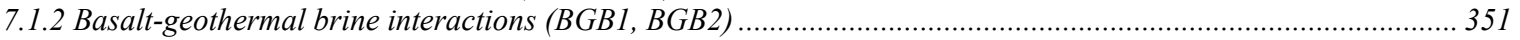

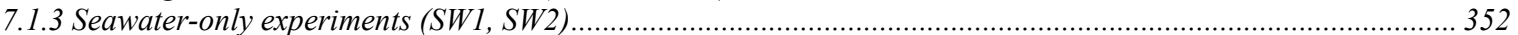

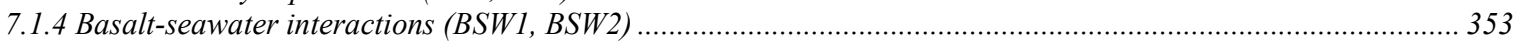

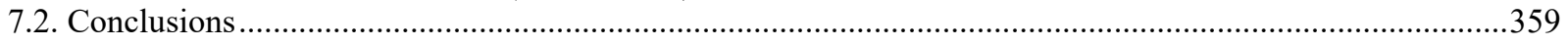

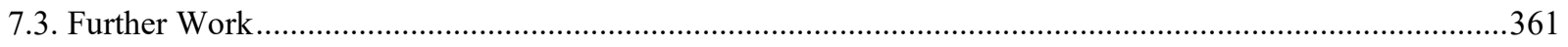

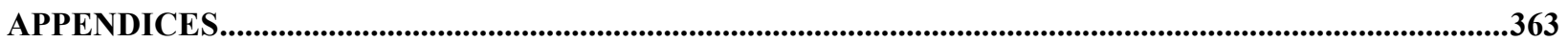

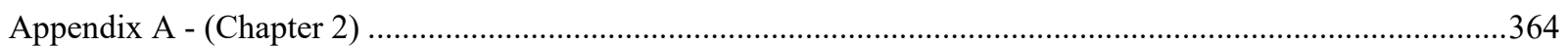

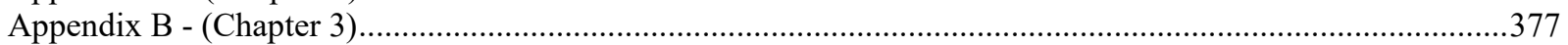

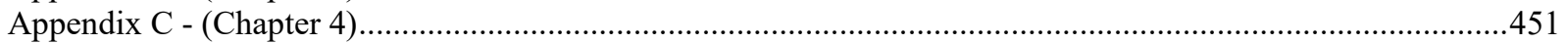

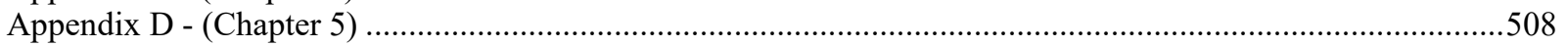

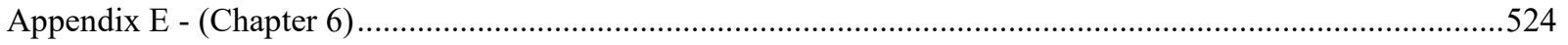




\section{List of figures}

Figure 1.1. Schematic diagram of a typical hydrothermal system within an oceanic ridge axial zone showing the hydrothermal fluid circulation (blue arrows) at recharge, reaction and discharge zones (Coelho et al., 2015).

Figure 1.2. (a) Pressure-temperature solid-liquid-vapour phase relations of pure water showing the critical point and critical isochore line; (b) temperature - density relations in the pure water system; (c) two component system showing the critical behaviour of pure water dominated fluids. (d) phase diagram of $\mathrm{H}_{2} \mathrm{O}-\mathrm{NaCl}$ versus temperature-pressure-composition (a),b), c) Liebscher and Heinrich, 2007; d) Driesner and Heinrich, 2007).....

Figure 1.3. Map of ocean floor age, based on age grid by Muller et al. (2008) revised version 3 (www.earthbyte.org/). Symbols represent DSDP, ODP, and IODP holes drilled in ocean from 1974 to 2011.

Figure 1.4. A comparison of the lithologies between Hole 1256D and Hole 504B drilled during the IODP and ODP expeditions, respectively, and cores of RN-17 and RN-15 recovered during the development of the IDDP-1 and IDDP-2 in Reykjanes region (Iceland), respectively (Friðleifsson et al., 2017).

Figure 1.5. (A) Lithostratigraphic section of the plutonic complex, Hole 1256D. (B) dike sample with granoblastic texture; (C) dike-gabbro boundary (gabbro extremely altered by hydrothermal circulation); (D) diorite rich in quartz and oxide altered to actinolite, hornblende and secondary plagioclase, chlorite and epidote; (E) Gabbro with oxides and patchy texture; (F) Gabbro strongly altered by hydrothermal circulation with veins of chlorite and actinolite; (G) sample of intruded dike within gabbro (all from Wilson et al, 2006).

Figure 1.6. Photomicrographs of the core from the IDDP-2, well RN-15, at $4637.81 \mathrm{~m}$ depth (Friðleifsson et al., 2017) (a) euhedral crystals of hydrothermal biotite covered by hematite which gives them a red coloration, formed during coring operation (b) open-spaces filled by quartz overgrown on hydrothermal biotite covered by hematite.

Figure 1.7. (a) $\mathrm{Mg}, \mathrm{Ca}, \mathrm{SO}_{4}$ and $\mathrm{pH}$ concentrations during the experiment of Bischoff and Seyfried (1978) from $25^{\circ} \mathrm{C}$ to $350^{\circ} \mathrm{C} / 500 \mathrm{bar}$; (b) Ion-Activity Products (IAP's) of brucite and anhydrite in thin lines calculated from the experiment from $25^{\circ} \mathrm{C}$ to $350^{\circ} \mathrm{C}$ compared to theoretical $\log \mathrm{K}$ values for dissolution equilibrium (thick lines) at 500 bar (Helgeson and Kirkham, 1974; Helgeson and Kirkham, 1976).......

Figure 1.8. (a-b) SEM pictures of the mineral precipitates from the experiment of Bischoff and Seyfried (1978) showing magnesium hydroxysulfate crystals $\left(10 \mu \mathrm{m}\right.$ scale increments) formed at $325^{\circ} \mathrm{C} / 500 \mathrm{bar}$.

Figure 1.9. $\mathrm{Fe}, \mathrm{Mn}, \mathrm{Cu}$ and $\mathrm{Zn}$ concentrations (in $\mu$ molal) versus temperature (350-375-400-425 $\mathrm{C} / 400$ bar) and $\mathrm{pH}$ by $\mathrm{Seyfried}$ and Janecky (1985).

Figure 1.10. SEM images from Seyfried and Janecky (1985) showing: (a) pyrrhotite crystals (hexagonal) (scale = 70 $\mu \mathrm{m})$; (b) pyrrhotite crystals with overgrowth pyrite $($ scale $=20 \mu \mathrm{m})$; (c) pyrite overgrowth on pyrrhotite $(\mathrm{scale}=5 \mu \mathrm{m})$; $(\mathrm{d})$ Tremolite/actinolite, fibrous crystals (scale $=20 \mu \mathrm{m})$.

Figure 2.1. $(\mathrm{a}, \mathrm{b})$ front and back view of the high temperature and pressure hydrothermal flow autoclave at the Experimental Geochemistry Laboratory of GNS Science, Wairakei Research Centre, Taupo, New Zealand; (c,d) individual components of the flow autoclave: $a$, double piston metering pump; $b$, accumulator vessel containing the piston which separates distilled water coming from the pump from the experimental fluid above the piston; $c$, pressure vessel (Reactor) containing the rock material enclosed by the furnace; $d$, back pressure regulator controller; $e$, back pressure regulator; $f$, collection syringe; $g$, partial cross section of the furnace assembly showing position of pressure vessel (Reactor).; $h$, plastic reservoir containing distilled water used by the metering pump. Yellow lines represent $1 / 8$ " titanium tube connections between components. Blue arrows show the flow path.

Figure 2.2. Schematic diagram of the hydrothermal flow autoclave. Blue arrows show the path of distilled water coming from the metering pump. Red arrows show the path of the experimental fluid exiting the accumulator vessel, passing down the side of the furnace and into the bottom of the pressure vessel (Reactor). The fluid then passes through the Reactor vessel containing the rock material and exits out the top, after which it moves to the back pressure regulator and into the collection syringe.

Figure 2.3. Fragments of basalt from the Eldvarpahraun lava flow, Reykjanes Peninsula, Iceland.

Figure 2.4. Thin section of the basalt showing the different areas analysed by EMPA (points A-B-C-D-E, in red rectangles). Yellow circles indicate the points where glass was analysed.

Figure 2.5. SEM-EDS elemental map of an unreacted basalt grain: (a) grey scale image; (b) composite colour image combining maps for c) $\mathrm{Mg}$, d) $\mathrm{Ca}$ and e) $\mathrm{Na}$. In (b) the composite colour image shows plagioclase (violet), pyroxene (turquoise), olivine (light green) and titanomagnetite (white). 
Figure 2.6. SEM-EDS images of the unaltered basalt: (a) Point C (Figure 2.4); (b) secondary electron image of the red rectangular area in (a); (c) composite colour image (b) combining maps for f) Al, g) Si, and h) P showing plagioclase (green), clinopyroxene (light red), volcanic glass (dark red), oxides (white) and apatite (blue-violet); (d) enlargement of yellow rectangle $\left(n^{\circ} 1\right)$ in (c) showing volcanic glass (outlined in yellow) including apatite and sulfides; (e) enlargement of yellow rectangular area $\left(n^{\circ} 2\right)$ in (c) showing other two areas of the volcanic glass (outlined in yellow)

Figure 2.7. SEM photographs of four different unreacted basalt grains: a) typical rough surface texture; b) - d) show euhedral lathes of plagioclase (plg) and anhedral interstitial clinopyroxene (cpx). The euhedral lathes are found as linings of the vesicles.

Figure 2.8. (a) sequential sieving equipment, Volcanic Petrology Laboratory, GNS Science, Taupo, (b) collected size fractions, (c) the typical appearance of the $355-500 \mu \mathrm{m}$ basalt grains size fraction, (d) example of the basalt block, which was positioned at the bottom of the reactor in all "rock present" experiments (excluding the basalt geothermal brine experiment, BGB1). The front surface of the block has been highly polished.

Figure 2.9. (a) Titanium pressure vessel referred to as the Reactor in this study with end caps, collars and thrust rings. The thrust rings push against the collars to make a cone-type seal against the caps. (b) Reactor filled with basalt grains. Titanium filters are placed at each end of the reactor to prevent passage of rock materials or reaction products. (c) the Reactor assembled............... 55

Figure 2.10. (a) Reactor, 1/4" titanium exit tube, high T-P valve, and aluminium and steel support; (b) Reactor, exit tube, and high

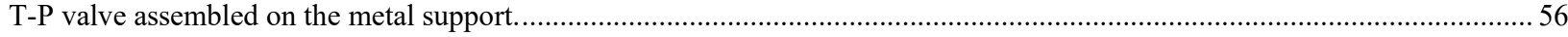

Figure 2.11. The de-oxygenation apparatus showing the experimental fluid contained in the glass flask. The flask is also connected to the three-way valve at the top of the $\mathrm{n}$ accumulator vessel. 57

Figure 2.12. (a) main accumulator vessel; (b) internal view of the accumulator vessel with the movable piston that separates the experimental solution from distilled water below. The metering pump injects distilled water into the bottom of the accumulator vessel. This causes the experimental solution to be force from the top of the accumulator vessel and through the autoclave. ...... 58

Figure 2.13. (a) the control unit of the back-pressure regulator (BPR); (b) the valve unit of the BPR; (c) schematic view of the BPR showing the vacuum oil syringe (vertical) and sample syringe (horizontal); (d) schematic view of the BPR valve box unit showing the diaphragm, vacuum oil syringe and sample syringe. Blue arrows indicate the direction of the experimental fluid coming from the Reactor.

Figure 2.14. (a) set-up for the BW1 experiment at $400^{\circ} \mathrm{C} / 502$ bar; (b) set-up for the $\mathrm{BW} 2$ experiment at $350^{\circ} \mathrm{C} / 490$ bar. In both experiments the upper chamber of the accumulator vessel was filled with water (distilled) which is pushed through the Reactor, up to the BPR, and collects in the collection syringe. Both experiments used basalt grains. The water is shown in blue. Red arrows show the direction of flow of the water.

61

Figure 2.15. (a) set-up for the BGB1 experiment at $400^{\circ} \mathrm{C} / 483$ bar; (b) set-up for the $\mathrm{BGB} 2$ experiment at $350^{\circ} \mathrm{C} / 486$ bar. In both experiments the upper chamber of the accumulator vessel was filled with geothermal brine which is pushed through the Reactor, up to the BPR, and collects in the collection syringe. Both experiments used basalt grains. The water is shown in blue. Red arrows show the direction of flow of the water.

Figure 2.16. The mineral saturation indices of selected $\mathrm{Ca}$ and $\mathrm{Mg}$ sulfate/hydroxysulfate phases in seawater with increasing temperature calculated using the Geochemist's Workbench ${ }^{\odot}$ (GWB) v. 12 software package (Bethke et al., 2018).

Figure 2.17. (a) the Preheater pressure vessel disassembled, (b) the Preheater assembled, (c) the Preheater connected in series with the Reactor vessel.

Figure 2.18. Experimental set-up with synthetic seawater at $400^{\circ} \mathrm{C} / 490$ bar. The Preheater extended approximately $20 \mathrm{~cm}$ outside the top of the furnace while the remainder of the vessel extended down towards the bottom of the furnace. The Preheater was connected at the top to the main accumulator vessel containing the synthetic seawater (blue) and on the bottom to the backpressure regulator (BPR). The BPR was fitted with a syringe that collected the synthetic seawater after passing through the Preheater. An electric fan cooled the top of the Preheater which created a temperature gradient from $40^{\circ} \mathrm{C}$ to $377^{\circ} \mathrm{C}$ at the bottom. There was no Reactor in this test experiment. The temperature of the Preheater was $377^{\circ} \mathrm{C}$ at the bottom. The yellow circle on bottom of the Preheater indicates the position of the retrograde phase precipitation which caused the blockage and exceeding of the safety pressure...

Figure 2.19. (a) zirconia beads sourced from Zircoa, Inc. ( $2 \mathrm{~mm} \mathrm{dia}$ ); (b) Preheater filled with zirconia beads $2 / 3^{\text {rd }}$ full. Black circles indicate where thermocouples were positioned to measure the temperature at the top and bottom of the vessel during experiment. .....

Figure 2.20. (a) experimental set-up of the seawater-only experiment (SW1) at $400^{\circ} \mathrm{C} / 488$ bar. The Preheater extended approximately $20 \mathrm{~cm}$ outside the top of the furnace while the remainder of the vessel extended down towards the bottom of the furnace. The Preheater is $2 / 3$ filled with zirconia beads. It was connected at the top to the main accumulator vessel containing the natural seawater (blue) and on the bottom to the back-pressure regulator (BPR). The BPR was fitted with a syringe that collected the seawater after passing through the zirconia beads. An electric fan cooled the top of the Preheater which created a temperature 
gradient from $40^{\circ} \mathrm{C}$ to $377^{\circ} \mathrm{C}$ at the bottom. There was no Reactor in this experiment. (b) experimental set-up of the basaltseawater experiment at $400^{\circ} \mathrm{C} / 488$ bar (BSW1). The Preheater was $2 / 3$ filled with zirconia beads. It was connected at the top to the main accumulator vessel containing natural seawater (blue) and on the bottom to the Reactor containing the basalt fragments. The temperature gradient between the top and the bottom of the Preheater was $40^{\circ} \mathrm{C}$ to $377^{\circ} \mathrm{C}$. The temperature of the Reactor was $400^{\circ} \mathrm{C}$. . .71

Figure 2.21. (a) experimental set-up of the seawater-only experiment (SW2) at $350^{\circ} \mathrm{C} / 488$ bar. The Preheater extended approximately $20 \mathrm{~cm}$ outside the top of the furnace while the remainder of the vessel extended down towards the bottom of the furnace. The Preheater is $2 / 3$ filled with zirconia beads. It was connected at the top to the main accumulator vessel containing the natural seawater (blue) and on the bottom to the back-pressure regulator (BPR). The BPR was fitted with a syringe that collected the seawater after passing through the zirconia beads. An electric fan cooled the top of the Preheater which created a temperature gradient from $40^{\circ} \mathrm{C}$ to $342^{\circ} \mathrm{C}$ at the bottom. There was no Reactor in this experiment. (b) experimental set-up of the basaltseawater experiment at $350^{\circ} \mathrm{C} / 488$ bar (BSW2). The Preheater was $2 / 3$ filled with zirconia beads. It was connected at the top to the main accumulator vessel containing natural seawater (blue) and on the bottom to the Reactor containing the basalt fragments. The temperature gradient between the top and the bottom of the Preheater is $40^{\circ} \mathrm{C}$ to $342^{\circ} \mathrm{C}$. The temperature of the Reactor was $350^{\circ} \mathrm{C}$.......

Figure 2.22. An example of an activity-activity diagram used in this study. This diagram plots the ratio of the free activity of Na divided by the activity of the hydrogen ion versus the same for potassium at $400^{\circ} \mathrm{C}$ and 500 bar. The diagram shows the mineral stability fields in contact with an aqueous phase for the minerals: albite (alb), K-feldspar (K-spar), paragonite (parag), muscovite (musc) and andalusite (and). .82

Figure 3.1. Major element concentrations in blank and effluent samples (mmol kg-1) versus time (hr) for the basalt-water experiment at $400^{\circ} \mathrm{C} / 502$ bar (BW1). Yellow symbols are blank sample composition of the water. Blue symbols are for effluents at room $\mathrm{T} / 502 \mathrm{bar}$ and $1.0 \mathrm{ml} \mathrm{hr}^{-1}$. Black symbols are effluents at $400^{\circ} \mathrm{C} / 502 \mathrm{bar}$ and $1.0 \mathrm{ml} \mathrm{hr}^{-1}$ flow rate. Red symbols are effluents at $400^{\circ} \mathrm{C} / 502$ bar and $0.5 \mathrm{ml} \mathrm{hr}^{-1}$ flow rate. In situ $\mathrm{pH}$ is the calculated $\mathrm{pH}$ at temperature. The limit of detection (LOD) is shown for each component.

Figure 3.2. Major element concentrations in blank and effluent samples (mmol kg-1) versus time (hr) for the basalt-water experiment at $400^{\circ} \mathrm{C} / 502$ bar (BW1). Yellow symbols are blank sample composition of the water. Blue symbols are for effluents at room $\mathrm{T} / 502 \mathrm{bar}$ and $1.0 \mathrm{ml} \mathrm{hr}{ }^{-1}$. Black symbols are effluents at $400^{\circ} \mathrm{C} / 502 \mathrm{bar}$ and $1.0 \mathrm{ml} \mathrm{hr}^{-1}$ flow rate. Red symbols are effluents at $400^{\circ} \mathrm{C} / 502$ bar and $0.5 \mathrm{ml} \mathrm{hr}^{-1}$ flow rate. The limit of detection (LOD) is shown for each component. .89

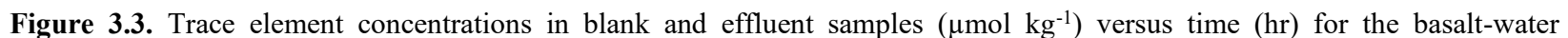
experiment at $400^{\circ} \mathrm{C} / 502$ bar (BW1). Yellow symbols are the blank sample composition of the water. Blue symbols are for

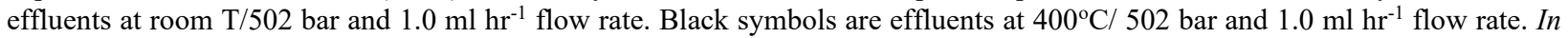
situ $\mathrm{pH}$ is the calculated $\mathrm{pH}$ at temperature. The limit of detection (LOD) is shown for each component.

. .91

Figure 3.4. Trace element concentrations in blank and effluent samples ( $\mu \mathrm{mol} \mathrm{kg}{ }^{-1}$ ) versus time (hr) for the basalt-water experiment at $400^{\circ} \mathrm{C} / 502$ bar (BW1). Yellow symbols are the blank sample composition of the water. Blue symbols are for effluents at room $\mathrm{T} / 502$ bar and $1.0 \mathrm{ml} \mathrm{hr}^{-1}$ flow rate. Black symbols are effluents at $400^{\circ} \mathrm{C} / 502 \mathrm{bar}$ and $1.0 \mathrm{ml} \mathrm{hr}^{-1} \mathrm{flow}$ rate. The limit of detection (LOD) is shown for each component. . .92

Figure 3.5. Schematic diagram of the Reactor showing position (Portion 1 and Portion 2) of reacted basalt grains shown in SEM photographs and the position of the basalt block for the BW1 experiment. The picture is not to scale.

Figure 3.6. (a-f) SEM images of reacted grains collected from the immediately adjacent to the fluid entry point (bottom, Portion 1) after the BW1 experiment (minerals were identified by SEM-EDS analysis): (a) grain entirely covered by wollastonite (Wo) occurring in groupings of acicular crystals and by garnet (Grt) which appears in well-formed dodecahedral crystals; (b) clusters of garnet crystals with sparse wollastonite; (c) enlargement of area in (b) (red rectangle) showing in more detail the wollastonite and garnet; (d) secondary plagioclase of anorthitic (An) composition, wollastonite (Wo) and visibly altered primary clinopyroxene (Cpx); ): (e) a reacted grain surface (enlargement) showing acicular wollastonite (Wo), euhedral garnet (Grt), and relict clinopyroxene (Cpx); (f) grain surface completely replaced by chlorite appearing as botryoidal masses composed of densely intergrown flakes.

Figure 3.7. SEM backscatter image and EDS compositional maps of an epoxy-mounted, polished grain from the bottom portion of the BW1 experiment: (a) backscatter image; (b) composite colour image combining the backscatter image and elemental maps for c) $\mathrm{Fe}$ in green, d) $\mathrm{Mg}$ in blue, and e) $\mathrm{Ca}$ in red. The composite image shows needles of wollastonite (pink acicular) and primary clinopyroxene (violet), plagioclase (anhedral pink remnants), and Fe oxide (green). .96

Figure 3.8. SEM backscatter and EDS compositional maps of an epoxy-mounted, polished grain from the bottom portion of the BW1 experiment: (a) backscatter image of entire grain; (b) backscatter image of rectangular area in (a); (c) composite colour image combining the backscatter image and the elemental maps for c) $\mathrm{Ca}$ in red, d) $\mathrm{Al}$ in green, and e) Fe in blue. The image shows remnant anorthite (green) and two crystals of garnet (pink). The Fe elemental map shows that there is a detectable concentration of $\mathrm{Fe}$ in the garnet..... . .98 
Figure 3.9. SEM backscatter and EDS compositional maps of an epoxy-mounted, polished grain of olivine from the bottom portion of the BW1 experiment: (a) backscatter image of entire grain; (b) composite colour image combining the backscatter image and the elemental maps for c) $\mathrm{Mg}$ in red, d) Al in blue, and e) Fe in green. The composite image shows remnant olivine (red) and a coating of chlorite (violet).

Figure 3.10. (a-e) SEM backscatter and EDS compositional maps of an epoxy-mounted, polished grain collected from about 2 $\mathrm{mm}$ further up the Reactor (bottom, Portion 1) after the BW1 experiment: (a) backscatter image of entire grain; (b) composite colour image combining the backscatter image and the elemental maps for c) $\mathrm{Mg}$ in green, d) Fe in red, and e) Ca in blue. The image shows highly-altered plagioclase (blue), relatively unaltered clinopyroxene (turquoise), Fe oxides (red), and olivine (yellow green). (f-g) SEM backscatter images of the two red rectangular areas in (a): (f) top of grain showing secondary plagioclase of anorthitic composition (An), primary clinopyroxene (Cpx), a remnant plagioclase of bytownite composition (Byt), grain edge coating of chlorite $(\mathrm{Chl})$, and Fe-Ti oxide (Tnt); $(\mathrm{g})$ bottom of grain showing extensive alteration of plagioclase to anorthite, a remnant lath of plagioclase of bytownite composition, chlorite, and Fe-Ti oxide...... 100

Figure 3.11. SEM backscatter image of a reacted grain showing secondary plagioclase of anorthitic composition (An), primary clinopyroxene (Cpx), chlorite ( $\mathrm{Chl})$, primary Fe-Ti oxide (Tnt), and secondary magnetite (Mag). 100

Figure 3.12. SEM images of grains from the top (Portion 2) of the reactor after the BW1 experiment (minerals were identified by SEM-EDS analysis): a) surface showing intense alteration of the primary plagioclase to secondary anorthite composition; b) reacted grain surface showing primary clinopyroxene $(\mathrm{Cpx})$ and secondary titanite $(\mathrm{Ttn})$; c) surface of a reacted grain showing rounded masses of the $\mathrm{K}-\mathrm{Na}-\mathrm{Mg}-\mathrm{Fe}$ aluminosilicate phase of secondary origin, concluded to be celadonite (Cel).

Figure 3.13. SEM backscatter image and EDS compositional maps of an epoxy-mounted, polished grain from the top portion of the BW1 experiment: (a) backscatter image of entire grain; (b) composite colour image combining the backscatter image and the elemental maps for c) $\mathrm{Ca}$ in blue, d) $\mathrm{Mg}$ in green, and e) Fe in red. The composite image shows plagioclase (dark blue), unaltered clinopyroxene (turquoise), titanomagnetite (red), and olivine (yellow green). 104

Figure 3.14. SEM backscatter images and EDS compositional maps of an epoxy-mounted, polished grain from the top portion of the BW1 experiment: (a) backscatter image of entire grain; (b) composite colour image combining the backscatter image and the elemental maps for $\mathrm{Ca}, \mathrm{Mg}$, and $\mathrm{Fe}$. The composite image shows plagioclase (dark blue), unaltered clinopyroxene (turquoise), titanomagnetite (red), and olivine yellow green). (c) enlargement of the red rectangle in (b) showing an overgrowth celadonite $(\mathrm{Cel})$ on the olivine $(\mathrm{Ol})$.

Figure 3.15. Dioctahedral mica ternary diagram $(\mathrm{Al}, \mathrm{Fe}, \mathrm{Mg})\left(\mathrm{n}^{\circ}\right.$ of atoms) with plotted results from the empirical formula of Table 3.2

Figure 3.16. (a-b) SEM backscatter images of the surface of the basalt block used in the BW1 experiment: a) unreacted block with interlocking lathes of plagioclase (dark gray), interstitial clinopyroxene (lighter gray), titanomagnetite (white), and isolated crystals of olivine (yellow ovals); b) reacted block showing celadonite replacing olivine. (c-d-e) SEM backscatter images of the basalt block surface after the BW1 experiment: c) enlargement of rectangular area in (b) showing celadonite (Cel) replacing olivine; d) SEM backscatter image showing celadonite (Cel), relatively unaltered clinopyroxene (Cpx) (lighter grey) and plagioclase with more $\mathrm{Na}$ content $(\mathrm{Plg})$ coating primary plagioclase; e) SEM backscatter image of celadonite (Cel) replacing olivine $(\mathrm{Ol})$ and altered plagioclase $(\mathrm{Plg})$. 108

Figure 3.17. Dioctahedral mica ternary diagram ( $\mathrm{Al}, \mathrm{Fe}, \mathrm{Mg}$ ) ( $\mathrm{n}^{\circ}$ of atoms) with plotted results from the empirical formula of Table 3.4

Figure 3.18. SEM backscatter images of the basalt block surface after the BW1 experiment: a) area of the basalt block surface before the BW1 experiment; (b) same area after the BW1 experiment showing larger plagioclase microphenocrysts surrounded by ophitic textured plagioclase, clinopyroxene, olivine and titanomagnetite; c) enlargement of the red triangular area in (b) showing secondary features in detail. Primary clinopyroxene $(\mathrm{Cpx})$ is unaltered while the plagioclase (Plg), altered, has a major $\mathrm{Na}$ content when compared to the primary bytownite (Appendix B). Bright spots are Fe-Ni-Cr oxide...... 110

Figure 3.19. Major element concentrations in blank and effluent samples (mmol kg-1) versus time (hr) for the basalt-water experiment at $350^{\circ} \mathrm{C} / 490$ bar (BW2). Yellow symbols are the blank sample composition of the water. Blue symbols are for effluents at room $\mathrm{T} / 490$ bar and $1.0 \mathrm{ml} \mathrm{hr}^{-1}$ flow rate. Black symbols are effluents at $350^{\circ} \mathrm{C} / 490 \mathrm{bar}$ and $1.0 \mathrm{ml} \mathrm{hr}{ }^{-1}$ flow rate. Red symbols are effluents at $350^{\circ} \mathrm{C} / 490$ bar and $0.5 \mathrm{ml} \mathrm{hr}^{-1}$ flow rate. In situ $\mathrm{pH}$ is the calculated $\mathrm{pH}$ at temperature. The limit of detection (LOD) is shown for each component. 113

Figure 3.20. Major element concentrations in blank and effluent samples (mmol kg-1) versus time (hr) for the basalt-water experiment at $350^{\circ} \mathrm{C} / 490$ bar (BW2). Yellow symbols are the blank sample composition of the water. Blue symbols are for effluents at room $\mathrm{T} / 490$ bar and $1.0 \mathrm{ml} \mathrm{hr}^{-1}$ flow rate. Black symbols are effluents at $350^{\circ} \mathrm{C} / 490 \mathrm{bar}$ and $1.0 \mathrm{ml} \mathrm{hr}^{-1}$ flow rate. Red symbols are effluents at $350^{\circ} \mathrm{C} / 490$ bar and $0.5 \mathrm{ml} \mathrm{hr}^{-1}$ flow rate. In situ $\mathrm{pH}$ is the calculated $\mathrm{pH}$ at temperature. The limit of detection (LOD) is shown for each component. 114

Figure 3.21. Trace element concentrations in blank and effluent samples ( $\mu \mathrm{mol} \mathrm{kg}{ }^{-1}$ ) versus time (hr) for the basalt-water experiment at $350^{\circ} \mathrm{C} / 490$ bar (BW2). Yellow symbols are the blank sample composition of the water. Blue symbols are for 
effluents at room $\mathrm{T} / 490$ bar and $1.0 \mathrm{ml} \mathrm{hr}^{-1}$ flow rate. Black symbols are effluents at $350^{\circ} \mathrm{C} / 490 \mathrm{bar}$ and $1.0 \mathrm{ml} \mathrm{hr}^{-1} \mathrm{flow}$ rate. In situ $\mathrm{pH}$ is the calculated $\mathrm{pH}$ at temperature. The limit of detection (LOD) is shown for each component.

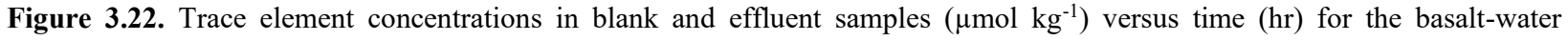
experiment at $350^{\circ} \mathrm{C} / 490$ bar (BW2). Yellow symbols are the blank sample composition of the water. Blue symbols are for effluents at room T/490 bar and $1.0 \mathrm{ml} \mathrm{hr}^{-1}$ flow rate. Black symbols are effluents at $350^{\circ} \mathrm{C} / 490 \mathrm{bar}$ and $1.0 \mathrm{ml} \mathrm{hr}{ }^{-1}$ flow rate. In situ $\mathrm{pH}$ is the calculated $\mathrm{pH}$ at temperature. The limit of detection (LOD) is shown for each component.

Figure 3.23. Schematic diagram of the Reactor showing position (Portion 1 and Portion 2) of reacted basalt grains shown in SEM photographs and the position of the basalt block for the BW2 experiment. The picture is not to scale. 118

Figure 3.24. SEM images of grains collected from bottom (Portion 1) of the Reactor after the BW2 experiment (minerals were identified by SEM-EDS analysis): a) grain covered by secondary chlorite and secondary titanite; (b) enlargement of red rectangular area in (a) showing in more detail the chlorite $(\mathrm{Chl})$ and titanite $(\mathrm{Ttn})$ which appears as prismatic crystals. (c) surface of a reacted grain showing chlorite $(\mathrm{Chl})$ as botryoidal masses composed of densely intergrown flakes; d) enlargement of the red rectangular area in (c) displaying intense alteration of the primary clinopyroxene (Cpx) to chlorite (Chl); (e) secondary chlorite formation (Chl) replacing the plagioclase (Plg). (f) grain entirely covered with chlorite of secondary origin appearing as botryoidal masses composed of densely intergrown flakes.

Figure 3.25. (a-f) SEM backscatter images and EDS compositional maps of an epoxy-mounted, polished grain collected from the bottom (Portion 1) of the Reactor after the BW2 experiment. (a) backscatter image of entire grain; (b) backscatter image of rectangular area in (a); (c) composite colour image combining the backscatter image and the elemental maps for d) Fe in red, e) $\mathrm{Mg}$ in green, and f) $\mathrm{Ca}$ in blue. The image shows remnant plagioclase (blue-purple), relatively unaltered clinopyroxene (turquoise), oxides (red) and a chlorite (green); (g) SEM backscatter image of the red rectangular area shown in (a) displaying secondary plagioclase of anorthitic composition (An), primary clinopyroxene ( $\mathrm{Cpx})$, secondary chlorite (Chl), primary Fe- $\mathrm{Ti}$ oxide (Tnt), and secondary magnetite (Mag)...... 121

Figure 3.26. SEM images of grains collected from the top of the Reactor after the BW2 experiment (minerals were identified by SEM-EDS analysis: a) surface of a reacted grain; b) enlargement of the red rectangular area in (a) showing the K-Na-Mg-Fe aluminosilicate of secondary origin (Cel); (c) surface of a reacted grain; (d) enlargement of the red rectangular area in (c) showing the K-Na-Mg-Fe aluminosilicate (Cel) of secondary origin; (e) portion of a reacted grain; (f) enlargement of the red rectangular area in (e) displaying crystals of titanite (Ttn) of secondary origin.

Figure 3.27. SEM backscatter images and EDS compositional maps of an epoxy-mounted, polished grain collected from the top portion of the Reactor after the BW2 experiment: (a) backscatter image of entire grain; (b) composite colour image combining the backscatter image and the elemental maps for c) $\mathrm{Mg}$ in green, d) $\mathrm{Ca}$ in blue, and e) Fe in red. The composite image shows unaltered plagioclase (dark blue), unaltered clinopyroxene (turquoise), unaltered olivine (yellow), oxides (red), and celadonite (green); (f) SEM backscatter image of the red rectangular area in (a) displaying plagioclase (Plg), primary olivine (Ol) and celadonite $(\mathrm{Cel})$.

Figure 3.28. Dioctahedral mica ternary diagram ( $\mathrm{Al}, \mathrm{Fe}, \mathrm{Mg})\left(\mathrm{n}^{\circ}\right.$ of atoms) with plotted results from the empirical formula of Table 3.7

Figure 3.29. SEM backscatter images: (a) portion (left border) of the basalt block surface before the BW2 experiment; (b) same portion (left border) of the basalt block after the BW2 experiment. In (a) primary plagioclase (Byt) appears in darker grey under backscatter electron detector, while clinopyroxene $(\mathrm{Cpx})$ in lighter gray. In (b) both plagioclase and clinopyroxene are strongly altered; (c) enlargement of red rectangular area in (b); (d) enlargement of red rectangular area in (c) showing in detail the presence of secondary plagioclase of anorthitic composition (An) and secondary chlorite formation (Chl); (e) left border of the basalt block surface before the BW2 experiment with primary plagioclase (Byt) and clinopyroxene (Cpx) and isolated crystals of olivine (yellow ovals); (f) same same area in (e) after the BW2 experiment with strongly altered plagioclase, clinopyroxene and olivine; (g) enlargement of the red rectangular area 1 in (f) showing secondary plagioclase of anorthitic composition (An); (h) enlargement of the red rectangular area 2 in (f) showing secondary plagioclase of anorthitic composition (An) and secondary chlorite formation $(\mathrm{Chl})$ where chlorite replaces all primary silicates (olivine, plagioclase and clinopyroxene). 128

Figure 3.30. SEM backscatter images of the basalt block after the BW2 experiment showing a relict clinopyroxene grain. The grain shas an unaltered inclusion of primary titanomagnetite and a secondary Fe-Ni-Cr oxide phase. Chlorite crystals surround the relict clinopyroxene. 129

Figure 3.31. $\mathrm{SiO}_{2}$ concentration $\left(\mathrm{mmol} \mathrm{kg}^{-1}\right)$ vs time (hr) for the $\mathrm{BW} 2$ and the $\mathrm{BW} 1$ experiments: a) total $\mathrm{SiO}_{2}$ flux for $\mathrm{BW} 2$ based on sample volume and solution composition (pink area); b) total $\mathrm{SiO}_{2}$ flux from silicate minerals (green) based on the average $\mathrm{SiO}_{2}$ concentration in the last two samples $\left(0.5 \mathrm{ml} \mathrm{hr}^{-1}\right.$ flow rate) less the input water composition (grey); c) the difference between a) and b) representing the net $\mathrm{SiO}_{2}$ flux from glass for $\mathrm{BW} 2$ (orange area); d) total $\mathrm{SiO}_{2}$ flux for $\mathrm{BW} 2$ (orange + green area); e) total $\mathrm{SiO}_{2}$ flux for $\mathrm{BW} 1$ based on sample volume and solution composition (pink area); f) total $\mathrm{SiO}_{2}$ flux from silicate minerals (green) based on the average $\mathrm{SiO}_{2}$ concentration in the last two samples $\left(0.5 \mathrm{ml} \mathrm{hr}^{-1}\right.$ flow rate) (green area); g) difference between a) and b) representing the total $\mathrm{SiO}_{2}$ flux from glass for $\mathrm{BW} 1$ (orange area). 
Figure 3.32. Secondary mineral growths in voids left by the dissolution of volcanic glass with the typical "rosette structure". This was found in the basalt block from the BW1 experiment $\left(400^{\circ} \mathrm{C} / 502\right.$ bar $)$.

Figure 3.33. Plots of $\mathrm{Cl}$ and $\left.\mathrm{K}(\mathrm{mmol} \mathrm{kg})^{-1}\right)$ versus $\mathrm{SiO}_{2}\left(\mathrm{mmol} \mathrm{kg}^{-1}\right)$ for the $\mathrm{BW} 1$ and $\mathrm{BW} 2$. Symbols in red represent values during glass dissolution, while symbols in blue represent values after glass dissolution.

Figure 3.34. Plots of $\mathrm{H}_{2} \mathrm{~S}$ and $\mathrm{SO}_{4}\left(\mathrm{mmol} \mathrm{kg}^{-1}\right)$ versus $\mathrm{SiO}_{2}\left(\mathrm{mmol} \mathrm{kg}^{-1}\right)$ and $\mathrm{Fe}\left(\mathrm{mmol} \mathrm{kg}^{-1}\right)$ versus $\mathrm{H}_{2} \mathrm{~S}\left(\mathrm{mmol} \mathrm{kg}^{-1}\right)$ for the BW1 and BW2. Symbols in red represent values during glass dissolution, while symbols in blue represent values after glass dissolution.

Figure 3.35. Plots of $\mathrm{Cu}\left(\mu \mathrm{mol} \mathrm{kg}{ }^{-1}\right)$ versus $\mathrm{SiO}_{2}$ and $\mathrm{H}_{2} \mathrm{~S}\left(\mu \mathrm{mol} \mathrm{kg}{ }^{-1}\right)$ for the $\mathrm{BW} 1$ and $\mathrm{BW} 2$. Symbols in red represent values during glass dissolution, while symbols in blue represent values after glass dissolution.

Figure 3.36. Plots of $\mathrm{Co}, \mathrm{Mo}, \mathrm{V}$ and $\mathrm{Fe}\left(\mu \mathrm{mol} \mathrm{kg}{ }^{-1}\right)$ versus $\mathrm{SiO}_{2}\left(\mu \mathrm{mol} \mathrm{kg}{ }^{-1}\right)$ for $\mathrm{BW} 1$ and $\mathrm{BW} 2$. Symbols in red represent values during glass dissolution, while symbols in blue represent values after glass dissolution...... 139

Figure 3.37. Plots of Co and Mo $\left(\mu \mathrm{mol} \mathrm{kg}{ }^{-1}\right)$ versus $\mathrm{H}_{2} \mathrm{~S}\left(\mu \mathrm{mol} \mathrm{kg} \mathrm{kg}^{-1}\right)$ for BW1 and BW2. Symbols in red represent values during glass dissolution, while symbols in blue represent values after glass dissolution.

Figure 3.38. Activity diagrams for the $\mathrm{CaO}-\mathrm{Al}_{2} \mathrm{O}_{3}-\mathrm{SiO}_{2}-\mathrm{H}_{2} \mathrm{O}$ system showing mineral stability fields for $\mathrm{BW} 1(\mathrm{a})$ and $\mathrm{BW} 2(\mathrm{~b})$. Black and red crosses show position of effluent samples collected at 1.0 and $0.5 \mathrm{ml} \mathrm{hr}^{-1}$ flow rate, respectively. Yellow circles show position of the unreacted fluid (water) at 400 and $350^{\circ} \mathrm{C} / 500$ bar. Black dotted line indicates quartz saturation while pink dotted lines represent the average of silica concentration (in log units) before and after dissolution of the basalt glass, calculated for the respective experiments. Blue arrows show the path of reacted fluids over the time of the experiments.

Figure 3.39. Activity diagrams for the $\mathrm{K}_{2} \mathrm{O}-\mathrm{Al}_{2} \mathrm{O}_{3}-\mathrm{SiO}_{2}-\mathrm{H}_{2} \mathrm{O}$ system showing mineral stability fields for $\mathrm{BW} 1(\mathrm{a})$ and $\mathrm{BW} 2(\mathrm{~b})$. Black and red crosses show position of effluent sample collected at 1.0 and $0.5 \mathrm{ml} \mathrm{hr}^{-1}$ flow rate, respectively. Yellow circles show position of the unreacted fluid (water) at 400 and $350^{\circ} \mathrm{C} / 500$ bar. Black dotted line indicates quartz saturation while pink dotted lines represent the average of silica concentration (in log units) during and after dissolution of the basalt glass, calculated for the respective experiments. Blue arrows show the path of reacted fluids over the time of the experiments. 145

Figure 3.40. Activity diagrams for the $\mathrm{MgO}-\mathrm{Al}_{2} \mathrm{O}_{3}-\mathrm{SiO}_{2}-\mathrm{H}_{2} \mathrm{O}$ systems showing mineral stability fields $(\mathrm{CL} 14 \mathrm{~A}=$ clinochlore) for BW1 and BW2. Black and red crosses show position of effluent sample collected at 1.0 and $0.5 \mathrm{ml} \mathrm{hr}^{-1}$ flow rate, respectively. Yellow circles show position of the unreacted fluid (water) at 400 and $350^{\circ} \mathrm{C} / 500$ bar. Black dotted line indicates quartz saturation while pink dotted lines represent the average of silica concentration (in log units) during and after dissolution of the basalt glass, calculated for the respective experiments. Blue arrows show the path of reacted fluids over the time of the experiments.

Figure 3.41. Activity diagrams for the $\mathrm{Na}_{2} \mathrm{O}-\mathrm{K}_{2} \mathrm{O}-\mathrm{Al}_{2} \mathrm{O}_{3}-\mathrm{SiO}_{2}-\mathrm{H}_{2} \mathrm{O}$ system showing mineral stability fields for $\mathrm{BW} 1(\mathrm{a})$ and BW2(b) during and after glass dissolution. Black and red crosses show position of effluent samples collected at 1.0 and $0.5 \mathrm{ml} \mathrm{hr}^{-}$ ${ }^{1}$ flow rate, respectively. Yellow circles show position of the unreacted fluid (water) at 400 and $350^{\circ} \mathrm{C} / 500$ bar. Blue arrows show the path of reacted fluids over the experiment. 153

Figure 3.42. Estimated temperatures $\left({ }^{\circ} \mathrm{C}\right)$ calculated using several cation geothermometers (Arnórsson, 1983; Fournier, 1979; Giggenbach, 1988b; Nieva and Nieva, 1987; Santoyo and Díaz-González, 2009; Tonani, 1980; Truesdell, 1976) together with $\mathrm{SiO}_{2}$, Na and $\mathrm{K}$ concentrations for BW1 and BW2 plotted versus time. Dotted black lines separate value of $\mathrm{SiO}_{2}$ above quartz saturation (during basalt glass dissolution) from those below quartz saturation (after basalt glass dissolution). Dotted red lines show experimental temperature of BW1 and BW2 over time. n: Sample number.

Figure 4.1. Major element concentrations in blank and effluent samples (mmol kg-1) versus time (hr) for the basalt - geothermal brine experiment at $400^{\circ} \mathrm{C} / 483$ bar (BGB1). Yellow symbols are the blank sample composition of the geothermal brine. Blue symbols are for effluents at room $\mathrm{T} / 483 \mathrm{bar}$ and $1.0 \mathrm{ml} \mathrm{hr}^{-1}$ flow rate. Black symbols are effluents at $400^{\circ} \mathrm{C} / 483 \mathrm{bar}$ and $1.0 \mathrm{ml} \mathrm{hr}-$ ${ }^{1}$ flow rate. Red symbols are effluents at $400^{\circ} \mathrm{C} / 483$ bar and $0.5 \mathrm{ml} \mathrm{hr}^{-1}$ flow rate. In situ $\mathrm{pH}$ is the calculated $\mathrm{pH}$ at temperature.

Figure 4.2. Major element concentrations in blank and effluent samples ( $\mathrm{mmol} \mathrm{kg}^{-1}$ ) versus time (hr) for the basalt - geothermal brine experiment at $400^{\circ} \mathrm{C} / 483$ bar (BGB1). Yellow symbols are the blank sample composition of the geothermal brine. Blue symbols are for effluents at room T/483 bar and $1.0 \mathrm{ml} \mathrm{hr}^{-1}$ flow rate. Black symbols are effluents at $400^{\circ} \mathrm{C} / 483 \mathrm{bar}$ and $1.0 \mathrm{ml} \mathrm{hr}-$ ${ }^{1}$ flow rate. Red symbols are effluents at $400^{\circ} \mathrm{C} / 483$ bar and $0.5 \mathrm{ml} \mathrm{hr}^{-1}$ flow rate. In situ $\mathrm{pH}$ is the calculated pH at temperature.

Figure 4.3. Trace element concentrations in blank and effluent samples ( $\mu \mathrm{mol} \mathrm{kg}{ }^{-1}$ ) versus time (hr) for the basalt - geothermal brine experiment at $400^{\circ} \mathrm{C} / 483$ bar (BGB1). Yellow symbols are the blank sample composition of the geothermal brine. Blue symbols are for effluents at room $\mathrm{T} / 483 \mathrm{bar}$ and $1.0 \mathrm{ml} \mathrm{hr}^{-1}$ flow rate. Black symbols are effluents at $400^{\circ} \mathrm{C} / 483 \mathrm{bar}$ and $1.0 \mathrm{ml} \mathrm{hr}-$ 
Figure 4.4. Trace element concentrations in blank and effluent samples ( $\mu \mathrm{mol} \mathrm{kg} \mathrm{kg}^{-1}$ ) versus time (hr) for the basalt - geothermal brine experiment at $400^{\circ} \mathrm{C} / 483$ bar (BGB1). Yellow symbols are the blank sample composition of the geothermal brine. Blue symbols are for effluents at room $\mathrm{T} / 483 \mathrm{bar}$ and $1.0 \mathrm{ml} \mathrm{hr}^{-1}$ flow rate. Black symbols are effluents at $400^{\circ} \mathrm{C} / 483 \mathrm{bar}^{\mathrm{and}} 1.0 \mathrm{ml} \mathrm{hr}-$ 1 flow rate. 168

Figure 4.5. Schematic diagram (not to scale) showing position (Portion 1 and Portion 2) of reacted basalt grains shown in SEM photographs. 169

Figure 4.6. SEM images of grains collected from the bottom (Portion 1) of the Reactor after the BGB1 experiment (minerals identified by SEM-EDS analysis): a) grain covered by anhydrite (Anh) occurring in isolated tabular euhedral crystals and biotite (Bt) in masses of foliated crystals; (b) reacted grain surface covered by a secondary mineral assemblage consisting of anhydrite and biotite; (c) enlargement of red rectangular area in (b) showing euhedral tabular crystals of anhydrite and stacked hexagonal plates of biotite; (e-f) are enlargements, respectively, of rectangular area in (d) showing biotite appearing in hexagonal stacked crystals.

Figure 4.7. SEM images from the bottom (Portion 1) of the Reactor after the BGB1 experiment (minerals identified by SEMEDS analysis): (a) grain surface showing a Cu-sulfide crystal appearing in hexagonal shape; (b) apatite (Ap), occurring in a radiating group of acicular crystals.

Figure 4.8. SEM backscatter images and EDS compositional maps of an epoxy-mounted, polished grain collected from immediately adjacent to the fluid entry point at bottom (Portion 1) of the Reactor: (a) backscatter image; (b) composite colour image combining the backscatter image and elemental maps for c) $\mathrm{K}$ in green, d) $\mathrm{Ca}$ in blue, and e) $\mathrm{S}$ in red. The composite image shows the anhydrite crystals (violet), biotite (green), unreacted plagioclase and clinopyroxene (blue), olivine (grey), and Fe-Ti oxides (white). 172

Figure 4.9. SEM images of grains collected from the top of the Reactor (Portion 2) : (a) entire grain; (b) enlargement of rectangular area in (a) showing the smectite $(\mathrm{Smc})$ and the primary plagioclase bytownite (Byt); (c) entire grain; d) enlargement of rectangular area in (c) showing typical smectite texture (Smc); (e) image of reacted grain; (f) enlargement of rectangular area in (e) showing the smectite $(\mathrm{Smc})$ and primary clinopyroxene $(\mathrm{Cpx})$ 175

Figure 4.10. SEM backscatter images and EDS compositional maps of an epoxy-mounted, polished grain collected from the top (Portion 2) of the Reactor: (a) backscatter image of entire grain; (b) composite colour image combining the backscatter image and elemental maps for c) $\mathrm{Mg}$ in green, d) $\mathrm{Ca}$ in blue, and e) $\mathrm{Fe}$ in red that shows plagioclase (dark blue), clinopyroxene (turquoise), olivine (yellow green), Fe-Ti oxide (red) and the smectite (green); (f) SEM backscatter image of rectangular area in (a) showing olivine (Ol), titanomagnetite (Tnt) and the $\mathrm{K}-\mathrm{Mg}$-Fe aluminosilicate (Smc). 176

Figure 4.11. Major element concentrations in blank and effluent samples ( $\mathrm{mmol} \mathrm{kg}^{-1}$ ) versus time (hr) for the basalt-geothermal brine experiment at $350^{\circ} \mathrm{C} / 486$ bar (BGB2). Yellow symbols are the blank sample composition of the brine. Blue symbols are for effluents at room $\mathrm{T} / 486$ bar and $1.0 \mathrm{ml} \mathrm{hr}^{-1}$ flow rate. Black symbols are effluents at $350^{\circ} \mathrm{C} / 486 \mathrm{bar}$ and $1.0 \mathrm{ml} \mathrm{hr}{ }^{-1} \mathrm{flow} \mathrm{rate.} \mathrm{In}$ situ $\mathrm{pH}$ is the calculated $\mathrm{pH}$ at temperature.

Figure 4.12. Major element concentrations in blank and effluent samples (mmol kg-1) versus time (hr) for the basalt-geothermal brine experiment at $350^{\circ} \mathrm{C} / 486$ bar (BGB2). Yellow symbols are the blank sample composition of the brine. Blue symbols are for effluents at room $\mathrm{T} / 486$ bar and $1.0 \mathrm{ml} \mathrm{hr}^{-1}$ flow rate. Black symbols are effluents at $350^{\circ} \mathrm{C} / 486 \mathrm{bar}$ and $1.0 \mathrm{ml} \mathrm{hr}^{-1} \mathrm{flow} \mathrm{rate.} \mathrm{In}$ situ $\mathrm{pH}$ is the calculated $\mathrm{pH}$ at temperature. 181

Figure 4.13. Trace element concentrations in blank and effluent samples ( $\mu \mathrm{mol} \mathrm{kg}{ }^{-1}$ ) versus time (hr) for the basalt-geothermal brine experiment at $350^{\circ} \mathrm{C} / 486$ bar (BGB2). Yellow symbols are the blank sample composition of the distilled water. Blue symbols are for effluents at room $\mathrm{T} / 486$ bar and $1.0 \mathrm{ml} \mathrm{hr}^{-1}$ flow rate. Black symbols are effluents at $350^{\circ} \mathrm{C} / 486 \mathrm{bar}$ and $1.0 \mathrm{ml} \mathrm{hr}$ 1 flow rate.

Figure 4.14. Trace element concentrations in blank and effluent samples ( $\mu \mathrm{mol} \mathrm{kg} \mathrm{kg}^{-1}$ ) versus time (hr) for the basalt-geothermal brine experiment at $350^{\circ} \mathrm{C} / 486$ bar (BGB2). Yellow symbols are the blank sample composition of the distilled water. Blue symbols are for effluents at room $\mathrm{T} / 486$ bar and $1.0 \mathrm{ml} \mathrm{hr}^{-1}$ flow rate. Black symbols are effluents at $350^{\circ} \mathrm{C} / 486 \mathrm{bar}$ and $1.0 \mathrm{ml} \mathrm{hr}-$ 1 flow rate...... 184

Figure 4.15. Schematic diagram showing position of Portion 1 and 2 of reacted basalt grains examined by SEM-EDS and the position of the basalt block (not to scale)...

Figure 4.16. SEM images of the surface of a grain collected from the bottom (Portion 1) of the Reactor after the BGB2 experiment: (a) grain with euhedral crystals of anhydrite (Anh), the smectite (Smc) appearing in masses of foliated crystals; (c) higher magnification view of smectite with interlocking rose petal-like morphology; (d) rectangular area shown in (b) the smectite (Na-K-Ca-Mg-Fe aluminosilicate) with rose petal-like morphology (bottom left) and with cornflake morphology (top right).

Figure 4.17. a) and b) SEM images of two $\mathrm{Cu}$-sulfide crystals found on the surface of two reacted grains from the BGB2 experiment 188 
Figure 4.18. SEM backscatter image and EDS compositional maps of an epoxy-mounted polished grain from the bottom (Portion 1) of the Reactor after the BGB2 experiment: a) backscatter image of the entire grain; (b) composite colour image combining the backscatter image and the elemental maps for c) $\mathrm{Mg}$ in green, d) $\mathrm{Ca}$ in blue, and e) Fe in red. The image shows plagioclase (blue), clinopyroxene (turquoise), Ti-Fe oxides (red), olivine (bright green), and the $\mathrm{K}-\mathrm{Na}-\mathrm{Mg}$-Fe aluminosilicate (dark green) on the borders of the grain growing from olivine crystals. 188

Figure 4.19. (a) and (b) SEM backscatter images of enlargements of rectangular areas (n1 and n2) of Figure 4.18a, respectively, showing primary minerals bytownite (Byt), olivine (Ol), titanomagnetite (Tnt) and the $\mathrm{K}-\mathrm{Na}-\mathrm{Mg}-\mathrm{Fe}$ aluminosilicate phase (Smc).

Figure 4.20. SEM images of grains collected from the top (Portion 2) of Reactor after BGB2: (a-b) smectite (Smc) in globular dense masses covering partially the surface of both grains. (c-d) SEM microphotographs of the rectangular areas in (a) and (b) respectively, showing in more detail the smectite.

Figure 4.21. SEM backscatter and EDS compositional maps of an epoxy-mounted polished grain collected from the top (Portion 2) of Reactor after the BGB2 experiment. (a) backscatter image of the entire grain; (b) composite colour image combining the backscatter image and the elemental maps for c) $\mathrm{Mg}$ in green, d) $\mathrm{Ca}$ in blue, and e) Fe in red. The composite image shows plagioclase (dark blue), unaltered clinopyroxene (turquoise), olivine (yellow), Fe-Ti oxides (red), and smectite (green). All data set points in Appendix (C).

Figure 4.22. (a-b) SEM images of the rectangular areas of Figure 4.22a and Figure 4.22b, respectively, plagioclase (Plg), olivine $(\mathrm{Ol})$, primary titanomagnetite and smectite $(\mathrm{Smc})$. The smectite has replaced the primary olivine......

Figure 4.23. SEM backscatter image of the basalt block surface after the BGB2 experiment. Dark gray subhedral spots (white arrows) are voids left by anhydrite crystal that were lost after collection. 195

Figure 4.24. SEM backscatter images of the reacted basalt surface after the BGB2 experiment: (a) enlargement of the red area $\mathrm{n}^{\circ} 1$ in Figure 4.23 showing two crystals of anhydrite surrounded by the smectite (Smc); (b) enlargement of the red area $n^{\circ} 2$ in Figure 4.23 showing spots of anhydrite partially dissolved after cleaning with distilled water; (c) enlargement of the red area $n^{\circ} 3$ in Figure 4.23 showing primary bytownite (Byt), the unknown Na-Ca-Mg-Fe-Ti-Mn aluminosilicate, anhydrite (Anh) and occurring on the plagioclase surface; (d) enlargement of the red area $n^{\circ} 4$ in Figure 4.23 showing primary plagioclase (Byt); (e-f) enlargements of the red areas in (c) and (d), respectively, showing in detail the hexagonal crystals of the unknown aluminosilicate.

Figure 4.25. $\mathrm{SiO}_{2}$ concentration (mmol kg-1) vs time (hr) for $\mathrm{BGB} 1$ and $\mathrm{BGB} 2$ : a) total $\mathrm{SiO}_{2}$ flux for BGB2 based on sample volume and solution compositions (pink area); b) total $\mathrm{SiO}_{2}$ flux from the input brine; c) the difference between a) and b) representing the net $\mathrm{SiO}_{2}$ flux from the rock for $\mathrm{BGB} 2$ (orange area); d) total $\mathrm{SiO}_{2}$ flux for $\mathrm{BGB} 1$ based on sample volume and solution compositions (pink area); e) total $\mathrm{SiO}_{2}$ flux from silicate minerals (green) based on the average $\mathrm{SiO}_{2}$ concentration in the last two samples less the input brine composition (grey); f) the difference between d) and e) representing the total $\mathrm{SiO}_{2}$ flux estimated from glass; $\mathrm{g}$ ) total $\mathrm{SiO}_{2}$ flux released from BGB1 (orange + green area).. 199

Figure 4.26. $\mathrm{Zn}$ and $\mathrm{Cu}\left(\mu \mathrm{mol} \mathrm{kg}{ }^{-1}\right)$ versus $\mathrm{SiO}_{2}$ and $\mathrm{H}_{2} \mathrm{~S}\left(\mu \mathrm{mol} \mathrm{kg}{ }^{-1}\right)$ for BGB1 and BGB2. Symbols in red represent values during glass dissolution, while symbols in blue represent values after glass dissolution. In BGB2, there are no analyses available for trace elements of the reacted fluid compositions collected after glass dissolution. 203

Figure 4.27. Mo and V ( $\mu \mathrm{mol} \mathrm{kg} \mathrm{kg}^{-1}$ ) versus $\mathrm{SiO}_{2}$ and $\mathrm{Mo}\left(\mu \mathrm{mol} \mathrm{kg}{ }^{-1}\right)$ versus $\mathrm{H}_{2} \mathrm{~S}\left(\mu \mathrm{mol} \mathrm{kg}{ }^{-1}\right)$ for BGB1 and BGB2. Symbols in red represent values during glass dissolution, while symbols in blue represent values after glass dissolution. In BGB2, there are no analyses available for trace elements of the reacted fluid compositions collected after basalt glass dissolution. 204

Figure 4.28. Activity diagrams for the $\mathrm{K}_{2} \mathrm{O}-\mathrm{Al}_{2} \mathrm{O}_{3}-\mathrm{SiO}_{2}-\mathrm{H}_{2} \mathrm{O}$ system showing mineral stability fields for $\mathrm{BGB} 1(\mathrm{a})$ and $\mathrm{BGB} 2(\mathrm{~b})$. Black and red crosses show position of effluent samples collected at 1.0 and $0.5 \mathrm{ml} \mathrm{hr}^{-1}$ flow rate, respectively. Yellow circles show position of the unreacted brine at 400 and $350^{\circ} \mathrm{C} / 500$ bar. Black dotted line shows quartz saturation while pink dotted lines represent the average of silica concentration (in log units) during and after dissolution of the basalt glass, calculated for the respective experiments. Blue arrows show the path of reacted fluids over the time of the experiments.....

Figure 4.29. Activity diagrams for the $\mathrm{K}_{2} \mathrm{O}-\mathrm{MgO}-\mathrm{Al}_{2} \mathrm{O}_{3}-\mathrm{SiO}_{2}-\mathrm{H}_{2} \mathrm{O}$ system showing mineral stability fields for $\mathrm{BGB}(\mathrm{a})$ and BGB2(b). Black and red crosses show position of effluent sample collected at 1.0 and $0.5 \mathrm{ml} \mathrm{hr}^{-1}$ flow rate, respectively. Yellow circles show position of the unreacted fluid at 400 and $350^{\circ} \mathrm{C} / 500$ bar. Blue arrows show the path of reacted fluids over the time of the experiments...... 208

Figure 4.30. Activity diagrams for the $\mathrm{Na}_{2} \mathrm{O}-\mathrm{K}_{2} \mathrm{O}-\mathrm{Al}_{2} \mathrm{O}_{3}-\mathrm{SiO}_{2}-\mathrm{H}_{2} \mathrm{O}$ system showing mineral stability fields for $\mathrm{BGB} 1(\mathrm{a})$ and $\mathrm{BGB}$ (b) during and after glass dissolution. Black and red crosses show position of effluent samples collected at 1.0 and $0.5 \mathrm{ml}$ $\mathrm{hr}^{-1}$ flow rate, respectively. Yellow circles show position of the unreacted fluid (geothermal brine) at 400 and $350^{\circ} \mathrm{C} / 500 \mathrm{bar} . .213$

Figure 4.31. Estimated temperatures $\left({ }^{\circ} \mathrm{C}\right)$ calculated using several cation geothermometers (Arnórsson, 1983; Fournier, 1979; Giggenbach, 1988b; Nieva and Nieva, 1987; Santoyo and Díaz-González, 2009; Tonani, 1980; Truesdell, 1976) together with $\mathrm{SiO}_{2}, \mathrm{Na}$ and $\mathrm{K}$ concentrations for BGB1 and BGB2 plotted versus time. Dotted black lines separate value of $\mathrm{SiO}_{2}$ above quartz 
saturation (during basalt glass dissolution) from those below quartz saturation (after basalt glass dissolution). Dotted red lines show experimental temperature of BGB1 and BGB2 over time. n: Sample number.

Figure 4.32. $\mathrm{pH}$ and major ions concentrations in the water and geothermal brine experiments at each temperature.

Figure 5.1. (a) Schematic diagram (not to scale) of the Preheater during the method development test with synthetic seawater (salt powder) without zirconia beads; (b) image of the solid mineral layer extracted from the bottom of the Preheater after completion of the test...

228

Figure 5.2. SEM images of the mineral precipitates extracted from the bottom of the Preheater after the experiment with synthetic seawater. (a-b) mineral clusters composed primarily of euhedral tabular aggregates of anhydrite; (c) enlargement of rectangular area in (b) showing a hexagonal crystal of brucite; (d-e-f) brucite crystals (Brc) on anhydrite surfaces (Anh). Fine material associated with brucite is a Mg-silicate phase, possibly talc (Tlc). 230

Figure 5.3. Major element concentrations in blank and effluent samples ( $\mathrm{mmol} \mathrm{kg}^{-1}$ ) versus time (hr) for the SW1 experiment at $377^{\circ} \mathrm{C} / 488$ bar and $1.0 \mathrm{ml} \mathrm{hr}^{-1}$ flow rate. Yellow symbols are the blank sample composition of natural seawater. Blue symbols show where distilled water was exiting the Preheater. Black symbols are effluent compositions during mixing and replacement of distilled water by seawater.

Figure 5.4. Major element concentrations in blank and effluent samples ( $\mathrm{mmol} \mathrm{kg}^{-1}$ ) versus time (hr) for the SW1 experiment at $377^{\circ} \mathrm{C} / 488$ bar and $1.0 \mathrm{ml} \mathrm{hr}{ }^{-1}$ flow rate. Yellow symbols are the blank sample composition of natural seawater. Blue symbols show where distilled water was exiting the Preheater. Black symbols are effluent compositions during mixing and replacement of distilled water by seawater. 234

Figure 5.5. Trace element concentrations in blank and effluent samples ( $\mu \mathrm{mol} \mathrm{kg}{ }^{-1}$ ) versus time (hr) for the SW1 experiment at $377^{\circ} \mathrm{C} / 488$ bar and $1.0 \mathrm{ml} \mathrm{hr}{ }^{-1}$ flow rate. Yellow symbols are the blank sample composition of natural seawater. Blue symbols show where distilled water was exiting the Preheater. Black symbols are effluent compositions during mixing and replacement of distilled water by seawater. 236

Figure 5.6. Trace element concentrations in blank and effluent samples ( $\mu \mathrm{mol} \mathrm{kg} \mathrm{kg}^{-1}$ ) versus time (hr) for the SW1 experiment at $377^{\circ} \mathrm{C} / 488$ bar and $1.0 \mathrm{ml} \mathrm{hr}^{-1}$ flow rate. Yellow symbols are the blank sample composition of natural seawater. Blue symbols show where distilled water was exiting the Preheater. Black symbols are effluent compositions during mixing and replacement of distilled water by seawater.

Figure 5.7. Schematic diagram (not to scale) of the Preheater for the SW1 experiment with natural seawater. Rectangular area in red indicates where reacted $\mathrm{ZrO}_{2}$ beads were collected.

238

Figure 5.8. SEM backscatter images and EDS compositional maps of the precipitate collected from the bottom of the Preheater after the SW1 experiment: (a) digital camera image of the precipitate; (b) backscatter image of rectangular area in (a); (c) composite colour image combining the backscatter image and elemental maps for d) $\mathrm{Ca}$ in green, e) $\mathrm{Mg}$ in red, and f) $\mathrm{S}$ in blue.

240

Figure 5.9. SEM images of reacted $\mathrm{ZrO}_{2}$ beads collected from the bottom of the Preheater after the SW1 experiment: a) SED image of a single bead with one caminite crystal and diamond-shaped growths of brucite; b) SED image of a single bead with several crystals of caminite; c) BED image of bead with of anhydrite (Anh) and caminite; (d) BED image showing a caminite crystal with intergrown brucite; (e) SEM backscatter image of rectangular area in (a) showing diamond-shaped growth of brucite; (f) composite colour image combining the backscatter image and elemental map for $\mathrm{Mg}$ in red.

Figure 5.10. Major element concentrations in blank and effluent samples ( $\mathrm{mmol} \mathrm{kg}^{-1}$ ) versus time (hr) for the SW2 experiment at $342^{\circ} \mathrm{C} / 488$ bar and $1.0 \mathrm{ml} \mathrm{hr}^{-1}$ flow rate. Yellow symbols are the blank sample composition of natural seawater. Blue symbols show where distilled water was exiting the Preheater. Black symbols are effluent compositions during mixing and replacement of distilled water by seawater. 244

Figure 5.11. Major element concentrations in blank and effluent samples ( $\mathrm{mmol} \mathrm{kg}^{-1}$ ) versus time (hr) for the SW2 experiment at $342^{\circ} \mathrm{C} / 488$ bar and $1.0 \mathrm{ml} \mathrm{hr}^{-1}$ flow rate. Yellow symbols are the blank sample composition of natural seawater. Blue symbols show where distilled water was exiting the Preheater. Black symbols are effluent compositions during mixing and replacement of distilled water by seawater.

245

Figure 5.12. Trace element concentrations in blank and effluent samples ( $\mu \mathrm{mol} \mathrm{kg} \mathrm{kg}^{-1}$ ) versus time (hr) for the SW2 experiment at $342^{\circ} \mathrm{C} / 488$ bar and $1.0 \mathrm{ml} \mathrm{hr}^{-1}$ flow rate. Yellow symbols are the blank sample composition of natural seawater. Blue symbols show where distilled water was exiting the Preheater. Black symbols are effluent compositions during mixing and replacement of distilled water by seawater. 247

Figure 5.13. Trace element concentrations in blank and effluent samples ( $\mu \mathrm{mol} \mathrm{kg} \mathrm{kg}^{-1}$ ) versus time (hr) for the $\mathrm{SW} 2$ experiment at $342^{\circ} \mathrm{C} / 488$ bar and $1.0 \mathrm{ml} \mathrm{hr}{ }^{-1}$ flow rate. Yellow symbols are the blank sample composition of natural seawater. Blue symbols 
show where distilled water was exiting the Preheater. Black symbols are effluent compositions during mixing and replacement of distilled water by seawater.

Figure 5.14. Schematic diagram (not to scale) of the Preheater for the SW2 experiment with natural seawater. Rectangular area in red indicates where reacted $\mathrm{ZrO}_{2}$ beads were collected.

Figure 5.15. SEM images of reacted $\mathrm{ZrO}_{2}$ beads collected from the bottom of the Preheater: (a) image of three reacted beads with precipitated phases; (b) surface of a reacted bead with the caminite and anhydrite (Anh); (c) surface area of a reacted bead with crystals of brucite; (d) a single brucite crystal.

251

Figure 5.16. $\log Q$ and $\log K_{\text {sp }}$ for anhydrite (a) and brucite (b). $\log K_{\text {sp }}$ for anhydrite and brucite from SUPCRT92. Log $K_{\text {sp }}$ for caminite (c) from Janecky and Seyfried (1983) (MHSH(0.625)) and compared with log Q from the experiment data in this study.

Figure 6.1. Major element concentrations in blank and effluent samples ( $\mathrm{mmol} \mathrm{kg}^{-1}$ ) versus time (hr) for the BSW1 experiment at $400^{\circ} \mathrm{C} / 488$ bar. Yellow squares at $\mathrm{t}=0$ are the blank sample composition of seawater from SW1. Light blue symbols show where distilled water was exiting the Reactor at $400^{\circ} \mathrm{C} / 488$ bar and $1.0 \mathrm{ml} \mathrm{hr}^{-1}$. Black symbols are effluent compositions (seawater) at $400^{\circ} \mathrm{C} / 488$ bar and $1.0 \mathrm{ml} \mathrm{hr}{ }^{-1}$ flow rate. Other coloured symbols show effluent compositions at different flow rates. In situ pH is the calculated $\mathrm{pH}$ at temperature. $\mathrm{LOD}=$ limit of detection.

Figure 6.2. Major element concentrations in blank and effluent samples ( $\mathrm{mmol} \mathrm{kg}^{-1}$ ) versus time (hr) for the BSW1 experiment at $400^{\circ} \mathrm{C} / 488$ bar. Yellow squares at $\mathrm{t}=0$ are the input composition of seawater from SW1. Light blue symbols show where distilled water was exiting the Reactor at $400^{\circ} \mathrm{C} / 488$ bar and $1.0 \mathrm{ml} \mathrm{hr}^{-1}$. Black symbols are effluent compositions at $400^{\circ} \mathrm{C} / 488 \mathrm{bar}$ and $1.0 \mathrm{ml} \mathrm{hr}{ }^{-1}$ flow rate. Other coloured symbols are effluent compositions at differing flow rate. In situ $\mathrm{pH}$ is the calculated $\mathrm{pH}$ at temperature. $\mathrm{LOD}=$ limit of detection. 266

Figure 6.3. Trace element concentrations in blank and effluent samples ( $\mu \mathrm{mol} \mathrm{kg}{ }^{-1}$ ) versus time (hr) for the basalt-seawater experiment at $400^{\circ} \mathrm{C} / 488$ bar (BSW1). Yellow squares at $\mathrm{t}=0$ are the blank composition of seawater from SW1. Light blue symbols show where distilled water was exiting the Reactor at $400^{\circ} \mathrm{C} / 488$ bar and $1.0 \mathrm{ml} \mathrm{hr}{ }^{-1}$. Black symbols are effluent compositions at $400^{\circ} \mathrm{C} / 488$ bar and $1.0 \mathrm{ml} \mathrm{hr}^{-1}$ flow rate. Other coloured symbols are effluent composition at differing flow rate. In situ $\mathrm{pH}$ is the calculated $\mathrm{pH}$ at temperature. $\mathrm{LOD}=$ limit of detection. 268

Figure 6.4. Trace element concentrations in blank and effluent samples ( $\mu \mathrm{mol} \mathrm{kg}{ }^{-1}$ ) versus time (hr) for the basalt-seawater experiment at $400^{\circ} \mathrm{C} / 488$ bar (BSW1). Yellow squares are the blank composition of seawater from SW1. Light blue symbols show where distilled water was exiting the Reactor at $400^{\circ} \mathrm{C} / 488$ bar and $1.0 \mathrm{ml} \mathrm{hr}{ }^{-1}$. Black symbols are effluent compositions at $400^{\circ} \mathrm{C} / 488$ bar and $1.0 \mathrm{ml} \mathrm{hr}^{-1}$ flow rate. Other coloured symbols are effluent compositions at differing flow rate. In situ $\mathrm{pH}$ is the calculated $\mathrm{pH}$ at temperature. $\mathrm{LOD}=$ limit of detection. 269

Figure 6.5. Schematic diagram showing position of reacted rock extracted from the Reactor after the completion of the BSW1 (not to scale). On the left, the reacted grains are shown after extraction and rinsing. On the right, are the same grains divided in seven portions numbered from 1 (bottom of the Reactor) to 7 (top of the Reactor). Also shown is the position of the basalt block.

271

Figure 6.6. Chemical composition (wt\%) of rock Portions analysed by XRF plotted against position in Reactor column (red circles). The unreacted basalt compositions shown by blue line. 275

Figure 6.7. SEM images of grains collected from the immediately adjacent fluid entry point (bottom) of the Reactor after $396 \mathrm{hrs}$ of the BSW1 experiment: (a) example of a reacted grain; (b-c) enlargements of rectangular area in (a) showing densely-packed flakes of chlorite $(\mathrm{Chl})$, euhedral crystals of anhydrite (Anh) and caminite with its tetragonal dipyramidal shape; (d) a different reacted grain; (e-f) enlargements of rectangular area in (d) showing an euhedral crystal of anhydrite (Anh) surrounded by chlorite (Chl).......

Figure 6.8. SEM images of the reacted grains collected from near the fluid exit point of the Reactor after 396 hrs of the BSW1 experiment: (a) example of a reacted grain; (b) enlargement of rectangular area ${ }^{\circ} 1$ in (a) showing the Na-Fe-Mg phase identified as smectite (Smc); (c) enlargement of rectangular area $n^{\circ} 2$ in (a) showing caminite in pyramidal shape surrounded by smectite (Smc); (d-e-f) three different reacted grains collected from the same Portion at top of the Reactor. 279

Figure 6.9. SEM images of reacted grains from Portion 1 after the BSW1 experiment: (a-b-c-d) grains covered by chlorite with caminite (e,f). 281

Figure 6.10. SEM backscatter and EDS compositional maps of a polished grain from the Portion 1 of the BSW1 experiment: (a) backscatter image; (b) composite colour image combining the backscatter image and elemental maps for c) $\mathrm{Mg}$ in green, d) Fe in red, and e) $\mathrm{Ca}$ in blue showing plagioclase (blue), clinopyroxene (light blue), secondary chlorite (green), olivine (orange-yellow), and Fe-Ti oxides (red); (f-g) SEM backscatter images of the rectangular areas $n^{\circ} 1$ and $n^{\circ} 2$ in (a) showing secondary chlorite $(\mathrm{Chl})$, plagioclase $(\mathrm{Plg})$, clinopyroxene $(\mathrm{Cpx})$, olivine $(\mathrm{Ol})$ and titanomagnetite $(\mathrm{Ox})$...... 282 
Figure 6.11. SEM backscatter and EDS compositional maps of two polished grains collected from the Portion 2-3 after the BSW1 experiment. (a) backscatter image of a reacted grain; (b) composite colour image combining the backscatter image and elemental maps for c) Mg in green and d) Fe in red showing secondary chlorite (green) with Fe oxides (red); (e) backscatter image of a second reacted grain; (b) composite colour image combining the backscatter image and elemental maps for g) $\mathrm{Mg}$ in green and h) Fe in red showing only chlorite (green) with Fe oxides (red). 283

Figure 6.12. (a-b) SEM secondary electron images of the two red rectangular areas shown in Figure 6.11a; (c-d) SEM backscatter images of the same two areas in (a-b). They show that the grains are completely replaced by chlorite with some primary but altered titanomagnetite (white spots). No primary plagioclase, clinopyroxene or olivine are present. Black holes are spaces void left by plagioclase dissolution. 284

Figure 6.13. SEM backscatter and EDS compositional maps of a polished grain from the Portion 4 after the BSW1 experiment: (a) backscatter image; (b) composite colour image combining the backscatter image and elemental maps for c) Mg in green, d) Fe in red, and e) $\mathrm{Ca}$ in blue showing plagioclase (blue), clinopyroxene (light blue), olivine (yellow), oxides (red) and smectite (green); (g-h) SEM backscatter images of the two red rectangular areas shown in (a). The grain is covered around the margin and internally by smectite $(\mathrm{Smc})$, with plagioclase $(\mathrm{Plg})$, clinopyroxene $(\mathrm{Cpx})$, olivine $(\mathrm{Ol})$ and titanomagnetite $(\mathrm{Ox}) \ldots \ldots \ldots \ldots \ldots \ldots . . . .286$

Figure 6.14. SEM backscatter and EDS compositional maps of a polished grain collected from the Portion 7 after the BSW1 experiment: (a) backscatter image of the reacted grain; (b) composite colour image combining the backscatter image and elemental maps for c) $\mathrm{Mg}$ in green, d) $\mathrm{Fe}$ in red, and e) $\mathrm{Ca}$ in blue showing plagioclase (blue), clinopyroxene (turquoise), olivine (orange-yellow), Fe-Ti oxides (red), and smectite (green); (f-g) SEM backscatter images of the two rectangular areas shown in (a). Images show a thin covering of smectite $(\mathrm{Smc})$ with primary plagioclase $(\mathrm{Plg})$, clinopyroxene $(\mathrm{Cpx})$, olivine $(\mathrm{Ol})$ and titanomagnetite (Tnt). 288

Figure 6.15. Composite image of reacted grains, backscatter images, and elemental maps of the epoxy-mounted, polished grains analysed from the BSW1 experiment. Flow direction is from the bottom of the figure to the top. The change in intensity of the alteration upwards is evident due to replacement by chlorite and smectite. 289

Figure 6.16. Digital photograph of the basalt block fragments extracted from the bottom of the Reactor after the BSW1 experiment. The block was originally $8 \times 8 \times 4 \mathrm{~mm}$. 290

Figure 6.17. Major element concentrations in blank and effluent samples ( $\mathrm{mmol} \mathrm{kg}^{-1}$ ) versus time (hr) for the BSW2 experiment at $350^{\circ} \mathrm{C} / 488$ bar. Yellow squares at $\mathrm{t}=0$ are the blank sample composition of seawater from SW2. Light blue symbols show where distilled water was exiting the Reactor at $350^{\circ} \mathrm{C} / 488$ bar and $1.0 \mathrm{ml} \mathrm{hr}^{-1}$. Black symbols are effluent compositions containing seawater at $350^{\circ} \mathrm{C} / 488$ bar and $1.0 \mathrm{ml} \mathrm{hr}^{-1}$ flow rate. Other coloured symbols show effluent compositions at different flow rates. In situ $\mathrm{pH}$ is the calculated $\mathrm{pH}$ at temperature. $\mathrm{LOD}=$ limit of detection. 294

Figure 6.18. Major element concentrations in blank and effluent samples ( $\mathrm{mmol} \mathrm{kg}^{-1}$ ) versus time (hr) for the BSW2 experiment at $350^{\circ} \mathrm{C} / 488$ bar. Yellow squares at $\mathrm{t}=0$ are the input composition of seawater from SW2. Light blue symbols show where distilled water was exiting the Reactor at $350^{\circ} \mathrm{C} / 488$ bar and $1.0 \mathrm{ml} \mathrm{hr}^{-1}$. Black symbols are effluent compositions containing seawater at $350^{\circ} \mathrm{C} / 488$ bar and $1.0 \mathrm{ml} \mathrm{hr}^{-1}$ flow rate. Other coloured symbols show effluent compositions at different flow rates. In situ $\mathrm{pH}$ is the calculated $\mathrm{pH}$ at temperature. $\mathrm{LOD}=$ limit of detection. 295

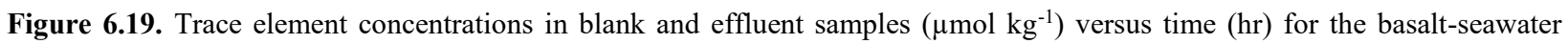
experiment at $350^{\circ} \mathrm{C} / 488$ bar (BSW2). Yellow squares at $\mathrm{t}=0$ are the blank composition of seawater from SW2. Light blue symbols show where distilled water was exiting the Reactor at $350^{\circ} \mathrm{C} / 488$ bar and $1.0 \mathrm{ml} \mathrm{hr}^{-1}$. Black symbols are effluent compositions at $350^{\circ} \mathrm{C} / 488$ bar and $1.0 \mathrm{ml} \mathrm{hr}^{-1}$ flow rate. Other coloured symbols are effluent compositions at differing flow rate. In situ $\mathrm{pH}$ is the calculated $\mathrm{pH}$ at temperature. $\mathrm{LOD}=$ limit of detection. 297

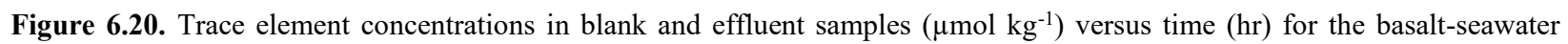
experiment at $350^{\circ} \mathrm{C} / 488$ bar (BSW2). Yellow squares at $\mathrm{t}=0$ are the blank composition of seawater from SW2. Light blue symbols show where distilled water was exiting the Reactor at $350^{\circ} \mathrm{C} / 488$ bar and $1.0 \mathrm{ml} \mathrm{hr}^{-1}$. Black symbols are effluent compositions at $350^{\circ} \mathrm{C} / 488$ bar and $1.0 \mathrm{ml} \mathrm{hr}^{-1}$ flow rate. Other coloured symbols are effluent compositions at differing flow rate. In situ $\mathrm{pH}$ is the calculated $\mathrm{pH}$ at temperature. $\mathrm{LOD}=$ limit of detection. 298

Figure 6.21. Schematic diagram showing position of reacted basalt portions extracted from the Reactor after completion of the BSW2 experiment (not to scale). On the right, are the reacted grains divided in 5 portions numbered from 1 (bottom of the Reactor) to 5 (top of the Reactor). Also shown is the position of the basalt block. 300

Figure 6.22. Chemical composition (wt \%) of rock Portions analysed by XRF plotted against position in Reactor column (red circles). The unreacted basalt compositions shown by blue line. 303

Figure 6.23. SEM images of reacted grains collected from Portion 1 of the Reactor after the BSW2 experiment: (a-f) grains covered by a surface coating of chlorite with isolated and intergrown anhydrite crystals. 305

Figure 6.24. SEM images and EDS compositional maps of an epoxy-mounted, polished grain collected from the Portion 1 after the BSW2 experiment: (a) backscatter image of the reacted grain; (b) composite colour image combining the backscatter image and elemental maps for c) $\mathrm{Mg}$ in green, d) $\mathrm{Ca}$ in blue, and e) Fe in red showing plagioclase (blue) and clinopyroxene (light blue), 
olivine (yellow), Fe-Ti oxides (red), and chlorite (green); (f-g) SEM backscatter images of the red rectangular areas $\mathrm{n}^{\circ} 1$ and $\mathrm{n}^{\circ} 2$ in (a) showing secondary chlorite $(\mathrm{Chl})$, the plagioclase $(\mathrm{Plg})$ and clinopyroxene $(\mathrm{Cpx})$, olivine $(\mathrm{Ol})$ and oxides $(\mathrm{Ox})$. 306

Figure 6.25. SEM images and EDS compositional maps of an epoxy-mounted, polished grain collected from the Portion 2-3 after the BSW2 experiment: (a) backscatter image; (b) composite colour image combining the backscatter image and elemental maps for c) Fe in red, d) $\mathrm{Ca}$ in blue and e) $\mathrm{Mg}$ in green showing plagioclase (blue), Fe-Ti oxides (red), and chlorite (green); (f-g) SEM backscatter images of the two rectangular areas shown in (a). 308

Figure 6.26. SEM images and EDS compositional maps of a polished grain collected from the Portion 2-3 after the BSW2 experiment: (a) backscatter image; (b) composite colour image combining the backscatter image and elemental maps for c) Mg in green, d) $\mathrm{Ca}$ in blue and e) Fe in red showing plagioclase (blue), Fe-Ti oxides (red), and smectite (green); f-g) SEM backscatter images of the two rectangular areas shown in (a). The grain has been largely replaced by smectite. 308

Figure 6.27. SEM images and EDS compositional maps of a polished grain from the Portion 4-5 after the BSW2 experiment: (a) backscatter image; (b) composite colour image combining the backscatter image and elemental maps for c) $\mathrm{Mg}$ in green, d) Ca in blue and e) $\mathrm{Fe}$ in red showing plagioclase (blue), and clinopyroxene (light blue), Fe-Ti oxides (red), and the secondary Na-Mg-Fe aluminosilicate (green) growing on the outside edge of the grain; (f-g) SEM backscatter images of the two $\mid$ rectangular areas shown in Figure 6.28(a).

Figure 6.28. Composite image showing the changing intensity of alteration of reacted grains analysed from the BSW 2 experiment. Flow direction is from the bottom to the top of the image. The decreasing degree of alteration is evident from the bleaching of the rock due to replacement by chlorite and smectite.

Figure 6.29. (a) SEM backscatter photomosaic of the basalt block surface before the BSW2 experiment. (b) SEM backscatter photomosaic of the basalt block surface after the BSW2 experiment. 315

Figure 6.30. SEM backscatter images of the reacted basalt block surface after the BSW2 experiment. This surface is covered by $\mathrm{Ni}$ - oxide 316

Figure 6.31. $\mathrm{pH}$ and major element concentrations in the seawater-only and seawater-basalt experiments at each temperature. 320

Figure 6.32. Mass changes ( $100 \mathrm{~g}^{-1}$ rock) of the Portions analysed by XRF plotted against position in Reactor column for the BSW1 (red) and for the BSW2 (yellow). The unreacted basalt composition is shown by black line. 329

Figure 6.33. Activity-activity diagrams showing mineral stability fields in the $\mathrm{MgO}-\mathrm{Al}_{2} \mathrm{O}_{3}-\mathrm{SiO}_{2}-\mathrm{H}_{2} \mathrm{O}$ system for a) the BSW1 $\left(400^{\circ} \mathrm{C} / 488\right.$ bar $)$ and b) the BSW2 $\left(350^{\circ} \mathrm{C} / 488\right.$ bar) experiment. Yellow circles show position of the output fluid composition from SW1 and SW2 at 377 and $342^{\circ} \mathrm{C} / 488$ bar, respectively. Arrows indicate fluid-path. Symbol colour refers to different flow rates as shown in the legend below the figure.

Figure 6.34. Activity-activity diagram showing mineral stability fields in the $\mathrm{MgO}-\mathrm{Al}_{2} \mathrm{O}_{3}-\mathrm{SiO}_{2}-\mathrm{H}_{2} \mathrm{O}$ system at $300^{\circ} \mathrm{C}$ using the phases in Figure 6.33 with the addition of Mg-saponite. Diagram constructed using GWB (Bethke, 1996) ..................... 333

Figure 6.35. The concentration of $\mathrm{Ca}, \mathrm{Mg}$ and $\mathrm{Fe}\left(\mathrm{mmol} \mathrm{kg}^{-1}\right)$ versus flow rate $\left(\mathrm{ml} \mathrm{hr}^{-1}\right)$ during the BSW experiments........... 337

Figure 7.1. Summary of the $\mathrm{pH}$ and major species concentrations in the water, geothermal brine and seawater experiments.... 356 


\section{List of tables}

Table 1.1. Mafic/Ultramafic rock - fluid interaction experiments carried out from the 1970 s to the present.

Table 2.1. Experimental protocols for the eight experiments conducted in this study.

Table 2.2. Major and trace element composition of the basalt (Peate et al., 2008).

Table 2.3. Mineral phase, ID and average mineral compositions determined by EMPA

Table 2.4. Quantitative XRD analysis of unreacted basalt. Margin of error: Abundance estimate are determined through successive refinement of cell parameters; the position, width and orientation of each mineral. Values are given to the nearest whole number. The margin of error for phase concentration is as follow: $0-10 \% \pm 10 \% ; 10-50 \% \pm 5 \% ; 50-100 \% \pm 2 \% \ldots \ldots .47$

Table 2.5. Starting experimental fluid compositions including major cations, anions, $\mathrm{H}_{2} \mathrm{~S}$ and $\mathrm{SO}_{4}{ }^{2-}\left(\mathrm{mmol} \mathrm{kg}^{-1}\right)$, trace elements $\left(\mu \mathrm{mol} \mathrm{kg} \mathrm{kg}^{-1}\right)$ and $\mathrm{pH}$ values at room temperature. Cells colours and number of the experiments refer to Table 2.1. n.a.: not analyzed.

Table 2.6. Mineralogical and chemical analytical methods for unreacted and reacted rock materials ..................................... 76

Table 2.7. Chemical analytical methods for experimental solutions ......

Table 2.8. Aqueous species and parameters used in the equilibrium solver spread-sheet linked to EqSolvR (Stefan Mroczek and Ed Mroczek, 2017). Log K data taken from Supcrt.92 slop98.dat database (http://geopig.asu.edu/?q=tools). The Debye-Hückel parameters $(A, B$ and $\dot{B})$ data were sourced from (Helgeson and Kirkham, 1974).

Table 3.1. Mineral assemblage detected by EMPA and SEM-EDS analysis of reacted grains extracted from bottom (Portion 1) of the Reactor after the BW1 experiment. Appendix B contains all SEM and EMPA results for this portion of the rock.

Table 3.2. Mineral assemblage found during analysis of reacted grains extracted from top of the Reactor (Portion 2) after the BW1 experiment. Analysis were made by SEM-EDS. Appendix B contains all SEM and EMPA results for this portion of the rock. . . 102

Table 3.3. Average composition (by SEM-EDS analysis) of the micaceous phase (celadonite) found during study of the reacted grains collected from the top (Portion 2) of the Reactor after the BW1 experiment. Empirical formulas reported in Table 3.2 . 105

Table 3.4. Mineral composition of reacted basalt block surface after the BW1 experiment. Appendix B contains all SEM results.

Table 3.5. Average composition (SEM-EDS analysis) of celadonite found during study of the reacted basalt surface collected from the bottom of the Reactor after the BW1. Empirical formula reported in Table 3.4. 109

Table 3.6. Mineral assemblage detected by EMPA and SEM-EDS analysis of reacted grains extracted from bottom (Portion 1) of the Reactor after the BW2 experiment. Appendix B contains all SEM and EMPA results. 119

Table 3.7. Mineral assemblage found during analysis of reacted grains collected from the top (Portion 2) of the Reactor after the BW2 experiment. Appendix B contains all SEM results for this portion of the rock.

Table 3.8. Average oxides composition (by SEM-EDS analysis) of celadonite found during the morphological examination and from the epoxy-mounted polished section study of grains collected from the top (Portion 2) of the Reactor after the BW2. Empirical formulas reported in Table 3.7. n.d.= not detected. 126

Table 3.9. Mineral composition of the reacted basalt block after the BW2 experiment 127

Table 3.10. Mass flux of major elements estimated by dissolution of volcanic glass and from the fluid sample compositions over the BW1 and BW2.

Table 3.11. Average and $1 \sigma$ of estimated temperature $\left({ }^{\circ} \mathrm{C}\right)$ during and after basalt glass dissolution using fluid compositions for the BW1 and BW2. Estimates were made using several geothermometers from literature (Arnórsson, 1983; Fournier and Truesdell, 1973; Fournier, 1979; Giggenbach, 1988b; Nieva and Nieva, 1987; Santoyo and Díaz-González, 2009; Tonani, 1980; Truesdell, 1976).

Table 4.1. Mineral assemblage detected by EMPA and SEM-EDS analysis of reacted grains extracted from the bottom (Portion 1) of Reactor after the BGB1 experiment. Appendix (C) contains all SEM and EMPA results for this portion of the rock......... 170 
Table 4.2. Mineral assemblage found during analysis of reacted grains extracted from top (Portion 2) of the Reactor after the BGB1 experiment. Analysis were effectuated by SEM-EDS. Appendix (C) contains all SEM results for this Portion of the rock.

Table 4.3. Average EDS analysis (wt. \%) of the smectite identified at top of the Reactor (epoxy mount). N: number of analysis effectuated. 177

Table 4.4. Mineral assemblage detected by SEM-EDS analysis of reacted grains extracted from the bottom (Portion 1) of the Reactor after the BGB2 experiment.

Table 4.5. Average EDS analysis (wt. \%) of the smectite identified at bottom of the Reactor (grains morphology). N: number of analysis.

Table 4.6. Mineral assemblage found during analysis of reacted grains extracted from the top (Portion 2) of the Reactor after the BGB2. Analysis were effectuated by SEM-EDS. Appendix (C) contains all SEM results for this portion of the rock. 191

Table 4.7. Average EDS analysis (wt. \%) of the K-Na-Ca-Mg-Fe aluminosilicate phase (smectite) identified at top of the Reactor (grains morphology and epoxy-mount). N: number of analysis. All data set points in Appendix (C). 194

Table 4.8. Mineral composition of the reacted basalt block surface after the BGB2. 194

Table 4.9. Total input mass (mg) and integrated elemental fluxes (mg) for selected components in BGB2 and BGB1. 200

Tale 4.10. Average and $1 \sigma$ of estimated temperature $\left({ }^{\circ} \mathrm{C}\right)$ during and after basalt glass dissolution using fluid compositions for the BGB1 and BGB2. Estimates were made using geothermometers from literature (Arnórsson, 1983; Fournier and Truesdell, 1973; Fournier, 1979; Giggenbach, 1988b; Nieva and Nieva, 1987; Santoyo and Díaz-González, 2009; Tonani, 1980; Truesdell, 1976).

Table 4.11. Secondary mineral assemblage identified after completion of the experiments with water and geothermal brine at 400 and $350^{\circ} \mathrm{C}$.

Table 5.1. Mineral phases identified during analysis of the precipitates collected from the bottom of the Preheater (Fig. 5.8 - 5.9) after the SW1 experiment. Analysis were made by SEM-EDS. Appendix D contains all SEM for this study.

Table 5.2. Average composition (SEM-EDS analysis) of caminite from the bottom of the Preheater (Fig. 5.8 - 5.9) after the SW1 experiment. .....

Table 5.3. Mineral phases identified during analysis of the precipitates from the bottom of the Preheater (Fig. 5.15) after the SW2 experiment. Analysis were made by SEM-EDS. Appendix D contains all SEM for this study.

Table 5.4. Average composition (SEM-EDS analysis) of caminite from the bottom of the Preheater (Fig. 5.15) after the SW2 experiment. .

Table 5.5. Total input mass $(\mathrm{mg})$ and integrated elemental fluxes $(\mathrm{mg})$ for selected components for SW1 and SW2 .............. 253

Table 5.6. Comparison between experimental results of Bischoff and Seyfried (1978) and this study...... 256

Table 6.1. Qualitative XRD analysis of Portion 1, 2-3, 4 and 7 from BSW1.

Table 6.2. XRF analysis of the reacted material collected from Portion 1, 2-3, 4 and 7 after the BSW1 experiment (wt\%). Also shown is the composition of the unreacted basalt rock. n.d.: not detected, n.m.: not measured.

Table 6.3. Correlation matrix of major oxides and sulfur for analyses shown in Table 6.2. Correlation coefficients significant at the $95 \%$ level are highlighted in yellow...... 274

Table 6.4. Mineral assemblage identified by SEM-EDS analysis of reacted grains extracted from the immediately adjacent to the fluid entry point into the Reactor after 396 hours of the BSW1 experiment. 276

Table 6.5. Mineral assemblage identified by SEM-EDS analysis of reacted grains extracted from the immediately adjacent to the fluid exit point of the Reactor after $396 \mathrm{hrs}$ of the BSW1 experiment.

Table 6.6. Average composition (by SEM-EDS analysis) of the clay-like phase found during study of the reacted grains collected from the immediately adjacent to the fluid exit point (top) of the Reactor after $393.6 \mathrm{hrs}$ of the BSW1. This phase is tentatively identified as smectite. 280

Table 6.7. Mineral assemblage identified by SEM-EDS analysis of reacted grains of Portion 1 after the BSW1 experiment..... 280

Table 6.8. Mineral assemblage detected by SEM-EDS analysis of reacted grains of Portion 2-3. 283 
Table 6.9. Mineral assemblage detected by SEM-EDS analysis of reacted grains of Portion 4 after the BSW1.

Table 6.10. Average composition (SEM-EDS) of the clay mineral phase found in Portion 4 after the completion (659 hrs) of the BSW1 experiment. This phase is tentatively identified as smectite.

Table 6.11. Mineral assemblage detected by SEM-EDS analysis of reacted grains of Portion 7 after the BSW1.

Table 6.12. Average composition (SEM-EDS) of the Na-Fe-Mg aluminosilicate phase found during study of the reacted grains collected from Portion 7 after the completion (659 hrs) of the BSW1 experiment.

Table 6.13. Qualitative XRD analysis of Portion 1, 2-3, 4-5 from BSW2.

Table 6.14. XRF analysis of the reacted material collected from Portion 1, 2-3, 4-5 after the BSW2 experiment (wt\%). Also shown is the composition of the unreacted basalt rock. n.m.: not measured.

Table 6.15. Correlation matrix of major oxides and sulfur for analyses shown in Table 6.14. Correlation coefficients significant at the $95 \%$ level are highlighted in yellow. 302

Table 6.16. Mineral assemblage identified by SEM-EDS analysis of the surface of reacted grains of Portion 1 after completion of the BSW2 experiment. 304

Table 6.17. Mineral assemblage identified by SEM-EDS analysis of reacted grains from Portion 2-3 after the BSW2 experiment. Only the compositions of plagioclase, chlorite and smectite were measured. 307

Table 6.18. Average composition (SEM-EDS) of smectite found in Portion 2-3 after the completion of the BSW2 experiment. 309

Table 6.19. Mineral assemblage detected by SEM-EDS analysis of reacted grains of Portion 4-5 after the BSW2 experiment. 310

Table 6.20. Average composition (by SEM-EDS analysis) of the clay mineral phase found during study of the reacted grains collected from Portion 4-5 after the BSW2

Table 6.21. Input and output fluid compositions $\left(\mathrm{mmol} \mathrm{kg}^{-1}\right)$ of seawater for selected components during the SW1 and BSW1 experiment. 318

Table 6.22. Input and output fluid compositions $\left(\mathrm{mmol} \mathrm{kg}^{-1}\right)$ of seawater for selected components during the SW2 and BSW2 experiment. ..... 318

Table 6.23. Total input mass $(\mathrm{mg})$ and integrated elemental fluxes $(\mathrm{mg})$ for selected components for BSW 2 and BSW1......... 322

Table 6.24. Comparison of $\mathrm{Fe}, \mathrm{Mn}, \mathrm{Zn}, \mathrm{Cu}, \mathrm{Li}(\mu \mathrm{mol} \mathrm{kg}-1=\mu \mathrm{m})$ and $\mathrm{H}_{2} \mathrm{~S}\left(\mathrm{mmol} \mathrm{kg}^{-1}=\mathrm{mm}\right)$ concentrations between previous experiments (Mottl et al., 1979, Seyfried and Janecky, 1985, Seewald and Seyfried , 1990), vent fluids (East Pacific Rise, MidAtlantic Ridge, Southern Juan de Fuca Ridge) and this study (BSW1 and BSW2) listed by sample number. Table also reports the value of temperature $(\mathrm{T})$, pressure $(\mathrm{P})$, flow-rate $\left(\mathrm{ml} \mathrm{hr}^{-1}\right)$, number of samples (samp), $\mathrm{pH}$ at room $\mathrm{T}$ and in situ $\mathrm{pH}$. ${ }^{\mathrm{a}}$ Von Damm et al., 1985 and Campbell et al., 1988; 'bata by Bowers et al., 1988; 'data by Campbell et al., 1988; data by Von Damm and

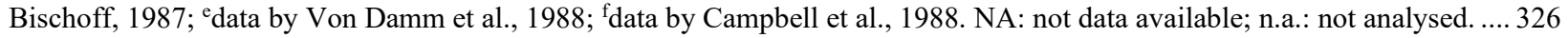

Table 6.25. Calculated mass changes ( $\left(100 \mathrm{~g}^{-1}\right.$ rock) for each portion of rock from the BSW1 and BSW2 experiments assuming $\mathrm{Al}_{2} \mathrm{O}_{3}$ immobility. 328

Table 6.26. Average and $1 \sigma$ of estimated temperature $\left({ }^{\circ} \mathrm{C}\right)$ using fluid compositions for BSW1 and BSW 2 and geothermometers provided in literature. .342

Table 7.1. Parameters and results from the experiments of this study 355 
xxiv 


\section{Chapter 1: Introduction}

\subsection{The Submarine Environment at Mid-Ocean Ridges}

The hydrothermal systems located in mid-ocean ridge basalts (MORB) at seafloor spreading centres are of global importance. They are not only responsible for the transfer of an enormous amount of heat, but also the exchange of chemical components between the oceanic crust and seawater (Alt, 2013; Edmond et al., 1979; Thompson, 1983). Submarine hydrothermal systems account for about $30 \%$ of the heat lost from the oceanic crust (Sclater et al., 1981; Stein and Stein, 1994; Williams, 1976). Their thermal potential is much larger than that of onshore geothermal resources and they could provide a significant part of the global future energy demand in an environmentally sustainable manner (Owusu and Asumadu-Sarkodie, 2016). Much of this potential is a result of the hydrothermal fluids being present at supercritical conditions $\left(>374^{\circ} \mathrm{C}\right.$ for pure water) and can therefore transfer a much larger amount of heat when compared to subcritical fluids.

Submarine hydrothermal systems develop where two oceanic plates diverge and up flowing basaltic magmatism forms a ridge. These can be identified as "fast" ridges having a narrow and shallow axial valley where the hydrothermal circulation is present near a welldefined heat source; or "slow" ridges which are defined as those with a deep and enclosed rift valley where there is frequently an absence of a well-defined heat source (Babcock et al., 1998; Detrick et al., 1987; Kent et al., 1990; Sinha and Evans, 2013; Sinton and Detrick, 1992). Figure 1.1 shows a typical section of a submarine hydrothermal system. It is composed of three main zones: the recharge zone; the reaction zone; and the discharge zone (Cann, 1971; Cann, 1969; Cann and Funnell, 1967; Chernysheva, 1971; Melson et al., 1968; Melson and van Andel, 1966; Miyashiro et al., 1971; Quon, 1963; Shido et al., 1974). The recharge zone is hosted by volcanic sediments, basalt, pillow-lava and breccia while the reaction zone is hosted by sheeted basaltic dikes and gabbros.

Changes in the mineral composition of oceanic crust and of seawater chemistry are regulated by the alteration processes occurring during fluid circulation. Cold seawater descends in the recharge zone through fractures away from the ridge. It becomes heated to subcritical and then supercritical conditions in reaction zone (4-5 $\mathrm{km}$ depth) by heat from uprising magma. The fluid then rises buoyantly to the seafloor through the discharge environment comprising 
"focussed" out-flow venting zones at high-temperatures $\left(300-400^{\circ} \mathrm{C}\right)$ where fluids create polymetallic mounds and steep-sided chimneys from a few meters to tens of meters in height at the seafloor; or "diffuse" out-flow venting zones at low-temperature $\left(<50^{\circ} \mathrm{C}\right)$ which typically take place through low mounds and cracks that are often occupied by biological communities (Cann and Strens, 1989; Scheirer et al., 2006). The distribution, morphology, rheology, lithology and thermal structure of MORB have been also described in detail by various authors (Atwater and Mudie, 1968; Ballard, 1977; Bott, 1996; Crawford and Webb, 2002; Karson et al., 2002; MacLeod and Yaouancq, 2000; McNutt, 1984; Parsons and Sclater, 1977; Searle and Escartín, 2013; Shaw, 1992; Watts, 1978; Weissel and Karner, 1989).

During circulation, the fluids can achieve temperatures over $400^{\circ} \mathrm{C}$ while ocean floor seawater normally has a temperature range between $2-4^{\circ} \mathrm{C}$ (Kingston Tivey, 2013; Macdonald et al., 1980). Contact between hot hydrothermal fluids and cold seawater, which have extremely different chemical and physical characteristics, forms vents, called black or white smokers. These are geologically important because of their capacity to transport heat and high concentrations of chemical elements, some of which precipitate immediately after mixing with cold seawater, in many cases giving rise to large ore deposits (mainly sulfide) (Hannington et al., 2013; Hannington, 1988; Haymon, 1983; Koski, 1987). The fluid chemistry at vents provides an important record of the alteration, temperature and pressure conditions that the fluid experienced during passage within the crust. Geochemical analysis around plumes reveal that the steady state concentrations of dissolved species and their solubility are controlled by mineral phases occurring in the reaction zone. These occur in the deepest part of a submarine hydrothermal system where the circulation occurs just above the magmatic heating source, close to the brittleductile boundary. In this zone, the intensity of the alteration process achieves a maximum and the kinetics of chemical reactions are fast at high $\mathrm{T}$ and $\mathrm{P}$ condition. In the reaction zone, the fluid (mainly seawater) is modified during circulation mostly by: 1) temperature and pressure (which determine the state of the fluid both in supercritical and subcritical states); 2) water-rock interaction; 3) magmatic degassing (input of volatiles such as $\mathrm{CO}_{2}, \mathrm{CH}_{4}, \mathrm{He}, \mathrm{H}_{2} \mathrm{~S}, \mathrm{SO}_{2}, \mathrm{HCl}, \mathrm{HF}$ $\mathrm{H}_{2}$ ); and (iv) redox reactions. Together, these factors determine the type of the hydrothermal alteration, the metals transported, the chemistry of the fluid and the final metals deposited on the seafloor (Bowers et al., 1988; Butterfield and Massoth, 1994; Campbell et al., 1988; German and Von Damm, 2004; Seyfried and Ding, 2013). 
Figure 1.1. Schematic diagram of a typical hydrothermal system within an oceanic ridge axial zone showing the hydrothermal fluid circulation (blue arrows) at recharge, reaction and discharge zones (Coelho et al., 2015).

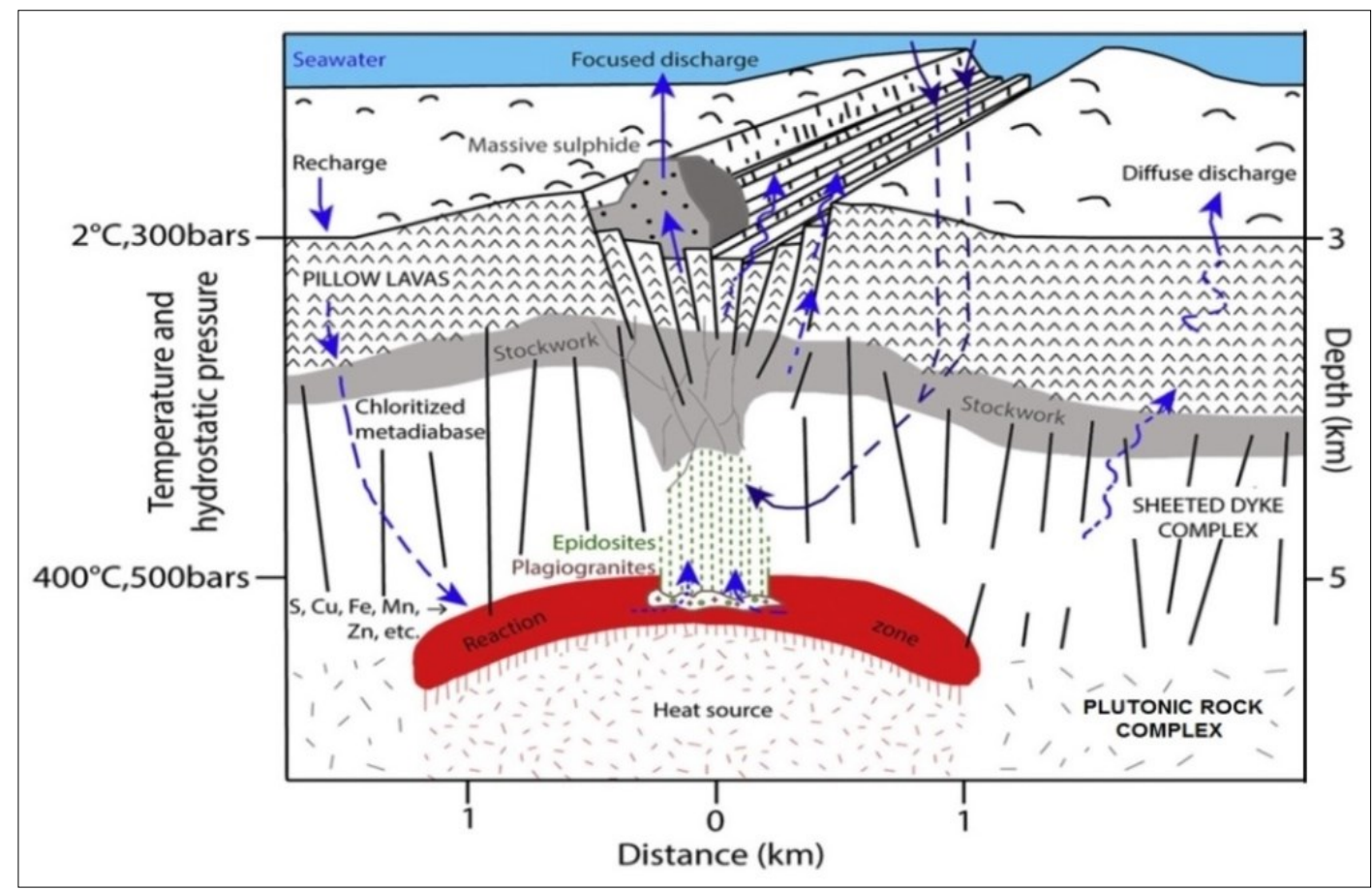

The terms supercritical and subcritical refer to conditions where a fluid has a temperature and pressure higher than its critical temperature $\left(\mathrm{T}_{\mathrm{c}}\right)$ and critical pressure $\left(\mathrm{P}_{\mathrm{c}}\right)$ or lower than $\mathrm{T}_{\mathrm{c}}$ and $\mathrm{P}_{\mathrm{c}}$, respectively. This terminology needs to be used carefully and clarified when dealing with one- or multi-component systems (Liebscher and Heinrich, 2007). In a onecomponent system, such as pure water, conditions above the critical point $\left(\mathrm{T}>374^{\circ} \mathrm{C}, \mathrm{P}>221\right.$ bar for pure water) there is a single-phase present, i.e., liquid and vapour are physically indistinguishable. While at conditions below the critical point for a one component system, two phases can exist along the liquid-vapour curve (Fig. 2a-b).

In a two-component system such as $\mathrm{H}_{2} \mathrm{O}-\mathrm{NaCl}$, the $\mathrm{T}_{\mathrm{c}}$ and $\mathrm{P}_{\mathrm{c}}$ differ from pure water and lie along the critical point curve that is dependent on $\mathrm{NaCl}$ concentration (Fig. 1.2). The $\mathrm{T}_{\mathrm{c}}$ and $\mathrm{P}_{\mathrm{c}}$ of seawater (3.2 wt.\% NaCl equivalent) is $\sim 404^{\circ} \mathrm{C}$ and 300 bars (Bischoff and Rosenbauer, 1984) which corresponds to a cold seawater depth of $\sim 3000 \mathrm{~m}$. At P-T conditions greater than the critical temperature $\left(\mathrm{T}_{\mathrm{c}}\right)$ and critical pressure $\left(\mathrm{P}_{\mathrm{c}}\right)$, seawater (e.g. $\mathrm{T}=407^{\circ} \mathrm{C}, 500$ bar), a supercritical single phase is present. A decrease in pressure at temperature that intersects the liquid-vapour two-phase surface causes the fluid to undergo phase separation. When the fluid intersects the liquid-vapour two-phase surface on the liquid side of the critical curve, the system 
starts to boil. In contrast, when the fluid intersects the liquid-vapour two-phase surface on the vapour side of the critical curve, the systems starts to condense (Liebscher and Heinrich, 2007). In both situations, two compositionally different fluid fractions form: a conjugate pair of low (vapour) and high (liquid) salinity and density aqueous solutions.

In this study, pressure ( $\sim 500$ bar) was consistently above the $\mathrm{P}_{\mathrm{c}}$ for pure water, geothermal brine and seawater, thus, the term supercritical is defined here as conditions where temperature is above $T_{c}$ for the fluid utilised. The term subcritical refers to conditions where temperature is below $\mathrm{T}_{\mathrm{c}}$ for the fluid utilised.

Whether the hydrothermal circulation is under subcritical or supercritical conditions is one of the most important factors affecting hydrothermal alteration and reflecting the compositional variability observed at hydrothermal vents on the seafloor. Under subcritical conditions, the fluid is nearly incompressible, has low thermal expansion, a low molar heat capacity and an elevated dielectric constant. In contrast, the fluid under supercritical conditions has a low density, viscosity and dielectric constant (almost zero) but a high thermal expansion and heat capacity (Anisimov et al., 2004; Norton, 1984).

At elevated temperatures and pressures the properties of water change dramatically due to the modification of its density and molecular structure. Hydrogen bonds are stable at low and moderate temperature, while an assembly of isolated polar water molecules are present at high and supercritical temperatures. At this point water loses its solvent power for ionic species (electrolytes), which tend to form ion-pairs, and becomes a good solvent for non-polar components. Hydrothermal alteration occurring at supercritical and/or at subcritical conditions generates significant dissimilar effects on mineral solubility, complex formation and metal transport. At higher T-P, aqueous species become more associated as there cannot be charged species near the critical point. Also, metal mobility increases substantially (Brunner, 2014).

Metal transport is ultimately controlled by the availability of important ligands during hydrothermal circulation both in the vapour phase and in the liquid phase. This, in turn, can affect the resulting metal assemblage in seafloor mineral deposits. Both chloride and hydrosulfide (HS') have a major impact on the metal mobility during hydrothermal circulation. They form important aqueous metal complexes, affect the ionic strength of the fluid, and the charge balance. This influences mineral solubility and controls the total concentration of cationic species that can be present in the fluid. As a consequence, measurements of salinity at vents are 
very important to constrain the evolution of the fluid during its residence in sub-seafloor reaction zones (Seyfried et al., 1991; Von Damm et al., 2002; Von Damm, 1988; Von Damm et al., 2003).

Figure 1.2. (a) Pressure-temperature solid-liquid-vapour phase relations of pure water showing the critical point and critical isochore line; (b) temperature - density relations in the pure water system; (c) two component system showing the critical behaviour of pure water dominated fluids. (d) phase diagram of $\mathrm{H}_{2} \mathrm{O}-\mathrm{NaCl}$ versus temperature-pressure-composition. (a-c) Liebscher and Heinrich, 2007; (d) Driesner and Heinrich, 2007).

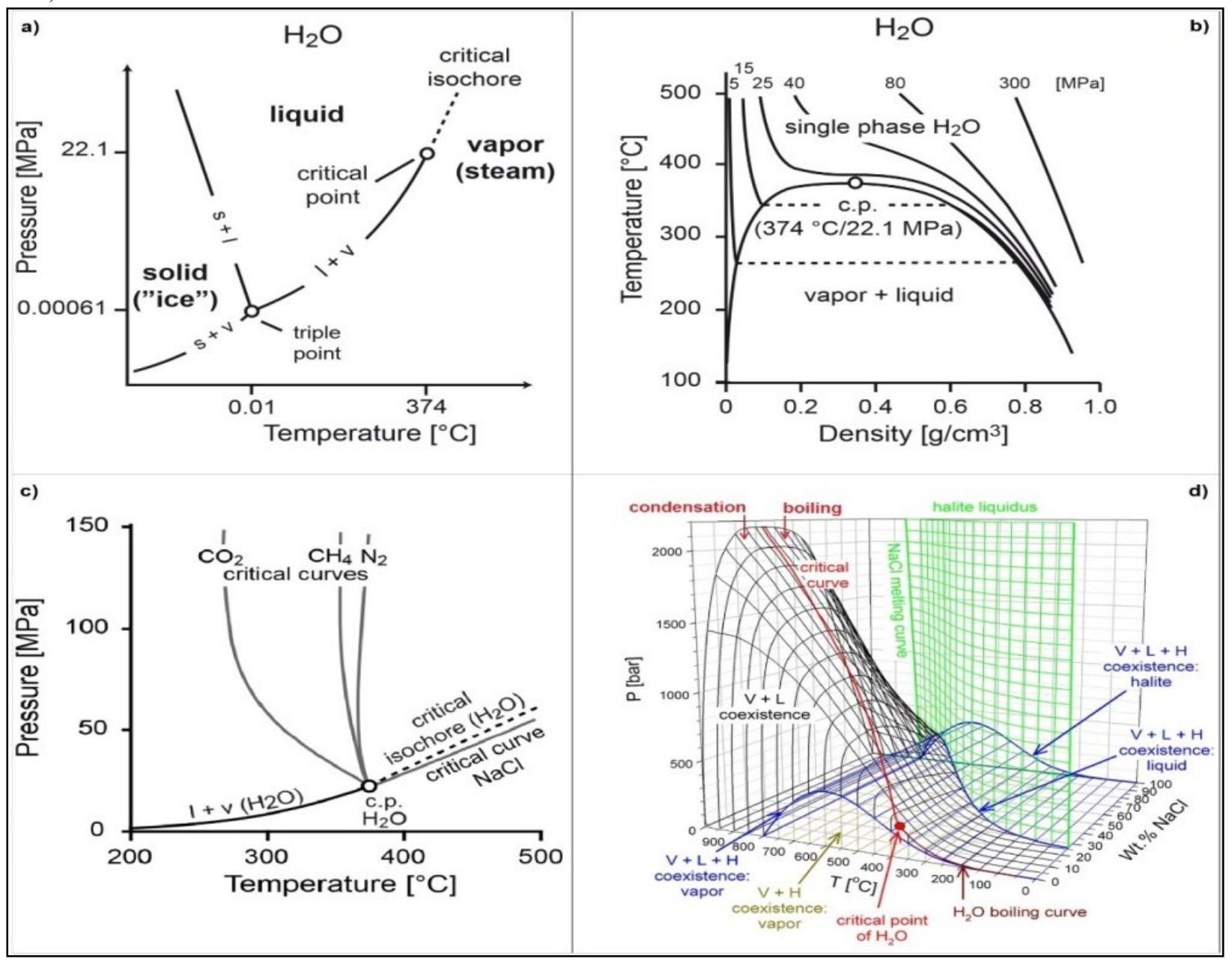




\subsection{Hydrothermal alteration during seawater circulation in submarine hydrothermal systems: field evidence}

Over the past 40 years, since the initial discovery of the hot springs at the Galapagos spreading centre (Edmond et al., 1979), many studies have been undertaken to better understand the mechanisms that occur during hydrothermal alteration. Hydrothermal alteration can be described as a "metamorphic" process which involves hot fluid in contact with rocks causing the conversion of the primary mineralisation into a set of new minerals in equilibrium with the conditions of temperature, pressure and chemical composition of the fluid. Furthermore, considering that the fluid can move rapidly, slowly or be stagnant during its passage through the crust, flow rate and resident time can also have a significant impact on the alteration that forms. The original texture of the rock can be totally or partially altered and fluid chemistry substantially modified (Pirajno, 1992).

The "metamorphic" process where there is re-equilibration of the mineral assemblage due to the passage of the fluid, material transport and changes in fluid composition, is known as metasomatism (Putnis and Austrheim, 2010). Metasomatism occurs in an open system and differs from standard "metamorphism" in which rock deformation can take place, a fluid phase is not necessarily involved, and no appreciable bulk chemical alteration occurs. A metasomatic process can be associated with a metamorphic or igneous environment, can include ore mineralisation, or alteration of the mantle, the oceanic lithosphere, the subducted oceanic, or the continental crust (Harlov and Austrheim, 2013).

At mid-ocean ridges, the intensity of hydrothermal alteration increases with the increase of temperature and pressure downwards into the oceanic crust (Fehn et al., 1983; Sleep, 1991). The grade of rock alteration and the changes in fluid composition are different for each zone in this environment. In the most recent studies of MORB alteration, three different metamorphic facies have been identified: (i) a zeolite facies in volcanic sediments and low greenschist facies in the upper sheeted dikes (recharge zone); (ii) a high greenschist facies in the lower dikes (shallowest part of the reaction zone) and (iii) an amphibolitic facies in the uppermost plutonic (gabbro) section (deepest part of the reaction zone) (Cann, 1971; Cann, 1969; Cann and Funnell, 1967; Melson et al., 1968; Melson and van Andel, 1966; Miyashiro et al., 1971; Quon, 1963; Shido et al., 1974).

The evidence that is available on the lithology and mineral composition of these zones is 
from sub-aerial exposures of ophiolites (e.g. the Samail ophiolite, Oman) (Gillis, 2008; Gillis and Roberts, 1999; Nehlig et al., 1994; Nicolas and Boudier, 1991; Nicolas et al., 2008), and from the petrological and mineralogical studies of drill core from mid-ocean ridges carried out in the last 40 years. These latest include: the Deep Sea Drilling Program (DSDP) in 1968; the Ocean Drilling Program (ODP) in 1985 and the Integrated Ocean Drilling Program (IODP) in 2003 (Fig. 1.3) (Benoit et al., 2014).

Hole 504B of the ODP was drilled in the equatorial Pacific Ocean and was the deepest ever drilled within the ocean crust $(2111 \mathrm{mbfs})$. It showed the presence of hydrothermal alteration up to the lower sheeted dikes (Alt et al., 1996; Bach et al., 2003; Becker et al., 1989; Vanko and Laverne, 1998). Only in IODP, Hole 1256D, from the eastern Pacific Ocean (1507mbsf) it was possible to penetrate to the dike/gabbro (plutonic) boundary for the first time (Koepke et al., 2008; Patten et al., 2016; Wilson et al., 2006). Important data about the geological setting at MORB also come from the Iceland Deep Drilling Project (IDDP), in the Reykjanes Peninsula, from two wells in particular: well RN-17 from IDDP-1 (3100 m) (Marks et al., 2011) and well RN-15, from IDDP-2 (4659 m) the deepest geothermal well drilled to date (Friðleifsson et al., 2017). These projects offer a unique opportunity to study a high-temperature active hydrothermal system at supercritical conditions.

Figure 1.3. Map of ocean floor age, based on age grid by Muller et al. (2008) revised version 3 (www.earthbyte.org/). Symbols represent DSDP, ODP, and IODP holes drilled in ocean from 1974 to 2011.

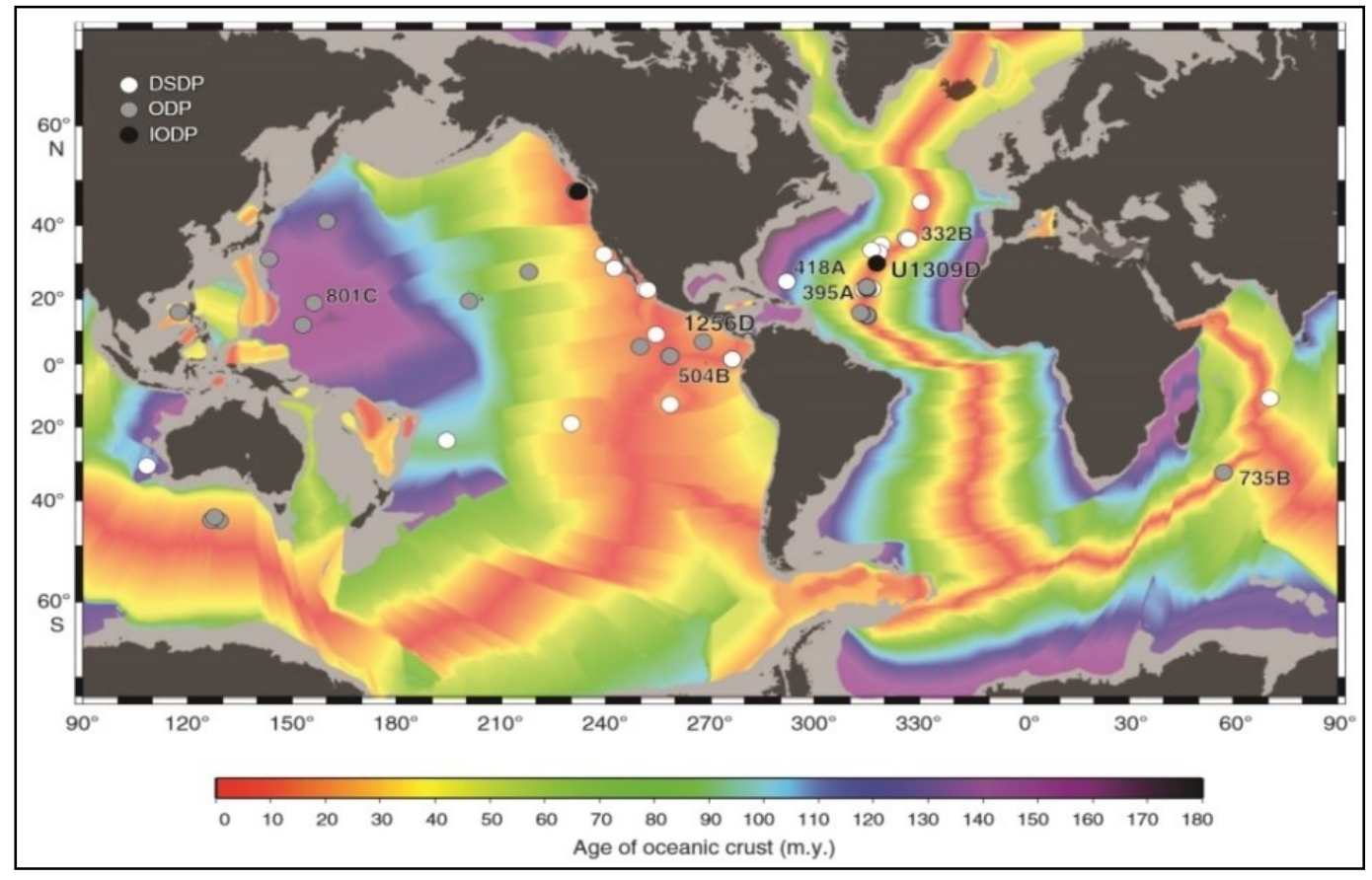


Fluid-rock interaction at mid-ocean ridges starts at the recharge zone adjacent to the ridge. Seawater penetrates through fractures, crossing the first shallow layer of pillow lava and lava flows, overlain by pelagic sedimentary rocks (Alt, 2013). The first alteration process that takes place is a low temperature (up to $40^{\circ} \mathrm{C}$ ) oxidation with the formation of Fe-oxyhydroxides which replace olivine and primary sulfide minerals, giving a typical red colour to the rock (Berndt and Seyfned Jr, 1986; Böhlke et al., 1981; Honnorez, 1983; Ridley et al., 1994) .

Celadonite and nontronite (ferric mica and smectite, respectively) also precipitate, trapping elements such as $\mathrm{Sb}, \mathrm{As}, \mathrm{Rb}, \mathrm{Cs}, \mathrm{B}, \mathrm{K}$, and in some cases Mn. Chemical evidence shows the highest values of $\mathrm{Fe}^{3+} / \mathrm{Fe}^{\text {Total }}$ and $\mathrm{K}_{2} \mathrm{O}$ in these altered rocks relative to unaltered rocks. The study of Vanko and Laverne (1998) on Hole 504B differentiates, at this stage, two different hydrothermal alterations at lower temperature $\left(<100^{\circ} \mathrm{C}\right)$. One oxidative sea floor weathering zone in the upper half of the extrusive section and one non-oxidative alteration zone in the lower extrusive section (Figure 1.4).

Patten et al. (2016), from a recent analysis on the sulfide mineral evolution and metal mobility in Hole 1256D, recognized five main groups of sulfides: magmatic, metasomatised, high temperature, low temperature and patchy sulphides. In their study, it is reported that magmatic sulfides in the volcanic portion of the hole are replaced by secondary sulfides including as pyrite, marcasite and chalcopyrite during lower temperature hydrothermal alteration. Laverne et al. (2006) also report the breakdown of titanomagnetite to schorlomite in altered basalt from Hole $1256 \mathrm{D}$, during low temperature hydrothermal alteration.

The temperature of hydrothermal fluids at this stage is less than $150^{\circ} \mathrm{C}$. Zeolites and carbonates are also present but more off-axis from the ridge. A prevalent reaction that occurs in this recharge zone is the precipitation of $\mathrm{Ca}-\mathrm{Mg}$ from seawater in the form of sulfate minerals. The most common sulfate mineral is anhydrite $\left(\mathrm{CaSO}_{4}\right)$ which precipitates at temperatures between $150-200^{\circ} \mathrm{C}$. The formation of anhydrite involves depletion of $\mathrm{Ca}$ from seawater which prevents the formation of appreciable Ca-silicates. From Hole 504B and hole 1256D, anhydrite is present in veins in the lower volcanics. Contemporaneously, ferrous iron is trapped by the formation of $\mathrm{Mg}$-smectite (saponite). This process contributes to the fixation of $\mathrm{Mg}$ from seawater with the highest $\mathrm{Mg}$ concentrations lost due to the formation of smectite at lower temperatures $\left(<200^{\circ} \mathrm{C}\right)$ and chlorite at higher temperatures $\left(\mathrm{T}>200^{\circ} \mathrm{C}\right)$.

As the fluid migrates deeper, it encounters the transition between the basal volcanics and 
the upper sheeted dikes, where temperature of the hydrothermal alteration increases up to 250$300^{\circ} \mathrm{C}$ (greenschist facies). Here albite replaces plagioclase (albitisation process) while chlorite and actinolite replace basaltic glass and olivine. Anhydrite is also present and suggests that sulfate is not completely lost in the low temperature reaction zone (Alt et al., 2010). Patten et al. (2016) report that in the upper sheeted dikes, magmatic sulfides such as pyrrhotite, chalcopyrite and marcasite are replaced by the formation of secondary sulfides such as pyrite (most abundant), chalcopyrite and sphalerite. During this stage, the first significant metal mobilisation occurs at moderate temperatures $\left(\sim 300^{\circ} \mathrm{C}\right)$.

Between the middle sheeted dike zone and the upper gabbro section, fluid temperatures reach $350-450^{\circ} \mathrm{C}$ (and higher) resulting in a significant change of metamorphic grade. This is where the most intense hydrothermal alteration occurs. The hydrothermal alteration at this reaction zone is not well-documented, however, early observations of this zone were reported from Hole 1256D by several authors (Figure 1.4). Wilson et al. (2006), Koepke et al. (2008) and Alt et al. (2010) report that within the lower sheeted dikes, the grade of alteration increases under reduced and more acidic fluid conditions. The mineral actinolite becomes more common than chlorite below 1300 mbsf. followed by the formation of Mg-hornblende with a greenish brown colour below 1350 mbfs. While the lowest $\sim 60 \mathrm{~m}$ of the dikes ( 1350 to $1407 \mathrm{mbs})$, basalt is partially to completely recrystallized to distinctive granoblastic textures, because of contact metamorphism by the underlying gabbroic intrusions.

Koepe et al. (2008) concluded that the granoblastic dikes portion in Hole 1256D was formed by the intrusion of the magmatic chamber and its relative conductive boundary layer overlapping the previously altered sheeted dikes. Thin section analysis of the granoblastic section showed two stages of hydrothermal alteration by seawater circulation. The first stage formed prior to the granoblastic overprint forming a greenschist facies matrix including quartz, albite, actinolite, sulfides and magnetite. The second stage occurred as a result of an overprinting by circulating seawater-derived fluids. This formed pseudomorphs of $\mathrm{Mg}$-hornblende from the actinolite aggregates of the earlier matrix. Plagioclase was converted to high Ab-rich compositions.

The top portion of the plutonic complex (gabbro and trondhjemite dikes between $1407 \mathrm{mbsf}$ and $1500_{\mathrm{mbsf}}$ approximately, Figure 1.5) in Hole 1256D was analysed by Wilson et al. (2006). Two major bodies of gabbros are separated by a layer of granoblastic dikes. The gabbros were 
altered by hydrothermal fluids to hornblende, actinolite, epidote, chlorite, prehnite, laumontite and secondary plagioclase.

Analysis of sulphide mineral evolution and metal mobility in Hole 1256D by Patten et al. (2016) demonstrates that temperatures in the lower dikes, up to the gabbro contact, are higher than $350-400^{\circ} \mathrm{C}$ resulting in reducing and more acidic conditions of the fluid. This drives a progressive and pronounced leaching and dissolution processes of the sulfides. Accurate mass balance equation analysis of different rock samples shows that these processes are responsible for the release of significant amounts of $\mathrm{Cu}$, Se and Au during hydrothermal alteration, while the mobilisation of elements such as $\mathrm{Zn}, \mathrm{Sb}, \mathrm{As}$, and $\mathrm{Pb}$ is controlled by silicate reactions and not by sulfide leaching.

Vanko and Laverne (1998) describe the lower portion of the sheeted dike complex of ODP Hole 504B (Fig. 1.4) and compared it with the Cretaceous Semail ophiolite in Oman (Nicolas and Boudier, 1991). After the drilling of the IODP Hole 1256D, Nicolas and Boudier (1991) revisited their paper incorporating a new detailed map and new information on the Oman ophiolite and made a comparison with Hole 1256D (Nicolas et al., 2008).

Vanko and Laverne (1998) study of Hole 504B gives important information about the transition between the magmatic and hydrothermal and about the hydrothermal reaction zones at mid-ocean ridges. Hydrothermal alteration consists of amphibolitic metasomatism (giving pressures between $380-850$ bar and temperatures higher than $425^{\circ} \mathrm{C}$ ). The mineral assemblage found consists of abundant Mg-hornblende and minor secondary hydrothermal Na- and Ti-rich diopside that replaces primary clinopyroxene (augite) and secondary, hydrothermal calcic plagioclase replacing magmatic plagioclase (from $\mathrm{An}_{55}$ to $\mathrm{An}_{95}$ ). This is consistent with experimental results at $400^{\circ} \mathrm{C}$ and 400 bar of (Berndt and Seyfried, 1993). They showed that secondary plagioclase formation buffers the $\mathrm{a}_{\mathrm{Ca}} / \mathrm{a}^{2} \mathrm{Na}$ of black smoker fluids.

Recent information on high-temperature alteration occurring at the reaction zones comes from the studies on cuttings recovered from the IDDP-1/RN-17 and IDD-2/RN-15 wells (Friðleifsson et al., 2017; Marks et al., 2011; Marks et al., 2010). The Iceland geological setting is of great interest when studying hydrothermal alteration occurring at mid-ocean ridges, particular when there is direct evidence of supercritical conditions at depth (Elders and Friðleifsson, 2010). The Iceland rift is part of the Atlantic oceanic rift system. The geology and tectonic conditions are similar to those of seafloor mid-oceanic ridges. Shallow magmatic 
activity facilitates the circulation of meteoric water and seawater through the crust. The geothermal systems are seawater-dominated and located inland on the extension of the MidAtlantic Ridge (Elders and Friðleifsson, 2010; Marks et al., 2011).

Many studies have been undertaken on the geological setting of Icelandic geothermal systems and many of these report information on the geochemistry of the fluid reservoirs at depth (Arnórsson, 1995; Arnórsson et al., 1978; Björnsson et al., 1970; Fowler et al., 2015; Franzson et al., 2008; Fridleifsson and Albertsson, 2000; Gudmundsson, 1986; Jakobsson et al., 1978; Kaasalainen and Stefánsson, 2012; Marks et al., 2011; Thordarson and Larsen, 2007; Weir et al., 2001; Ásmundsson et al., 2014). The recent completion of the Iceland Deep Drilling Project at Reykjanes region (IDDP-1 and IDDP-2, well RN-17 and well RN-15, respectively) has provided important insights into the geochemistry of supercritical geothermal systems. Well RN15 achieved a total depth of $4659 \mathrm{~m}(\sim 4.5 \mathrm{~km}$ vertical depth) and supercritical conditions have been found $\left(427^{\circ} \mathrm{C} / 340 \mathrm{bar}\right)$. The goal is to produce fluid with a temperature higher than the critical temperature of seawater $\left(407^{\circ} \mathrm{C}\right)$ and a pressure less than the critical pressure (298 bar), resulting in superheated steam. As this fluid rises quickly, the enthalpy decrease by conduction is insufficient to allow phase separation and the fluid reaches the surface with a greater power conversion efficiency. It is estimated that this well can yield to $50 \mathrm{MWe}$ of electric power alone, tenfold better than a typical conventional subcritical two phase well (Fridleifsson and Elders, 2005; Fridleifsson et al., 2017).

Marks et al. (2010, 2011) studied the lower portion of the RN-17/ IDDP-1 (Fig. 1.4) where they observed hydrothermal alteration passing from the zeolite facies $(\sim 400 \mathrm{~m})$ to the greenschist facies alteration at about $400 \mathrm{~m}$ depth. This alteration is composed of actinolite, albite, chlorite, quartz, epidote, titanite and magnetite (up to $\sim 2300 \mathrm{~m}$ depth). Between $2300 \mathrm{~m}$ and $3100 \mathrm{~m}$ depth the mineral assemblage changes to amphibolite facies alteration in conjunction with granoblastic hornfels derived by contact metamorphism. The granoblastic texture shows evidence of being formed by recrystallisation of the greenschist facies minerals. Hydrothermal hornblende and clinopyroxene (from $\mathrm{Wo}_{49} \mathrm{En}_{3} \mathrm{Fs}_{48}$ to $\mathrm{Wo}_{53} \mathrm{En}_{30} \mathrm{Fo}_{17}$ ) are present in veins with calcic plagioclase, epidote and quartz.

Fridleifsson et al. (2017) reports on the active seawater-recharged hydrothermal system in well RN-15/IDDP-2 (Fig. 1.4). The lowest portion of this well is at supercritical conditions ( $\mathrm{T}=$ $427^{\circ} \mathrm{C}$ and $\mathrm{P}=340 \mathrm{bar}$ ). Between $1100 \mathrm{~m}$ and $1400 \mathrm{~m}$ depth, epidote-actinolite facies alteration 
is present in basalt flows and pillow lavas. Between 1400 and $3600 \mathrm{~m}$ depth the extrusive and intrusive transition is found. Here, epidote, hornblende (replacing actinolite), chlorite and calcic plagioclase are present. Below $3600 \mathrm{~m}$, typical amphibolite facies alteration occurs. Hornblende is the most abundant amphibole, with actinolite and chlorite being almost absent and igneous plagioclase remains relatively unaltered. From $4260 \mathrm{~m}$ to the lowermost portion of the core, igneous clinopyroxene is altered to hornblende. Hydrothermal biotite is found in fractures and is stained red by a coating of hematite (Figure 1.6). The presence of hematite is explained by the oxidation of iron when oxygenated water was pumped downhole for cooling. $\mathrm{Cu}-\mathrm{Fe}$ sulfides and pyrrhotite were also found in the deepest core, although in minor amount. 
Figure 1.4. A comparison of the lithologies between Hole 1256D and Hole 504B drilled during the IODP and ODP expeditions, respectively, and cores of RN-17 and RN-15 recovered during the development of the IDDP-1 and IDDP-2 in Reykjanes region (Iceland), respectively (Friðleifsson et al., 2017).

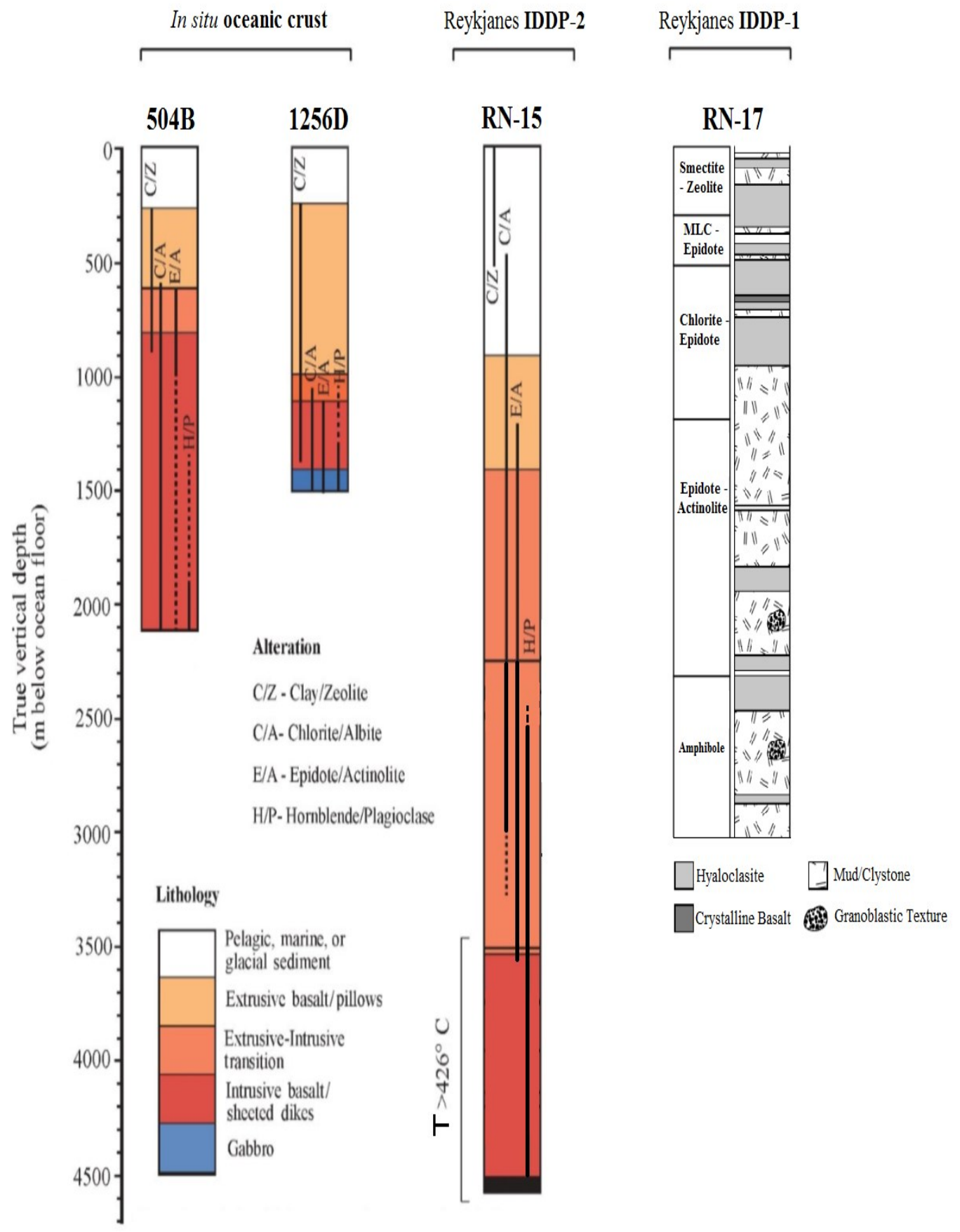




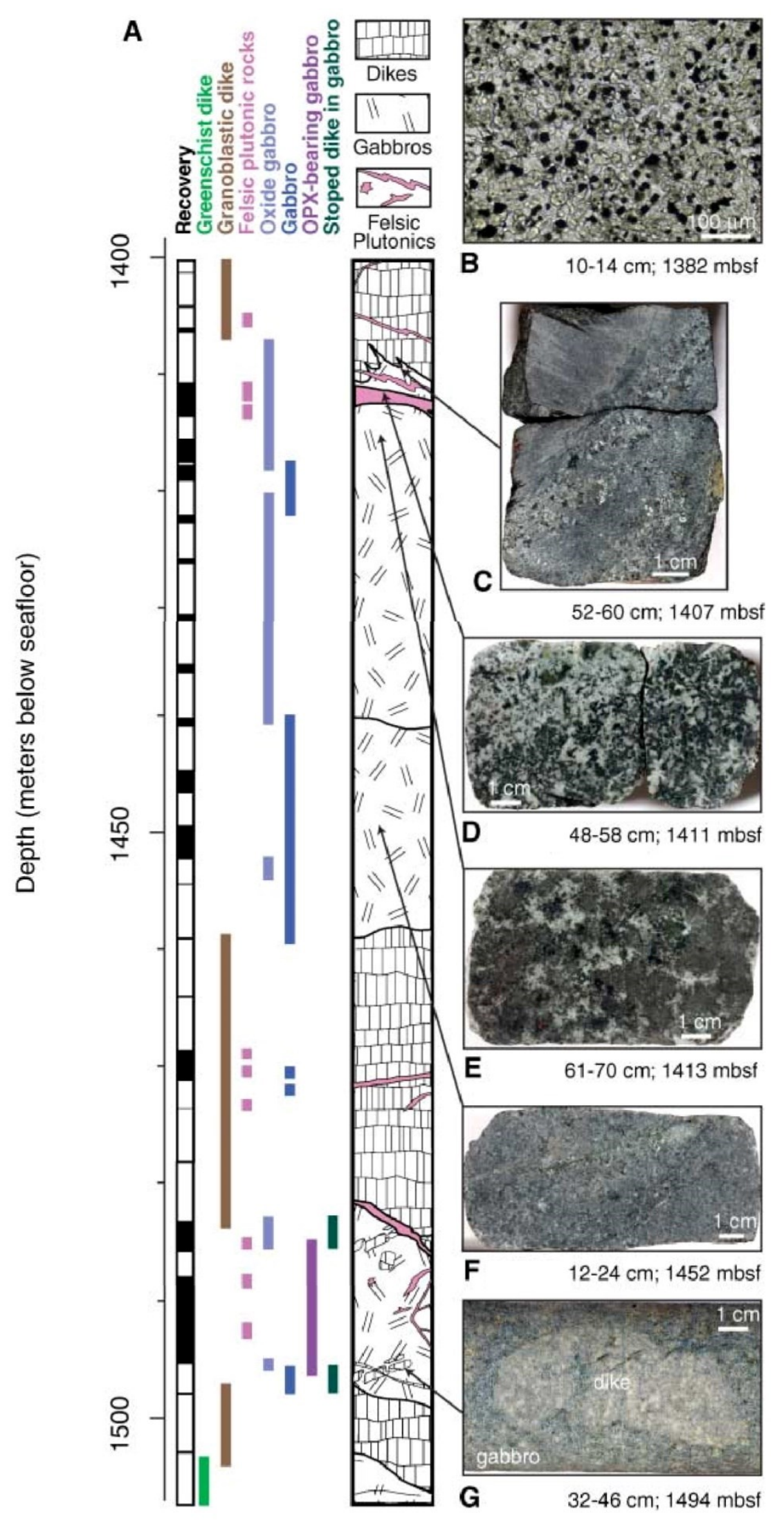

Figure 1.5. (A) Lithostratigraphic section of the plutonic complex, Hole 1256D. (B) dike sample with granoblastic texture; (C) dikegabbro boundary (gabbro extremely altered by hydrothermal circulation); (D) diorite rich in quartz and oxide altered to actinolite, hornblende and secondary plagioclase, chlorite and epidote; (E) Gabbro with oxides and patchy texture; (F) Gabbro strongly altered by hydrothermal circulation with veins of chlorite and actinolite; (G) sample of intruded dike within gabbro (all from Wilson et al, 2006). 
Figure 1.6. Photomicrographs of the core from the IDDP-2, well RN-15, at $4637.81 \mathrm{~m}$ depth (Friðleifsson et al., 2017) (a) euhedral crystals of hydrothermal biotite covered by hematite which gives them a red coloration, formed during coring operation (b) open-spaces filled by quartz overgrown on hydrothermal biotite covered by hematite.
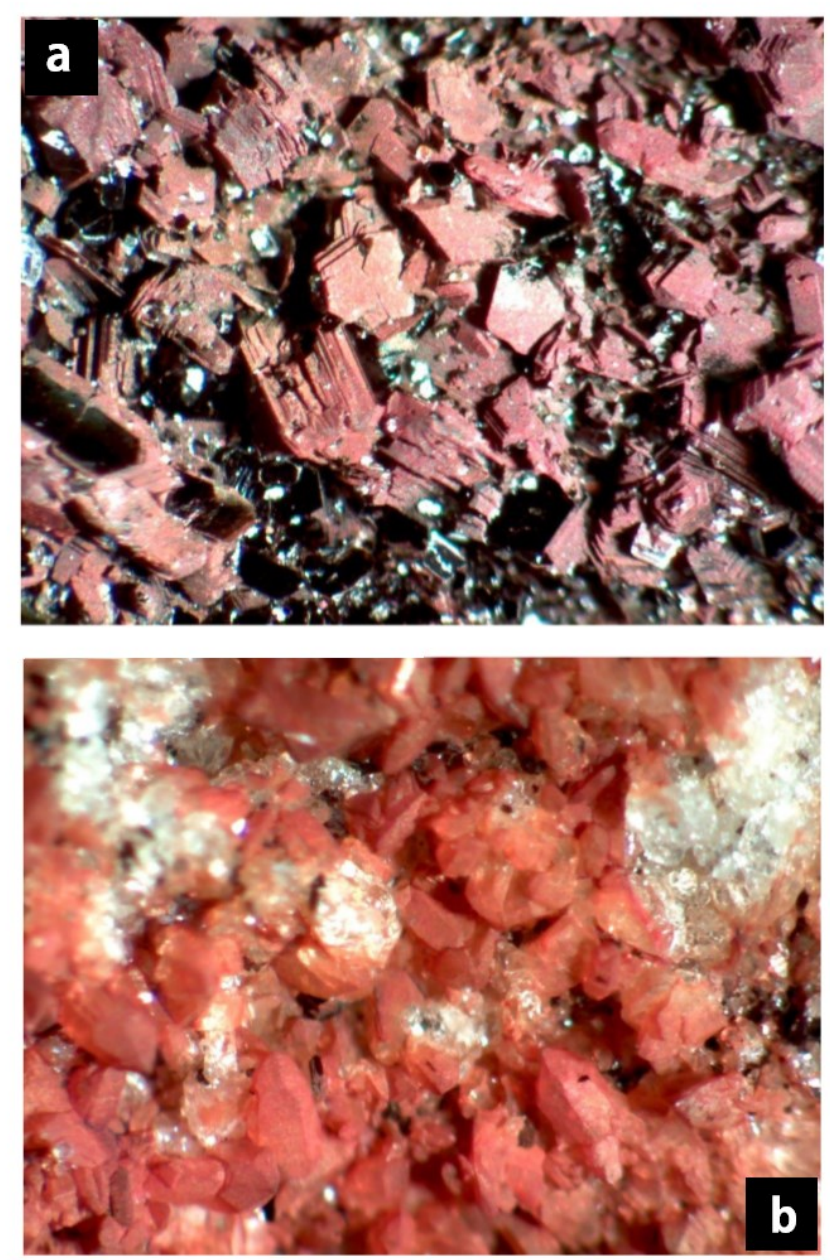
The locations where fluids containing metals and sulfur rise to the seafloor in a submarine hydrothermal systems are referred to as zones of up-welling (Richardson et al., 1987). A large fluid/rock ratio results in a mineral assemblage controlled by the fluid chemistry rather than by the surrounding rock (Vanko and Laverne, 1998). It has been estimated that the residence time of this fluid, from the deep reaction zone to seafloor, is less than one year (Kadko et al., 1985; Kadko and Moore, 1988; Macdonald et al., 1980). The deepest zone of upwelling coincides with the deep reaction zone up to sea bottom. These portions of the crust are altered to granular epidote, quartz and titanite (epidosites). They can extend into quartz and epidote veins and can be linked to quartz, sulfide and epidote veins beneath sulfide deposits at sea floor (Bettison-Varga et al., 1992; Harper et al., 1988; Haymon et al., 1989; Nehlig et al., 1994). When compared to the fresh diabase, the epidosites show high contents in $\mathrm{Ca}, \mathrm{Sr}, \mathrm{Fe}^{3+} / \mathrm{Fe}^{\mathrm{T}}$ and are depleted in $\mathrm{Mg}, \mathrm{Na}, \mathrm{K}, \mathrm{Cu}, \mathrm{Zn}$, and $\mathrm{S}$ indicating alteration processes occurring at temperatures between $300-400^{\circ} \mathrm{C}$.

Ore deposit formation is strictly linked to vent activity at sea floor. This activity is essentially determined by parameters which control metal transport during hydrothermal circulation. The most important are $\mathrm{pH}$, redox $\left(f \mathrm{O}_{2}\right)$, the fugacity of sulphur $\left(f \mathrm{~S}_{2}\right)$, fluid mixing, and temperature decrease. These factors determine the carrying capacity which is directly proportional to the availability (activity) of ligands present in solution (such as $\mathrm{Cl}^{-}, \mathrm{HS}^{-}$and $\mathrm{OH}^{-}$) which form complexes with metals.

The first observations of vents were made at Axial Seamount, Juan de Fuca Ridge (Hannington, 1988) and at $9^{\circ} 50$ N, East Pacific Rise (Haymon et al., 1993). Recent studies suggest that the origin of their manifestations can be strictly attributed to magma intrusions close to sea floor, fracturing and sub-volcanic eruptions which permit the rise of the fluids.

In a submarine hydrothermal environment, at the seafloor, the two main deposit types formed are: 1) sulfate deposits, formed by white smokers, so-called because of the white colour of the plume due to the high concentration of $\mathrm{Ba}$ and $\mathrm{Ca}$ sulfate and silica particles (Hannington et al., 2013); and 2) sulfide deposits, formed by black smokers, so-called due to the black colour of the plume which contains high concentrations of metals (mostly $\mathrm{Cu}, \mathrm{Zn}, \mathrm{Pb}, \mathrm{Fe}$ ) and $\mathrm{S}$. White smokers normally have lower temperatures $\left(100-300^{\circ} \mathrm{C}\right)$ than black smokers and for this reason they are insufficient to transport metals and reduced sulfur. The typical mineral precipitation related to a white smoker consists of amorphous silica $\left(\mathrm{SiO}_{2}\right)$ and barite $\left(\mathrm{BaSO}_{4}\right)$ which are the 
first, and last to precipitate, respectively. This is due to conductive cooling and mixing with the cold seawater rich in $\mathrm{SO}_{4}{ }^{2-}$. Anhydrite also forms, however, its solubility is retrograde. As a result, it dissolves back into cold seawater while the amorphous silica and barite remain.

In contrast, black smokers are typically hotter $\left(350-400^{\circ} \mathrm{C}\right)$ with extensive deposits of ore metals and S. When hot fluids from vents mix with the cold surrounding seawater, the solubility of transition sulfides decreases dramatically, causing instantaneous precipitation and formation of massive sulfide layers on the seafloor. The typical mineral precipitates consist of an assemblage of chalcopyrite $\left(\mathrm{CuFeS}_{2}\right)$, pyrrhotite and wurtzite $[(\mathrm{Zn}, \mathrm{Fe}) \mathrm{S}]$ at high temperature and low $f \mathrm{O}_{2}-f \mathrm{~S}_{2}$ while an assemblage of pyrite, marcasite (orthorhombic $\mathrm{FeS}_{2}$ ) and sphalerite $(\mathrm{ZnS})$ forms at lower temperatures but higher $f \mathrm{O}_{2}$ and $f \mathrm{~S}_{2}$ (Janecky and Seyfried, 1984). The main mineral precipitates at black smokers are sulfides but sulfate and silicate minerals are also observed. Anhydrite has also been identified but far from the vent plumes (Haymon, 1983; Tivey and Delaney, 1986). Other minerals found include Mg-silicates such as lizardite $\left[\left(\mathrm{Mg}_{3} \mathrm{Si}_{2} \mathrm{O}_{5}(\mathrm{OH})_{4}\right]\right.$, stevensite $\left[(\mathrm{Ca}, \mathrm{Na})_{x} \mathrm{Mg}_{3-\mathrm{x}} \mathrm{Si}_{4} \mathrm{O}_{10}(\mathrm{OH})_{2}\right]$ and some Mg-hydroxysulfates such as caminite $\left[\mathrm{Mg}_{7}\left(\mathrm{SO}_{4}\right)_{5}(\mathrm{OH})_{4} \cdot \mathrm{H}_{2} \mathrm{O}\right]$ and starkeyite $\left(\mathrm{MgSO}_{4} \cdot 4 \mathrm{H}_{2} \mathrm{O}\right)$ may also occur in minor amounts. 


\subsection{Experimental simulations of seawater-rock interaction: Previous work}

Table 1.1 presents a summary of water-mafic/ultramafic rock interaction experiments conducted during the past $\sim 40$ years with relevance to mid-ocean ridge hydrothermal systems.

The earliest experiments were carried out in the mid-1970's. Hajash (1975) reacted basalt with seawater at low fluid/rock ratios under medium-high $\mathrm{T}$ and high $\mathrm{P}$ conditions $\left(200-500^{\circ} \mathrm{C} /\right.$ 500-800 bar) using a cold-seal pressure vessel. The experiments revealed the role of rock composition in buffering $\mathrm{pH}$ and redox state. The main goal of the experiments was to determine the nature and the rate of chemical exchange and the nature of resulting mineral precipitates. At the time, there was lack of thermodynamic data to account for the relevant alteration minerals that formed in equilibrium with fluid.

Bischoff and Dickson (1975) improved on the above by using a Teflon-cell described in Dickson et al. (1963) and in Seyfried et al. (1987) that allowed sampling at higher fluid/rock ratios. They reacted seawater with tholeiitic basalt at $200^{\circ} \mathrm{C} / 500$ bar, conditions typical of geothermal systems of the Reykjanes area. In their experiments, a small amount of glass was dissolved, and the major secondary phases formed were anhydrite and montmorillonite (smectite group). Fluid analyses showed that $\mathrm{SiO}_{2}$ was saturated with respect to amorphous silica while $\mathrm{Mg}$ and $\mathrm{SO}_{4}$ decreased to below detection limit.

Seyfried and Bischoff (1977) used a similar approach to study the hydrothermal transport of trace metals, mineralogical changes and mineral reactions as a function of time, as well as the effect of water/rock ratio. The experiments were batch-type without fluid flow. They reacted seawater with basaltic glass at $260^{\circ} \mathrm{C} / 500$ bar with 50:1 water/rock ratio. The results showed efficient leaching from the rock of metals such as $\mathrm{Cu}, \mathrm{Zn}$ and $\mathrm{Ba}$, which achieved elevated concentrations in solution. These experiments were innovative for the time; however, it was not possible to reach the temperature and pressure regime present deep in the sub-seafloor using Teflon reaction vessel liners.

Bischoff and Seyfried (1978) investigated the kinetics of precipitation and compared results with theoretical solubilities of minerals including anhydrite, brucite, dolomite, magnesite and calcite in their experiments. They heated seawater to $350^{\circ} \mathrm{C}$ for approximately one month without the presence of rock material. This caused an increase in acidity of the fluid and the depletion of $\mathrm{Mg}, \mathrm{Ca}$ and $\mathrm{SO}_{4}$ from solution (Fig. 1.7). Mineral precipitates consisted of anhydrite 
and magnesium hydroxysulfate (Fig. 1.8) but not brucite. The $\mathrm{pH}$ at experimental conditions was calculated to be 3.3 .

Figure 1.7. (a) $\mathrm{Mg}, \mathrm{Ca}, \mathrm{SO}_{4}$ and $\mathrm{pH}$ concentrations during the experiment of Bischoff and Seyfried (1978) from $25^{\circ} \mathrm{C}$ to $350^{\circ} \mathrm{C} / 500 \mathrm{bar}$; (b) IonActivity Products (IAP's) of brucite and anhydrite in thin lines calculated from the experiment from $25^{\circ} \mathrm{C}$ to $350^{\circ} \mathrm{C}$ compared to theoretical log $\mathrm{K}$ values for dissolution equilibrium (thick lines) at 500 bar (Helgeson and Kirkham, 1974; Helgeson and Kirkham, 1976).

$\mathbf{a}$

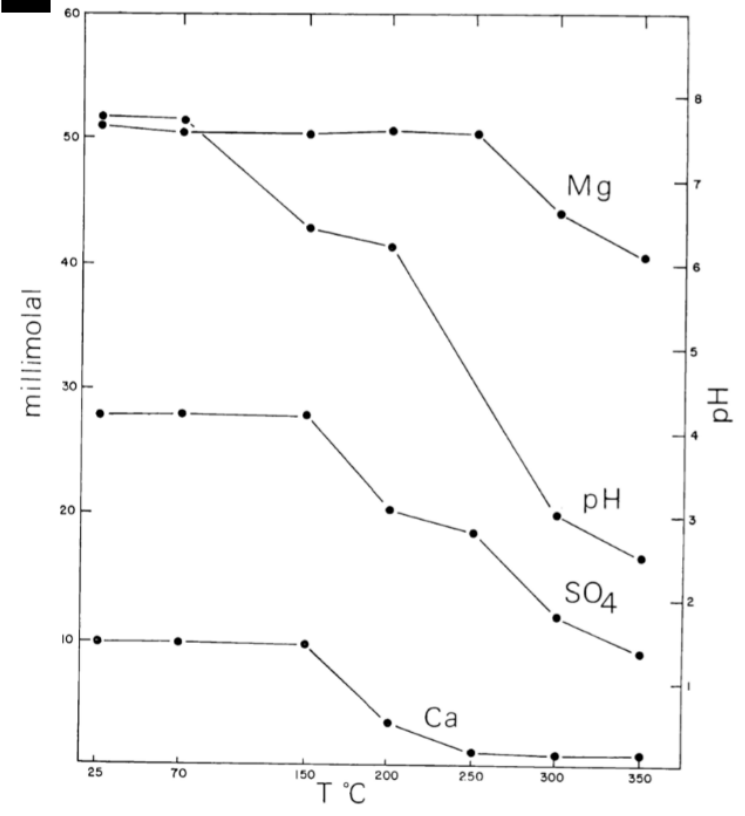

b

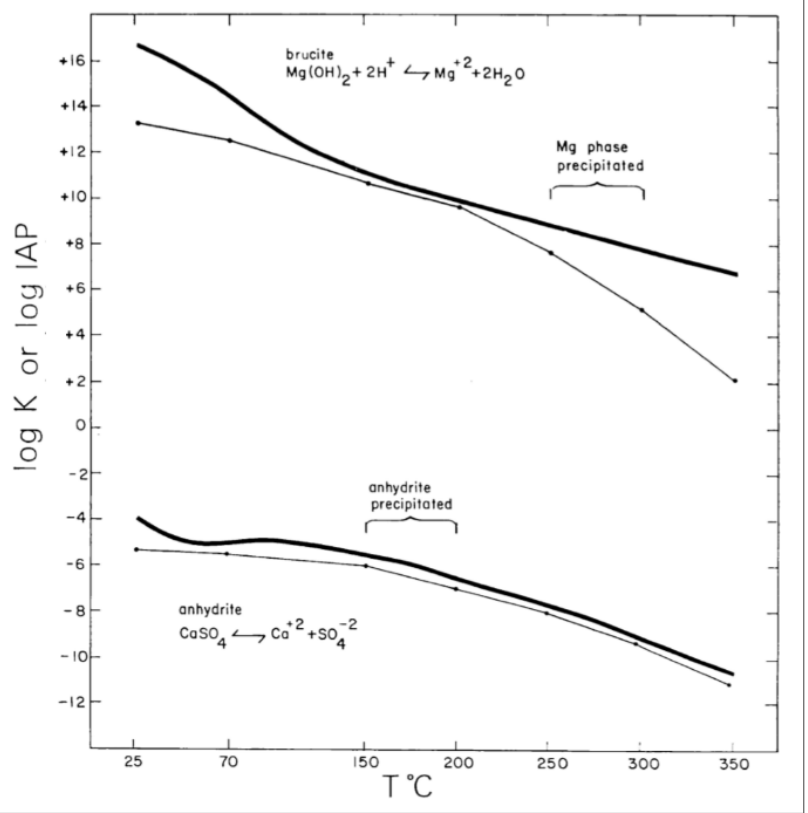

Figure 1.8. (a-b) SEM pictures of the mineral precipitates from the experiment of Bischoff and Seyfried (1978) showing magnesium hydroxysulfate crystals $\left(10 \mu \mathrm{m}\right.$ scale increments) formed at $325^{\circ} \mathrm{C} / 500 \mathrm{bar}$.
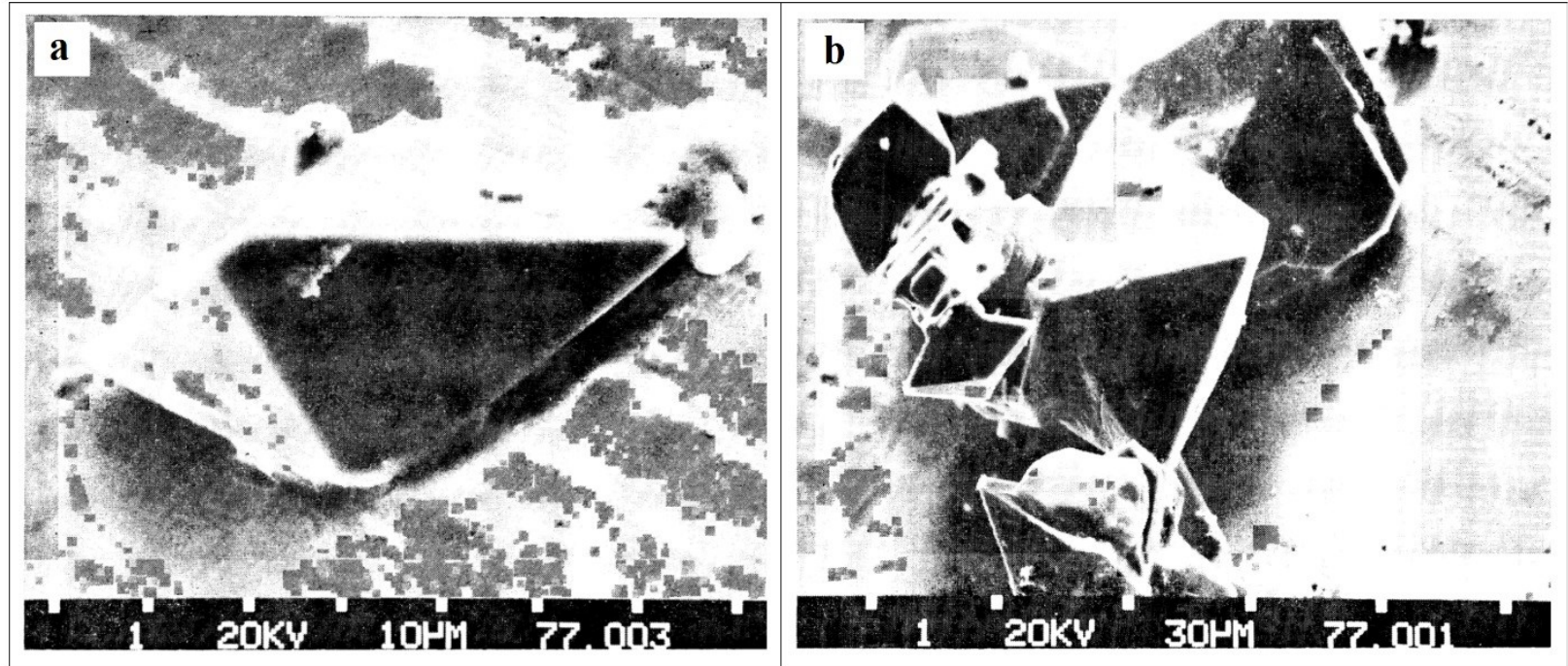
Using gold-lined pressure vessels, Seyfried and Bischoff (1979) and Mottl et al. (1978, 1979) were able to conduct experiments at higher temperature and pressure, closer to the conditions deep in sub-seafloor hydrothermal systems (Mottl et al., 1979). The results were significant in terms of understanding the chemical changes that occurred in the seawater at higher temperature and it was possible to study the behaviour of some important base metals under these conditions. The release and uptake of elements to and from the fluid phase such as $\mathrm{Mg}, \mathrm{Fe}, \mathrm{Mn}$ and $\mathrm{Cu}$ caused changes in $\mathrm{H}^{+}$concentration and a consequent variation in solution $\mathrm{pH}$.

Mottl et al. $(1978,1979)$ performed forty experiments reacting seawater and artificial seawater with mid-ocean ridge basalts of varying crystallinity at different temperatures and pressures: $200^{\circ} \mathrm{C} / 500$ bar; $300^{\circ} \mathrm{C} / 600$ bar; $400^{\circ} \mathrm{C} / 700$ bar; and $500^{\circ} \mathrm{C} / 1000$ bar. The total experimental time was between 2 and 20 months. They used sealed $15 \mathrm{~cm}^{3}$ gold capsules filled with crushed rock ( $<149 \mu \mathrm{m}$ size). Results for major elements showed two principal exchanges: $\mathrm{Mg}$ for $\mathrm{Ca}$ and $\mathrm{Na}$ for $\mathrm{Ca}$. There was an almost complete loss of $\mathrm{Mg}$ from the seawater due to the formation of smectite and tremolite-actinolite. Ca-bearing phases including anhydrite, truscottite, tremolite and actinolite were the main alteration minerals. $\mathrm{SiO}_{2}$ concentrations achieved quartz saturation at temperatures above $300^{\circ} \mathrm{C}$. Sulfur, iron and manganese showed near-constant concentrations at high $\mathrm{T}\left(400-500^{\circ} \mathrm{C}\right)$, but not at lower temperatures $\left(200-300^{\circ} \mathrm{C}\right)$. Oxide and sulfide minerals found in the experiments showed an assemblage of pyrite, pyrrhotite, chalcopyrite, and hematite.

Seyfried and Bischoff (1979) described three experiments where basaltic glass was reacted with seawater at $70^{\circ} \mathrm{C} / 1$ bar and $150^{\circ} \mathrm{C} / 500$ bar, and diabase was reacted with seawater at $150^{\circ} \mathrm{C} / 500$ bar. At low temperature $\left(70^{\circ} \mathrm{C}\right)$ there was a loss of $\mathrm{Mg}$, $\mathrm{Na}$ and $\mathrm{K}$ from solution and enrichment of $\mathrm{SiO}_{2}$ and $\mathrm{Ca}$ in the fluid. At higher temperature $\left(150^{\circ} \mathrm{C}\right) \mathrm{Mg}$ and $\mathrm{SO}_{4}$ were lost from the fluid in a greater amount, while $\mathrm{Ca}, \mathrm{SiO}_{2}, \mathrm{Fe}, \mathrm{Na}, \mathrm{K}, \mathrm{Mn}$ and $\mathrm{B}$ were added to the seawater. Smectite was the major alteration product recovered from both basaltic glass and diabase experiments at $150^{\circ} \mathrm{C}$.

Mottl (1983) discussed in detail how seawater-basalt interactions are influenced by the role of $\mathrm{Mg}$. The formation of smectite, chlorite and other minerals such as brucite $\left[\mathrm{Mg}(\mathrm{OH})_{2}\right]$ and $\mathrm{Mg}$ hydroxysulfates rapidly removes $\mathrm{Mg}$ from the fluid, transferring high concentrations of 
$\mathrm{H}^{+}$into the solution. The low $\mathrm{pH}$ causes the alteration of the primary silicates, consuming $\mathrm{H}^{+}$via hydrolysis reactions. This leads to extensive exchange of cations with the rock.

Further experimental work by Seyfried and Bischoff (1981), Seyfried and Mottl (1982), Seyfried and Janecky (1985), Seyfried et al. (1986), Gilles et al. (1987) and Berndt et al. (1989) investigated chemical reactions and mineralogical changes during fluid-rock interaction using an improved reaction cell design (Seyfried Jr, 1979; Seyfried et al., 1987). They demonstrated the importance of the pressure on fluid density (particularly under supercritical conditions) as well as the importance of chloro-complexes in determining metal mobility at subcritical and supercritical conditions. They used crystalline basalt, basalt glass and diabase and reacted these with seawater and $\mathrm{NaCl}$ solution at different water/rock ratios. Temperature $\left(300-425^{\circ} \mathrm{C}\right)$ and pressure $(250-$ 500 bar) were changed from conditions below to above the $T_{c}$ and $P_{c}$ of seawater.

Seyfried and Bischoff (1981) found an increase in $\mathrm{SiO}_{2}, \mathrm{H}_{2} \mathrm{~S}, \mathrm{Ca}, \mathrm{Fe}, \mathrm{Mn}, \mathrm{K}, \mathrm{Ba}$ and $\mathrm{Al}$ in solution, while there was depletion of $\mathrm{Mg}$ and $\mathrm{SO}_{4}$. Secondary minerals found included anhydrite, smectite, hematite in the basalt glass and layered chlorite/smectite, anhydrite and magnetite in diabase. Analysis for heavy metals showed low concentrations in the solution during the experiments. From these results, the authors concluded that chloride-complexing cannot be considered the dominant mechanism in regulating the heavy-metal solubility, at least at $300^{\circ} \mathrm{C}$ for seawater.

Seyfried and Mottl (1982) reacted basaltic glass and diabase at $150-300^{\circ} \mathrm{C} / 500$ bar at different fluid/rock ratios and found similar results to Seyfried and Bischoff (1981). The depletion of $\mathrm{Mg}$ and the consequent production of $\mathrm{H}^{+}$was a very important as this mechanism regulates: (1) heavy metal mobility and (2) hydrolysis reactions. The reactive capacity of a hydrothermal solution (the capacity to hydrolytically decompose silicates) is determined largely by its acidity. The authors observed a significant increase in Fe, Mn and $\mathrm{Zn}$ in solution at low $\mathrm{pH}$. In contrast, the concentrations drop markedly when $\mathrm{Mg}$ removal was near completion and the glass hydrolysed. At higher temperature $\left(300^{\circ} \mathrm{C}\right)$ almost all $\mathrm{Ca}, \mathrm{Na}, \mathrm{Zn}, \mathrm{Cu}$ and most of $\mathrm{Ba}$, $\mathrm{Sr}, \mathrm{K}$ and $\mathrm{Mn}$ were leached from the rock. $\mathrm{Si}, \mathrm{Al}$ and $\mathrm{H}_{2} \mathrm{~S}$ were also mobilised while $\mathrm{Cr}, \mathrm{V}$ and $\mathrm{Ni}$, remained relatively immobile.

Seyfried and Janecky (1985) investigated heavy metal and sulfur transport during subcritical and supercritical hydrothermal alteration of rocks of basaltic composition. Diabase, basalt glass and crystalline basalt were reacted with a $\mathrm{Na}-\mathrm{Ca}-\mathrm{K}-\mathrm{Cl}$ fluid of seawater composition 
at $350-425^{\circ} \mathrm{C} / 375-400 \mathrm{bar}$, with fluid/rock ratio of $1.0-0.5$. The $\mathrm{pH}$ decreased with increasing temperature at constant pressure, changing from 4.8 to 2.7 at 350 and $425^{\circ} \mathrm{C}$, respectively (Fig. 1.9). $\mathrm{Fe}$ and $\mathrm{Mn}$ concentrations increased with increasing temperature in all experiments except with basalt glass. $\mathrm{Cu}, \mathrm{Zn}$ and $\mathrm{H}_{2} \mathrm{~S}$ showed maximum concentrations at $375-400^{\circ} \mathrm{C} / 400$ bar, however, they did not increase when temperature was increased to $425^{\circ} \mathrm{C}$ (Fig. 1.9). This suggests that sulfides are more insoluble under these conditions. From these studies, it was concluded that pressure plays a key role in metal transport and on $\mathrm{H}^{+}$generation. Results from experiments at $425^{\circ} \mathrm{C} / 400$ bar showed that metal concentrations (especially $\mathrm{Fe}$ and $\mathrm{Mn}$ ) were higher of those reported from experiments by Mottl and Holland (1978) and by Mottl et al. (1979) at $500^{\circ} \mathrm{C} / 1000$ bar. A pressure decrease at $\mathrm{T}>\mathrm{T}_{\mathrm{c}}$ for seawater causes a decrease in solution density and a decrease of the dielectric constant causing an increase in the chlorocomplex stability. The dominant alteration phase in these experiments was mixed layer chlorite/smectite (Fig. 1.10). Poorly crystalline tremolite and actinolite were found from the basalt glass experiment, while clinozoisite (epidote) was found only in the diabase experiment (Fig. 1.10). Secondary magnetite was identified only in the experiment at $425^{\circ} \mathrm{C} / 400$ bar. Pyrite formed at $400^{\circ} \mathrm{C}$ and $425^{\circ} \mathrm{C} / 400$ bar while pyrrhotite was found in experiments at $\mathrm{T} \leq 375^{\circ} \mathrm{C}$ (Fig. $1.10)$. 
Figure 1.9. $\mathrm{Fe}, \mathrm{Mn}, \mathrm{Cu}$ and $\mathrm{Zn}$ concentrations (in $\mu$ molal) versus temperature (350-375-400-425 $\mathrm{C} / 400 \mathrm{bar}$ ) and $\mathrm{pH}$ by Seyfried and Janecky (1985).

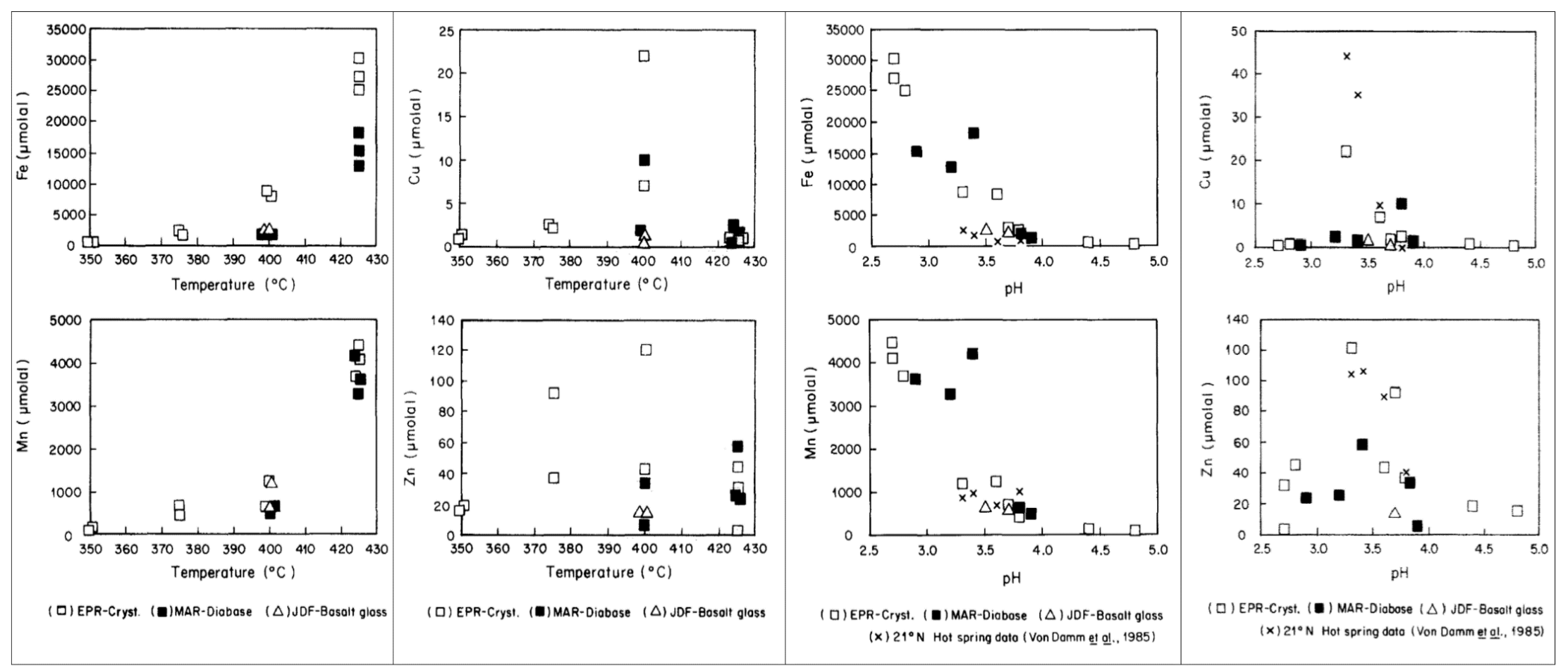


Figure 1.10. SEM images from Seyfried and Janecky (1985) showing: (a) pyrrhotite crystals (hexagonal) (scale = 70 $\mu$ m); (b) pyrrhotite crystals with overgrowth pyrite $($ scale $=20 \mu \mathrm{m})$; $(\mathrm{c})$ pyrite overgrowth on pyrrhotite $(\mathrm{scale}=5 \mu \mathrm{m})$; $(\mathrm{d})$ Tremolite/actinolite, fibrous crystals $($ scale $=$ $20 \mu \mathrm{m})$.
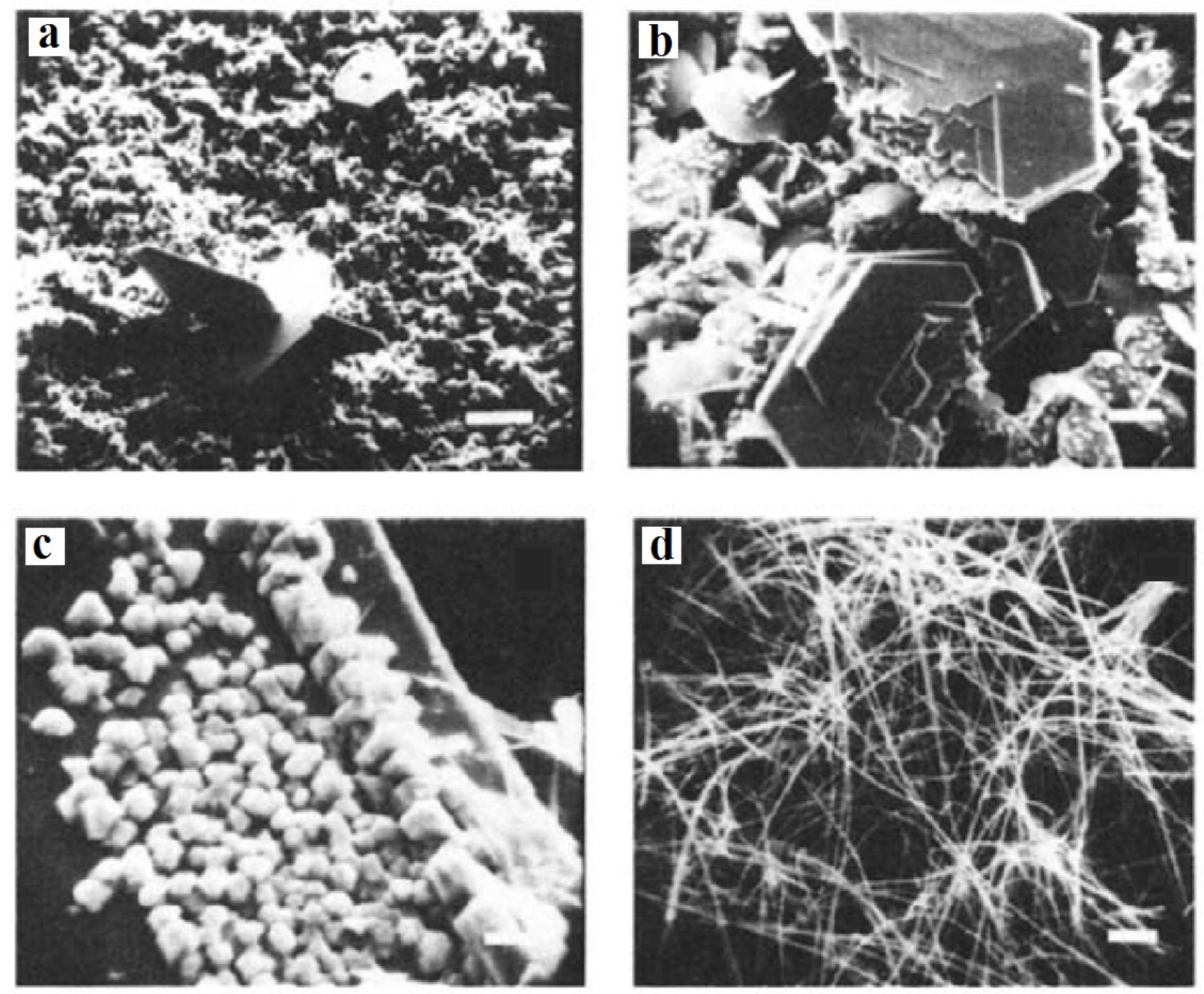

Berndt et al. (1989) showed the difference in the alteration process as a result of different dissolved $\mathrm{SiO}_{2}$ concentrations and compositions of plagioclase. In diabase experiments ( 0.5 to 1 water/rock ratio), fluids were produced that were undersaturated with respect to quartz and caused the hydration of olivine and orthopyroxene. In contrast, basalt experiments produced fluids slightly oversaturated with respect to quartz, via the dissolution of the glass, and the formation of secondary smectite and amphibole. Fluid chemistry gave constraints on the equilibrium state which appeared to approach equilibrium with the albite and anorthite components of plagioclase. The $\mathrm{pH}$ values were consistent with equilibrium between plagioclase and epidote. 
During the 1990's, the study of fluid-rock interaction became more advanced, using more sophisticated equipment, which provided better control on temperature and pressure. The combination of new exploration technologies, which permitted field investigations at deep sea vents, and better experimental methodologies, significantly increased the knowledge of the nature and geochemical evolution of fluids during hydrothermal alteration. This produced new and more reliable thermodynamic data allowing better numerical modelling, especially for the prediction of $\mathrm{pH}$, redox constraints, mineral solubilities and the stability of metal complexes in solution. Experiments on talc-quartz equilibria and on the stability of magnesium chloride complexes below and near the critical point of seawater were undertaken by Saccocia and Seyfried (1990). The determination of the stability of Fe-Cl complexing was studied by Heinrich and Seward (1990). While the effect of redox on the relative solubilities of copper and iron in Clbearing aqueous fluids at elevated temperatures and pressures was studied by Ding and Seyfried (1992).

Further experiments (Seewald and Seyfried, 1990; Berndt, 1993) conducted at subcritical and near supercritical conditions of the fluid using crystalline basalt, provided evidence on the role of temperature during metal transport. Their work revealed that the dissolved concentrations of $\mathrm{Zn}, \mathrm{Cu}, \mathrm{Fe}$ and $\mathrm{Mn}$ measured at vents $\left(\mathrm{T}<375^{\circ} \mathrm{C}\right)$ were not consistent with those found during experimental simulations. The concentrations measured in situ could only be achieved or exceeded at temperatures $\geq 400^{\circ} \mathrm{C}$. This result confirmed that hydrothermal vent fluids lost heat and possibly dissolved metals during ascent to the seafloor from a higher temperature reaction zone.

Since the beginning of the 21th century, only a few experimental fluid-rock simulations have been undertaken. Their goal was mainly focused on better assessment of hydrothermal alteration processes in the ultramafic systems at mid-ocean ridges. More information collected from field investigations and the experimental simulations allowed better understanding of the parameters that control chemical compositions at vents (Seyfried et al., 2013). These experiments reported significant information on redox and $\mathrm{pH}$ constraints.

Recent experiments used different mineral assemblages including olivineorthopyroxene-clinopyroxene in reaction with $\mathrm{NaCl}$ and $\mathrm{MgCl}_{2}$ at $400^{\circ} \mathrm{C} / 500$ bar (Allen and Seyfried, 2003); magnetite-bornite-anhydrite with a Na-K-Cl bearing aqueous fluid at 375$400^{\circ} \mathrm{C} / 500$ bar (Foustoukos and Seyfried, 2005); and peridotite in reaction with seawater at 
$200^{\circ} \mathrm{C} / 500$ bar (Seyfried and Foustoukos, 2007). These studies revealed the development of low $\mathrm{pH}$ values $(4.9-5.2)$ with substantial changes in fluid composition and mineral solubilities; slower reaction of olivine with increasing $\mathrm{T}$ and $\mathrm{P}$; and high concentrations of $\mathrm{SiO}_{2}$ and $\mathrm{Ca}$ in the fluid. The increase in $\mathrm{Ca}$ concentration was attributed to the dissolution of pyroxene, with tremolite and talc becoming stable according to the observed $\mathrm{pH}$ values. High $\mathrm{H}_{2 \text { (aq) }}$ concentrations, from the oxidation of ferrous silicates (especially pyroxene), confirmed high $\mathrm{Fe}$ solubilities which was consistent with measurements in situ at Rainbow and Logatchev, on the Mid-Atlantic-Ridge. Low $\mathrm{H}_{2} \mathrm{~S}$ concentrations and high dissolved $\mathrm{Ni}$ and $\mathrm{Cu}$ showed fluid equilibria with magnetite - bornite - chalcocite $\left(\mathrm{Cu}_{2} \mathrm{~S}\right)$ - heazlewoodite $\left(\mathrm{Ni}_{3} \mathrm{~S}_{2}\right)$. Experimental data revealed that $\mathrm{Cu}$ concentrations in solution were more sensitive to temperature changes than with respect to $\mathrm{H}_{2} \mathrm{~S}$ and Fe concentrations. In contrast, Fe concentrations were more sensitive to $\mathrm{pH}$ and chloride concentrations in the fluid.

More recently, Zhang et al. (2015) conducted a simulation reacting basalt with pure water and $5 \% \mathrm{NaCl}$ using a flow-through reactor at temperatures from 20 to $400^{\circ} \mathrm{C} / 230$ bar. The aim was to better understand the nature of hydrothermal reactions in basaltic rocks and the genesis of the large magnetite ore deposits. Their study gave constraints on the changes in metal release rates under increasing temperature conditions. Unfortunately, their work did not address the possibility of the formation of secondary minerals phases, especially at higher temperatures, therefore, the interpretation of their work is somewhat problematic. 
Table 1.1. Mafic/Ultramafic rock - fluid interaction experiments carried out from the 1970s to the present.

\begin{tabular}{|c|c|c|c|c|c|c|c|}
\hline Authors & $\begin{array}{c}\text { T-P } \\
\text { conditions }\end{array}$ & Experimental set-up & Fluid & Rock & $\begin{array}{c}\text { System } \\
\text { conditions }\end{array}$ & Experimental time & Number of Samples \\
\hline Hajash, 1975 & $\begin{array}{l}200-500^{\circ} \mathrm{C} \\
500-800 \mathrm{bar}\end{array}$ & $\begin{array}{l}\text { Cold-seal pressure vessel } \\
\text { (Bridgman seal vessel) }\end{array}$ & seawater & basalt & static fluid & & \\
\hline Bischoff and Dickson, 1975 & $\begin{array}{l}200^{\circ} \mathrm{C} \\
500 \text { bar }\end{array}$ & $\begin{array}{l}\text { Rocking Autoclaves For } \\
\text { Hydrothermal Experiments } \\
\text { (TEFLON cell); on-line sampling } \\
\text { Rocking Autoclaves For }\end{array}$ & seawater (300 g) & $\begin{array}{l}\text { tholeiitic basalt (30 } \\
\text { g) }\end{array}$ & static fluid & $4752 \mathrm{hrs}$ & 19 samples of $6 \mathrm{ml}$ \\
\hline Seyfried and Bischoff, 1977 & $\begin{array}{l}260^{\circ} \mathrm{C} \\
500 \mathrm{bar}\end{array}$ & $\begin{array}{l}\text { Hydrothermal Experiments } \\
\text { (TEFLON cell and stainless steel } \\
\text { pressure vessel); on-line sampling }\end{array}$ & artificial seawater (200 g) & basaltic glass $(4 \mathrm{~g})$ & static fluid & $2400 \mathrm{hrs}$ & 6 samples of $10 \mathrm{ml}$ \\
\hline Bischoff and Seyfried, 1978 & $\begin{array}{l}70-350^{\circ} \mathrm{C} \\
500 \mathrm{bar}\end{array}$ & $\begin{array}{l}\text { Rocking Autoclaves For } \\
\text { Hydrothermal Experiments (Gold } \\
\text { cell); on-line sampling }\end{array}$ & seawater $(100 \mathrm{ml})$ & no rock & static fluid & $\sim 1$ month & \\
\hline Mottl et al., 1978, 1979 & $\begin{array}{l}200-500^{\circ} \mathrm{C} \\
500-1000 \text { bar }\end{array}$ & $\begin{array}{l}\text { Rocking Autoclaves For } \\
\text { Hydrothermal Experiments (Gold } \\
\text { cell); on-line sampling }\end{array}$ & $\begin{array}{c}\text { seawater } \\
\text { artificial seawater }\end{array}$ & $\begin{array}{c}\text { basalt } \\
\text { andesite } \\
\text { (1:3 fluid/rock ratio) }\end{array}$ & static fluid & 2 to 20 months & \\
\hline Seyfried and Bischoff, 1979 & $\begin{array}{c}70^{\circ} \mathrm{C}, 1 \mathrm{bar} \\
150^{\circ} \mathrm{C}, 500 \mathrm{bar}\end{array}$ & $\begin{array}{l}\text { Rocking Autoclaves For } \\
\text { Hydrothermal Experiments } \\
\text { (TEFLON cell); on-line sampling }\end{array}$ & seawater $(200 \mathrm{~g})$ & $\begin{array}{l}\text { basalt }(20 \mathrm{~g}) \\
\text { diabase }(20 \mathrm{~g})\end{array}$ & static fluid & $\begin{array}{c}3600 \mathrm{hrs} \text { at } 70^{\circ} \mathrm{C} \text { with basalt } \\
3564 \text { hrs with basalt } \\
11,058 \text { hrs with diabase at } 150^{\circ} \mathrm{C}\end{array}$ & $\begin{array}{c}5 \text { samples at } 70^{\circ} \mathrm{C} \\
8 \text { at } 150^{\circ} \mathrm{C} \text { with basalt glass } \\
8 \text { samples with diabase at } 150^{\circ} \mathrm{C}\end{array}$ \\
\hline Seyfried and Bischoff, 1981 & $\begin{array}{l}300^{\circ} \mathrm{C} \\
500 \mathrm{bar}\end{array}$ & $\begin{array}{l}\text { NEW Rocking Autoclaves Design } \\
\text { For Hydrothermal Experiments } \\
\text { (Titanium-Gold cell and chrome- } \\
\text { vanadium pressure vessel); on-line } \\
\text { sampling }\end{array}$ & $\begin{array}{l}\text { seawater } \\
\mathrm{NaCl} \text { solution }\end{array}$ & $\begin{array}{l}\text { basalt glass } \\
\text { diabase } \\
\text { (fluid/rock ratio of } \\
\text { 10) }\end{array}$ & static fluid & $\begin{array}{c}2028 \text { hrs basalt glass-seawater exp. } \\
1968 \text { hrs diabase-seawater exp. } \\
400 \text { hrs basalt glass-NaCl solution exp. }\end{array}$ & $\begin{array}{l}9 \text { samples for the basalt glass-seawater exp. } \\
6 \text { samples for the diabase-seawater exp. } \\
4 \text { samples for the basalt-glass- } \mathrm{NaCl} \text { solution exp. }\end{array}$ \\
\hline Seyfried and Mottl, 1982 & $\begin{array}{l}150-300^{\circ} \mathrm{C} \\
500 \mathrm{bar}\end{array}$ & As above & seawater & $\begin{array}{l}\text { basalt glass } \\
\text { diabase } \\
\text { (fluid/rock ratios of } \\
50,62 \text { and } 125 \text { ) }\end{array}$ & static fluid & between 120 and 150 days & \\
\hline Seyfried and Janecky, 1985 & $\begin{array}{l}350-425^{\circ} \mathrm{C} \\
375-400 \mathrm{bar}\end{array}$ & As above & Na-Ca-K-Cl fluid & $\begin{array}{l}\text { crystalline basalt } \\
\text { diabase } \\
\text { basalt glass }\end{array}$ & static fluid & & $\begin{array}{l}4 \text { samples at } 350^{\circ} \mathrm{C} \\
4 \text { samples at } 375^{\circ} \mathrm{C} \\
4 \text { samples at } 400^{\circ} \mathrm{C} \\
4 \text { samples at } 425^{\circ} \mathrm{C}\end{array}$ \\
\hline Berndt et al., 1989 & $\begin{array}{c}350-425^{\circ} \mathrm{C} \\
250-400 \text { bar }\end{array}$ & As above & Na-Ca-K-Cl fluid & $\begin{array}{c}\text { basalt glass } \\
\text { diabase } \\
\text { (fluid/rock ratio } \\
\text { ranged between } 0.5 \\
\text { to } 5.0\end{array}$ & static fluid & $\sim 2500 \mathrm{hrs}$ & 2-3 samples at each $T$ \\
\hline $\begin{array}{l}\text { Seewald and Seyfried } \\
\text { (1990) }\end{array}$ & $\begin{array}{l}400^{\circ} \mathrm{C}, 400 \mathrm{bar} \\
350^{\circ} \mathrm{C}, 400 \mathrm{bar} \\
300^{\circ} \mathrm{C}, 400 \mathrm{bar}\end{array}$ & As above & $\mathrm{Na}-\mathrm{Ca}-\mathrm{K}-\mathrm{Cl}$ fluid & $\begin{array}{l}\text { crystalline basalt } \\
\text { fluid/rock ratio of } 1\end{array}$ & static fluid & $\begin{array}{l}990.5 \mathrm{hrs} \text { at } 400^{\circ} \mathrm{C} \\
1516 \mathrm{hrs} \text { at } 350^{\circ} \mathrm{C} \\
2183 \mathrm{hrs} \text { at } 300^{\circ} \mathrm{C}\end{array}$ & $\begin{array}{l}4 \text { samples at } 400^{\circ} \mathrm{C} \\
3 \text { samples at } 350^{\circ} \mathrm{C} \\
3 \text { samples at } 300^{\circ} \mathrm{C} \\
1 \text { samples at } 400^{\circ} \mathrm{C}\end{array}$ \\
\hline Zhang et al. (2015) & $\begin{array}{l}\text { between } \\
25^{\circ} \mathrm{C} \text { to } 400^{\circ} \mathrm{C} \\
230 \text { bar }\end{array}$ & Flow-Through reactor system & $\begin{array}{c}\text { Pure water and } \\
\mathrm{NaCl}(5 \mathrm{wt} \%) \text { - pure water } \\
\text { (flow-rate } \\
\left.\text { of } 0.5-8.0 \mathrm{ml} \mathrm{min}^{-1}\right)\end{array}$ & basalt & $\begin{array}{l}\text { Continuous } \\
\text { flow }\end{array}$ & & $\begin{array}{l}1 \text { sample every } 1 \mathrm{hr} \\
\text { at constant T-P and flow-rate }\end{array}$ \\
\hline
\end{tabular}




\subsection{Proposed research: framework and questions}

In this study, experiments have been performed simulating the reaction of basalt with various fluids at near-supercritical/supercritical $\left(400^{\circ} \mathrm{C} / 500 \mathrm{bar}\right)$ and subcritical $\left(350^{\circ} \mathrm{C} / 500 \mathrm{bar}\right)$ conditions that would be typical of reaction zones in sub-seafloor hydrothermal systems.

Previous experimental studies, as summarised above, provided insight into the fluid-rock exchanges that give rise to the fluid's chemical signature; however, many fundamental questions involving the equilibrium and kinetic aspects of fluid-rock interaction, are still poorly constrained. To simulate fluid-rock interactions at supercritical and subcritical conditions, computer modelling is somewhat deficient due to a lack of reliable thermodynamic data. Therefore, the experimental approach offers the only alternative to directly duplicate fluidmineral interactions that occur in the reaction zone in submarine hydrothermal systems. The experiments conducted in this study have used a novel experimental approach able to simulate high T-P conditions occurring where seawater reacts with basaltic rocks in the sub-seafloor. Using the results of the experiments, it has been possible to investigate the reaction-path chemistry of different fluids including pure water, geothermal brine, and seawater both at nearsupercritical, supercritical, and subcritical conditions. For the first time, flow-through reaction of seawater with rocks with a high sampling frequency without altering P-T conditions of the system has been undertaken.

In previous experimental studies, important insight has been gained into the fluid-rock exchanges that give rise to a fluid's chemical signature. However, several fundamental questions that result from the hydrothermal alteration at supercritical, near-supercritical and subcritical conditions in flow-through (open-system), remain. The aims of this study are to investigate, in detail, the mineralogical changes, kinetic of reactions, chemical evolution of the fluid, and elementals fluxes of major and trace elements. This information is then compared with previous experimental data and to natural analogues. 
The thesis is divided into seven chapters:

\section{Chapter 1: Introduction}

\section{Chapter 2: Experimental Method}

- description of the experimental apparatus used in for the experiments

- description of the unreacted experimental fluids and rock substrate used in the experiments

- the experimental protocols/methodology used for each set of experiments (distilled water, geothermal brine, seawater)

- the analytical techniques used to analyse the input solutions, effluent samples and unreacted and reacted rock substrate

- the methodology for the calculation of at temperature $\mathrm{pH}$ values, species concentrations and activities, and mineral saturation indices

\section{Chapter 3: Basalt - water interactions under hydrothermal conditions}

- an introduction to the experiments reacting basalt rock with distilled water at subcritical and supercritical conditions

- the presentation of the results of these experiments including fluid chemistry and mineralogical analysis

- discussion of the results of the experiments including major and trace elements fluxes, fluid-rock interaction path, implications to $\mathrm{Na} / \mathrm{K}$ geothermometry, and geological implications

\section{Chapter 4: Basalt - geothermal brine interactions under hydrothermal conditions}

- an introduction to the experiments reacting basalt rock with geothermal brine at subcritical and supercritical conditions

- the presentation of the results of these experiments including fluid chemistry and mineralogical analysis

- discussion of the results of the experiments including major and trace elements fluxes, fluid-rock interaction path, implications to $\mathrm{Na} / \mathrm{K}$ geothermometry, and geological implications

- a comparison between the distilled water and geothermal brine experiments. 


\section{Chapter 5: The experimental behaviour of seawater}

- an introduction to the experiments preheating seawater to subcritical and nearsupercritical conditions

- the presentation of the results of these experiments including fluid chemistry and mineralogical analysis

- discussion of the results of the experiments including major element fluxes and mineralogical implications

\section{Chapter 6: Basalt - seawater interactions under hydrothermal conditions}

- an introduction to the experiments reacting basalt rock with seawater at subcritical and near-supercritical conditions

- the presentation of the results of these experiments including fluid chemistry and mineralogical analysis

- discussion of the results of the experiments including major and trace elements fluxes, fluid-rock interaction path, implications to $\mathrm{Na} / \mathrm{K}$ geothermometry, and geological implications

\section{Chapter 7: Summary and conclusions}




\subsection{References}

Allen, D.E. and Seyfried Jr, W.E., 2003, Compositional controls on vent fluids from ultramafichosted hydrothermal systems at mid-ocean ridges: An experimental study at $400^{\circ} \mathrm{C}, 500$ bars. Geochimica et Cosmochimica Acta, 67: 1531-1542.

Alt, J.C., Teagle, D.A.H., Bach, W., Halliday, A.N. and Erzinger, J., 1996, Stable and strontium isotopic profiles through hydrothermally altered upper oceanic crust, Hole 504B. Proceedings of the Ocean Drilling Program; scientific results, Costa Rica Rift; covering Leg 148 of the cruises of the Drilling Vessel JOIDES Resolution, Balboa Harbor, Panama, to Balboa Harbor, Panama, sites 504 and 896, 21 January-10 March 1993, 148: 57.

Alt, J.C., Laverne, C., Coggon, R.M., Teagle, D.A.H., Banerjee, N.R., Morgan, S., Smith-Duque, C.E., Harris, M. and Galli, L., 2010, Subsurface structure of a submarine hydrothermal system in ocean crust formed at the East Pacific Rise, ODP/IODP Site 1256. Geochemistry, Geophysics, Geosystems, 11: n/a-n/a.

Alt, J.C., 2013, Subseafloor Processes in Mid-Ocean Ridge Hydrothennal Systems. Seafloor Hydrothermal Systems: Physical, Chemical, Biological, and Geological Interactions. American Geophysical Union85-114.

Anisimov, M.A., Sengers, J.V. and Levelt Sengers, J.M.H., 2004, Chapter 2 - Near-critical behavior of aqueous systems A2 - Palmer, Donald A. In: Fernández-Prini, R. and Harvey, A.H. (eds.), Aqueous Systems at Elevated Temperatures and Pressures. Academic Press, London, 29-71.

Arnórsson, S., Grönvold, K. and Sigurdsson, S., 1978, Aquifer chemistry of four hightemperature geothermal systems in Iceland. Geochimica et Cosmochimica Acta, 42: 523536.

Arnórsson, S., 1995, Geothermal systems in Iceland: Structure and conceptual models-I. Hightemperature areas. Geothermics, 24: 561-602.

Atwater, T.M. and Mudie, J.D., 1968, Block Faulting on the Gorda Rise. Science, 159: 729-731.

Babcock, J.M., Harding, A.J., Kent, G.M. and Orcutt, J.A., 1998, An examination of along-axis variation of magma chamber width and crustal structure on the East Pacific Rise between $13^{\circ} 30^{\prime} \mathrm{N}$ and $12^{\circ} 20^{\prime} \mathrm{N}$. Journal of Geophysical Research: Solid Earth, 103: 30451-30467.

Bach, W., Peucker-Ehrenbrink, B., Hart, S.R. and Blusztajn, J.S., 2003, Geochemistry of hydrothermally altered oceanic crust: DSDP/ODP Hole 504B - Implications for seawater-crust exchange budgets and $\mathrm{Sr}$ - and $\mathrm{Pb}$-isotopic evolution of the mantle. Geochemistry, Geophysics, Geosystems, 4: n/a-n/a.

Ballard, R.D.A.-V.A., Tjered H. , 1977, Morphology and tectonics of the inner rift valley at lat $36^{\circ} 50^{\prime} \mathrm{N}$ on the Mid-Atlantic Ridge. GSA Bulletin, 88: 507-530.

Becker, K., Sakai, H., Adamson, A.C., Alexandrovich, J., Alt, J.C., Anderson, R.N., Bideau, D., Gable, R., Herzig, P.M., Houghton, S., Ishizuka, H., Kawahata, H., Kinoshita, H., Langseth, M.G., Lovell, M.A., Malpas, J., Masuda, H., Merrill, R.B., Morin, R.H., Mottl, M.J., Pariso, J.E., Pezard, P., Phillips, J., Sparks, J. and Uhlig, S., 1989, Drilling deep into young oceanic crust, Hole 504B, Costa Rica Rift. Reviews of Geophysics, 27: 79-102.

Benoit, I., Abe, N., Godard, M., Morris, A., Teagle, D.A.H. and Umino, S., 2014, Chapter 4.2.1 Formation and Evolution of Oceanic Lithosphere: New Insights on Crustal Structure and Igneous Geochemistry from ODP/IODP Sites 1256, U1309, and U1415. In: Stein, R., Blackman, D.K., Inagaki, F. and Larsen, H.-C. (eds.), Developments in Marine Geology. Elsevier449-505. 
Berndt, M. and Seyfned Jr, W., 1986, B, Li, and asscociated trace element chemistry of alteration minerals, Holes 597B and 597C1. Init. Repts. DSDP: Washington, DC, US Govt. Printing Office: 49.

Berndt, M.E., Seyfried, W.E. and Janecky, D.R., 1989, Plagioclase and epidote buffering of cation ratios in mid-ocean ridge hydrothermal fluids: Experimental results in and near the supercritical region. Geochimica et Cosmochimica Acta, 53: 2283-2300.

Berndt, M.E. and Seyfried, W.E., 1993, Calcium and sodium exchange during hydrothermal alteration of calcic plagioclase at $400^{\circ} \mathrm{C}$ and 400 bars. Geochimica et Cosmochimica Acta, 57: 4445-4451.

Bettison-Varga, L., Varga, R. and Schiffman, P., 1992, Relation between ore-forming hydrothermal systems and extensional deformation in the Solea graben spreading center, Troodos ophiolite, Cyprus

Bischoff, J.L. and Dickson, F.W., 1975, Seawater-basalt interaction at $200^{\circ} \mathrm{C}$ and 500 bars: Implications for origin of sea-floor heavy-metal deposits and regulation of seawater chemistry. Earth and Planetary Science Letters, 25: 385-397.

Bischoff, J.L. and Seyfried, W.E., 1978, Hydrothermal chemistry of seawater from 25 degrees to 350 degrees C. American Journal of Science, 278: 838-860.

Bischoff, J.L. and Rosenbauer, R.J., 1984, The critical point and two-phase boundary of seawater, $200-500^{\circ} \mathrm{C}$. Earth and Planetary Science Letters, 68: 172-180.

Björnsson, S., Arnórsson, S. and Tómasson, J.J.G., 1970, Exploration of the Reykianes thermal brine area. 2: 1640-1650.

Bott, M.H.P., 1996, Flexure associated with planar faulting. Geophysical Journal International, 126: F21-F24.

Bowers, T.S., Campbell, A.C., Measures, C.I., Spivack, A.J., Khadem, M. and Edmond, J.M., 1988, Chemical controls on the composition of vent fluids at $13^{\circ}-11^{\circ} \mathrm{N}$ and $21^{\circ} \mathrm{N}$, East Pacific Rise. Journal of Geophysical Research: Solid Earth, 93: 4522-4536.

Brunner, G., 2014, Chapter 1 - Introduction. In: Brunner, G. (ed.), Supercritical Fluid Science and Technology. Elsevier1-7.

Butterfield, D.A. and Massoth, G.J., 1994, Geochemistry of north Cleft segment vent fluids: Temporal changes in chlorinity and their possible relation to recent volcanism. Journal of Geophysical Research: Solid Earth, 99: 4951-4968.

Böhlke, J., Honnorez, J., Honnorez-Guerstein, B.M., Muehlenbachs, K. and Petersen, N., 1981, Heterogeneous alteration of the upper oceanic crust: correlation of rock chemistry, magnetic properties, and $\mathrm{O}$ isotope ratios with alteration patterns in basalts from site 396B, DSDP. Journal of Geophysical Research: Solid Earth, 86: 7935-7950.

Campbell, A.C., Bowers, T.S., Measures, C.I., Falkner, K.K., Khadem, M. and Edmond, J.M., 1988, A time series of vent fluid compositions from $21^{\circ} \mathrm{N}$, East Pacific Rise (1979, 1981, 1985), and the Guaymas Basin, Gulf of California (1982, 1985). Journal of Geophysical Research: Solid Earth, 93: 4537-4549.

Cann, J., 1971, Petrology of Basement Rocks from Palmer Ridge, NE Atlantic 605-617 p.

Cann, J.R. and Funnell, B.M., 1967, Palmer Ridge: a Section through the Upper Part of the Ocean Crust? Nature, 213: 661.

Cann, J.R., 1969, Spilites from the Carlsberg Ridge, Indian Ocean. Journal of Petrology, 10: 1 19.

Cann, J.R. and Strens, M.R., 1989, Modeling periodic megaplume emission by black smoker systems. Journal of Geophysical Research: Solid Earth, 94: 12227-12237. 
Chernysheva, V.I., 1971, Greenstone-altered rocks of rift zones in median ridges of Indian Ocean. International Geology Review, 13: 903-913.

Coelho, G., Branquet, Y., Sizaret, S., Arbaret, L., Champallier, R. and Rozenbaum, O., 2015, Permeability of sheeted dykes beneath oceanic ridges: Strain experiments coupled with 3D numerical modeling of the Troodos Ophiolite, Cyprus. Tectonophysics, 644-645: 138-150.

Crawford, W.C. and Webb, S.C., 2002, Variations in the distribution of magma in the lower crust and at the Moho beneath the East Pacific Rise at $9^{\circ}-10^{\circ} \mathrm{N}$. Earth and Planetary Science Letters, 203: 117-130.

Detrick, R.S., Buhl, P., Vera, E., Mutter, J., Orcutt, J., Madsen, J. and Brocher, T., 1987, Multichannel seismic imaging of a crustal magma chamber along the East Pacific Rise. Nature, 326: 35.

Dickson, F., W. Blount, C. and Tunell, G., 1963, Use of hydrothermal solution equipment to determine the solubility of anhydrite in water from 100 degrees $\mathrm{C}$ to 275 degrees $\mathrm{C}$ and from 1 bar to 1000 bars pressure $61-78 \mathrm{p}$.

Driesner, T. and Heinrich, C.A., 2007, The system H2O-NaCl. Part I: Correlation formulae for phase relations in temperature-pressure-composition space from 0 to $1000{ }^{\circ} \mathrm{C}, 0$ to 5000 bar, and 0 to $1 \mathrm{XNaCl}$. Geochimica et Cosmochimica Acta, 71: 4880-4901.

Edmond, J.M., Measures, C., McDuff, R.E., Chan, L.H., Collier, R., Grant, B., Gordon, L.I. and Corliss, J.B., 1979, Ridge crest hydrothermal activity and the balances of the major and minor elements in the ocean: The Galapagos data. Earth and Planetary Science Letters, 46: 1-18.

Elders, W. and Friðleifsson, G.Ó., 2010, Implications of the Iceland Deep Drilling Project for Improving Understanding of Hydrothermal Processes at Slow-Spreading Mid-Ocean Ridges 91-112 p.

Fehn, U., Green, K.E., Von Herzen, R.P. and Cathles, L.M., 1983, Numerical models for the hydrothermal field at the Galapagos Spreading Center. Journal of Geophysical Research: Solid Earth, 88: 1033-1048.

Foustoukos, D.I. and Seyfried Jr, W.E., 2005, Redox and pH constraints in the subseafloor root zone of the TAG hydrothermal system, $26^{\circ} \mathrm{N}$ Mid-Atlantic Ridge. Earth and Planetary Science Letters, 235: 497-510.

Fowler, A.P.G., Zierenberg, R.A., Schiffman, P., Marks, N. and Friðleifsson, G.Ó., 2015, Evolution of fluid-rock interaction in the Reykjanes geothermal system, Iceland: Evidence from Iceland Deep Drilling Project core RN-17B. Journal of Volcanology and Geothermal Research, 302: 47-63.

Franzson, H., Zierenberg, R. and Schiffman, P., 2008, Chemical transport in geothermal systems in Iceland: Evidence from hydrothermal alteration. Journal of Volcanology and Geothermal Research, 173: 217-229.

Fridleifsson, G.O. and Elders, W.A., 2005, The Iceland Deep Drilling Project: a search for deep unconventional geothermal resources. Geothermics, 34: 269-285.

Fridleifsson, G.Ó. and Albertsson, A., Year, Deep geothermal drilling at Reykjanes Ridge: opportunity for an international collaboration. Proceedings of the World Geothermal Congress, F7-5.

Fridleifsson, G.Ó., Elders, W.A., Zierenberg, R.A., Stefánsson, A., Fowler, A.P.G., Weisenberger, T.B., Harðarson, B.S. and Mesfin, K.G., 2017, The Iceland Deep Drilling 
Project $4.5 \mathrm{~km}$ deep well, IDDP-2, in the seawater-recharged Reykjanes geothermal field in SW Iceland has successfully reached its supercritical target. Sci. Dril., 23: 1-12.

Friðleifsson, G.Ó., Elders, W.A., Zierenberg, R.A., Stefánsson, A., Fowler, A.P.G., Weisenberger, T.B., Harðarson, B.S. and Mesfin, K.G., 2017, The Iceland Deep Drilling Project $4.5 \mathrm{~km}$ deep well, IDDP-2, in the seawater-recharged Reykjanes geothermal field in SW Iceland has successfully reached its supercritical target. Sci. Dril., 23: 1-12.

German, C. and Von Damm, K.L., 2004, Hydrothermal processes

Gilles, B., Schott, J. and Loubet, M., 1987, Fundamental processes controlling the first stage of alteration of a basalt glass by seawater: an experimental study between $200^{\circ}$ and $320^{\circ} \mathrm{C}$. Earth and Planetary Science Letters, 84: 431-445.

Gillis, K.M. and Roberts, M.D., 1999, Cracking at the magma-hydrothermal transition: evidence from the Troodos Ophiolite, Cyprus. Earth and Planetary Science Letters, 169: 227-244.

Gillis, K.M., 2008, The roof of an axial magma chamber: A hornfelsic heat exchanger. Geology, 36: 299-302.

Gudmundsson, A.J.J.o.G.R.S.E., 1986, Mechanical aspects of postglacial volcanism and tectonics of the Reykjanes Peninsula, southwest Iceland. 91: 12711-12721.

Hannington, M.D., Jonasson, I.R., Herzig, P.M. and Petersen, S., 2013, Physical and Chemical Processes of Seafloor Mineralization at Mid-Ocean Ridges. Seafloor Hydrothermal Systems: Physical, Chemical, Biological, and Geological Interactions. American Geophysical Union115-157.

Hannington, M.D.A.-S., Steven D., 1988, Mineralogy and geochemistry of a hydrothermal silicasulfide-sulfate spire in the caldera of Axial Seamount, Juan De Fuca Ridge. The Canadian Mineralogist, 26: 603-625.

Harlov, D.E. and Austrheim, H., 2013, Metasomatism and the Chemical Transformation of Rock: Rock-Mineral-Fluid Interaction in Terrestrial and Extraterrestrial Environments. Metasomatism and the Chemical Transformation of Rock: The Role of Fluids in Terrestrial and Extraterrestrial Processes. Springer Berlin Heidelberg, Berlin, Heidelberg, $1-16$.

Harper, G.D., Bowman, J.R. and Kuhns, R., 1988, A field, chemical, and stable isotope study of subseafloor metamorphism of the Josephine ophiolite, California-Oregon. Journal of Geophysical Research: Solid Earth, 93: 4625-4656.

Haymon, R., 1983, Haymon, R. M. Growth history of hydrothermal black smoker chimneys. Nature 301, 695-698 695-698 p.

Haymon, R.M., AU - Koski, R.A. and AU - Abrams, M.J., 1989, Hydrothermal discharge zones beneath massive sulfide deposits mapped in the Oman ophiolite. Geology, 17: 531-535.

Haymon, R.M., Fornari, D.J., Von Damm, K.L., Lilley, M.D., Perfit, M.R., Edmond, J.M., Shanks, W.C., Lutz, R.A., Grebmeier, J.M., Carbotte, S., Wright, D., McLaughlin, E., Smith, M., Beedle, N. and Olson, E., 1993, Volcanic eruption of the mid-ocean ridge along the East Pacific Rise crest at $9^{\circ} 45-52^{\prime} \mathrm{N}$ : Direct submersible observations of seafloor phenomena associated with an eruption event in April, 1991. Earth and Planetary Science Letters, 119: 85-101.

Hajash, A., 1975, Hydrothermal processes along mid-ocean ridges: An experimental investigation. Contributions to Mineralogy and Petrology, 53: 205-226.

Heinrich, C. and Seward, T.J.G.e.C.A., 1990, A spectrophotometric study of aqueous iron (II) chloride complexing from 25 to 200 C. 54 : 2207-2221. 
Helgeson, H.C. and Kirkham, D.H., 1974, Theoretical prediction of the thermodynamic behavior of aqueous electrolytes at high pressures and temperatures; I, Summary of the thermodynamic/electrostatic properties of the solvent. American Journal of Science, 274: 1089-1198.

Helgeson, H.C. and Kirkham, D.H., 1976, Theoretical prediction of thermodynamic properties of aqueous electrolytes at high pressures and temperatures. III. Equation of state for aqueous species at infinite dilution. Am. J. Sci.;(United States), 276.

Honnorez, J., 1983, Basalt-Seawater Exchange: A Perspective from an Experimental Viewpoint. Hydrothermal Processes at Seafloor Spreading Centers. Springer169-176.

Jakobsson, S.P., Jónsson, J. and Shido, F.J.J.o.P., 1978, Petrology of the western Reykjanes peninsula, Iceland. 19: 669-705.

Janecky, D.R. and Seyfried, W.E., 1984, Formation of massive sulfide deposits on oceanic ridge crests: Incremental reaction models for mixing between hydrothermal solutions and seawater. Geochimica et Cosmochimica Acta, 48: 2723-2738.

Kaasalainen, H. and Stefánsson, A., 2012, The chemistry of trace elements in surface geothermal waters and steam, Iceland. Chemical Geology, 330: 60-85.

Kadko, D., Koski, R., Tatsumoto, M. and Bouse, R., 1985, An estimate of hydrothermal fluid residence times and vent chimney growth rates based on $210 \mathrm{~Pb} / \mathrm{Pb}$ ratios and mineralogic studies of sulfides dredged from the Juan de Fuca Ridge. Earth and Planetary Science Letters, 76: 35-44.

Kadko, D. and Moore, W., 1988, Radiochemical constraints on the crustal residence time of submarine hydrothermal fluids: Endeavour Ridge. Geochimica et Cosmochimica Acta, 52: 659-668.

Karson, J.A., Klein, E.M., Hurst, S.D., Lee, C.E., Rivizzigno, P.A., Curewitz, D., Morris, A.R., Miller, D.J., Varga, R.G., Christeson, G.L., Cushman, B., O'Neill, J.M., Brophy, J.G., Gillis, K.M., Stewart, M.A. and Sutton, A.L., 2002, Structure of uppermost fast-spread oceanic crust exposed at the Hess Deep Rift: Implications for subaxial processes at the East Pacific Rise. Geochemistry, Geophysics, Geosystems, 3: n/a-n/a.

Kent, G.M., Harding, A.J. and Orcutt, J.A., 1990, Evidence for a smaller magma chamber beneath the East Pacific Rise at $9^{\circ} 30^{\prime}$ N. Nature, 344: 650.

Kingston Tivey, M., 2013, Modeling Chimney Growth and Associated Fluid Flow at Seafloor Hydrothermal Vent Sites. Seafloor Hydrothermal Systems: Physical, Chemical, Biological, and Geological Interactions. American Geophysical Union158-177.

Koepke, J., Christie, D.M., Dziony, W., Holtz, F., Lattard, D., Maclennan, J., Park, S., Scheibner, B., Yamasaki, T. and Yamazaki, S., 2008, Petrography of the dike-gabbro transition at IODP Site 1256 (equatorial Pacific): The evolution of the granoblastic dikes. Geochemistry, Geophysics, Geosystems, 9: n/a-n/a.

Koski, R.A., 1987, Sulfide Deposits on the Sea Floor: Geological Models and Resource Perspectives Based on Studies in Ophiolite Sequences. In: Teleki, P.G., Dobson, M.R., Moore, J.R. and von Stackelberg, U. (eds.), Marine Minerals: Advances in Research and Resource Assessment. Springer Netherlands, Dordrecht, 301-316.

Laverne, C., Grauby, O., Alt, J.C. and Bohn, M., 2006, Hydroschorlomite in altered basalts from Hole 1256D, ODP Leg 206: The transition from low-temperature to hydrothermal alteration. Geochemistry, Geophysics, Geosystems, 7.

Liebscher, A. and Heinrich, C.A., 2007, Fluid-Fluid Interactions in the Earth's Lithosphere. Reviews in Mineralogy and Geochemistry, 65: 1-13. 
Macdonald, K.C., Becker, K., Spiess, F.N. and Ballard, R.D., 1980, Hydrothermal heat flux of the "black smoker" vents on the East Pacific Rise. Earth and Planetary Science Letters, 48: $1-7$.

MacLeod, C.J. and Yaouancq, G., 2000, A fossil melt lens in the Oman ophiolite: Implications for magma chamber processes at fast spreading ridges. Earth and Planetary Science Letters, 176: 357-373.

Marks, N., Schiffman, P., Zierenberg, R.A., Franzson, H. and Fridleifsson, G.Ó., 2010, Hydrothermal alteration in the Reykjanes geothermal system: Insights from Iceland deep drilling program well RN-17. Journal of Volcanology and Geothermal Research, 189: 172-190.

Marks, N., Schiffman, P. and Zierenberg, R.A., 2011, High-grade contact metamorphism in the Reykjanes geothermal system: Implications for fluid-rock interactions at mid-oceanic ridge spreading centers. Geochemistry, Geophysics, Geosystems, 12: n/a-n/a.

McNutt, M.K., 1984, Lithospheric flexure and thermal anomalies. Journal of Geophysical Research: Solid Earth, 89: 11180-11194.

Melson, W.G. and van Andel, T.H., 1966, Metamorphism in the Mid-Atlantic Ridge, $22^{\circ} \mathrm{N}$ latitude. Marine Geology, 4: 165-186.

Melson, W.G., Thompson, G. and van Andel, T.H., 1968, Volcanism and metamorphism in the Mid-Atlantic Ridge, $22^{\circ} \mathrm{N}$ latitude. Journal of Geophysical Research, 73: 5925-5941.

Miyashiro, A., Shido, F. and Ewing, M., 1971, Metamorphism in the Mid-Atlantic Ridge near $24^{\circ}$ and $30^{\circ} \mathrm{N} 589-603 \mathrm{p}$.

Mottl, M.J. and Holland, H.D., 1978, Chemical exchange during hydrothermal alteration of basalt by seawater-I. Experimental results for major and minor components of seawater. Geochimica et Cosmochimica Acta, 42: 1103-1115.

Mottl, M.J., Holland, H.D. and Corr, R.F., 1979, Chemical exchange during hydrothermal alteration of basalt by seawater-II. Experimental results for Fe, Mn, and sulfur species. Geochimica et Cosmochimica Acta, 43: 869-884.

Mottl, M.J., 1983, Hydrothermal Processes at Seafloor Spreading Centers: Application of BasaltSeawater Experimental Results. In: Rona, P.A., Boström, K., Laubier, L. and Smith, K.L. (eds.), Hydrothermal Processes at Seafloor Spreading Centers. Springer US, Boston, MA, 199-224.

Müller, R.D., Sdrolias, M., Gaina, C. and Roest, W.R., 2008, Age, spreading rates, and spreading asymmetry of the world's ocean crust. Geochemistry, Geophysics, Geosystems, 9: n/a$\mathrm{n} / \mathrm{a}$.

Nehlig, P., Juteau, T., Bendel, V. and Cotten, J., 1994, The root zones of oceanic hydrothermal systems: Constraints from the Samail ophiolite (Oman). Journal of Geophysical Research: Solid Earth, 99: 4703-4713.

Nicolas, A. and Boudier, F., Year, Rooting of the Sheeted Dike Complex in the Oman Ophiolite. Dordrecht, 39-54.

Nicolas, A., Boudier, F., Koepke, J., France, L., Ildefonse, B. and Mevel, C., 2008, Root zone of the sheeted dike complex in the Oman ophiolite. Geochemistry, Geophysics, Geosystems, 9: n/a-n/a.

Norton, D.L., 1984, Theory of Hydrothermal Systems. Annual Review of Earth and Planetary Sciences, 12: 155-177.

Owusu, P.A. and Asumadu-Sarkodie, S., 2016, A review of renewable energy sources, sustainability issues and climate change mitigation. Cogent Engineering, 3: 1167990. 
Parsons, B. and Sclater, J.G., 1977, An analysis of the variation of ocean floor bathymetry and heat flow with age. Journal of Geophysical Research, 82: 803-827.

Patten, C.G.C., Pitcairn, I.K., Teagle, D.A.H. and Harris, M., 2016, Sulphide mineral evolution and metal mobility during alteration of the oceanic crust: Insights from ODP Hole 1256D. Geochimica et Cosmochimica Acta, 193: 132-159.

Pirajno, F., 1992, Hydrothermal Alteration. Hydrothermal Mineral Deposits: Principles and Fundamental Concepts for the Exploration Geologist. Springer Berlin Heidelberg, Berlin, Heidelberg, 101-155.

Putnis, A. and Austrheim, H., 2010, Fluid-induced processes: metasomatism and metamorphism. Geofluids, 10: 254-269.

Quon, S.H.-E., Ernest G, 1963, Rocks of Northern Part of Mid-Atlantic Ridge. GSA Bulletin, 74: $1-8$.

Richardson, C.J., Cann, J.R., Richards, H.G. and Cowan, J.G., 1987, Metal-depleted root zones of the Troodos ore-forming hydrothermal systems, Cyprus. Earth and Planetary Science Letters, 84: 243-253.

Ridley, W.I., Perfit, M.R., Josnasson, I.R. and Smith, M.F., 1994, Hydrothermal alteration in oceanic ridge volcanics: A detailed study at the Galapagos Fossil Hydrothermal Field. Geochimica et Cosmochimica Acta, 58: 2477-2494.

Saccocia, P.J. and Seyfried, W.E., 1990, Talc-quartz equilibria and the stability of magnesium chloride complexes in $\mathrm{NaCl}-\mathrm{MgCl} 2$ solutions at 300,350 , and $400^{\circ} \mathrm{C}, 500$ bars. Geochimica et Cosmochimica Acta, 54: 3283-3294.

Scheirer, D.S., Shank, T.M. and Fornari, D.J., 2006, Temperature variations at diffuse and focused flow hydrothermal vent sites along the northern East Pacific Rise. Geochemistry, Geophysics, Geosystems, 7: n/a-n/a.

Sclater, J.G., Parsons, B. and Jaupart, C., 1981, Oceans and continents: Similarities and differences in the mechanisms of heat loss. Journal of Geophysical Research: Solid Earth, 86: $11535-11552$.

Searle, R.C. and Escartín, J., 2013, The Rheology and Morphology of Oceanic Lithosphere and Mid-Ocean Ridges. Mid-Ocean Ridges. American Geophysical Union63-93.

Seewald, J.S. and Seyfried, W.E., 1990, The effect of temperature on metal mobility in subseafloor hydrothermal systems: constraints from basalt alteration experiments. Earth and Planetary Science Letters, 101: 388-403.

Seyfried Jr, W.E. and Bischoff, J.L., 1979, Low temperature basalt alteration by sea water: an experimental study at $70^{\circ} \mathrm{C}$ and $150^{\circ} \mathrm{C}$. Geochimica et Cosmochimica Acta, 43: 19371947.

Seyfried Jr, W.E., Foustoukos, D.I. and Fu, Q., 2007, Redox evolution and mass transfer during serpentinization: An experimental and theoretical study at $200{ }^{\circ} \mathrm{C}, 500$ bar with implications for ultramafic-hosted hydrothermal systems at Mid-Ocean Ridges. Geochimica et Cosmochimica Acta, 71: 3872-3886.

Seyfried Jr, W.E., Gordon Peter, C., and Dickson Frank, W., 1979, A new reaction cell for hydrothermal solution equipment. American Mineralogist, 64: 646449.

Seyfried, W. and Bischoff, J.L., 1977, Hydrothermal transport of heavy metals by seawater: The role of seawater/basalt ratio. Earth and Planetary Science Letters, 34: 71-77.

Seyfried, W.E. and Bischoff, J.L., 1981, Experimental seawater-basalt interaction at $300^{\circ} \mathrm{C}, 500$ bars, chemical exchange, secondary mineral formation and implications for the transport of heavy metals. Geochimica et Cosmochimica Acta, 45: 135-147. 
Seyfried, W.E. and Mottl, M.J., 1982, Hydrothermal alteration of basalt by seawater under seawater-dominated conditions. Geochimica et Cosmochimica Acta, 46: 985-1002.

Seyfried, W.E. and Janecky, D.R., 1985, Heavy metal and sulfur transport during subcritical and supercritical hydrothermal alteration of basalt: Influence of fluid pressure and basalt composition and crystallinity. Geochimica et Cosmochimica Acta, 49: 2545-2560.

Seyfried, W.E., Berndt, M.E. and Janecky, D.R., 1986, Chloride depletions and enrichments in seafloor hydrothermal fluids: Constraints from experimental basalt alteration studies. Geochimica et Cosmochimica Acta, 50: 469-475.

Seyfried, W.E., Janecky, D. and Berndt, M.E., 1987, Rocking autoclaves for hydrothermal experiments: II. The flexible reaction-cell system 216-239 p.

Seyfried, W.E., Ding, K. and Berndt, M.E., 1991, Phase equilibria constraints on the chemistry of hot spring fluids at mid-ocean ridges. Geochimica et Cosmochimica Acta, 55: 35593580 .

Seyfried, W.E. and Ding, K., 2013, Phase Equilibria in Subseafloor Hydrothermal Systems: a Review of the Role of Redox, Temperature, $\mathrm{Ph}$ and Dissolved $\mathrm{Cl}$ on the Chemistry of Hot Spring Fluids at Mid-Ocean Ridges. Seafloor Hydrothermal Systems: Physical, Chemical, Biological, and Geological Interactions. American Geophysical Union248272.

Seyfried, W.E., Foustoukos, D.I. and Allen, D.E., 2013a, Ultramafic-Hosted Hydrothermal Systems at Mid-Ocean Ridges: Chemical and Physical Controls on pH, Redox and Carbon Reduction Reactions. Mid-Ocean Ridges. American Geophysical Union267-284.

Seyfried, W.E., Pester, N. and Fu, Q., 2013b, Phase Equilibria Controls on the Chemistry of Vent Fluids from Hydrothermal Systems On Slow Spreading Ridges: Reactivity Of Plagioclase and Olivine Solid Solutions And The Ph-Silica Connection. Diversity Of Hydrothermal Systems On Slow Spreading Ocean Ridges. American Geophysical Union297-320.

Shaw, P.R., 1992, Ridge segmentation, faulting and crustal thickness in the Atlantic Ocean. Nature, 358: 490.

Shido, F., Miyashiro, A. and Ewing, M., 1974, Compositional variation in pillow lavas from the Mid-Atlantic Ridge. Marine Geology, 16: 177-190.

Sinha, M.C. and Evans, R.L., 2013, Gephysical Constraints upon the Thermal Regime of the Ocean Crust. Mid-Ocean Ridges. American Geophysical Union19-62.

Sinton, J.M. and Detrick, R.S., 1992, Mid-ocean ridge magma chambers. Journal of Geophysical Research: Solid Earth, 97: 197-216.

Sleep, N.H., 1991, Hydrothermal circulation, anhydrite precipitation, and thermal structure at ridge axes. Journal of Geophysical Research: Solid Earth, 96: 2375-2387.

Stein, C.A. and Stein, S., 1994, Constraints on hydrothermal heat flux through the oceanic lithosphere from global heat flow. Journal of Geophysical Research: Solid Earth, 99: 3081-3095.

Thompson, G., 1983, Basalt - Seawater Interaction. In: Rona, P.A., Boström, K., Laubier, L. and Smith, K.L. (eds.), Hydrothermal Processes at Seafloor Spreading Centers. Springer US, Boston, MA, 225-278.

Thordarson, T. and Larsen, G.J.J.o.G., 2007, Volcanism in Iceland in historical time: Volcano types, eruption styles and eruptive history. 43: 118-152.

Tivey, M.K. and Delaney, J.R., 1986, Growth of large sulfide structures on the endeavour segment of the Juan de Fuca ridge. Earth and Planetary Science Letters, 77: 303-317. 
Vanko, D.A. and Laverne, C., 1998, Hydrothermal anorthitization of plagioclase within the magmatic/hydrothermal transition at mid-ocean ridges: examples from deep sheeted dikes (Hole 504B, Costa Rica Rift) and a sheeted dike root zone (Oman ophiolite). Earth and Planetary Science Letters, 162: 27-43.

Von Damm, K., M. Parker, C., Feeney, R. and P. Loveless, J., 2002, Chemical Evolution of Hydrothermal Fluids From EPR 21 ${ }^{\circ}$ N: 23 Years Later in a Phase Separating World 1365 p.

Von Damm, K.L., 1988, Systematics of and postulated controls on submarine hydrothermal solution chemistry. Journal of Geophysical Research: Solid Earth, 93: 4551-4561.

Von Damm, K.L., Lilley, M.D., Shanks, W.C., Brockington, M., Bray, A.M., O’Grady, K.M., Olson, E., Graham, A. and Proskurowski, G., 2003, Extraordinary phase separation and segregation in vent fluids from the southern East Pacific Rise. Earth and Planetary Science Letters, 206: 365-378.

Watts, A.B., 1978, An analysis of isostasy in the world's oceans 1. Hawaiian-Emperor Seamount Chain. Journal of Geophysical Research: Solid Earth, 83: 5989-6004.

Weir, N.R.W., White, R.S., Brandsdóttir, B., Einarsson, P., Shimamura, H. and Shiobara, H., 2001, Crustal structure of the northern Reykjanes Ridge and Reykjanes Peninsula, southwest Iceland. 106: 6347-6368.

Weissel, J.K. and Karner, G.D., 1989, Flexural uplift of rift flanks due to mechanical unloading of the lithosphere during extension. Journal of Geophysical Research: Solid Earth, 94: $13919-13950$.

Williams, D.L., 1976, Submarine geothermal resources. Journal of Volcanology and Geothermal Research, 1: 85-100.

Wilson, D.S., Teagle, D.A.H., Alt, J.C., Banerjee, N.R., Umino, S., Miyashita, S., Acton, G.D., Anma, R., Barr, S.R., Belghoul, A., Carlut, J., Christie, D.M., Coggon, R.M., Cooper, K.M., Cordier, C., Crispini, L., Durand, S.R., Einaudi, F., Galli, L., Gao, Y., Geldmacher, J., Gilbert, L.A., Hayman, N.W., Herrero-Bervera, E., Hirano, N., Holter, S., Ingle, S., Jiang, S., Kalberkamp, U., Kerneklian, M., Koepke, J., Laverne, C., Vasquez, H.L.L., Maclennan, J., Morgan, S., Neo, N., Nichols, H.J., Park, S.-H., Reichow, M.K., Sakuyama, T., Sano, T., Sandwell, R., Scheibner, B., Smith-Duque, C.E., Swift, S.A., Tartarotti, P., Tikku, A.A., Tominaga, M., Veloso, E.A., Yamasaki, T., Yamazaki, S. and Ziegler, C., 2006, Drilling to Gabbro in Intact Ocean Crust. Science, 312: 1016-1020.

Zhang, R., Zhang, X. and Hu, S., 2015, Basalt-water interactions at high temperatures: 1. Dissolution kinetic experiments of basalt in water and $\mathrm{NaCl}-\mathrm{H} 2 \mathrm{O}$ at temperatures up to $400{ }^{\circ} \mathrm{C}, 23 \mathrm{MPa}$ and implications. Journal of Asian Earth Sciences, 110: 189-200.

Ásmundsson, R., Pezard, P., Sanjuan, B., Henninges, J., Deltombe, J.-L., Halladay, N., Lebert, F., Gadalia, A., Millot, R., Gibert, B., Violay, M., Reinsch, T., Naisse, J.-M., Massiot, C., Azaïs, P., Mainprice, D., Karytsas, C. and Johnston, C., 2014, High temperature instruments and methods developed for supercritical geothermal reservoir characterisation and exploitation-The HiTI project. Geothermics, 49: 90-98. 


\section{Chapter 2: Experimental Method}

\subsection{Experimental Apparatus}

A high pressure and temperature (P-T) titanium alloy autoclave system (Coretest Systems Ltd.) was used in this study (Fig. 2.1 - 2.2). The experimental set-up allows single-pass continuous flow of aqueous fluid through rock or mineral materials at a maximum temperature ( $\left.\mathrm{T}_{\max }\right)$ and pressure $\left(\mathrm{P}_{\max }\right)$ of $400^{\circ} \mathrm{C}$ and 500 bar, respectively. Continuous flow is achieved by a computer-controlled double-piston metering pump with a flow rate range from 0.001 to $15 \mathrm{ml}$ $\min ^{-1}$ (Fig. 2.2). The pump (a, Fig. 2.1c) injects distilled water from the plastic reservoir ( $h$, Fig. 2.1d) into the bottom of the 1 litre titanium accumulator vessel (b, Fig. 2.1c) containing a movable metal piston. The experimental fluid is located above the piston which separates the fluid from the distilled water. As distilled water is pumped into the bottom of the accumulator vessel, this forces the piston upwards pushing the experimental fluid out of the accumulator vessel and through the experimental apparatus (Fig. 2.1c). In this way, the stainless-steel metering pump does not come in contact with the potentially corrosive experimental solution.

The rock or mineral material is enclosed in a titanium pressure vessel (Reactor) (19.2 $\left.\mathrm{cm}^{3}\right)\left(c\right.$, Fig. 2.1c,d) which is externally-heated in one of the two high temperature furnace $\left(\mathrm{T}_{\max }\right.$ $\left.=400^{\circ} \mathrm{C}\right)(g$, Fig. 2.1c,d). After passing through the pressure vessel, the fluid exits via the digital back pressure regulator ( $d$ - e, Fig. $2.1 \mathrm{c}, \mathrm{d})$ and collects in a standard disposable plastic syringe $(f$, Fig. 2.1d). All the components of the autoclave are connected using 1/8" titanium tubing (Fig. 2.1c,d).

The flow through autoclave is connected to a dedicated computer that records the experimental conditions using Quizix PumpWorks v. 7.03 for pressure logging and Coretest HFS-340 v. 1.20.2082 for temperature logging. The experimental temperature and pressure are recorded every 300 seconds. 
Figure 2.1. (a,b) front and back view of the high temperature and pressure hydrothermal flow autoclave at the Experimental Geochemistry Laboratory of GNS Science, Wairakei Research Centre, Taupo, New Zealand; (c,d) individual components of the flow autoclave: $a$, double piston metering pump; $b$, accumulator vessel containing the piston which separates distilled water coming from the pump from the experimental fluid above the piston; $c$, pressure vessel (Reactor) containing the rock material enclosed by the furnace; $d$, back pressure regulator controller; $e$, back pressure regulator; $f$, collection syringe; $g$, partial cross section of the furnace assembly showing position of pressure vessel (Reactor).; $h$, plastic reservoir containing distilled water used by the metering pump. Yellow lines represent $1 / 8$ " titanium tube connections between components. Blue arrows show the flow path.

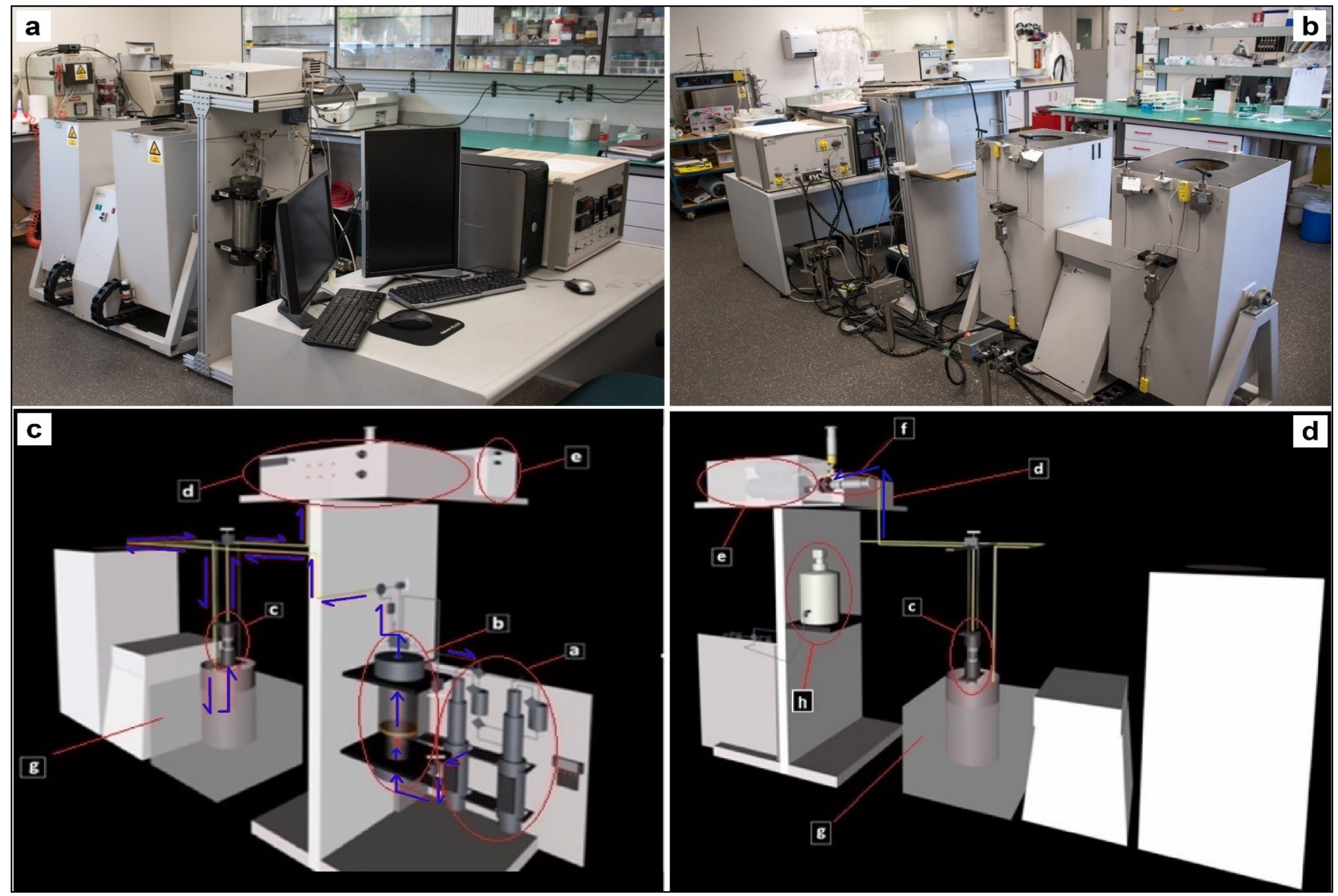


Figure 2.2. Schematic diagram of the hydrothermal flow autoclave. Blue arrows show the path of distilled water coming from the metering pump. Red arrows show the path of the experimental fluid exiting the accumulator vessel, passing down the side of the furnace and into the bottom of the pressure vessel (Reactor). The fluid then passes through the Reactor vessel containing the rock material and exits out the top, after which it moves to the back pressure regulator and into the collection syringe.

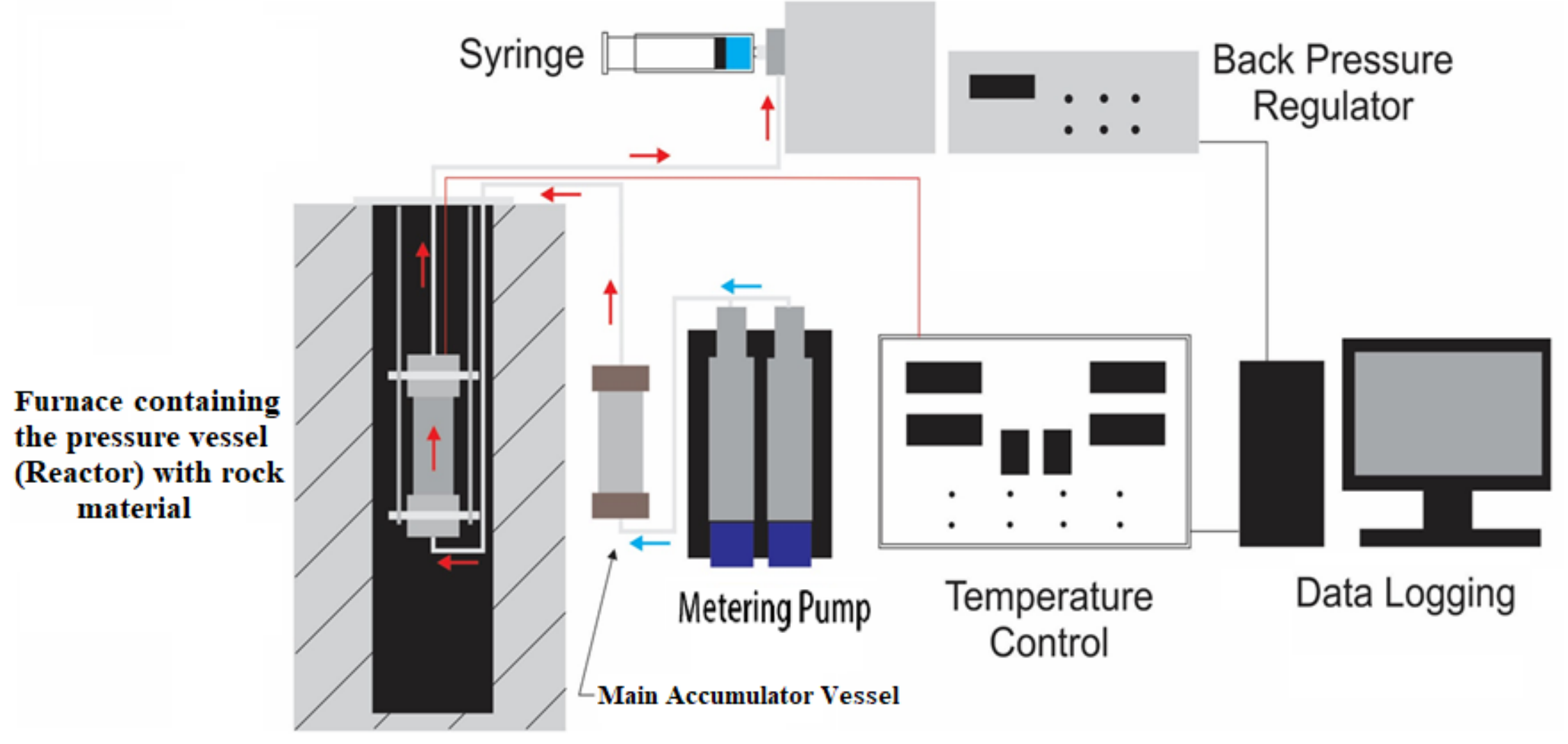




\subsection{Experimental Protocols}

In this thesis, the results of eight experimental studies are presented (Table 2.1). Basalt of typical mid-ocean ridge lithology was the sole rock substrate. Three different aqueous fluids were utilised including: distilled water, geothermal brine and natural seawater. Each basalt fluid reaction set was conducted at two temperatures: $350^{\circ} \mathrm{C}$ (sub-critical) and $400^{\circ} \mathrm{C}$ (supercritical/near-supercritical depending on the fluid) totalling six "rock" experiments. The pressure range during these experiments was 488-502 bar. Two further experiments were also undertaken to study possible heterogeneous equilibria which may occur when seawater (with no basalt) is heated to $342^{\circ} \mathrm{C}$ and $377^{\circ} \mathrm{C} / 488$ bar.

\subsection{Experimental Substrate and Fluids}

\subsubsection{Unreacted basalt: mineralogy, texture and mineral chemistry}

The lithology used in all rock-present experiments is a tholeiitic basalt sourced from the Eldvraphraun flow, Reykjanes, Iceland (Fig. 2.3). The unreacted basalt was studied in detail using: 1) electron microprobe analysis (EMPA) on a petrographic thin section for unreacted mineral and glass compositions; 2) scanning electron microscopy with electron dispersive spectroscopic analysis (SEM-EDS) for elemental mapping of unreacted rock textural information; and 3) quantitative X-ray diffraction analysis (XRD) to determine rock mineralogical composition.

Major and trace element data are reported in Table 2.2, in $\mathrm{wt} \%$ and $\mathrm{ppm}$, respectively (Peate et al., 2008). The basalt is completely devoid of secondary mineralisation or alteration.

Figure 2.3. Fragments of basalt from the Eldvarpahraun lava flow, Reykjanes Peninsula, Iceland.

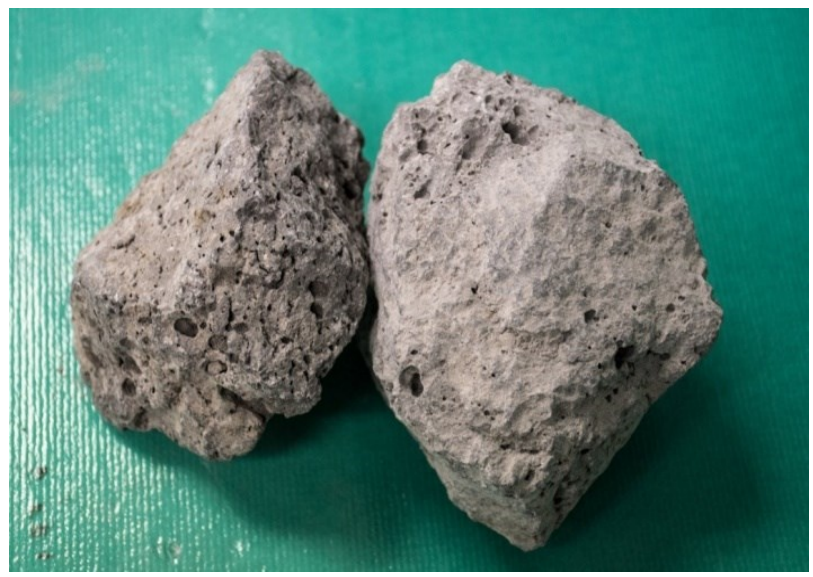


Table 2.1. Experimental protocols for the eight experiments conducted in this study.

\begin{tabular}{|c|c|c|c|c|c|c|c|c|}
\hline Experiment Designation & BW1 & BW2 & BGB1 & BGB2 & SW1 & BSW1 & SW2 & BSW2 \\
\hline Rock Substrate & Basalt & Basalt & Basalt & Basalt & & Basalt & & Basalt \\
\hline Type of fluid & Water (distilled) & Water (distilled) & Geothermal Brine & Geothermal Brine & Seawater (natural) & Seawater (natural) & Seawater (natural) & Seawater (natural) \\
\hline Room T Period $/{ }^{\circ} \mathrm{C}$ & 20 & 20 & 20 & 20 & no Room T period & no Room $\mathrm{T}$ period & no Room T period & no Room $\mathrm{T}$ period \\
\hline Time at Room T/hr & 167.3 & 160.5 & 190.9 & 187.8 & & & & \\
\hline $\mathbf{T}_{\max } /{ }^{\circ} \mathrm{C}$ & 400 & 350 & 400 & 350 & 377 (Preheater) & $\begin{array}{c}377 \text { (Preheater) } \\
400 \text { (Reactor) }\end{array}$ & 342 (Preheater) & $\begin{array}{c}342 \text { (Preheater) } \\
350 \text { (Reactor) }\end{array}$ \\
\hline Time at $T_{\max } / \mathrm{hr}$ & 746.2 & 984.2 & 662.3 & 720 & 546.7 & 659 & 381.2 & 311 \\
\hline $\mathbf{P}_{\max } / \mathrm{bar}$ & 502 & 490 & 483 & 486 & 488 & 488 & 488 & 488 \\
\hline Time at $P_{\max } / \mathbf{h r}$ & 913.5 & 1144.7 & 853.2 & 907.8 & 546.7 & 659 & 381.2 & 311 \\
\hline De-oxygenation & $\begin{array}{l}\text { Deoxygenated } \\
\text { solution }\end{array}$ & Deoxygenated solution & Deoxygenated solution & $\begin{array}{l}\text { Deoxygenated } \\
\text { solution }\end{array}$ & $\begin{array}{c}\text { Solution not } \\
\text { deoxygenated }\end{array}$ & $\begin{array}{l}\text { Deoxygenated } \\
\text { solution for } 626.8 \mathrm{hr} \text {, } \\
\text { Last } 32.2 \mathrm{hr} \text { solution } \\
\text { not deoxygenated }\end{array}$ & $\begin{array}{c}\text { Solution not } \\
\text { deoxygenated }\end{array}$ & Deoxygenated solution \\
\hline $\begin{array}{c}\text { Preheater vessel } \\
\text { and/or } \\
\text { Reactor vessel }\end{array}$ & Reactor Only & Reactor Only & Reactor Only & Reactor Only & Preheater Only & $\begin{array}{l}\text { Preheater and } \\
\text { Reactor }\end{array}$ & Preheater Only & Preheater and Reactor \\
\hline $\mathrm{ZrO}_{2}$ Beads Used/g & - & - & - & - & 157.0 & 160.5 & 166.3 & 168.7 \\
\hline Basalt grains size/ $\mu \mathrm{m}$ & $355-500$ & $355-500$ & $355-500$ & $355-500$ & - & $355-500$ & - & $355-500$ \\
\hline Weight of basalt/g & 26.2 & 26.6 & 27.0 & 26.4 & - & 22.5 & - & 23.3 \\
\hline Basalt Block Added & Yes & Yes & No & Yes & No & Yes & No & Yes \\
\hline Total Fluid Flux/L & 0.77 & 1.02 & 0.69 & 0.75 & 0.40 & 1.48 & 0.33 & 1.15 \\
\hline $\begin{array}{c}\text { Time } / \mathbf{h r}: \\
\text { Flow-rate/ml hr-1 }\end{array}$ & $\begin{array}{l}\text { 819.1: } 1 \\
\text { 94.4: } 0.5\end{array}$ & $\begin{array}{l}\text { 1002.1: } 1 \\
\text { 142.6: } 0.5\end{array}$ & $\begin{array}{l}\text { 767.5: } 1 \\
85.7: 0.5\end{array}$ & 907.8: 1 & 546.7: 1 & $\begin{array}{c}532.6: 1 \\
50.2: 1.5 \\
44: 10 \\
24.5: 7.5 \\
7.7: 5\end{array}$ & 381.2: 1 & $\begin{array}{c}\text { 119.8: } 1 \\
\text { 47.5: } 10 \\
23.5: 5 \\
73.5: 2.5 \\
46.6: 1\end{array}$ \\
\hline Number of Samples & 35 & 46 & 34 & 38 & 23 & 43 & 16 & 27 \\
\hline Total time $/ \mathrm{hr}$ & 913.5 & 1144.7 & 853.2 & 907.8 & 546.7 & 659 & 381.2 & 311 \\
\hline
\end{tabular}


Table 2.2. Major and trace element composition of the basalt (Peate et al., 2008).

\begin{tabular}{|c|c|c|c|}
\hline Major Elements & wt\% & Trace Elements & ppm \\
\hline $\mathrm{SiO}_{2}$ & 48.85 & $\mathrm{Sc}$ & 51 \\
\hline $\mathrm{TiO}_{2}$ & 2.13 & V & 467 \\
\hline $\mathrm{Al}_{2} \mathrm{O}_{3}$ & 13.41 & $\mathrm{Cr}$ & 124 \\
\hline $\mathrm{Fe}_{2} \mathrm{O}_{3}(\mathrm{~T})$ & 15.11 & Co & 56 \\
\hline $\mathrm{MnO}$ & 0.24 & $\mathrm{Ni}$ & 65 \\
\hline $\mathrm{MgO}$ & 6.5 & $\mathrm{Cu}$ & 167 \\
\hline $\mathrm{CaO}$ & 10.94 & $\mathrm{Zn}$ & 124 \\
\hline $\mathrm{Na}_{2} \mathrm{O}$ & 2.35 & $\mathrm{Ga}$ & 20 \\
\hline $\mathrm{K}_{2} \mathrm{O}$ & 0.25 & $\mathrm{Rb}$ & 4.3 \\
\hline $\mathrm{P}_{2} \mathrm{O}_{5}$ & 0.22 & $\mathrm{Sr}$ & 156 \\
\hline Volatiles & 0.66 & $\mathrm{Y}$ & 35.3 \\
\hline \multirow[t]{14}{*}{ Total } & 99.84 & $\mathrm{Zr}$ & 108 \\
\hline & & $\mathrm{Nb}$ & 13.5 \\
\hline & & $\mathrm{Ba}$ & 66.8 \\
\hline & & la & 9.19 \\
\hline & & $\mathrm{Ce}$ & 22.66 \\
\hline & & $\operatorname{Pr}$ & 3.25 \\
\hline & & $\mathrm{Nd}$ & 15.46 \\
\hline & & $\mathrm{Sm}$ & 4.36 \\
\hline & & $\mathrm{Eu}$ & 1.53 \\
\hline & & $\mathrm{Gd}$ & 5.38 \\
\hline & & Dy & 5.88 \\
\hline & & $\mathrm{Er}$ & 3.61 \\
\hline & & $\mathrm{Yb}$ & 3.33 \\
\hline & & $\mathrm{Lu}$ & 0.49 \\
\hline
\end{tabular}


Electron Microprobe Analysis (EMPA)

EMPA analysis was undertaken on five areas of the petrographic thin section (Area A E, Fig. 2.4). Areas A and B focused on mineral compositions while Areas $C-E$ focused on the composition of the glass. Table 2.3 summarises the mineral compositions. Complete EMPA analyses and detailed SEM photographs of Area A - E are shown in Appendix A.

Table 2.3. Mineral phase, ID and average mineral compositions determined by EMPA.

\begin{tabular}{|c|c|c|}
\hline Phase & $\begin{array}{l}\text { Mineral } \\
\text { Identified }\end{array}$ & $\begin{array}{l}\text { Average Mineral } \\
\text { Composition }\end{array}$ \\
\hline Plagioclase & Bytownite & $\mathrm{Ca}_{0.7} \mathrm{Na}_{0.3} \mathrm{Si}_{2.3} \mathrm{Al}_{1.7} \mathrm{O}_{8}\left(\mathrm{An}_{76}-\mathrm{Ab}_{24}\right)$ \\
\hline Pyroxene & Augite & $\mathrm{Ca}_{0.7} \mathrm{Mg}_{0.9} \mathrm{Fe}_{0.3} \mathrm{Al}_{0.1} \mathrm{Si}_{1.9} \mathrm{Al}_{0.1} \mathrm{O}_{6}$ \\
\hline Olivine & Forsterite & $\mathrm{Mg}_{1.4} \mathrm{Fe}_{0.6} \mathrm{SiO}_{4}\left(\mathrm{Fo}_{70}-\mathrm{Fa}_{30}\right)$ \\
\hline Oxide & Titanomagnetite & $\mathrm{Fe}^{2+}\left(\mathrm{Fe}^{3+}, \mathrm{Ti}\right)_{2} \mathrm{O}_{4}$ \\
\hline Glass & - & $\begin{array}{c}\text { wt\%: } \mathrm{SiO}_{2} 67.88, \mathrm{Al}_{2} \mathrm{O}_{3} 16.22, \mathrm{FeO}_{(\mathrm{T})} 4.08, \mathrm{TiO}_{2} 0.65 \\
\mathrm{Na}_{2} \mathrm{O} \text { 6.13, } \mathrm{K}_{2} \mathrm{O} 1.37, \mathrm{CaO} 5.29, \mathrm{MgO} 0.79 \\
\mathrm{SO}_{2} 0.04, \mathrm{Cl} 0.09, \mathrm{P}_{2} \mathrm{O}_{5} 0.32, \mathrm{MnO} 0.07\end{array}$ \\
\hline
\end{tabular}

Figure 2.4. Thin section of the basalt showing the different areas analysed by EMPA (points A-B-C-D-E, in red rectangles). Yellow circles indicate the points where glass was analysed.

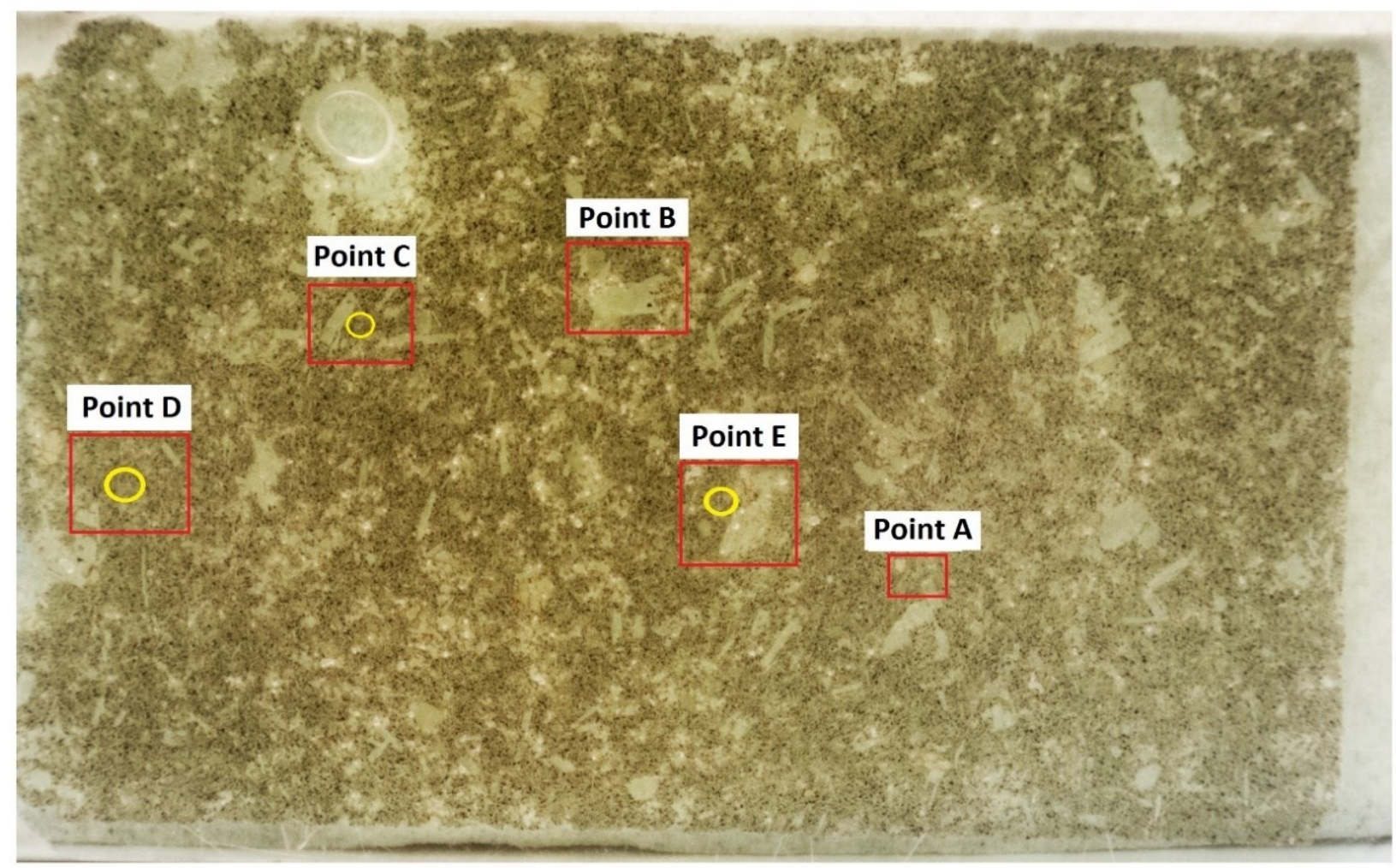




\section{SEM-EDS analysis of unreacted basalt}

SEM-EDS mapping was made on epoxy-mounted, polished basalt grains to examine their textural details and on different thin section areas to identify the volcanic glass. EDS measurements of selected mineral compositions were also undertaken to compare with the EMPA analyses and are listed in Appendix A. Figure 2.5 and Figure 2.6 show examples of one of these elemental maps for unreacted basalt grains texture and volcanic glass identification, respectively.

The basalt has an ophitic texture composed of interlocking plagioclase (bytownite) laths with interstitial pyroxene (augite). Olivine (forsterite) occurs as isolated anhedral crystals. These three minerals comprise $>95 \%$ of the basalt. Titanomagnetite is the next most abundant phase followed by minor amounts of volcanic glass that contain inclusions of Fe-sulfide and apatite. The basalt is vesicular with plagioclase lathes projecting into the void spaces. SEM examination shows that the basalt has no hydrous phases and is completely unaltered.

\section{Quantitative XRD analysis}

The quantitative XRD analysis of the unaltered basalt is shown in Table 2.4 Results show the predominance of plagioclase and clinopyroxene (99\%). According to the SEM analyses olivine and titanomagnetite are clearly present, however, they were not detected by the quantitative XRD analysis. This emphasises the poor sensitivity of this type of analysis. Nevertheless, these results are provided in order that the quantitative XRD analyses of the reacted basalt samples can be compared.

Table 2.4. Quantitative XRD analysis of unreacted basalt. Margin of error: Abundance estimate are determined through successive refinement of cell parameters; the position, width and orientation of each mineral. Values are given to the nearest whole number. The margin of error for phase concentration is as follow: $0-10 \% \pm 10 \% ; 10-50 \% \pm 5 \% ; 50-100 \% \pm 2 \%$.

\begin{tabular}{|rc|}
\hline & Abundance \% \\
Plagioclase & 60 \\
Clinopyroxene & 39 \\
Other & 1 \\
\hline
\end{tabular}


Figure 2.5. SEM-EDS elemental map of an unreacted basalt grain: (a) grey scale image; (b) composite colour image combining maps for c) Mg, d) $\mathrm{Ca}$ and e) $\mathrm{Na}$. In (b) the composite colour image shows plagioclase (violet), pyroxene (turquoise), olivine (light green) and titanomagnetite (white).
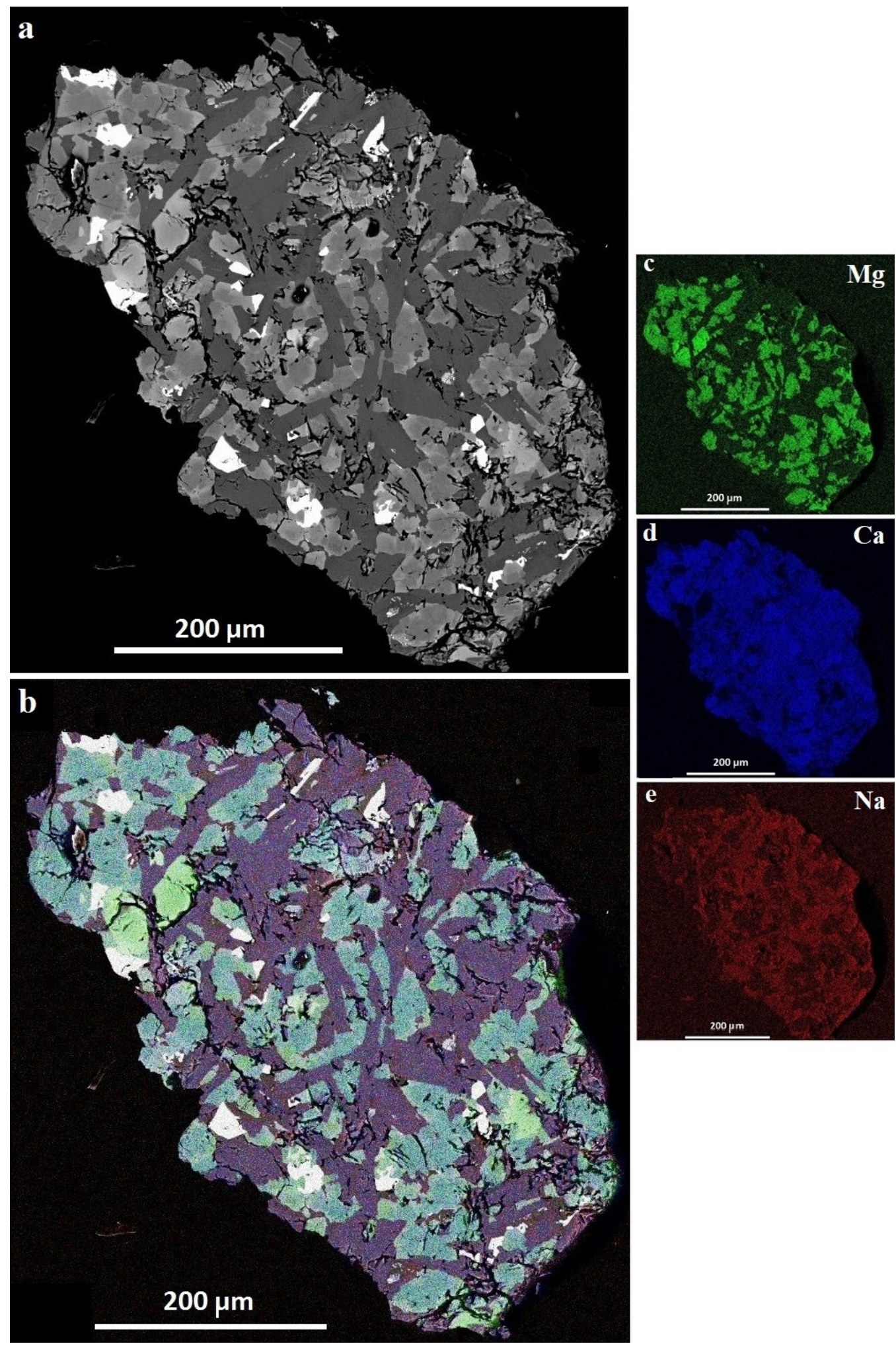
Figure 2.6. SEM-EDS images of the unaltered basalt: (a) Point $\mathrm{C}$ (Figure 2.4); (b) secondary electron image of the red rectangular area in (a); (c) composite colour image (b) combining maps for f) $\mathrm{Al}, \mathrm{g}$ ) Si, and h) $\mathrm{P}$ showing plagioclase (green), clinopyroxene (light red), volcanic glass (dark red), oxides (white) and apatite (blue-violet); (d) enlargement of yellow rectangle ( ${ }^{\circ} 1$ ) in (c) showing volcanic glass (outlined in yellow) including apatite and sulfides; (e) enlargement of yellow rectangular area ( $\left.n^{\circ} 2\right)$ in (c) showing other two areas of the volcanic glass (outlined in yellow).
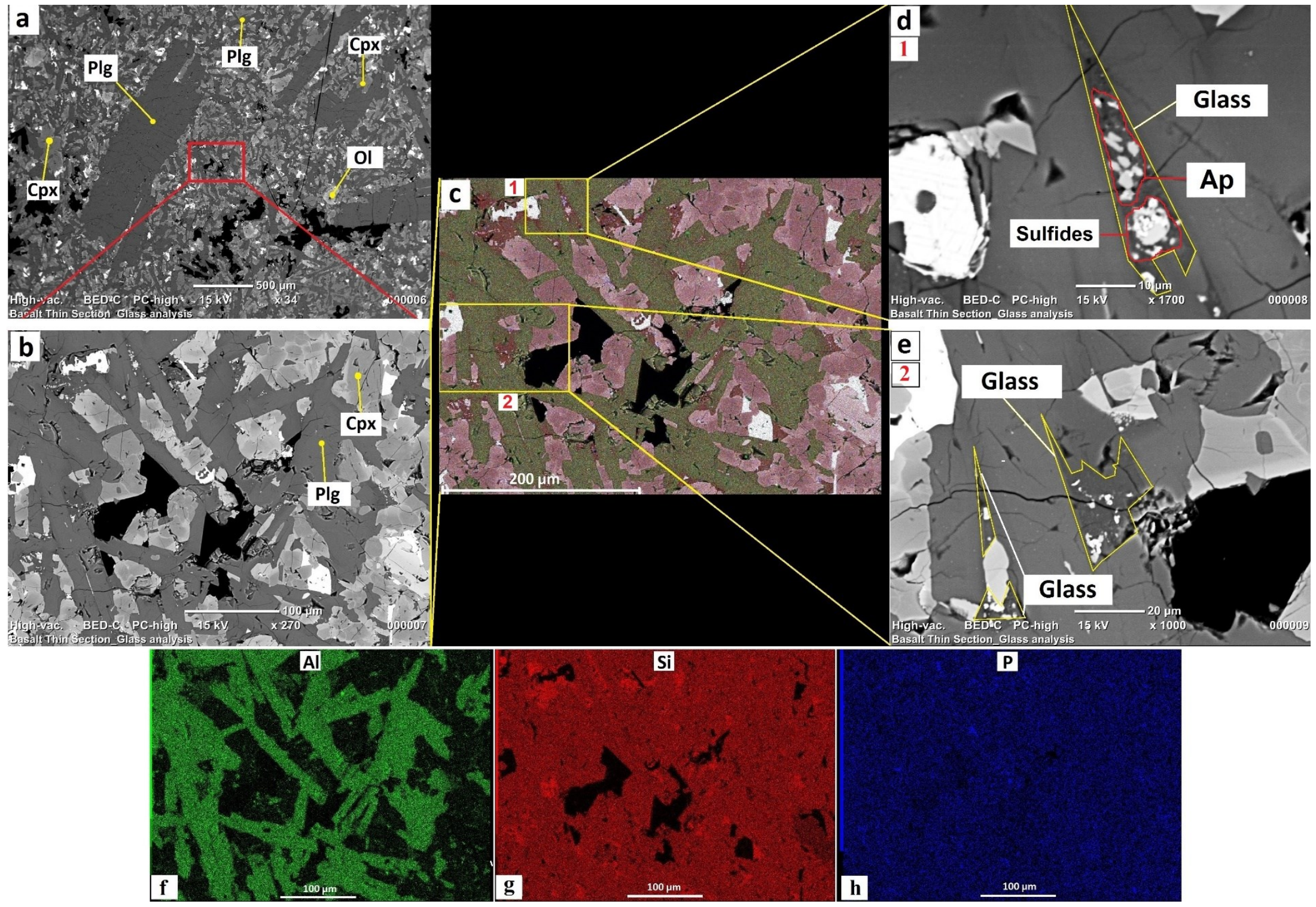

$\mathbf{P}$ 


\section{SEM examination of unreacted basalt grains}

Figure 2.6 shows SEM photographs of four unreacted basalt grains. Two distinctive fabric types are present: idiomorphic granular, composed of well-formed crystal faces of interlocking euhedral plagioclase lathes of tabular, prismatic shape; and allotriomorphic granular, composed of unbounded crystal faces of anhedral and interstitial clinopyroxene. Olivine and oxides are also interstitial to the plagioclase lathes. Appendix A provides the complete set of SEM photographs of unreacted grains.

Figure 2.7. SEM photographs of four different unreacted basalt grains: a) typical rough surface texture; b) - d) show euhedral lathes of plagioclase (plg) and anhedral interstitial clinopyroxene (cpx). The euhedral lathes are found as linings of the vesicles.

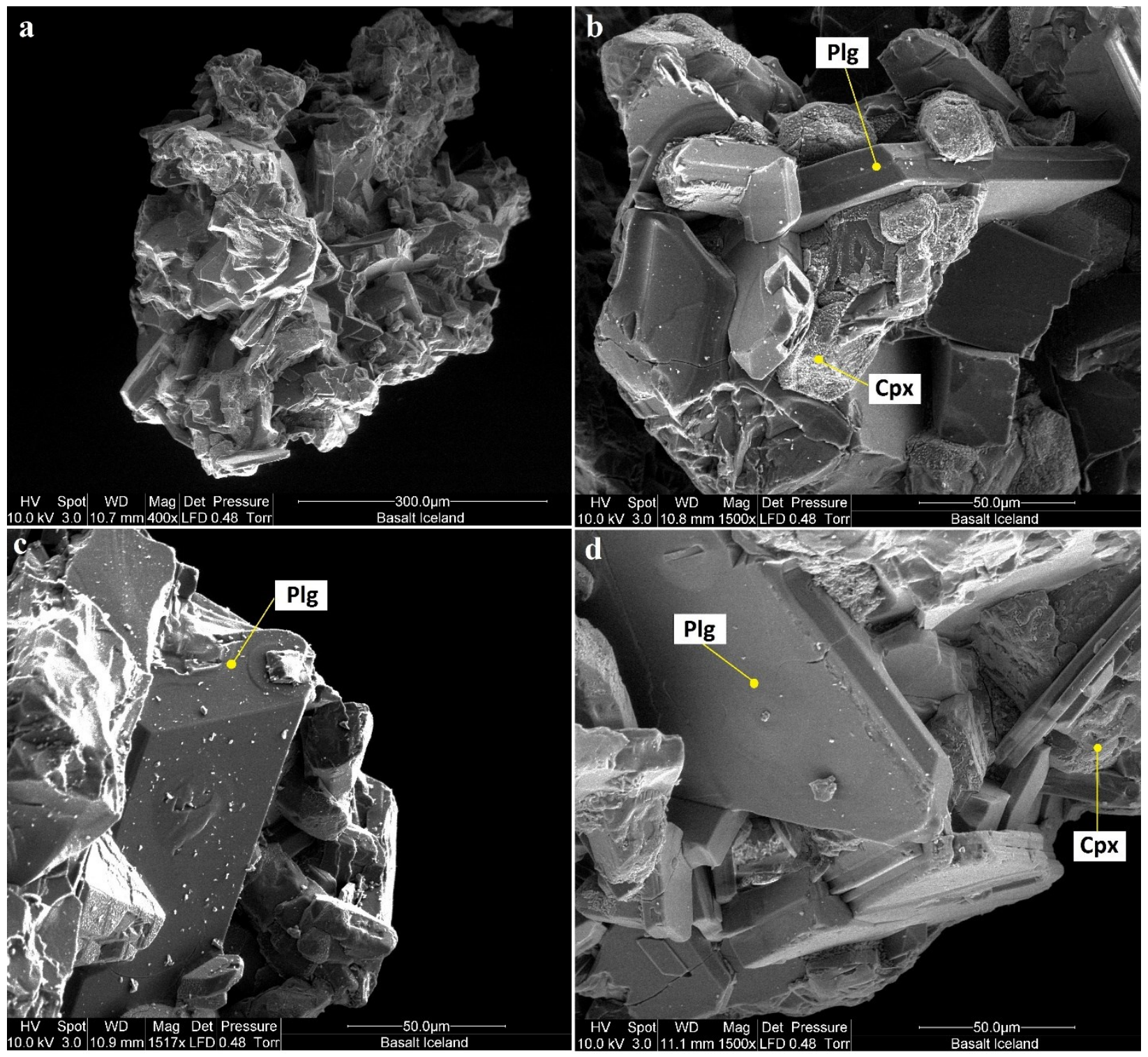




\subsubsection{Experimental Fluids}

Three experimental fluids were utilised in the experiments:

1. Doubly distilled water from an Arium ${ }^{\circledR}$ pro-Ultrapure water system;

2. Low-pressure flash geothermal brine, collected from the Nga Awa Purua geothermal power station, Rotokawa, New Zealand;

3. Natural seawater collected at the New Zealand National Aquarium, Napier, New Zealand.

Fluid compositions are reported in Table 2.5. 
Table 2.5. Starting experimental fluid compositions including major cations, anions, $\mathrm{H}_{2} \mathrm{~S}$ and $\mathrm{SO}_{4}{ }^{2-}\left(\mathrm{mmol} \mathrm{kg}^{-1}\right)$, trace elements $\left(\mu \mathrm{mol} \mathrm{kg}^{-1}\right)$ and $\mathrm{pH}$ values at room temperature. Cells colours and number of the experiments refer to Table 2.1. n.a.: not analyzed.

\begin{tabular}{|c|c|c|c|c|c|c|c|c|}
\hline Experiment & BW1 & BW2 & BGB1 & BGB2 & SW1 & $\begin{array}{c}\text { BSW1 } \\
\text { (output SW1) }\end{array}$ & SW2 & $\begin{array}{c}\text { BSW2 } \\
\text { (output SW2) }\end{array}$ \\
\hline Fluid & Water (distilled) & Water (distilled) & Geothermal Brine & Geothermal Brine & Seawater (natural) & Seawater (natural) & Seawater (natural) & Seawater (natural) \\
\hline $\mathrm{pH}\left(\sim 21^{\circ} \mathrm{C}\right)$ & 7.83 & 6.80 & 3.91 & 4.28 & 7.75 & 7.75 & 7.65 & 8.20 \\
\hline \multicolumn{9}{|l|}{$\mathrm{mmol} \mathrm{kg}^{-1}$} \\
\hline As & $<0.0002$ & 0.001 & 0.02 & 0.002 & $<0.0002$ & $<0.0002$ & $<0.0002$ & 0.02 \\
\hline B & $<0.03$ & 0.2 & 4.5 & 5.1 & 0.2 & 0.6 & 0.5 & 0.5 \\
\hline $\mathbf{C a}$ & 0.01 & 0.02 & 0.08 & 0.2 & 9.4 & 2.1 & 8 & 1.4 \\
\hline $\mathbf{F e}$ & $<0.001$ & $<0.001$ & 0.001 & $<0.001$ & 0.002 & 1.3 & 0.002 & 1.7 \\
\hline $\mathbf{K}$ & $<0.02$ & 0.08 & 3 & 3 & 9.4 & 8.4 & 8.6 & 8.4 \\
\hline Mg & 0.001 & 0.004 & 0.01 & 0.04 & 45.8 & 24.4 & 36.7 & 22.8 \\
\hline $\mathbf{N a}$ & $<0.03$ & 0.3 & 31.6 & 31.6 & 420 & 360 & 361 & 360 \\
\hline $\mathrm{SiO}_{2}$ & $<0.01$ & 0.04 & 12.6 & 14.7 & 0.1 & 0.9 & 0.1 & 0.25 \\
\hline Al & $<0.006$ & $<0.006$ & 0.06 & 0.4 & 0.01 & 0.01 & 0.007 & $<0.006$ \\
\hline $\mathbf{L i}$ & $<0.001$ & $<0.001$ & 0.8 & 1 & 0.02 & 0.02 & 0.02 & 0.02 \\
\hline $\mathbf{H}_{2} \mathrm{~S}$ & $<0.0003$ & $<0.0003$ & 0.004 & $<0.0003$ & $<0.0003$ & $<0.0003$ & $<0.0003$ & $<0.0003$ \\
\hline $\mathrm{Cl}^{-}$ & 0.004 & $<0.003$ & 26.5 & 27.1 & 432 & 447 & 439 & 450 \\
\hline $\mathrm{SO}_{4}{ }^{2-}$ & 0.001 & $<0.001$ & 4.2 & 4.2 & 22 & 1.2 & 23 & 2.7 \\
\hline$\mu \mathrm{mol} \mathrm{kg}{ }^{-1}$ & & & & & \multicolumn{3}{|c|}{ Starting seawater SW1 } & Starting seawater SW2 \\
\hline $\mathbf{V}$ & $<0.002$ & $<0.001$ & 0.04 & n.a. & 0.04 & 0.04 & 0.04 & 0.04 \\
\hline $\mathrm{Cr}$ & $<0.004$ & $<0.004$ & 0.06 & n.a. & $<0.004$ & $<0.004$ & $<0.004$ & $<0.004$ \\
\hline Co & $<0.002$ & $<0.002$ & $<0.002$ & 0.001 & $<0.002$ & $<0.002$ & $<0.002$ & $<0.002$ \\
\hline $\mathbf{N i}$ & $<0.003$ & $<0.003$ & 0.1 & 0.2 & $<0.003$ & $<0.003$ & $<0.003$ & $<0.003$ \\
\hline $\mathbf{C u}$ & $<0.0009$ & $<0.0009$ & 0.3 & 0.8 & $<0.0009$ & $<0.0009$ & $<0.0009$ & $<0.0009$ \\
\hline Zn & $<0.008$ & $<0.008$ & 1.9 & 2.9 & $<0.008$ & $<0.008$ & $<0.008$ & $<0.008$ \\
\hline $\mathbf{R b}$ & $<0.001$ & $<0.001$ & 8.5 & n.a. & 0.1 & 0.1 & 0.1 & 0.1 \\
\hline Mo & $<0.002$ & $<0.002$ & 0.1 & 0.03 & n.a. & n.a. & n.a. & n.a. \\
\hline Ag & $<0.0005$ & $<0.0005$ & 0.006 & 0.003 & $<0.0005$ & $<0.0005$ & $<0.0005$ & $<0.0005$ \\
\hline Cd & $<0.0009$ & $<0.0009$ & 0.6 & 0.002 & $<0.0009$ & $<0.0009$ & $<0.0009$ & $<0.0009$ \\
\hline $\mathbf{B a}$ & $<0.001$ & $<0.001$ & $<0.001$ & 0.05 & $<0.001$ & $<0.001$ & $<0.001$ & $<0.001$ \\
\hline Au & $<0.001$ & $<0.001$ & 1 & 0.04 & 0.01 & 0.01 & 0.01 & 0.01 \\
\hline $\mathbf{P b}$ & $<0.001$ & $<0.001$ & 0.01 & 0.02 & $<0.001$ & $<0.001$ & $<0.001$ & $<0.001$ \\
\hline Mn & $<0.13$ & $<0.13$ & $<0.13$ & 2.5 & $<0.13$ & $<0.13$ & $<0.13$ & $<0.13$ \\
\hline
\end{tabular}




\subsection{Experimental Procedure}

\subsubsection{Preparation of the Reactor}

The coarse basalt pieces were crushed and sieved to obtain different size fractions in the range of $155 \mu \mathrm{m}$ to $2 \mathrm{~mm}$ (Fig. 2.8a-b). The different size fractions were ultrasonically cleaned using distilled water in order to remove powdered fines. This is necessary as fines are highly reactive and not representative of the true basalt surface. Basalt grains of the size fraction 355 $500 \mu \mathrm{m}$ were utilised in all the "rock present" experiments (Table 2.1, Fig. 2.7c).

The pressure vessel (15 cm length, $1.27 \mathrm{~cm} \mathrm{ID,} 19.3 \mathrm{~cm}^{3}$ internal volume), here after referred to as the Reactor, is composed of titanium alloy cylinder and two titanium alloy end caps (Fig. 2.9a). The top cap of the reactor has a hole into which a K-type thermocouple can be inserted to measure temperature during experiment. At each end of the column, $1.2 \mathrm{~cm}$ diameter titanium frits $(0.45 \mu \mathrm{m}$ pore size $)$ are placed which acted as filters to prevent the passage of particles or reaction products from exiting the Reactor either from the bottom or top (Fig. 2.9b). The reactor vessel is sealed using two collars and thrust rings that compress the column into cone-typed seals in the caps (Fig. 2.9a).

After sealing one end of the Reactor, it is weighed, after which the basalt grains are added. It is re-weighed to determine the weight of rock present. The Reactor can contain a maximum of $19.2 \mathrm{~cm}^{3}$ of fluid (without rock material). The weight of rock present in the Reactor (at maximum capacity and without fluid) is $\sim 26-27 \mathrm{~g}$, for all experiments. This is equal to a solid volume (Vs) of $\sim 9 \mathrm{~cm}^{3}$ considering a density of the basalt of $2.9 \mathrm{~g} \mathrm{~cm}^{-3}$ and it gives a pore volume (Vp) of $\sim 10 \mathrm{~cm}^{3}$. At a flow rate of $1 \mathrm{ml} \mathrm{hr}^{-1}$ and assuming plug flow, the average residence time of fluid is about 10 hours, based on a porosity of $\sim 53 \%$, in the Reactor. Calculation of the porosity in the Reactor was made using the following equation:

$$
\text { porosity }(P t)(\%)=\frac{\text { pore volume }(V p)}{\text { total volume }(V t)} \cdot 100
$$

Where $\mathrm{Vt}$ is the sum of the pore volume $(\mathrm{Vp})$ and the solid volume (Vs).

In all "rock present" experiments (excluding basalt - geothermal brine experiment, BGB1) a small block of basalt ( $8 \times 8 \times 2 \mathrm{~mm}$ with one polished surface) (Fig. 2.8d) was positioned at the bottom of the Reactor. After sealing the top cap, the Reactor is ready for the experiment (Fig. 2.9c). 
Figure 2.8. (a) sequential sieving equipment, Volcanic Petrology Laboratory, GNS Science, Taupo, (b) collected size fractions, (c) the typical appearance of the $355-500 \mu \mathrm{m}$ basalt grains size fraction, (d) example of the basalt block, which was positioned at the bottom of the reactor in all "rock present" experiments (excluding the basalt geothermal brine experiment, BGB1). The front surface of the block has been highly polished.
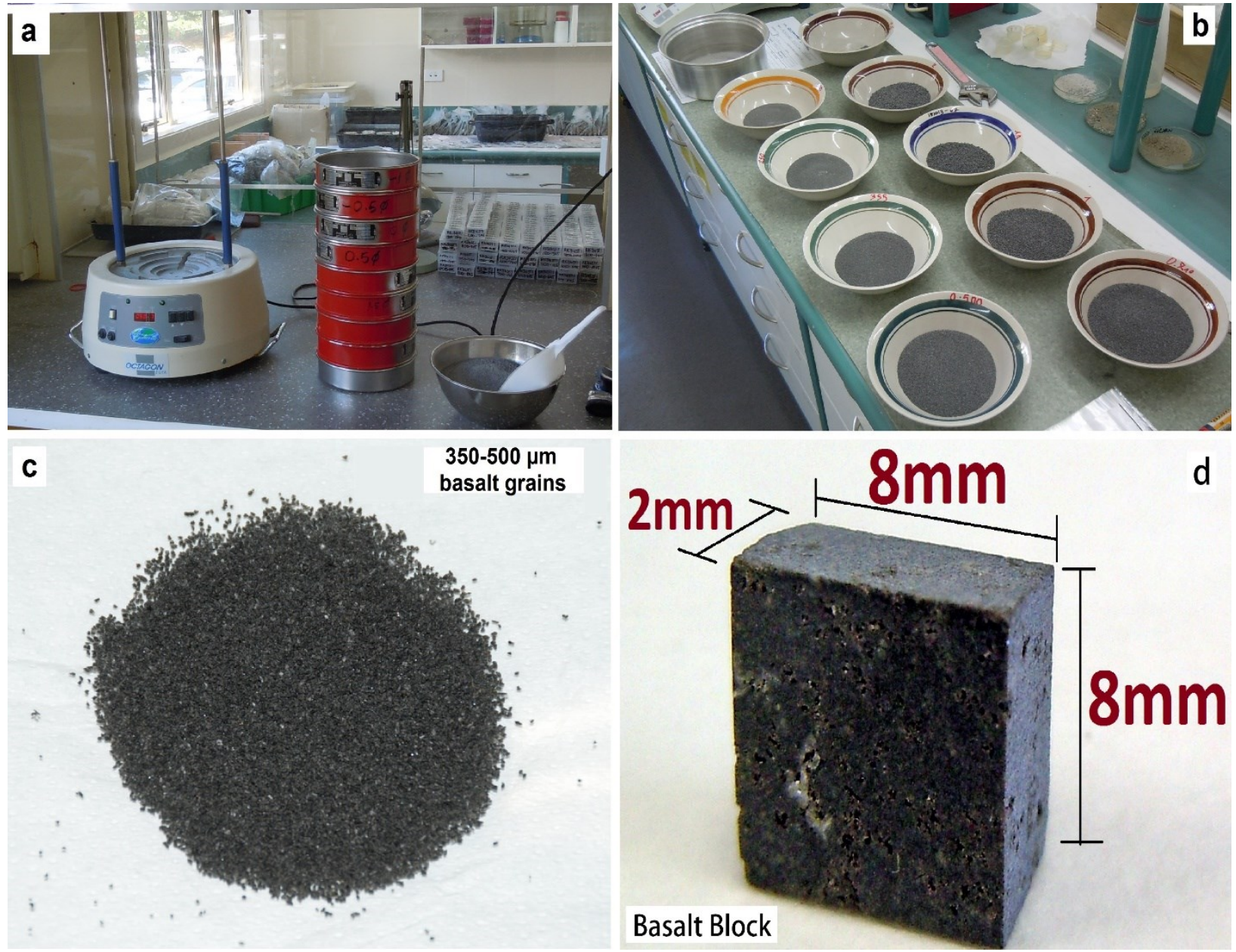
Figure 2.9. (a) Titanium pressure vessel referred to as the Reactor in this study with end caps, collars and thrust rings. The thrust rings push against the collars to make a cone-type seal against the caps. (b) Reactor filled with basalt grains. Titanium filters are placed at each end of the reactor to prevent passage of rock materials or reaction products. (c) the Reactor assembled.
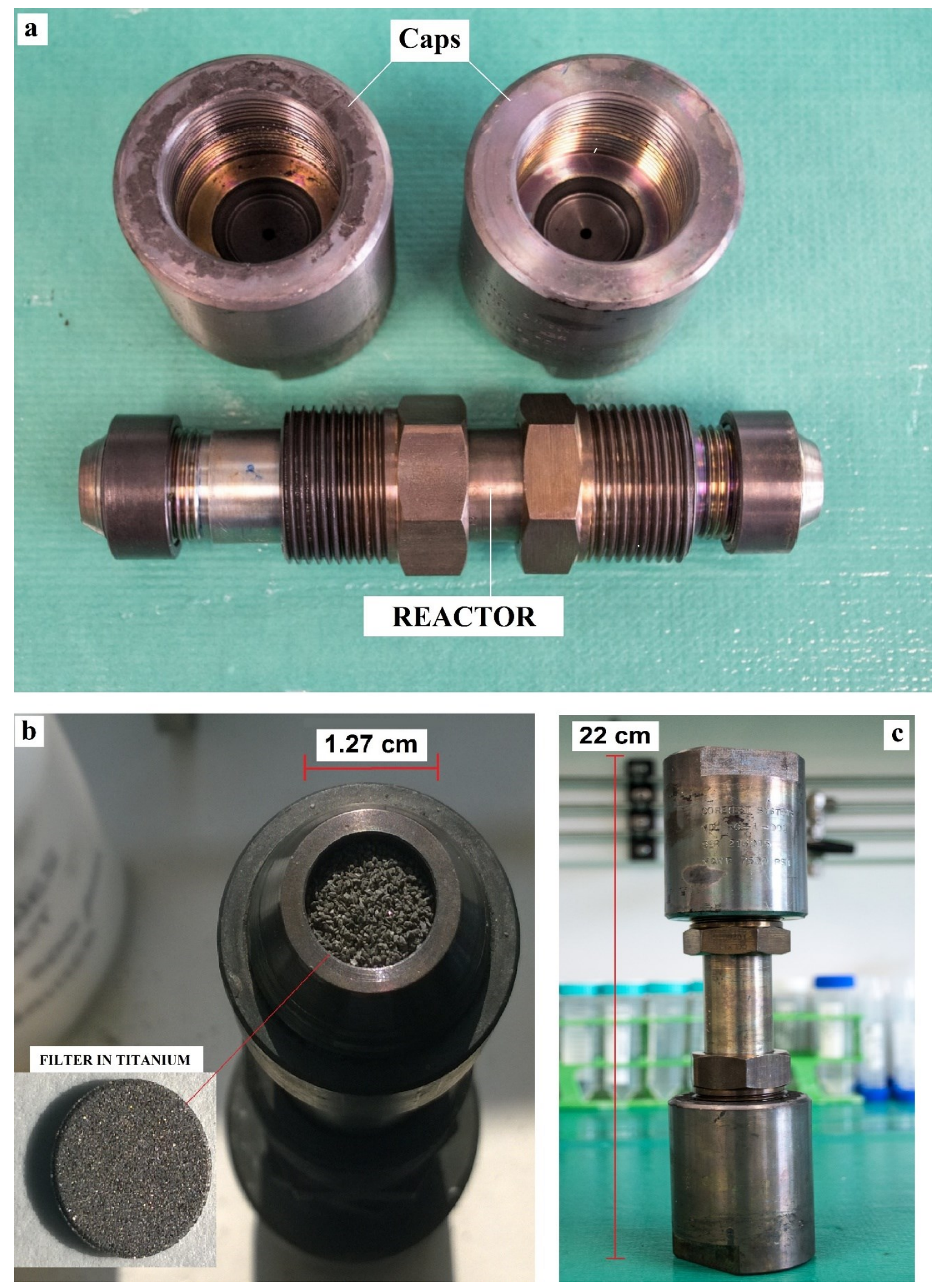
Once the Reactor is prepared, it is positioned in an aluminium and steel support (Fig. 2.10). The top of the Reactor is connected to a $1 / 4$ " titanium exit tube which is then connected to a titanium-lined high temperature and pressure (T-P) valve (Fig. 2.10a). The bottom of the Reactor is connected to $1 / 8$ " titanium tubing which provides the experimental fluid from the accumulator vessel. This assembly (Fig. 2.10b) is inserted into the furnace. The high T-P valve is connected with the back-pressure regulator (BPR) and can be closed when necessary to allow maintenance of the BPR.

Figure 2.10. (a) Reactor, $1 / 4$ " titanium exit tube, high T-P valve, and aluminium and steel support; (b) Reactor, exit tube, and high T-P valve assembled on the metal support.

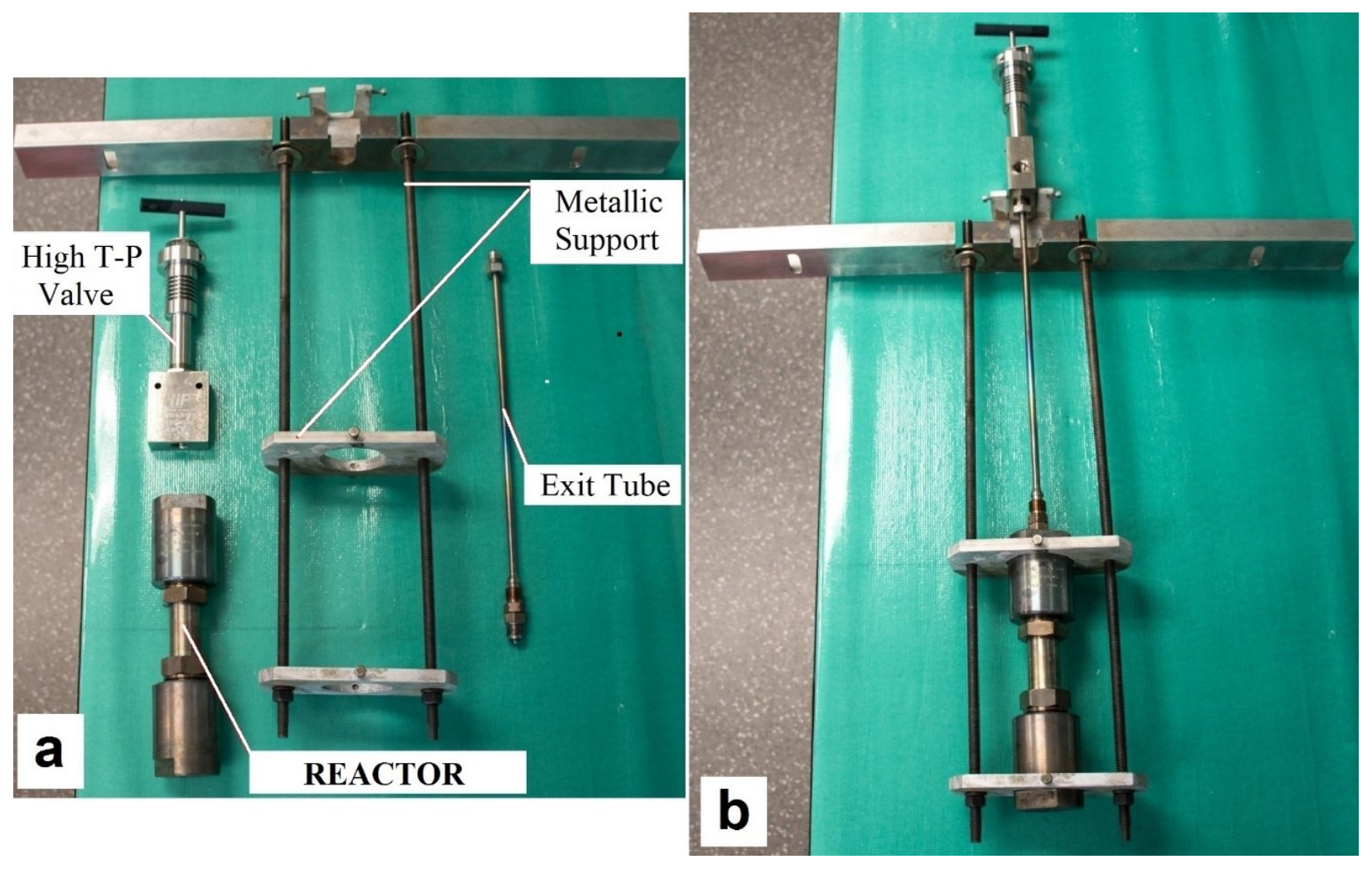

\subsubsection{Preparation of the Experimental Fluid}

In order to remove atmospheric oxygen from the aqueous fluid, approximately 1.5 litre of solution was placed into a 2-litre glass flask (Fig. 2.11). A glass bubbler was inserted into the flask and this was connected to a high purity 100 ppm $\mathrm{H}_{2}$ in $\mathrm{N}_{2}$ composition compressed gas cylinder. The gas was bubbled typically for about 10 minutes.

After de-oxygenation, the flask was connected to the accumulator vessel with plastic 
tubing and the connecting tubing was evacuated. The plastic tubing from the flask is attached to the accumulator vessel by way of a three-way titanium valve (Fig. 2.11). With both sides of the valve open and a vacuum applied, the entire assembly including the connecting tubing, the $1 / 8$ " titanium tubing and the Reactor are evacuated.

When filling the accumulator vessel with experimental fluid, the piston inside the accumulator vessel is positioned at the top (Fig. 2.12) and the volume below the piston is filled with distilled water. To fill the accumulator vessel, the glass flask is opened, filling the plastic tubing with fluid. The pump in then engaged in reverse mode. This causes the distilled water to be drawn out of the accumulator, causing the piston to lower and drawing in the experimental fluid from the flask. This is done at the maximum pump rate of $15 \mathrm{ml} \mathrm{min}^{-1}$.

Figure 2.11. The de-oxygenation apparatus showing the experimental fluid contained in the glass flask. The flask is also connected to the threeway valve at the top of the $n$ accumulator vessel.

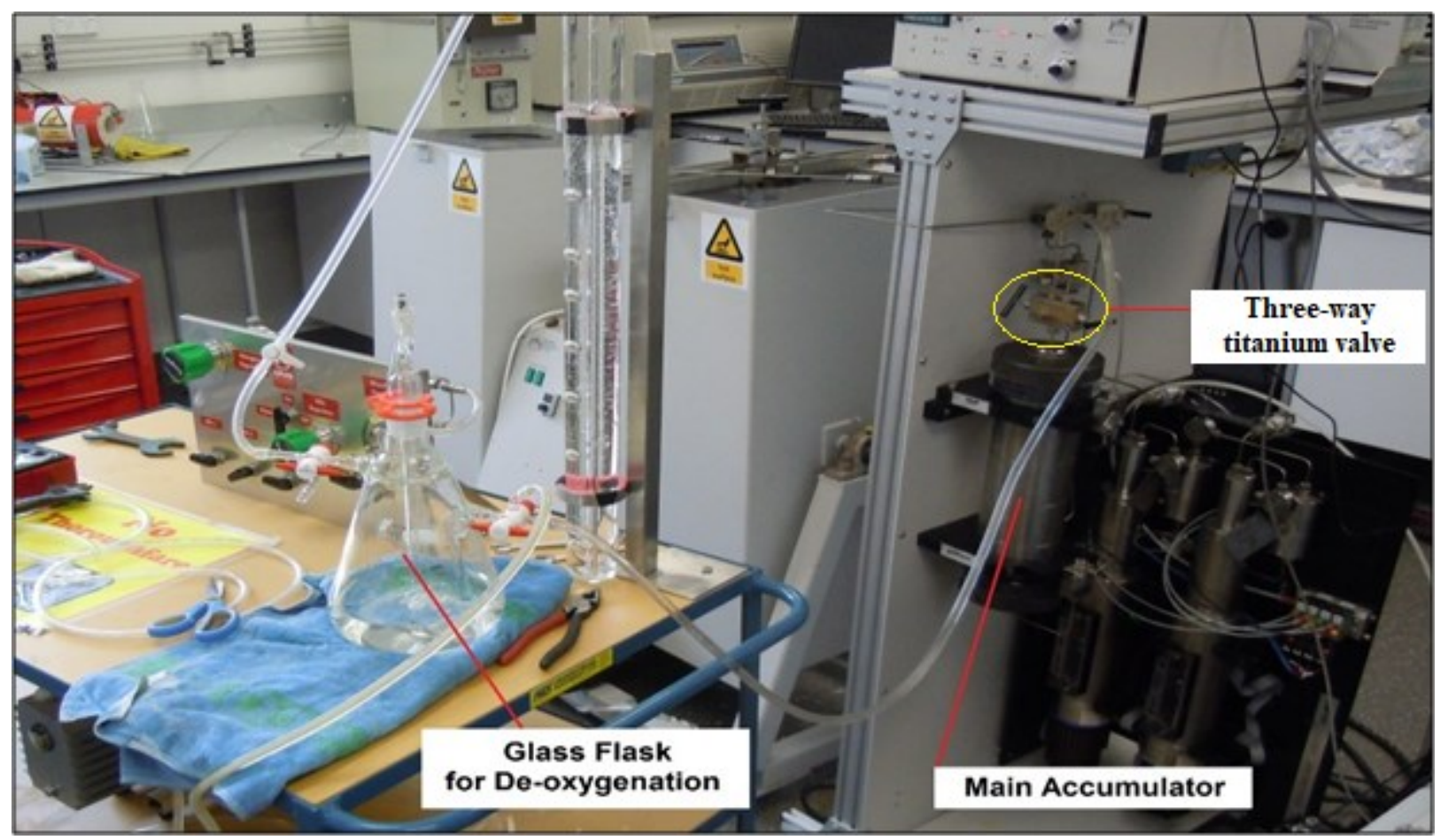


Figure 2.12. (a) main accumulator vessel; (b) internal view of the accumulator vessel with the movable piston that separates the experimental solution from distilled water below. The metering pump injects distilled water into the bottom of the accumulator vessel. This causes the experimental solution to be force from the top of the accumulator vessel and through the autoclave.
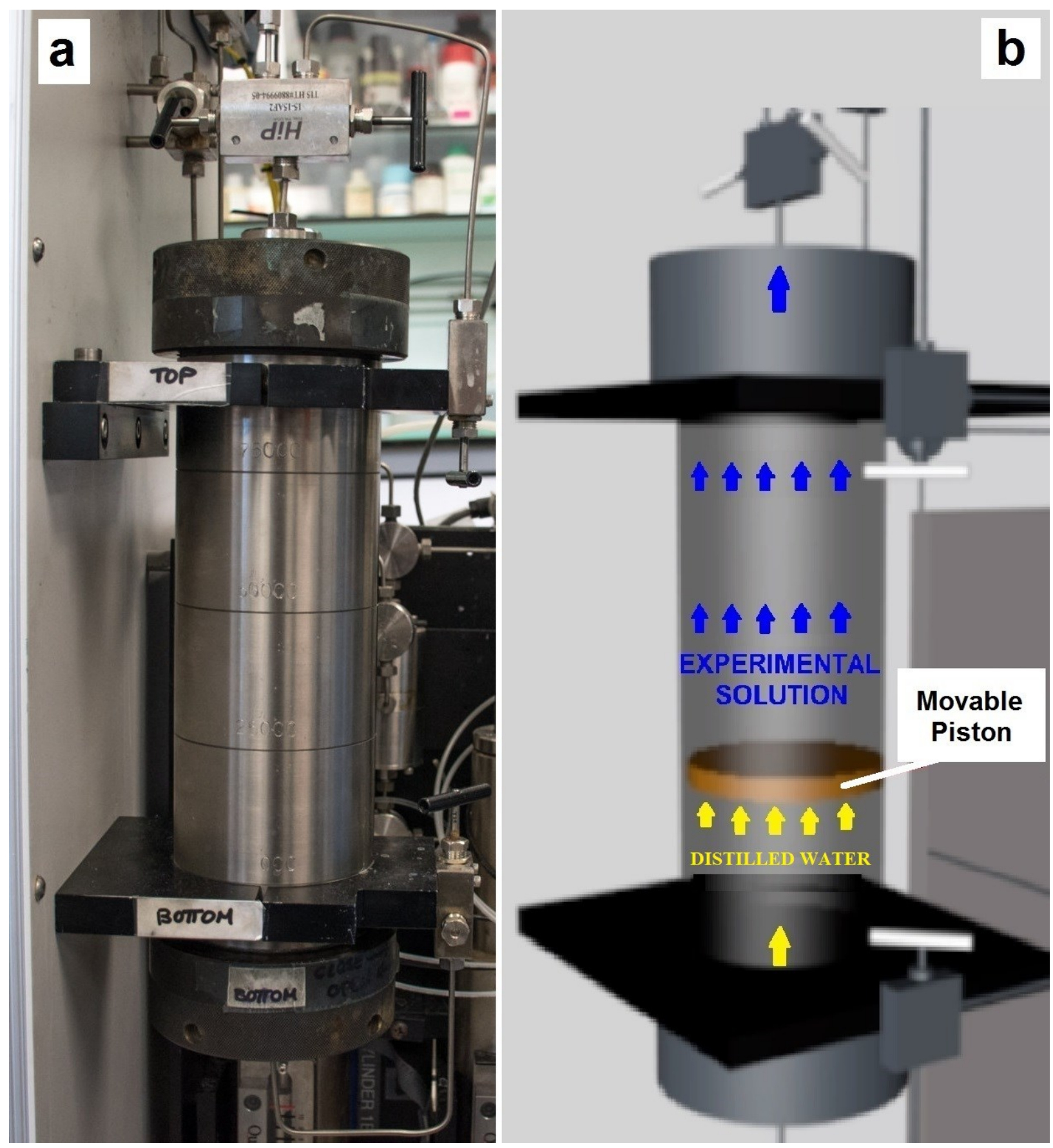


\subsubsection{The Back-pressure Regulator and Temperature Control}

Pressure in the autoclave is maintained by the back-pressure regulator (BPR) (Fig. 2.13). This is composed of the control unit (Fig. 2.13a,c) and the valve unit (Fig. 2.13b,d). The unit electronically controls the valve and relays pressure information to the computer software. The valve unit comprises back pressure regulation system in which a small reservoir $(\sim 1 \mathrm{ml})$ of vacuum oil is compressed against a PEEK or Teflon diaphragm by a piston. The pressure of the oil determines the pressure in the entire autoclave.

The BPR determines the internal pressure of the autoclave but the metering pump maintains the pressure. The experimental fluid is pushed out of the accumulator vessel and through the Reactor towards the BPR. As the reacted fluid pushes against the plastic diaphragm in the BPR its pressure builds until it equalises that of the vacuum oil, allowing the fluid to leak out into the syringe.

The temperature of the autoclave is controlled by a separate control unit to which are connected four thermocouples, two for each furnace and the analog signals from this unit are converted to digital and recorded by the computer software.

Figure 2.13. (a) the control unit of the back-pressure regulator (BPR); (b) the valve unit of the BPR; (c) schematic view of the BPR showing the vacuum oil syringe (vertical) and sample syringe (horizontal); (d) schematic view of the BPR valve box unit showing the diaphragm, vacuum oil syringe and sample syringe. Blue arrows indicate the direction of the experimental fluid coming from the Reactor.
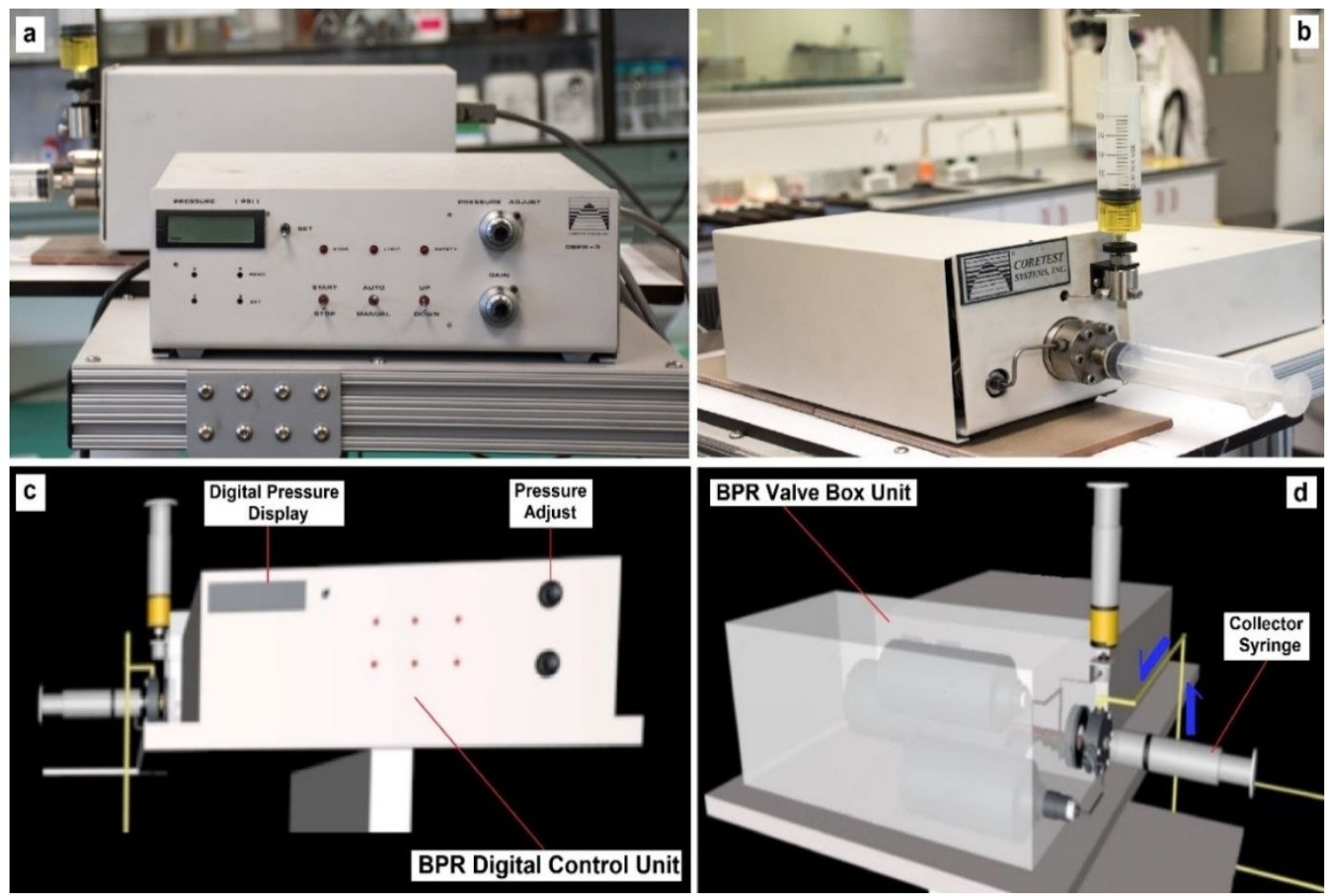


\subsubsection{Experimental Set-up: Water and Geothermal Brine}

The experimental set-up for the basalt - water (BW1, BW2) and the basalt - geothermal brine (BGB1, BGB2) experiments is illustrated in Figure 2.14 and Figure 2.15, respectively. In these experiments a single pressure vessel (the Reactor) was used.

In the BW1 and BW2 experiments, the upper part of the accumulator vessel was filled with distilled water and the Reactor with basalt grains. In the BGB1 and BGB2 experiments, the upper chamber of the accumulator vessel was filled with geothermal brine and the Reactor with basalt grains. 
Figure 2.14. (a) set-up for the BW1 experiment at $400^{\circ} \mathrm{C} / 502$ bar; (b) set-up for the $\mathrm{BW} 2$ experiment at $350^{\circ} \mathrm{C} / 490$ bar. In both experiments the upper chamber of the accumulator vessel was filled with water (distilled) which is pushed through the Reactor, up to the BPR, and collects in the collection syringe. Both experiments used basalt grains. The water is shown in blue. Red arrows show the direction of flow of the water.
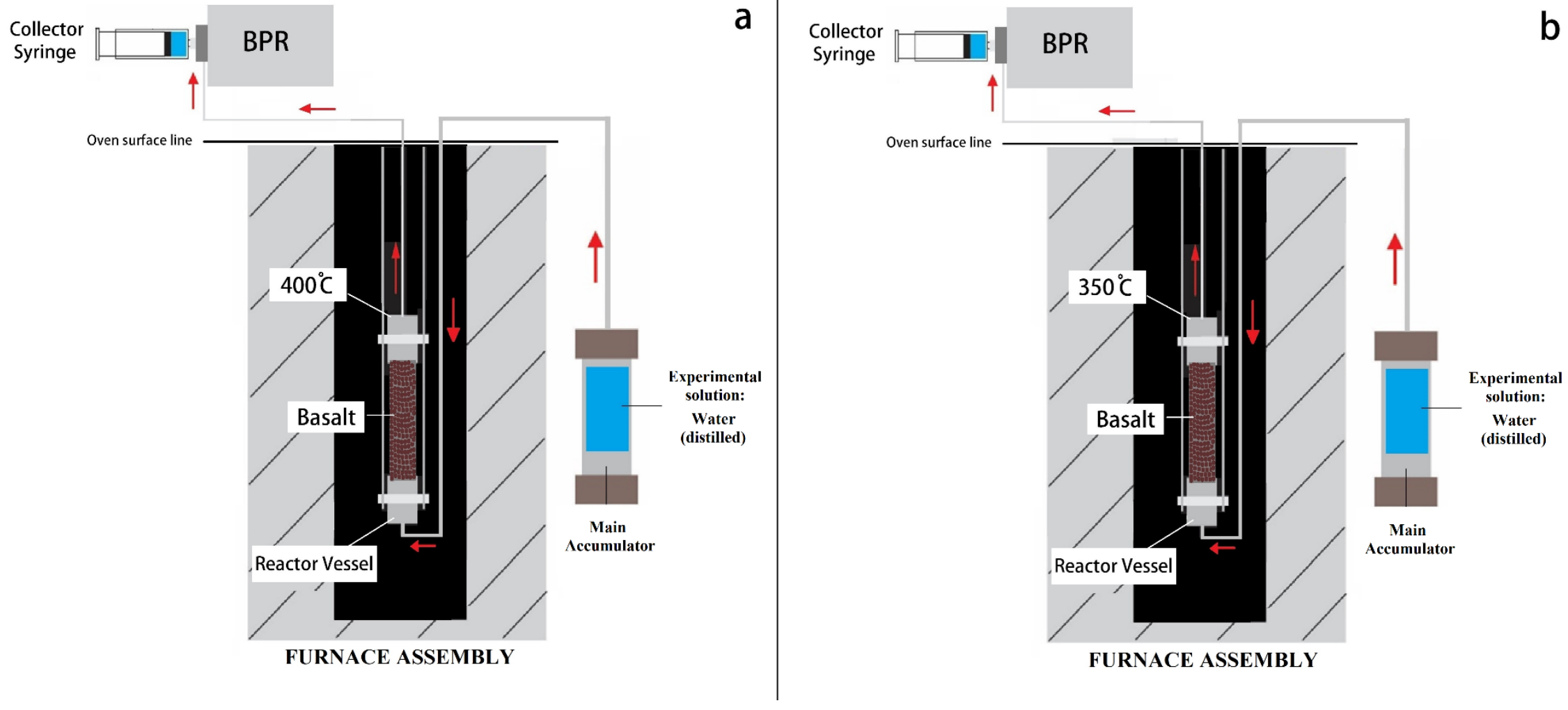
Figure 2.15. (a) set-up for the BGB1 experiment at $400^{\circ} \mathrm{C} / 483$ bar; (b) set-up for the $\mathrm{BGB} 2$ experiment at $350^{\circ} \mathrm{C} / 486$ bar. In both experiments the upper chamber of the accumulator vessel was filled with geothermal brine which is pushed through the Reactor, up to the BPR, and collects in the collection syringe. Both experiments used basalt grains. The water is shown in blue. Red arrows show the direction of flow of the water
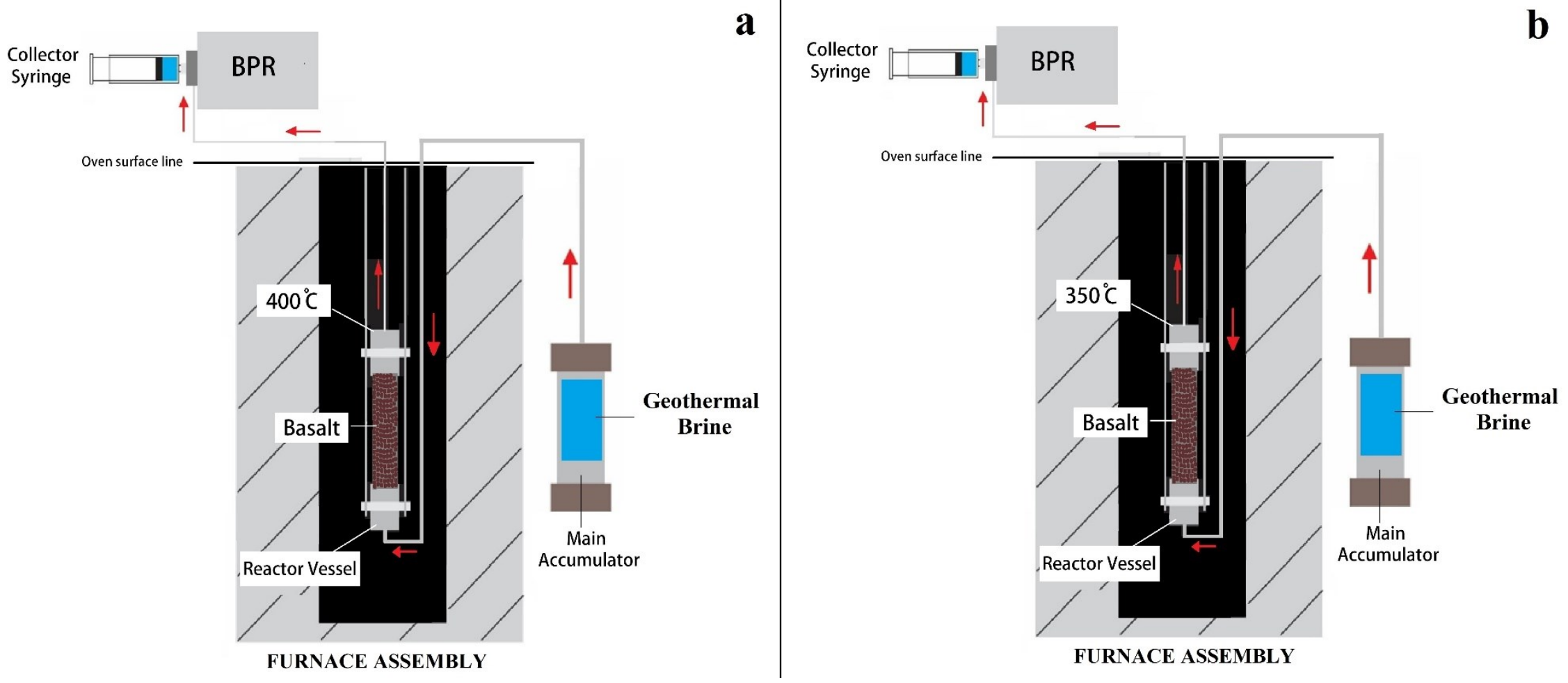


\subsubsection{Experimental Set-up: Seawater (A New Approach)}

With distilled water and geothermal brine experiments, there is no expectation of mineral phases with retrograde solubility precipitating during heating. This, however, is not the case for seawater. The use of seawater as the experimental fluid in a flow-through situation is complicated by the retrograde solubility of minerals such as anhydrite, brucite and magnesium sulfate/hydroxysulfates (Bischoff and Seyfried, 1978b). At the slow flow rates used in the present experiments, mineral precipitation would occur in the $1 / 8$ " titanium inlet tubing before entry into the Reactor and would rapidly cause a blockage.

Figure 2.16 shows the saturation indices of four phases: anhydrite $\left(\mathrm{CaSO}_{4}\right)$, brucite $\left(\mathrm{Mg}(\mathrm{OH})_{2}\right)$, magnesium hydroxysulfate $\left(\mathrm{MHSH}\left(\mathrm{Mg}_{1.5}\right)\right)$, and $\mathrm{MgSO}_{4}(\mathrm{c})$ as average seawater is heated from 25 to $300^{\circ} \mathrm{C}$. These were calculated using Geochemist's Workbench ${ }^{\odot}(\mathrm{GWB})$ v. 12 software package (Bethke et al., 2018; Bethke and Yeakel, 2009; Bethke and Yeakel, 2015). At $70^{\circ} \mathrm{C}$, seawater saturates with respect to brucite; at $108^{\circ} \mathrm{C}$ it saturates with respect to anhydrite, and at $193^{\circ} \mathrm{C}$, it saturates with respect to $\mathrm{Mg}$ hydroxysulfate. GWB's database is limited up to $300^{\circ} \mathrm{C}$, however, it is also expected that anhydrous $\mathrm{MgSO}_{4}$ will saturate just above $300^{\circ} \mathrm{C}$. In a simulated GWB run including mineral precipitation, when heating $1 \mathrm{~kg}$ of average seawater to $300^{\circ} \mathrm{C}, 1.4 \mathrm{~g}$ of anhydrite and $1.3 \mathrm{~g}$ of Mg-hydroxysulfate will precipitate. In a flow-through situation, as used in this study, small bore tubing would become quickly blocked after a short period of time. One approach to avoid this is to use synthetic seawater without significant $\mathrm{Ca}$ or Mg (Berndt et al., 1989; Gilles et al., 1987; Seewald and Seyfried, 1990; Seyfried et al., 1986; Seyfried and Janecky, 1985). Alternatively, batch-type experiments can be used.

One of the objectives of this study was to develop a method by which natural seawater can be used in a flow-through water-rock interaction simulation. This would allow flow of seawater through the rock, continuously replenishing the rock with "fresh" pore fluid and greatly increasing the integrated fluid/rock ratio.

To our knowledge, there have be no published, geochemically-related, continuous-flow seawater/rock interaction studies. All previous published studies have used batch-type reactors (Berndt and Seyfried, 1993; Berndt et al., 1989; Bischoff and Dickson, 1975; Bischoff and Seyfried, 1978b; Gilles et al., 1987; Hajash, 1975; Mottl and Holland, 1978; Mottl et al., 1979; Seewald and Seyfried, 1990; Seyfried Jr, 1979; Seyfried Jr and Bischoff, 1979; Seyfried and Bischoff, 1977; Seyfried et al., 1986; Seyfried and Bischoff, 1981; Seyfried et al., 1987; Seyfried 
and Janecky, 1985; Seyfried and Mottl, 1982; Seyfried et al., 1979).

Figure 2.16. The mineral saturation indices of selected $\mathrm{Ca}$ and $\mathrm{Mg}$ sulfate/hydroxysulfate phases in seawater with increasing temperature calculated using the Geochemist's Workbench ${ }^{\odot}(\mathrm{GWB})$ v. 12 software package (Bethke et al., 2018).

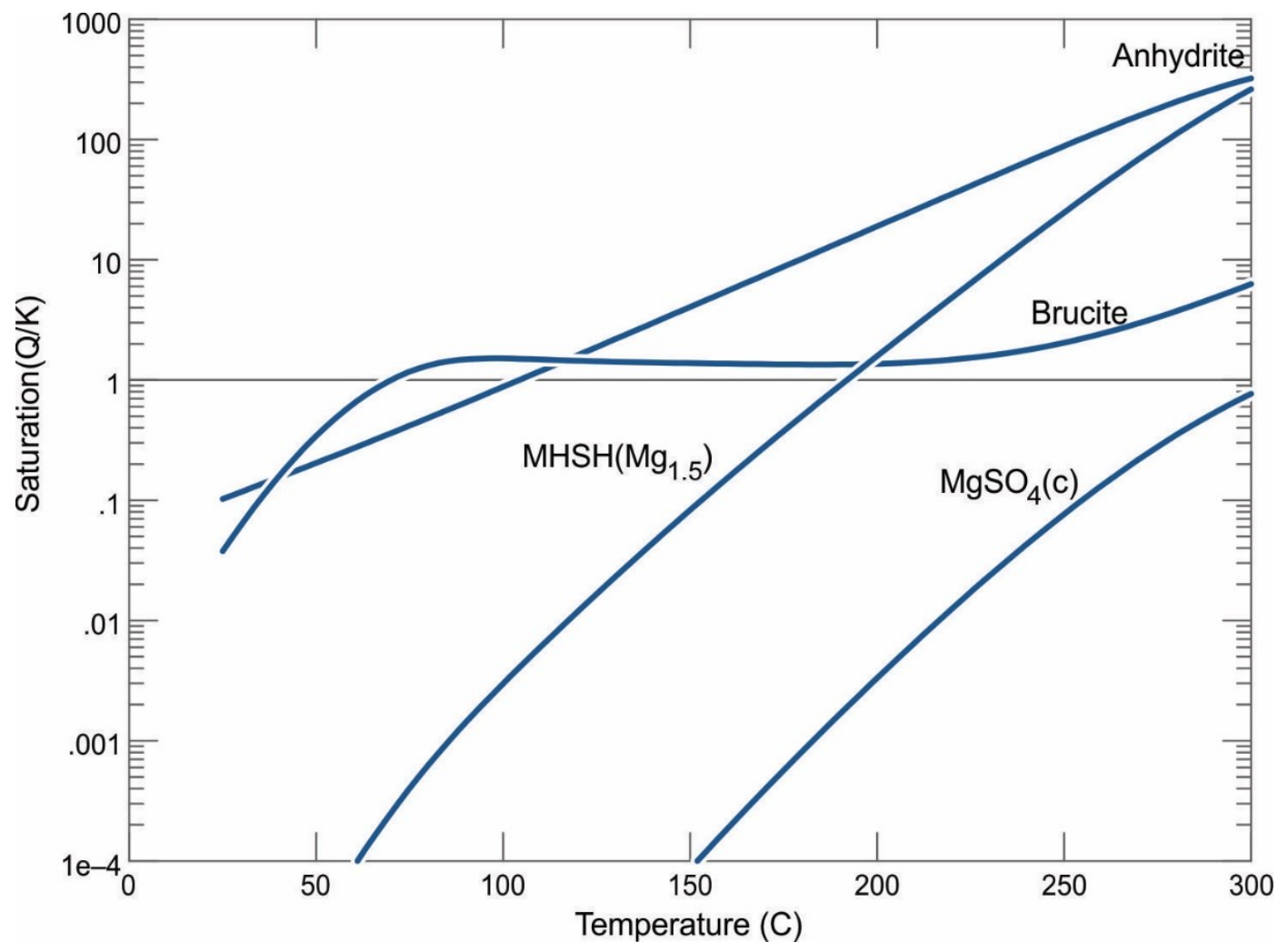

In order to eliminate the problem of retrograde mineral precipitation when using flowing natural seawater, a new experimental method needed to be developed. It was conjectured that preheating of the water in a larger pressure vessel would allow retrograde phases to precipitate before entering the smaller bore tubing at the bottom of the Reactor containing the rock. It is, however, necessary that permeability along the flow path, while the seawater is being heated, be sufficiently high to prevent blockage. In order to accomplish this, a large pressure vessel was constructed $\left(56 \mathrm{~cm}\right.$ in length and $25 \mathrm{~cm}$ in diameter and has an internal volume of $71 \mathrm{~cm}^{3}$; Fig. $2.17 \mathrm{a}, \mathrm{b})$. The function of the pressure vessel, hereafter referred to as the Preheater, is to allow gradual heating of the seawater up to $\sim 400^{\circ} \mathrm{C}$ at a sufficiently slow rate to allow precipitation of retrograde phases, thus preventing blockage of the small bore Ti tubing. The Preheater is connected in series with the Reactor containing the rock material (Fig. 2.17c). The seawater enters the top of the Preheater and moves "downwards" to the bottom after which it passes through the connecting tubing and into the bottom of the Reactor which contains the basalt rock. 
It is expected that the actual path of the seawater in the Preheater is complex and consists of multiple convection cells, however, the overall result is $\sim 400^{\circ} \mathrm{C}$ seawater leaving the bottom of the Preheater.

Figure 2.17. (a) the Preheater pressure vessel disassembled, (b) the Preheater assembled, (c) the Preheater connected in series with the Reactor vessel.

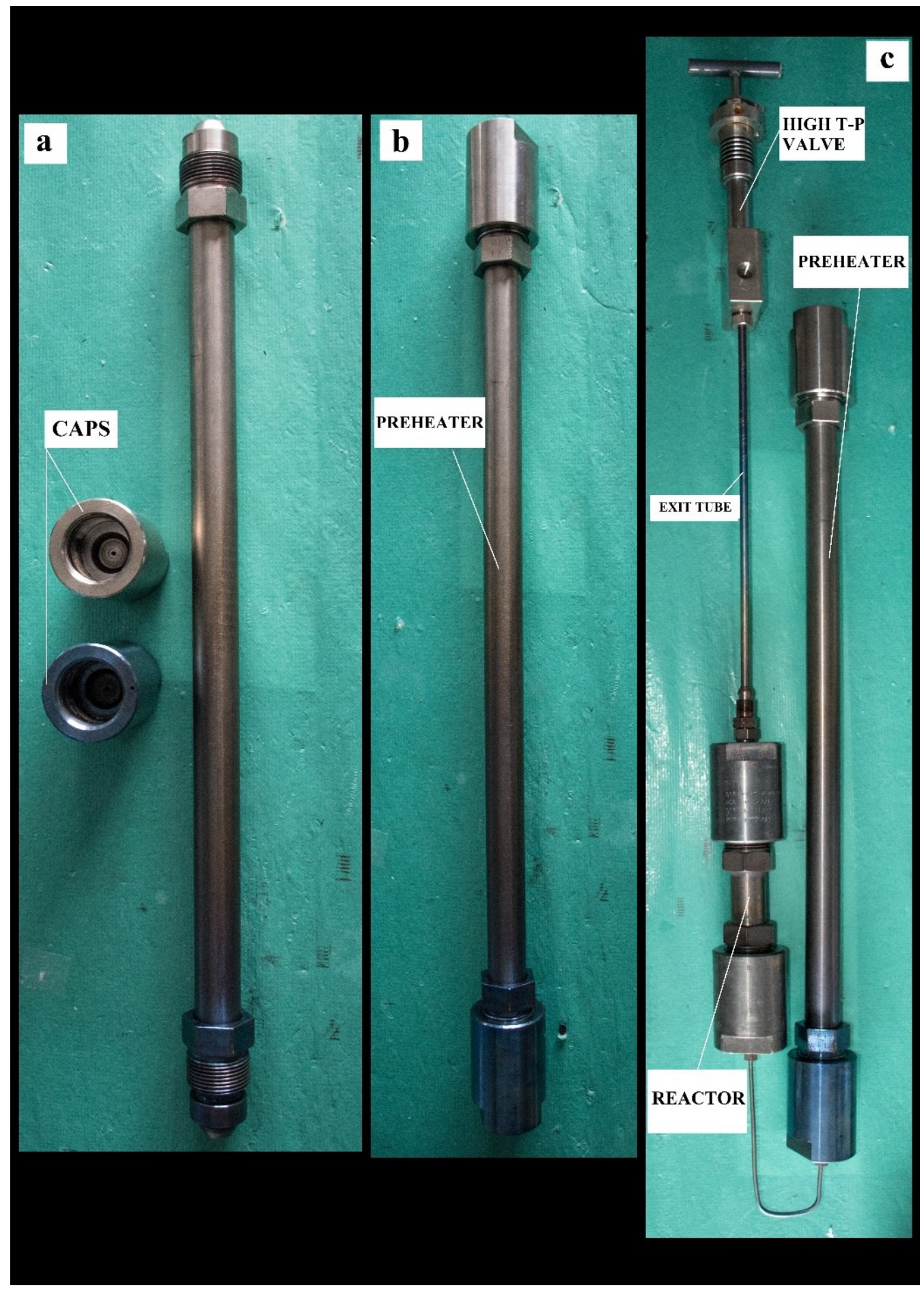


For the SW experiments using only seawater, the Preheater, without the Reactor, is mounted in the furnace using the metal support. The top $20 \mathrm{~cm}$ of the Preheater extends outside of the furnace while the remainder extends down towards the bottom of the furnace. An electric fan is used to cool the top of the Preheater. This creates a large temperature gradient between the top $\left(\sim 40^{\circ} \mathrm{C}\right)$ and bottom $\left(\sim 400^{\circ} \mathrm{C}\right)$ of the Preheater (Fig. 2.18$)$.

As this approach had not previously been tested, it was necessary to conduct some preliminary experiments to determine its efficacy. These are included in this section as they are considered method development experiments (Fig. 2.17).

At the beginning of all experiments using seawater, the Preheater and connected tubing are filled with distilled water. This prevents mineral precipitation in the Ti tubing during heat-up. Once the required temperature and pressure are reached, seawater flow is initiated. Chemical analyses of the effluent solutions show that it takes $3-7$ days for the distilled water to be completely displaced by seawater at $1 \mathrm{ml} \mathrm{hr}^{-1}$ depending on the temperature. This shows some degree of turbulent flow in the Preheater as with a plug flow regime it should take only about 71 hours.

The first method development experiment was conducted to test the efficiency of the Preheater at removing retrograde phases (set-up in Fig. 2.18). The temperature in the furnace was at $400^{\circ} \mathrm{C}$ while the temperature registered at the bottom of the Preheater was $377^{\circ} \mathrm{C}$. The pressure was maintained at 490 bar. For expediency, it was performed using synthetic seawater made from Seachem reef salt powder $\left(\mathrm{pH} 8.4,10.8 \mathrm{mmol} \mathrm{kg}^{-1} \mathrm{Ca}, 53.5 \mathrm{mmol} \mathrm{kg}{ }^{-1} \mathrm{Mg}, 13.5 \mathrm{mmol} \mathrm{kg}^{-1}\right.$ K (https://www.seachem.com/vibrant-sea.php). Continuous flow at $1 \mathrm{ml} \mathrm{hr}^{-1}$ was maintained for 13 days indicating that about $300 \mathrm{~g}$ of seawater had passed through the Preheater. At 13 days, pump pressure increased to the safety pressure value (7500 psi/503 bar) and pump flow ceased indicating a blockage. Upon opening of the Preheater, a solid crystalline mineral layer was found at the bottom. This was responsible for the blockage. 
Figure 2.18. Experimental set-up with synthetic seawater at $400^{\circ} \mathrm{C} / 490$ bar. The Preheater extended approximately $20 \mathrm{~cm}$ outside the top of the furnace while the remainder of the vessel extended down towards the bottom of the furnace. The Preheater was connected at the top to the main accumulator vessel containing the synthetic seawater (blue) and on the bottom to the back-pressure regulator (BPR). The BPR was fitted with a syringe that collected the synthetic seawater after passing through the Preheater. An electric fan cooled the top of the Preheater which created a temperature gradient from $40^{\circ} \mathrm{C}$ to $377^{\circ} \mathrm{C}$ at the bottom. There was no Reactor in this test experiment. The temperature of the Preheater was $377^{\circ} \mathrm{C}$ at the bottom. The yellow circle on bottom of the Preheater indicates the position of the retrograde phase precipitation which caused the blockage and exceeding of the safety pressure.

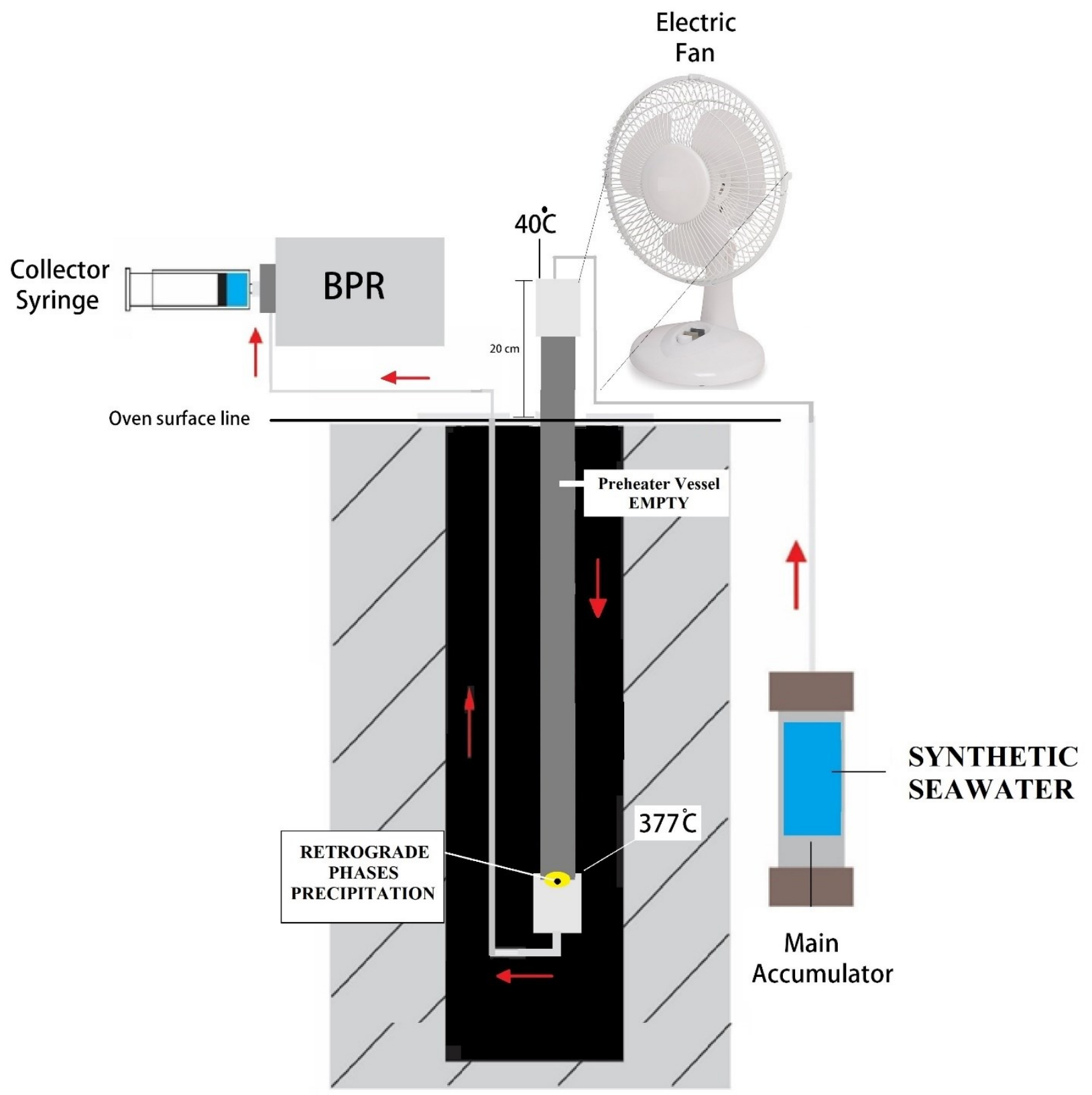

FURNACE ASSEMBLY 
As anhydrite saturates at $106^{\circ} \mathrm{C}$ in seawater, it was expected that precipitates would be found on the walls of the Preheater at a higher level. However, this was not the case and evidently the titanium walls of the Preheater do not provide a suitable nucleation point for anhydrite crystal growth. We conjecture that the mechanism is nucleation in solution and once the crystallites reach a critical size, they settle to the bottom of the Preheater. This test experiment shows that the use of a Preheater vessel for removal of retrograde phases is successful, but the duration before blockage ( $\sim 13$ days) is too short to be useful for this study.

If the above precipitation mechanism is active, then the blockage of the exit point of the Preheater could be prevented by packing the pressure vessel with suitable material to: 1) increase the surface area for precipitation and; 2) prevent crystal nuclei from settling to the bottom. This material must not reduce permeability and be unreactive with the heated seawater. In this study, we used zirconia ceramic beads (2 mm dia) sourced from Zircoa, Inc. (Fig. 2.19). These beads are not large enough to impede fluid flow, provide greatly enhanced surface area in the Preheater and are relatively unreactive, even at high temperatures. The beads are composed of predominantly of $\mathrm{ZrO}_{2}(\sim 97 \%)$ and $\mathrm{MgO}(\sim 3 \%)$, with minor concentrations at $<0.30 \%$ each of $\mathrm{SiO}_{2}, \mathrm{CaO}, \mathrm{Fe}_{2} \mathrm{O}_{3}, \mathrm{Al}_{2} \mathrm{O}_{3}, \mathrm{TiO}_{2}$. For all the experiments described in this thesis, the Preheater was filled 2/3 with zirconia beads (Fig. 2.19). 
Figure 2.19. (a) zirconia beads sourced from Zircoa, Inc. ( $2 \mathrm{~mm}$ dia); (b) Preheater filled with zirconia beads $2 / 3^{\text {rd }}$ full. Black circles indicate where thermocouples were positioned to measure the temperature at the top and bottom of the vessel during experiment.

a

\section{Zirconia Beads}

\section{$2 \mathbf{m m}$}

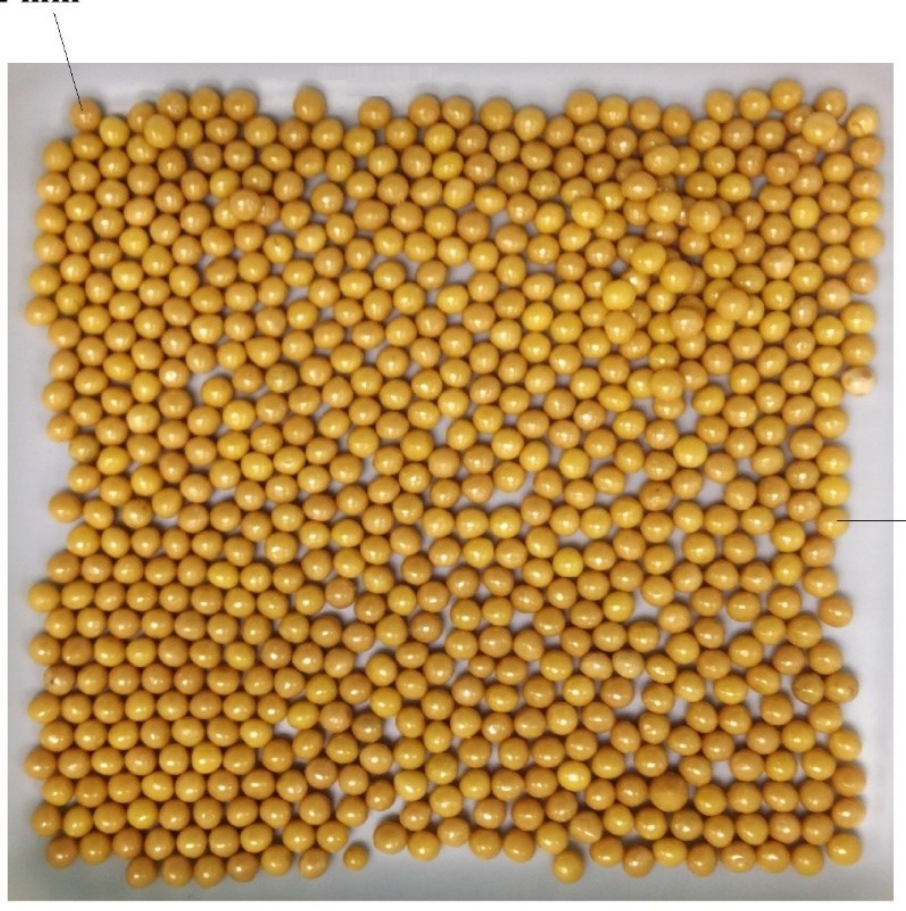

\section{Preheater Vessel}

b
$52 \mathrm{~cm}$

$71 \mathrm{cC}$

Thermocouple Well 
To differentiate the effects of fluid-rock interaction from those caused by the fluidzirconia interaction, two control experiments, SW1 and SW2, were conducted. The set-up for these experiments involves use of the Preheater vessel containing zirconia beads without use of the Reactor vessel (Fig. 2.20a and 2.21a). While, for the fluid-rock interaction experiments BSW1 and BSW2, the set-up involved the use of the Preheater filled with zirconia beads connected in series to the Reactor containing the basalt rock fragments (Fig. 2.20b and 2.21b).

The ideal temperature for the SW1 and BSW1 experiments was $400^{\circ} \mathrm{C}$ and $350^{\circ} \mathrm{C}$ for the SW2 and BSW2 experiments. The experimental configuration involved positioning the top $1 / 3$ of the Preheater outside the furnace and the bottom $2 / 3$ in the furnace. The top cooled by a fan resulting in a temperature $\sim 40^{\circ} \mathrm{C}$ at the top of the Preheater, however, the maximum temperature at the bottom of the Preheater was $377^{\circ} \mathrm{C}$ in SW1 and BSW1 and $342^{\circ} \mathrm{C}$ for SW2 and BSW2. The temperature for the Reactor in $\mathrm{BSW} 1$ and $\mathrm{BSW} 2$ was $400^{\circ} \mathrm{C}$ and $350^{\circ} \mathrm{C}$, respectively (Fig. $2.20 \mathrm{~b}$ and 2.21b). The difference in temperature between the bottom of the Preheater and the Reactor is due to rapid heat conduction up the Preheater vessel and out of the furnace. A pressure of 488 bar was maintained constant for all experimental configurations. 
Figure 2.20. (a) experimental set-up of the seawater-only experiment (SW1) at $400^{\circ} \mathrm{C} / 488$ bar. The Preheater extended approximately $20 \mathrm{~cm}$ outside the top of the furnace while the remainder of the vessel extended down towards the bottom of the furnace. The Preheater is $2 / 3$ filled with zirconia beads. It was connected at the top to the main accumulator vessel containing the natural seawater (blue) and on the bottom to the back-pressure regulator (BPR). The BPR was fitted with a syringe that collected the seawater after passing through the zirconia beads. An electric fan cooled the top of the Preheater which created a temperature gradient from $40^{\circ} \mathrm{C}$ to $377^{\circ} \mathrm{C}$ at the bottom. There was no Reactor in this experiment. (b) experimental set-up of the basalt-seawater experiment at $400^{\circ} \mathrm{C} / 488$ bar (BSW1). The Preheater was 2/3 filled with zirconia beads. It was connected at the top to the main accumulator vessel containing natural seawater (blue) and on the bottom to the Reactor containing the basalt fragments. The temperature gradient between the top and the bottom of the Preheater was $40^{\circ} \mathrm{C}$ to $377^{\circ} \mathrm{C}$. The temperature of the Reactor was $400^{\circ} \mathrm{C}$.

a

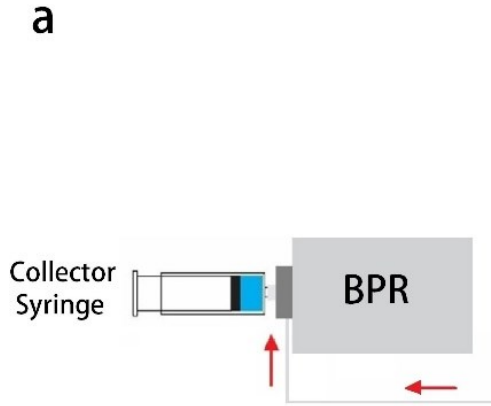

Oven surface line

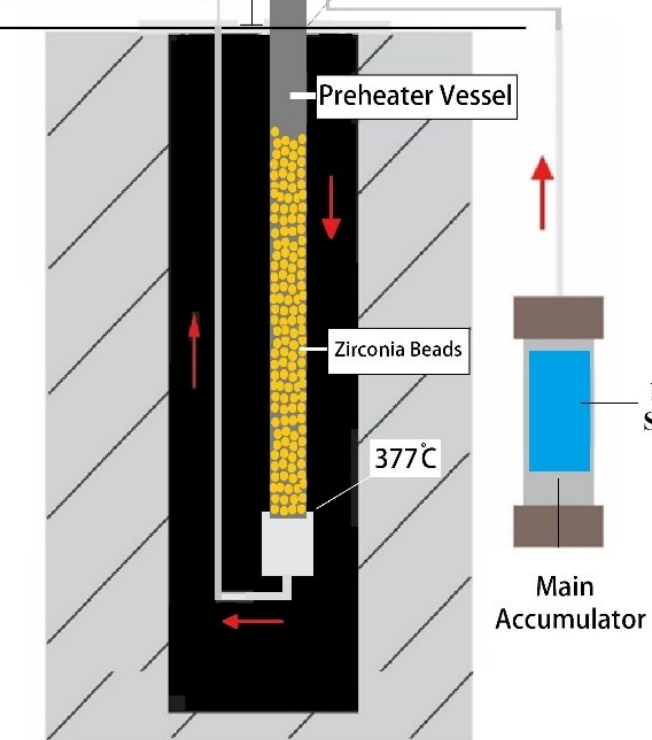

FURNACE ASSEMBLY b

NATURAL EAWATER

Electric

$400^{\circ}$
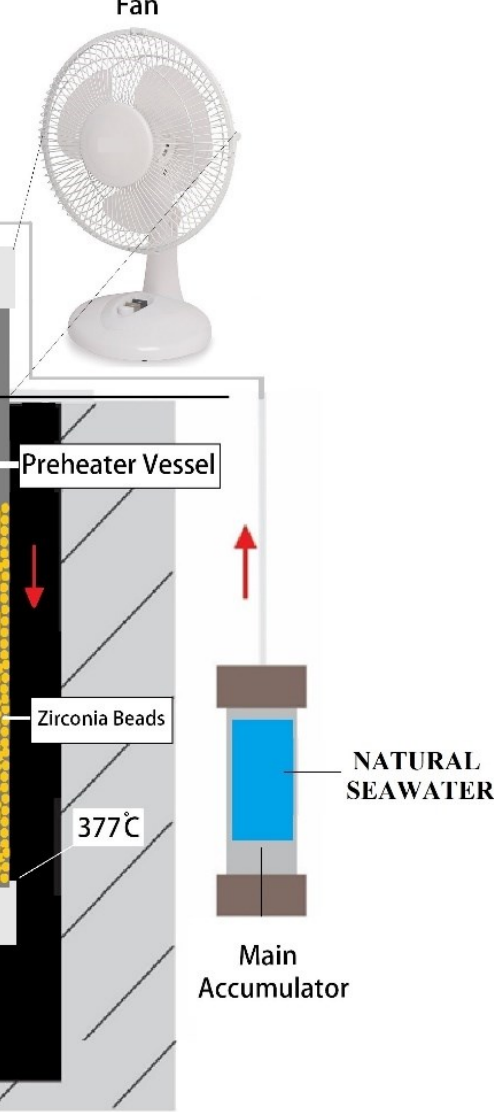

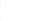

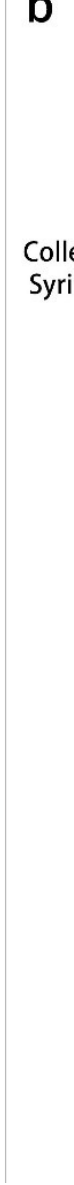

Electric

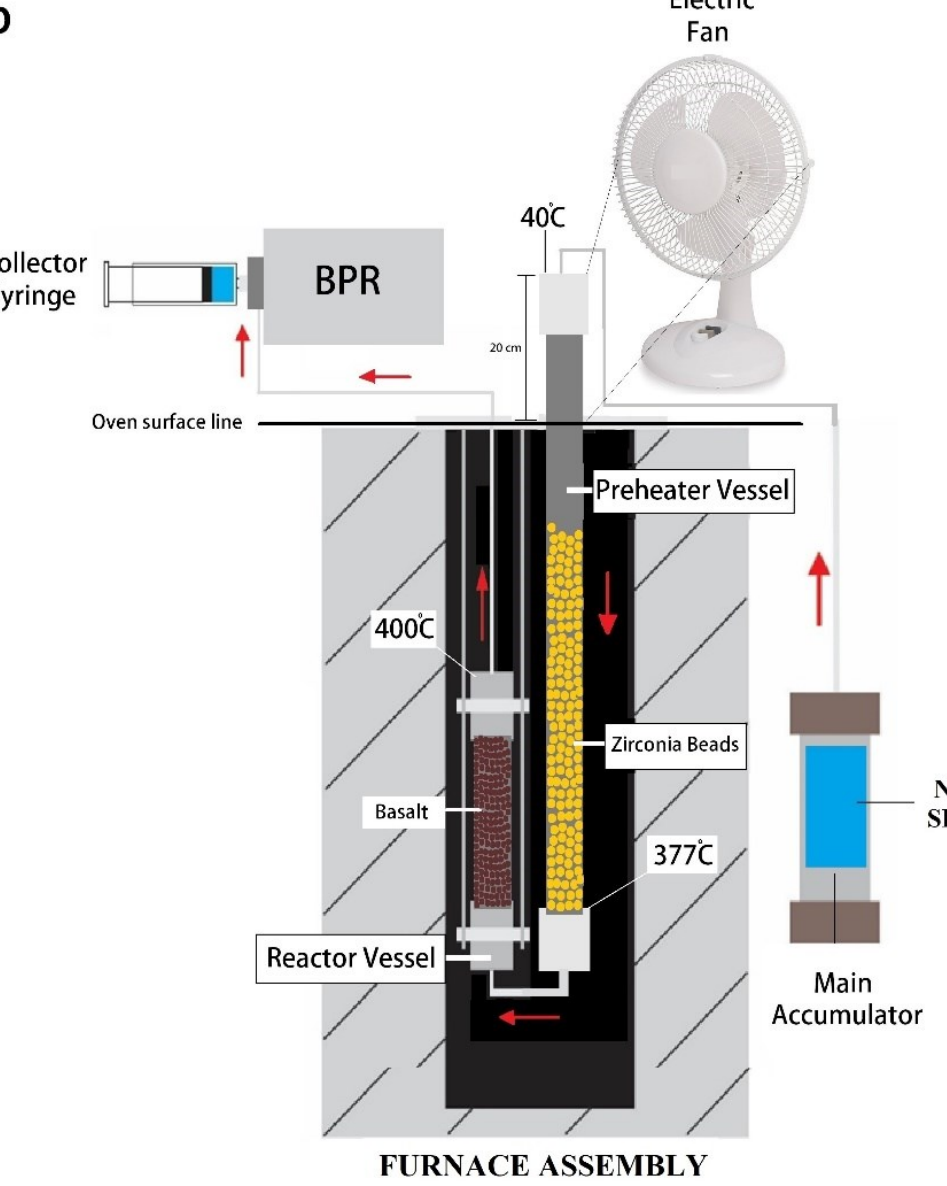


Figure 2.21. (a) experimental set-up of the seawater-only experiment (SW2) at $350^{\circ} \mathrm{C} / 488$ bar. The Preheater extended approximately $20 \mathrm{~cm}$ outside the top of the furnace while the remainder of the vessel extended down towards the bottom of the furnace. The Preheater is $2 / 3$ filled with zirconia beads. It was connected at the top to the main accumulator vessel containing the natural seawater (blue) and on the bottom to the back-pressure regulator (BPR). The BPR was fitted with a syringe that collected the seawater after passing through the zirconia beads. An electric fan cooled the top of the Preheater which created a temperature gradient from $40^{\circ} \mathrm{C}$ to $342^{\circ} \mathrm{C}$ at the bottom. There was no Reactor in this experiment. (b) experimental set-up of the basalt-seawater experiment at $350^{\circ} \mathrm{C} / 488$ bar (BSW2). The Preheater was 2/3 filled with zirconia beads. It was connected at the top to the main accumulator vessel containing natural seawater (blue) and on the bottom to the Reactor containing the basalt fragments. The temperature gradient between the top and the bottom of the Preheater is $40^{\circ} \mathrm{C}$ to $342^{\circ} \mathrm{C}$. The temperature of the Reactor was $350^{\circ} \mathrm{C}$.

a

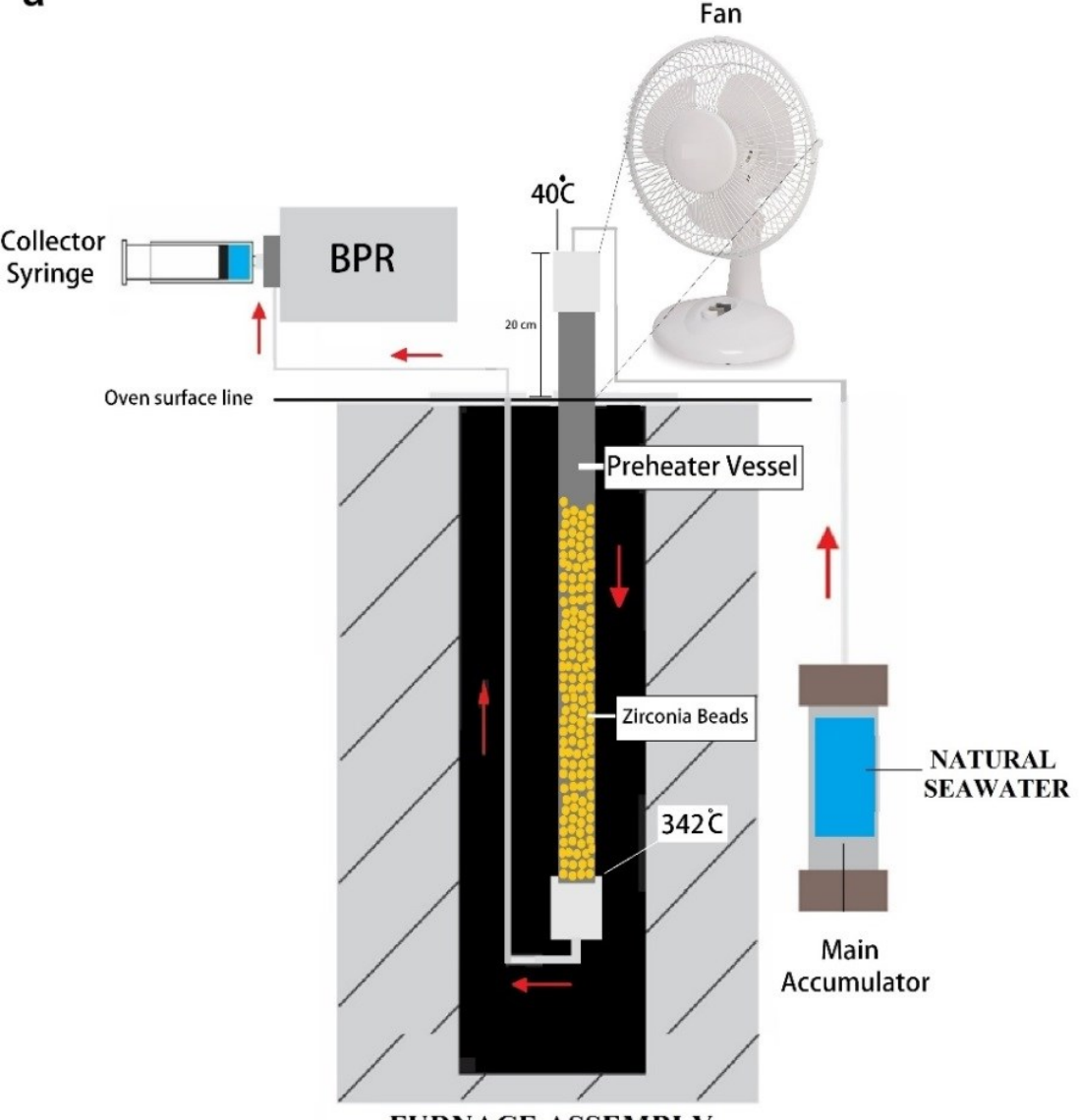

FURNACE ASSEMBLY b

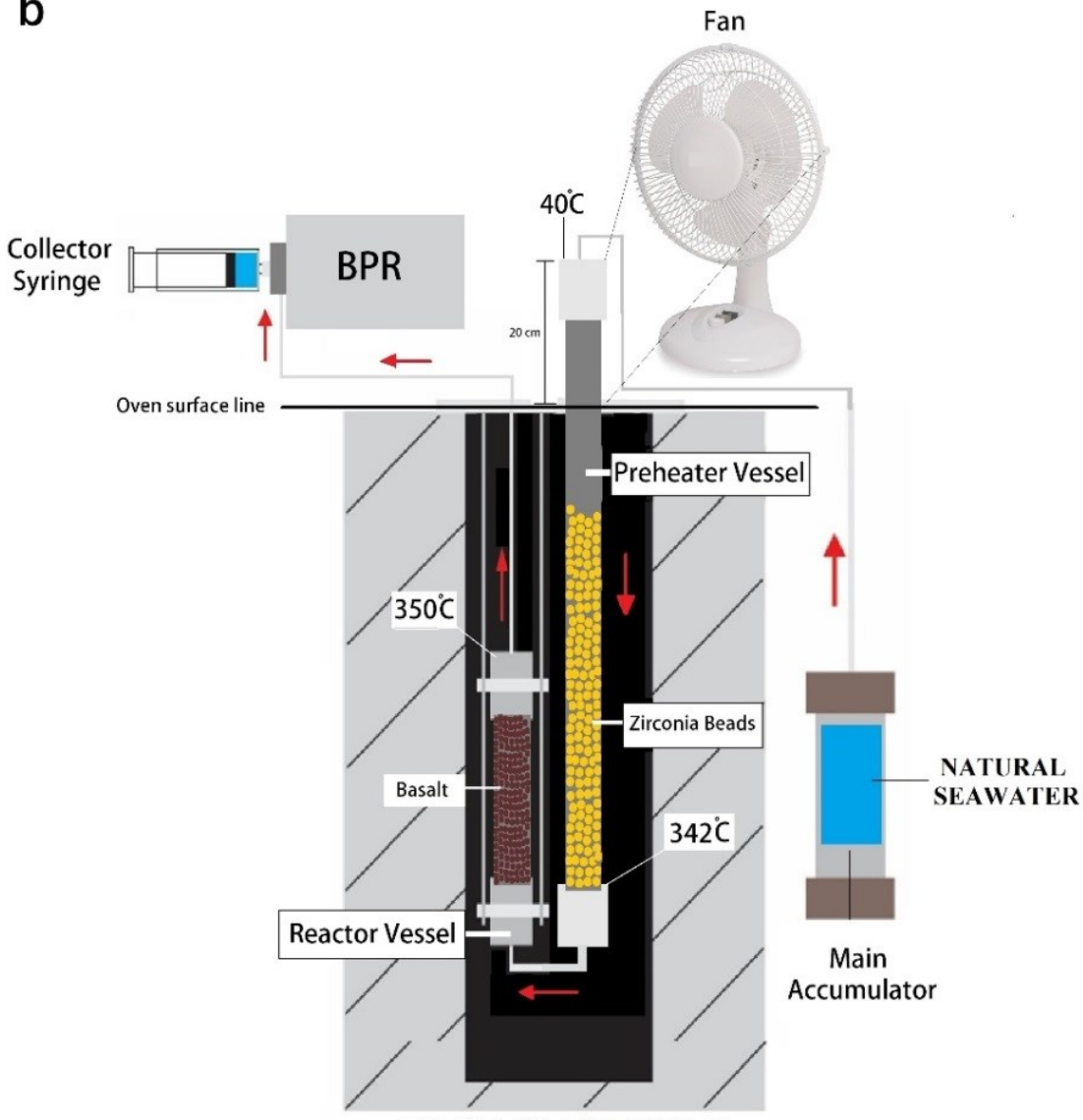

FURNACE ASSEMBLY 


\subsection{Analytical Techniques}

\subsubsection{Rock material}

The methods of analysis of the mineralogical and chemical composition both of unreacted and reacted rock material are listed in Table 2.6. These included:

1. scanning electron microscopy with energy dispersive spectroscopy (SEM-EDS) using instruments at the Research Centre for Surface and Materials Science, University of Auckland, New Zealand and at the Wairakei Research Centre, GNS Science, New Zealand;

2. X-ray diffraction (XRD) performed at the Callaghan Innovation Centre, Lower Hutt, New Zealand. The X-ray diffraction data was collected using a Philips X'Pert Pro (P1700 series) instrument utilising $\mathrm{CoK} \alpha$ radiation and the following operating conditions:

Start Position $\left[{ }^{\circ} 2 \theta\right] \quad 3.000$

End Position $\left[{ }^{\circ} 2 \theta\right] \quad 80.000$

Step Size $\left[{ }^{\circ} 2 \theta\right] \quad 0.050$

Scan Step Time [s] 1.00

Generator Settings $\quad 40 \mathrm{kV}, 35 \mathrm{~mA}$

The mineralogy of the samples was determined using PANalytical interpretive software X'Pert High Score;

3. X-ray fluorescence (XRF) analysed by SpectraChem, CRL Energy Ltd, Lower Hutt, New Zealand. Multi-element analyis of the samples was performed using the following method: Pressed powder / X-ray spectrometry/ Spectraplus SQ46. The values are reported as wt\% with Lower Level Detection (LLD) of 0.001; and

4. electron microprobe analysis (EMPA) performed at the College of Earth, Ocean, and Atmospheric Sciences, Electron Microprobe Laboratory, Oregon State University, Corvallis, United States. The EMPA analysis were conducted using a Cameca SX100 electron microprobe with a $30 \mathrm{nA}$ beam current, $15 \mathrm{kV}$ accelerating potential, and $5 \mu \mathrm{m}$ beam diameter.

\subsubsection{Experimental Fluids (initial and reacted)}

The methods used to analyse the experimental solutions (effluents), both initial and unreacted, are listed in Table 2.7. These included:

1. inductively-coupled plasma optical emission spectroscopy analysis (ICP-OES) for Li, $\mathrm{Na}$, 
$\mathrm{K}, \mathrm{Mg}, \mathrm{Ca}, \mathrm{Sr}, \mathrm{Mn}, \mathrm{Fe}, \mathrm{As}, \mathrm{Al}, \mathrm{B}$ and $\mathrm{SiO}_{2}$ with detection limits of $\mathrm{Li}, 0.01 ; \mathrm{Na}, 0.8 ; \mathrm{K}$, 0.9; Mg, 0.01; Ca, 0.05; Sr, 0.003; Mn, 0.007; Fe, 0.08; As, 0.015; Al, 0.15; B, 0.3; Si, $0.6 \mathrm{mg} \mathrm{kg}^{-1}$. The major cation concentrations were measured by inductively-coupled plasma-optical emission spectroscopy (ICP-OES) with a Thermo Scientific iCap 7600 Duo ICP-OES with a ceramic plasma torch, quartz spray chamber and nebulizer with attached Cetac ASX-520 Autosampler, and Qtegra software. The aliquots for ICP-OES analysis were acidified with $\mathrm{HNO}_{3}$;

2. ion chromatography analysis (IC) for chloride and sulfate with detection limits of $\mathrm{Cl}$,

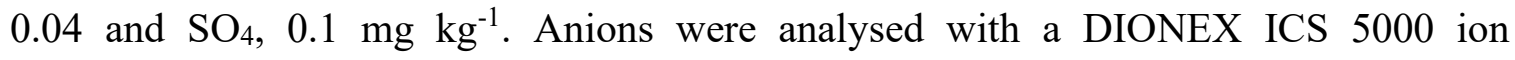
chromatograph with AS14 Column and attached AS 50 Autosampler, and Chromeleon software;

3. total reduced sulfur as $\mathrm{H}_{2} \mathrm{~S}$ by UV-Vis spectroscopy using the methylene blue method with a detection limit of $0.01 \mathrm{mg} \mathrm{kg}^{-1}$. The concentrations of hydrogen sulfide were determined spectrophotometrically with a Dynamica DB-30 UV/VIS spectrophotometer;

4. quench (room temperature) $\mathrm{pH}$, using a $\mathrm{pH}$ electrode and standard $\mathrm{pH}$ buffers. The $\mathrm{pH}$ of the experimental solutions was measured with a Metrohm $\mathrm{pH}$ meter (with a temperature probe). The $\mathrm{pH}$ meter was calibrated against standard buffer solutions daily.

All the above methods were performed at the Wairakei Research Centre, GNS Science, New Zealand. Samples for ICP-OES analysis were diluted and acidified using with $\mathrm{HNO}_{3}$ to $0.5 \%$ acid by weight. Samples for IC and $\mathrm{H}_{2} \mathrm{~S}$ analysis were diluted with doubly-distilled water.

Selected effluents were also analysed for trace metal concentrations using inductively coupled plasma mass spectroscopy (ICP-MS) for $\mathrm{Co}, \mathrm{Ni}, \mathrm{Cu}, \mathrm{Zn}, \mathrm{Mo}, \mathrm{Ag}, \mathrm{Cd}, \mathrm{Ba}, \mathrm{Au}, \mathrm{Pb}, \mathrm{Cr}, \mathrm{V}$, Rb. Detection limits for elements were as follow: Co, $<0.05 ; \mathrm{Ni},<0.20 ; \mathrm{Cu},<0.06 ; \mathrm{Zn},<0.50$; Mo, <0.20; Ag, <0.05; Cd, <0.10; Ba, <0.20; Au, <0.20; Pb, <0.20; Cr, <0.20; V, <0.10; and $\mathrm{Rb},<0.10 \mu \mathrm{g} \mathrm{L}^{-1}$. Solutions were diluted with doubly-distilled water and acidified to $0.5 \%$ using ultrapure $\mathrm{HNO}_{3}$. Samples were analysed at Edith Cowan University, Science Analytical Facility Laboratories, Perth, Australia. Trace elements were analysed by ICP-MS system and autosampler iCAP Q ICP-MS (S/N IC76DC141606) ASX-520 AutoSampler by Thermo-Fisher Scientific; Teledyne Cetac (Omaha, USA). 
Note that $\mathrm{CO}_{2}$ concentrations were not measured on the effluent samples due to the large sample size required $(50 \mathrm{ml})$. Four measurements of total inorganic carbon as $\mathrm{HCO}_{3}{ }^{-}$were measured during the BSW1 and BSW2 experiments when flow rate was $10 \mathrm{ml} \mathrm{hr}^{-1}$. These ranged from 24 - $99 \mathrm{mg} \mathrm{kg}^{-1}$. $\mathrm{CO}_{2}$ in distilled water and the geothermal brine are both $<20 \mathrm{mg} \mathrm{kg}^{-1}$. The $\mathrm{CO}_{2}$ quantification was made using a Metrohm 809 Titrino automatic titrator with a Metrohm 814 Sample Processor, Metrohm 834 Pump Station, and Tiamo software 2.5-2014. 
Table 2.6. Mineralogical and chemical analytical methods for unreacted and reacted rock materials

\begin{tabular}{|c|c|c|c|c|c|c|c|c|c|}
\hline & $\begin{array}{l}\text { Unreacted } \\
\text { Material }\end{array}$ & BW1 & BW2 & BGB1 & BGB2 & SW1 & BSW1 & SW2 & BSW2 \\
\hline SEM-EDS & $\begin{array}{c}\text { - Fresh basalt grains } \\
\text { - Basalt blocks polished } \\
\text { surface }\end{array}$ & $\begin{array}{l}\text { - Reacted basalt grains } \\
\text { (bottom and top of } \\
\text { Reactor) } \\
\text { - Reacted basalt block } \\
\text { surface }\end{array}$ & $\begin{array}{l}\text { - Reacted basalt grains } \\
\text { - Reacted basalt block } \\
\text { surface }\end{array}$ & $\begin{array}{c}\text { - Reacted basalt grains } \\
\text { (bottom and top } \\
\text { Reactor) }\end{array}$ & $\begin{array}{l}\text { - Reacted basalt grains } \\
\text { (bottom and top of } \\
\text { Reactor) } \\
\text { - Reacted basalt block } \\
\text { surface }\end{array}$ & $\begin{array}{l}\text { - Zirconia beads } \\
\text { (Preheater) }\end{array}$ & $\begin{array}{l}\text { - Reacted basalt grains } \\
\text { (bottom, middle and top of } \\
\text { Reactor) } \\
\text { - Reacted basalt block }\end{array}$ & $\begin{array}{l}\text { - Zirconia beads } \\
\text { (Preheater) }\end{array}$ & $\begin{array}{c}\text { - Reacted basalt grains } \\
\text { (bottom, middle and top } \\
\text { of the Reactor) } \\
\text { - Reacted basalt block }\end{array}$ \\
\hline XRD & & $\begin{array}{c}\text { - Reacted basalt grains } \\
\text { (bottom and top of the } \\
\text { Reactor) }\end{array}$ & $\begin{array}{l}\text { Reacted basalt grains } \\
\text { (bottom and top of the } \\
\text { Reactor) }\end{array}$ & $\begin{array}{l}\text { Reacted basalt grains } \\
\text { (bottom and top of the } \\
\text { Reactor) }\end{array}$ & $\begin{array}{l}\text { Reacted basalt grains } \\
\text { (bottom and top of the } \\
\text { Reactor) }\end{array}$ & & $\begin{array}{l}\text { - Reacted basalt grains } \\
\text { (bottom, middle and top of } \\
\text { Reactor) }\end{array}$ & & $\begin{array}{c}\text { - Reacted basalt grains } \\
\text { (bottom, middle and top } \\
\text { of Reactor) }\end{array}$ \\
\hline XRF & - Unreacted rock powder & & & & & & $\begin{array}{l}\text { - Reacted basalt grains } \\
\text { (bottom, middle and top } \\
\text { of Reactor) }\end{array}$ & & $\begin{array}{c}\text { - Reacted basalt grains } \\
\text { (bottom, middle and top } \\
\text { of Reactor) }\end{array}$ \\
\hline EMPA & $\begin{array}{l}\text { - Fresh basalt rock thin } \\
\text { section }\end{array}$ & $\begin{array}{l}\text { - Reacted basalt grains } \\
\text { (bottom of Reactor) }\end{array}$ & $\begin{array}{l}\text { - Reacted basalt grains } \\
\text { (bottom of Reactor) }\end{array}$ & $\begin{array}{l}- \text { Reacted basalt grains } \\
\text { (bottom of Reactor) }\end{array}$ & $\begin{array}{l}\text { - Reacted basalt grains } \\
\text { (bottom of Reactor) }\end{array}$ & & & & \\
\hline
\end{tabular}

Table 2.7. Chemical analytical methods for experimental solutions

\begin{tabular}{|c|c|c|c|c|c|c|c|c|c|}
\hline & Starting fluids & BW1 & BW2 & BGB1 & BGB2 & SW1 & BSW1 & SW2 & BSW2 \\
\hline ICP-OES & Yes & Yes & Yes & Yes & Yes & Yes & Yes & Yes & Yes \\
\hline IC & Yes & Yes & Yes & Yes & Yes & Yes & Yes & Yes & Yes \\
\hline $\mathrm{H}_{2} \mathrm{~S}$ & No & Yes & Yes & Yes & Yes & No & Yes & No & Yes \\
\hline ICP-MS & Yes & Yes & Yes & Yes & Yes & Yes & Yes & Yes & Yes \\
\hline
\end{tabular}




\subsection{Determination of experimental $\mathrm{pH}$ and solute speciation at high temperature and pressure conditions $\left(325-400^{\circ} \mathrm{C}\right.$ and 500 bar)}

The calculation of solute activities at high temperature and pressure is necessary to determine experimental $\mathrm{pH}$ and mineral saturation indices at experimental conditions. This requires consideration of all the relevant equilibria. Several computational software packages are available to calculate such equilibria but are restricted by the temperature limitation of their databases (e.g. Geochemist's Workbench ${ }^{\odot}, \leq 300^{\circ} \mathrm{C}$ ). However, all experiments in the current study were conducted at temperatures $\geq 342^{\circ} \mathrm{C}$ and these software packages are not applicable.

To properly quantify the mechanisms that control the chemical exchanges between fluid and rock at hydrothermal conditions, several chemical and thermodynamic concepts must be considered. These include:

1. all relevant chemical equilibria (solution and mineral);

2. the concentrations of dissolved species (molal, $m_{i}$ );

3. the activity coefficients all these species $\left(\gamma_{i}\right)$;

4. the solution ionic strength $(I)$.

The calculation of mineral solubility and solute concentration and speciation are based on equilibrium thermodynamics. To evaluate the state of equilibrium for a given reaction, the concentration of reactants and products and the equilibrium constant of the reaction, $K$, are required. For simple reaction,

$$
x \mathrm{~A}+y \mathrm{~B} \quad \leftrightarrow \quad z \mathrm{C}
$$

The equilibrium constant is expressed as

$$
\mathrm{K}=\frac{a_{\mathrm{C}}^{z}}{a_{\mathrm{A}}{ }^{x} \cdot a_{\mathrm{B}}{ }^{y}}
$$

where $\left[a_{i}\right]$ are the species' activities. 
A species activity $\left[a_{i}\right]$ is related to its concentration $\left(m_{i}\right)$ through the activity coefficient, $\gamma_{i}$, by

$$
a_{\mathrm{i}}=m_{i} \cdot \gamma_{i}
$$

and Equation (2) can be written as

$$
K=\frac{\left[m_{C} \cdot \gamma_{C}\right]^{z}}{\left[m_{A} \cdot \gamma_{A}\right]^{x} \cdot\left[m_{B} \cdot \gamma_{B}\right]^{y}}
$$

Where $m_{(i)}$ and $\gamma_{(i)}$ is the concentration and the activity coefficient of species, $i$, respectively.

The activities coefficients are a function of ionic strength $(I)$ as given by the extended Debye-Hückel expression (Helgeson, 1969)

$$
-\log \gamma_{i}=\frac{A z_{i}^{2} \sqrt{\mathrm{I}}}{1+\mathrm{B} \mathrm{a}_{i} \sqrt{\mathrm{I}}}+\dot{\mathrm{B}} \cdot \mathrm{I}
$$

and

$$
\mathrm{I}=1 / 2 \sum \mathrm{m}_{i} \cdot z_{i}^{2}
$$

where $I$ is the ionic strength, $z_{i}$ is the ion charge, $A, B$, and $\dot{B}$ are temperature dependent constants and $\stackrel{a}{a}$ is the ion size parameter.

In this study, an iterative approach is taken to simplify the calculation. This method "tracks" all the species present, distributing the total concentration of each species in solution. An Excel spread-sheet has been developed that is linked to the software package EqSolvR (Stefan Mroczek and Ed Mroczek, 2017) (https://github.com/shearwavesplitter/EqSolvR), an equilibrium solver based on the Newton-Raphson method. This spreadsheet can perform iterative computations between all geochemical equations and parameters to calculate the speciation and, consequently, the $\mathrm{pH}$ at the experimental temperature and pressure.

The iterative approach uses a non-linear system of equations in including:

1. the mass action equations (e.g. Equation 1);

2. the mass balance equations;

3. the charge balance equation. 
An example of a mass balance equation is, for example, that for $\mathrm{Na}$

$$
\mathrm{m}_{\mathrm{Na} \text { toal }}=\mathrm{m}_{\mathrm{Na}^{+}}+\mathrm{m}_{\mathrm{NaOH}^{\circ}}+\mathrm{m}_{\mathrm{NaCl}}+\mathrm{m}_{\mathrm{NaSO}^{2}+} \mathrm{m}_{\mathrm{NaCl}}
$$

where $m_{i}$ is the species' concentration in molality.

The charge balance equation (solutions are assumed to be electrically neutral) can be expressed as

$$
\left.\left.\sum \text { [positive charge }\right]=\sum \text { [negative charge }\right]
$$

All relevant aqueous species are considered and their thermodynamic data utilised including: $\log K\left(325,350,375,400^{\circ} \mathrm{C}\right.$ and 500 bar), $A, B$ and $\dot{B}$ parameters for Equation (6) $\left(350,375,400^{\circ} \mathrm{C}\right.$ and $\left.500 \mathrm{bar}\right), z_{i}$ and $\stackrel{\circ}{a}_{i}$, are listed in Table 2.8. Equilibrium constants $(\log K)$ were calculated using Supcrt.92 slop98.dat (https://reaktoro.org/thermodynamic-databases.html). The Debye-Hückel parameters $(A, B$ and $\dot{B}$ ) data were sourced from (Helgeson and Kirkham, 1974). 


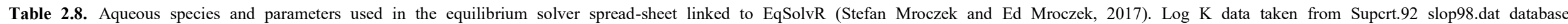
(http://geopig.asu.edu/?q=tools). The Debye-Hückel parameters ( $A, B$ and $\dot{B}$ ) data were sourced from (Helgeson and Kirkham, 1974).

\begin{tabular}{|c|c|c|c|c|c|c|c|c|c|c|c|c|c|c|}
\hline & $\log K$ & $\log K$ & $\log K$ & $\log K$ & $\mathbf{z}$ & $\begin{array}{c}\stackrel{̊}{a} \\
\left(10^{-8} \mathrm{~cm}\right)\end{array}$ & $A$ & $\boldsymbol{B}$ & $A$ & $\boldsymbol{B}$ & $A$ & $\boldsymbol{B}$ & $B-d o t$ & \\
\hline & $\begin{array}{l}325^{\circ} \mathrm{C} / \\
500 \mathrm{bar}\end{array}$ & $\begin{array}{l}350^{\circ} \mathrm{C} / \\
500 \mathrm{bar}\end{array}$ & $\begin{array}{l}375^{\circ} \mathrm{C} / \\
500 \mathrm{bar}\end{array}$ & $\begin{array}{l}400^{\circ} \mathrm{C} / \\
500 \mathrm{bar}\end{array}$ & & & $\begin{array}{l}350^{\circ} \mathrm{C} / \\
500 \text { bar } \\
\mathbf{1 . 3 2 6 7}\end{array}$ & $\begin{array}{l}350^{\circ} \mathrm{C} / \\
500 \text { bar } \\
\mathbf{0 . 4 0 0 4}\end{array}$ & $\begin{array}{c}375^{\circ} \mathrm{C} / \\
500 \text { bar } \\
\mathbf{1 . 5 4 6 4}\end{array}$ & $\begin{array}{c}375^{\circ} \mathrm{C} / \\
500 \text { bar } \\
\mathbf{0 . 4 1 0 4}\end{array}$ & $\begin{array}{l}400^{\circ} \mathrm{C} / \\
500 \mathrm{bar} \\
\mathbf{1 . 8 7 8 9}\end{array}$ & $\begin{array}{c}400^{\circ} \mathrm{C} / \\
500 \text { bar } \\
\mathbf{0 . 4 2 3}\end{array}$ & $\begin{array}{c}350,375 \\
400^{\circ} \mathrm{C} \\
\mathbf{0}\end{array}$ & $\begin{array}{c}\text { at } 350,375, \\
400^{\circ} \mathrm{C} \\
\mathbf{0}\end{array}$ \\
\hline \multicolumn{15}{|c|}{ Aqueous species } \\
\hline $\mathbf{H}^{+}$ & & & & & 1 & 9 & & & & & & & & \\
\hline $\mathbf{O H}^{-}$ & & & & & -1 & 4 & & & & & & & & \\
\hline $\mathrm{Cl}^{-}$ & & & & & -1 & 3.5 & & & & & & & & \\
\hline $\mathbf{K}^{+}$ & & & & & 1 & 3 & & & & & & & & \\
\hline $\mathbf{N a}^{+}$ & & & & & 1 & 4 & & & & & & & & \\
\hline $\mathrm{SO}_{4}{ }^{2-}$ & & & & & -2 & 4 & & & & & & & & \\
\hline $\mathrm{Ca}^{2+}$ & & & & & 2 & 6 & & & & & & & & \\
\hline $\mathrm{Mg}^{2+}$ & & & & & 2 & 8 & & & & & & & & \\
\hline $\mathrm{Fe}^{2+}$ & & & & & 2 & 6 & & & & & & & & \\
\hline $\mathrm{H}_{2} \mathrm{O}$ & -10.976 & -11.112 & -11.159 & -11.356 & & & & & & & & & & \\
\hline $\mathrm{NaCl}^{\circ}$ & -0.899 & -1.184 & -1.383 & -1.737 & 0 & 0 & & & & & & & & \\
\hline $\mathrm{KCl}^{\circ}$ & -0.271 & -0.590 & -0.841 & -1.236 & 0 & 0 & & & & & & & & \\
\hline $\mathbf{H C l}^{\circ}$ & -1.174 & -1.601 & -2.033 & -2.689 & 0 & 0 & & & & & & & & \\
\hline $\mathbf{K O H}^{\circ}$ & -0.849 & -1.080 & -1.187 & -1.446 & 0 & 0 & & & & & & & & \\
\hline $\mathrm{NaOH}^{\circ}$ & -0.615 & -0.840 & -0.922 & -1.164 & 0 & 0 & & & & & & & & \\
\hline $\mathrm{NaSO}_{4}^{-}$ & -2.725 & -3.055 & -3.219 & -3.549 & -1 & 4 & & & & & & & & \\
\hline $\mathrm{HSO}_{4}^{-}$ & -6.190 & -6.652 & -6.975 & -7.444 & -1 & 4 & & & & & & & & \\
\hline $\mathrm{KSO}_{4}^{-}$ & -3.003 & -3.351 & -3.541 & -3.899 & -1 & 4 & & & & & & & & \\
\hline $\mathrm{MgCl}^{+}$ & -2.216 & -2.594 & -2.809 & -3.180 & 1 & 8 & & & & & & & & \\
\hline $\mathrm{FeCl}^{+}$ & -6.598 & -6.476 & -6.153 & -5.745 & 1 & 6 & & & & & & & & \\
\hline $\mathrm{CaCl}^{+}$ & -2.647 & -3.061 & -3.298 & -3.692 & 1 & 6 & & & & & & & & \\
\hline $\mathrm{CaCl}_{2}^{\circ}$ & -2.932 & -3.633 & -4.048 & -4.783 & 0 & 0 & & & & & & & & \\
\hline $\mathrm{MgOH}^{+}$ & -5.197 & -5.610 & -5.800 & -6.149 & 1 & 8 & & & & & & & & \\
\hline $\mathrm{CaOH}^{+}$ & -4.724 & -5.139 & -5.308 & -5.635 & 1 & 6 & & & & & & & & \\
\hline $\mathrm{CaSO}_{4}^{\circ}$ & -4.874 & -5.424 & -5.638 & -6.173 & 0 & 0 & & & & & & & & \\
\hline $\mathrm{MgSO}_{4}{ }^{\circ}$ & -4.898 & -5.439 & -5.565 & -6.014 & 0 & 0 & & & & & & & & \\
\hline $\mathrm{FeSO}_{4}{ }^{\circ}$ & & -3.6129 & & -3.8140 & 0 & 0 & & & & & & & & \\
\hline
\end{tabular}


A mineral saturation index (SI) is a measure of the degree to which a solution is in equilibrium with respect to a specific mineral. It is defined as the ratio of the ion activity product (IAP or $Q$ ) for that mineral's solubility reaction to equilibrium solubility product $\mathrm{K}_{\mathrm{sp}}$ (Clark, 2015):

$$
S I=\frac{\mathrm{IAP}}{K_{s p}}
$$

when

$$
\begin{array}{lll}
S I>1 & \text { or } \log S I>0 & \text { the mineral is supersaturated } \\
S I=1 & \text { or } \log S I=0 & \text { the mineral is in equilibrium with solution } \\
S I<1 & \text { or } \log S I<0 & \text { the mineral is undersaturated }
\end{array}
$$

\section{Activity-activity diagrams}

Activity-activity diagrams show mineral stability fields in contact with the aqueous phase. They plot the activity of an un-associated free ion versus a second ion at the specified $\mathrm{T}$ and P. It is normal to plot the logarithm of the free ion's activity divided by the activity of the hydrogen ion $\left(10^{-\mathrm{pH}}\right)$ effectively allowing a third degree of freedom in the phase diagram (eg. Fig. 2.22). These diagrams provide a convenient graphical method of representing solution mineral saturations and for predicting the consequences of mineral reactions (Bowers et al., 1984).

In this study, experimental results have been plotted on these diagrams to evaluate the degree to which natural analogues match theoretical representations. Plotting multiple sample flow-through results allows monitoring of the path of fluid-rock interactions. These graphical representations can also give some information on the "speed" of the geochemical reactions. 
Figure 2.22. An example of an activity-activity diagram used in this study. This diagram plots the ratio of the free activity of Na divided by the activity of the hydrogen ion versus the same for potassium at $400^{\circ} \mathrm{C}$ and 500 bar. The diagram shows the mineral stability fields in contact with an aqueous phase for the minerals: albite (alb), K-feldspar (K-spar), paragonite (parag), muscovite (musc) and andalusite (and).

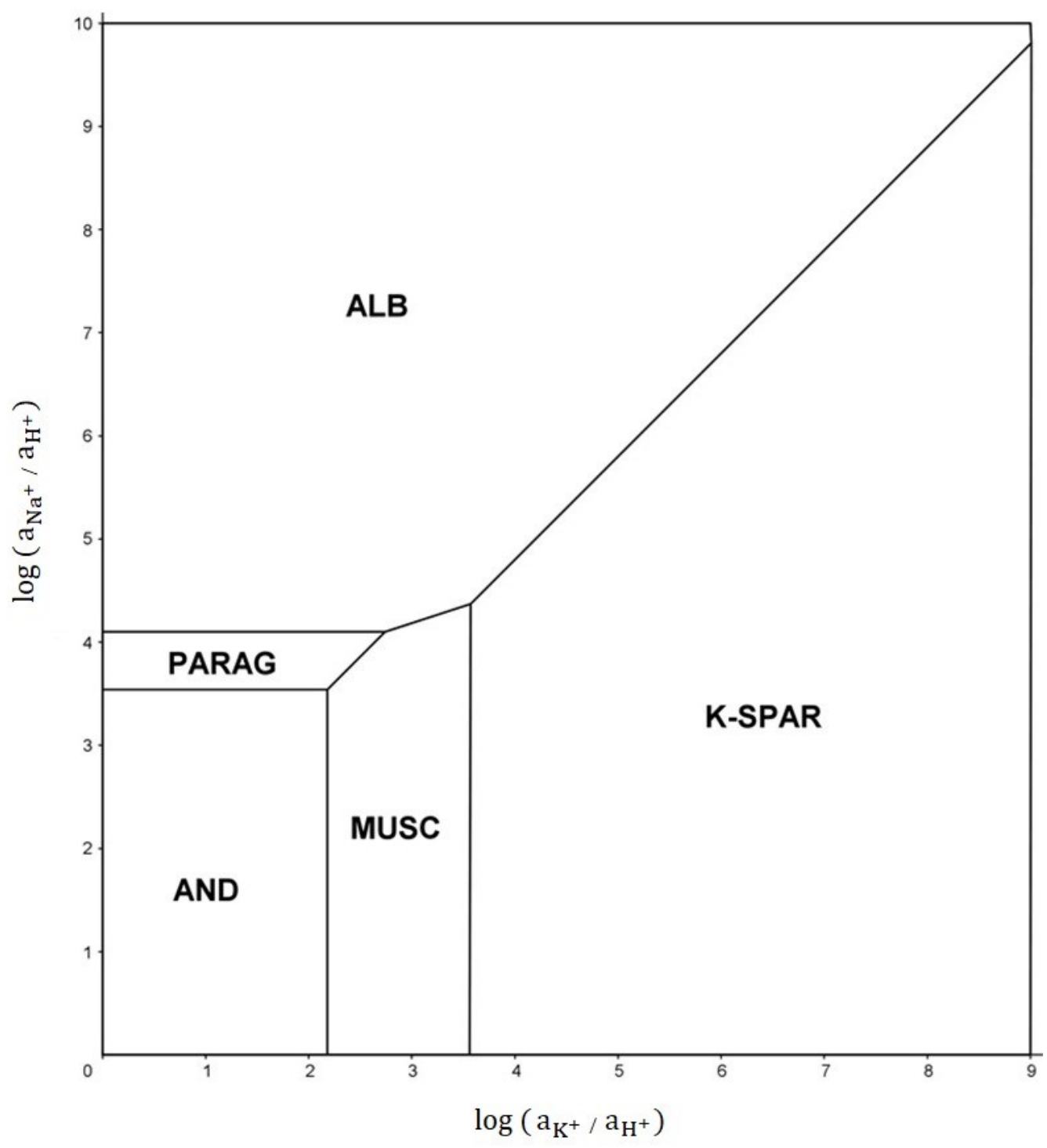




\subsection{References}

Berndt, M. E., and Seyfried, W. E., 1993, Calcium and sodium exchange during hydrothermal alteration of calcic plagioclase at $400^{\circ} \mathrm{C}$ and 400 bars: Geochimica et Cosmochimica Acta, v. 57, no. 18, p. 4445-4451.

Berndt, M. E., Seyfried, W. E., and Janecky, D. R., 1989, Plagioclase and epidote buffering of cation ratios in mid-ocean ridge hydrothermal fluids: Experimental results in and near the supercritical region: Geochimica et Cosmochimica Acta, v. 53, no. 9, p. 2283-2300.

Bethke, C., Farrell, B., and Yeakel, S., 2018, The Geochemist's Workbench, Version 12.0: GWB Essentials Guide. Aqueous Solutions, LLC, Champaign, Illinois, US.

Bethke, C., and Yeakel, S., 2009, Geochemist's Workbench: Release 8.0 GWB Essentials Guide, RockWare Incorporated.

Bethke, C., and Yeakel, S., 2015, GWB essentials guide: Aqueous Solutions, p. 149.

Bischoff, J. L., and Dickson, F. W., 1975, Seawater-basalt interaction at $200^{\circ} \mathrm{C}$ and 500 bars: Implications for origin of sea-floor heavy-metal deposits and regulation of seawater chemistry: Earth and Planetary Science Letters, v. 25, no. 3, p. 385-397.

Bischoff, J. L., and Seyfried, W. E., 1978, Hydrothermal chemistry of seawater from 25C to 350C: American Journal of Science, v. 278, no. 6, p. 838-860.

Bowers, T. S., Jackson, K. J., and Helgeson, H. C., 1984, Equilibrium Activity Diagrams: For Coexisting Minerals and Aqueous Solutions at Pressures and Temperatures to $5 \mathrm{~kb}$ and $600{ }^{\circ} \mathrm{C}$, Springer Berlin Heidelberg.

Clark, I., 2015, Groundwater Geochemistry and Isotopes. CRC Press

Gilles, B., Schott, J., and Loubet, M., 1987, Fundamental processes controlling the first stage of alteration of a basalt glass by seawater: an experimental study between $200^{\circ}$ and $320^{\circ} \mathrm{C}$ : Earth and Planetary Science Letters, v. 84, no. 4, p. 431-445.

Hajash, A., 1975, Hydrothermal processes along mid-ocean ridges: An experimental investigation: Contributions to Mineralogy and Petrology, v. 53, no. 3, p. 205-226.

Helgeson, H. C., 1969, Thermodynamics of hydrothermal systems at elevated temperatures and pressures: American journal of science, v. 267, no. 7, p. 729-804.

Helgeson, H. C., and Kirkham, D. H., 1974, Theoretical prediction of the thermodynamic behavior of aqueous electrolytes at high pressures and temperatures; I, Summary of the thermodynamic/electrostatic properties of the solvent: American Journal of Science, v. 274, no. 10, p. 1089-1198.

Mottl, M. J., and Holland, H. D., 1978, Chemical exchange during hydrothermal alteration of basalt by seawater-I. Experimental results for major and minor components of seawater: Geochimica et Cosmochimica Acta, v. 42, no. 8, p. 1103-1115.

Mottl, M. J., Holland, H. D., and Corr, R. F., 1979, Chemical exchange during hydrothermal alteration of basalt by seawater-II. Experimental results for Fe, Mn, and sulfur species: Geochimica et Cosmochimica Acta, v. 43, no. 6, p. 869-884.

Peate, D. W., Baker, J. A., Jakobsson, S. P., Waight, T. E., Kent, A. J. R., Grassineau, N. V., and Skovgaard, A. C., 2008, Historic magmatism on the Reykjanes Peninsula, Iceland: a snap-shot of melt generation at a ridge segment: Contributions to Mineralogy and Petrology, v. 157, no. 3, p. 359-382.

Seewald, J. S., and Seyfried, W. E., 1990, The effect of temperature on metal mobility in subseafloor hydrothermal systems: constraints from basalt alteration experiments: Earth and Planetary Science Letters, v. 101, no. 2, p. 388-403.

Seyfried Jr, W. E., and Bischoff, J. L., 1979, Low temperature basalt alteration by sea water: an experimental study at $70^{\circ} \mathrm{C}$ and $150^{\circ} \mathrm{C}$ : Geochimica et Cosmochimica Acta, v. 43, no. 12 , p. 1937-1947. 
Seyfried Jr, W. E., Gordon Peter, C., and Dickson Frank, W., 1979, A new reaction cell for hydrothermal solution equipment: American Mineralogist, v. 64, p. 646449.

Seyfried, W., and Bischoff, J. L., 1977, Hydrothermal transport of heavy metals by seawater: The role of seawater/basalt ratio: Earth and Planetary Science Letters, v. 34, no. 1, p. 71-77.

Seyfried, W. E., Berndt, M. E., and Janecky, D. R., 1986, Chloride depletions and enrichments in seafloor hydrothermal fluids: Constraints from experimental basalt alteration studies: Geochimica et Cosmochimica Acta, v. 50, no. 3, p. 469-475.

Seyfried, W. E., and Bischoff, J. L., 1981, Experimental seawater-basalt interaction at $300^{\circ} \mathrm{C}$, 500 bars, chemical exchange, secondary mineral formation and implications for the transport of heavy metals: Geochimica et Cosmochimica Acta, v. 45, no. 2, p. 135147.

Seyfried, W. E., Janecky, D., and Berndt, M. E., 1987, Rocking autoclaves for hydrothermal experiments: II. The flexible reaction-cell system, 216-239 p.:

Seyfried, W. E., and Janecky, D. R., 1985, Heavy metal and sulfur transport during subcritical and supercritical hydrothermal alteration of basalt: Influence of fluid pressure and basalt composition and crystallinity: Geochimica et Cosmochimica Acta, v. 49 , no. 12 , p. $2545-2560$.

Seyfried, W. E., and Mottl, M. J., 1982, Hydrothermal alteration of basalt by seawater under seawater-dominated conditions: Geochimica et Cosmochimica Acta, v. 46, no. 6, p. 985-1002.

Seyfried, W. E. J., Gordon, P. C., and Dickson, F. W., 1979, New reaction cell for hydrothermal solution equipment: Am. Mineral.; (United States), p. Medium: X; Size: Pages: 646-649.

Stefan Mroczek and Ed Mroczek (2017). EqSolvR: Chemical Equilibrium Solver. R package version 1.2.5. 


\section{Chapter 3: Basalt - Water Interactions under Hydrothermal Conditions}

\subsection{A brief introduction}

Water occurs ubiquitously throughout the Earth's crust where it can react with rocks at elevated temperatures and pressures. Of particular interest are basalt - water and basalt seawater interactions which have important applications to sub-seafloor environments and the evolution of hydrothermal discharges into the oceans. Despite the fundamental importance of reactions, there are relatively few experimental studies designed to provide insight into the chemistry of heterogeneous basalt - water equilibria. A number of basalt - water reactions and dissolution rates have been studied at subcritical and supercritical conditions with pure water using packed-bed reactors systems (Ronghua et al., 2000; Ronghua et al., 2002; Zhang et al., 2011; Zhang et al., 1990; Zhang et al., 2007). More recently, Zhang et al. (2015) studied the dissolution and reaction kinetics of basalt - water interaction up to $400^{\circ} \mathrm{C}$ and $23 \mathrm{MPa}$ using a packed-bed reactor.

In this chapter, we report the results of two experiments simulating basalt - water interaction carried out using a high T-P flow-through apparatus. These were named BW1 $400^{\circ} \mathrm{C} / 502$ bar (supercritical water) and BW2 $-350^{\circ} \mathrm{C} / 490$ bar (subcritical water).

Our results indicate that water reacts aggressively with the basalt both at supercritical and subcritical conditions. Major changes in solution chemistry are evident, in both experiments, after the temperature shift. These changes consist of: 1) an increase in solution of all major ions and generation of $\mathrm{H}_{2} \mathrm{~S}, \mathrm{SO}_{4}{ }^{2-}$ and $\mathrm{Cl}^{-}$; 2) moderate mobility of the trace elements in solution; and 3) the rise of $\mathrm{pH}$ to alkaline values. Major ion concentrations were higher at $350^{\circ} \mathrm{C}$ than at $400^{\circ} \mathrm{C}$ whereas the concentrations of the trace elements were lower. Analysis of the reacted basalt was conducted on grains collected both from the bottom and top positions in the Reactor at the conclusion of the experiments. Results show that the bottom portion of the Reactor (first 1-2 mm), located at the entry point of the unreacted fluid, was the most altered portion of the basalt. While the top portion (upper 1-2 mm), located at the exit point of the reacted fluid into Reactor, represented the least altered portion of the basalt.

\subsection{Results}

In this chapter the results are presented for the: 
1) major element analyses of experimental solutions;

2) trace element analyses of experimental solutions;

3) chemical, mineralogical and textural analyses of reacted basalt grains

Appendix B contains complete XRD, EMPA and SEM-EDS results as well as quantitative analyses for the reacted material for both experiments. Note that SEM-EDS and EMPA analysis cannot measure the hydrogen content. For this reason, all mineral chemistries were normalised to $100 \%$ anhydrous (ignoring water content), for both experiments.

\subsubsection{BW1: Basalt - water at $400^{\circ} \mathrm{C} / 502$ bar}

The first basalt - water experiment (BW1) ran for $913.5 \mathrm{hr}$. The first $144.2 \mathrm{hr}$ were at room temperature and 502 bar and the remaining $769 \mathrm{hr}$ were at $400^{\circ} \mathrm{C}$ and 502 bar. The flow rate was $1 \mathrm{ml} \mathrm{hr}^{-1}$ up to $819.1 \mathrm{hr}$ after which it was changed to $0.5 \mathrm{ml} \mathrm{hr}^{-1}$ for the remaining $94.4 \mathrm{hr}$. The flow-rate was set-up to guarantee the collection of enough solution for all chemical analyses at each approximately 24 hours interval. During this experiment, analyses of major ions were conducted for the total number (36) of the fluid samples collected. Analyses of trace elements were made for the first 30 fluid samples collected.

\subsubsection{Major element concentrations}

Appendix B lists the complete experimental parameters ( $T, P$, flow rate, chemistry). Figure 3.1 and Figure 3.2 show these results plotted against time in hours. The unreacted distilled water composition is shown at $\mathrm{t}=0$. Trace concentrations of $\mathrm{Ca}\left(0.01 \mathrm{mmol} \mathrm{kg}{ }^{-1}\right)$ and $\mathrm{K}\left(0.01 \mathrm{mmol} \mathrm{kg}^{-1}\right)$ were detected in this analysis. All other major elements were below detection limit.

During the room temperature $\left(21^{\circ} \mathrm{C}\right)$ period, no significant changes in solution composition are evident. The $\mathrm{pH}$ values are on average lower than the starting blank but are quite irregular. $\mathrm{Ca}$ and $\mathrm{K}$ remain stable reflecting the composition of the input solution.

The change in temperature to $400^{\circ} \mathrm{C}$ was initiated at 144 hours and took about 3 hours, thus only about $3 \mathrm{ml}$ of solution were in contact with the rock during heat-up. Major changes in solution chemistry are evident after the temperature shift.

Effluent quench pH (ambient temperature) slowly increases from just below 7 at 144 hours to about 9 by 450 hours. It remains near this alkaline value for the remainder of the experiment. The calculated in situ $\mathrm{pH}$ at $400^{\circ} \mathrm{C}$ declines from 7 after the temperature shift to 5.8 by the end of the experiment. 
$\mathrm{SiO}_{2}$ increases to $33.2 \mathrm{mmol} \mathrm{kg} \mathrm{kg}^{-1}$ (1994 ppm) which exceeds quartz saturation at $400^{\circ} \mathrm{C} / 500$ bar (1238 ppm, Supcrt92). Between 200 and 400 hours, silica concentration remains elevated but then after about 400 hours, the silica concentration rapidly decreases over about four days to $11 \mathrm{mmol} \mathrm{kg}^{-1}$ then declines gradually to $7.8 \mathrm{mmol} \mathrm{kg}^{-1}$ by the end of the experiment.

Both $\mathrm{Na}$ and $\mathrm{K}$ show a sharp increase after the temperature shift and then decline over the next five days before increasing again at 450 hours. After this, their behaviours diverge with $\mathrm{Na}$ slowly increasing to $1.8 \mathrm{mmol} \mathrm{kg}{ }^{-1}$ and remaining near this value for the remainder of the experiment. Potassium increases to a maximum of $0.35 \mathrm{mmol} \mathrm{kg}^{-1}$ and then declines, rapidly at first, then slowly to about $0.075 \mathrm{mmol} \mathrm{kg}^{-1}$ by 914 hours.

Al concentration remains at about $0.2 \mathrm{mmol} \mathrm{kg}^{-1}$ up to 450 hours after which it increases sharply to $0.75 \mathrm{mmol} \mathrm{\textrm {kg } ^ { - 1 }}$ within 24 hours, finally reaching a maximum of 0.9 mmol kg-1 at 850 hours. Ca concentration is elevated in only the first four samples after the temperature increase, after which it decreases to about $0.02 \mathrm{mmol} \mathrm{kg}^{-1}$ and remains near this value for the remainder of the experiment. $\mathrm{Fe}$ and $\mathrm{Mg}$ increase to 0.04 and $0.02 \mathrm{mmol} \mathrm{kg}^{-1}$, respectively, immediately after temperature increase and then decline to values near or below detection limit over the remaining time.

$\mathrm{SO}_{4}$ and $\mathrm{Cl}$ show similar behaviour to $\mathrm{Fe}$ with their maximum values of 0.2 and 0.5 mmol $\mathrm{kg}^{-1}$, respectively, occurring immediately after temperature increase, then decline to near detection limit values over the remainder of the experiment. $\mathrm{H}_{2} \mathrm{~S}$ concentration increases to a maximum of $0.085 \mathrm{mmol} \mathrm{kg}^{-1}$ two days after temperature increase. It then declines in a linear manner over the next ten days after which it remains at $0.01 \mathrm{mmol} \mathrm{kg}^{-1}$ for the remaining time.

The change in flow rate to $0.5 \mathrm{ml} \mathrm{hr}^{-1}$ (the final two effluent samples) did not cause any significant effects on elemental concentrations and $\mathrm{pH}$ values (i.e., fluid composition remains fairly stable during the last $94.4 \mathrm{hrs}$ of experiment). 
Figure 3.1. Major element concentrations in blank and effluent samples (mmol kg-1) versus time (hr) for the basalt-water experiment at $400^{\circ} \mathrm{C} / 502$ bar (BW1). Yellow symbols are blank sample composition of the water. Blue symbols are for effluents at room T/502 bar and 1.0 $\mathrm{ml} \mathrm{hr}{ }^{-1}$. Black symbols are effluents at $400^{\circ} \mathrm{C} / 502$ bar and $1.0 \mathrm{ml} \mathrm{hr}^{-1}$ flow rate. Red symbols are effluents at $400^{\circ} \mathrm{C} / 502 \mathrm{bar}$ and $0.5 \mathrm{ml} \mathrm{hr}^{-1}$ flow rate. In situ $\mathrm{pH}$ is the calculated $\mathrm{pH}$ at temperature. The limit of detection (LOD) is shown for each component.
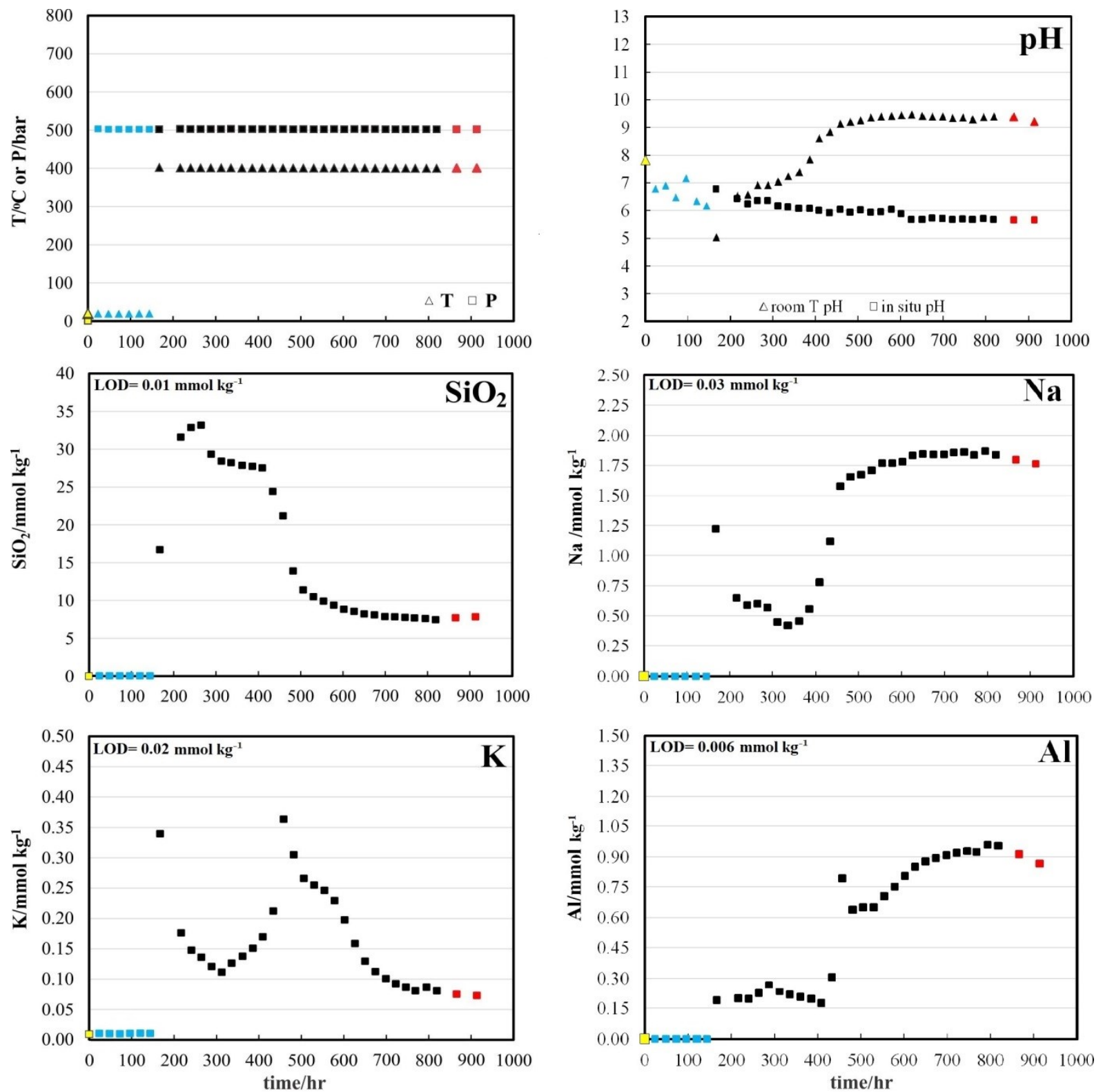

$\triangle \square$ blank

$\Delta \quad \operatorname{room} \mathrm{T} / 502 \mathrm{bar} / 1.0 \mathrm{ml} \mathrm{hr}^{-1}$

$\Delta \square 400^{\circ} \mathrm{C} / 502 \mathrm{bar} / 1.0 \mathrm{ml} \mathrm{hr}^{-1}$

$\triangle 400^{\circ} \mathrm{C} / 502 \mathrm{bar} / 0.5 \mathrm{ml} \mathrm{hr}^{-1}$ 
Figure 3.2. Major element concentrations in blank and effluent samples (mmol kg-1) versus time (hr) for the basalt-water experiment at $400^{\circ} \mathrm{C} / 502$ bar (BW1). Yellow symbols are blank sample composition of the water. Blue symbols are for effluents at room T/502 bar and 1.0 $\mathrm{ml} \mathrm{hr}{ }^{-1}$. Black symbols are effluents at $400^{\circ} \mathrm{C} / 502$ bar and $1.0 \mathrm{ml} \mathrm{hr}^{-1}$ flow rate. Red symbols are effluents at $400^{\circ} \mathrm{C} / 502 \mathrm{bar}$ and $0.5 \mathrm{ml} \mathrm{hr}^{-1}$ flow rate. The limit of detection (LOD) is shown for each component.
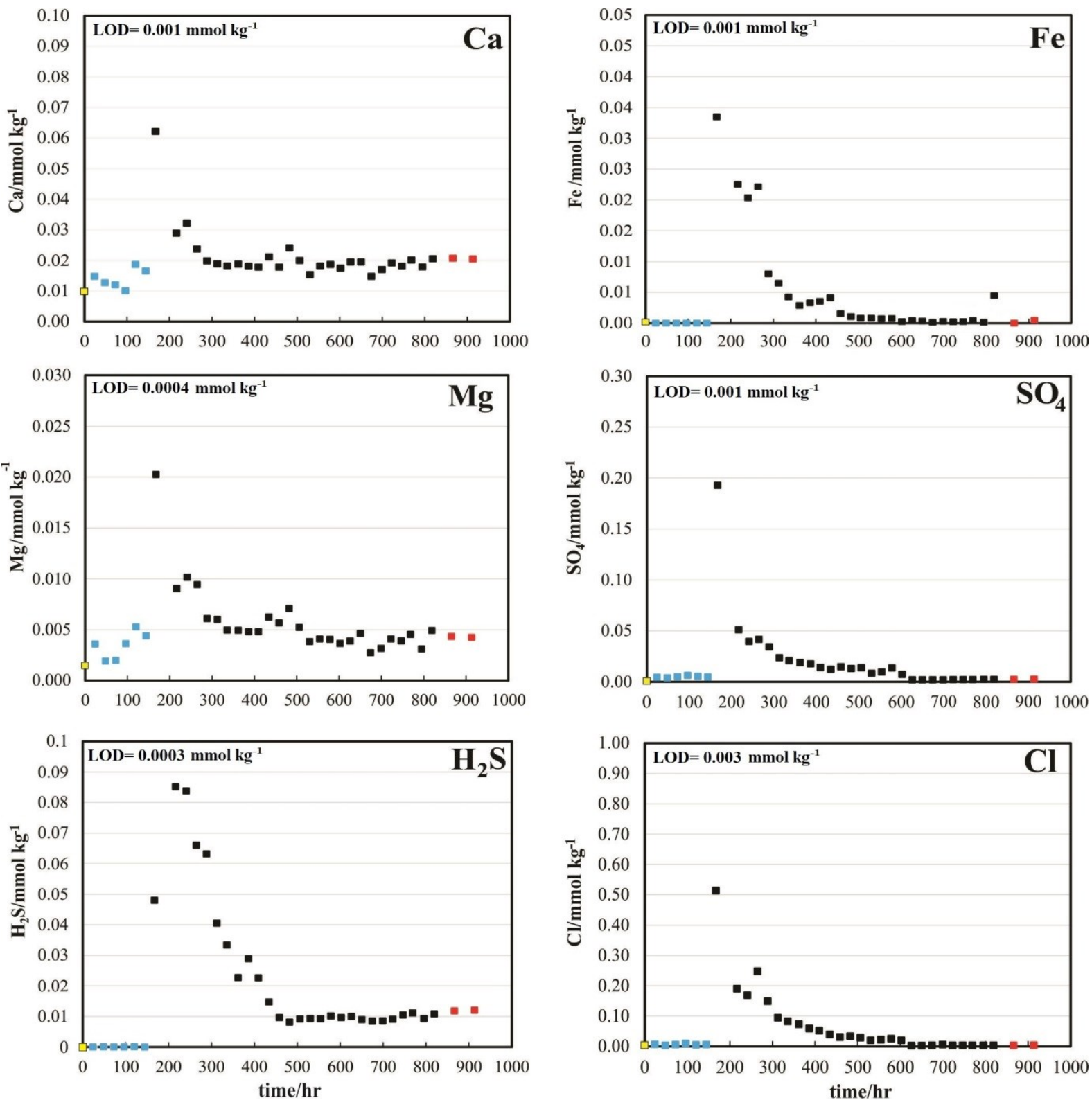

$\triangle \square$ blank

$\Delta$ room $\mathrm{T} / 502 \mathrm{bar} / 1.0 \mathrm{ml} \mathrm{hr}^{-1}$

$\Delta \square 400^{\circ} \mathrm{C} / 502 \mathrm{bar} / 1.0 \mathrm{ml} \mathrm{hr}^{-1}$

$\triangle \quad 400^{\circ} \mathrm{C} / 502 \mathrm{bar} / 0.5 \mathrm{ml} \mathrm{hr}^{-1}$ 


\subsubsection{Trace element concentrations}

Appendix B lists the complete trace element results. Figure 3.3 and Figure 3.4 show these results plotted against time in hours. The unreacted distilled water composition is shown at $\mathrm{t}=0$. All trace element concentrations are below detection limit in the starting solution.

During the room temperature $\left(\sim 21^{\circ} \mathrm{C}\right)$ period, measurable overall increases in $\mathrm{Co}, \mathrm{Ni}$, $\mathrm{Cr}$, Mo and, in particular, $\mathrm{Zn}$ are present. There are two elevated values for Au that are likely analytical noise. The high and erratic values of $\mathrm{Zn}$, that are similar in magnitude to those found for the remainder of the experiment, suggest an artefact of the method rather than meaningful values due to water-rock interaction. The concentrations of Ag remain below detection limit throughout the experiment.

After the temperature shift to $400^{\circ} \mathrm{C}$, several trace elements noticeably increase in concentration including $\mathrm{Co}, \mathrm{Au}, \mathrm{Ni}, \mathrm{Rb}, \mathrm{Cd}, \mathrm{Pb}, \mathrm{Cr}, \mathrm{Cu}, \mathrm{Mo}, \mathrm{Ba}$ and $\mathrm{Mn}$. For the remainder of the experiment several behaviours are observed. $\mathrm{Co}, \mathrm{Cr}$, and $\mathrm{Cu}$ decrease over 150 to 200 hours to relatively constant but elevated values. Mn declines below detection limit after 280 hours, while Mo decreases gradually over the whole experiment. Zn and Au display irregular values that show no particular trend over time. The $\mathrm{Pb}$ concentration increases slightly after temperature shift. V displays a gradual increase in concentration over time. Finally, Ba and $\mathrm{Rb}$ decline to minimums at 250 and 300 hours, respectively, after which they increase again to reach maximums at 330 and 400 hours, and then decrease over the remainder of the experiment. 
Figure 3.3. Trace element concentrations in blank and effluent samples ( $\mu$ mol kg-1) versus time (hr) for the basalt-water experiment at $400^{\circ} \mathrm{C} / 502$ bar (BW1). Yellow symbols are the blank sample composition of the water. Blue symbols are for effluents at room T/502 bar and $1.0 \mathrm{ml} \mathrm{hr}^{-1}$ flow rate. Black symbols are effluents at $400^{\circ} \mathrm{C} / 502$ bar and $1.0 \mathrm{ml} \mathrm{hr}^{-1}$ flow rate. In situ $\mathrm{pH}$ is the calculated $\mathrm{pH}$ at temperature. The limit of detection (LOD) is shown for each component.
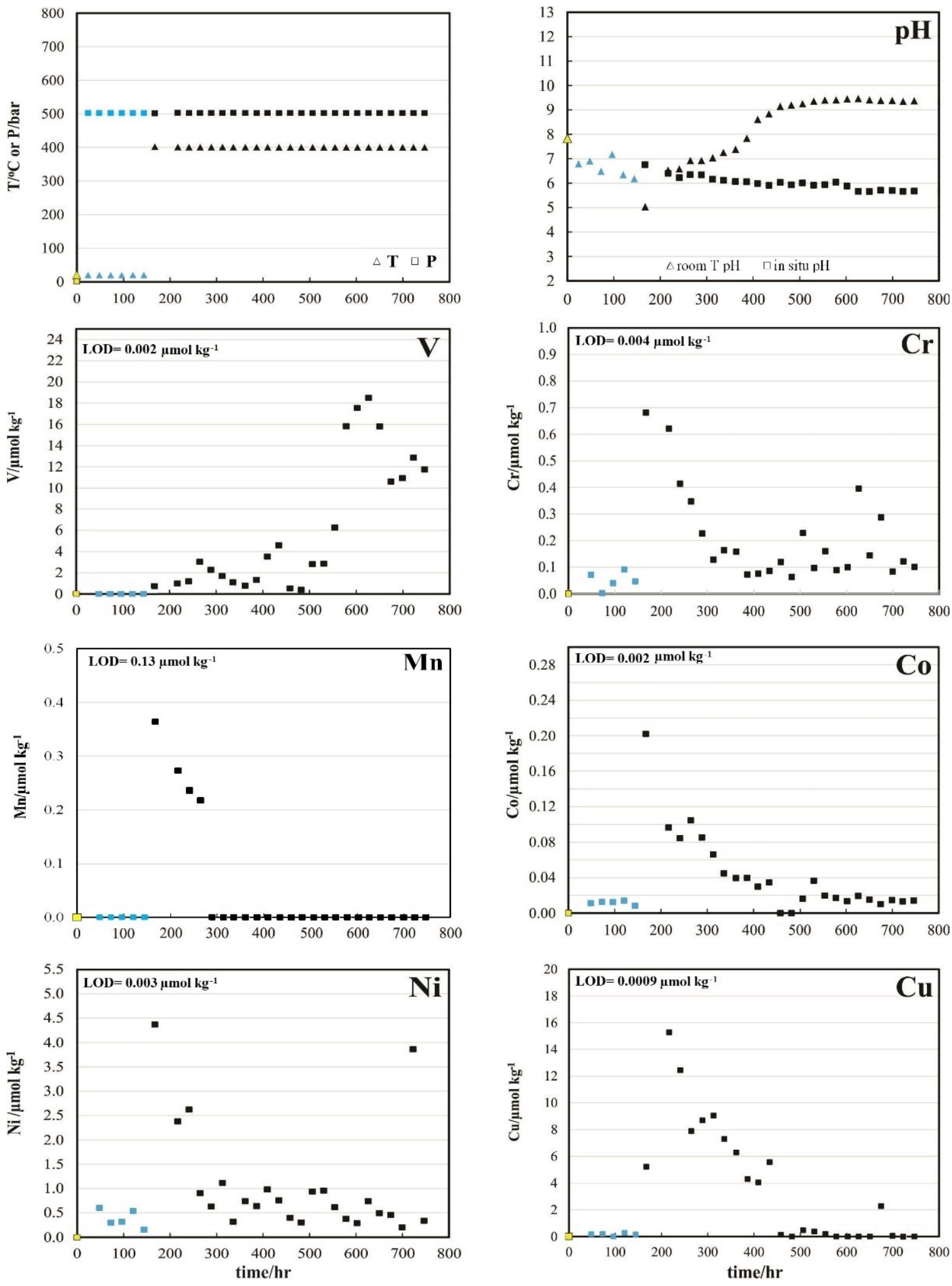

$\triangle \square$ blank

$\Delta$ room $\mathrm{T} / 502 \mathrm{bar} / 1.0 \mathrm{ml} \mathrm{hr}{ }^{-1}$

$\Delta \square 400^{\circ} \mathrm{C} / 502 \mathrm{bar} / 1.0 \mathrm{ml} \mathrm{hr}^{-1}$ 
Figure 3.4. Trace element concentrations in blank and effluent samples ( $\mu \mathrm{mol} \mathrm{kg} \mathrm{kg}^{-1}$ ) versus time (hr) for the basalt-water experiment at $400^{\circ} \mathrm{C} / 502$ bar (BW1). Yellow symbols are the blank sample composition of the water. Blue symbols are for effluents at room T/502 bar and $1.0 \mathrm{ml} \mathrm{hr}^{-1}$ flow rate. Black symbols are effluents at $400^{\circ} \mathrm{C} / 502$ bar and $1.0 \mathrm{ml} \mathrm{hr}^{-1}$ flow rate. The limit of detection (LOD) is shown for each component.
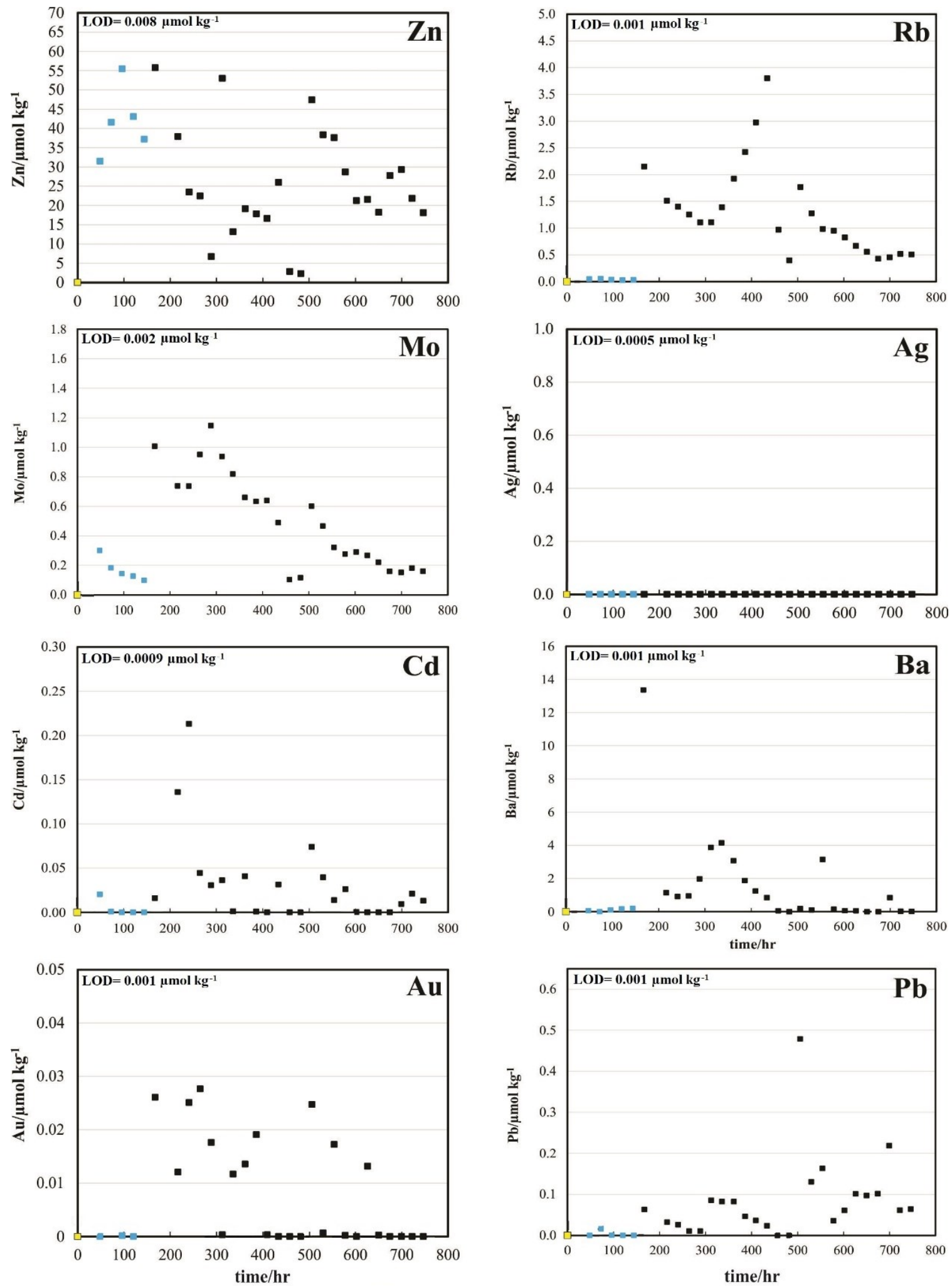

$\triangle \square$ blank

$\Delta$ room $\mathrm{T} / 502 \mathrm{bar} / 1.0 \mathrm{ml} \mathrm{hr}^{-1}$

$\Delta-400^{\circ} \mathrm{C} / 502 \mathrm{bar} / 1.0 \mathrm{ml} \mathrm{hr}^{-1}$ 


\subsubsection{Mineralogy and Texture of Reacted Basalt: Bottom of the Reactor (Portion 1)}

Upon the conclusion of the experiment, the reacted basalt grains were extracted from the Reactor onto absorbent paper. They were rinsed with distilled water to remove precipitated soluble salts such as $\mathrm{NaCl}$ and $\mathrm{KCl}$ and then air-dried. A portion of grains were collected from the bottom of the Reactor (Portion 1) and one portion was collected from the top of the Reactor (Portion 2) (Fig. 3.5). Note that no reacted grains in between Portion 1 and Portion 2 were collected for analysis. We estimate that there are more than 200,000 basalt grains in each experiment.

In this section we report the results of mineralogical and textural analysis of grains from the bottom of the Reactor (Portion 1). This portion is located at the entry point of the unreacted fluid into the Reactor.

Selected grains were mounted on aluminium stubs for textural analyses by SEM and several grains were epoxy-mounted and polished for SEM-EDS and EMPA analysis. Appendix B contains all SEM and EMPA results for Portion 1 (bottom of the Reactor).

Figure 3.5. Schematic diagram of the Reactor showing position (Portion 1 and Portion 2) of reacted basalt grains shown in SEM photographs and the position of the basalt block for the BW1 experiment. The picture is not to scale.

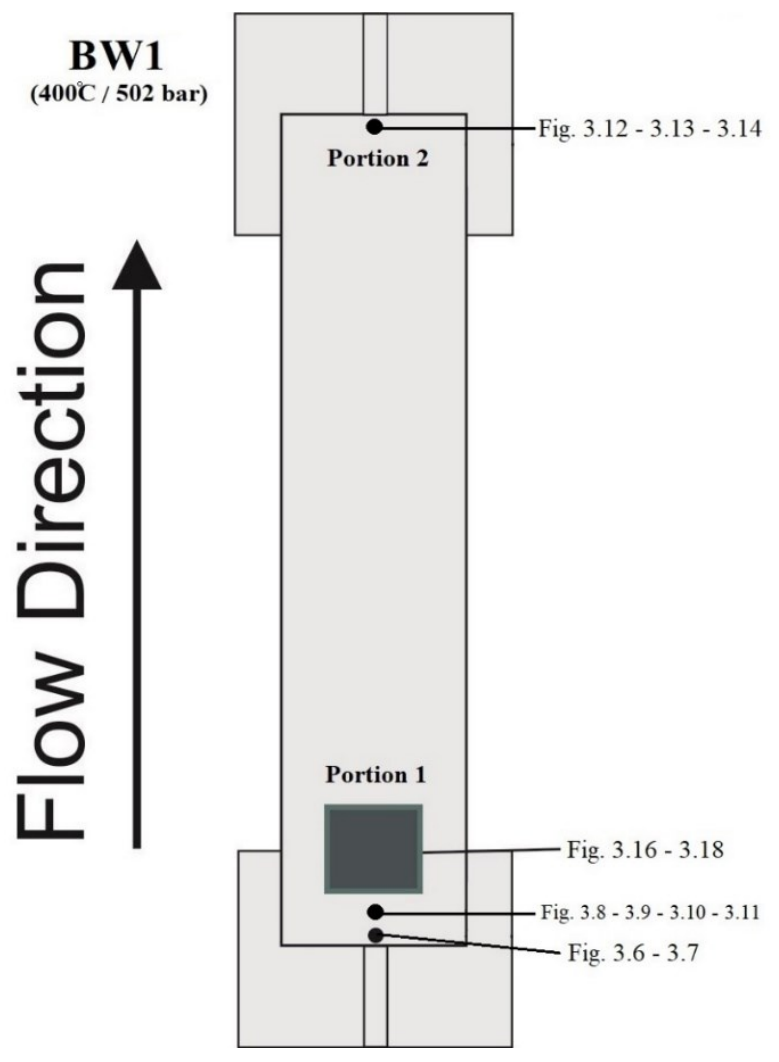




\section{SEM-EDS and EMPA analysis}

Grains from immediately adjacent to the fluid entry point of Portion 1 were examined. Extensive alteration of the basalt leading to strong residual Ca-metasomatism (in the sense that the resulting phases are predominantly $\mathrm{Ca}$ minerals, i.e., $\mathrm{Ca}$ was not added from the fluid) was observed. The minerals of secondary origin detected were: anorthite, wollastonite, grossular, chlorite and magnetite. The presence of remnant, unreacted primary bytownite, clinopyroxene, olivine, and titanomagnetite (Table 3.1) was noted.

Table 3.1. Mineral assemblage detected by EMPA and SEM-EDS analysis of reacted grains extracted from bottom (Portion 1) of the Reactor after the BW1 experiment. Appendix B contains all SEM and EMPA results for this portion of the rock.

\begin{tabular}{|c|c|c|c|}
\hline Type of Analysis & $\begin{array}{l}\text { Analysis } \\
\text { Material }\end{array}$ & $\begin{array}{l}\text { Mineral } \\
\text { Identified }\end{array}$ & $\begin{array}{c}\text { Average } \\
\text { Mineral Composition }\end{array}$ \\
\hline EMPA & polished grains & Anorthite & $\mathrm{Ca}_{0.98} \mathrm{Al}_{2} \mathrm{Si}_{2} \mathrm{O}_{8}\left(\mathrm{An}_{98}-\mathrm{Ab}_{2}\right)$ \\
\hline SEM-EDS & polished grains & Bytownite & $\mathrm{Ca}_{0.68} \mathrm{Na}_{0.28} \mathrm{Si}_{2.40} \mathrm{Al}_{1.65} \mathrm{O}_{8}\left(\mathrm{An}_{71}-\mathrm{Ab}_{29}\right)$ \\
\hline EMPA & polished grains & Augite & $\mathrm{Ca}_{0.70} \mathrm{Mg}_{0.83} \mathrm{Fe}_{0.36} \mathrm{Si}_{2} \mathrm{O}_{6}$ \\
\hline EMPA & polished grains & Forsterite & $\mathrm{Mg}_{1.4} \mathrm{Fe}_{0.6} \mathrm{SiO}_{4}\left(\mathrm{Fo}_{70}-\mathrm{Fa}_{30}\right)$ \\
\hline SEM-EDS & polished grains & Titanomagnetite & $\mathrm{Fe}^{2+}\left(\mathrm{Fe}^{3+}, \mathrm{Ti}\right)_{2} \mathrm{O}_{4}$ \\
\hline SEM-EDS & polished grains & Magnetite & $\mathrm{Fe}^{3+} \mathrm{Fe}^{2+}{ }_{2} \mathrm{O}_{4}$ \\
\hline EMPA & polished grains & Chlorite & $\begin{array}{c}\mathrm{Mg}_{3.6} \mathrm{Fe}_{1.4} \mathrm{Al}_{0.8} \mathrm{Si}_{3.4} \mathrm{Al}_{0.5} \mathrm{O}_{10}(\mathrm{OH})_{8} \\
\text { (calculated based on the anhydrous composition with } 14 \text { oxygens) }\end{array}$ \\
\hline EMPA & polished grains & Wollastonite & $\mathrm{Ca}_{0.98} \mathrm{Si}_{0.96} \mathrm{O}_{3}$ \\
\hline EMPA & polished grains & Grossular & $\mathrm{Ca}_{6.32} \mathrm{Mg}_{0.16} \mathrm{Ti}_{0.27} \mathrm{Fe}_{1.87} \mathrm{Al}_{1.75} \mathrm{Si}_{6.23} \mathrm{O}_{24}$ \\
\hline
\end{tabular}

Figure 3.6 shows SEM images of the most reacted grains from the position immediately next to the entry point of the fluid (Portion1, Fig. 3.5). Wollastonite appears in groupings of acicular crystals, surrounding and surrounded by euhedral grossular garnet crystals occurring in dense aggregates. Anorthite occurs as anhedral fenestral pseudomorphs of plagioclase. Chlorite appears as aggregates of dense flakes in botryoidal masses. The intense alteration indicates that this is the most reacted portion of the basalt coinciding with the entry point of the unreacted fluid. Petrographic observation shows that the wollastonite lathes are white in colour while the garnets are brown, common with grossular (composition confirmed by EMPA analysis).

Figure 3.7 shows SEM backscatter images and EDS maps of a polished mount of one of the grains described above. The grain is highly corroded with primary clinopyroxene (violet), titanomagnetite (green), and minor amounts of remnant plagioclase remaining. Wollastonite laths (pink acicular) fill the void spaces left by primary plagioclase. The 
hydrothermal (secondary) plagioclase is anorthitic, however, relicts of the primary bytownite were also found by SEM-EDS. Clinopyroxene appears relatively unaffected when compared with the plagioclase. SEM-EDS analysis confirm the presence of primary titanomagnetite as well as the formation of secondary magnetite. 
Figure 3.6. (a-f) SEM images of reacted grains collected from the immediately adjacent to the fluid entry point (bottom, Portion 1) after the BW1 experiment (minerals were identified by SEM-EDS analysis): (a) grain entirely covered by wollastonite (Wo) occurring in groupings of acicular crystals and by garnet (Grt) which appears in well-formed dodecahedral crystals; (b) clusters of garnet crystals with sparse wollastonite; (c) enlargement of area in (b) (red rectangle) showing in more detail the wollastonite and garnet; (d) secondary plagioclase of anorthitic (An) composition, wollastonite (Wo) and visibly altered primary clinopyroxene (Cpx); ): (e) a reacted grain surface (enlargement) showing acicular wollastonite (Wo), euhedral garnet (Grt), and relict clinopyroxene (Cpx); (f) grain surface completely replaced by chlorite appearing as botryoidal masses composed of densely intergrown flakes.
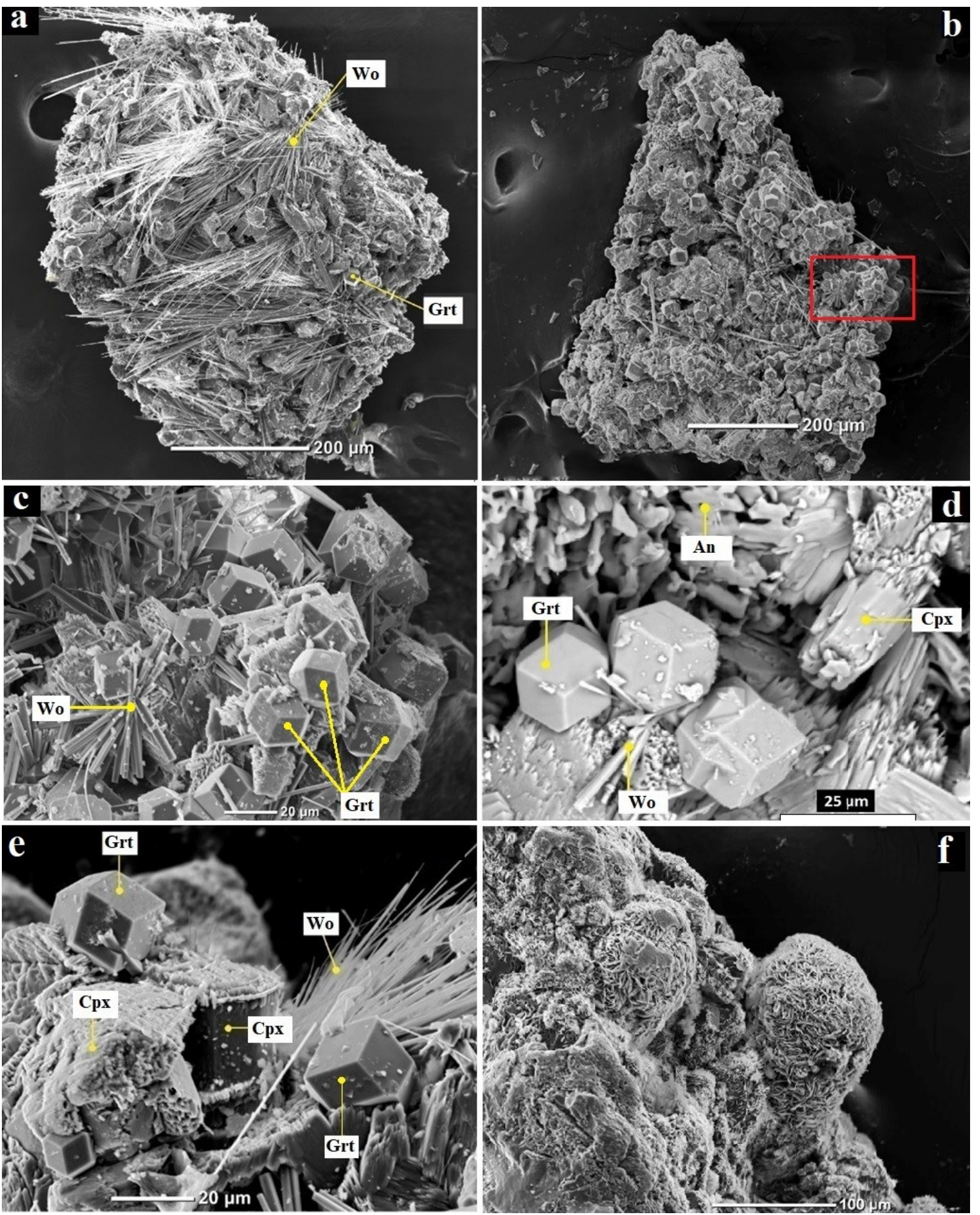
Figure 3.7. SEM backscatter image and EDS compositional maps of an epoxy-mounted, polished grain from the bottom portion of the BW1 experiment: (a) backscatter image; (b) composite colour image combining the backscatter image and elemental maps for c) Fe in green, d) $\mathrm{Mg}$ in blue, and e) $\mathrm{Ca}$ in red. The composite image shows needles of wollastonite (pink acicular) and primary clinopyroxene (violet), plagioclase (anhedral pink remnants), and Fe oxide (green).

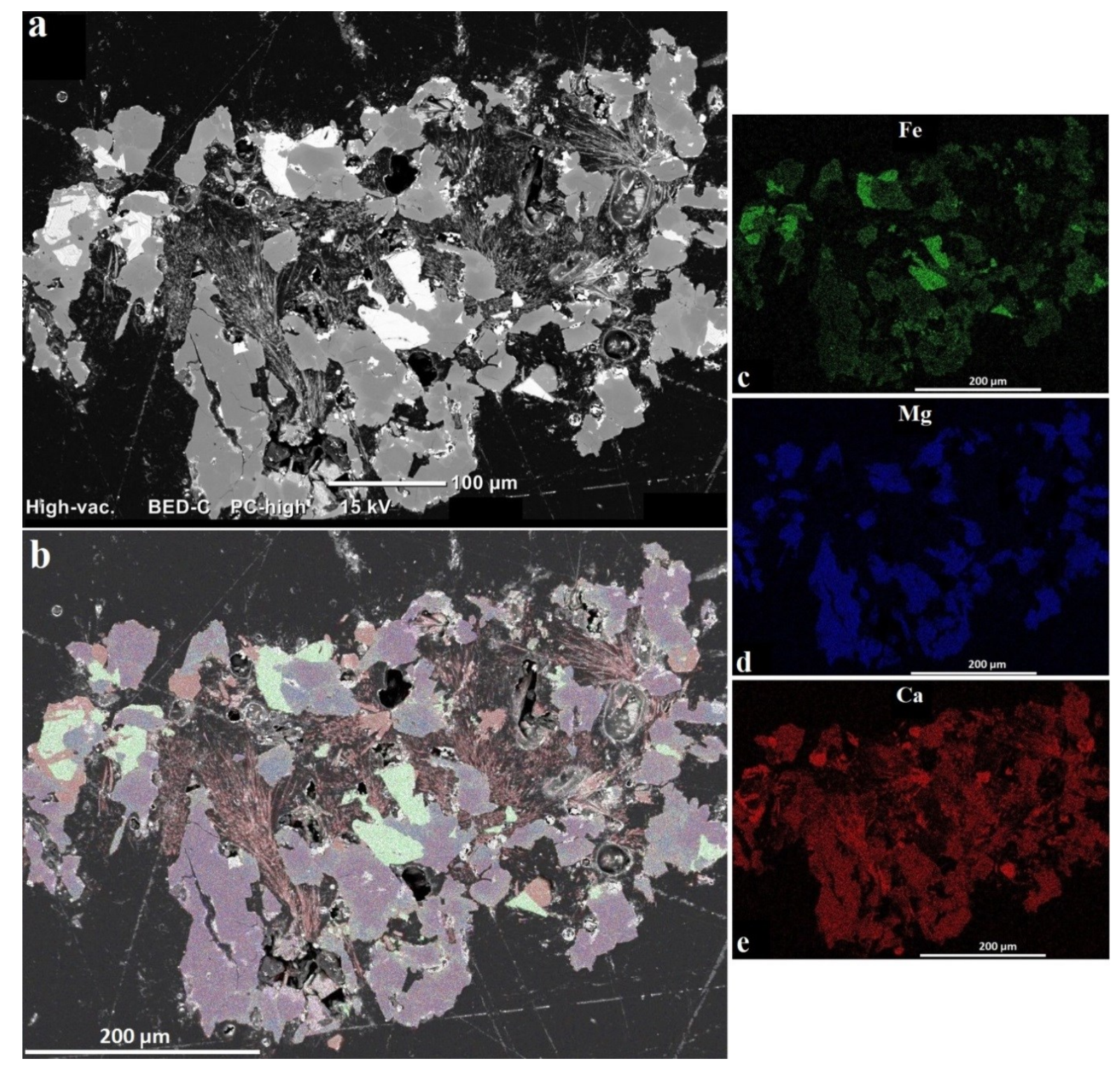

Figure 3.8 shows SEM backscatter images and EDS maps of a polished mount of one grain from about $2 \mathrm{~mm}$ further up the reactor (Portion 1) (Fig. 3.5). This grain shows the presence of garnet (pink in Fig. 3.8c) and plagioclase (green). No wollastonite is observed. Primary clinopyroxene is relatively unaltered while plagioclase is clearly altered but to a lesser extent than the grain in Figure 3.7a. The plagioclase displays a corroded fenestral texture and is anorthitic in composition. Titanomagnetite is unaltered. 
Figure 3.9 shows a grain composed originally entirely of olivine (red) located from the same position in the Reactor as the previous grain. The grain is surrounded by a thick coating of chlorite (violet).

Figure 3.10a-e shows a further reacted grain from the same position in the Reactor as the above grains. In this grain the corroded nature of the plagioclase lathes is evident leaving a desiccated, fenestral texture. The plagioclase is anorthitic in composition with remnants of bytownite present, as observed in the large lath located inside the red square. Olivine (lime green) and titanomagnetite (white) appear internally unaffected. Close-up backscatter images of this grain are shown in Figure 3.10f, g. Clinopyroxene is relatively unaltered, however, the grain has coating of chlorite.

Figure 3.11 shows a further grain from a similar position to the above. This grain shows secondary chlorite with intergrowths of secondary magnetite.

Figure 3.8. SEM backscatter and EDS compositional maps of an epoxy-mounted, polished grain from the bottom portion of the BW1 experiment: (a) backscatter image of entire grain; (b) backscatter image of rectangular area in (a); (c) composite colour image combining the backscatter image and the elemental maps for c) $\mathrm{Ca}$ in red, d) $\mathrm{Al}$ in green, and e) Fe in blue. The image shows remnant anorthite (green) and two crystals of garnet (pink). The Fe elemental map shows that there is a detectable concentration of Fe in the garnet.
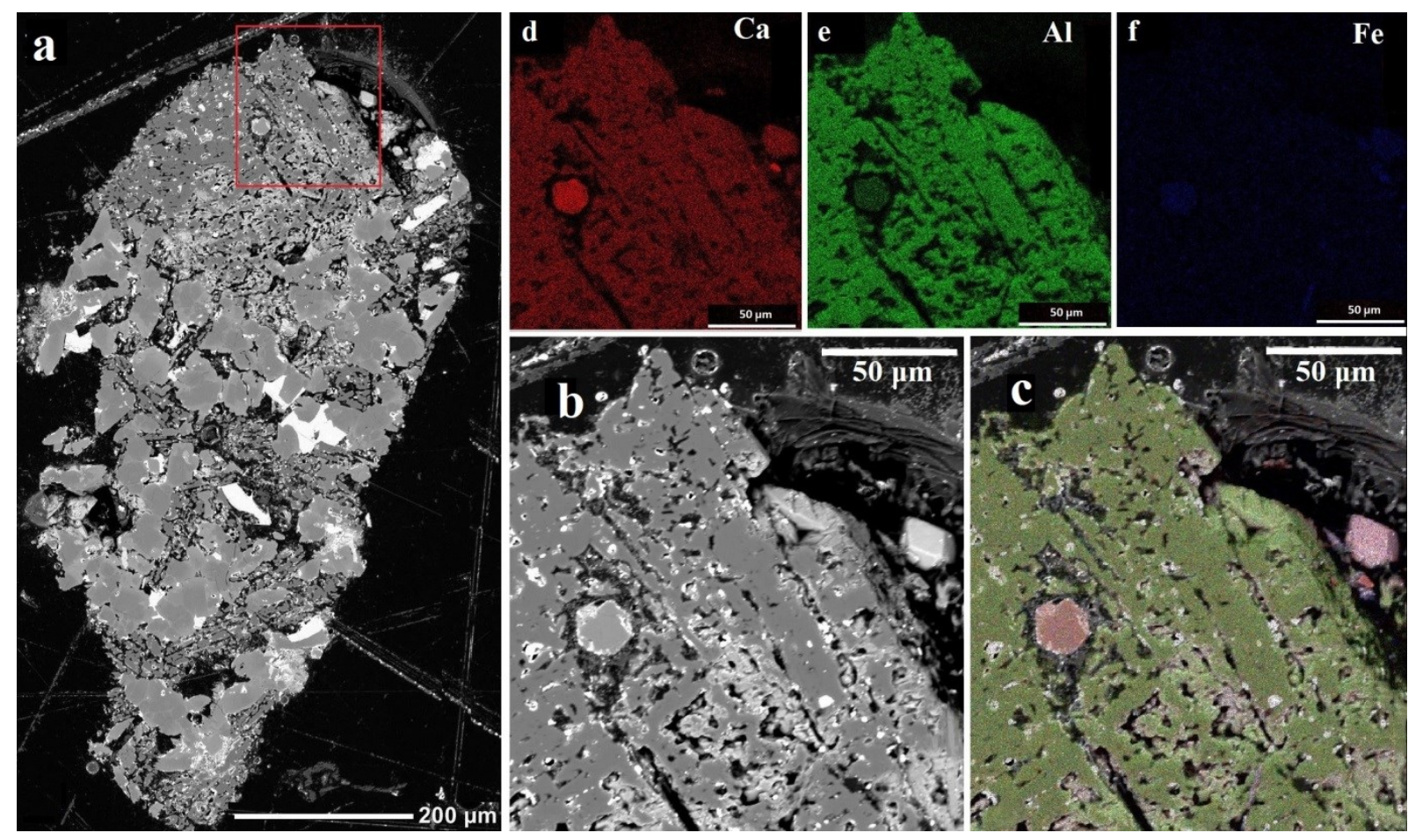
Figure 3.9. SEM backscatter and EDS compositional maps of an epoxy-mounted, polished grain of olivine from the bottom portion of the BW1 experiment: (a) backscatter image of entire grain; (b) composite colour image combining the backscatter image and the elemental maps for c) $\mathrm{Mg}$ in red, d) $\mathrm{Al}$ in blue, and e) Fe in green. The composite image shows remnant olivine (red) and a coating of chlorite (violet).
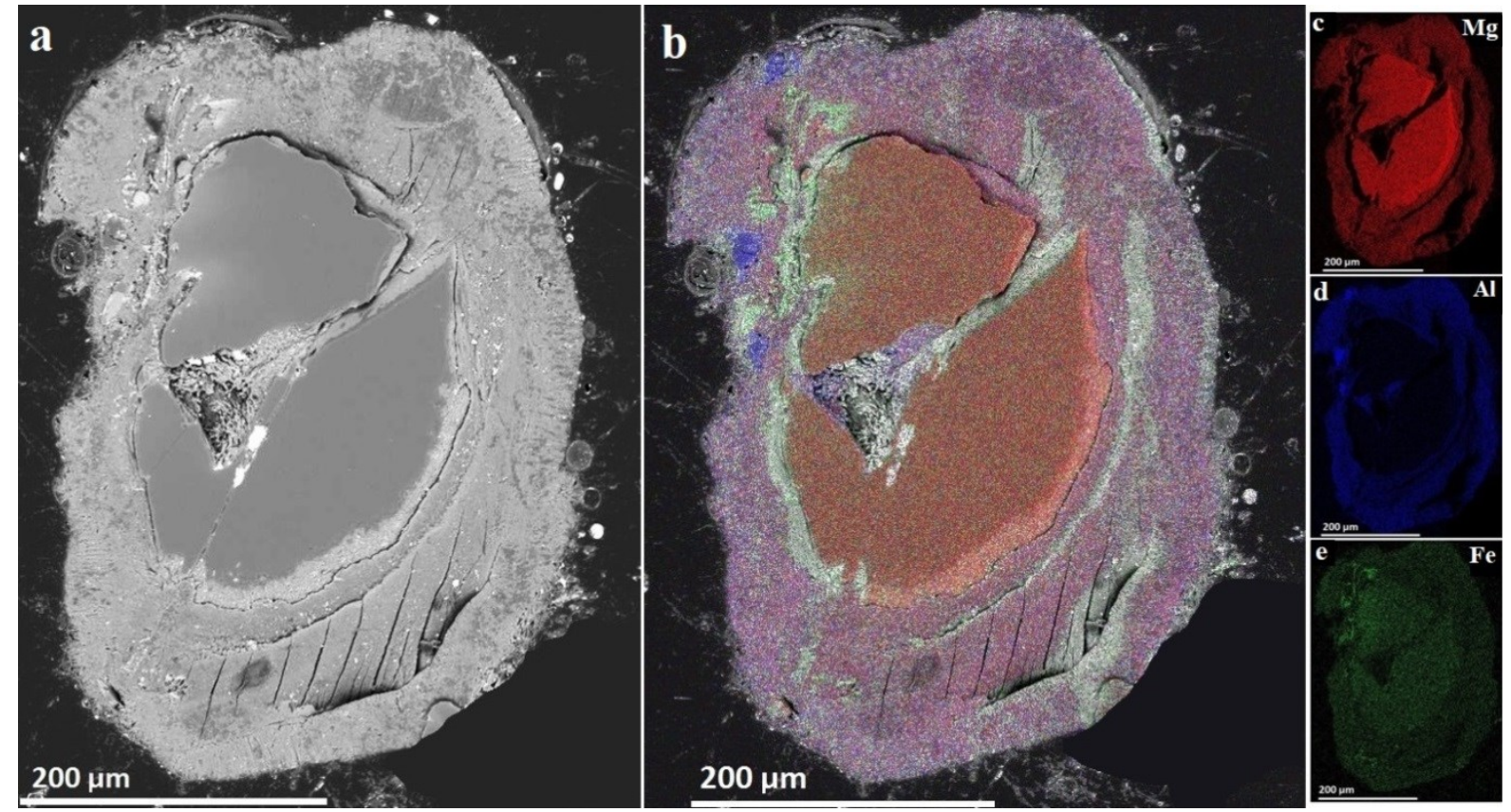
Figure 3.10. (a-e) SEM backscatter and EDS compositional maps of an epoxy-mounted, polished grain collected from about 2 mm further up the Reactor (bottom, Portion 1) after the BW1 experiment: (a) backscatter image of entire grain; (b) composite colour image combining the backscatter image and the elemental maps for c) $\mathrm{Mg}$ in green, d) Fe in red, and e) $\mathrm{Ca}$ in blue. The image shows highly-altered plagioclase (blue), relatively unaltered clinopyroxene (turquoise), Fe oxides (red), and olivine (yellow green). (f-g) SEM backscatter images of the two red rectangular areas in (a): (f) top of grain showing secondary plagioclase of anorthitic composition (An), primary clinopyroxene $(\mathrm{Cpx})$, a remnant plagioclase of bytownite composition (Byt), grain edge coating of chlorite (Chl), and Fe-Ti oxide (Tnt); (g) bottom of grain showing extensive alteration of plagioclase to anorthite, a remnant lath of plagioclase of bytownite composition, chlorite, and Fe-Ti oxide.
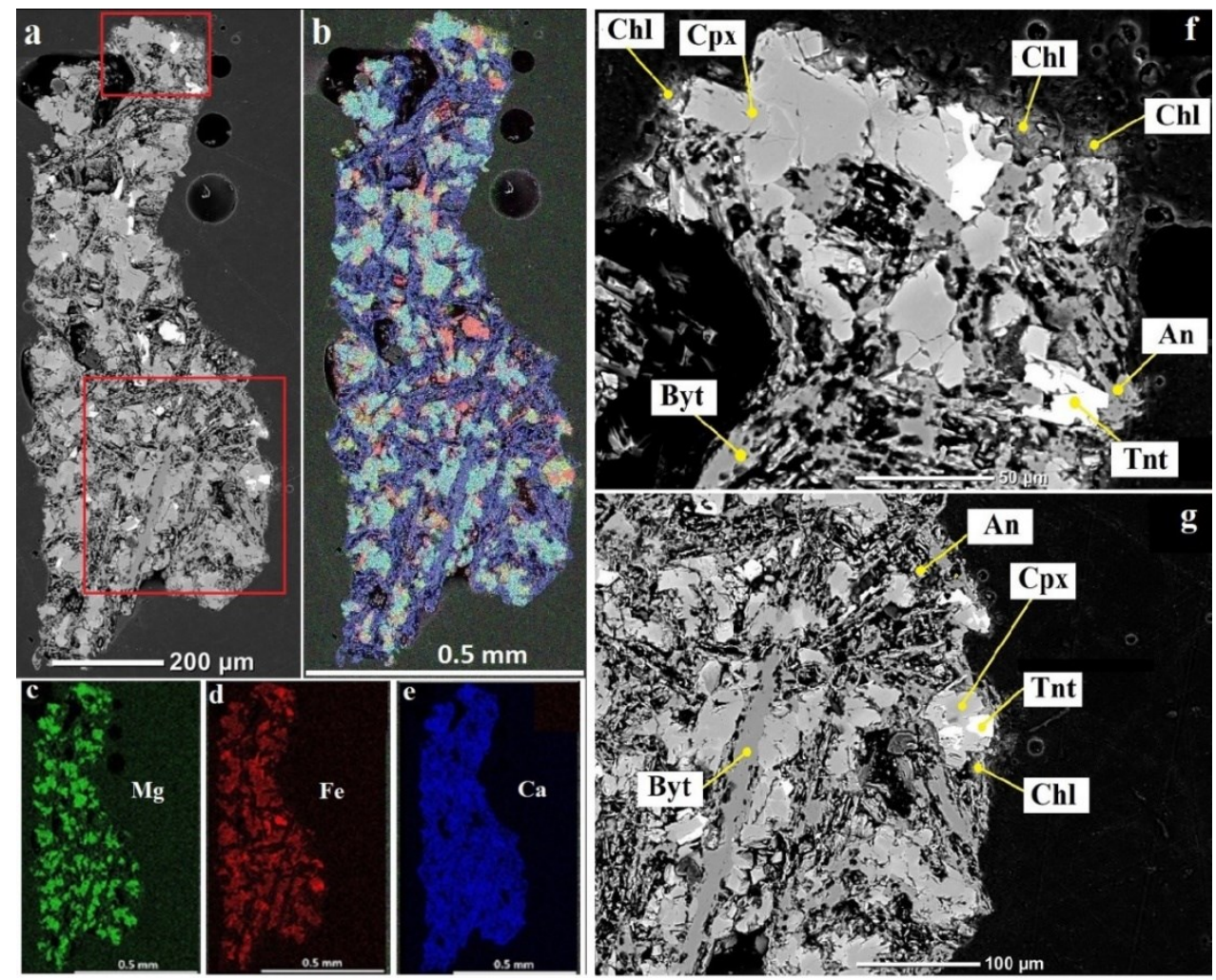

Figure 3.11. SEM backscatter image of a reacted grain showing secondary plagioclase of anorthitic composition (An), primary clinopyroxene (Cpx), chlorite (Chl), primary Fe-Ti oxide (Tnt), and secondary magnetite (Mag).

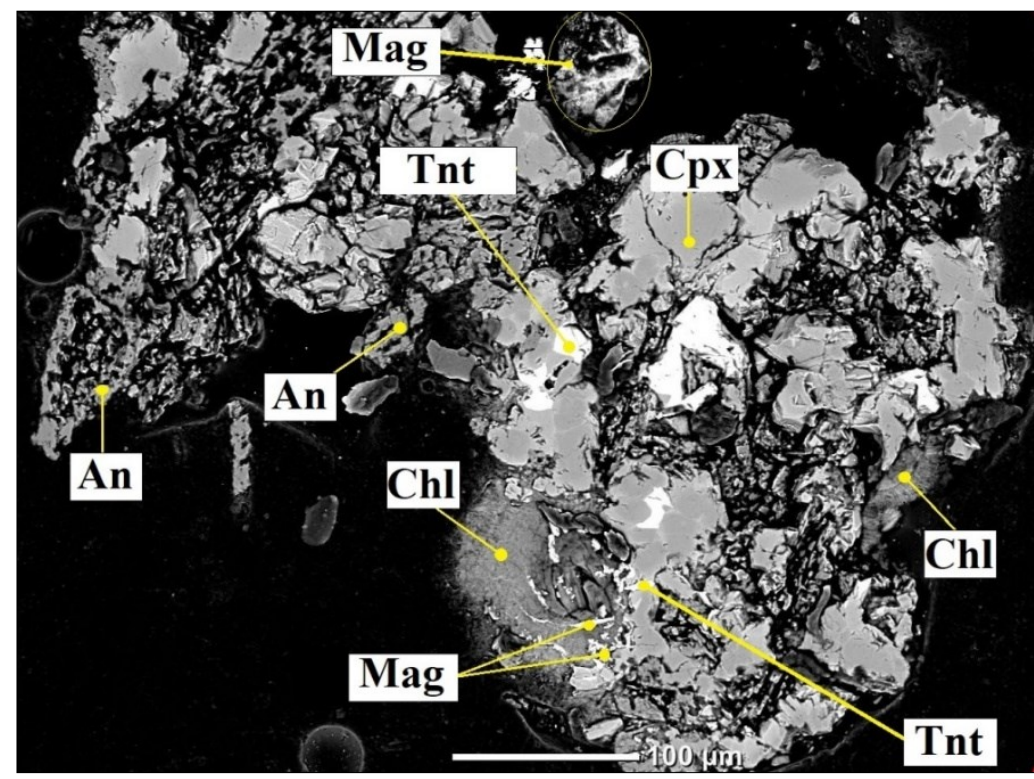




\subsubsection{Mineralogy and Texture of Reacted Basalt: Top of the Reactor (Portion 2)}

Selected grains were taken of the rock basalt immediately next to the exit point of the fluid (Portion 2, Fig. 3.5). These were mounted on aluminium stubs for textural analyses by SEM. Selected grains were also mounted in epoxy and polished for SEM-EDS analysis. Appendix B lists complete results.

\section{SEM-EDS analysis}

Several grains adjacent to the fluid exit point were examined (Fig. 3.5). The results confirm a lower grade of alteration of the basalt grains when compared with the bottom portion of the Reactor (Portion 1). Minerals of secondary origin detected were: plagioclase of anorthitic composition, chlorite, a K-Na-Mg-Fe aluminosilicate and titanite. The data also confirm the presence of the primary, unreacted minerals clinopyroxene, olivine, and titanomagnetite (Table 3.2).

Figure 3.12 shows the surface texture of grains from the top portion of the vessel. EDS backscatter images at low magnification show the presence of relict clinopyroxene visibly altered, secondary plagioclase of anorthitic composition, the K-Na-Mg-Fe aluminosilicate and titanite. In detail, anorthite shows an allotriomorphic habit, with no crystal-faces boundaries, while titanite appears as euhedral crystals. The $\mathrm{K}-\mathrm{Na}-\mathrm{Mg}-\mathrm{Fe}$ aluminosilicate forms dense foliated masses. No evidence of wollastonite and/or garnet was found during analysis.

Figure 3.13 and Figure 3.14 show SEM backscatter images and EDS maps for two examples of epoxy-mounted, polished grains collected from the top portion in the Reactor. The lower intensity of hydrothermal alteration is evident when compared with grains from near the bottom of the Reactor. Primary minerals appear moderately affected by the hydrothermal activity. Also present is the $\mathrm{K}-\mathrm{Na}-\mathrm{Mg}-\mathrm{Fe}$ aluminosilicate composition that replaces olivine (Fig. 3.14c). Secondary Fe oxide was not observed in these grains. 
Table 3.2. Mineral assemblage found during analysis of reacted grains extracted from top of the Reactor (Portion 2) after the BW1 experiment. Analysis is made by SEM-EDS. Appendix B contains all SEM and EMPA results for this portion of the rock.

\begin{tabular}{|c|c|c|c|}
\hline $\begin{array}{l}\text { Type of } \\
\text { Analysis }\end{array}$ & $\begin{array}{l}\text { Analysis } \\
\text { Material }\end{array}$ & $\begin{array}{c}\text { Mineral } \\
\text { Identified }\end{array}$ & $\begin{array}{c}\text { Average } \\
\text { Mineral Composition }\end{array}$ \\
\hline SEM-EDS & polished grains & Bytownite & - \\
\hline SEM-EDS & polished grains & Augite & $\mathrm{Ca}_{0.58} \mathrm{Mg}_{0.87} \mathrm{Fe}_{0.47} \mathrm{Al}_{0.1} \mathrm{Si}_{2} \mathrm{O}_{6}$ \\
\hline SEM-EDS & polished grains & Forsterite & $\mathrm{Mg}_{1.2} \mathrm{Fe}_{0.8} \mathrm{SiO}_{4}\left(\mathrm{Fo}_{60}-\mathrm{Fa}_{40}\right)$ \\
\hline SEM-EDS & polished grains & Titanomagnetite & $\mathrm{Fe}^{2+}\left(\mathrm{Fe}^{3+}, \mathrm{Ti}_{2}\right)_{4}$ \\
\hline SEM-EDS & polished grains & Celadonite & $\begin{array}{l}\mathrm{K}_{0.27} \mathrm{Na}_{0.14} \mathrm{Mg}_{1.9} \mathrm{Fe}_{0.9} \mathrm{Al}_{0.26} \mathrm{Si}_{3.19} \mathrm{Al}_{0.81} \mathrm{O}_{10}(\mathrm{OH})_{2} \\
\text { (calculated based on the anhydrous composition with } 11 \text { oxygens) }\end{array}$ \\
\hline SEM-EDS & grains surface & Celadonite & $\begin{array}{l}\mathrm{K}_{0.39} \mathrm{Na}_{0.36} \mathrm{Mg}_{1.5} \mathrm{Fe}_{1.45} \mathrm{Al}_{0.12} \mathrm{Si}_{3.0} \mathrm{Al}_{0.98} \mathrm{O}_{10}(\mathrm{OH})_{2} \\
\text { (calculated based on the anhydrous composition with } 11 \text { oxygens) }\end{array}$ \\
\hline SEM-EDS & grain surface & Anorthite & $\mathrm{Ca} 0.84 \mathrm{Al}_{2} \mathrm{Si}_{2} \mathrm{O}_{8}\left(\mathrm{An}_{97}-\mathrm{Ab}_{3}\right)$ \\
\hline SEM-EDS & grain surface & Sphene & $\mathrm{Ca}_{0.99} \mathrm{Ti}_{0.77} \mathrm{Al}_{0.24} \mathrm{SiO}_{5}$ \\
\hline
\end{tabular}

SEM analyses of the K-Na-Mg-Fe aluminosilicate are shown in Table 3.3. It is possible that these growths (Fig. 3.14c) are a mixture of two or more phases. However, repeat SEM-EDS analyses, made both on epoxy-mounted polished grains and during morphology examination, show the mineral to be composed of fairly consistent concentrations of iron, aluminium, silica and magnesium with a significant concentration of sodium and potassium but no calcium. The presence of $\mathrm{Na}_{2} \mathrm{O}$ and $\mathrm{K}_{2} \mathrm{O}$, the high percentage of $\mathrm{FeO}$ and $\mathrm{MgO}$, the lack of calcium, and the micaceous habit suggest a phyllosilicate rather than anphibole. The most likely phase to have these properties is celadonite. This mineral is a common constituent of altered mafic and andesitic volcanic rocks (Andrews, 1980; Baker et al., 2012; Chesworth et al., 2004; Li et al., 1997; Li et al., 2011; Parra et al., 1985). It's ideal formula is $\mathrm{K}\left(\mathrm{Mg}, \mathrm{Fe}^{2+}\right)\left(\mathrm{Al}, \mathrm{Fe}^{3+}\right) \mathrm{Si}_{4} \mathrm{O}_{10}(\mathrm{OH})_{2}$ with possible substitutions of $\mathrm{Na}$ and/or $\mathrm{Ca}$ in the interlayer site (Hendricks and Ross, 1941; Wise and Eugster, 1964). This is consistent with chemical compositions reported in Table 3.3. Figure 3.15 shows the average composition of this mineral plotted on the dioctahedral mica ternary diagram (Tappert et al., 2013). 
Figure 3.12. SEM images of grains from the top (Portion 2) of the reactor after the BW1 experiment (minerals were identified by SEMEDS analysis): a) surface showing intense alteration of the primary plagioclase to secondary anorthite composition; b) reacted grain surface showing primary clinopyroxene (Cpx) and secondary titanite (Ttn); c) surface of a reacted grain showing rounded masses of the K-Na-MgFe aluminosilicate phase of secondary origin, concluded to be celadonite $(\mathrm{Cel})$.
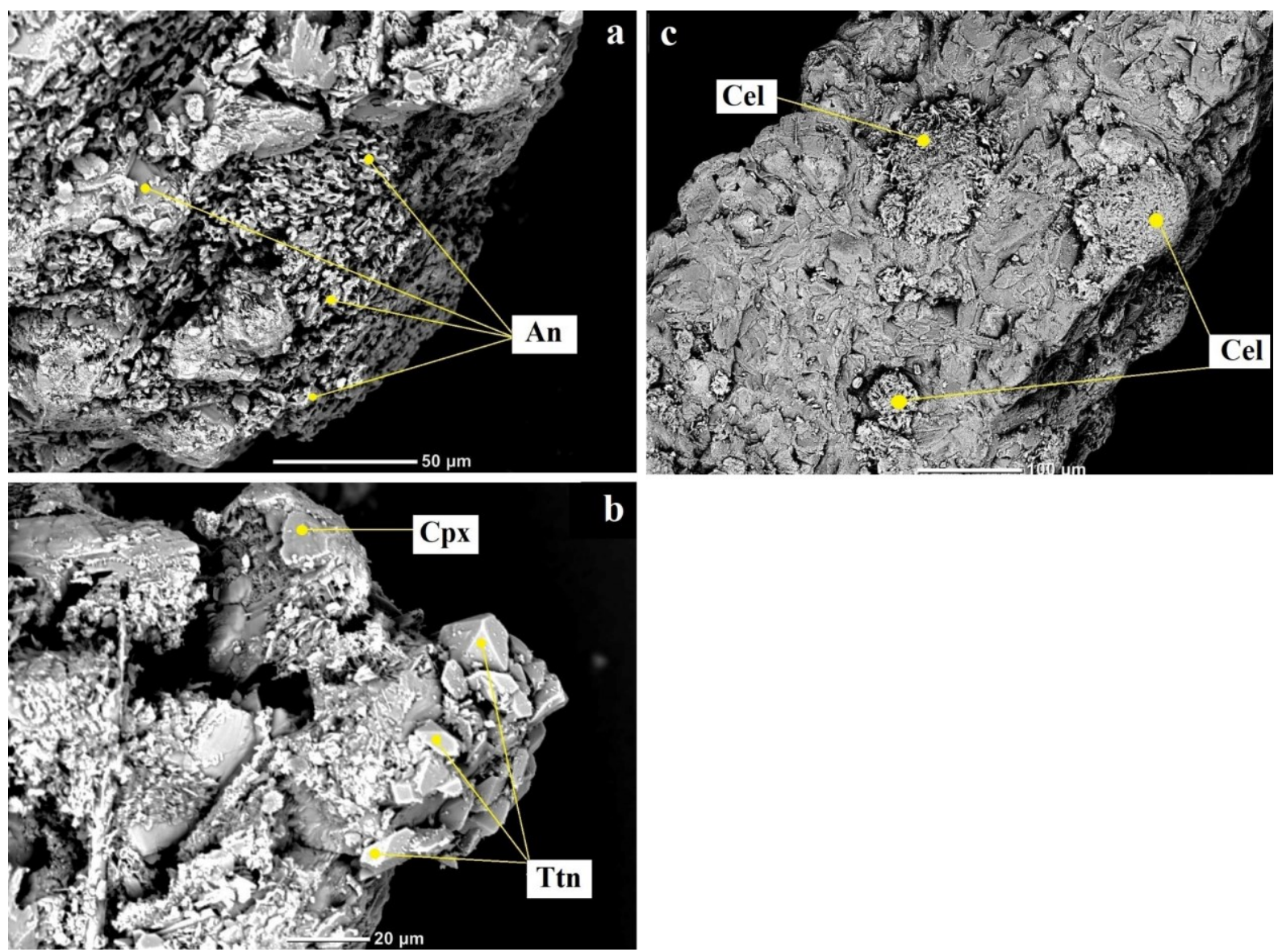
Figure 3.13. SEM backscatter image and EDS compositional maps of an epoxy-mounted, polished grain from the top portion of the BW1 experiment: (a) backscatter image of entire grain; (b) composite colour image combining the backscatter image and the elemental maps for c) $\mathrm{Ca}$ in blue, d) $\mathrm{Mg}$ in green, and e) Fe in red. The composite image shows plagioclase (dark blue), unaltered clinopyroxene (turquoise), titanomagnetite (red), and olivine (yellow green).
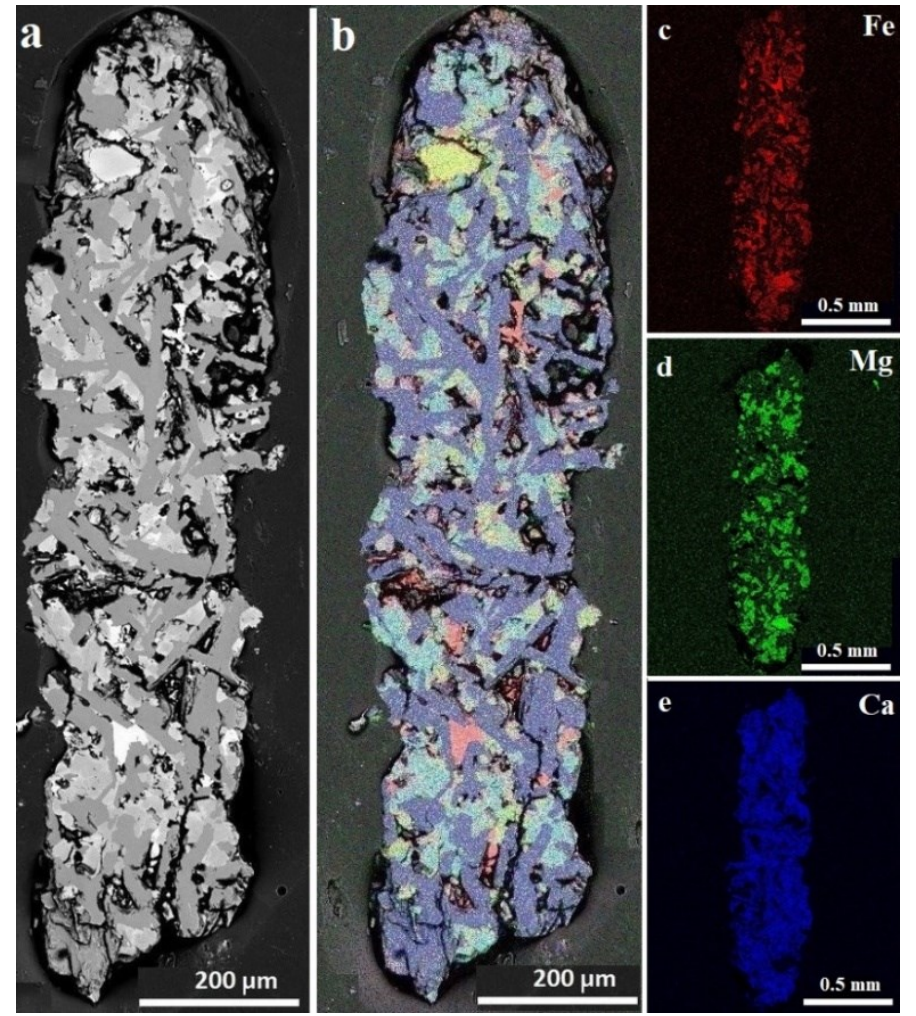

Figure 3.14. SEM backscatter images and EDS compositional maps of an epoxy-mounted, polished grain from the top portion of the BW1 experiment: (a) backscatter image of entire grain; (b) composite colour image combining the backscatter image and the elemental maps for $\mathrm{Ca}, \mathrm{Mg}$, and $\mathrm{Fe}$. The composite image shows plagioclase (dark blue), unaltered clinopyroxene (turquoise), titanomagnetite (red), and olivine yellow green). (c) enlargement of the red rectangle in (b) showing an overgrowth celadonite (Cel) on the olivine (Ol).
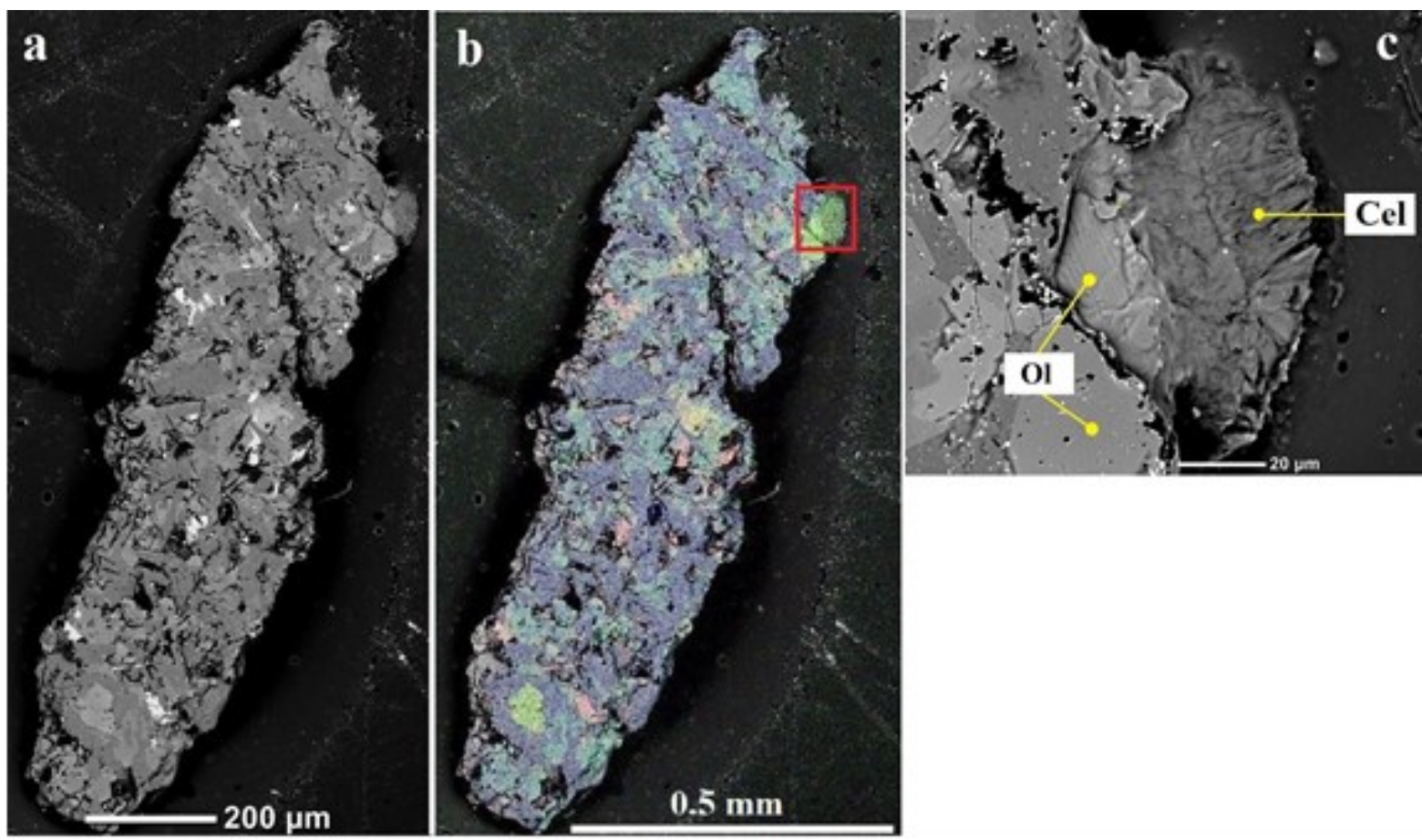
Table 3.3. Average composition (by SEM-EDS analysis) of the micaceous phase (celadonite) found during study of the reacted grains collected from the top (Portion 2) of the Reactor after the BW1 experiment. Empirical formulas reported in Table 3.2.

\begin{tabular}{|ccccc|}
\hline & $\begin{array}{c}\text { Unpolished } \\
(\mathbf{N}=\mathbf{1 0})\end{array}$ & & \multicolumn{2}{c|}{$\begin{array}{c}\text { Polished } \\
(\mathbf{N}=\mathbf{5})\end{array}$} \\
oxide & $\begin{array}{c}\text { average } \\
\mathrm{Wt} \%\end{array}$ & $\pm 1 \sigma$ & $\begin{array}{c}\text { average } \\
\mathrm{Wt} \%\end{array}$ & $\pm 1 \sigma$ \\
& & & & \\
$\mathbf{N a}_{2} \mathbf{O}$ & 2.55 & 0.9 & 1.08 & 0.2 \\
$\mathbf{M g O}$ & 14.07 & 3.2 & 18.81 & 1.6 \\
$\mathbf{A l}_{2} \mathbf{O}_{3}$ & 12.89 & 1.1 & 13.41 & 0.5 \\
$\mathbf{S i O}_{2}$ & 42.22 & 3.4 & 47.28 & 0.9 \\
$\mathbf{K}_{2} \mathbf{O}$ & 4.25 & 1.3 & 3.10 & 0.8 \\
$\mathbf{F e O}$ & 24.03 & 7.0 & 16.34 & 2.7 \\
$\mathrm{Total}$ & 100.01 & & 100.02 & \\
\hline
\end{tabular}

Figure 3.15. Dioctahedral mica ternary diagram ( $\mathrm{Al}, \mathrm{Fe}, \mathrm{Mg})\left(\mathrm{n}^{\circ}\right.$ of atoms) with plotted results from the empirical formula of Table 3.2 .

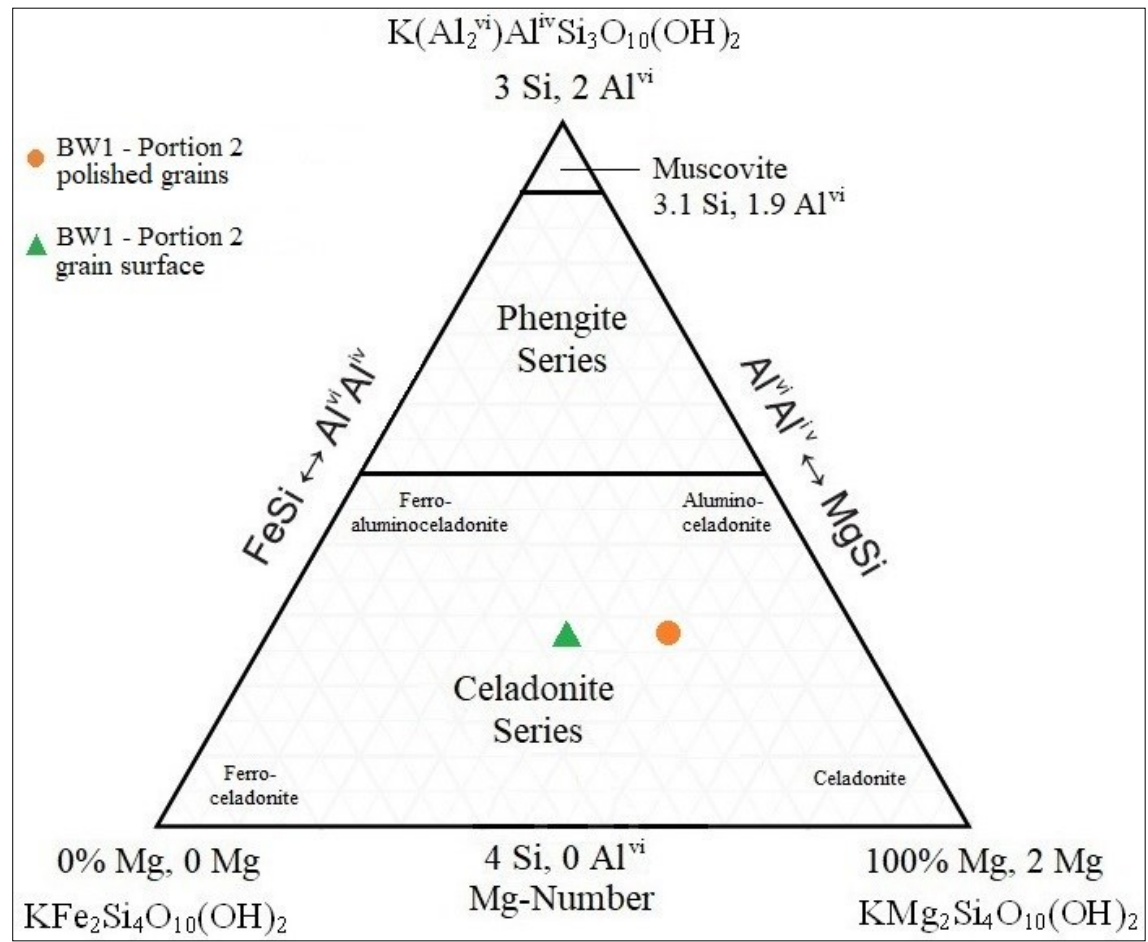




\subsubsection{Mineralogy and Texture of Reacted Basalt: Basalt Block}

The basalt block ( $8 \times 8 \times 4 \mathrm{~mm})$ with one polished surface was positioned vertically near the bottom of the Reactor approximately $0.5-1.0 \mathrm{~cm}$ above the titanium frit (Fig. 3.5). The block was used to investigate the relationship between primary and secondary minerals along a simulated "fracture surface". Upon the conclusion of the experiment, the reacted block was mounted on an aluminium stub for SEM-EDS analysis (Table 3.4). Composite mosaic images of the basalt block surface, before and after the experiment, are shown in Appendix B.

Table 3.4. Mineral composition of reacted basalt block surface after the BW1 experiment. Appendix B contains all SEM results.

\begin{tabular}{|c|c|c|c|}
\hline $\begin{array}{l}\text { Type of } \\
\text { Analysis }\end{array}$ & $\begin{array}{l}\text { Analysis } \\
\text { Material }\end{array}$ & $\begin{array}{l}\text { Mineral } \\
\text { Identified }\end{array}$ & $\begin{array}{c}\text { Average } \\
\text { Mineral Composition }\end{array}$ \\
\hline SEM-EDS & basalt block & Plagioclase & - \\
\hline SEM-EDS & basalt block & Augite & $\mathrm{Ca}_{0.65} \mathrm{Mg}_{0.81} \mathrm{Fe}_{0.44} \mathrm{Al}_{0.1} \mathrm{Si}_{2} \mathrm{O}_{6}$ \\
\hline SEM-EDS & basalt block & Titanomagnetite & $\mathrm{Fe}^{2+}\left(\mathrm{Fe}^{3+}, \mathrm{Ti}\right)_{2} \mathrm{O}_{4}$ \\
\hline SEM-EDS & basalt block & $\begin{array}{l}\text { Fe-Ni-Cr } \\
\text { Oxide }\end{array}$ & - \\
\hline SEM-EDS & basalt block & Celadonite & $\begin{array}{c}\mathrm{K}_{0.46} \mathrm{Na}_{0.33} \mathrm{Mg}_{1.4} \mathrm{Fe}_{1.6} \mathrm{Al}_{0.07} \mathrm{Si}_{2.9} \mathrm{Al}_{1.1} \mathrm{O}_{10}(\mathrm{OH})_{2} \\
\text { (calculated based on the anhydrous composition with } 11 \text { oxygens) }\end{array}$ \\
\hline
\end{tabular}

Figure 3.16a shows an SEM backscatter image of the corner of the unreacted basalt block. It shows the ophitic texture, composed of interlocking plagioclase (bytownite) laths (darker grey) with interstitial clinopyroxene (lighter grey). Olivine occurs as isolated anhedral crystals (examples circled in yellow), while oxides (titanomagnetite) appear white. Figure $3.16 \mathrm{~b}$ shows the same area above after reaction. At low magnification, the most significant observation is the growth of amoeboid masses of celadonite exclusively on primary olivine crystals. The growths of celadonite were large enough to be examined under the optical microscope and appeared green-blue in colour.

Figure 3.16c shows a higher magnification image of this phase. Table 3.5 shows the average of 24 SEM-EDS analyses of this phase. When compared to Table 3.3, the composition of the celadonite analysed on the basalt block surface is similar to that measured from reacted grains (Table 3.2). The mineral habit is similar to that shown in Figure 3.12c, thus they are interpreted to be the same phase. Figure 3.17 shows the average composition of this mineral plotted on the dioctahedral mica ternary diagram (Tappert et al., 2013). 
At higher magnification, a further observation is the etching of the twin planes in plagioclase (Fig. 3.16d,e). EDS analysis shows the plagioclase has an increase is Na content relative to the original bytownite (Appendix B). It is uncertain to what depth this enrichment has occurred. Clinopyroxene and titanomagnetite appear unaffected.

Also observed is the growth of a Fe-Ni-Cr oxide. Figure 3.18a shows an area of the unreacted basalt block while Figure $3.18 \mathrm{~b}$ shows the same area after reaction. Along the twin planes and edges of the plagioclase laths there appear bright lines of a secondary phase. These are evident in the higher magnification image (Fig. 3.18c). EDS analyses of this material shows it to be composed of $\mathrm{Fe}, \mathrm{Ni}$, and $\mathrm{Cr}$. It is most likely an oxide phase. 
Figure 3.16. (a-b) SEM backscatter images of the surface of the basalt block used in the BW1 experiment: a) unreacted block with interlocking lathes of plagioclase (dark gray), interstitial clinopyroxene (lighter gray), titanomagnetite (white), and isolated crystals of olivine (yellow ovals); b) reacted block showing celadonite replacing olivine. (c-d-e) SEM backscatter images of the basalt block surface after the BW1 experiment: c) enlargement of rectangular area in (b) showing celadonite (Cel) replacing olivine; d) SEM backscatter image showing celadonite $(\mathrm{Cel})$, relatively unaltered clinopyroxene $(\mathrm{Cpx})$ (lighter grey) and plagioclase with more Na content (Plg) coating primary plagioclase; e) SEM backscatter image of celadonite (Cel) replacing olivine (Ol) and altered plagioclase (Plg).
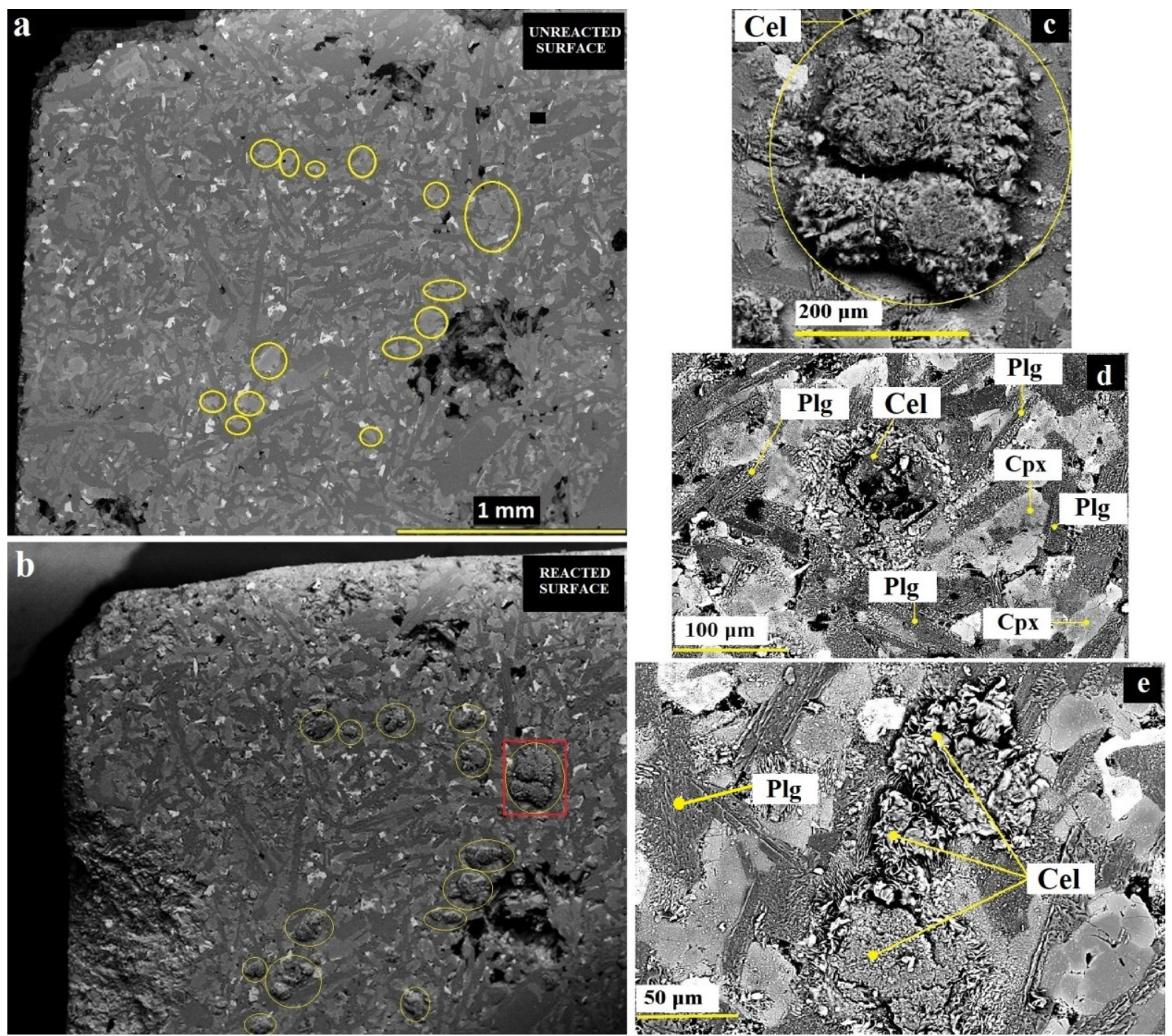
Table 3.5. Average composition (SEM-EDS analysis) of celadonite found during study of the reacted basalt surface collected from the bottom of the Reactor after the BW1. Empirical formula reported in Table 3.4.

\begin{tabular}{|ccc|} 
& $\begin{array}{c}\text { Basalt Block } \\
(\mathbf{N}=\mathbf{2 4})\end{array}$ & \\
& & \\
oxide & average & $\pm 1 \sigma$ \\
& Wt \% & \\
$\mathbf{N a}_{2} \mathbf{O}$ & & \\
$\mathbf{M g O}$ & 2.28 & 0.93 \\
$\mathbf{A l}_{2} \mathbf{O}_{3}$ & 12.81 & 3.02 \\
$\mathrm{SiO}_{2}$ & 13.16 & 2.01 \\
$\mathbf{K}_{2} \mathbf{O}$ & 40.00 & 4.25 \\
FeO & 4.91 & 1.90 \\
Total & 26.85 & 8.59 \\
\hline
\end{tabular}

Figure 3.17. Dioctahedral mica ternary diagram $(\mathrm{Al}, \mathrm{Fe}, \mathrm{Mg})\left(\mathrm{n}^{\circ}\right.$ of atoms) with plotted results from the empirical formula of Table 3.4 .

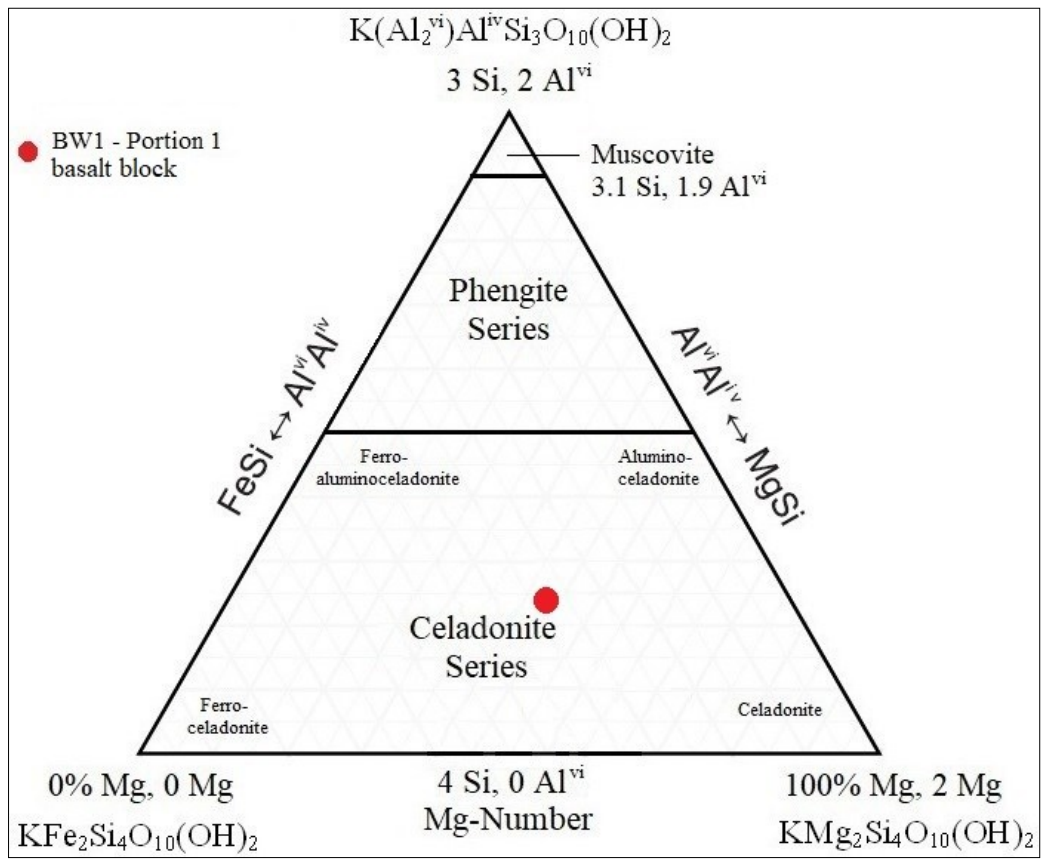


Figure 3.18. SEM backscatter images of the basalt block surface after the BW1 experiment: a) area of the basalt block surface before the BW1 experiment; (b) same area after the BW1 experiment showing larger plagioclase microphenocrysts surrounded by ophitic textured plagioclase, clinopyroxene, olivine and titanomagnetite; c) enlargement of the red rectangular area in (b) showing secondary features in detail. Primary clinopyroxene $(\mathrm{Cpx})$ is unaltered while the plagioclase $(\mathrm{Plg})$, altered, has a major Na content when compared to the primary bytownite (Appendix B). Bright spots are Fe-Ni-Cr oxide.
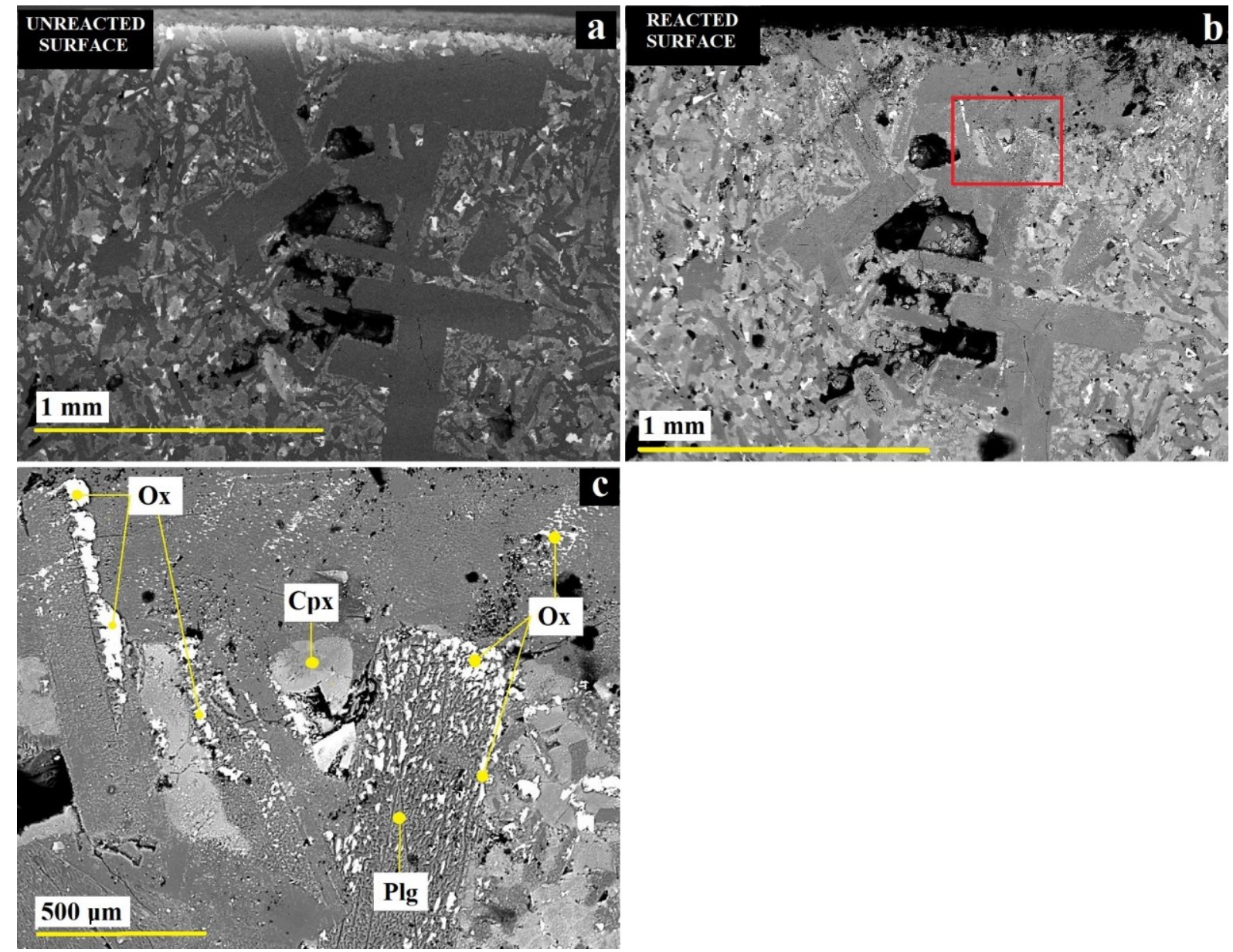


\subsubsection{BW2: Basalt - water at $350^{\circ} \mathrm{C} / 490$ bar}

The second basalt-water experiment (BW2) ran for total time of $1145 \mathrm{hr}$. The first 136 $\mathrm{hr}$ were at room temperature and 490 bar and the remaining $1008 \mathrm{hr}$ were at $350^{\circ} \mathrm{C}$ and 490 bar. The flow rate was $1 \mathrm{ml} \mathrm{hr}^{-1}$ up to $1002 \mathrm{hr}$ after which it was changed to $0.5 \mathrm{ml} \mathrm{hr}^{-1}$ for the remaining $143 \mathrm{hr}$. Analyses of major ions were made for the total number (46) of fluid samples. Analyses of trace elements were made for the first 29 fluid samples.

\subsubsection{Major element concentrations}

Appendix B lists the complete experimental parameters (T, P, flow rate, chemistry). Figure 3.19 and Figure 3.20 show the major element results plotted against time in hours. The unreacted distilled water composition is shown at $\mathrm{t}=0$. Trace concentrations of $\mathrm{Ca}(0.02$ mmol kg$\left.{ }^{-1}\right), \mathrm{K}\left(0.08 \mathrm{mmol} \mathrm{kg}{ }^{-1}\right), \mathrm{Na}\left(0.29 \mathrm{mmol} \mathrm{kg}{ }^{-1}\right)$, and $\mathrm{SiO}_{2}\left(0.04 \mathrm{mmol} \mathrm{kg}^{-1}\right)$, were detected. All other major elements were below detection limit.

During the room temperature $\left(\sim 21^{\circ} \mathrm{C}\right)$ period, no significant changes in solution composition are evident. The $\mathrm{pH}$ values are on average slightly higher (6.94) than the starting blank but are quite irregular. $\mathrm{Ca}, \mathrm{K}$ and $\mathrm{Na}$ remain stable reflecting the composition of the input solution. $\mathrm{SiO}_{2}$ slightly rises in concentration.

The change in temperature to $350^{\circ} \mathrm{C}$ was initiated at 136 hours. Major changes in solution chemistry are evident after the temperature shift. Effluent quench $\mathrm{pH}$ slowly increases from just above 7 at 184 hours to about 9 by 378 hours and remains near this alkaline value for the remainder of the experiment. The calculated in situ $\mathrm{pH}$ declines from 6.24 after the temperature shift to $5.3-5.4$ by the end of the experiment.

$\mathrm{SiO}_{2}$ increases to $32.25 \mathrm{mmol} \mathrm{kg}^{-1}$ (1937 ppm) which is more than double quartz saturation at $350^{\circ} \mathrm{C} / 500$ bar ( 981 ppm, Supcrt92). Between 184 and 403 hours, silica concentration remains elevated but decreases to about $20 \mathrm{mmol} \mathrm{kg}^{-1}$. After about 400 hours,

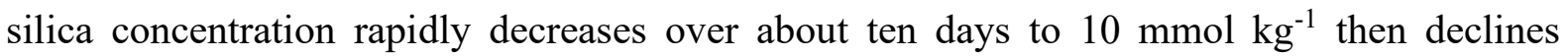
gradually to $8.2 \mathrm{mmol} \mathrm{kg}^{-1}$ by the end of the experiment.

$\mathrm{Na}$ and $\mathrm{K}$ both show a sharp increase after the temperature shift, then decline over the next five days and then increase again up to about 500 hours. After this, their concentrations diverge with $\mathrm{Na}$ stabilising at around $2.5 \mathrm{mmol} \mathrm{kg}-1$ up to 800 hours then decreasing to 2 mmol kg-1 for the remainder of the experiment. Potassium increases to a maximum of 0.62 mmol kg-1 and then concentrations decline to about $0.41 \mathrm{mmol} \mathrm{kg}^{-1}$ by 800 hours after which they decrease sharply to $0.13-0.14 \mathrm{mmol} \mathrm{kg}^{-1}$ for the remainder of the experiment. 
Aluminium concentration increases to about $0.4 \mathrm{mmol} \mathrm{kg}^{-1}$ after the temperature shift and remains relatively constant up to 419 hours, after which it increases to about $1 \mathrm{mmol} \mathrm{kg}^{-1}$ and remains near this value until the change in flow rate at 1000 hours. At the lower flow rate, $\mathrm{Al}$ concentration decreases slightly. On average, $\mathrm{Ca}$ concentration increases after the temperature shift to a value around $0.04 \mathrm{mmol} \mathrm{kg}^{-1}$ for the remaining experiment, however, it is highly irregular. $\mathrm{Mg}$ behaves similarly, displaying highly irregular, low values averaging around $0.09 \mathrm{mmol} \mathrm{kg}{ }^{-1}$. Fe increases sharply to $0.027 \mathrm{mmol} \mathrm{kg}{ }^{-1}$ immediately after temperature shift and then consistently declines to values near or below detection limit over the remaining experiment.

$\mathrm{SO}_{4}$ concentration increases immediately after temperature shift to a value of 0.12 mmol $\mathrm{kg}^{-1}$. It then declines to near detection limit values over the remainder of the experiment. Similarly, $\mathrm{Cl}$ concentration increases to $0.56 \mathrm{mmol} \mathrm{kg}^{-1}$ after the temperature shift and then declines to between $0.01-0.02 \mathrm{mmol} \mathrm{kg}^{-1}$ by the end of the experiment. $\mathrm{H}_{2} \mathrm{~S}$ concentration increases to a maximum of $0.3 \mathrm{mmol} \mathrm{kg}^{-1}$ three days after temperature increase. It then decreases in a linear manner over the next thirteen days after which it declines to values near or below detection limit for the remaining time.

The change in flow rate to $0.5 \mathrm{ml} \mathrm{hr}^{-1}$ (the final three effluent samples) did not cause any significant effects on elemental concentrations and $\mathrm{pH}$ values, i.e., fluid composition remains stable during the last 143 hrs of experiment. 
Figure 3.19. Major element concentrations in blank and effluent samples (mmol kg-1) versus time (hr) for the basalt-water experiment at $350^{\circ} \mathrm{C} / 490$ bar (BW2). Yellow symbols are the blank sample composition of the water. Blue symbols are for effluents at room T/490 bar and $1.0 \mathrm{ml} \mathrm{hr}{ }^{-1}$ flow rate. Black symbols are effluents at $350^{\circ} \mathrm{C} / 490$ bar and $1.0 \mathrm{ml} \mathrm{hr}^{-1}$ flow rate. Red symbols are effluents at $350^{\circ} \mathrm{C} / 490 \mathrm{bar}$ and $0.5 \mathrm{ml} \mathrm{hr}^{-1}$ flow rate. In situ $\mathrm{pH}$ is the calculated $\mathrm{pH}$ at temperature. The limit of detection (LOD) is shown for each component.
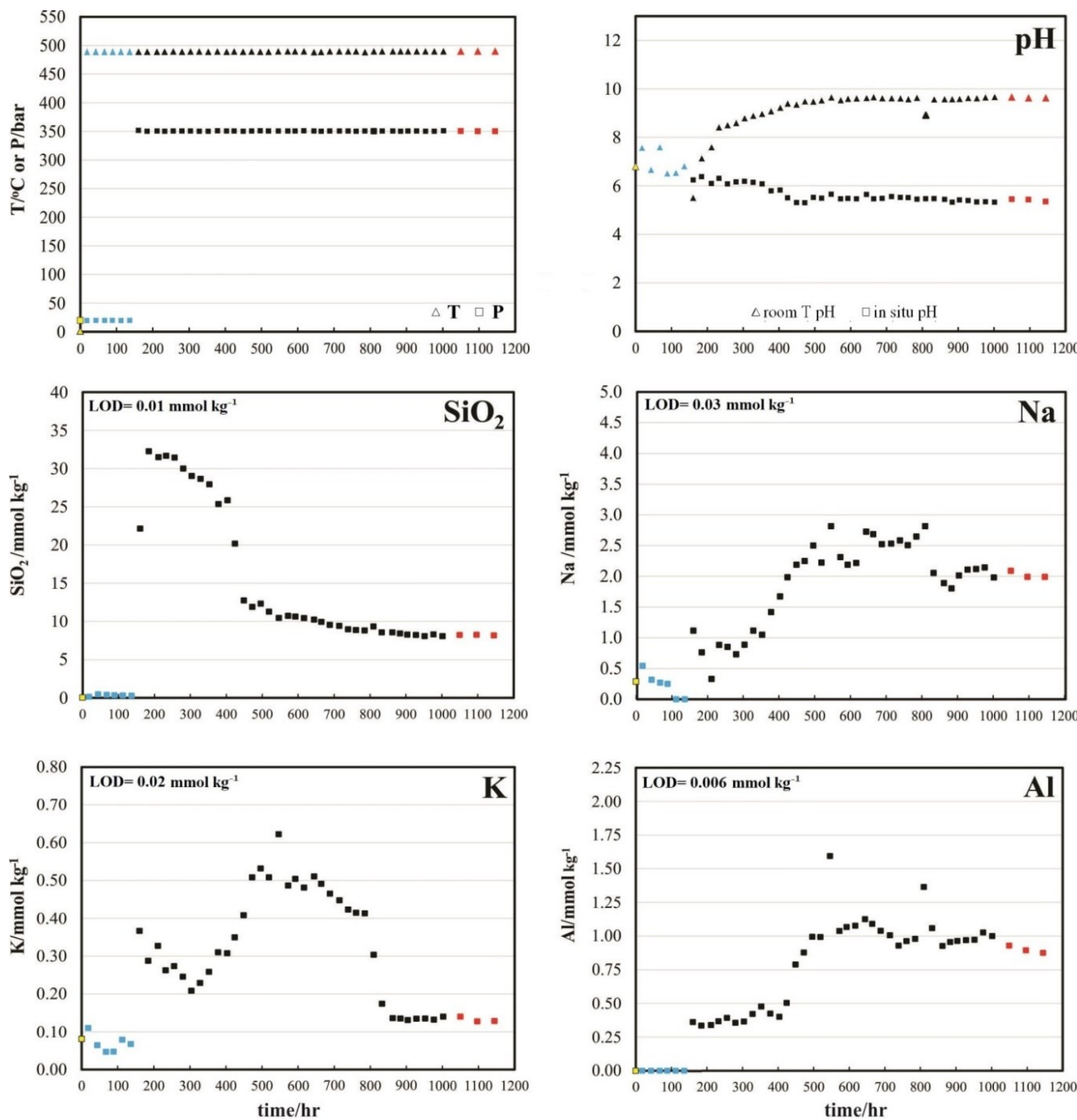

$\triangle \square$ blank

$\Delta$ room $\mathrm{T} / 490 \mathrm{bar} / 1.0 \mathrm{ml} \mathrm{hr}^{-1}$

$\Delta$ — $350^{\circ} \mathrm{C} / 490$ bar/1.0 ml hr ${ }^{-1}$

$\Delta \quad 350^{\circ} \mathrm{C} / 490 \mathrm{bar} / 0.5 \mathrm{ml} \mathrm{hr}^{-1}$ 
Figure 3.20. Major element concentrations in blank and effluent samples (mmol kg${ }^{-1}$ ) versus time (hr) for the basalt-water experiment at $350^{\circ} \mathrm{C} / 490$ bar (BW2). Yellow symbols are the blank sample composition of the water. Blue symbols are for effluents at room T/490 bar and $1.0 \mathrm{ml} \mathrm{hr}{ }^{-1}$ flow rate. Black symbols are effluents at $350^{\circ} \mathrm{C} / 490$ bar and $1.0 \mathrm{ml} \mathrm{hr}^{-1}$ flow rate. Red symbols are effluents at $350^{\circ} \mathrm{C} / 490 \mathrm{bar}$ and $0.5 \mathrm{ml} \mathrm{hr}^{-1}$ flow rate. In situ $\mathrm{pH}$ is the calculated $\mathrm{pH}$ at temperature. The limit of detection (LOD) is shown for each component.
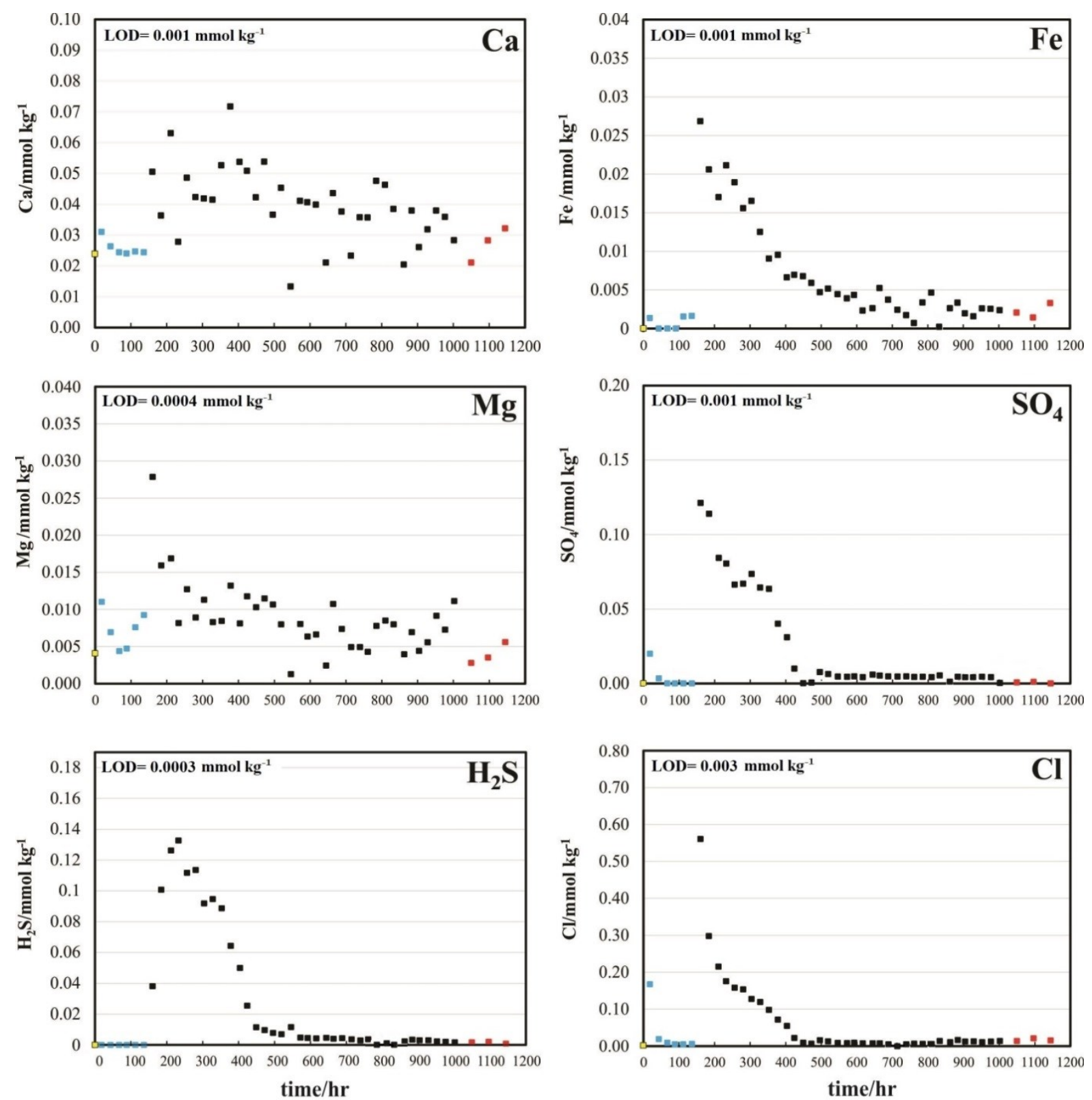

$\triangle \square$ blank

$\Delta$ room $\mathrm{T} / 490 \mathrm{bar} / 1.0 \mathrm{ml} \mathrm{hr} \mathrm{r}^{-1}$

$\Delta \square 350^{\circ} \mathrm{C} / 490 \mathrm{bar} / 1.0 \mathrm{ml} \mathrm{hr}^{-1}$

$\Delta \quad 350^{\circ} \mathrm{C} / 490 \mathrm{bar} / 0.5 \mathrm{ml} \mathrm{hr}^{-1}$ 


\subsubsection{Trace element concentrations}

Appendix B lists the complete trace element results. Figure 3.21 and Figure 3.22 show these results plotted against experimental time in hours. The unreacted water composition is shown at $\mathrm{t}=0$. All trace element concentrations are below detection limit.

As with the basalt - water experiment at supercritical conditions (BW1), during the room temperature $\left(\sim 21^{\circ} \mathrm{C}\right)$ period, measurable consistent increases in trace elements $\mathrm{Cr}, \mathrm{Ni}$, $\mathrm{Zn}, \mathrm{Mo}$, and $\mathrm{Au}$ are observed. $\mathrm{Zn}$ concentrations are similar in magnitude to those found for the remainder of the experiment, suggesting an artefact of the method rather than meaningful values due to water-rock interaction.

After the temperature shift to $350^{\circ} \mathrm{C}$, four trace elements sharply increase in concentration including $\mathrm{Mn}, \mathrm{Co}, \mathrm{Rb}$, and Mo. V slowly increases over the remainder of the experiment while Mo decreases. Overall decreases are also observed for $\mathrm{Cr}$, $\mathrm{Mn}$, and perhaps $\mathrm{Au} . \mathrm{Rb}$ peaks at 450 hours and then decreases. Other elements are low and erratic in concentration over the experiment $(\mathrm{Co}, \mathrm{Cu}, \mathrm{Ag}, \mathrm{Cd}, \mathrm{Ba}, \mathrm{Pb})$. 
Figure 3.21. Trace element concentrations in blank and effluent samples ( $\mu$ mol $\mathrm{kg}^{-1}$ ) versus time (hr) for the basalt-water experiment at $350^{\circ} \mathrm{C} / 490$ bar (BW2). Yellow symbols are the blank sample composition of the water. Blue symbols are for effluents at room T/490 bar and $1.0 \mathrm{ml} \mathrm{hr}{ }^{-1}$ flow rate. Black symbols are effluents at $350^{\circ} \mathrm{C} / 490$ bar and $1.0 \mathrm{ml} \mathrm{hr}^{-1}$ flow rate. In situ $\mathrm{pH}$ is the calculated pH at temperature. The limit of detection (LOD) is shown for each component.
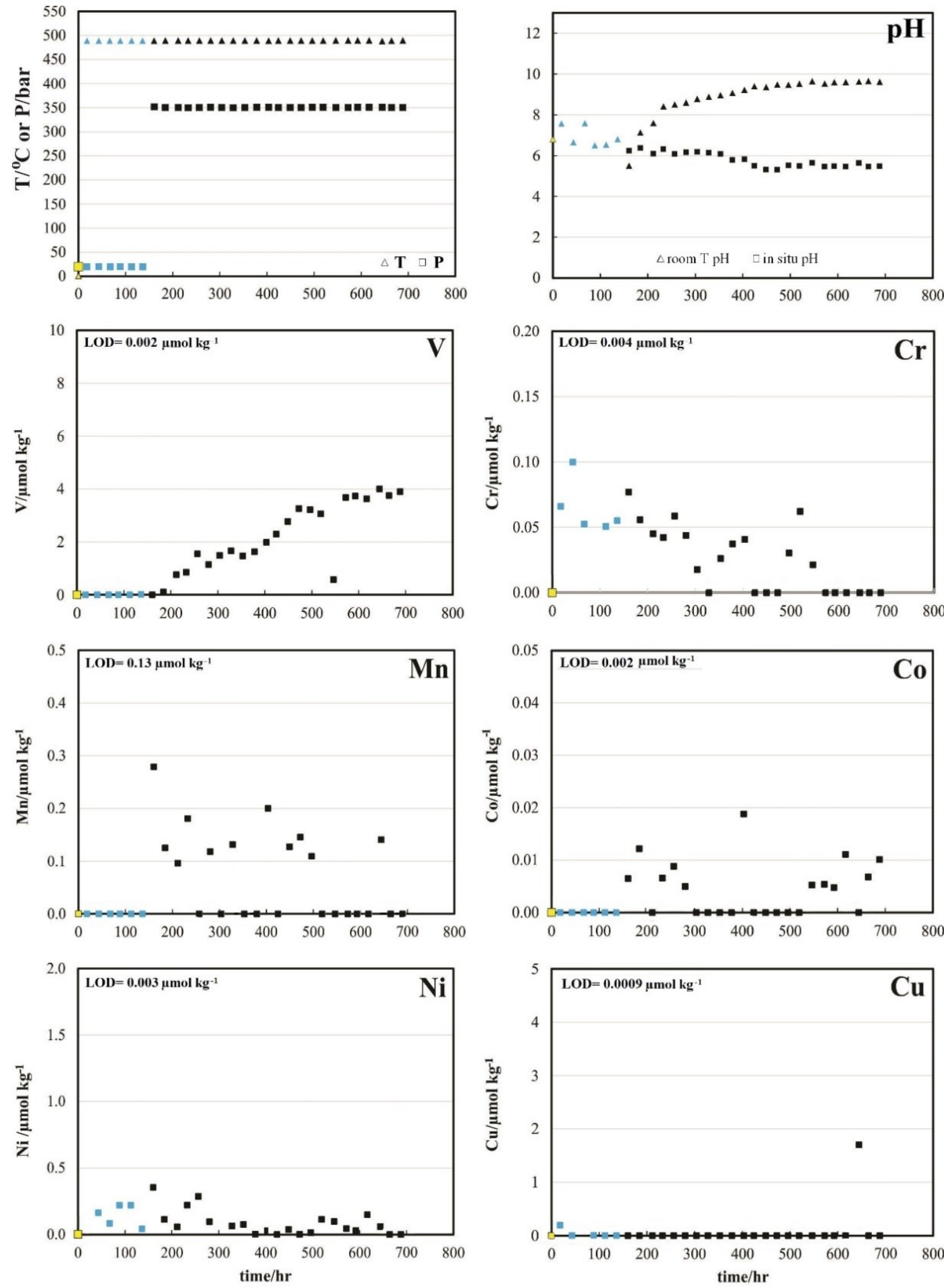

$\triangle \square$ blank

$\Delta$ in $\operatorname{room} \mathrm{T} / 490 \mathrm{bar} / 1.0 \mathrm{ml} \mathrm{hr}^{-1}$

$\Delta$ - $350^{\circ} \mathrm{C} / 490 \mathrm{bar} / 1.0 \mathrm{ml} \mathrm{hr}^{-1}$ 
Figure 3.22. Trace element concentrations in blank and effluent samples ( $\mu$ mol $\left.\mathrm{kg}^{-1}\right)$ versus time (hr) for the basalt-water experiment at $350^{\circ} \mathrm{C} / 490$ bar (BW2). Yellow symbols are the blank sample composition of the water. Blue symbols are for effluents at room T/490 bar and $1.0 \mathrm{ml} \mathrm{hr}^{-1}$ flow rate. Black symbols are effluents at $350^{\circ} \mathrm{C} / 490$ bar and $1.0 \mathrm{ml} \mathrm{hr}^{-1}$ flow rate. In situ $\mathrm{pH}$ is the calculated $\mathrm{pH}$ at temperature. The limit of detection (LOD) is shown for each component.
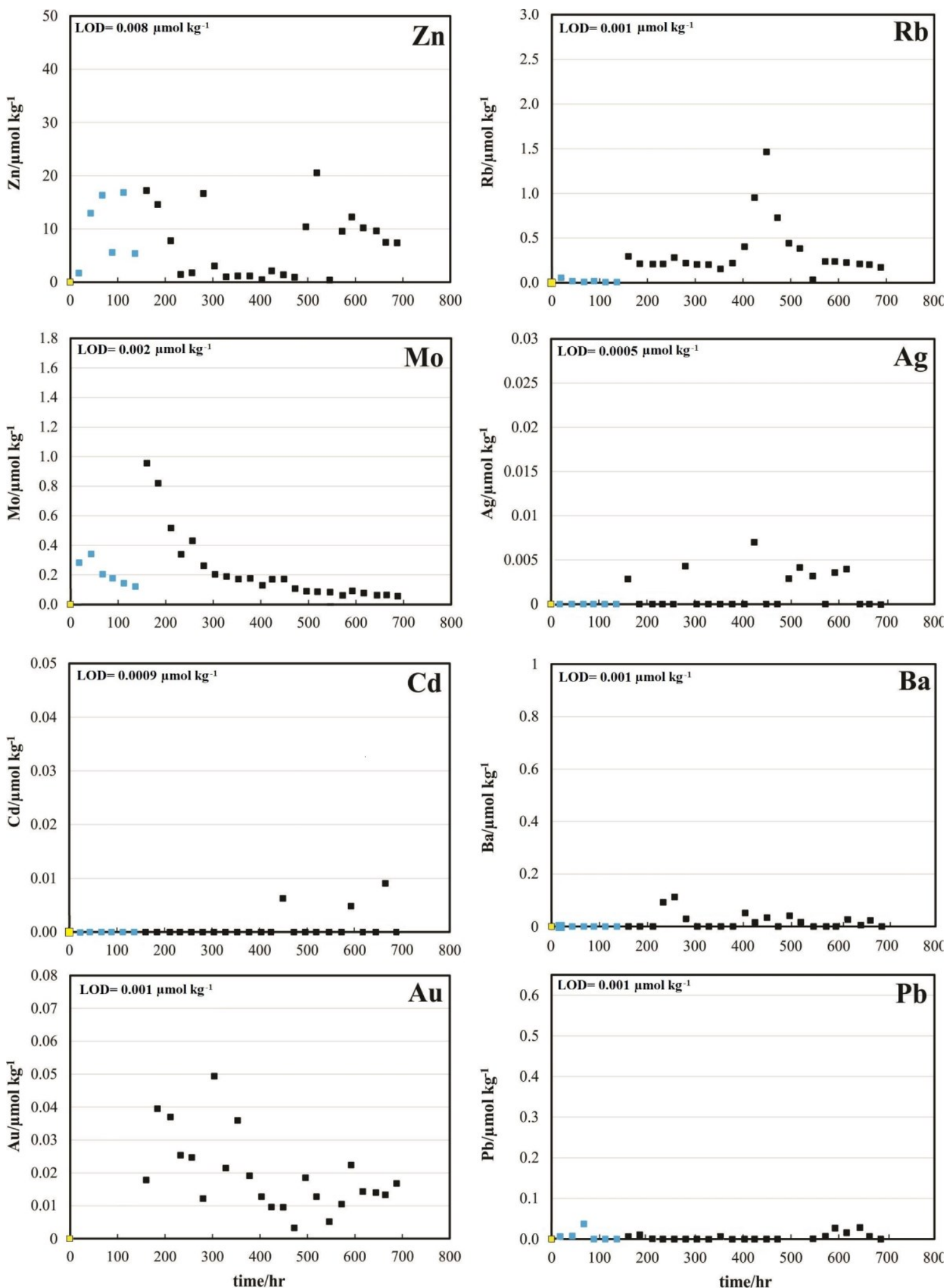

$\triangle \square$ blank

$\Delta$ [ room $\mathrm{T} / 490 \mathrm{bar} / 1.0 \mathrm{ml} \mathrm{hr}^{-1}$

$\Delta$ - $350^{\circ} \mathrm{C} / 490 \mathrm{bar} / 1.0 \mathrm{ml} \mathrm{hr}^{-1}$ 


\subsubsection{Mineralogy and Texture of Reacted Basalt: Bottom of the Reactor (Portion 1)}

Upon conclusion of the experiment, the reacted basalt grains were extracted from the Reactor onto absorbent paper. They were rinsed with distilled water to remove precipitated soluble salts such as $\mathrm{NaCl}$ and $\mathrm{KCl}$ and were air-dried. Several grains were collected from the bottom of the Reactor (Portion 1) and from the top of the Reactor (Portion 2) (Fig. 3.23). Note that, no reacted grains in between Portion 1 and Portion 2 were collected for analysis.

Selected grains were mounted on aluminium stubs for textural analyses by SEM and several grains were epoxy-mounted and polished for SEM-EDS and EMPA analysis. Appendix B contains all SEM and EMPA results for this portion of the rock.

Figure 3.23. Schematic diagram of the Reactor showing position (Portion 1 and Portion 2) of reacted basalt grains shown in SEM photographs and the position of the basalt block for the BW2 experiment. The picture is not to scale.

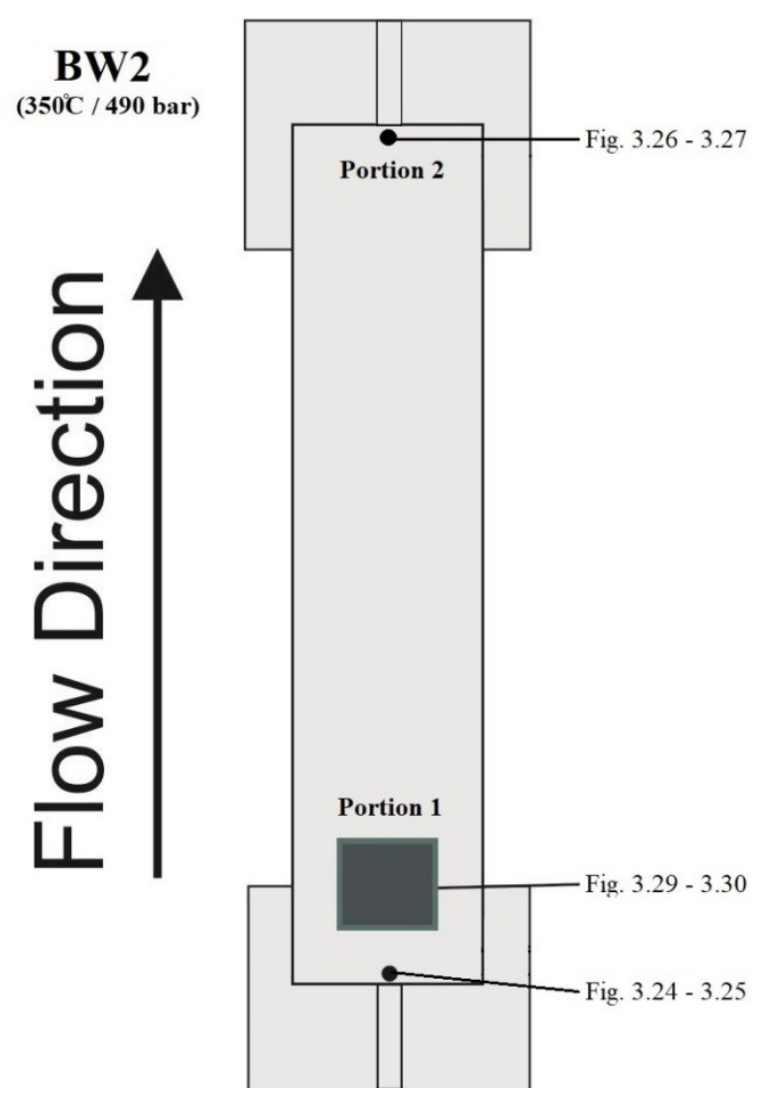


Results confirm substantial alteration of the basalt caused by water-rock interaction. Minerals of secondary origin detected were: anorthite, chlorite, magnetite and titanite. Data also confirm the presence of the primary minerals clinopyroxene, olivine and titanomagnetite (Table 3.6).

Table 3.6. Mineral assemblage detected by EMPA and SEM-EDS analysis of reacted grains extracted from bottom (Portion 1) of the Reactor after the BW2 experiment. Appendix B contains all SEM and EMPA results.

\begin{tabular}{|c|c|c|c|}
\hline $\begin{array}{l}\text { Type of } \\
\text { Analysis }\end{array}$ & $\begin{array}{l}\text { Analysis } \\
\text { Material }\end{array}$ & $\begin{array}{c}\text { Mineral } \\
\text { Identified }\end{array}$ & $\begin{array}{c}\text { Average } \\
\text { Mineral Composition }\end{array}$ \\
\hline EMPA & polished grains & Anorthite & $\mathrm{Ca}_{0.88} \mathrm{Na}_{0.09} \mathrm{Al}_{2} \mathrm{Si}_{2} \mathrm{O}_{8}\left(\mathrm{An}_{91}-\mathrm{Ab}_{9}\right)$ \\
\hline EMPA & polished grains & Augite & $\mathrm{Ca}_{0.44} \mathrm{Mg}_{0.93} \mathrm{Fe}_{0.60} \mathrm{Ti}_{0.18} \mathrm{Si}_{2} \mathrm{O}_{6}$ \\
\hline EMPA & polished grains & Forsterite & $\mathrm{Mg}_{1.43} \mathrm{Fe}_{0.56} \mathrm{SiO}_{4}\left(\mathrm{Fo}_{72}-\mathrm{Fa}_{28}\right)$ \\
\hline SEM-EDS & polished grains & Titanomagnetite & $\mathrm{Fe}^{2+}\left(\mathrm{Fe}^{3+}, \mathrm{Ti}\right)_{2} \mathrm{O}_{4}$ \\
\hline SEM-EDS & polished grains & Magnetite & $\mathrm{Fe}^{3+} \mathrm{Fe}^{2+}{ }_{2} \mathrm{O}_{4}$ \\
\hline EMPA & polished grains & Chlorite & $\begin{array}{l}\mathrm{Mg}_{2.9} \mathrm{Fe}_{1.8} \mathrm{AlSi}_{3} \mathrm{AlO}_{10}(\mathrm{OH})_{8} \\
\text { (calculated based on the anhydrous composition with } 14 \text { oxygens) }\end{array}$ \\
\hline SEM-EDS & grain surface & Sphene & $\mathrm{CaTi}_{0.85} \mathrm{Al}_{0.27} \mathrm{SiO}_{5}$ \\
\hline
\end{tabular}

Figure 3.24 show SEM images of the most reacted grains from the position immediately next to the entry point of the fluid (Fig. 3.23). In Figure 3.24a-b, the grain has chlorite as irregular masses of densely-packed flakes intergrown with euhedral titanite crystals. In Figure 3.24c-d, a second grain has anorthite occurring as subhedral fenestral pseudomorphs of plagioclase. Chlorite displays three habits: botryoidal masses of randomly oriented flakes; epitaxially-oriented pseudomorphs of clinopyroxene; and as intergrowths with anorthite.

Figure 3.25a-f shows SEM backscatter images and EDS maps of an epoxy-mounted, polished grain from the bottom of the Reactor. The grain is considerably altered, with highlycorroded plagioclase (blue), relatively unaffected clinopyroxene (turquoise), Fe-Ti and Fe oxides (red), and chlorite (green). Figure $3.25 \mathrm{~g}$ is a higher magnification image of the rectangular area in Figure 3.25a showing chlorite (green) that has grown internally and outside the margin of the grain in a botryoidal habit, mostly replacing olivine. The chlorite is intergrown with secondary magnetite. Plagioclase is anorthitic in composition. Internally, primary clinopyroxene and titanomagnetite are relatively unaffected. 
Figure 3.24. SEM images of grains collected from bottom (Portion 1) of the Reactor after the BW2 experiment (minerals were identified by SEM-EDS analysis): a) grain covered by secondary chlorite and secondary titanite; (b) enlargement of red rectangular area in (a) showing in more detail the chlorite $(\mathrm{Chl})$ and titanite (Ttn) which appears as prismatic crystals. (c) surface of a reacted grain showing chlorite (Chl) as botryoidal masses composed of densely intergrown flakes; d) enlargement of the red rectangular area in (c) displaying intense alteration of the primary clinopyroxene (Cpx) to chlorite (Chl); (e) secondary chlorite formation (Chl) replacing the plagioclase (Plg). (f) grain entirely covered with chlorite of secondary origin appearing as botryoidal masses composed of densely intergrown flakes.
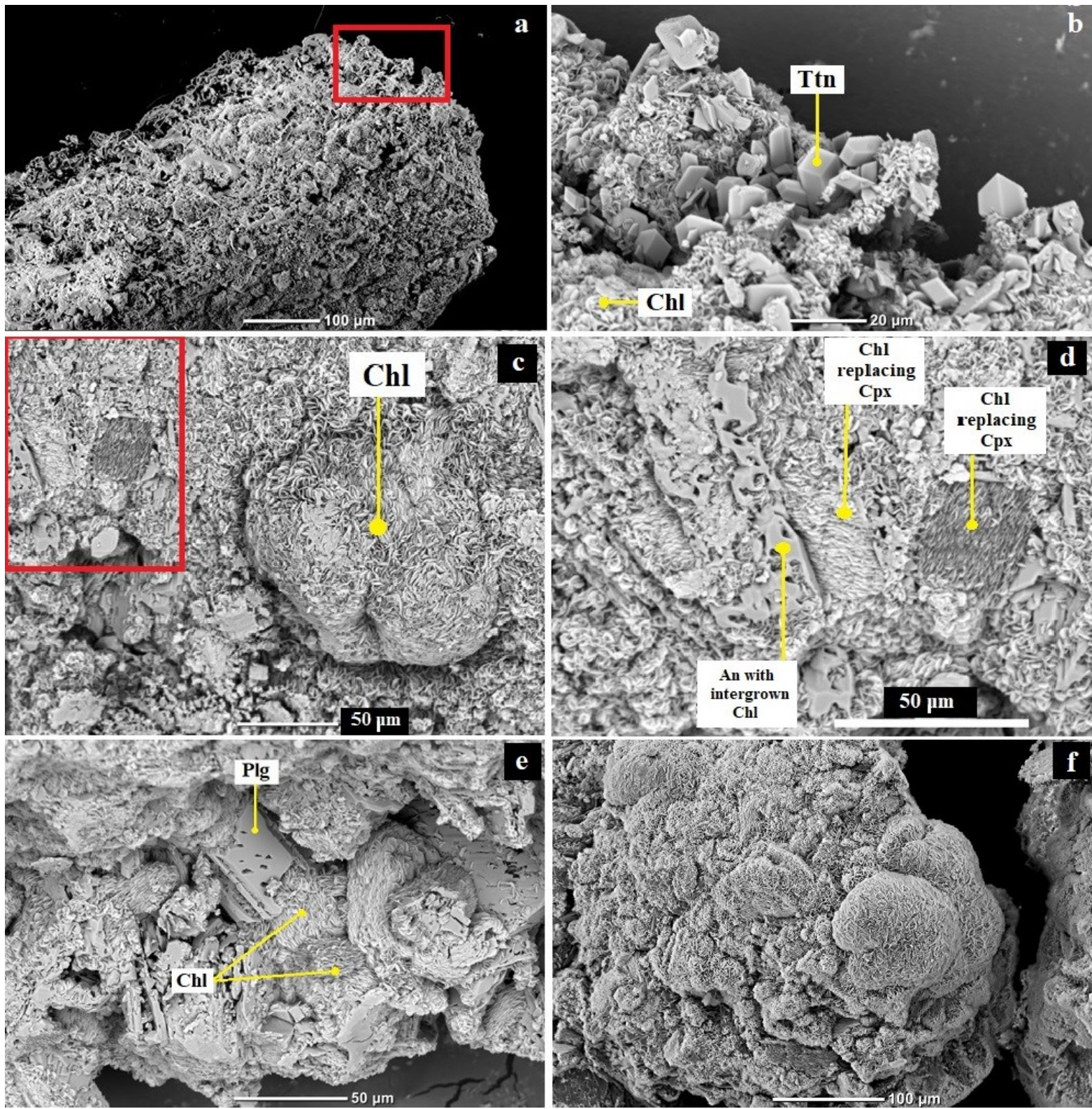
Figure 3.25. (a-f) SEM backscatter images and EDS compositional maps of an epoxy-mounted, polished grain collected from the bottom (Portion 1) of the Reactor after the BW2 experiment. (a) backscatter image of entire grain; (b) backscatter image of rectangular area in (a); (c) composite colour image combining the backscatter image and the elemental maps for d) Fe in red, e) $\mathrm{Mg}$ in green, and $\mathrm{f}$ ) Ca in blue. The image shows remnant plagioclase (blue-purple), relatively unaltered clinopyroxene (turquoise), oxides (red) and a chlorite (green); (g) SEM backscatter image of the red rectangular area shown in (a) displaying secondary plagioclase of anorthitic composition (An), primary clinopyroxene (Cpx), secondary chlorite (Chl), primary Fe-Ti oxide (Tnt), and secondary magnetite (Mag).
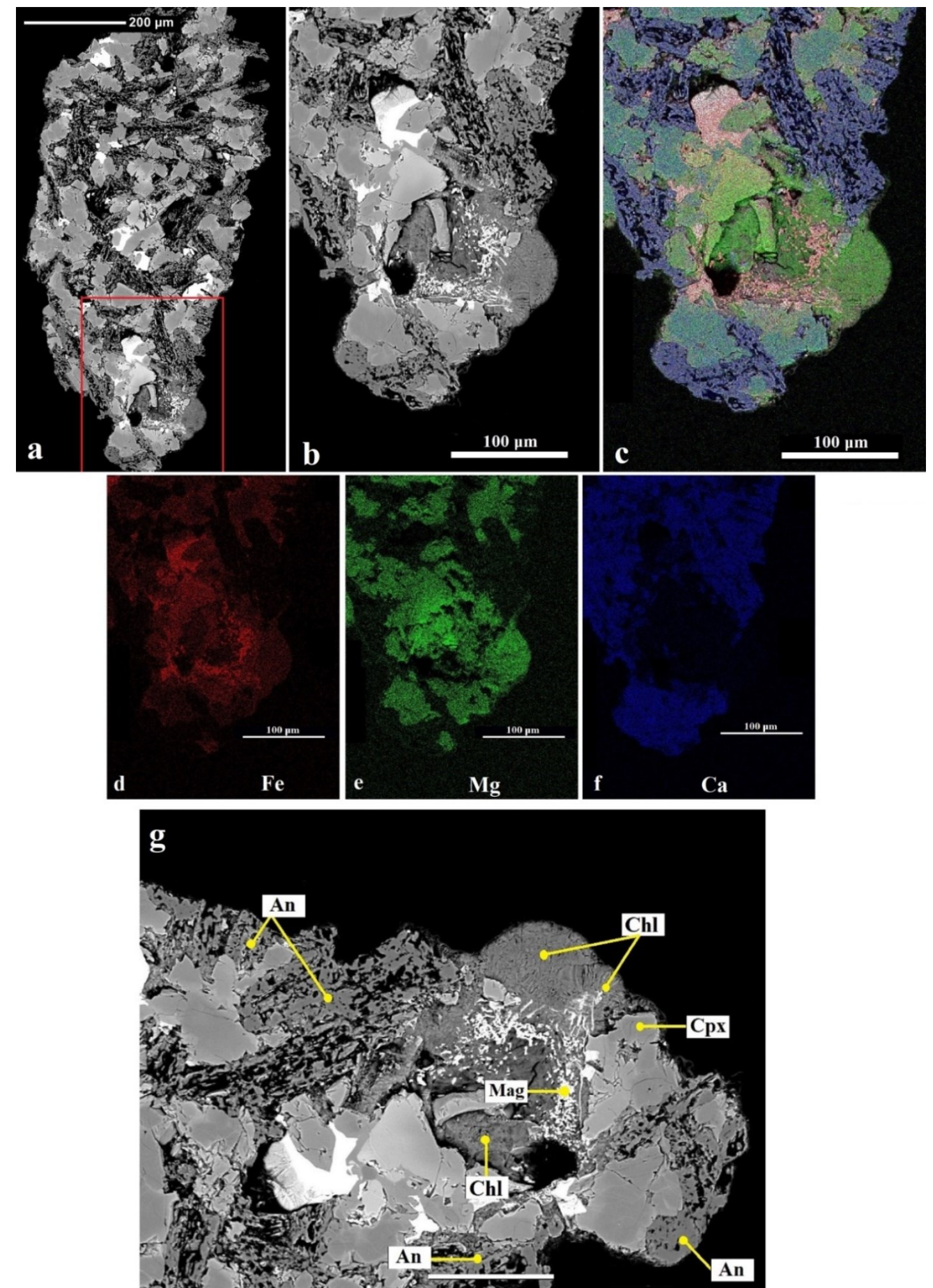


\subsubsection{Mineralogy and Texture of Reacted Basalt: Top of the Reactor (Portion 2)}

Selected grains were taken on the top portion of the rock immediately next to the exit point of the fluid (Fig. 3.23). These were mounted on aluminium stubs for textural analyses by SEM. Selected grains were also mounted in epoxy and polished for SEM-EDS analysis. Appendix B lists complete results for these analyses.

\section{SEM-EDS analysis}

Results confirm less alteration of the basalt grains when compared with the bottom (Portion 1) of the Reactor. Minerals of secondary origin detected were celadonite and titanite. Primary plagioclase, clinopyroxene, olivine and titanomagnetite were also present (Table 3.7).

Table 3.7. Mineral assemblage found during analysis of reacted grains collected from the top (Portion 2) of the Reactor after the BW2 experiment. Appendix B contains all SEM results for this portion of the rock.

\begin{tabular}{|c|c|c|c|}
\hline $\begin{array}{l}\text { Type of } \\
\text { Analysis }\end{array}$ & $\begin{array}{l}\text { Analysis } \\
\text { Material }\end{array}$ & $\begin{array}{l}\text { Mineral } \\
\text { Identified }\end{array}$ & $\begin{array}{c}\text { Average } \\
\text { Mineral Composition }\end{array}$ \\
\hline SEM-EDS & $\begin{array}{l}\text { polished } \\
\text { grains }\end{array}$ & Bytownite & - \\
\hline SEM-EDS & $\begin{array}{l}\text { polished } \\
\text { grains }\end{array}$ & Augite & - \\
\hline SEM-EDS & $\begin{array}{l}\text { polished } \\
\text { grains }\end{array}$ & Forsterite & $\mathrm{Mg}_{1.14} \mathrm{Fe}_{0.85} \mathrm{SiO}_{4},\left(\mathrm{Fo}_{57}-\mathrm{Fa}_{43}\right)$ \\
\hline SEM-EDS & $\begin{array}{l}\text { polished } \\
\text { grains }\end{array}$ & Celadonite & $\begin{array}{l}\qquad \mathrm{K}_{0.17} \mathrm{Mg}_{1.5} \mathrm{Fe}_{1.3} \mathrm{Al}_{0.3} \mathrm{Si}_{3.2} \mathrm{Al}_{0.8} \mathrm{O}_{10}(\mathrm{OH})_{2} \\
\text { (calculated based on the anhydrous composition with } 11 \text { oxygens) }\end{array}$ \\
\hline SEM-EDS & grain surface & Celadonite & $\begin{array}{l}\mathrm{K}_{0.42} \mathrm{Na}_{0.20} \mathrm{Mg}_{1.23} \mathrm{Fe}_{1.62} \mathrm{Al}_{0.25} \mathrm{Si}_{2.98} \mathrm{Al}_{1} \mathrm{O}_{10}(\mathrm{OH})_{2} \\
\text { (calculated based on the anhydrous composition with } 11 \text { oxygens) }\end{array}$ \\
\hline SEM-EDS & grain surface & Sphene & $\mathrm{Ca}_{1.13} \mathrm{Fe}_{0.13} \mathrm{Ti}_{0.80} \mathrm{Al}_{0.23} \mathrm{SiO}_{5}$ \\
\hline SEM-EDS & $\begin{array}{l}\text { polished } \\
\text { grains }\end{array}$ & Titanomagnetite & - \\
\hline
\end{tabular}

Figure 3.26 shows surface textures of grains from the top portion of the Reactor. EDS backscatter images at low magnification show celadonite and titanite. Celadonite forms dense foliated masses while titanite appears as euhedral crystals. No evidence of chlorite or anorthite was found.

Figure 3.27a - e shows SEM backscatter images and EDS maps for epoxy-mounted, polished grains collected from the top portion in the Reactor. The lower intensity of hydrothermal alteration is evident when compared with grains from the bottom of the Reactor (Fig. 3.24). Primary minerals appear relatively unaffected. Also present (Fig. 3.27f) is 
celadonite and relict olivine with substantial loss in $\mathrm{Mg}$ when compared to the unreacted olivine (Table 2.3). Secondary Fe oxide was not observed in these grains.

SEM results for celadonite are summarised in Table 3.8. Repeat SEM-EDS analyses of the epoxy-mounted polished grains show the mineral to contain high concentrations of iron and magnesium with a substantial amount of sodium and potassium but no calcium. Results are very similar to those obtained during analysis of the grains collected from Portion 2 (top of the Reactor) after the BW1 experiment and on the reacted basalt block from this experiment. Table 3.8 reports chemical compositions of the celadonite while Figure 3.28 shows results plotted on the dioctahedral mica ternary diagram (Tappert et al., 2013). 
Figure 3.26. SEM images of grains collected from the top of the Reactor after the BW2 experiment (minerals were identified by SEM-EDS analysis: a) surface of a reacted grain; b) enlargement of the red rectangular area in (a) showing the $\mathrm{K}-\mathrm{Na}-\mathrm{Mg}-\mathrm{Fe}$ aluminosilicate of secondary origin (Cel); (c) surface of a reacted grain; (d) enlargement of the red rectangular area in (c) showing the $\mathrm{K}-\mathrm{Na}-\mathrm{Mg}$-Fe aluminosilicate $(\mathrm{Cel})$ of secondary origin; (e) portion of a reacted grain; (f) enlargement of the red rectangular area in (e) displaying crystals of titanite (Ttn) of secondary origin.
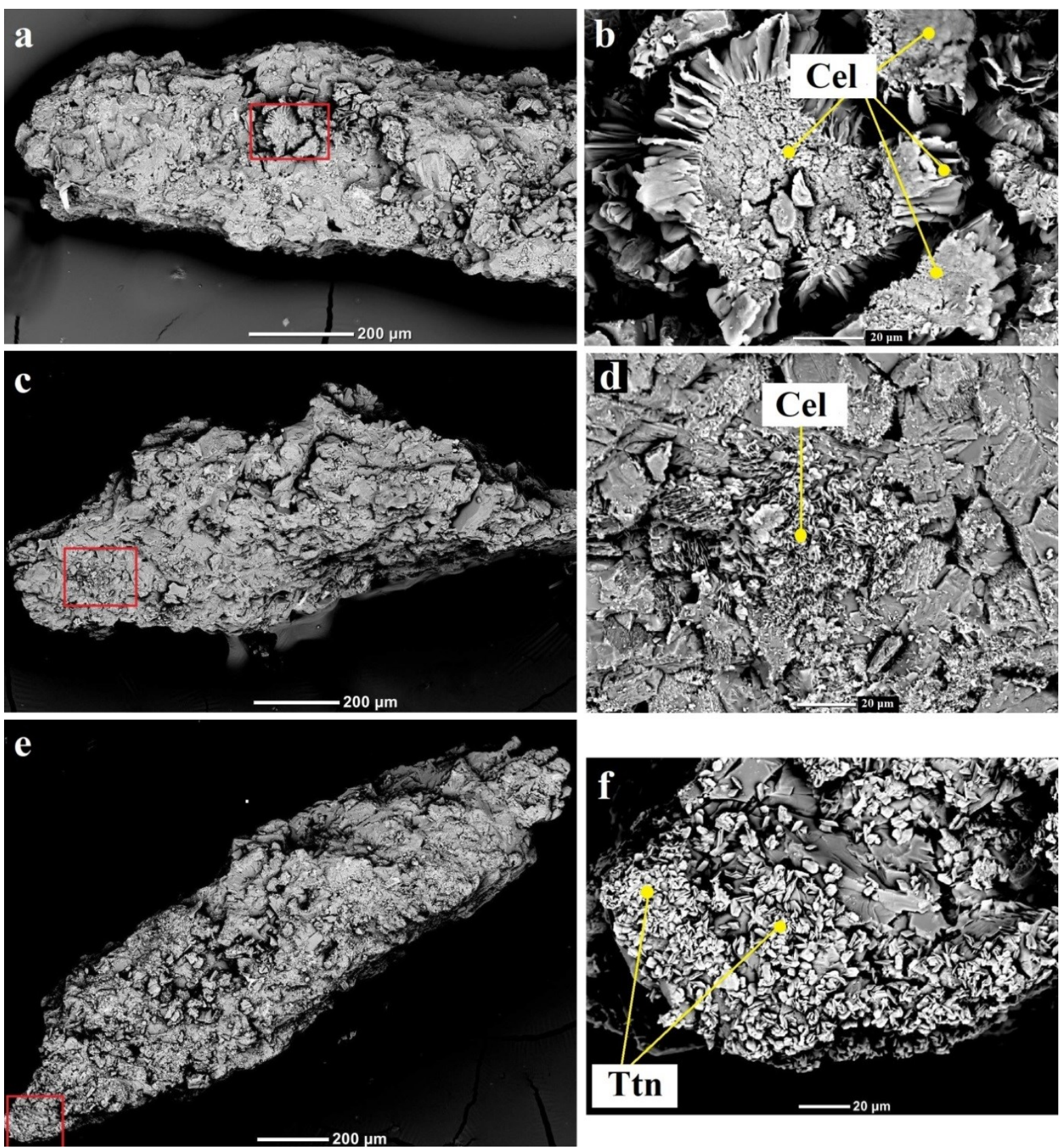
Figure 3.27. SEM backscatter images and EDS compositional maps of an epoxy-mounted, polished grain collected from the top portion of the Reactor after the BW2 experiment: (a) backscatter image of entire grain; (b) composite colour image combining the backscatter image and the elemental maps for c) $\mathrm{Mg}$ in green, d) $\mathrm{Ca}$ in blue, and e) Fe in red. The composite image shows unaltered plagioclase (dark blue), unaltered clinopyroxene (turquoise), unaltered olivine (yellow), oxides (red), and celadonite (green); (f) SEM backscatter image of the red rectangular area in (a) displaying plagioclase $(\mathrm{Plg})$, primary olivine $(\mathrm{Ol})$ and celadonite $(\mathrm{Cel})$.
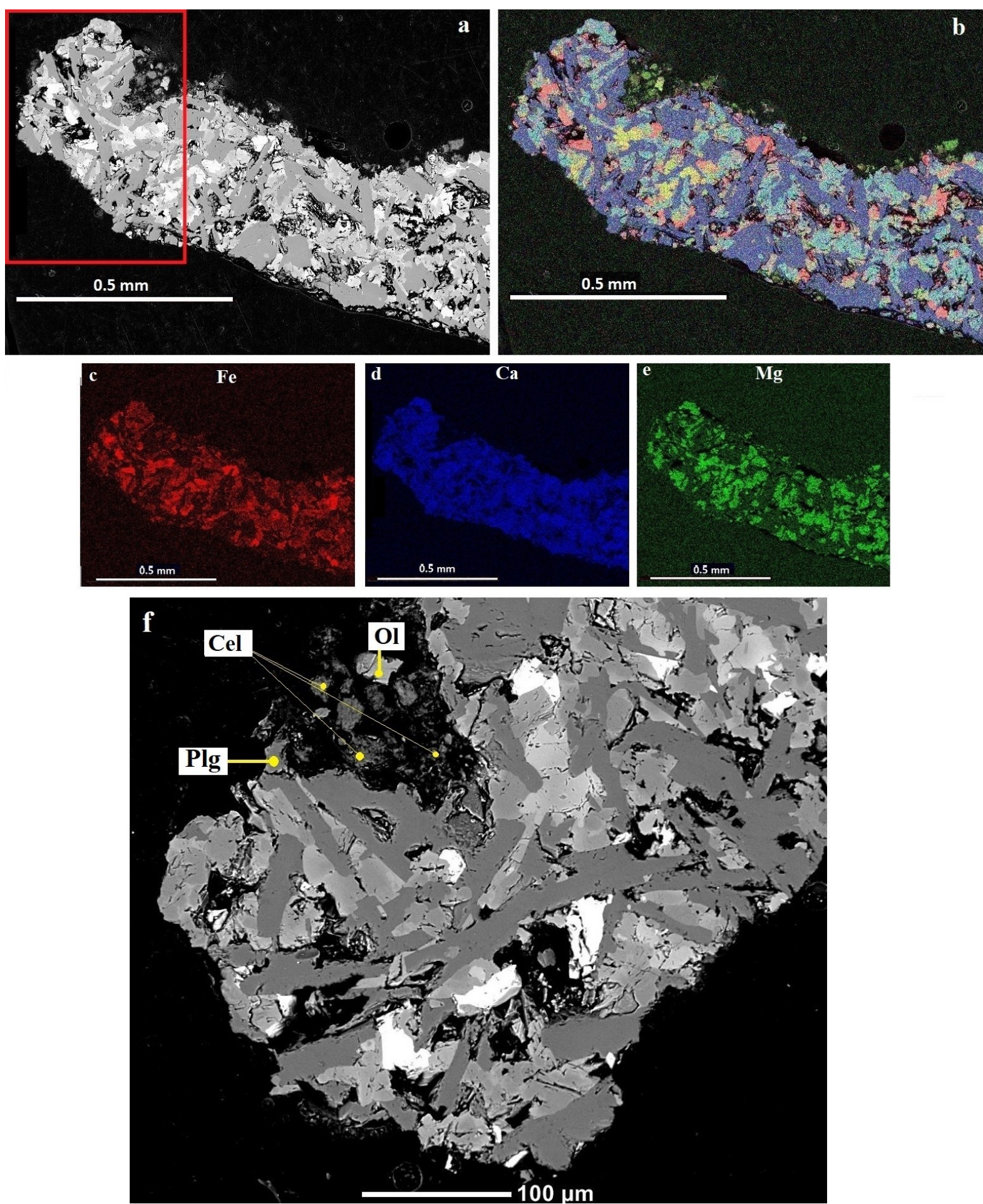
Table 3.8. Average oxides composition (by SEM-EDS analysis) of celadonite found during the morphological examination and from the epoxy-mounted polished section study of grains collected from the top (Portion 2) of the Reactor after the BW2. Empirical formulas reported in Table 3.7. n.d.= not detected.

\begin{tabular}{|ccccc|}
\hline & $\begin{array}{c}\text { Unpolished } \\
(\mathbf{N}=7)\end{array}$ & & \multicolumn{3}{c|}{$\begin{array}{c}\text { Polished } \\
(\mathbf{N}=\mathbf{3})\end{array}$} \\
oxide & $\begin{array}{c}\text { average } \\
\text { Wt } \%\end{array}$ & $\pm 1 \sigma$ & $\begin{array}{c}\text { average } \\
\text { Wt } \%\end{array}$ & $\pm 1 \sigma$ \\
& & & & \\
$\mathbf{N a}_{2} \mathbf{O}$ & 1.43 & 1.38 & n.d. & - \\
$\mathbf{M g O}$ & 11.37 & 3.18 & 14.40 & 1.22 \\
$\mathbf{A l}_{2} \mathbf{O}_{3}$ & 14.76 & 2.22 & 13.88 & 1.28 \\
$\mathbf{S i O}_{2}$ & 41.15 & 3.65 & 46.74 & 1.82 \\
$\mathbf{K}_{2} \mathbf{O}$ & 4.51 & 2.85 & 1.86 & 1.21 \\
$\mathbf{F e O}$ & 26.77 & 5.83 & 23.12 & 0.66 \\
Total & 100.01 & & 100.00 & \\
\hline
\end{tabular}

Figure 3.28. Dioctahedral mica ternary diagram $(\mathrm{Al}, \mathrm{Fe}, \mathrm{Mg})\left(\mathrm{n}^{\circ}\right.$ of atoms) with plotted results from the empirical formula of Table 3.7.

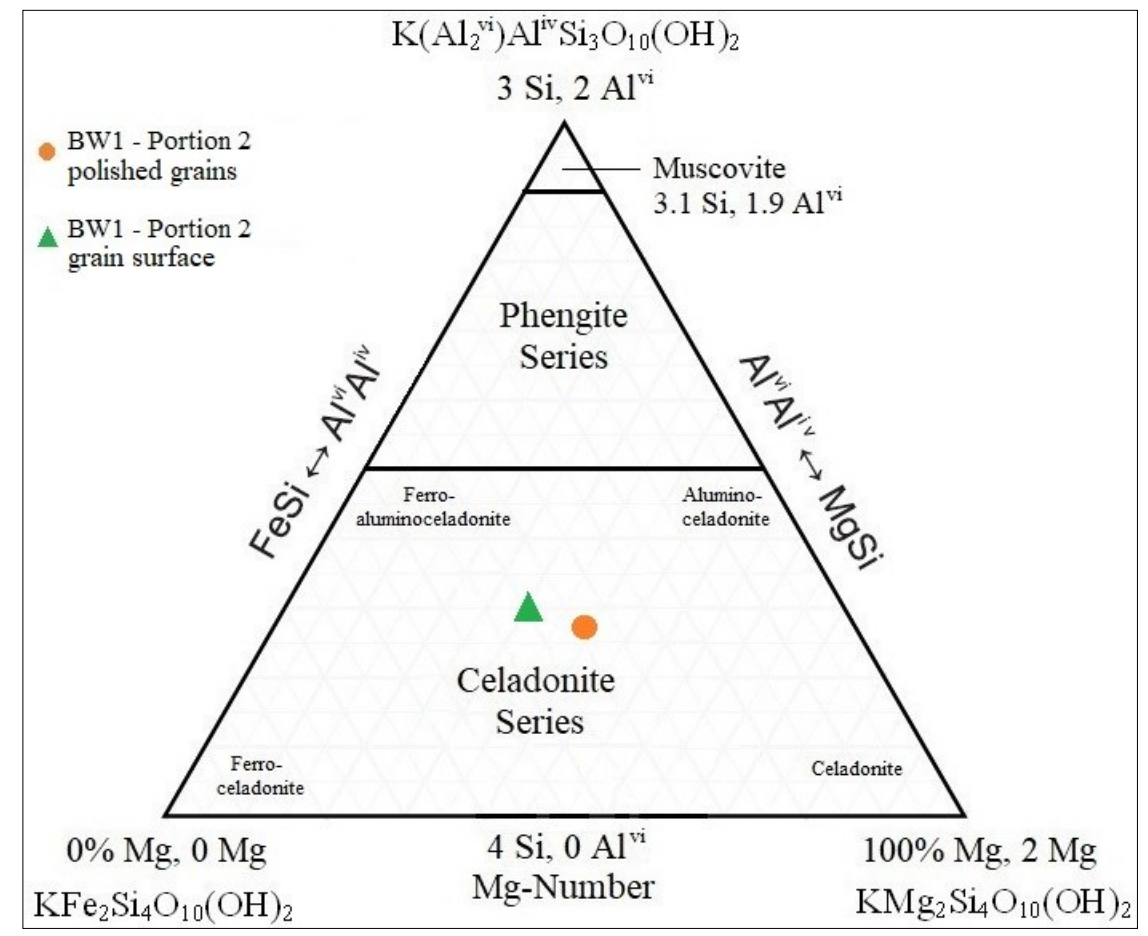

\subsubsection{Mineralogy and Texture of Reacted Basalt: Basalt Block}

The basalt block ( $8 \times 8 \times 4 \mathrm{~mm}$ ) with one polished surface, was positioned vertically near the bottom of the Reactor approximately $0.5-1.0 \mathrm{~cm}$ above the titanium frit (Fig. 3.23). Upon the conclusion of the experiment, the reacted block was mounted on an aluminium stub for SEM-EDS analysis (Table 3.9). Composite mosaic images of the basalt block surface, before and after the experiment are provided in Appendix B. 
Table 3.9. Mineral composition of the reacted basalt block after the BW2 experiment.

\begin{tabular}{|c|c|c|c|}
\hline $\begin{array}{l}\text { Type of } \\
\text { Analysis }\end{array}$ & $\begin{array}{l}\text { Analysis } \\
\text { Material }\end{array}$ & $\begin{array}{l}\text { Mineral } \\
\text { Identified }\end{array}$ & $\begin{array}{c}\text { Average } \\
\text { Mineral Composition }\end{array}$ \\
\hline SEM-EDS & basalt block & Anorthite & $\mathrm{CaAl}_{2} \mathrm{Si}_{2} \mathrm{O}_{8},\left(\mathrm{An}_{94}-\mathrm{Ab}_{6}\right)$ \\
\hline SEM-EDS & basalt block & Augite & $\mathrm{Ca}_{0.40} \mathrm{Mg}_{0.66} \mathrm{Fe}_{0.90} \mathrm{Al}_{0.19} \mathrm{Si}_{1.52} \mathrm{Al}_{0.48} \mathrm{O}_{6}$ \\
\hline SEM-EDS & basalt block & Titanomagnetite & $\mathrm{Fe}^{2+}\left(\mathrm{Fe}^{3+}, \mathrm{Ti}\right)_{2} \mathrm{O}_{4}$ \\
\hline SEM-EDS & basalt block & $\begin{array}{l}\text { Fe-Ni-Cr } \\
\text { Oxide }\end{array}$ & - \\
\hline SEM-EDS & basalt block & Chlorite & $\begin{array}{l}\qquad \mathrm{Mg}_{1.9} \mathrm{Fe}_{2.8} \mathrm{Al}_{1.18} \mathrm{Si}_{2.83} \mathrm{Al}_{1.17} \mathrm{O}_{10}(\mathrm{OH})_{8} \\
\text { (calculated based on the anhydrous composition with } 14 \text { oxygens) }\end{array}$ \\
\hline
\end{tabular}

Figure 3.29a,e show SEM backscatter images of two areas of the unreacted basalt block. They show the ophitic texture, composed of interlocking plagioclase (bytownite) laths (darker grey) with interstitial clinopyroxene (lighter grey). Olivine occurs as isolated anhedral crystals (Fig. 3.29e, examples circled in yellow), while oxides (titanomagnetite) appear as bright white.

Figure $3.29 \mathrm{~b}$,f show the same areas above after reaction. Comparison with the unreacted surfaces show an increase in surface roughness. At low magnification, the most significant observation is the growth of chlorite which replaces clinopyroxene, olivine and, partially, plagioclase. Celadonite was not observed on the block.

Figure $3.29 \mathrm{~g}$, h show higher magnification images of the respective reacted areas (red rectangular areas) showing more in detail the replacement by chlorite. EDS analysis confirms the plagioclase has an anorthitic composition, at least on its surface and has inclusions of chlorite. Clinopyroxene is replaced by epitaxial growths of chlorite. Titanomagnetite appears unaffected. Also identified was the secondary Fe-Ni-Cr oxide phase shown in Figure 3.30 (also identified on basalt block from the BW1 experiment, Fig. 3.18c). In this case, it is found on a relict clinopyroxene grains. 
Figure 3.29. SEM backscatter images: (a) portion (left border) of the basalt block surface before the BW2 experiment; (b) same portion (left border) of the basalt block after the BW2 experiment. In (a) primary plagioclase (Byt) appears in darker grey under backscatter electron detector, while clinopyroxene $(\mathrm{Cpx})$ in lighter gray. In (b) both plagioclase and clinopyroxene are strongly altered; (c) enlargement of red rectangular area in (b); (d) enlargement of red rectangular area in (c) showing in detail the presence of secondary plagiocla se of anorthitic composition (An) and secondary chlorite formation (Chl); (e) left border of the basalt block surface before the BW2 experiment with primary plagioclase (Byt) and clinopyroxene (Cpx) and isolated crystals of olivine (yellow ovals); (f) same same area in (e) after the BW2 experiment with strongly altered plagioclase, clinopyroxene and olivine; (g) enlargement of the red rectangular area 1 in (f) showing secondary plagioclase of anorthitic composition (An); (h) enlargement of the red rectangular area 2 in (f) showing secondary plagioclase of anorthitic composition (An) and secondary chlorite formation (Chl) where chlorite replaces all primary silicates (olivine, plagioclase and clinopyroxene).
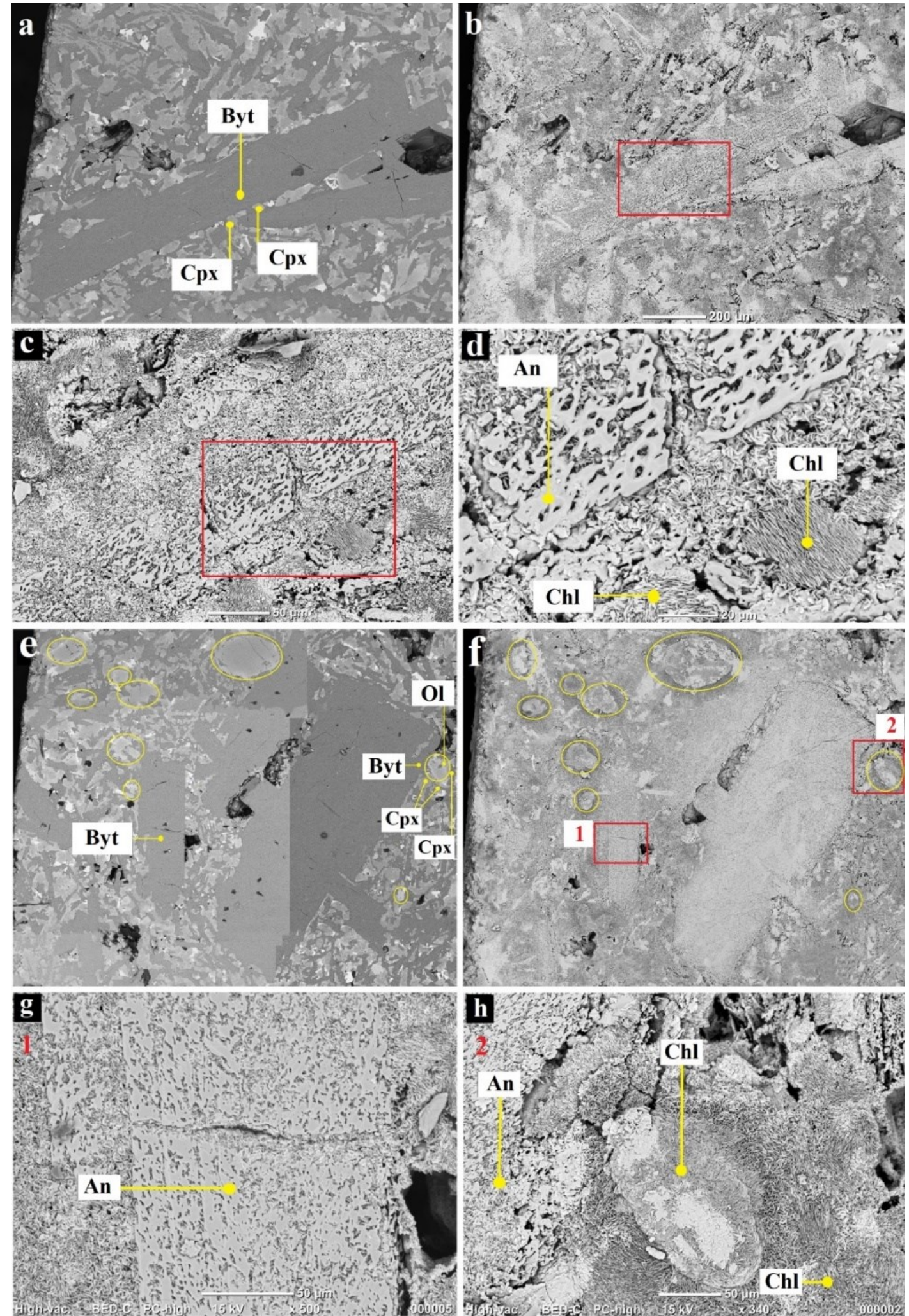
Figure 3.30. SEM backscatter images of the basalt block after the BW2 experiment showing a relict clinopyroxene grain. The mineral has an unaltered inclusion of primary titanomagnetite and a secondary Fe-Ni-Cr oxide phase. Chlorite crystals surround the relict clinopyroxene.

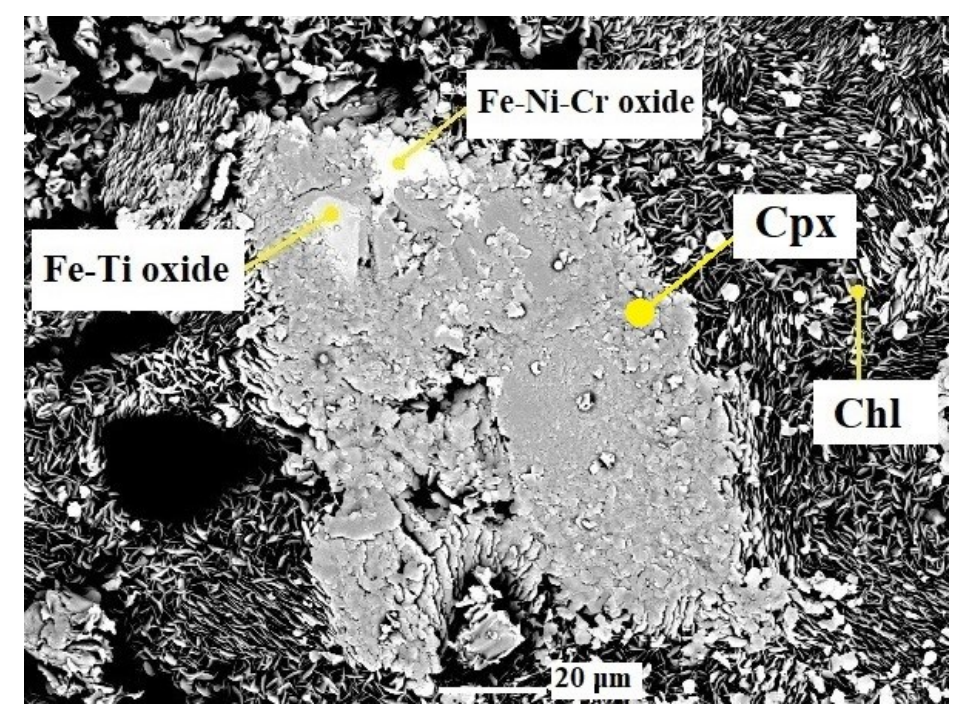




\subsection{Discussion}

\subsubsection{Major and trace element exchange during water - rock interaction}

Major ions

The basalt-water experiments were conducted at room $\mathrm{T}$ for the first week and then conditions were shifted to $350^{\circ} \mathrm{C}(\mathrm{BW} 2)$ and $400^{\circ} \mathrm{C}$ (BW1). Pressure was maintained constant at 490 and 502 bar for BW2 and BW1, respectively. During room temperature conditions, several major ions $\left(\mathrm{SiO}_{2}, \mathrm{Al}, \mathrm{Ca}, \mathrm{Na}, \mathrm{Fe}, \mathrm{Mg}\right.$ and $\left.\mathrm{Cl}\right)$ increase in the solution, but only in small amounts. In the same way, trace elements such as $\mathrm{Cr}, \mathrm{Co}, \mathrm{Ni}, \mathrm{Cu}, \mathrm{Zn}, \mathrm{Mo}$ and $\mathrm{Pb}$ increase to a minor degree.

After temperature increase, silica concentrations remain oversaturated with respect to quartz in both experiments. After $\sim 243 \mathrm{hr}$ at subcritical condition and $\sim 242 \mathrm{hr}$ at supercritical conditions, they decrease below saturation with respect to quartz. The initial high $\mathrm{SiO}_{2}$ values are attributed to the dissolution of volcanic glass after the shift in temperature, both at 350 and $400^{\circ} \mathrm{C}$. The decrease in $\mathrm{SiO}_{2}$ concentrations at $\sim 240 \mathrm{hr}$ indicates complete dissolution of basaltic glass in both experiments (Fig. 3.31).

In order to estimate the amount of volcanic glass present in the experiments, the integrated $\mathrm{SiO}_{2}$ flux was calculated (Fig. 3.31a, e). This was done by summing the total volume of each sample multiplied by the silica concentration in that sample. For BW2 and BW1 this is equal to 896 and $769 \mathrm{mg}$, respectively. Note that after the loss of the volcanic glass, $\mathrm{SiO}_{2}$ concentration decreases to a lower steady state value. If it is assumed that this $\mathrm{SiO}_{2}$ flux is due to dissolution of primary basalt minerals (plagioclase, pyroxene, olivine), this can be subtracted from the total flux to estimate $\mathrm{SiO}_{2}$ content released from glass. The $\mathrm{SiO}_{2}$ flux from silicate minerals (Fig. 3.31b,f) was estimated using the average silica contents of the last two fluid samples and applying this over the whole experiment. This amounted to 489 and $347 \mathrm{mg}$ for BW2 (including blank input mass composition supposing no fluid-rock exchange) and BW1, respectively. These values were subtracted from the total $\mathrm{SiO}_{2}$ flux to estimate the amount of silica released from the glass. This resulted in a value of 405 and 422 $\mathrm{mg}$ of $\mathrm{SiO}_{2}$ for BW2 and BW1, respectively. The total amount of glass can be then calculated from the EMPA analyses (Table 2.3). This gives $\sim 597 \mathrm{mg}$ of glass for the BW2 and $\sim 622$ of glass for the BW1. This means that the basalt contains about $2.5 \%$ glass by weight. This seems reasonable given the low abundance of glass found during petrographic examination.

It should be emphasised that this is an estimate as there is evidence that secondary minerals have formed in some of the voids where glass was present. Figure 3.32 shows the 
typical "rosette structure" (Carstens, 1975; Jafri and Charan, 1992) left over during the glass devitrification process. The constituents of these minerals likely came from the original glass. This is supported by the low concentrations of $\mathrm{Ca}$ and $\mathrm{Al}$ in the fluid relative to that expected from congruent dissolution of the glass (Table 3.10). In addition, it is assumed that the dissolution of primary minerals is not suppressed by the high $\mathrm{SiO}_{2}$ concentrations during glass dissolution, thus the calculation is a minimum estimate of the amount of glass. All details of the calculations are reported in Appendix B.

Table 3.10. Mass flux of major elements estimated by dissolution of volcanic glass and from the fluid sample compositions over the BW1 and BW2.

\begin{tabular}{|c|c|c|c|c|c|c|c|}
\hline $\begin{array}{c}\text { BW2 } \\
\left(350^{\circ} \mathrm{C} / 490 \text { bar }\right)\end{array}$ & $\mathbf{K}$ & Cl & $\mathrm{SO}_{2}$ & Ca & $\mathbf{N a}$ & Mg & $\mathbf{F e}$ \\
\hline $\begin{array}{c}\text { Elements Estimated } \\
\text { From Volcanic Glass / mg } \\
\text { (over the entire experiment) }\end{array}$ & 6.6 & 0.52 & 0.12 & 21.9 & 26.3 & 2.8 & 18 \\
\hline $\begin{array}{c}\text { Total Elements Flux } \\
\text { From Fluid Samples / mg } \\
\text { (over the entire experiment) }\end{array}$ & 9 & 2 & $\mathbf{S}_{\mathrm{tot}}=1.5$ & 0.6 & 38.1 & 0.11 & 0.37 \\
\hline $\begin{array}{c}\text { BW1 } \\
\left(400^{\circ} \mathrm{C} / 502 \text { bar }\right)\end{array}$ & $\mathbf{K}$ & $\mathrm{Cl}$ & $\mathrm{SO}_{2}$ & $\mathrm{Ca}$ & $\mathbf{N a}$ & Mg & $\mathbf{F e}$ \\
\hline $\begin{array}{c}\text { Elements Estimated } \\
\text { From Volcanic Glass / mg } \\
\text { (over the entire experiment) }\end{array}$ & 7.1 & 0.56 & 0.12 & 23 & 28 & 3 & 20 \\
\hline $\begin{array}{l}\text { Total Elements Flux } \\
\text { From Fluid Samples / mg } \\
\text { (over the entire experiment) }\end{array}$ & 4.8 & 1.7 & $\mathbf{S}_{\text {tot }}=1.4$ & 0.36 & 24.2 & 0.075 & 0.22 \\
\hline
\end{tabular}


Figure 3.31. $\mathrm{SiO}_{2}$ concentration $\left(\mathrm{mmol} \mathrm{kg}^{-1}\right)$ vs time (hr) for the $\mathrm{BW} 2$ and the $\mathrm{BW} 1$ experiments: a) total $\mathrm{SiO} 2$ flux for $\mathrm{BW} 2$ based on sample volume and solution composition (pink area); b) total $\mathrm{SiO}_{2}$ flux from silicate minerals (green) based on the average $\mathrm{SiO} \mathrm{O}_{2}$ concentration in the last two samples $\left(0.5 \mathrm{ml} \mathrm{hr}^{-1}\right.$ flow rate) less the input water composition (grey); c) the difference between a) and b) representing the net $\mathrm{SiO}_{2}$ flux from glass for $\mathrm{BW} 2$ (orange area); d) total $\mathrm{SiO}_{2}$ flux for $\mathrm{BW} 2$ (orange + green area); e) total $\mathrm{SiO}{ }_{2}$ flux for BW1 based on sample volume and solution composition (pink area); f) total $\mathrm{SiO}_{2}$ flux from silicate minerals (green) based on the average $\mathrm{SiO}_{2}$ concentration in the last two samples $\left(0.5 \mathrm{ml} \mathrm{hr}^{-1}\right.$ flow rate) (green area); g) difference between a) and b) representing the total $\mathrm{SiO} 2$ flux from glass for BW1 (orange area).
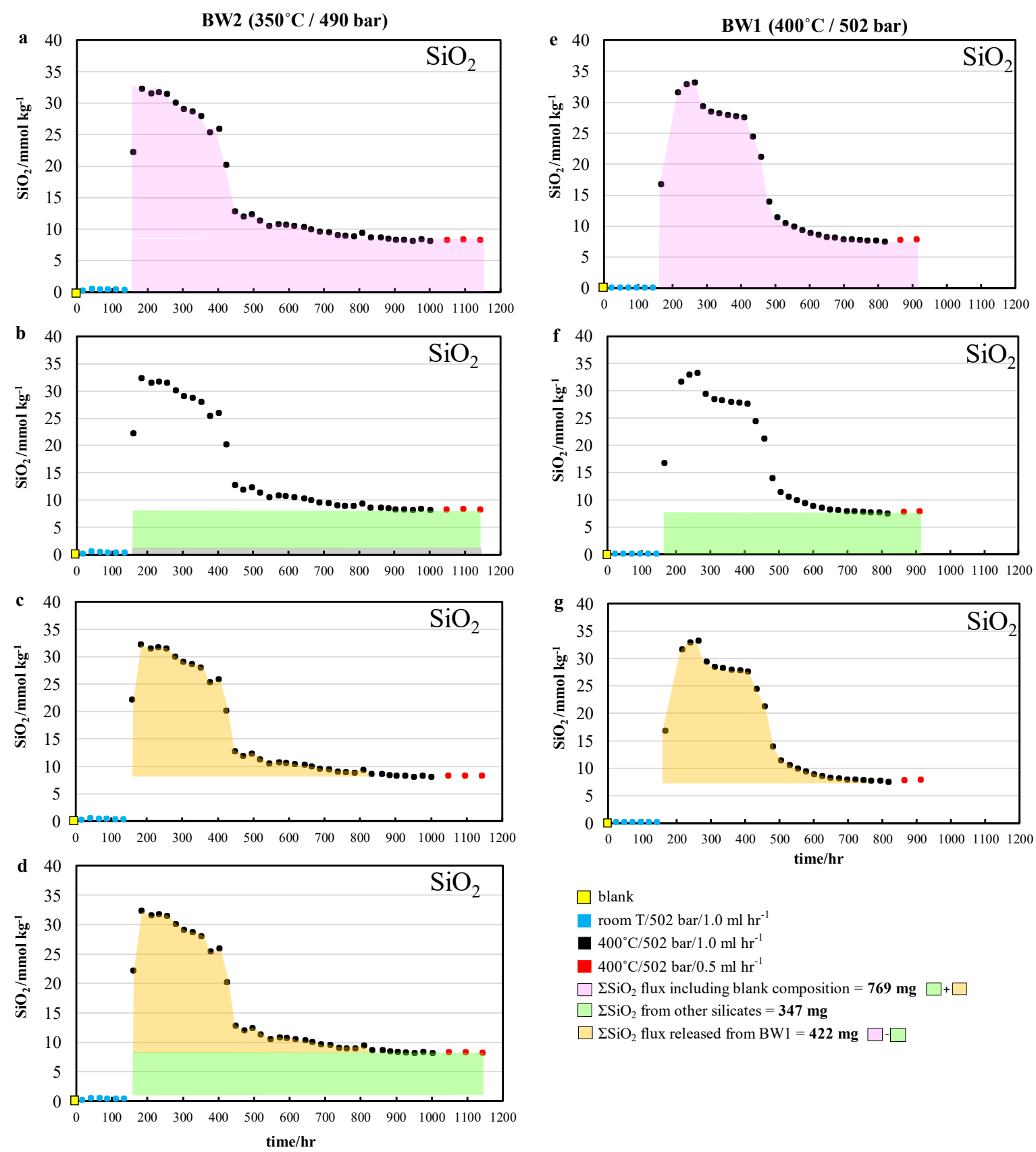

$\square$ blank

room $\mathrm{T} / 502 \mathrm{bar} / 1.0 \mathrm{ml} \mathrm{hr}^{-1}$

$400^{\circ} \mathrm{C} / 502 \mathrm{bar} / 1.0 \mathrm{ml} \mathrm{hr}^{-1}$

$400^{\circ} \mathrm{C} / 502 \mathrm{bar} / 0.5 \mathrm{ml} \mathrm{hr}^{-1}$

$\square \mathrm{SiO}_{2}$ flux including blank composition $=\mathbf{7 6 9} \mathbf{~ m g} \square+\square$

$\Sigma \mathrm{SiO}_{2}$ from other silicates $=\mathbf{3 4 7} \mathbf{~ m g}$

$\square \Sigma \mathrm{SiO}_{2}$ flux released from $\mathrm{BW} 1=\mathbf{4 2 2} \mathbf{~ m g} \square-\square$

$\square$ blank

room $\mathrm{T} / 490 \mathrm{bar} / 1.0 \mathrm{ml} \mathrm{hr}^{-1}$

$350^{\circ} \mathrm{C} / 490 \mathrm{bar} / 1.0 \mathrm{ml} \mathrm{hr}^{-1}$

$350^{\circ} \mathrm{C} / 490 \mathrm{bar} / 0.5 \mathrm{ml} \mathrm{hr}^{-1}$

$\Sigma \mathrm{SiO}_{2}$ flux including blank composition $=896 \mathrm{mg} \quad \square+\square+\square$

$\square \Sigma \mathrm{SiO}_{2}$ imput mass calculated based on blank composition $=\mathbf{2 . 4} \mathbf{~ m g}$

$\square \Sigma \mathrm{SiO}_{2}$ flux from other silicates $=\mathbf{4 8 9} \mathbf{~ m g} \square-(\square+\square)$

$\square+\square \Sigma \mathrm{SiO}_{2}$ area subtracted for the glass calculation $=\mathbf{4 9 1} \mathbf{~ m g}$

$\square \Sigma \mathrm{SiO}_{2}$ flux from glass for $\mathrm{BW} 2=\mathbf{4 0 5} \mathbf{~ m g}$

$\square+\square \Sigma \mathrm{SiO}_{2}$ flux realesed from $\mathrm{BW} 2=\mathbf{8 9 4} \mathbf{~ m g}$ 
Figure 3.32. Secondary mineral growths in voids left by the dissolution of volcanic glass with the typical "rosette structure". This was found in the basalt block from the BW1 experiment $\left(400^{\circ} \mathrm{C} / 502\right.$ bar $)$.
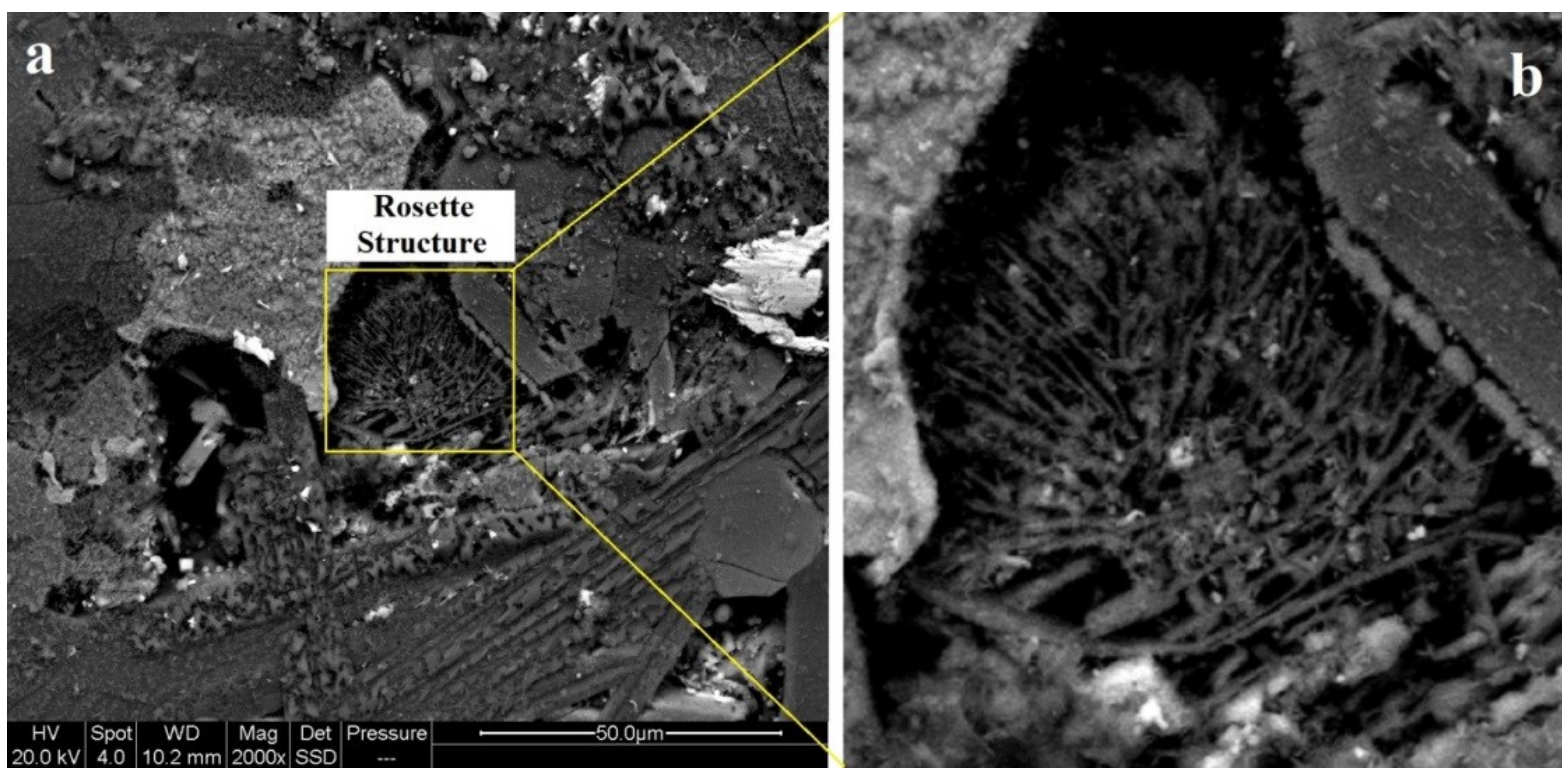

With an estimate of the amount of volcanic glass, the amount of its constituent elements can be estimated. This is done by multiplying the $w t \%$ of a component from the EMPA results by the weight of the volcanic glass estimated above. Total element flux from the experiment can also be calculated from the chemistry of the reacted fluid compositions. These results allow a comparison of the content of a component in the rock with its total flux from the experiment. For example, the concentration of $\mathrm{Cl}$ in the glass measured by EMPA analysis is $0.09 \mathrm{wt} \%$. This is equal to $\sim 0.6 \mathrm{mg}$ of chlorine available in the glass during the experiments. The $\Sigma \mathrm{Cl}$ flux measured from fluid chemistry is higher at $\sim 2 \mathrm{mg}$ in both experiments. The large difference could be explained by inhomogeneity in the glass $\mathrm{Cl}$ content and thus the amount of $\mathrm{Cl}$ may be underestimated based on EMPA analyses. For example, the glass contains distinct crystals of apatite which could contain a higher $\mathrm{Cl}$ content. The correlation of $\mathrm{SiO}_{2}$ released during glass dissolution with $\mathrm{Cl}$ concentration over the same period (Fig. 3.33a,b) shows that $\mathrm{Cl}$ must have been derived from the glass.

Potassium is derived mainly from the volcanic glass (indeed glass was identified in the polished thin section by EDS maps of K). The plagioclase in the rock is also expected to contain a small amount of $\mathrm{K}$. Microprobe analysis of the glass gave a concentration of $\mathrm{K}_{2} \mathrm{O}$ of $1.37 \mathrm{wt} \%$, or $1.14 \mathrm{wt} \%$ of $\mathrm{K}$. This equates $\sim 7 \mathrm{mg}$ of $\mathrm{K}$ available in both experiments. The $\Sigma \mathrm{K}$ flux calculated from fluid chemistry is $9 \mathrm{mg}$ (BW2) and $4.8 \mathrm{mg}$ (BW1) from the rock. At $350^{\circ} \mathrm{C}$, the higher amount of potassium calculated in the fluid flux indicates the complete release of $\mathrm{K}$ present in the glass plus an extra amount released by a stronger dissolution of the plagioclase. At $400^{\circ} \mathrm{C}$, the lower amount of potassium calculated in the fluid flux indicates 
precipitation of a greater amount of the secondary K-bearing mineral phase. The precipitation of a secondary K-bearing phase is supported by the SEM results and the negative correlation between $\mathrm{K}$ and $\mathrm{SiO}_{2}$ during glass dissolution (Fig. 3.33c,d). Once the glass has been dissolved, concentrations of $\mathrm{K}$ are higher at the same time silica is low. At this point, the lower concentration of $\mathrm{K}$ is controlled by minerals in the basalt.

Figure 3.33. Plots of $\mathrm{Cl}$ and $\mathrm{K}\left(\mathrm{mmol} \mathrm{kg}{ }^{-1}\right)$ versus $\mathrm{SiO}_{2}\left(\mathrm{mmol} \mathrm{kg}^{-1}\right)$ for the $\mathrm{BW} 1$ and $\mathrm{BW}$. Symbols in red represent values during glass dissolution, while symbols in blue represent values after glass dissolution.
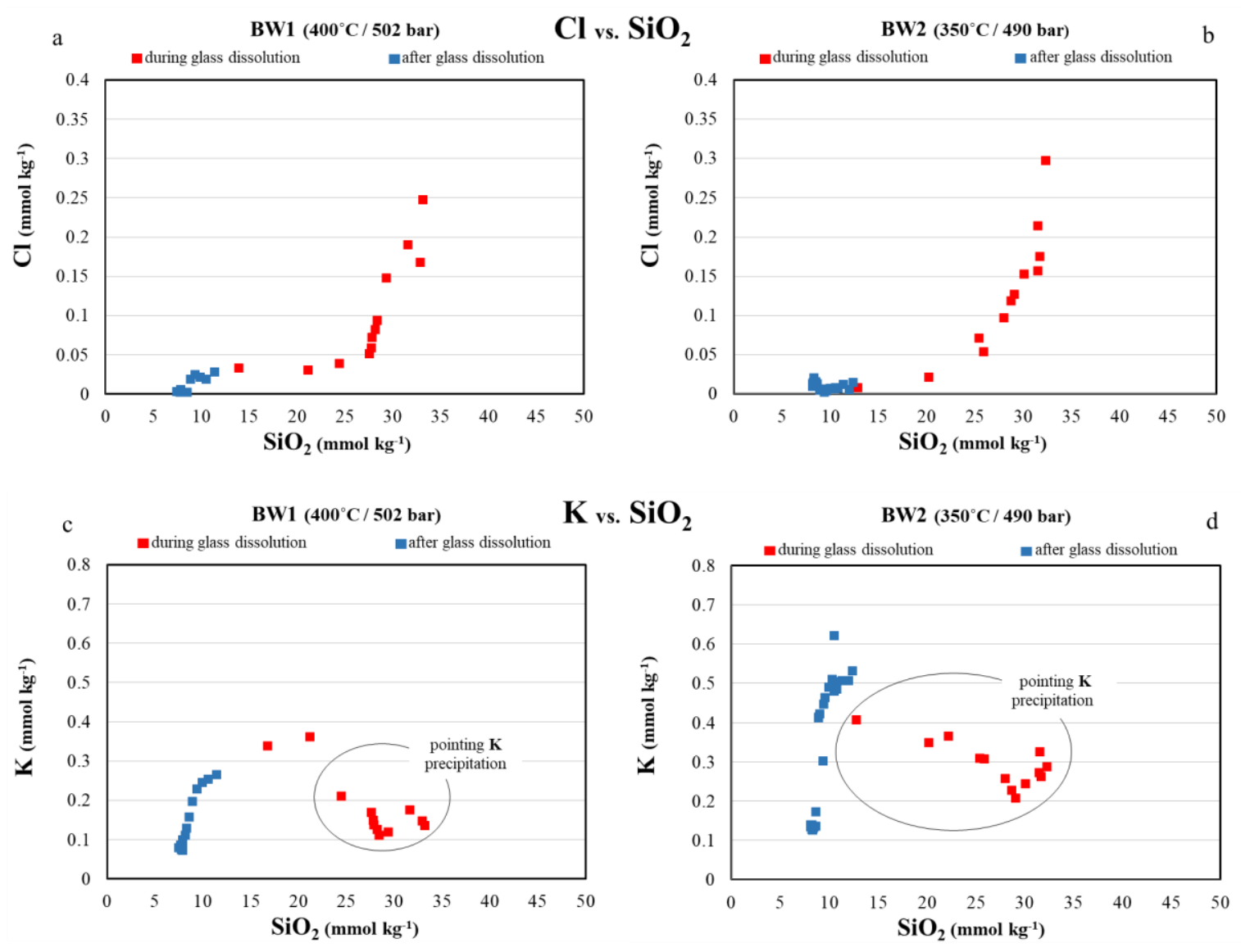

The presence of $\mathrm{H}_{2} \mathrm{~S}$ and $\mathrm{SO}_{4}{ }^{2-}$ in the fluid are attributed to dissolution of $\mathrm{SO}_{2}$ and immiscible sulfide blebs trapped in the volcanic glass. Hydrogen sulfide can be generated from dissolution of Fe sulfide (eq. 1):

$$
\mathrm{FeS}+2 \mathrm{H}^{+}=\mathrm{Fe}^{2+}+\mathrm{H}_{2} \mathrm{~S}
$$

It is also possible that some sulfide is generated by the reduction of $\mathrm{SO}_{2}$ (eq. 2):

$$
4 \mathrm{SO}_{2}+4 \mathrm{H}_{2} \mathrm{O}=\mathrm{H}_{2} \mathrm{~S}+3 \mathrm{H}_{2} \mathrm{SO}_{4}
$$

However, there is a strong correlation between $\mathrm{SiO}_{2}$ and $\mathrm{H}_{2} \mathrm{~S}$ (Fig. 3.34a,b) showing that the sulfide is being released solely from the glass. 
The release of $\mathrm{SO}_{2}$ to the solution explains the presence of $\mathrm{SO}_{4}{ }^{2-}$. This occurs when sulfurous acid $\left(\mathrm{H}_{2} \mathrm{SO}_{3}\right)$ forms by the dissolution of $\mathrm{SO}_{2}$ in the fluid (eq. 3), followed by its oxidation to sulfate possibly in either the experiment or in the sampling syringe (eq. 4):

$$
\begin{aligned}
\mathrm{SO}_{2}+\mathrm{H}_{2} \mathrm{O} & =\mathrm{H}_{2} \mathrm{SO}_{3} \\
\mathrm{H}_{2} \mathrm{SO}_{3}+\frac{1}{2} \mathrm{O}_{2} & =\mathrm{SO}_{4}{ }^{2-}+2 \mathrm{H}^{+}
\end{aligned}
$$

The concentration of $\mathrm{SO}_{2}$ in the glass (Table 2.3) is $0.04 \mathrm{wt} \%$ or $0.02 \mathrm{wt} \%$ of $\mathrm{S}$. This is equal to $0.12 \mathrm{mg}$ of $\mathrm{S}$ available in the unaltered glass in both experiments. The amount of total S (reduced and oxidized) calculated from the fluid chemistry ( $\Sigma \mathrm{H}_{2} \mathrm{~S}$ and $\Sigma \mathrm{SO}_{4}{ }^{2-}$ flux) after completion of the BW2 and BW1 is $1.5 \mathrm{mg}$. The higher flux of S calculated from the fluid samples is due to the dissolution of Fe sulfide blebs present in the volcanic glass which apparently were not encountered during EMPA measurements.

The release of $\mathrm{S}$ from the glass also explains the initial low quench $\mathrm{pH}$ values measured after the temperature change. Once the glass is depleted the quench $\mathrm{pH}$ values become basic at 9.6 and 9.2 at 350 and $400^{\circ} \mathrm{C}$, respectively. However, the in situ $\mathrm{pH}$ at the experimental temperature is close to neutral, with an average value of 6.0 and 5.5 for BW1 and BW2, respectively.

At temperature the sulfite/sulfate anion created by the release of $\mathrm{SO}_{2}$ from the glass is protonated forming bisulfite and/or bisulfate (eq. 5 and 6):

$$
\begin{aligned}
& \mathrm{H}^{+}+\mathrm{SO}_{3}^{2-}=\mathrm{HSO}_{3}^{-} \\
& \mathrm{H}^{+}+\mathrm{SO}_{4}^{2-}=\mathrm{HSO}_{4}^{-}
\end{aligned}
$$

This buffers in situ $\mathrm{pH}$ to near neutral, however, these anions deprotonate upon cooling and thus room temperature $\mathrm{pH}$ is acid.

Once the volcanic glass is dissolved there is no longer a source for $\mathrm{S}$. This results in $\mathrm{pH}$ increasing to basic values due to cation exchange with the rock minerals. In order to dissolve cations such as $\mathrm{Ca}, \mathrm{Na}$ and $\mathrm{K}$ from the rock, it requires the consumption of $\mathrm{H}^{+}$and which explains the $\mathrm{pH}$ increase. Figure 3.34a-f shows the correlations between $\mathrm{H}_{2} \mathrm{~S}$ and $\mathrm{SO}_{4}$ versus $\mathrm{SiO}_{2}$ and of Fe versus $\mathrm{H}_{2} \mathrm{~S}$. There are clear correlations between $\mathrm{H}_{2} \mathrm{~S}$ and $\mathrm{SO}_{4}$ versus $\mathrm{SiO}_{2}$. There is also a strong correlation between $\mathrm{Fe}$ and $\mathrm{H}_{2} \mathrm{~S}$. This confirms that the hydrogen sulfide formation is due to the dissolution of Fe-sulfide present in the volcanic glass. 
Figure 3.34. Plots of $\mathrm{H}_{2} \mathrm{~S}$ and $\mathrm{SO}_{4}\left(\mathrm{mmol} \mathrm{kg}^{-1}\right)$ versus $\mathrm{SiO}_{2}\left(\mathrm{mmol} \mathrm{kg}^{-1}\right)$ and $\mathrm{Fe}\left(\mathrm{mmol} \mathrm{kg}{ }^{-1}\right)$ versus $\mathrm{H}_{2} \mathrm{~S}\left(\mathrm{mmol} \mathrm{kg}^{-1}\right)$ for the BW1 and BW2. Symbols in red represent values during glass dissolution, while symbols in blue represent values after glass dissolution.
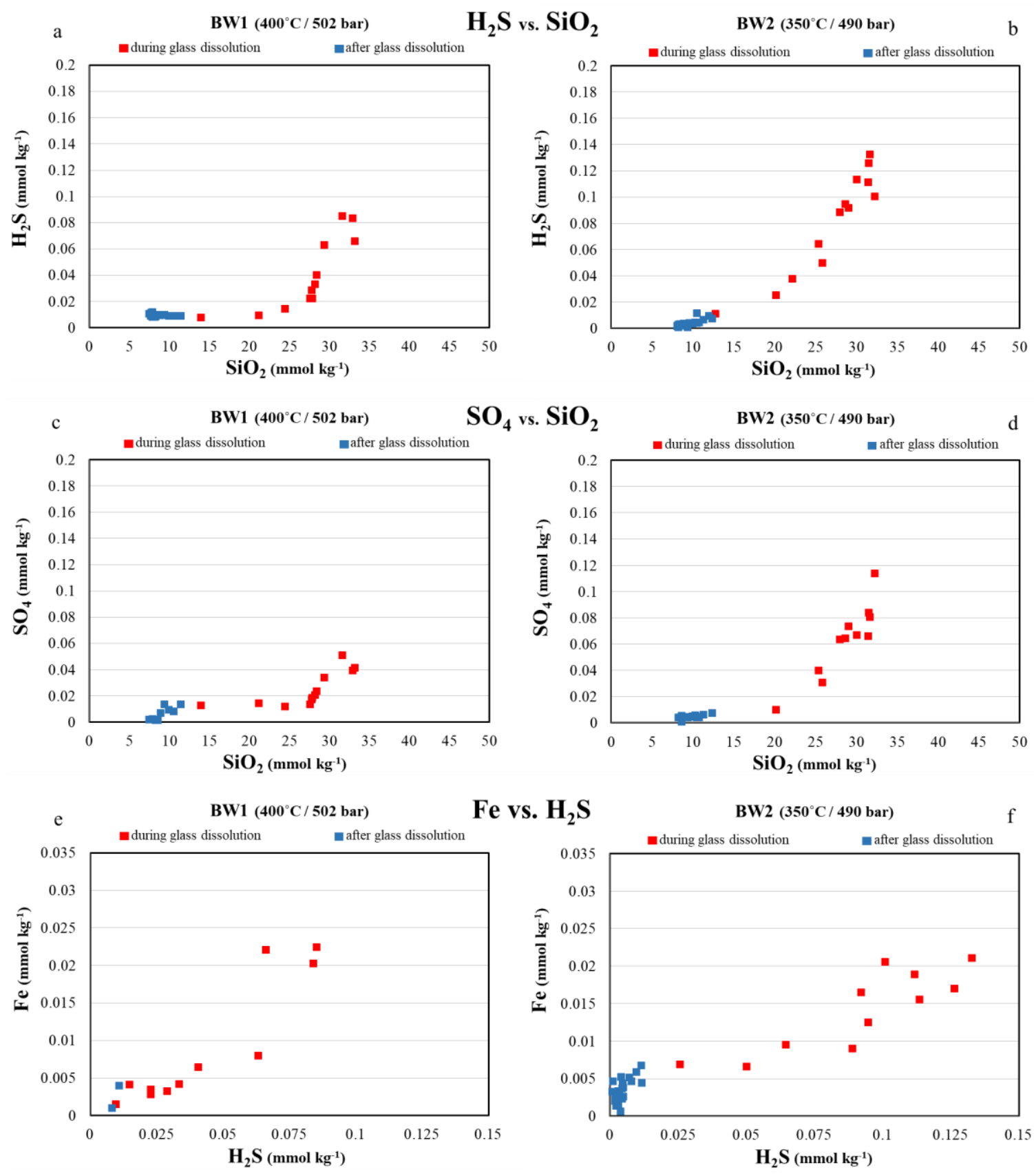


\section{Trace elements}

Trace element concentrations give important information about the capacity of basalt to release or retain these elements during water - rock interaction, both at subcritical and at supercritical experimental conditions (Fig. 3.3 - 3.4, Fig. 3.21 - 3.22). In the following discussion, only elements that show clear trends are considered. These include $\mathrm{Cu}, \mathrm{Co}$, Mo and V. Elements which do not show clear trends were excluded (Mn, Ni, $\mathrm{Zn}, \mathrm{Pb}, \mathrm{Ba}, \mathrm{Cr}, \mathrm{Au}$ and $\mathrm{Ag})$.

$\mathrm{Cu}$. At $400^{\circ} \mathrm{C}$ there is a good correlation between $\mathrm{Cu}$ and $\mathrm{SiO}_{2}$ (Fig. 3.35a) indicating that $\mathrm{Cu}$ is being released during the dissolution of volcanic glass. The correlation between $\mathrm{Cu}$ and $\mathrm{H}_{2} \mathrm{~S}$ indicates that copper is hosted by the Fe sulfide blebs in the glass. At $350^{\circ} \mathrm{C}$ (Fig. 35b), there is ample evidence that the glass is dissolving (Fig. 3.34), however, there is essentially no detectable copper. This suggests the precipitation of a $\mathrm{Cu}$-bearing phase.

Figure 3.35. Plots of $\mathrm{Cu}\left(\mu \mathrm{mol} \mathrm{kg}{ }^{-1}\right)$ versus $\mathrm{SiO}_{2}$ and $\mathrm{H}_{2} \mathrm{~S}\left(\mu \mathrm{mol} \mathrm{kg}{ }^{-1}\right)$ for the $\mathrm{BW} 1$ and $\mathrm{BW} 2$. Symbols in red represent values during glass dissolution, while symbols in blue represent values after glass dissolution.
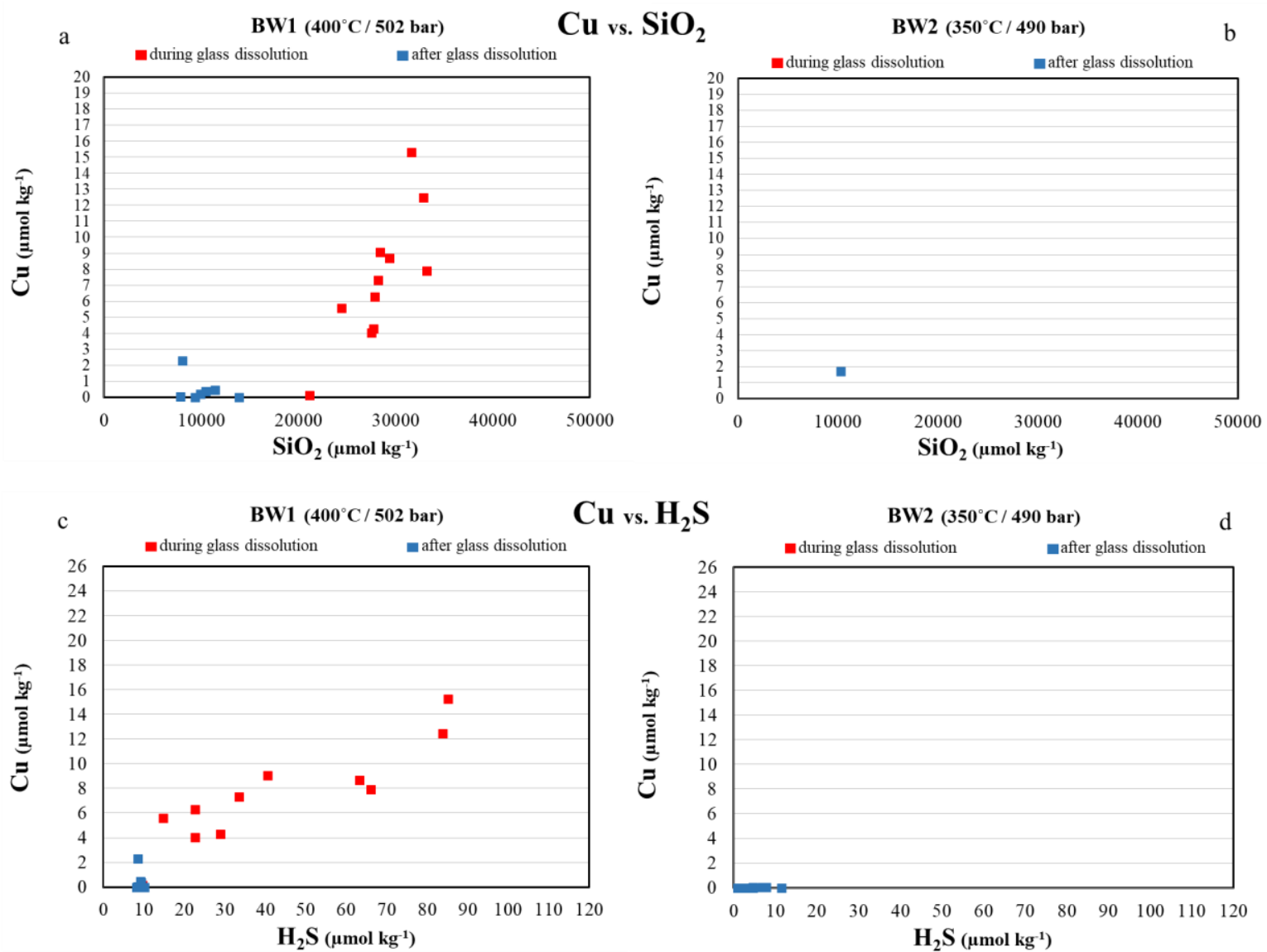
Co, Mo. At $350^{\circ} \mathrm{C}$ there appears to be no significant difference in Co concentrations during and after glass dissolution (Fig. 3.36b), however, at $400^{\circ} \mathrm{C}$ there is a positive relationship between $\mathrm{Co}$ and $\mathrm{SiO}_{2}$ when glass is dissolving (Fig. 3.36a). This suggests that, as with copper, Co is derived from sulfides in the volcanic glass but that at $350^{\circ} \mathrm{C}$ its mobility is limited and it is precipitating in a secondary phase. For Mo, there is a positive correlation with $\mathrm{SiO}_{2}$ at both temperatures (Fig. 3.36c,d). This suggests its derivation from the volcanic glass, or the sulfide blebs in the glass (Fig. 3.37).

$V$. At $350^{\circ} \mathrm{C}$, there is a negative correlation between $\mathrm{V}$ and $\mathrm{SiO}_{2}$ (Fig. 3.36f), while at $400^{\circ} \mathrm{C}$, the highest $\mathrm{V}$ values are encountered after the glass has been removed (Fig. 3.36e). Vanadium occurs as a component of titanomagnetite (Hukkanen and Walden, 1985). It is possible that elevated $\mathrm{Fe}$ concentrations during glass dissolution could suppress titanomagnetite dissolution thus leading to lower $\mathrm{V}$ concentrations. This is a possible mechanism to explain the results at $350^{\circ} \mathrm{C}$ (Fig. $3.36 \mathrm{~h}$ ); however, at $400^{\circ} \mathrm{C}$, this is not as clear. Figure 3.36g shows there is no clear correlation between $\mathrm{Fe}$ and $\mathrm{SiO}_{2}$ at $400^{\circ} \mathrm{C}$. As in situ $\mathrm{pH}$ does not vary significantly over the experiment, the difference in $\mathrm{V}$ mobility cannot be explained by $\mathrm{pH}$ change.

The results show that, from elements discussed above, there is higher mobility in solution at $400^{\circ} \mathrm{C}$ than at $350^{\circ} \mathrm{C}$. As there is no significant difference in concentrations of $\mathrm{Cl}$ and $\mathrm{H}_{2} \mathrm{~S}$ released during glass dissolution, the most plausible explanation is that at $400^{\circ} \mathrm{C}$ there is higher mineral solubility and thus secondary trace element-containing phases do not precipitate. The release of significant concentrations of some of the trace elements in solution is mostly dependent on the dissolution from the volcanic glass and to a lesser degree from primary minerals (Fig. 3.35). 
Figure 3.36. Plots of $\mathrm{Co}, \mathrm{Mo}, \mathrm{V}$ and $\mathrm{Fe}\left(\mu \mathrm{mol} \mathrm{kg}{ }^{-1}\right)$ versus $\mathrm{SiO}_{2}\left(\mu \mathrm{mol} \mathrm{kg}{ }^{-1}\right)$ for $\mathrm{BW} 1$ and $\mathrm{BW} 2$. Symbols in red represent values during glass dissolution, while symbols in blue represent values after glass dissolution.
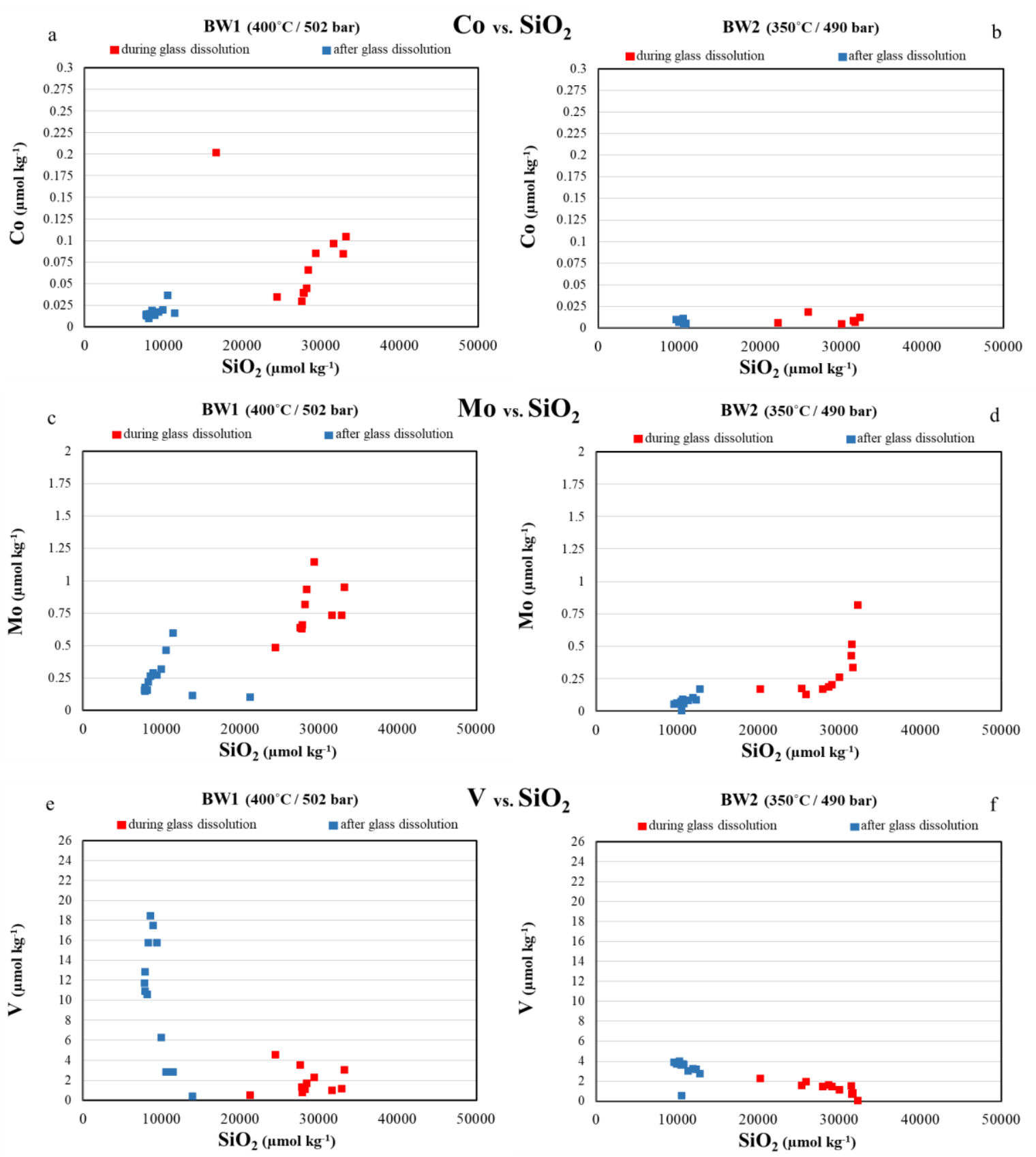

vs. $\mathrm{SiO}_{2}$
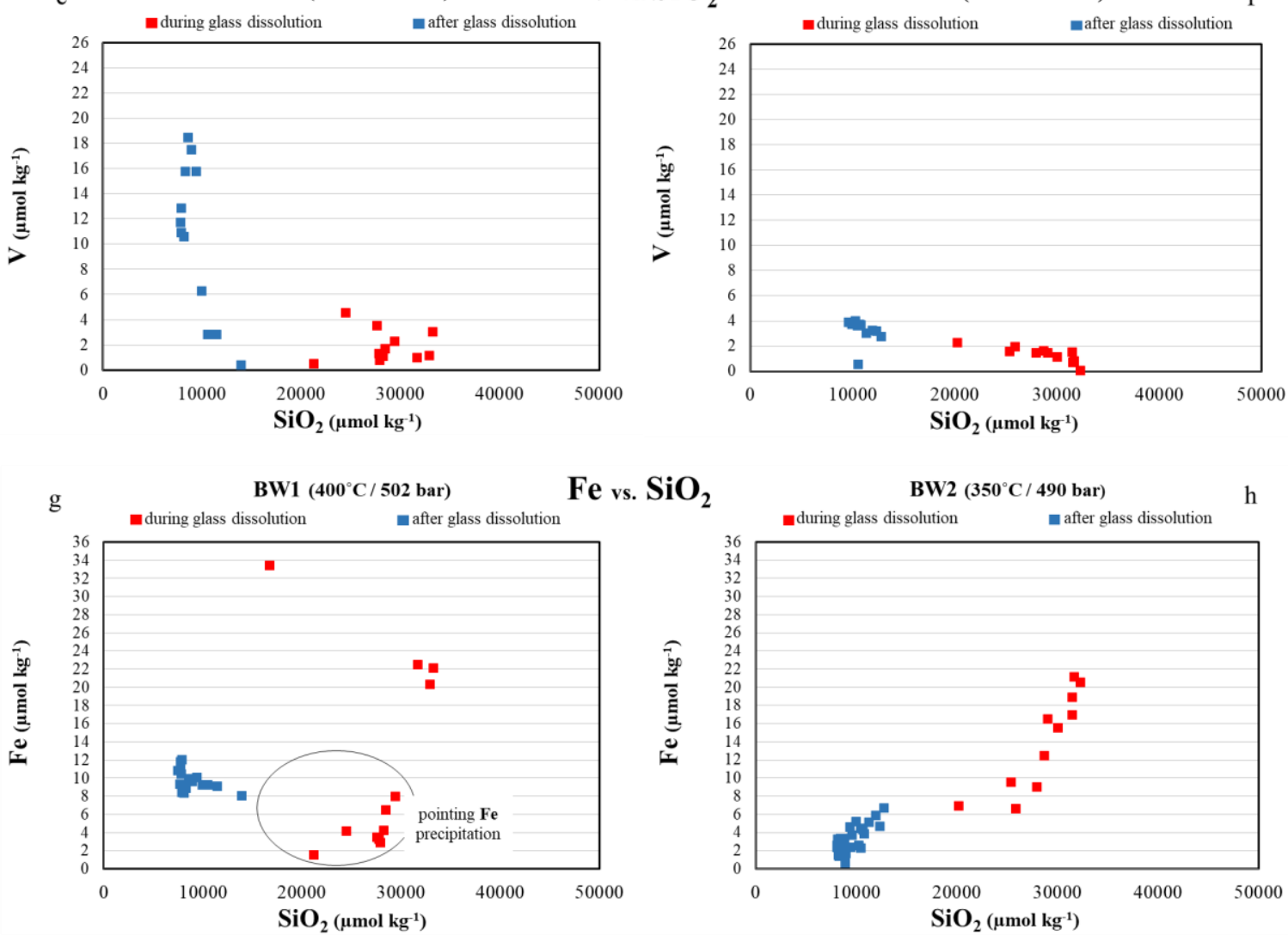
Figure 3.37. Plots of Co and $\mathrm{Mo}\left(\mu \mathrm{mol} \mathrm{kg}^{-1}\right)$ versus $\mathrm{H}_{2} \mathrm{~S}\left(\mu \mathrm{mol} \mathrm{kg}^{-1}\right)$ for BW1 and BW2. Symbols in red represent values during glass dissolution, while symbols in blue represent values after glass dissolution.

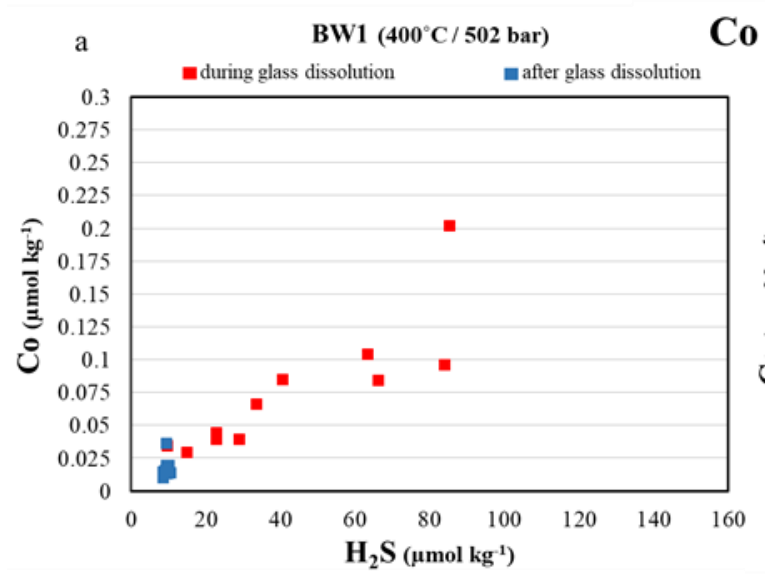

\section{$\mathrm{Co}$ vs. $\mathrm{H}_{2} \mathrm{~S}$}
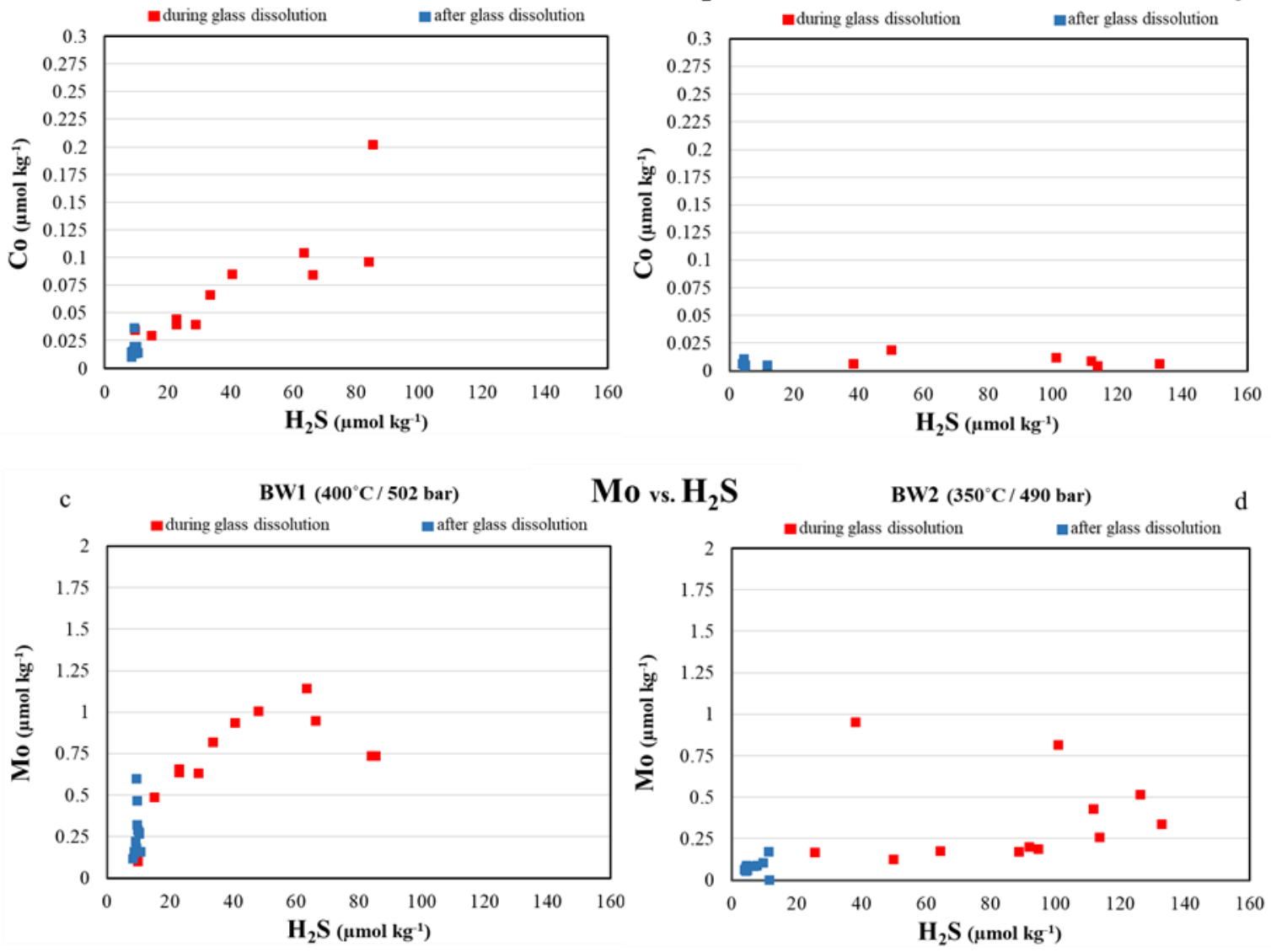


\subsubsection{The path of fluid-rock interaction}

\section{Activity-activity diagrams}

The path of fluid-rock interaction can be examined by plotting aqueous species' activities/activity ratios on activity phase diagrams. The software EqSolvR was used to determine the species activities and $\mathrm{pH}$ values (Chapter 2).

Activity diagrams were constructed for the experimental $\mathrm{T}\left(350\right.$ and $\left.400^{\circ} \mathrm{C}\right)$ and a pressure of 500 bar, assuming unit activity of mineral phases. There was no period during the experiments where quartz was saturated, quartz was neither observed in the original basalt, nor in the reacted rock. This means that $\mathrm{SiO}_{2}$ activity cannot be fixed by the presence of quartz, thus, for activity diagrams that do not plot $\mathrm{SiO}_{2}$ activity as a variable, it is necessary to define $\mathrm{SiO}_{2}$ activity. The average $\mathrm{SiO}_{2}$ concentrations during and after the volcanic glass dissolution were used to determine $\mathrm{SiO}_{2}$ activity. These were (in log units): -1.54 (during glass dissolution) and -2.0 (after glass dissolution) at $350^{\circ} \mathrm{C} / 490$ bar and -1.57 and -2.06 at $400^{\circ} \mathrm{C} / 502$ bar.

Activity diagrams show that the location of the fluid compositions in activity-activity space. When a fluid composition lies within a particular mineral stability field, this indicates that the composition is consistent with the stability of this mineral. Note, however, that these projections are two dimensional and are "projected" through other components. This means that, although, a particular mineral may be stable according to the phase diagram, another mineral may actually be more stable when other components are present. Selected diagrams are presented in the discussion below. All activity diagrams calculated are reported in Appendix B.

Fluid samples were collected approximately daily during the experiments. The cation activity ratios shown in the activity diagrams thus represent the average fluid composition over that period. At a flow rate of $1 \mathrm{ml} \mathrm{hr}^{-1}$ and a porosity of $\sim 53 \%$ (Chapter $2, \S 2.4 .1$ ) this constitutes approximately 2.2 pore volumes of fluid each day (ignoring expansion of the pressure vessel and rock). The average fluid composition plotted on the activity diagram thus indicates that 2.2 pore volumes reached this composition on average. Note that the in situ $\mathrm{pH}$ was relatively constant over the experiments, thus changes in cation activity ratios (e.g. $\left.a_{\mathrm{Ca}^{2+}} / a_{\mathrm{H}^{+}}^{2}\right)$ mainly reflect changes in cation concentration.

Figure 3.38a shows the activity diagram for the $\mathrm{CaO}-\mathrm{Al}_{2} \mathrm{O}_{3}-\mathrm{SiO}_{2}-\mathrm{H}_{2} \mathrm{O}$ system at $400^{\circ} \mathrm{C}$. This initial blank composition had detectable $\mathrm{Ca}$ and $\log a_{\mathrm{SiO}_{2}}$ is assumed to be $<-4$, 
thus the blank composition plots as shown (yellow circle). After 24 hours at $400^{\circ} \mathrm{C}$, the average solution composition passes quartz saturation and $a_{C a^{2+}}$ increases about two orders of magnitude. The average fluid composition lies in the grossular stability field. The rapid increase in $\mathrm{SiO}_{2}$ activity highlights the fast rate of glass dissolution where the concentration of $\mathrm{SiO}_{2}$ is controlled by the competition between the flow rate and the precipitation of secondary minerals (i.e., steady state). Over the next $\sim 15$ days, $\log \left(a_{\mathrm{SiO}_{2}}\right)$ remains elevated (-1.6) as glass dissolves, however, $\log \left(a_{\mathrm{Ca}^{2+}}\right)$ decreases gradually such that fluid passes through prehnite field, past the prehnite-anorthite-wairakite triple point and into the anorthite field. At this time, glass becomes depleted, $\log \left(a_{\mathrm{SiO}_{2}}\right)$ decreases to below quartz saturation, while $a_{\mathrm{Ca}^{2+}}$ remains fairly constant. Once $\log \left(a_{\mathrm{SiO}_{2}}\right)$ reaches steady state at -2.1 , $\log \left(a_{\mathrm{Ca}^{2+}}\right)$ begins to decrease again and the fluid composition passes into the margarite field.

The assemblage grossular-wollastonite was found immediately at the entry point of the fluid. This testifies to fast reaction rates that rapidly shift the blank composition to grossular stability. This is due to quantitative removal of $\mathrm{Na}$ and $\mathrm{K}$ and, to a much lesser degree $\mathrm{Ca}$, from the rock leaving a Ca-silicate assemblage behind. If the experiment had continued for a longer period of time, it is expected that an alteration front, defined by the removal of $\mathrm{Na}$ and $\mathrm{K}$ from the rock, would be found to have moved up the column. This shows how water, with an absence of alkali cations, is effective at removing $\mathrm{Na}$ and $\mathrm{K}$ during hydrothermal alteration.

Figure $3.38 \mathrm{~b}$ shows the same diagram $\left(\mathrm{CaO}-\mathrm{Al}_{2} \mathrm{O}_{3}-\mathrm{SiO}_{2}-\mathrm{H}_{2} \mathrm{O}\right.$ system $)$ for the experiment at $350^{\circ} \mathrm{C}$. Initial output fluid compositions do not reach the field of grossular at $350^{\circ} \mathrm{C}$ but lie in the prehnite field while glass was dissolving. This indicates that the lower temperature did not allow $\log \left(a_{\mathrm{Ca}^{2+}} / a_{\mathrm{H}^{+}}^{2}\right)$ to increase high enough to stabilise this mineral. No evidence of prehnite was found during SEM-EDS examination; however, the absence of grossular is in agreement with fluid chemistry. Once glass dissolution is complete, the equilibrium shifts to the prehnite-clinozoisite mineral phase boundary for almost 48 hours and then to the clinozoisite-anorthite mineral phase boundary for only 24 hours, finally passing through the anorthite field and into the margarite stability field. Of the above minerals only anorthite was found in the reacted basalt. This indicates that margarite was metastable perhaps due to the abundance of plagioclase to act as a substrate for anorthite precipitation or that margarite was not the stable phase due to the presence of $\mathrm{Mg}$ and $\mathrm{Fe}$ in the fluid stabilising celadonite. The presence of celadonite replacing olivine suggests that 
while glass was dissolving, and $\mathrm{K}$ activity was higher, $\mathrm{Mg} / \mathrm{Fe}$ released from olivine formed this mineral.

In the $\mathrm{K}_{2} \mathrm{O}-\mathrm{Al}_{2} \mathrm{O}_{3}-\mathrm{SiO}_{2}-\mathrm{H}_{2} \mathrm{O}$ activity space (Fig. 3.39) the path of the fluid composition is similar at both temperatures. At $350^{\circ} \mathrm{C}$, quartz immediately becomes supersaturated and fluid composition lies in the muscovite field (Fig. $3.39 \mathrm{~b}$ ) while at $400^{\circ} \mathrm{C}$ quartz is slightly undersaturated and also in the muscovite field (Fig. 3.39a). In both experiments, the concentration of $\mathrm{K}$ is elevated in the first sample after temperature shift, however, it declines over the following 5 days, in both experiments. The source of $\mathrm{K}$ in the basalt is primarily the glass. It would be expected that if $\mathrm{K}$ was being congruently released while glass was dissolving, its trend should follow that of $\mathrm{SiO}_{2}$. The decrease in $\mathrm{K}$ concentration thus indicates precipitation of a secondary K-bearing phase. Celadonite is the only K-bearing secondary phase observed in the run products of the experiments and its precipitation is concluded to be the cause of the decrease in $\mathrm{K}$ concentration. The incorporation of $\mathrm{Na}$ into celadonite also explains the decrease in $\mathrm{Na}$ over the same period.

Celadonite is a dioctahedral mica isostructural with muscovite, where $\mathrm{Fe}^{\mathrm{VI}} \mathrm{Si}^{\mathrm{IV}}$ and $\mathrm{Mg}^{\mathrm{VI}} \mathrm{Si}^{\mathrm{IV}}$ substitutes for $\mathrm{Al}^{\mathrm{VI}} \mathrm{Al}^{\mathrm{IV}}$, and $\mathrm{Fe}^{3+}$ for $\mathrm{Al}^{\mathrm{VI}}$, thus there will be fixed activity of muscovite in this mineral (Schmidt et al., 2001). This is consistent with the position of the fluid composition in the activity diagrams (Fig. 3.39). At both temperatures, the fluid path lies colinear with the muscovite-pyrophyllite join.

At $350^{\circ} \mathrm{C}$, once quartz becomes undersaturated, $\log \left(a_{K^{+}} / a_{H^{+}}\right)$increases along the muscovite - andalusite join indicating that $\mathrm{K}$ was being released to the fluid. This suggests that celadonite (being the only K-bearing phase identified) is dissolving again, probably because of lower silica activities. At $400^{\circ} \mathrm{C}$, the path is similar but the increase in log $\left(a_{K^{+}} / a_{H^{+}}\right)$is less obvious.

For the last several days, both at 350 and $400^{\circ} \mathrm{C}$, fluid composition moves to lower $\log \left(a_{K^{+}} / a_{H^{+}}\right)$into the andalusite and corundum fields, respectively. The chemistry results show that this is due to a substantial decrease in $\mathrm{K}$ concentration (Fig. 3.1 and 3.19) suggesting that the secondary mineral releasing $\mathrm{K}$ became exhausted. This, however, is inconsistent with the SEM results where the presence of celadonite was confirmed. The explanation for the significant decrease in $\mathrm{K}$ is therefore uncertain.

The overall path of fluid-rock interaction in the $\mathrm{K}_{2} \mathrm{O}-\mathrm{Al}_{2} \mathrm{O}_{3}-\mathrm{SiO}_{2}-\mathrm{H}_{2} \mathrm{O}$ system at both temperatures is similar indicating that the mineral reactions involved are likely the same. 
In Figure 3.39, the red crosses show positions of effluents collected at $0.5 \mathrm{ml} \mathrm{hr}^{-1}$ flow rate for the last few days of the experiments. There is no noticeable difference from earlier samples collected at $1.0 \mathrm{ml} \mathrm{hr} \mathrm{h}^{-1}$. This confirms that changes in flow rate did not affect cation activity ratios.

Figure 3.38. Activity diagrams for the $\mathrm{CaO}-\mathrm{Al}_{2} \mathrm{O}_{3}-\mathrm{SiO}_{2}-\mathrm{H}_{2} \mathrm{O}$ system showing mineral stability fields for $\mathrm{BW} 1(\mathrm{a})$ and $\mathrm{BW} 2(\mathrm{~b})$. $\mathrm{Black}$ and red crosses show position of effluent samples collected at 1.0 and $0.5 \mathrm{ml} \mathrm{hr}^{-1}$ flow rate, respectively. Yellow circles show position of the unreacted fluid (water) at 400 and $350^{\circ} \mathrm{C} / 500$ bar. Black dotted line indicates quartz saturation while pink dotted lines represent the average of silica concentration (in log units) before and after dissolution of the basalt glass, calculated for the respective experiments. Blue arrows show the path of reacted fluids over the time of the experiments.
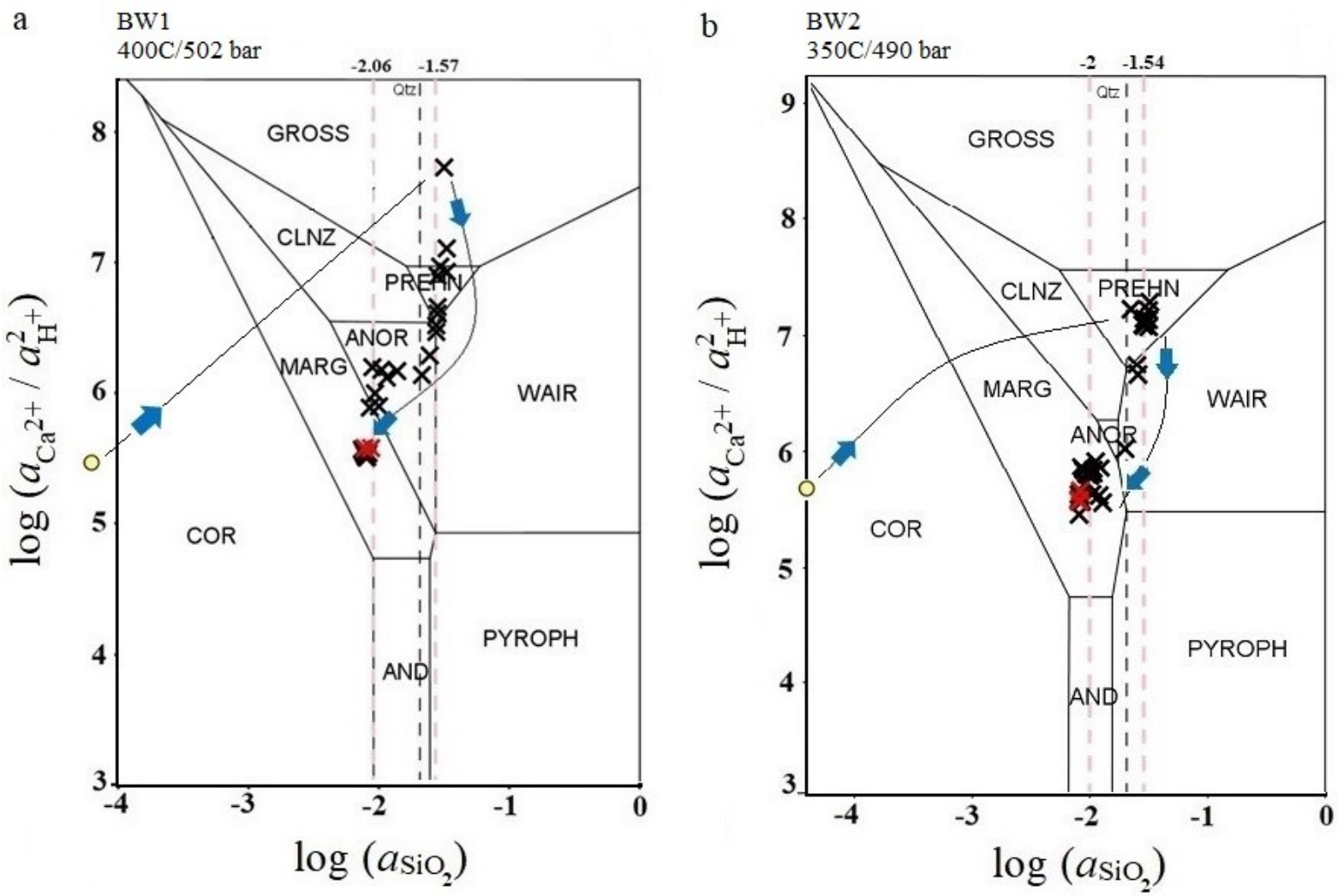
Figure 3.39. Activity diagrams for the $\mathrm{K}_{2} \mathrm{O}-\mathrm{Al}_{2} \mathrm{O}_{3}-\mathrm{SiO}_{2}-\mathrm{H}_{2} \mathrm{O}$ system showing mineral stability fields for $\mathrm{BW} 1$ (a) and $\mathrm{BW}$ (b). $\mathrm{Black}$ and red crosses show position of effluent sample collected at 1.0 and $0.5 \mathrm{ml} \mathrm{hr}^{-1}$ flow rate, respectively. Yellow circles show position of the unreacted fluid (water) at 400 and $350^{\circ} \mathrm{C} / 500$ bar. Black dotted line indicates quartz saturation while pink dotted lines represent the average of silica concentration (in log units) during and after dissolution of the basalt glass, calculated for the respective experiments. Blue arrows show the path of reacted fluids over the time of the experiments.

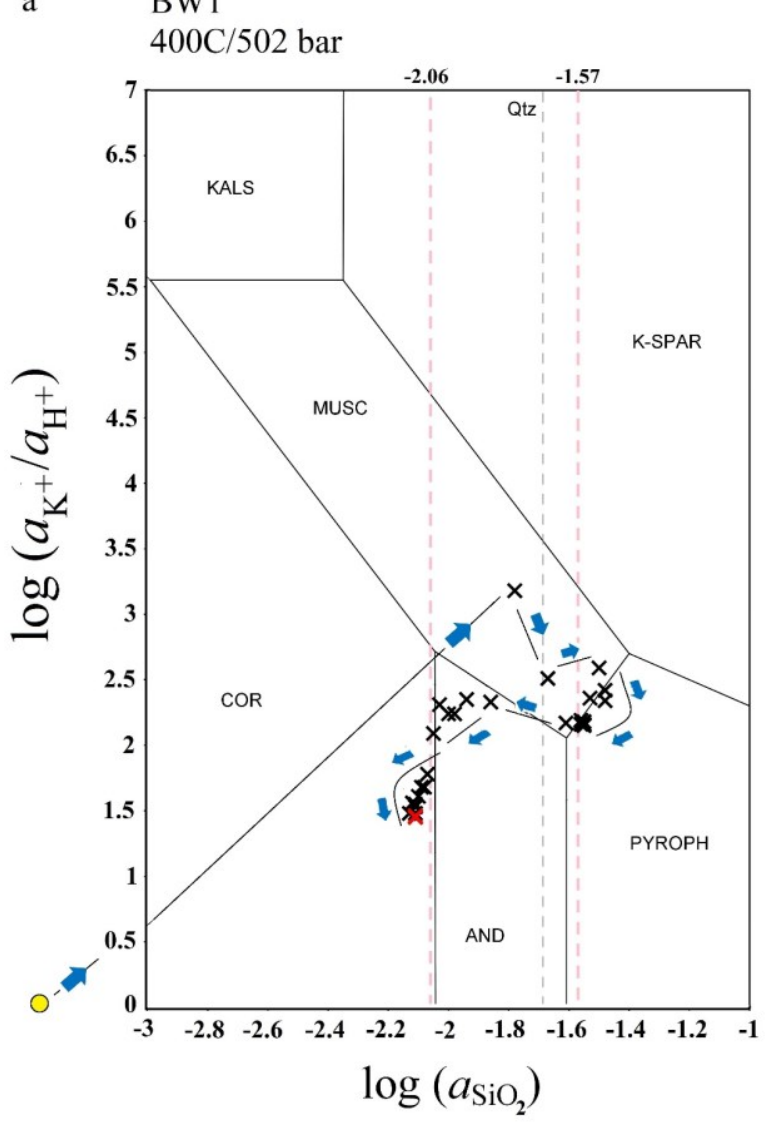

b $\quad$ BW2 $350 \mathrm{C} / 490 \mathrm{bar}$

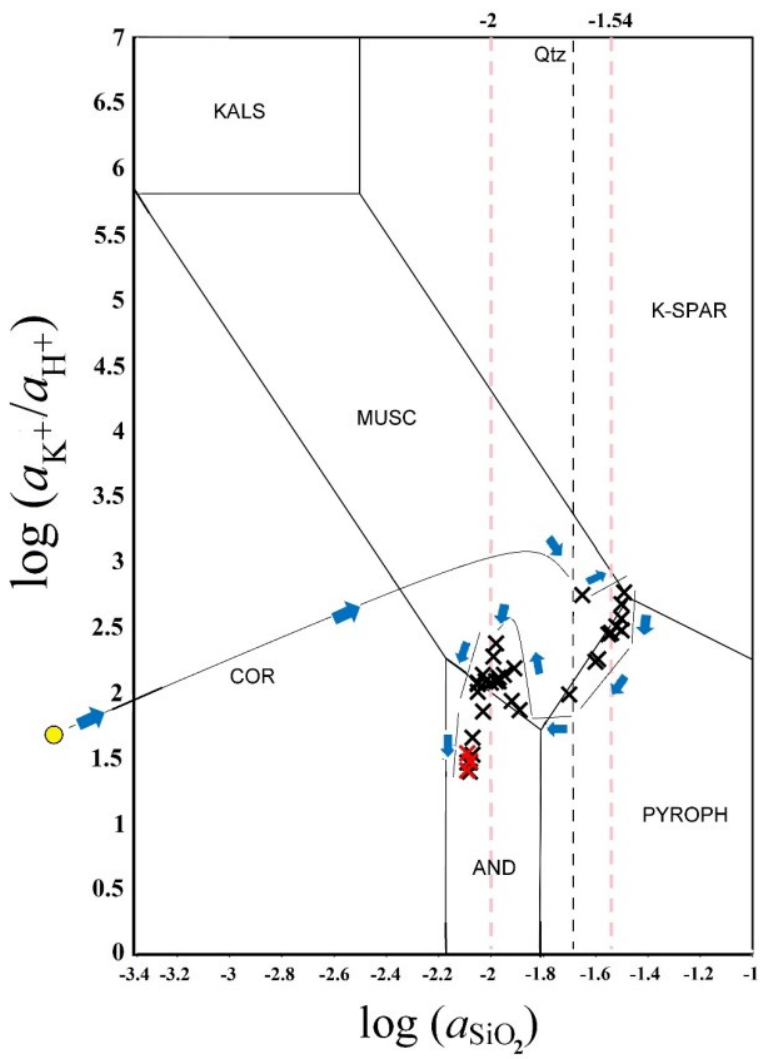

Chlorite was also identified as a common secondary aluminosilicate in the experiments (Fig. 3.6 - 3.11, 3.24 - 3.25, 3.29 - 3.30). Figure 3.40 shows the activity ratio diagrams for the $\mathrm{MgO}-\mathrm{Al}_{2} \mathrm{O}_{3}-\mathrm{SiO}_{2}-\mathrm{H}_{2} \mathrm{O}$ systems at 350 and $400^{\circ} \mathrm{C} / 500$ bar. Both at 350 and $400^{\circ} \mathrm{C}$, during and after the basalt glass dissolution, the decrease in cation activity ratios of $\log \left(a_{\mathrm{Mg}^{2+}} / \mathrm{a}_{\mathrm{H}^{+}}^{2}\right)$ mainly reflect changes in cation concentration, as the in situ $\mathrm{pH}$ was relatively constant over the experiments.

This initial blank composition had detectable $\mathrm{Mg}$ and $\log a_{\mathrm{SiO}_{2}}$ is assumed to be $<-4$. After 24 hours in both experiments, the average solution compositions pass quartz saturation and $\mathrm{a}_{\mathrm{Mg}} \mathrm{g}^{+}$increases about two orders of magnitude. The average fluid compositions lie in the chlorite stability field $(\mathrm{CL} 14 \mathrm{~A}=$ clinochlore) both for the BW1 and BW2. Over the next 11 days, $\log \left(a_{\mathrm{SiO}_{2}}\right)$ remains elevated $(\sim-1.6)$ as glass dissolves, however, $\log \left(a_{\mathrm{Mg}^{2+}}\right)$ decreases gradually to an activity of $\sim-5.5$ in both experiments. At this point, glass becomes 
depleted, $\log \left(a_{\mathrm{SiO}_{2}}\right)$ decreases to below quartz saturation, while $a_{M g^{2+}}$ remains fairly constant during BW1, while it visibly decreases during BW2. Once log $\left(a_{\mathrm{SiO}_{2}}\right)$ reaches steady state at $\sim-2.1$ and -2.0 in BW1 and BW2, respectively, $a_{M g^{2+}}$ begins to decrease again in both experiments and the fluid compositions remain the chlorite field by the end of the experiment.

In BW1 $\left(400^{\circ} \mathrm{C}\right)$ chlorite was found intergrown with the other secondary mineral phases including grossular and wollastonite and replacing primary plagioclase, clinopyroxene and olivine. In BW2 $\left(350^{\circ} \mathrm{C}\right)$, chlorite appears as the main secondary aluminosilicate. It was identified at the bottom of the Reactor after the conclusion of both experiments while no evidence of this mineral was found at the top of the Reactor after both simulations. The identification of the chlorite during rock analysis demonstrates that fluid compositions must have been saturated with respect to this mineral. This is consistent with the activity diagrams where the fluid compositions lie within the chlorite field in both experiments (Fig. 3.40).

Figure 3.40. Activity diagrams for the $\mathrm{MgO}-\mathrm{Al}_{2} \mathrm{O}_{3}-\mathrm{SiO}_{2}-\mathrm{H}_{2} \mathrm{O}$ systems showing mineral stability fields $(\mathrm{CL} 14 \mathrm{~A}=\mathrm{clinochlore})$ for $\mathrm{BW} 1$ and BW2. Black and red crosses show position of effluent sample collected at 1.0 and $0.5 \mathrm{ml} \mathrm{hr}^{-1}$ flow rate, respectively. Yellow circles show position of the unreacted fluid (water) at 400 and $350^{\circ} \mathrm{C} / 500$ bar. Black dotted line indicates quartz saturation while pink dotted lines represent the average of silica concentration (in log units) during and after dissolution of the basalt glass, calculated for the respective experiments. Blue arrows show the path of reacted fluids over the time of the experiments.
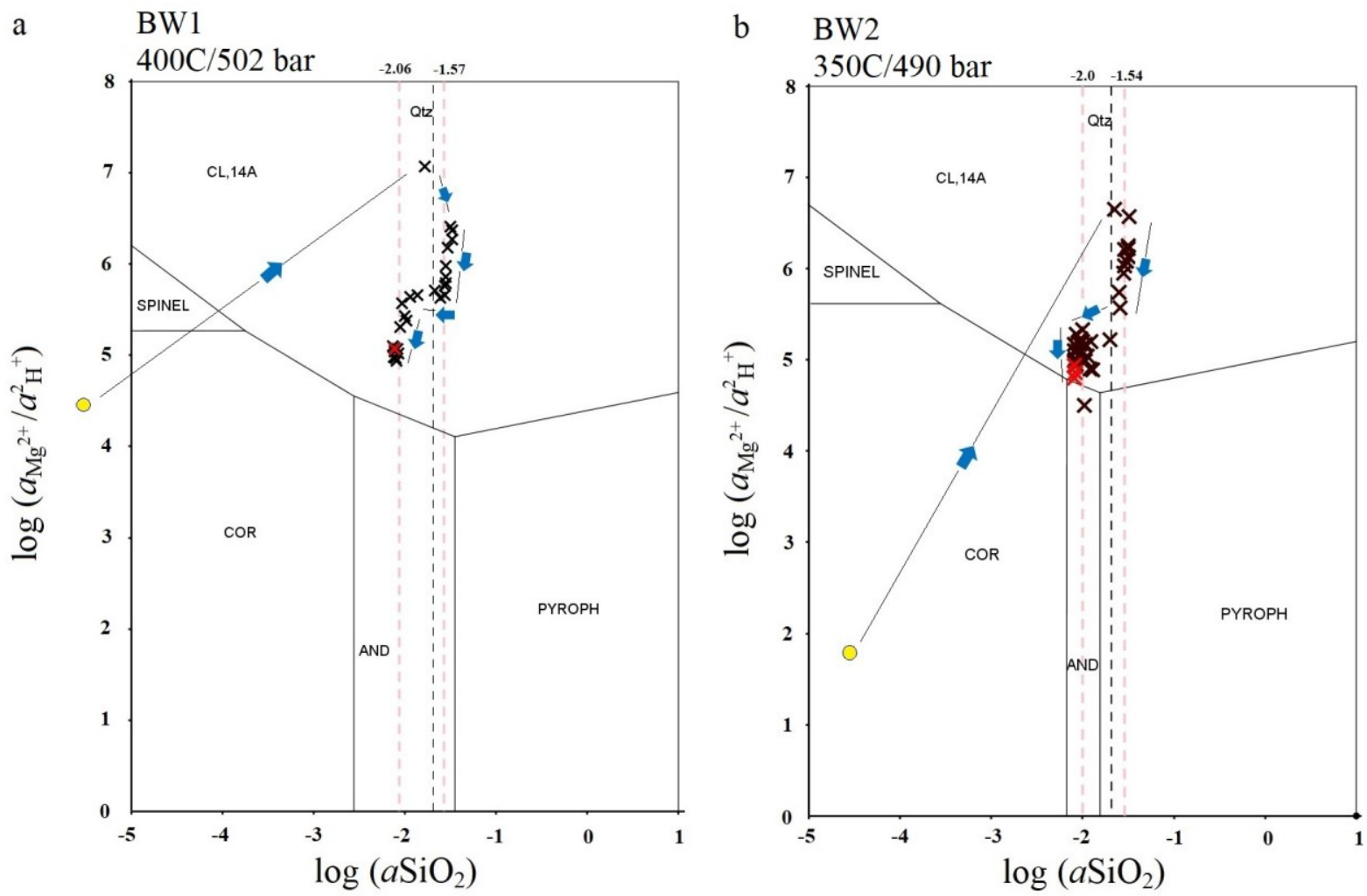
The fluid-mineral reactions that occurred during the experiments can provide information on the chemical path that the fluid took while passing through the rock and the resulting effects on the mineral assemblage.

At $400^{\circ} \mathrm{C}$, exclusively Ca-aluminosilicate phases formed at bottom of the Reactor. The source of $\mathrm{Ca}, \mathrm{Al}$ and $\mathrm{SiO}_{2}$ was provided by the rock, as these components are not present in the input fluid. The extreme rearrangement of rock components during the alteration means that it is not possible to relate any particular secondary phase to a primary mineral. To form anorthite, grossular and wollastonite, both plagioclase and clinopyroxene can be the source for $\mathrm{Ca}$, while plagioclase is the main source of Al. During the first approximately 15 days, the main source of $\mathrm{SiO}_{2}$ was the volcanic glass.

SEM analysis shows that both clinopyroxene and plagioclase had almost completely dissolved in grains collected from immediately adjacent to the fluid entry point. The precipitation of anorthite, grossular and wollastonite (end-members in the reactions) at the expense of plagioclase and clinopyroxene in the experiments can be represented in Reactions 7-11:

$$
\begin{aligned}
& 1.43 \mathrm{Ca}_{0.7} \mathrm{Na}_{0.3} \mathrm{Al}_{1.7} \mathrm{Si}_{2.3} \mathrm{O}_{8}+1.72 \mathrm{H}^{+} \\
& \leftrightarrow \mathrm{CaAl}_{2} \mathrm{Si}_{2} \mathrm{O}_{8}+0.43 \mathrm{Na}^{+}+0.43 \mathrm{Al}^{3+}+1.29 \mathrm{SiO}_{2}+0.86 \mathrm{H}_{2} \mathrm{O} \\
& \mathrm{Ca}_{0.7} \mathrm{Mg}_{0.9} \mathrm{Fe}_{0.3} \mathrm{Al}_{0.2} \mathrm{Si}_{1.9} \mathrm{O}_{6}+3.2 \mathrm{H}^{+} \\
& \leftrightarrow 0.1 \mathrm{Ca}_{3} \mathrm{Al}_{2} \mathrm{Si}_{3} \mathrm{O}_{12}+0.4 \mathrm{Ca}^{2+}+0.9 \mathrm{Mg}^{2+}+0.3 \mathrm{Fe}^{2+}+1.6 \mathrm{SiO}_{2}+1.6 \mathrm{H}_{2} \mathrm{O} \\
& \mathrm{Ca}_{0.7} \mathrm{Na}_{0.3} \mathrm{Al}_{1.7} \mathrm{Si}_{2.3} \mathrm{O}_{8}+4.04 \mathrm{H}^{+} \\
& \leftrightarrow 0.23 \mathrm{Ca}_{3} \mathrm{Al}_{2} \mathrm{Si}_{3} \mathrm{O}_{12}+0.3 \mathrm{Na}^{+}+1.24 \mathrm{Al}^{3+}+1.61 \mathrm{SiO}_{2}+2.02 \mathrm{H}_{2} \mathrm{O} \\
& 1.4 \mathrm{Ca}_{0.7} \mathrm{Mg}_{0.9} \mathrm{Fe}_{0.3} \mathrm{Al}_{0.2} \mathrm{Si}_{1.9} \mathrm{O}_{6}+4.3 \mathrm{H}^{+} \\
& \leftrightarrow \mathrm{CaSiO}_{3}+0.4 \mathrm{Fe}^{2+}+1.3 \mathrm{Mg}^{2+}+0.3 \mathrm{Al}^{3+}+1.7 \mathrm{SiO}_{2}+2.1 \mathrm{H}_{2} \mathrm{O} \\
& 1.4 \mathrm{Ca}_{0.7} \mathrm{Na}_{0.3} \mathrm{Al}_{1.7} \mathrm{Si}_{2.3} \mathrm{O}_{8}+7.7 \mathrm{H}^{+} \\
& \leftrightarrow \mathrm{CaSiO}_{3}+2.4 \mathrm{Al}^{3+}+0.4 \mathrm{Na}^{+}+2.4 \mathrm{SiO}_{2}+3.8 \mathrm{H}_{2} \mathrm{O}
\end{aligned}
$$


All of these reactions consume $\mathrm{H}^{+}$explaining the high quench $\mathrm{pH}$ values during the experiment relative to the input water $\mathrm{pH}$ (after 400 hours, Fig. 3.1). The reactions also release the $\mathrm{Na}, \mathrm{Mg}$ and $\mathrm{Fe}$ from the minerals to the fluid. After complete glass dissolution, $\mathrm{Al}$ concentrations also significantly increase.

Further up the Reactor, chlorite was observed with a lesser concentration of Caaluminosilicates. The source of $\mathrm{Mg}$ and $\mathrm{Fe}$ for chlorite is from olivine and clinopyroxene and cannot be from the input fluid, while Al could be provided directly from the dissolution of primary minerals as per Reactions $7-11$. The formation of chlorite at the expense of clinopyroxene and olivine is represented in Reactions 12 and 13:

$$
\begin{aligned}
& \mathrm{Ca}_{0.7} \mathrm{Mg}_{0.9} \mathrm{Fe}_{0.3} \mathrm{Al}_{0.2} \mathrm{Si}_{1.9} \mathrm{O}_{6}+0.07 \mathrm{Al}^{3+}+1.68 \mathrm{H}^{+} \\
& \leftrightarrow 0.21 \mathrm{Mg}_{3.6} \mathrm{Fe}_{1.4} \mathrm{Al}_{1.3} \mathrm{Si}_{3.4} \mathrm{O}_{10}(\mathrm{OH})_{8}+0.7 \mathrm{Ca}^{2+}+0.14 \mathrm{Mg}^{2+}+1.19 \mathrm{SiO}_{2} \\
& \mathrm{Mg}_{1.4} \mathrm{Fe}_{0.6} \mathrm{SiO}_{4}+0.6 \mathrm{Al}^{3+}+0.14 \mathrm{Mg}^{2+}+0.46 \mathrm{SiO}_{2}+2.82 \mathrm{H}_{2} \mathrm{O} \\
& \leftrightarrow 0.43 \mathrm{Mg}_{3.6} \mathrm{Fe}_{1.4} \mathrm{Al}_{1.3} \mathrm{Si}_{3.4} \mathrm{O}_{10}(\mathrm{OH})_{8}+2.2 \mathrm{H}^{+}
\end{aligned}
$$

During these reactions, the formation of chlorite from clinopyroxene dissolution consumes $\mathrm{H}^{+}$while the formation of chlorite from olivine produces hydrogen ion.

Celadonite was observed at top of the Reactor. From SEM analysis of the basalt block, celadonite appeared in dense foliated masses that only replaced olivine. The celadonite contains both $\mathrm{K}$ and $\mathrm{Na}$. Potassium was provided by the glass (as there are no Kbearing minerals in the basalt) while sodium is from plagioclase dissolution. As concentrations of both elements decrease from the beginning of glass dissolution (higher $\mathrm{SiO}_{2}$ activity) (Fig. 3.1, §3.2.1.1) it indicates that celadonite began to form immediately after temperature shift. However, celadonite does not appear as a secondary mineral at bottom of the Reactor. This implies that when fresh fluid entered the Reactor, the extreme disequilibrium between the distilled water and the rock minerals caused rapid formation of grossular, wollastonite and chlorite. This only occurred in the very bottom millimetre of the Reactor and resulted in the extreme "leaching" of the cations $\mathrm{Na}, \mathrm{K}, \mathrm{Fe}$ and $\mathrm{Mg}$ from the rock. As these reactions occurred, the concentrations of these components would have increased leading to equilibration with celadonite.

The celadonite formation at the expense of olivine can be represented by Reaction 14: 


$$
\begin{gathered}
\mathrm{Mg}_{1.4} \mathrm{Fe}_{0.6} \mathrm{SiO}_{4}+0.27 \mathrm{~K}^{+}+0.14 \mathrm{Na}^{+}+1.07 \mathrm{Al}^{3+}+0.3 \mathrm{Fe}^{2+}+0.5 \mathrm{Mg}^{2+}+2.19 \mathrm{SiO}_{2}+3.62 \mathrm{H}_{2} \mathrm{O} \\
\leftrightarrow K_{0.27} \mathrm{Na}_{0.14} \mathrm{Mg}_{1.9} \mathrm{Fe}_{0.9} \mathrm{Al}_{1.07} \mathrm{Si}_{3.19} \mathrm{O}_{10}(\mathrm{OH})_{2}+5.24 \mathrm{H}^{+}
\end{gathered}
$$

The concentrations of $\mathrm{Al}, \mathrm{Na}$ and $\mathrm{K}$ (Fig. 3.1, §3.2.1.1) show a sharp increase in solution at approximately $400 \mathrm{hrs}$. This coincides with values of silica at lower activity (after glass dissolution). The sudden rise of $\mathrm{K}, \mathrm{Al}$ and $\mathrm{Na}$ in the solution suggests that celadonite started to dissolve at this point.

During these reactions it is evident that the consumption of $\mathrm{H}^{+}$by the formation of Ca-aluminosilicates and chlorite is greater than the production of $\mathrm{H}^{+}$by the formation of celadonite. Although it is not possible to determine a proportion between minerals dissolved and precipitated during experiment, the formation of $\mathrm{Ca}$-aluminosilicates must have been greater than celadonite. This explains why the $\mathrm{pH}$ reached values highly basic in BW1.

In $\mathrm{BW} 2$, at $350^{\circ} \mathrm{C}$, anorthite and chlorite were the main secondary minerals identified at the bottom of the Reactor. Neither grossular nor wollastonite was found. The formation of chlorite required a source for $\mathrm{Mg}, \mathrm{Fe}$ and $\mathrm{Al}$ that could be provided only by the rock as these are not present in the distilled water. The formation of chlorite and anorthite at the expense of clinopyroxene, olivine and plagioclase can be represented in Reactions 15-17:

$$
\begin{aligned}
& \mathrm{Ca}_{0.7} \mathrm{Na}_{0.3} \mathrm{Al}_{1.7} \mathrm{Si}_{2.3} \mathrm{O}_{8}+\mathrm{Ca}_{0.7} \mathrm{Mg}_{0.9} \mathrm{Fe}_{0.3} \mathrm{Al}_{0.2} \mathrm{Si}_{1.9} \mathrm{O}_{6}+8.48 \mathrm{H}^{+} \\
& \leftrightarrow 0.17 \mathrm{Mg}_{2.9} \mathrm{Fe}_{1.8} \mathrm{Al}_{2} \mathrm{Si}_{3} \mathrm{O}_{10}(\mathrm{OH})_{8}+1.4 \mathrm{Ca}^{2+}+0.41 \mathrm{Mg}^{2+}+0.3 \mathrm{Na}^{+}+1.56 \mathrm{Al}^{3+}+3.69 \mathrm{SiO}_{2} \\
& +3.56 \mathrm{H}_{2} \mathrm{O} \\
& \mathrm{Mg}_{1.4} \mathrm{Fe}_{0.6} \mathrm{SiO}_{4}+0.66 \mathrm{Al}^{3+}+1.94 \mathrm{H}_{2} \mathrm{O} \\
& \left.\leftrightarrow 0.33 \mathrm{Mg}_{2.9} \mathrm{Fe}_{1.8} \mathrm{Al}_{2} \mathrm{Si}_{3} \mathrm{O}_{10} \mathrm{OH}\right)_{8}+0.43 \mathrm{Mg}^{2+}+1.24 \mathrm{H}^{+} \\
& 1.43 \mathrm{Ca}_{0.7} \mathrm{Na}_{0.3} \mathrm{Al}_{1.7} \mathrm{Si}_{2.3} \mathrm{O}_{8}+1.72 \mathrm{H}^{+} \\
& \leftrightarrow \mathrm{CaAl}_{2} \mathrm{Si}_{2} \mathrm{O}_{8}+0.43 \mathrm{Na}^{+}+0.43 \mathrm{Al}^{3+}+1.29 \mathrm{SiO}_{2}+0.86 \mathrm{H}_{2} \mathrm{O}
\end{aligned}
$$

During these reactions, both clinopyroxene and olivine can be the source of $\mathrm{Mg}$ and Fe. The conversion of plagioclase to anorthite is a residual reaction whereby the albite 
component is being removed by the fluid. This is supported by the textural evidence seen in SEM examination (Fig. $3.24-25$ - 29).

Celadonite was only observed at top of the Reactor. The formation mechanism of the celadonite is similar to the experiment at $400^{\circ} \mathrm{C}$, but in this case, it does not contain $\mathrm{Na}$. The progressive increase of $\mathrm{Na}$ after $\mathrm{T}$ shift during glass dissolution (Fig. 3.19, §3.2.2.2) confirms that this element is not involved in the celadonite formation at $350^{\circ} \mathrm{C}$. The sudden rise of $\mathrm{K}$ and $\mathrm{Al}$ in the solution at $350-400 \mathrm{hrs}$ (lower silica activity) suggests that celadonite started to dissolve at this point, as in BW1 (Fig. 3.19, §3.2.2.2).

Celadonite formation at top of the Reactor at the expense of olivine can be represented in Reactions 18:

$$
\begin{gathered}
\mathrm{Mg}_{1.4} \mathrm{Fe}_{0.6} \mathrm{SiO}_{4}+0.17 \mathrm{~K}^{+}+1.11 \mathrm{Al}^{3+}+0.7 \mathrm{Fe}^{2+}+0.1 \mathrm{Mg}^{2+}+2.2 \mathrm{SiO}_{2}+3.6 \mathrm{H}_{2} \mathrm{O} \\
\leftrightarrow K_{0.17} \mathrm{Mg}_{1.5} \mathrm{Fe}_{1.3} \mathrm{Al}_{1.11} \mathrm{Si}_{3.2} \mathrm{O}_{10}(\mathrm{OH})_{2}+5.2 \mathrm{H}^{+}
\end{gathered}
$$

During these reactions it is evident that the consumption of $\mathrm{H}^{+}$by the formation of chlorite and anorthite is greater than the production of $\mathrm{H}^{+}$by the formation of celadonite. As with BW1, it is not possible to determine the proportion between minerals dissolved and precipitated. However, it is supposed that the formation of chlorite and anorthite must have been greater than celadonite. This explains why the $\mathrm{pH}$ reached basic values as with BW1. 


\subsection{3. $\mathrm{Na} / \mathrm{K}$ geothermometers}

Figure 3.41 shows the activity ratio diagrams for the $\mathrm{Na}_{2} \mathrm{O}-\mathrm{K}_{2} \mathrm{O}-\mathrm{Al}_{2} \mathrm{O}_{3}-\mathrm{SiO}_{2}-\mathrm{H}_{2} \mathrm{O}$ systems at 350 and $400^{\circ} \mathrm{C} / 500$ bar. The diagrams show that at 350 and $400^{\circ} \mathrm{C}$, during basalt glass dissolution, fluid compositions move towards equilibrium with muscovite. After glass dissolution, both at 350 and $400^{\circ} \mathrm{C}$, fluid compositions move to lower log $\left(a_{K^{+}} / a_{H^{+}}\right)$but constant $\log \left(a_{\mathrm{Na}^{+}} / a_{\mathrm{H}^{+}}\right)$into the andalusite field.

In these diagrams, many fluid compositions lie close to the metastable extension of the albite - K-feldspar join. If a fluid composition is on this line the $\mathrm{Na} / \mathrm{K}$ ratio should reflect equilibrium at temperature and can be used as a geothermometer (Ellis, 1970; Ellis and Mahon, 1977; Fournier, 1981; Fournier and Truesdell, 1974; Fournier, 1979; Henley et al., 1984). Cation ratio geothermometers (eg. Na-K, Na-K-Ca) are used extensively to estimate aquifer temperatures in geothermal systems, however, it is of great interest to geochemists how quickly these geothermometers equilibrate.

Table 3.11 and Figure 3.42 report the average estimated temperature $\left({ }^{\circ} \mathrm{C}\right)$ calculated both for the BW1 and BW2 fluid compositions utilising several cation geothermometers reported in literature (Arnórsson, 1983; Fournier and Truesdell, 1973; Fournier, 1979; Giggenbach, 1988b; Nieva and Nieva, 1987; Santoyo and Díaz-González, 2009; Tonani, 1980; Truesdell, 1976).

For the BW1 experiment, during glass dissolution (Sample 7-18), the estimated temperature by several $\mathrm{Na}-\mathrm{K}$ geothermometers is close to $400^{\circ} \mathrm{C}$ within one standard deviation. The Na-K-Ca geothermometer gives an average estimate well below $400^{\circ} \mathrm{C}$ indicating that $\mathrm{Ca}$ concentration is far from the equilibrium concentration expected at this temperature. After glass dissolution ceases (Sample 19-35), temperature estimates for all geothermometers are well below the experimental temperature of $400^{\circ} \mathrm{C}$. This is due to the decrease in $\mathrm{K}$ concentrations because of the loss of glass and the lower solubility of the secondary K-bearing minerals. Changing the flow rate to $0.5 \mathrm{ml} \mathrm{hr}^{-1}$ (Sample $34-35$ ) made no difference to the accuracy of temperature estimates.

In BW2, the situation is reversed. During glass dissolution (Sample 7-18), temperature estimates from the $\mathrm{Na}-\mathrm{K}$ geothermometers are significantly higher than the experimental temperature, while the Na-K-Ca geothermometer gives a low temperature. After glass dissolution ceases, and while $\mathrm{K}$ concentrations are high due to celadonite dissolution, temperature estimates from several geothermometers are close to the experimental temperature of $350^{\circ} \mathrm{C}$ within one standard deviation. Again, the Na-K-Ca geothermometer 
gives a low value. After K concentrations decrease (Sample 35 - 46), the estimates fall well below the actual experimental temperature.

Figure 3.42 shows estimated temperature $\left({ }^{\circ} \mathrm{C}\right)$ plotted versus time. Also, in this figure are plotted the $\mathrm{SiO}_{2}, \mathrm{Na}$ and $\mathrm{K}$ concentrations. The trends for silica are similar and the time taken for removal of glass is the same in both experiments, however, the estimated temperatures at $400^{\circ} \mathrm{C}$ are much closer than at $350^{\circ} \mathrm{C}$. It is evident that during glass dissolution at $350^{\circ} \mathrm{C}, \mathrm{K}$ concentrations are overall higher than at $400^{\circ} \mathrm{C}$ while $\mathrm{Na}$ concentrations are similar. This leads to overestimation of the temperature at $350^{\circ} \mathrm{C}$. After glass dissolution, $\mathrm{K}$ concentrations remain higher at $350^{\circ} \mathrm{C}$ due to dissolution of celadonite, thus the assemblage of muscovite (in celadonite) and albite (in plagioclase) is maintaining fluid $\mathrm{Na} / \mathrm{K}$ near the equilibrium value. It is evident that without a secondary K-bearing phase, $\mathrm{Na} / \mathrm{K}$ ratios are not useful in estimating temperature. 
Figure 3.41. Activity diagrams for the $\mathrm{Na}_{2} \mathrm{O}-\mathrm{K}_{2} \mathrm{O}-\mathrm{Al}_{2} \mathrm{O}_{3}-\mathrm{SiO}_{2}-\mathrm{H}_{2} \mathrm{O}$ system showing mineral stability fields for $\mathrm{BW} 1$ (a) and $\mathrm{BW} 2(\mathrm{~b})$ during and after glass dissolution. Black and red crosses show position of effluent samples collected at 1.0 and $0.5 \mathrm{ml} \mathrm{hr}^{-1} \mathrm{flow}$ rate, respectively. Yellow circles show position of the unreacted fluid (water) at 400 and $350^{\circ} \mathrm{C} / 500$ bar. Blue arrows show the path of reacted fluids over the experiment.
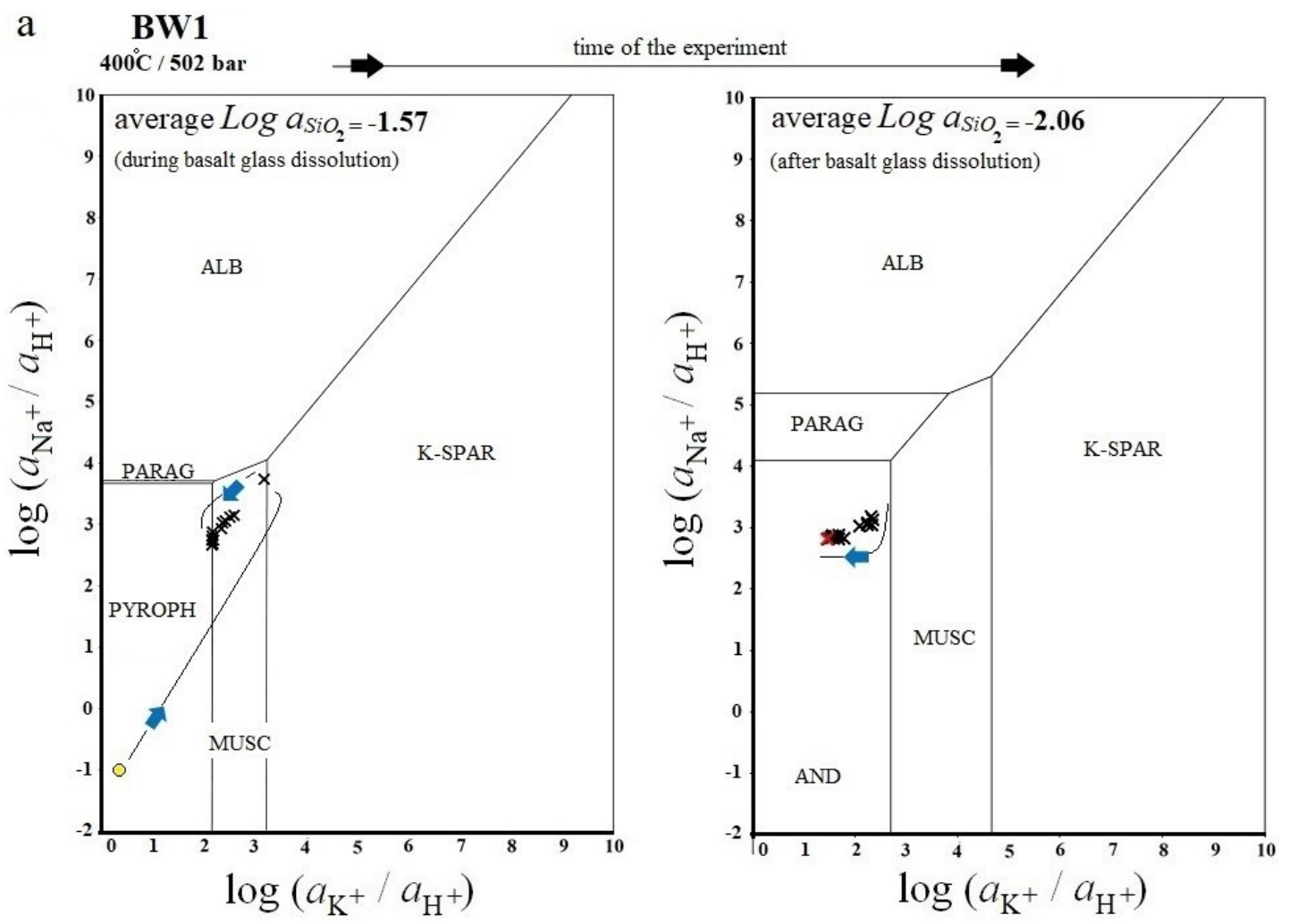

b
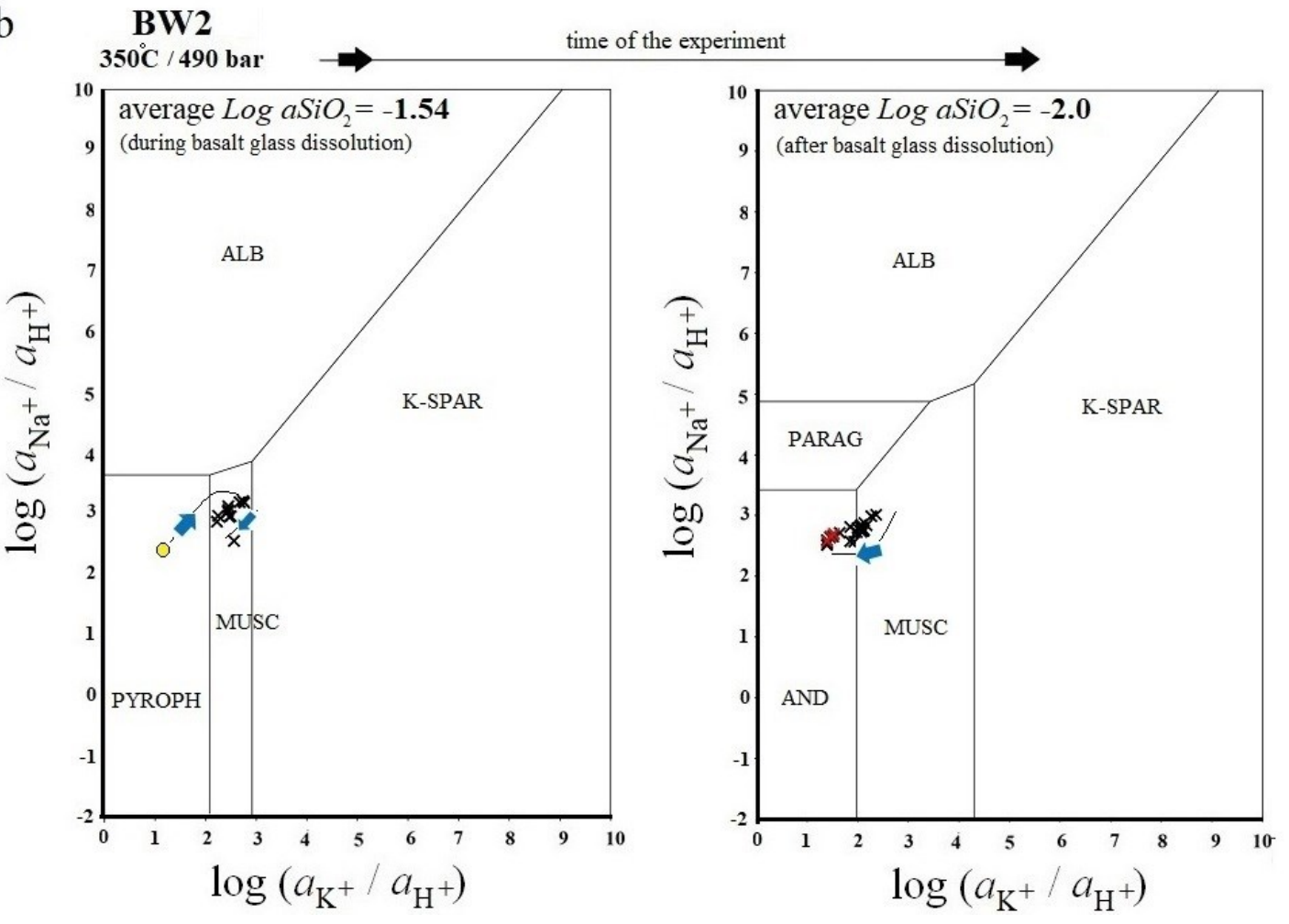
Table 3.11. Average and $1 \sigma$ of estimated temperature $\left({ }^{\circ} \mathrm{C}\right)$ during and after basalt glass dissolution using fluid compositions for the BW1 and BW2. Estimates were made using several geothermometers from literature (Arnórsson, 1983; Fournier and Truesdell, 1973; Fournier, 1979; Giggenbach, 1988b; Nieva and Nieva, 1987; Santoyo and Díaz-González, 2009; Tonani, 1980; Truesdell, 1976).

\begin{tabular}{|c|c|c|c|c|c|c|c|c|c|}
\hline & & $\begin{array}{c}\mathbf{N a} / \mathbf{K} \\
\text { (Fournier } \\
1979)\end{array}$ & $\begin{array}{c}\mathbf{N a} / \mathbf{K} \\
\text { (Truesdell } \\
1976)\end{array}$ & $\begin{array}{c}\mathbf{N a} / \mathbf{K} / \mathbf{C a} \\
\text { (Fournier and } \\
\text { Truesdell } \\
1973) \\
(\beta=1 / 3)\end{array}$ & $\begin{array}{c}\mathbf{N a} / \mathbf{K} \\
\text { (Santoyo and } \\
\text { Díaz-González } \\
\text { 2009) }\end{array}$ & $\begin{array}{c}\mathbf{N a} / \mathbf{K} \\
\text { (Arnorsson } \\
1983) \\
\left(250-350^{\circ} \mathrm{C} \text { ) }\right.\end{array}$ & $\begin{array}{c}\mathbf{N a} / \mathbf{K} \\
\text { (Tonani } \\
1980)\end{array}$ & $\begin{array}{c}\mathbf{N a} / \mathbf{K} \\
\text { (Nieva and } \\
\text { Nieva } \\
1987 \text { ) }\end{array}$ & $\begin{array}{c}\mathbf{N a} / \mathbf{K} \\
\text { (Giggenbach } \\
1988)\end{array}$ \\
\hline \multirow[t]{5}{*}{$\begin{array}{c}\text { BW1 } \\
400^{\circ} \mathrm{C} / 502 \text { bar }\end{array}$} & $\begin{array}{l}\text { During basalt glass } \\
\text { dissolution } \\
\text { (Sample 7-18) }\end{array}$ & 383 & 424 & 254 & 408 & 364 & 451 & 366 & 382 \\
\hline & $1 \sigma$ & 22 & 36 & 10 & 34 & 19 & 40 & 22 & 20 \\
\hline & $\begin{array}{l}\text { After basalt glass } \\
\text { dissolution } \\
\text { (Sample 19-33) }\end{array}$ & 250 & 233 & 205 & 224 & 246 & 244 & 236 & 263 \\
\hline & $\begin{array}{c}1 \sigma \\
\text { After basalt glass }\end{array}$ & 53 & 71 & 31 & 69 & 48 & 76 & 52 & 49 \\
\hline & $\begin{array}{c}\text { dissolution } \\
\text { (Sample 34-35) } \\
0.5 \mathrm{ml} \mathrm{hr}^{-1}\end{array}$ & 190 & 154 & 166 & 147 & 191 & 160 & 177 & 207 \\
\hline \multirow[t]{6}{*}{$\begin{array}{c}\text { BW2 } \\
350^{\circ} \mathrm{C} / 490 \text { bar }\end{array}$} & $\begin{array}{l}\text { During basalt glass } \\
\text { dissolution } \\
\text { (Sample 7-18) }\end{array}$ & 390 & 437 & 222 & 420 & 370 & 466 & 374 & 388 \\
\hline & $1 \sigma$ & 41 & 67 & 15 & 64 & 36 & 74 & 40 & 36 \\
\hline & $\begin{array}{l}\text { After basalt glass } \\
\text { dissolution } \\
\text { (Sample 19-33) }\end{array}$ & 348 & 368 & 216 & 354 & 333 & 390 & 332 & 351 \\
\hline & $\begin{array}{c}1 \sigma \\
\text { After basalt glass }\end{array}$ & 18 & 27 & 9 & 26 & 16 & 30 & 18 & 16 \\
\hline & & 234 & 209 & 159 & 200 & 231 & 218 & 220 & 248 \\
\hline & $1 \sigma$ & 15 & 20 & 8 & 20 & 14 & 22 & 15 & 14 \\
\hline
\end{tabular}


Figure 3.42. Estimated temperatures $\left({ }^{\circ} \mathrm{C}\right)$ calculated using several cation geothermometers (Arnórsson, 1983; Fournier, 1979; Giggenbach, 1988b; Nieva and Nieva, 1987; Santoyo and Díaz-González, 2009; Tonani, 1980; Truesdell, 1976) together with $\mathrm{SiO}_{2}$, Na and K concentrations for BW1 and BW2 plotted versus time. Dotted black lines separate value of $\mathrm{SiO}_{2}$ above quartz saturation (during basalt glass dissolution) from those below quartz saturation (after basalt glass dissolution). Dotted red lines show experimental temperature of BW1 and BW2 over time. n: Sample number.

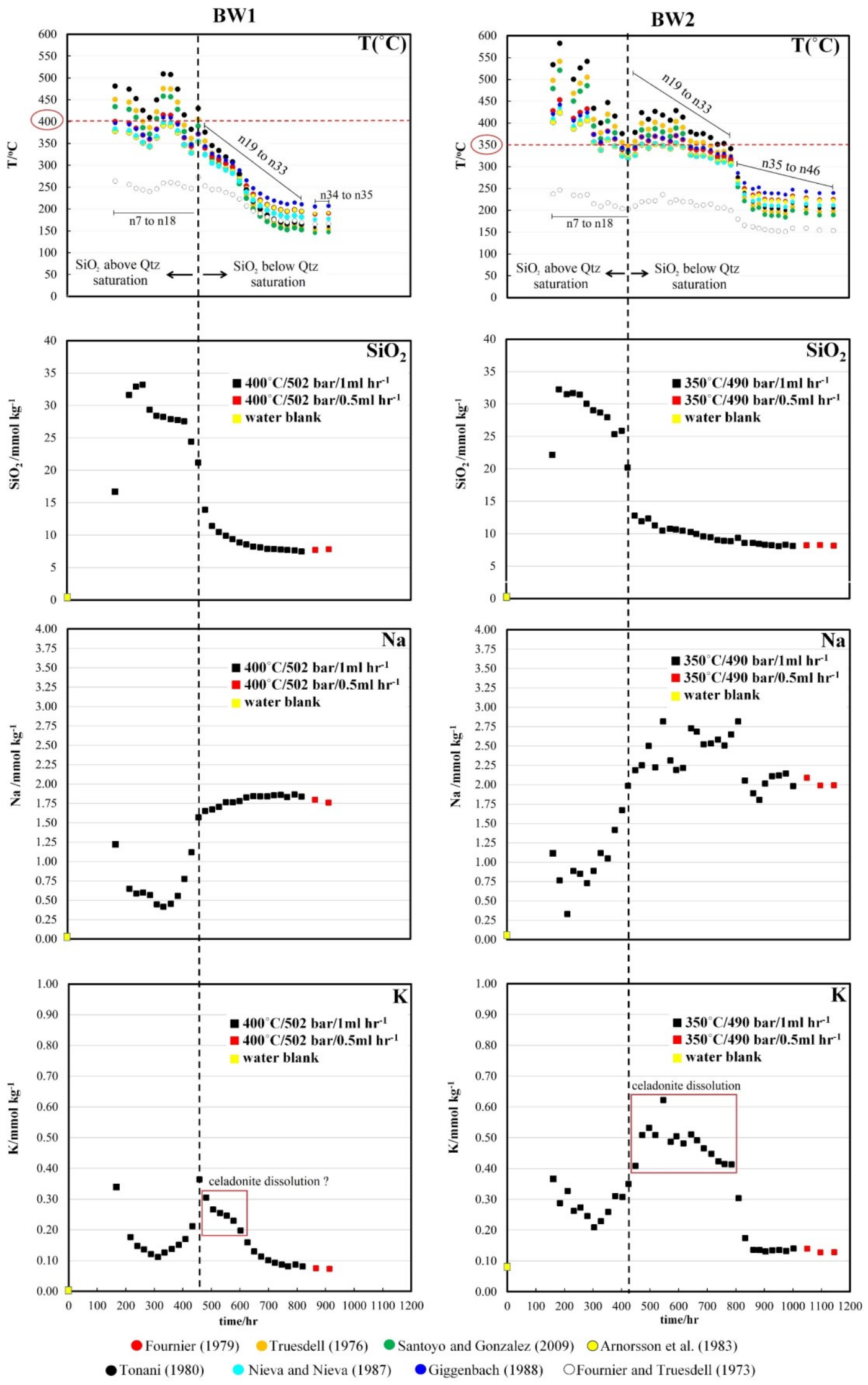




\subsubsection{Geological implications}

Although the interaction between basalt and (distilled) water is an unlikely scenario in the natural environment, the presence of celadonite as an alteration product is notable and significant. Celadonite was formed in both the $350^{\circ} \mathrm{C}$ and $400^{\circ} \mathrm{C}$ experiments. The experiments show that it can be formed by the interaction of deuteric water and basalt without any other added components, provided that the basalt has sufficient glass as a source for $\mathrm{SiO}_{2}$ and $\mathrm{K}$ and mafics as a source for $\mathrm{Mg}$ and $\mathrm{Fe}$. Celadonite is known as a hydrothermal alteration product derived by the interaction between basalt and seawater where it is known to replace both olivine and pyroxene (Baker et al., 2012).

Examination of the basalt block shows that celadonite is replacing olivine (Fig. 3.16). As olivine is more soluble that the accompanying aluminosilicates (Brantley, 2008; Oelkers, 2001; Oelkers et al., 2018; Schott et al., 2009; Velbel, 2009), this resulted in it being the only mineral replaced by the celadonite (Hendricks and Ross, 1941). There was no evidence of augite and/or plagioclase replacement by celadonite. Our experiments demonstrate that celadonite can form by an "auto-metasomatic" process whereby only heated meteoric water in contact with fresh basalt is necessary. This conclusion implies that seawater is not necessary to supply $\mathrm{K}$ for celadonite formation if sufficient $\mathrm{K}$ is released from dissolving basaltic glass.

Celadonite occurred both at 350 and $400^{\circ} \mathrm{C} / 500$ bar with chlorite. This implies that the experiments reproduced a metamorphic grade up to lower greenschist facies (Brown, 1967; Velde, 2003; Wise and Eugster, 1964). 


\subsection{References}

Andrews, A.J., 1980, Saponite and celadonite in layer 2 basalts, DSDP Leg 37. Contributions to Mineralogy and Petrology, 73: 323-340.

Arnórsson, S., 1983, Chemical equilibria in icelandic geothermal systems-Implications for chemical geothermometry investigations. Geothermics, 12: 119-128.

Baker, L.L., Rember, W.C., Sprenke, K.F. and Strawn, D.G., 2012, Celadonite in continental flood basalts of the Columbia River Basalt Group. American Mineralogist, 97: 12841290.

Brantley, S.L., 2008, Kinetics of Mineral Dissolution. In: Brantley, S.L., Kubicki, J.D. and White, A.F. (eds.), Kinetics of Water-Rock Interaction. Springer New York, New York, NY, 151-210.

Brown, E.H., 1967, The greenschist facies in part of eastern Otago, New Zealand. Contributions to Mineralogy and Petrology, 14: 259-292.

Carstens, H., 1975, Thermal history of impact melt rocks in the Fennoscandian shield. Contributions to Mineralogy and Petrology, 50: 145-155.

Chesworth, W., Dejou, J., Larroque, P. and Rodeja, E.G., 2004, Alteration of olivine in a basalt from central France. Catena, 56: 21-30.

Ellis, A., 1970, Quantitative interpretation of chemical characteristics of hydrothermal systems. Geothermics, 2: 516-528.

Ellis, A.J. and Mahon, W., 1977, Chemistry and geothermanl systems

Fournier, R. and Truesdell, A., 1973, An empirical Na $\square$ K $\square$ Ca geothermometer for natural waters. Geochimica et Cosmochimica Acta, 37: 1255-1275.

Fournier, R. and Truesdell, A., 1974, Geochemical indicators of subsurface temperature. II. Estimation of temperature and fraction of hot water mixed with cold water.

Fournier, R., 1981, Application of water geochemistry to geothermal exploration and reservoir engineering. Geothermal System: Principles and Case Histories.

Fournier, R.O., 1979, A revised equation for the $\mathrm{Na} / \mathrm{K}$ geothermometer. Transactions of the Geothermal Resources Council, 3: 221-224.

Giggenbach, W.F., 1988b, Geothermal solute equilibria. derivation of Na-K-Mg-Ca geoindicators. Geochimica et cosmochimica acta, 52: 2749-2765.

Hendricks, S.B. and Ross, C.S., 1941, Chemical composition and genesis of glauconite and celadonite. American Mineralogist: Journal of Earth and Planetary Materials, 26: 683708.

Henley, R.W., Truesdell, A., Barton, P. and Whitney, J., 1984, Fluid-mineral equilibria in hydrothermal systems. Society of Economic Geologists Yale

Hukkanen, E. and Walden, H., 1985, The production of vanadium and steel from titanomagnetites. International Journal of Mineral Processing, 15: 89-102.

Jafri, S.H. and Charan, S.N., 1992, Quench textures in pillow basalt from the AndamanNicobar Islands, Bay of Bengal, India. Proceedings of the Indian Academy of Sciences - Earth and Planetary Sciences, 101: 99-107.

Li, G., Peacor, D.R., Coombs, D.S. and Kawachi, Y., 1997, Solid solution in the celadonite family; the new minerals ferrosceladonite, $\mathrm{K} 2 \mathrm{Fe} 2+2 \mathrm{Fe} 3+2 \mathrm{Si} 8 \mathrm{O} 20(\mathrm{OH}) 4$, and ferroaluminoceladonite, K2Fe2+2A12 Si8 O20 (OH)4. American Mineralogist, 82: 503-511.

Li, H., Zhang, L. and Christy, A.G., 2011, 7 - The Correlation Between Raman Spectra and the Mineral Composition of Muscovite and Phengite. In: Dobrzhinetskaya, L.F., Faryad, S.W., Wallis, S. and Cuthbert, S. (eds.), Ultrahigh-Pressure Metamorphism. Elsevier, London, 187-212. 
Nieva, D. and Nieva, R., 1987, Developments in geothermal energy in Mexico-part twelve. A cationic geothermometer for prospecting of geothermal resources. Heat Recovery Systems and CHP, 7: 243-258.

Oelkers, E.H., 2001, General kinetic description of multioxide silicate mineral and glass dissolution. Geochimica et Cosmochimica Acta, 65: 3703-3719.

Oelkers, E.H., Declercq, J., Saldi, G.D., Gislason, S.R. and Schott, J., 2018, Olivine dissolution rates: A critical review. Chemical Geology, 500: 1-19.

Parra, M., Delmont, P., Ferragne, A., Latouche, C., Pons, J. and Puechmaille, C., 1985, Origin and evolution of smectites in recent marine sediments of the NE Atlantic. Clay Minerals, 20: 335-346.

Ronghua, Z., Shumin, H. and Xuetong, Z., 2000, Kinetics of Hydrothermal Reactions of Minerals in Near-critical and Supercritical Water. Acta Geologica Sinica - English Edition, 74: 400-405.

Ronghua, Z., Shumin, H. and Yanfeng, S., 2002, Hydrothermal Alteration Zoning and Kinetic Process of Mineral-Water Interactions. Acta Geologica Sinica - English Edition, 76: 351-366.

Santoyo, E. and Díaz-González, L., Year, A New Improved Proposal of the Na / K Geothermometer to Estimate Deep Equilibrium Temperatures and their Uncertainties in Geothermal Systems.

Schmidt, M.W., Dugnani, M. and Artioli, G., 2001, Synthesis and characterization of white micas in the join muscovite-aluminoceladonite. American Mineralogist, 86: 555-565.

Schott, J., Pokrovsky, O.S. and Oelkers, E.H., 2009, The Link Between Mineral Dissolution/Precipitation Kinetics and Solution Chemistry. Reviews in Mineralogy and Geochemistry, 70: 207-258.

Tappert, M.C., Rivard, B., Giles, D., Tappert, R. and Mauger, A., 2013, The mineral chemistry, near-infrared, and mid-infrared reflectance spectroscopy of phengite from the Olympic Dam IOCG deposit, South Australia. Ore Geology Reviews, 53: 26-38.

Tonani, F., Year, Some Remarks on the Application of Geochemical Techniques in geothermal exploration.

Truesdell, A., Year, Geochemical Techniques in Exploration: Summary of Section III. Proceedings of the Second UN Symposium on the Development and Use of Geothermal Resources, 1976, Iiii-Ixxix.

Velbel, M.A., 2009, Dissolution of olivine during natural weathering. Geochimica et Cosmochimica Acta, 73: 6098-6113.

Velde, B., 2003, 7.12 - Green Clay Minerals. In: Holland, H.D. and Turekian, K.K. (eds.), Treatise on Geochemistry. Pergamon, Oxford, 309-324.

Wise, W.S. and Eugster, H.P., 1964, Celadonite: synthesis, thermal stability and occurrence1. American Mineralogist, 49: 1031-1083.

Zhang, R., Zhang, X. and Hu, S., 2011, Experimental study on water rock interactions at temperatures up to $435^{\circ} \mathrm{C}$ and implications for geophysical features in upper midcrust condition. Tectonophysics, 502: 276-292.

Zhang, R.-H., J., P.-D., R., H., Maria, B., David, C. and Hu, S.-M., 1990, Kinetics Studies Of Mineral-Water Reactions In Hydrothermal Flow Systems At Elevated Temperatures And Pressures. Science in China Series B-Chemistry, Life Sciences \& Earth Sciences, 33: 1136.

Zhang, R.H., Zhang, X.T., Hu, S.M. and Su, Y.F., 2007, Kinetic experiments of water rock interactions at high temperatures and high pressures corresponding to the middle crust conditions. Acta Petrologica Sinica, 23: 2933-2942. 
Zhang, R., Zhang, X. and $\mathrm{Hu}$, S., 2015, Basalt-water interactions at high temperatures: 1. Dissolution kinetic experiments of basalt in water and $\mathrm{NaCl}-\mathrm{H} 2 \mathrm{O}$ at temperatures up to $400^{\circ} \mathrm{C}, 23 \mathrm{MPa}$ and implications. Journal of Asian Earth Sciences, 110: 189-200. 


\section{Chapter 4: Basalt - Geothermal Brine Interactions Under Hydrothermal Conditions}

\subsection{A brief introduction}

Basalt-geothermal brine interactions, both at supercritical and subcritical conditions, can reflect many real scenarios occurring in the geothermal environment. During circulation, a geothermal fluid achieves its temperature depending on the depth, path, and its proximity to the heat source. The higher the enthalpy content of the fluid, the more energy that can be extracted usefully.

The chemical composition of the hydrothermal fluid reflects the temperature, pressure and geological setting of the surrounding host rocks. It is therefore expected that the composition will be markedly different depending on whether the fluid is at subcritical or supercritical conditions. It is also expected that the fluid will be in equilibrium with its host rock minerals before extraction and will give an indication of its pressure and temperature conditions. For example, geothermometers using the cation concentrations in the fluid are used to estimate aquifer temperatures in geothermal systems (Fournier and Truesdell, 1973; Fournier, 1979; Giggenbach et al., 1983; Giggenbach, 1988b; Henley and Ellis, 1983; Marini, 2000).

One example of supercritical hydrothermal circulation is at the Reykjanes and Krafla geothermal fields in Iceland. Many studies have been carried out investigating these geothermal reservoirs especially during the Icelandic Deep Drilling Project, (Armannsson et al., 2014; Arnórsson, 1995; Arnórsson et al., 1978; Asmundsson et al., 2014; Elders and Friðleifsson, 2010; Fowler et al., 2015; Franzson et al., 2008; Fridleifsson and Elders, 2005; Fridleifsson et al., 2017; Friðleifsson et al., 2014; Marks et al., 2010; Mortensen et al., 2014; Pálsson et al., 2014; Thórhallsson et al., 2014; Weir et al., 2001). Icelandic geothermal systems are dominated by hydrothermal circulation involving seawater mixed with meteoric water, heated by a shallow magmatic source. As a result, supercritical fluids are located at relatively shallow depths when compared to geothermal fields elsewhere.

Few experimental simulations have been carried out to investigate geothermal brine rock interactions at geothermal conditions. Examples include: greywacke (Taupo Volcanic Zone, New Zealand) and geothermal brine (Wairakei field, New Zealand) at $25-203^{\circ} \mathrm{C} / 35$ bar using a flow-through hydrothermal apparatus (Sonney and Mountain, 2013); between basaltic glass (Stapafell, Iceland) and natural geothermal brine (Krafla field, Iceland) at $260^{\circ} \mathrm{C}$ and $400-420^{\circ} \mathrm{C} / 69$ bar using a flow-through system (Heřmanská et al., 2019). 
In the present study, tholeiitic basalt (Eldvarpahraun, Iceland) was reacted with natural geothermal brine (Rotokawa field, New Zealand) at $400^{\circ} \mathrm{C} / 483$ bar and at $350^{\circ} \mathrm{C} / 486$ bar, using a flow-through hydrothermal apparatus. The geothermal fluid used for these experiments contains significant concentrations of $\mathrm{K}, \mathrm{Na}, \mathrm{Ca}, \mathrm{SO}_{4}, \mathrm{SiO}_{2}$ and $\mathrm{Cl}$ when compared to distilled water, but at the same time, it is more diluted when compared to natural seawater (Chapter 6). The brine has a low initial $\mathrm{pH}$ due to the addition of sulfuric acid $\left(\mathrm{H}_{2} \mathrm{SO}_{4}\right)$ at the plant to inhibit silica polymerisation and subsequent silica scaling (Addison et al., 2015).

Our results indicate that the geothermal brine reacted aggressively with the basalt in both experiments. Major changes in solution chemistry occurred after temperature shift. These consisted of: (1) silica concentrations consistently over quartz saturation for two weeks at $400^{\circ} \mathrm{C}$, while there was a progressive decrease from quartz supersaturation at $350^{\circ} \mathrm{C}$; (2) $\mathrm{pH}$ values strongly correlated with silica concentrations mainly due to the dissolution of volcanic glass; (3) lower concentrations of $\mathrm{K}$ and $\mathrm{SO}_{4}{ }^{2-}$ relative to the starting brine while there was a measurable depletion of Ca only at $350^{\circ} \mathrm{C}$; (4) measurable concentrations of $\mathrm{H}_{2} \mathrm{~S}$ that were greater at $400^{\circ} \mathrm{C}$ than at $350^{\circ} \mathrm{C}$; and (5) a moderate but higher mobility of the trace elements in solution at 400 rather than at $350^{\circ} \mathrm{C}$.

Analysis of the reacted rock material was conducted on basalt grains collected both from the bottom and top portion of the Reactor. Results show that the bottom portion (first 1$2 \mathrm{~mm}$ ), located at the entry point of the unreacted fluid, is the most altered portion of the basalt, while the top portion (last 1-2 mm), located at the exit point of the reacted fluid into Reactor, is the least altered portion of the basalt. 


\subsection{Results}

In this chapter the results are presented for the:

1) major element analyses of experimental solutions;

2) trace element analyses of experimental solutions;

3) chemical, mineralogical and textural analyses of reacted basalt grains.

\subsubsection{BGB1: Basalt - Geothermal brine at $400^{\circ} \mathrm{C} / 483$ bar}

The first basalt - geothermal brine experiment (BGB1) ran for total time of $853 \mathrm{hrs}$ (Fig. 4.1). The first $167 \mathrm{hr}$ were at room temperature/483 bar and the remaining $687 \mathrm{hr}$ were at $400^{\circ} \mathrm{C} / 483$ bar. The flow rate was $1 \mathrm{ml} \mathrm{hr}^{-1}$ up to $768 \mathrm{hr}$ after which it was changed to 0.5 $\mathrm{ml} \mathrm{hr}{ }^{-1}$ for the remaining $86 \mathrm{hr}$. As for the BW experiments, the flow-rate was set-up to guarantee the collection of enough solution for all chemical analyses at the approximately 24 hours interval. For this experiment, analysis of major ions was undertaken for 34 fluid samples. Trace element analysis was undertaken for the first 30 fluid samples.

\subsubsection{Major element concentrations}

Appendix (C) lists the complete experimental parameters and results (T, P, flow rate, chemistry). Figure 4.1 and Figure 4.2 show selected elements plotted against experimental time in hours. The unreacted geothermal brine composition is shown at time $=0$. Initial concentrations of major ions were measured as follow: As $\left(0.02 \mathrm{mmol} \mathrm{kg}^{-1}\right), \mathrm{B}(4.45 \mathrm{mmol}$ $\left.\mathrm{kg}^{-1}\right), \mathrm{Ca}\left(0.08 \mathrm{mmol} \mathrm{kg}^{-1}\right), \mathrm{Fe}\left(<0.08 \mathrm{mmol} \mathrm{kg}^{-1}\right), \mathrm{K}\left(3.0 \mathrm{mmol} \mathrm{kg}{ }^{-1}\right), \mathrm{Mg}\left(0.01 \mathrm{mmol} \mathrm{kg}{ }^{-1}\right)$, $\mathrm{Na}\left(31.6 \mathrm{mmol} \mathrm{kg}^{-1}\right), \mathrm{SiO}_{2}\left(12.6 \mathrm{mmol} \mathrm{kg}{ }^{-1}\right), \mathrm{Al}\left(0.06 \mathrm{mmol} \mathrm{kg}{ }^{-1}\right), \mathrm{Sr}\left(<0.003 \mathrm{mmol} \mathrm{kg}^{-1}\right), \mathrm{Li}$ $\left(0.82 \mathrm{mmol} \mathrm{kg}^{-1}\right), \mathrm{H}_{2} \mathrm{~S}\left(<0.01 \mathrm{mmol} \mathrm{kg}^{-1}\right), \mathrm{Cl}\left(26.54 \mathrm{mmol} \mathrm{kg}^{-1}\right)$ and $\mathrm{SO}_{4}\left(4.22 \mathrm{mmol} \mathrm{kg}{ }^{-1}\right)$.

During the room temperature $\left(\sim 21^{\circ} \mathrm{C}\right)$ period, the significant changes in solution composition are increases in $\mathrm{Al}, \mathrm{Ca}, \mathrm{Fe}$ and $\mathrm{Mg}$. The $\mathrm{pH}$ values are on average higher (5.63) than the starting blank (3.91). Over the seven-day room temperature period Fe concentration increases while $\mathrm{Ca}$ and $\mathrm{Al}$ decrease.

The temperature shift to $400^{\circ} \mathrm{C}$ was initiated at 167 hours and took approximately 3 hours, thus only about $3 \mathrm{ml}$ of the first sample were collected while heating was occurring. Major changes in solution chemistry are observed after the temperature shift. Effluent quench $\mathrm{pH}$ decreases to between 2.87 and 3.5 for approximately 250 hours and then increases to about 7 over the next 200 hours after which it remains between 7 and 8 for the remainder of 
the experiment. The change in flow rate at 768 hours does not noticeably effect $\mathrm{pH}$. Calculated in situ $\mathrm{pH}$ stays constant after the temperature shift at about 7.

$\mathrm{SiO}_{2}$ increases to $34.6 \mathrm{mmol} \mathrm{kg}{ }^{-1}$ ( 2080 ppm) which greatly exceeds quartz saturation at $400^{\circ} \mathrm{C} / 500$ bar (1238 ppm, Supcrt92). Between 215 and 550 hours, silica concentration remains elevated and relatively constant at an average value of $31.1 \mathrm{mmol} \mathrm{kg}^{-1}$. It then decreases to about $16 \mathrm{mmol} \mathrm{kg}^{-1}$ by 600 hours after which it remains relatively stable for the remainder of the experiment. The change in flow rate at 768 hours does not significantly affect $\mathrm{SiO}_{2}$ concentration.

$\mathrm{Na}$ concentration decreases slightly after the temperature shift but only for three days after which it remains similar to the blank sample. K shows an increase after temperature shift, reaching $\sim 5.0 \mathrm{mmol} \mathrm{kg}^{-1}$ for two days. It decreases to $3.8 \mathrm{mmol} \mathrm{kg}^{-1}$ after one day and then gradually decreases to $2.3 \mathrm{mmol} \mathrm{kg}^{-1} 620$ hours and then remains constant.

Al concentration decreases after the temperature shift to between 0.02 and $0.03 \mathrm{mmol}$ $\mathrm{kg}^{-1}$ up to 550 hours, after which it increases to $0.22 \mathrm{mmol} \mathrm{kg}^{-1}$ by $768 \mathrm{hrs}$. After the flow rate change, it decreases to $0.16 \mathrm{mmol} \mathrm{kg}^{-1}$ at $809 \mathrm{hrs}$ and $0.17 \mathrm{mmol} \mathrm{kg}{ }^{-1}$ at $853 \mathrm{hrs}$.

$\mathrm{Ca}$ concentration decreases, after the temperature shift, to a minimum of $0.05 \mathrm{mmol}$ $\mathrm{kg}^{-1}$ at 215 hours and then increases up to $0.12 \mathrm{mmol} \mathrm{kg}^{-1}$ by 550 hours. It remains stable around $0.10-0.11 \mathrm{mmol} \mathrm{kg}^{-1}$ to 768 hours. After the change in flow rate, Ca concentration peaks at $0.14 \mathrm{mmol} \mathrm{kg}^{-1}$ and decreases back to $0.1 \mathrm{mmol} \mathrm{kg}^{-1}$ in the last sample.

Fe decreases to near or below detection limit after temperature shift and remains at this value for the remainder of the experiment. $\mathrm{Mg}$ concentration also decreases after temperature shift and remains near blank values for the next 450 hours after which it increases to between 0.01 and $0.02 \mathrm{mmol} \mathrm{kg}^{-1}$ up until the flow rate change at 768 hours.

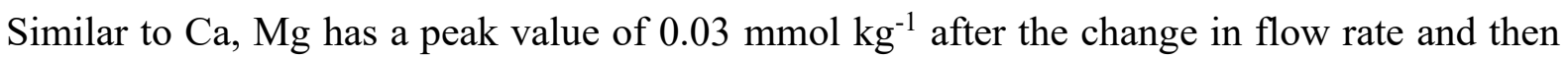
decreases to $0.05 \mathrm{mmol} \mathrm{kg}^{-1}$ in the last sample.

$\mathrm{SO}_{4}$ concentration decreases to a minimum of $2.50 \mathrm{mmol} \mathrm{kg}^{-1}$ immediately after temperature shift. It then increases to a value of $3.8 \mathrm{mmol} \mathrm{kg}^{-1}$ by 406 hours after which there is an overall small decrease to $3.2 \mathrm{mmol} \mathrm{kg}^{-1}\left(1.0 \mathrm{mmol} \mathrm{kg}^{-1}\right.$ less the input solution) by 768 hours. The change in flow rate to $0.5 \mathrm{ml} \mathrm{hr}^{-1}$ did not significantly affect its concentration. $\mathrm{H}_{2} \mathrm{~S}$ concentration increases to a maximum of $\sim 0.05 \mathrm{mmol} \mathrm{kg}^{-1}$ for three days after temperature increase. It then gradually decreases over the remainder of the experiment reaching a value of $0.01 \mathrm{mmol} \mathrm{kg}^{-1}$ at 768 hours. The change in flow rate did not cause a significant change in concentration. 
$\mathrm{Cl}$ concentration remains close to the input solution value throughout the experiment indicating that the apparatus was behaving correctly.

Figure 4.1. Major element concentrations in blank and effluent samples (mmol kg-1) versus time (hr) for the basalt - geothermal brine experiment at $400^{\circ} \mathrm{C} / 483$ bar (BGB1). Yellow symbols are the blank sample composition of the geothermal brine. Blue symbols are for effluents at room $\mathrm{T} / 483$ bar and $1.0 \mathrm{ml} \mathrm{hr}^{-1}$ flow rate. Black symbols are effluents at $400^{\circ} \mathrm{C} / 483 \mathrm{bar}$ and $1.0 \mathrm{ml} \mathrm{hr}{ }^{-1} \mathrm{flow}$ rate. Red symbols are effluents at $400^{\circ} \mathrm{C} / 483$ bar and $0.5 \mathrm{ml} \mathrm{hr}^{-1}$ flow rate. In situ $\mathrm{pH}$ is the calculated $\mathrm{pH}$ at temperature.
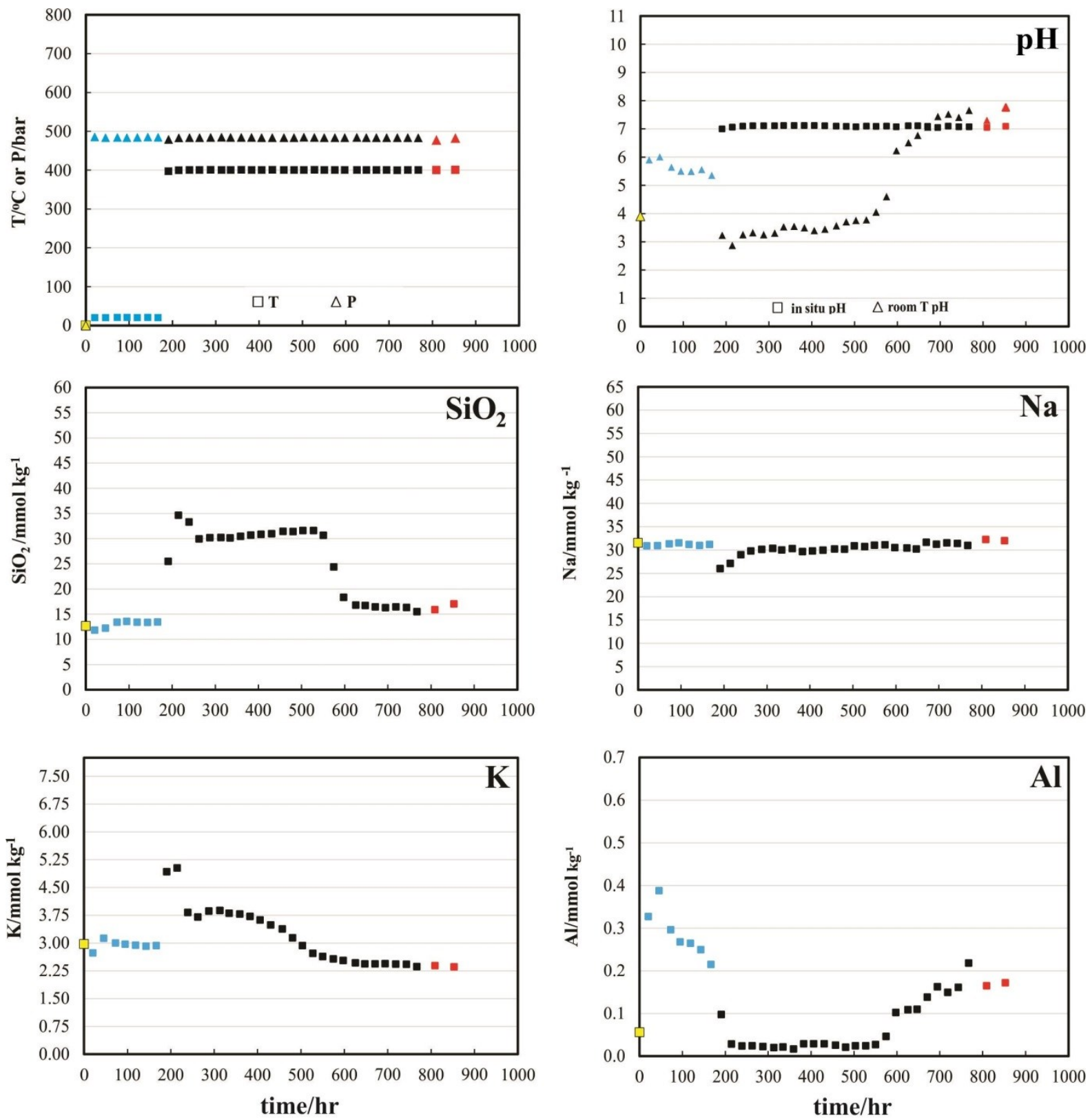
$\square$ blank
- $\triangle \operatorname{room~} \mathrm{T} / 483 \mathrm{bar} / 1.0 \mathrm{ml} \mathrm{hr}^{-1}$
- $\triangle 400^{\circ} \mathrm{C} / 483 \mathrm{bar} / 1.0 \mathrm{ml} \mathrm{hr}^{-1}$
$\triangle 400^{\circ} \mathrm{C} / 483 \mathrm{bar} / 0.5 \mathrm{ml} \mathrm{hr}^{-1}$ 
Figure 4.2. Major element concentrations in blank and effluent samples (mmol kg ${ }^{-1}$ ) versus time (hr) for the basalt - geothermal brine experiment at $400^{\circ} \mathrm{C} / 483$ bar (BGB1). Yellow symbols are the blank sample composition of the geothermal brine. Blue symbols are for effluents at room $\mathrm{T} / 483$ bar and $1.0 \mathrm{ml} \mathrm{hr}^{-1}$ flow rate. Black symbols are effluents at $400^{\circ} \mathrm{C} / 483 \mathrm{bar}$ and $1.0 \mathrm{ml} \mathrm{hr}^{-1}$ flow rate. Red symbols are effluents at $400^{\circ} \mathrm{C} / 483$ bar and $0.5 \mathrm{ml} \mathrm{hr}^{-1}$ flow rate. In situ $\mathrm{pH}$ is the calculated $\mathrm{pH}$ at temperature.
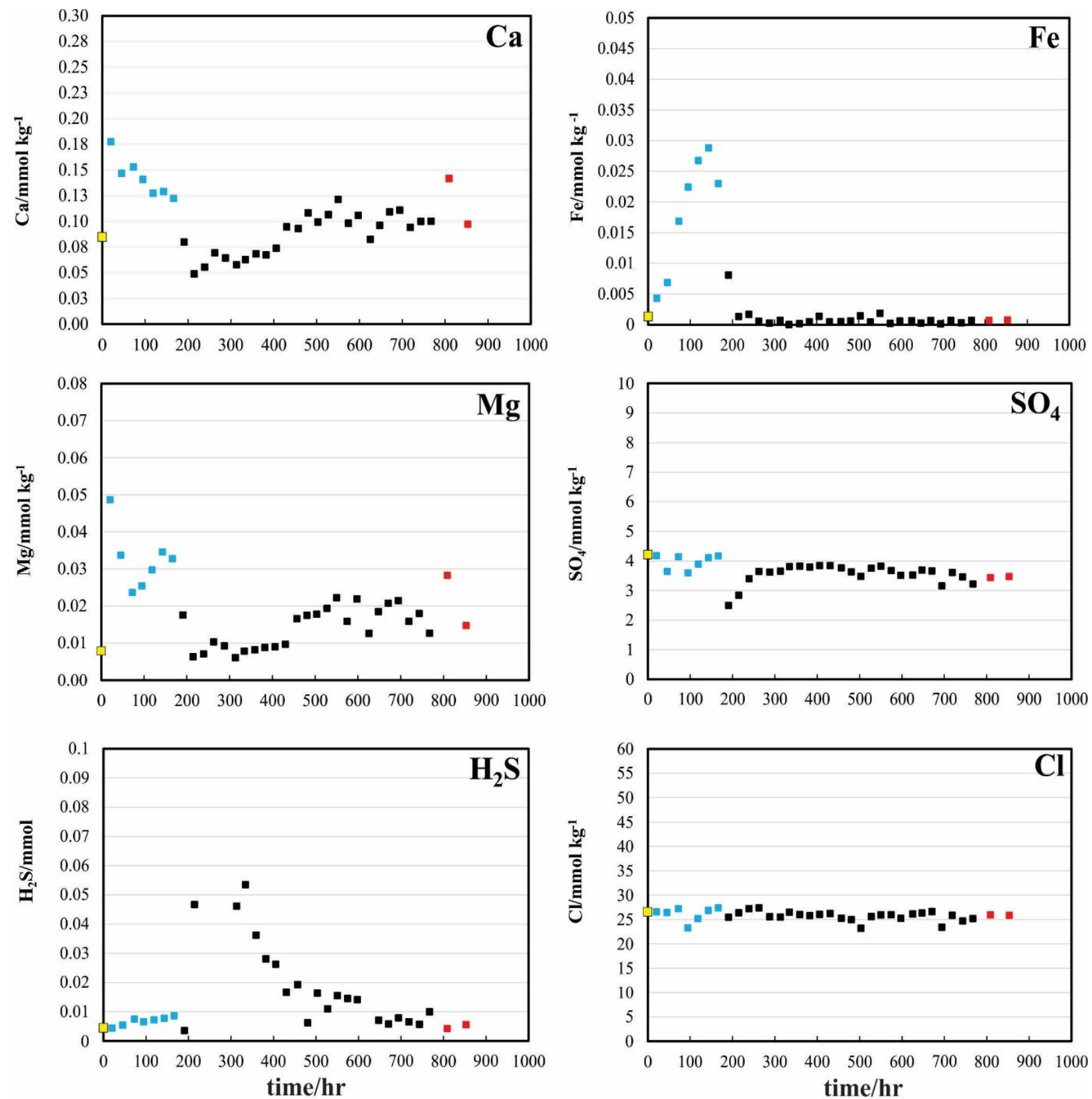

$\square \triangle$ blank

$\Delta \operatorname{room} \mathrm{T} / 483 \mathrm{bar} / 1.0 \mathrm{ml} \mathrm{hr}^{-1}$

- $\triangle 400^{\circ} \mathrm{C} / 483$ bar $/ 1.0 \mathrm{ml} \mathrm{hr}^{-1}$

- $\triangle 400^{\circ} \mathrm{C} / 483$ bar/0.5 ml hr ${ }^{-1}$ 


\subsubsection{Trace element concentrations}

Appendix (C) lists the complete trace element results. Figure 4.3 and Figure 4.4 show these results plotted against time in hours. The unreacted geothermal brine composition is shown at $\mathrm{t}=0$. All trace elements (except for $\mathrm{Co}$ and $\mathrm{Ba}$ ) are detectable in the input solution. In particular, elevated values of $\mathrm{Zn}\left(1.9 \mu \mathrm{mol} \mathrm{kg}{ }^{-1}\right), \mathrm{Rb}\left(8.5 \mu \mathrm{mol} \mathrm{\textrm {kg } ^ { - 1 }}\right)$ and $\mathrm{Au}(1.0 \mu \mathrm{mol} \mathrm{kg}$ 1) are notable.

During the room temperature $\left(\sim 21^{\circ} \mathrm{C}\right)$ period, measurable increases in trace element concentration, including $\mathrm{Cr}, \mathrm{Mn}, \mathrm{Co}, \mathrm{Ni}, \mathrm{Ba}, \mathrm{Pb}$ and, in particular, $\mathrm{Cu}$ and $\mathrm{Zn}$, are present in the effluent. $\mathrm{V}, \mathrm{Cd}$ and $\mathrm{Au}$ decrease in solution, while $\mathrm{Rb}$ and Mo remain relatively unchanged. Ag has values near or below detection limit.

After the temperature shift to $400^{\circ} \mathrm{C}$, several trace elements including $\mathrm{Cr}, \mathrm{Mn}, \mathrm{Co}, \mathrm{Ni}$, $\mathrm{Cu}, \mathrm{Ag}$, and $\mathrm{Ba}$ decrease sharply to values at or below the detection limit. V concentration remains below $0.1 \mu \mathrm{mol} \mathrm{kg}{ }^{-1}$ until 600 hours after which it increases to between 0.2 and 0.3

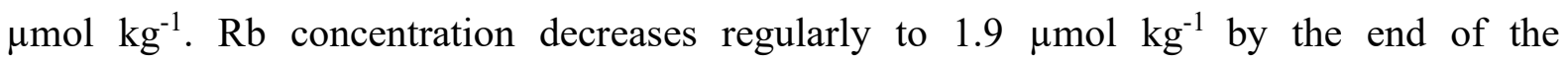
experiment. Mo concentration remains relatively unchanged for the entire experiment while $\mathrm{Pb}$ concentration is highly irregular.

Au displays interesting behaviour. The concentration in the blank geothermal brine is

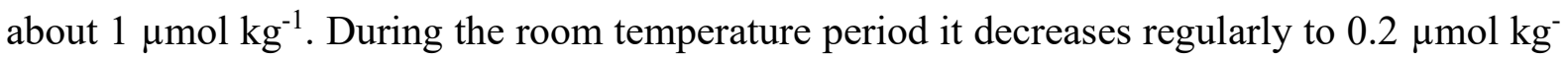
1 and, after the temperature shift, it continues to decline in a regular manner until near detection limit. The clear exponential decrease, which is independent of temperature, suggests precipitation in the separator before passage through the rock.

$\mathrm{Zn}$ is the only trace element that shows a consistent increase after the temperature shift reaching up to $42 \mu \mathrm{mol} \mathrm{kg}$. The increase in $\mathrm{Zn}$ concentration correlates with elevated $\mathrm{SiO}_{2}$ values suggesting that $\mathrm{Zn}$ is dissolving from the volcanic glass. Its concentration decreases after 550 hours and remains so over the remainder of the experiment. 
Figure 4.3. Trace element concentrations in blank and effluent samples ( $\mu$ mol kg-1) versus time (hr) for the basalt - geothermal brine experiment at $400^{\circ} \mathrm{C} / 483$ bar (BGB1). Yellow symbols are the blank sample composition of the geothermal brine. Blue symbols are for effluents at room $\mathrm{T} / 483$ bar and $1.0 \mathrm{ml} \mathrm{hr}^{-1}$ flow rate. Black symbols are effluents at $400^{\circ} \mathrm{C} / 483 \mathrm{bar}$ and $1.0 \mathrm{ml} \mathrm{hr}{ }^{-1} \mathrm{flow}$ rate.
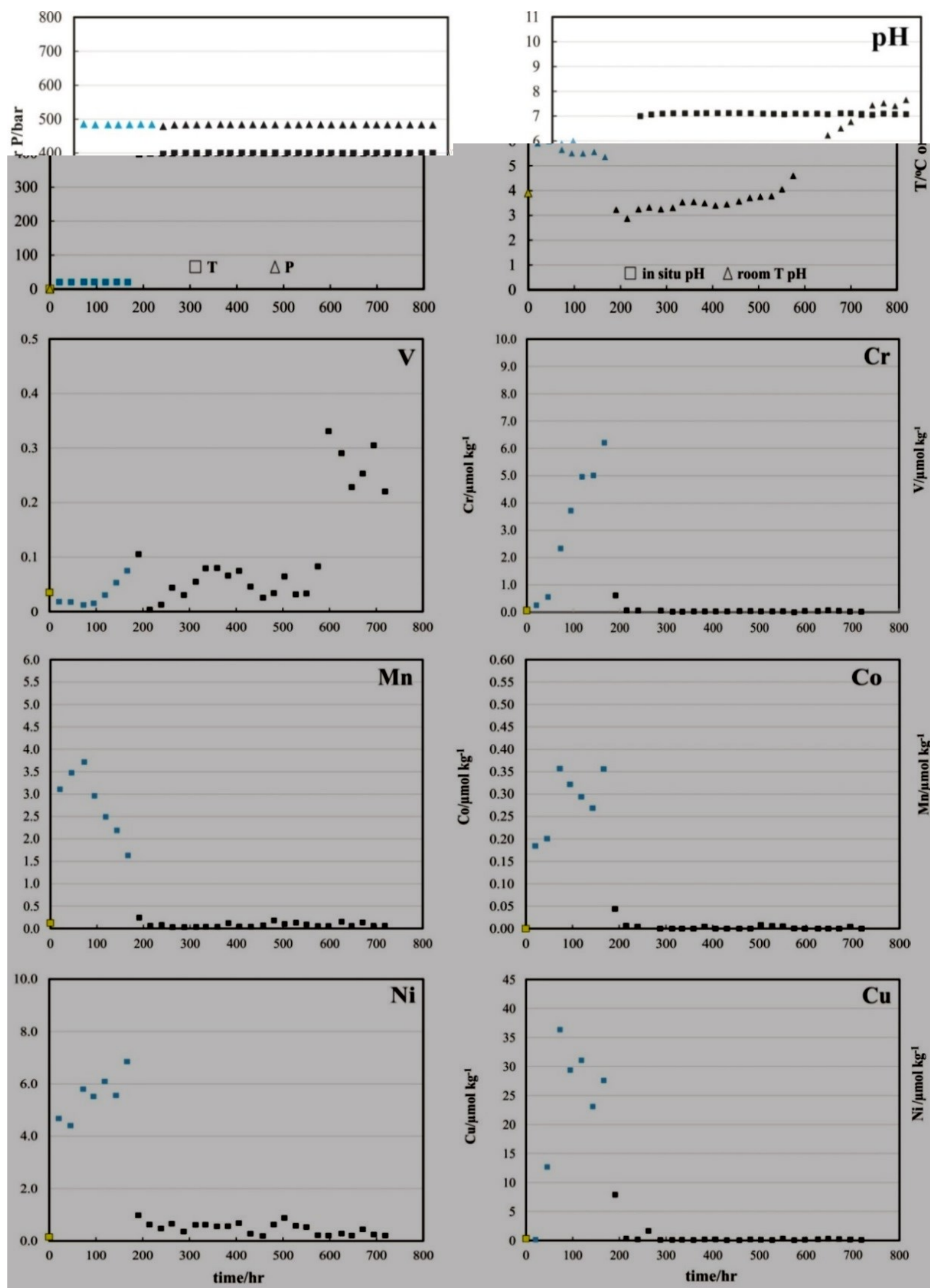

$\square \triangle$ blank

a room $\mathrm{T} / 483 \mathrm{bar} / 1.0 \mathrm{ml} \mathrm{hr}^{-1}$

- $\triangle 400^{\circ} \mathrm{C} / 483 \mathrm{bar} / 1.0 \mathrm{ml} \mathrm{hr}^{-1}$ 
Figure 4.4. Trace element concentrations in blank and effluent samples ( $\mu \mathrm{mol} \mathrm{kg}{ }^{-1}$ ) versus time (hr) for the basalt - geothermal brine experiment at $400^{\circ} \mathrm{C} / 483$ bar (BGB1). Yellow symbols are the blank sample composition of the geothermal brine. Blue symbols are for effluents at room $\mathrm{T} / 483$ bar and $1.0 \mathrm{ml} \mathrm{hr}^{-1}$ flow rate. Black symbols are effluents at $400^{\circ} \mathrm{C} / 483 \mathrm{bar}$ and $1.0 \mathrm{ml} \mathrm{hr}{ }^{-1} \mathrm{flow}$ rate.
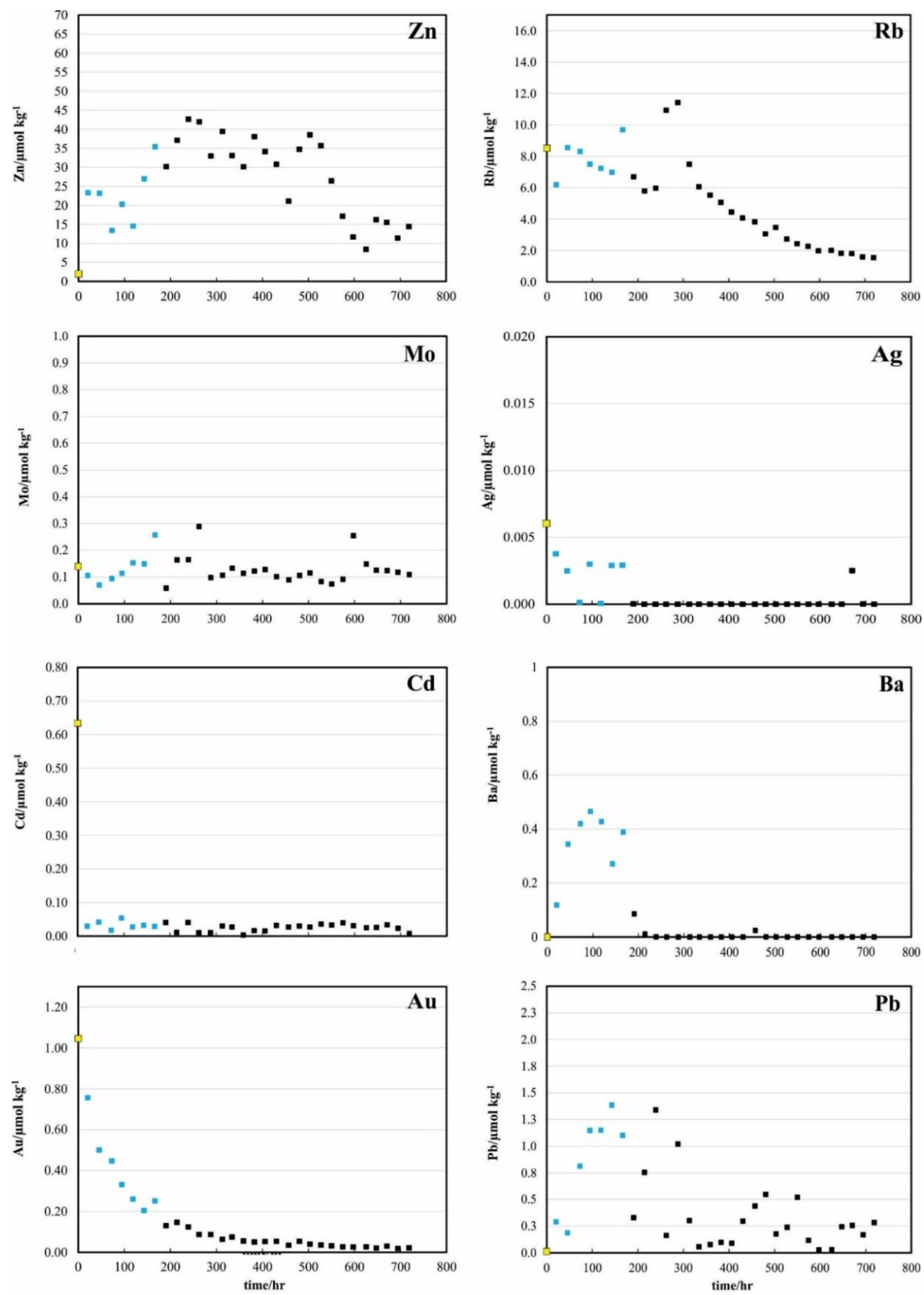

$\square \triangle$ blank

$\Delta \operatorname{room} \mathrm{T} / 483 \mathrm{bar} / 1.0 \mathrm{ml} \mathrm{hr}^{-1}$

a $400^{\circ} \mathrm{C} / 483 \mathrm{bar} / 1.0 \mathrm{ml} \mathrm{hr}^{-1}$ 


\subsubsection{Mineralogy and texture of reacted basalt: Bottom of Reactor (Portion 1)}

Mineralogical and textural analysis were undertaken on reacted grains collected from the bottom (Portion 1) of the Reactor (Fig. 4.5). Upon completion of the experiment, the reacted basalt grains were extracted from the Reactor. The rinsing and drying procedure of the grains was the same as described for BW1 and BW2 (Chapter 3). The basalt block was not introduced at the bottom of Reactor for this experiment.

Selected grains were mounted on aluminium stubs for textural analyses by SEM and several grains were epoxy-mounted and polished for SEM-EDS and EMPA analysis. Appendix C contains all SEM and EMPA results for this portion of the rock.

Figure 4.5. Schematic diagram (not to scale) showing position (Portion 1 and Portion 2) of reacted basalt grains shown in SEM photographs.

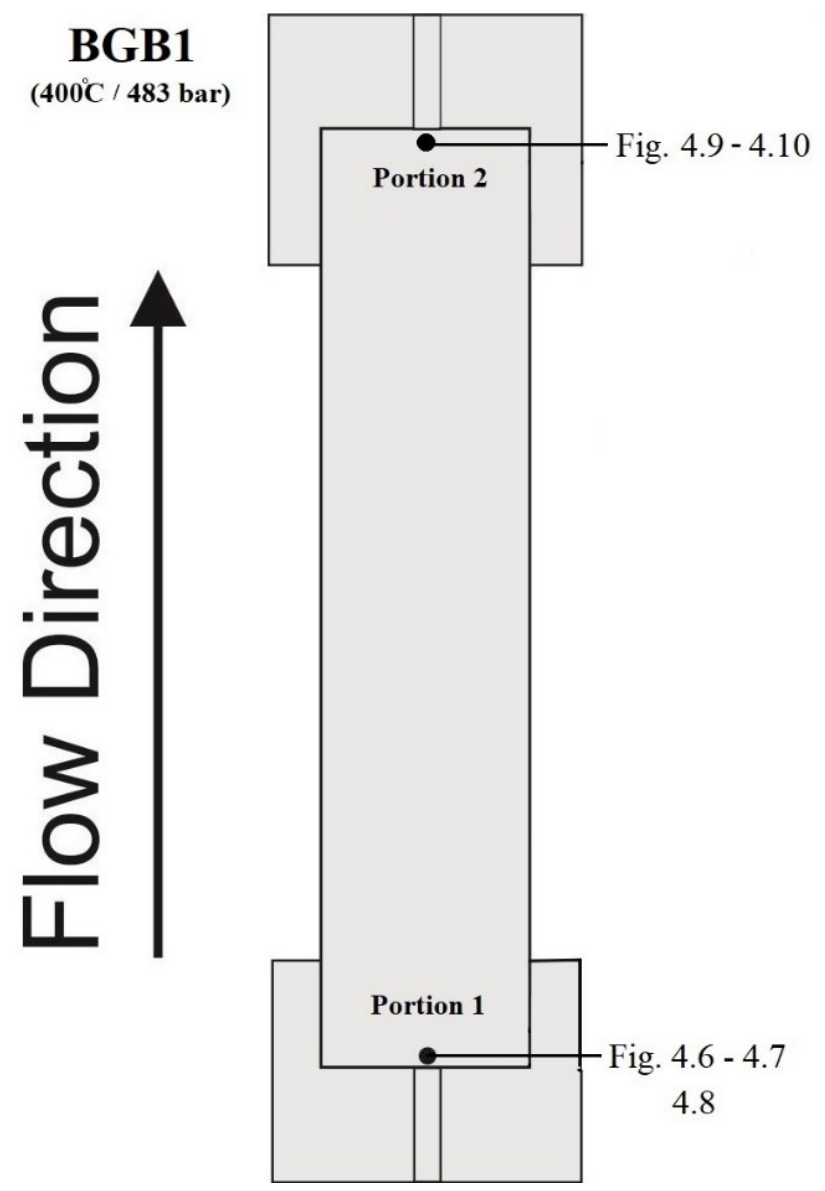


Several grains (Fig. 4.6 - 4.8) from immediately adjacent to the fluid entry point (Portion 1, Fig. 4.5) were examined. Results confirm a high degree of alteration of the basalt caused by intense hydrothermal activity. Minerals of secondary origin identified were anhydrite, biotite, apatite (?), $\mathrm{Cu}$-sulfide, and Fe oxides. Results also confirm the presence of the primary minerals bytownite, clinopyroxene, olivine, and titanomagnetite (Table 4.1).

Table 4.1. Mineral assemblage detected by EMPA and SEM-EDS analysis of reacted grains extracted from the bottom (Portion 1) of Reactor after the BGB1 experiment. Appendix (C) contains all SEM and EMPA results for this portion of the rock.

\begin{tabular}{|c|c|c|c|}
\hline Type of Analysis & $\begin{array}{l}\text { Analysis } \\
\text { Material }\end{array}$ & $\begin{array}{l}\text { Mineral } \\
\text { Identified }\end{array}$ & $\begin{array}{c}\text { Average } \\
\text { Mineral Composition }\end{array}$ \\
\hline SEM-EDS & polished grains & Bytownite & $\mathrm{Ca}_{0.70} \mathrm{Na}_{0.19} \mathrm{Al}_{1.79} \mathrm{Si}_{2.31} \mathrm{O}_{8},\left(\mathrm{An}_{78}-\mathrm{Ab}_{22}\right)$ \\
\hline EMPA & polished grains & Augite & $\mathrm{Ca}_{0.70} \mathrm{Mg}_{0.90} \mathrm{Fe}_{0.37} \mathrm{Si}_{2} \mathrm{O}_{6}$ \\
\hline EMPA & polished grains & Biotite & $\begin{array}{l}\mathrm{K}_{0.49} \mathrm{Ca} 0.1 \mathrm{Na} 0.07 \mathrm{Mg}_{1.4} \mathrm{Fe}_{1.4} \mathrm{Ti}_{0.05} \mathrm{Al}_{1.16} \mathrm{Si}_{2.92} \mathrm{Al}_{0.08} \mathrm{O}_{10}(\mathrm{OH})_{2} \\
\text { (calculated based on an anhydrous composition of } 11 \text { oxygens) }\end{array}$ \\
\hline EMPA & polished grains & Anhydrite & $(\mathrm{Ca}, \mathrm{Fe}) \mathrm{SO}_{4}$ \\
\hline SEM-EDS & grain surface & Apatite & $\mathrm{Ca}_{5}\left(\mathrm{PO}_{4}\right)_{3}(\mathrm{OH}, \mathrm{F}, \mathrm{Cl})$ \\
\hline SEM-EDS & grain surface & $\begin{array}{l}\text { Cu-sulfide } \\
\text { (covellite?) }\end{array}$ & $\mathrm{Cu}_{0.79 \mathrm{Fe}_{0.16} \mathrm{~S}_{1.16}}$ \\
\hline SEM-EDS & polished grains & $\begin{array}{l}\text { Fe-Ti Oxide } \\
\text { Fe-Oxide }\end{array}$ & \\
\hline
\end{tabular}

Figure 4.6 shows SEM images of the reacted grains from the position immediately next to the entry point of the fluid. Anhydrite appears as singular euhedral tabular crystals, surrounded by hexagonal aligned plates of biotite, occurring in dense aggregates. There was no evidence of primary plagioclase and clinopyroxene on the surface of these grains. Only a few grains with this intensity of alteration, shown by a noticeable change in colour, were observed. Petrographic observation shows that the anhydrite crystals are transparent.

Figure $4.7 \mathrm{a}, \mathrm{b}$ shows SEM images of rare minerals in the reacted grains including a copper sulfide phase with a hexagonal habit. The EDS analysis shows a composition close to idaite $\left(\mathrm{Cu}_{5} \mathrm{FeS}_{6}\right)$ or possibly covellite $(\mathrm{CuS})$ with minor Fe substitution. Also found were radiating acicular crystals of apatite. The occurrence of the apatite in a void suggests that they may be remnant crystals that were originally trapped in volcanic glass.

Figure 4.8 shows SEM backscatter images and EDS maps of a polished mount of a grain from Portion 1. Both plagioclase and clinopyroxene (both blue) are highly corroded and are replaced by biotite (green). Biotite occurs along the margins and inside the grain. Isolated 
anhydrite crystals (violet) surround the grain and small areas of anhydrite occur internally. A large olivine crystal (grey) appears unreacted as it was isolated from the brine by surrounding minerals (the crack likely occurred during sample prep). EDS analysis of the Fe and Ti oxides reveal secondary magnetite and $\mathrm{TiO}_{2}$, however, the primary titanomagnetite was also present.

Figure 4.6. SEM images of grains collected from the bottom (Portion 1) of the Reactor after the BGB1 experiment (minerals identified by SEM-EDS analysis): a) grain covered by anhydrite (Anh) occurring in isolated tabular euhedral crystals and biotite (Bt) in masses of foliated crystals; (b) reacted grain surface covered by a secondary mineral assemblage consisting of anhydrite and biotite; (c) enlargement of red rectangular area in (b) showing euhedral tabular crystals of anhydrite and stacked hexagonal plates of biotite; (e-f) are enlargements, respectively, of rectangular area in (d) showing biotite appearing in hexagonal stacked crystals.
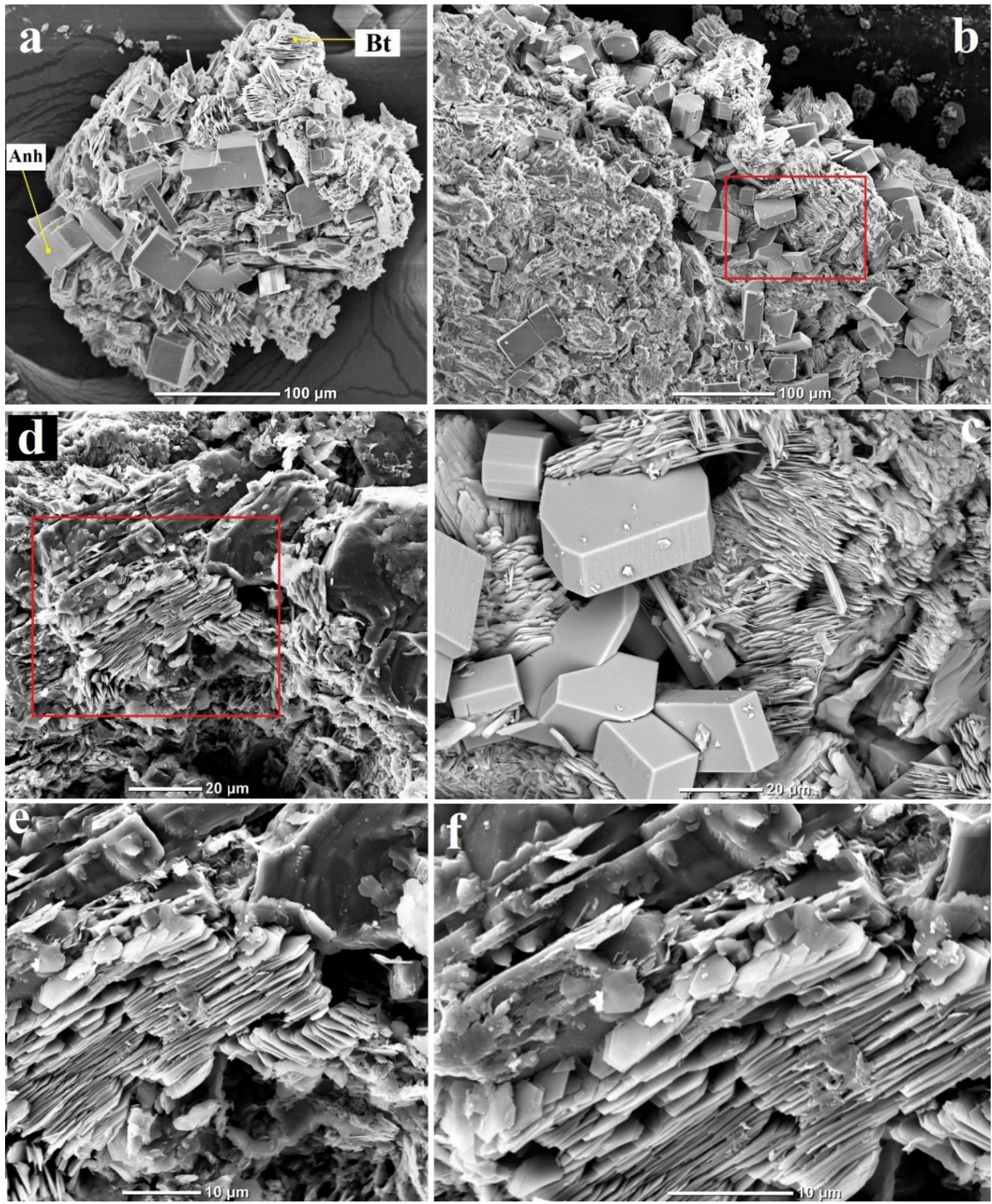
Figure 4.7. SEM images from the bottom (Portion 1) of the Reactor after the BGB1 experiment (minerals identified by SEM-EDS analysis): (a) grain surface showing a Cu-sulfide crystal appearing in hexagonal shape; (b) apatite (Ap), occurring in a radiating group of acicular crystals.
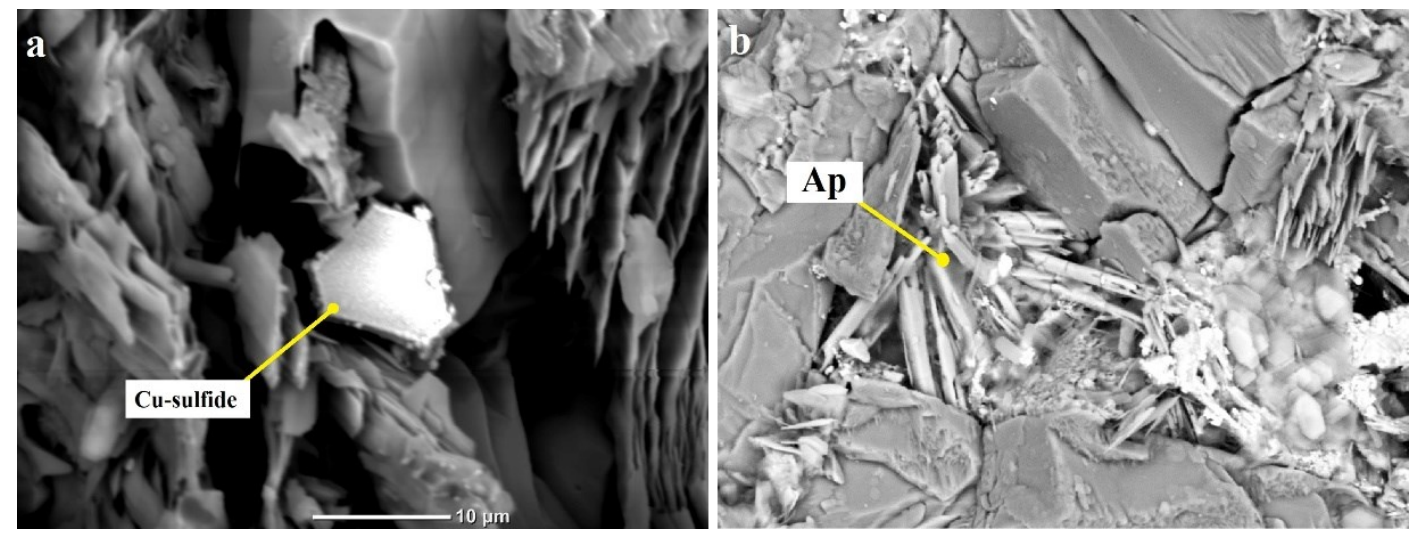

Figure 4.8. SEM backscatter images and EDS compositional maps of an epoxy-mounted, polished grain collected from immediately adjacent to the fluid entry point at bottom (Portion 1) of the Reactor: (a) backscatter image; (b) composite colour image combining the backscatter image and elemental maps for c) $\mathrm{K}$ in green, d) $\mathrm{Ca}$ in blue, and e) $\mathrm{S}$ in red. The composite image shows the anhydrite crystals (violet), biotite (green), unreacted plagioclase and clinopyroxene (blue), olivine (grey), and Fe-Ti oxides (white).
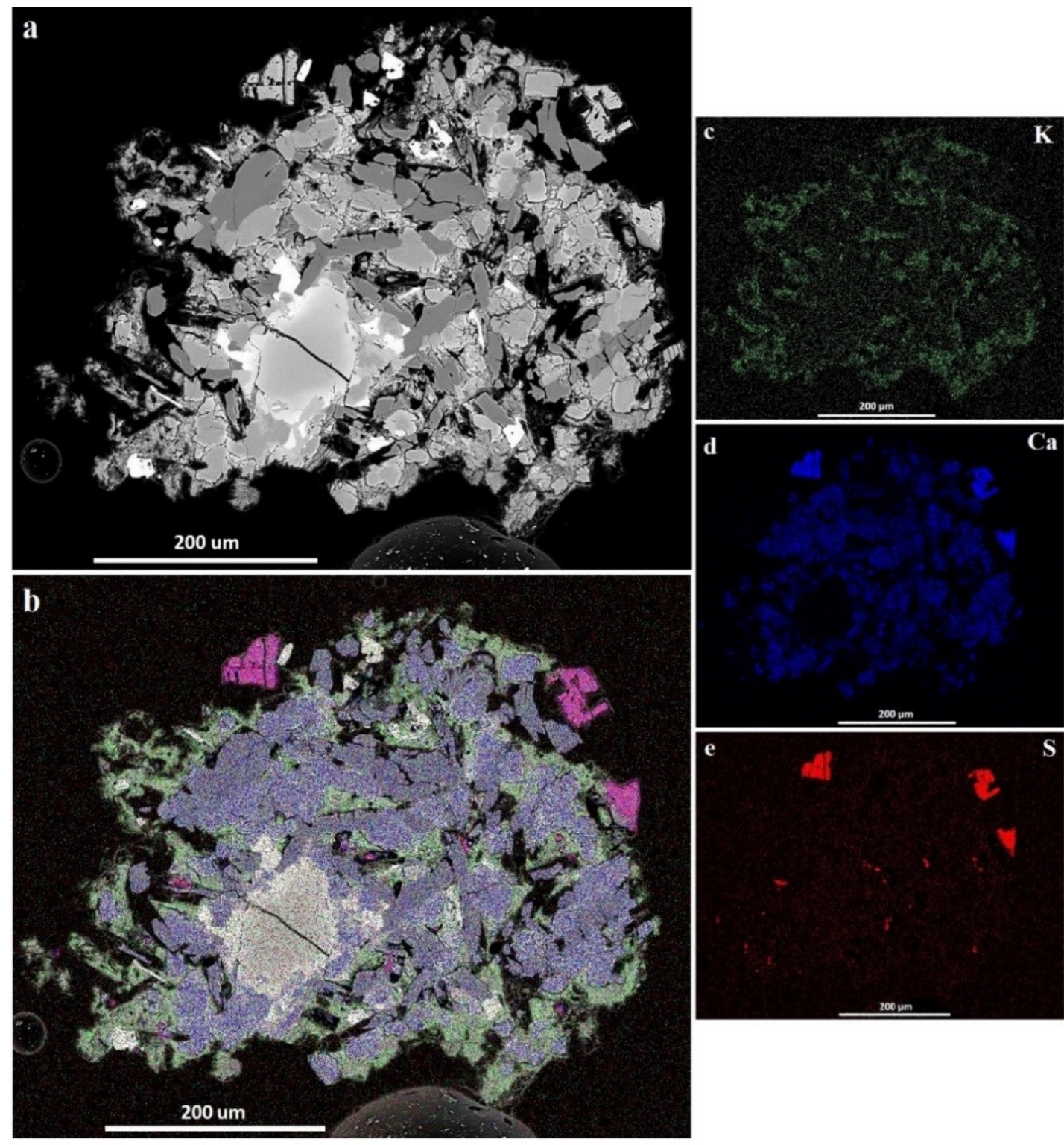


\subsubsection{Mineralogy and texture of reacted basalt: Top of Reactor (Portion 2)}

Several grains (Fig. $4.9-4.10$ ) from immediately adjacent to the fluid exit point (Portion 2, Fig. 4.5) were examined. These were mounted on aluminium stubs for textural analyses by SEM while several grains were mounted in epoxy and polished for SEM-EDS analysis. Appendix (C) lists complete results for this portion of the altered basalt.

\section{SEM-EDS analysis}

Results show less intense alteration of the basalt grains when compared with the bottom of the Reactor (Portion 1). Minerals of secondary origin detected were a $\mathrm{K}-\mathrm{Mg}-\mathrm{Fe}-$ bearing aluminosilicate, identified here as smectite. Data also confirm the presence of the primary minerals bytownite, clinopyroxene, olivine, and titanomagnetite (Table 4.2).

Table 4.2. Mineral assemblage found during analysis of reacted grains extracted from top (Portion 2) of the Reactor after the BGB1 experiment. Analysis were effectuated by SEM-EDS. Appendix (C) contains all SEM results for this Portion of the rock.

\begin{tabular}{|c|c|c|c|}
\hline $\begin{array}{l}\text { Type of } \\
\text { Analysis }\end{array}$ & $\begin{array}{l}\text { Analysis } \\
\text { Material }\end{array}$ & $\begin{array}{l}\text { Mineral } \\
\text { Identified }\end{array}$ & $\begin{array}{c}\text { Average } \\
\text { Mineral Composition }\end{array}$ \\
\hline SEM-EDS & grain surface & Bytownite & $\mathrm{Ca}_{0.9} \mathrm{Na}_{0.2} \mathrm{Al}_{1.5} \mathrm{Si}_{2.4} \mathrm{O}_{8}\left(\mathrm{An}_{81}-\mathrm{Ab}_{19}\right)$ \\
\hline SEM-EDS & grain surface & Augite & $\mathrm{Ca} 0.3 \mathrm{Mg}_{0.8} \mathrm{Fe}_{0.6} \mathrm{Al}_{0.2} \mathrm{Si}_{2} \mathrm{O}_{6}$ \\
\hline SEM-EDS & polished grains & Fayalite & $\mathrm{Mg}_{0.7} \mathrm{Fe}_{1.2} \mathrm{SiO}_{4}\left(\mathrm{Fo}_{37}-\mathrm{Fa}_{63}\right)$ \\
\hline SEM-EDS & polished grains & Smectite & $\begin{array}{l}\mathrm{K}_{0.1} \mathrm{Mg}_{1.5} \mathrm{Fe}_{1.3} \mathrm{Al}_{0.2} \mathrm{Si}_{3.3} \mathrm{Al}_{0.7} \mathrm{O}_{10}(\mathrm{OH})_{2} \cdot n \mathrm{H}_{2} \mathrm{O} \\
\text { (calculated based on an anhydrous composition with } 11 \text { oxygens) }\end{array}$ \\
\hline SEM-EDS & polished grains & Titanomagnetite & $\mathrm{Fe}^{2+}\left(\mathrm{Fe}^{3+}, \mathrm{Ti}\right)_{2} \mathrm{O}_{4}$ \\
\hline
\end{tabular}

Figure 4.9 shows surface textures of three different grains collected from the top (Portion 2) of the Reactor. EDS backscatter images at low magnification show the K-Mg-Febearing secondary phase with a honeycomb texture similar to smectite, primary clinopyroxene and plagioclase. In detail, the smectite-like phase occurs as foliated masses. Clinopyroxene appears relatively unaffected. Anhydrite and biotite were not observed within or on these grains.

Figure 4.10a-e shows SEM backscatter images and EDS maps for an epoxy-mounted, polished grain from the top (Portion 2) of the Reactor. A lesser degree of alteration is evident when compared with the grains analysed from the bottom (Portion 1) of the Reactor (Fig. 4.8). Primary minerals (plagioclase, clinopyroxene, olivine and oxides) appear moderately affected internally by alteration. 
Figure 4.10f is the enlargement of the rectangular area in Figure 4.10a. The average composition of the K-Mg-Fe aluminosilicate phase from EDS analyses of the epoxy mounted grain is shown in Table 4.3. It contains a high $\mathrm{FeO}$ and $\mathrm{MgO}$ content with lesser $\mathrm{K}_{2} \mathrm{O}$. The low percentage concentration of $\mathrm{K}_{2} \mathrm{O}$ excludes celadonite. A smectite clay such as saponite or nontronite (Cheshire et al., 2018; Haldar, 2020) fits the composition, however, the high temperature would seem to exclude a swelling clay as they would not be expected to be stable at $400^{\circ} \mathrm{C}$ (Bird, 1984; Browne, 1978; Browne and Ellis, 1970; Essene and Peacor, 1995; Hedenquist et al., 2000; Henley and Ellis, 1983; Reyes, 1990; Steiner, 1977). However, Yardley et al (2014) found saponite as a run product when reacting hornfels with water up to $500^{\circ} \mathrm{C}$. Another possibility is corrensite, a mixed-layer chlorite - trioctahedral smectite clay mineral (Beaufort et al., 1997). In the present study, the composition and smectite-like texture, lead us to conclude that this phase is smectite and it will be referred to as such. Without more detailed analysis using more sophisticated analytical techniques, it is difficult to refine this further. 
Figure 4.9. SEM images of grains collected from the top of the Reactor (Portion 2) : (a) entire grain; (b) enlargement of rectangular area in (a) showing the smectite (Smc) and the primary plagioclase bytownite (Byt); (c) entire grain; d) enlargement of rectangular area in (c) showing typical smectite texture (Smc); (e) image of reacted grain; (f) enlargement of rectangular area in (e) showing the smectite (Smc) and primary clinopyroxene $(\mathrm{Cpx})$.
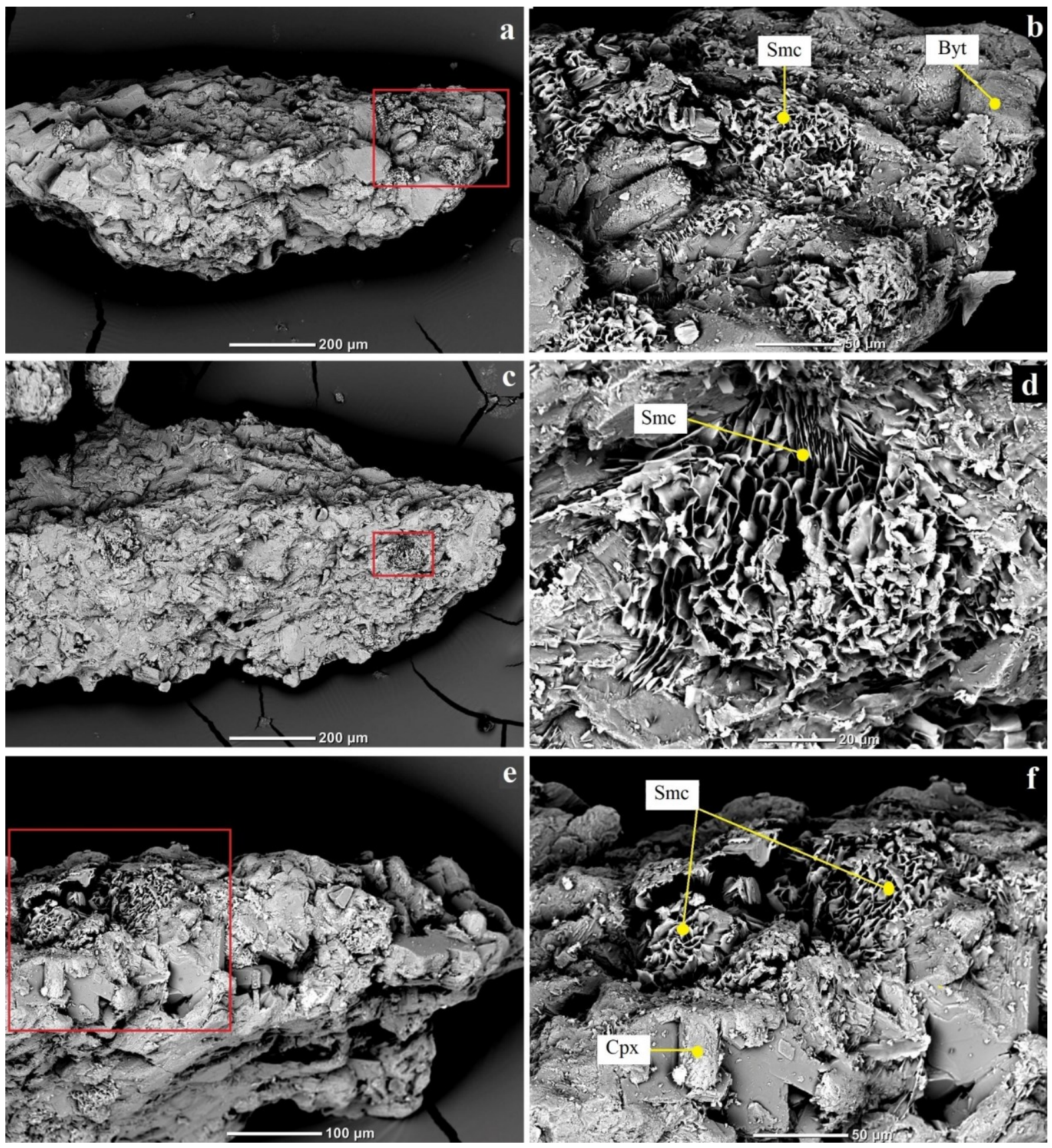
Figure 4.10. SEM backscatter images and EDS compositional maps of an epoxy-mounted, polished grain collected from the top (Portion 2) of the Reactor: (a) backscatter image of entire grain; (b) composite colour image combining the backscatter image and elemental maps for c) $\mathrm{Mg}$ in green, d) $\mathrm{Ca}$ in blue, and e) Fe in red that shows plagioclase (dark blue), clinopyroxene (turquoise), olivine (yellow green), Fe-Ti oxide (red) and the smectite (green); (f) SEM backscatter image of rectangular area in (a) showing olivine (Ol), titanomagnetite (Tnt) and the $\mathrm{K}-\mathrm{Mg}-\mathrm{Fe}$ aluminosilicate $(\mathrm{Smc})$.
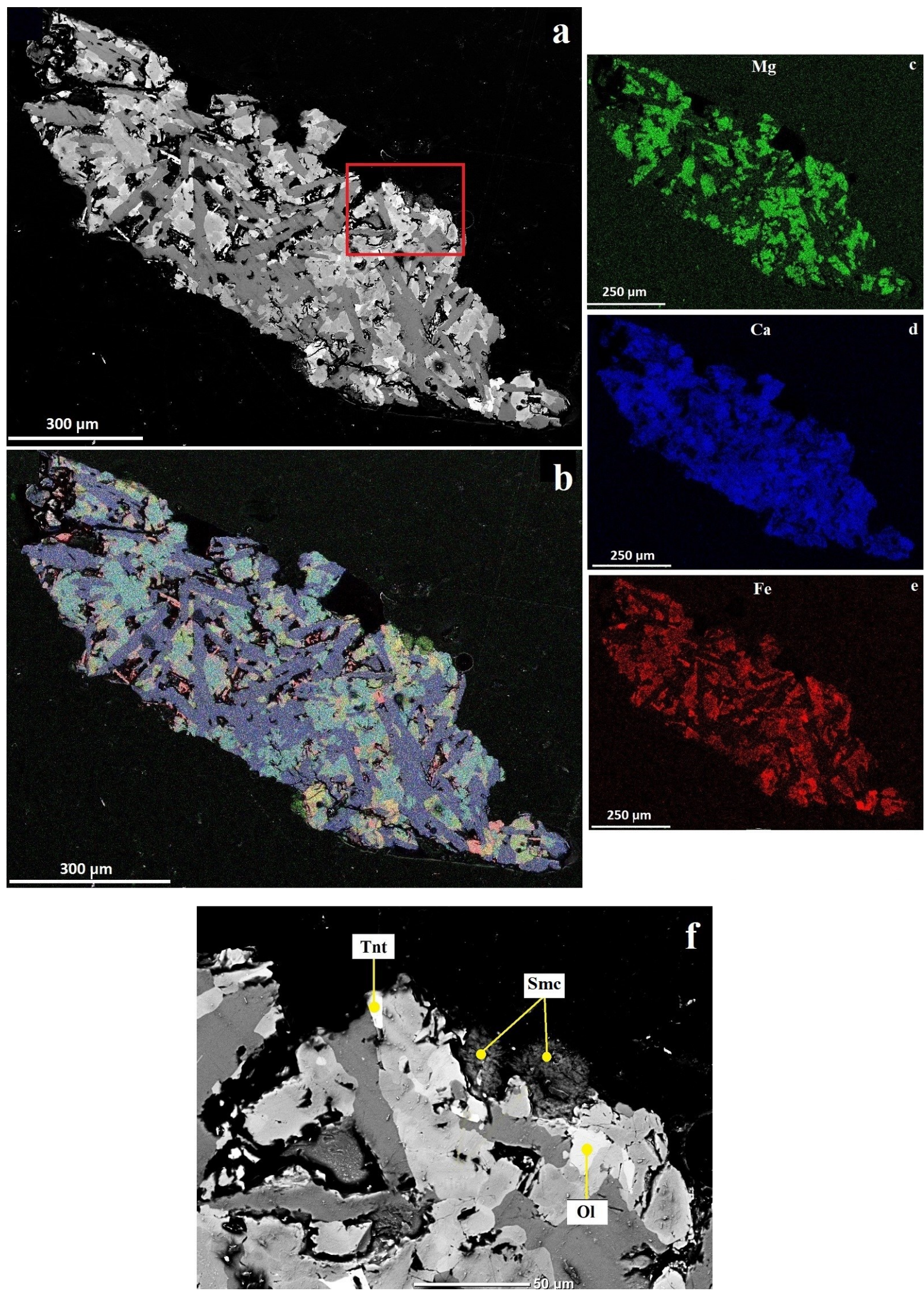
Table 4.3. Average EDS analysis (wt. \%) of the smectite identified at top of the Reactor (epoxy mount). N: number of analyses.

\begin{tabular}{|ccc|}
\hline & $\begin{array}{c}\text { Polished } \\
\text { (N=5) }\end{array}$ & \\
oxide & $\begin{array}{c}\text { average } \\
\text { Wt } \%\end{array}$ & $\pm 1 \sigma$ \\
& & \\
$\mathbf{K}_{2} \mathbf{O}$ & 1.03 & 0.50 \\
$\mathbf{A l}_{2} \mathbf{O}_{3}$ & 11.42 & 0.76 \\
$\mathbf{S i O}_{2}$ & 48.83 & 1.10 \\
$\mathbf{M g O}$ & 15.22 & 0.94 \\
$\mathbf{F e O}$ & 23.52 & 1.56 \\
Total & 100.00 & \\
\hline
\end{tabular}




\subsubsection{BGB2: Basalt - Geothermal brine at $350^{\circ} \mathrm{C} / 486$ bar}

The second basalt - geothermal brine experiment (BGB2) ran for total time of $908 \mathrm{hrs}$ (Fig. 4.12). The first $166 \mathrm{hrs}$ were at room temperature, 486 bar and the remaining $742 \mathrm{hrs}$ were at $350^{\circ} \mathrm{C}, 486$ bar. The flow rate was $1 \mathrm{ml} \mathrm{hr}^{-1}$ for the entire experiment. As for the BW experiments, the flow-rate was set-up to ensure the collection of sufficient solution for all chemical analyses at the approximately 24 hour interval. Analysis of major cations and anions were made for 38 fluid samples. Analysis of trace elements (except for $\mathrm{V}, \mathrm{Cr}$ and $\mathrm{Rb}$ ) were made for the first 29 fluid samples.

\subsubsection{Major element concentrations}

Appendix (C) lists the complete experimental parameters (T, P, flow rate, chemistry). Figure 4.11 and Figure 4.12 show these results plotted against time in hours. The unreacted geothermal brine composition is shown at $\mathrm{t}=0$. Initial concentrations of major ions in the unreacted fluid were detected as follow: As $\left(0.00 \mathrm{mmol} \mathrm{kg}^{-1}\right), \mathrm{B}\left(5.13 \mathrm{mmol} \mathrm{kg}^{-1}\right), \mathrm{Ca}(0.18$ mmol kg-1), Fe $\left(<0.08 \mathrm{mmol} \mathrm{kg}^{-1}\right), \mathrm{K}\left(3 \mathrm{mmol} \mathrm{kg}{ }^{-1}\right), \mathrm{Mg}\left(0.04 \mathrm{mmol} \mathrm{kg}{ }^{-1}\right), \mathrm{Na}(31.6 \mathrm{mmol}$ $\left.\mathrm{kg}^{-1}\right), \mathrm{SiO}_{2}\left(14.70 \mathrm{mmol} \mathrm{kg}{ }^{-1}\right), \mathrm{Al}\left(0.35 \mathrm{mmol} \mathrm{kg}^{-1}\right), \mathrm{Sr}\left(<0.003 \mathrm{mmol} \mathrm{kg}{ }^{-1}\right)$, Li $(0.97 \mathrm{mmol}$ $\left.\mathrm{kg}^{-1}\right), \mathrm{H}_{2} \mathrm{~S}\left(<0.01 \mathrm{mmol} \mathrm{kg}^{-1}\right), \mathrm{Cl}\left(27.14 \mathrm{mmol} \mathrm{kg}{ }^{-1}\right)$ and $\mathrm{SO}_{4}\left(4.23 \mathrm{mmol} \mathrm{kg}{ }^{-1}\right)$.

During the room temperature $\left(\sim 21^{\circ} \mathrm{C}\right)$ period small decreases in $\mathrm{B}, \mathrm{Ca}, \mathrm{K}$ and in particular $\mathrm{Na}$ are present. The $\mathrm{pH}$ values are on average an order of magnitude higher (5.3) than the starting blank (4.28). As, $\mathrm{Fe}, \mathrm{SiO}_{2}, \mathrm{Sr}, \mathrm{Li}, \mathrm{Cl}$ and $\mathrm{SO}_{4}$ remain unchanged reflecting the composition of the input solution.

The change in temperature to $350^{\circ} \mathrm{C}$ was initiated at 166 hours and took approximately 2.5 hours, thus only about $2.5 \mathrm{ml}$ of solution were produced during heat-up. Major changes in solution chemistry are present after the temperature shift.

Effluent quench $\mathrm{pH}$ decreases to a minimum of 3.39 at 211 hours then slowly increases to $\sim 4.5$ at 260 hours to greater than 7 by 428 hours. It remains near this alkaline value for the remainder of the experiment, approaching 8.0 for the last eight days. The calculated in situ $\mathrm{pH}$ remains constant after the temperature shift to 6.80 by the end of the experiment.

$\mathrm{SiO}_{2}$ increases to $30.97 \mathrm{mmol} \mathrm{kg}^{-1}$ ( $\left.1860 \mathrm{ppm}\right)$ at 211 hours, which exceeds quartz saturation at $350^{\circ} \mathrm{C}$ and 500 bar ( $\sim 981 \mathrm{ppm}$, Supcrt92), after which it regularly decreases by the end of the experiment to a stable values of $13.7 \mathrm{mmol} \mathrm{kg}^{-1}, 1 \mathrm{mmol} \mathrm{kg}^{-1}$ lower than the starting brine. 
$\mathrm{K}$ shows a significant increase immediately after the temperature shift, reaching a peak value of $6.74 \mathrm{mmol} \mathrm{kg}^{-1}$ at 211 hours. It then decreases to $2.97 \mathrm{mmol} \mathrm{kg}^{-1}$ at 356 hours after which it remains near $3 \mathrm{mmol} \mathrm{kg}^{-1}$ for the remainder of the experiment. $\mathrm{Na}$ concentration decreases to a minimum of $24.97 \mathrm{mmol} \mathrm{kg}^{-1}$ at 211 hours after which it increases to input value $\left(\sim 31 \mathrm{mmol} \mathrm{kg}^{-1}\right)$ for the remainder of the experiment.

After the temperature shift, Al concentration decreases to $0.01 \mathrm{mmol} \mathrm{kg}^{-1}$ at 211 hours, after which it increases to $0.05 \mathrm{mmol} \mathrm{kg}^{-1}$ within eight days (at $403 \mathrm{hrs}$ ). It decreases again up to $0.01 \mathrm{mmol} \mathrm{kg}^{-1}$ by 571 hours and then rises again to stable values of $0.06 \mathrm{mmol}$ $\mathrm{kg}^{-1}$ by the end of the experiment. Concentrations are all below the starting brine value. $\mathrm{Ca}$ concentration decreases, after the temperature shift, to a minimum of $0.02 \mathrm{mmol} \mathrm{kg}^{-1}$ at 236 hours and then stabilise between 0.05 and $0.06 \mathrm{mmol} \mathrm{kg}^{-1}$ for the remainder of the experiment. Ca concentrations are all lower than in the starting brine.

Magnesium decreases to near detection limit two days after temperature increase after which it gradually rises to $0.01 \mathrm{mmol} \mathrm{kg} \mathrm{kg}^{-1}$ by 850 hours. The last three samples average 0.005 $\mathrm{mmol} \mathrm{kg}{ }^{-1}$. All Mg concentrations are well below the input solution value.

Sulfate decreases to a minimum peak of $2.16 \mathrm{mmol} \mathrm{kg}^{-1}$ two days after temperature increase and then increases to between 2.95 and $3.97 \mathrm{mmol} \mathrm{kg}^{-1}$ for the remainder of the experiment. The $\mathrm{H}_{2} \mathrm{~S}$ concentrations reach a maximum of $0.06 \mathrm{mmol} \mathrm{kg}^{-1}$ three days after temperature increase. It remains around $0.05 \mathrm{mmol} \mathrm{kg}^{-1}$ for five days and then decreases over twenty-eight days to near or below detection limit. Chloride concentrations remain near the input brine values for the entire experiment showing that the apparatus behaved correctly without boiling or dilution. 
Figure 4.11. Major element concentrations in blank and effluent samples (mmol kg-1) versus time (hr) for the basalt-geothermal brine experiment at $350^{\circ} \mathrm{C} / 486$ bar (BGB2). Yellow symbols are the blank sample composition of the brine. Blue symbols are for effluents at room $\mathrm{T} / 486$ bar and $1.0 \mathrm{ml} \mathrm{hr}^{-1}$ flow rate. Black symbols are effluents at $350^{\circ} \mathrm{C} / 486$ bar and $1.0 \mathrm{ml} \mathrm{hr}^{-1}$ flow rate. In situ pH is the calculated $\mathrm{pH}$ at temperature.
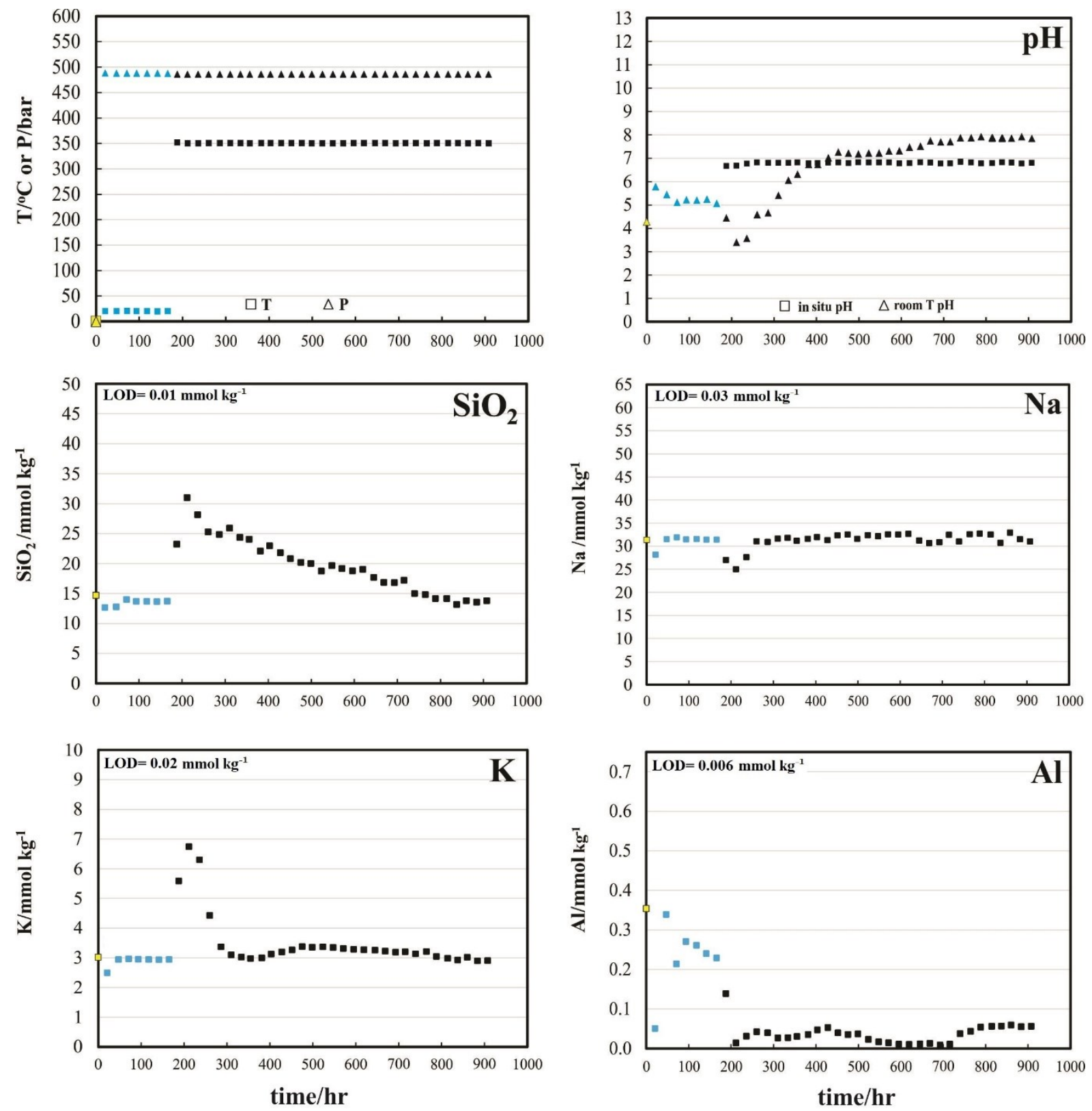

$\square \triangle$ blank

— $\mathrm{D}$ room $\mathrm{T} / 486 \mathrm{bar} / 1.0 \mathrm{ml} \mathrm{hr}^{-1}$

- $\triangle 350^{\circ} \mathrm{C} / 486$ bar $/ 1.0 \mathrm{ml} \mathrm{hr}^{-1}$ 
Figure 4.12. Major element concentrations in blank and effluent samples (mmol kg-1) versus time (hr) for the basalt-geothermal brine experiment at $350^{\circ} \mathrm{C} / 486$ bar (BGB2). Yellow symbols are the blank sample composition of the brine. Blue symbols are for effluents at room $\mathrm{T} / 486$ bar and $1.0 \mathrm{ml} \mathrm{hr}^{-1}$ flow rate. Black symbols are effluents at $350^{\circ} \mathrm{C} / 486$ bar and $1.0 \mathrm{ml} \mathrm{hr}^{-1}$ flow rate. In situ $\mathrm{pH}$ is the calculated $\mathrm{pH}$ at temperature.
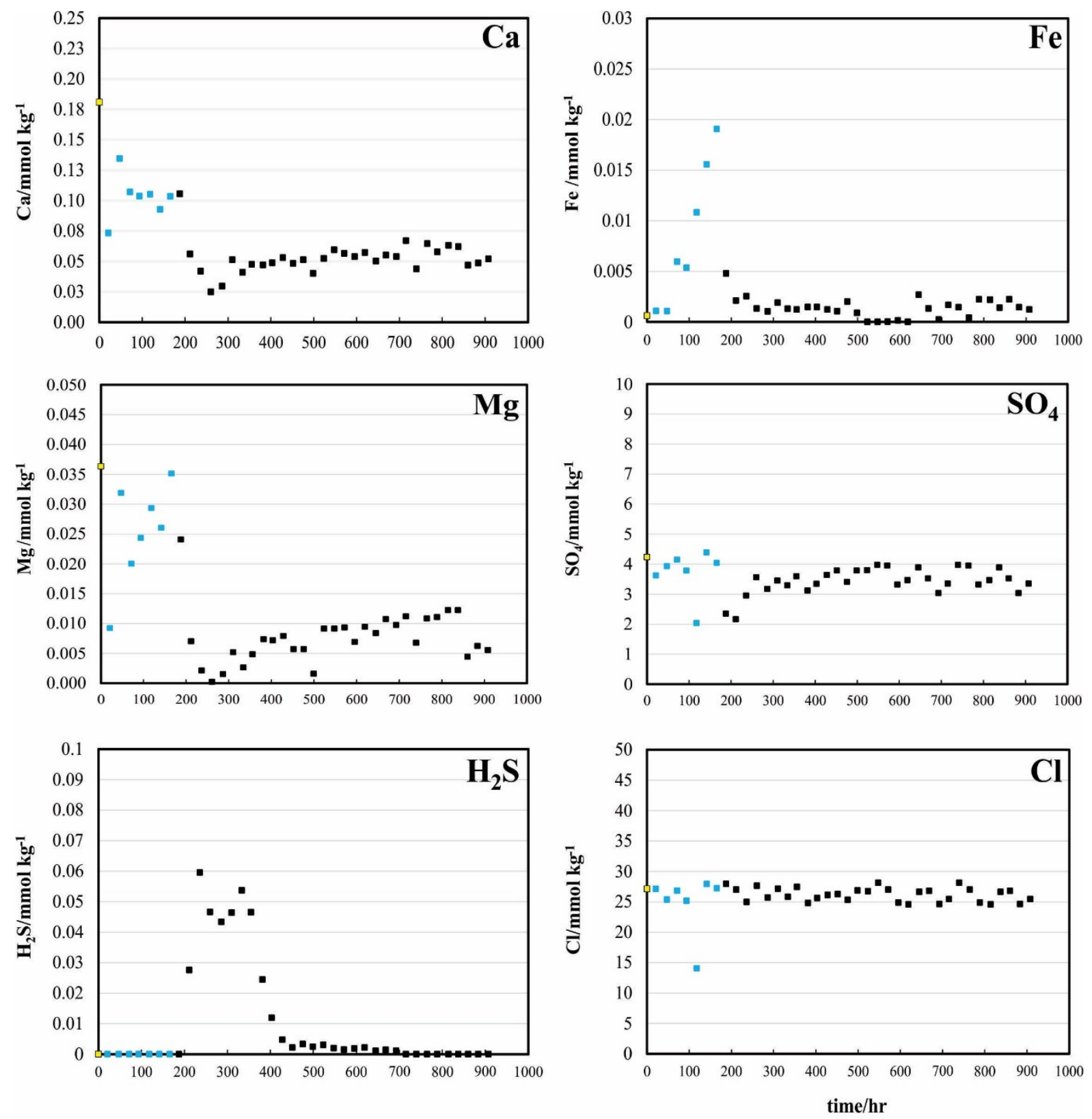

$\square \triangle$ blank

- $\Delta \operatorname{room~} \mathrm{T} / 486 \mathrm{bar} / 1.0 \mathrm{ml} \mathrm{hr}^{-1}$

a $\triangle 350^{\circ} \mathrm{C} / 486 \mathrm{bar} / 1.0 \mathrm{ml} \mathrm{hr}$ 


\subsubsection{Trace element concentration}

Appendix (C) lists the complete trace element results. Figure 4.13 and Figure 4.14 show these results plotted against time in hours. The unreacted geothermal brine composition is shown at $\mathrm{t}=0$. All trace element concentrations (except for $\mathrm{Ag}$ and $\mathrm{Mn}$ ) are present in the starting brine. In particular, are high values of $\mathrm{Ni}(2.9 \mu \mathrm{mol} \mathrm{hr}-1), \mathrm{Cu}\left(5.9 \mu \mathrm{mol} \mathrm{hr}^{-1}\right)$ and $\mathrm{Zn}$ $\left(27.2 \mu \mathrm{mol} \mathrm{hr}^{-1}\right)$.

During the room temperature $\left(21^{\circ} \mathrm{C}\right)$ period, overall decreases in several trace elements including $\mathrm{Co}, \mathrm{Ni} \mathrm{Zn}, \mathrm{Mo}, \mathrm{Au}$ and $\mathrm{Pb}$ are present. While $\mathrm{Cu}, \mathrm{Cd}, \mathrm{Ba}$ and $\mathrm{Mn}$ increase in solution relative to the starting brine. Silver concentrations are near detection limit.

Except for Mo, which rises to $\sim 1.0 \mu \mathrm{mol} \mathrm{hr}{ }^{-1}$, all the other trace elements decrease substantially after the temperature shift to $350^{\circ} \mathrm{C}$. $\mathrm{Co}, \mathrm{Ni}, \mathrm{Ag}, \mathrm{Cd}, \mathrm{Au}$ and $\mathrm{Mn}$ are near or below detection limit, while only $\mathrm{Cu}\left(0.07 \mu \mathrm{mol} \mathrm{hr}{ }^{-1}\right), \mathrm{Zn}\left(2.9 \mu \mathrm{mol} \mathrm{hr}{ }^{-1}\right)$, Mo $(0.37 \mu \mathrm{mol} \mathrm{hr}$ $\left.{ }^{1}\right), \mathrm{Ba}\left(0.07 \mu \mathrm{mol} \mathrm{hr}{ }^{-1}\right)$ and $\mathrm{Pb}\left(0.005 \mu \mathrm{mol} \mathrm{hr}^{-1}\right)$ display measurable concentrations by the end of the experiment. 
Figure 4.13. Trace element concentrations in blank and effluent samples ( $\mu$ mol $\mathrm{kg}^{-1}$ ) versus time (hr) for the basalt-geothermal brine experiment at $350^{\circ} \mathrm{C} / 486$ bar (BGB2). Yellow symbols are the blank sample composition of the distilled water. Blue symbols are for effluents at room $\mathrm{T} / 486$ bar and $1.0 \mathrm{ml} \mathrm{hr}^{-1}$ flow rate. Black symbols are effluents at $350^{\circ} \mathrm{C} / 486$ bar and $1.0 \mathrm{ml} \mathrm{hr} \mathrm{flow} \mathrm{rate}^{-1}$
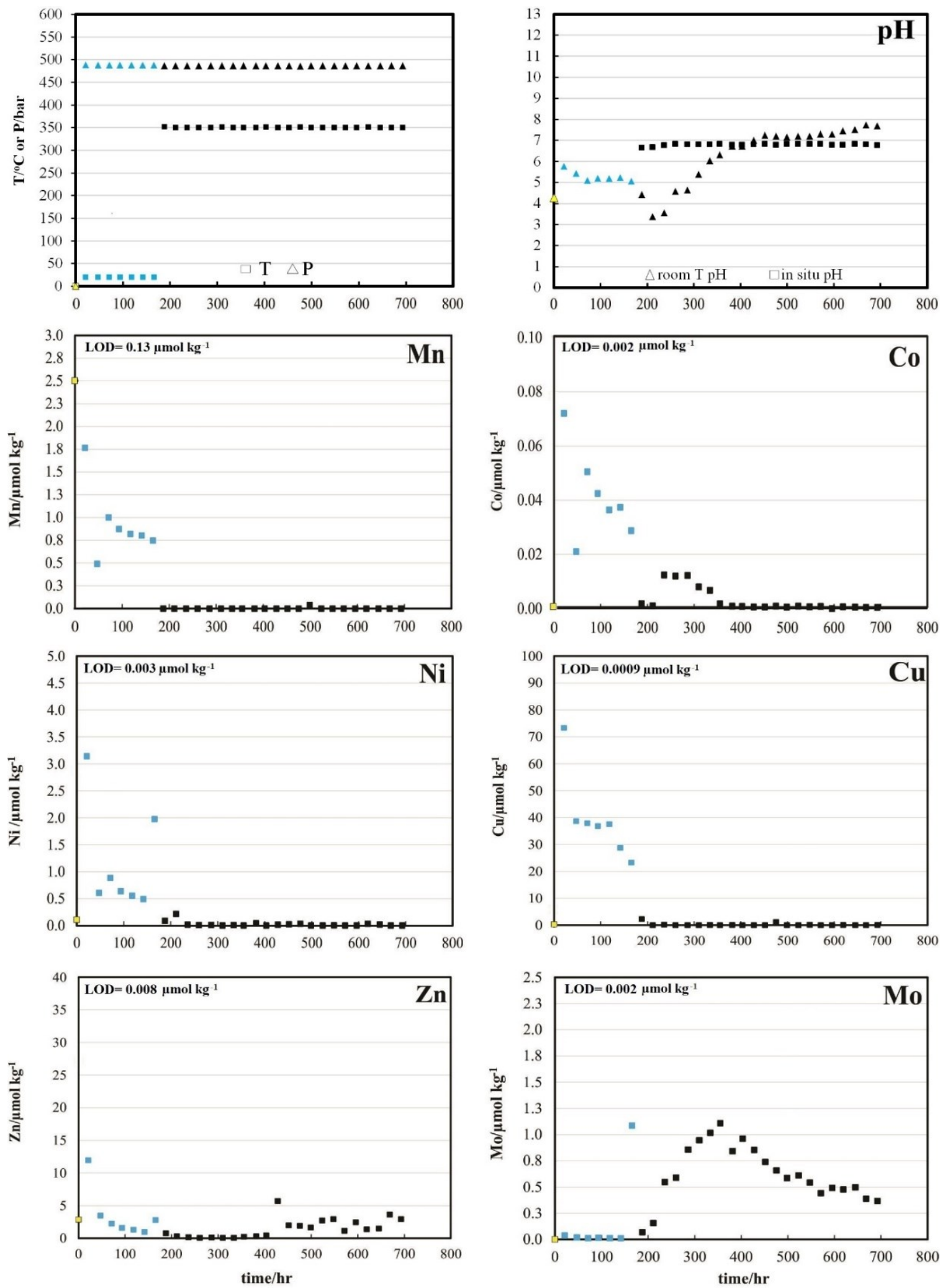

$\square \triangle$ blank

$\triangle \operatorname{room} \mathrm{T} / 486 \mathrm{bar} / 1.0 \mathrm{ml} \mathrm{hr}^{-1}$

- $\triangle 350^{\circ} \mathrm{C} / 486$ bar/1.0 $\mathrm{ml} \mathrm{hr}^{-1}$ 
Figure 4.14. Trace element concentrations in blank and effluent samples ( $\mu$ mol $\mathrm{kg}^{-1}$ ) versus time (hr) for the basalt-geothermal brine experiment at $350^{\circ} \mathrm{C} / 486$ bar (BGB2). Yellow symbols are the blank sample composition of the distilled water. Blue symbols are for effluents at room $\mathrm{T} / 486$ bar and $1.0 \mathrm{ml} \mathrm{hr}^{-1}$ flow rate. Black symbols are effluents at $350^{\circ} \mathrm{C} / 486 \mathrm{bar}$ and $1.0 \mathrm{ml} \mathrm{hr} \mathrm{flow} \mathrm{rate}^{-1}$
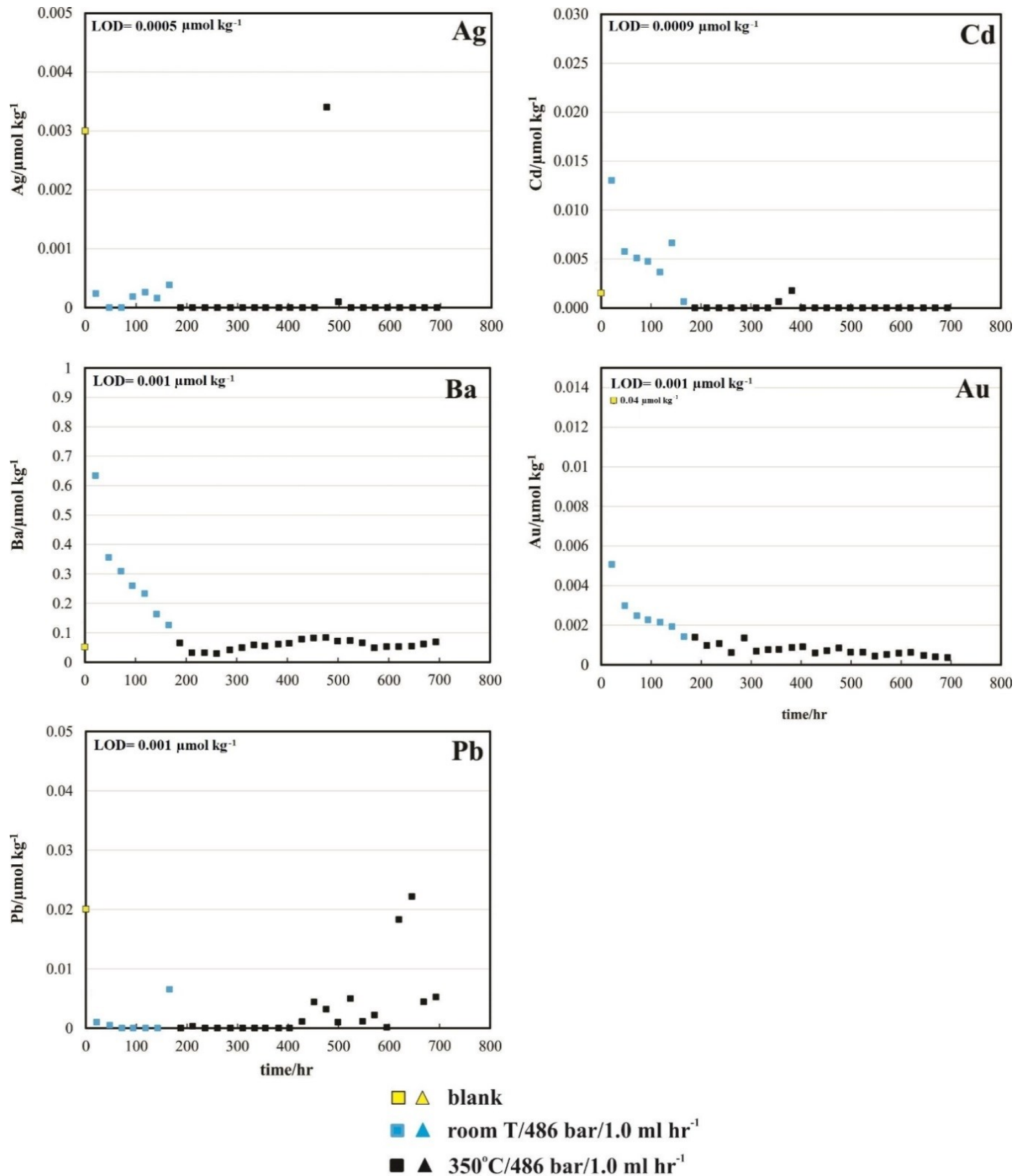


\subsubsection{Mineralogy and Texture of Reacted Basalt: Bottom of Reactor (Portion 1)}

Upon the conclusion of the experiment, the reacted basalt grains were extracted from the Reactor. The cleaning, drying and apportioning of the reacted material was as described for BW1 and BW2 (Chapter 3, §3.2.1.3). In this section we report the results of mineralogical and textural analysis of reacted grains from the bottom (Portion 1) of the Reactor (Fig. 4.15).

Selected grains were mounted on aluminium stubs for textural analyses by SEM while several grains were epoxy-mounted and polished for SEM-EDS analysis. Appendix C contains all SEM results for this Portion of the rock.

Figure 4.15. Schematic diagram showing position of Portion 1 and 2 of reacted basalt grains examined by SEM-EDS and the position of the basalt block (not to scale).

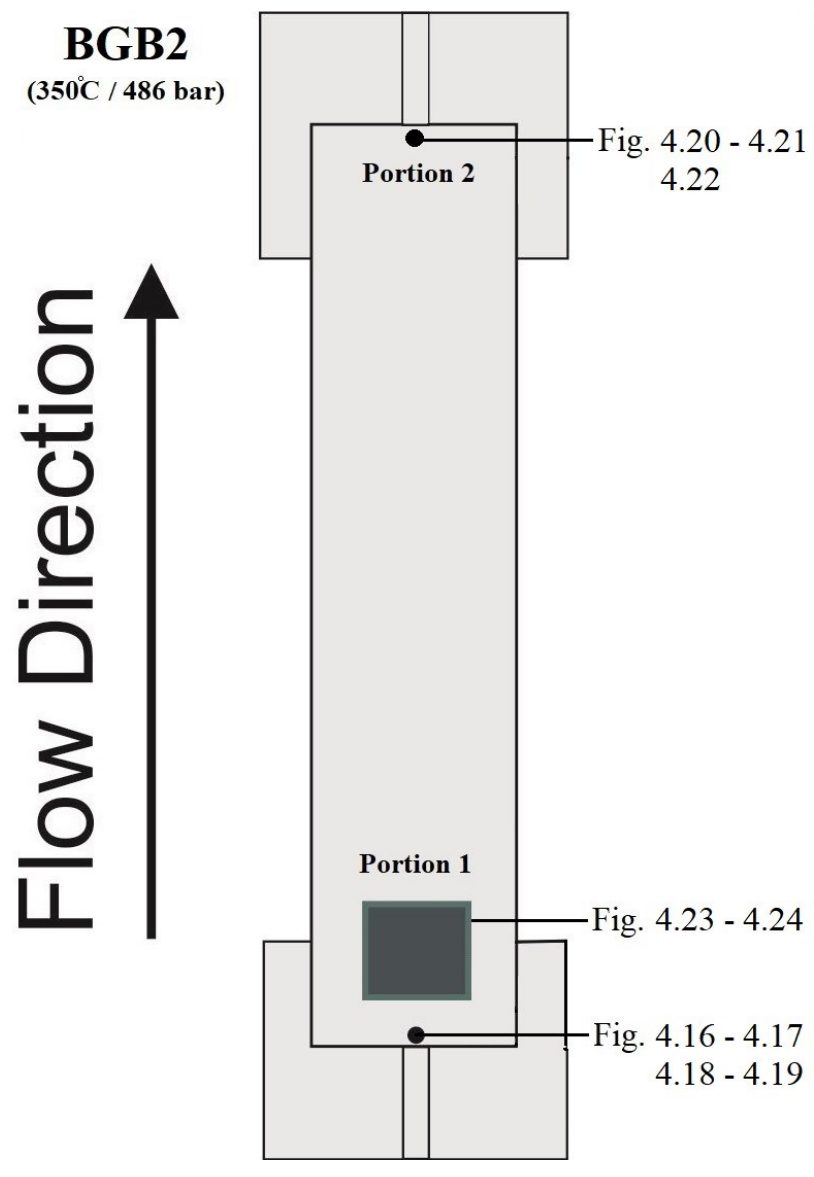




\section{SEM-EDS analysis}

Several grains from immediately adjacent to the fluid entry point (Portion 1, Fig. 4.15) are shown in Figure 4.16 - 4.19. The results confirm a substantial degree of alteration of the basalt due to fluid-rock interaction. Minerals of secondary origin detected were anhydrite, smectite and Cu-sulfide (Table 4.4). Results also confirm the presence of the original primary minerals plagioclase, clinopyroxene, olivine and titanomagnetite. Biotite was not observed in this portion of the rock.

Table 4.4. Mineral assemblage detected by SEM-EDS analysis of reacted grains extracted from the bottom (Portion 1) of the Reactor after the BGB2 experiment.

\begin{tabular}{|c|c|c|c|}
\hline Type of Analysis & $\begin{array}{l}\text { Analysis } \\
\text { Material }\end{array}$ & $\begin{array}{l}\text { Mineral } \\
\text { Identified }\end{array}$ & $\begin{array}{c}\text { Average } \\
\text { Mineral Composition }\end{array}$ \\
\hline SEM-EDS & polished grains & Bytownite & $\mathrm{Ca} 0.7 \mathrm{Na}_{0.2} \mathrm{Al}_{1.7} \mathrm{Si}_{2.4} \mathrm{O}_{8}\left(\mathrm{An}_{77}-\mathrm{Ab}_{23}\right)$ \\
\hline SEM-EDS & polished grains & Augite & $\mathrm{Ca} 0.7 \mathrm{Mg}_{0 .}{ }_{9} \mathrm{Fe}_{0.4} \mathrm{Si}_{2} \mathrm{O}_{6}$ \\
\hline SEM-EDS & polished grains & Titanomagnetite & $\mathrm{Fe}^{2+}\left(\mathrm{Fe}^{3+}, \mathrm{Ti}_{2}\right)_{4}$ \\
\hline SEM-EDS & grain surface & Smectite 1 & $\begin{array}{l}\mathrm{K}_{0.1} \mathrm{Na}_{0.3} \mathrm{Ca}_{0.1} \mathrm{Mg}_{1.5} \mathrm{Fe}_{1.1} \mathrm{Al}_{0.3} \mathrm{Si}_{3.4} \mathrm{Al}_{0.6} \mathrm{O}_{10}(\mathrm{OH})_{2} \cdot n \mathrm{H}_{2} \mathrm{O} \\
\text { (calculated based on an anhydrous composition with } 11 \text { oxygens) }\end{array}$ \\
\hline SEM-EDS & grain surface & Smectite 2 & $\begin{array}{l}\mathrm{K}_{0.1} \mathrm{Na}_{0.2} \mathrm{Ca}_{0.3} \mathrm{Mg}_{1.6} \mathrm{Fe}_{1.2} \mathrm{Al}_{0.1} \mathrm{Si}_{3.4} \mathrm{Al}_{0.6} \mathrm{O}_{10}(\mathrm{OH})_{2} \cdot n \mathrm{H}_{2} \mathrm{O} \\
\text { (calculated based on an anhydrous composition with } 11 \text { oxygens) }\end{array}$ \\
\hline SEM-EDS & grain surface & Anhydrite & $\mathrm{CaSO}_{4}$ \\
\hline SEM-EDS & grain surface & $\begin{array}{l}\text { Cu-sulfide } \\
\text { (covellite?) }\end{array}$ & $\mathrm{Cu}_{0.90} \mathrm{Fe}_{0.15} \mathrm{~S}_{0.96}$ \\
\hline
\end{tabular}

Figure 4.16 shows SEM images of two highly altered grains from the position immediately next to the fluid entry point. An assemblage of secondary minerals covers their surface consisting of isolated euhedral crystals of anhydrite (Fig. 4.16a) and smectite with two morphologies (Fig. 4.16b). Smectite 1 (Table 4.4) consists of densely packed, foliated layers resembling rose petals (Fig. 4.16c) and Smectite 2 (Table 4.4) has a honeycomb texture (Fig. 4.17d). SEM-EDS analysis of these two morphologies shows that they have similar compositions (Table 4.5). Only a few grains with this intensity of alteration were found at the bottom of the Reactor.

It is hypothesised here that in the BGB2 experiment, the ameboid densely-packed morphology is due to growth from olivine while the second texture is due to growth from either plagioclase or clinopyroxene (or possibly both). 
Figure 4.17 shows two SEM images of copper sulfide crystals with a hexagonal habit similar to those found in BGB1. These could be idaite or possibly covellite.

Figure 4.18 shows SEM backscatter images and EDS maps of a polished mount of a grain from the bottom of the Reactor. It is moderately altered with the smectite occurring on the edge of the grain. Plagioclase and clinopyroxene are present, with olivine and $\mathrm{Fe}-\mathrm{Ti}$ oxide. The average composition of the K-Na-Mg-Fe aluminosilicate phase from EDS analyses of the epoxy mounted grain is shown in Table 4.4. It contains almost identical composition of $\mathrm{SiO}_{2}, \mathrm{Al}_{2} \mathrm{O}_{3}, \mathrm{MgO}, \mathrm{FeO}$ and $\mathrm{K}_{2} \mathrm{O}$ of the mineral identified in BGB1 (Table 4.3) with the addition of $\mathrm{CaO}$ and $\mathrm{Na}_{2} \mathrm{O}$. XRD results for Portion 1 (Appendix $\mathrm{C}$ ) give small peaks for montmorillonite, confirming the presence of a swelling clay like smectite.

Figure 4.19a,b show two enlargements of rectangular areas in Figure 4.18a showing bytownite, the smectite, and Fe-Ti oxide of possible secondary origin, as well as primary minerals bytownite, clinopyroxene, olivine, and titanomagnetite. 
Figure 4.16. SEM images of the surface of a grain collected from the bottom (Portion 1) of the Reactor after the BGB2 experiment: (a) grain with euhedral crystals of anhydrite (Anh), the smectite (Smc) appearing in masses of foliated crystals; (c) higher magnification view of smectite with interlocking rose petal-like morphology; (d) rectangular area shown in (b) the smectite (Na-K-Ca-Mg-Fe aluminosilicate) with rose petal-like morphology (bottom left) and with cornflake morphology (top right).

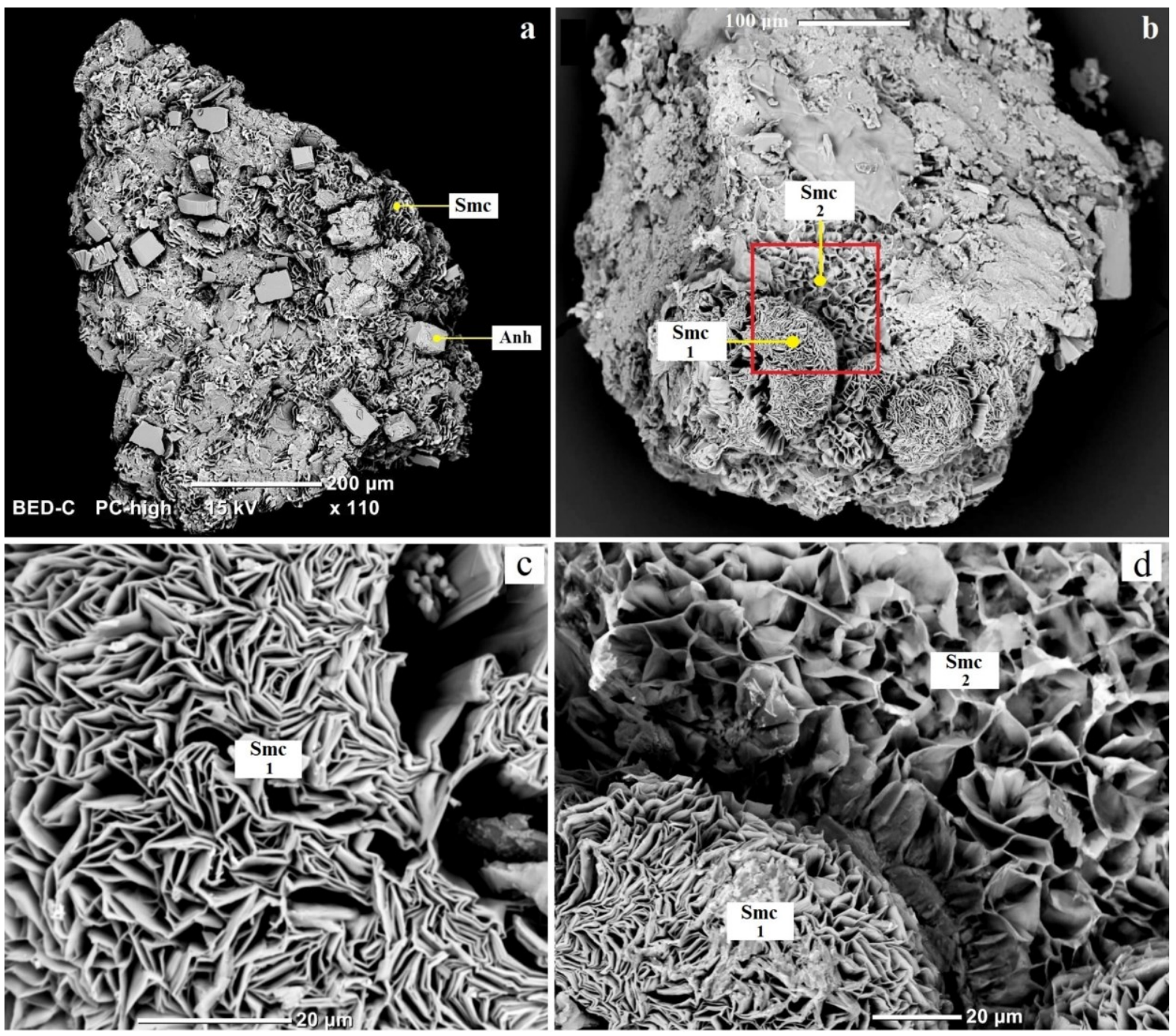

Figure 4.17. a) and b) SEM images of two Cu-sulfide crystals found on the surface of two reacted grains from the BGB2 experiment.
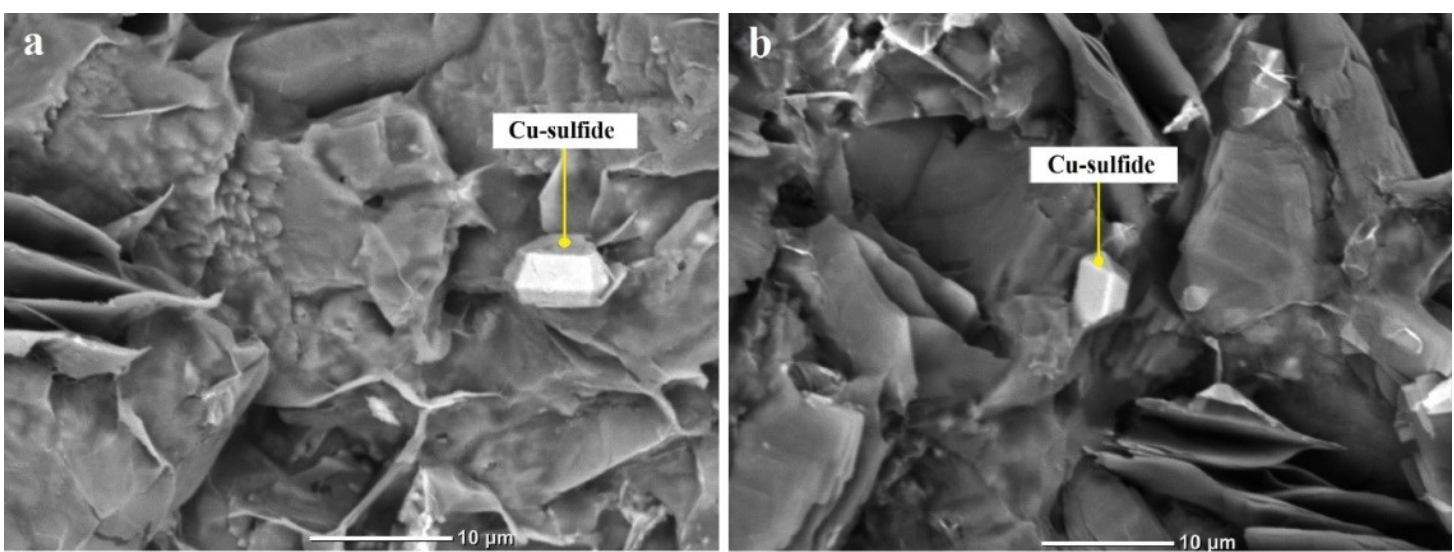
Figure 4.18. SEM backscatter image and EDS compositional maps of an epoxy-mounted polished grain from the bottom (Portion 1) of the Reactor after the BGB2 experiment: a) backscatter image of the entire grain; (b) composite colour image combining the backscatter image and the elemental maps for c) $\mathrm{Mg}$ in green, d) $\mathrm{Ca}$ in blue, and e) $\mathrm{Fe}$ in red. The image shows plagioclase (blue), clinopyroxene (turquoise), Ti-Fe oxides (red), olivine (bright green), and the $\mathrm{K}-\mathrm{Na}-\mathrm{Mg}-\mathrm{Fe}$ aluminosilicate (dark green) on the borders of the grain growing from olivine crystals.

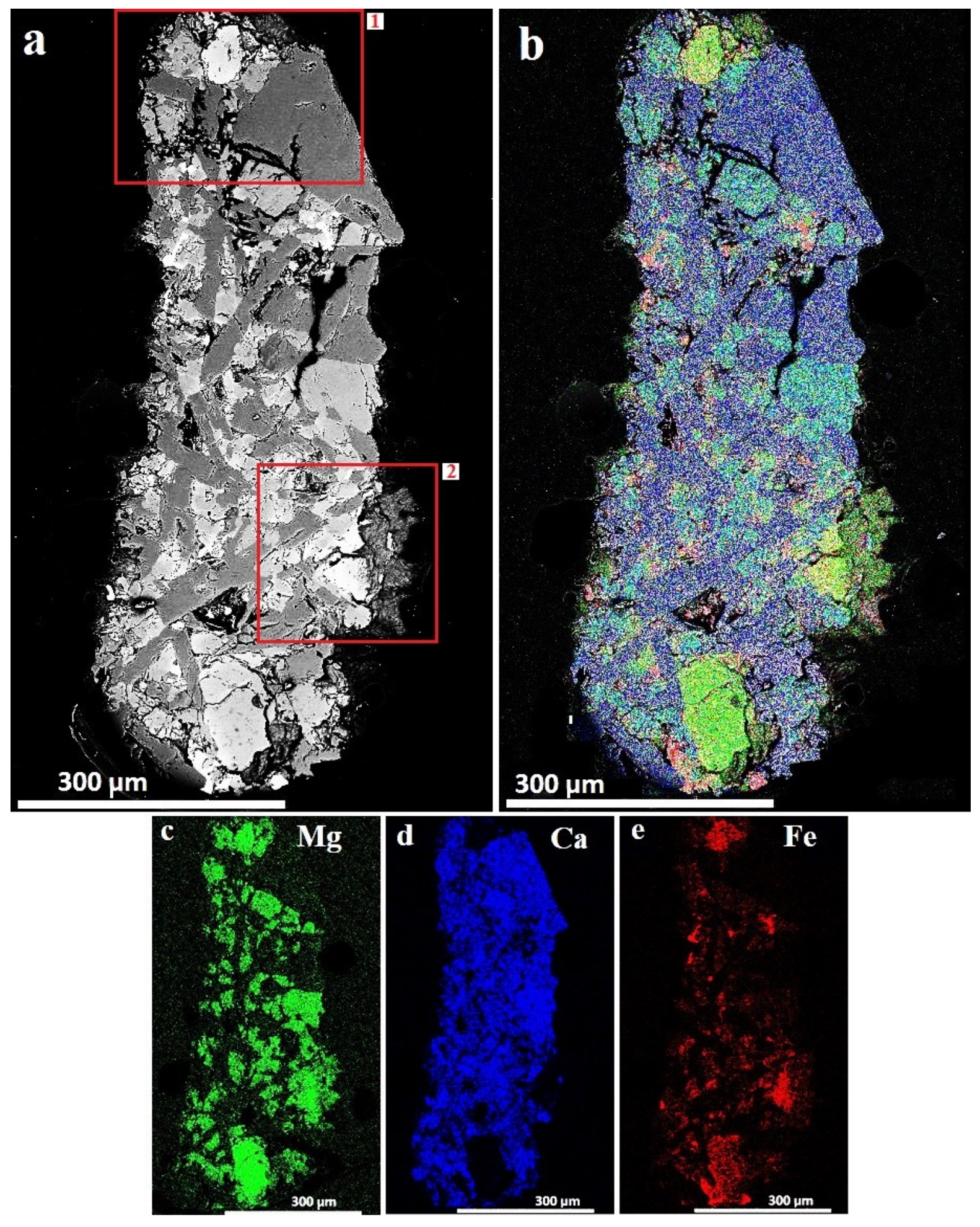


Figure 4.19. (a) and (b) SEM backscatter images of enlargements of rectangular areas (n1 and n2) of Figure 4.18a, respectively, showing primary minerals bytownite (Byt), olivine (Ol), titanomagnetite (Tnt) and the K-Na-Mg-Fe aluminosilicate phase (Smc).
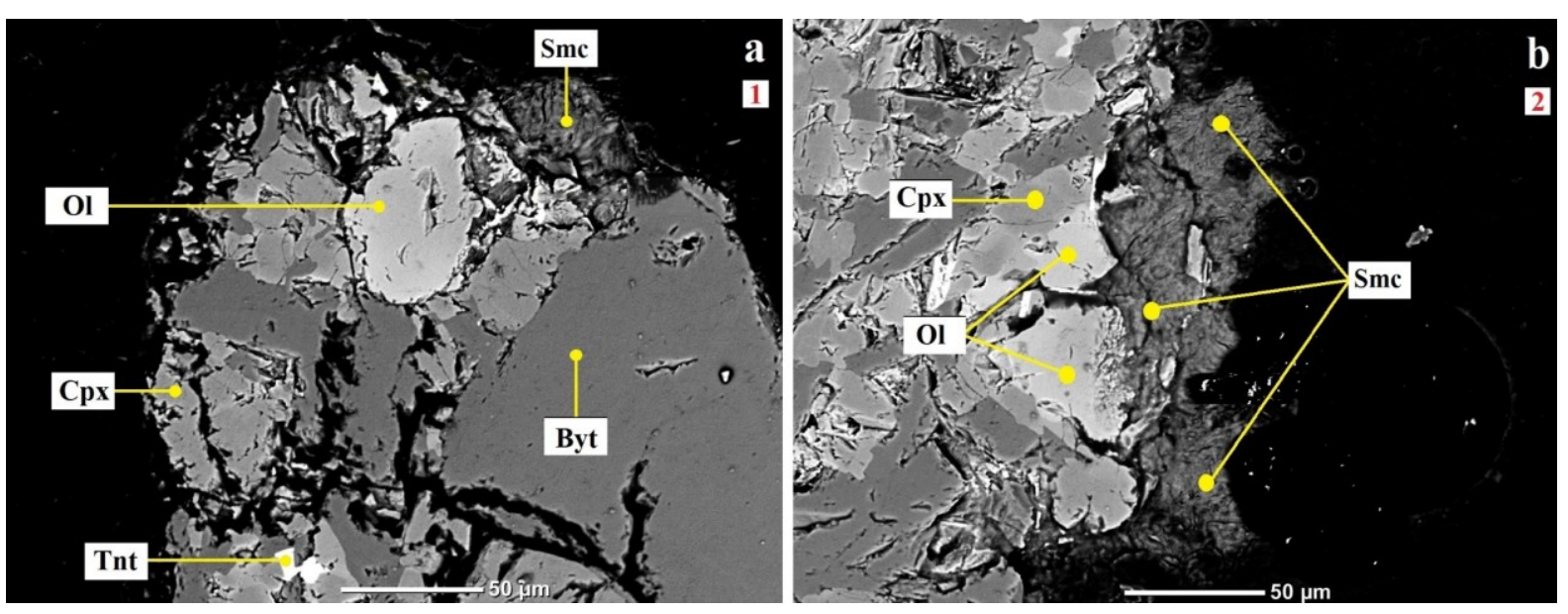

Table 4.5. Average EDS analysis (wt. \%) of the smectite identified at bottom of the Reactor (grains morphology). N: number of analysis.

\begin{tabular}{|lcccc|}
\hline & $\begin{array}{c}\text { Smectite 2 } \\
\text { Unpolished } \\
\mathbf{N}=\mathbf{1 5}\end{array}$ & & $\begin{array}{c}\text { Smectite 1 } \\
\text { Unpolished } \\
\text { N=5 }\end{array}$ & \\
oxide & $\begin{array}{c}\text { average } \\
\text { Wt \% }\end{array}$ & $\pm 1 \sigma$ & $\begin{array}{c}\text { average } \\
\text { Wt \% }\end{array}$ & $\pm 1 \sigma$ \\
& & & & \\
$\mathbf{N a}_{2} \mathbf{O}$ & 2.48 & 0.47 & 1.51 & 0.67 \\
$\mathbf{M g O}$ & 15.15 & 2.41 & 15.69 & 2.44 \\
$\mathbf{A l}_{2} \mathbf{O}_{3}$ & 10.90 & 1.40 & 9.03 & 0.70 \\
$\mathbf{S i O}_{2}$ & 50.92 & 2.04 & 48.77 & 1.71 \\
$\mathbf{K}_{2} \mathbf{O}$ & 0.60 & 0.44 & 1.53 & 0.36 \\
$\mathbf{F e O}$ & 18.58 & 2.88 & 19.89 & 3.18 \\
$\mathbf{C a O}$ & 1.33 & 0.58 & 3.58 & 0.28 \\
Total & 99.96 & & 100.00 & \\
\hline
\end{tabular}




\subsubsection{Mineralogy and Texture of Reacted Basalt: Top of Reactor (Portion 2)}

Several grains (Fig. 4.20 - 4.22) from the immediately adjacent to the fluid exit point at the top of the Reactor (Portion 2, Fig. 4.15) were examined. These were mounted on aluminium stubs for morphological analysis by SEM. Several grains were also mounted in epoxy and polished for SEM-EDS analysis. Appendix C lists the complete results for this Portion of the basalt.

\section{SEM-EDS analysis}

SEM examination confirms a lesser degree of alteration of the reacted grains when compared to the bottom (Portion 1) of the Reactor. Only one mineral of secondary origin was detected, a clay-like phase thought to be smectite. Data also confirm the presence of the primary minerals bytownite, clinopyroxene, olivine and titanomagnetite (Table 4.6). No evidence of biotite or anhydrite was found during analysis.

Table 4.6. Mineral assemblage found during analysis of reacted grains extracted from the top (Portion 2) of the Reactor after the BGB2. Analysis was effectuated by SEM-EDS. Appendix (C) contains all SEM results for this portion of the rock.

\begin{tabular}{|c|c|c|c|}
\hline Type of Analysis & $\begin{array}{l}\text { Analysis } \\
\text { Material }\end{array}$ & $\begin{array}{l}\text { Mineral } \\
\text { Identified }\end{array}$ & $\begin{array}{l}\text { Average } \\
\text { Mineral Composition }\end{array}$ \\
\hline SEM-EDS & polished grains & Bytownite & $\mathrm{Ca} 0.7 \mathrm{Na}_{0.3} \mathrm{Al}_{1.6} \mathrm{Si}_{2.4} \mathrm{O}_{8}\left(\mathrm{An}_{73}-\mathrm{Ab}_{27}\right)$ \\
\hline SEM-EDS & polished grains & Augite & $\mathrm{Ca}_{0.5} \mathrm{Mg}_{0.7} \mathrm{Fe}_{0.7} \mathrm{Al}_{0.8} \mathrm{Si}_{2} \mathrm{O}_{6}$ \\
\hline SEM-EDS & polished grains & Fayalite & $\mathrm{Mg}_{0.7} \mathrm{Fe}_{1.2} \mathrm{SiO}_{4}$ \\
\hline SEM-EDS & polished grains & Titanomagnetite & $\mathrm{Fe}^{2+}\left(\mathrm{Fe}^{3+}, \mathrm{Ti}\right)_{2} \mathrm{O}_{4}$ \\
\hline SEM-EDS & polished grains & Smectite & $\begin{array}{c}\mathrm{K}_{0.1} \mathrm{Na}_{0.2} \mathrm{Ca}_{0.1} \mathrm{Mg}_{1.5} \mathrm{Fe}_{1.3} \mathrm{Al}_{0.2} \mathrm{Si}_{3.5} \mathrm{Al}_{0.5} \mathrm{O}_{10}(\mathrm{OH})_{2} \cdot n \mathrm{H}_{2} \mathrm{O} \\
\text { (calculated based on an anhydrous composition with } 11 \text { oxygens) }\end{array}$ \\
\hline SEM-EDS & grain surface & Smectite & $\begin{array}{c}\mathrm{K}_{0.1} \mathrm{Na}_{0.3} \mathrm{Ca}_{0.2} \mathrm{Mg}_{1.6} \mathrm{Fe}_{1.2} \mathrm{Al}_{0.2} \mathrm{Si}_{3.3} \mathrm{Al}_{0.7} \mathrm{O}_{10}(\mathrm{OH})_{2} \cdot n \mathrm{H}_{2} \mathrm{O} \\
\text { (calculated based on an anhydrous composition with } 11 \text { oxygens) }\end{array}$ \\
\hline
\end{tabular}

Figure 4.20 shows the surface textures of two different grains extracted from the top (Portion 2) of the Reactor. EDS backscatter images show that the surface is partially altered and covered by the aluminosilicate phase appearing in sparse globular masses. The mineral shows similar shape and chemical composition when compared with the phase identified at bottom (Portion 1) of the Reactor (Table 4.4). Figure 4.20c,d shows, in detail, the aluminosilicate appearing in globular masses of dense flakes.

Figure 4.21 shows SEM backscatter images and EDS maps for an epoxy-mounted, polished grain collected from the top (Portion 2) in the Reactor. The lower intensity of 
hydrothermal alteration is evident when compared with grains collected at bottom of the Reactor (Portion 1, Fig. 4.18). Analysis of chemical composition by SEM-EDS show that primary plagioclase bytownite (dark blue) is essentially unaltered. Also present is a $\mathrm{K}-\mathrm{Na}-\mathrm{Ca}-$ Mg-Fe aluminosilicate phase (smectite). The primary clinopyroxene (turquoise) and titanomagnetite are relatively unaffected, while olivine (yellow) is richer in Fe rather than of $\mathrm{Mg}$ when compared with results of the unaltered material (Table 2.2).

Figure 4.22a,b are the two enlargements of red square areas in Figure 4.21a,b showing relict clinopyroxene, titanomagnetite and smectite. This mineral shows similar shape and chemical composition when compared with the phase identified from the bottom portion of the Reactor. It appears in isolated masses on the reacted grains surface suggesting that it replaces a single primary mineral, most likely olivine. Table 4.7 reports the average EDS analyses of this mineral both from the polished mount and from surface analysis.

Figure 4.20. SEM images of grains collected from the top (Portion 2) of Reactor after BGB2: (a-b) smectite (Smc) in globular dense masses covering partially the surface of both grains. (c-d) SEM microphotographs of the rectangular areas in (a) and (b) respectively, showing in more detail the smectite.
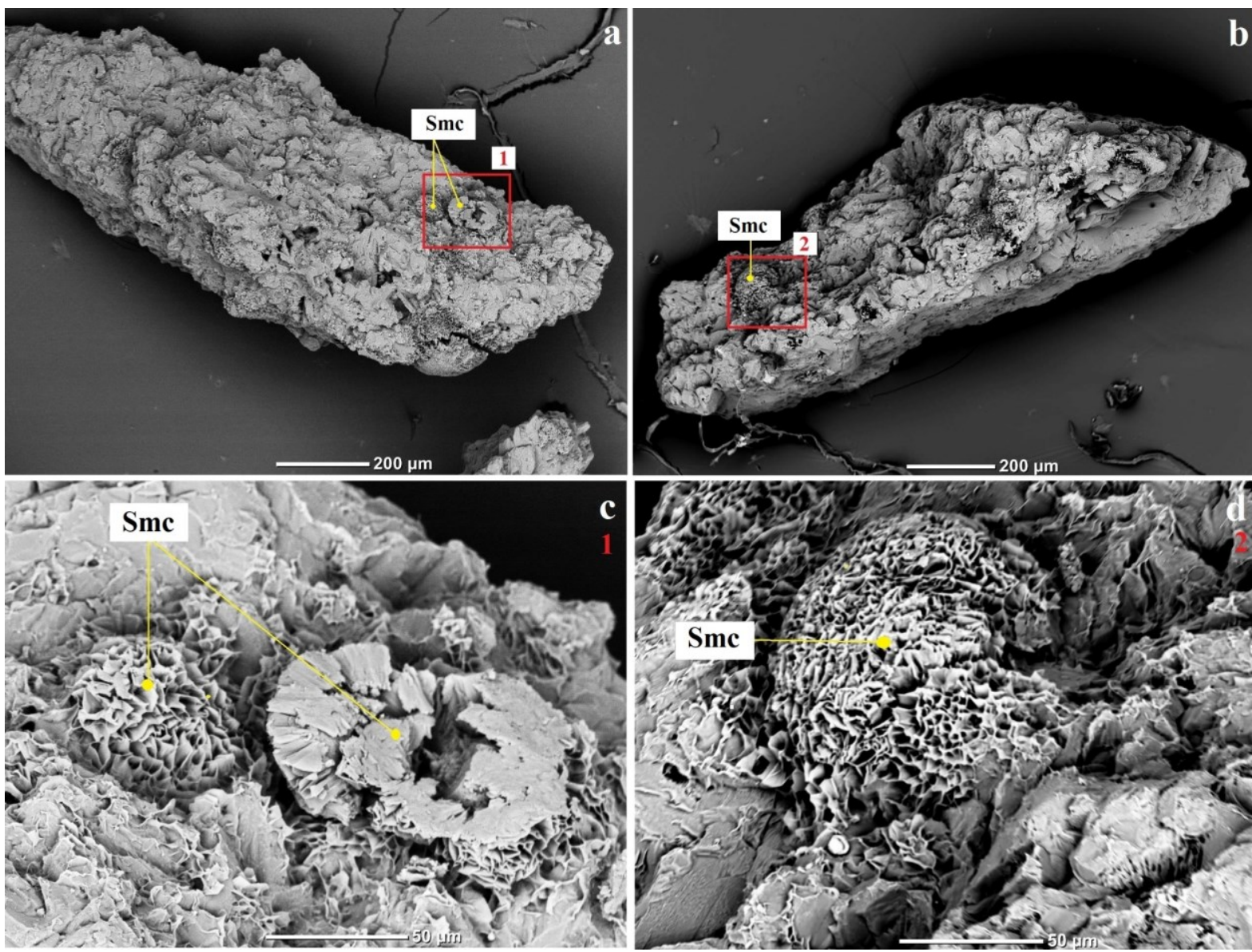
Figure 4.21. SEM backscatter and EDS compositional maps of an epoxy-mounted polished grain collected from the top (Portion 2) of Reactor after the BGB2 experiment. (a) backscatter image of the entire grain; (b) composite colour image combining the backscatter image and the elemental maps for c) $\mathrm{Mg}$ in green, d) $\mathrm{Ca}$ in blue, and e) $\mathrm{Fe}$ in red. The composite image shows plagioclase (dark blue), unaltered clinopyroxene (turquoise), olivine (yellow), Fe-Ti oxides (red), and smectite (green). All data set points in Appendix (C).
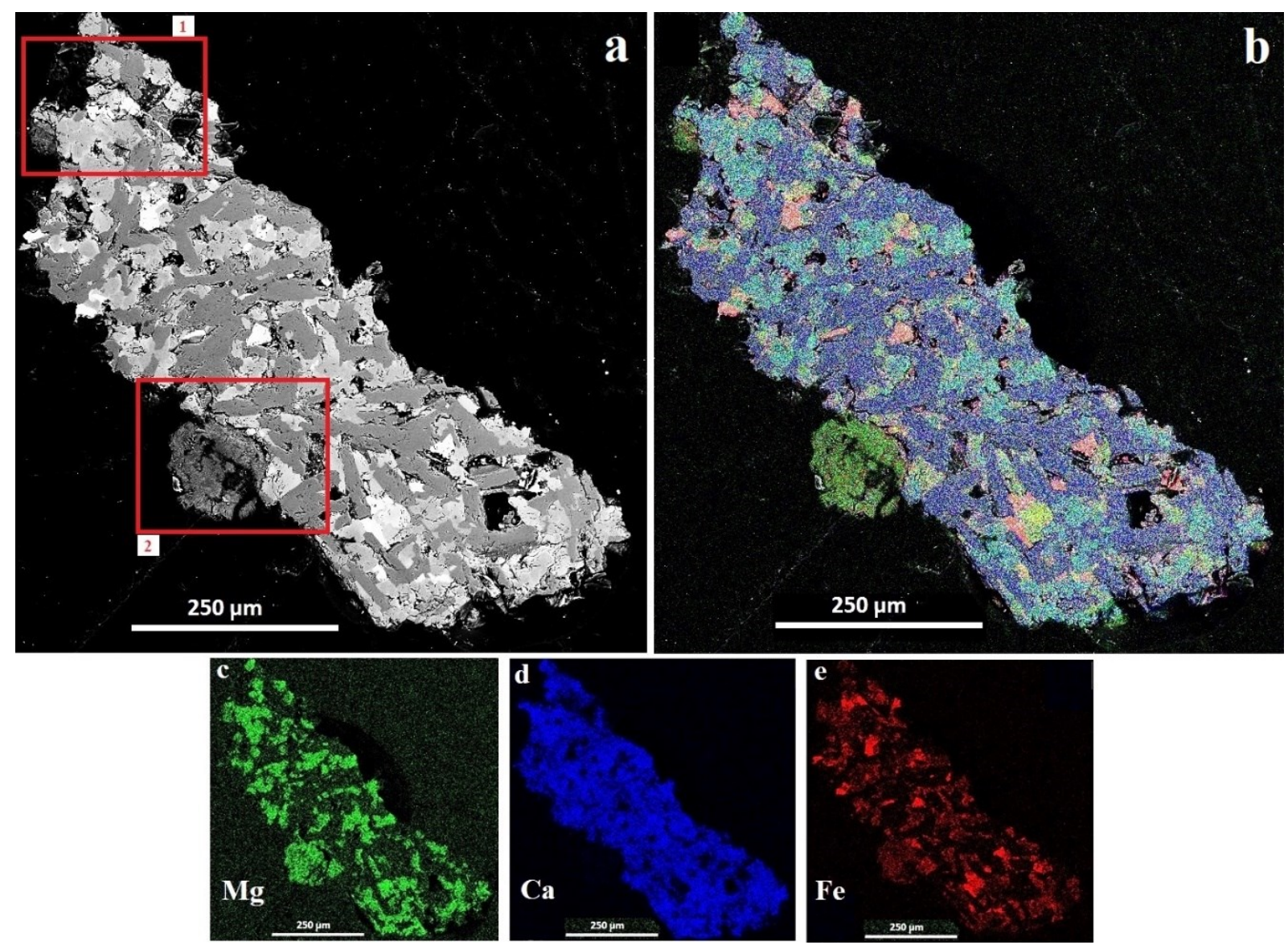

Figure 4.22. (a-b) SEM images of the rectangular areas of Figure 4.22a and Figure 4.22b, respectively, plagioclase (Plg), olivine (Ol), primary titanomagnetite and smectite $(\mathrm{Smc})$. The smectite has replaced the primary olivine.
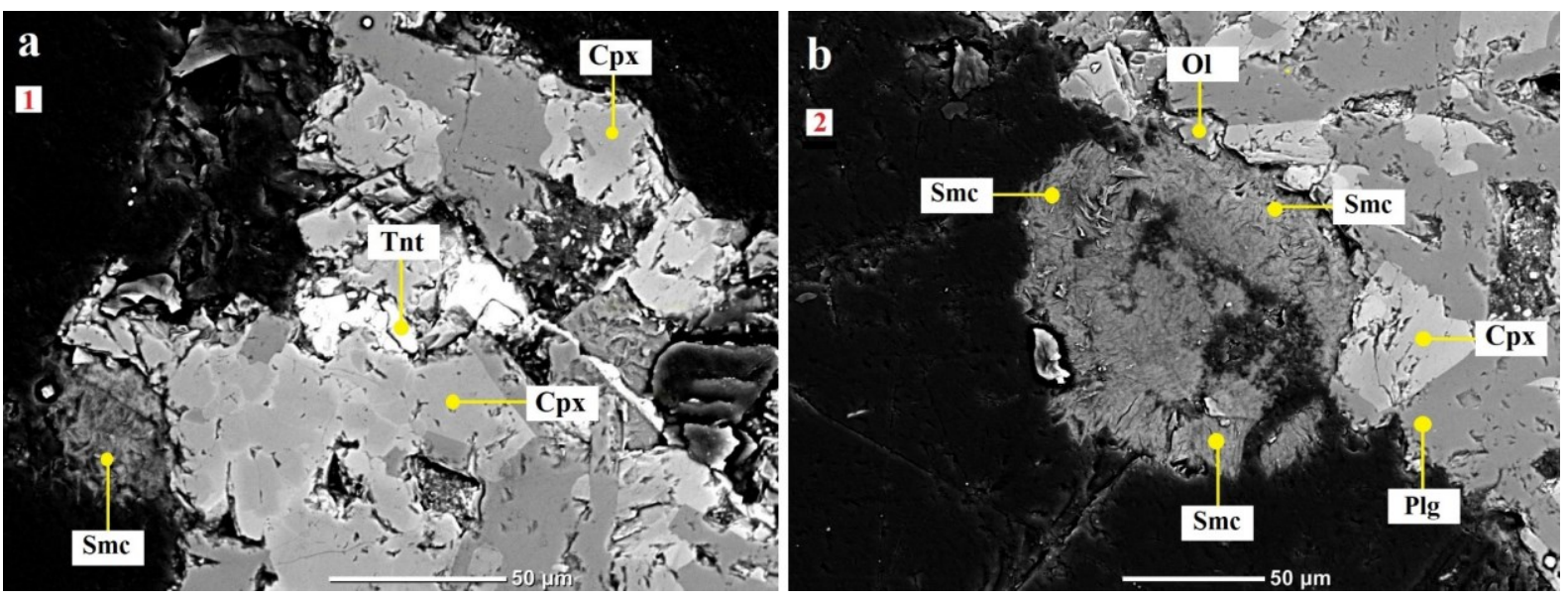
Table 4.7. Average EDS analysis (wt. \%) of the K-Na-Ca-Mg-Fe aluminosilicate phase (smectite) identified at top of the Reactor (grains morphology and epoxy-mount). N: number of analysis. All data set points in Appendix (C).

\begin{tabular}{|ccccc|}
\hline & $\begin{array}{c}\text { Unpolished } \\
\mathbf{N = 2}\end{array}$ & & \multicolumn{3}{c|}{$\begin{array}{c}\text { Polished } \\
\mathbf{N}=\mathbf{1 1}\end{array}$} \\
& & & & \\
oxide & $\begin{array}{c}\text { average } \\
\text { average }\end{array}$ & $\pm 1 \sigma$ & Wt \% & $\pm 1 \sigma$ \\
& & & & \\
$\mathbf{N a}_{2} \mathbf{O}$ & 2.02 & 0.37 & 0.99 & 0.86 \\
$\mathbf{M g O}$ & 15.04 & 1.62 & 15.06 & 2.14 \\
$\mathbf{A l}_{2} \mathbf{O}_{3}$ & 11.22 & 0.64 & 8.68 & 0.54 \\
$\mathbf{S i O}_{2}$ & 47.74 & 0.83 & 50.70 & 1.32 \\
$\mathbf{K}_{2} \mathbf{O}$ & 0.78 & 0.03 & 0.59 & 0.38 \\
$\mathbf{F e O}$ & 21.25 & 1.38 & 23.08 & 3.37 \\
$\mathbf{C a O}$ & 1.98 & 0.47 & 0.86 & 0.40 \\
Total & 100.00 & & 99.95 & \\
\hline
\end{tabular}

\subsubsection{Mineralogy and Texture of Reacted Basalt: Basalt Block}

The basalt block $(8 \times 8 \times 4 \mathrm{~mm})$ with one polished surface, was positioned vertically near the bottom of the Reactor approximately $0.5-1.0 \mathrm{~cm}$ above the titanium frit (Fig. 4.15). Upon the completion of the experiment, the block was mounted on an aluminium stub for SEM-EDS analysis (Table 4.8). Complete SEM results for the reacted basalt block surface are reported in Appendix (C).

Table 4.8. Mineral composition of the reacted basalt block surface after the BGB2.

\begin{tabular}{|c|c|c|c|}
\hline $\begin{array}{c}\text { Type of } \\
\text { Analysis }\end{array}$ & $\begin{array}{l}\text { Analysis } \\
\text { Material }\end{array}$ & $\begin{array}{l}\text { Mineral } \\
\text { Identified }\end{array}$ & $\begin{array}{c}\text { Average } \\
\text { Mineral Composition }\end{array}$ \\
\hline SEM-EDS & basalt block & Bytownite & $\mathrm{Ca}_{0.7} \mathrm{Na}_{0.3} \mathrm{Al}_{1.6} \mathrm{Si}_{2.4} \mathrm{O}_{8}\left(\mathrm{An}_{75}-\mathrm{Ab}_{25}\right)$ \\
\hline SEM-EDS & basalt block & Anhydrite & $\mathrm{CaSO}_{4}$ \\
\hline SEM-EDS & basalt block & Smectite & $\begin{array}{c}\mathrm{K}_{0.1} \mathrm{Na} 0.7 \mathrm{Ca} 0.3 \mathrm{Mg}_{1.5} \mathrm{Fe}_{1.6} \mathrm{Si}_{3.1} \mathrm{Al}_{0.7} \mathrm{O}_{10}(\mathrm{OH})_{2} \cdot n \mathrm{H}_{2} \mathrm{O} \\
\text { (calculated based on an anhydrous composition with } 11 \text { oxygens) }\end{array}$ \\
\hline SEM-EDS & basalt block & $\begin{array}{c}\text { Unknown } \\
\text { Na-Ca-Mg-Fe-Ti-Mn } \\
\text { aluminosilicate }\end{array}$ & - \\
\hline
\end{tabular}

Figure 4.23 shows the complete surface of the reacted basalt block which appears visibly altered. The smectite and anhydrite are the main secondary minerals identified. Plagioclase is essentially unaffected. EDS analysis confirms that the dark spots with a subhedral shape are anhydrite. It is possible that the anhydrite crystals were partially dissolved during cleaning of the block with distilled water after extraction from the Reactor. Unfortunately, it was not possible to remove all the brine salt remnants from the surface thus 
EDS analysis were found to contain measureable quantities of $\mathrm{Na}$ and $\mathrm{Cl}$. This must be considered when interpreting the EDS results.

Figure 4.24 shows SEM backscatter images of rectangular areas of Figure 4.23. Primary bytownite, the smectite, anhydrite and the Ca-Na-Mg-Fe-Mn-Ti aluminosilicate. The primary minerals clinopyroxene and titanomagnetite were also identified. Anhydrite appears as tabular crystals, the smectite has flaky habit while the unknown Ca-Na-Mg-Fe-Mn-Ti aluminosilicate appears in platy crystals of hexagonal shape.

Figure 4.23. SEM backscatter image of the basalt block surface after the BGB2 experiment. Dark gray subhedral spots (white arrows) are voids left by anhydrite crystal that were lost after collection.

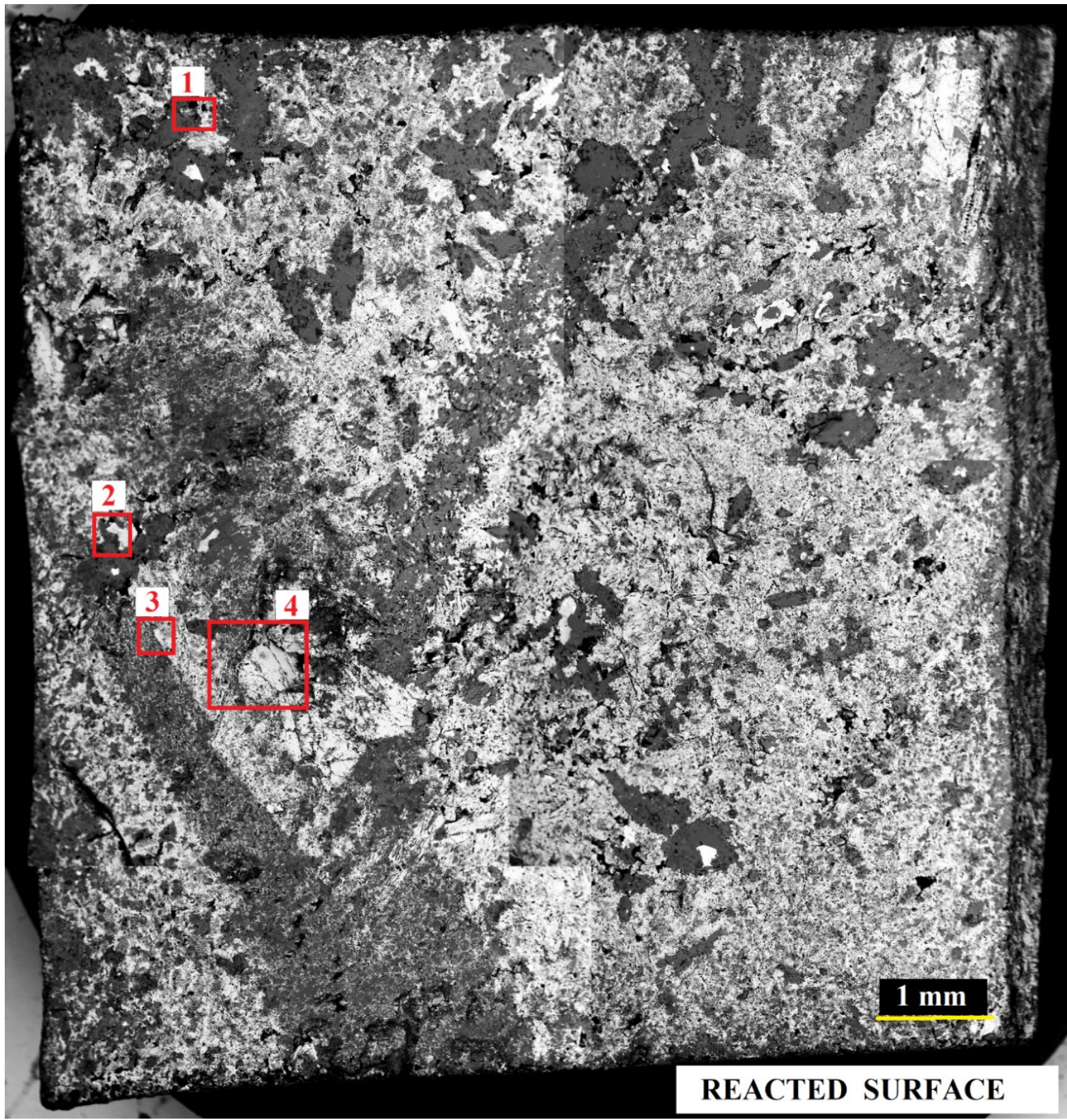


Figure 4.24. SEM backscatter images of the reacted basalt surface after the BGB2 experiment: (a) enlargement of the red area ${ }^{\circ} 1$ in Figure 4.23 showing two crystals of anhydrite surrounded by the smectite (Smc); (b) enlargement of the red area $n^{\circ} 2$ in Figure 4.23 showing spots of anhydrite partially dissolved after cleaning with distilled water; (c) enlargement of the red area $\mathrm{n}^{\circ} 3$ in Figure 4.23 showing primary bytownite (Byt), the unknown Na-Ca-Mg-Fe-Ti-Mn aluminosilicate, anhydrite (Anh) and occurring on the plagioclase surface; (d) enlargement of the red area $n^{\circ} 4$ in Figure 4.23 showing primary plagioclase (Byt); (e-f) enlargements of the red areas in (c) and (d), respectively, showing in detail the hexagonal crystals of the unknown aluminosilicate.
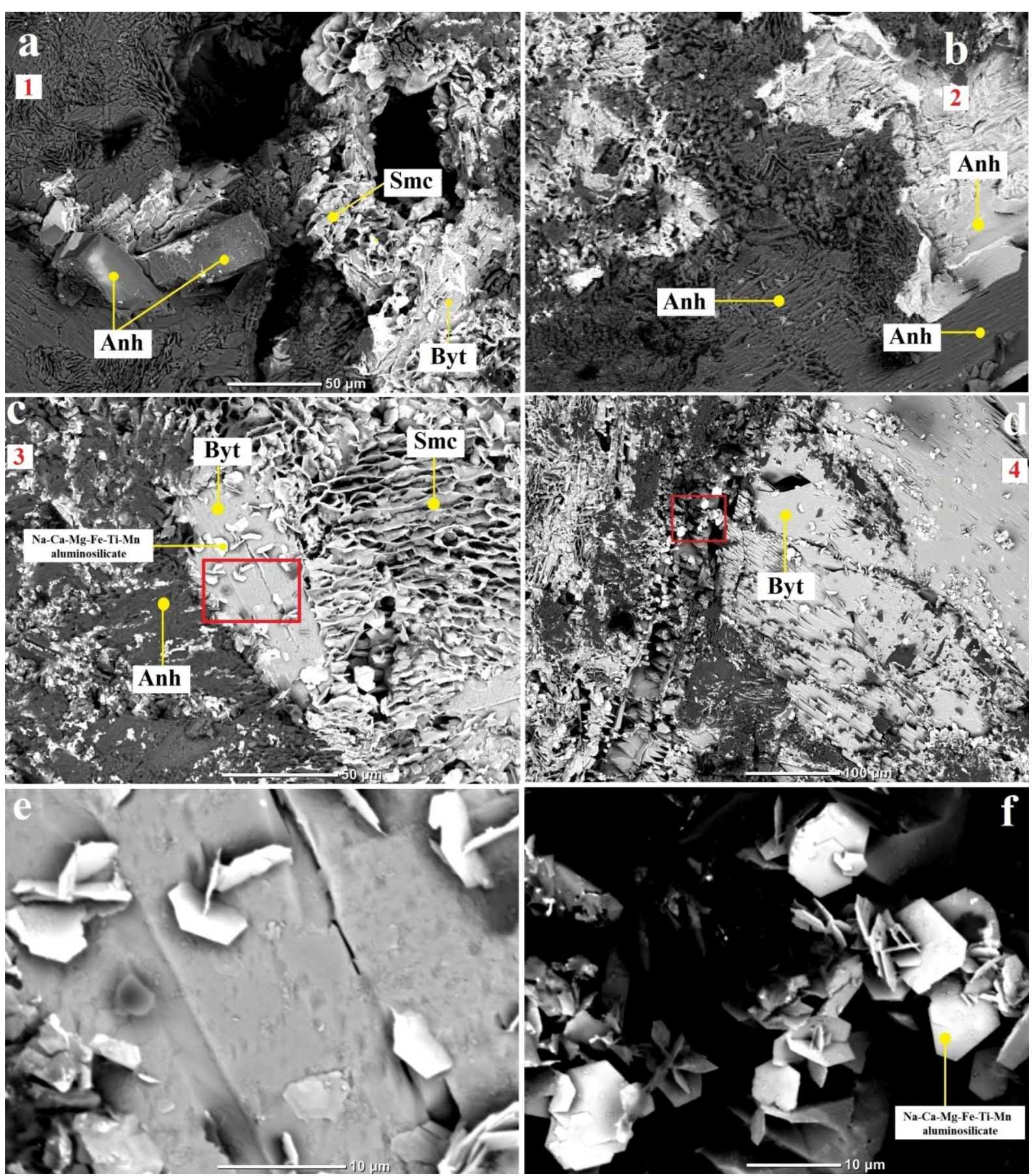


\subsection{Discussion}

\subsubsection{Major and trace element exchange during water - rock interaction}

Major ions

The basalt - geothermal brine experiments were conducted at room temperature for the first week after which conditions were shifted to $350^{\circ} \mathrm{C}$ (BGB2) and $400^{\circ} \mathrm{C}$ (BGB1). After temperature increase to $400^{\circ} \mathrm{C}, \mathrm{SiO}_{2}$ concentrations remain oversaturated with respect to quartz for $\sim 384$ hours and at $\sim 600 \mathrm{hr}$ the concentrations decrease below saturation. In comparison, after temperature increase to $350^{\circ} \mathrm{C}, \mathrm{SiO}_{2}$ concentration also reaches oversaturation with respect to quartz $\left(\sim 30 \mathrm{mmol} \mathrm{kg}^{-1}\right)$ but, in contrast to the $400^{\circ} \mathrm{C}$ experiment, it immediately starts to decrease until it passes below quartz saturation at $740 \mathrm{hr}$. At the end of both experiments $\mathrm{SiO}_{2}$ concentration is similar at $\sim 15 \mathrm{mmol} \mathrm{kg}^{-1}$. This suggests that there are similar mineral reactions controlling $\mathrm{SiO}_{2}$ concentration. The initial high $\mathrm{SiO}_{2}$ values in both experiments are attributed to the dissolution of volcanic glass after temperature shift. However, the plateau shaped trend and rapid decrease in $\mathrm{SiO}_{2}$ concentrations at $\sim 600 \mathrm{hr}$ at $400^{\circ} \mathrm{C}$ indicate relatively constant release of silica until the glass is exhausted, while at $350^{\circ} \mathrm{C}$, the constant decreasing trend indicates that released silica was incorporated into new minerals (Fig. 4.25).

In the brine experiments, the input solution initially contains dissolved silica $(\sim 12$ mmol $\mathrm{kg}^{-1}$ ). This concentration is well below quartz saturation at 350 and $400^{\circ} \mathrm{C}$. The higher $\mathrm{SiO}_{2}$ concentrations after temperature shift, in both brine experiments, confirm that volcanic glass was certainly dissolving; however, the silica concentrations reached are similar to those of the distilled water experiments. This is evidence of mineral precipitation controlling silica concentration, rather than a kinetic effect due to flow rate, i.e., fluid residence time. Using the same procedure described for the BW experiments (Chapter $3, \S 3.31$ ) the amount of glass dissolved was estimated for BGB2 and BGB1 (Appendix C). This calculation gives $\sim 330 \mathrm{mg}$ of glass for BGB2 and $\sim 530 \mathrm{mg}$ for BGB1.

In the BW experiments, the correlation of some components, namely $\mathrm{K}, \mathrm{H}_{2} \mathrm{~S}, \mathrm{SO}_{4}$ and $\mathrm{Cl}$ with $\mathrm{SiO}_{2}$ concentration was evidence of release from volcanic glass (Chapter 3, §3.3.1). In the BGB experiments, geothermal brine was used which contains much higher concentrations of $\mathrm{K}, \mathrm{SO}_{4}$ and $\mathrm{Cl}$, nevertheless, further increases in $\mathrm{K}$ were observed during glass dissolution in $\mathrm{BGB} 1$ at $400^{\circ} \mathrm{C}$. This was not observed in $\mathrm{BGB} 2$ at $350^{\circ} \mathrm{C}$, which is evidence of greater $\mathrm{K}$ incorporation into secondary minerals at this temperature. Any 
correlation of $\mathrm{SO}_{4}$ and $\mathrm{Cl}$ concentrations with glass dissolution are masked by the high initial concentrations in the brine.

Elevated concentrations of $\mathrm{H}_{2} \mathrm{~S}$ are observed during glass dissolution in both experiments but there is no clear correlation with $\mathrm{SiO}_{2}$ concentrations suggesting sulfide mineral precipitation.

The presence of $\mathrm{H}_{2} \mathrm{~S}$ in the fluid is attributed to the dissolution of sulfide blebs and the generation of $\mathrm{SO}_{3}$ by the release of $\mathrm{SO}_{2} . \mathrm{H}_{2} \mathrm{~S}$ and $\mathrm{SO}_{2}$ are expected to be both trapped in the volcanic glass. The release of sulfur from the glass also explains the initial low quench $\mathrm{pH}$ values measured after the temperature change, especially at $400^{\circ} \mathrm{C}$. Once the glass is depleted, the quench $\mathrm{pH}$ values change from 3.4 to 7.8 and from 2.9 to 7.7 at 350 and $400^{\circ} \mathrm{C}$, respectively; however, the in situ $\mathrm{pH}$ is constant, with an average of 6.8 and 7.0 for BGB2 and BGB1. At temperature, the sulfite/sulfate anion created by the release of $\mathrm{SO}_{2}$ from the glass is protonated forming bisulfite and/or bisulfate. This causes in situ $\mathrm{pH}$ to be near neutral, however, these anions deprotonate upon cooling and thus room temperature $\mathrm{pH}$ is acid. Once the volcanic glass is dissolved there is no longer a source of sulfur and the $\mathrm{pH}$ increases due to cation exchange with the rock minerals.

For the fluid to equilibrate with the rock it requires the consumption of $\mathrm{H}^{+}$and this explains the increase in $\mathrm{pH}$. Unlike the distilled water experiments, much of the chemistry is controlled by the fluid and not by the rock. $\mathrm{Ca}, \mathrm{Na}$ and $\mathrm{K}$ do not transfer to the fluid as these elements are already present in the geothermal brine. For this reason, the consumption of $\mathrm{H}^{+}$ occurs to a lesser degree when compared to the experiments with distilled water. This explains why the quench $\mathrm{pH}$ increases to 7.7 - 7.8 during the BGB experiments while it reached values above 9 in the BW experiments.

Table 4.9 shows the input total mass (mg) and integrated elemental fluxes (mg) for selected components. The input total mass represents the amount of material that entered the Reactor based on the total fluid flux $(0.75 \mathrm{~L}$ in BGB2 and 0.69 L in BGB1) and input brine composition. The integrated elemental flux is the net mass of component integrated over the entire experiment based on daily fluid flux and the effluent composition.

For the BGB2 $\left(350^{\circ} \mathrm{C}\right)$, the integrated flux calculation shows a net flux of $+226 \mathrm{mg}$ $\mathrm{SiO}_{2}$ to the fluid while BGB1 $\left(400^{\circ} \mathrm{C}\right)$ has a net positive flux of $+504 \mathrm{mg} \mathrm{SiO}{ }_{2}$. This indicates that $55 \%$ less silica was released at $350^{\circ} \mathrm{C}$ than at $400^{\circ} \mathrm{C}$. This can be explained by greater incorporation of released silica into secondary mineral phases. 
Figure 4.25. $\mathrm{SiO}_{2}$ concentration (mmol kg-1) vs time (hr) for $\mathrm{BGB} 1$ and $\mathrm{BGB} 2$ : a) total $\mathrm{SiO}_{2}$ flux for BGB2 based on sample volume and solution compositions (pink area); b) total $\mathrm{SiO}_{2}$ flux from the input brine; c) the difference between a) and b) representing the net $\mathrm{SiO}_{2}$ flux from the rock for BGB2 (orange area); d) total $\mathrm{SiO}_{2}$ flux for BGB1 based on sample volume and solution compositions (pink area); e) total $\mathrm{SiO}_{2}$ flux from silicate minerals (green) based on the average $\mathrm{SiO}_{2}$ concentration in the last two samples less the input brine composition (grey); f) the difference between d) and e) representing the total $\mathrm{SiO}_{2}$ flux estimated from glass; g) total $\mathrm{SiO}{ }_{2}$ flux released from $\mathrm{BGB} 1$ (orange + green area).
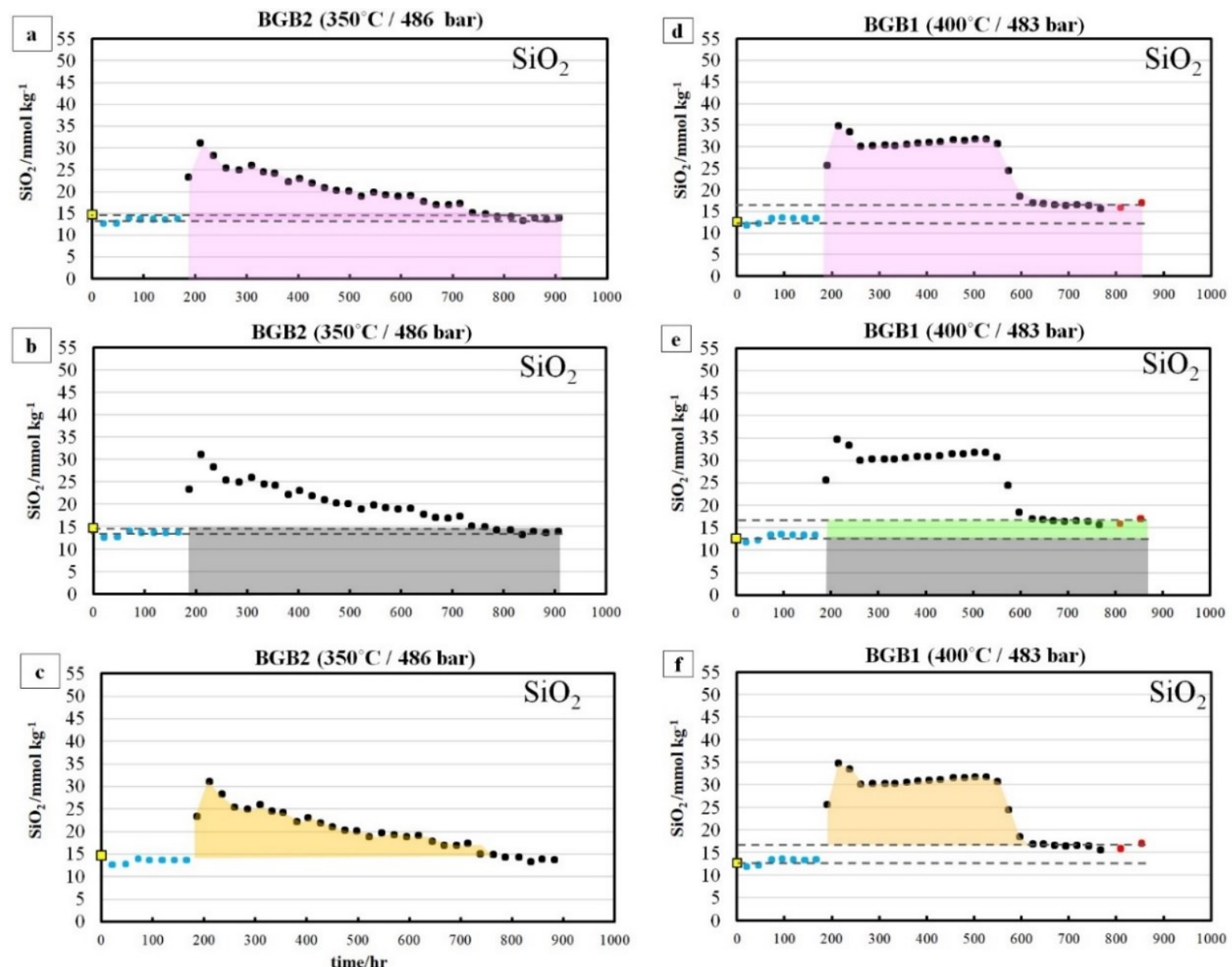

$\square$ blank (geothermal brine)

room $\mathrm{T} / 486 \mathrm{bar} / 1.0 \mathrm{ml} \mathrm{hr}^{-1}$

$350^{\circ} \mathrm{C} / 486 \mathrm{bar} / 1.0 \mathrm{ml} / \mathrm{hr}^{2}$

$\square \Sigma \mathrm{SiO}_{2}$ flux including blank composition $=\mathbf{8 8 7} \mathbf{~ m g ~} \square+\square$

$\square \mathrm{\Sigma SiO}_{2}$ imput mass calculated based on blank composition $=661.5 \mathrm{mg}$

$\square \Sigma \mathrm{SiO}_{2}$ flux released from BGB2 $=\mathbf{2 2 6} \mathbf{~ m g ~} \square \cdot \square$

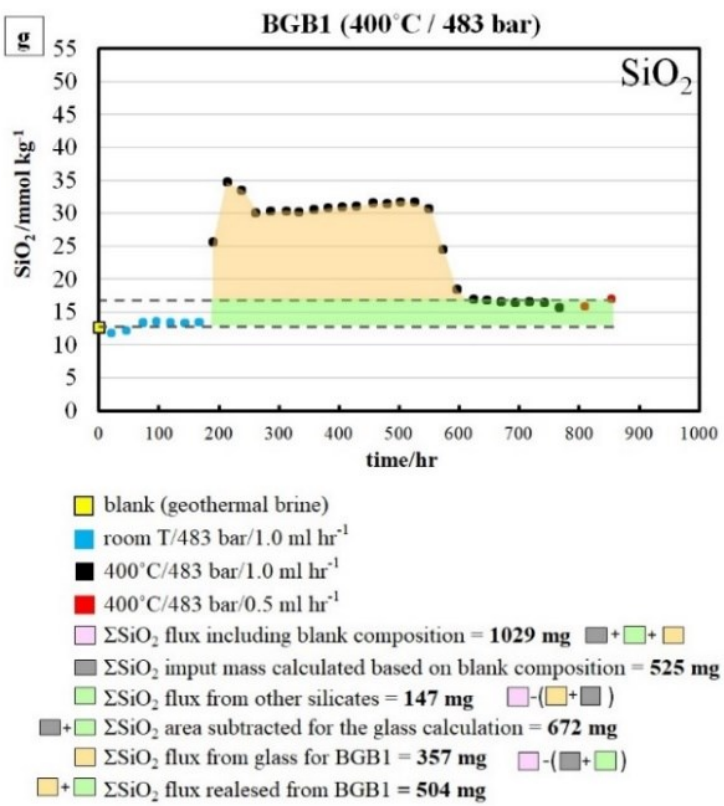


Table 4.9. Total input mass (mg) and integrated elemental fluxes (mg) for selected components in BGB2 and BGB1.

\begin{tabular}{|c|c|c|c|c|c|c|c|c|}
\hline $\begin{array}{c}\text { BGB2 } \\
\left(350^{\circ} \mathrm{C} / 486 \text { bar }\right)\end{array}$ & $\mathrm{SiO}_{2}$ & $\mathbf{K}$ & $\mathrm{SO}_{4}$ & $\mathbf{H}_{2} \mathrm{~S}$ & $\mathbf{C a}$ & $\mathbf{N a}$ & Mg & $\mathbf{F e}$ \\
\hline Blank composition $\left(\mathrm{mg} \mathrm{kg}^{-1}\right)$ & 884 & 116 & 406 & $<0.01$ & 7.2 & 725 & 0.9 & $<0.08$ \\
\hline $\begin{array}{l}\text { Total input mass (mg) (based on } 0.75 \mathrm{~L} \\
\text { total brine) }\end{array}$ & 662 & 86.9 & 305 & - & 5.4 & 543 & 0.7 & - \\
\hline $\begin{array}{l}\text { Total integrated elemental flux (mg) } \\
\text { (over the entire experiment) }\end{array}$ & +226 & +15.4 & -58 & +0.3 & -3.8 & -4.7 & -0.5 & +0.07 \\
\hline $\begin{array}{c}\text { BGB1 } \\
\left(400^{\circ} \mathrm{C} / 483 \text { bar }\right)\end{array}$ & $\mathrm{SiO}_{2}$ & $\mathbf{K}$ & $\mathrm{SO}_{4}$ & $\mathbf{H}_{2} \mathrm{~S}$ & $\mathbf{C a}$ & $\mathbf{N a}$ & Mg & $\mathbf{F e}$ \\
\hline Blank composition $\left(\mathrm{mg} \mathrm{kg}^{-1}\right)$ & 759 & 116 & 404 & 0.2 & 3.4 & 725 & 0.2 & 0.08 \\
\hline $\begin{array}{l}\text { Total input mass (mg) (based on } 0.69 \mathrm{~L} \\
\text { total brine) }\end{array}$ & 525 & 80 & 280 & 0.1 & 2.4 & 502 & 0.1 & 0.1 \\
\hline $\begin{array}{l}\text { Total integrated elemental flux (mg) } \\
\text { (over the entire experiment) }\end{array}$ & +504 & +3.7 & -45 & +0.7 & +0.2 & -18 & +0.1 & +0.009 \\
\hline
\end{tabular}

At $350^{\circ} \mathrm{C}$, the total integrated flux for $\mathrm{SO}_{4}$ is $-58 \mathrm{mg}$ (the negative sign indicates a loss from the fluid), $-3.8 \mathrm{mg}$ for $\mathrm{Ca},+15.4 \mathrm{mg}$ for $\mathrm{K},-4.7 \mathrm{mg}$ for $\mathrm{Na}$, and $-0.5 \mathrm{mg}$ for $\mathrm{Mg} . \mathrm{H}_{2} \mathrm{~S}$ and Fe show small positive values of +0.3 and $+0.07 \mathrm{mg}$, respectively. The results agree with the mineralogy identified by SEM-EDS. The significant loss of $\mathrm{SO}_{4}$ is explained by the precipitation of anhydrite. The small Ca flux relative to $\mathrm{SO}_{4}$ indicates that the source of most of the $\mathrm{Ca}$ in anhydrite is from the rock. At $350^{\circ} \mathrm{C}$, there is evidence for precipitation of $\mathrm{K}$ as smectite, however, the high concentration in the input brine masks any small changes in $\mathrm{K}$ due to glass dissolution and/or secondary mineral precipitation. The loss of $\mathrm{Na}$ is attributed to the formation of the secondary smectite, however, given the high concentration of $\mathrm{Na}$ in the brine this change may be within uncertainties. The total integrated flux for $\mathrm{Fe}(+0.07 \mathrm{mg})$ and $\mathrm{Mg}(-0.5 \mathrm{mg})$ are small. This shows that in terms of mass balance, $\mathrm{Fe}$ and $\mathrm{Mg}$ remain fixed in the rock in secondary minerals. $\mathrm{Fe}$ and $\mathrm{Mg}$ are both low in concentration in the input brine thus dissolution of primary minerals must be the source for secondary mica precipitation. The small positive total integrated flux for $\mathrm{H}_{2} \mathrm{~S}$ indicates that it is sourced from the rock.

At $400^{\circ} \mathrm{C}$, the total integrated flux for $\mathrm{SO}_{4}$ is $-45 \mathrm{mg}$ and for $\mathrm{Na}$ is $-18 \mathrm{mg}$. $\mathrm{Ca}, \mathrm{Mg}$, $\mathrm{H}_{2} \mathrm{~S}, \mathrm{Fe}$ and $\mathrm{K}$ all have small positive values of $+0.2,+0.1,+0.7,+0.009$ and $+3.7 \mathrm{mg}$, respectively, meaning that they were conservative. As in $\mathrm{BGB} 2$, the significant loss of $\mathrm{SO}_{4}$ is explained by the precipitation anhydrite with the primary source of $\mathrm{Ca}$ being clinopyroxene and/or plagioclase. At $400^{\circ} \mathrm{C}$, there is evidence for precipitation of $\mathrm{K}$ as both biotite and smectite, however, the high concentration in the input brine masks any small changes in $\mathrm{K}$ due to glass dissolution and/or secondary mineral precipitation, as at $350^{\circ} \mathrm{C}$. The loss of $\mathrm{Na}$ at $400^{\circ} \mathrm{C}$ is difficult to explain by mineral precipitation as the secondary minerals measured by 
SEM-EDS did not contain significant Na. It is likely that, as with $\mathrm{K}$, any small change may not be resolvable from due to the high input concentration.

\section{Trace elements}

Trace element concentrations give important information on the capacity of basalt to release or retain these elements during fluid - rock interaction, both at subcritical and supercritical experimental conditions (Fig. 4.3 - 4.4, Fig. 4.13 - 4.14). In the following discussion, only elements that show evident trends are considered. These include $\mathrm{Zn} \mathrm{Cu}$, Mo and $\mathrm{V}$. Elements which do not show clear trends were excluded in the discussion $(\mathrm{Ni}, \mathrm{Pb}, \mathrm{Mn}$, $\mathrm{Ba}, \mathrm{Co}, \mathrm{Cr}, \mathrm{Cd}, \mathrm{Rb}, \mathrm{Au}$ and $\mathrm{Ag})$. It should be noted that $\mathrm{V}, \mathrm{Cr}$ and $\mathrm{Rb}$ were analysed only in BGB1 $\left(400^{\circ} \mathrm{C}\right)$ and not in $\mathrm{BGB} 2\left(350^{\circ} \mathrm{C}\right)$. Also, for BGB2, trace elements analyses of the fluid samples collected after basalt glass dissolution are not available.

$\mathrm{V}, \mathrm{Cr}, \mathrm{Co}, \mathrm{Mn}, \mathrm{Pb}$ (only in BGB1), $\mathrm{Cd}$ (only in BGB2) and $\mathrm{Ni}, \mathrm{Cu}, \mathrm{Zn}, \mathrm{Mo}, \mathrm{Ba}$ in both experiments, are present in the geothermal brine at very low concentration, nevertheless they increase in solution at room temperature and pressure $\sim 500$ bar. This indicates that minor amounts of these elements were extracted from the rock at room temperature. Au and Ag are also present in the geothermal brine, but they show decreases over the experiment not related to temperature change. It is possible that the two trace elements actually precipitate in the fluid reservoir due to reaction in the experimental apparatus.

$\mathrm{Zn}, \mathrm{Cu}$. At $400^{\circ} \mathrm{C}$ there is a correlation between $\mathrm{Zn}$ and $\mathrm{SiO}_{2}$ (Fig. 4.26a) supporting the conclusion that $\mathrm{Zn}$ is being released during the dissolution of volcanic glass. A correlation between $\mathrm{Zn}$ and $\mathrm{H}_{2} \mathrm{~S}$ (Fig. 4.26c) is not present indicating that $\mathrm{Zn}$ sulfide precipitation is not occurring. At $350^{\circ} \mathrm{C}, \mathrm{Zn}$ values are very low when compared to $400^{\circ} \mathrm{C}$ (Fig. $4.26 \mathrm{~b}$ ). If $\mathrm{Zn}$ is being released by glass dissolution, then it must be re-precipitating at $350^{\circ} \mathrm{C}$. This is supported by concurrent low sulfide concentrations (Fig. 4.26d).

$\mathrm{Cu}$. The input concentration of $\mathrm{Cu}$ in the geothermal brine is very low $\left(0.3 \mu \mathrm{mol} \mathrm{kg}^{-1}\right.$ in BGB1 and $0.8 \mu \mathrm{mol} \mathrm{kg}{ }^{-1}$ in BGB2). $\mathrm{Cu}$ is present in the volcanic glass in the Fe sulfide blebs as previously demonstrated in Chapter 3 (\$3.3.1). In the effluent samples, both at 350 and $400^{\circ} \mathrm{C}$, there is no clear correlation of $\mathrm{Cu}$ with either $\mathrm{SiO}_{2}$ or $\mathrm{H}_{2} \mathrm{~S}$ (Fig. 4.26e-h). However, a $\mathrm{Cu}$ sulfide phase was identified in the run products in both experiments (Fig. 4.7 and 4.17). It may be that the concentrations of $\mathrm{Cu}$ are so low that statistically meaningful correlations with $\mathrm{H}_{2} \mathrm{~S}$ and $\mathrm{SiO}_{2}$ are not possible.

Mo. At $400^{\circ} \mathrm{C}$, there is no correlation between $\mathrm{Mo}$ and $\mathrm{SiO}_{2}$ (Fig. 4.27a), while at $350^{\circ} \mathrm{C}$ there is a suggestion of a positive correlation (Fig. 4.27b). This is comparable to the 
distilled water experiments. The effluent composition trends with time for Mo (Fig. 4.13) show a progressive increase over eight days while at the same time $\mathrm{SiO}_{2}$ decreases, after which it parallels $\mathrm{SiO}_{2}$, decreasing over the remainder of the experiment. This suggests that Mo is derived from the volcanic glass but then precipitates as secondary mineral precipitation proceeds. Molybdenum has a siderophile rather than a chalcophile element behaviour (Lodders and Palme, 1991) and it is predominantly present in basaltic volcanic rocks in ilmenite, magnetite, but can also be present in the interstitial glass (Arnórsson and Óskarsson, 2007; Greaney et al., 2018; Greaney et al., 2017).

$V$. Geothermal brine contains a very low concentration of vanadium. At $400^{\circ} \mathrm{C}$, there is a negative correlation between $\mathrm{V}$ and $\mathrm{SiO}_{2}$ (Fig. 4.27e), while for the experiment at $350^{\circ} \mathrm{C}$ the analyses were not available. Higher $\mathrm{V}$ values are encountered after the glass has been removed. Vanadium, as discussed in the previous Chapter $3(\S 3.3 .1)$ occurs as a component of titanomagnetite (Hukkanen and Walden, 1985). It is possible that elevated $\mathrm{Fe}$ concentrations during glass dissolution could suppress titanomagnetite dissolution thus leading to lower $\mathrm{V}$ concentrations. 
Figure 4.26. $\mathrm{Zn}$ and $\mathrm{Cu}\left(\mu \mathrm{mol} \mathrm{kg}{ }^{-1}\right)$ versus $\mathrm{SiO}_{2}$ and $\mathrm{H}_{2} \mathrm{~S}\left(\mu \mathrm{mol} \mathrm{kg}{ }^{-1}\right)$ for BGB1 and BGB2. Symbols in red represent values during glass dissolution, while symbols in blue represent values after glass dissolution. In BGB2, there are no analyses available for trace elements of the reacted fluid compositions collected after glass dissolution.
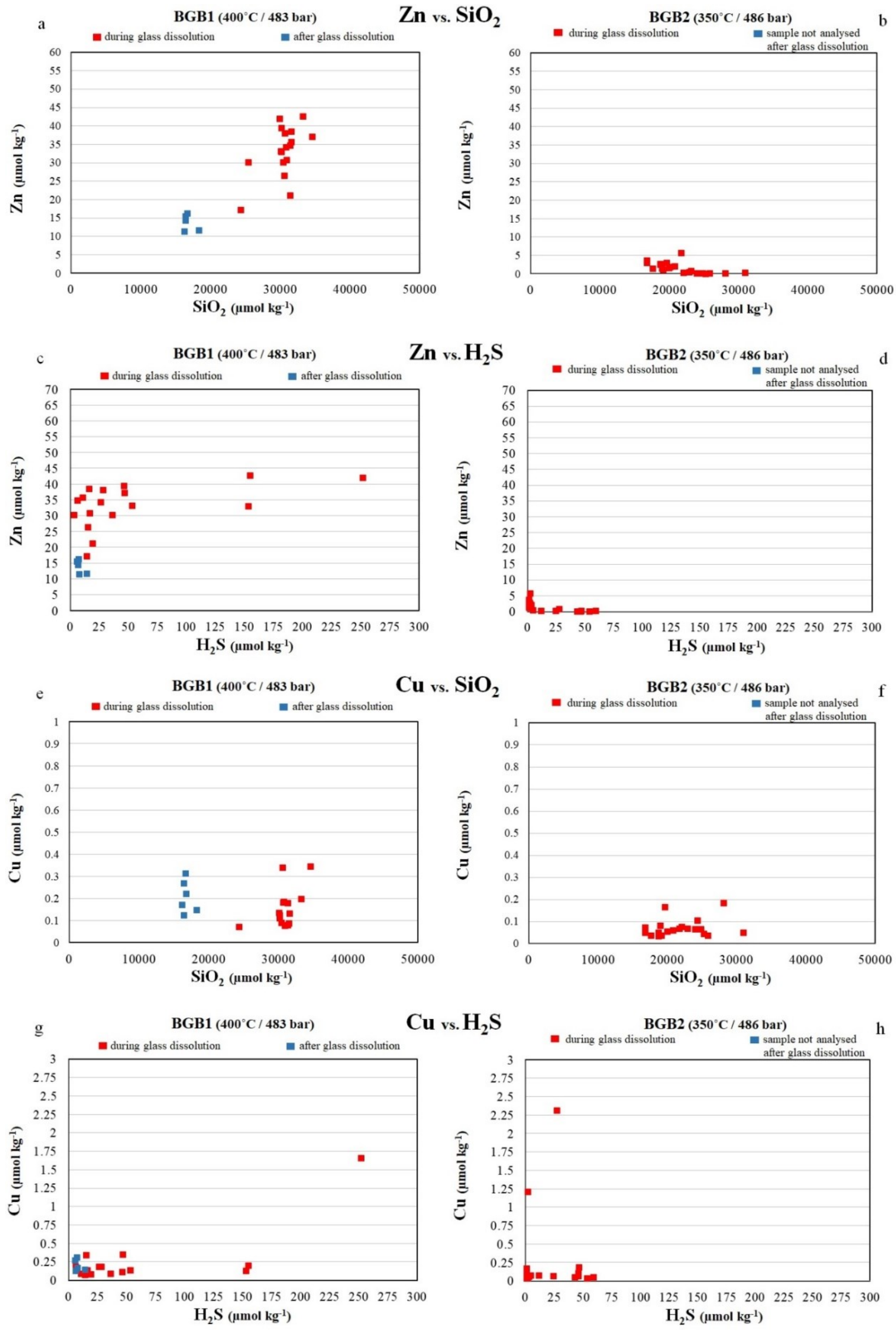
Figure 4.27. Mo and $\mathrm{V}\left(\mu \mathrm{mol} \mathrm{kg}{ }^{-1}\right)$ versus $\mathrm{SiO}_{2}$ and $\mathrm{Mo}\left(\mu \mathrm{mol} \mathrm{kg}{ }^{-1}\right)$ versus $\mathrm{H}_{2} \mathrm{~S}\left(\mu \mathrm{mol} \mathrm{kg}{ }^{-1}\right)$ for BGB1 and BGB2. Symbols in red represent values during glass dissolution, while symbols in blue represent values after glass dissolution. In BGB2, there are no analyses available for trace elements of the reacted fluid compositions collected after basalt glass dissolution.

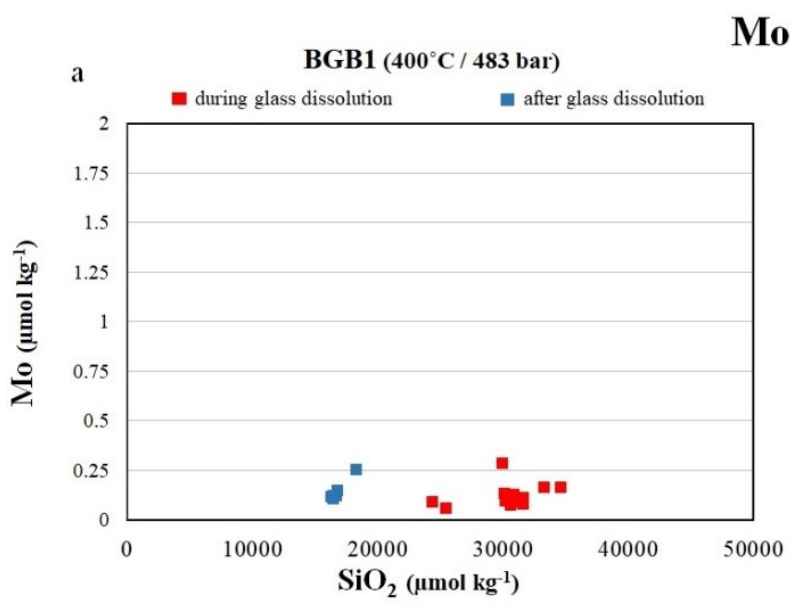

\section{$\mathrm{Mo}$ vs. $\mathrm{SiO}_{2}$}
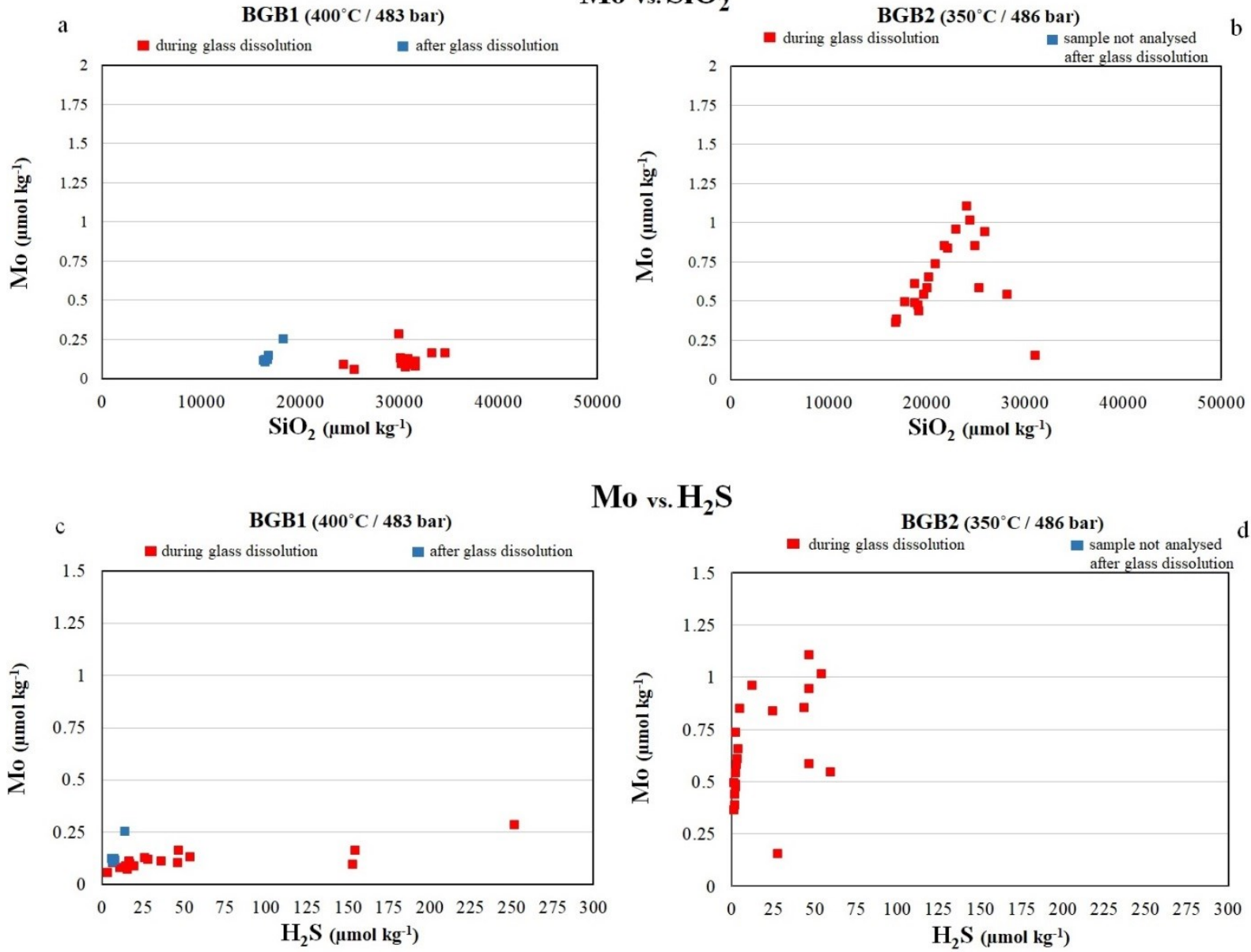

Mo vs. $\mathrm{H}_{2} \mathrm{~S}$
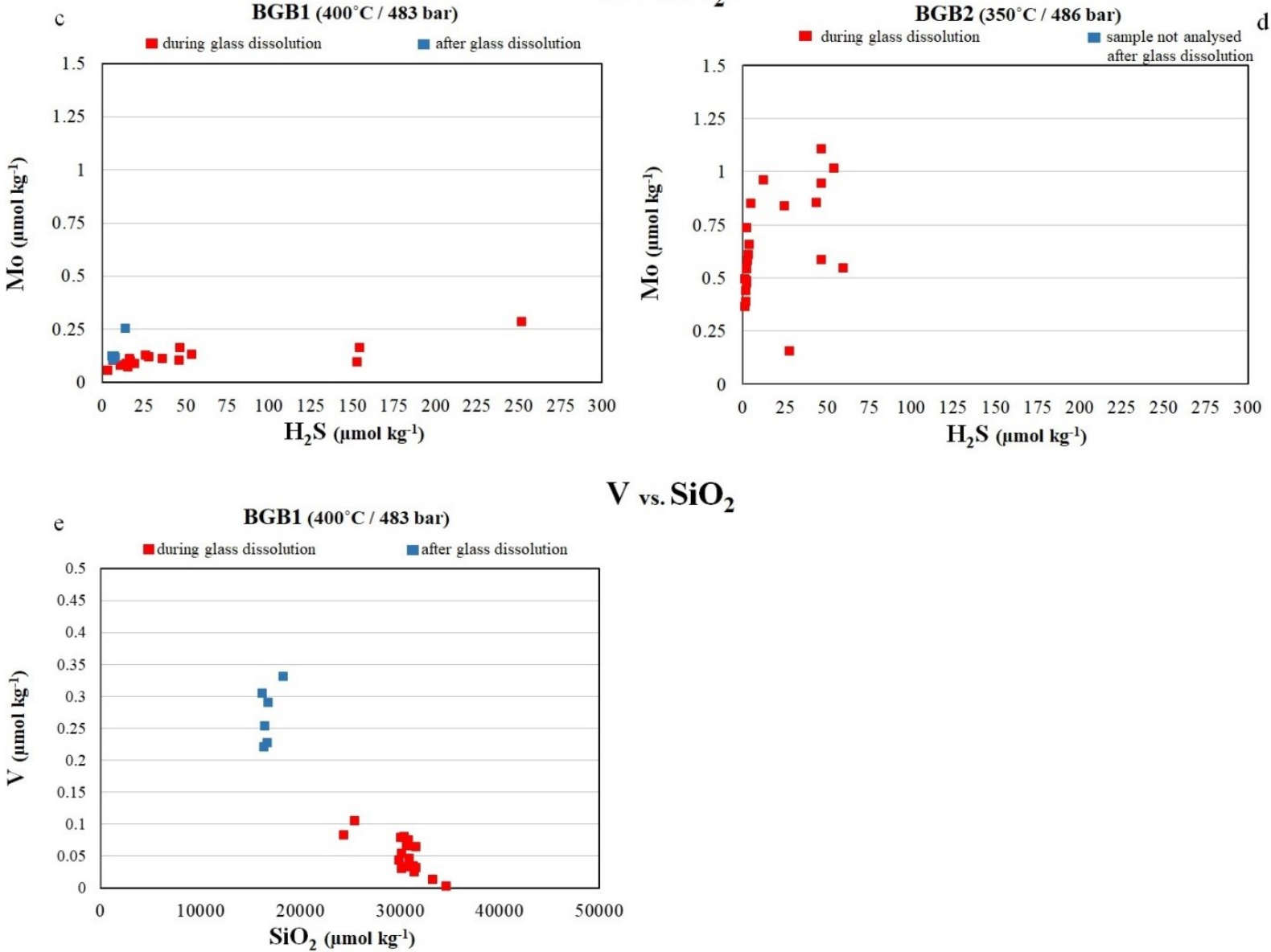

$\mathrm{V}_{\text {vs. }} \mathrm{SiO}_{2}$ 


\subsubsection{The path of fluid-rock interaction}

The path of fluid-rock interaction was examined using activity diagrams based on aqueous species' activities and in situ pH calculated using the EqSolvR software package (Chapter 2).

Activity ratio diagrams were constructed for the experimental temperatures and 500 bar, assuming unit activity of mineral phases. There was no period during the experiments when quartz remained saturated thus $\mathrm{SiO}_{2}$ activity for the diagrams must be adjusted based on solution chemistry (Chapter $3, \S 3.3 .3$ ). At $400^{\circ} \mathrm{C}$, these limits were based on the average silica concentration when glass dissolution was occurring $\left[\log \left(a_{\mathrm{SiO}_{2}}\right)=-1.52\right]$ and after glass dissolution $\left[\log \left(a_{\mathrm{SiO}_{2}}\right)=-1.8\right]$. At $350^{\circ} \mathrm{C}$, there is no clear plateau for $\mathrm{SiO}_{2}$ concentration during glass dissolution (Fig. 4.11) but instead a continuous decrease from a maximum after temperature change $\left[\log \left(a_{\mathrm{SiO}_{2}}\right)=-1.51\right]$ to a minimum near the end of the experiment $\left[\log \left(a_{\mathrm{SiO}_{2}}\right)=-1.87\right]$. These limits are used for the diagrams at $350^{\circ} \mathrm{C}$. All the phase diagrams for the BGB1 and the BGB2 are reported in Appendix C.

In the $\mathrm{K}_{2} \mathrm{O}-\mathrm{Al}_{2} \mathrm{O}_{3}-\mathrm{SiO}_{2}-\mathrm{H}_{2} \mathrm{O}$ activity space (Fig. 4.28a,b), the fluid path is similar, but not identical, at both temperatures. The unreacted geothermal brine composition (yellow circles) lies on the muscovite-K-feldspar join, both at 350 and $400^{\circ} \mathrm{C}$. At $400^{\circ} \mathrm{C}$ (Fig. 4.28a), after the shift in temperature, quartz immediately becomes supersaturated and compositions move into the K-feldspar stability field and reach maximum $\mathrm{SiO}_{2}$ activity. Potassium feldspar was not observed during SEM examination of the top and bottom portions of the reacted rock. Potassium concentration reaches the highest values in the first samples after temperature shift and $\log \left(a_{K^{+}} / a_{H^{+}}\right)$remains higher than input value during removal of the glass. As the glass dissolves, $\log \left(a_{K^{+}} / a_{H^{+}}\right)$decreases. At $400^{\circ} \mathrm{C}$, the ratio decreases at constant silica activity keeping the fluid in the $\mathrm{K}$-feldspar field, while at $350^{\circ} \mathrm{C}$, it decreases along with silica activity moving the fluid towards the muscovite field.

The decrease in $\mathrm{K}$ concentration in both experiments is due to the precipitation of secondary K-bearing phases. Biotite (found at the bottom of the Reactor) and smectite (found at the top) are observed at $400^{\circ} \mathrm{C}$. The mineral precipitation appears to be occurring while $\log$ $\left(a_{\mathrm{SiO}_{2}}\right)$ is relatively constant. At $350^{\circ} \mathrm{C}, \log \left(a_{K^{+}} / a_{H^{+}}\right)$decreases simultaneously with the decrease in $\log \left(a_{\mathrm{SiO}_{2}}\right)$ indicating that K-bearing silicate mineral precipitation was occurring immediately after temperature change. Smectite was found both at the bottom and top of the Reactor while biotite was observed only at the bottom at $400^{\circ} \mathrm{C}$. Evidently, the $50^{\circ} \mathrm{C}$ difference did not allow biotite to stabilise at the lower temperature. 
The identification of the biotite at $400^{\circ} \mathrm{C}$ demonstrates that fluid compositions must have been saturated with respect to this mineral. This is consistent with the $\mathrm{K}_{2} \mathrm{O}-\mathrm{MgO}-\mathrm{Al}_{2} \mathrm{O}_{3}-$ $\mathrm{SiO}_{2}-\mathrm{H}_{2} \mathrm{O}$ activity diagram (Fig. 4.29a) where the fluid compositions lie within the phlogopite field. Biotite is a trioctahedral mica with the end members phlogopite and annite. At $400^{\circ} \mathrm{C}$, the presence of biotite indicates that while glass was dissolving, $\mathrm{K}$ activity was sufficient to allow $\mathrm{Mg}$ and $\mathrm{Fe}$ released from clinopyroxene and olivine to form this mineral. Once the glass had been removed, $\mathrm{K}$ activities decreased, and any $\mathrm{Mg}$ and Fe released formed smectite.

At $350^{\circ} \mathrm{C}$, in the $\mathrm{K}_{2} \mathrm{O}-\mathrm{MgO}-\mathrm{Al}_{2} \mathrm{O}_{3}-\mathrm{SiO}_{2}-\mathrm{H}_{2} \mathrm{O}$ activity diagram (Fig. 4.29b), fluid compositions also lie in the phlogopite field, however, biotite was not observed. It would appear that immediate onset of mineral precipitation (smectite) at this temperature reduced $\mathrm{K}$ activities such that biotite did not stabilise.

In Figure $4.28 \mathrm{a}-4.29 \mathrm{a}$, the red crosses show positions of effluents collected at $0.5 \mathrm{ml}$ $\mathrm{hr}^{-1}$ flow rate for the BGB1 experiment. There is no noticeable difference from earlier samples collected at $1.0 \mathrm{ml} \mathrm{hr}^{-1}$. This confirms that changes in flow rate did not affect cation activity ratios and presumably mineral precipitation. 
Figure 4.28. Activity diagrams for the $\mathrm{K}_{2} \mathrm{O}-\mathrm{Al}_{2} \mathrm{O}_{3}-\mathrm{SiO}_{2}-\mathrm{H}_{2} \mathrm{O}$ system showing mineral stability fields for BGB1(a) and BGB2(b). Black and red crosses show position of effluent samples collected at 1.0 and $0.5 \mathrm{ml} \mathrm{hr}^{-1}$ flow rate, respectively. Yellow circles show position of the unreacted brine at 400 and $350^{\circ} \mathrm{C} / 500$ bar. Black dotted line shows quartz saturation while pink dotted lines represent the average of silica concentration (in log units) during and after dissolution of the basalt glass, calculated for the respective experiments. Blue arrows show the path of reacted fluids over the time of the experiments.

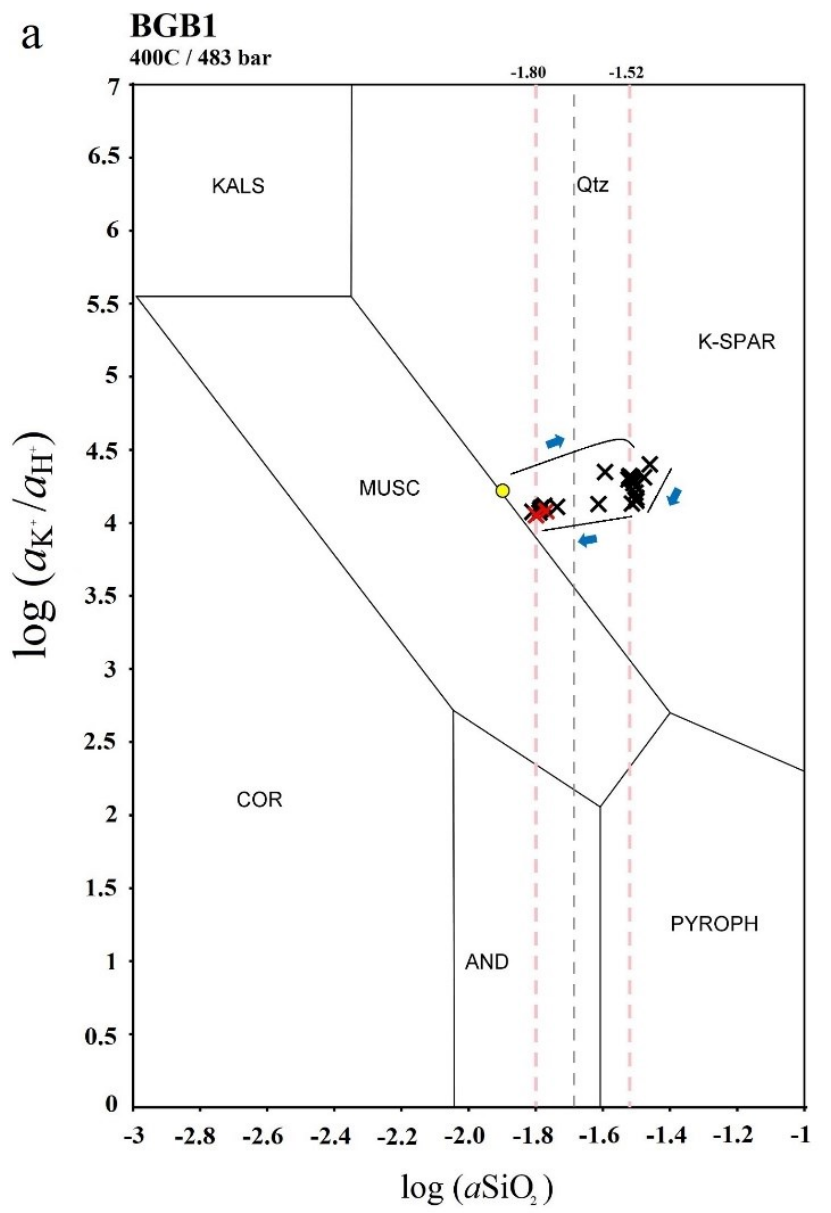

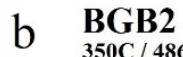

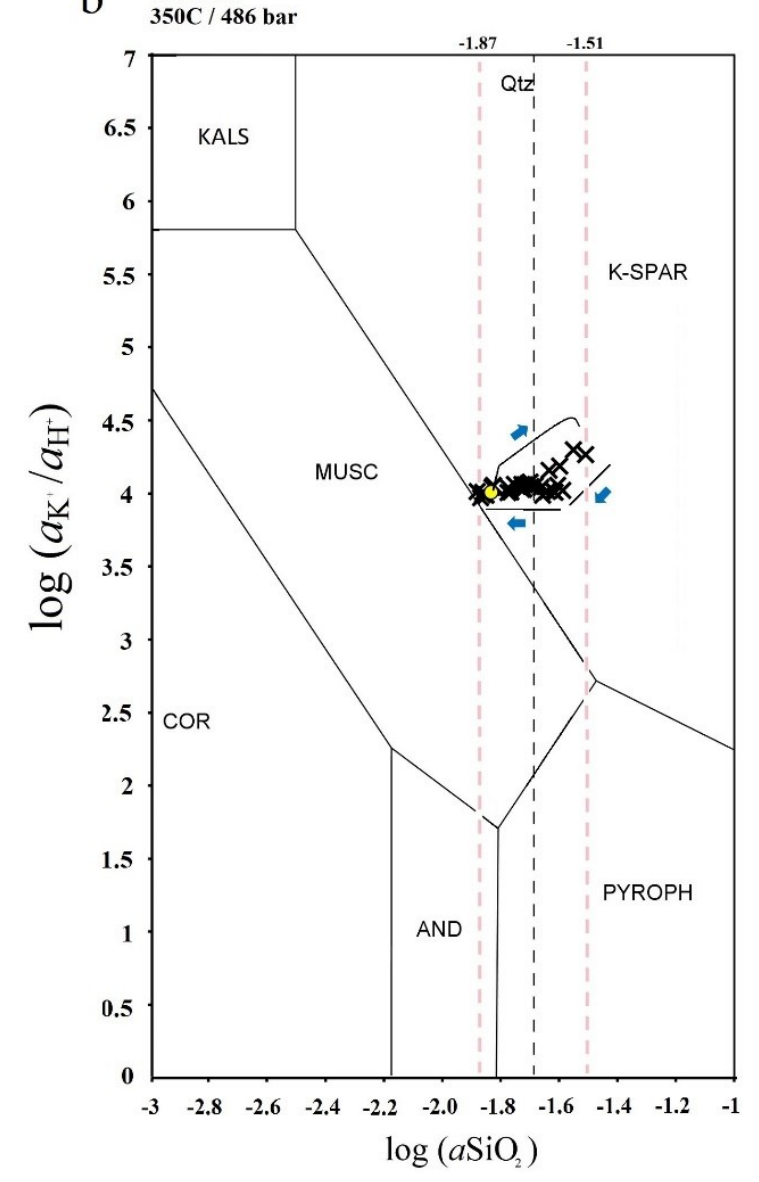


Figure 4.29. Activity diagrams for the $\mathrm{K}_{2} \mathrm{O}-\mathrm{MgO}-\mathrm{Al}_{2} \mathrm{O}_{3}-\mathrm{SiO}_{2}-\mathrm{H}_{2} \mathrm{O}$ system showing mineral stability fields for $\mathrm{BGB} 1(\mathrm{a})$ and $\mathrm{BGB} 2(\mathrm{~b})$. Black and red crosses show position of effluent sample collected at 1.0 and $0.5 \mathrm{ml} \mathrm{hr}^{-1}$ flow rate, respectively. Yellow circles show position of the unreacted fluid at 400 and $350^{\circ} \mathrm{C} / 500$ bar. Blue arrows show the path of reacted fluids over the time of the experiments.

a

\section{BGB1}

$400 \mathrm{C} / 483$ bar

average $\log a_{\mathrm{SiO}_{2}}=\mathbf{- 1 . 5 2}$

time of the experiment

(during basalt glass dissolution)

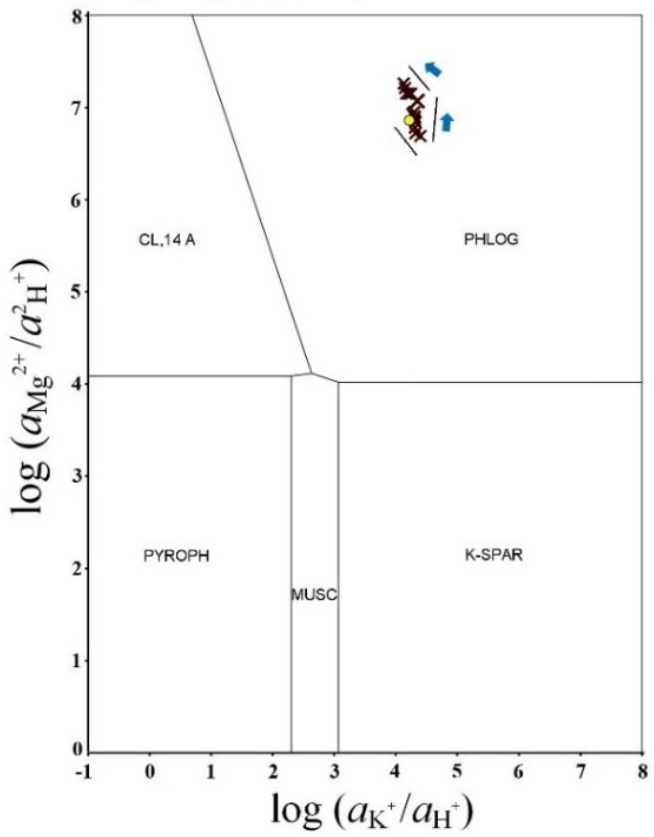

$\Longrightarrow$ average $\log a_{\mathrm{SiO}_{2}}=\mathbf{- 1 . 8 0}$

(after basalt glass dissolution)

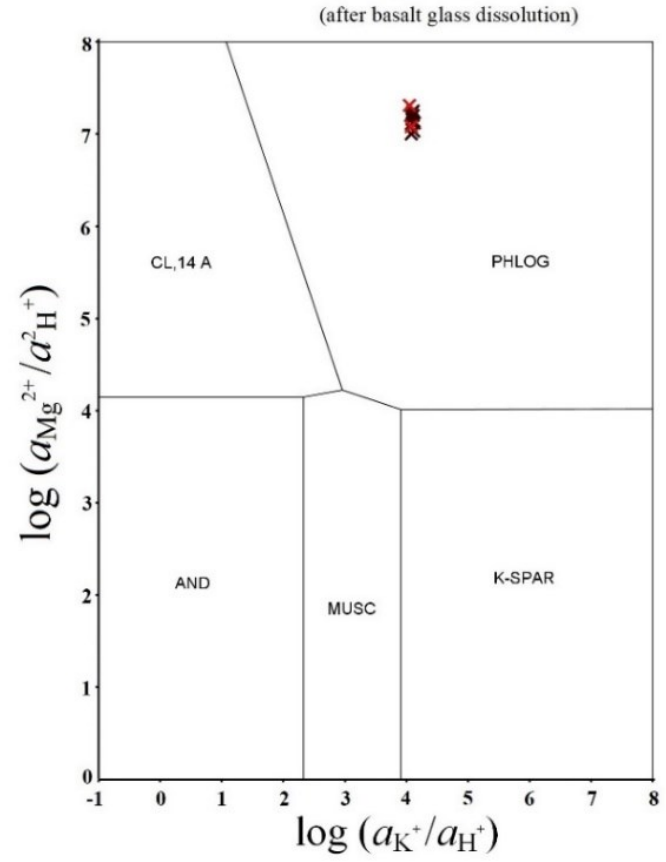

b BGB2

$350 \mathrm{C} / 486$ bar

average $\log a_{\mathrm{SiO}_{2}}=\mathbf{- 1 . 5 1}$ time of the experiment $\longrightarrow$ average $\log a_{\mathrm{SiO}_{2}}=\mathbf{- 1 . 8 7}$
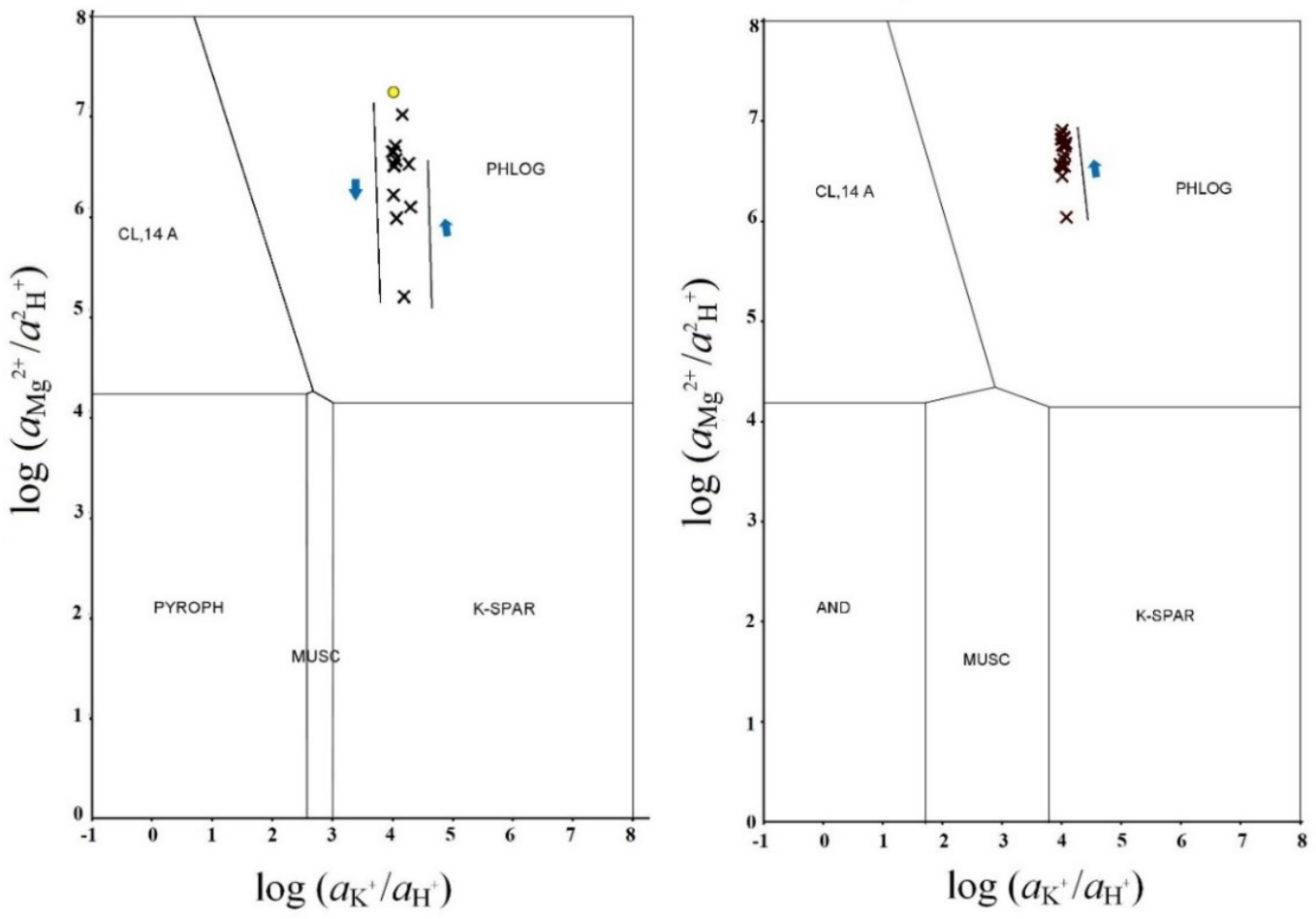
The fluid-mineral reactions that occurred during the experiments can provide information on the chemical path that the fluid took while passing through the rock and the resulting effects on the mineral assemblage.

In both experiments, anhydrite was observed. The anhydrite could not have precipitated solely from the geothermal brine as this would have occurred while the brine was heating up in the tubing before the Reactor. The brine is the source of sulfate and dissolution of rock minerals the source of calcium. SEM analysis shows that both clinopyroxene and plagioclase dissolved. The precipitation of anhydrite at the expense of these minerals is represented by Reactions 1 and 2:

$$
\begin{gathered}
1.43 \mathrm{Ca}_{0.7} \mathrm{Na}_{0.3} \mathrm{Al}_{1.7} \mathrm{Si}_{2.3} \mathrm{O}_{8}+\mathrm{HSO}_{4}^{-}+8.72 \mathrm{H}^{+} \\
\leftrightarrow \mathrm{CaSO}_{4}+2.43 \mathrm{Al}^{3+}+0.43 \mathrm{Na}^{+}+3.29 \mathrm{SiO}_{2}+4.86 \mathrm{H}_{2} \mathrm{O} \\
1.43 \mathrm{Ca}_{0.7} \mathrm{Mg}_{0.9} \mathrm{Fe}_{0.3} \mathrm{Al}_{0.2} \mathrm{Si}_{1.9} \mathrm{O}_{6}+\mathrm{HSO}_{4}^{-}+5.28 \mathrm{H}^{+} \\
\leftrightarrow \mathrm{CaSO}_{4}+0.29 \mathrm{Al}^{3+}+1.29 \mathrm{Mg}^{2+}+0.43 \mathrm{Fe}^{2+}+2.72 \mathrm{SiO}_{2}+3.14 \mathrm{H}_{2} \mathrm{O}
\end{gathered}
$$

During both reactions, anhydrite precipitates, hydrogen ion is consumed, and $\mathrm{Al}$ is produced. In Reaction 2, the dissolution of clinopyroxene also supplies a source of $\mathrm{Mg}$ and Fe. At both temperatures, the release of $\mathrm{Al}$ initiates aluminosilicate precipitation at the high concentration of silica present.

At $400^{\circ} \mathrm{C}$, in addition to anhydrite, biotite was also observed at bottom of the Reactor. Biotite formed when brine containing $\mathrm{K}$ entered the rock immediately adjacent to the fluid entry point. Although some $\mathrm{K}$ was supplied by glass dissolution, the bulk of the $\mathrm{K}$ is supplied by the brine. The local presence of $\mathrm{Al}$ and $\mathrm{K}$ initiated biotite precipitation at the expense of clinopyroxene and olivine. $\mathrm{Mg}$ and $\mathrm{Fe}$ were provided by the rock as concentrations of these components are very low in the brine. The formation of biotite at the expense of clinopyroxene and olivine at bottom of the Reactor is represented in Reactions 3 and 4:

$$
\begin{aligned}
& \mathrm{Ca}_{0.7} \mathrm{Mg}_{0.9} \mathrm{Fe}_{0.3} \mathrm{Al}_{0.2} \mathrm{Si}_{1.9} \mathrm{O}_{6}+0.5 \mathrm{~K}^{+}+0.1 \mathrm{Na}^{+}+0.5 \mathrm{Mg}^{2+}+1.1 \mathrm{Fe}^{2+}+1.1 \mathrm{Al}^{3+}+\mathrm{SiO}_{2}+4 \mathrm{H}_{2} \mathrm{O} \\
& \leftrightarrow K_{0.5} \mathrm{Ca}_{0.1} \mathrm{Na}_{0.1} \mathrm{Mg}_{1.4} \mathrm{Fe}_{1.4} \mathrm{Al}_{1.3} \mathrm{Si}_{2.9} \mathrm{O}_{10}(\mathrm{OH})_{2}+0.6 \mathrm{Ca}^{2+}+6 \mathrm{H}^{+} \\
& \mathrm{Mg}_{1.4} \mathrm{Fe}_{0.6} \mathrm{SiO}_{4}+0.42 \mathrm{~K}^{+}+0.084 \mathrm{Na}^{+}+1.1 \mathrm{Al}^{3+}+0.084 \mathrm{Ca}^{2+}+1.44 \mathrm{SiO}_{2}+3.21 \mathrm{H}_{2} \mathrm{O} \\
& \leftrightarrow 0.84 K_{0.5} \mathrm{Ca}_{0.1} \mathrm{Na}_{0.1} \mathrm{Mg}_{1.4} \mathrm{Fe}_{1.4} \mathrm{Al}_{1.3} \mathrm{Si}_{2.9} \mathrm{O}_{10}(\mathrm{OH})_{2}+0.22 \mathrm{Mg}^{2+}+4.74 \mathrm{H}^{+}
\end{aligned}
$$


In these reactions, biotite precipitates and the dissolution of clinopyroxene and olivine releases $\mathrm{H}^{+}$. The presence of $\mathrm{Na}$ in the mineral structure explains why sodium concentrations started to decrease after the T shift (Fig. 4.1, §4.2.1.1).

Smectite was observed at top of the Reactor in dense foliated masses that replaced olivine. Smectite does not appear at bottom of the Reactor with anhydrite and biotite. This implies that when fresh brine entered in contact with basalt, the formation of anhydrite and biotite occurred rapidly at the immediate bottom of the Reactor. $\mathrm{K}$ and $\mathrm{SiO}_{2}$ concentrations reach their highest values after temperature shift (Fig. 4.1). It is suggested that these high concentrations caused biotite to be supersaturated. This initiated biotite precipitation and a decrease to lower $\mathrm{K}$ and $\mathrm{SiO}_{2}$ values after 2 - 3 days. As more brine entered, biotite precipitation continued at the bottom of the column, keeping $\mathrm{K}$ and $\mathrm{SiO}_{2}$ fixed, i.e., glass dissolution competes with biotite precipitation to maintain $\mathrm{K}, \mathrm{Al}$ and $\mathrm{SiO}_{2}$ at steady state (or equilibrium). At some point upwards in the Reactor, $\mathrm{K} / \mathrm{Al} / \mathrm{SiO}_{2}$ ratios must have changed sufficiently to stabilise smectite over biotite. As the fluid continued to move upwards, $\mathrm{Mg}$ and $\mathrm{Fe}$ was sourced mainly from olivine, $\mathrm{Al}$ from plagioclase, and $\mathrm{K}$ from the fluid to form smectite according to Reaction 5:

$$
\begin{aligned}
\mathrm{Mg}_{1.4} \mathrm{Fe}_{0.6} \mathrm{SiO}_{4}+ & 0.046 \mathrm{~K}^{+}+0.41 \mathrm{Al}^{3+}+0.52 \mathrm{SiO}_{2}+0.48 \mathrm{H}_{2} \mathrm{O} \\
& \leftrightarrow 0.46 \mathrm{~K}_{0.1} \mathrm{Mg}_{1.5} \mathrm{Fe}_{1.3} \mathrm{Al}_{0.9} \mathrm{Si}_{3.3} \mathrm{O}_{10}(\mathrm{OH})_{2}+0.71 \mathrm{Mg}^{2+}+0.04 \mathrm{H}^{+}
\end{aligned}
$$

Although it is not possible to determine the relative extent of the above reactions, it is evident that the consumption of $\mathrm{H}^{+}$during anhydrite precipitation (Reaction 1 and 2) and the conversion of clinopyroxene and olivine to biotite (Reaction 3 - 4) must have been more than offset by the formation of smectite from olivine (Reaction 5) as the quench $\mathrm{pH}$ of the fluid becomes acid after temperature shift. This is a net shift of $\mathrm{pH}$ down about $\sim 0.5 \log$ units over the input brine $\mathrm{pH}(\sim 4$, Fig. 4.1). After the loss of volcanic glass, quench $\mathrm{pH}$ then increases above input brine $\mathrm{pH}$ indicating that Reactions $1-2$ must have become more important than Reaction 5.

At $350^{\circ} \mathrm{C}$, the formation of anhydrite is also represented by Reactions 1 and 2 . Only smectite was found at bottom and top of the Reactor in this experiment. No biotite was identified. SEM analysis shows that at the bottom, smectite was observed to replace not only olivine but also other silicate minerals. Major element trends (Fig. 4.11 - 4.12) also show that mineral precipitation decreased $\mathrm{K}$ and $\mathrm{SiO}_{2}$ concentrations substantially after temperature shift unlike at $400^{\circ} \mathrm{C}$. The quench $\mathrm{pH}$ also shifted to more alkaline values above the input 
brine $\mathrm{pH}$ much sooner than at $400^{\circ} \mathrm{C}$. The conversion of olivine to smectite is represented by Reaction 5 while the conversion of plagioclase and clinopyroxene to smectite is represented by Reaction 6 and 7:

$$
\begin{gathered}
0.1 \mathrm{Ca}_{0.7} \mathrm{Na}_{0.3} \mathrm{Al}_{1.7} \mathrm{Si}_{2.3} \mathrm{O}_{8}+0.03 \mathrm{Ca}^{2+}+0.1 \mathrm{~K}^{+}+0.27 \mathrm{Na}^{+}+1.5 \mathrm{Mg}^{2+}+1.1 \mathrm{Fe}^{2+}+0.73 \mathrm{Al}^{3+} \\
+3.17 \mathrm{SiO}_{2}+4.86 \mathrm{H}_{2} \mathrm{O} \\
\leftrightarrow \mathrm{K}_{0.1} \mathrm{Na}_{0.3} \mathrm{Ca}_{0.1} \mathrm{Mg}_{1.5} \mathrm{Fe}_{1.1} \mathrm{Al}_{0.9} \mathrm{Si}_{3.4} \mathrm{O}_{10}(\mathrm{OH})_{2}+7.72 \mathrm{H}^{+} \\
0.1 \mathrm{Ca}_{0.7} \mathrm{Mg}_{0.9} \mathrm{Fe}_{0.3} \mathrm{Al}_{0.2} \mathrm{Si}_{1.9} \mathrm{O}_{6}+0.03 \mathrm{Ca}^{2+}+0.1 \mathrm{~K}^{+}+0.3 \mathrm{Na}^{+}+0.49 \mathrm{Mg}^{2+}+1.07 \mathrm{Fe}^{2+} \\
+0.88 \mathrm{Al}^{3+}+3.21 \mathrm{SiO}_{2}+4.98 \mathrm{H}_{2} \mathrm{O} \\
\leftrightarrow \mathrm{K}_{0.1} \mathrm{Na}_{0.3} \mathrm{Ca}_{0.1} \mathrm{Mg}_{1.5} \mathrm{Fe}_{1.1} \mathrm{Al}_{0.9} \mathrm{Si}_{3.4} \mathrm{O}_{10}(\mathrm{OH})_{2}+7.96 \mathrm{H}^{+}
\end{gathered}
$$

The more rapid shift of $\mathrm{pH}$ upwards suggests that Reactions $1-2$ must have become more substantial than Reaction 6-7. 


\subsection{3. $\mathrm{Na} / \mathrm{K}$ geothermometers}

Figure 4.30a,b shows the activity ratio diagrams for the $\mathrm{Na}_{2} \mathrm{O}-\mathrm{K}_{2} \mathrm{O}-\mathrm{Al}_{2} \mathrm{O}_{3}-\mathrm{SiO}_{2}-\mathrm{H}_{2} \mathrm{O}$ systems at 350 and $400^{\circ} \mathrm{C} / 500$ bar. The diagrams show that at 350 and $400^{\circ} \mathrm{C}$, despite changes in silica activity, fluid compositions lie on or close to the albite - K-feldspar join, including the input brine composition. Only at $400^{\circ} \mathrm{C}$, and after glass dissolution, is the fluid composition consistently above this phase boundary, albeit to a very small degree (Fig. 4.33).

The estimated temperatures for the BGB1 and BGB2 fluid compositions were calculated utilising several geothermometers for $\mathrm{Na} / \mathrm{K}$ and $\mathrm{Na}-\mathrm{K}-\mathrm{Ca}$ reported in literature (Arnórsson, 1983; Fournier and Truesdell, 1973; Fournier, 1979; Giggenbach, 1988b; Nieva and Nieva, 1987; Santoyo and Díaz-González, 2009; Tonani, 1980; Truesdell, 1976). Table 4.10 reports the averages of these geothermometers calculated at silica concentrations during and after glass dissolution. The results show that all calculated values are well below the experimental temperatures.

Figure 4.31 shows the estimated temperatures using the geothermometers plotted versus time. Also shown are the $\mathrm{SiO}_{2}, \mathrm{Na}$ and $\mathrm{K}$ concentrations. The plots for silica concentration emphasise the difference in the two experiments. At $400^{\circ} \mathrm{C}$ there is a clear change when glass dissolution ceases while at $350^{\circ} \mathrm{C}$ this distinction is masked by mineral precipitation. At $400^{\circ} \mathrm{C}$ there appears to be an attempt by the rock to adjust the fluid composition towards equilibrium as the calculated temperatures move upwards. At $350^{\circ} \mathrm{C}$ no such attempt is evident.

Sodium concentrations are comparable in both experiments, while $\mathrm{K}$ is higher during glass dissolution at $400^{\circ} \mathrm{C}$ than at $350^{\circ} \mathrm{C}$. The results show underestimation of all temperatures calculated from the reacted fluids. The predominant values coincide with the estimated temperature calculated from composition of the unreacted geothermal brine (blank in Fig. 4.31). This implies that the $\mathrm{Na} / \mathrm{K}$ ratio did not change sufficiently during fluid-rock interaction.

It is evident that because of the absence of the K-bearing minerals in the basalt, and the high amount of $\mathrm{Na}$ and $\mathrm{K}$ continuously supplied by the unreacted brine, the $\mathrm{Na} / \mathrm{K}$ ratio is controlled by the fluid and not by the rock. This is likely due to the short residence time of the fluid. The estimated residence time is only $\sim 10 \mathrm{hrs}$ at $1 \mathrm{ml} \mathrm{hr} \mathrm{hr}^{-1}$ and $\sim 20 \mathrm{hrs}$ at $0.5 \mathrm{ml} \mathrm{hr}^{-1}$. This is clearly too short to allow the $\mathrm{Na} / \mathrm{K}$ ratio to shift sufficiently to the equilibrium value, both at 350 and $400^{\circ} \mathrm{C}$. 
Figure 4.30. Activity diagrams for the $\mathrm{Na}_{2} \mathrm{O}-\mathrm{K}_{2} \mathrm{O}-\mathrm{Al}_{2} \mathrm{O}_{3}-\mathrm{SiO}_{2}-\mathrm{H}_{2} \mathrm{O}$ system showing mineral stability fields for $\mathrm{BGB} 1$ (a) and $\mathrm{BGB} 2$ (b) during and after glass dissolution. Black and red crosses show position of effluent samples collected at 1.0 and $0.5 \mathrm{ml} \mathrm{hr}^{-1} \mathrm{flow}$ rate, respectively. Yellow circles show position of the unreacted fluid (geothermal brine) at 400 and $350^{\circ} \mathrm{C} / 500 \mathrm{bar}$.

\section{a BGB}

$400 \mathrm{C} / 483$ bar

average $\log a_{\mathrm{SiO}_{2}}=\mathbf{- 1 . 5 2}$

time of the experiment

(during basalt glass dissolution)
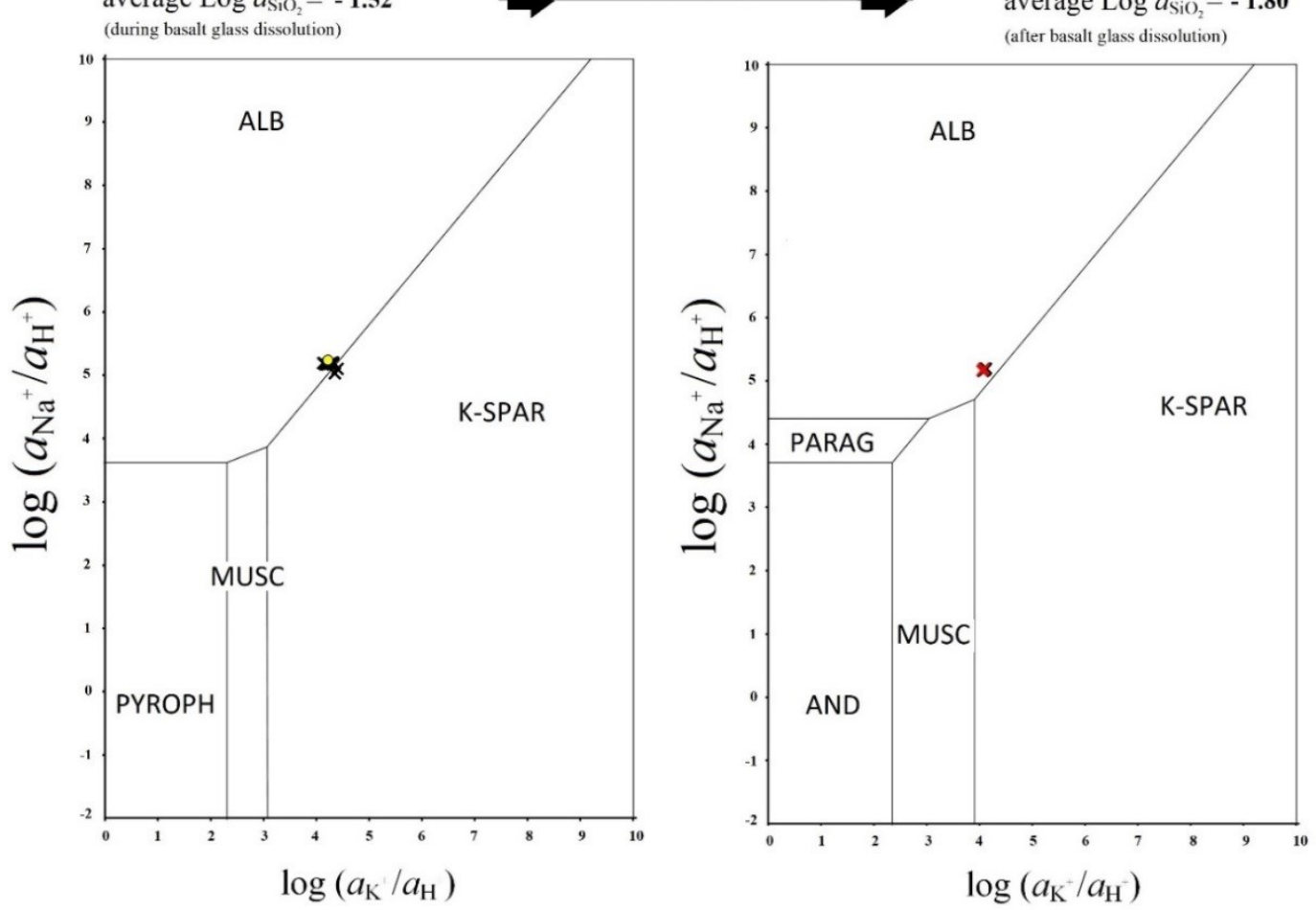

b BGB2

$350 \mathrm{C} / 486$ bar

average $\log a_{\mathrm{SiO}_{2}}=\mathbf{- 1 . 5 1}$

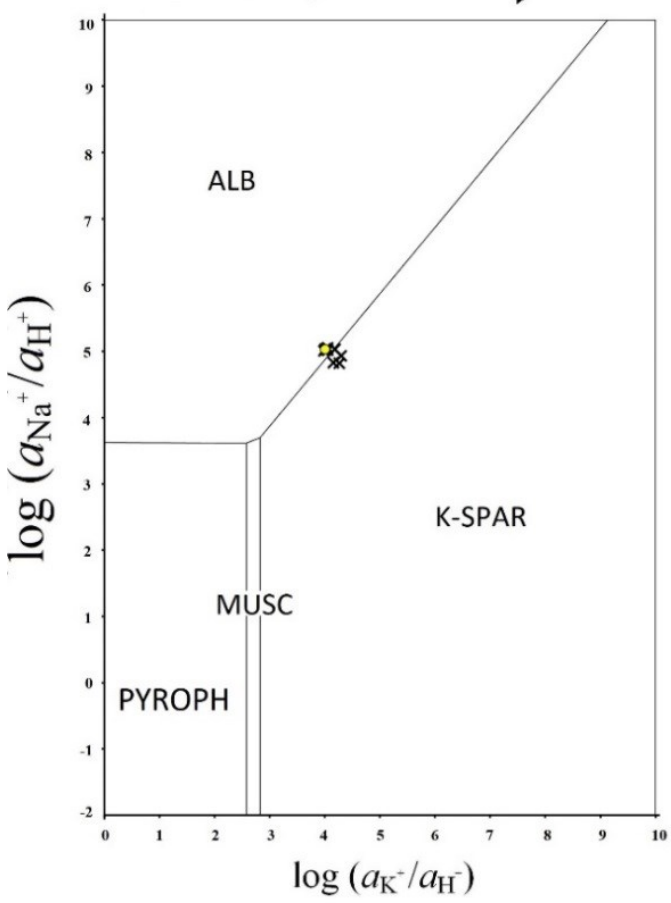

time of the experiment

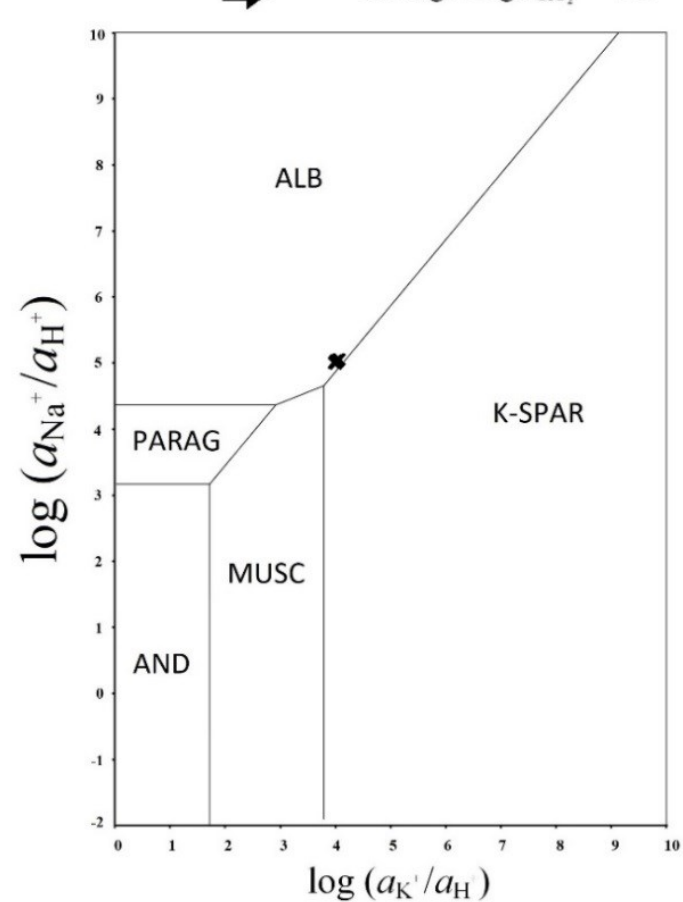


Tale 4.10. Average and $1 \sigma$ of estimated temperature $\left({ }^{\circ} \mathrm{C}\right)$ during and after basalt glass dissolution using fluid compositions for the BGB 1 and BGB2. Estimates were made using geothermometers from literature (Arnórsson, 1983; Fournier and Truesdell, 1973; Fournier, 1979; Giggenbach, 1988b; Nieva and Nieva, 1987; Santoyo and Díaz-González, 2009; Tonani, 1980; Truesdell, 1976).

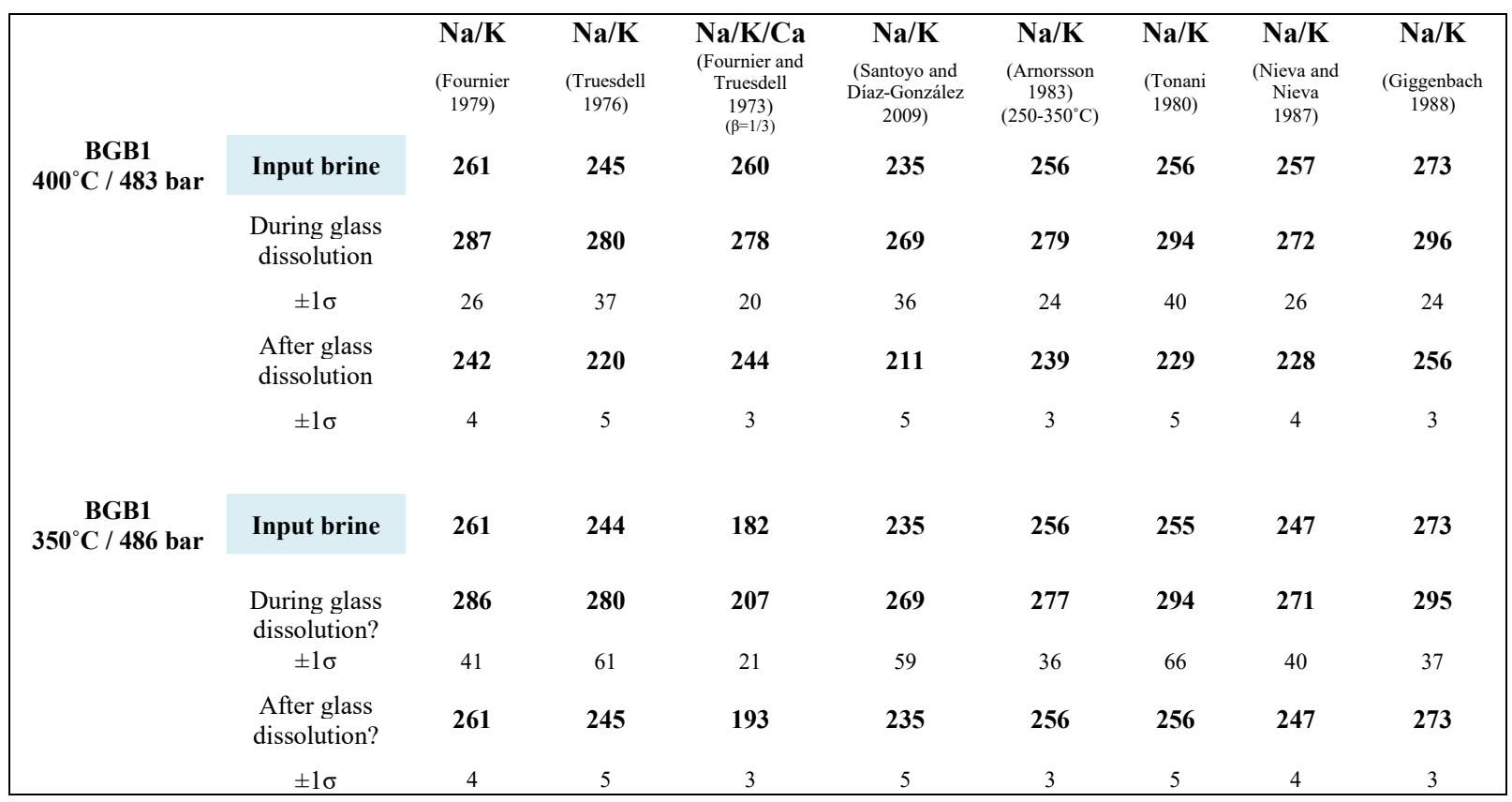


Figure 4.31. Estimated temperatures $\left({ }^{\circ} \mathrm{C}\right)$ calculated using several cation geothermometers (Arnórsson, 1983; Fournier, 1979; Giggenbach, 1988b; Nieva and Nieva, 1987; Santoyo and Díaz-González, 2009; Tonani, 1980; Truesdell, 1976) together with $\mathrm{SiO}_{2}$, Na and K concentrations for BGB1 and BGB2 plotted versus time. Dotted black lines separate value of $\mathrm{SiO}_{2}$ above quartz saturation (during basalt glass dissolution) from those below quartz saturation (after basalt glass dissolution). Dotted red lines show experimental temperature of BGB1 and BGB2 over time. n: Sample number.

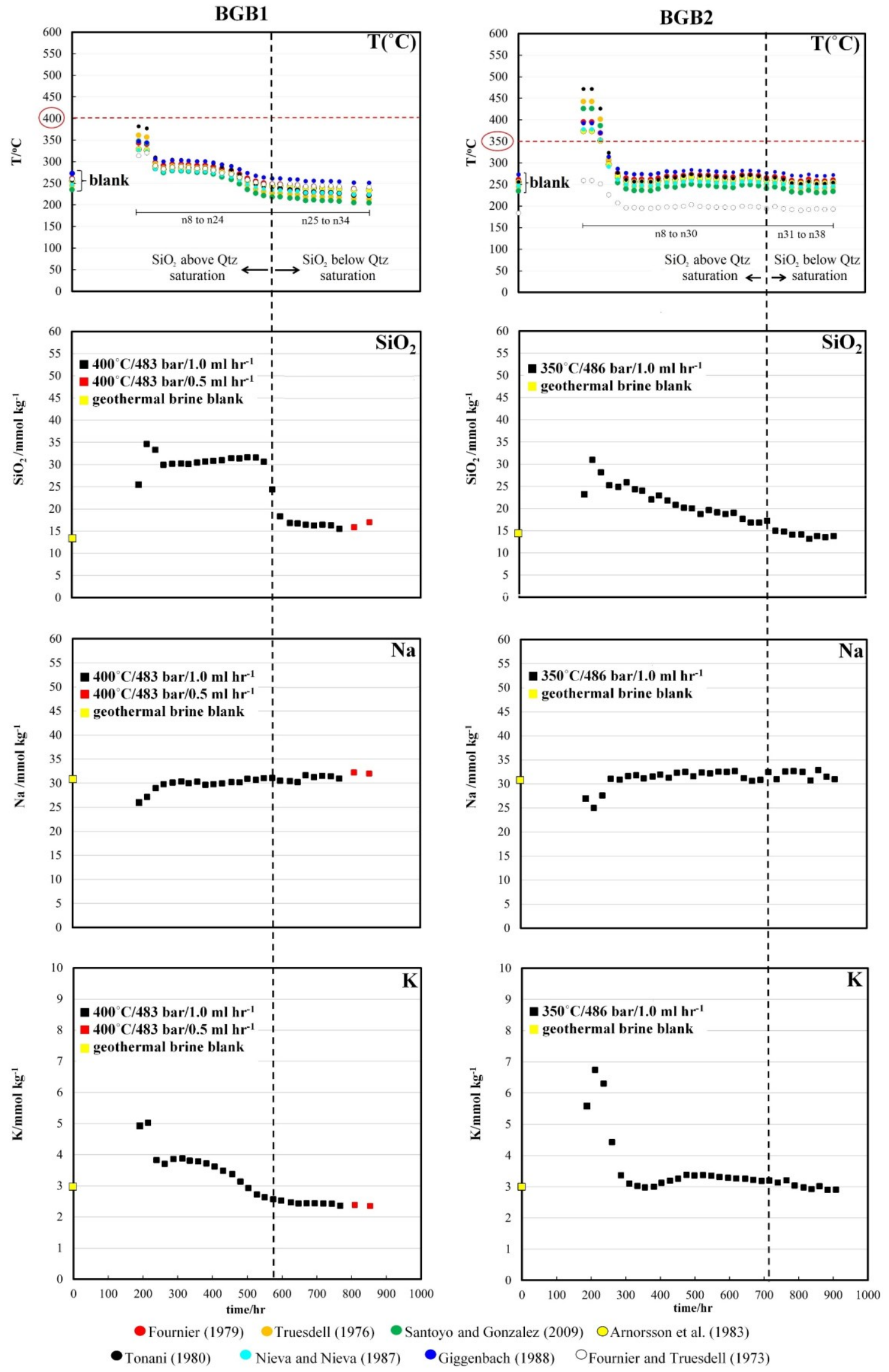




\subsubsection{Comparison of Distilled Water and Brine Experiments}

In the experiments described so far, the interaction was between a basalt (from Iceland) and either distilled water or geothermal brine (from New Zealand). The main purpose of these two sets of experiments was investigate fluid-rock interaction paths at subcritical and supercritical conditions for the different fluids as they react with basalt. To this effect, results from fluid chemistry and secondary mineralogy at same temperature are compared, i.e., BW1 with BGB1 $\left(400^{\circ} \mathrm{C}\right)$ and BW2 with BGB2 $\left(350^{\circ} \mathrm{C}\right)$. Table 4.11 summarises the identified secondary minerals that formed during the experiments. Figure 4.32 shows the comparison of chemistry results for all components at the same temperature but with the differing fluids.

In the following discussion, only $\mathrm{pH}$ and major aqueous species that show significant differences between experiments are considered. These include quench and in situ $\mathrm{pH}, \mathrm{SiO}_{2}$, $\mathrm{K}, \mathrm{Na}, \mathrm{Al}, \mathrm{Ca}$ and $\mathrm{SO}_{4}$. Aqueous species that do not show significant differences include $\mathrm{Fe}$, $\mathrm{Mg}$, and $\mathrm{H}_{2} \mathrm{~S}$.

Table 4.11. Secondary mineral assemblage identified after completion of the experiments with water and geothermal brine at 400 and $350^{\circ} \mathrm{C}$.

\begin{tabular}{|c|c|c|c|c|}
\hline & $\begin{array}{c}\text { Basalt-Water } \\
(\mathrm{BW} 1) \\
400^{\circ} \mathrm{C}\end{array}$ & $\begin{array}{c}\text { Basalt-Geothermal Brine } \\
(\mathrm{BGB} 1) \\
\mathbf{4 0 0}^{\circ} \mathrm{C}\end{array}$ & $\begin{array}{c}\text { Basalt-Water } \\
(\mathrm{BW} 2) \\
\mathbf{3 5 0} \mathrm{C}\end{array}$ & $\begin{array}{c}\text { Basalt-Geothermal Brine } \\
(\mathrm{BGB} 2) \\
\mathbf{3 5 0}^{\circ} \mathrm{C}\end{array}$ \\
\hline Secondary Mineralogy & $\begin{array}{l}\text { Anorthite } \\
\text { Chlorite } \\
\text { Wollastonite } \\
\text { Grossular } \\
\text { Celadonite } \\
\text { Magnetite }\end{array}$ & $\begin{array}{l}\text { Anhydrite } \\
\text { Biotite } \\
\text { Smectite } \\
\text { Cu-sulfide } \\
\text { Magnetite }\end{array}$ & $\begin{array}{l}\text { Anorthite } \\
\text { Chlorite } \\
\text { Celadonite }\end{array}$ & $\begin{array}{l}\text { Anhydrite } \\
\text { Smectite } \\
\text { Cu-sulfide }\end{array}$ \\
\hline
\end{tabular}

Distilled water and geothermal brine enter the Reactor with different initial chemical compositions and $\mathrm{pH}$. Distilled water has a near zero ionic strength and neutral $\mathrm{pH}(\sim 7$ at $25^{\circ} \mathrm{C}$ ) while geothermal brine contains a much higher ionic strength (0.04) and an acid $\mathrm{pH}$ $\left(\sim 4\right.$ at $\left.25^{\circ} \mathrm{C}\right)$. These are the major difference in the input fluid compositions.

In terms of secondary mineralogy, at $400^{\circ} \mathrm{C}$, a mineral assemblage composed by grossular, anorthite, wollastonite and chlorite was found at the bottom of the Reactor in the distilled water experiment. With geothermal brine at same temperature, anhydrite and biotite were the predominant secondary mineral phases. At the top of the Reactor, anorthite and celadonite were found as the major secondary phases at $400^{\circ} \mathrm{C}$, while smectite was the only major secondary phase identified at $350^{\circ} \mathrm{C}$. 
At $350^{\circ} \mathrm{C}$, in the water experiment, a mineral assemblage composed of chlorite and anorthite was found at the bottom of the Reactor. With geothermal brine, smectite was the only secondary mineral identified at the bottom of the Reactor. Celadonite and smectite were the dominant secondary phases in the upper part of the Reactor in the distilled water and brine experiment, respectively.

Quench $p H$. In all four experiments, after the $\mathrm{T}$ shift, the quench $\mathrm{pH}$ initially becomes more acidic than the input value. At $400^{\circ} \mathrm{C}$ quench $\mathrm{pH}$ rises to alkaline values in the distilled water experiment while it remains acidic while glass is dissolving with geothermal brine. At $350^{\circ} \mathrm{C}$, both experiments behave similarly but the quench $\mathrm{pH}$ is $\sim 2 \log$ units higher than with the brine.

In situ $\mathrm{pH}$. After temperature shift, the in situ $\mathrm{pH}$ is higher for the brine experiments than for the distilled water experiments. It is $\sim 3 \log$ units higher than the input brine $\mathrm{pH}$ at both temperatures indicating neutralisation of brine acidity by fluid-rock interactions. For the distilled water experiments, $\mathrm{pH}$ is initially $\sim 1 \log$ unit lower than the input $\mathrm{pH}$ and then decreases over time indicating production of acidity during fluid-rock interaction at both temperatures.

At high temperature, ionic species tend to associate and the $\mathrm{H}^{+}$and/or $\mathrm{OH}^{-}$in solution forms complexes and ion pairs (Chapter 2, §2.6, Table 2.8). In contrast, when the solution cools down, these species dissociate and hydrogen and hydroxide ions are released to the solution. These reactions determine the shift of the $\mathrm{pH}$ to more acid or basic values at room temperature.

$\mathrm{SiO}_{2}$. Distilled water contains only trace concentrations of silica while the geothermal brine has an input value of $14-15 \mathrm{mmol} \mathrm{\textrm {kg } ^ { - 1 }}$. Despite the difference in the initial concentration, after the $\mathrm{T}$ shift, $\mathrm{SiO}_{2}$ reached the same maximum value in both the distilled water and brine experiments at $400^{\circ} \mathrm{C}$ (Fig. 4.32). This indicates that $\mathrm{SiO}_{2}$ concentrations were controlled by similar fluid-rock interactions rather than by the dissolution rate of the volcanic glass. $\mathrm{SiO}_{2}$ concentrations remained elevated during glass dissolution for a longer period of time in the brine experiment due to the higher input $\mathrm{SiO}_{2}$ concentrations. At $350^{\circ} \mathrm{C}$, the time required for glass dissolution into distilled water is similar to that at $400^{\circ} \mathrm{C}$ and the final $\mathrm{SiO}_{2}$ concentration is similar in both experiments.

The behaviour with geothermal brine at $350^{\circ} \mathrm{C}$ is markedly different with a gradual decrease of $\mathrm{SiO}_{2}$ concentrations after temperature increase. This is due to the initiation of smectite precipitation immediately after $\mathrm{T}$ shift causing $\mathrm{SiO}_{2}$ concentrations to decline even 
though volcanic glass was dissolving. This is the only experiment where smectite was identified both at the bottom (with anhydrite) and at top of the Reactor. Unlike the brine experiment, with distilled water at same temperature, chlorite was the predominant phase identified at the bottom of the Reactor, rather than smectite.

$\mathrm{K}, \mathrm{Na}$. In the experiments with geothermal brine, $\mathrm{Na}$ and $\mathrm{K}$ are mainly supplied by the fluid. In contrast, in the experiments with distilled water, $\mathrm{K}$ was supplied entirely by the volcanic glass and $\mathrm{Na}$ by the dissolution of plagioclase. The high concentrations of these elements present in the brine when compared to the low concentrations in distilled water are evident in the results (Fig. 4.32).

At both temperatures with geothermal brine, there is an uptake of $\mathrm{Na}$ immediately after temperature increase, however, $\mathrm{Na}$ concentration remains relatively unchanged from input values for the remainder of the experiments. With distilled water, $\mathrm{Na}$ concentration increases but appears suppressed while glass dissolution is occurring after which it reaches similar values at both temperatures. This suggests uptake of $\mathrm{Na}$ into secondary minerals which cannot be detected at the high $\mathrm{Na}$ concentration in the brine.

The behaviour of $\mathrm{K}$ between brine and water experiments is markedly different. In all experiments, $\mathrm{K}$ concentration increases after temperature shift, however, the relative increase in the brine experiments is much larger. Given the much higher concentration of $\mathrm{K}$ in the geothermal brine this relative difference must be due to either the lower $\mathrm{pH}$ of the brine or to the high $\mathrm{Cl}$ concentration in the brine allowing formation of $\mathrm{KCl}$ ion pair (increasing $\mathrm{K}$ concentration in the brine). In either case, the effect does not continue as $\mathrm{K}$ concentration decreases again after a few days due to the formation of secondary K-bearing phases. It is also notable that, at $400^{\circ} \mathrm{C}, \mathrm{K}$ remains elevated during glass dissolution and then decreases below the input value for the remainder of the experiments. This is not the case at $350^{\circ} \mathrm{C}$ indicating greater uptake of $\mathrm{K}$ by the rock at $400^{\circ} \mathrm{C}$.

$A l$. At room temperature the brine experiments show much higher $\mathrm{Al}$ concentrations than the water experiments. This is attributed to the low $\mathrm{pH}$ of the brine which allowed some dissolution of aluminosilicates at room temperature. Upon temperature increase in both distilled water experiments, $\mathrm{Al}$ concentrations increase while in the brine experiments, they decrease to near detection limit values (except at $400^{\circ} \mathrm{C}$ after glass dissolution). This is attributed to immediate secondary mineral precipitation with the brine because of its high cation concentrations. Note the $\mathrm{SiO}_{2}$ concentrations in both fluids are similar at this point. It is notable that $\mathrm{Al}$ concentrations are much higher in the distilled water experiments than in 
the brine experiments. This is attributed to the higher $\mathrm{SiO}_{2}$ concentrations in the brine after glass dissolution inducing greater secondary mineral formation during the brine experiments.

$\mathrm{Ca}$ and $\mathrm{SO}_{4}$. At $400^{\circ} \mathrm{C}$, brine $\mathrm{Ca}$ concentrations are consistently higher than with distilled water. They fall below the input value after temperature increase due to the precipitation of anhydrite. Sulfate also follows this trend (note the difference in ordinate scales for $\mathrm{Ca}$ and $\mathrm{SO}_{4}$ ). In the water experiments, $\mathrm{SO}_{4}$ increases slightly due to the dissolution of $\mathrm{SO}_{2}$ from the glass with a possible contribution from $\mathrm{H}_{2} \mathrm{~S}$ oxidation in the sampling syringe. No anhydrite precipitated in the distilled water experiments.

A secondary $\mathrm{Ca}$ mineral assemblage consisting of grossular, wollastonite and anorthite was found with distilled water at $400^{\circ} \mathrm{C}$, while in the brine experiment, anhydrite was the only secondary Ca-bearing mineral identified. The mineral saturations calculated for the brine experiment (Appendix C) reveal that fluid composition was also saturated with respect to grossular. It is suggested that the higher concentration of $\mathrm{SO}_{4}$ in the input brine favoured the formation of anhydrite over grossular during the brine experiment. It is notable that while glass dissolution was occurring $\mathrm{Ca}$ concentration decreased markedly under the input value, however, once the glass was depleted it returns to the input value. Hence, the elevated $\mathrm{SiO}_{2}$ concentrations triggered $\mathrm{Ca}$ fixation in the rock.

At $350^{\circ} \mathrm{C}$, Ca reaches similar concentrations in both fluids, however, in the brine experiment, the final $\mathrm{Ca}$ concentrations are significantly lower than the input value. This shows significant fixation of $\mathrm{Ca}$ in the secondary phases. The $\mathrm{Ca}$ concentrations during the $400^{\circ} \mathrm{C}$ experiment are much higher indicating that there was less fixation of $\mathrm{Ca}$ at supercritical conditions (at least after $\mathrm{SiO}_{2}$ concentration decreased). 
Figure 4.32. $\mathrm{pH}$ and major ions concentrations in the water and geothermal brine experiments at each temperature.
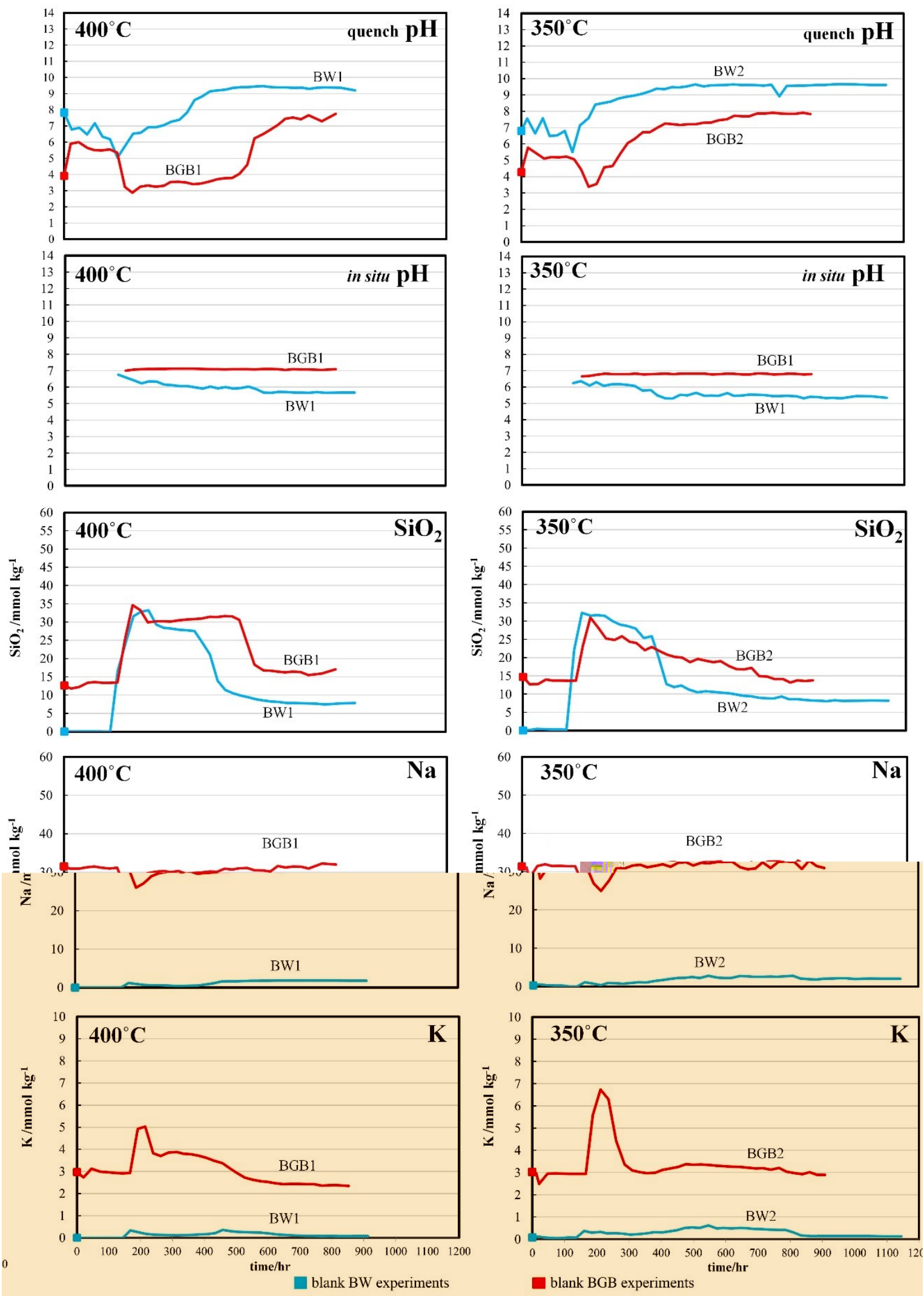

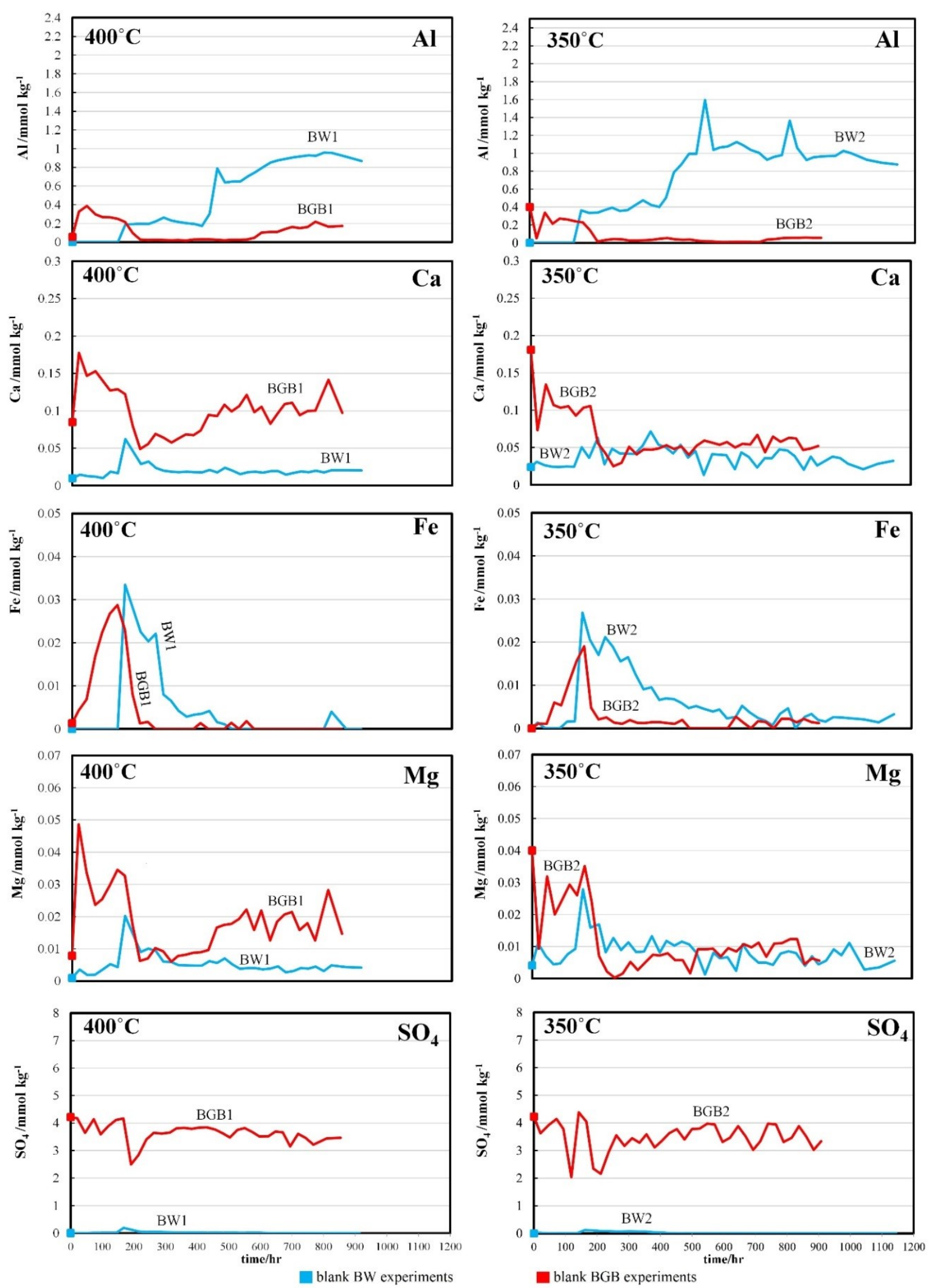

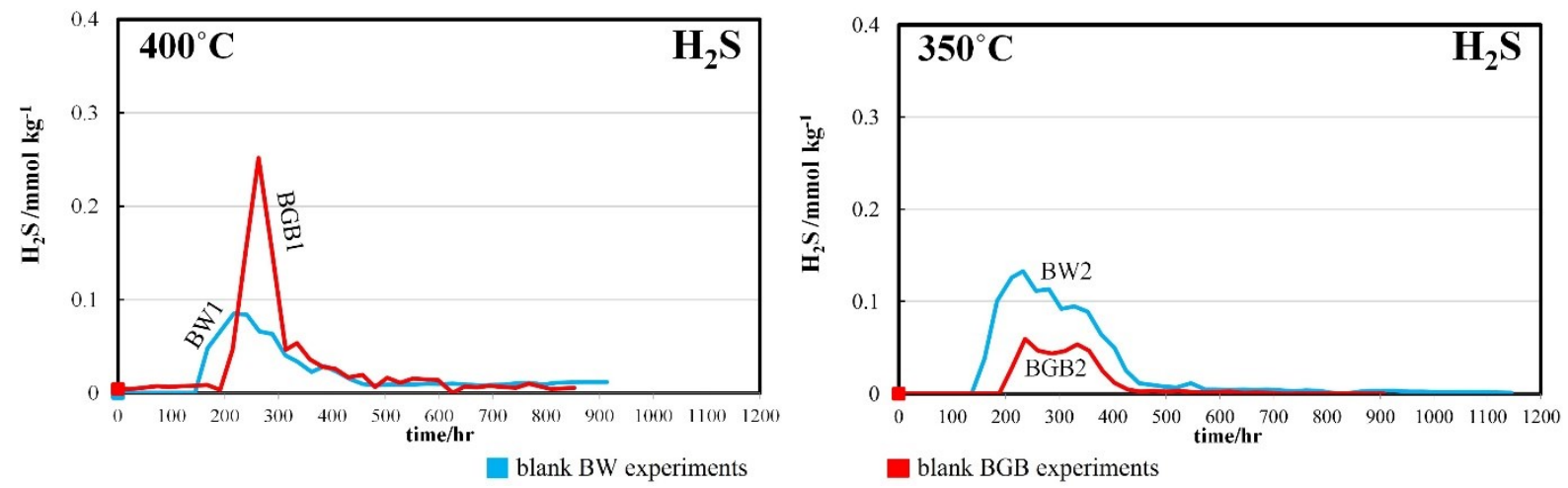


\subsection{References}

Addison, S., Brown, K., von Hirtz, P., Gallup, D., Winick, J., L Siega, F. and J Gresham, T., 2015, Brine Silica Management at Mighty River Power, New Zealand

Armannsson, H., Fridriksson, T., Gudfinnsson, G.H., Ólafsson, M., Óskarsson, F. and Thorbjörnsson, D., 2014, IDDP-The chemistry of the IDDP-01 well fluids in relation to the geochemistry of the Krafla geothermal system. Geothermics, 49: 66-75.

Arnórsson, S., Grönvold, K. and Sigurdsson, S., 1978, Aquifer chemistry of four hightemperature geothermal systems in Iceland. Geochimica et Cosmochimica Acta, 42: 523-536.

Arnórsson, S., 1983, Chemical equilibria in icelandic geothermal systems-Implications for chemical geothermometry investigations. Geothermics, 12: 119-128.

Arnórsson, S., 1995, Geothermal systems in Iceland: Structure and conceptual models-I. High-temperature areas. Geothermics, 24: 561-602.

Arnórsson, S. and Óskarsson, N., 2007, Molybdenum and tungsten in volcanic rocks and in surface and $<100 \mathrm{C}$ ground waters in Iceland. Geochimica et Cosmochimica Acta, 71: 284-304.

Asmundsson, R., Pezard, P., Sanjuan, B., Henninges, J., Deltombe, J.-L., Halladay, N., Lebert, F., Gadalia, A., Millot, R., Gibert, B., Violay, M., Reinsch, T., Naisse, J.-M., Massiot, C., Azaïs, P., Mainprice, D., Karytsas, C. and Johnston, C., 2014, High temperature instruments and methods developed for supercritical geothermal reservoir characterisation and exploitation-The HiTI project. Geothermics, 49: 90-98.

Beaufort, D., Baronnet, A., Lanson, B., and Meunier, A., 1997, Corrensite; a single phase or a mixed-layer phyllosilicate in saponite-to-chlorite conversion series? A case study of Sancerre-Couy deep drill hole (France): American Mineralogist, v. 82, no. 1-2, p. 109-124.

Bird, P., 1984, Hydration-phase diagrams and friction of montmorillonite under laboratory and geologic conditions, with implications for shale compaction, slope stability, and strength of fault gouge. Tectonophysics, 107: 235-260.

Browne, P. and Ellis, A., 1970, The Ohaki-Broadlands hydrothermal area, New Zealand; mineralogy and related geochemistry. American Journal of Science, 269: 97-131.

Browne, P., 1978, Hydrothermal alteration in active geothermal fields. Annual review of earth and planetary sciences, 6: 229-250.

Cheshire, M. C., Caporuscio, F. A., Colón, C. J., and Norskog, K. E., 2018, Fe-saponite growth on low-carbon and stainless steel in hydrothermal-bentonite experiments: Journal of Nuclear Materials, v. 511, p. 353-366.

Elders, W. and Friðleifsson, G.Ó., 2010, Implications of the Iceland Deep Drilling Project for Improving Understanding of Hydrothermal Processes at Slow-Spreading Mid-Ocean Ridges 91-112 p.

Essene, E. and Peacor, D., 1995, Clay mineral thermometry-a critical perspective. Clays and clay minerals, 43: 540-553.

Fournier, R. and Truesdell, A., 1973, An empirical Na $\square \mathrm{K} \square$ Ca geothermometer for natural waters. Geochimica et Cosmochimica Acta, 37: 1255-1275.

Fournier, R.O., 1979, A revised equation for the $\mathrm{Na} / \mathrm{K}$ geothermometer. Transactions of the Geothermal Resources Council, 3: 221-224.

Fowler, A.P.G., Zierenberg, R.A., Schiffman, P., Marks, N. and Friðleifsson, G.Ó., 2015, Evolution of fluid-rock interaction in the Reykjanes geothermal system, Iceland: Evidence from Iceland Deep Drilling Project core RN-17B. Journal of Volcanology and Geothermal Research, 302: 47-63. 
Franzson, H., Zierenberg, R. and Schiffman, P., 2008, Chemical transport in geothermal systems in Iceland: Evidence from hydrothermal alteration. Journal of Volcanology and Geothermal Research, 173: 217-229.

Fridleifsson, G.O. and Elders, W.A., 2005, The Iceland Deep Drilling Project: a search for deep unconventional geothermal resources. Geothermics, 34: 269-285.

Fridleifsson, G.Ó., Elders, W.A., Zierenberg, R.A., Stefánsson, A., Fowler, A.P.G., Weisenberger, T.B., Harðarson, B.S. and Mesfin, K.G., 2017, The Iceland Deep Drilling Project $4.5 \mathrm{~km}$ deep well, IDDP-2, in the seawater-recharged Reykjanes geothermal field in SW Iceland has successfully reached its supercritical target. Sci. Dril., 23: 1-12.

Friðleifsson, G.Ó., Elders, W.A. and Albertsson, A., 2014, The concept of the Iceland deep drilling project. Geothermics, 49: 2-8.

Giggenbach, W., Gonfiantini, R., Jangi, B. and Truesdell, A., 1983, Isotopic and chemical composition of Parbati valley geothermal discharges, north-west Himalaya, India. Geothermics, 12: 199-222.

Giggenbach, W.F., 1988b, Geothermal solute equilibria. derivation of Na-K-Mg-Ca geoindicators. Geochimica et cosmochimica acta, 52: 2749-2765.

Greaney, A.T., Rudnick, R.L., Helz, R.T., Gaschnig, R.M., Piccoli, P.M. and Ash, R.D., 2017, The behavior of chalcophile elements during magmatic differentiation as observed in Kilauea Iki lava lake, Hawaii. Geochimica et Cosmochimica Acta, 210: 71-96.

Greaney, A.T., Rudnick, R.L., Gaschnig, R.M., Whalen, J.B., Luais, B. and Clemens, J.D., 2018, Geochemistry of molybdenum in the continental crust. Geochimica et Cosmochimica Acta, 238: 36-54.

Haldar, S. K., 2020, Introduction to mineralogy and petrology, Elsevier.

Hedenquist, J., Arribas, A. and Gonzalez-Urien, E., 2000, Exploration for Epithermal Gold Deposits. Reviews in Economic Geology, 13: 245-277.

Henley, R.W. and Ellis, A.J., 1983, Geothermal systems ancient and modern: a geochemical review. Earth-science reviews, 19: 1-50.

Heřmanská, M., Kleine, B. and Stefansson, A., 2019, Supercritical Fluid Geochemistry in Geothermal Systems. Geofluids, 2019: 1-14.

Hukkanen, E. and Walden, H., 1985, The production of vanadium and steel from titanomagnetites. International Journal of Mineral Processing, 15: 89-102.

Lodders, K. and Palme, H., 1991, On the chalcophile character of molybdenum: determination of sulfide/silicate partition coefficients of Mo and W. Earth and Planetary Science Letters, 103: 311-324.

Marini, L., 2000, Geochemical techniques for the exploration and exploitation of geothermal energy. Italy: University of Genua.

Marks, N., Schiffman, P., Zierenberg, R.A., Franzson, H. and Fridleifsson, G.Ó., 2010, Hydrothermal alteration in the Reykjanes geothermal system: Insights from Iceland deep drilling program well RN-17. Journal of Volcanology and Geothermal Research, 189: 172-190.

Mortensen, A.K., Egilson, P., Gautason, B., Árnadóttir, S. and Guðmundsson, Á., 2014, Stratigraphy, alteration mineralogy, permeability and temperature conditions of well IDDP-1, Krafla, NE-Iceland. Geothermics, 49: 31-41.

Nieva, D. and Nieva, R., 1987, Developments in geothermal energy in Mexico-part twelve. A cationic geothermometer for prospecting of geothermal resources. Heat Recovery Systems and CHP, 7: 243-258.

Pálsson, B., Hólmgeirsson, S., Guðmundsson, Á., Bóasson, H.Á., Ingason, K., Sverrisson, H. and Thórhallsson, S., 2014, Drilling of the well IDDP-1. Geothermics, 49: 23-30. 
Reyes, A.G., 1990, Petrology of Philippine geothermal systems and the application of alteration mineralogy to their assessment. Journal of Volcanology and Geothermal Research, 43: 279-309.

Santoyo, E. and Díaz-González, L., Year, A New Improved Proposal of the Na / K Geothermometer to Estimate Deep Equilibrium Temperatures and their Uncertainties in Geothermal Systems.

Sonney, R. and Mountain, B., 2013, Experimental simulation of greywacke-fluid interaction under geothermal conditions. Geothermics, 47: 27-39.

Steiner, A., 1977, The Wairakei geothermal area, North Island, New Zealand : its subsurface geology and hydrothermal rock alteration / by A. Steiner. New Zealand Dept. of Scientific and Industrial Research, Wellington

Thórhallsson, S., Pálsson, B., Hólmgeirsson, S., Ingason, K., Matthíasson, M., Bóasson, H.Á. and Sverrisson, H., 2014, Well design for the Iceland Deep Drilling Project (IDDP). Geothermics, 49: 16-22.

Tonani, F., Year, Some Remarks on the Application of Geochemical Techniques in geothermal exploration.

Truesdell, A., Year, Geochemical Techniques in Exploration: Summary of Section III. Proceedings of the Second UN Symposium on the Development and Use of Geothermal Resources, 1976, Iiii-Ixxix.

Weir, N.R.W., White, R.S., Brandsdóttir, B., Einarsson, P., Shimamura, H. and Shiobara, H., 2001, Crustal structure of the northern Reykjanes Ridge and Reykjanes Peninsula, southwest Iceland. 106: 6347-6368.

Yardley, B. W. D., Rhede, D., and Heinrich, W., 2014, Rates of Retrograde Metamorphism and their Implications for the Rheology of the Crust: an Experimental Study: Journal of Petrology, v. 55, no. 3, p. 623-641. 


\section{Chapter 5: The Experimental Behaviour of Seawater}

\subsection{Introduction}

The seawater - basalt experiments described in Chapter 6 were performed using a new experimental design (Chapter 2, $\S 2.4 .5$, Fig. $2.20 \mathrm{~b}-2.21 \mathrm{~b}$ ). The seawater-only experiments described in this chapter were carried out for the purpose of determining seawater behaviour in the absence of the basalt. These are essentially control experiments that use the Preheater only without the Reactor (Chapter 2, §2.4.5, Fig. 2.20a-2.21a). As discussed in the Methods section, the retrograde solubility of sulfate minerals makes it difficult to conduct flowthrough experiments with seawater. The other reason for conducting these experiments was to determine the influence of the $\mathrm{ZrO}_{2}$ beads on the solution composition.

The experiments reproduced (on a small scale) the submarine hydrothermal process where seawater is depleted in $\mathrm{Ca}, \mathrm{Mg}$ and $\mathrm{SO}_{4}$ during its initial descent into the oceanic crust, crossing first the recharge zone before accessing the reaction zone (Babcock et al., 1998; Cann, 1971; Cann, 1969; Cann and Funnell, 1967; Chernysheva, 1971; Coelho et al., 2015; Detrick et al., 1987; Kent et al., 1990; Melson et al., 1968; Melson and van Andel, 1966; Miyashiro et al., 1971; Quon, 1963; Shido et al., 1974; Sinha and Evans, 2013; Sinton and Detrick, 1992). The set-up had a temperature gradient along the Preheater column which allowed entry of seawater at its top at a low enough temperature to avoid sulfate mineral precipitation. As the seawater descends through the Preheater, crystallisation of retrograde solubility minerals occurs.

The experiments did not reproduce, in total, the natural environmental conditions at MORBs. This is because the passage of seawater down the Preheater column occurred without influence from any sediments or basalt. However, the experiments allowed the measurement of the solubility of major elements in solution both at near-supercritical and at subcritical conditions, giving helpful insight into retrograde mineral precipitation phases and their reaction rates.

There are few laboratory experiments where seawater alone has been heated to supercritical and subcritical conditions to investigate retrograde mineral precipitation. The only experiment available in literature, describes these reactions when seawater is heated from 25 to $350^{\circ} \mathrm{C} / 500$ bar using a batch reactor without rock (Bischoff and Seyfried, 1978). 
In our experiments, we used for the first time a novel method to test the thermal stability of seawater at near-supercritical $\left(377^{\circ} \mathrm{C} / 488\right.$ bar $)$ and at subcritical $\left(342^{\circ} \mathrm{C} / 488\right.$ bar $)$ conditions using a high T-P hydrothermal flow-through apparatus.

In Chapter 2 (\$2.4.5, Fig. 2.17) we described an initial experiment with the Preheater to test its efficiency at removing retrograde phases. This used synthetic seawater (seawater powder) and the empty Preheater. The test ran for 12 days at $377^{\circ} \mathrm{C} / 490$ bar after which the pressure of the system suddenly exceeded the safety pressure ( $\sim 517$ bar). This was caused by a blockage at the exit point of the Preheater consisting of secondary mineral precipitates. The experimental set-up was modified to include $2 \mathrm{~mm}$ diameter $\mathrm{ZrO}_{2}$ beads filled partway up the Preheater (Chapter 2, $\$ 2.4 .5$, Fig. 2.19). The use of the $\mathrm{ZrO}_{2}$ beads had two aims: (1) to increase the surface area for retrograde mineral phase precipitation, and (2) to prevent crystal nuclei from settling to the bottom of the vessel and blocking the exit. This set-up was successful in preventing blockage of the exit point of the Preheater.

Two experiments were then conducted using this set-up and natural seawater: SW1 $\left(377^{\circ} \mathrm{C} / 488\right.$ bar) and SW2 $\left(342^{\circ} \mathrm{C} / 488\right.$ bar $)$. The temperature of the furnace for the SW1 experiment was set to $400^{\circ} \mathrm{C}$, however, a maximum temperature of $377^{\circ} \mathrm{C}$ was measured in the bottom cap of the Preheater (Chapter 2, §2.4.5, Fig. 2.20a). The temperature of the furnace for the SW2 experiment was set to $350^{\circ} \mathrm{C}$, however, a maximum temperature of $342^{\circ} \mathrm{C}$ was measured in the bottom cap of the Preheater (Chapter 2, §2.4.5, Fig. 2.21a).

Our results show that significant changes in seawater chemistry occurred at both experimental conditions. These consisted of: 1) achievement of rapid steady state element concentrations in solution; 2) strong depletion of $\mathrm{Ca}, \mathrm{Mg}$ and $\mathrm{SO}_{4}$ from the seawater at both conditions; and 3) significant decreases of quench $\mathrm{pH}$ to acidic values.

\subsection{Results}

In this chapter the results for the development tests, SW1, and SW2 experiments are presented. These include:

1) major element analyses of experimental solutions for SW1 and SW2;

2) trace element analyses of experimental solutions for SW1 and SW2;

3) chemical, mineralogical and textural analyses of mineral precipitates from the Preheater for a) the initial method development test (Chapter 2, §2.4.5, Fig. 2.17) and b) from the SW1 and SW2 experiments.

Fluid chemistry results from the development test are not reported. 


\subsubsection{Method development test $\left(377^{\circ} \mathrm{C} / 490\right.$ bar $)$ : Mineralogy of precipitated phases}

SEM analysis was performed on the precipitated mineral phases extracted from the bottom portion of the Preheater after the development test. This test used synthetic seawater in the absence of $\mathrm{ZrO}_{2}$ beads (Chapter 2, §2.4.5, Fig. 2.17). During the experiment, a solid disc of secondary minerals formed at the bottom of the Preheater (Fig. 5.1a). During extraction, this disc broke into numerous clear crystal aggregates up to a millimetre in size (Fig. 5.1b). Samples of this material were mounted on aluminium stubs for SEM-EDS analyses. Appendix D contains all SEM results for this study.

Figure 5. 1. (a) Schematic diagram (not to scale) of the Preheater during the method development test with synthetic seawater (salt powder) without zirconia beads; (b) image of the solid mineral layer extracted from the bottom of the Preheater after completion of the test

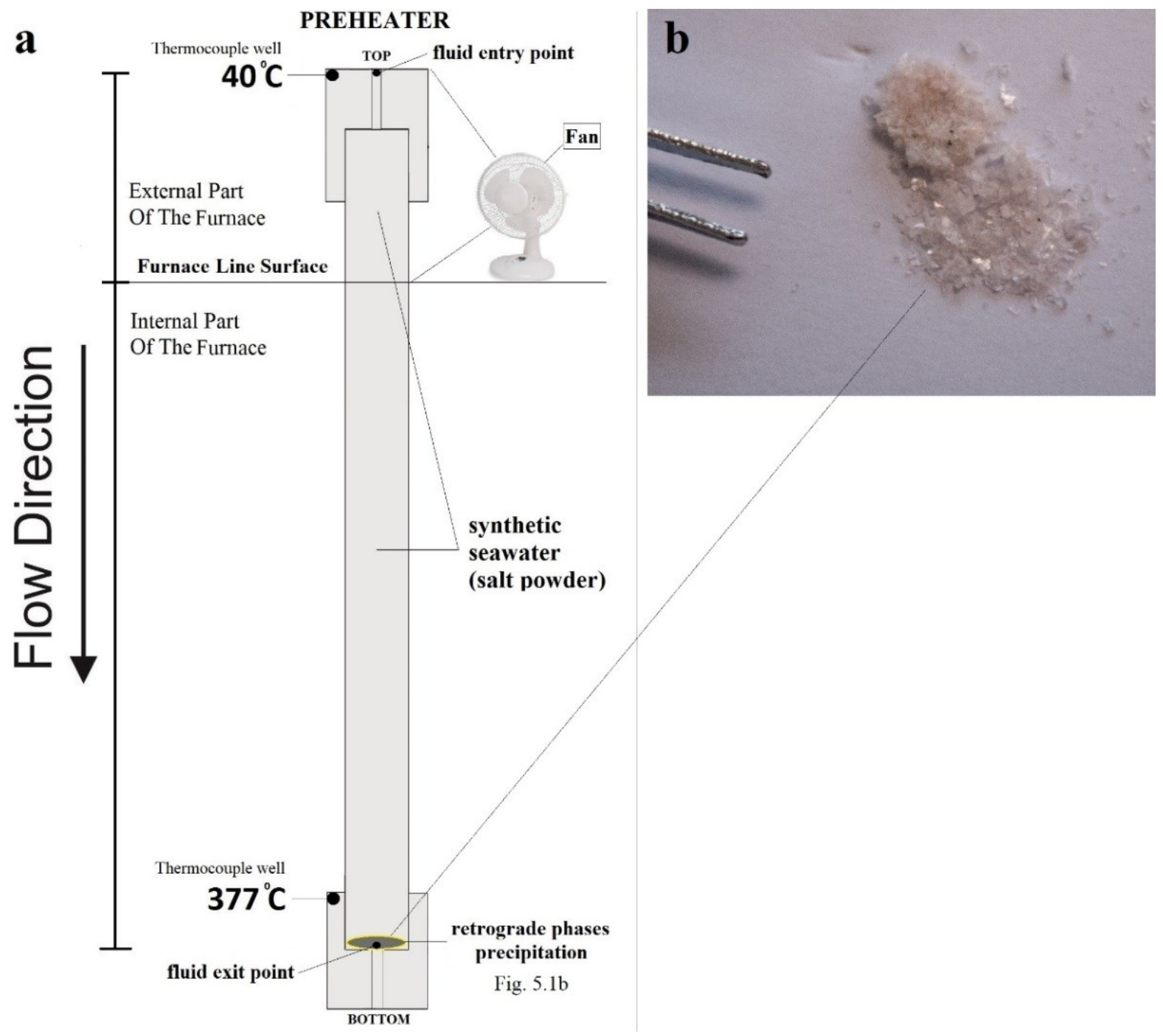


SEM images of the mineral phases that precipitated at the bottom of the Preheater during the development are shown in Figure 5.2. The precipitated mineral layer is composed predominantly of aggregates of intergrown tabular anhydrite crystals. Closer examination reveals numerous hexagonal platelets of brucite. Associated exclusively with the brucite crystals are submicron aggregates of a $\mathrm{Mg}$-silicate phase. It is uncertain which $\mathrm{Mg}$-silicate phase this represents; however, talc is a likely candidate. It is interesting to note that no $\mathrm{Mg}$ sulfate phases were identified in the precipitate.

As discussed in Chapter 2, it is expected that anhydrite nucleated high in the column where it saturates at $108^{\circ} \mathrm{C}$. These crystallites, however, did not adhere to the walls of the Preheater and descended by gravity to the bottom, continuing to grow in the process. It is also evident that brucite and its associated Mg-silicate (talc?) grew exclusively on the surface of anhydrite crystals. 
Figure 5.2. SEM images of the mineral precipitates extracted from the bottom of the Preheater after the experiment with synthetic seawater. (a-b) mineral clusters composed primarily of euhedral tabular aggregates of anhydrite; (c) enlargement of rectangular area in (b) showing a hexagonal crystal of brucite; (d-e-f) brucite crystals (Brc) on anhydrite surfaces (Anh). Fine material associated with brucite is a Mg-silicate phase, possibly talc (Tlc).
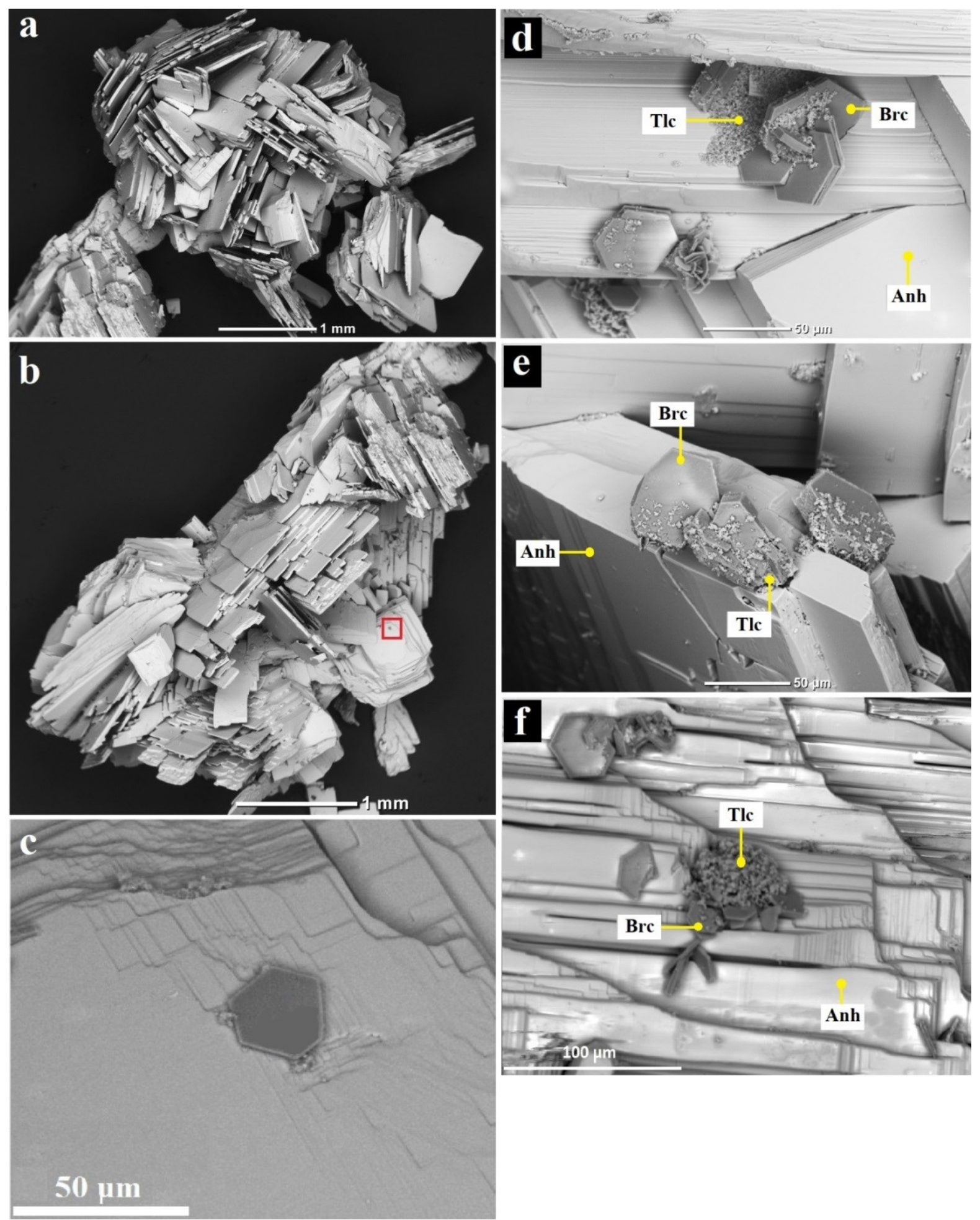


\subsubsection{SW1: Natural seawater $\left(377^{\circ} \mathrm{C} / 488\right.$ bar $)$}

The first seawater experiment (SW1) ran for a total time of $547 \mathrm{hrs}$. Note that there was no room temperature period for these experiments. Initially, distilled water was pumped into the system and the experimental pressure of 488 bar was reached. The internal volume of the Preheater is $70 \mathrm{ml}$ with approximately half of this volume taken up by the $\mathrm{ZrO}_{2}$ beads. The heating procedure was started with the distilled water in the Preheater to prevent mineral precipitation in the apparatus during heat-up. The heating procedure took approximately 3 hrs. Once the experimental temperature was achieved at the bottom of the Preheater $\left(377^{\circ} \mathrm{C}\right)$, flow was initiated allowing seawater to enter the Preheater. The flow rate was $1 \mathrm{ml} \mathrm{hr}^{-1}$ for the entire experiment. Analysis of major and trace elements were made for the total number of fluid samples (23) collected.

\subsubsection{Major element concentrations}

Appendix D lists the complete experimental parameters (T, P, time, flow rate, in situ and room temperature $\mathrm{pH}$, chemistry). Figure 5.3 and Figure 5.4 show these results plotted against time in hours. The unreacted natural seawater composition is shown at $t=0$. The blank composition of distilled water is not shown. The concentrations of major ions for the first $163 \mathrm{hrs}$ are essentially for distilled water as it required approximately $6-7$ days for seawater to begin to exit the Preheater at $1 \mathrm{ml} \mathrm{hr}^{-1}$.

The room temperature $\mathrm{pH}$ of the unreacted Napier seawater is 7.75 . This seawater is more dilute $\left(432 \mathrm{mmol} \mathrm{kg}^{-1} \mathrm{Cl}\right)$ with respect to average seawater $\left(547 \mathrm{mmol} \mathrm{kg}^{-1} \mathrm{Cl}\right)$ due to freshwater inflow from the Clive River to the south of Napier. While distilled water was present, the quench and in situ $\mathrm{pH}$ values are irregular due to the low ionic strength of the solution. Once seawater begins to exit the Preheater, in situ $\mathrm{pH}$ stabilises at $\sim 5.4$ while quench $\mathrm{pH}$ decreases to $\sim 3.2$ for the remainder of the experiment.

$\mathrm{SiO}_{2}$ concentrations are low when distilled water is present. Once seawater begins to appear in the effluents $(\sim 150 \mathrm{hr}), \mathrm{SiO}_{2}$ concentrations begin to increase and reach a value of $\sim 1 \mathrm{mmol} \mathrm{kg}^{-1}$ (Fig. 5.1). There is only $\sim 0.1 \mathrm{mmol} \mathrm{kg}^{-1} \mathrm{SiO}_{2}$ in seawater thus the elevated $\mathrm{SiO}_{2}$ values must be derived from the $\mathrm{ZrO}_{2}$ beads. As shown in Chapter 2, §2.4.5, Figure 2.19, the $\mathrm{ZrO}_{2}$ beads are not pure and contain minor amounts of $\mathrm{Si}, \mathrm{Fe}, \mathrm{Mg}, \mathrm{Ca}$, and $\mathrm{Al}$. However, $\mathrm{SiO}_{2}$ concentrations are not elevated when distilled water was present at $377^{\circ} \mathrm{C}$. The $\mathrm{SiO}_{2}$ concentrations only increase when seawater passes through the column. This indicates that the lower in situ $\mathrm{pH}$ and much higher ionic strength is inducing $\mathrm{SiO}_{2}$ release 
from the beads. Note that a $\mathrm{SiO}_{2}$ concentration of $1 \mathrm{mmol} \mathrm{kg}^{-1}$ is relatively insignificant when compared to concentrations encountered in experiments using basalt.

A similar explanation can be applied to the behavior of $\mathrm{Fe}$ and $\mathrm{Al}$. Fe concentrations only increase when seawater passes through the Preheater. This is attributed to dissolution from the beads (Fig. 5.4). Aluminum concentrations are on average higher while seawater passes through the Preheater (Fig. 5.3) but they are consistently low, irregular, and relatively insignificant when compared to the basalt experiments.

For $\mathrm{Na}, \mathrm{K}$, and $\mathrm{Cl}$, results show conservative behavior. Potassium concentrations return to seawater values after mixing with distilled water. Sodium concentrations attain lower values $\left(\sim 380 \mathrm{mmol} \mathrm{kg}^{-1}\right)$ than the input value $\left(420 \mathrm{mmol} \mathrm{kg}^{-1}\right)$. The explanation for this decrease is uncertain and may be due to an analytical issue. There were no Na-bearing minerals identified in the precipitated phases. Chloride concentrations are conservative and show an expected mixing line with distilled water.

Significant changes are encountered with the other major components $\mathrm{Ca}, \mathrm{Mg}$, and $\mathrm{SO}_{4}$ present in seawater. The seawater contains $9.4 \mathrm{mmol} \mathrm{kg}^{-1} \mathrm{Ca}$ (Fig. 5.2). While distilled water is exiting the Preheater, $\mathrm{Ca}$ concentrations remain at detection limit. Once seawater begins to exit the Ca concentration rises to reach $\sim 2.1 \mathrm{mmol} \mathrm{kg}^{-1}$ after two days and remains at this value for the remainder of the experiment. This represents a significant decrease in $\mathrm{Ca}$ concentration from the original seawater.

The $\mathrm{Mg}$ concentration in the seawater is $45.8 \mathrm{mmol} \mathrm{kg}^{-1}$. While distilled water is exiting the Preheater, $\mathrm{Mg}$ concentrations remain low. Upon the exit of seawater, the $\mathrm{Mg}$ concentrations increase gradually and reach a final concentration of $24.4 \mathrm{mmol} \mathrm{kg}^{-1}$. As with $\mathrm{Ca}$, there is a significant loss of $\mathrm{Mg}$ during the experiment.

The above changes in $\mathrm{Ca}$ and $\mathrm{Mg}$ concentrations are mirrored in the changes in $\mathrm{SO}_{4}$. The input $\mathrm{SO}_{4}$ concentration for the seawater is $22 \mathrm{mmol} \mathrm{kg}^{-1}$ (Fig. 5.2). While distilled water exits the Preheater $\mathrm{SO}_{4}$ concentrations are low. Upon the exit of seawater, $\mathrm{SO}_{4}$ increases and maintains a final concentration of $1.2 \mathrm{mmol} \mathrm{kg}^{-1}$. The behaviour of $\mathrm{Ca}, \mathrm{Mg}$, and $\mathrm{SO}_{4}$ indicates significant precipitation of secondary phases.

There were no detectable concentrations of $\mathrm{H}_{2} \mathrm{~S}$ during the experiment (Fig. 5.3). This indicates that no measurable amount of sulfate reduction was occurring at the experimental condition. 
Figure 5.3. Major element concentrations in blank and effluent samples ( $\mathrm{mmol} \mathrm{kg}^{-1}$ ) versus time (hr) for the SW1 experiment at $377^{\circ} \mathrm{C} / 488$ bar and $1.0 \mathrm{ml} \mathrm{hr}^{-1}$ flow rate. Yellow symbols are the blank sample composition of natural seawater. Blue symbols show where distilled water was exiting the Preheater. Black symbols are effluent compositions during mixing and replacement of distilled water by seawater.
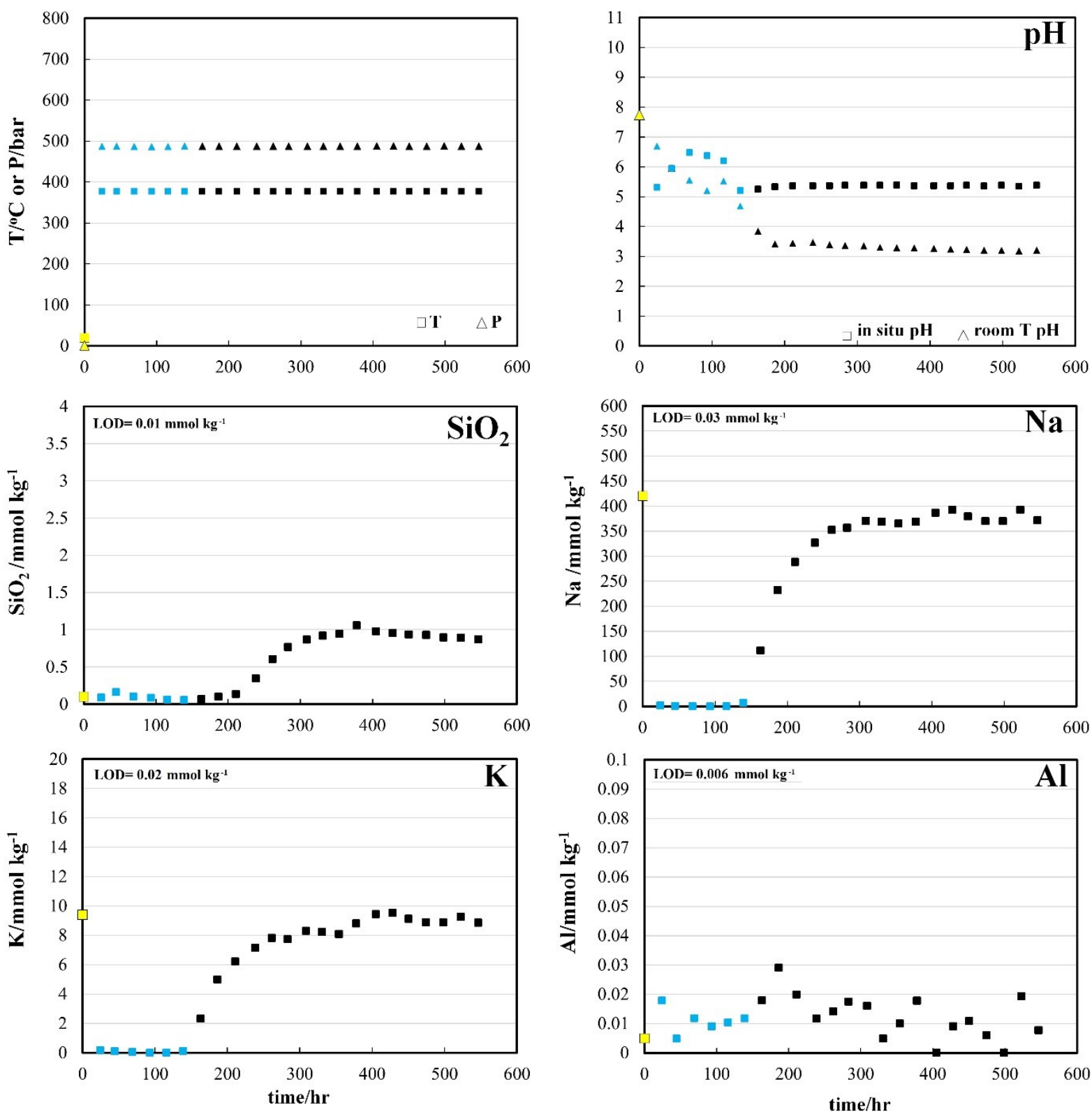

$\llcorner\triangle$ blank seawater

口 $377^{\circ} \mathrm{C} / 488 \mathrm{bar} / 1 \mathrm{ml} \mathrm{hr}^{-1}$ (distilled water)

口 $377^{\circ} \mathrm{C} / 488 \mathrm{bar} / 1 \mathrm{ml} \mathrm{hr}{ }^{-1}$ (seawater) 
Figure 5.4. Major element concentrations in blank and effluent samples ( $\mathrm{mmol} \mathrm{kg}^{-1}$ ) versus time (hr) for the $\mathrm{SW} 1 \mathrm{experiment}$ at $377^{\circ} \mathrm{C} / 488$ bar and $1.0 \mathrm{ml} \mathrm{hr}^{-1}$ flow rate. Yellow symbols are the blank sample composition of natural seawater. Blue symbols show where distilled water was exiting the Preheater. Black symbols are effluent compositions during mixing and replacement of distilled water by seawater.
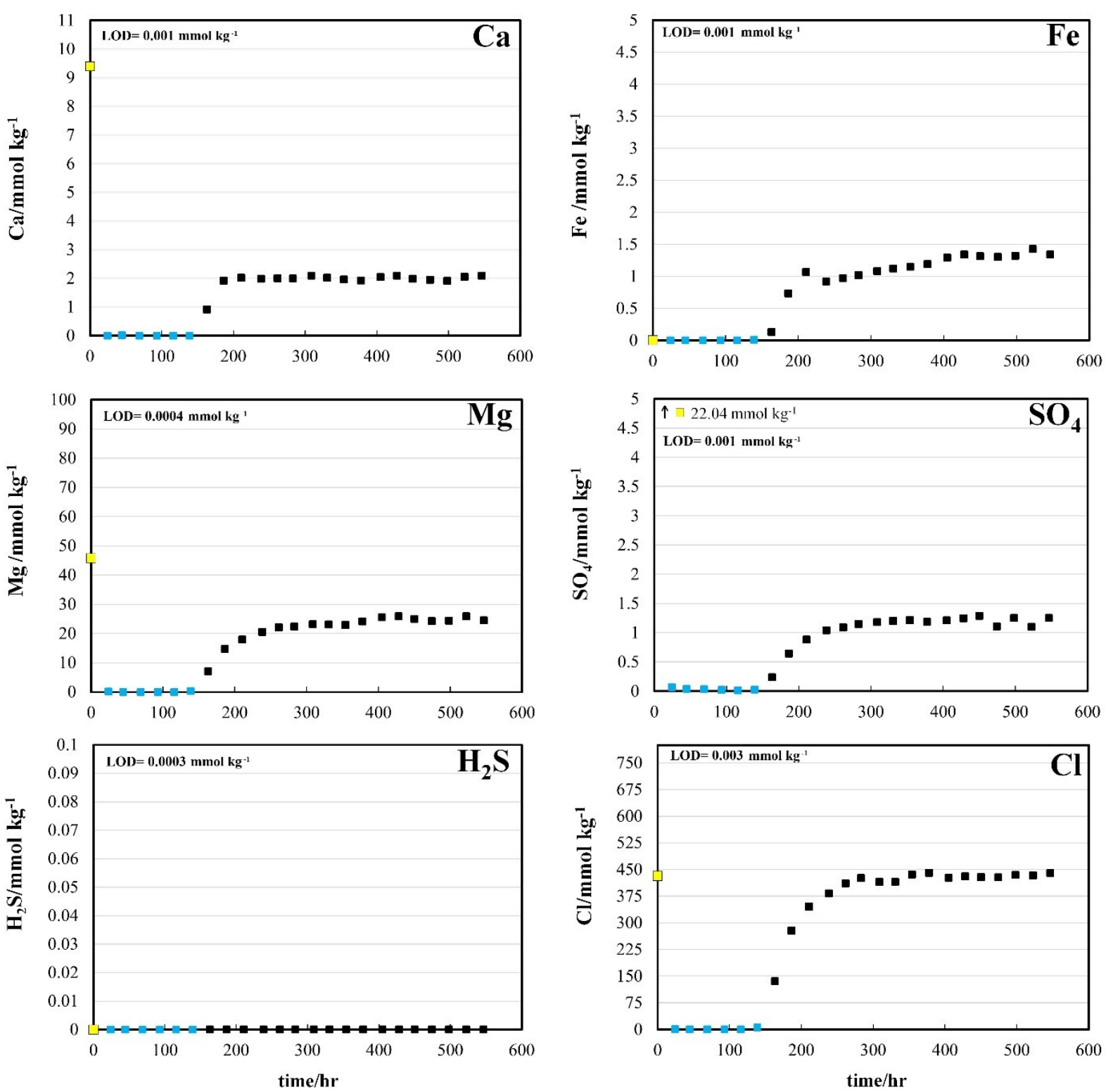

$\square \triangle$ blank seawater

- $377^{\circ} \mathrm{C} / 488 \mathrm{bar} / 1 \mathrm{ml} \mathrm{hr}^{-1}$ (distilled water)

口 $377^{\circ} \mathrm{C} / 488 \mathrm{bar} / 1 \mathrm{ml} \mathrm{hr}{ }^{-1}$ (seawater) 


\subsubsection{Trace element concentrations}

Figure 5.5 and Figure 5.6 show the trace element results plotted against time in hours. The unreacted natural seawater concentrations are shown at $\mathrm{t}=0$. Most trace elements are below detection limit with only $\mathrm{V}, \mathrm{Rb}, \mathrm{Au}$ and $\mathrm{Mn}$ showing detectable concentrations. The distilled water concentrations are not shown but are generally lower than seawater. Complete trace element results are listed in Appendix D.

While distilled water exits the Preheater ( 0 - $163 \mathrm{hr})$ trace element concentrations are low and irregular with perhaps small increases in $\mathrm{Cr}, \mathrm{Zn}$, and $\mathrm{Ba}$. This indicates that the $\mathrm{ZrO}_{2}$ beads do not release significant amounts of trace elements at $377^{\circ} \mathrm{C}$ in the presence of distilled water.

Once seawater begins to exit the Preheater several elements including V, Co, Ni, and perhaps $\mathrm{Pb}$, display increasing concentration with time over the experiment. The values are much higher than the input seawater values and therefore must be derived from the $\mathrm{ZrO}_{2}$ beads. Unfortunately, we do not have trace element analyses for the beads. The in situ $\mathrm{pH}$ and ionic strength of the fluid are constant after about 300 hours, therefore, the reason for the upward trends over time is uncertain but is attributed to some kinetic surface area effect of the $\mathrm{ZrO}_{2}$ beads.

$\mathrm{Mn}$ and Au show trends that are similar to Fe (Fig. 5.4) indicating regular extraction from the beads. The concentrations of $\mathrm{Cr}$ and $\mathrm{Cu}$ remain low and irregular while $\mathrm{Zn}$ concentrations shown no clear trend and are likely spurious and subject to contamination.

The results for $\mathrm{Rb}$ show a mixing line identical with $\mathrm{Cl}$ and this suggests derivation from the seawater. However, the blank value is not at the level expected for natural seawater. The average global concentration of $\mathrm{Rb}$ in seawater is $1.4 \mu \mathrm{mol} \mathrm{kg}^{-1}$ (Smith et al., 1965). Given that the seawater is slightly diluted, the final concentration of $1 \mu \mathrm{mol} \mathrm{kg}^{-1}$ seems reasonable.

Barium shows unique behaviour with its highest concentration of $7 \mu \mathrm{mol} \mathrm{kg}{ }^{-1}$ found in the first sample after which it continuously decreases to a final value of $\sim 0.5 \mu \mathrm{mol} \mathrm{\textrm {kg } ^ { - 1 }}$. The average global concentration of $\mathrm{Ba}$ in seawater is only $0.04 \mu \mathrm{mol} \mathrm{kg}{ }^{-1}$ (Field et al., 2007; Hsieh and Henderson, 2017), therefore, Ba must be efficiently extracted from the beads after which it declines to $10 \mathrm{x}$ seawater concentration. Also, Ba concentrations decrease with increasing $\mathrm{SO}_{4}$ concentrations suggesting precipitation of barite. The minor amount of barite precipitated would be difficult to identify in SEM examination. 
Figure 5.5. Trace element concentrations in blank and effluent samples ( $\mu \mathrm{mol} \mathrm{kg}{ }^{-1}$ ) versus time (hr) for the $\mathrm{SW} 1$ experiment at $377^{\circ} \mathrm{C} / 488$ bar and $1.0 \mathrm{ml} \mathrm{hr}^{-1}$ flow rate. Yellow symbols are the blank sample composition of natural seawater. Blue symbols show where distilled water was exiting the Preheater. Black symbols are effluent compositions during mixing and replacement of distilled water by seawater.
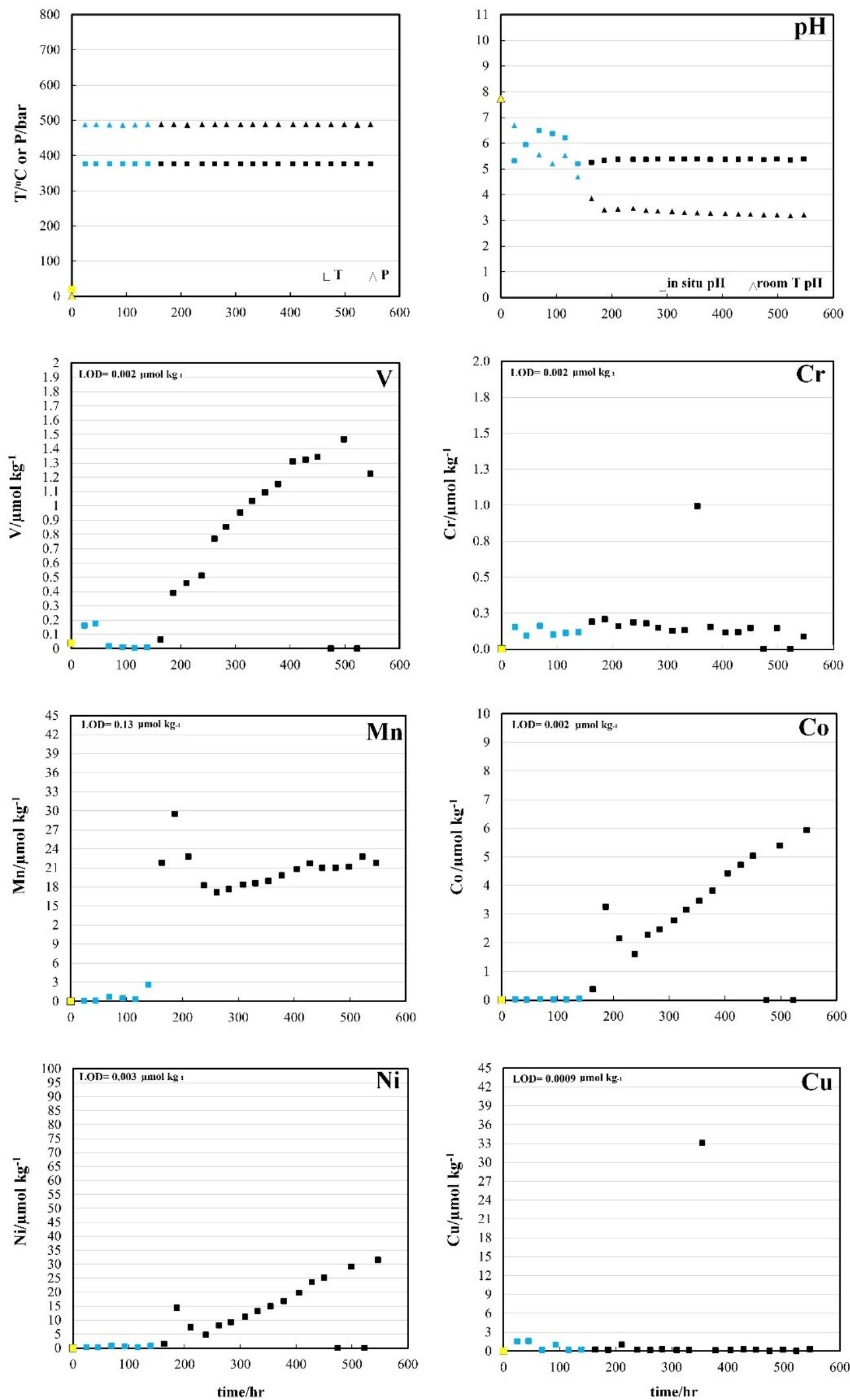

$\sqcup \wedge$ blank scawater

- $377^{\circ} \mathrm{C} / 488 \mathrm{bar} / 1 \mathrm{ml} \mathrm{hr}{ }^{-1}$ (distilled water)

- $377^{\circ} \mathrm{C} / 488 \mathrm{bar} / 1 \mathrm{ml} \mathrm{hr}^{-1}$ (scawater) 
Figure 5.6. Trace element concentrations in blank and effluent samples ( $\mu \mathrm{mol} \mathrm{kg}{ }^{-1}$ ) versus time (hr) for the $\mathrm{SW} 1$ experiment at $377^{\circ} \mathrm{C} / 488$ bar and $1.0 \mathrm{ml} \mathrm{hr}^{-1}$ flow rate. Yellow symbols are the blank sample composition of natural seawater. Blue symbols show where distilled water was exiting the Preheater. Black symbols are effluent compositions during mixing and replacement of distilled water by seawater.
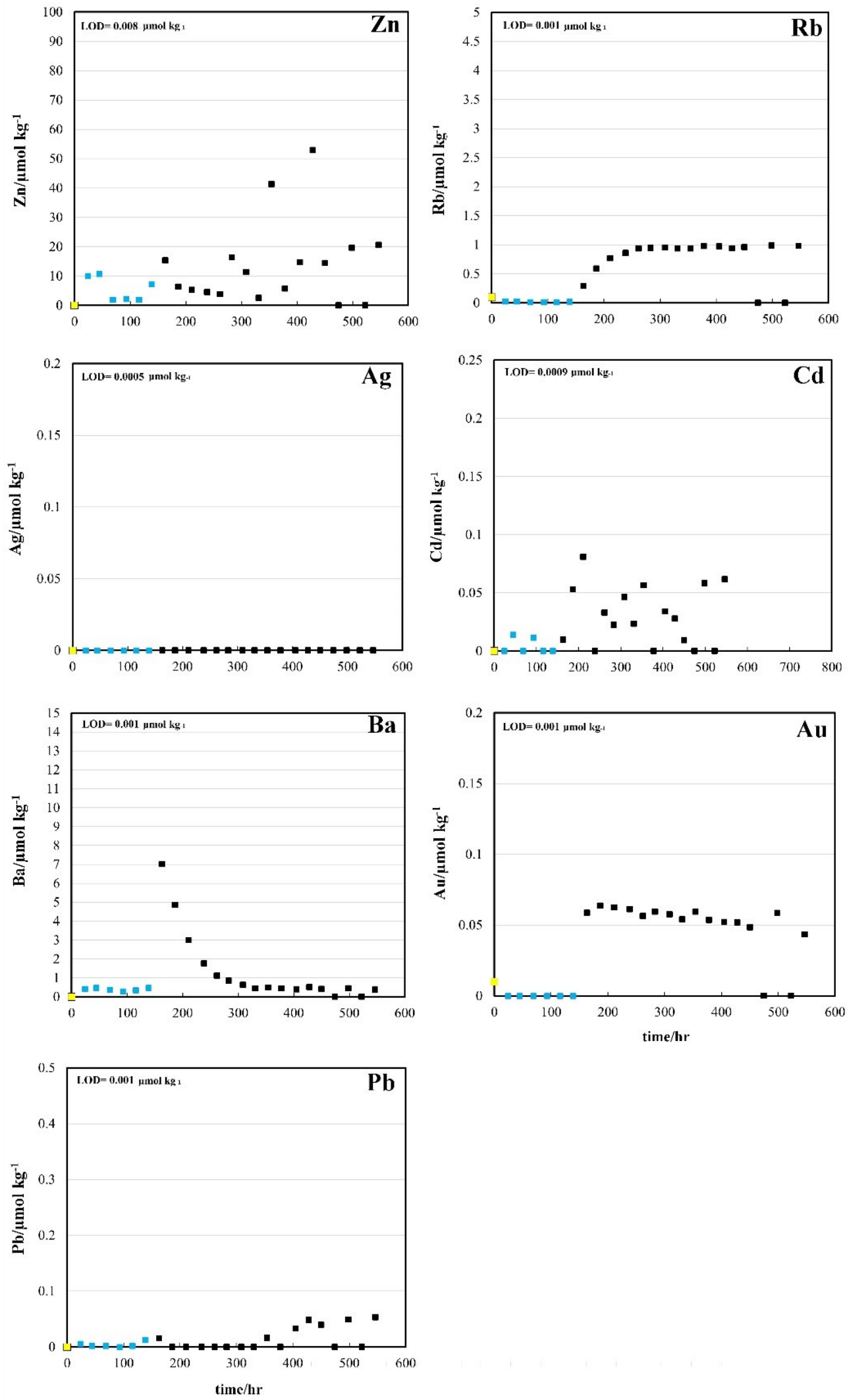

$\sqcup \triangle$ blank seawater

- $377^{\circ} \mathrm{C} / 488 \mathrm{bar} / 1 \mathrm{ml} \mathrm{hr}^{-1}$ (distilled water)

- $377^{\circ} \mathrm{C} / 488 \mathrm{bar} / 1 \mathrm{ml} \mathrm{hr}^{-1}$ (seawater) 


\subsubsection{Mineralogy of precipitated phases}

Mineral precipitates and beads were selected from the bottom of the Preheater (Fig. 5.7, rectangular area). These were mounted on Al stubs for SEM-EDS analysis. Appendix D contains complete SEM results.

Figure 5.7. Schematic diagram (not to scale) of the Preheater for the SW1 experiment with natural seawater. Rectangular area in red indicates where reacted $\mathrm{ZrO}_{2}$ beads were collected.

\section{PREHEATER}

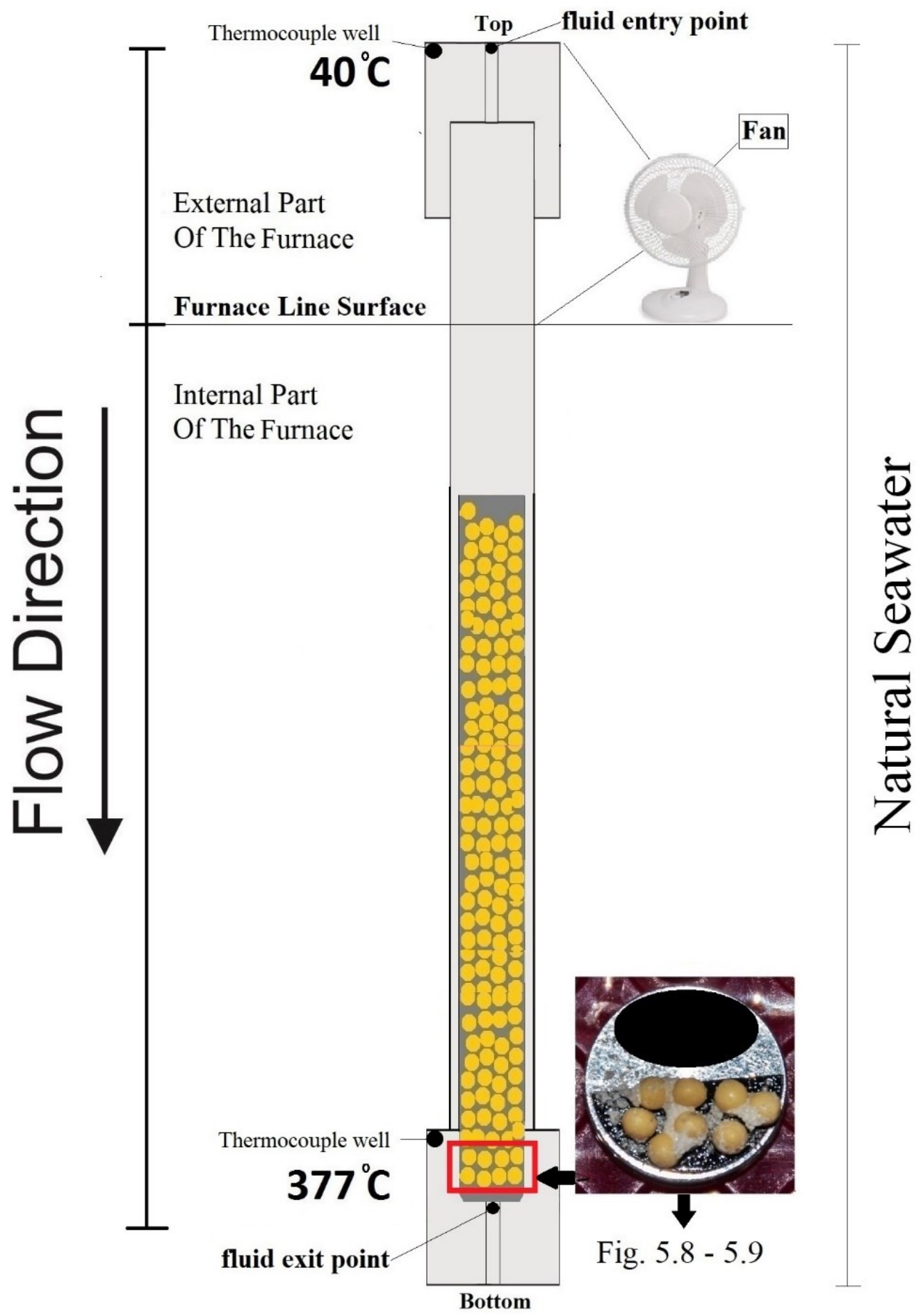




\section{SEM-EDS analysis}

SEM-EDS results confirm the white mineral precipitate to be composed of anhydrite, Mg sulfate or hydroxysulfate, and brucite (Table 5.1). No evidence of Mg-silicate/talc was found during analysis. The average SEM-EDS analysis of the Mg phase (Table 5.2) shows a $\mathrm{Mg}: \mathrm{S}$ molar ratio of $\sim 2.2: 1.2$. In nature, a mineral of this composition has not been identified. However, given the semi-quantitative nature of the EDS analyses (similar analyses of anhydrite gave a $\mathrm{Ca}: \mathrm{S}$ ratio of $\sim 2: 2.2)$ it is likely that this is the mineral caminite $\left(\mathrm{Mg}_{7}\left(\mathrm{SO}_{4}\right)_{5}(\mathrm{OH})_{4} \cdot \mathrm{H}_{2} \mathrm{O}\right.$ or $\left.\mathrm{MgSO}_{4}: 0.4 \mathrm{Mg}(\mathrm{OH})_{2}: 0.2 \mathrm{H}_{2} \mathrm{O}\right)$ which has an ideal $\mathrm{Mg}: \mathrm{S}$ ratio of 2:1.4. There is some variability in the $\mathrm{Mg}(\mathrm{OH})_{2}$ component in caminite which could accommodate slight differences in the $\mathrm{Mg}: \mathrm{S}$ ratio (Haymon and Kastner, 1986).

Caminite has the crystal form of tetragonal bipyramidal which is consistent with crystals found in the experiments (Fig. 5.9, 5.15, 6.6). Caminite was identified as a naturally occurring mineral in precipitates from black smoker chimneys on the East Pacific Rise relatively recently (Haymon and Kastner, 1986). There are several different $\mathrm{Mg}$ hydroxysulfate formulas in the literature such as $\operatorname{MHSH}(0.67)$ or $\mathrm{MgSO}_{4}: 1 / 3 \mathrm{Mg}(\mathrm{OH})_{2}: 1 / 3 \mathrm{H}_{2} \mathrm{O}$ (Hochella et al., 1983; Keefer et al., 1981), $\mathrm{MHSH}(0.625)$ or $\mathrm{MgSO}_{4}: 1 / 4 \mathrm{Mg}(\mathrm{OH})_{2}: 1 / 2 \mathrm{H}_{2} \mathrm{O}, \quad \operatorname{MHSH}(0.16) \quad$ or $\quad \mathrm{MgSO}_{4}: 1 / 6 \mathrm{Mg}(\mathrm{OH})_{2}: 2 / 3 \mathrm{H}_{2} \mathrm{O}$, and $\operatorname{MHSH}(0.75)$ or $\mathrm{MgSO}_{4}: 1 / 2 \mathrm{Mg}(\mathrm{OH})_{2}$ (Bischoff and Rosenbauer, 1983; Fleet and Knipe, 1997; Janecky and Seyfried, 1983). The Mg-hydroxysulfate precipitate found in the experiments of Bischoff and Seyfried (1978) is also considered to be caminite.

Table 5.1. Mineral phases identified during analysis of the precipitates collected from the bottom of the Preheater (Fig. 5.8 - 5.9) after the SW1 experiment. Analysis were made by SEM-EDS. Appendix D contains all SEM for this study.

\begin{tabular}{|ccc|}
\hline $\begin{array}{c}\text { Type of } \\
\text { Analysis }\end{array}$ & $\begin{array}{c}\text { Mineral } \\
\text { Identified }\end{array}$ & Mineral Composition \\
SEM-EDS & Anhydrite & $\mathrm{CaSO}_{4}$ \\
SEM-EDS & Caminite & $\mathrm{Mg}_{7}\left(\mathrm{SO}_{4}\right)_{5}(\mathrm{OH})_{4} \cdot \mathrm{H}_{2} \mathrm{O}$ \\
SEM-EDS & Brucite & $\mathrm{Mg}(\mathrm{OH})_{2}$ \\
\hline
\end{tabular}

Table 5.2. Average composition (SEM-EDS analysis) of caminite from the bottom of the Preheater (Fig. 5.8 - 5.9) after the SW1 experiment.

\begin{tabular}{|ccc|}
\hline & $\begin{array}{c}\text { Caminite } \\
(\mathbf{N}=\mathbf{5})\end{array}$ & \\
& & \\
oxide & average & $\pm 1 \sigma$ \\
& Wt $\%$ & \\
MgO & 46.10 & 3.33 \\
SO3 & 53.90 & 3.33 \\
Total & 100.00 & \\
\hline
\end{tabular}


Figure 5.8 shows SEM backscatter images and EDS maps of the mineral phases collected from the bottom of the Preheater after the SW1 experiment (Fig. 5.7, rectangular area). The composite colour image shows crystals of anhydrite and caminite. Anhydrite appears as euhedral rectangular crystals while caminite occurs as polyhedral grains.

Figure 5.9 shows SEM images of reacted $\mathrm{ZrO}_{2}$ beads collected from the bottom of the Preheater. The surface of the beads shows larger crystals of caminite with lesser anhydrite (Fig. 5.9a-c). Brucite was also identified as discreet polygonal crystals (Fig. 5.9d) and as diamond-shaped growths on the surface of the beads (Fig. 5.9a,e,f). These diamond-shaped growths are composed of contiguous crystals of brucite along the outside edge with isolated growths within (Fig 5.9e).

Figure 5.8. SEM backscatter images and EDS compositional maps of the precipitate collected from the bottom of the Preheater after the SW1 experiment: (a) digital camera image of the precipitate; (b) backscatter image of rectangular area in (a); (c) composite colour image combining the backscatter image and elemental maps for d) $\mathrm{Ca}$ in green, e) $\mathrm{Mg}$ in red, and f) $\mathrm{S}$ in blue.
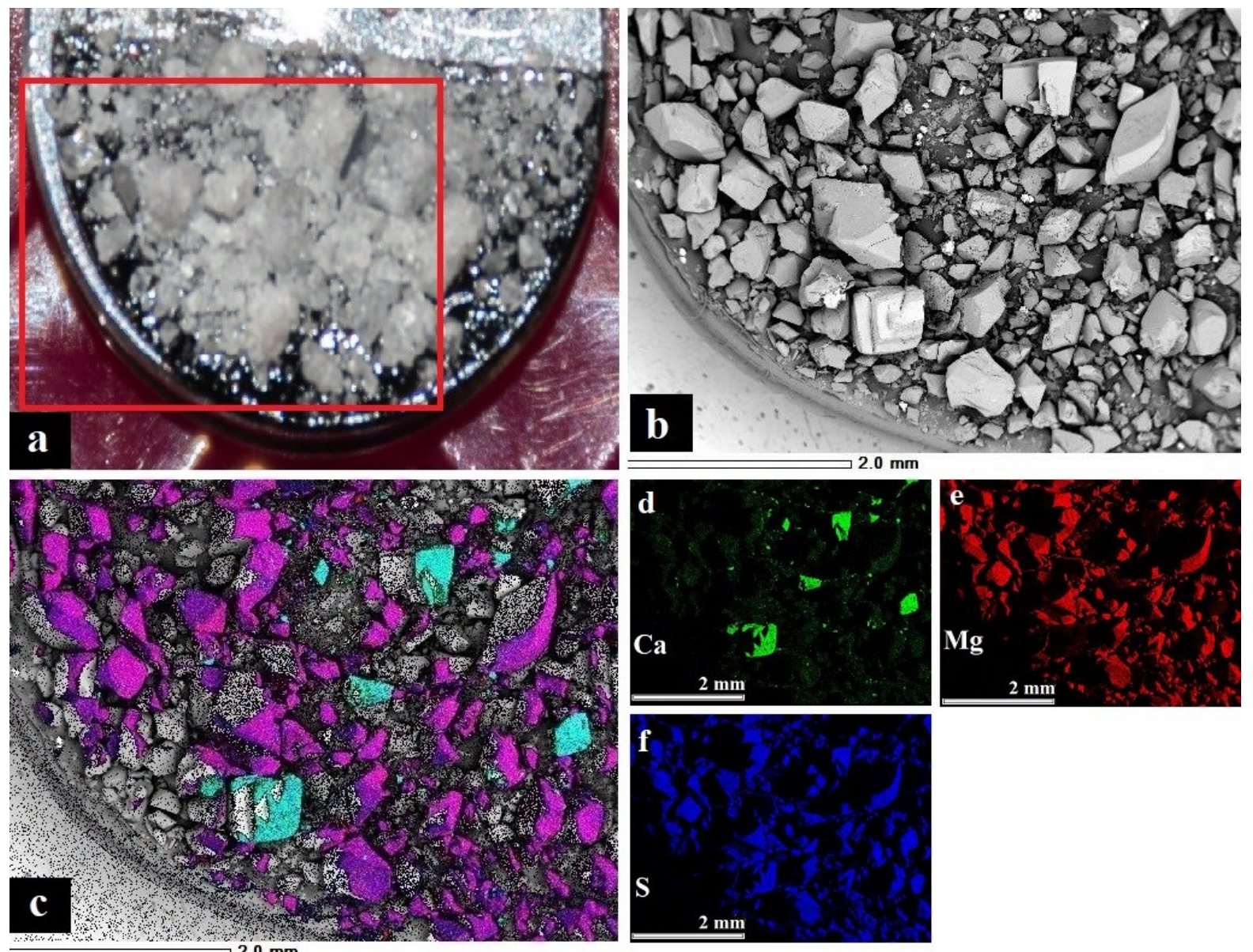
Figure 5.9. SEM images of reacted $\mathrm{ZrO}_{2}$ beads collected from the bottom of the Preheater after the SW1 experiment: a) SED image of a single bead with one caminite crystal and diamond-shaped growths of brucite; b) SED image of a single bead with several crystals of caminite; c) BED image of bead with of anhydrite (Anh) and caminite; (d) BED image showing a caminite crystal with intergrown brucite; (e) SEM backscatter image of rectangular area in (a) showing diamond-shaped growth of brucite; (f) composite colour image combining the backscatter image and elemental map for $\mathrm{Mg}$ in red.
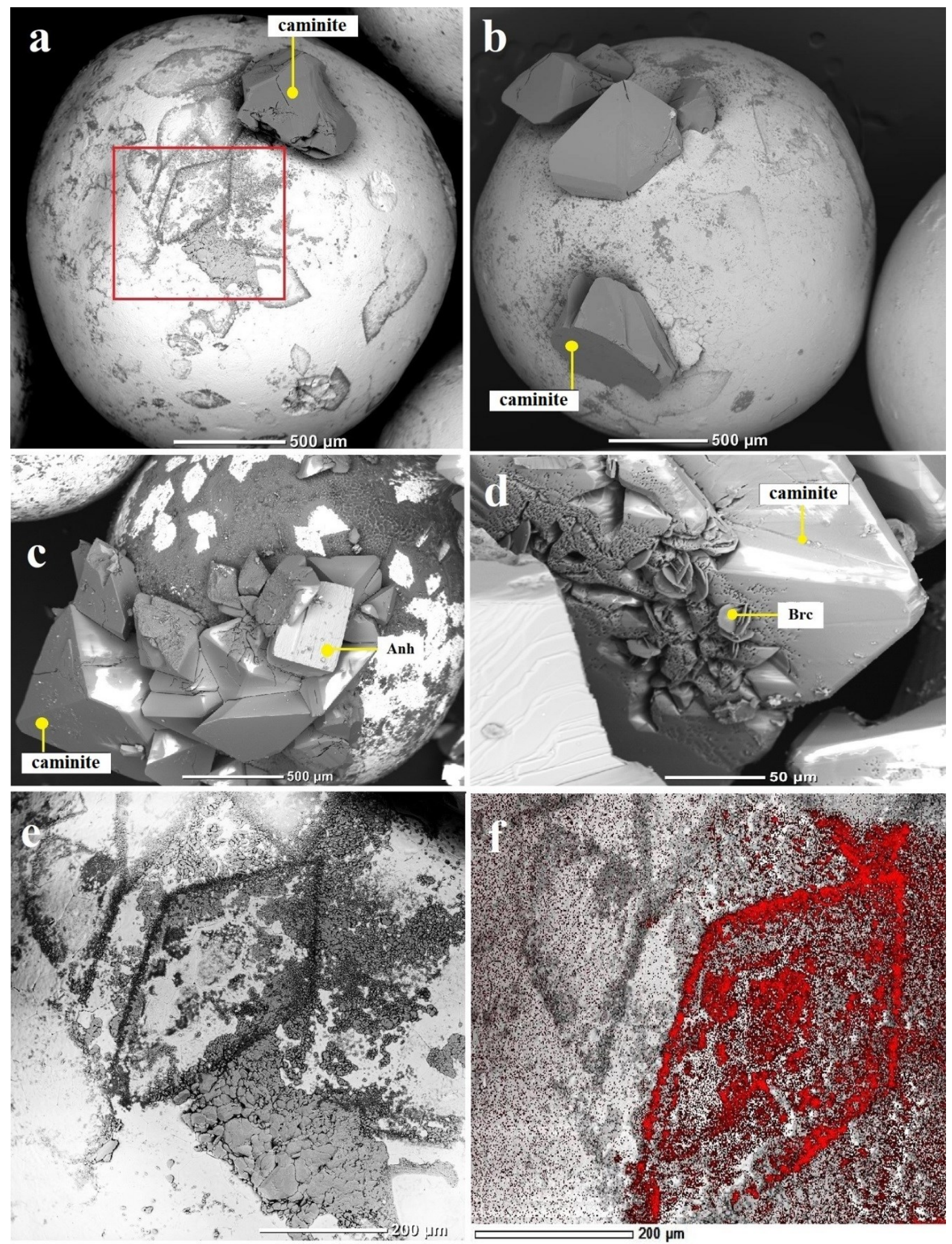


\subsubsection{SW2: Natural seawater $\left(342^{\circ} \mathrm{C} / 488\right.$ bar $)$}

The second seawater-only experiment (SW2) ran for a total time of $381 \mathrm{hrs}$. There was no room temperature period. The heating procedure using distilled water, initially in the Preheater, was the same as utilised for SW1. The flow rate was $1 \mathrm{ml} \mathrm{hr}^{-1}$ and analyses for major and trace elements were made for the total number of fluid samples collected (16).

\subsubsection{Major element concentrations}

Appendix D lists the complete experimental parameters ( $\mathrm{T}, \mathrm{P}$, time, flow rate, in situ and room $\mathrm{T}$ pH, chemistry). Figure 5.10 and Figure 5.11 show these results plotted against time in hours. The unreacted natural seawater composition is shown at $t=0$. The blank composition of distilled water is not shown. The concentrations of major ions for the first 50 hrs are essentially for distilled water as it required at least 2 days for seawater to begin to exit the Preheater at $1 \mathrm{ml} \mathrm{hr}^{-1}$.

The room temperature $\mathrm{pH}$ for the unreacted seawater is 7.65 . Once the seawater begins to exit the Preheater, in situ $\mathrm{pH}$ stabilises at $\sim 5.5$ while quench $\mathrm{pH}$ decreases to $\sim 2.7$ for the remainder of the experiment.

At $\sim 80$ hours, $\mathrm{SiO}_{2}$ concentrations begin to increase and stabilised at a value of $\sim 0.25$ mmol kg-1 (Fig. 5.10). As in $\mathrm{SW} 1, \mathrm{SiO}_{2}$ is derived from the $\mathrm{ZrO}_{2}$ beads. Note that this concentration is insignificant when compared to concentrations encountered in experiments using basalt.

A similar explanation can be applied the behavior of Fe. Aluminum concentrations do not show any consistent increase in concentration. Iron only increases when seawater passes through the Preheater. This is attributed to dissolution from the beads (Fig. 5.11). Iron reaches a maximum concentration of $\sim 1.8 \mathrm{mmol} \mathrm{kg}^{-1}$ while $\mathrm{Al}$ concentrations are at or below detection limit for the entire experiment. The Fe concentrations are insignificant when compared to the basalt experiments.

For $\mathrm{Na}, \mathrm{K}$, and $\mathrm{Cl}$, results show conservative behavior, as in the experiment at $377^{\circ} \mathrm{C}$. The $\mathrm{K}, \mathrm{Na}$ and $\mathrm{Cl}$ concentrations reach seawater values after displacement of the distilled water at six days.

Significant changes are encountered with the other major components $\mathrm{Ca}, \mathrm{Mg}$, and $\mathrm{SO}_{4}$ present in seawater. The seawater contains $8 \mathrm{mmol} \mathrm{kg}^{-1} \mathrm{Ca}$ (Fig. 5.11). While distilled water is exiting the Preheater, Ca concentrations remain at detection limit. Once seawater begins to exit the $\mathrm{Ca}$ concentration rises to reach $\sim 1.7 \mathrm{mmol} \mathrm{kg}^{-1}$ after six days and then 
decreases to $1.4 \mathrm{mmol} \mathrm{kg}^{-1}$ for the remainder of the experiment. This represents a significant decrease in $\mathrm{Ca}$ concentration from the original seawater.

The $\mathrm{Mg}$ concentration in the seawater is $36.7 \mathrm{mmol} \mathrm{kg}^{-1}$. While distilled water is exiting the Preheater, $\mathrm{Mg}$ concentrations remain low. Upon the exit of seawater, the $\mathrm{Mg}$ concentrations increase gradually and maintain a final concentration of $22.8 \mathrm{mmol} \mathrm{kg}^{-1}$. As with $\mathrm{Ca}$, there is a significant loss of $\mathrm{Mg}$ during the experiment.

The above changes in $\mathrm{Ca}$ and $\mathrm{Mg}$ concentrations reflect the changes in $\mathrm{SO}_{4}$. The input $\mathrm{SO}_{4}$ concentration for the seawater is $23 \mathrm{mmol} \mathrm{kg}^{-1}$ (Fig. 5.11). While distilled water exits the Preheater, $\mathrm{SO}_{4}$ concentrations are low. Upon exit of seawater, $\mathrm{SO}_{4}$ increases and maintains a final concentration of $2.7 \mathrm{mmol} \mathrm{kg}$. The behavior of $\mathrm{Ca}, \mathrm{Mg}$, and $\mathrm{SO}_{4}$ indicate significant precipitation of secondary phases. The total loss of $\mathrm{Ca}$ is $6.6 \mathrm{mmol} \mathrm{kg}^{-1}$, for $\mathrm{Mg} 13.9 \mathrm{mmol}$ $\mathrm{kg}^{-1}$ and for $\mathrm{SO}_{4} 20.3 \mathrm{mmol} \mathrm{kg}^{-1}$. If it is assumed that all Ca came from the seawater, this implies that $6.6 \mathrm{mmol} \mathrm{kg}^{-1}$ of $\mathrm{SO}_{4}$ precipitated as anhydrite. This means that there is 13.7 mmol kg${ }^{-1}$ left to form caminite which would require $19.2 \mathrm{mmol} \mathrm{kg}^{-1}$ of $\mathrm{Mg}$. This is greater than amount of $\mathrm{Mg}$ lost, thus implying another source of $\mathrm{Mg}$ other than the seawater. This must be from the $\mathrm{ZrO}_{2}$ beads which contain 3\% MgO.

There were no detectable concentrations of $\mathrm{H}_{2} \mathrm{~S}$ during the experiment (Fig. 5.11). This indicates that no measurable amount of sulfate reduction was occurring at $342^{\circ} \mathrm{C}$. 
Figure 5.10. Major element concentrations in blank and effluent samples ( $\mathrm{mmol} \mathrm{kg}^{-1}$ ) versus time (hr) for the $\mathrm{SW} 2$ experiment at $342^{\circ} \mathrm{C} / 488$ bar and $1.0 \mathrm{ml} \mathrm{hr}^{-1}$ flow rate. Yellow symbols are the blank sample composition of natural seawater. Blue symbols show where distilled water was exiting the Preheater. Black symbols are effluent compositions during mixing and replacement of distilled water by seawater.
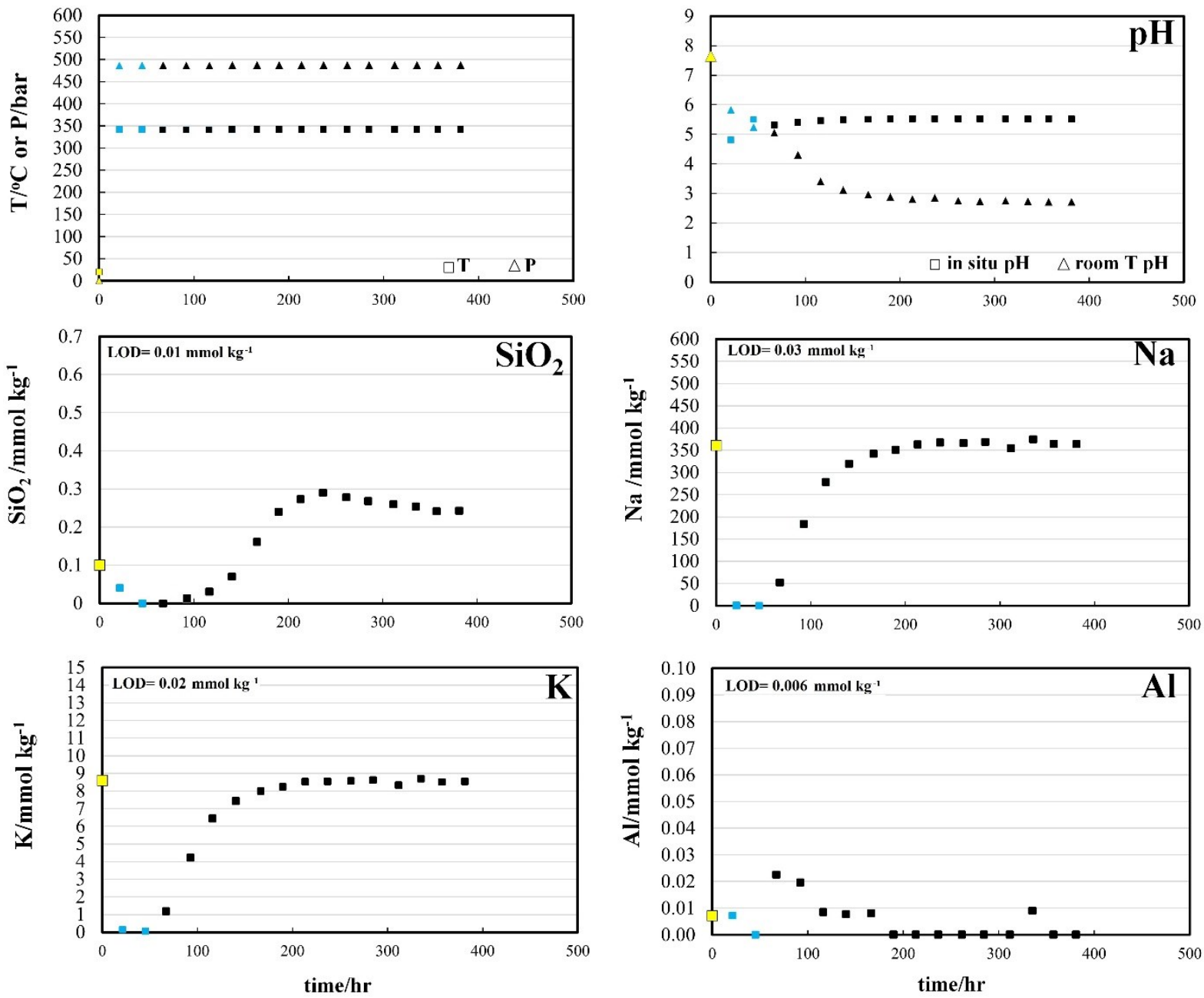

$\square \triangle$ blank seawater

- $342^{\circ} \mathrm{C} / 488 \mathrm{bar} / 1 \mathrm{ml} \mathrm{hr}{ }^{-1}$ (distilled water)

口 $\Delta 42^{\circ} \mathrm{C} / 488 \mathrm{bar} / 1 \mathrm{ml} \mathrm{hr}{ }^{-1}$ (seawater) 
Figure 5.11. Major element concentrations in blank and effluent samples $\left(\mathrm{mmol} \mathrm{kg}^{-1}\right)$ versus time (hr) for the $\mathrm{SW} 2$ experiment at $342^{\circ} \mathrm{C} / 488$ bar and $1.0 \mathrm{ml} \mathrm{hr}^{-1}$ flow rate. Yellow symbols are the blank sample composition of natural seawater. Blue symbols show where distilled water was exiting the Preheater. Black symbols are effluent compositions during mixing and replacement of distilled water by seawater.
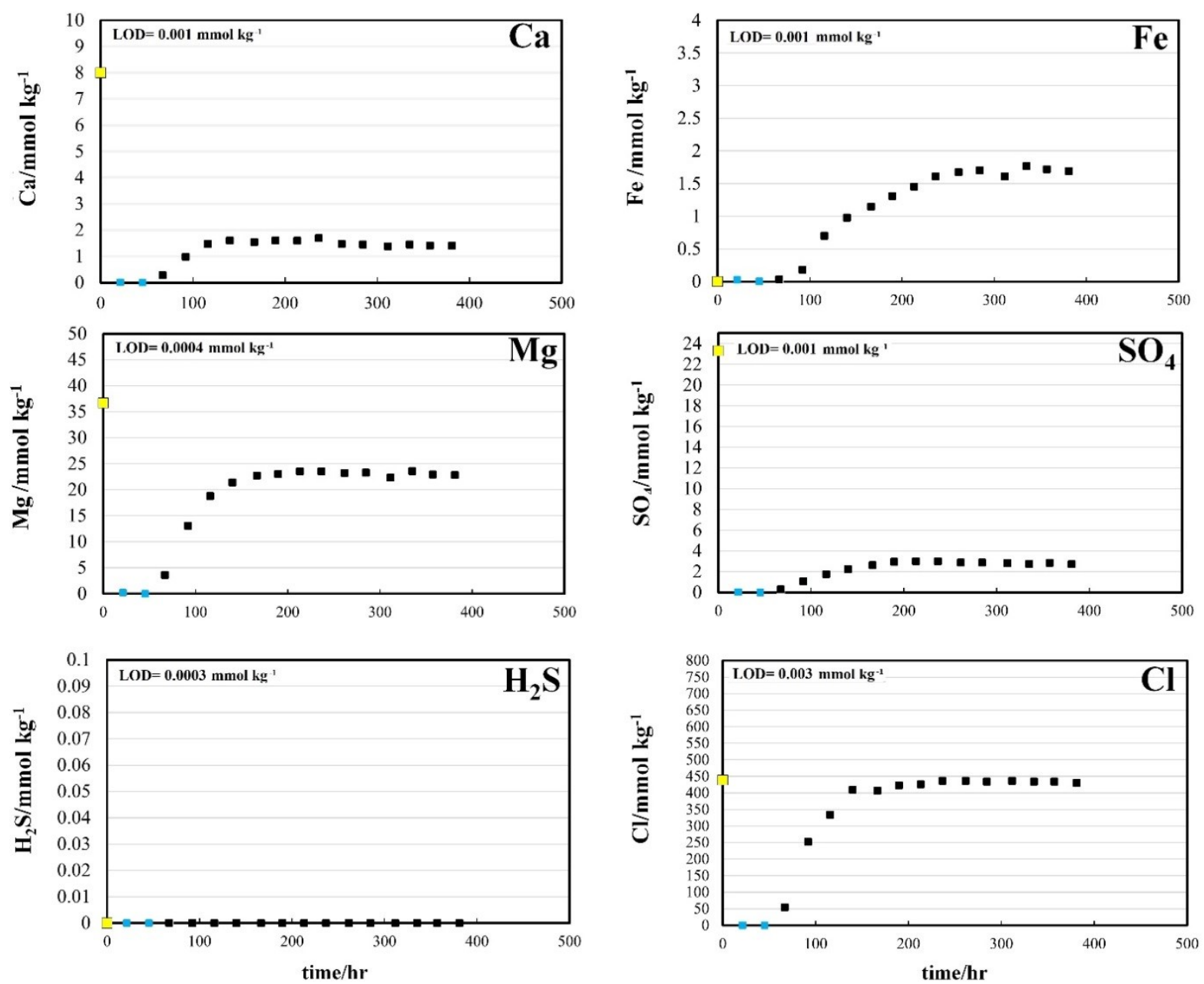

$\square \triangle$ blank seawater

- $342^{\circ} \mathrm{C} / 488 \mathrm{bar} / 1 \mathrm{ml} \mathrm{hr}^{-1}$ (distilled water)

- A $342^{\circ} \mathrm{C} / 488 \mathrm{bar} / 1 \mathrm{ml} \mathrm{hr}{ }^{-1}$ (seawater) 


\subsubsection{Trace element concentrations}

Complete trace element results are listed in Appendix D. Figure 5.12 and Figure 5.13 show these results plotted against time in hours. The unreacted natural seawater concentrations are shown at $\mathrm{t}=0$. Most trace elements are below detection limit with only $\mathrm{V}$, $\mathrm{Rb}, \mathrm{Au}$ and $\mathrm{Mn}$ showing detectable concentrations.

While distilled water exits the Preheater ( 0 - $50 \mathrm{hr})$, trace element concentrations are low and irregular with perhaps small increases in $\mathrm{Cr}, \mathrm{Zn}, \mathrm{Cd}, \mathrm{Ba}$ and $\mathrm{Pb}$. This indicates that the $\mathrm{ZrO}_{2}$ beads do not release significant amounts of trace elements also at $342^{\circ} \mathrm{C}$ in the presence of distilled water.

While seawater exits the Preheater, Ni displays increasing concentration with time over the experiment while $\mathrm{Mn}$ and Co reach a steady state in solution at $\sim 35$ and $15 \mu \mathrm{mol} \mathrm{\textrm {kg } ^ { - }}$ 1 , respectively. The values are much higher than the input seawater values and therefore must be derived from the $\mathrm{ZrO}_{2}$ beads.

$\mathrm{V}, \mathrm{Au}$ and also $\mathrm{Cd}$ show linear trends indicating regular extraction from the beads. The $\mathrm{Cr}$ concentration remains low and irregular while $\mathrm{Ag}$ and $\mathrm{Pb}$ appear close to detection limit for the entire experiment.

The results for $\mathrm{Rb}$ show the same behaviour as at $377^{\circ} \mathrm{C}$ with a final concentration of $1 \mu \mathrm{mol} \mathrm{kg}{ }^{-1}$. Given that the seawater used in the experiment was slightly dilute, this concentration seems reasonable.

The $\mathrm{Zn}$ and $\mathrm{Cu}$ concentrations initially show a significant increase in solution after full replacement of distilled water by seawater and then decrease to low values. The final

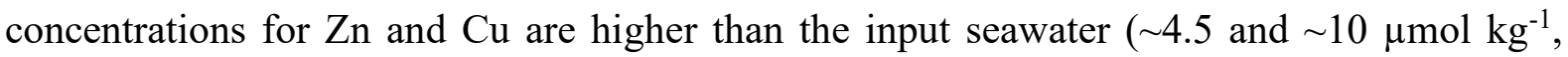
respectively). The absence of reduced $\mathrm{S}$ excludes precipitation of these elements in mineral

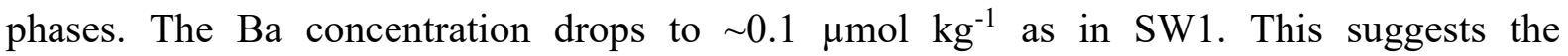
precipitation of barite at $342^{\circ} \mathrm{C}$. 
Figure 5.12. Trace element concentrations in blank and effluent samples ( $\left.\mu \mathrm{mol} \mathrm{kg}{ }^{-1}\right)$ versus time (hr) for the SW2 experiment at $342^{\circ} \mathrm{C} / 488$ bar and $1.0 \mathrm{ml} \mathrm{hr}^{-1}$ flow rate. Yellow symbols are the blank sample composition of natural seawater. Blue symbols show where distilled water was exiting the Preheater. Black symbols are effluent compositions during mixing and replacement of distilled water by seawater.
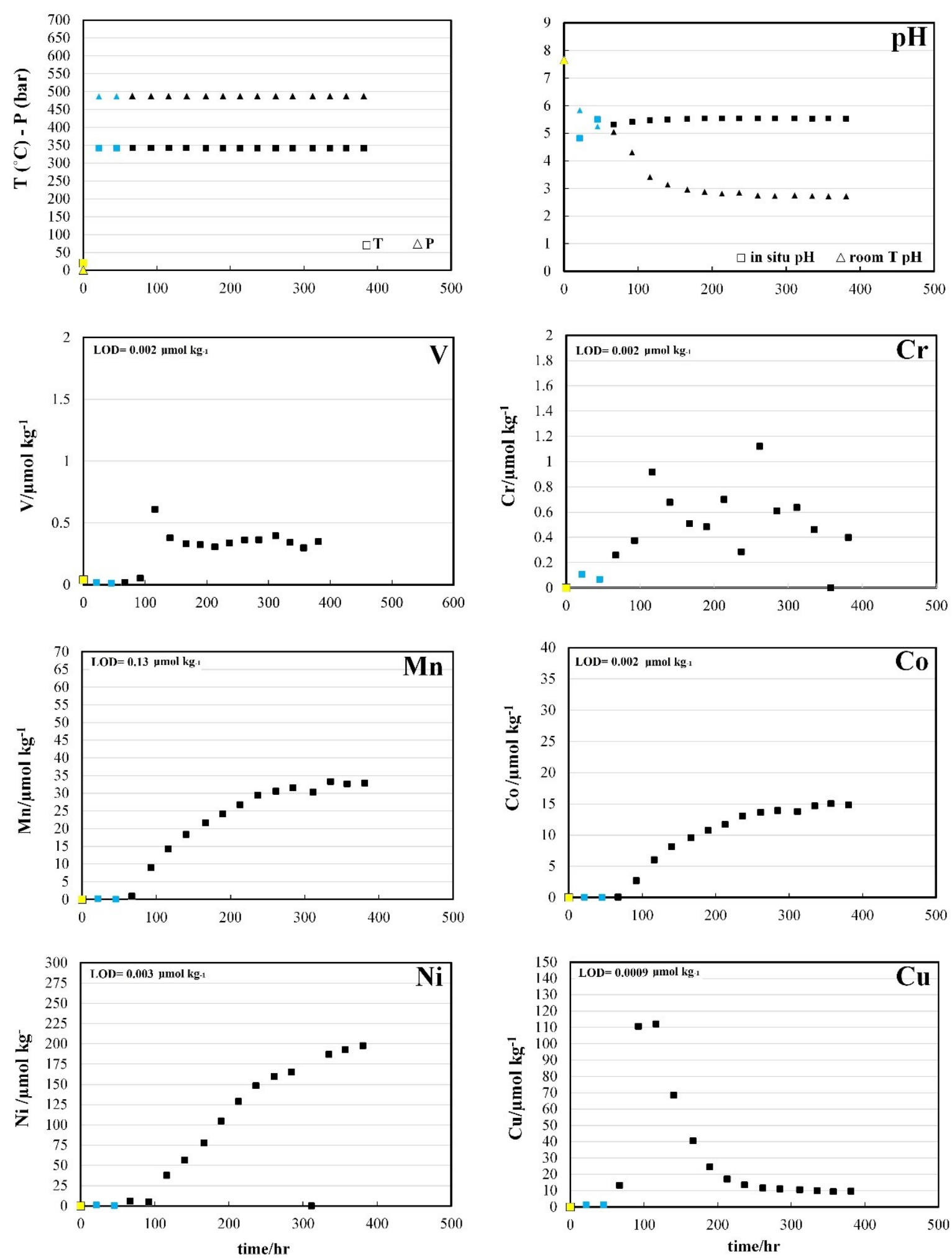

$\square \triangle$ blank seawater

- $342^{\circ} \mathrm{C} / 488 \mathrm{bar} / 1 \mathrm{ml} \mathrm{hr}{ }^{-1}$ (distilled water)

- $1422^{\circ} \mathrm{C} / 488 \mathrm{bar} / 1 \mathrm{ml} \mathrm{hr}{ }^{-1}$ (seawater) 
Figure 5.13. Trace element concentrations in blank and effluent samples ( $\left.\mu \mathrm{mol} \mathrm{kg}{ }^{-1}\right)$ versus time (hr) for the SW2 experiment at $342^{\circ} \mathrm{C} / 488$ bar and $1.0 \mathrm{ml} \mathrm{hr}^{-1}$ flow rate. Yellow symbols are the blank sample composition of natural seawater. Blue symbols show where distilled water was exiting the Preheater. Black symbols are effluent compositions during mixing and replacement of distilled water by seawater.
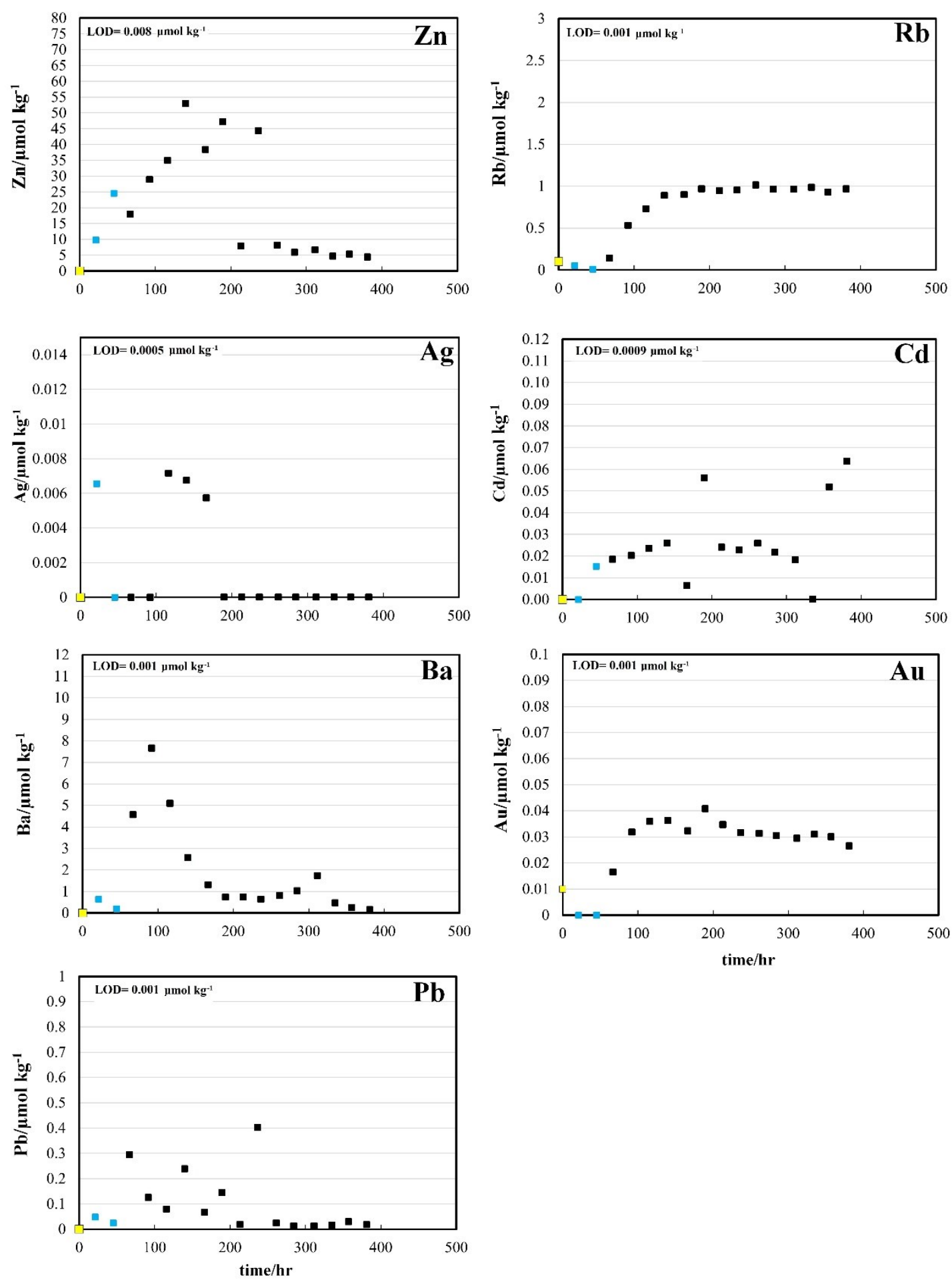

$\square \triangle$ blank seawater

- $342^{\circ} \mathrm{C} / 488 \mathrm{bar} / 1 \mathrm{ml} \mathrm{hr}^{-1}$ (distilled water)

- $342^{\circ} \mathrm{C} / 488 \mathrm{bar} / 1 \mathrm{ml} \mathrm{hr}^{-1}$ (seawater) 


\subsubsection{Mineralogy of precipitated phases}

$\mathrm{ZrO}_{2}$ beads and associated mineral precipitates were collected from the bottom of the Preheater (Fig. 5.14, rectangular area) and mounted on Al stubs for analysis by SEM-EDS. Appendix D contains complete SEM results.

Figure 5.14. Schematic diagram (not to scale) of the Preheater for the SW2 experiment with natural seawater. Rectangular area in red indicates where reacted $\mathrm{ZrO}_{2}$ beads were collected.

PREHEATER

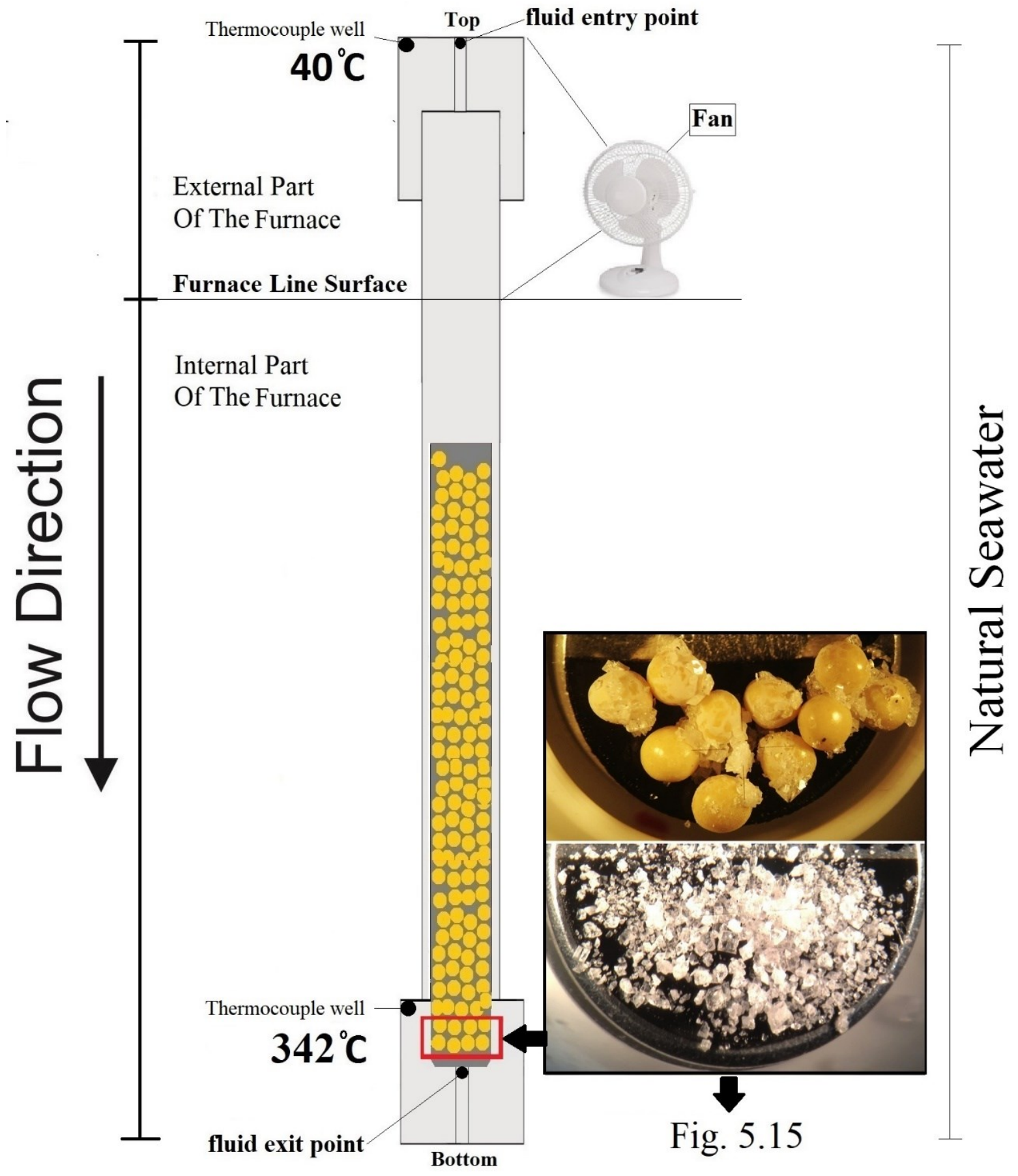


SEM-EDS results confirm that the white mineral precipitates are composed of anhydrite, Mg sulfate, and brucite (Table 5.4). SEM-EDS analysis of the Mg sulfate phase gives the $\mathrm{Mg}: \mathrm{S}$ ratio of 2:1.2 which is consistent with caminite.

Table 5.3. Mineral phases identified during analysis of the precipitates from the bottom of the Preheater (Fig. 5.15) after the SW2 experiment. Analysis were made by SEM-EDS. Appendix D contains all SEM for this study.

\begin{tabular}{|ccc|}
\hline $\begin{array}{c}\text { Type of } \\
\text { Analysis }\end{array}$ & $\begin{array}{c}\text { Mineral } \\
\text { Identified }\end{array}$ & Mineral Composition \\
SEM-EDS & Anhydrite & $\mathrm{CaSO}_{4}$ \\
SEM-EDS & Caminite & $\mathrm{Mg}_{7}\left(\mathrm{SO}_{4}\right)_{5}(\mathrm{OH})_{4} \cdot \mathrm{H}_{2} \mathrm{O}$ \\
SEM-EDS & Brucite & $\mathrm{Mg}(\mathrm{OH})_{2}$ \\
\hline
\end{tabular}

Table 5.4. Average composition (SEM-EDS analysis) of caminite from the bottom of the Preheater (Fig. 5.15) after the SW2 experiment.

\begin{tabular}{|ccc|}
\hline & $\begin{array}{c}\text { Caminite } \\
(\mathbf{N}=\mathbf{1})\end{array}$ & \\
& $\begin{array}{c}\text { average } \\
\text { Wt } \%\end{array}$ & $\pm 1 \sigma$ \\
oxide & & \\
& & \\
MgO & 45.58 & - \\
SO $_{3}$ & 54.42 & - \\
Total & 100.00 & \\
\hline
\end{tabular}

Figure 5.15 shows reacted $\mathrm{ZrO}_{2}$ beads collected from the bottom of the Preheater. The bead surfaces are covered by a mixture of cube-like anhydrite, polyhedral caminite, and hexagonal brucite (Fig. 5.15). 
Figure 5.15. SEM images of reacted $\mathrm{ZrO}_{2}$ beads collected from the bottom of the Preheater: (a) image of three reacted beads with precipitated phases; (b) surface of a reacted bead with the caminite and anhydrite (Anh); (c) surface area of a reacted bead with crystals of brucite; (d) a single brucite crystal.
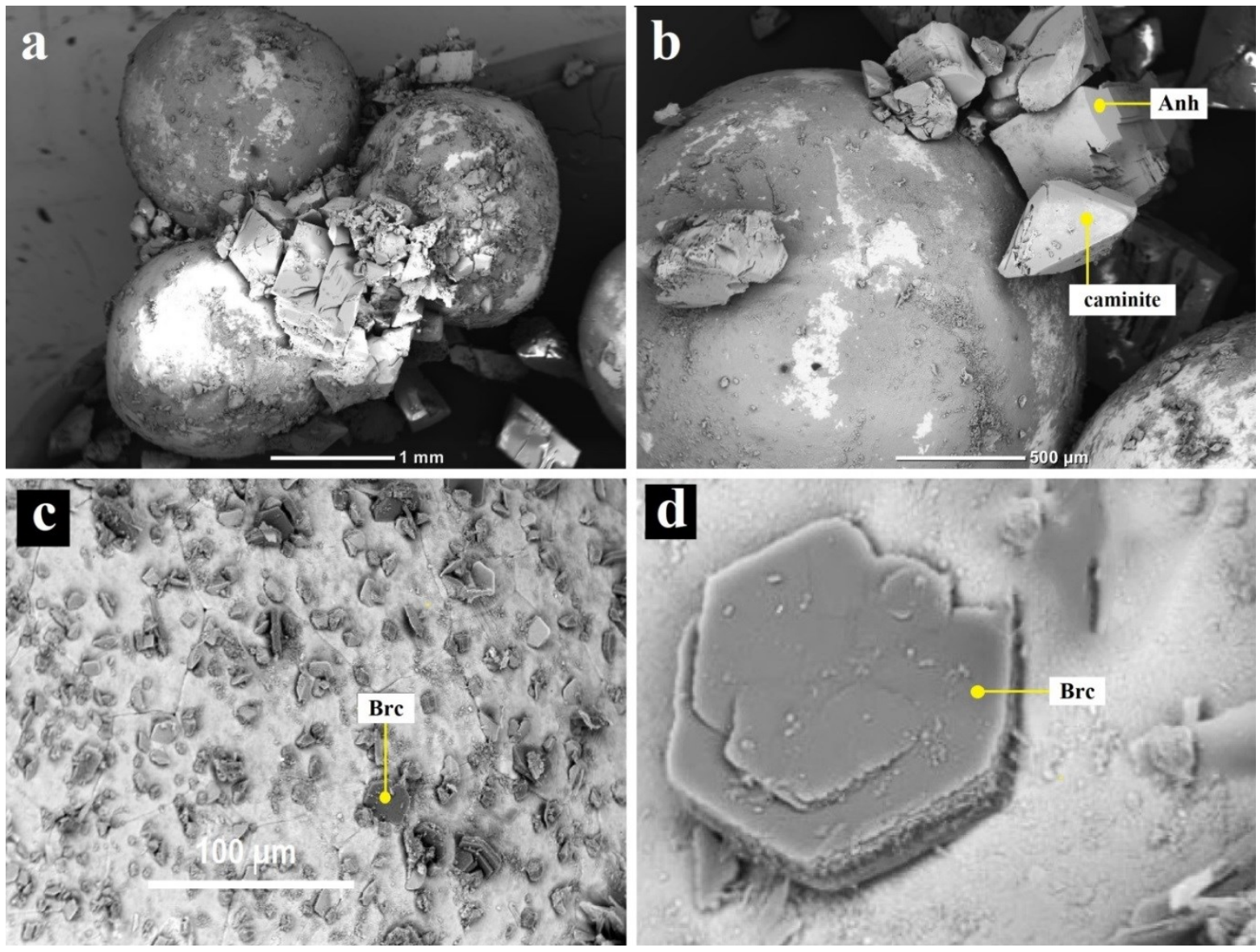


\subsection{Discussion}

Table 5.5 shows the input total mass $(\mathrm{mg})$ and integrated elemental fluxes $(\mathrm{mg})$ for selected components for the seawater-only experiments. The input total mass represents the amount of material that entered the Preheater based on the total fluid flux $(0.33 \mathrm{~L}$ in SW2 and $0.40 \mathrm{~L}$ in SW1) and the input seawater composition. The integrated elemental flux is the total mass of component integrated over the entire experiment based on daily fluid flux and the effluent composition. The calculations excluded the first six samples in SW1 and the first two samples in SW2, due to the time necessary for seawater to displace distilled water in the system.

For the SW2 $\left(342^{\circ} \mathrm{C}\right)$, the integrated flux calculation shows a positive net flux of +3.8 $\mathrm{mg} \mathrm{SiO} 2$ and $+23 \mathrm{mg}$ Fe to the fluid while SW1 $\left(377^{\circ} \mathrm{C}\right)$ has a net positive flux of $+17 \mathrm{mg}$ $\mathrm{SiO}_{2}$ and $+25 \mathrm{mg}$ Fe to the fluid. This can be explained by silica and iron released from the $\mathrm{ZrO}_{2}$ beads during the interaction with seawater.

At $342^{\circ} \mathrm{C}$, the total integrated flux is $-669 \mathrm{mg}$ for $\mathrm{SO}_{4},-89 \mathrm{mg}$ for $\mathrm{Ca}$, and $-130 \mathrm{mg}$ for $\mathrm{Mg}$. The results agree with the mineralogy identified by SEM-EDS. The significant decreases in $\mathrm{Ca}, \mathrm{Mg}$, and $\mathrm{SO}_{4}$ concentration can be explained by the precipitation of anhydrite, caminite, and brucite.

At $377^{\circ} \mathrm{C}$, the total integrated elemental flux is $-814 \mathrm{mg}$ for $\mathrm{SO}_{4},-121 \mathrm{mg}$ for $\mathrm{Ca}$, and $-235 \mathrm{mg}$ for $\mathrm{Mg}$. The SEM-EDS results also confirm that the significant decreases in $\mathrm{Ca}, \mathrm{Mg}$ and $\mathrm{SO}_{4}$ concentrations are explained by the precipitation anhydrite, caminite, and brucite. It is also noted that at $377^{\circ} \mathrm{C}$ there was significantly more $\mathrm{SO}_{4}, \mathrm{Ca}$, and $\mathrm{Mg}$ removed from solution when compared to the losses at $342^{\circ} \mathrm{C}$. This is consistent with the retrograde solubility of the precipitated phases. 
Table 5.5. Total input mass (mg) and integrated elemental fluxes (mg) for selected components for SW1 and SW2.

\begin{tabular}{|c|c|c|c|c|c|}
\hline $\begin{array}{c}\text { SW2 } \\
\left(342^{\circ} \mathrm{C} / 488 \text { bar }\right)\end{array}$ & $\mathrm{SiO}_{2}$ & $\mathrm{SO}_{4}$ & $\mathbf{C a}$ & Mg & $\mathbf{F e}$ \\
\hline Blank composition $\left(\mathrm{mg} \mathrm{kg}^{-1}\right)$ & 5.8 & 2237 & 321 & 892 & 0.1 \\
\hline $\begin{array}{c}\text { Total input mass }(\mathrm{mg}) \\
\text { (based on } 0.33 \mathrm{~L} \text { total natural seawater) }\end{array}$ & 1.9 & 746 & 107 & 297 & 0.03 \\
\hline $\begin{array}{l}\text { Total integrated elemental flux (mg) } \\
\text { (over the entire experiment) }\end{array}$ & +3.8 & -669 & -89 & -130 & +23 \\
\hline $\begin{array}{c}\text { SW1 } \\
\left(377^{\circ} \mathrm{C} / 488 \text { bar }\right)\end{array}$ & $\mathrm{SiO}_{2}$ & $\mathrm{SO}_{4}$ & $\mathbf{C a}$ & Mg & $\mathbf{F e}$ \\
\hline Blank composition $\left(\mathrm{mg} \mathrm{kg}^{-1}\right)$ & 6.7 & 2117 & 377 & 1112 & 0.1 \\
\hline $\begin{array}{c}\text { Total input mass }(\mathrm{mg}) \\
\text { (based on } 0.40 \mathrm{~L} \text { total natural seawater) }\end{array}$ & 2.7 & 856 & 152 & 450 & 0.04 \\
\hline $\begin{array}{l}\text { Total integrated elemental flux (mg) } \\
\text { (over the entire experiment) }\end{array}$ & +17.3 & -814 & -121 & -235 & +25 \\
\hline
\end{tabular}

The precipitation of brucite, anhydrite, and caminite, all produce $\mathrm{H}^{+}$ion as can be seen in the following reactions:

$$
\begin{gathered}
\mathrm{Mg}^{2+}+2 \mathrm{H}_{2} \mathrm{O} \leftrightarrow \mathrm{Mg}(\mathrm{OH})_{2(\mathrm{~s})}+2 \mathrm{H}^{+} \\
\mathrm{Ca}^{2+}+\mathrm{HSO}_{4}^{-} \leftrightarrow \mathrm{CaSO}_{4(\mathrm{~s})}+\mathrm{H}^{+} \\
7 \mathrm{Mg}^{2+}+5 \mathrm{SO}_{4}{ }^{2-}+5 \mathrm{H}_{2} \mathrm{O} \leftrightarrow \mathrm{Mg}_{7}\left(\mathrm{SO}_{4}\right)_{5}(\mathrm{OH})_{4} \cdot \mathrm{H}_{2} \mathrm{O}_{(s)}+4 \mathrm{H}^{+}
\end{gathered}
$$

At high temperature, $\mathrm{SO}_{4}$ is mostly protonated, occurring as $\mathrm{HSO}_{4}^{-}$, which dissociates upon cooling to room temperature, liberating protons and lowering $\mathrm{pH}$ to highly acidic values.

Using the in situ $\mathrm{pH}$ and individual species' activities calculated as described previously, the ion activity product ( $\log$ Q) were determined at 342 and $377^{\circ} \mathrm{C}$ (Fig. 5.16). The solubility product $\left(\log \mathrm{K}_{\mathrm{sp}}\right)$ for anhydrite and brucite were sourced from SUPCRT92 (Johnson et al., 1992). $\log \mathrm{K}_{\mathrm{sp}}$ for $\operatorname{MHSH}(0.625)$ and $\mathrm{MHSH}(0.75)$ were sourced by Janecky and Seyfried (1983) up to $350^{\circ} \mathrm{C}$. They observed $\mathrm{MHSH}(0.625)$ as the stable phase above $300^{\circ} \mathrm{C}$. The $\mathrm{K}_{\mathrm{sp}}$ for this phase is plotted in Figure 5.16, extrapolated linearly to $400^{\circ} \mathrm{C}$. The $\log \mathrm{Q}$ for caminite was determined using the species' activities and in situ $\mathrm{pH}$ calculated from our experiment data. Appendix D reports all calculations for solution composition and mineral saturation indices.

The $\log \mathrm{Q}$ for anhydrite and brucite show that, when only reacted seawater was exiting the Preheater, these minerals were at equilibrium with the fluid at both temperatures (Fig. 5.16). This is shown by $\log \mathrm{Q}$ being comparable to the $\log \mathrm{K}_{\mathrm{sp}}$ at temperature for these minerals. The $\log \mathrm{Q}$ for caminite, calculated using the precipitation reaction for 
MSHS(0.625) from Janecky and Seyfried (1983) and our species's activities and pH (both at $342^{\circ} \mathrm{C}$ and $377^{\circ} \mathrm{C}$ ), are within $1 / 2 \log$ unit of their extrapolated $\log \mathrm{K}_{\mathrm{sp}}$. This supports the conclusion that the mineral identified in this study is caminite.

Figure 5.16. $\log \mathrm{Q}$ and $\log \mathrm{K}_{\mathrm{sp}}$ for anhydrite (a) and brucite (b). $\log \mathrm{K}_{\mathrm{sp}}$ for anhydrite and brucite from SUPCRT92. Log $\mathrm{K}_{\mathrm{sp}}$ for caminite (c) from Janecky and Seyfried (1983) (MHSH(0.625)) and compared with log Q from the experiment data in this study.

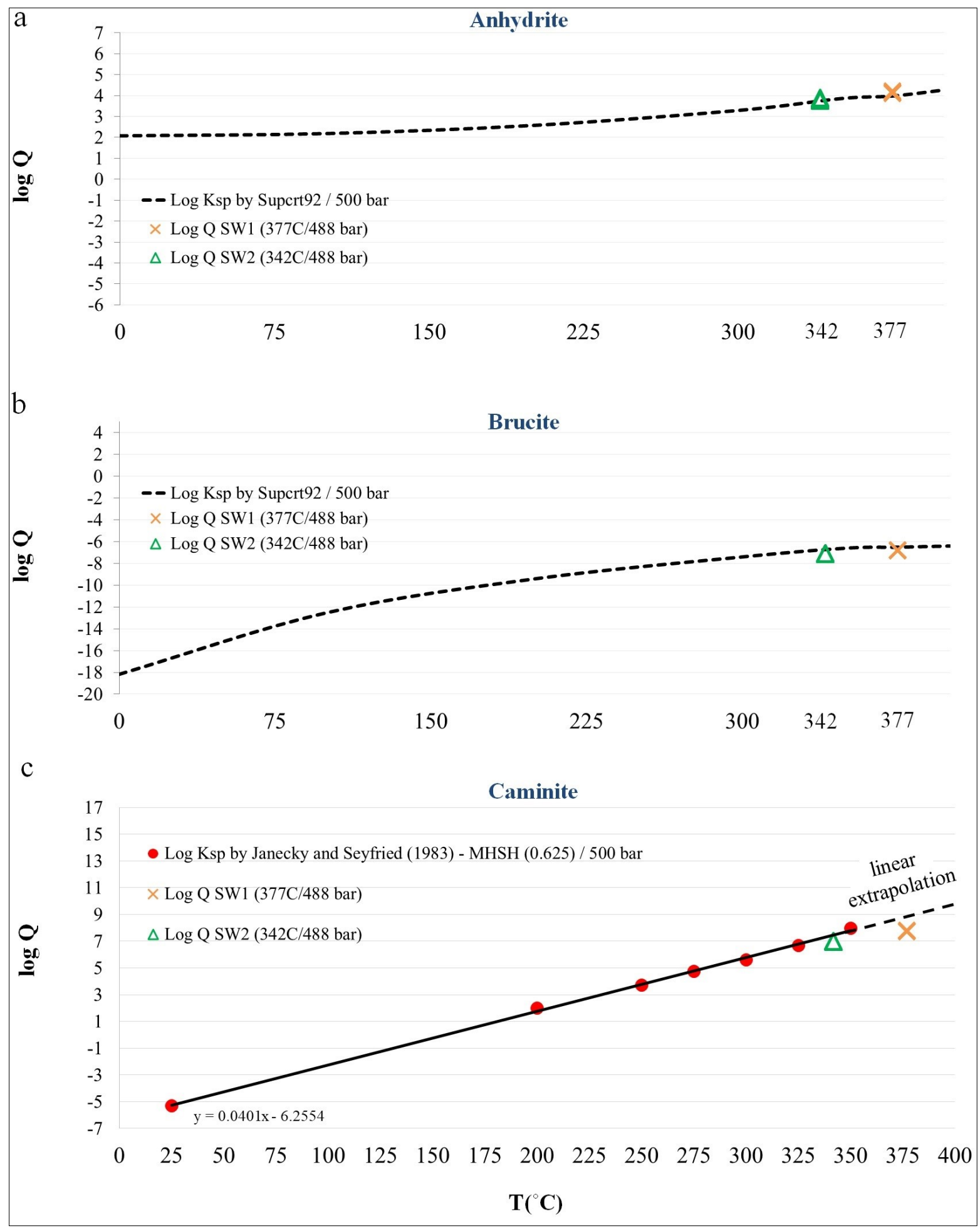


Bischoff and Seyfried (1978) reported results from an experiment study in which seawater was heated to elevated temperature up to $350^{\circ} \mathrm{C}$. Table 5.6 lists the fluid chemistry and fluxes from this work along with a summary of the results from our study. Bischoff and Seyfried used closed system, batch reactors to investigate the kinetics of precipitation of minerals from seawater. Their results show little change in solute concentrations or $\mathrm{pH}$ until above $150^{\circ} \mathrm{C}$. This is contrary to the expectation of brucite saturation at $70^{\circ} \mathrm{C}$ and anhydrite saturation at $108^{\circ} \mathrm{C}$ for standard seawater (Fig. 2.16). Note, however, that brucite saturation is sensitive to $\mathrm{pH}$ while anhydrite saturation is not, at least at lower temperatures, possibly explaining the absence of brucite in their experiments. The explanation for the absence of anhydrite precipitation above $108^{\circ} \mathrm{C}$ is uncertain but is unlikely due to kinetics given that their experiments lasted one month.

At 200 and $250^{\circ} \mathrm{C}$ it appears that only anhydrite precipitated with no accompanying $\mathrm{Mg}$-bearing phase. $\mathrm{Mg}$ hydroxysulfate was only identified at 300 and $350^{\circ} \mathrm{C}$. Bischoff and Seyfried (1978) did not identify brucite in any of their experiments, however, the excess for $\mathrm{Mg}$ over sulfate (once anhydrite is removed) can be explain by the precipitation of caminite.

For caminite, the thermodynamic data from GWB show that $\operatorname{MHSH}\left(\mathrm{Mg}_{1.5}\right)$ should saturate at $\sim 193^{\circ} \mathrm{C}$ (Fig. 2.16). Evidently this was not the case in Bischoff and Seyfried (1978). Their results are more consistent with the precipitation of caminite at 300 and $350^{\circ} \mathrm{C}$. In this study we do not have data for mineral precipitates at lower temperatures, however, the SEM-EDS data confirm that the $\mathrm{Mg}$-bearing sulfate phase has a $\mathrm{Mg}: \mathrm{S}$ ratio of $\sim 2: 1.2$ is consistent with the precipitation of caminite at $350^{\circ} \mathrm{C}$. The earlier study also measured a large decrease in quench $\mathrm{pH}$ above $250^{\circ} \mathrm{C}$. This is consistent with our results.

It should be noted that there is a fundamental difference between this study and the earlier experiments. Bischoff and Seyfried (1978) used closed system, batch experiments while this study used open-system, continuous flow-through. In the former, mineral precipitates are controlled not only by thermodynamic properties but also on total mass of solute available. In our study, the latter was not restricted with fresh seawater being continuously supplied. This may explain some of the differences in mineral precipitates encountered.

As previously mentioned at the beginning of this chapter, the experiments using only seawater were performed to determine fluid behaviour in the absence of the basalt and to determine the influence of the $\mathrm{ZrO}_{2}$ beads on the solution composition. At the conclusion of these simulations, the composition of the fluid exiting the Preheater from SW1 and SW2, can 
be assumed as equal to that entering the Reactor in the basalt-seawater experiments, BSW1 and BSW2, respectively.

Table 5.6. Comparison between experimental results of Bischoff and Seyfried (1978) and this study.

\begin{tabular}{|c|c|c|c|c|c|c|c|c|c|}
\hline $\begin{array}{c}\text { Bischoff } \\
\text { Seyfried } \\
\text { (1978) }\end{array}$ & & & & \multicolumn{3}{|c|}{$\left(\mathrm{mmol} \mathrm{kg}^{-1}\right)$} & \multicolumn{3}{|c|}{$\begin{array}{c}\text { Precipitated } \\
\left(\mathrm{mmol} \mathrm{kg}^{-1}\right)\end{array}$} \\
\hline $\begin{array}{c}\mathrm{T} \\
\left({ }^{\circ} \mathrm{C}\right)\end{array}$ & $\underset{\text { (bar) }}{\mathbf{P}}$ & $\underset{(\text { room T) }}{\mathbf{p H}}$ & & $\mathrm{SO}_{4}$ & $\mathbf{M g}$ & $\mathrm{Ca}$ & $\mathrm{SO}_{4}$ & Mg & $\mathrm{Ca}$ \\
\hline 25 & - & 7.63 & & 27 & 51.1 & 9.8 & & & \\
\hline 70 & 500 & 7.7 & & 27 & 50.4 & 9.9 & & & \\
\hline 150 & 500 & 6.43 & & 27 & 50.4 & 9.9 & & & \\
\hline 200 & 500 & 6.2 & & 20 & 51 & 3 & -6.9 & - & -6.8 \\
\hline 250 & 500 & 5.8 & & 18 & 50.6 & 1.5 & -8.4 & - & -8.3 \\
\hline 300 & 500 & 3.01 & & 11 & 43.8 & 1 & -15.3 & -7.3 & -8.7 \\
\hline 350 & 500 & 2.52 & & 9 & 40.2 & 1 & -18 & -10.9 & -8.8 \\
\hline SW2 & & & & & & & & ecipita & \\
\hline 25 & 1 & 7.75 & input & 23 & 36.7 & 8 & & & \\
\hline 342 & 488 & 2.79 & output & 2.7 & 22.8 & 1.4 & -20.3 & -13.9 & -6.6 \\
\hline SW1 & & & & & & & & & \\
\hline 25 & 1 & 7.75 & input & 22 & 45.8 & 9.4 & & & \\
\hline 377 & 488 & 3.34 & output & 1.2 & 24.4 & 2.1 & -20.8 & -21.4 & -7.3 \\
\hline
\end{tabular}




\subsection{References}

Babcock, J.M., Harding, A.J., Kent, G.M. and Orcutt, J.A., 1998, An examination of alongaxis variation of magma chamber width and crustal structure on the East Pacific Rise between $13^{\circ} 30^{\prime} \mathrm{N}$ and $12^{\circ} 20^{\prime} \mathrm{N}$. Journal of Geophysical Research: Solid Earth, 103: 30451-30467.

Bischoff, J.L. and Seyfried, W.E., 1978, Hydrothermal chemistry of seawater from 25C to 350C. American Journal of Science, 278: 838-860.

Bischoff, J.L. and Rosenbauer, R.J., 1983, A note on the chemistry of seawater in the range $350^{\circ}-500^{\circ} \mathrm{C}$. Geochimica et Cosmochimica Acta, 47: 139-144.

Cann, J., 1971, Petrology of Basement Rocks from Palmer Ridge, NE Atlantic 605-617 p.

Cann, J.R. and Funnell, B.M., 1967, Palmer Ridge: a Section through the Upper Part of the Ocean Crust? Nature, 213: 661.

Cann, J.R., 1969, Spilites from the Carlsberg Ridge, Indian Ocean. Journal of Petrology, 10: 1-19.

Chernysheva, V.I., 1971, Greenstone-altered rocks of rift zones in median ridges of Indian Ocean. International Geology Review, 13: 903-913.

Coelho, G., Branquet, Y., Sizaret, S., Arbaret, L., Champallier, R. and Rozenbaum, O., 2015, Permeability of sheeted dykes beneath oceanic ridges: Strain experiments coupled with 3D numerical modeling of the Troodos Ophiolite, Cyprus. Tectonophysics, 644645: 138-150.

Detrick, R.S., Buhl, P., Vera, E., Mutter, J., Orcutt, J., Madsen, J. and Brocher, T., 1987, Multi-channel seismic imaging of a crustal magma chamber along the East Pacific Rise. Nature, 326: 35.

Field, M.P., LaVigne, M., Murphy, K.R., Ruiz, G.M. and Sherrell, R.M., 2007, Direct determination of $\mathrm{P}, \mathrm{V}, \mathrm{Mn}, \mathrm{As}, \mathrm{Mo}, \mathrm{Ba}$ and $\mathrm{U}$ in seawater by SF-ICP-MS. Journal of Analytical Atomic Spectrometry, 22: 1145-1151.

Fleet, M.E. and Knipe, S.W., 1997, Structure of Magnesium Hydroxide Sulfate [2MgSO4. $\mathrm{Mg}(\mathrm{OH}) 2]$ and Solid Solution in Magnesium Hydroxide Sulfate Hydrate and Caminite. Acta crystallographica. Section B, Structural science, 53: 358-363.

Haymon, R.M. and Kastner, M., 1986, Caminite: A new magnesium-hydroxide-sulfatehydrate mineral found in a submarine hydrothermal deposit, East Pacific Rise, 21 degree N. The American mineralogist, 71: 819-825.

Hochella, M.F., Keefer, K.D. and deJong, B.H.W.S., 1983, The crystal chemistry of a naturally occurring magnesium hydroxide sulfate hydrate, a precipitate of heated seawater. Geochimica et Cosmochimica Acta, 47: 2053-2058.

Hsieh, Y.-T. and Henderson, G.M., 2017, Barium stable isotopes in the global ocean: Tracer of $\mathrm{Ba}$ inputs and utilization. Earth and Planetary Science Letters, 473: 269-278.

Janecky, D.R. and Seyfried, W.E., 1983, The solubility of magnesium-hydroxide-sulfatehydrate in seawater at elevated temperatures and pressures. American Journal of Science, 283: 831-860.

Johnson, J.W., Oelkers, E.H. and Helgeson, H.C., 1992, SUPCRT92: A software package for calculating the standard molal thermodynamic properties of minerals, gases, aqueous species, and reactions from 1 to 5000 bar and 0 to $1000^{\circ} \mathrm{C}$. Computers \& Geosciences, 18: 899-947.

Keefer, K.D., Hochella, M. and de Jong, B.H., 1981, The structure of the magnesium hydroxide sulfate hydrate MgSO4. $1 / 3 \mathrm{Mg}(\mathrm{OH}) 2.1 / 3 \mathrm{H} 2 \mathrm{O}$. Acta Crystallographica Section B: Structural Crystallography and Crystal Chemistry, 37: 1003-1006.

Kent, G.M., Harding, A.J. and Orcutt, J.A., 1990, Evidence for a smaller magma chamber beneath the East Pacific Rise at $9^{\circ} 30^{\prime}$ N. Nature, 344: 650. 
Melson, W.G. and van Andel, T.H., 1966, Metamorphism in the Mid-Atlantic Ridge, $22^{\circ} \mathrm{N}$ latitude. Marine Geology, 4: 165-186.

Melson, W.G., Thompson, G. and van Andel, T.H., 1968, Volcanism and metamorphism in the Mid-Atlantic Ridge, $22^{\circ} \mathrm{N}$ latitude. Journal of Geophysical Research, 73: 59255941.

Miyashiro, A., Shido, F. and Ewing, M., 1971, Metamorphism in the Mid-Atlantic Ridge near $24^{\circ}$ and $30^{\circ} \mathrm{N} 589-603 \mathrm{p}$.

Quon, S.H.-E., Ernest G, 1963, Rocks of Northern Part of Mid-Atlantic Ridge. GSA Bulletin, 74: $1-8$.

Shido, F., Miyashiro, A. and Ewing, M., 1974, Compositional variation in pillow lavas from the Mid-Atlantic Ridge. Marine Geology, 16: 177-190.

Sinha, M.C. and Evans, R.L., 2013, Gephysical Constraints upon the Thermal Regime of the Ocean Crust. Mid-Ocean Ridges. American Geophysical Union19-62.

Sinton, J.M. and Detrick, R.S., 1992, Mid-ocean ridge magma chambers. Journal of Geophysical Research: Solid Earth, 97: 197-216.

Smith, R.C., Pillai, K., Chow, T.J. and Folsom, T.R., 1965, Determination of rubidium in seawater. Limnology and Oceanography, 10: 226-232. 


\section{Chapter 6: Basalt - Seawater Interactions under Hydrothermal Conditions}

\subsection{A brief introduction}

The experimental approach adopted for the basalt - seawater interactions is the most innovative aspect of this study. Simulations were performed using a high T-P hydrothermal apparatus in an open system (flow-through) rather than in a closed system (batch reactor). This method used a Preheater, allowing pre-treatment of the seawater, and a Reactor, containing the basalt, connected in series. This permitted simulation of MORB conditions where seawater, first depleted in $\mathrm{Ca}, \mathrm{Mg}$ and $\mathrm{SO}_{4}$ descends through a temperature gradient into the reaction zone and comes into contact with the basalt (Chapter 2, §2.4.5, Fig. 2.19b $2.20 \mathrm{~b}$ ). Note, however, this apparatus only reproduces the loss of retrograde phases upon descent and does not reproduce any seawater - rock interactions along the descent path.

The high T-P hydrothermal apparatus used in this study allowed collection of multiple samples allowing monitoring of fluid - rock interaction path and variation of flow rate to test equilibrium conditions.

There are several studies in the literature of laboratory experiments describing basalt seawater interactions at supercritical, near-supercritical and at subcritical conditions, however, these were performed using only batch reactors. Nevertheless, these experimental simulations provided great insights and fundamental implications to understanding basaltseawater interaction occurring in the reaction zones at MORBs (Berndt and Seyfried, 1993; Bischoff and Dickson, 1975; Bischoff and Seyfried, 1978; Cann, 1979; Hajash, 1975; Hochella et al., 1983; Janecky and E. Seyfried, 1983; Mottl and E. Seyfried, 2019; Mottl and Seyfried Jr, 1980; Mottl and Holland, 1978; Mottl et al., 1979; Ohmoto and Rye, 1974; Seewald and Seyfried, 1990; Seyfried and Mottl, 1977; Seyfried et al., 1988; Seyfried and Bischoff, 1981; Seyfried and Mottl, 1982).

In this section we describe two basalt - seawater interaction experiments carried out at near-supercritical and subcritical conditions using the continuous flow apparatus: BSW1 at $400^{\circ} \mathrm{C} / 488$ bar and $\mathrm{BSW} 2$ at $350^{\circ} \mathrm{C} / 488$ bar.

The results from both experiments indicate that seawater reacted aggressively with the basalt. Equilibrium (or steady state) was reached at different flow rates and rate of reactions occurred rapidly at both experimental conditions. Major changes in solution chemistry consisted of: (1) almost total depletion of $\mathrm{Mg}$ and $\mathrm{SO}_{4}$ from solution; (2) significant changes in concentrations in $\mathrm{Ca}$ and $\mathrm{Fe}$ depending on flow rate; (3) $\mathrm{SiO}_{2}$ 
solubilities well above quartz saturation during both experiments; (4) the absence of $\mathrm{K}$ in mineral precipitates from both experiments; (5) the generation of measurable concentrations of $\mathrm{H}_{2} \mathrm{~S}$; (6) highly acidic quench $\mathrm{pH}$ values; and (7) low trace element mobility in both experiments.

Analysis of the reacted basalt was conducted on grains collected from the Reactor at the conclusion of the experiments. These results show a distinct mineralisation front occurring at the approximate middle of the rock column in both experiments. At $400^{\circ} \mathrm{C}$, analysis revealed that the most highly reacted grains coincided with the Portion of rock situated at $\sim 2-3 \mathrm{~cm}$ above the fluid entry point in the Reactor. However, at $350^{\circ} \mathrm{C}$, the most highly reacted grains were found immediately adjacent of the fluid entry point in the Reactor. In both experiments, the least altered basalt was encountered immediately adjacent of the fluid exit point of the Reactor.

\subsection{Results}

In this chapter the results are presented for the:

1) major element analyses of experimental solutions collected;

2) trace element analyses of experimental solutions collected;

3) chemical, mineralogical and textural analyses of the reacted rock material.

Note also that retrograde mineral precipitates in the Preheater were not examined after the basalt - seawater experiments. These precipitates are assumed to be the same as in SW1 and SW2 (Chapter 5). It is also assumed that the input composition of the pre-treated seawater in the basalt - seawater experiments is equal to that of the effluent compositions in SW1 and SW2. 


\subsubsection{BSW1: Basalt-seawater at $400^{\circ} \mathrm{C} / 488$ bar}

The laboratory set-up for the BSW1 experiment consisted of the Preheater containing zirconia beads and the Reactor filled with rock material mounted in series (Chapter 2, §2.4.5, Fig. 2.19b). The experimental configuration maintained a temperature gradient of $40^{\circ} \mathrm{C}$ at the top to $377^{\circ} \mathrm{C}$ at the bottom of Preheater, while the Reactor was kept at a temperature of $400^{\circ} \mathrm{C}$. Pressure remained stable at 488 bar.

The experiment ran for a total time of $659 \mathrm{hrs}$. At the start of the experiment, distilled water was pumped through the system for the first $24 \mathrm{hrs}$ until pressure was stable. After this, the heating procedure increased the oven temperature until a Reactor temperature of $400^{\circ} \mathrm{C}$ was reached ( $\sim 3$ hours), then fluid flow was switched to seawater. It required approximately three days for seawater to begin to exit the Reactor at $1 \mathrm{ml} \mathrm{hr}^{-1}$ (See Cl concentrations in Fig. 6.2). Distilled water was completely displaced from the combined Preheater and Reactor after about four days.

After 400 hrs (approximately two weeks) the pressure of the system suddenly dropped due to a leak in the apparatus. This required the experiment to be shut down which provided an opportunity to collected basalt grains during an experiment. The Preheater and Reactor were removed, and the Reactor was opened and several grains were collected from immediately adjacent of the fluid entry and exit point. These grains were rinsed with distilled water, dried, and mounted on the aluminium stubs for SEM-EDS analysis.

The experiment was shut down for three hours, after which the start-up procedure was repeated. At $603 \mathrm{hr}$ the separator was re-filled with seawater. In this case, the seawater was not de-oxygenated. The flow rate was varied during the experiment as follows:

- $\quad 1 \mathrm{ml} \mathrm{hr}^{-1}$ for $533 \mathrm{hr}$ (23 samples collected)

- $\quad 1.5 \mathrm{ml} \mathrm{hr}^{-1}$ for $50 \mathrm{hr}$ (2 samples collected)

- $10 \mathrm{ml} \mathrm{hr}^{-1}$ for $44 \mathrm{hr}$ (10 samples collected)

- $7.5 \mathrm{ml} \mathrm{hr}^{-1}$ for $25 \mathrm{hr}$ (5 samples collected)

- $5 \mathrm{ml} \mathrm{hr}^{-1}$ for $8 \mathrm{hr}$ (4 samples collected)

Analysis for major and trace elements was made for the total number of the fluid samples collected (46). Distilled water and seawater blanks were included. 


\subsubsection{Major Element Concentrations}

Complete experimental parameters and results $(\mathrm{T}, \mathrm{P}$, time, flow rate, in situ and room $\mathrm{T}$ pH, chemistry) are listed in Appendix E. Figure 6.1 and Figure 6.2 show these results plotted versus time in hours. The unreacted seawater composition is shown at $t=0$. The composition of unreacted distilled water is not shown. The concentrations of major ions for the first $70 \mathrm{hrs}$ are essentially for distilled water as it required approximately 3 days for seawater to begin to exit the Reactor at $1 \mathrm{ml} \mathrm{hr}^{-1}$.

The room temperature $\mathrm{pH}$ of the unreacted Napier seawater is 7.75 (Fig. 6.1). While distilled water was exiting the Reactor, quench $\mathrm{pH}$ decreases from 6.37 to 4.17 while the in situ $\mathrm{pH}$ decreases from 7.17 to 6.71 . Once seawater displaces distilled water the quench $\mathrm{pH}$ stabilises at $\sim 4.1$ after about seven days which translates into a stable in situ $\mathrm{pH}$ of $\sim 5.8$. After re-starting the experiment at 400 hours, the quench and in situ $\mathrm{pH}$ values return to the above values after two days. The quench $\mathrm{pH}$ increases marginally to $\sim 4.5$ when flow rate was changed to $10,7.5$ and $5 \mathrm{ml} \mathrm{hr}^{-1}$, however, the in situ $\mathrm{pH}$ remains stable at $\sim 5.80$ for this period. The entry in situ $\mathrm{pH}$ of the pre-treated seawater into the Reactor is assumed to be $\sim 5.4$ based on the results of the SW1 experiment.

$\mathrm{SiO}_{2}$ concentrations increases to $\sim 31 \mathrm{mmol} \mathrm{kg}^{-1}(\sim 1860 \mathrm{ppm})$ while distilled water is exiting the Reactor for the first three days (Fig. 6.1). Once seawater begins to appear in the effluents $(\sim 70 \mathrm{hr}), \mathrm{SiO}_{2}$ concentration stabilises to $\sim 28 \mathrm{mmol} \mathrm{kg}^{-1}$ and then remains at this value for the remainder of the experiment. The variation of the flow from $1-10 \mathrm{ml} \mathrm{hr}^{-1}$ does not affect effluent $\mathrm{SiO}_{2}$ concentrations. A $\mathrm{SiO}_{2}$ concentration of $28 \mathrm{mmol} \mathrm{kg} \mathrm{m}^{-1}$ (1682 ppm) exceeds quartz saturation at $400^{\circ} \mathrm{C} / 500$ bar $(1238 \mathrm{ppm})$. Note that it is assumed that the $\mathrm{SiO}_{2}$ concentration entering the Reactor is $0.7 \mathrm{mmol} \mathrm{kg}^{-1}$ based on the SW1 experiment.

Sodium concentration remains low while distilled water is exiting the Reactor. Once seawater begins to appear in the effluents, $\mathrm{Na}$ concentrations begin to increase and reach a value of $\sim 400 \mathrm{mmol} \mathrm{kg}^{-1}$ after seven days. Na concentration averages around this value for the next eleven days. Sodium was conservative in the SW1 experiment thus $\mathrm{Na}$ concentrations entering the Reactor are expected to be similar to input seawater. On average the $\mathrm{Na}$ concentrations appear to be slightly higher, however, this is believed to be an analytical artefact and not from release of $\mathrm{Na}$ from the rock. This is supported by the $\mathrm{Na}$ results after the experiment was restarted which show the $\mathrm{Na}$ concentration stable at the seawater value, irrespective of the flow rate. 
The behaviour of $\mathrm{K}$ is also conservative. The $\mathrm{K}$ concentration exactly reflects the $\mathrm{Na}$ concentrations and $\mathrm{Na} / \mathrm{K}$ ratio is essentially constant (Fig. 6.1). Potassium concentration is on average higher than the input value between 100 and 400 hours. This is also attributed to an analytical artefact. After the experiment was restarted at 400 hours, K concentration stabilises

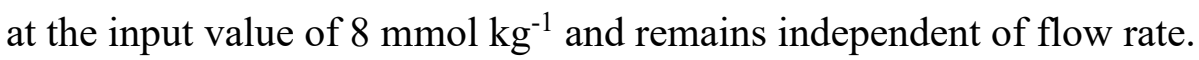

Aluminium concentrations are slightly elevated when distilled water is present in the Reactor. Once seawater begins to appear in the effluents, Al concentrations decrease to close to the detection limit and remain so for the remainder of the experiment irrespective of flow rate.

Calcium concentration is below detection limit while distilled water is exiting the Reactor (Fig. 6.2). Once seawater begins to appear in the effluents after three days, $\mathrm{Ca}$ concentration increases to a steady value of $\sim 20 \mathrm{mmol} \mathrm{kg}^{-1}$. After restarting at 400 hours, $\mathrm{Ca}$ again reaches this concentration at $1-1.5 \mathrm{ml} \mathrm{hr}^{-1}$ flow rate (Fig. 6.1). At $10 \mathrm{ml} \mathrm{hr}^{-1}$, Ca concentration decreases to $15 \mathrm{mmol} \mathrm{kg}^{-1}$. It then increases marginally upon decreasing the flow rate to 7.5 and $5 \mathrm{ml} \mathrm{hr}^{-1}$. Note that the input Ca concentration from the Preheater is assumed to be $2 \mathrm{mmol} \mathrm{kg}^{-1}$ based on the results from the SW1 experiment (Fig. 5.4). This indicates that a significant amount of $\mathrm{Ca}$ is being added to the fluid by the rock.

Iron concentration is below detection limit while distilled water is exiting the Reactor (Fig. 6.2). Once seawater appears, Fe concentration increases over time from $\sim 0.8 \mathrm{mmol} \mathrm{kg}^{-1}$ to $\sim 3 \mathrm{mmol} \mathrm{kg}^{-1}$. After restarting at 400 hours, Fe remains near $1 \mathrm{mmol} \mathrm{kg}^{-1}$ at 1 and $1.5 \mathrm{ml}$ $\mathrm{hr}^{-1}$ flow rate. Upon increase of flow rate to $10 \mathrm{ml} \mathrm{hr}^{-1}$, Fe concentration increases significantly to $7.5 \mathrm{mmol} \mathrm{kg}^{-1}$. It then decreases upon decreasing flow rate to 7.5 and $5 \mathrm{ml} \mathrm{hr}$ 1. The input Fe concentration is assumed to be $\sim 1 \mathrm{mmol} \mathrm{kg}^{-1}$ based on the results from the SW1 experiment (Fig. 5.4). The Fe results indicate that there may be a slight increase in Fe derived from the rock but, as with $\mathrm{Ca}$, the Fe contributed is dependent on the flow rate.

The behaviour of $\mathrm{Mg}$ is significantly different between the BSW1 and SW1 experiments. In BSW1, Mg concentrations remain under detection limit $\left(<0.0004 \mathrm{mmol} \mathrm{kg}^{-1}\right)$ both in presence with distilled water and also once the seawater begins to appear in the effluents, but only when flow rate is at $1 \mathrm{ml} \mathrm{hr}^{-1}$ (Fig. 6.2). At $1.5 \mathrm{ml} \mathrm{hr}^{-1}$ there is a detectable increase in $\mathrm{Mg}$ concentration while at $10 \mathrm{ml} \mathrm{hr}^{-1}$ a significant increase occurs with $\mathrm{Mg}$ concentration rising to $0.1 \mathrm{mmol} \mathrm{kg}{ }^{-1}$. Decreasing the flow rate to $7.5 \mathrm{ml} \mathrm{hr}^{-1}$ results in a decrease in $\mathrm{Mg}$ to $0.09 \mathrm{mmol} \mathrm{kg}^{-1}$ while at $5 \mathrm{ml} \mathrm{hr}^{-1} \mathrm{Mg}$ decreases to $0.07 \mathrm{mmol} \mathrm{kg}^{-1}$. The input $\mathrm{Mg}$ concentration is assumed to be $\sim 24 \mathrm{mmol} \mathrm{kg}^{-1}$ based on the results of the SW1 
experiments (Fig. 5.4). This indicates that all $\mathrm{Mg}$ remaining from seawater after precipitation of retrograde phases is fixed in the basalt due to fluid - rock interaction. This fixation, however, is dependent on flow rate.

Sulfate concentration is irregular over the experiment (Fig. 6.2). While seawater is exiting the Reactor, several values of $\sim 0.05 \mathrm{mmol} \mathrm{kg}-1$ are reached. There is no significant increase when flow rate is increased to $1.5 \mathrm{ml} \mathrm{hr}^{-1}$, however, when it is increased to $10 \mathrm{ml} \mathrm{hr}^{-}$ 1, there are measurable increases in $\mathrm{SO}_{4}$ up to $0.1 \mathrm{mmol} \mathrm{kg}$. This concentration is not maintained and $\mathrm{SO}_{4}$ decreases back to $\sim 0.5 \mathrm{mmol} \mathrm{kg}^{-1}$ over the following days regardless of flow rate. The input concentration of $\mathrm{SO}_{4}$ is assumed to be $\sim 1 \mathrm{mmol} \mathrm{kg}^{-1}$ based on results from SW1 (Fig. 5.4). This indicates that the remaining $\mathrm{SO}_{4}$ in the pre-treated seawater is also precipitating during reaction with the basalt.

There are detectable $\mathrm{H}_{2} \mathrm{~S}$ concentrations in the effluents from the BSW1 experiment (Fig. 6.2). This differs from the SW1 experiment which show no detectable $\mathrm{H}_{2} \mathrm{~S}$ (Fig. 5.4). The highest $\mathrm{H}_{2} \mathrm{~S}$ concentrations occur just after seawater begins to exit the Reactor. This suggests release of $\mathrm{H}_{2} \mathrm{~S}$ from sulfide inclusions in volcanic glass. Also, $\mathrm{H}_{2} \mathrm{~S}$ increases again after restarting at 400 hours. There is also limited evidence that $\mathrm{H}_{2} \mathrm{~S}$ concentrations are also dependent on the flow rate. The overall gradual decrease in concentration over the experiment is attributed to gradual dissolution of basalt glass dissolution.

Chloride is conservative and reflects mixing between distilled water and seawater. The concentrations are independent of flow rate (Fig. 6.2). 
Figure 6.1. Major element concentrations in blank and effluent samples (mmol $\left.\mathrm{kg}^{-1}\right)$ versus time (hr) for the BSW1 experiment at $400^{\circ} \mathrm{C} / 488$ bar. Yellow squares at $\mathrm{t}=0$ are the blank sample composition of seawater from SW1. Light blue symbols show where distilled water was exiting the Reactor at $400^{\circ} \mathrm{C} / 488$ bar and $1.0 \mathrm{ml} \mathrm{hr}^{-1}$. Black symbols are effluent compositions (seawater) at $400^{\circ} \mathrm{C} / 488$ bar and $1.0 \mathrm{ml} \mathrm{hr}{ }^{-1}$ flow rate. Other coloured symbols show effluent compositions at different flow rates. In situ $\mathrm{pH}$ is the calculated $\mathrm{pH}$ at temperature. $\mathrm{LOD}=$ limit of detection.
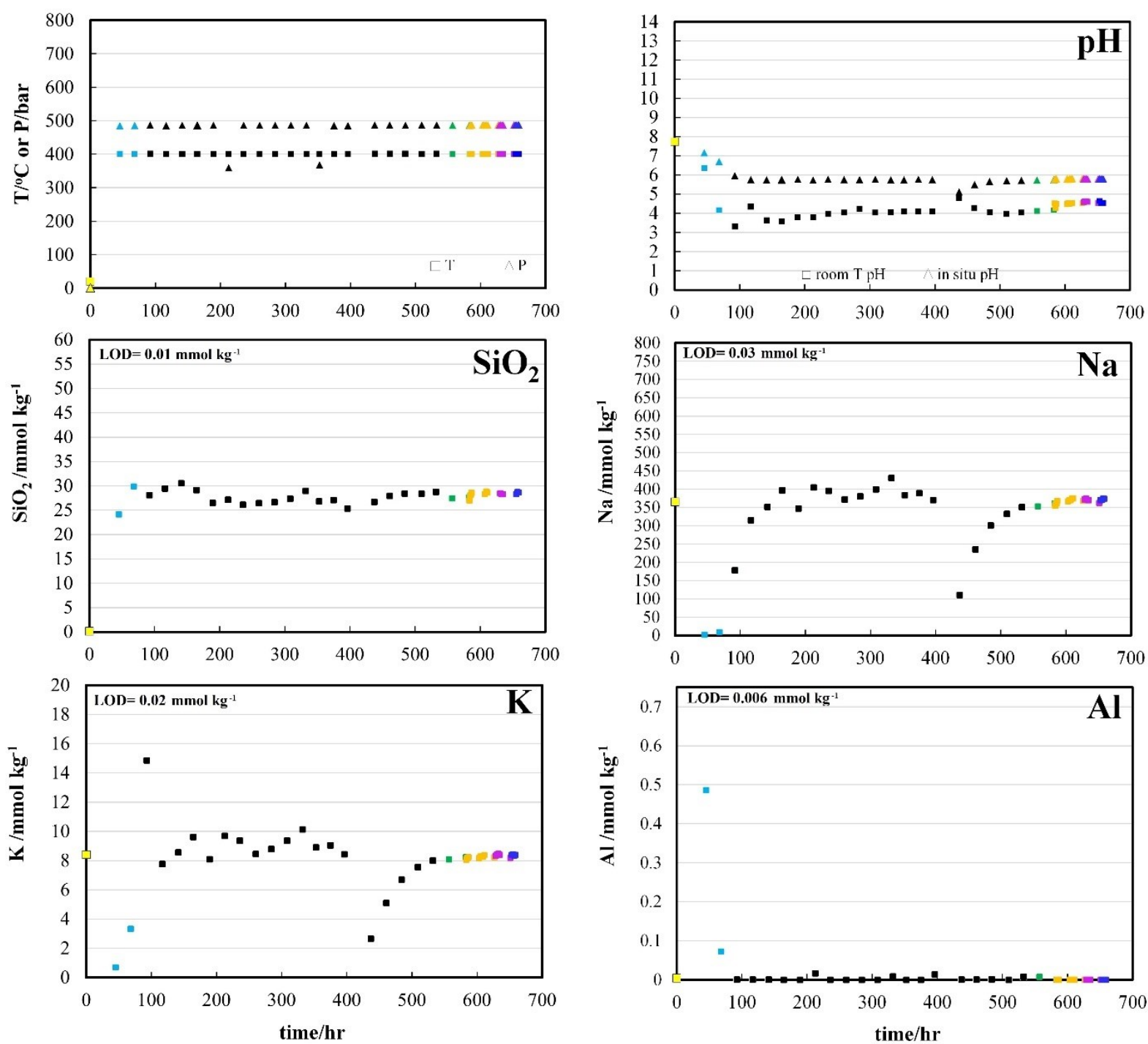

$\square \triangle$ blank seawater

$\Delta$ distilled water $400^{\circ} \mathrm{C} / 488 \mathrm{bar} / 1 \mathrm{ml} \mathrm{hr}^{-1}$

口 $\Delta$ seawater $400^{\circ} \mathrm{C} / 488 \mathrm{bar} / 1 \mathrm{ml} \mathrm{hr}^{-1}$

a seawater $400^{\circ} \mathrm{C} / 488 \mathrm{bar} / 1.5 \mathrm{ml} \mathrm{hr}^{-1}$

a seawater $400^{\circ} \mathrm{C} / 488 \mathrm{bar} / 10 \mathrm{ml} \mathrm{hr}^{-1}$

a seawater $400^{\circ} \mathrm{C} / 488 \mathrm{bar} / 7.5 \mathrm{ml} \mathrm{hr}^{-1}$

a seawater $400^{\circ} \mathrm{C} / 488 \mathrm{bar} / 5 \mathrm{ml} \mathrm{hr}^{-1}$ 
Figure 6.2. Major element concentrations in blank and effluent samples (mmol $\left.\mathrm{kg}^{-1}\right)$ versus time (hr) for the BSW1 experiment at $400^{\circ} \mathrm{C} / 488$ bar. Yellow squares at $\mathrm{t}=0$ are the input composition of seawater from SW1. Light blue symbols show where distilled water was exiting the Reactor at $400^{\circ} \mathrm{C} / 488$ bar and $1.0 \mathrm{ml} \mathrm{hr}^{-1}$. Black symbols are effluent compositions at $400^{\circ} \mathrm{C} / 488 \mathrm{bar}^{2}$ and $1.0 \mathrm{ml} \mathrm{hr}{ }^{-1}$ flow rate. Other coloured symbols are effluent compositions at differing flow rate. In situ $\mathrm{pH}$ is the calculated $\mathrm{pH}$ at temperature. $\mathrm{LOD}=$ limit of detection.
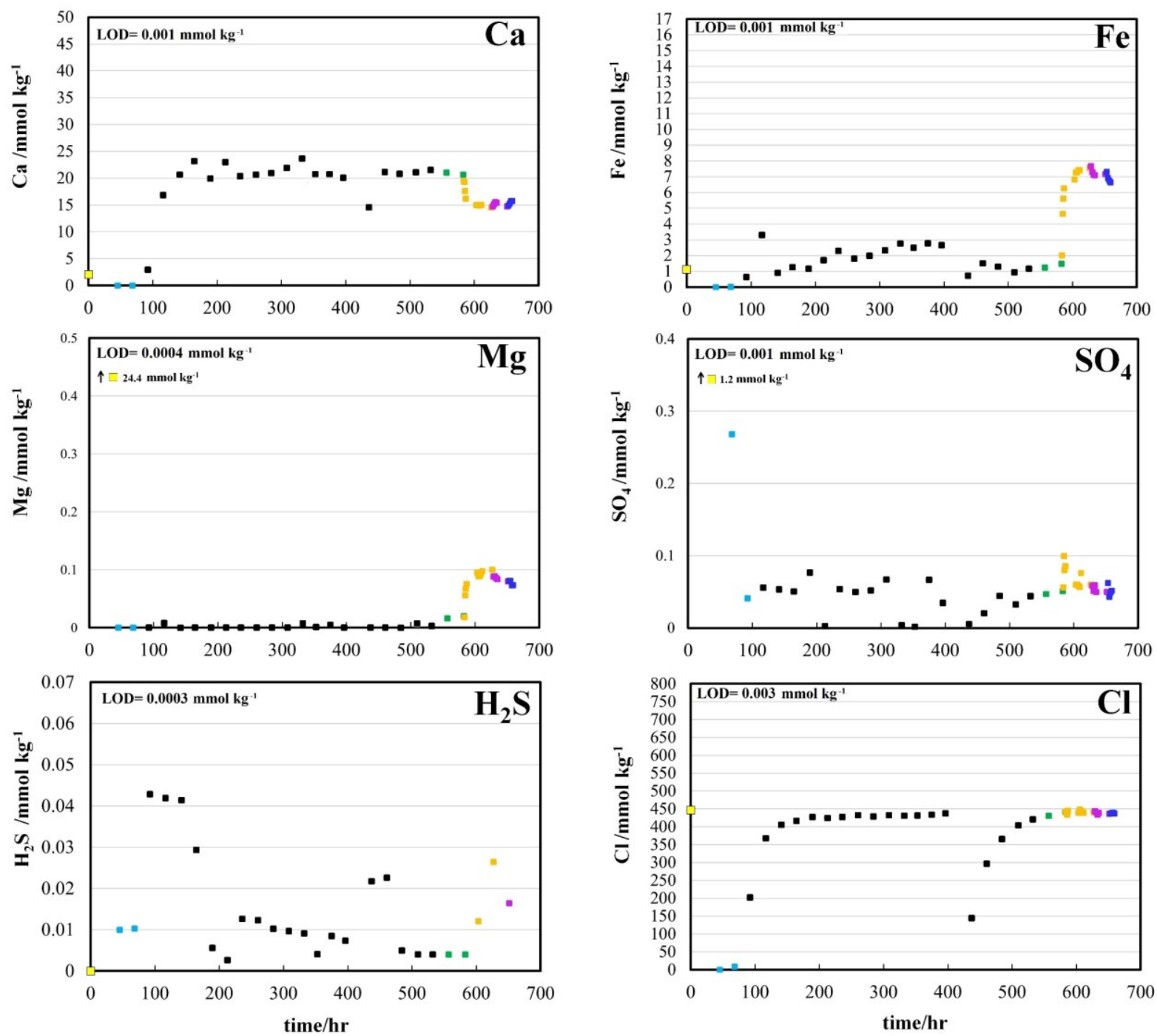

$\square \triangle$ blank seawater

$\Delta$ distilled water $400^{\circ} \mathrm{C} / 488 \mathrm{bar} / 1 \mathrm{ml} \mathrm{hr}^{-1}$

口 $\Delta$ seawater $400^{\circ} \mathrm{C} / 488 \mathrm{bar} / 1 \mathrm{ml} \mathrm{hr}^{-1}$

口 $\Delta$ seawater $400^{\circ} \mathrm{C} / 488 \mathrm{bar} / 1.5 \mathrm{ml} \mathrm{hr}^{-1}$

- $\triangle$ seawater $400^{\circ} \mathrm{C} / 488 \mathrm{bar} / 10 \mathrm{ml} \mathrm{hr}{ }^{-1}$

— $\Delta$ seawater $400^{\circ} \mathrm{C} / 488 \mathrm{bar} / 7.5 \mathrm{ml} \mathrm{hr}^{-1}$

口 $\Delta$ seawater $400^{\circ} \mathrm{C} / 488 \mathrm{bar} / 5 \mathrm{ml} \mathrm{hr}^{-1}$ 


\subsubsection{Trace Element Concentrations}

In SW1, trace elements showed some mobility and semi-regular to irregular trends caused by the interaction between seawater and the $\mathrm{ZrO}_{2}$ beads (Fig. 5.5 and 5.6). It is evident that the beads were releasing measurable concentrations of some trace elements including $\mathrm{V}$, $\mathrm{Mn}, \mathrm{Co}, \mathrm{Ni}, \mathrm{Ba}$, and perhaps Au. Effluents also showed seawater concentrations of Rb.

Figure 6.3 and Figure 6.4 show trace element results plotted versus time in hours for the BSW1 experiment. The unreacted natural seawater composition is shown at $t=0$. Most trace elements are below detection limit with only $\mathrm{V}, \mathrm{Rb}, \mathrm{Au}$ and $\mathrm{Mn}$ showing detectable concentrations. The distilled water concentrations are not shown but are generally lower than seawater. Complete trace element results are listed in Appendix E.

While seawater exits that Reactor, the only elements that show regular trends are $\mathrm{Mn}$, $\mathrm{Rb}, \mathrm{Ba}, \mathrm{Au}$ and perhaps $\mathrm{Pb}$. All other element concentrations are either below detection limit or are highly irregular. Mn shows a regular concentration of $\sim 0.5 \mathrm{mmol} \mathrm{kg}^{-1}$ up to 400 hours. Mn concentration would at first appear to be dependent on flow rate, however, the concentration at $10 \mathrm{ml} \mathrm{hr}^{-1}$ is lower than at $1 \mathrm{ml} \mathrm{hr}^{-1}$ while at 7.5 and $5 \mathrm{ml} \mathrm{hr}^{-1}$, the concentration is unchanged.

Except for the isolated high value at the start of the experiment, $\mathrm{Rb}$ concentrations reflect the input seawater (Fig. 6.4).

As with SW1, Ba concentration is highest at the beginning of the exit of seawater, it decreases over the remainder of the experiment. This is attributed to the precipitation of barite. Ba concentrations are independent of flow rate.

$\mathrm{Au}$ concentrations are interesting in that they are the highest once seawater begins egress from the Reactor after which they decline regularly to below detection limit by the end of the experiment. This behaviour differs from the seawater-only experiment where $\mathrm{Au}$ remained at a relatively steady value of $0.05 \mu \mathrm{mol} \mathrm{kg} \mathrm{kg}^{-1}$ (Fig. 5.6). This suggests possible release of $\mathrm{Au}$ from the $\mathrm{ZrO}_{2}$ beads and then fixation in the rock.

The trace element results are rather unremarkable, nevertheless, it is evident that trace element mobility is less when the basalt is present. This suggests fixation of trace elements by the rock during fluid - rock interaction rather than release from it. 
Figure 6.3. Trace element concentrations in blank and effluent samples ( $\mu \mathrm{mol} \mathrm{kg}{ }^{-1}$ ) versus time (hr) for the basalt-seawater experiment at $400^{\circ} \mathrm{C} / 488$ bar (BSW1). Yellow squares at $\mathrm{t}=0$ are the blank composition of seawater from SW1. Light blue symbols show where distilled water was exiting the Reactor at $400^{\circ} \mathrm{C} / 488$ bar and $1.0 \mathrm{ml} \mathrm{hr}^{-1}$. Black symbols are effluent compositions at $400^{\circ} \mathrm{C} / 488 \mathrm{bar}^{2}$ and $1.0 \mathrm{ml} \mathrm{hr}{ }^{-1}$ flow rate. Other coloured symbols are effluent composition at differing flow rate. In situ $\mathrm{pH}$ is the calculated $\mathrm{pH}$ at temperature. $\mathrm{LOD}=$ limit of detection.
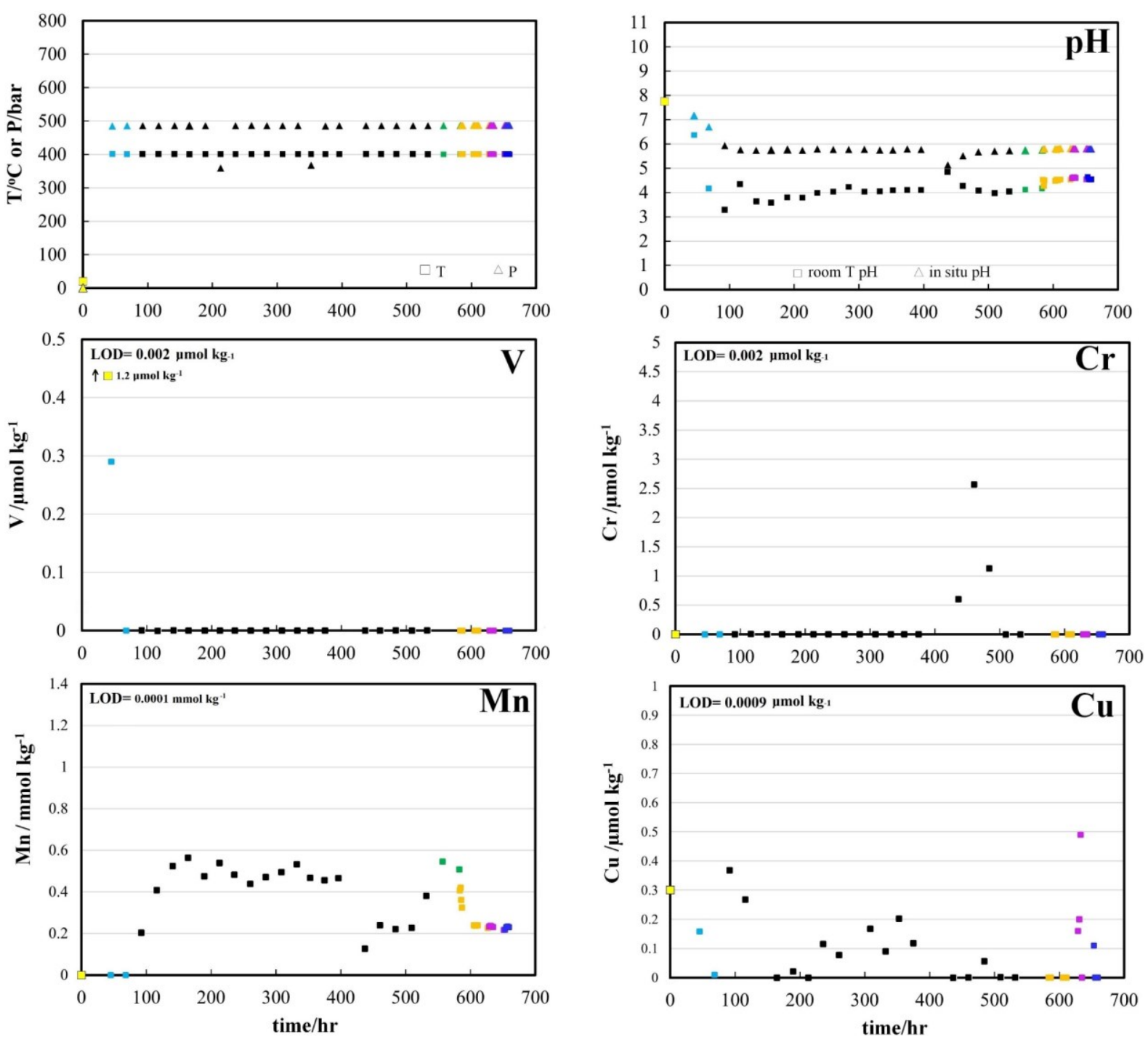

$\square$ blank seawater

$\Delta$ distilled water mixed to seawater $400^{\circ} \mathrm{C} / 488 \mathrm{bar} / 1 \mathrm{ml} \mathrm{hr}^{-1}$

-4 seawater $400^{\circ} \mathrm{C} / 488 \mathrm{bar} / 1 \mathrm{ml} \mathrm{hr}{ }^{-1}$

a seawater $400^{\circ} \mathrm{C} / 488 \mathrm{bar} / 1.5 \mathrm{ml} \mathrm{hr}^{-1}$

1. $\triangle$ seawater $400^{\circ} \mathrm{C} / 488 \mathrm{bar} / 10 \mathrm{ml} \mathrm{hr}^{-1}$

- $\Delta$ seawater $400^{\circ} \mathrm{C} / 488 \mathrm{bar} / 7.5 \mathrm{ml} \mathrm{hr}{ }^{-1}$

- $\Delta$ seawater $400^{\circ} \mathrm{C} / 488 \mathrm{bar} / 5 \mathrm{ml} \mathrm{hr}^{-1}$ 
Figure 6.4. Trace element concentrations in blank and effluent samples ( $\mu \mathrm{mol} \mathrm{kg}{ }^{-1}$ ) versus time (hr) for the basalt-seawater experiment at $400^{\circ} \mathrm{C} / 488$ bar (BSW1). Yellow squares are the blank composition of seawater from SW1. Light blue symbols show where distilled water was exiting the Reactor at $400^{\circ} \mathrm{C} / 488$ bar and $1.0 \mathrm{ml} \mathrm{hr}^{-1}$. Black symbols are effluent compositions at $400^{\circ} \mathrm{C} / 488 \mathrm{bar}$ and $1.0 \mathrm{ml} \mathrm{hr}{ }^{-1}$ flow rate. Other coloured symbols are effluent compositions at differing flow rate. In situ $\mathrm{pH}$ is the calculated $\mathrm{pH}$ at temperature. $\mathrm{LOD}=$ limit of detection.
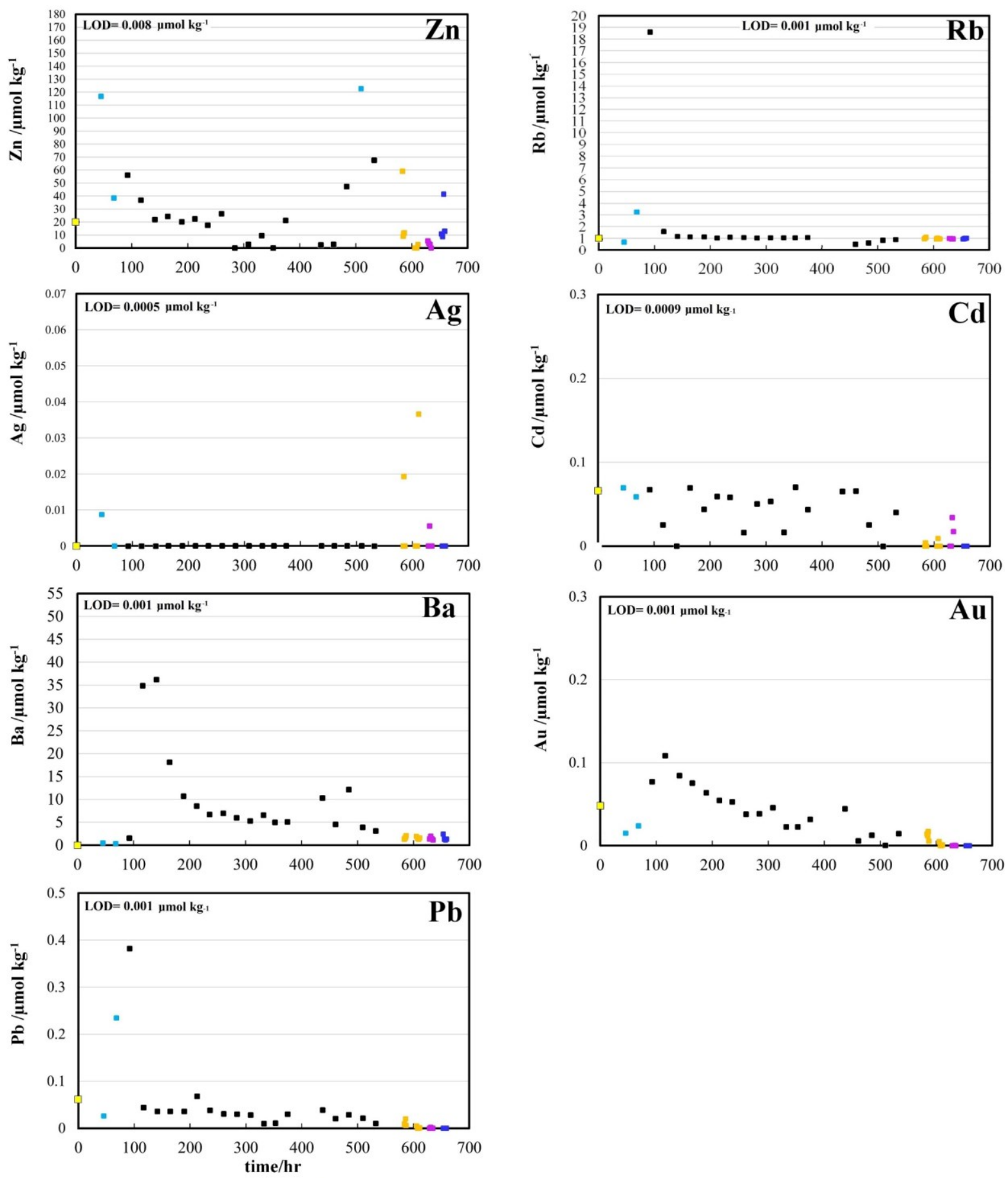

$\square \triangle$ blank seawater

口 $\Delta$ distilled water mixed to seawater $400^{\circ} \mathrm{C} / 488 \mathrm{bar} / 1 \mathrm{ml} \mathrm{hr}^{-1}$

— A seawater $400^{\circ} \mathrm{C} / 488 \mathrm{bar} / 1 \mathrm{ml} \mathrm{hr}^{-1}$

¿ seawater $400^{\circ} \mathrm{C} / 488 \mathrm{bar} / 1.5 \mathrm{ml} \mathrm{hr}^{-1}$

⿴囗十 seawater $400^{\circ} \mathrm{C} / 488 \mathrm{bar} / 10 \mathrm{ml} \mathrm{hr}^{-1}$

口 $\Delta$ seawater $400^{\circ} \mathrm{C} / 488 \mathrm{bar} / 7.5 \mathrm{ml} \mathrm{hr}^{-1}$

- \ seawater $400^{\circ} \mathrm{C} / 488 \mathrm{bar} / 5 \mathrm{ml} \mathrm{hr}^{-1}$ 


\subsubsection{Mineralogy and Texture of Reacted Basalt}

Upon the completion of the experiment $(659 \mathrm{hrs})$, the reacted basalt was extracted from the Reactor onto absorbent paper. The run products were rinsed with distilled water to remove precipitated soluble salts and air-dried. The reacted material was initially divided into seven portions which were numbered from 1 (bottom of the Reactor) to 7 (top of the Reactor) (Fig. 6.5). The remnants of the basalt block from the bottom of the Reactor were extracted and rinsed with distilled water.

Figure 6.5 shows the reacted grains after extraction from the Reactor upon completion of the experiment. The change of colour of the grains from bottom to top shows that the rock is visibly altered. Also present is a large amount of fine material which indicates partial disintegration of the rock grains during alteration. Portion 1 is light green-gray, Portion 2 and 3 are also light green-gray but have an additional pinkish tone, Portion 4 is gray with no pink coloration, while Portions 5 to 7 show a gradual darkening of the rock to dark green.

In order to reduce the amount of analysis required, grains from Portion 2 and 3 were combined, and run products from Portions 1, 2-3, 4 and 7 were mounted on aluminium stubs for SEM analysis. Run products from these portions were also epoxy-mounted and polished for SEM analysis. Larger samples were also collected for XRD and XRF analysis. 
Figure 6.5. Schematic diagram showing position of reacted rock extracted from the Reactor after the completion of the BSW1 (not to scale). On the left, the reacted grains are shown after extraction and rinsing. On the right, are the same grains divided in seven portions numbered from 1 (bottom of the Reactor) to 7 (top of the Reactor). Also shown is the position of the basalt block.

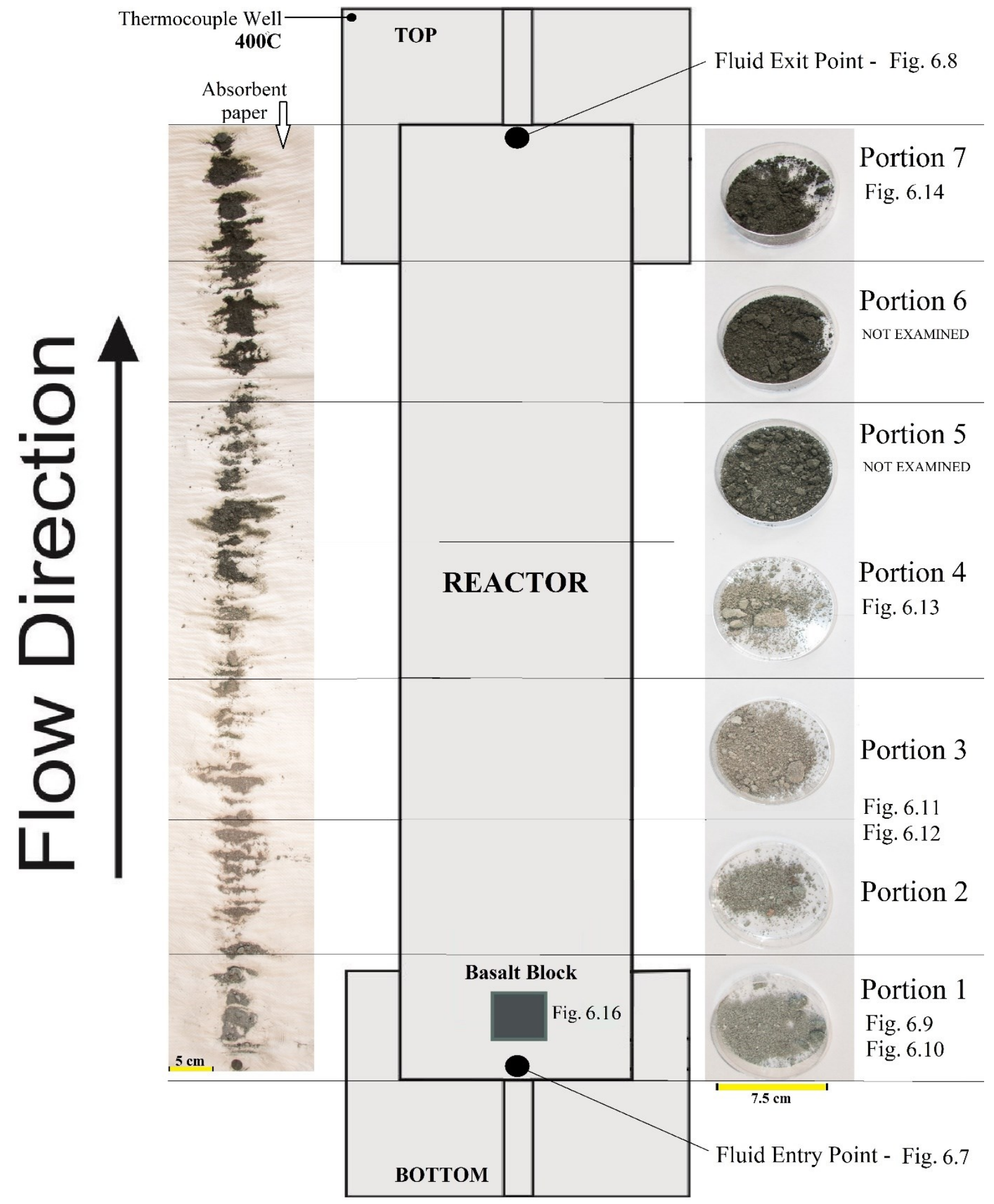




\section{Qualitative XRD analysis}

Qualitative XRD results for the reacted material are listed in Table 6.2. They show that plagioclase was detected in all portions while augite was identified only Portion 7, which is located at the top of the Reactor. These results indicate that at least some plagioclase remains after reaction while pyroxene has been almost completely removed, at least up to Portion 4. This coincides with the loss of the dark green coloration of the basalt. All other minerals identified are interpreted to be secondary in origin including chlorite, maghemite, hematite, calcite, smectite, and ankerite. Hematite is found only in Portion 2-3 which explains the pink coloration of the rock. Smectite and ankerite are found only in Portion 7. The identification of smectite is unusual as swelling clays should not form at the high temperature of the experiment. Complete XRD scans and qualitative results are reported in Appendix E.

Table 6.1. Qualitative XRD analysis of Portion 1, 2-3, 4 and 7 from BSW1.

\begin{tabular}{|rcccc|}
\hline & Portion 1 & Portion 2-3 & Portion 4 & Portion 7 \\
Chlorite & $\mathrm{x}$ & $\mathrm{x}$ & $\mathrm{x}$ & \\
Plagioclase & $\mathrm{x}$ & $\mathrm{x}$ & $\mathrm{x}$ & $\mathrm{x}$ \\
Maghemite & $\mathrm{x}$ & & & \\
Hematite & & $\mathrm{x}$ & & \\
Calcite & $\mathrm{x}$ & & & \\
Smectite & & & & $\mathrm{x}$ \\
Ankerite & & & & $\mathrm{x}$ \\
Augite & & & & $\mathrm{x}$ \\
\hline
\end{tabular}

\section{XRF analysis}

The high degree of visible alteration indicated that whole rock analysis of the reacted basalt would show measurable differences in composition upwards through the Reactor. Table 6.2 lists the XRF results for the portions examined. Notable changes in rock chemistry are evident. In order to test for significant relationships between elements during fluid - rock exchange a correlation matrix was made (Table 6.3). At the 95\% significance level and with $\mathrm{n}=5$, the level of significance of $\mathrm{r}= \pm 0.88$ ( \pm 0.95 for $\mathrm{S})$. The correlation coefficients with values of $-0.88 \leq \mathrm{r} \geq+0.88$ are highlighted in yellow. Based on these coefficients, selected elements are plotted in Figure 6.6. These show the oxide composition of the altered basalt plotted by position in the Reactor column. Also shown is the unreacted basalt composition for comparison. 
There are several notable observations to be made from these graphs. It is evident that the chemical composition of the rock changes upward through the Reactor. This is also evidenced by the change in colour (Fig. 6.5). This supports the conclusion that the flow regime in the Reactor is by plug flow whereby little mixing occurs between horizontal fluid layers (Saldaña et al., 2016). If the Reactor were well-mixed through turbulent flow, zonation of chemistry with vertical distance up the column would not be expected.

It can be seen from the correlation matrix there is significant positive correlation between $\mathrm{CaO}, \mathrm{Na}_{2} \mathrm{O}$ and $\mathrm{SiO}_{2}$ while with $\mathrm{MgO}$ these three elements show a significant negative correlation. There is also weaker positive correlation between $\mathrm{CaO}$ and $\mathrm{Fe}_{2} \mathrm{O}_{3}$ and weaker negative correlation between $\mathrm{Fe}_{2} \mathrm{O}_{3}$ and $\mathrm{MgO}$.

The highest $\mathrm{Al}_{2} \mathrm{O}_{3}$ concentration is in Portions $2+3$ plotted at position 2.5 in Figure 6.6. As there was no detectable $\mathrm{Al}$ in most effluent samples, it is assumed that Al was immobile during fluid - rock interaction. This means that the highest mass loss occurred a position 2-3 in the Reactor column. This is supported by lows in $\mathrm{SiO}_{2}, \mathrm{Na}_{2} \mathrm{O}$, and $\mathrm{CaO}$ at this position. The only elements that appear to have gained appreciable mass are $\mathrm{MgO}$ and $\mathrm{S}$. The $\mathrm{S}$ concentration is highest at position $4(0.8 \%)$. Except for $\mathrm{K}_{2} \mathrm{O}$ and $\mathrm{TiO}_{2}$, all elements approach the unaltered composition at the top of the Reactor.

Table 6.2. XRF analysis of the reacted material collected from Portion 1, 2-3, 4 and 7 after the BSW1 experiment (wt\%). Also shown is the composition of the unreacted basalt rock. n.d.: not detected, n.m.: not measured.

\begin{tabular}{|cccccccccccc|}
\hline & $\mathrm{Na}_{2} \mathrm{O}$ & $\mathbf{C a O}$ & $\mathrm{MgO}$ & $\mathrm{SiO}_{2}$ & $\mathrm{TiO}_{2}$ & $\mathrm{Al}_{2} \mathrm{O}_{3}$ & $\mathrm{Fe}_{2} \mathrm{O}_{3}$ & $\mathrm{MnO}$ & $\mathrm{K}_{2} \mathrm{O}$ & $\mathbf{P}_{2} \mathrm{O}_{5}$ & $\mathrm{~S}_{(\mathrm{ppm})}$ \\
Portion 7 & 2.51 & 10.76 & 5.74 & 46.64 & 1.47 & 14.49 & 12.34 & 0.13 & 0.06 & 0.31 & n.d. \\
Portion 4 & 1.31 & 3.76 & 23.38 & 39.58 & 1.87 & 15.21 & 6.72 & 0.01 & 0.06 & 0.28 & 8460 \\
Portion 2-3 & 0.22 & 2.04 & 26.20 & 32.30 & 2.19 & 15.87 & 8.20 & 0.008 & 0.02 & 0.14 & 6410 \\
Portion 1 & 0.63 & 3.83 & 23.05 & 38.29 & 1.97 & 13.87 & 7.66 & 0.02 & 0.03 & 0.25 & 610 \\
Unreacted & 2.35 & 10.94 & 6.50 & 48.85 & 2.13 & 13.41 & 15.11 & 0.24 & 0.25 & 0.22 & n.m. \\
\hline
\end{tabular}


Table 6.3. Correlation matrix of major oxides and sulfur for analyses shown in Table 6.2. Correlation coefficients significant at the $95 \%$ level are highlighted in yellow.

\begin{tabular}{|c|c|c|c|c|c|c|c|c|c|c|c|}
\hline & $\mathrm{Na}_{2} \mathrm{O}$ & $\mathrm{CaO}$ & MgO & $\mathrm{SiO}_{2}$ & $\mathrm{TiO}_{2}$ & $\mathbf{A l}_{2} \mathbf{O}_{3}$ & $\mathrm{Fe}_{2} \mathrm{O}_{3}$ & MnO & $\mathbf{K}_{2} \mathrm{O}$ & $\mathbf{P}_{2} \mathbf{O}_{5}$ & $\mathbf{S}$ \\
\hline $\mathrm{Na}_{2} \mathrm{O}$ & 1 & & & & & & & & & & \\
\hline $\mathrm{CaO}$ & 0.96 & 1 & & & & & & & & & \\
\hline MgO & -0.95 & -1.00 & 1 & & & & & & & & \\
\hline $\mathrm{SiO}_{2}$ & 0.97 & 0.96 & -0.94 & 1 & & & & & & & \\
\hline $\mathrm{TiO}_{2}$ & -0.56 & -0.45 & 0.47 & -0.43 & 1 & & & & & & \\
\hline $\mathrm{Al}_{2} \mathrm{O}_{3}$ & -0.56 & -0.66 & 0.63 & -0.75 & 0.07 & 1 & & & & & \\
\hline $\mathrm{Fe}_{2} \mathrm{O}_{3}$ & 0.80 & 0.92 & -0.92 & 0.84 & -0.10 & -0.63 & 1 & & & & \\
\hline MnO & 0.83 & 0.92 & -0.91 & 0.89 & -0.07 & -0.70 & 0.98 & 1 & & & \\
\hline $\mathrm{K}_{2} \mathrm{O}$ & 0.65 & 0.70 & -0.67 & 0.75 & 0.25 & -0.67 & 0.82 & 0.90 & 1 & & \\
\hline $\mathrm{P}_{2} \mathrm{O}_{5}$ & 0.62 & 0.47 & -0.45 & 0.59 & -0.86 & -0.36 & 0.09 & 0.15 & 0.00 & 1 & \\
\hline $\mathbf{S}$ & -0.41 & -0.65 & 0.65 & -0.56 & 0.53 & 0.81 & -0.67 & -0.68 & -0.01 & -0.40 & 1 \\
\hline
\end{tabular}


Figure 6.6. Chemical composition (wt\%) of rock Portions analysed by XRF plotted against position in Reactor column (red circles). The unreacted basalt compositions shown by blue line.
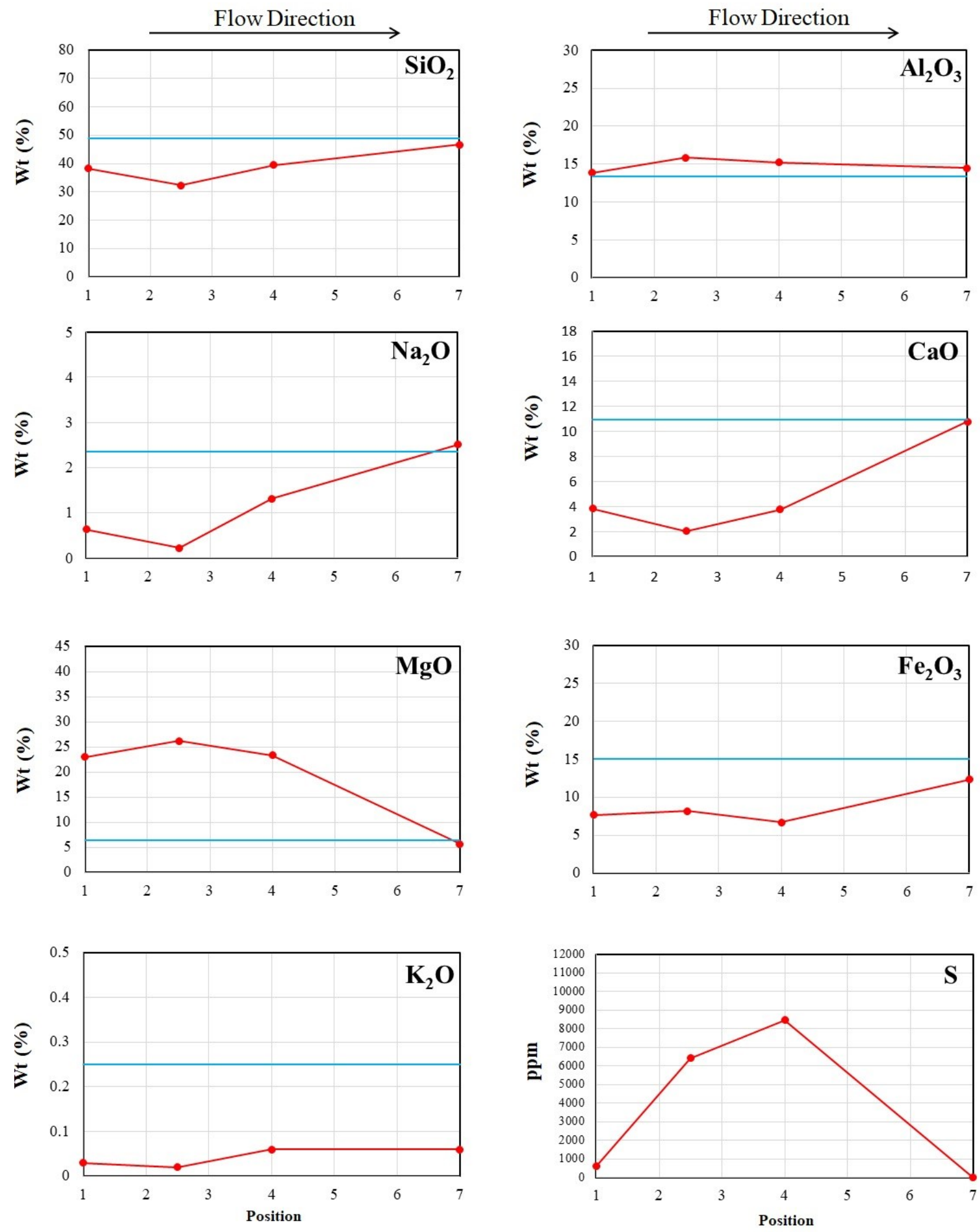

— unreacted basalt 
SEM-EDS results are presented in this section for grains collected and divided into Portion 1, 2-3, 4 and 7 as shown in Figure 6.5. Also analysed were grains collected from the immediately adjacent to the fluid entry and exit point of the Reactor after 396 hours (§6.2.1). All SEM results are listed in Appendix E.

Reacted grains - Bottom of Reactor $(396 \mathrm{~h})$

Table 6.4 lists the minerals identified from grains collected from the bottom of the Reactor sample at $396 \mathrm{hr}$. These grains represent reacted basalt from immediately adjacent to the fluid entry point. The grains display a high degree of alteration. Minerals of secondary origin identified were anhydrite, chlorite, and caminite (Fig. 6.7). No evidence of the primary plagioclase, clinopyroxene or olivine was found during SEM examination of the grains.

Figure 6.7 shows SEM images of reacted grains covered by the secondary mineral assemblage. Chlorite appears in masses as densely intergrown flakes. Anhydrite occurs as euhedral crystals while caminite appears with its tetragonal dipyramid shape.

Table 6.4. Mineral assemblage identified by SEM-EDS analysis of reacted grains extracted from the immediately adjacent to the fluid entry point into the Reactor after 396 hours of the BSW1 experiment.

\begin{tabular}{|c|c|c|c|}
\hline $\begin{array}{l}\text { Type of } \\
\text { Analysis }\end{array}$ & $\begin{array}{l}\text { Analysis } \\
\text { Material }\end{array}$ & $\begin{array}{c}\text { Mineral } \\
\text { Identified }\end{array}$ & $\begin{array}{c}\text { Average } \\
\text { Mineral Composition }\end{array}$ \\
\hline SEM-EDS & grain surface & Anhydrite & $\mathrm{CaSO}_{4}$ \\
\hline SEM-EDS & grain surface & Caminite & $\mathrm{Mg}_{7}\left(\mathrm{SO}_{4}\right)_{5}(\mathrm{OH})_{4} \cdot \mathrm{H}_{2} \mathrm{O}$ \\
\hline SEM-EDS & grain surface & Chlorite & $\begin{array}{l}\qquad \mathrm{Mg}_{4.0} \mathrm{Fe}_{0.4} \mathrm{Al}_{1.4} \mathrm{Si}_{3.1} \mathrm{Al}_{0.9} \mathrm{O}_{10}(\mathrm{OH})_{8} \\
\text { (calculated based on an anhydrous composition with } 14 \text { oxygens) }\end{array}$ \\
\hline
\end{tabular}


Figure 6.7. SEM images of grains collected from the immediately adjacent fluid entry point (bottom) of the Reactor after 396 hrs of the BSW1 experiment: (a) example of a reacted grain; (b-c) enlargements of rectangular area in (a) showing densely-packed flakes of chlorite (Chl), euhedral crystals of anhydrite (Anh) and caminite with its tetragonal dipyramidal shape; (d) a different reacted grain; (e-f) enlargements of rectangular area in (d) showing an euhedral crystal of anhydrite (Anh) surrounded by chlorite (Chl).
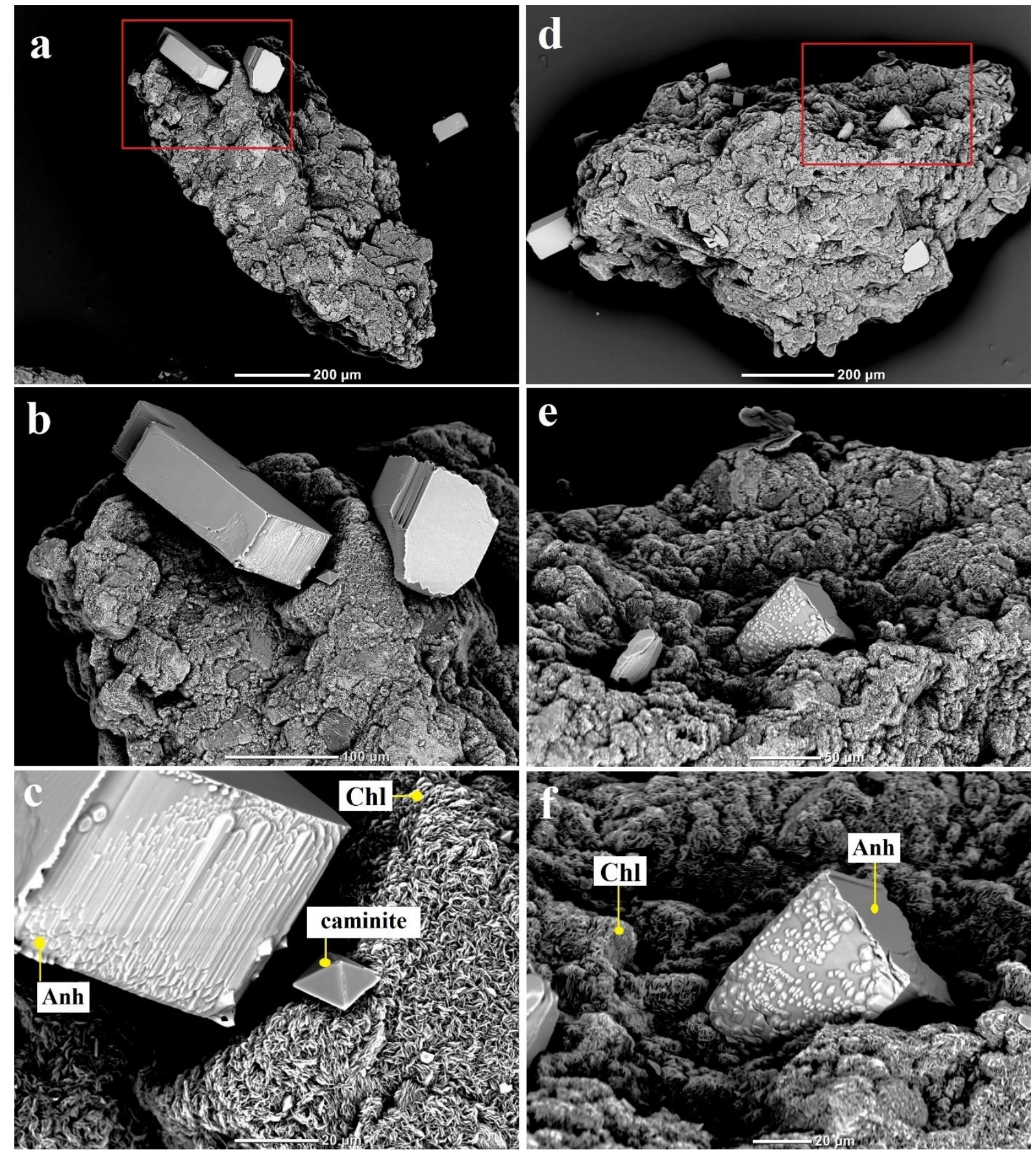
Table 6.5 lists minerals identified by SEM-EDS examination of several grains collected from the top of the Reactor when the experiment was stopped at $396 \mathrm{hr}$. The results confirm a lower grade of alteration of the grains when compared to those from the bottom of the Reactor (Fig. 6.7). Minerals of secondary origin identified were a clay-like Na-Mg-Fe aluminosilicate and caminite (Fig. 6.8). Primary plagioclase and pyroxene were observed on the outer surface of the grains, however, the grains were almost completely covered with the secondary Na-Mg-Fe phase (Fig. 6.8).

SEM analyses of the Na-Mg-Fe aluminosilicate are shown in Table 6.6. Repeat SEMEDS analyses show the mineral to be composed of fairly consistent concentrations of iron, aluminium, silica and magnesium with a measurable concentration of sodium and calcium but no potassium. It should be emphasised, however, that SEM-EDS analyses of such a delicate phase are at best approximate.

The presence of $\mathrm{Na}_{2} \mathrm{O}$ and $\mathrm{CaO}$, the high percentage of $\mathrm{FeO}$ and $\mathrm{MgO}$, and the claylike habit suggest a clay mineral. The XRD results of the final run products from the top of the Reactor gave a strong peak for montmorillonite suggesting the presence of a smectite phase such as Fe-saponite (Cheshire et al., 2018; Yardley et al., 2014) or nontronite (Haldar, 2020) or a related smectite phase. Seyfried and Bischoff (1979) found smectite as the major secondary phase in experiments reacting diabase and basaltic glass with seawater at $150^{\circ} \mathrm{C}$. Another possibility is corrensite a mixed-layer chlorite - trioctahedral smectite clay mineral (Beaufort et al., 1997). The presence of a swelling clay is unusual given the high temperature of the experiments, however, Yardley et al (2014) found saponite as a run product when reacting hornfels with water up to $500^{\circ} \mathrm{C}$. Thus, the composition, smectite-like texture, and $\mathrm{XRD}$ results lead us to conclude that this phase is smectite-related phase and it will be referred to as such. Without more detailed analysis using more sophisticated analytical techniques, it is difficult to refine this further.

Table 6.5. Mineral assemblage identified by SEM-EDS analysis of reacted grains extracted from the immediately adjacent to the fluid exit point of the Reactor after $396 \mathrm{hrs}$ of the BSW1 experiment.

\begin{tabular}{|c|c|c|c|}
\hline $\begin{array}{l}\text { Type of } \\
\text { Analysis } \\
\text { SEM-EDS }\end{array}$ & $\begin{array}{c}\text { Analysis } \\
\text { Material } \\
\text { grain surface }\end{array}$ & $\begin{array}{l}\text { Mineral } \\
\text { Identified } \\
\text { Bytownite }\end{array}$ & $\begin{array}{c}\text { Average } \\
\text { Mineral Composition } \\
\mathrm{Ca}_{0.8} \mathrm{Na}_{0.1} \mathrm{Al}_{1.9} \mathrm{Si}_{2.2} \mathrm{O}_{8}\left(\mathrm{An}_{89}-\mathrm{Ab}_{11}\right)\end{array}$ \\
\hline SEM-EDS & grain surface & Augite & $\mathrm{Ca}_{0.1} \mathrm{Mg}_{0.8} \mathrm{Fe}_{0.9} \mathrm{Al}_{0.2} \mathrm{Si}_{1.9} \mathrm{Al}_{0.1} \mathrm{O}_{6}$ \\
\hline SEM-EDS & grain surface & Caminite & $\mathrm{Mg}_{7}\left(\mathrm{SO}_{4}\right)_{5}(\mathrm{OH})_{4} \cdot \mathrm{H}_{2} \mathrm{O}$ \\
\hline SEM-EDS & grain surface & Smectite & $\begin{array}{l}\mathrm{Na}_{0.4} \mathrm{Ca} \mathrm{Ca}_{0.1} \mathrm{Mg}_{1.6} \mathrm{Fe}_{1.1} \mathrm{Al}_{0.25} \mathrm{Si}_{3.3} \mathrm{Al}_{0.7} \mathrm{O}_{10}(\mathrm{OH})_{2} \cdot n \mathrm{H}_{2} \mathrm{O} \\
\text { (calculated based on an anhydrous composition with } 11 \text { oxygens) }\end{array}$ \\
\hline
\end{tabular}


Figure 6.8. SEM images of the reacted grains collected from near the fluid exit point of the Reactor after 396 hrs of the BSW1 experiment: (a) example of a reacted grain; (b) enlargement of rectangular area ${ }^{\circ} 1$ in (a) showing the Na-Fe-Mg phase identified as smectite (Smc); (c) enlargement of rectangular area $n^{\circ} 2$ in (a) showing caminite in pyramidal shape surrounded by smectite (Smc); (d-e-f) three different reacted grains collected from the same Portion at top of the Reactor.
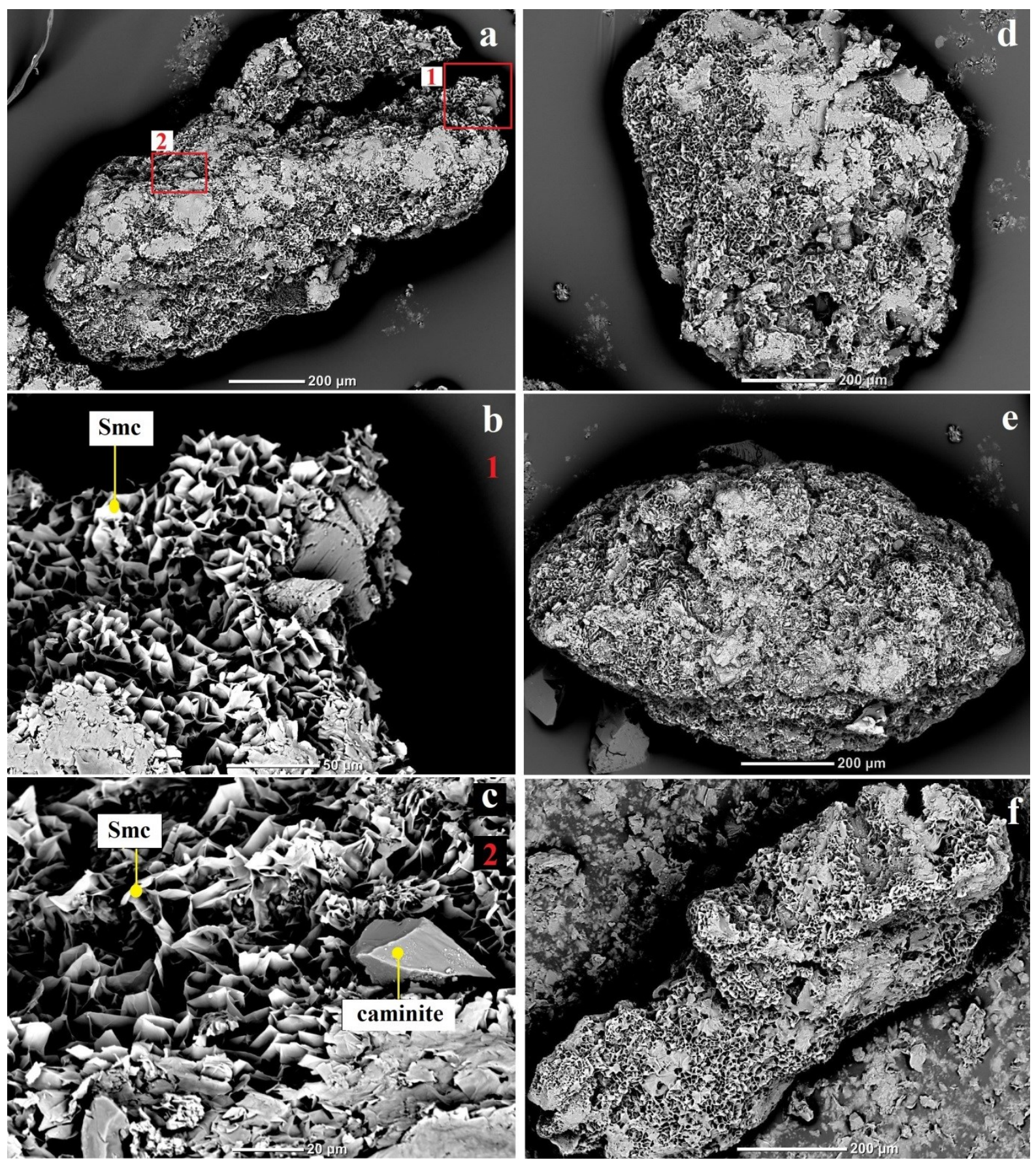
Table 6.6. Average composition (by SEM-EDS analysis) of the clay-like phase found during study of the reacted grains collected from the immediately adjacent to the fluid exit point (top) of the Reactor after $393.6 \mathrm{hrs}$ of the BSW1. This phase is tentatively identified as smectite.

\begin{tabular}{|ccc|}
\hline \multicolumn{3}{c|}{$\begin{array}{c}\text { Grain Surface } \\
(\mathbf{N}=\mathbf{2})\end{array}$} \\
& & \\
oxide & average & $\pm 1 \sigma$ \\
& Wt \% & \\
$\mathbf{N a}_{2} \mathbf{O}$ & 3.03 & 0.21 \\
$\mathbf{M g O}$ & 15.92 & 1.35 \\
$\mathbf{A l}_{2} \mathbf{O}_{3}$ & 11.95 & 1.96 \\
$\mathrm{SiO}_{2}$ & 49.03 & 2.02 \\
$\mathbf{C a O}$ & 1.69 & 0.14 \\
FeO & 18.34 & 1.29 \\
Total & 99.95 & \\
\hline
\end{tabular}

Portion $1(659 \mathrm{hr})$

Selected grains from Portion 1 (Fig. 6.5) were mounted on aluminium stubs for analyses by SEM and several grains were epoxy-mounted and polished. Results confirm a high grade of alteration due to fluid - rock interaction. Minerals of secondary origin identified were chlorite, caminite and $\mathrm{Fe}-\mathrm{Ni}-\mathrm{Cr}$ oxides. The results also confirm the presence of the primary minerals plagioclase, clinopyroxene, olivine and titanomagnetite (Table 6.7). Appendix E contains all SEM results for this Portion of the rock.

Table 6.7. Mineral assemblage identified by SEM-EDS analysis of reacted grains of Portion 1 after the BSW1 experiment.

\begin{tabular}{|c|c|c|c|}
\hline $\begin{array}{l}\text { Type of } \\
\text { Analysis }\end{array}$ & $\begin{array}{l}\text { Analysis } \\
\text { Material }\end{array}$ & $\begin{array}{l}\text { Mineral } \\
\text { Identified }\end{array}$ & $\begin{array}{c}\text { Average } \\
\text { Mineral Composition }\end{array}$ \\
\hline SEM-EDS & polished grains & Plagioclase & - \\
\hline SEM-EDS & polished grains & Augite & $\mathrm{Ca}_{0.60} \mathrm{Mg}_{0.91} \mathrm{Fe}_{0.42} \mathrm{Si}_{2} \mathrm{O}_{6}$ \\
\hline SEM-EDS & polished grains & Olivine & $\mathrm{Mg}_{1.24} \mathrm{Fe}_{0.75} \mathrm{SiO}_{4}$ \\
\hline SEM-EDS & polished grains & Chlorite & $\begin{array}{c}\mathrm{Mg}_{4.2} \mathrm{Fe}_{0.6} \mathrm{Al}_{0.9} \mathrm{Si}_{3.8} \mathrm{Al}_{0.2} \mathrm{O}_{10}(\mathrm{OH})_{8} \\
\text { (calculated based on an anhydrous composition with } 14 \text { oxygens) }\end{array}$ \\
\hline SEM-EDS & grain surface & Caminite & $\mathrm{Mg}_{7}\left(\mathrm{SO}_{4}\right)_{5}(\mathrm{OH})_{4} \cdot \mathrm{H}_{2} \mathrm{O}$ \\
\hline SEM-EDS & polished grains & Fe-Ti-Cr oxides & - \\
\hline
\end{tabular}

Figure 6.9 show secondary electron images of the reacted grains. There are surrounded by densely-packed plates of chlorite. Also present are isolated crystals of caminite. No evidence of the primary plagioclase and clinopyroxene were observed on the outside of the unpolished grains. No anhydrite was observed. 
Figure 6.9. SEM images of reacted grains from Portion 1 after the BSW1 experiment: (a-b-c-d) grains covered by chlorite with caminite $(\mathrm{e}, \mathrm{f})$.
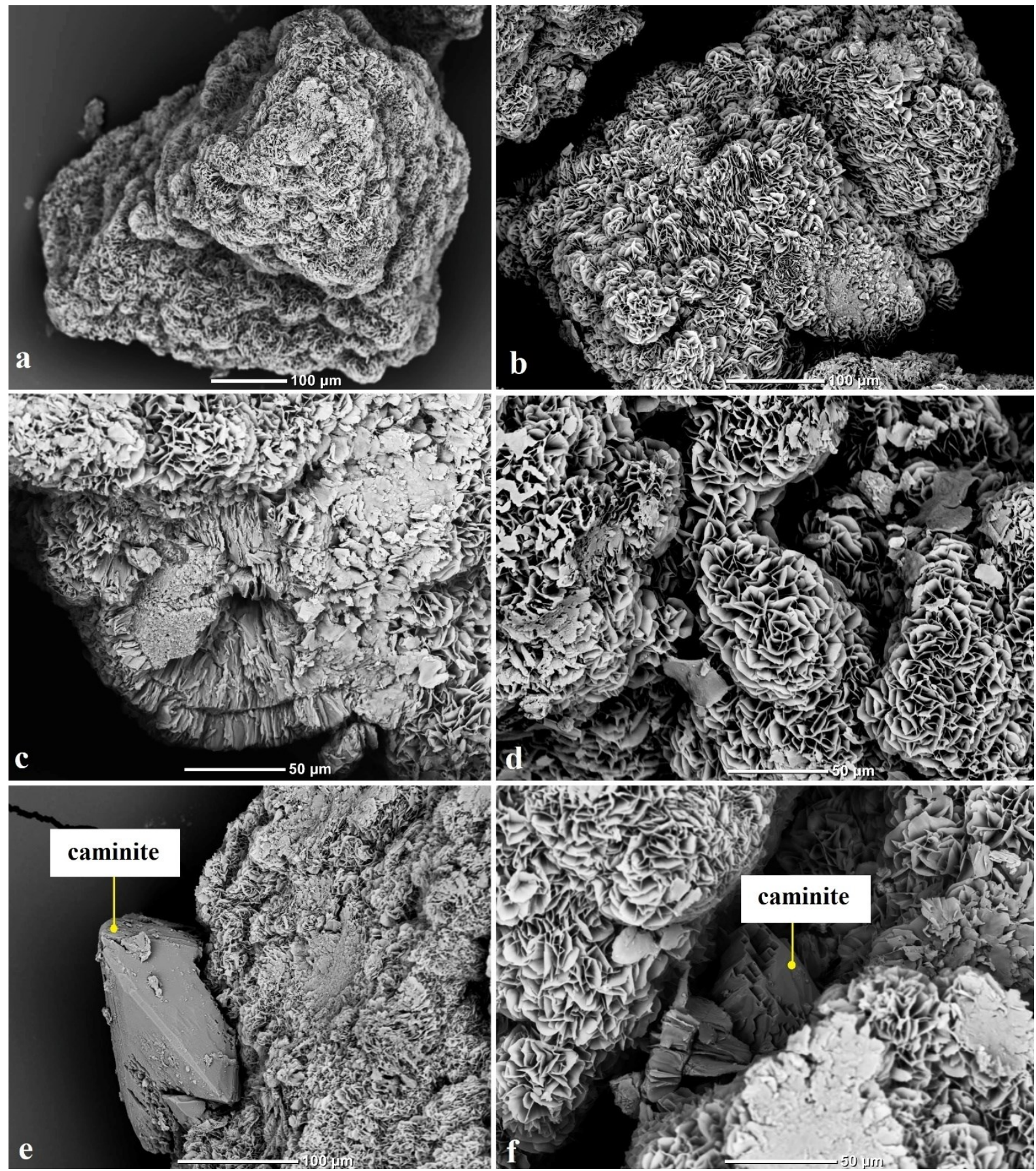

SEM examination of polished grains shows extensive chloritization with a significant amount of original plagioclase remaining but only remnants of the original clinopyroxene (Fig. 6.10). Chloritization is pervasive and has preferentially replaced clinopyroxene, however, plagioclase lathes also appear to have been partially replaced. Some olivine is also present and was likely isolated from the fluid and has been preserved. Titanomagnetite appears relatively unaffected. 
Figure 6.10. SEM backscatter and EDS compositional maps of a polished grain from the Portion 1 of the BSW1 experiment: (a) backscatter image; (b) composite colour image combining the backscatter image and elemental maps for c) $\mathrm{Mg}$ in green, d) Fe in red, and e) Ca in blue showing plagioclase (blue), clinopyroxene (light blue), secondary chlorite (green), olivine (orange-yellow), and Fe-Ti oxides (red); (f-g) SEM backscatter images of the rectangular areas $n^{\circ} 1$ and $n^{\circ} 2$ in (a) showing secondary chlorite (Chl), plagioclase (Plg), clinopyroxene $(\mathrm{Cpx})$, olivine $(\mathrm{Ol})$ and titanomagnetite $(\mathrm{Ox})$.
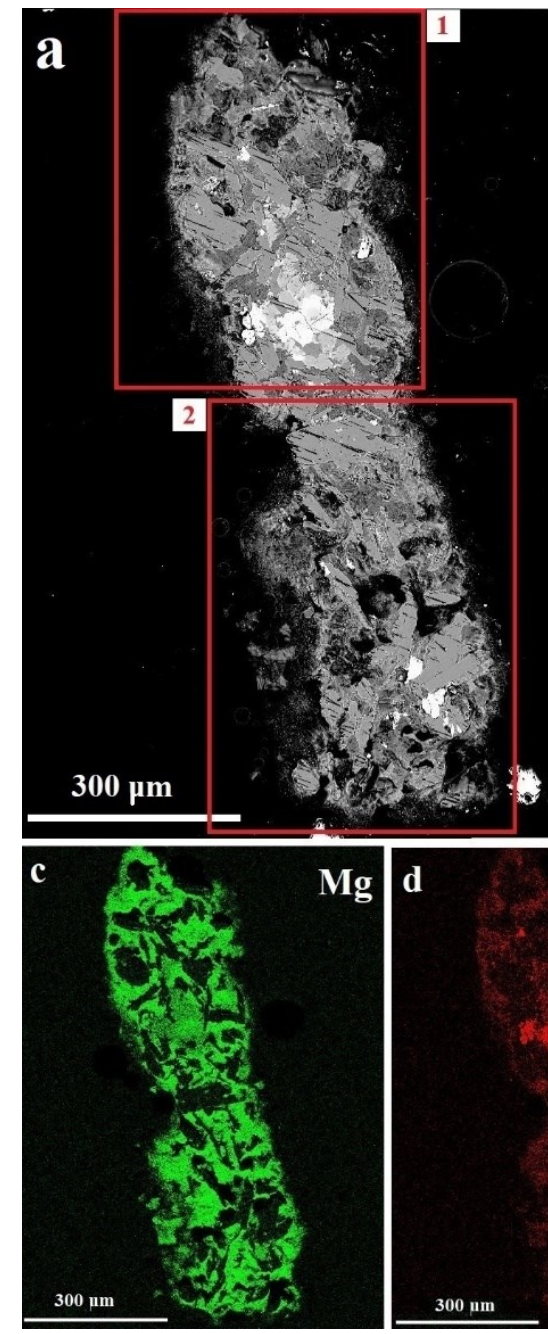
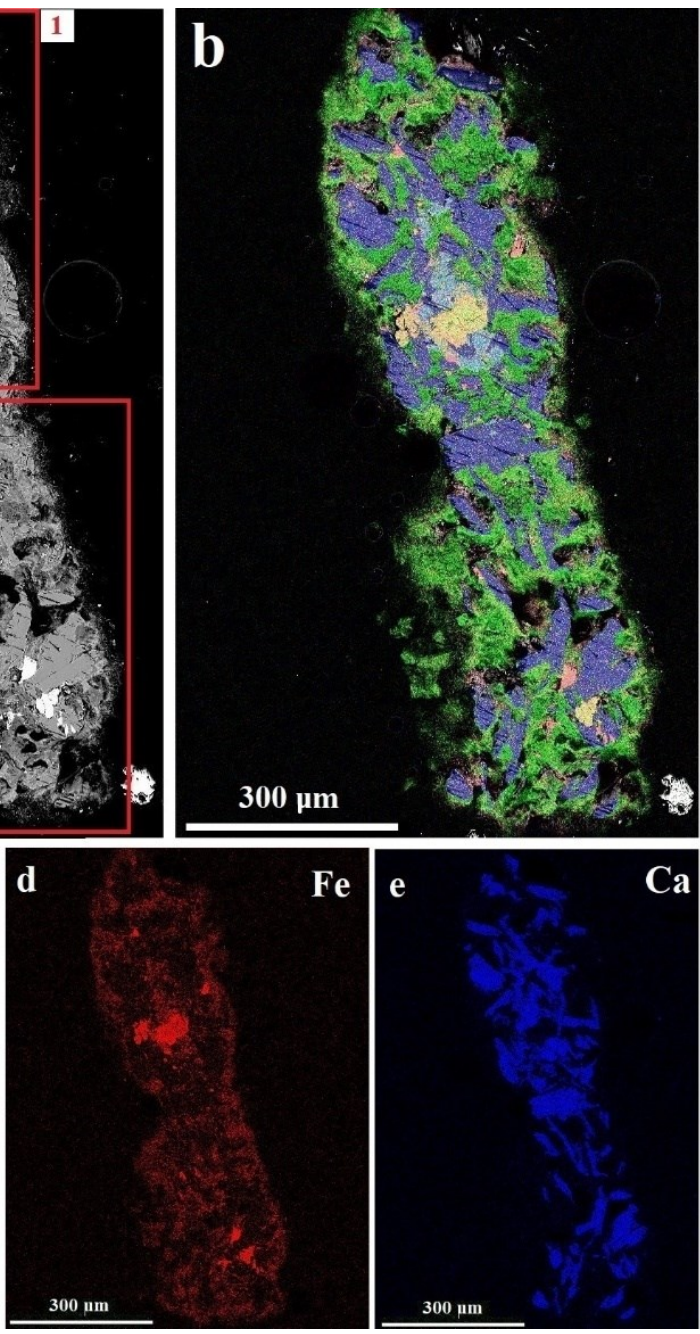
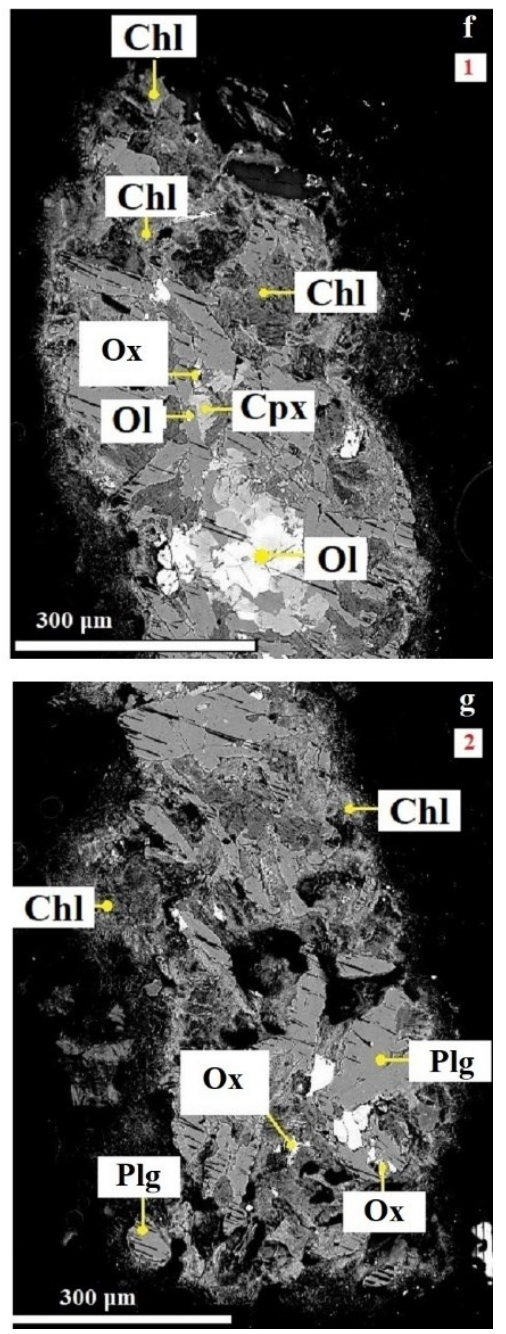

Portion $2-3(659 \mathrm{hr})$

Selected grains from Portion 2-3 (Fig. 6.5) were mounted on aluminium stubs for textural analyses and several grains were epoxy-mounted and polished for examination by SEM-EDS. Appendix E contains all SEM results for this Portion of the rock.

SEM examination of epoxy-mounted polished grains (Fig. 6.11) confirm this to be the most intensely altered portion of the basalt. The only minerals identified are chlorite with altered primary titanomagnetite (Table 6.8). No evidence of the primary plagioclase, clinopyroxene, or olivine was found. Hematite was identified in the XRD results and likely comprises some of the altered Fe-Ti oxides. 
Table 6.8. Mineral assemblage detected by SEM-EDS analysis of reacted grains of Portion 2-3.

\begin{tabular}{|ccc|}
\hline $\begin{array}{c}\text { Analysis } \\
\text { Material }\end{array}$ & $\begin{array}{c}\text { Mineral } \\
\text { Identified }\end{array}$ & $\begin{array}{c}\text { Average } \\
\text { Mineral Composition }\end{array}$ \\
polished grains & Chlorite & $\mathrm{Mg}_{3.6} \mathrm{Fe}_{0.7} \mathrm{Al}_{1.3} \mathrm{Si}_{3.1} \mathrm{Al}_{0.9} \mathrm{O}_{10}(\mathrm{OH}) 8$ \\
polished grains & Altered oxides & - \\
\hline
\end{tabular}

Figure 6.11. SEM backscatter and EDS compositional maps of two polished grains collected from the Portion 2-3 after the BSW1 experiment. (a) backscatter image of a reacted grain; (b) composite colour image combining the backscatter image and elemental maps for c) $\mathrm{Mg}$ in green and d) Fe in red showing secondary chlorite (green) with Fe oxides (red); (e) backscatter image of a second reacted grain; (b) composite colour image combining the backscatter image and elemental maps for g) $\mathrm{Mg}$ in green and h) Fe in red showing only chlorite (green) with Fe oxides (red).
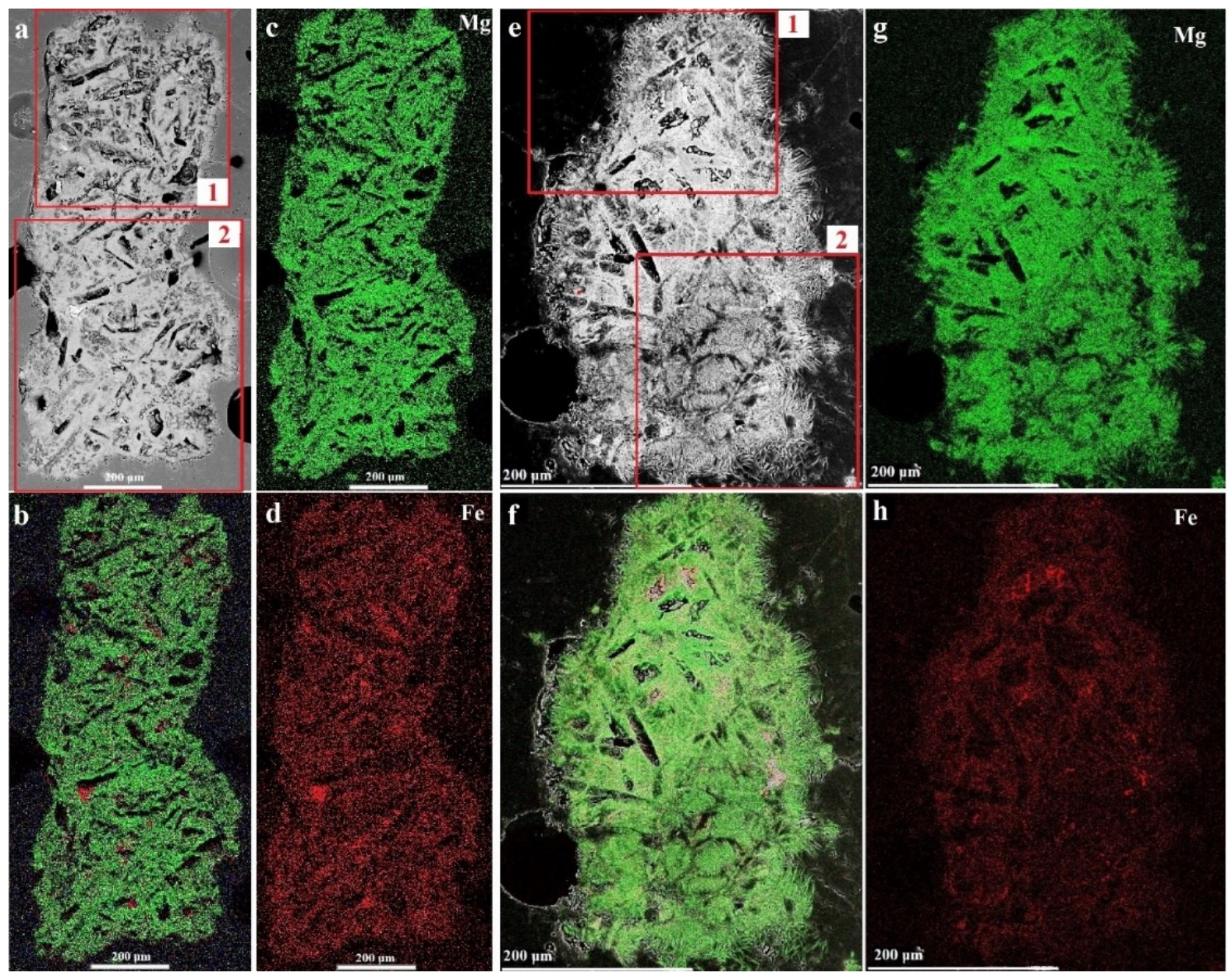
Figure 6.12. (a-b) SEM secondary electron images of the two red rectangular areas shown in Figure 6.11a; (c-d) SEM backscatter images of the same two areas in (a-b). They show that the grains are completely replaced by chlorite with some primary but altered titanomagnetite (white spots). No primary plagioclase, clinopyroxene or olivine are present. Black holes are spaces void left by plagioclase dissolution.

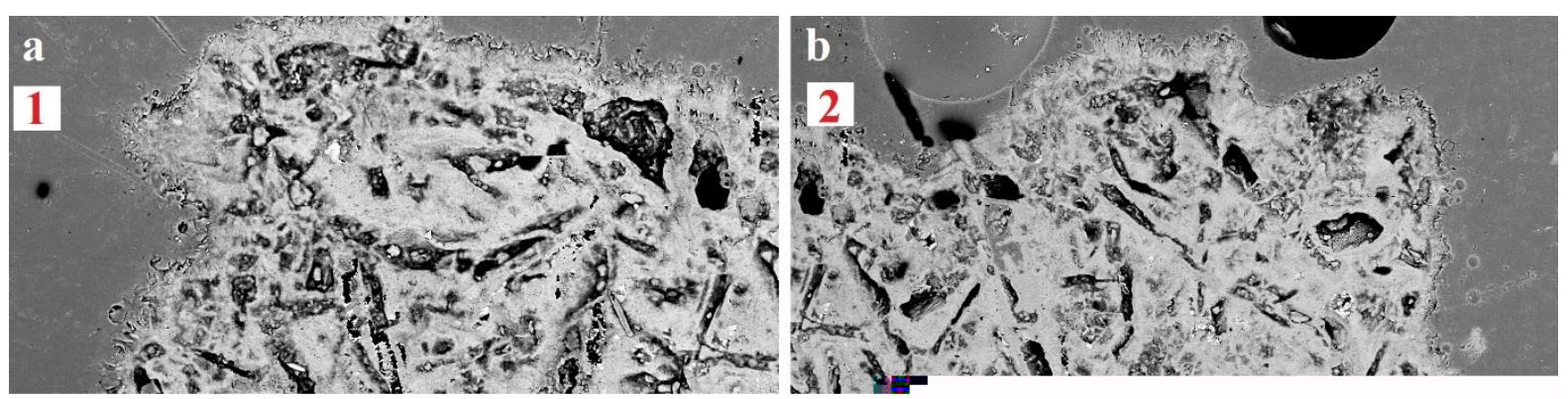

Portion $4(659 \mathrm{hr})$

SEM examination showed that these grains were less altered when compared to the results of Portion 2-3 (Fig. 6.13). The grain shown has a coating of a secondary Na-Mg-Fe aluminosilicate, tentatively identified as smectite. This phase is similar to that described previous portion and, at least for this grain, is the only secondary mineral present (Table 6.9). The original plagioclase is still present but highly corroded, while only minor amounts of remnant clinopyroxene and olivine are observed. These were preserved likely due to isolation from the fluids in the interior of the grain. Titanomagnetite appears altered. No clear evidence of chlorite was found in the grains analysed. This contradicts the XRD results which clearly chlorite present but no detectable clay mineral. The lack of XRD peaks for smectite may imply that there is $<5 \%$ present, however, chlorite must be present but was not seen in the SEM examination. 
Table 6.9. Mineral assemblage detected by SEM-EDS analysis of reacted grains of Portion 4 after the BSW1.

\begin{tabular}{|c|c|c|c|}
\hline $\begin{array}{l}\text { Type of } \\
\text { Analysis }\end{array}$ & $\begin{array}{l}\text { Analysis } \\
\text { Material }\end{array}$ & $\begin{array}{l}\text { Mineral } \\
\text { ID }\end{array}$ & $\begin{array}{c}\text { Average } \\
\text { Mineral Composition }\end{array}$ \\
\hline SEM-EDS & polished grains & Plagioclase & - \\
\hline SEM-EDS & polished grains & Augite & $\mathrm{Ca}_{0.6} \mathrm{Mg}_{0.9} \mathrm{Fe}_{0.3} \mathrm{Al}_{0.1} \mathrm{Si}_{1.8} \mathrm{Al}_{0.2} \mathrm{O}_{6}$ \\
\hline SEM-EDS & polished grains & Olivine & $\mathrm{Mg}_{1.24} \mathrm{Fe}_{0.75} \mathrm{SiO}_{4}$ \\
\hline SEM-EDS & polished grains & Smectite & $\begin{array}{l}\mathrm{Na}_{0.2} \mathrm{Mg}_{2.3} \mathrm{Fe}_{0.5} \mathrm{Al}_{0.3} \mathrm{Si}_{3.2} \mathrm{Al}_{0.8} \mathrm{O}_{10}(\mathrm{OH})_{2} \cdot n \mathrm{H}_{2} \mathrm{O} \\
\text { (calculated based on an anhydrous composition with } 11 \text { oxygens) }\end{array}$ \\
\hline SEM-EDS & polished grains & Altered Oxides & - \\
\hline
\end{tabular}

Numerous SEM-EDS analyses were made of the Na-Mg-Fe aluminosilicate phase that is tentatively identified as smectite (Table 6.10). These show fairly consistent concentrations of aluminium and silica comparable to the clay-like phase identified from the top of the Reactor after $396 \mathrm{hr}$. Note that this composition has a lower Al:Si ratio than previous identified chlorite (Table 6.7) and contains a measurable Na content.

Table 6.10. Average composition (SEM-EDS) of the clay mineral phase found in Portion 4 after the completion (659 hrs) of the BSW1 experiment. This phase is tentatively identified as smectite.

\begin{tabular}{|ccc|}
\hline & $\begin{array}{c}\text { Polished } \\
(\mathbf{N}=62)\end{array}$ & \\
oxide & $\begin{array}{c}\text { average } \\
\text { Wt } \%\end{array}$ & $\pm 1 \sigma$ \\
& & \\
$\mathbf{N a}_{2} \mathbf{O}$ & 1.72 & 1.05 \\
$\mathbf{M g O}$ & 24.24 & 3.72 \\
$\mathrm{Al}_{2} \mathbf{O}_{3}$ & 14.40 & 3.32 \\
$\mathrm{SiO}_{2}$ & 50.38 & 4.13 \\
$\mathbf{F e O}$ & 8.46 & 3.36 \\
$\mathrm{TiO}_{2}$ & 0.52 & 2.43 \\
$\mathrm{Total}$ & 99.7 & \\
\hline
\end{tabular}


Figure 6.13. SEM backscatter and EDS compositional maps of a polished grain from the Portion 4 after the BSW1 experiment: (a) backscatter image; (b) composite colour image combining the backscatter image and elemental maps for c) $\mathrm{Mg}$ in green, d) Fe in red, and e) $\mathrm{Ca}$ in blue showing plagioclase (blue), clinopyroxene (light blue), olivine (yellow), oxides (red) and smectite (green); (g-h) SEM backscatter images of the two red rectangular areas shown in (a). The grain is covered around the margin and internally by smectite (Smc), with plagioclase (Plg), clinopyroxene (Cpx), olivine (Ol) and titanomagnetite (Ox).
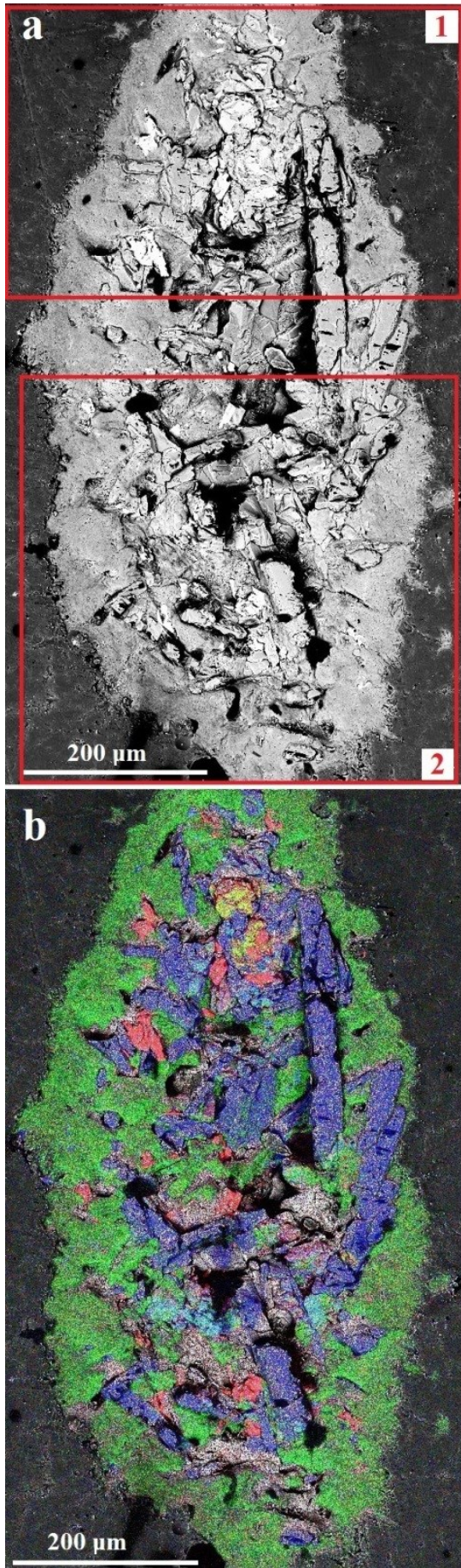
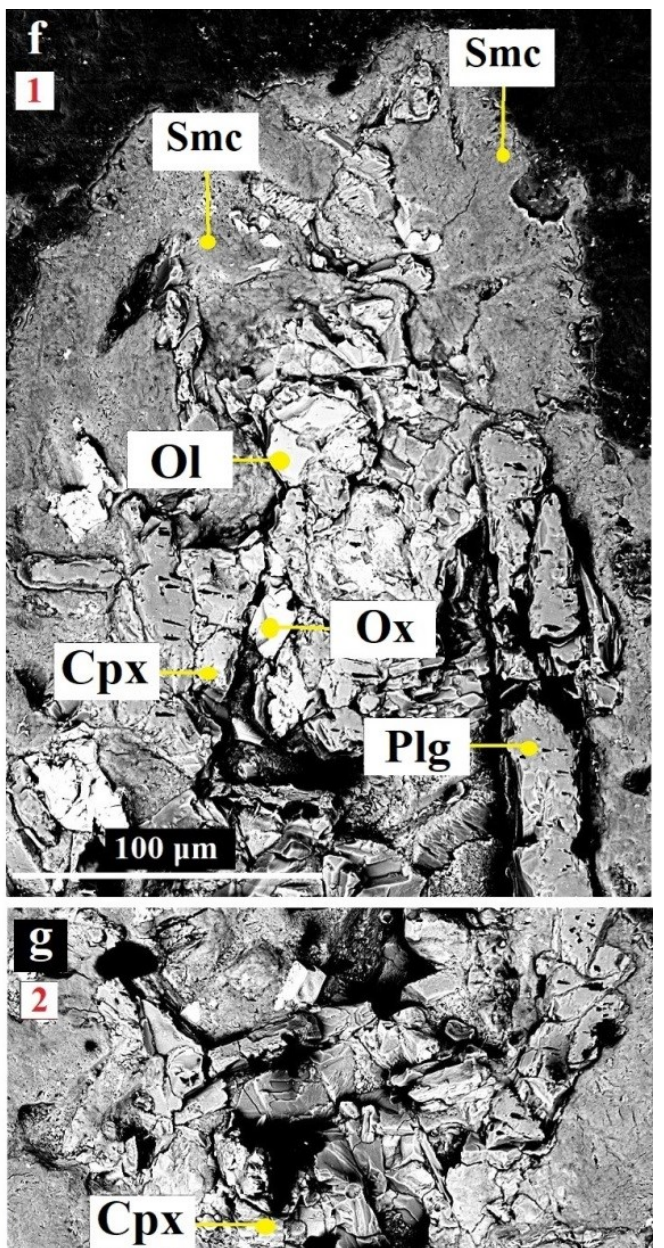

Ca
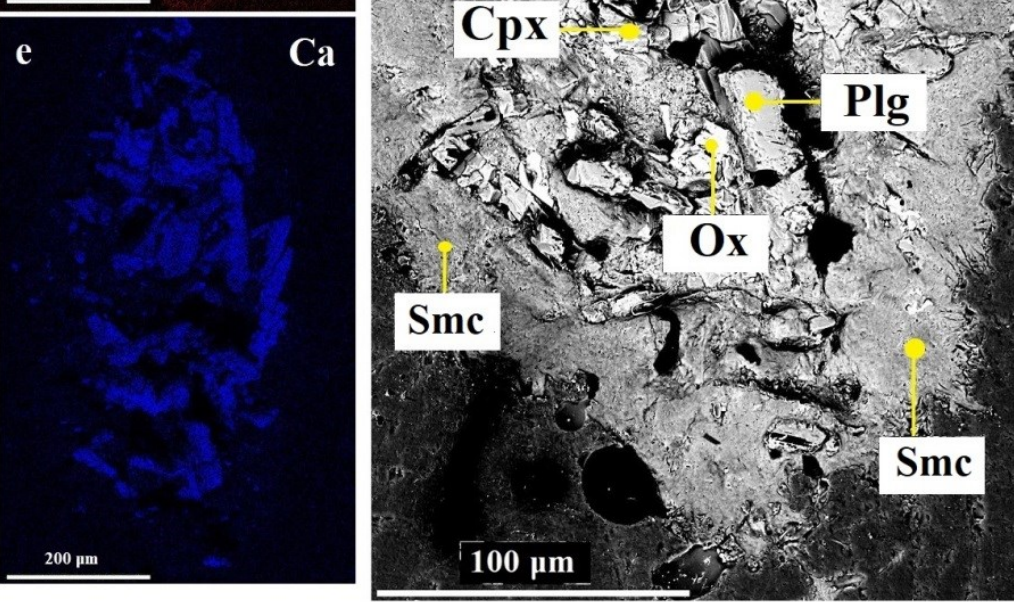
SEM analysis confirms a much lower intensity of alteration of the grains when compared to previous portions. The only secondary mineral identified was smectite with a composition similar to that described above (Table 6.11).

Table 6.11. Mineral assemblage detected by SEM-EDS analysis of reacted grains of Portion 7 after the BSW1.

\begin{tabular}{|c|c|c|c|}
\hline $\begin{array}{l}\text { Type of } \\
\text { Analysis }\end{array}$ & $\begin{array}{l}\text { Analysis } \\
\text { Material }\end{array}$ & $\begin{array}{l}\text { Mineral } \\
\text { Identified }\end{array}$ & $\begin{array}{c}\text { Average } \\
\text { Mineral Composition }\end{array}$ \\
\hline SEM-EDS & polished grains & Plagioclase & - \\
\hline SEM-EDS & polished grains & Augite & $\mathrm{Ca}_{0.7} \mathrm{Mg}_{0.8} \mathrm{Fe}_{0.4} \mathrm{Si}_{1.9} \mathrm{O}_{6}$ \\
\hline SEM-EDS & polished grains & Olivine & $\mathrm{Mg}_{1.4} \mathrm{Fe}_{0.6} \mathrm{SiO}_{4}$ \\
\hline SEM-EDS & polished grains & Smectite & $\begin{array}{l}\mathrm{Na}_{0.3} \mathrm{Mg}_{1.3} \mathrm{Fe}_{1.4} \mathrm{Al}_{0.3} \mathrm{Si}_{3.5} \mathrm{Al}_{0.5} \mathrm{O}_{10}(\mathrm{OH})_{2} \cdot n \mathrm{H}_{2} \mathrm{O} \\
\text { (calculated based on an anhydrous composition with } 11 \text { oxygens) }\end{array}$ \\
\hline SEM-EDS & polished grains & Titanomagnetite & - \\
\hline
\end{tabular}

Figure 6.14a-e shows SEM backscatter image and EDS maps of a polished mount of one grain collected from Portion 7. Plagioclase, clinopyroxene, olivine and oxides are mostly unaffected. The only secondary mineral detected is smectite occurring as a thin layer around the outside of the grain.

The average SEM-EDS analyses for smectite is shown in Table 6.12. Results show the mineral to be composed of similar concentrations of $\mathrm{Al}_{2} \mathrm{O}_{3}, \mathrm{SiO}_{2}$ and $\mathrm{Na}_{2} \mathrm{O}$ the clay phase identified in Portion 4. The major difference is the higher Fe:Mg ratio.

Figure 6.15 shows a summary photo of the reacted basalt grains, the backscatter images, and the EDS compositional maps for comparison. The bleaching of the rock can be attributed to the replacement of primary clinopyroxene, olivine and plagioclase by chlorite up to Portion 3 and then by smectite from Portion 4 upwards. This implies a transition from chlorite to smectite as the dominant secondary phase about one third way up the Reactor. For Portions 5 to 7 , the intensity of alteration decreases, and the colour of the grains darkens as more clinopyroxene remains unaltered and replacement by smectite is reduced. 
Figure 6.14. SEM backscatter and EDS compositional maps of a polished grain collected from the Portion 7 after the BSW1 experiment: (a) backscatter image of the reacted grain; (b) composite colour image combining the backscatter image and elemental maps for c) Mg in green, d) $\mathrm{Fe}$ in red, and e) $\mathrm{Ca}$ in blue showing plagioclase (blue), clinopyroxene (turquoise), olivine (orange-yellow), Fe-Ti oxides (red), and smectite (green); (f-g) SEM backscatter images of the two rectangular areas shown in (a). Images show a thin covering of smectite (Smc) with primary plagioclase $(\mathrm{Plg})$, clinopyroxene $(\mathrm{Cpx})$, olivine $(\mathrm{Ol})$ and titanomagnetite $(\mathrm{Tnt})$.
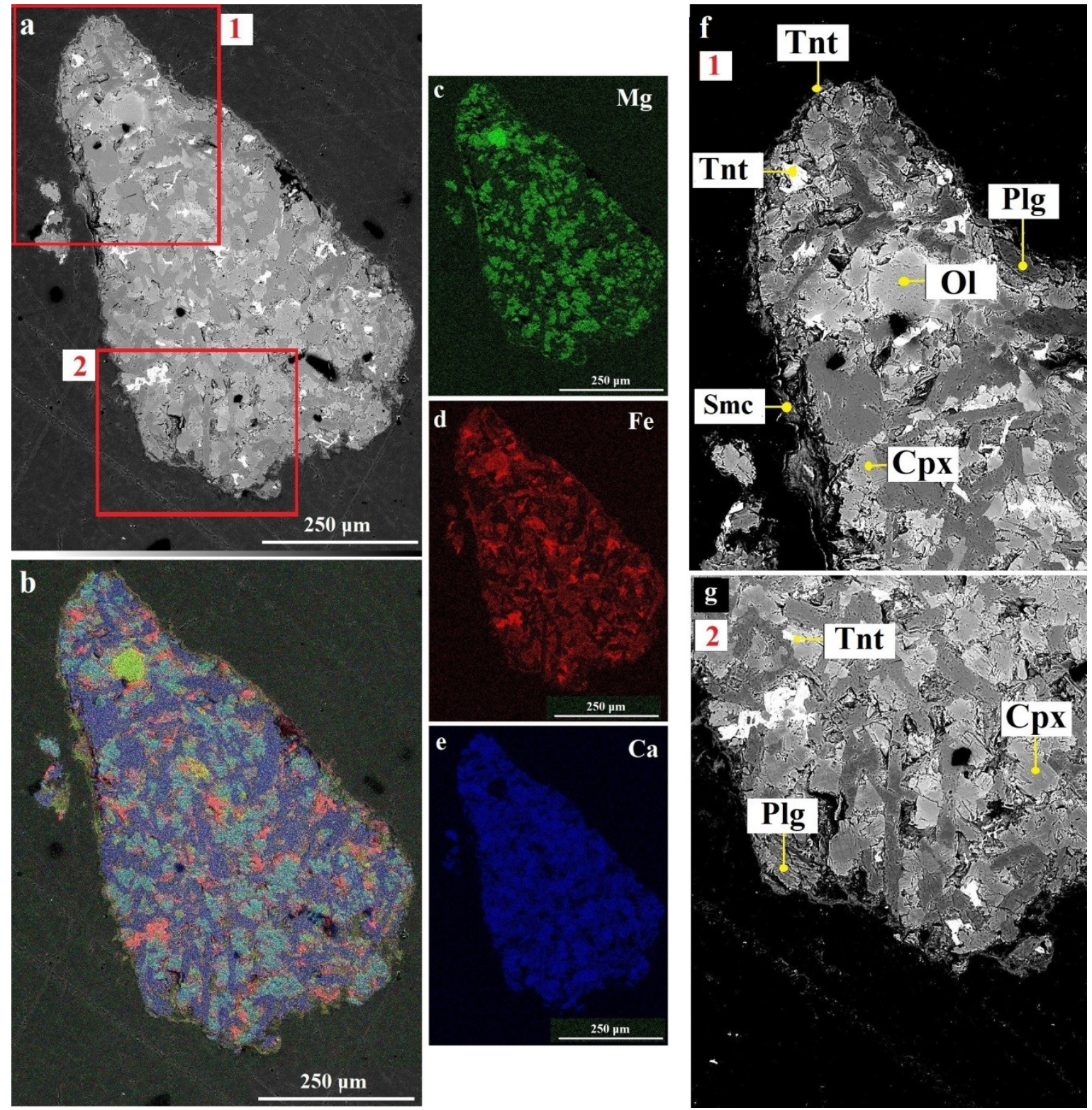

Table 6.12. Average composition (SEM-EDS) of the Na-Fe-Mg aluminosilicate phase found during study of the reacted grains collected from Portion 7 after the completion $(659 \mathrm{hrs})$ of the BSW1 experiment.

\begin{tabular}{|ccc|}
\hline & $\begin{array}{c}\text { Polished } \\
(\mathbf{N}=19)\end{array}$ & \\
oxide & $\begin{array}{c}\text { average } \\
\text { Wt \% }\end{array}$ & $\pm 1 \sigma$ \\
& & \\
$\mathbf{N a}_{2} \mathbf{O}$ & 1.85 & 0.58 \\
$\mathbf{M g O}$ & 12.35 & 2.37 \\
$\mathbf{A l}_{2} \mathbf{O}_{3}$ & 10.46 & 1.13 \\
$\mathrm{SiO}_{2}$ & 50.06 & 5.05 \\
$\mathbf{F e O}_{\mathrm{TeO}}$ & 24.35 & 3.17 \\
$\mathrm{Total}$ & 99.06 & \\
\hline
\end{tabular}


Figure 6.15. Composite image of reacted grains, backscatter images, and elemental maps of the epoxy-mounted, polished grains analysed from the BSW1 experiment. Flow direction is from the bottom of the figure to the top. The change in intensity of the alteration upwards is evident due to replacement by chlorite and smectite.

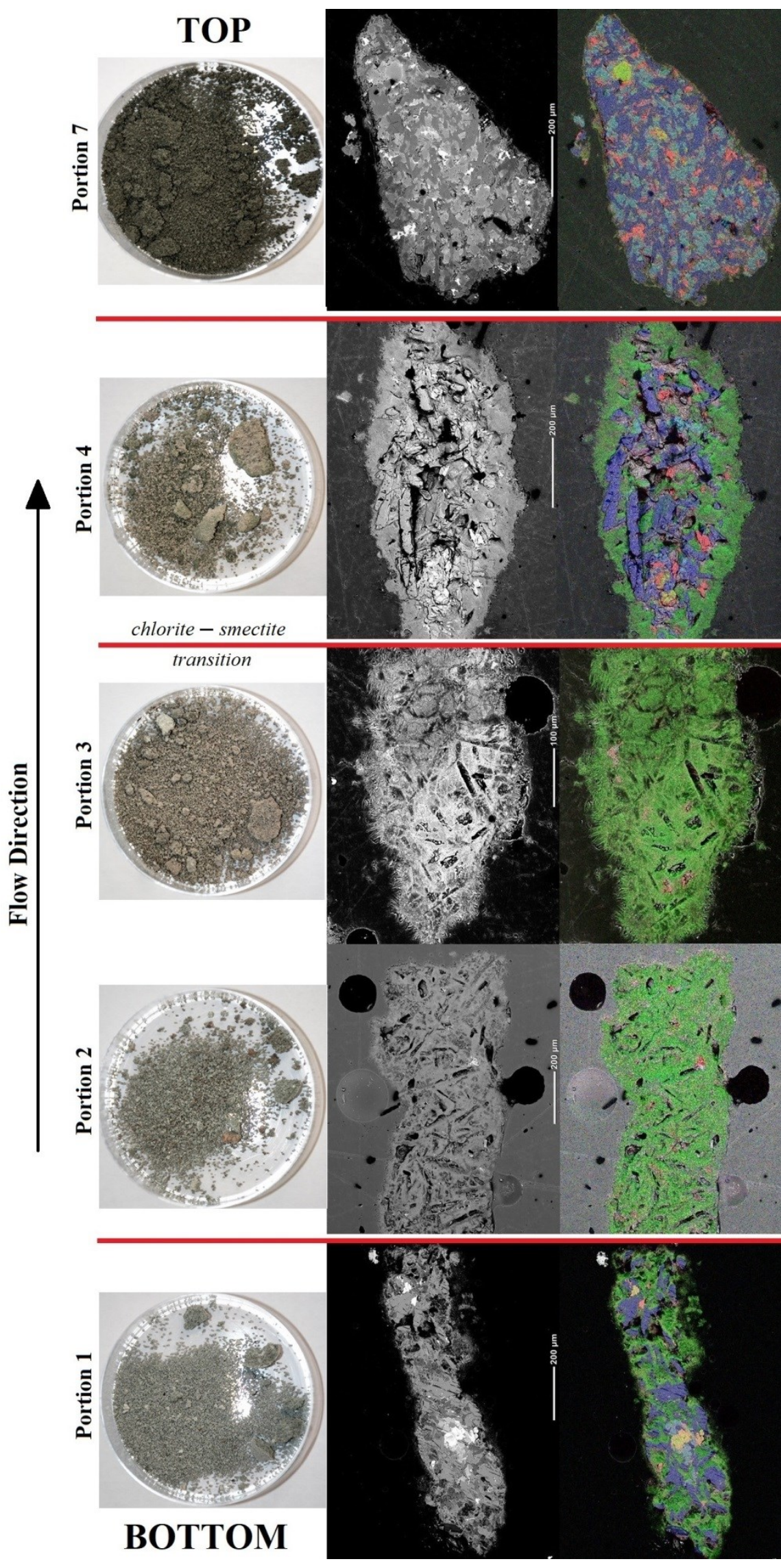




\subsubsection{Mineralogy and Texture of Reacted Basalt: Basalt Block}

The basalt block $(8 \times 8 \times 4 \mathrm{~mm})$, was positioned vertically near the bottom of the Reactor approximately $0.5 \mathrm{~cm}$ above the titanium frit (Fig. 6.5). Upon opening the Reactor, it was revealed that the block had disintegrated into several pieces (Fig. 6.16). SEM-EDS analysis was not performed on the block. It is evident, however, that there has been severe bleaching of the rock. This has completely penetrated the block. This attests to the intensity of the alteration at this position in the Reactor.

Figure 6.16. Digital photograph of the basalt block fragments extracted from the bottom of the Reactor after the BSW1 experiment. The block was originally $8 \times 8 \times 4 \mathrm{~mm}$.

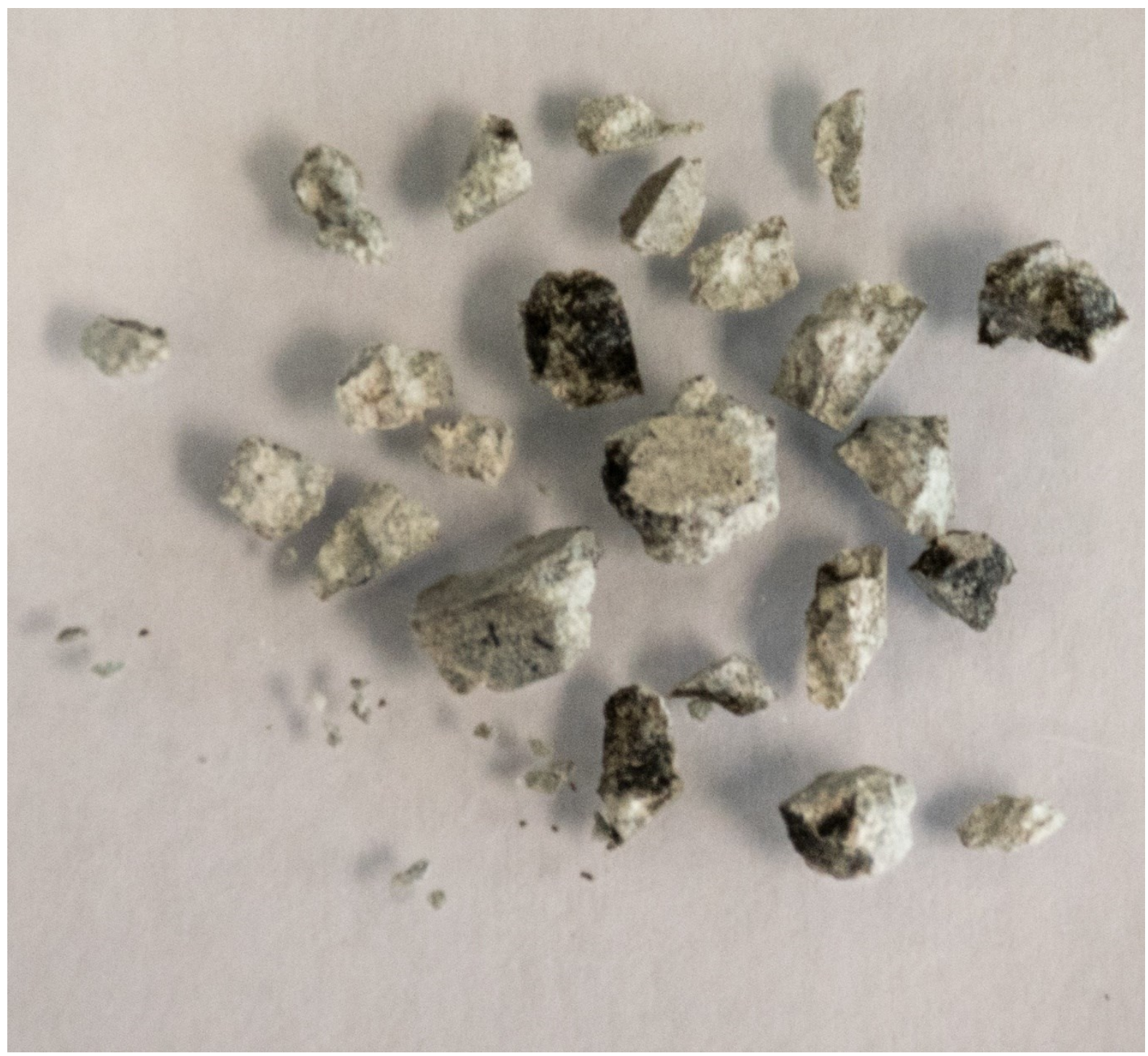




\subsubsection{BSW2: Basalt-seawater experiment at $350^{\circ} \mathrm{C} / 488$ bar}

The laboratory set-up for the BSW2 experiment consisted of the Preheater containing zirconia beads and the Reactor filled with rock material mounted in series (Chapter 2, §2.4.5, Fig. 2.20b). The experimental configuration maintained a temperature gradient of $40^{\circ} \mathrm{C}$ at the top to $342^{\circ} \mathrm{C}$ at the bottom of the Preheater, while the Reactor was kept at a temperature of $350^{\circ} \mathrm{C}$. Pressure remained stable at 488 bar.

The experiment ran for a total time of 311 hours. At the start of the experiment, distilled water was pumped through the system until pressure was stable. After this, the heating procedure increased the oven temperature until a Reactor temperature of $350^{\circ} \mathrm{C}$ was reached ( $\sim 3$ hours), then fluid flow was switched to seawater. It required approximately 1 day for seawater to begin to exit the Reactor at $1 \mathrm{ml} \mathrm{hr}^{-1}$ (See $\mathrm{Cl}$ concentrations in Fig. 6.18). Distilled water was completely displaced from the combined Preheater and Reactor after about four days. The flow rate was varied during the experiment changed as follow:

- $\quad 1 \mathrm{ml} \mathrm{hr}^{-1}$ for the first $120 \mathrm{hrs}$ (5 samples collected)

- $10 \mathrm{ml} \mathrm{hr}^{-1}$ for $48 \mathrm{hrs}$ (10 samples collected)

- $5 \mathrm{ml} \mathrm{hr}^{-1}$ for $24 \mathrm{hrs}$ (5 samples collected)

- $2.5 \mathrm{ml} \mathrm{hr}^{-1}$ for $74 \mathrm{hrs}$ (5 samples collected)

- $1 \mathrm{ml} \mathrm{hr}^{-1}$ for the last $47 \mathrm{hrs}$ (2 samples collected)

Analysis for major and trace elements was made for the total number of the fluid samples collected (29). Distilled water and seawater blanks were included.

\subsubsection{Major Element Concentrations}

Complete experimental parameters and results $(\mathrm{T}, \mathrm{P}$, time, flow rate, in situ and room $\mathrm{T}$ pH, chemistry) are listed in Appendix E. Figure 6.17 and Figure 6.18 show these results plotted versus time in hours. The unreacted seawater composition is shown at $t=0$. The composition of unreacted distilled water is not shown. The concentrations of major ions for the first $24 \mathrm{hrs}$ are essentially for distilled water as it required approximately 1 day for seawater to begin to exit the Reactor at $1 \mathrm{ml} \mathrm{hr}^{-1}$.

The room temperature $\mathrm{pH}$ of the unreacted Napier seawater is 8.20 (Fig. 6.17). While distilled water is exiting the Reactor, quench $\mathrm{pH}$ is 5.15 while the in situ $\mathrm{pH}$ is 6.61 . Once seawater displaces distilled water, the quench $\mathrm{pH}$ stabilises at $\sim 4.7$ after about 4 days which translates into a stable in situ $\mathrm{pH}$ of $\sim 5.3$. The quench $\mathrm{pH}$ increases marginally to $\sim 4.3$ when 
flow rate was changed to $10,5,2.5$ and again $1 \mathrm{ml} \mathrm{hr}^{-1}$, however, the in situ $\mathrm{pH}$ remains stable at $\sim 5.3$ for this period. The entry in situ $\mathrm{pH}$ of the pre-treated seawater into the Reactor is assumed to be $\sim 5.5$ based on the results of the SW2 experiment.

$\mathrm{SiO}_{2}$ concentration increases to $\sim 32 \mathrm{mmol} \mathrm{kg}^{-1}$ ( $\left.\sim 1930 \mathrm{ppm}\right)$ while distilled water is exiting the Reactor for the first day (Fig. 6.17). Once seawater begins to appear in the effluents ( $\sim 48 \mathrm{hr}), \mathrm{SiO}_{2}$ concentration stabilises to $\sim 35 \mathrm{mmol} \mathrm{kg}^{-1}$ for four days. The change to $10 \mathrm{ml} \mathrm{hr}^{-1}$ initially causes an increase in $\mathrm{SiO}_{2}$ concentration to $42 \mathrm{mmol} \mathrm{kg}^{-1}$. It then decreases over the next several hours back to $28 \mathrm{mmol} \mathrm{kg}^{-1}$. There is an incremental decrease in $\mathrm{SiO}_{2}$ concentration at 5 and $2.5 \mathrm{ml} \mathrm{hr}^{-1}$ flow rates. Finally, at $1 \mathrm{ml} \mathrm{hr}^{-1}$, the $\mathrm{SiO}_{2}$ concentration is $\sim 25 \mathrm{mmol} \mathrm{kg}$. This concentration (1500 ppm) exceeds quartz saturation at $350^{\circ} \mathrm{C} / 500$ bar $(980 \mathrm{ppm})$. Note that it is assumed that the $\mathrm{SiO}_{2}$ concentration entering the Reactor is $0.25 \mathrm{mmol} \mathrm{kg}{ }^{-1}$ based on the SW2 experiment.

Sodium concentration remains low while distilled water is exiting the Reactor. Once seawater begins to appear in the effluent, $\mathrm{Na}$ concentration increases and reaches a value of $\sim 370 \mathrm{mmol} \mathrm{kg}^{-1}$ after seven days. It remains at this value for the remainder of the experiment. This value is similar to the input seawater composition, thus $\mathrm{Na}$ behaviour is conservative and independent of flow rate.

In the first sample containing seawater in the effluent, $\mathrm{K}$ concentration is highly elevated $\left(20 \mathrm{mmol} \mathrm{kg}^{-1}\right)$. This is much higher than the input seawater $\mathrm{K}$ concentration. However, after another 24 hours, the $\mathrm{K}$ concentration decreases to the input value and remains there for the remainder of the experiment. This value is similar to the input value and $\mathrm{K}$ concentrations are independent of flow rate.

The Al concentration is elevated in the single sample where distilled water was exiting the Reactor ( $24 \mathrm{hr})$. Once seawater begins to appear in the effluents, Al concentrations are below detection limit and remain so for the remainder of the experiment irrespective of flow rate.

Calcium concentration is below detection limit while distilled water is exiting the Reactor (Fig. 6.18). Once seawater begins to appear in the effluent, Ca concentration increases to a value of $20 \mathrm{mmol} \mathrm{kg}^{-1}$ at a flow rate of $1 \mathrm{ml} \mathrm{hr}^{-1}$. A measurable decrease in Ca is evident when flow rate is changed to $10 \mathrm{ml} \mathrm{hr}^{-1}$ where it stabilises at $19 \mathrm{mmol} \mathrm{kg}^{-1}$. Further decreases in flow rate to $5,2.5$ and $1 \mathrm{ml} \mathrm{hr}^{-1}$ result in a stable $22 \mathrm{mmol} \mathrm{kg}^{-1} \mathrm{Ca}$ for the remainder of the experiment. Note that the input $\mathrm{Ca}$ concentration from the Preheater is assumed to be $1.4 \mathrm{mmol} \mathrm{kg}^{-1}$ based on the results from the SW2 experiment (Fig. 5.11). This indicates that a significant amount of $\mathrm{Ca}$ is being added to the fluid from the rock. 
Iron concentration is $0.4 \mathrm{mmol} \mathrm{kg}^{-1}$ while distilled water is exiting the Reactor (Fig. 6.18). Once seawater appears, Fe remains under detection limit at $1 \mathrm{ml} \mathrm{hr}^{-1}$ flow rate. Upon increase of flow rate to $10 \mathrm{ml} \mathrm{hr}^{-1}$, Fe concentration significantly increases to $\sim 6 \mathrm{mmol} \mathrm{\textrm {kg } ^ { - 1 }}$ and then over the next several hours decreases to $\sim 3 \mathrm{mmol} \mathrm{kg}^{-1}$. A further decrease in flow rate to $5 \mathrm{ml} \mathrm{hr}^{-1}$ appears to have little effect on Fe concentrations as they continue to decrease to below detection limit. At 2.5 and $1 \mathrm{ml} \mathrm{hr}^{-1} \mathrm{Fe}$ concentrations remains near or below detection limit. The input Fe concentration is assumed to be $\sim 1.7 \mathrm{mmol} \mathrm{kg}^{-1}$ based on the results from the SW2 experiment (Fig. 5.11).

The behaviour of $\mathrm{Mg}$ is significantly different between the BSW2 and SW2 experiments. In BSW2, Mg concentrations remain below detection limit $\left(<0.0004 \mathrm{mmol} \mathrm{\textrm {kg } ^ { - 1 }}\right)$ both in presence of distilled water and as seawater begins to appear in the effluents at a flow rate of $1 \mathrm{ml} \mathrm{hr}^{-1}$ (Fig. 6.18). When flow rate is increased to $10 \mathrm{ml} \mathrm{hr}^{-1}$, a significant increase in $\mathrm{Mg}$ concentration occurs, rising to $5 \mathrm{mmol} \mathrm{kg}{ }^{-1}$, after which it decreases to $1 \mathrm{mmol} \mathrm{kg}^{-1}$. Decreasing the flow rate to $5 \mathrm{ml} \mathrm{hr}^{-1}$ results in a decrease in $\mathrm{Mg}$ to $0.4 \mathrm{mmol} \mathrm{kg}{ }^{-1}$ while at 2.5 $\mathrm{ml} \mathrm{hr}{ }^{-1}$ it decreases further to $0.3 \mathrm{mmol} \mathrm{kg}^{-1}$, and finally to $\sim 0.2 \mathrm{mmol} \mathrm{kg}^{-1}$ at $1 \mathrm{ml} \mathrm{hr}^{-1}$ flow rate. The input $\mathrm{Mg}$ concentration is assumed to be $\sim 23 \mathrm{mmol} \mathrm{kg}^{-1}$ based on the results of the SW2 experiments (Fig. 5.11). These results show that almost all $\mathrm{Mg}$ remaining in the seawater after passage through the Preheater is fixed in the rock.

Sulfate concentration is $\sim 0.25 \mathrm{mmol} \mathrm{kg}^{-1}$ when in presence of distilled water (Fig. 6.18). When seawater is exiting the Reactor, it reaches a value of $0.05-0.1 \mathrm{mmol} \mathrm{kg}^{-1}$ over the following four days. Upon increase of flow rate to $10 \mathrm{ml} \mathrm{hr}^{-1}$, there are moderate increases in $\mathrm{SO}_{4}$ up to $\sim 0.25 \mathrm{mmol} \mathrm{kg}^{-1}$. This concentration is not maintained and $\mathrm{SO}_{4}$ decreases back to $\sim 0.08 \mathrm{mmol} \mathrm{kg}^{-1}$ over the following days independent of flow rate. The input concentration of $\mathrm{SO}_{4}$ is assumed to be $\sim 1.7 \mathrm{mmol} \mathrm{kg}^{-1}$ based on results from SW2 (Fig. 5.11). This indicates that the remaining $\mathrm{SO}_{4}$ in the pre-treated seawater is precipitating during reaction with the basalt.

There are detectable $\mathrm{H}_{2} \mathrm{~S}$ concentrations in the effluents from the BSW2 experiment (Fig. 6.18). This differs from the SW2 experiment which show no detectable $\mathrm{H}_{2} \mathrm{~S}$ (Fig. 5.11). The highest $\mathrm{H}_{2} \mathrm{~S}$ concentrations occur just after seawater begins to exit the Reactor, as in BSW1. This suggests release of $\mathrm{H}_{2} \mathrm{~S}$ from sulfide inclusions trapped in volcanic glass. The overall decrease in concentration over the experiment is attributed to complete dissolution of volcanic glass.

Chloride is conservative and reflects mixing between distilled water and seawater. The concentrations are independent of flow rate (Fig. 6.18). 
Figure 6.17. Major element concentrations in blank and effluent samples (mmol kg-1) versus time (hr) for the BSW2 experiment at $350^{\circ} \mathrm{C} / 488$ bar. Yellow squares at $\mathrm{t}=0$ are the blank sample composition of seawater from SW2. Light blue symbols show where distilled water was exiting the Reactor at $350^{\circ} \mathrm{C} / 488$ bar and $1.0 \mathrm{ml} \mathrm{hr}^{-1}$. Black symbols are effluent compositions containing seawater at $350^{\circ} \mathrm{C} / 488$ bar and $1.0 \mathrm{ml} \mathrm{hr}^{-1}$ flow rate. Other coloured symbols show effluent compositions at different flow rates. In situ $\mathrm{pH}$ is the calculated $\mathrm{pH}$ at temperature. $\mathrm{LOD}=$ limit of detection.
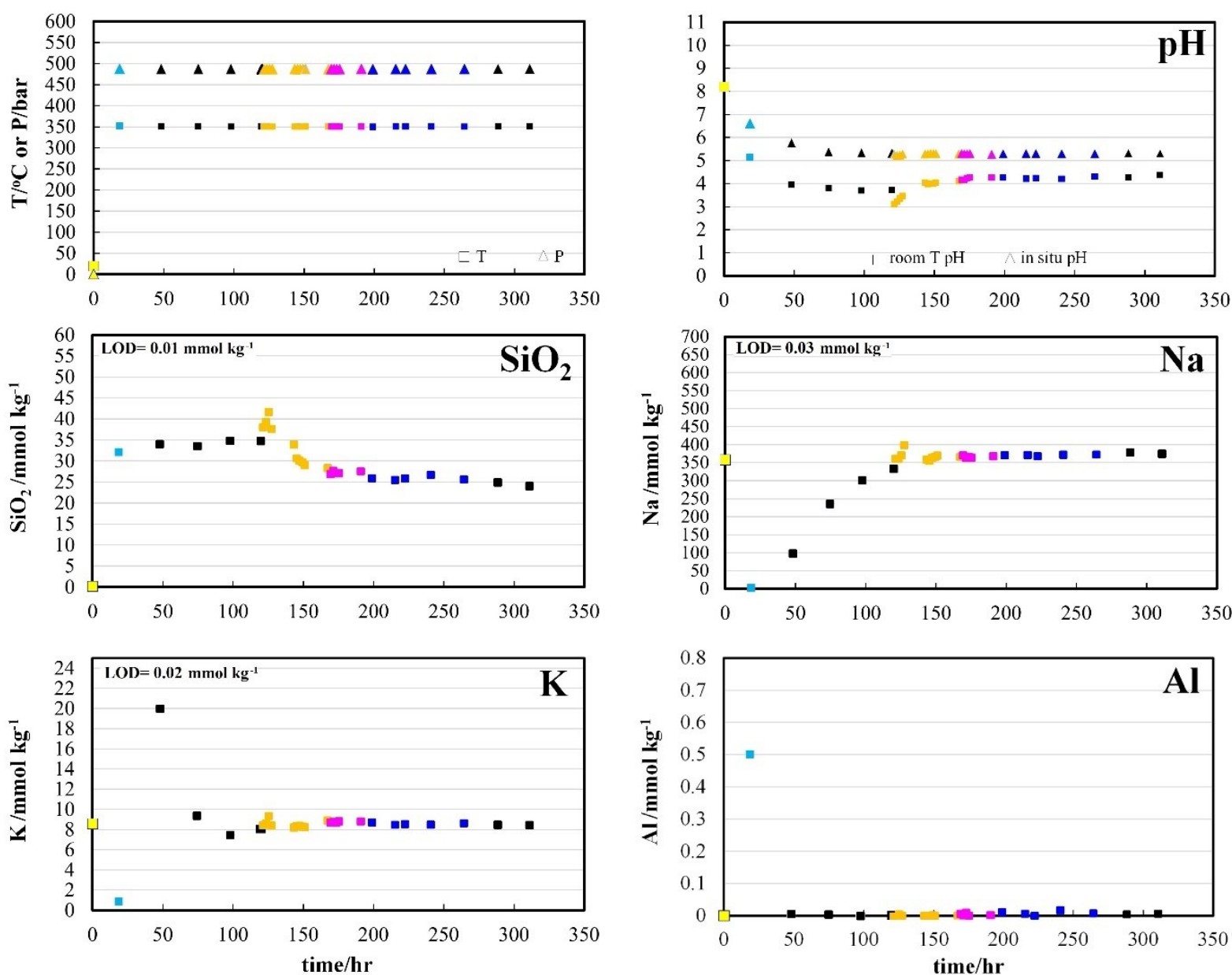

$\square \triangle$ blank (seawater)

- $\Delta$ distilled water $350^{\circ} \mathrm{C} / 488 \mathrm{bar} / 1 \mathrm{ml} \mathrm{hr}{ }^{-1}$

- A seawater $350^{\circ} \mathrm{C} / 488 \mathrm{bar} / 1 \mathrm{ml} \mathrm{hr}^{-1}$

In seawater $350^{\circ} \mathrm{C} / 488 \mathrm{bar} / 10 \mathrm{ml} \mathrm{hr}^{-1}$

- $\Delta$ seawater $350^{\circ} \mathrm{C} / 488 \mathrm{bar} / 5 \mathrm{ml} \mathrm{hr}^{-1}$

- A seawater $350^{\circ} \mathrm{C} / 488 \mathrm{bar} / 2.5 \mathrm{ml} \mathrm{hr}^{-1}$ 
Figure 6.18. Major element concentrations in blank and effluent samples (mmol kg-1) versus time (hr) for the BSW2 experiment at $350^{\circ} \mathrm{C} / 488$ bar. Yellow squares at $\mathrm{t}=0$ are the input composition of seawater from SW2. Light blue symbols show where distilled water was exiting the Reactor at $350^{\circ} \mathrm{C} / 488$ bar and $1.0 \mathrm{ml} \mathrm{hr}^{-1}$. Black symbols are effluent compositions containing seawater at $350^{\circ} \mathrm{C} / 488$ bar and 1.0 $\mathrm{ml} \mathrm{hr}{ }^{-1}$ flow rate. Other coloured symbols show effluent compositions at different flow rates. In situ $\mathrm{pH}$ is the calculated $\mathrm{pH}$ at temperature. $\mathrm{LOD}=$ limit of detection.
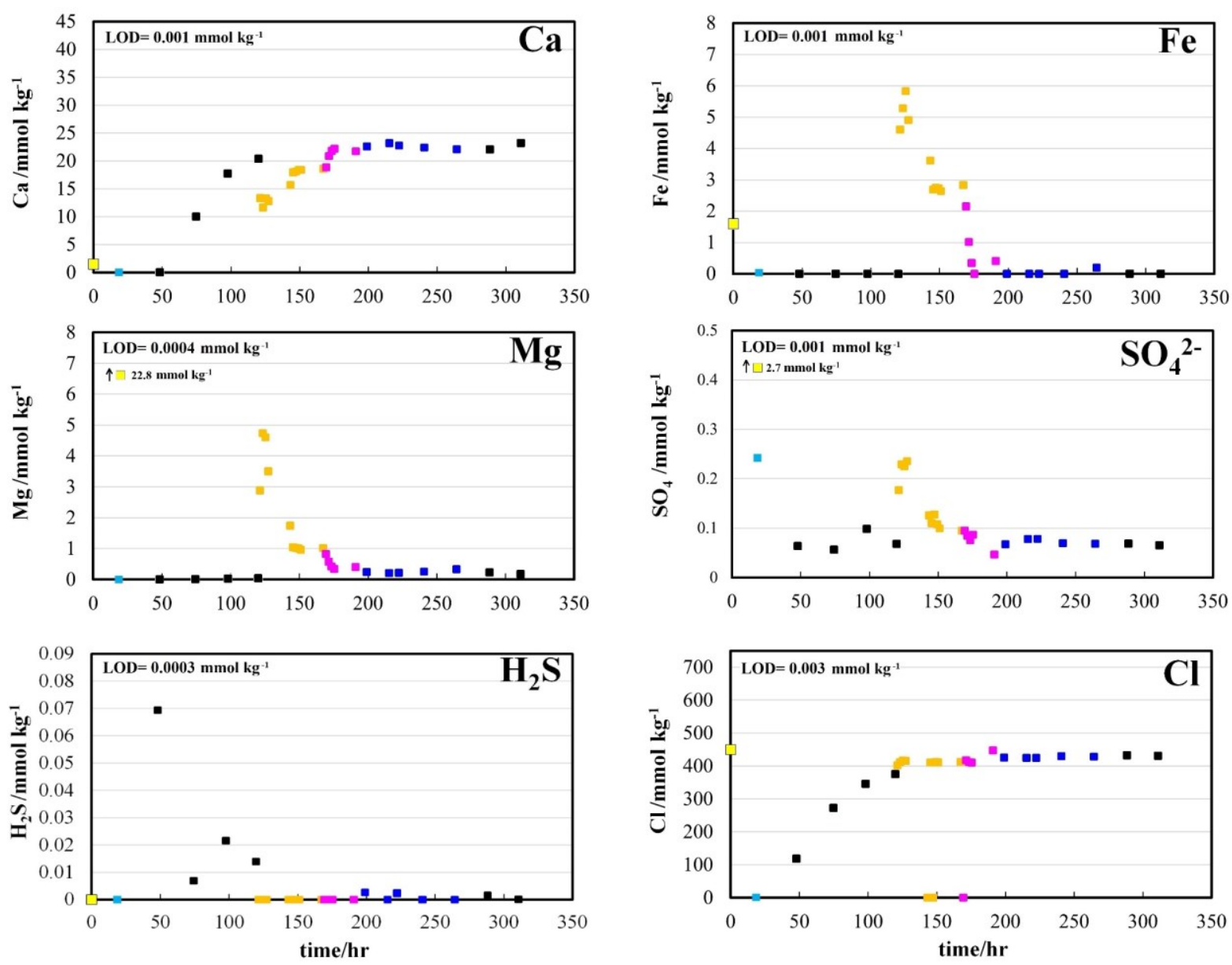

$\square \triangle$ blank (seawater)

$\Delta$ distilled water $350^{\circ} \mathrm{C} / 488 \mathrm{bar} / 1 \mathrm{ml} \mathrm{hr}^{-1}$

口 $\Delta$ seawater $350^{\circ} \mathrm{C} / 488 \mathrm{bar} / 1 \mathrm{ml} \mathrm{hr}^{-1}$

a seawater $350^{\circ} \mathrm{C} / 488 \mathrm{bar} / 10 \mathrm{ml} \mathrm{hr}^{-1}$

口 $\Delta$ seawater $350^{\circ} \mathrm{C} / 488 \mathrm{bar} / 5 \mathrm{ml} \mathrm{hr}{ }^{-1}$

口 $\Delta$ seawater $350^{\circ} \mathrm{C} / 488 \mathrm{bar} / 2.5 \mathrm{ml} \mathrm{hr}^{-1}$ 


\subsubsection{Trace Element Concentrations}

In the seawater-only experiment (SW2), trace elements showed some mobility and semi-regular to irregular trends caused by the interaction between seawater and the $\mathrm{ZrO}_{2}$ beads (Fig. 5.12 and 5.13). It is evident that the beads were releasing measurable concentrations of some trace elements including $\mathrm{V}, \mathrm{Cr}, \mathrm{Mn}, \mathrm{Co}, \mathrm{Ni}, \mathrm{Cu}, \mathrm{Zn}, \mathrm{Cd}, \mathrm{Ba}, \mathrm{Pb}$ and perhaps Au. Effluents also showed seawater concentrations of Rb.

Figure 6.19 and Figure 6.20 show trace element results plotted versus time in hours for the BSW2 experiment. The unreacted natural seawater composition is shown at $\mathrm{t}=0$. Most trace elements are below detection limit with $\mathrm{Mn}, \mathrm{Zn}, \mathrm{Ag}, \mathrm{Ba}, \mathrm{Cd}$ and $\mathrm{Au}$ showing low, but detectable concentrations. The distilled water concentrations are not shown but are generally lower than seawater. Complete trace element results for this experiment are listed in Appendix E.

While seawater exits that Reactor, elements that show regular trends are $\mathrm{Mn}, \mathrm{Rb}, \mathrm{Ag}$, $\mathrm{Ba}$ and $\mathrm{Au}$. The concentrations of $\mathrm{Zn}, \mathrm{Cu}$ and $\mathrm{Cd}$ are elevated only at higher flow rates but overall their trends are highly irregular. The Mn concentrations reach values of $0.3-0.5$ mmol kg-1 and are not dependent on flow rate. All other element concentrations are near or below detection limit.

Except for the isolated high value at the start of the experiment, $\mathrm{Rb}$ concentrations reflect the input seawater, as in BSW1 (Fig. 6.20).

As with SW2, Ba concentration is highest at the beginning of the exit of seawater, it decreases over the remainder of the experiment. This is attributed to the precipitation of barite, $\mathrm{Ba}$ concentrations are independent of flow rate.

The $\mathrm{Ag}$ and $\mathrm{Au}$ concentrations are the highest once seawater begins to exit the Reactor after which Au decreases regularly to below detection limit, while Ag remains stable at $0.0015 \mu \mathrm{mol} \mathrm{kg}{ }^{-1}$ to the end of the experiment. Their behaviours differ from the seawateronly experiment in which Au remained at a relatively steady value of $0.03 \mu \mathrm{mol} \mathrm{kg}^{-1}$ while Ag remained under detection limit after 200 hrs (Fig. 5.13). This suggest Au is released from the $\mathrm{ZrO}_{2}$ beads but then is fixed in the rock. The concentrations of $\mathrm{Ag}$ are very close to the detection limit and are all of similar value. This suggests some caution using the Ag data.

The trace element results, as with BSW2, are unremarkable. However, the apparent lower mobility when the basalt is present suggests fixation of trace elements by the rock during fluid - rock interaction rather than release from it. 
Figure 6.19. Trace element concentrations in blank and effluent samples ( $\mu \mathrm{mol} \mathrm{kg}{ }^{-1}$ ) versus time (hr) for the basalt-seawater experiment at $350^{\circ} \mathrm{C} / 488$ bar (BSW2). Yellow squares at $\mathrm{t}=0$ are the blank composition of seawater from SW2. Light blue symbols show where distilled water was exiting the Reactor at $350^{\circ} \mathrm{C} / 488$ bar and $1.0 \mathrm{ml} \mathrm{hr}^{-1}$. Black symbols are effluent compositions at $350^{\circ} \mathrm{C} / 488 \mathrm{bar}^{2}$ and $1.0 \mathrm{ml} \mathrm{hr}^{-1}$ flow rate. Other coloured symbols are effluent compositions at differing flow rate. In situ $\mathrm{pH}$ is the calculated $\mathrm{pH}$ at temperature. $\mathrm{LOD}=$ limit of detection.
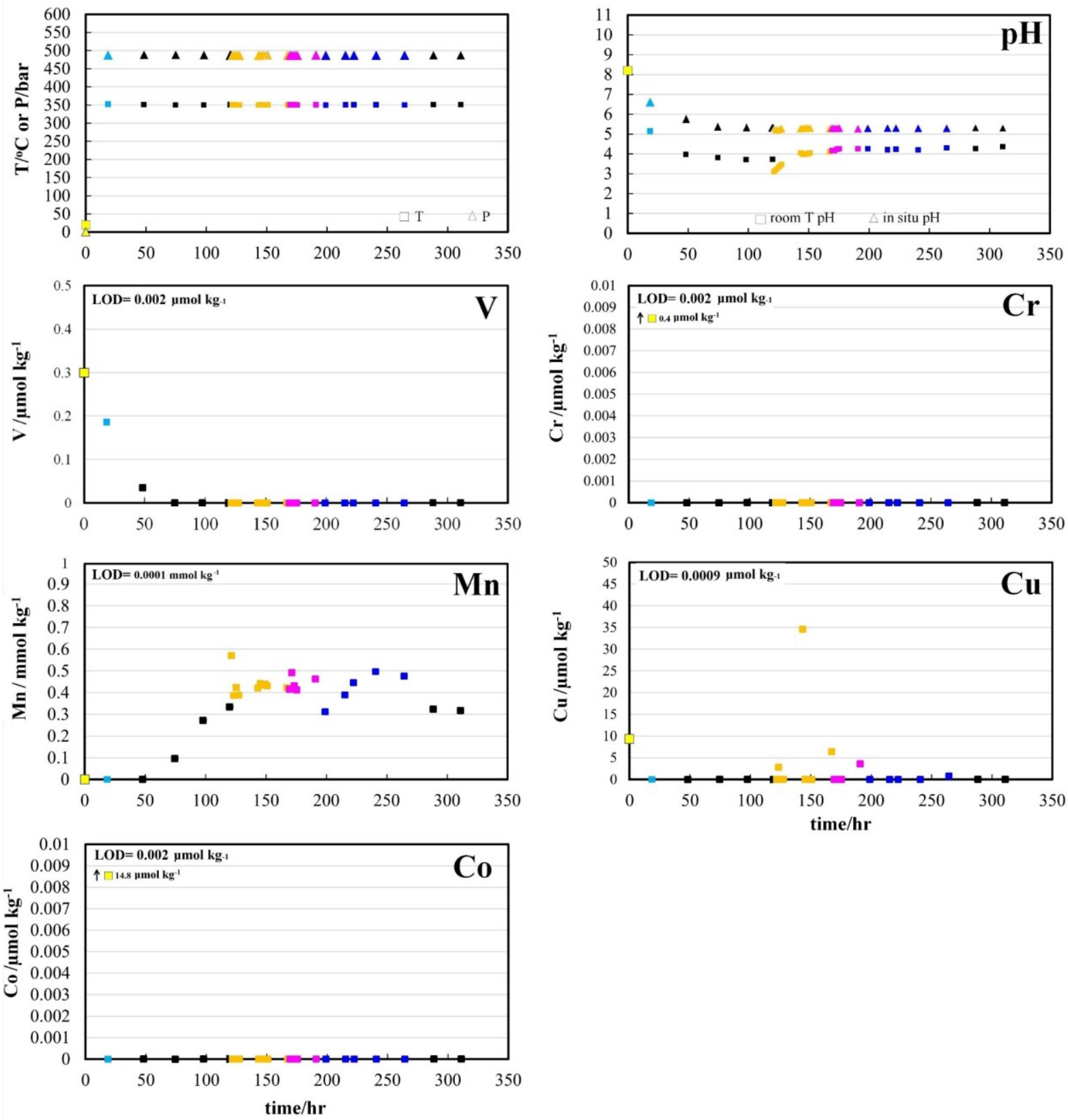

$\square \triangle$ blank (seawater)

- $\Delta$ distilled water $350^{\circ} \mathrm{C} / 488 \mathrm{bar} / 1 \mathrm{ml} \mathrm{hr}^{-1}$

口 $\Delta$ seawater $350^{\circ} \mathrm{C} / 488 \mathrm{bar} / 1 \mathrm{ml} \mathrm{hr^{-1 }}$

$\triangle$ seawater $350^{\circ} \mathrm{C} / 488 \mathrm{bar} / 10 \mathrm{ml} \mathrm{hr}^{-1}$

- $\Delta$ seawater $350^{\circ} \mathrm{C} / 488 \mathrm{bar} / 5 \mathrm{ml} \mathrm{hr}^{-1}$

口 \ seawater $350^{\circ} \mathrm{C} / 488 \mathrm{bar} / 2.5 \mathrm{ml} \mathrm{hr}^{-1}$ 
Figure 6.20. Trace element concentrations in blank and effluent samples ( $\mu \mathrm{mol} \mathrm{kg}{ }^{-1}$ ) versus time (hr) for the basalt-seawater experiment at $350^{\circ} \mathrm{C} / 488$ bar (BSW2). Yellow squares at $\mathrm{t}=0$ are the blank composition of seawater from SW2. Light blue symbols show where distilled water was exiting the Reactor at $350^{\circ} \mathrm{C} / 488$ bar and $1.0 \mathrm{ml} \mathrm{hr}^{-1}$. Black symbols are effluent compositions at $350^{\circ} \mathrm{C} / 488 \mathrm{bar}^{2}$ and $1.0 \mathrm{ml} \mathrm{hr}^{-1}$ flow rate. Other coloured symbols are effluent compositions at differing flow rate. In situ $\mathrm{pH}$ is the calculated $\mathrm{pH}$ at temperature. $\mathrm{LOD}=$ limit of detection.
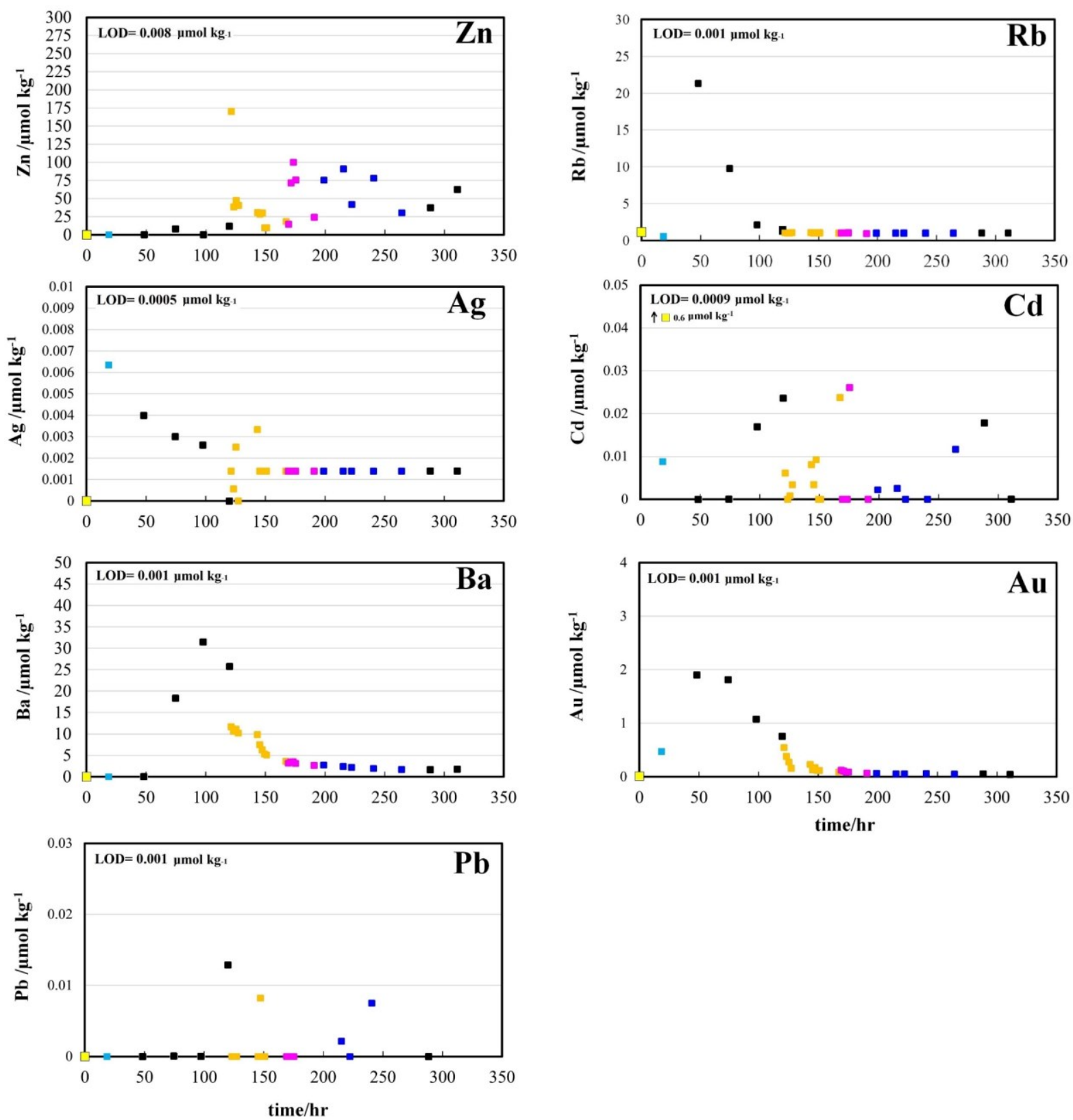

$\square \triangle$ blank (seawater)

$\Delta$ distilled water $350^{\circ} \mathrm{C} / 488 \mathrm{bar} / 1 \mathrm{ml} \mathrm{hr}^{-1}$

ם $\Delta$ seawater $350^{\circ} \mathrm{C} / 488 \mathrm{bar} / 1 \mathrm{ml} \mathrm{hr}^{-1}$

a seawater $350^{\circ} \mathrm{C} / 488 \mathrm{bar} / 10 \mathrm{ml} \mathrm{hr}^{-1}$

口 $\Delta$ seawater $350^{\circ} \mathrm{C} / 488 \mathrm{bar} / 5 \mathrm{ml} \mathrm{hr}^{-1}$

口 $\Delta$ seawater $350^{\circ} \mathrm{C} / 488 \mathrm{bar} / 2.5 \mathrm{ml} \mathrm{hr}^{-1}$ 


\subsubsection{Mineralogy and Texture of Reacted Basalt}

Upon the completion of the experiment $(311 \mathrm{hrs})$, the reacted basalt was extracted from the Reactor onto absorbent paper. The run products were rinsed with distilled water to remove precipitated soluble salts and air-dried. The reacted material was initially divided into 5 portions numbered from 1 (bottom of the Reactor) to 5 (top of the Reactor) (Fig. 6.21). The basalt block from the bottom of the Reactor was extracted and rinsed with distilled water.

Figure 6.21 shows the reacted grains after extraction from the Reactor. The change of colour of the grains from bottom to top shows that the rock is visibly altered. Portion 1 is light gray, Portion 2 and 3 are light green-gray, while Portions 4 to 5 show the darker graygreen colour of the original basalt.

In order to reduce the amount of analyses required, grains from Portion 2 and 3 were combined as were grains from Portion 4 and 5. Run products from Portions 1, 2-3, 4-5 were mounted on aluminium stubs for SEM analysis. Run products from these portions were also epoxy-mounted and polished for SEM analysis. Larger samples were collected for XRD and $\mathrm{XRF}$ analysis.

\section{Qualitative XRD analysis}

The qualitative XRD results for all Portion 1, 2-3, and 4-5 are shown in Table 6.13. These confirm plagioclase is present in all Portions. This is assumed to be the original bytownite. Clinopyroxene was detected in only in Portion 2 - 5 showing that it has been essentially replaced by secondary phases. Secondary minerals identified are chlorite (which is found in all portions), magnetite, anhydrite and ankerite. Anhydrite was found only in Portion 1 at the bottom of the Reactor. Ankerite is found only at the top. All XRD results are reported in Appendix E.

Table 6.13. Qualitative XRD analysis of Portion 1, 2-3, 4-5 from BSW2.

\begin{tabular}{|rccc|}
\hline & Portion 1 & Portion 2-3 & Portion 4-5 \\
Chlorite & $\mathrm{x}$ & $\mathrm{x}$ & $\mathrm{x}$ \\
Plagioclase & $\mathrm{x}$ & $\mathrm{x}$ & $\mathrm{x}$ \\
Magnetite & $\mathrm{x}$ & & \\
Anhydrite & $\mathrm{x}$ & & \\
Ankerite & & & $\mathrm{x}$ \\
Augite & & $\mathrm{x}$ & $\mathrm{x}$ \\
\hline
\end{tabular}


Figure 6.21. Schematic diagram showing position of reacted basalt portions extracted from the Reactor after completion of the BSW2 experiment (not to scale). On the right, are the reacted grains divided in 5 portions numbered from 1 (bottom of the Reactor) to 5 (top of the Reactor). Also shown is the position of the basalt block.

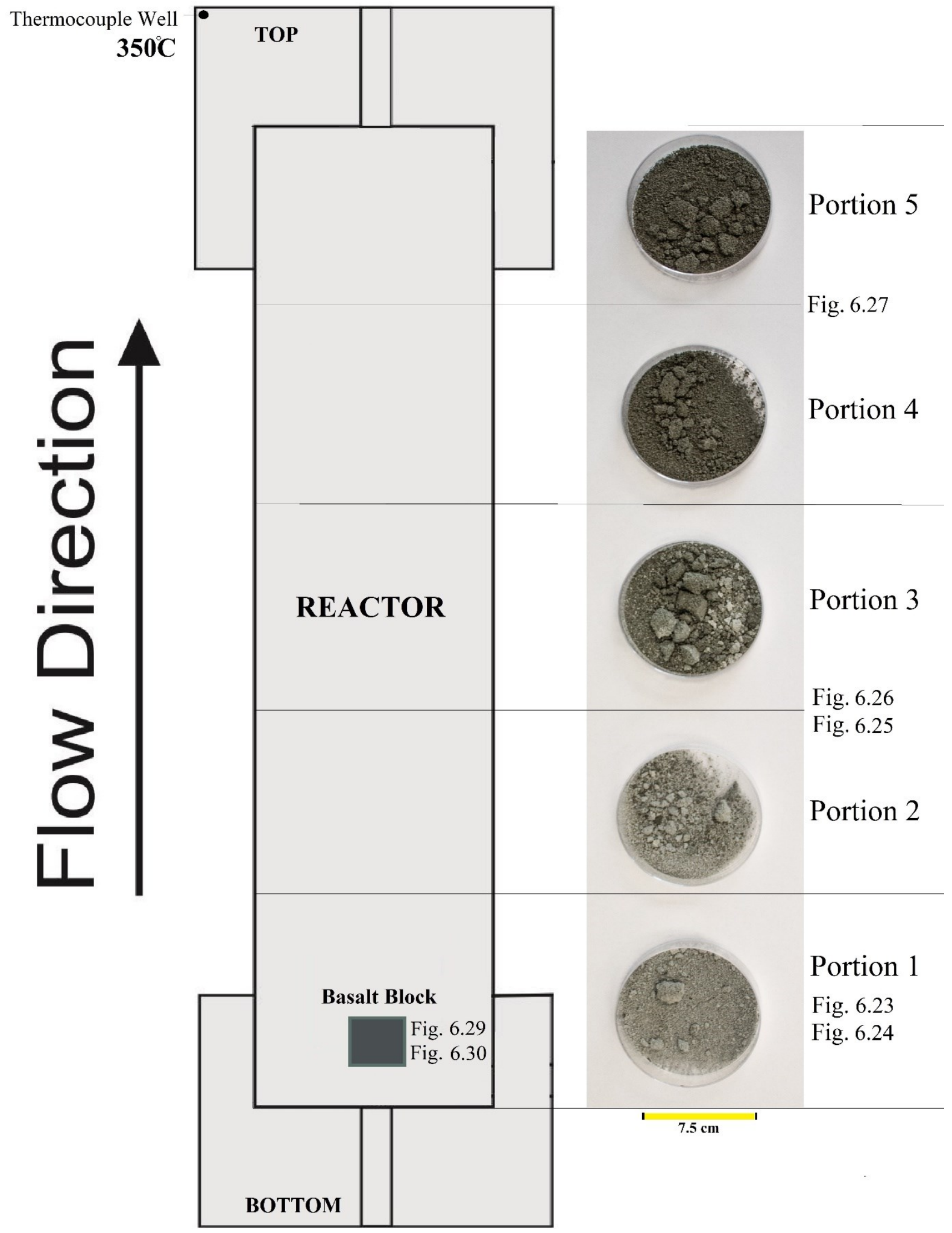




\section{XRF analysis}

Table 6.14 lists the XRF results for the portions examined. Significant changes in rock chemistry are evident. In order to determine the relationship between elements during fluid - rock exchange a correlation matrix, similar to that constructed for the $400^{\circ} \mathrm{C}$ experiment, was made (Table 6.15). At the 95\% significance level and with $n=4$, the level of significance of $r= \pm 0.95$ ( \pm 0.997 for $S$ ). The correlation coefficients with values of $-0.95 \leq r$ $\geq+0.95$ are highlighted in yellow in the table. Selected elements are plotted by position in Figure 6.22. Also shown is the unreacted basalt composition for comparison. It can be seen from the correlation matrix that there is a significant positive correlation between $\mathrm{Na}_{2} \mathrm{O}$ and $\mathrm{SiO}_{2}$ while $\mathrm{MgO}$ correlates negatively with $\mathrm{Na}_{2} \mathrm{O}$. There is also significant positive correlation between $\mathrm{Fe}_{2} \mathrm{O}_{3}$ and $\mathrm{SiO}_{2}$.

As there was no detectable $\mathrm{Al}$ in the effluent samples, it is assumed that $\mathrm{Al}$ was immobile during fluid - rock interaction. The highest Al value is in Portion 4 - 5 which should be the least altered portion near to the top of the Reactor. This suggests some variability in the unreacted rock $\mathrm{Al}_{2} \mathrm{O}_{3}$ content. It is evident that the greatest mass loss occurred in Portion 1 as indicated by substantial decreases in $\mathrm{SiO}_{2}, \mathrm{Na}_{2} \mathrm{O}, \mathrm{CaO}$, and $\mathrm{Fe}_{2} \mathrm{O}_{3}$ without an accompanying increase in $\mathrm{Al}_{2} \mathrm{O}_{3} \cdot \mathrm{K}_{2} \mathrm{O}$ is uniformly lost throughout the Reactor. As with the experiment at $400^{\circ} \mathrm{C}, \mathrm{MgO}$ and $\mathrm{S}$ appear to be the only components to have increased in mass.

Table 6.14. XRF analysis of the reacted material collected from Portion 1, 2-3, 4-5 after the BSW2 experiment (wt\%). Also shown is the composition of the unreacted basalt rock. n.m.: not measured.

\begin{tabular}{|cccccccccccccc|c|}
\hline & $\mathrm{Na}_{2} \mathrm{O}$ & $\mathbf{C a O}$ & $\mathbf{M g O}$ & $\mathrm{SiO}_{2}$ & $\mathrm{TiO}_{2}$ & $\mathrm{Al}_{2} \mathrm{O}_{3}$ & $\mathrm{Fe}_{2} \mathrm{O}_{3}$ & $\mathrm{MnO}$ & $\mathrm{K}_{2} \mathbf{O}$ & $\mathbf{P}_{2} \mathrm{O}_{5}$ & $\mathrm{~S}_{(\mathrm{ppm})}$ \\
Portion 4-5 & 2.36 & 10.47 & 6.33 & 45.35 & 1.44 & 15.32 & 12.48 & 0.14 & 0.06 & 0.18 & 120 \\
Portion 2-3 & 1.37 & 5.11 & 17.08 & 43.43 & 1.59 & 13.60 & 11.44 & 0.04 & 0.05 & 0.17 & 5330 \\
Portion 1 & 0.42 & 6.00 & 22.55 & 34.87 & 1.80 & 13.66 & 9.08 & 0.03 & 0.03 & 0.13 & 19900 \\
Unreacted rock & 2.35 & 10.94 & 6.50 & 48.85 & 2.13 & 13.41 & 15.11 & 0.24 & 0.25 & 0.22 & n.m. \\
\hline
\end{tabular}


Table 6.15. Correlation matrix of major oxides and sulfur for analyses shown in Table 6.14 . Correlation coefficients significant at the $95 \%$ level are highlighted in yellow.

\begin{tabular}{|c|c|c|c|c|c|c|c|c|c|c|c|}
\hline & $\mathrm{Na}_{2} \mathrm{O}$ & $\mathrm{CaO}$ & $\mathrm{MgO}$ & $\mathrm{SiO}_{2}$ & $\mathrm{TiO}_{2}$ & $\mathrm{Al}_{2} \mathrm{O}_{3}$ & $\mathrm{Fe}_{2} \mathrm{O}_{3}$ & MnO & $\mathrm{K}_{2} \mathrm{O}$ & $\mathbf{P}_{2} \mathbf{O}_{5}$ & $\mathbf{S}$ \\
\hline $\mathrm{Na}_{2} \mathrm{O}$ & 1.00 & & & & & & & & & & \\
\hline $\mathrm{CaO}$ & 0.85 & 1.00 & & & & & & & & & \\
\hline MgO & -0.99 & -0.92 & 1.00 & & & & & & & & \\
\hline $\mathrm{SiO}_{2}$ & 0.95 & 0.71 & -0.90 & 1.00 & & & & & & & \\
\hline $\mathrm{TiO}_{2}$ & 0.03 & 0.26 & -0.07 & 0.19 & 1.00 & & & & & & \\
\hline $\mathrm{Al}_{2} \mathrm{O}_{3}$ & 0.42 & 0.42 & -0.46 & 0.14 & -0.74 & 1.00 & & & & & \\
\hline $\mathrm{Fe}_{2} \mathrm{O}_{3}$ & 0.90 & 0.79 & -0.89 & 0.96 & 0.43 & 0.00 & 1.00 & & & & \\
\hline MnO & 0.83 & 0.92 & -0.87 & 0.82 & 0.55 & 0.05 & 0.93 & 1.00 & & & \\
\hline $\mathbf{K}_{2} \mathbf{O}$ & 0.63 & 0.68 & -0.65 & 0.74 & 0.79 & -0.36 & 0.89 & 0.91 & 1.00 & & \\
\hline $\mathbf{P}_{2} \mathbf{O}_{5}$ & 0.88 & 0.72 & -0.86 & 0.97 & 0.41 & -0.05 & 0.99 & 0.89 & 0.88 & 1.00 & \\
\hline $\mathbf{S}$ & -0.96 & -0.58 & 0.90 & -1.00 & 0.98 & -0.68 & -1.00 & -0.74 & -1.00 & -0.99 & 1.00 \\
\hline
\end{tabular}

The $\mathrm{S}$ concentration is highest at position $1(2 \%)$. The host for the added $\mathrm{S}$ is anhydrite, thus, unlike the experiment at $400^{\circ} \mathrm{C}$, the highest concentration of anhydrite is at the bottom of the Reactor. $\mathrm{K}_{2} \mathrm{O}$ is almost completely removed at all positions in the column. This indicates that glass has been removed from the entire column, similar to the $400^{\circ} \mathrm{C}$ experiment. Except for $\mathrm{K}_{2} \mathrm{O}$ and $\mathrm{TiO}_{2}$ (not shown in Figure 6.22), all elements approach the unaltered composition at the top of the Reactor. 
Figure 6.22. Chemical composition (wt\%) of rock Portions analysed by XRF plotted against position in Reactor column (red circles). The unreacted basalt compositions shown by blue line.
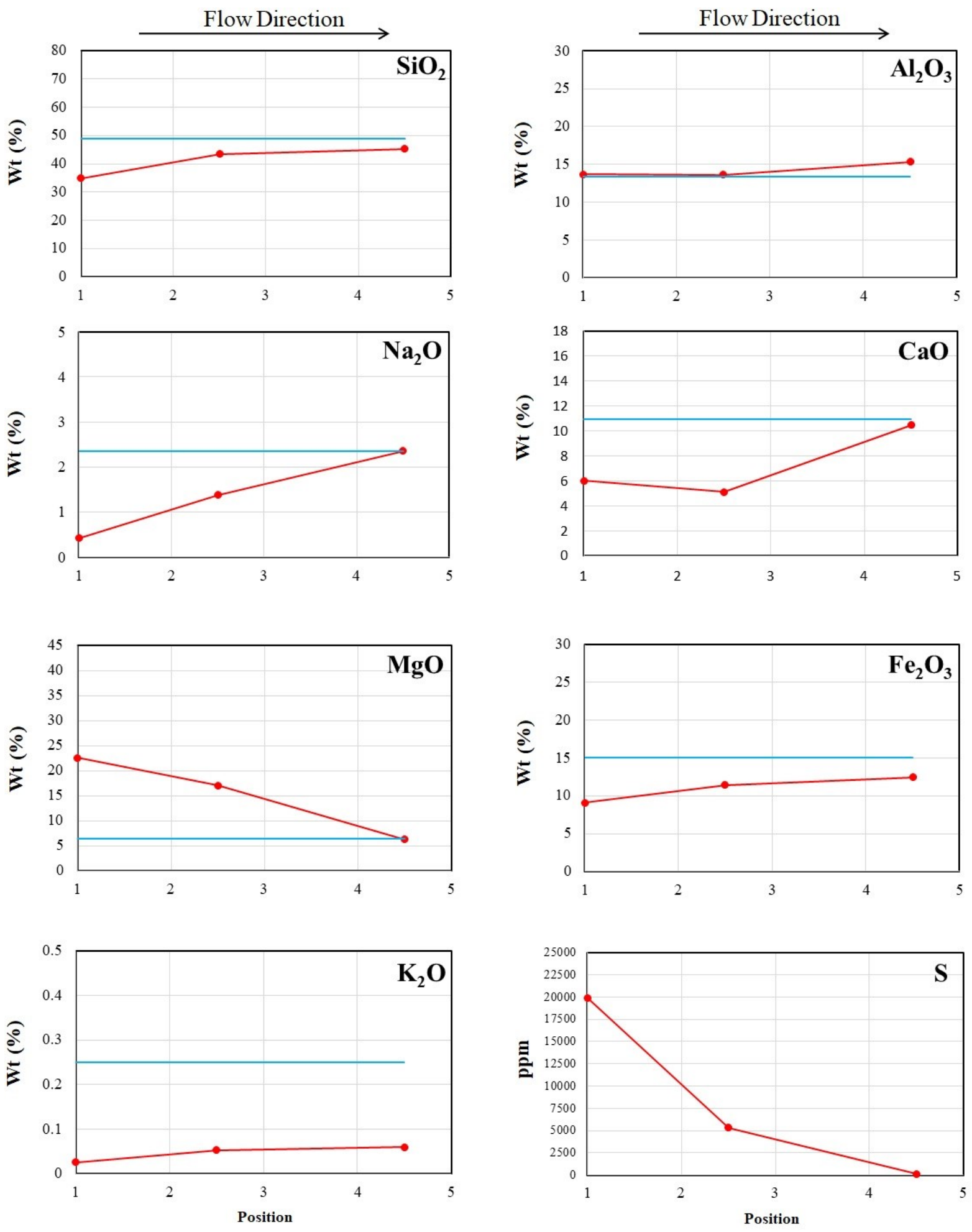

unreacted basalt

reacted basalt 


\section{Reacted grains - Portion 1}

SEM examination shows a significant degree of alteration due to fluid - rock interaction. Minerals of secondary origin identified were chlorite and anhydrite. The results also confirm the presence of the primary minerals plagioclase, clinopyroxene, olivine and titanomagnetite (Table 6.16). No evidence of caminite was found. Appendix E contains all SEM results for this Portion of the rock.

Table 6.16. Mineral assemblage identified by SEM-EDS analysis of the surface of reacted grains of Portion 1 after completion of the BSW2 experiment.

\begin{tabular}{|c|c|c|c|}
\hline $\begin{array}{l}\text { Type of } \\
\text { Analysis }\end{array}$ & $\begin{array}{l}\text { Analysis } \\
\text { Material }\end{array}$ & $\begin{array}{l}\text { Mineral } \\
\text { Identified }\end{array}$ & $\begin{array}{c}\text { Average } \\
\text { Mineral Composition }\end{array}$ \\
\hline SEM-EDS & polished grains & Plagioclase & - \\
\hline SEM-EDS & polished grains & Augite & $\mathrm{Ca}_{0.7} \mathrm{Mg}_{0.9} \mathrm{Fe}_{0.2} \mathrm{Al}_{0.1} \mathrm{Si}_{2} \mathrm{O}_{6}$ \\
\hline SEM-EDS & polished grains & Olivine & $\mathrm{Mg}_{0.9} \mathrm{FeSi}_{1.1} \mathrm{O}_{4}\left(\mathrm{Fo}_{49}-\mathrm{Fa}_{51}\right)$ \\
\hline SEM-EDS & polished grains & Chlorite & $\begin{array}{l}\mathrm{Mg}_{3.8} \mathrm{Fe}_{0.5} \mathrm{Al}_{1.5} \mathrm{Si}_{3.5} \mathrm{Al}_{0.5} \mathrm{O}_{10}(\mathrm{OH})_{8} \\
\text { (calculated based on an anhydrous composition with } 14 \text { oxygens) }\end{array}$ \\
\hline SEM-EDS & polished grains & Anhydrite & $\mathrm{CaSO}_{4}$ \\
\hline SEM-EDS & polished grains & Titanomagnetite & - \\
\hline
\end{tabular}

Figure 6.23 shows SEM images of selected reacted grains from Portion 1. These are covered with a continuous layer of chlorite and isolated euhedral anhydrite crystals. No evidence of the primary plagioclase, clinopyroxene, and olivine is found on the surface of the grains.

Figure 6.24a-e shows SEM backscatter images and EDS maps of a polished mount of a grain collected from Portion 1. The images show the high degree of alteration where clinopyroxene is almost entirely replaced by chlorite. Remnant clinopyroxene is internal to the grain. Plagioclase is also highly corroded, but a significant amount remains. Fe-Ti oxides appear relatively unaltered although some titanite was identified. Remnant olivine persists and was likely isolated from the fluid.

Figure 6.24f,g are SEM backscatter detailed images of Figure 6.24a. EDS analyses reveal the $\mathrm{Mg}-\mathrm{Fe}$ aluminosilicate to be chlorite with a higher concentration of magnesium then iron. The plagioclase remaining is the original bytownite. Fe-Ti oxides are relatively unaffected. 
Figure 6.23. SEM images of reacted grains collected from Portion 1 of the Reactor after the BSW2 experiment: (a-f) grains covered by a surface coating of chlorite with isolated and intergrown anhydrite crystals.
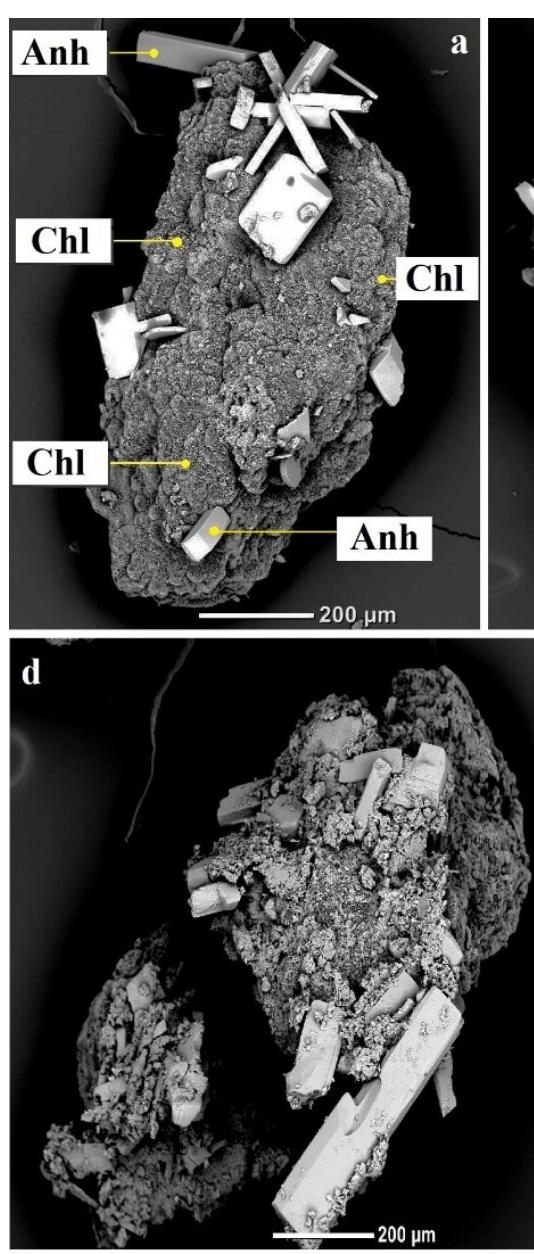
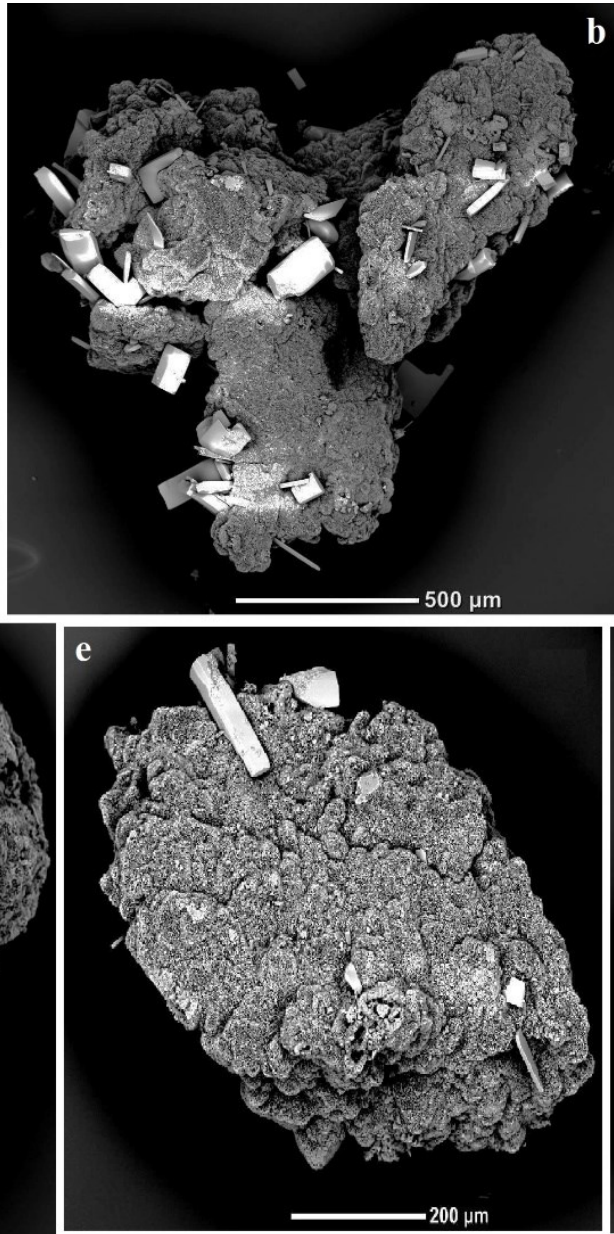
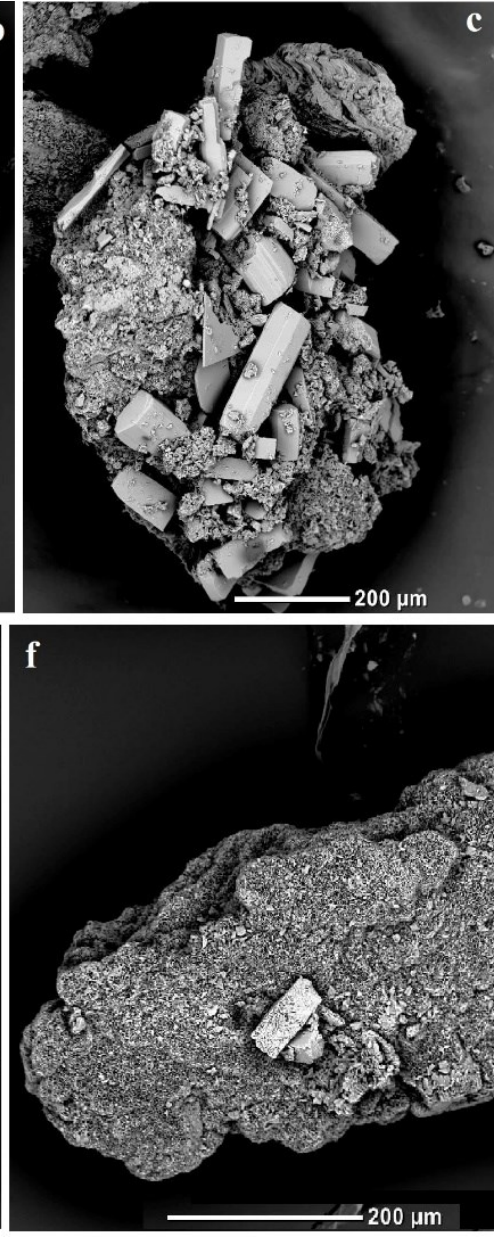
Figure 6.24. SEM images and EDS compositional maps of an epoxy-mounted, polished grain collected from the Portion 1 after the BSW2 experiment: (a) backscatter image of the reacted grain; (b) composite colour image combining the backscatter image and elemental maps for c) $\mathrm{Mg}$ in green, d) $\mathrm{Ca}$ in blue, and e) $\mathrm{Fe}$ in red showing plagioclase (blue) and clinopyroxene (light blue), olivine (yellow), Fe-Ti oxides (red), and chlorite (green); (f-g) SEM backscatter images of the red rectangular areas $n^{\circ} 1$ and $n^{\circ} 2$ in (a) showing secondary chlorite (Chl), the plagioclase $(\mathrm{Plg})$ and clinopyroxene $(\mathrm{Cpx})$, olivine $(\mathrm{Ol})$ and oxides $(\mathrm{Ox})$.
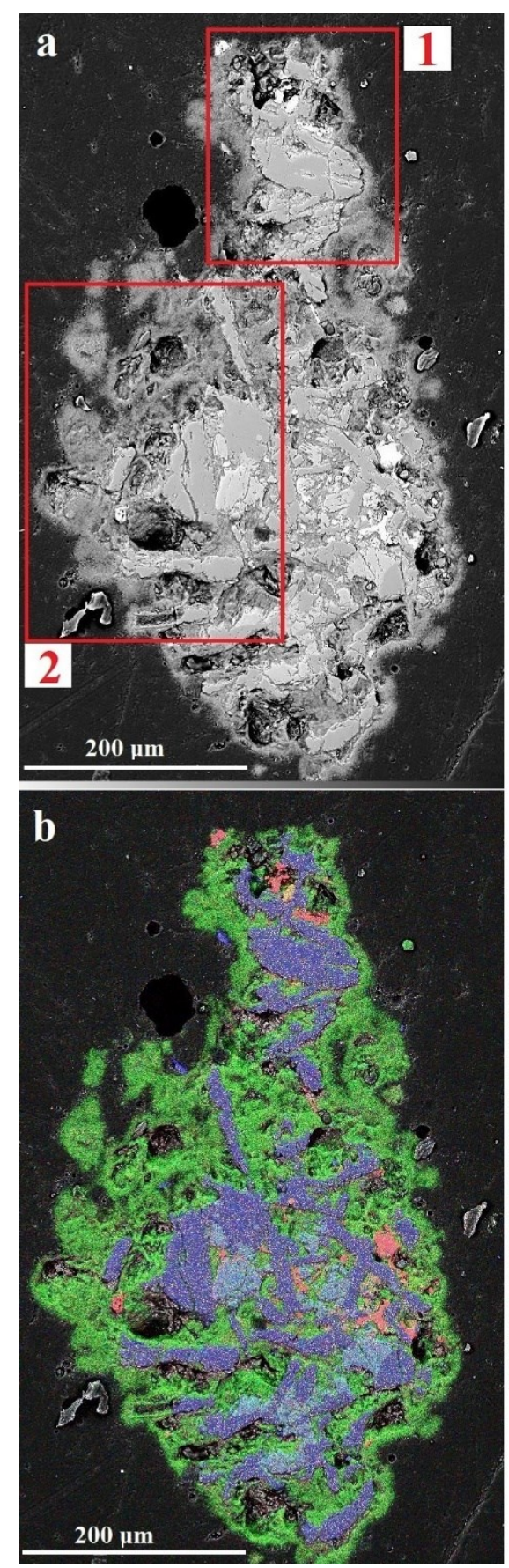
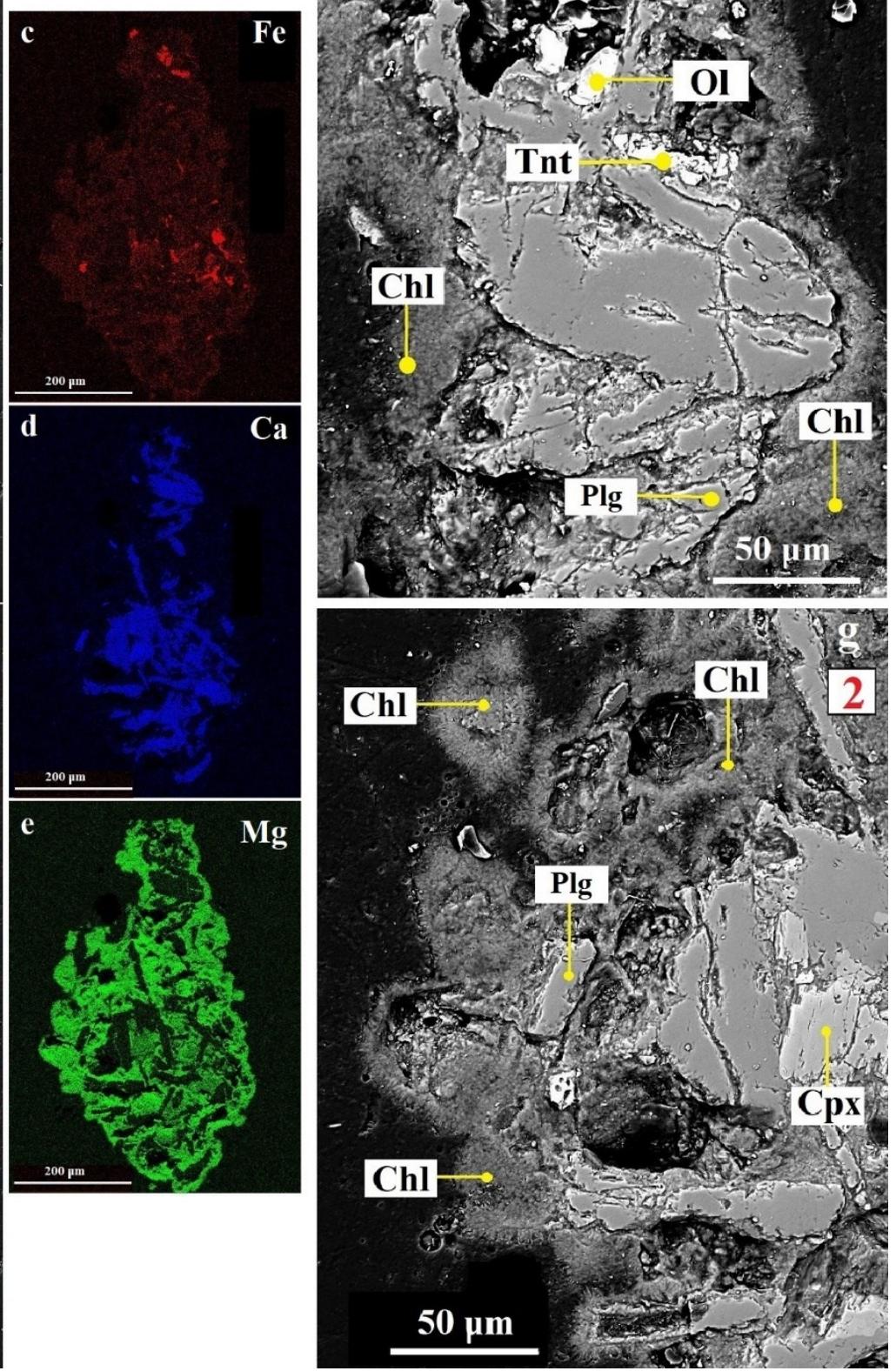
SEM results show a significant degree of alteration. Secondary minerals identified are chlorite, anhydrite and a smectite (Table 6.17). The primary minerals plagioclase, clinopyroxene, olivine and titanomagnetite were also identified.

Table 6.17. Mineral assemblage identified by SEM-EDS analysis of reacted grains from Portion 2-3 after the BSW2 experiment. Only the compositions of plagioclase, chlorite and smectite were measured.

\begin{tabular}{|c|c|c|c|}
\hline $\begin{array}{l}\text { Type of } \\
\text { Analysis }\end{array}$ & $\begin{array}{l}\text { Analysis } \\
\text { Material }\end{array}$ & $\begin{array}{c}\text { Mineral } \\
\text { Identified }\end{array}$ & $\begin{array}{c}\text { Average } \\
\text { Mineral Composition }\end{array}$ \\
\hline SEM-EDS & polished grains & Plagioclase & $\mathrm{Ca}_{0.7} \mathrm{Na}_{0.2} \mathrm{Al}_{1.6} \mathrm{Si}_{2.4} \mathrm{O}_{8}\left(\mathrm{An}_{74}-\mathrm{Ab}_{26}\right)$ \\
\hline SEM-EDS & polished grains & Augite & - \\
\hline SEM-EDS & polished grains & Olivine & - \\
\hline SEM-EDS & polished grains & Chlorite & $\begin{array}{c}\qquad \mathrm{Mg}_{3.5} \mathrm{Fe}_{0.7} \mathrm{Al}_{1.3} \mathrm{Si}_{3.5} \mathrm{Al}_{0.5} \mathrm{O}_{10}(\mathrm{OH})_{8} \\
\text { (calculated based on an anhydrous composition with } 14 \text { oxygens) }\end{array}$ \\
\hline SEM-EDS & grain surface & Anhydrite & $\mathrm{CaSO}_{4}$ \\
\hline SEM-EDS & polished grains & Titanomagnetite & - \\
\hline SEM-EDS & polished grains & Smectite & $\begin{array}{l}\mathrm{Na}_{0.1} \mathrm{Mg}_{2.1} \mathrm{Fe}_{0.6} \mathrm{Al}_{0.3} \mathrm{Si}_{3.4} \mathrm{Al}_{0.5} \mathrm{O}_{10}(\mathrm{OH})_{2} \cdot n \mathrm{H}_{2} \mathrm{O} \\
\text { (calculated based on an anhydrous composition with } 11 \text { oxygens) }\end{array}$ \\
\hline
\end{tabular}

Figure 6.25a-e shows SEM backscatter images and EDS maps of a polished mount of a grain collected from Portion 2-3. Clinopyroxene has been almost entirely replaced by chlorite while the remnant plagioclase is corroded but persists. Chlorite surrounds the rim of the grain and internally replaces clinopyroxene, plagioclase, and presumably olivine. Fe-Ti oxide appear relatively unaffected.

Figure 6.26a-e shows SEM backscatter images and EDS maps of a second polished grain collected from Portion 2-3. The grains show a high degree of alteration with clinopyroxene almost entirely replaced while plagioclase was more resistant. This grain differs from the previous shown in Figure 6.25 as the secondary phase surrounding and replacing the grain is not chlorite. The average SEM-EDS analysis of this mineral (Table 6.18) show measurable concentrations of $\mathrm{Na}$, a lower $\mathrm{Mg} / \mathrm{Fe}$ ratio and higher $\mathrm{Si} / \mathrm{Al}$ ratio than that of the chlorite found in the previous grain and in Portion 1. This mineral replaces mainly clinopyroxene and surrounds the outside of the grain.

This phase is comparable in composition to the clay-like phase encountered in the BSW1 experiment at $400^{\circ} \mathrm{C}$. Given that the XRD results from the latter experiment it is concluded that the most likely candidate for this mineral is smectite. 
Figure 6.25. SEM images and EDS compositional maps of an epoxy-mounted, polished grain collected from the Portion 2-3 after the BSW2 experiment: (a) backscatter image; (b) composite colour image combining the backscatter image and elemental maps for c) Fe in red, d) Ca in blue and e) Mg in green showing plagioclase (blue), Fe-Ti oxides (red), and chlorite (green); (f-g) SEM backscatter images of the two rectangular areas shown in (a).
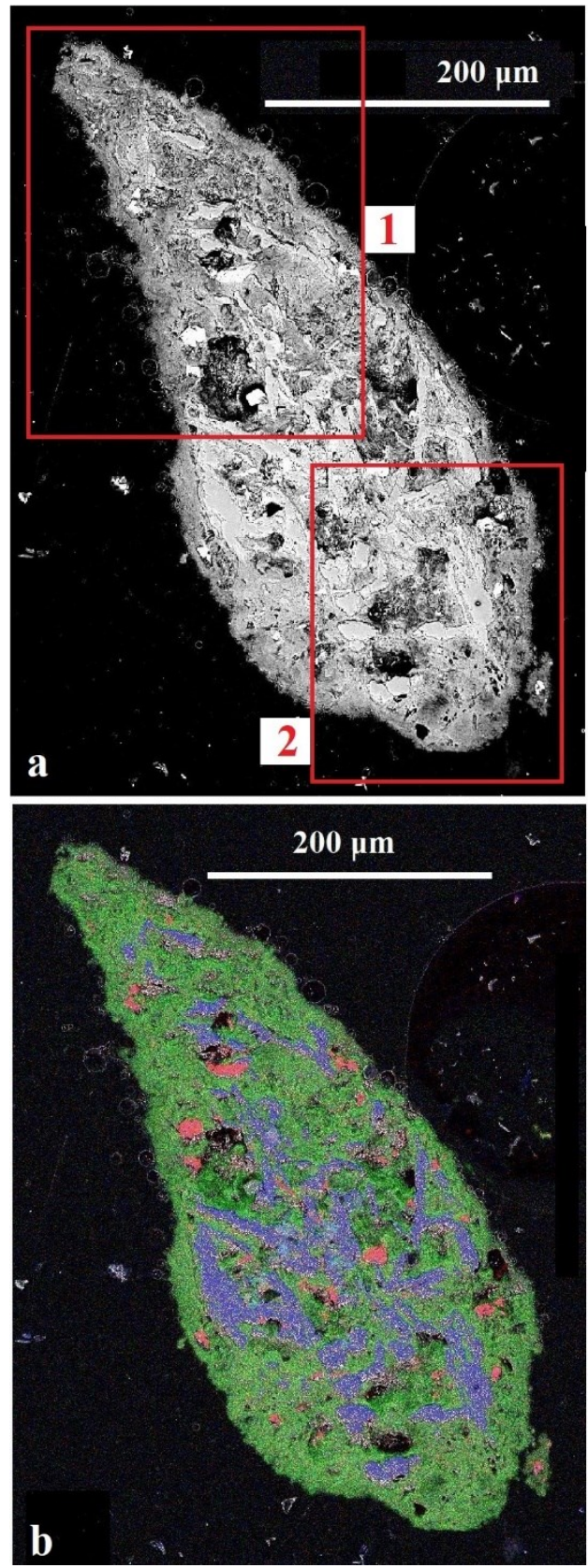
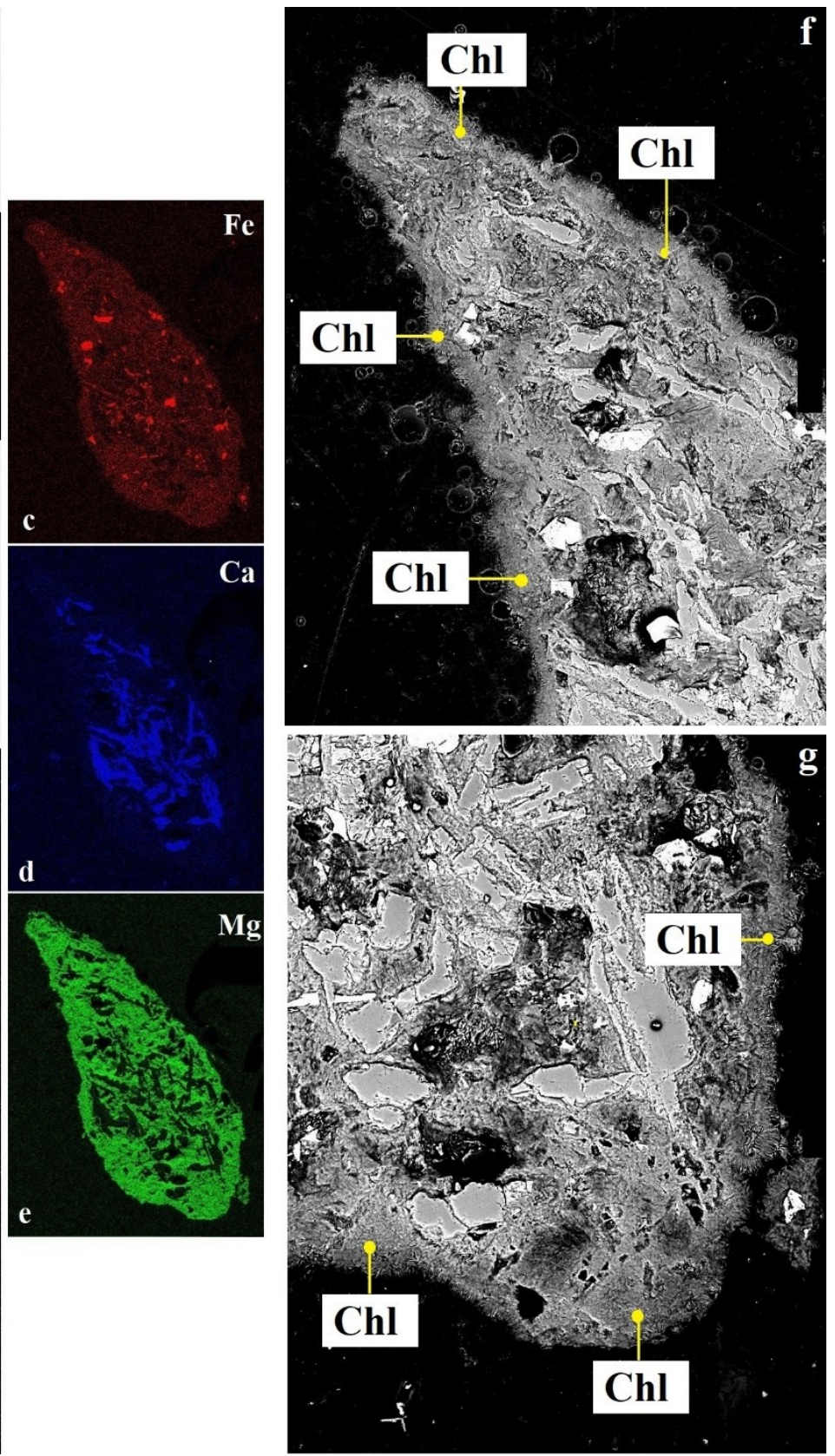
Figure 6.26. SEM images and EDS compositional maps of a polished grain collected from the Portion 2-3 after the BSW2 experiment: (a) backscatter image; (b) composite colour image combining the backscatter image and elemental maps for c) $\mathrm{Mg}$ in green, d) Ca in blue and e) Fe in red showing plagioclase (blue), Fe-Ti oxides (red), and smectite (green); f-g) SEM backscatter images of the two rectangular areas shown in (a). The grain has been largely replaced by smectite.
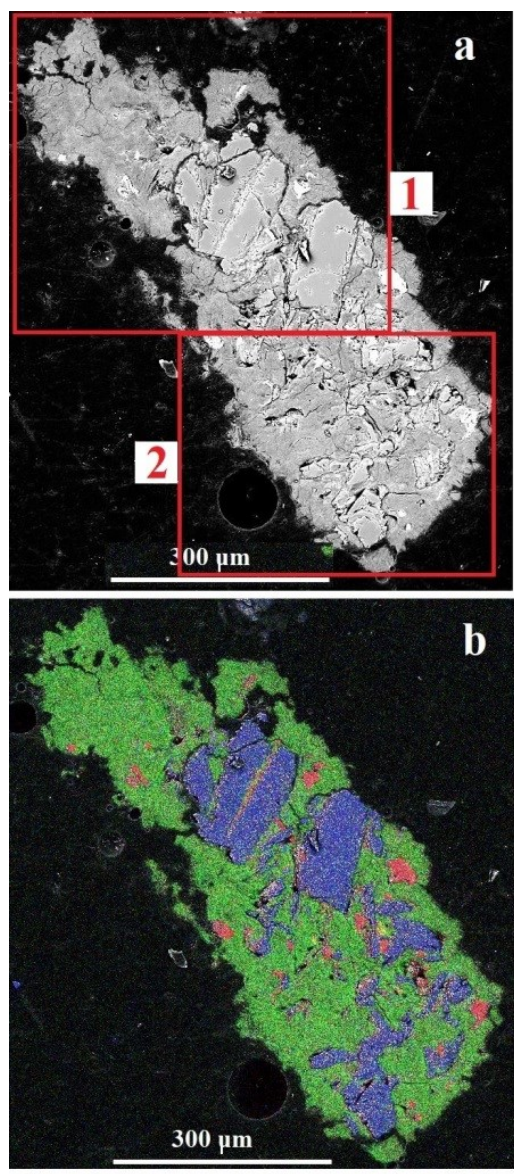

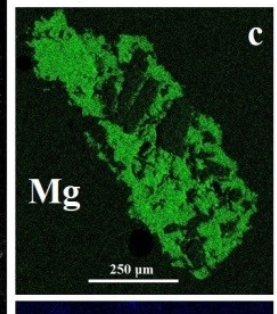

d
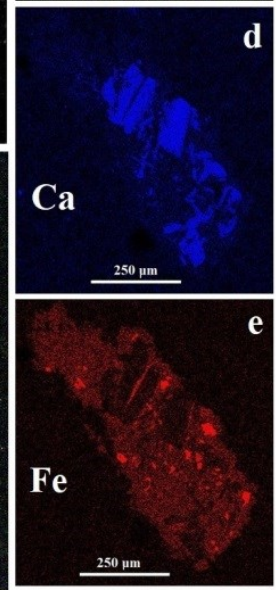

$\underline{250 \mu \mathrm{m}}$
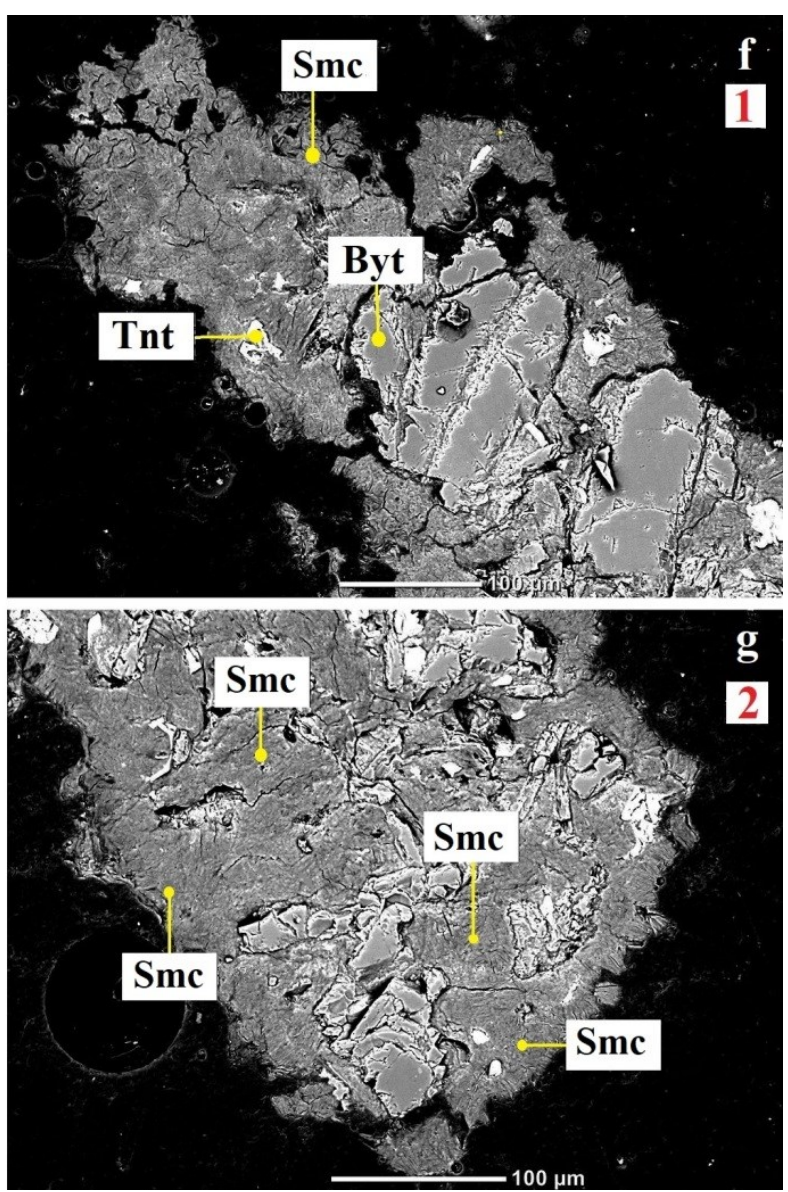

Table 6.18. Average composition (SEM-EDS) of smectite found in Portion 2-3 after the completion of the BSW2 experiment.

\begin{tabular}{|ccc|}
\hline & $\begin{array}{c}\text { Polished } \\
(\mathbf{N}=\mathbf{1 3})\end{array}$ & \\
& average & $\pm 1 \sigma$ \\
oxide & Wt \% & \\
& & 0.21 \\
$\mathbf{N a}_{2} \mathbf{O}$ & 0.72 & 1.15 \\
$\mathbf{M g O}$ & 22.25 & 0.91 \\
$\mathbf{A l}_{2} \mathbf{O}_{3}$ & 11.71 & 1.55 \\
$\mathbf{S i O}_{2}$ & 53.45 & 1.78 \\
$\mathbf{F e O}$ & 11.59 & \\
Total & 99.82 &
\end{tabular}




\section{Portion 4-5}

SEM analysis of grain from the top two portions of reacted grains show a lower intensity of alteration of the rock. The only secondary mineral identified is smectite. Note that no chlorite or anhydrite was identified in the top two portions of the Reactor. This is consistent with the XRD results.

Table 6.19. Mineral assemblage detected by SEM-EDS analysis of reacted grains of Portion 4-5 after the BSW2 experiment.

\begin{tabular}{|c|c|c|c|}
\hline $\begin{array}{l}\text { Type of } \\
\text { Analysis }\end{array}$ & $\begin{array}{l}\text { Analysis } \\
\text { Material }\end{array}$ & $\begin{array}{l}\text { Mineral } \\
\text { Identified }\end{array}$ & $\begin{array}{c}\text { Average } \\
\text { Mineral Composition }\end{array}$ \\
\hline SEM-EDS & polished grains & Plagioclase & - \\
\hline SEM-EDS & polished grains & Augite & $\mathrm{Ca}_{0.5} \mathrm{Mg}_{0.9} \mathrm{Fe}_{0.4} \mathrm{Al}_{0.1} \mathrm{Si}_{2} \mathrm{O}_{6}$ \\
\hline SEM-EDS & polished grains & Titanomagnetite & - \\
\hline SEM-EDS & polished grains & Smectite & $\begin{array}{l}\mathrm{Na}_{0.2} \mathrm{Ca}_{0.1} \mathrm{Mg}_{1.3} \mathrm{Fe}_{1.2} \mathrm{Al}_{0.4} \mathrm{Si}_{3.4} \mathrm{Al}_{0.6} \mathrm{O}_{10}(\mathrm{OH})_{2} \cdot n \mathrm{H}_{2} \mathrm{O} \\
\text { (calculated based on an anhydrous composition with } 11 \text { oxygens) }\end{array}$ \\
\hline
\end{tabular}

Figure 6.27a-e show SEM backscatter images and EDS maps of a polished mount of a grain collected from Portion 4-5. Primary plagioclase and clinopyroxene are relatively unaffected with smectite growing only on the outside edge of the grain. Primary titanomagnetite is unaffected.

Figure $6.27 \mathrm{f}, \mathrm{g}$ are SEM backscatter detailed images of the grain shown in Figure 6.27a. EDS analyses show the smectite is high in $\mathrm{FeO}$ and $\mathrm{MgO}$ and with measurable $\mathrm{Na}_{2} \mathrm{O}$. The plagioclase appears slightly altered when compared to the unaltered rock while clinopyroxene and olivine are unaffected.

The average SEM-EDS analysis for smectite is shown in Table 6.20. It has similar concentrations of $\mathrm{Al}_{2} \mathrm{O}_{3}$ and $\mathrm{SiO}_{2}$, but has higher $\mathrm{Na}_{2} \mathrm{O}$ and $\mathrm{CaO}$ than the smectite found in Portion 2 - 3. Also, when compared to the smectite found at the top of the Reactor in the $350^{\circ} \mathrm{C}$ experiment (Table 6.12), it has a higher Fe:Mg ratio.

To summarise, Figure 6.28 shows a composite diagram of the reacted basalt grains, the backscatter images, and the EDS compositional maps for the BSW2 experiment at $350^{\circ} \mathrm{C}$. The decrease in the intensity of alteration between Portions 1-3 and Portion 4-5 is evident. The bleaching of the rock can be attributed to the replacement of primary clinopyroxene, olivine, and plagioclase by chlorite up to Portion 2. Within Portion 2 and 3, replacement by chlorite and smectite are both present but do not occur together. This implies a transition from chlorite to smectite as the dominant secondary phase about one quarter the way up the 
Reactor. For Portions 3 to 5, the intensity of alteration decreases, and the colour of the grains darkens as more clinopyroxene remains unaltered and replacement by smectite is reduced.

Figure 6.27. SEM images and EDS compositional maps of a polished grain from the Portion 4-5 after the BSW2 experiment: (a) backscatter image; (b) composite colour image combining the backscatter image and elemental maps for c) $\mathrm{Mg}$ in green, d) $\mathrm{Ca}$ in blue and e) Fe in red showing plagioclase (blue), and clinopyroxene (light blue), Fe-Ti oxides (red), and the secondary Na-Mg-Fe aluminosilicate (green) growing on the outside edge of the grain; (f-g) SEM backscatter images of the two \rectangular areas shown in Figure 6.28(a).
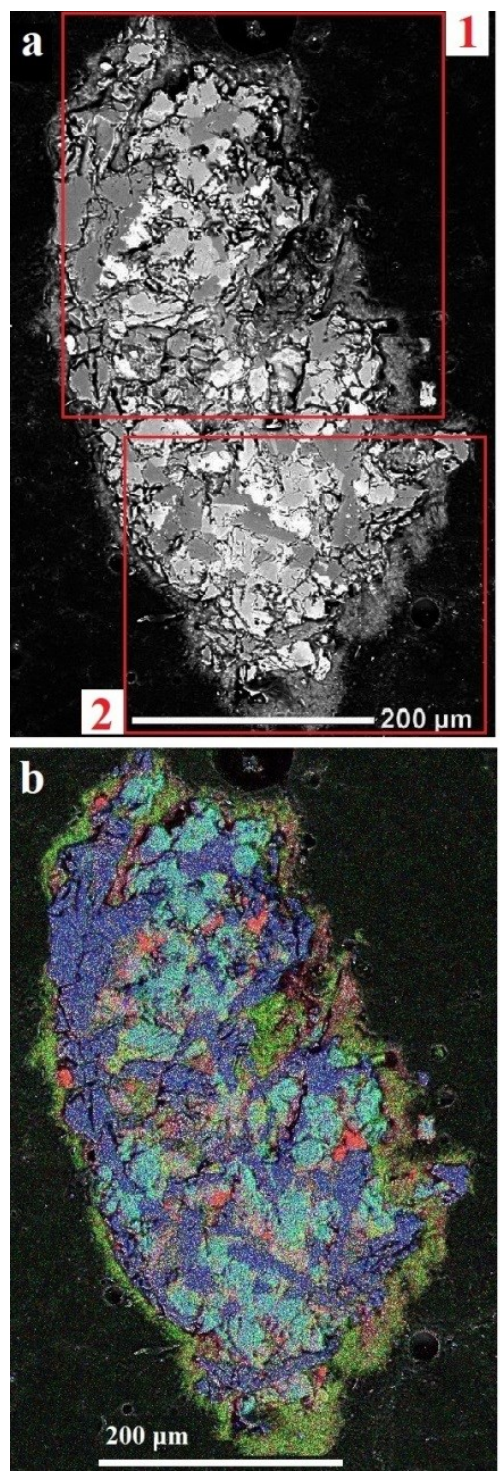
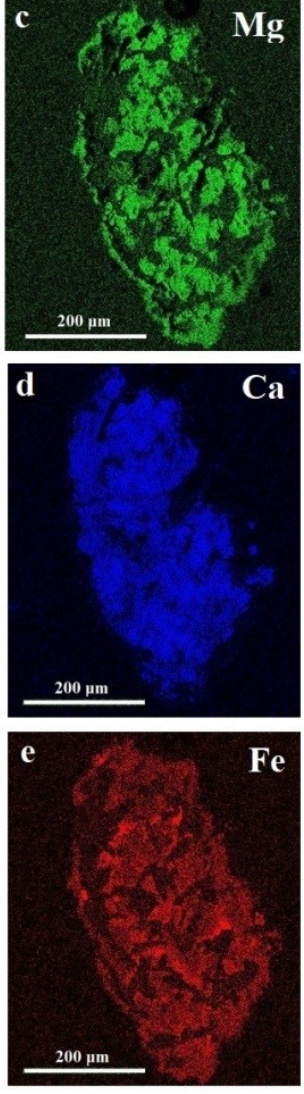
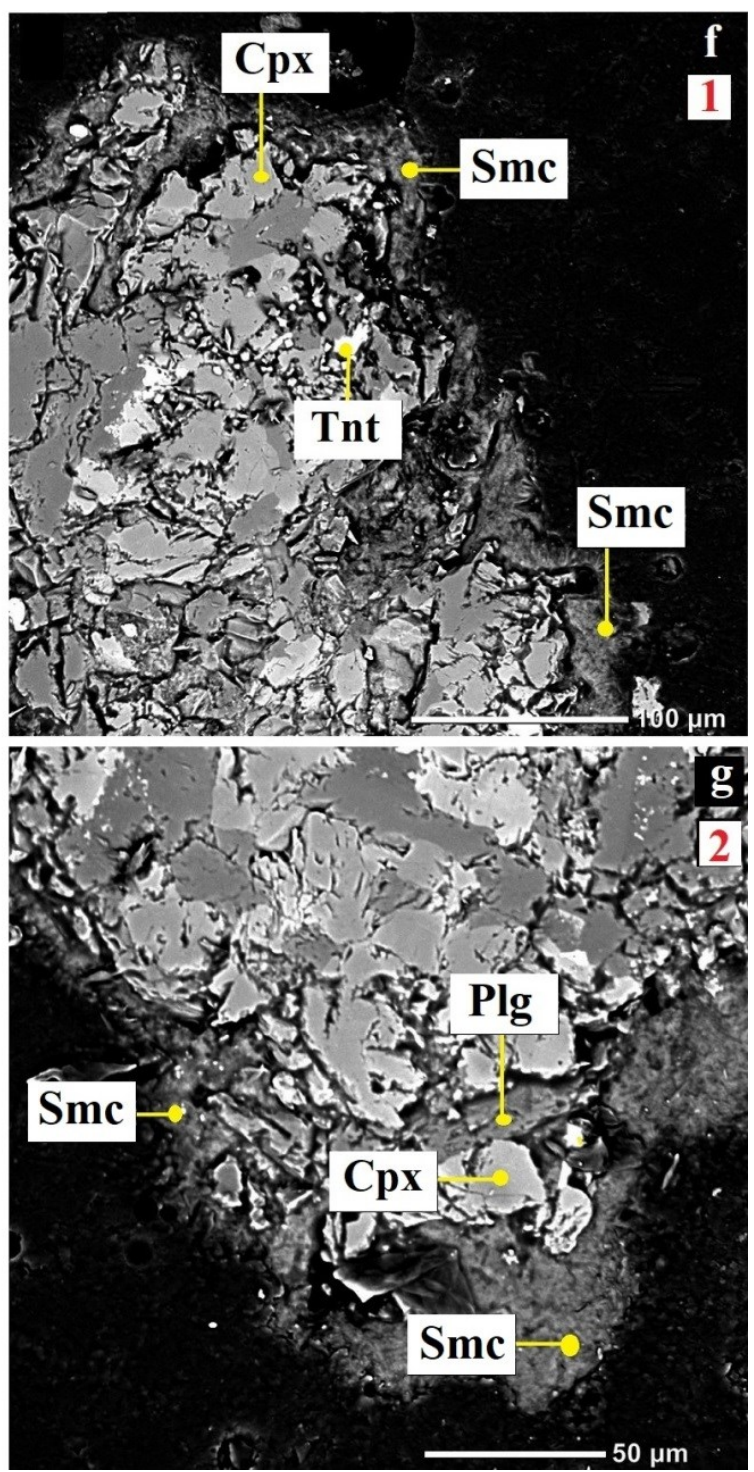
Table 6.20. Average composition (by SEM-EDS analysis) of the clay mineral phase found during study of the reacted grains collected from Portion 4-5 after the BSW2.

\begin{tabular}{|ccc|}
\hline & $\begin{array}{c}\text { Polished } \\
(\mathbf{N}=\mathbf{2 6})\end{array}$ & \\
oxide & $\begin{array}{c}\text { average } \\
\text { Wt \% }\end{array}$ & $\pm 1 \sigma$ \\
& & \\
$\mathbf{N a}_{2} \mathbf{O}$ & 1.57 & 0.76 \\
$\mathbf{M g O}$ & 13.02 & 2.43 \\
$\mathbf{A l}_{2} \mathbf{O}_{3}$ & 12.11 & 1.14 \\
$\mathbf{S i O}_{2}$ & 50.28 & 1.73 \\
$\mathbf{C a O}$ & 0.87 & 0.39 \\
$\mathbf{F e O}$ & 22.12 & 4.38 \\
Total & 99.97 & \\
\hline
\end{tabular}


Figure 6.28. Composite image showing the changing intensity of alteration of reacted grains analysed from the BSW 2 experiment. Flow direction is from the bottom to the top of the image. The decreasing degree of alteration is evident from the bleaching of the rock due to replacement by chlorite and smectite.

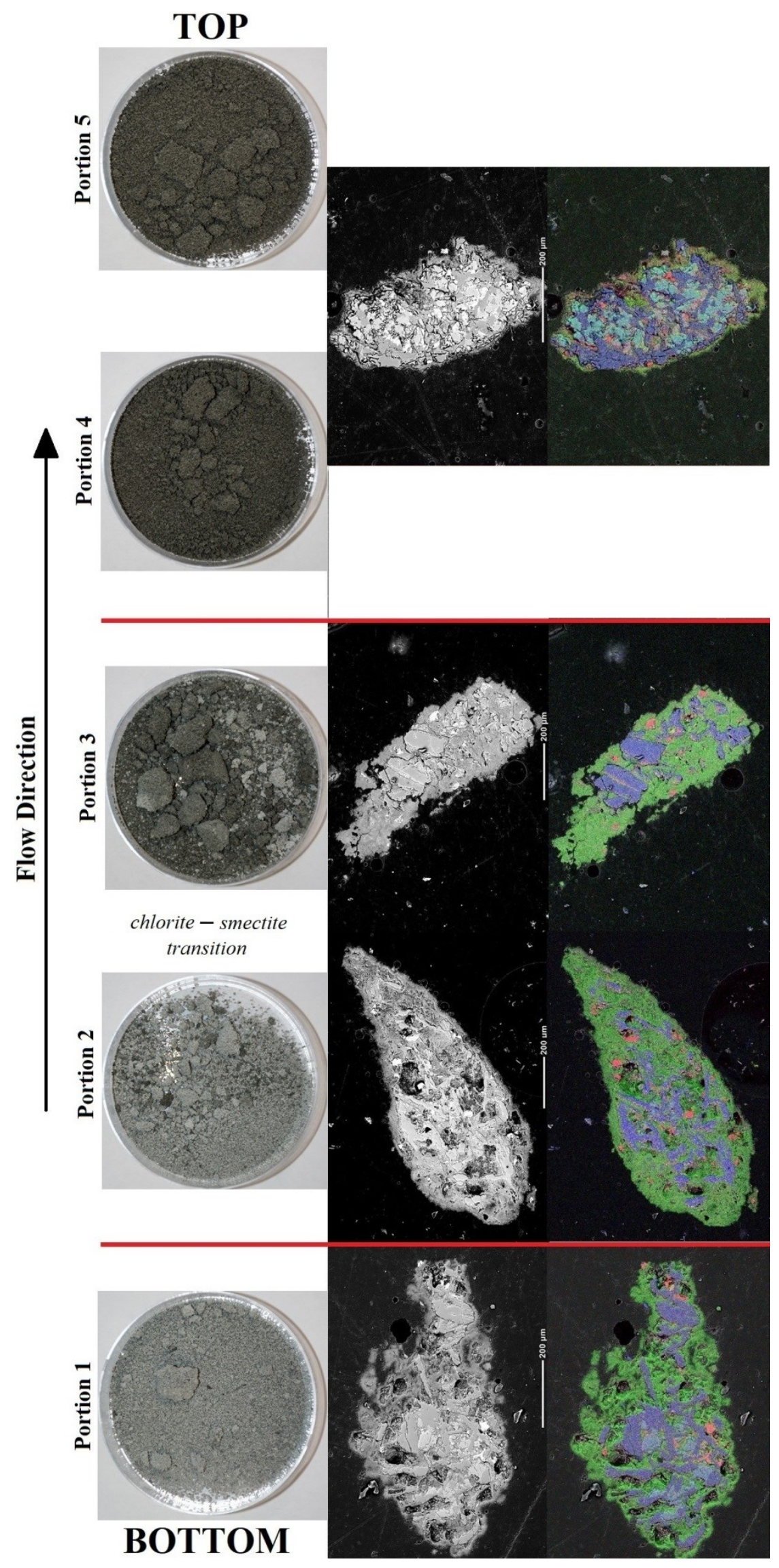




\subsubsection{Mineralogy and Texture of Reacted Basalt: Basalt Block}

The basalt block ( $8 \times 8 \times 4 \mathrm{~mm})$ (Fig. 6.29a) was positioned vertically near the bottom of the Reactor approximately $0.5 \mathrm{~cm}$ above the titanium frit (Fig. 6.21). Upon opening the Reactor, the basalt block was well-preserved, with abundant evidence of reaction on left side and left top corner of the block (Fig. 6.29b). Once extracted, the reacted basalt block was mounted on an aluminium stub for SEM analysis. Complete SEM results are reported in Appendix E.

Figure 6.30 shows SEM backscatter images of the reacted surface of the basalt block. The bright backscatter image shows that the block is covered by a higher atomic weight element than the expected $\mathrm{Na}, \mathrm{Mg}, \mathrm{Ca}, \mathrm{Al}$, and $\mathrm{Si}$. EDS analysis shows this coating is composed of Ni oxide. For this reason, the underlying minerals could not be analysed. The only observation that can be made is that there is considerably more porosity in the rock due to the dissolution of primary minerals. The origin of this coating of Ni oxide is unknown. It was not observed in the grains from Portion 1 and suggests something acquired after extraction from the Reactor. 
Figure 6.29. (a) SEM backscatter photomosaic of the basalt block surface before the BSW2 experiment. (b) SEM backscatter photomosaic of the basalt block surface after the BSW2 experiment.
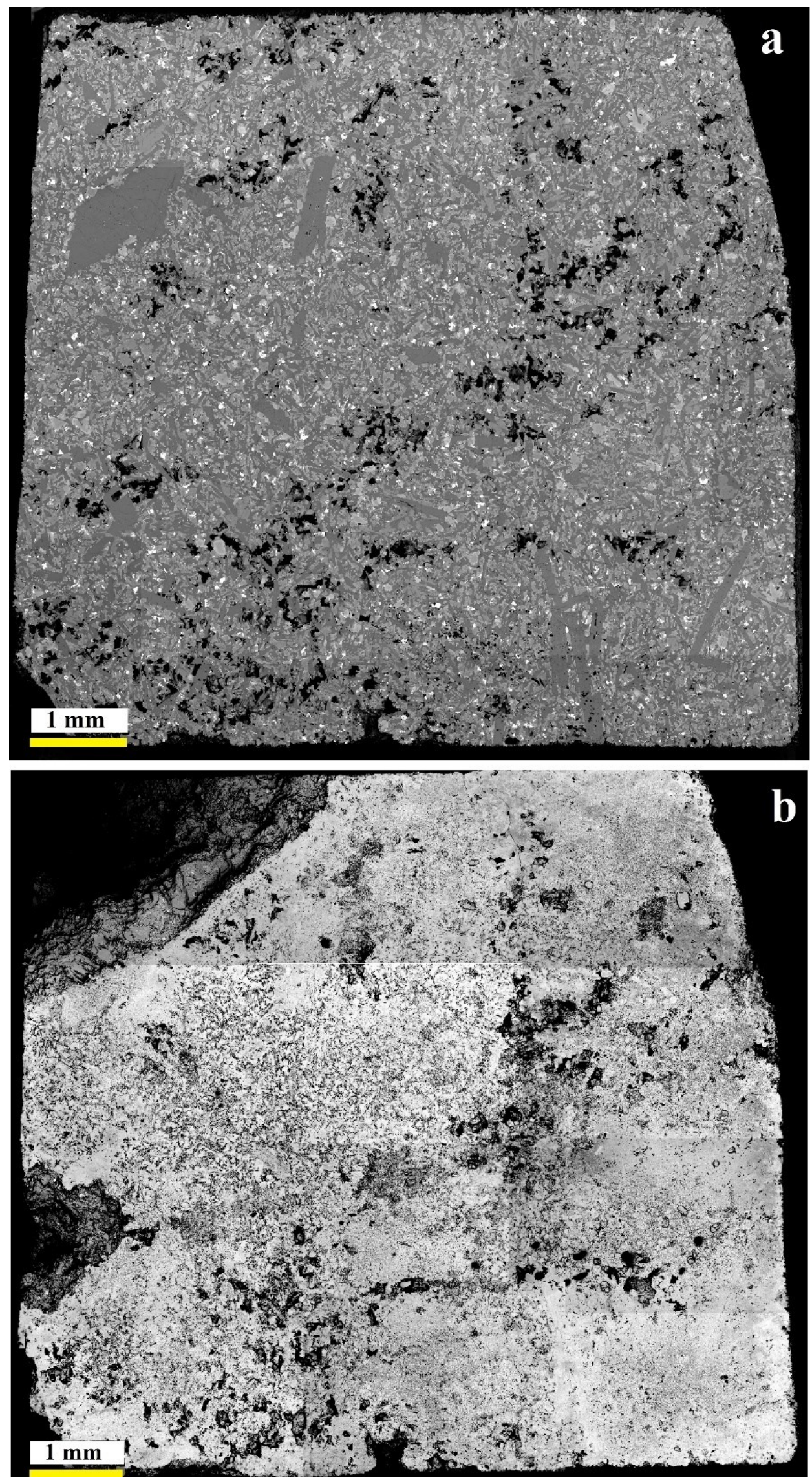
Figure 6.30. SEM backscatter images of the reacted basalt block surface after the BSW2 experiment. This surface is covered by Ni- oxide.

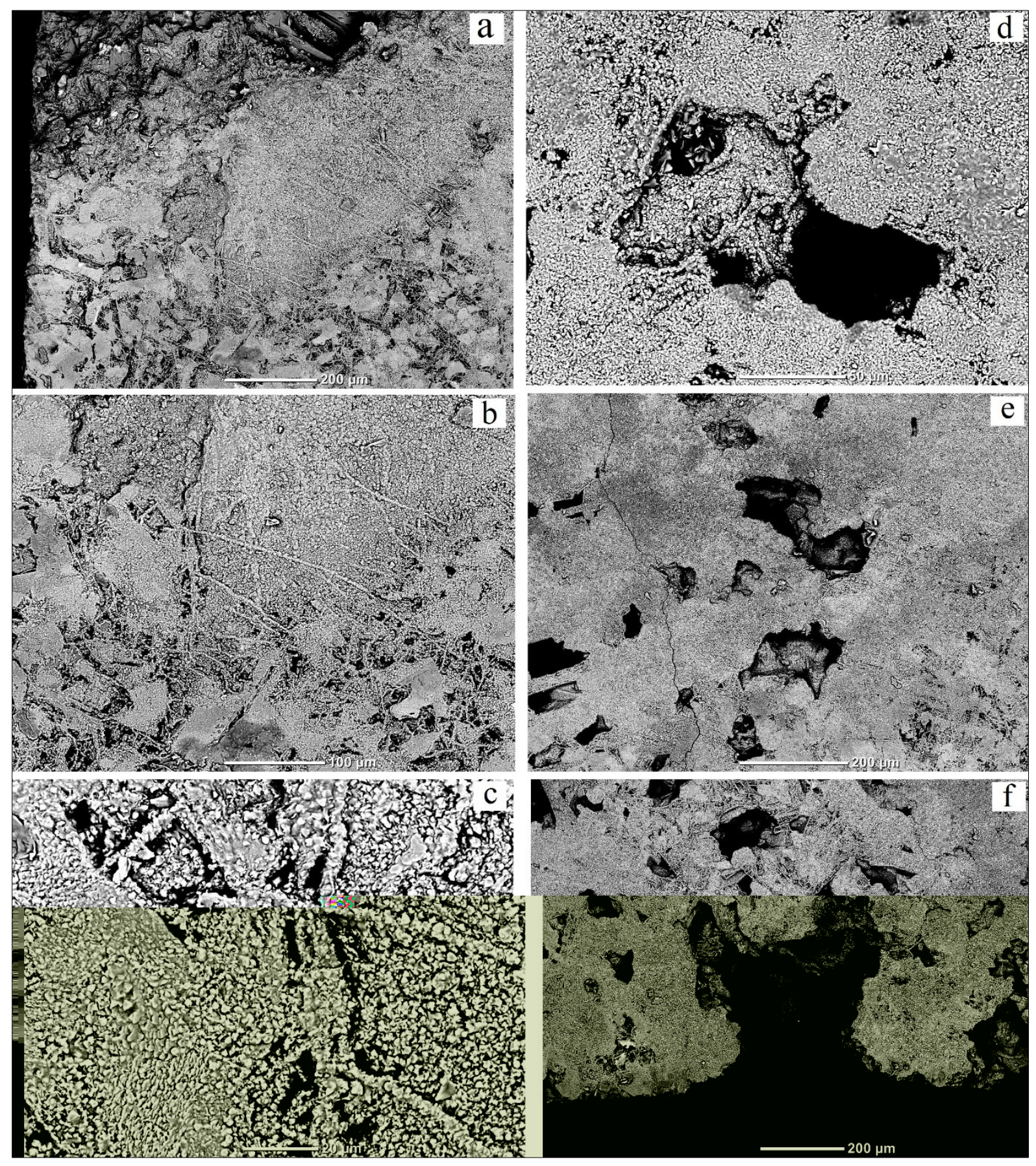




\subsection{Discussion}

\subsubsection{Major and trace element exchange during seawater - basalt interaction}

\section{Major elements}

It is assumed that the composition of the fluid entering the Reactor in the seawater basalt experiments has the same composition as the effluent from the seawater-only experiments (Chapter 5). For the purposes of discussion these values are summarised in Table 6.21 and Table 6.22 along with the "stable" effluent concentrations from the seawater-basalt experiments (listed according to flow rate).

Figure 6.31 shows major element concentrations in effluent samples from the seawater-only and seawater-basalt experiments plotted together versus time. This allows the comparison of SW1 with BSW1 $\left(400^{\circ} \mathrm{C}\right)$ and SW2 with BSW2 $\left(350^{\circ} \mathrm{C}\right)$.

Table 6.23 shows the input total mass $(\mathrm{mg})$ and integrated elemental fluxes $(\mathrm{mg})$ for selected components for BSW1 and BSW2. The input total mass represents the amount of material that entered the Reactor based on the total fluid flux $(1.48 \mathrm{~kg}$ in BSW1 and $1.15 \mathrm{~kg}$ in BSW2) and output seawater composition from the Preheater. The integrated elemental flux is the total mass of component integrated over the entire experiment based on daily fluid flux and the effluent composition. Also shown is the elemental flux normalised to total fluid flux (mg per kg brine). Appendix E shows all data.

Quench $p H$. The quench $\mathrm{pH}$ of seawater exiting the Preheater during the SW1 and SW2 experiments stabilised at 3.3 and 2.8, respectively (Fig. 6.31). The difference in $\mathrm{pH}$ is likely due to greater reaction with the $\mathrm{ZrO}_{2}$ beads at the higher temperature. In BSW1 and BSW2, after reaction with the basalt, quench $\mathrm{pH}$ values shift upwards to $\sim 4.0$ and $\sim 3.7$ at 1 $\mathrm{ml} \mathrm{hr}{ }^{-1}$ flow rate. As previously noted, the acidic quench $\mathrm{pH}$ values in the seawater-only experiments are due to the release of hydrogen ion from $\mathrm{HSO}_{4}{ }^{-}$and $\mathrm{H}_{2} \mathrm{O}$ during precipitation of retrograde phases (anhydrite, caminite, brucite). The increase of quench $\mathrm{pH}$, in both seawater-basalt experiments shows the neutralisation of $\mathrm{H}^{+}$by fluid-rock reaction. 
Table 6.21. Input and output fluid compositions $\left(\mathrm{mmol} \mathrm{kg}^{-1}\right)$ of seawater for selected components during the SW1 and BSW1 experiment.

\begin{tabular}{|c|c|c|c|c|c|c|c|c|c|c|c|c|c|c|}
\hline & Experiment & $\begin{array}{c}\mathbf{T} \\
{ }^{\circ} \mathrm{C}\end{array}$ & $\begin{array}{c}\text { Flow } \\
\text { Rate } \\
\left(\mathrm{ml} \mathrm{h}^{-1}\right)\end{array}$ & $\begin{array}{c}\mathbf{p H} \\
\left(25^{\circ} \mathrm{C}\right)\end{array}$ & $\begin{array}{c}\mathbf{p H} \\
\text { (in situ) }\end{array}$ & $\mathrm{SiO}_{2}$ & Al & $\mathbf{K}$ & $\mathrm{SO}_{4}$ & $\mathrm{H}_{2} \mathrm{~S}$ & $\mathbf{C a}$ & $\mathrm{Na}$ & Mg & $\mathbf{F e}$ \\
\hline Input & SW1 & 377 & - & 7.75 & - & 0.1 & 0.01 & 8.4 & 22 & - & 9.4 & 360 & 45.8 & 0.002 \\
\hline \multirow[t]{2}{*}{ Output } & SW1 & 377 & 1 & 3.34 & 5.37 & 0.9 & 0.01 & 8.4 & 1.2 & - & 2.1 & 360 & 24.4 & 1.3 \\
\hline & $\downarrow$ & $\downarrow$ & & $\downarrow$ & $\downarrow$ & $\downarrow$ & $\downarrow$ & $\downarrow$ & $\downarrow$ & $\downarrow$ & $\downarrow$ & $\downarrow$ & $\downarrow$ & $\downarrow$ \\
\hline \multirow[t]{3}{*}{ Input } & BSW1 & 400 & - & 3.34 & 5.37 & 0.9 & 0.01 & 8.4 & 1.2 & - & 2.1 & 360 & 24.4 & 1.3 \\
\hline & BSW1 & 400 & 1 & 4.04 & 5.73 & 28.7 & 0.07 & 8 & 0.04 & 0.004 & 21.5 & 351 & 0.003 & 1.1 \\
\hline & BSW1 & 400 & 1.5 & 4.17 & 5.75 & 27.6 & $<0.006$ & 8.2 & 0.05 & 0.004 & 20.7 & 362 & 0.02 & 1.5 \\
\hline \multirow[t]{3}{*}{ Output } & BSW1 & 400 & 10 & 4.53 & 5.82 & 28.6 & $<0.006$ & 8.2 & 0.06 & 0.03 & 14.6 & 369 & 0.1 & 7.6 \\
\hline & BSW1 & 400 & 7.5 & 4.55 & 5.81 & 28.3 & $<0.006$ & 8.2 & 0.05 & 0.02 & 14.8 & 362 & 0.08 & 7.2 \\
\hline & BSW1 & 400 & 5 & 4.55 & 5.80 & 28.7 & $<0.006$ & 8.4 & 0.05 & - & 15.8 & 374 & 0.07 & 6.7 \\
\hline
\end{tabular}

Table 6.22. Input and output fluid compositions $\left(\mathrm{mmol} \mathrm{kg}^{-1}\right)$ of seawater for selected components during the SW2 and BSW2 experiment.

\begin{tabular}{|c|c|c|c|c|c|c|c|c|c|c|c|c|c|c|}
\hline & Experiment & $\begin{array}{c}\mathbf{T} \\
{ }^{\circ} \mathrm{C}\end{array}$ & $\begin{array}{c}\text { Flow } \\
\text { Rate } \\
\left(\mathrm{ml} \mathrm{h}^{-1}\right)\end{array}$ & $\underset{\left(25^{\circ} \mathrm{C}\right)}{\mathbf{p H}}$ & $\begin{array}{l}\mathbf{p H} \\
\text { (in } \\
\text { situ) }\end{array}$ & $\mathrm{SiO}_{2}$ & Al & $\mathbf{K}$ & $\mathrm{SO}_{4}$ & $\mathrm{H}_{2} \mathrm{~S}$ & $\mathrm{Ca}$ & $\mathbf{N a}$ & Mg & $\mathbf{F e}$ \\
\hline Input & SW2 & 342 & - & 7.75 & - & $<0.01$ & 0.007 & 8.4 & 23 & - & 8 & 360 & 36.7 & 0.002 \\
\hline \multirow[t]{2}{*}{ Output } & SW2 & 342 & 1 & 2.77 & 5.49 & 0.25 & $<0.006$ & 8.4 & 2.7 & - & 1.4 & 360 & 22.8 & 1.7 \\
\hline & $\downarrow$ & $\downarrow$ & & $\downarrow$ & $\downarrow$ & $\downarrow$ & $\downarrow$ & $\downarrow$ & $\downarrow$ & $\downarrow$ & $\downarrow$ & $\downarrow$ & $\downarrow$ & $\downarrow$ \\
\hline \multirow[t]{3}{*}{ Input } & BSW2 & 350 & - & 2.77 & 5.49 & 0.25 & $<0.006$ & 8.4 & 2.7 & - & 1.4 & 360 & 22.8 & 1.7 \\
\hline & BSW2 & 350 & 1 & 3.73 & 5.31 & 34.7 & 0.004 & 8 & 0.07 & 0.01 & 20.3 & 333 & 0.04 & $<0.001$ \\
\hline & BSW2 & 350 & 10 & 4.11 & 5.28 & 28.3 & 0.001 & 8.9 & 0.09 & $<0.0003$ & 18.6 & 366 & 1 & 2.8 \\
\hline \multirow[t]{3}{*}{ Output } & BSW2 & 350 & 5 & 4.26 & 5.27 & 27.5 & 0.002 & 8.8 & 0.05 & $<0.0003$ & 21.7 & 368 & 0.4 & 0.4 \\
\hline & BSW2 & 350 & 2.5 & 4.31 & 5.29 & 25.6 & 0.007 & 8.6 & 0.07 & 0.002 & 22.1 & 372 & 0.3 & 0.2 \\
\hline & BSW2 & 350 & 1 & 4.36 & 5.29 & 24 & 0.005 & 8.4 & 0.06 & 0.001 & 23.2 & 374 & 0.2 & $<0.001$ \\
\hline
\end{tabular}

In situ $\mathrm{pH}$. The calculated in situ $\mathrm{pH}$ for the $\mathrm{SW} 1$ and $\mathrm{SW} 2$ experiments was 5.3 and 5.5 , respectively. Given the uncertainties in the high temperature thermodynamic data, these two values are comparable. After reaction with the rock, in situ $\mathrm{pH}$ for BSW1 and BSW2 is 5.8 and 5.3, respectively (Fig. 6.31). The $0.5 \mathrm{log}$ unit of difference between these values suggests either a difference in the mineral reactions controlling the $\mathrm{pH}$ or alternatively, higher ion pairing at $400^{\circ} \mathrm{C}$.

$\mathrm{SiO}_{2}$. In $\mathrm{BSW} 1$ and $\mathrm{BSW} 2, \mathrm{SiO}_{2}$ concentration remains oversaturated with respect to quartz for the duration of both experiments with a final value of $\sim 25 \mathrm{mmol} \mathrm{kg}^{-1}$ (Fig. 6.31). Output seawater from SW1 and SW2 contains low dissolved silica at 0.9 and $0.25 \mathrm{mmol} \mathrm{kg}^{-1}$, respectively. This shows that $\mathrm{SiO}_{2}$ released from the $\mathrm{ZrO}_{2}$ beads makes only a small 
contribution to the final $\mathrm{SiO}_{2}$ in solution. Hence, $\mathrm{SiO}_{2}$ is derived predominantly from fluidrock interaction. At $350^{\circ} \mathrm{C}, \mathrm{SiO}_{2}$ concentration shows higher values for the first 150 hours which may be evidence of volcanic glass dissolution. At $400^{\circ} \mathrm{C}, \mathrm{SiO}_{2}$ concentration is constant over the experiment and there is no discernible evidence of glass dissolution. Since glass must have been dissolving, this implies that fluid-mineral reactions were buffering silica concentration.

The low concentration of $\mathrm{SiO}_{2}$ in the input solution lead to aggressive attack by the fluid. This is aided by the high chloride concentrations promoting cation solubility. Note that the in situ $\mathrm{pH}$ of $\sim 5.5$ at both temperatures is near-neutral at 350 and $400^{\circ} \mathrm{C} / 500 \mathrm{bar}$. The normalised $\mathrm{SiO}_{2}$ flux is $+1896 \mathrm{mg} \mathrm{kg}^{-1}$ brine for BSW2 $\left(350^{\circ} \mathrm{C}\right)$ and $+1640 \mathrm{mg} \mathrm{kg}^{-1}$ brine for $\mathrm{BSW} 1\left(400^{\circ} \mathrm{C}\right)$ (Table 6.23 ). This indicates that $\sim 16 \%$ of more silica was released at $400^{\circ} \mathrm{C}$ than at $350^{\circ} \mathrm{C}$. This can be explained by higher silicate mineral solubilities and faster kinetics at the higher temperature.

$K, \mathrm{Na}$. The concentrations of $\mathrm{K}$ and $\mathrm{Na}$ in the $\mathrm{SW} 2$ and $\mathrm{SW} 1$ experiments are essentially conservative. The same is true after reaction with basalt in BSW1 and BSW2. This is demonstrated by their overall steady concentrations over most of the experiment and values similar to the input concentration (Fig. 6.31). Potassium does show initial high peaks at the beginning of the seawater experiments; however, the same high values are observed in BW1, BGB1, and BGB2 experiments. These high peaks are attributed to rapid $\mathrm{K}$ release from glass leading to supersaturation of secondary mineral phases when, once nucleated, quickly bring $\mathrm{K}$ concentration back down to input values.

The normalised flux for $\mathrm{K}\left(+15 \mathrm{mg} \mathrm{kg}^{-1}\right.$ brine at $350^{\circ} \mathrm{C}$ and $-3.6 \mathrm{mg} \mathrm{kg}^{-1}$ brine at $\left.400^{\circ} \mathrm{C}\right)$ and $\mathrm{Na}\left(-99 \mathrm{mg} \mathrm{kg}^{-1}\right.$ brine at $350^{\circ} \mathrm{C}$ and $-34 \mathrm{mg} \mathrm{kg}^{-1}$ brine at $\left.400^{\circ} \mathrm{C}\right)$ are relatively small compared to their total concentrations (Table 6.23) and are likely within the uncertainty of the calculation. $\mathrm{Na}$ was measured in the smectite but $\mathrm{Na}$ can also be sourced from plagioclase and overall there was no significant change in concentration.

$A l$. Aluminium concentrations in the effluent samples from the SW experiments are very low $\left(<0.02 \mathrm{mmol} \mathrm{kg}{ }^{-1}\right.$, Fig. 5.3 and 5.10). Aluminium in these experiments is derived from the $\mathrm{ZrO}_{2}$ beads in which $\mathrm{Al}$ is an impurity. In BSW1 and $\mathrm{BSW} 2$, the same low concentrations are encountered (Fig. 6.1 and 6.17). This indicates that despite the high concentrations of $\mathrm{Al}$ in the unreacted basalt, $\mathrm{Al}$ was essentially immobile during fluid-rock interaction. 
Figure 6.31. $\mathrm{pH}$ and major element concentrations in the seawater-only and seawater-basalt experiments at each temperature.
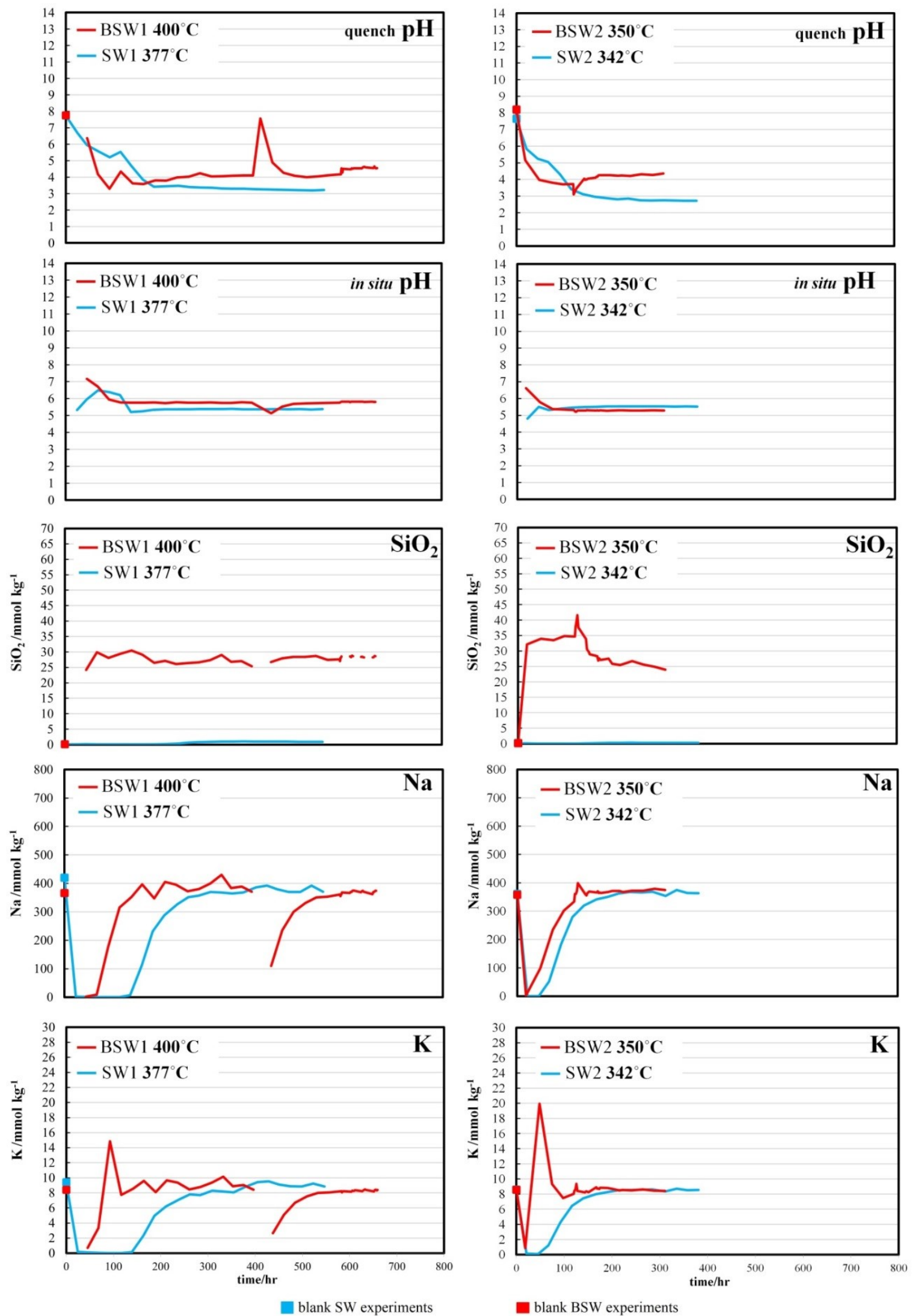

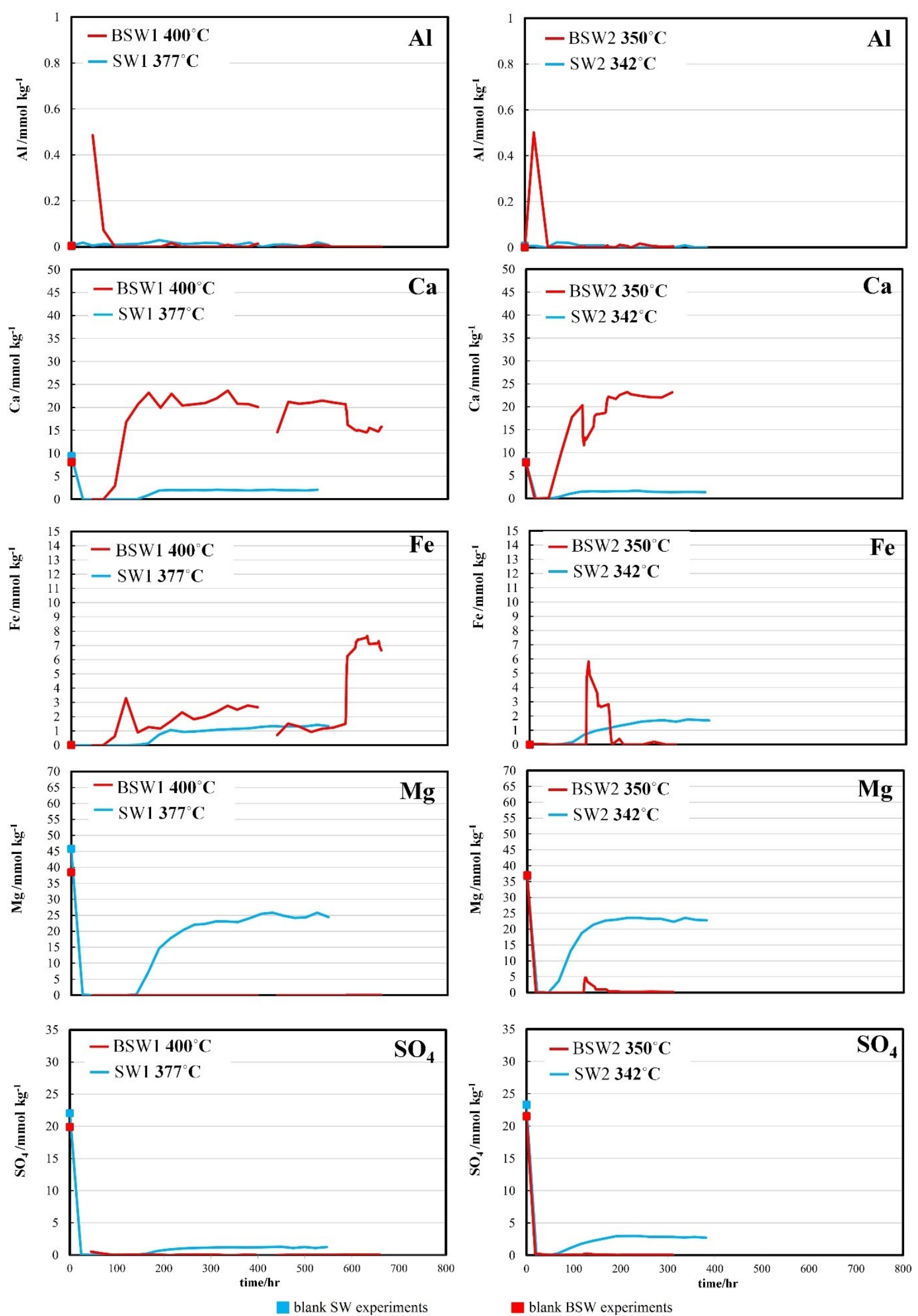


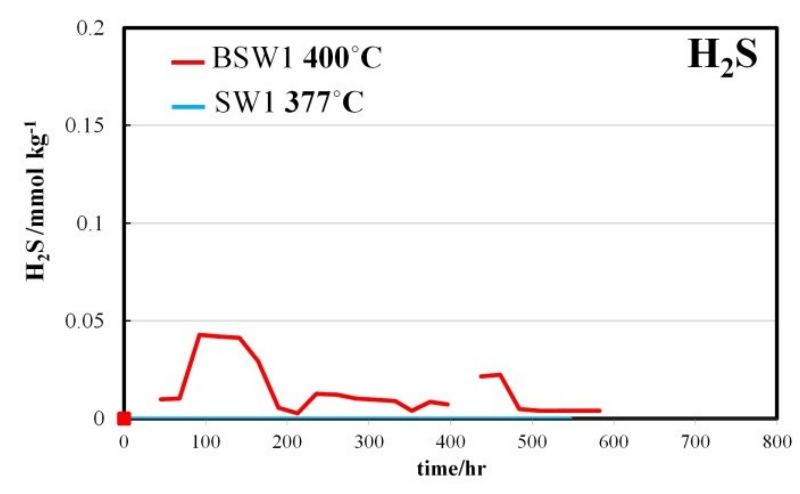

blank SW experiments

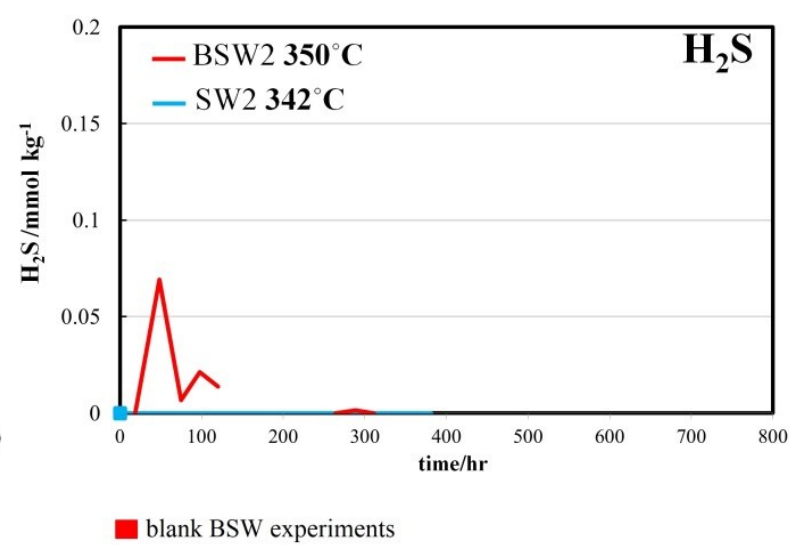

blank BSW experiments

Ca. Calcium in the SW experiments is what remains in the seawater after anhydrite precipitation in the Preheater. These concentrations are assumed to be the input concentrations for the BSW experiments. At $350^{\circ} \mathrm{C}$ and $400^{\circ} \mathrm{C}$, effluent Ca concentrations are similar at $1.4-2.1 \mathrm{mmol} \mathrm{kg}^{-1}$ (Fig. 6.31). In contrast, steady state Ca concentrations in the BSW experiments are significantly higher at $21-23 \mathrm{mmol} \mathrm{kg}^{-1}$. This $\mathrm{Ca}$ is derived from the dissolution of clinopyroxene and plagioclase. Anhydrite was identified both in BSW1 and BSW2. The normalised flux for Ca reveals a significant transfer of this element to the fluid (+592 $\mathrm{mg} \mathrm{kg}^{-1}$ brine in BSW1, and $+630 \mathrm{mg} \mathrm{kg}^{-1}$ brine in BSW2).

Table 6.23. Total input mass (mg) and integrated elemental fluxes (mg) for selected components for BSW2 and BSW1.

\begin{tabular}{|c|c|c|c|c|c|c|c|c|}
\hline $\begin{array}{c}\text { BSW1 } \\
\left(400^{\circ} \mathrm{C} / 488 \text { bar }\right)\end{array}$ & $\mathrm{SiO}_{2}$ & $\mathbf{K}$ & $\mathrm{SO}_{4}$ & $\mathbf{H}_{2} \mathrm{~S}$ & $\mathbf{C a}$ & $\mathbf{N a}$ & Mg & Fe \\
\hline $\begin{array}{l}\text { Input composition }\left(\mathrm{mg} \mathrm{kg}^{-1}\right) \\
\text { based on SW1 }\end{array}$ & 54 & 328 & 115 & - & 84 & 8276 & 561 & 73 \\
\hline $\begin{array}{c}\text { Total input mass (mg) } \\
\text { (based on } 1.48 \mathrm{~kg} \text { total brine) }\end{array}$ & 80 & 487 & 171 & - & 125 & 12278 & 832 & 108 \\
\hline $\begin{array}{l}\text { Total integrated elemental flux (mg) } \\
\quad \text { (over the entire experiment) }\end{array}$ & +2427 & -5.4 & -143 & +0.34 & +876 & -51 & -657 & +317 \\
\hline Normalised elemental flux $\left(\mathrm{mg} \mathrm{kg}^{-1}\right)$ & +1640 & -3.6 & -97 & +0.23 & +592 & -34 & -444 & +214 \\
\hline $\begin{array}{c}\text { BSW2 } \\
\left(350^{\circ} \mathrm{C} / 488 \text { bar }\right)\end{array}$ & $\mathrm{SiO}_{2}$ & $\mathbf{K}$ & $\mathrm{SO}_{4}$ & $\mathrm{H}_{2} \mathrm{~S}$ & $\mathbf{C a}$ & $\mathbf{N a}$ & Mg & $\mathbf{F e}$ \\
\hline $\begin{array}{l}\text { Input composition }\left(\mathrm{mg} \mathrm{kg}^{-1}\right) \\
\text { based on SW2 }\end{array}$ & 15 & 328 & 259 & - & 56 & 8276 & 524 & 95 \\
\hline $\begin{array}{c}\text { Total input mass (mg) } \\
\text { (based on } 1.15 \mathrm{~kg} \text { total brine) }\end{array}$ & 17 & 377 & 298 & - & 64 & 9512 & 602 & 109 \\
\hline $\begin{array}{l}\text { Total integrated elemental flux (mg) } \\
\quad \text { (over the entire experiment) }\end{array}$ & +2180 & +17 & -285 & +0.13 & +725 & -114 & -537 & +159 \\
\hline Normalised elemental flux $\left(\mathrm{mg} \mathrm{kg}^{-1}\right)$ & +1896 & +15 & -248 & +0.11 & +630 & -99 & -467 & +138 \\
\hline
\end{tabular}


$F e$. Final Fe concentrations in the effluent samples from the SW experiments are $1.3-$ $1.7 \mathrm{mmol} \mathrm{kg}^{-1}$ (Fig. 6.31). This Fe is derived from the $\mathrm{ZrO}_{2}$ beads. After reaction with basalt, Fe concentrations are irregular but in general higher at $400^{\circ} \mathrm{C}$. Iron concentration also shows a dependence on flow rate with significant increases at $10,7.5$ and $5 \mathrm{ml} \mathrm{hr}^{-1}$. At $350^{\circ} \mathrm{C}, \mathrm{Fe}$ concentration is near detection limit at $1 \mathrm{ml} \mathrm{hr}^{-1}$ while at higher flow rate, Fe increases in concentration. The source of Fe is the dissolution of olivine and clinopyroxene with the latter likely dominating Fe transfer to the fluid as there is considerably more clinopyroxene in the rock. SEM-EDS analysis shows that some Fe is fixed chlorite and smectite, however, the normalised flux for Fe (Table 6.23) shows significant transfers of this element to solution (+214 $\mathrm{mg} \mathrm{kg}^{-1}$ brine in BSW1, and $+138 \mathrm{mg} \mathrm{kg}^{-1}$ brine in BSW2). The higher Fe flux at $400^{\circ} \mathrm{C}$ is due to higher silicate mineral solubility and faster dissolution kinetics. It is evident that although some Fe is fixed in secondary phases, the net flux of Fe is to the fluid.

Mg. Magnesium shows the most significant difference between the SW and BSW experiments. The large decrease in $\mathrm{Mg}$ concentration in the SW experiments is explained by the precipitation of caminite and brucite in the Preheater (Chapter 5). However, a high concentration is still available in the fluid exiting the Preheater $\left(23-25 \mathrm{mmol} \mathrm{kg}^{-1}\right)$. After reaction with the basalt, $\mathrm{Mg}$ concentration decreases to very low values $\left(0.003 \mathrm{mmol} \mathrm{kg}{ }^{-1}\right.$ at

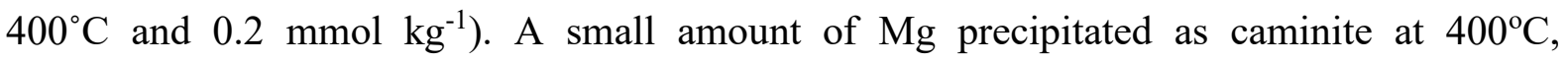
however, at $350^{\circ} \mathrm{C}$, caminite was not identified. The majority of $\mathrm{Mg}$ was fixed in chlorite as evidenced by the high $\mathrm{MgO}$ concentrations in the XRD analyses of the lower portions from the Reactor. Some $\mathrm{Mg}$ was also fixed in smectite. The fixation of $\mathrm{Mg}$ through fluid-rock interaction is emphasised by the large negative normalised fluxes of $\mathrm{Mg}$ to the fluid (-444 $\mathrm{mg}$ $\mathrm{kg}^{-1}$ brine at $400^{\circ} \mathrm{C}$ and $-537 \mathrm{mg} \mathrm{kg}^{-1}$ at $350^{\circ} \mathrm{C}$ ).

$\mathrm{SO}_{4}$. The significant decrease of $\mathrm{SO}_{4}$ in the $\mathrm{SW}$ experiments is also attributed to the precipitation of anhydrite and caminite within the Preheater (Chapter 5). The output concentration differs between temperatures with $1.2 \mathrm{mmol} \mathrm{kg}^{-1}$ at $400^{\circ} \mathrm{C}$ and $2.7 \mathrm{mmol} \mathrm{kg}^{-1}$ at $350^{\circ} \mathrm{C}$. The difference is explained by the lower solubility of anhydrite and caminite at the higher temperature (Fig. 5.16). The $\mathrm{SO}_{4}$ concentration in the effluent samples from the BSW experiments are even lower at $0.05-0.06 \mathrm{mmol} \mathrm{kg}^{-1}$. This is due to further sulfate mineral precipitation in the basalt. The normalised $\mathrm{SO}_{4}$ flux shows negative transfers of $-97 \mathrm{mg} \mathrm{kg}^{-1}$ brine and $-248 \mathrm{mg} \mathrm{kg}^{-1}$ brine at $400^{\circ} \mathrm{C}$ and $350^{\circ} \mathrm{C}$, respectively. The lower transfer of $\mathrm{SO}_{4}$ to the rock at $400^{\circ} \mathrm{C}$ can be explained by the lower input $\mathrm{SO}_{4}$ concentration at this temperature (Table 6.21 and 6.22). 
$\mathrm{H}_{2} \mathrm{~S}$. During the SW experiments, there are no measurable concentrations of $\mathrm{H}_{2} \mathrm{~S}$ in solution. In the BSW experiments, there is a small positive normalised flux in BSW2 $(+0.11$ $\mathrm{mg} \mathrm{kg}{ }^{-1}$ brine) and BSW1 $\left(+0.23 \mathrm{mg} \mathrm{kg}^{-1}\right.$ brine, Table 6.23). The highest values of $\mathrm{H}_{2} \mathrm{~S}$ are observed in first 3 - 4 samples after $\mathrm{T}$ shift (Fig. 6.31). This is attributed to rapid glass dissolution after temperature shift. The lower flux of $\mathrm{H}_{2} \mathrm{~S}$ at $350^{\circ} \mathrm{C}$ is perhaps due to greater sulfide mineral precipitation at this temperature.

\section{Trace elements}

The data sets available in the literature on trace elements mobility (i.e. $\mathrm{Mn}, \mathrm{Cu}, \mathrm{Zn}$, Li) are found in laboratory investigations conducted at temperatures and pressures typical of the reaction zone using seawater batch-type reactors (Mottl et al., 1979; Seewald and Seyfried, 1990; Seyfried and Janecky, 1985). In this study, trace element mobility was monitored under dynamic conditions and at different flow rates but at similar temperaturepressure conditions of previous simulations. A comparison between trace elements concentrations measured from this study, and those reported from previous experimental investigations and in situ at vents, is shown in Figure 6.24.

The $\mathrm{BW}$ experiments show that at least $\mathrm{Cu}, \mathrm{Co}$, and $\mathrm{Mo}$ are released from the volcanic glass at $350^{\circ} \mathrm{C}$ due to the dissolution of sulfide inclusions. However, in the BGB and BSW experiments, because of the high concentrations of $\mathrm{SiO}_{2}$ in the input and effluent samples, it is difficult to relate trace metal concentrations with glass dissolution.

The results do show that the mobility of trace elements, both at $350^{\circ} \mathrm{C}(\mathrm{BSW} 2)$ and $400^{\circ} \mathrm{C}$ (BSW1), is very low in the experiments. Only Mn shows significant concentrations at both temperatures while $\mathrm{Zn}$ appears clearly more mobile than $\mathrm{Cu}$. The low concentrations of $\mathrm{H}_{2} \mathrm{~S}$ in solution do not permit any correlation between trace elements and sulfide mineral. Changes in flow rate did not have any significant influence on their mobility at both temperatures.

Comparing the results from previous studies (Table 6.24) and those of this study show some similarities and significant differences. In particular:

1. Room temperature $\mathrm{pH}$ values from previous studies and vents are predominantly between 3 and 4 while those from this study are typically between 4 and 4.5 . They are comparable between the previous experimental studies, vents and this study.

2. $\mathrm{H}_{2} \mathrm{~S}$ concentrations are much higher in previous batch studies and in vent samples.

3. Fe concentrations are in many cases comparable between previous work and this 
study although some vent samples show much higher concentrations.

4. Mn and other trace element concentrations are consistently lower in this study when compared to earlier work and vent samples.

It is proposed here that the lower $\mathrm{H}_{2} \mathrm{~S}, \mathrm{Fe}, \mathrm{Mn}$ and trace element concentrations in this study is due to the very short residence time of the fluid within the rock. At an estimated porosity of $\sim 53 \%$ and a flow rate of $1 \mathrm{ml} \mathrm{hr}^{-1}$, the average residence time of the fluid within the rock, i.e., within the Reactor, is approximately 10 hours. It is possible that some trace elements are being released, however, the concentrations are extremely low due to the short reaction period. This may demonstrate a drawback of flow-through studies when compared to batch experiments. Nevertheless, the results in this study show that vastly more information on major element chemistry, reaction rates, and secondary mineralogy is obtained using a flow-through approach. 
Table 6.24. Comparison of Fe, $\mathrm{Mn}, \mathrm{Zn}, \mathrm{Cu}, \mathrm{Li}\left(\mu \mathrm{mol} \mathrm{kg}{ }^{-1}=\mu \mathrm{m}\right)$ and $\mathrm{H}_{2} \mathrm{~S}\left(\mathrm{mmol} \mathrm{kg}^{-1}=\mathrm{mm}\right)$ concentrations between previous experiments (Mottl et al., 1979, Seyfried and Janecky, 1985, Seewald and Seyfried, 1990), vent fluids (East Pacific Rise, Mid-Atlantic Ridge, Southern Juan de Fuca Ridge) and this study (BSW1 and BSW2) listed by sample number. Table also reports the value of temperature (T), pressure (P), flowrate $\left(\mathrm{ml} \mathrm{hr}^{-1}\right)$, number of samples (samp), $\mathrm{pH}$ at room T and in situ $\mathrm{pH}$. ${ }^{\mathrm{a} V o n}$ Damm et al., 1985 and Campbell et al., 1988; bata by Bowers et al., 1988; 'data by Campbell et al., 1988; data by Von Damm and Bischoff, 1987; ${ }^{\mathrm{e}}$ data by Von Damm et al., 1988; ${ }^{\mathrm{f}}$ data by Campbell et al., 1988. NA: not data available; n.a.: not analysed.

\begin{tabular}{|c|c|c|c|c|c|c|c|c|c|c|c|c|c|c|c|c|c|c|c|c|c|c|c|c|c|c|c|c|c|}
\hline & \multirow[b]{2}{*}{ Rock Type } & \multirow[b]{2}{*}{$\begin{array}{c}\text { T } \\
\left({ }^{\circ} \mathrm{C}\right)\end{array}$} & \multirow[b]{2}{*}{$\begin{array}{c}\mathbf{P} \\
\mathrm{bar}\end{array}$} & \multirow[b]{2}{*}{ samp } & \multirow[b]{2}{*}{$\underset{(\text { room T) }}{\mathbf{p H}}$} & \multirow[b]{2}{*}{$\begin{array}{c}\mathbf{\Sigma} \mathbf{H}_{2} \mathbf{S} \\
(\mathrm{mm})\end{array}$} & \multirow[b]{2}{*}{$\begin{array}{c}\mathbf{F e} \\
(\mu \mathrm{m})\end{array}$} & \multirow[b]{2}{*}{$\begin{array}{l}\text { Mn } \\
(\mu \mathrm{m})\end{array}$} & \multirow[b]{2}{*}{$\begin{array}{c}\mathbf{Z n} \\
(\mu \mathrm{m})\end{array}$} & \multirow[b]{2}{*}{$\begin{array}{c}\mathbf{C u} \\
(\mu \mathrm{m})\end{array}$} & \multirow[b]{2}{*}{$\begin{array}{c}\mathbf{L i} \\
(\mu \mathrm{m})\end{array}$} & & & & W1 (400 & ${ }^{\circ} \mathrm{C} / 488$ & 8 bar) & & & & & & BSW2 & $2\left(350^{\circ} \mathrm{C} / 4\right.$ & 488 bar) & & & & \\
\hline & & & & & & & & & & & & samp & 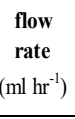 & $\begin{array}{c}\mathbf{p H} \\
20.1 \\
{ }^{\circ} \mathrm{C}\end{array}$ & $\begin{array}{c}\boldsymbol{\Sigma}_{\mathbf{2}} \mathbf{S} \\
(\mathrm{mm})\end{array}$ & $\begin{array}{c}\mathrm{Fe} \\
(\mu \mathrm{m})\end{array}$ & $\begin{array}{c}\text { Mn } \\
(\mu \mathrm{m})\end{array}$ & $\begin{array}{c}\mathbf{Z n} \\
(\mu \mathrm{m})\end{array}$ & $\begin{array}{c}\text { Cu } \\
(\mu \mathrm{m})\end{array}$ & $\begin{array}{c}\mathbf{L i} \\
(\mu \mathrm{m})\end{array}$ & samp & 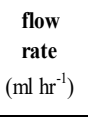 & $\begin{array}{c}\mathbf{p H} \\
20.1^{\circ} \mathrm{C}\end{array}$ & $\begin{array}{l}\boldsymbol{\Sigma} \mathbf{H}_{2} \mathbf{S} \\
(\mathrm{mm})\end{array}$ & $\begin{array}{c}\mathbf{F e} \\
(\mu \mathrm{m})\end{array}$ & $\begin{array}{c}\text { Mn } \\
(\mu \mathrm{m})\end{array}$ & $\begin{array}{c}\mathbf{Z n} \\
(\mu \mathrm{m})\end{array}$ & $\begin{array}{c}\mathrm{Cu} \\
(\mu \mathrm{m})\end{array}$ & $\begin{array}{c}\mathbf{L i} \\
(\mu \mathrm{m})\end{array}$ \\
\hline Mottl et al. (1979) & $\begin{array}{l}\text { crystalline basalt } \\
\text { crystalline basalt }\end{array}$ & $\begin{array}{l}400 \\
400\end{array}$ & $\begin{array}{l}700 \\
700\end{array}$ & $\begin{array}{l}2 \mathrm{~A} \\
2 \mathrm{~F}\end{array}$ & $\begin{array}{l}4.1 \\
3.9\end{array}$ & $\begin{array}{l}5.9 \\
6.2\end{array}$ & 0 & 0 & $\begin{array}{l}\mathrm{NA} \\
\mathrm{NA}\end{array}$ & $\begin{array}{l}\mathrm{NA} \\
\mathrm{NA}\end{array}$ & $\begin{array}{l}\mathrm{NA} \\
\mathrm{NA}\end{array}$ & 1 & 1 & 6.5 & n.a. & n.a. & n.a. & n.a. & n.a. & $\begin{array}{l}\text { n.a. } \\
\end{array}$ & 1 & 1 & 5.2 & $<0.0003$ & 36 & $<0.1$ & $<0.008$ & $8<0.0009$ & 32 \\
\hline & $\begin{array}{l}\text { basalt-glass }>90 \% \\
\text { b }\end{array}$ & 6400 & 700 & $2 \mathrm{~B}$ & 3.9 & $\begin{array}{l}6.2 \\
6.5\end{array}$ & 0 & 0 & $\mathrm{NA}$ & $\mathrm{NA}$ & $\begin{array}{l}\mathrm{NA} \\
\mathrm{NA}\end{array}$ & 2 & 1 & 6.4 & 0.01 & $<1$ & $<0.0001$ & 1117 & 0.2 & 17 & 2 & 1 & 4.0 & 0.07 & $<1$ & $<0.1$ & $<0.008$ & $8<0.0009$ & 165 \\
\hline & crystalline + & & & & & & & & & & & & 1 & 4.2 & 0.01 & 6 & $<0.0001$ & $1 \quad 38$ & 0.01 & 114 & 3 & 1 & 3.8 & 0.01 & $<1$ & 95 & 8 & $<0.0009$ & 36 \\
\hline & glassy: $40 \%$ & 400 & 700 & $2 \mathrm{C}$ & 3.6 & 7.3 & 0 & 0 & $\mathrm{NA}$ & $\mathrm{NA}$ & $\mathrm{NA}$ & 4 & 1 & 3.3 & 0.04 & 624 & 204 & 56 & 0.4 & 72 & 4 & 1 & 3.7 & 0.02 & $<1$ & 272 & $<0.008$ & $8<0.0009$ & 36 \\
\hline & crystalline + & & & & & & & & & & & 5 & 1 & 4.3 & 0.04 & 3297 & 409 & 37 & 0.3 & 50 & 5 & 1 & 3.7 & 0.01 & $<1$ & 334 & 12 & $<0.0009$ & 38 \\
\hline & glassy: $40 \%$ & 400 & 700 & $2 \mathrm{D}$ & 3.8 & 6.8 & 0 & 0 & NA & $\mathrm{NA}$ & $\mathrm{NA}$ & 6 & 1 & 3.6 & 0.04 & 892 & 524 & 22 & n.a. & 46 & 6 & 10 & 3.1 & n.a. & 4606 & 570 & 170 & $<0.0009$ & 25 \\
\hline & $\begin{array}{l}\text { crystalline + } \\
\text { crystan }\end{array}$ & & & & & & & & & & & 7 & 1 & 3.6 & 0.03 & 1271 & 564 & 24 & $<0.0009$ & 50 & 7 & 10 & 3.2 & n.a. & 5282 & 387 & 39 & 3 & 29 \\
\hline & $\begin{array}{l}\text { crystalline + } \\
\text { glassy: } 40 \%\end{array}$ & 400 & 700 & $2 \mathrm{E}$ & 3.85 & 7 & 0 & 0 & NA & $\mathrm{NA}$ & $\mathrm{NA}$ & 8 & 1 & 3.8 & 0.01 & 1168 & 475 & 20 & 0.02 & 39 & 8 & 10 & 3.4 & n.a. & 5829 & 423 & 47 & $<0.0009$ & 30 \\
\hline Seyfried and Janecky (1985) & EPR-crystalline & 350 & 400 & 1 & 4.8 & 6.8 & 192 & & 16 & 0.6 & $\mathrm{NA}$ & 9 & 1 & 3.8 & 0.003 & 1706 & 540 & 22 & $<0.0009$ & 42 & 9 & 10 & 3.5 & $<0.0003$ & 4910 & 388 & 40 & $<0.0009$ & 33 \\
\hline & & & & 2 & 4.4 & 6.2 & 247 & 167 & 19 & 0.9 & & 10 & 1 & 4 & 0.01 & 2298 & 483 & 17 & 0.1 & 35 & 10 & 10 & 4.1 & n.a. & 3617 & 421 & 31 & 35 & 27 \\
\hline & EPR-crystalline & 375 & 400 & 1 & 3.8 & $\begin{array}{l}0.2 \\
11.5\end{array}$ & 1754 & 451 & 37 & 2.5 & NA & 11 & 1 & 4 & 0.01 & 1815 & 439 & 26 & 0.1 & 39 & 11 & 10 & 4.0 & n.a. & 2687 & 441 & 29 & $<0.0009$ & 36 \\
\hline & 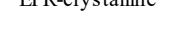 & (3/J & & 2 & $\begin{array}{l}3.0 \\
3.7\end{array}$ & 12.9 & 2328 & $\begin{array}{l}431 \\
688\end{array}$ & 92 & 2.2 & NA & 12 & 1 & 4.2 & 0.01 & 1991 & 472 & $<0.008$ & n.a. & 33 & 12 & 10 & 4.0 & n.a. & 2743 & 436 & 30 & $<0.0009$ & 30 \\
\hline & EPR-crystalline & 400 & 400 & 1 & 3.3 & 17.7 & 8684 & 1202 & 121 & 22 & NA & 13 & 1 & 4 & 0.01 & 2329 & 495 & 3 & 0.2 & 39 & 13 & 10 & 4.0 & n.a. & 2725 & 439 & 10 & $<0.0009$ & 33 \\
\hline & & & & 2 & 3.6 & 9 & 8326 & 1256 & 43 & 7 & $\mathrm{NA}$ & 14 & 1 & 4.1 & 0.01 & 2764 & 533 & 9 & 0.1 & 43 & 14 & 10 & 4.1 & $<0.0003$ & 2643 & 431 & 10 & $<0.0009$ & 35 \\
\hline & EPR-crystalline & 425 & 400 & 1 & 2.8 & 30 & 25067 & 3677 & 45 & 0.8 & $\mathrm{NA}$ & 15 & 1 & 4.1 & 0.004 & 2496 & 468 & $<0.008$ & 0.2 & 32 & 15 & 10 & 4.1 & n.a. & 2831 & 423 & 18 & 6 & 25 \\
\hline & & & & 2 & 2.7 & 30 & 26947 & 4400 & 32 & 0.6 & $\mathrm{NA}$ & 16 & 1 & 4.1 & 0.01 & 2783 & 456 & 21 & 0.1 & 35 & 16 & 5 & 4.2 & n.a. & 2152 & 415 & 15 & $<0.0009$ & 25 \\
\hline & & & & 3 & 2.7 & 14 & 30117 & 4091 & 3.5 & 0.6 & $\mathrm{NA}$ & 17 & 1 & 4.1 & 0.01 & 2661 & 467 & n.a. & n.a. & 45 & 17 & 5 & 4.2 & n.a. & 1013 & 492 & 72 & $<0.0009$ & 30 \\
\hline & JDF-Basalt glass & 400 & 375 & 1 & 3.7 & 10.9 & 2468 & 638 & 14 & 0.5 & NA & 19 & 1 & 7.6 & n.a. & n.a. & n.a. & n.a. & n.a. & n.a. & 18 & 5 & 4.2 & n.a. & 345 & 431 & 100 & $<0.0009$ & 32 \\
\hline & 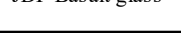 & & 我 & 2 & 3.5 & 11.8 & 2613 & 655 & $\mathrm{NA}$ & 1.6 & $\mathrm{NA}$ & 20 & 1 & 4.9 & 0.02 & 700 & 100 & 2.7 & $<0.0009$ & n.a. & 19 & 5 & 4.3 & $<0.0003$ & 1 & 412 & 76 & $<0.0009$ & 29 \\
\hline Seewald and Seyfried (1990) & crystalline basalt & 400 & 400 & & 3.2 & 17.5 & 3975 & 1005 & 214 & 31 & 274 & 21 & 1 & 4.3 & 0.02 & 1500 & 200 & 3 & $<0.0009$ & n.a. & 20 & 5 & 4.3 & n.a. & 406 & 463 & 24 & 4 & 32 \\
\hline & crystalline basalt & 350 & 400 & & 4.8 & 5 & 154 & 118 & 28 & 6 & 317 & 22 & 1 & 4.1 & 0.005 & 1300 & 200 & 47 & 0.1 & n.a. & 21 & 2.5 & 4.3 & 0.003 & $<1$ & 312 & 76 & $<0.0009$ & 36 \\
\hline & & & & & & & & & & & & 23 & 1 & 4 & 0.004 & 900 & 200 & 123 & $<0.0009$ & n.a. & 22 & 2.5 & 4.2 & n.a. & $<1$ & 389 & 91 & $<0.0009$ & 31 \\
\hline East Pacific Rise, $21^{\circ} N^{a}$ & & & & & pitu & & & & & & & 24 & 1 & 4 & 0.004 & 1100 & 400 & 68 & $<0.0009$ & n.a. & 23 & 2.5 & 4.2 & 0.002 & $<1$ & 446 & 42 & $<0.0009$ & 30 \\
\hline & & & & & situ & & & & & & & 25 & 1.5 & 4.1 & 0.003 & 1236 & 546 & n.a. & n.a. & 34 & 24 & 2.5 & 4.2 & n.a. & $<1$ & 497 & 78 & $<0.0009$ & 30 \\
\hline $\operatorname{NGS(1979)}$ & & 350 & & & $\mathrm{NA}$ & NA & 1491 & 1030 & NA & $\mathrm{NA}$ & 997 & 26 & 1.5 & 4.2 & 0.002 & 1487 & 508 & n.a. & n.a. & 23 & 25 & 2.5 & 4.3 & $<0.0003$ & 194 & 476 & 30 & 1 & 32 \\
\hline & & 273 & & & 3.8 & 6.6 & 871 & 1002 & 40 & $<2$ & 1033 & 27 & 10 & 4.5 & n.a. & 2017 & 408 & 59 & $<0.0009$ & 29 & 26 & 1 & 4.3 & 0.001 & $<1$ & 323 & 37 & $<0.0009$ & 30 \\
\hline $\operatorname{NGS}(15$ & & 260 & & & $\mathrm{NA}$ & 6.8 & 646 & 864 & NA & $\mathrm{NA}$ & 1091 & 28 & 10 & 4.3 & $\begin{array}{l}\text { n.t.a. } \\
\text { n.a. }\end{array}$ & 4654 & 421 & 9 & n.a. & 24 & 27 & 1 & 4.4 & 0.001 & $<1$ & 317 & 63 & $<00009$ & $\begin{array}{l}30 \\
35\end{array}$ \\
\hline (1979) & & 350 & & & $\mathrm{NA}$ & NA & NA & NA & NA & $\mathrm{NA}$ & 896 & 28 & 10 & 4.3 & n.a. & $\begin{array}{l}4654 \\
5612\end{array}$ & $\begin{array}{l}421 \\
378\end{array}$ & 9 & n.a. & 24 & 27 & 1 & 4.4 & n.a. & $<1$ & 317 & 63 & $<0.0009$ & 35 \\
\hline $\mathrm{OB}$ & & 351 & & & 3.4 & 7.3 & 1664 & 960 & 106 & 35 & 891 & 29 & 10 & 4.3 & n.a. & 5612 & 378 & 11 & n.a. & 21 & & & & & & & & & \\
\hline OBS(19 & & 340 & & & 3.4 & 7.6 & 1530 & 1024 & NA & $\mathrm{NA}$ & 92 & 30 & 10 & 4.5 & n.a. & 6263 & 341 & 12 & $<0.0009$ & 25 & & & & & & & & & \\
\hline SW(1979) & & 350 & & & NA & NA & NA & NA & NA & $\mathrm{NA}$ & 956 & 31 & 10 & 4.5 & 0.01 & 6829 & 269 & ila. & n.a. & 21 & & & & & & & & & \\
\hline SW(1981) & & $346 / 355^{\mathbf{e}}$ & & & 3.6 & 7.4 & 750 & 699 & 89 & 9.7 & 899 & 32 & 10 & 4.5 & n.a. & 7265 & 256 & $<0.008$ & $<0.0009$ & 21 & & & & & & & & & \\
\hline & & & & & & & & & & & & & & 4.5 & n.a. & 7286 & 254 & $<0.008$ & $<0.0009$ & 22 & & & & & & & & & \\
\hline SW(1985) & & $335^{1}$ & & & 4 & 8.1 & 660 & 763 & NA & $\mathrm{NA}$ & 969 & 34 & 10 & 4.5 & n.a. & 7430 & 256 & $<0.008$ & $<0.0009$ & 21 & & & & & & & & & \\
\hline HG(1981) & & 351 & & & 3.3 & 8.4 & 2429 & 878 & 104 & 44 & 1322 & 35 & 10 & 4.5 & 11. & 7409 & 256 & 3 & $<0.0009$ & 21 & & & & & & & & & \\
\hline $\mathrm{HG}(1985)$ & & 332 & & & 3.6 & 7.9 & 1308 & 640 & NA & $\mathrm{NA}$ & 1448 & 36 & 10 & 4.5 & 0.03 & 7553 & 244 & n.a. & n.a. & 20 & & & & & & & & & \\
\hline Fast Pacific Rise $11^{\circ}-13^{\circ} \mathbf{v}^{\mathrm{b}}$ & & & & & & & & & & & & 37 & 7.5 & 4.6 & n.a. & 7663 & 250 & 5 & 0.2 & 20 & & & & & & & & & \\
\hline & & & & & & & & & & & & 38 & 7.5 & 4.6 & n.a. & 7301 & 254 & 4 & 0.2 & 18 & & & & & & & & & \\
\hline Vent 4 & & 347 & & & 3.1 & 8 & 5271 & 766 & 105 & $\mathrm{NA}$ & 884 & 39 & 7.5 & 4.6 & n.a. & 7119 & 250 & 3 & 0.5 & 28 & & & & & & & & & \\
\hline Mid-Atlantic Ridge ${ }^{c}$ & & & & & & & & & & & & 40 & 7.5 & 4.6 & n.a. & 7091 & 248 & $<0.008$ & $<0.0009$ & 32 & & & & & & & & & \\
\hline MARK-1 & & 350 & & & 3.9 & 5.9 & 2180 & 491 & 50 & 17 & 84 & 41 & 7.5 & 4.6 & 0.02 & 7155 & 234 & n.a. & n.a. & & & & & & & & & & \\
\hline MARK-2 & & 335 & & & 3.7 & 5.9 & 1832 & 493 & 47 & 10 & 849 & 42 & 5 & 4.7 & n.a. & 7303 & 235 & 11 & & & & & & & & & & & \\
\hline Southern Juande Fuca Ridop d & & & & & & & & & & & & 43 & 5 & 4.6 & n.a. & 6912 & 248 & 9 & $<0.0009$ & 28 & & & & & & & & & \\
\hline Southern Juan de Fuca Ridge & & & & & & & & & & & & 44 & 5 & 4.5 & n.a. & 157 & 251 & 41 & $<0.0009$ & 30 & & & & & & & & & \\
\hline Plume & & 224 & & & 3.2 & 3.5 & 18700 & 3590 & 900 & $<2$ & 1718 & 45 & 5 & 4.6 & n.a. & 6653 & 247 & 13 & $<0.0009$ & 29 & & & & & & & & & \\
\hline
\end{tabular}




\subsubsection{Mass exchange and alteration fronts}

Tables 6.3 and 6.15 show the correlation coefficients between major element concentrations at different levels in the Reactor. These correlations are indicative of related mass changes during alteration. It is also important to take into consideration the overall mass change of the rock to correctly interpret individual component changes. This calculation can be made using an element that is assumed (or demonstrated) to be immobile during the alteration process. Typically, elements such as $\mathrm{Al}, \mathrm{Ti}$, or $\mathrm{Zr}$ are chosen as the immobile component (Finlow-Bates and Stumpfl, 1981; Mathieu, 2018; Petersen, 1983). In this study, most major elements display mobility in that measurable concentrations were detected in the effluents. Ti analyses in the fluid are not available, however, at both 350 and $400^{\circ} \mathrm{C}$, there is no detectable $\mathrm{Al}$ in most effluent samples. This justifies the assumption of overall immobility of $\mathrm{Al}$ during fluid-rock interaction. Note, however, that it must also be assumed that $\mathrm{Al}$ was not mobile within the Reactor, i.e., it did not move between the divided portions of run products.

Based on these assumptions, the individual mass changes for the major elements can be calculated using the equation:

$$
\Delta M_{i}=\left[\frac{C_{A l_{u}}}{C_{A l_{a}}} C_{a_{i}}\right]-C_{u_{i}}
$$

where $\Delta M_{i}$ is the mass change of component $i$ in $\mathrm{g} 100 \mathrm{~g}^{-1}$ rock, $C_{A l_{u}}$ is the $\mathrm{Al}_{2} \mathrm{O}_{3}$ concentration in the unreacted rock, $C_{A l_{a}}$ is the $\mathrm{Al}_{2} \mathrm{O}_{3}$ concentration in the reacted rock, $C_{a_{i}}$ and $C_{u_{i}}$ are the measured concentrations of component $i$ in the altered and unaltered rock, respectively. The $\mathrm{Al}_{2} \mathrm{O}_{3}$ concentration in the unreacted basalt is $13.41 \%$ (Table 2.2). Table 6.25 lists the mass changes calculated for both experiments using $\mathrm{Al}_{2} \mathrm{O}_{3}$ as the immobile element. Figure 6.32 plots these results versus position in the Reactor (bottom to top).

In both experiments there is a uniform loss of $\mathrm{K}_{2} \mathrm{O}\left(\sim 0.2 \mathrm{~g} 100 \mathrm{~g}^{-1}\right.$ rock $)$ in all portions examined, which is $80 \%$ of the original basalt concentration of $0.25 \%$ (Table 2.2 ). This loss is attributed to the complete removal of volcanic glass from the rock. It implies that an alteration front of glass dissolution passed completely through the Reactor at both temperatures. Note that the $350^{\circ} \mathrm{C}$ experiment lasted only two weeks, thus complete glass dissolution was accomplished in this time period. This is supported by the BW1, BW2, and BGB1 experiments where the passage of this front is shown by a sharp decrease in $\mathrm{SiO}_{2}$ concentrations after about two weeks. 
Table 6.25. Calculated mass changes ( $\mathrm{g} 100 \mathrm{~g}^{-1}$ rock) for each portion of rock from the $\mathrm{BSW} 1$ and $\mathrm{BSW}_{2}$ experiments assuming $\mathrm{Al}_{2} \mathrm{O}_{3}$ immobility.

\begin{tabular}{|c|c|c|c|c|c|c|c|c|c|c|c|c|}
\hline \multicolumn{13}{|c|}{$\begin{array}{c}\text { BSW1 } \\
\left(400^{\circ} \mathrm{C} / 488 \text { bar }\right)\end{array}$} \\
\hline \multicolumn{2}{|c|}{ Portions } & $\mathrm{Na}_{2} \mathrm{O}$ & $\mathrm{CaO}$ & MgO & $\mathrm{SiO}_{2}$ & $\mathrm{TiO}_{2}$ & $\mathbf{A l}_{2} \mathbf{O}_{3}$ & $\mathrm{Fe}_{2} \mathrm{O}_{3}$ & MnO & $\mathbf{K}_{2} \mathrm{O}$ & $\mathbf{P}_{2} \mathbf{O}_{5}$ & $\mathbf{S}_{(\mathbf{T})}$ \\
\hline \multirow[t]{3}{*}{ Top } & 7 & -0.03 & -0.98 & -1.19 & -5.69 & -0.77 & 0.00 & -3.69 & -0.12 & -0.19 & 0.07 & 0.00 \\
\hline & 4 & -1.20 & -7.62 & 14.11 & -13.95 & -0.48 & 0.00 & -9.19 & -0.23 & -0.20 & 0.03 & 0.75 \\
\hline & $2-3$ & -2.16 & -9.22 & 15.64 & -21.56 & -0.28 & 0.00 & -8.18 & -0.23 & -0.23 & -0.10 & 0.54 \\
\hline Bottom & 1 & -1.74 & -7.24 & 15.79 & -11.83 & -0.23 & 0.00 & -7.70 & -0.22 & -0.22 & 0.02 & 0.06 \\
\hline \multicolumn{2}{|c|}{ Unreacted } & 0.00 & 0.00 & 0.00 & 0.00 & 0.00 & 0.00 & 0.00 & 0.00 & 0.00 & 0.00 & 0.00 \\
\hline \multicolumn{13}{|c|}{$\begin{array}{c}\text { BSW2 } \\
\left(350^{\circ} \mathrm{C} / 488 \text { bar }\right)\end{array}$} \\
\hline \multicolumn{2}{|c|}{ Portions } & $\mathrm{Na}_{2} \mathrm{O}$ & $\mathrm{CaO}$ & MgO & $\mathrm{SiO}_{2}$ & $\mathrm{TiO}_{2}$ & $\mathbf{A l}_{2} \mathbf{O}_{3}$ & $\mathrm{Fe}_{2} \mathrm{O}_{3}$ & MnO & $\mathbf{K}_{2} \mathbf{O}$ & $\mathrm{P}_{2} \mathrm{O}_{5}$ & $\mathbf{S}_{(\mathbf{T})}$ \\
\hline \multirow[t]{2}{*}{ Top } & 4.5 & -0.29 & -1.78 & -0.96 & -9.16 & -0.87 & 0.00 & -4.19 & -0.12 & -0.20 & -0.06 & 0.01 \\
\hline & $2-3$ & -0.99 & -5.90 & 10.33 & -6.04 & -0.56 & 0.00 & -3.84 & -0.20 & -0.20 & -0.05 & 0.52 \\
\hline Bottom & 1 & -1.94 & -5.05 & 15.64 & -14.62 & -0.36 & 0.00 & -6.20 & -0.21 & -0.22 & -0.09 & 1.95 \\
\hline \multicolumn{2}{|c|}{ Unreacted } & 0.00 & 0.00 & 0.00 & 0.00 & 0.00 & 0.00 & 0.00 & 0.00 & 0.00 & 0.00 & 0.00 \\
\hline
\end{tabular}

At both temperatures, the rock has gained a significant amount of $\mathrm{MgO}$ of up to $\sim 15 \mathrm{~g}$ $100 \mathrm{~g}^{-1}$ rock. At $400^{\circ} \mathrm{C}$, this amount is gained in Portions $1-3$ while the gain is only $1 \mathrm{~g}$ less in Portion 4. At Portion 7 (top of the Reactor) the mass gain is essentially zero. Portion 2 - 3 coincides with the most intense chloritization of the rock (the rock is essentially a chloritite at

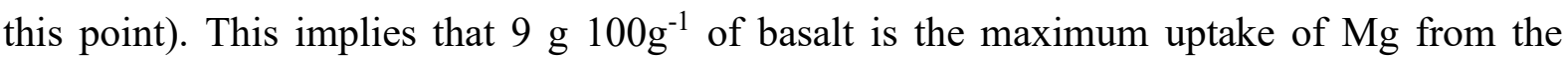
seawater after which $\mathrm{Mg}$ must pass further up the Reactor. This represents a second alteration front: chloritization of the basalt.

At $350^{\circ} \mathrm{C}$, this maximum uptake of $15 \mathrm{~g} \mathrm{MgO}$ is only found in Portion 1 and decreases to zero by Portion 4-5. Chlorite was identified by XRD in all portions of rock but was not observed as present during SEM analysis of Portion $4-5$. Based on the results of the $400^{\circ} \mathrm{C}$ experiment, it is concluded that the chloritization front progressed completely only as far as the bottom portion of the rock at $350^{\circ} \mathrm{C}$. However, it should be noted that this experiment was only two weeks in duration, half that of the $400^{\circ} \mathrm{C}$ experiment. It is also possible the slower reaction kinetics at $350^{\circ} \mathrm{C}$ reduced the rate of progression of chloritization through the Reactor. It can be concluded that $\sim 9 \mathrm{~g}$ is the maximum uptake of $\mathrm{Mg}$ by the basalt at both temperatures.

The chloritization of the basalt is mirrored by significant losses of $\mathrm{SiO}_{2}$ and $\mathrm{CaO}$ and, to a lesser extent, $\mathrm{Na}_{2} \mathrm{O}$ and $\mathrm{Fe}_{2} \mathrm{O}_{3}$. This suggests that initially the major source of $\mathrm{Fe}$ and $\mathrm{SiO}_{2}$ for the formation of chlorite is clinopyroxene (olivine constitutes only a minor component of the basalt). With intense chloritization, plagioclase is also consumed. This is supported by the SEM results in which plagioclase is shown to be more resistant than 
clinopyroxene. In the case of $\mathrm{Al}_{2} \mathrm{O}_{3}$, some is sourced from the dissolution of clinopyroxene but the major source for $\mathrm{Al}_{2} \mathrm{O}_{3}$ is plagioclase.

Figure 6.32. Mass changes ( $100 \mathrm{~g}^{-1}$ rock) of the Portions analysed by XRF plotted against position in Reactor column for the BSW1 (red) and for the BSW2 (yellow). The unreacted basalt composition is shown by black line.
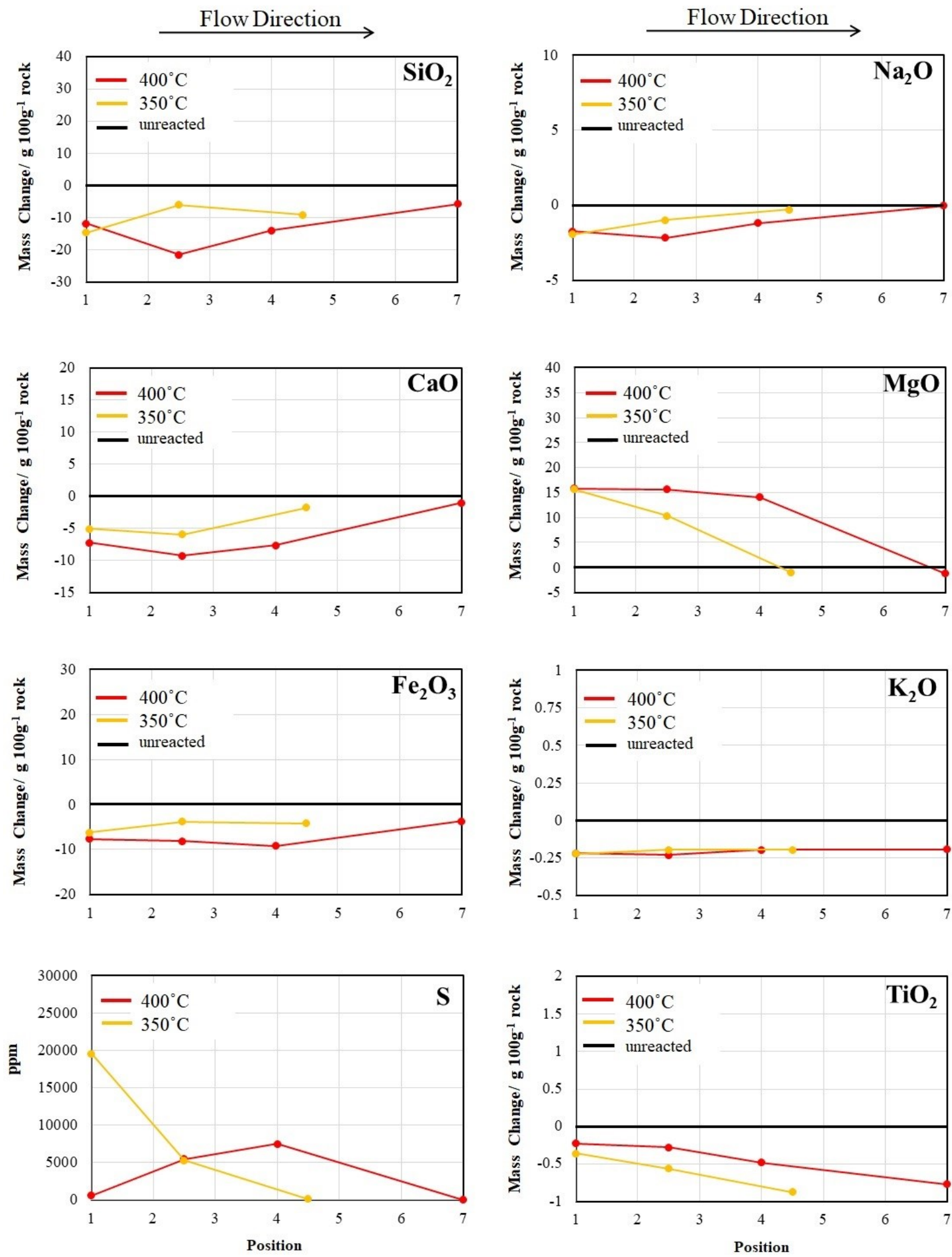
Sulfur is only a trace component in the unreacted basalt. In the reacted basalt, $\mathrm{S}$ is hosted in the secondary minerals anhydrite and caminite as $\mathrm{SO}_{4}$. At $400^{\circ} \mathrm{C}$, S mass change is near zero at the bottom of the Reactor (Portion 1). The S mass change increases in Portion $2-$ 3 and reaches its maximum in Portion 4, halfway up the Reactor. At the top of the Reactor, $\mathrm{S}$ was not detected in the XRF analyses. The concentration of $\mathrm{S}$ in Portion 4 is only about $0.8 \%$ which explains why neither anhydrite nor caminite were detected in the XRD analyses (Table $6.1)$.

At $350^{\circ} \mathrm{C}$, the largest mass increase in $\mathrm{S}\left(2 \mathrm{~g} 100 \mathrm{~g}^{-1}\right.$ rock $)$ is found in the bottom portion of the rock. It then decreases to near essentially zero by Potion $4-5$. This is reflected in the XRD results in which anhydrite was identified in Portion 1 (Table 6.13) due to the much larger $\mathrm{S}$ gain when compared to the $400^{\circ} \mathrm{C}$ experiment. The difference between the experiments in the amount of S added can be explained by the difference in the solution composition entering the Preheater. The input $\mathrm{SO}_{4}$ concentration at $350^{\circ} \mathrm{C}$ is higher $(2.7$ mmol kg-1, Table 6.21) than at $400^{\circ} \mathrm{C}\left(1.2 \mathrm{mmol} \mathrm{kg}^{-1}\right.$, Table 6.22). This means that if most of the $\mathrm{SO}_{4}$ precipitated there should be $\sim 2.25 \mathrm{x}$ more $\mathrm{S}$ at $350^{\circ} \mathrm{C}$.

The results for $\mathrm{S}$ suggest that precipitation of anhydrite was facilitated by fluid-rock interaction where intense chloritization released $\mathrm{Ca}$ thereby inducing anhydrite precipitation. The implication is that this represents a third alteration front: anhydrite precipitation. Because of the shorter experimental time and lower temperature, this front only advanced into the bottom portion of the rock at $350^{\circ} \mathrm{C}$.

It is proposed that once chloritization of the rock is complete, no further $\mathrm{Ca}$ can be released, and incoming seawater must have become undersaturated with respect to anhydrite causing it to dissolve again. This implies that, if the experiment were continued for sufficient time, the peak in anhydrite precipitation would progress through the rock, ahead of the chloritization front. The rock would be completely chloritized, and no anhydrite would be found in the run products.

The presence of hematite in in Portions $2-3$ of BSW1 is explained by the oxidation of least some of the Fe released during intense chloritization. This may be an experimental artefact since, as noted previously, the second aliquot of seawater used to refill the separator was not deoxygenated. 


\subsubsection{The path of fluid-rock interaction}

The path of fluid-rock interaction was examined using activity diagrams based on aqueous solution species' activities. The EqSolvR software package was used to calculate the species' activities and in situ $\mathrm{pH}$ values (Chapter 2).

Activity ratio diagrams were constructed for the respective experimental temperatures $\left(350\right.$ and $\left.400^{\circ} \mathrm{C}\right)$ and a pressure of 488 bar, assuming unit activity of pure mineral phases. There was no period during the experiments where quartz was saturated, thus $\mathrm{SiO}_{2}$ activity for the diagrams must be based on solution chemistry (Chapter $3, \S 3.3 .3$ ). For the experiment at $350^{\circ} \mathrm{C}$, the average $\log \left(a_{\mathrm{SiO}_{2}}\right)$ is -1.52 while for the experiment at $400^{\circ} \mathrm{C}$ the average $\log$ $\left(a_{\mathrm{SiO}_{2}}\right)$ is -1.56 . All the phase diagrams for the BSW1 and BSW2 experiments are provided in Appendix E.

Figure 3.33 shows the activity ratio diagrams for the $\mathrm{MgO}-\mathrm{Al}_{2} \mathrm{O}_{3}-\mathrm{SiO}_{2}-\mathrm{H}_{2} \mathrm{O}$ system at 350 and $400^{\circ} \mathrm{C} / 500$ bar. At both temperatures, the changes in cation activity ratio mainly reflect changes in $\mathrm{Mg}^{2+}$ as the in situ $\mathrm{pH}$ values are relatively constant. The input composition of the preheated seawater is shown by the yellow circles (SW1 and SW2). Early effluent samples from both experiments were comprised of a mixture of distilled water and seawater. In these samples, $\mathrm{SiO}_{2}$ concentration quickly reached elevated levels such that even the distilled water/seawater mixtures had high $\log \left(a_{\mathrm{SiO}_{2}}\right)$ (black crosses in Fig. 6.33). At the same time, $\mathrm{Mg}$ must have been increasing in the fluid, however, it was also being fixed in the rock resulting in measurable but lower $\log \left(a_{\mathrm{Mg}^{2+}} / a_{H^{+}}^{2}\right)$ values. At both temperatures, these early values lie below the clinochlore (CL-14A) field (distilled water effect in Fig. 6.33).

Once $100 \%$ preheated seawater was entering the Reactor, exit fluid compositions all lie in the clinochlore field. At $400^{\circ} \mathrm{C}$, fluid flow rate was maintained at $1 \mathrm{ml} \mathrm{hr}^{-1}$ for most of the experiment and these fluid compositions cluster at $\log \left(a_{M g^{2+}} / a_{H^{+}}^{2}\right)=5$, however, there is a slight variation with flow rate. At $350^{\circ} \mathrm{C}$, flow rate was increased to $10 \mathrm{ml} \mathrm{hr}^{-1}$ once seawater was exiting the Reactor. This resulted in higher $\mathrm{Mg}$ concentrations in the fluid and, due to the relatively constant in situ $\mathrm{pH}$, higher $\log \left(a_{M g^{2+}} / a_{H^{+}}^{2}\right)$ values (Fig. 6.33, BSW2). Decreasing the flow rate at this temperature caused $\log \left(a_{\mathrm{Mg}^{2+}} / a_{\mathrm{H}^{+}}^{2}\right)$ to decrease but fluid compositions remain the clinochlore field. 
Figure 6.33. Activity-activity diagrams showing mineral stability fields in the $\mathrm{MgO}-\mathrm{Al}_{2} \mathrm{O}_{3}-\mathrm{SiO}_{2}-\mathrm{H}_{2} \mathrm{O}$ system for a) the $\mathrm{BSW}$ $\left(400^{\circ} \mathrm{C} / 488\right.$ bar $)$ and b) the BSW2 $\left(350^{\circ} \mathrm{C} / 488\right.$ bar $)$ experiment. Yellow circles show position of the output fluid composition from SW1 and $\mathrm{SW} 2$ at 377 and $342^{\circ} \mathrm{C} / 488$ bar, respectively. Arrows indicate fluid-path. Symbol colour refers to different flow rates as shown in the legend below the figure.

$$
\text { a }
$$

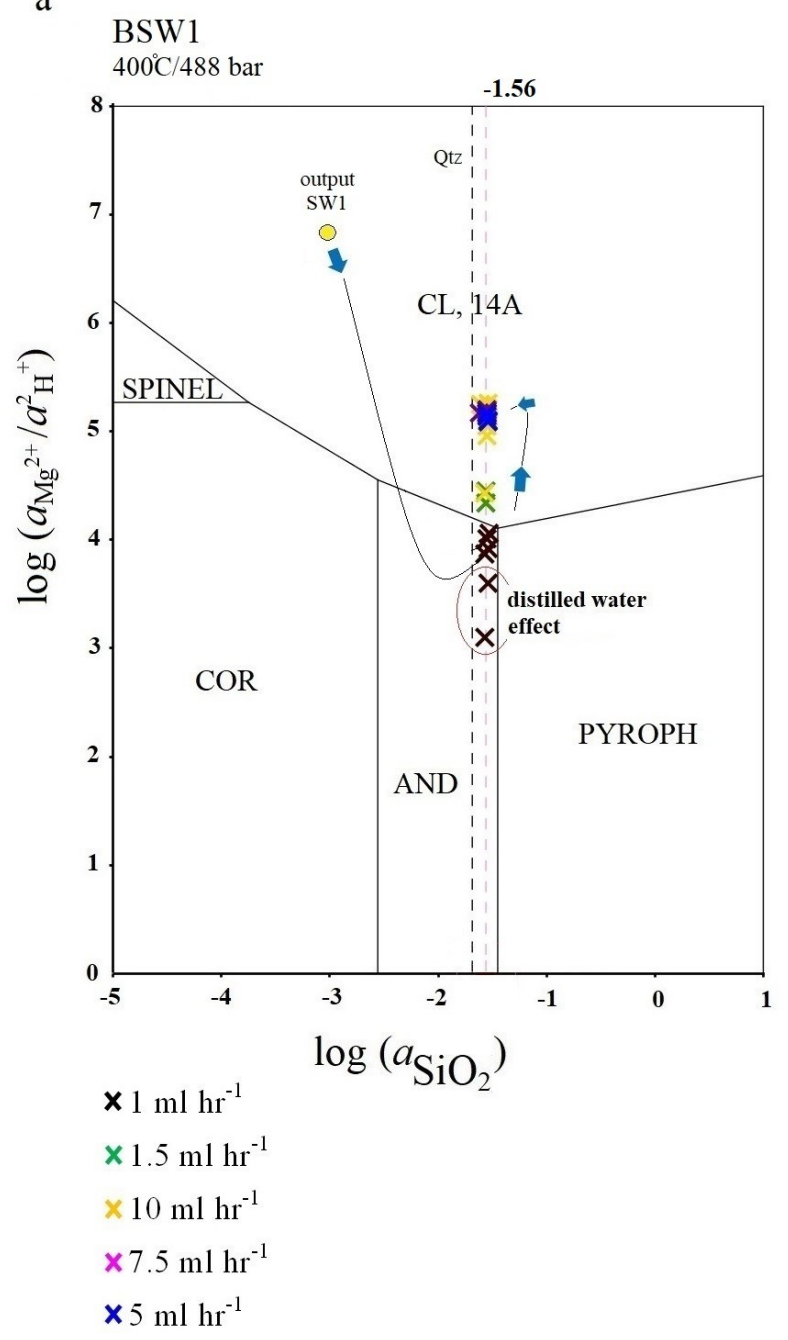

b

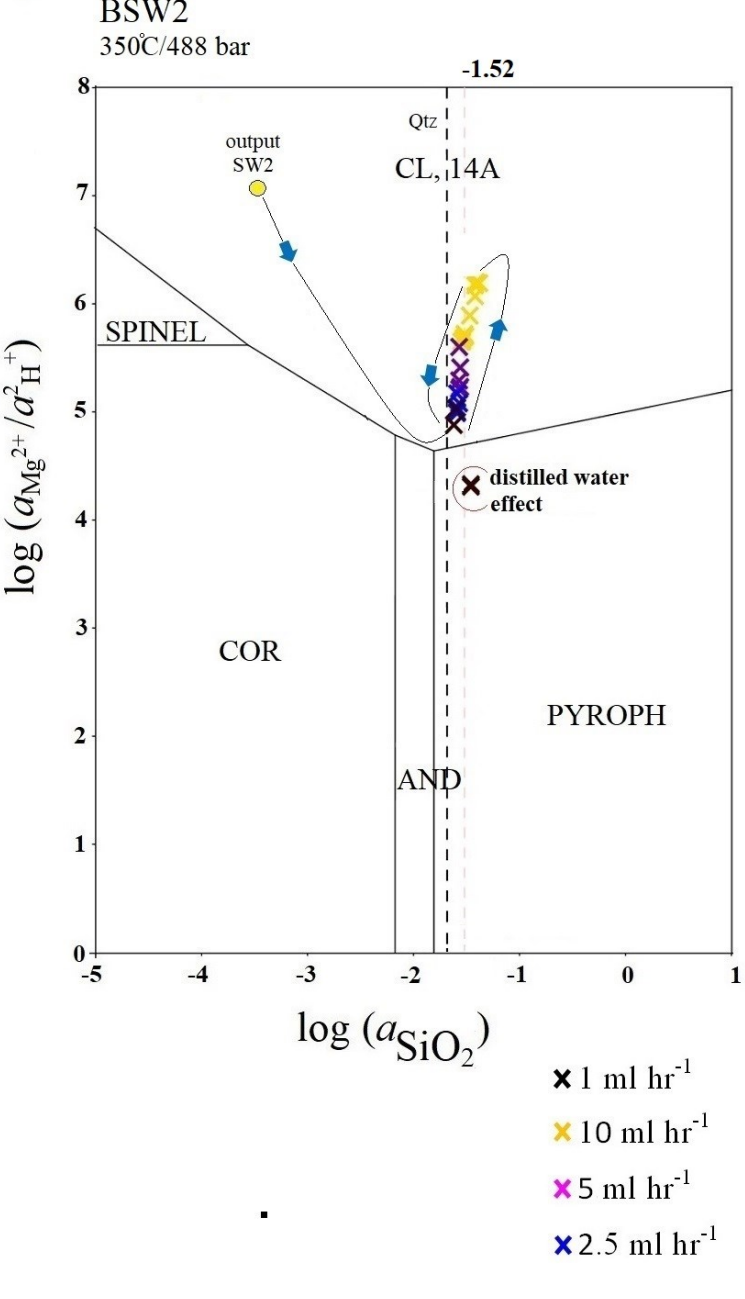

The predominance of chlorite as a secondary phase demonstrates that fluid compositions were saturated with respect to this mineral. This is consistent with Figure 6.33. The overall path of fluid-rock interaction in the $\mathrm{MgO}-\mathrm{K}_{2} \mathrm{O}-\mathrm{Al}_{2} \mathrm{O}_{3}-\mathrm{SiO}_{2}-\mathrm{H}_{2} \mathrm{O}$ system at both temperatures is similar indicating that the mineral reactions involved are the same which agrees with the minerals observed. However, there is a noticeable effect of flow rate on cation activity ratios both at 350 and $400^{\circ} \mathrm{C}$ (more below).

In the portions of reacted basalt above the zone of intense chloritization, smectite is present as the most common secondary phase. Unfortunately, there are no thermodynamic data available for common smectite minerals at 350 and $400^{\circ} \mathrm{C}$ so these cannot be incorporated in the activity diagrams. However, some insight can be gained by examining the 
equilibrium between chlorite and smectite. Using clinochlore and Mg-saponite as proxies for chlorite and smectite, respectively, the following reaction (2) can be written:

$$
\text { Clinochlore }+16.24 \mathrm{H}_{2} \mathrm{O}+14.18 \mathrm{Mg}^{2+}+19.24 \mathrm{SiO}_{2} \leftrightarrow 6.061[\mathrm{Mg}-\text { Saponite }]+28.36 \mathrm{H}^{+}
$$

This reaction shows that saponite stability is favoured by higher $\mathrm{Mg}^{2+}$ and $\mathrm{SiO}_{2}$ activity, and higher $\mathrm{pH}$. The relative positions of these minerals in the $\log \left(a_{\mathrm{Mg}^{2+}} / a_{\mathrm{H}^{+}}^{2}\right)-\log \left(a_{\mathrm{SiO}_{2}}\right)$ space can be seen by constructing a similar diagram to Figure 6.33 at $300^{\circ} \mathrm{C}$ using the same mineral phases, of which thermodynamic data are available (Fig. 6.34).

Figure 6.34. Activity-activity diagram showing mineral stability fields in the $\mathrm{MgO}-\mathrm{Al}_{2} \mathrm{O}_{3}-\mathrm{SiO}_{2}-\mathrm{H}_{2} \mathrm{O}$ system at $300^{\circ} \mathrm{C}$ using the phases in Figure 6.33 with the addition of Mg-saponite. Diagram constructed using GWB (Bethke, 1996).

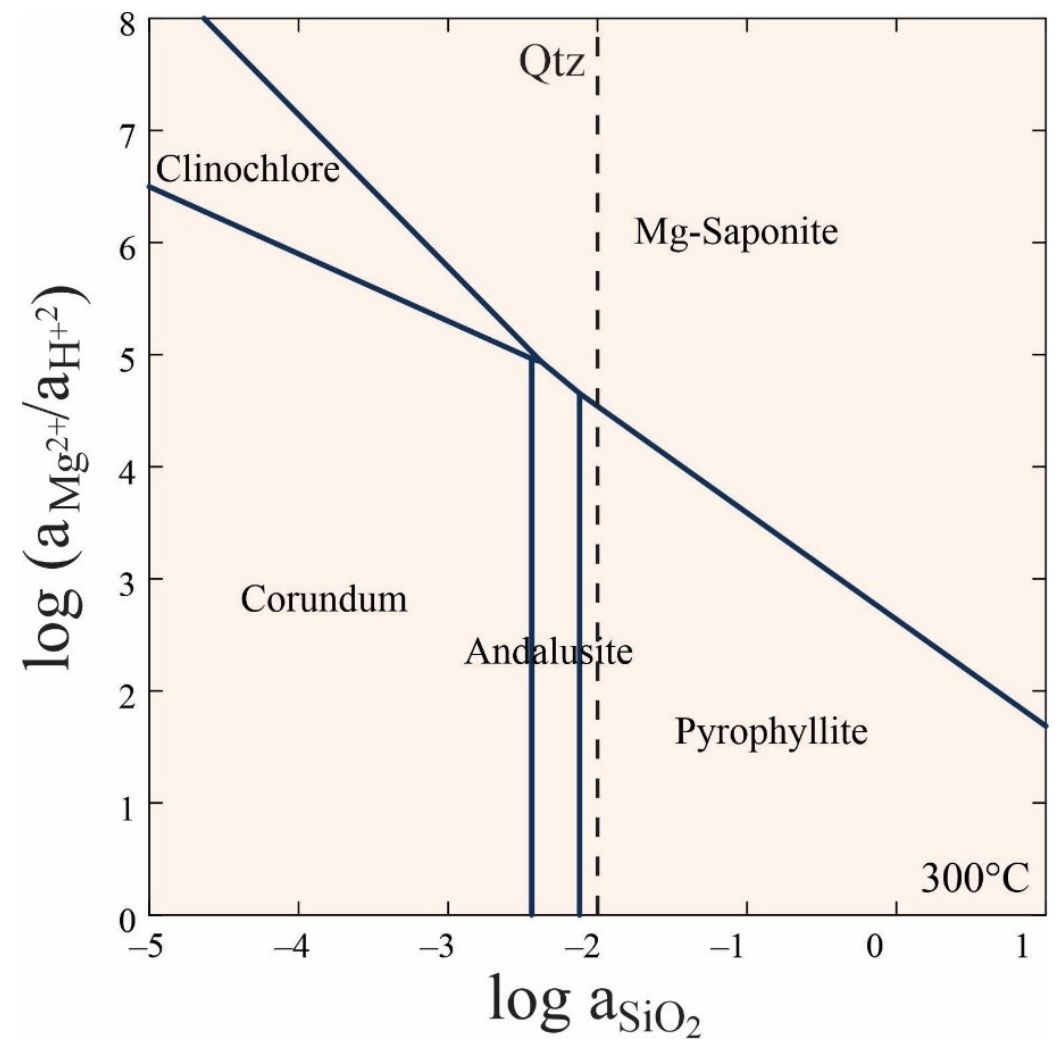

At 350 and $400^{\circ} \mathrm{C}$, the phase boundaries will move but the overall relative position of the minerals will not change. In the experiments, the dominant secondary phase switches from chlorite to smectite up the Reactor. This occurs closer to the bottom of the Reactor at $350^{\circ} \mathrm{C}$ and about halfway up the Reactor at $400^{\circ} \mathrm{C}$. The position of the fluid compositions in Figure 6.33 are therefore conjectured to lie near the equilibrium phase boundary between chlorite and smectite in $\log \left(a_{\mathrm{Mg}^{2+}} / a_{\mathrm{H}^{+}}^{2}\right)-\log \left(a_{\mathrm{SiO}_{2}}\right)$ space. We cannot confirm this without thermodynamic data and end member mineral activities but the shift from chlorite to 
smectite does occur in both experiments which indicates that a mineral phase boundary must have been traversed.

With the above information on the distribution of secondary minerals and some knowledge of the position of the fluid compositions in activity space, the reactions that occurred during fluid-rock interaction can be addressed. These reactions are complex as they involve multiple phases at the same time. To examine the fluid-rock interaction process, the reactions are broken down into individual mineral reactions.

In both BSW experiments, glass dissolution was the only pervasive "reaction" throughout the Reactor. As stated previously, a reaction front of glass dissolution passed through the rock in about two weeks but, unlike earlier experiments (BW1, BW2, BGB1), there are no elevated $\mathrm{SiO}_{2}$ values directly relatable to glass dissolution. This indicates that secondary mineral precipitation was already controlling $\mathrm{SiO}_{2}$ concentrations in the $\mathrm{BSW}$ experiments. The small amount of glass in the rock implies that glass dissolution did not have a major effect on the secondary minerals precipitated. The most significant result of glass dissolution was an $80 \%$ loss of $\mathrm{K}_{2} \mathrm{O}$ from the rock.

The distilled water experiments (BW1 and BW2) show that after glass the next most reactive phase was olivine. The dissolution of olivine can provide a source for $\mathrm{Fe}, \mathrm{Mg}$, and $\mathrm{SiO}_{2}$ but not $\mathrm{Al}$. The conversion of olivine to chlorite requires a source for $\mathrm{Al}$ and this cannot be the seawater, thus the transformation of olivine to chlorite must occurred simultaneously with the dissolution of clinopyroxene and/or plagioclase. As with glass, the amount of olivine in the basalt is probably $<5 \%$ as it was not detected in the XRD analysis of the unaltered rock.

The dominant secondary phase found at the bottom of the Reactor in both basalt seawater experiments is chlorite, with the chloritization front proceeding about twice as far up the column at $400^{\circ} \mathrm{C}$ than at $350^{\circ} \mathrm{C}$. Pervasive chloritization shows that all minerals (except Fe-Ti oxides) were converted to chlorite. The reactions for the replacement of olivine, clinopyroxene and plagioclase by chlorite, assuming conservation of $\mathrm{Al}$, can be written as:

$$
\begin{aligned}
\mathrm{Mg}_{1.4} \mathrm{Fe}_{0.6} \mathrm{SiO}_{4}+1.1 \mathrm{Al}^{3+}+ & 2.8 \mathrm{Mg}^{2+}+2.8 \mathrm{SiO}_{2}+8.4 \mathrm{H}_{2} \mathrm{O} \\
\leftrightarrow & \mathrm{Mg}_{4.2} \mathrm{Fe}_{0.6} \mathrm{Al}_{1.1} \mathrm{Si}_{3.8} \mathrm{O}_{10}(\mathrm{OH})_{8}+8.8 \mathrm{H}^{+}
\end{aligned}
$$




$$
\begin{aligned}
& 5.5 \mathrm{Ca}_{0.7} \mathrm{Mg}_{0.9} \mathrm{Fe}_{0.3} \mathrm{Al}_{0.2} \mathrm{Si}_{1.9} \mathrm{O}_{6}+11.3 \mathrm{H}^{+} \\
& \quad \leftrightarrow \mathrm{Mg}_{4.2} \mathrm{Fe}_{0.6} \mathrm{Al}_{1.1} \mathrm{Si}_{3.8} \mathrm{O}_{10}(\mathrm{OH})_{8}+3.85 \mathrm{Ca}^{2+}+1.05 \mathrm{Fe}^{2+}+0.75 \mathrm{Mg}^{2+}+6.65 \mathrm{SiO}_{2}+1.65 \mathrm{H}_{2}
\end{aligned}
$$

$$
\begin{aligned}
\mathrm{Ca}_{0.7} \mathrm{Na}_{0.3} \mathrm{Al}_{1.7} \mathrm{Si}_{2.3} \mathrm{O}_{8}+6.49 \mathrm{Mg}^{2+}+0.93 \mathrm{Fe}^{2+}+3.57 \mathrm{SiO}_{2}+12.75 \mathrm{H}_{2} \mathrm{O} \\
\leftrightarrow 1.54 \mathrm{Mg}_{4.2} \mathrm{Fe}_{0.6} \mathrm{Al}_{1.1} \mathrm{Si}_{3.8} \mathrm{O}_{10}(\mathrm{OH})_{8}+0.7 \mathrm{Ca}^{2+}+0.3 \mathrm{Na}^{+}+13.13 \mathrm{H}^{+}
\end{aligned}
$$

Note that in this discussion we ignore ion pairing for convenience. If the cations were, for example, $\mathrm{Cl}$ complexed, the reaction would have the same form.

As stated above, the conversion of olivine to chlorite (Reaction 3) requires a source of Al thus dissolution of clinopyroxene or plagioclase must provide this, however, olivine is a minor phase and this reaction is not expected to be important during intense chloritization.

The SEM results show that the conversion of clinopyroxene to chlorite is the next reaction (Reaction 4) that goes to completion, followed finally by the conversion of the remaining plagioclase to chlorite (Reaction 5). Chloritization of clinopyroxene consumes $\mathrm{H}^{+}$ and produces $\mathrm{SiO}_{2}, \mathrm{Ca}, \mathrm{Mg}$, and $\mathrm{Fe}$. Chloritization of plagioclase consumes $\mathrm{SiO}_{2}, \mathrm{Mg}$, and $\mathrm{Fe}$, and produces $\mathrm{H}^{+}, \mathrm{Na}^{+}$and $\mathrm{Ca}$, thus $\mathrm{Ca}$ is released by both chloritization reactions. Input

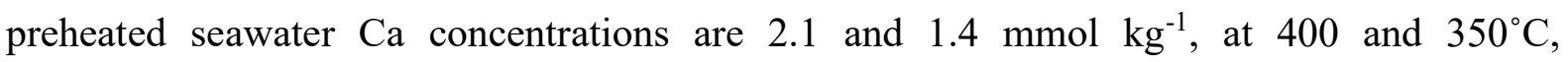
respectively, while output $\mathrm{Ca}$ concentrations are 21.5 and $20.3 \mathrm{mmol} \mathrm{kg}^{-1}$ (at $1 \mathrm{ml} \mathrm{hr}^{-1}$ ). This shows a 10 - 15-fold increase in Ca concentration in the effluent samples. This is due to the chloritization of the primary silicate minerals.

It is informative to combine Reaction 4 and 5 to see the combined effect of chloritization. This gives:

$$
\begin{aligned}
& 5.5 \mathrm{Ca}_{0.7} \mathrm{Mg}_{0.9} \mathrm{Fe}_{0.3} \mathrm{Al}_{0.2} \mathrm{Si}_{1.9} \mathrm{O}_{6}+\mathrm{Ca}_{0.7} \mathrm{Na}_{0.3} \mathrm{Al}_{1.7} \mathrm{Si}_{2.3} \mathrm{O}_{8}+5.74 \mathrm{Mg}^{2+}+11.10 \mathrm{H}_{2} \mathrm{O} \\
& \leftrightarrow 2.54 \mathrm{Mg}_{4.2} \mathrm{Fe}_{0.6} \mathrm{Al}_{1.1} \mathrm{Si}_{3.8} \mathrm{O}_{10}(\mathrm{OH})_{8}+4.55 \mathrm{Ca}^{2+}+0.12 \mathrm{Fe}^{2+}+3.08 \mathrm{SiO}_{2}+0.3 \mathrm{Na}^{+}+2 \mathrm{H}^{+}
\end{aligned}
$$

This reaction shows that complete chloritization of clinopyroxene and plagioclase requires addition of a significant amount of $\mathrm{Mg}$, sourced from seawater, and releases significant $\mathrm{Ca}$, from the primary minerals. Note that the clinopyroxene/plagioclase ratio in this reaction is 5.5:1 while in the rock it is about $0.5: 1$. This means that during chloritization, assuming conservation of $\mathrm{Al}$, other components including $\mathrm{Fe}$ and $\mathrm{SiO}_{2}$ must be moving within the column, i.e., chloritization is not just simply the addition of $\mathrm{Mg}$ and the removal of $\mathrm{Ca}$. 
Sulfate concentration entering the bottom of the Reactor ranges from $1.2-2.1 \mathrm{mmol}$ $\mathrm{kg}^{-1}$ while in the effluent it is much less at $0.04-0.07 \mathrm{mmol} \mathrm{kg}^{-1}$. This indicates that most of the $\mathrm{SO}_{4}$ precipitated in the Reactor. The peak in $\mathrm{S}$ concentration by XRF was found in Portion 4 approximately halfway up the column. The precipitation of anhydrite and caminite can be written as follows:

$$
\begin{gathered}
\mathrm{Ca}^{2+}+\mathrm{HSO}_{4}^{-} \leftrightarrow \mathrm{CaSO}_{4}+\mathrm{H}^{+} \\
7 \mathrm{Mg}^{2+}+5 \mathrm{HSO}_{4}^{-}+5 \mathrm{H}_{2} \mathrm{O} \leftrightarrow \mathrm{Mg}_{7}\left(\mathrm{SO}_{4}\right)_{5}(\mathrm{OH})_{4} \cdot\left(\mathrm{H}_{2} \mathrm{O}\right)_{(\mathrm{s})}+9 \mathrm{H}^{+}
\end{gathered}
$$

Both these reactions consume cation and $\mathrm{HSO}_{4}$ from the fluid and produce $\mathrm{H}^{+}$.

It is assumed that the preheated seawater is in equilibrium with both minerals when entering the bottom of the Reactor, therefore any precipitation of these phases requires a change in solution chemistry. From Reactions 4 and 5, chloritization of both clinopyroxene and plagioclase releases $\mathrm{Ca}$. This induces anhydrite precipitation according to Reaction 7 . In addition, the chloritization of clinopyroxene consumes $\mathrm{H}^{+}$increasing $\mathrm{pH}$ which can further induce sulfate mineral precipitation. Given the extensive amount of chloritization, this could be expected to surpass any $\mathrm{H}^{+}$produced by anhydrite precipitation. Caminite was also present in the run products but was rare, possibly due to the precipitation of anhydrite which consumed $\mathrm{SO}_{4}$ ?

As long as $\mathrm{Ca}$ is provided by clinopyroxene and plagioclase dissolution, and more $\mathrm{SO}_{4}$ was entering the bottom of the column, anhydrite precipitation would continue. Once clinopyroxene begins to be depleted, chloritization of plagioclase would take over as the dominant reaction and $\mathrm{pH}$ would decrease according to Reaction 5, meaning that $\mathrm{H}^{+}$would now be produced, $\mathrm{pH}$ would fall, and anhydrite would re-dissolve. This implies that the front of anhydrite precipitation will overlap the position where the dominant chloritization reaction switches from clinopyroxene to plagioclase.

At $350^{\circ} \mathrm{C}$, the shorter experiment time and lower temperature meant that chloritization did not progress as far up the column and anhydrite precipitation is a maximum near the entry point at the bottom of the Reactor.

During the BSW experiments, the flow rate was varied to test for the equilibrium state of the system. Figure 6.35 shows the $\mathrm{Ca}, \mathrm{Mg}$ and Fe concentrations versus flow rate in both experiments. These results show that, at both temperatures, $\mathrm{Mg}$ and $\mathrm{Fe}$ concentrations 
increase with increased flow rate while $\mathrm{Ca}$ concentration decreases. Both $\mathrm{Al}$ and $\mathrm{SiO}_{2}$ (not shown) remain constant showing no relation to flow rate (Table 6.21 and 6.22).

Figure 6.35. The concentration of $\mathrm{Ca}, \mathrm{Mg}$ and $\mathrm{Fe}\left(\mathrm{mmol} \mathrm{kg}^{-1}\right)$ versus flow rate $\left(\mathrm{ml} \mathrm{hr}^{-1}\right)$ during the $\mathrm{BSW}$ experiments
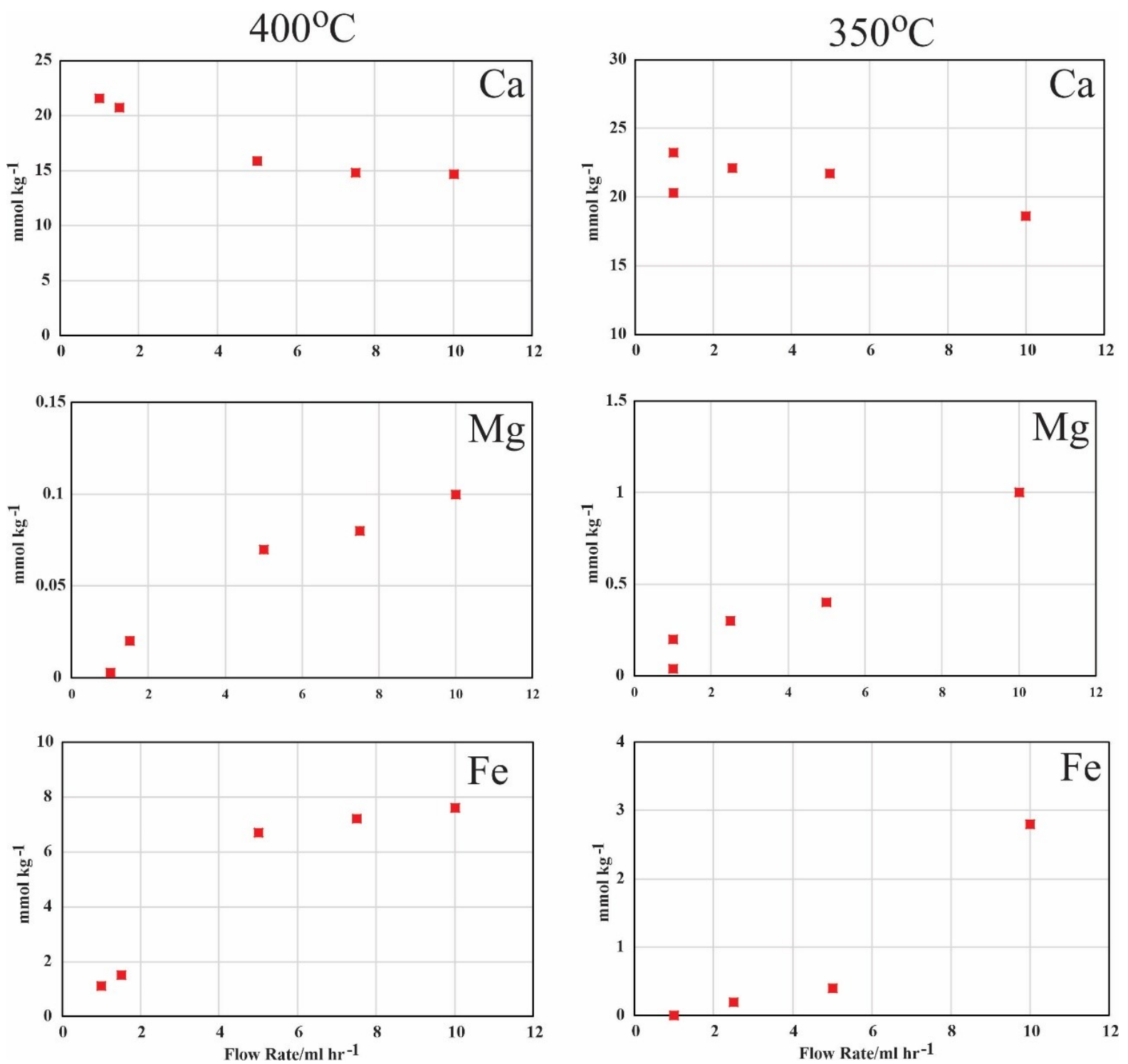

Both $\mathrm{Mg}$ and Fe can be sourced from olivine and clinopyroxene, but as stated above, it is assumed that olivine is not of sufficient abundance to significantly contribute to overall fluid-rock reactions. It is proposed that clinopyroxene is the primary source of Fe for chloritization. Note that the $\mathrm{Mg}$ concentrations in Figure 6.35 are very low when compared to the input values in the seawater $\left(23-24 \mathrm{mmol} \mathrm{kg}^{-1}\right)$. This demonstrates the efficiency of $\mathrm{Mg}$ fixation by the rock, even at a flow rate of $10 \mathrm{ml} \mathrm{hr}^{-1}$ where the average residence time of the fluid is only $1 \mathrm{hr}$. 
The concentration of $\mathrm{Ca}$ decreases with increased flow rate, however, $\mathrm{Ca}$ remains much higher in concentration than in the preheated seawater $\left(1.4-2.1 \mathrm{mmol} \mathrm{kg}^{-1}\right)$. Because $\mathrm{Fe}$ increases in concentration with flow rate, this indicates that the release of $\mathrm{Ca}$ from clinopyroxene should not be decreasing. The implication, therefore, is that the dissolution rate of plagioclase is slower and cannot compete with the increased flow rate. This would result in higher Fe but lower Ca.

Both $\mathrm{Mg}$ and $\mathrm{Fe}$ increase with increased flow rate. These elements should be consumed by the precipitation of chlorite. This shows that the rate of chloritization is also affected by flow rate resulting in retention of these elements in the fluid. This interpretation is also supported by the fact the that, if a curve were fitted to the datapoints for $\mathrm{Mg}$ and $\mathrm{Fe}$ in Figure 6.35, the shape of this curve would be similar for $\mathrm{Mg}$ and $\mathrm{Fe}$ at each temperature.

A change to smectite as the dominant secondary phase within the Reactor was observed in both experiments. At $400^{\circ} \mathrm{C}$ this was observed in Portion 4 and at $350^{\circ} \mathrm{C}$ at Portion 2-3. These two secondary phases were not found together, however, this is not unexpected due the limited number of grains analysed and the difficulty of preserving the exact position of the grains when extracted. Nevertheless, it is clear that chlorite precipitation ceased and smectite became the dominant secondary phase in both experiments. The basalt grain shown in Figure 6.26 shows complete replacement of olivine and clinopyroxene and partial replacement of plagioclase by smectite. This indicates that there is a zone of intense smectitization within the Reactor. Without further investigation it is uncertain how far this progresses. At the top of the Reactor, smectite occurs only as a thin layer around the outside of relatively unaltered basalt (Fig. 6.27).

$\mathrm{The} \mathrm{Mg} / \mathrm{Fe}$ ratio in the dominant secondary phases provides insight into the change from chlorite to smectite. The chlorites from the BSW experiments have $\mathrm{Mg} / \mathrm{Fe}$ ratios of 5 10 (Table 6.4, 6.7, 6.8, 6.16, 6.17) and are a mixture of clinochlore $\left(\mathrm{Mg}_{5} \mathrm{Al}_{2} \mathrm{Si}_{3} \mathrm{O}_{10}(\mathrm{OH})_{8}\right)$ with a lesser chamosite $\left(\mathrm{Fe}_{5} \mathrm{Al}_{2} \mathrm{Si}_{3} \mathrm{O}_{10}(\mathrm{OH})_{8}\right)$ component. The smectite from the experiments are a mixture of montmorillonite $\left((\mathrm{Na}, \mathrm{Ca})_{0.33}(\mathrm{Al}, \mathrm{Mg})_{2}\left(\mathrm{Si}_{4} \mathrm{O}_{10}(\mathrm{OH})_{2}\right)\right.$ and nontronite $\left(\mathrm{Na}_{0.3} \mathrm{Fe}_{2}\left((\mathrm{Si}, \mathrm{Al})_{4} \mathrm{O}_{10}\right)(\mathrm{OH})_{2}\right)$. However, it should be noted, there is the possibility that this phase is corrensite, which is an interlayered mixture of chlorite and smectite. In BSW1, smectite was found at Portion 4 where some grains display intense smectitization. The $\mathrm{Mg} / \mathrm{Fe}$ ratio in this smectite is 4.6 (Table 6.9). In BSW2, smectite was found in Portion 2-3 and its $\mathrm{Mg} / \mathrm{Fe}$ ratio is 3.5 (Table 6.17). Smectite was also identified in the top portions of both experiments with a $\mathrm{Mg} / \mathrm{Fe}$ of $0.9-1.1$ (Table 6.11 and 6.19). 
It can be seen that the $\mathrm{Mg} / \mathrm{Fe}$ ratio in smectite is much higher where the transition from chlorite occurs, while at the top of the Reactor its ratio is $\sim 1$ in both experiments. This supports the supposition that the dominant secondary mineral composition is controlled by the $\mathrm{Mg}$ activity in the fluid. The influx of seawater with a high $\mathrm{Mg}$ content drives chloritization, consuming the $\mathrm{Mg}$ and creating chlorite that is dominated by the clinochlore component. Upon the change from chloritization to smectitization, the Mg activity must still be high, forming smectites with high $\mathrm{Mg} / \mathrm{Fe}$ ratio. At this point however, the $\mathrm{Mg}$ activity must decrease rapidly as the smectites at the top of the Reactor have much lower $\mathrm{Mg} / \mathrm{Fe}$ ratio and there is essentially no $\mathrm{Mg}$ left in the fluid. In other words, at the top of the Reactor the composition of smectite is determined by the rock composition and not the fluid.

This is supported by the $\mathrm{Mg} / \mathrm{Fe}$ ratios in: celadonite $(0.7-2.1)$ from the $\mathrm{BW}$ experiments where distilled water was the fluid (Chapter 3); and biotite (1) and smectite (1.1 - 1.4) in the BGB experiments (Chapter 4) in which geothermal brine with low $\mathrm{Mg}$ was the fluid.

As stated above, there must be some position in the column where chlorite and smectite are both present, at which point the fluid composition must lie on the phase boundary, and as the fluid moves upwards its composition moves into the smectite stability field. Using the chlorite and smectite compositions in Potion 4 of BSW1, where both minerals are found (Table 6.8 and 6.9), the phase boundary can be represented by the following reaction:

$$
\begin{gathered}
0.5 \mathrm{Mg}_{3.6} \mathrm{Fe}_{0.7} \mathrm{Al}_{2.2} \mathrm{Si}_{3.1} \mathrm{O}_{10}(\mathrm{OH})_{8}+0.2 \mathrm{Na}^{+}+0.15 \mathrm{Fe}^{2+}+0.5 \mathrm{Mg}^{2+}+1.65 \mathrm{SiO}_{2} \\
\leftrightarrow \mathrm{Na}_{0.2} \mathrm{Mg}_{2.3} \mathrm{Fe}_{0.5} \mathrm{Al}_{1.1} \mathrm{Si}_{3.2} \mathrm{O}_{10}(\mathrm{OH})_{2}+0.3 \mathrm{H}_{2} \mathrm{O}+1.5 \mathrm{H}^{+}
\end{gathered}
$$

Again, this reaction assumes conservation of Al. The reaction shows that an increase in $\mathrm{Na}$, $\mathrm{SiO}_{2}, \mathrm{Mg}$ or Fe activity, favours smectite stability while a decrease in $\mathrm{pH}$ activity favours chlorite. $\mathrm{Na}$ is released from plagioclase, but the $\mathrm{Na}$ activity is not expected to change significantly because of its high concentration in seawater. $\mathrm{SiO}_{2}$ activity is also not expected to change significantly also due to its high concentration. This leaves $\mathrm{Fe}, \mathrm{Mg}$ and $\mathrm{pH}$ to determine the chlorite/smectite equilibrium. T log K expression for Reaction 9 can be written as:

$$
\log K_{9}=-0.5 \log \left(\frac{a_{M g^{2+}}}{a_{H^{+}}^{2}}\right)-0.15 \log \left(\frac{a_{F e^{2+}}}{a_{H^{+}}^{2}}\right)-0.2 \log \left(\frac{a_{N a^{+}}}{a_{H^{+}}}\right)-1.65 \log a_{S i O_{2}}+1.5 \log H^{+}
$$


Assuming constant activity for $\mathrm{Na}$ and $\mathrm{SiO}_{2}$, this shows the relative effects of $\mathrm{Mg}, \mathrm{Fe}$ and $\mathrm{pH}$ on smectite stability. An increase in $\mathrm{Mg}$ or Fe favours smectite stability while a decrease in $\mathrm{pH}$ favours chlorite. $\mathrm{Mg}$ activity is expected to decrease in concentration at this point thus favouring chlorite. The explanation must be that increased Fe concentration and/or decreased $\mathrm{pH}$ is stabilising smectite over chlorite.

In comparison, using the smectite composition at the top of the Reactor (Portion 7) gives the following reaction between chlorite and smectite:

$$
\begin{array}{r}
0.73 \mathrm{Mg}_{4.2} \mathrm{Fe}_{0.6} \mathrm{Al}_{1.1} \mathrm{Si}_{3.8} \mathrm{O}_{10}(\mathrm{OH})_{8}+0.3 \mathrm{Na}^{+}+0.96 \mathrm{Fe}^{2+}+0.73 \mathrm{SiO}_{2}+1.3 \mathrm{H}^{+} \\
\leftrightarrow \mathrm{Na}_{0.3} \mathrm{Mg}_{1.3} \mathrm{Fe}_{1.4} \mathrm{Al}_{0.8} \mathrm{Si}_{3.5} \mathrm{O}_{10}(\mathrm{OH})_{2}+1.75 \mathrm{Mg}^{2+}+2.55 \mathrm{H}_{2} \mathrm{O}
\end{array}
$$

For this reaction the equilibrium expression is:

$$
\log K_{11}=+1.75 \log \left(\frac{a_{\mathrm{Mg}^{2+}}}{a_{H^{+}}^{2}}\right)-0.96 \log \left(\frac{a_{F e^{2+}}}{a_{H^{+}}^{2}}\right)-0.3 \log \left(\frac{a_{N a^{+}}}{a_{H^{+}}}\right)-0.73 \log a_{S i O_{2}}-1.3 \log H^{+}
$$

In this case, both lower $\mathrm{Mg}$ activity and lower $\mathrm{pH}$ favour smectite stability. It is proposed that by the time the smectite composition is controlled by rock chemistry (mainly by $\mathrm{Mg}$ and $\mathrm{Fe}$ released from olivine and clinopyroxene), $\mathrm{Mg}$ concentration reaches the low values found in the effluent samples. The interpretation is that there is a sharp gradient in $\mathrm{Mg}$ concentration at the point where chlorite switches to smectite (Portion 4), the latter mineral consuming the remaining $\mathrm{Mg}$ in the fluid, and the composition of smectites forming further up the column being controlled solely by the rock.

At the top of the Reactor, smectite is present but occurs only as a thin coating around relatively unaltered rock (Fig. 6.14 and 6.27). As discussed previously it is concluded that all glass, accessible by the fluid, has been removed. This means that the $\mathrm{Mg}$ and Fe required to form smectite is sourced from the rock minerals. As the alteration is weak, olivine could have been contributing significant $\mathrm{Mg}$ and $\mathrm{Fe}$, however, clinopyroxene is expected to have been the dominant source. The conversion of olivine, clinopyroxene and plagioclase, to smectite can be expressed as:

$$
\begin{aligned}
\mathrm{Mg}_{1.4} \mathrm{Fe}_{0.6} \mathrm{SiO}_{4}+0.3 \mathrm{Na}^{+}+0.8 \mathrm{Al}^{3+}+0.8 \mathrm{Fe}^{2+}+2.5 \mathrm{SiO}_{2}+3 \mathrm{H}_{2} \mathrm{O} \\
\leftrightarrow \mathrm{Na}_{0.3} \mathrm{Mg}_{1.3} \mathrm{Fe}_{1.4} \mathrm{Al}_{0.8} \mathrm{Si}_{3.5} \mathrm{O}_{10}(\mathrm{OH})_{2}+0.1 \mathrm{Mg}^{2+}+4 \mathrm{H}^{+}
\end{aligned}
$$




$$
\begin{gathered}
\mathrm{Ca}_{0.7} \mathrm{Mg}_{0.9} \mathrm{Fe}_{0.3} \mathrm{Al}_{0.2} \mathrm{Si}_{1.9} \mathrm{O}_{6}+0.07 \mathrm{Na}^{+}+0.05 \mathrm{Fe}^{2+}+2.42 \mathrm{H}^{+} \\
\leftrightarrow 0.25 \mathrm{Na}_{0.3} \mathrm{Mg}_{1.3} \mathrm{Fe}_{1.4} \mathrm{Al}_{0.8} \mathrm{Si}_{3.5} \mathrm{O}_{10}(\mathrm{OH})_{2}+0.7 \mathrm{Ca}^{2+}+0.57 \mathrm{Mg}^{2+}+1.02 \mathrm{SiO}_{2}+0.96 \mathrm{H}_{2} \mathrm{O} \\
0.47 \mathrm{Ca}_{0.7} \mathrm{Na}_{0.3} \mathrm{Al}_{1.7} \mathrm{Si}_{2.3} \mathrm{O}_{8}+0.16 \mathrm{Na}^{+}+1.4 \mathrm{Fe}^{2+}+1.3 \mathrm{Mg}^{2+}+2.42 \mathrm{SiO}_{2}+3.4 \mathrm{H}_{2} \mathrm{O} \\
\leftrightarrow \mathrm{Na}_{0.3} \mathrm{Mg}_{1.3} \mathrm{Fe}_{1.4} \mathrm{Al}_{0.8} \mathrm{Si}_{3.5} \mathrm{O}_{10}(\mathrm{OH})_{2}+0.33 \mathrm{Ca}^{2+}+4.8 \mathrm{H}^{+}
\end{gathered}
$$

Reaction 13 shows that, if conservation of $\mathrm{Al}$ is assumed, Al must be sourced from either clinopyroxene or plagioclase to convert olivine to smectite. The conversion of clinopyroxene to smectite (Reaction 14) requires only a small amount of $\mathrm{Fe}$, consumes $\mathrm{H}^{+}$, while producing $\mathrm{Ca}$ and $\mathrm{Mg}$, thus this reaction can proceed without significant addition of outside components. The conversion of plagioclase to smectite requires a significant addition of $\mathrm{Mg}$ and $\mathrm{Fe}$ and is expected to be a relatively minor reaction by the time the fluid reaches the top of the Reactor.

Note the above interpretation is based mainly on the results from BSW1 at $400^{\circ} \mathrm{C}$, however, it is concluded, based on the identical mineralogy, that the same processes were occurring at $350^{\circ} \mathrm{C}$. In the case of BSW2 is it interpreted that the lower temperature and shorter experiment time lead to progression of the chloritization only within the immediate bottom of the Reactor. 


\subsection{4. $\mathrm{Na} / \mathrm{K}$ geothermometers}

Fluid chemistry results for both seawater experiments showed that $\mathrm{Na}$ and $\mathrm{K}$ were conservative during fluid-rock interaction. This implies that the rock was unable to affect their concentrations over the residence time of the fluid. As a result, the fluid $\mathrm{Na} / \mathrm{K}$ ratio did not change from its original seawater value and any estimated temperatures based on this ratio will simply reflect the seawater composition. The same would be true for experiments of longer duration as pervasive chloritization does not alter the fluid's $\mathrm{Na} / \mathrm{K}$ ratio. The precipitation of smectite did incorporate some $\mathrm{Na}$ but not enough to sufficiently adjust the high $\mathrm{Na}$ concentration in seawater. Table 6.26 confirms this, as all of the estimated temperatures are low and are similar to that estimated using the input seawater composition.

Table 6.26. Average and $1 \sigma$ of estimated temperature $\left({ }^{\circ} \mathrm{C}\right)$ using fluid compositions for BSW1 and BSW2 and geothermometers provided in literature.

\begin{tabular}{|c|c|c|c|c|c|c|c|c|c|}
\hline \multirow{4}{*}{$\begin{array}{c}\text { BSW1 } \\
400^{\circ} \mathrm{C} / 483 \text { bar }\end{array}$} & & $\begin{array}{c}\mathbf{N a} / \mathbf{K} \\
\text { (Fournier } \\
1979)\end{array}$ & $\begin{array}{c}\mathbf{N a} / \mathbf{K} \\
\text { (Truesdell } \\
1976)\end{array}$ & $\begin{array}{c}\mathbf{N a} / \mathbf{K} / \mathbf{C a} \\
\text { (Fournier and } \\
\text { Truesdell 1973) } \\
(\beta=1 / 3)\end{array}$ & $\begin{array}{c}\mathbf{N a} / \mathbf{K} \\
\text { (Santoyo and } \\
\text { Díaz-González } \\
\text { 2009) }\end{array}$ & $\begin{array}{c}\mathbf{N a} / \mathbf{K} \\
\text { (Arnorsson } \\
1983) \\
\left(250-350^{\circ} \mathrm{C}\right)\end{array}$ & $\begin{array}{c}\mathbf{N a} / \mathbf{K} \\
\text { (Tonani } \\
1980)\end{array}$ & $\begin{array}{c}\mathbf{N a} / \mathbf{K} \\
\text { (Nieva and } \\
\text { Nieva 1987) }\end{array}$ & $\begin{array}{c}\mathbf{N a} / \mathbf{K} \\
\text { (Giggenbach } \\
1988 \text { ) }\end{array}$ \\
\hline & $\begin{array}{c}\text { Blank } \\
\text { Seawater }\end{array}$ & 148 & 105 & 175 & 99 & 152 & 108 & 136 & 167 \\
\hline & Samples & 147 & 104 & 168 & 98 & 151 & 107 & 136 & 167 \\
\hline & $\pm 1 \sigma$ & 1.6 & 1.8 & 3.5 & 1.7 & 1.5 & 1.9 & 1.5 & 1.5 \\
\hline \multirow[t]{3}{*}{$\begin{array}{c}\text { BSW2 } \\
350^{\circ} \mathrm{C} / 488 \text { bar }\end{array}$} & $\begin{array}{c}\text { Blank } \\
\text { Seawater }\end{array}$ & 150 & 108 & 109 & 102 & 154 & 111 & 139 & 169 \\
\hline & Samples & 148 & 105 & 102 & 99 & 152 & 108 & 137 & 168 \\
\hline & $\pm 1 \sigma$ & 1.4 & 1.7 & 1.6 & 1.6 & 1.4 & 1.7 & 1.4 & 1.4 \\
\hline
\end{tabular}




\subsubsection{Geological implications}

The altered basalt from the BSW experiments contain several secondary minerals that have formed during seawater-basalt interaction. These include chlorite, smectite, anhydrite, caminite, calcite, ankerite and altered oxides (magnetite, maghemite, hematite). Of these minerals, chlorite is by far the most abundant, with smectite comprising the second most common secondary phase. Locally anhydrite is an important phase while caminite is rare. Calcite and ankerite were identified by XRD analyses but were not found during SEM examination. This secondary mineral assemblage is consistent with the observations made in the deeper section of the drill cuttings at Hole 1256D and Hole 504B (Alt et al., 2010; Koepke et al., 2008; Nicolas and Boudier, 1991; Nicolas et al., 2008; Vanko and Laverne, 1998; Wilson et al., 2006) and at the Reykjanes geothermal field (Fridleifsson et al., 2017; Marks et al., 2011; Marks et al., 2010).

The results from the BSW experiments show that the metamorphic grade is consistent with lower greenschist facies at both temperatures (Alt, 1995; Honnorez, 2003). One exception is the lack of actinolite and epidote. No evidence of these minerals was found and these are common in natural altered basalts at this grade (Honnorez, 2003; Nehlig et al., 1994). This could be the result of kinetic inhibition of these minerals. Another possibility is that to form these minerals, the fluid must be maintained at quartz saturation. Quartz is a common alteration mineral in altered MORB; however, it was not observed in our experiments. Experiments conducted in our lab with New Zealand basement greywacke at $400^{\circ} \mathrm{C}$ (unpublished data) have actinolite as the most abundant secondary phase. This rock contains up to $40 \%$ quartz and effluent samples maintained quartz saturation during the experiments. In all experiments conducted in the present study, $\mathrm{SiO}_{2}$ concentrations were consistently above quartz saturation and chlorite was the dominant secondary mineral.

The experiments were designed to allow the interaction of seawater with basalt in a continuous flow regime. This required the use of the Preheater to remove retrograde phases including anhydrite, caminite and brucite which would have blocked the apparatus. This setup mimics the process of seawater influx away from the mid-ocean ridge, heating as it descends into the Reaction zone, and alteration of the basaltic rocks. The main difference between the experiments and the natural situation, besides the geographic scale and time, is that lack of fluid-rock interaction in the influx zone. In the influx zone, fluid-rock interactions occur to modify solution chemistry other than just sulfate mineral precipitation so that the fluid entering the reaction zone will be much more complex than in the experiments. 
Nevertheless, anhydrite is found in the Reaction zone in MORB (Lowell and Yao, 2002; Scheuermann et al., 2019) showing that the experiments do reproduce the process of $\mathrm{Ca}$ fixation in anhydrite rather than as secondary Ca-silicate minerals. This may also be evidence for the lack of actinolite and epidote in the experiments.

The lack of caminite as a common secondary mineral in naturally altered MORB is due to the presence of abundant aluminosilicate phases in the influx zone. The experiments demonstrate the effectiveness of the existing aluminosilicate phases in fixing essentially all $\mathrm{Mg}$ in the descending fluid. Caminite was identified as a naturally-occurring mineral only in black smoker pipes where the heating of seawater allowed its precipitation (Haymon, 1983; Haymon and Kastner, 1981; Haymon and Kastner, 1986).

The most notable result from the BSW experiments is the rate of reaction. The BSW1 experiment at $400^{\circ} \mathrm{C}$ contained $22.5 \mathrm{~g}$ of basalt and a total seawater flux of $1.48 \mathrm{~kg}$. This represents a fluid/rock ratio of only $66: 1$. Even at this low fluid/rock ratio the seawater was able to alter $\sim 40 \%$ of the rock to chloritite in four weeks. This shows the efficiency of $\mathrm{Mg}$ fixation during fluid-rock interactions. Indeed, even at a flow rate of $10 \mathrm{ml} \mathrm{hr}^{-1}$, where the average fluid residence time would have been only 1 hour, all $\mathrm{Mg}$ was essentially removed from the fluid. This shows that, in the natural environment, the fixation of $\mathrm{Mg}$ by aluminosilicate phases is exceedingly fast.

Combining the observations from all experiments, it is possible to form a sequence of events that would occur during interaction of basalt with seawater. The first "phase" that would be removed is the volcanic glass. This would occur very rapidly at low fluid/rock ratio. This results in almost complete dissolution of $\mathrm{K}$ from the rock. The next most reactive mineral is olivine, which dissolves releasing $\mathrm{Mg}$ and $\mathrm{Fe}$ to the fluid. In the $\mathrm{BW}$ experiments this results in the formation of celadonite, using $\mathrm{K}$ from the glass and $\mathrm{Mg}$ and $\mathrm{Fe}$ from olivine. The formation of this mineral, however, requires Al. This Al is sourced from either the glass or minor dissolution of clinopyroxene and/or plagioclase.

From the BSW experiments, it is observed that clinopyroxene is the next most reactive phase with seawater. This releases $\mathrm{Ca}, \mathrm{Fe}$ and $\mathrm{Mg}$ to the fluid, the latter two being immediately incorporated into chlorite, and with the high $\mathrm{Mg}$ in the seawater, this results in chlorites with a high $\mathrm{Mg}$ component. Beside the Fe-Ti oxides, which are the most refractory phase in the basalt, plagioclase is next phase to be replaced. It should be noted that albite was not encountered in the secondary mineral assemblage. This implies that even with the high 
activity of $\mathrm{Na}$ in seawater, the conversion of plagioclase to chlorite was surpassed by $\mathrm{Mg}$ fixation.

The previous sequence of events emphasises the role of $\mathrm{Al}$ in the progression of fluidrock interactions. The first "phase" removed was the glass. The glass contains significant Al $(16 \%)$ however most of this Al remained in secondary minerals that formed in the glass voids (Fig. 3.32). Olivine contains little $\mathrm{Al}$ and was the next phase showing replacement. This is followed by clinopyroxene with a small Al component, and finally by plagioclase. This suggests that the relative resistance of the minerals to alteration is due to their Al content. This is supported by the lack of $\mathrm{Al}$ in the effluents from the experiments.

The trace element results from the distilled water-basalt experiments (BW1 and BW2) show that there is some release of elements from volcanic glass. In the seawater-only experiments (SW1 and SW2) the $\mathrm{ZrO}_{2}$ beads appear to be releasing some of these elements. Trace element results from the seawater-basalt experiments, however, in general, show lower abundances. The suggestion is that, if higher trace element concentrations enter the Reactor, or are being released by the glass, these are being removed during fluid-rock interaction with the basalt. This implies that during initial interaction between seawater and unaltered basalt, trace elements are not produced but are consumed during interaction. It is only at deeper levels in mid-ocean ridges where higher grade alteration releases the elements necessary to form volcanogenic massive sulfide deposits. 


\subsection{References}

Alt, J.C., 1995, Subseafloor processes in mid-ocean ridge hydrothermal systems. Geophysical Monograph-American Geophysical Union, 91: 85-85.

Alt, J.C., Laverne, C., Coggon, R.M., Teagle, D.A.H., Banerjee, N.R., Morgan, S., SmithDuque, C.E., Harris, M. and Galli, L., 2010, Subsurface structure of a submarine hydrothermal system in ocean crust formed at the East Pacific Rise, ODP/IODP Site 1256. Geochemistry, Geophysics, Geosystems, 11: n/a-n/a.

Arnórsson, S., Gunnlaugsson, E. and Svavarsson, H., 1983, The chemistry of geothermal waters in Iceland. III. Chemical geothermometry in geothermal investigations. Geochimica et Cosmochimica Acta, 47: 567-577.

Beaufort, D., Baronnet, A., Lanson, B. and Meunier, A., 1997, Corrensite; a single phase or a mixed-layer phyllosilicate in saponite-to-chlorite conversion series? A case study of Sancerre-Couy deep drill hole (France). American Mineralogist, 82: 109-124.

Berndt, M.E. and Seyfried, W.E., 1993, Calcium and sodium exchange during hydrothermal alteration of calcic plagioclase at $400^{\circ} \mathrm{C}$ and 400 bars. Geochimica et Cosmochimica Acta, 57: 4445-4451.

Bethke, C., 1996, Geochemical reaction modeling: Concepts and applications. Oxford University Press on Demand

Bischoff, J.L. and Dickson, F.W., 1975, Seawater-basalt interaction at $200^{\circ} \mathrm{C}$ and 500 bars: Implications for origin of sea-floor heavy-metal deposits and regulation of seawater chemistry. Earth and Planetary Science Letters, 25: 385-397.

Bischoff, J.L. and Seyfried, W.E., 1978, Hydrothermal chemistry of seawater from 25C to 350C. American Journal of Science, 278: 838-860.

Bowers, T.S., Campbell, A.C., Measures, C.I., Spivack, A.J., Khadem, M. and Edmond, J.M., 1988 , Chemical controls on the composition of vent fluids at $13^{\circ}-11^{\circ} \mathrm{N}$ and $21^{\circ} \mathrm{N}$, East Pacific Rise. Journal of Geophysical Research: Solid Earth, 93: 4522-4536.

Campbell, A.C., Bowers, T.S., Measures, C.I., Falkner, K.K., Khadem, M. and Edmond, J.M., 1988a, A time series of vent fluid compositions from $21^{\circ} \mathrm{N}$, East Pacific Rise $(1979,1981,1985)$, and the Guaymas Basin, Gulf of California (1982, 1985). Journal of Geophysical Research: Solid Earth, 93: 4537-4549.

Campbell, A.C., Palmer, M.R., Klinkhammer, G.P., Bowers, T.S., Edmond, J.M., Lawrence, J.R., Casey, J.F., Thompson, G., Humphris, S., Rona, P. and Karson, J.A., 1988b, Chemistry of hot springs on the Mid-Atlantic Ridge. Nature, 335: 514-519.

Cann, J.R., 1979, Metamorphism in the ocean crust. Deep Drilling Results in the Atlantic Ocean: Ocean Crust, 2: 230-238.

Cheshire, M.C., Caporuscio, F.A., Colón, C.J. and Norskog, K.E., 2018, Fe-saponite growth on low-carbon and stainless steel in hydrothermal-bentonite experiments. Journal of Nuclear Materials, 511: 353-366.

Finlow-Bates, T. and Stumpfl, E.F., 1981, The behaviour of so-called immobile elements in hydrothermally altered rocks associated with volcanogenic submarine-exhalative ore deposits. Mineralium Deposita, 16: 319-328.

Fournier, R.O., 1979, A revised equation for the $\mathrm{Na} / \mathrm{K}$ geothermometer. Transactions of the Geothermal Resources Council, 3: 221-224.

Fournier, R.O. and Potter, R.W., 1979, Magnesium correction to the $\mathrm{Na} \cdot \mathrm{K} \cdot \mathrm{Ca}$ chemical geothermometer. Geochimica et Cosmochimica Acta, 43: 1543-1550.

Fridleifsson, G.Ó., Elders, W.A., Zierenberg, R.A., Stefánsson, A., Fowler, A.P.G., Weisenberger, T.B., Harðarson, B.S. and Mesfin, K.G., 2017, The Iceland Deep Drilling Project $4.5 \mathrm{~km}$ deep well, IDDP-2, in the seawater-recharged Reykjanes 
geothermal field in SW Iceland has successfully reached its supercritical target. Sci. Dril., 23: 1-12.

Giggenbach, W., 1988, Geothermal solute equilibria. Derivation of Na-K-Mg-Ca geoindicators. Geochimica et Cosmochimica Acta, 52: 2749-2765.

Hajash, A., 1975, Hydrothermal processes along mid-ocean ridges: An experimental investigation. Contributions to Mineralogy and Petrology, 53: 205-226.

Haldar, S.K., 2020, Introduction to mineralogy and petrology. Elsevier

Haymon, R.M. and Kastner, M., 1981, Hot spring deposits on the East Pacific Rise at $21 \mathrm{~N}$ : preliminary description of mineralogy and genesis. Earth and Planetary Science Letters, 53: 363-381.

Haymon, R.M., 1983, Growth history of hydrothermal black smoker chimneys. Nature, 301: 695-698.

Haymon, R.M. and Kastner, M., 1986, Caminite: A new magnesium-hydroxide-sulfatehydrate mineral found in a submarine hydrothermal deposit, East Pacific Rise, 21 degree N. The American mineralogist, 71: 819-825.

Hochella, M.F., Keefer, K.D. and deJong, B.H.W.S., 1983, The crystal chemistry of a naturally occurring magnesium hydroxide sulfate hydrate, a precipitate of heated seawater. Geochimica et Cosmochimica Acta, 47: 2053-2058.

Honnorez, J., 2003, Hydrothermal alteration vs. ocean-floor metamorphism. A comparison between two case histories: the TAG hydrothermal mound (Mid-Atlantic Ridge) vs. DSDP/ODP Hole 504B (Equatorial East Pacific). Comptes Rendus Geoscience, 335: 781-824.

Janecky, D. and E. Seyfried, W., 1983, The solubility of magnesium-hydroxide-sulfatehydrate in seawater at elevated temperatures and pressures. American Journal of Science, 283: 831-860.

Koepke, J., Christie, D.M., Dziony, W., Holtz, F., Lattard, D., Maclennan, J., Park, S., Scheibner, B., Yamasaki, T. and Yamazaki, S., 2008, Petrography of the dike-gabbro transition at IODP Site 1256 (equatorial Pacific): The evolution of the granoblastic dikes. Geochemistry, Geophysics, Geosystems, 9: n/a-n/a.

Lowell, R.P. and Yao, Y., 2002, Anhydrite precipitation and the extent of hydrothermal recharge zones at ocean ridge crests. Journal of Geophysical Research: Solid Earth, 107: EPM 2-1-EPM 2-9.

Marks, N., Schiffman, P., Zierenberg, R.A., Franzson, H. and Fridleifsson, G.Ó., 2010, Hydrothermal alteration in the Reykjanes geothermal system: Insights from Iceland deep drilling program well RN-17. Journal of Volcanology and Geothermal Research, 189: 172-190.

Marks, N., Schiffman, P. and Zierenberg, R.A., 2011, High-grade contact metamorphism in the Reykjanes geothermal system: Implications for fluid-rock interactions at midoceanic ridge spreading centers. Geochemistry, Geophysics, Geosystems, 12: n/a-n/a.

Mathieu, L., 2018, Quantifying hydrothermal alteration: A review of methods. Geosciences, 8: 245.

Mottl, M. and Seyfried Jr, W.E., 1980, Sub-seafloor hydrothermal systems: Rock-vs. Seawater dominanted, seafloor spreading centers hydrothermal systems. Benchmark Papersin Geology, 56: 66-82.

Mottl, M. and E. Seyfried, W., 2019, Exerpmental basalt-seawater interaction: rock- vs. seawater-dominated systems and the origin of submarine hydrothermal deposits.

Mottl, M.J. and Holland, H.D., 1978, Chemical exchange during hydrothermal alteration of basalt by seawater-I. Experimental results for major and minor components of seawater. Geochimica et Cosmochimica Acta, 42: 1103-1115. 
Mottl, M.J., Holland, H.D. and Corr, R.F., 1979, Chemical exchange during hydrothermal alteration of basalt by seawater-II. Experimental results for Fe, Mn, and sulfur species. Geochimica et Cosmochimica Acta, 43: 869-884.

Nehlig, P., Juteau, T., Bendel, V. and Cotten, J., 1994, The root zones of oceanic hydrothermal systems: Constraints from the Samail ophiolite (Oman). Journal of Geophysical Research: Solid Earth, 99: 4703-4713.

Nicolas, A. and Boudier, F., 1991, Rooting of the Sheeted Dike Complex in the Oman Ophiolite. Dordrecht, 39-54.

Nicolas, A., Boudier, F., Koepke, J., France, L., Ildefonse, B. and Mevel, C., 2008, Root zone of the sheeted dike complex in the Oman ophiolite. Geochemistry, Geophysics, Geosystems, 9: n/a-n/a.

Nieva, D. and Nieva, R., 1987, Developments in geothermal energy in Mexico-part twelve. A cationic geothermometer for prospecting of geothermal resources. Heat Recovery Systems and CHP, 7: 243-258.

Ohmoto, H. and Rye, R.O., 1974, Hydrogen and Oxygen Isotopic Compositions of Fluid Inclusions in the Kuroko Deposits, Japan. Economic Geology, 69: 947-953.

Petersen, M.D., 1983, The use of the "immobile" elements $\mathrm{Zr}$ and Ti in lithogeochemical exploration for massive sulphide deposits in the precambrian pecos greenstone belt of northern New Mexico. Journal of Geochemical Exploration, 19: 615-617.

Saldaña, A.G.M., Kaya, E., Zarrouk, S.J., Callos, V. and Mountain, B.W., Year, Numerical simulation of mixed brine-CO2/H2S-Rock interaction during the reinjection of noncondensable gases. 41st Workshop on Geothermal Reservoir Engineering Stanford University, Stanford, California SGP-TR-209

Santoyo, E. and Díaz-González, L., Year, A New Improved Proposal of the $\mathrm{Na} / \mathrm{K}$ Geothermometer to Estimate Deep Equilibrium Temperatures and their Uncertainties in Geothermal Systems.

Scheuermann, P.P., Tutolo, B.M. and Seyfried, W.E., 2019, Anhydrite solubility in lowdensity hydrothermal fluids: Experimental measurements and thermodynamic calculations. Chemical Geology, 524: 184-195.

Seewald, J.S. and Seyfried, W.E., 1990, The effect of temperature on metal mobility in subseafloor hydrothermal systems: constraints from basalt alteration experiments. Earth and Planetary Science Letters, 101: 388-403.

Seyfried, W. and Mottl, M., 1977, Origin of submarine metal-rich hydrothermal solutions: experimental basalt-seawater interaction in a seawater dominated system at $300^{\circ} \mathrm{C}$, 500 bars. Proc. of the Second International Symposium on Water-Rock Interaction, I.A.G.C.: 173-180.

Seyfried Jr, W.E. and Bischoff, J.L., 1979, Low temperature basalt alteration by sea water: an experimental study at $70^{\circ} \mathrm{C}$ and $150^{\circ} \mathrm{C}$. Geochimica et Cosmochimica Acta, 43: 19371947.

Seyfried, W.E. and Bischoff, J.L., 1981, Experimental seawater-basalt interaction at $300^{\circ} \mathrm{C}$, 500 bars, chemical exchange, secondary mineral formation and implications for the transport of heavy metals. Geochimica et Cosmochimica Acta, 45: 135-147.

Seyfried, W.E. and Mottl, M.J., 1982, Hydrothermal alteration of basalt by seawater under seawater-dominated conditions. Geochimica et Cosmochimica Acta, 46: 985-1002.

Seyfried, W.E. and Janecky, D.R., 1985, Heavy metal and sulfur transport during subcritical and supercritical hydrothermal alteration of basalt: Influence of fluid pressure and basalt composition and crystallinity. Geochimica et Cosmochimica Acta, 49: 25452560 . 
Seyfried, W.E., Berndt, M.E. and Seewald, J.S., 1988, Hydrothermal alteration processes at mid-ocean ridges; constraints from diabase alteration experiments, hot spring fluids and composition of the oceanic crust. The Canadian Mineralogist, 26: 787-804.

Tonani, F., Year, Some Remarks on the Application of Geochemical Techniques in geothermal exploration.

Truesdell, A., Year, Geochemical Techniques in Exploration: Summary of Section III. Proceedings of the Second UN Symposium on the Development and Use of Geothermal Resources, 1975, Iiii-Ixxix.

Vanko, D.A. and Laverne, C., 1998, Hydrothermal anorthitization of plagioclase within the magmatic/hydrothermal transition at mid-ocean ridges: examples from deep sheeted dikes (Hole 504B, Costa Rica Rift) and a sheeted dike root zone (Oman ophiolite). Earth and Planetary Science Letters, 162: 27-43.

Von Damm, K.L., Edmond, J.M., Grant, B., Measures, C.I., Walden, B. and Weiss, R.F., 1985, Chemistry of submarine hydrothermal solutions at $21^{\circ} \mathrm{N}$, East Pacific Rise. Geochimica et Cosmochimica Acta, 49: 2197-2220.

Von Damm, K.L. and Bischoff, J.L., 1987, Chemistry of hydrothermal solutions from the southern Juan de Fuca Ridge. Journal of Geophysical Research: Solid Earth, 92: 11334-11346.

Von Damm, K.L., 1988, Systematics of and postulated controls on submarine hydrothermal solution chemistry. Journal of Geophysical Research: Solid Earth, 93: 4551-4561.

Wilson, D.S., Teagle, D.A.H., Alt, J.C., Banerjee, N.R., Umino, S., Miyashita, S., Acton, G.D., Anma, R., Barr, S.R., Belghoul, A., Carlut, J., Christie, D.M., Coggon, R.M., Cooper, K.M., Cordier, C., Crispini, L., Durand, S.R., Einaudi, F., Galli, L., Gao, Y., Geldmacher, J., Gilbert, L.A., Hayman, N.W., Herrero-Bervera, E., Hirano, N., Holter, S., Ingle, S., Jiang, S., Kalberkamp, U., Kerneklian, M., Koepke, J., Laverne, C., Vasquez, H.L.L., Maclennan, J., Morgan, S., Neo, N., Nichols, H.J., Park, S.-H., Reichow, M.K., Sakuyama, T., Sano, T., Sandwell, R., Scheibner, B., Smith-Duque, C.E., Swift, S.A., Tartarotti, P., Tikku, A.A., Tominaga, M., Veloso, E.A., Yamasaki, T., Yamazaki, S. and Ziegler, C., 2006, Drilling to Gabbro in Intact Ocean Crust. Science, 312: 1016-1020.

Yardley, B.W.D., Rhede, D. and Heinrich, W., 2014, Rates of Retrograde Metamorphism and their Implications for the Rheology of the Crust: an Experimental Study. Journal of Petrology, 55: 623-641. 


\section{Chapter 7: Summary and conclusions}

\subsection{Summary}

In this study six laboratory experiments simulating fluid-rock interactions between distilled water, geothermal brine, and seawater and a tholeiitic basalt from Reykjanes, Iceland, were performed at subcritical, near-supercritical and supercritical condition (350 $400^{\circ} \mathrm{C} / 500$ bar). Two further experiments with seawater only were completed as controls. The important parameters and elemental fluxes are summarised in Table 7.1. Figure 7.1 shows a comparison of fluid chemistries over time for all simulations (seawater-only experiment results excluded).

\subsubsection{Basalt - distilled water interaction (BW1, BW2)}

Two experiments simulated the interaction between distilled water and basalt at supercritical and subcritical conditions (blue lines, Fig. 7.1).

Fluid chemistry results show that in situ $\mathrm{pH}$ values stabilise at $5.7\left(400^{\circ} \mathrm{C}\right)$ and 5.3 $\left(350^{\circ} \mathrm{C}\right)$ over the experiments. Upon cooling, the $\mathrm{pH}$ values increase to $\sim 9.5$ in both experiments. This is due to the dissociation of ion pairs containing $\mathrm{OH}^{-}$during cooling, resulting in alkaline values. Such high $\mathrm{pH}$ values are indicative of $\mathrm{H}^{+}$consumption from the fluid during cation exchange with the rock.

Elevated concentrations of $\mathrm{SiO}_{2}$, well above quartz saturation, along with increases in $\mathrm{K}, \mathrm{H}_{2} \mathrm{~S}, \mathrm{SO}_{4}$ and $\mathrm{Cl}$ are found for approximately 12 days after temperature increase in both experiments. This is attributed to the dissolution of volcanic glass and its included sulfide blebs. After complete removal of the volcanic glass, these elements decrease in concentration while $\mathrm{Na}$ and $\mathrm{Al}$ concentrations increase. The latter changes due to enhanced dissolution of plagioclase in the presence of lower $\mathrm{SiO}_{2}$ concentrations.

Trace elements results at $400^{\circ} \mathrm{C}$ show correlations between $\mathrm{Cu}, \mathrm{Co}$, and Mo with $\mathrm{H}_{2} \mathrm{~S}$, and $\mathrm{SiO}_{2}$. This indicates that these elements are released by volcanic glass dissolution in the presence of distilled water. These correlations are not present at $350^{\circ} \mathrm{C}$ suggesting fixation by sulfide minerals at subcritical conditions.

SEM analysis of the basalt reacted at $400^{\circ} \mathrm{C}$ show intense alteration at the bottom of the Reactor with a Ca skarn-like assemblage of grossular, wollastonite, anorthite, and chlorite. At the top of the Reactor only celadonite was found as a secondary phase. At $350^{\circ} \mathrm{C}$, the alteration assemblage at the bottom of the Reactor consisted of chlorite and anorthite. Celadonite was also found as the sole secondary phase at the top of the Reactor. The intensity 
of alteration at the top of the reactor is weak in both experiments with only the conversion of olivine to celadonite as the dominant reaction. With the exception of particularly intense alteration adjacent to the entry point of the fluid, most primary rock minerals (plagioclase, clinopyroxene, Fe-Ti oxides) remain relatively unaffected.

The results show the effectiveness of distilled water, which lacks any alkali cations, at removing $\mathrm{Na}$ and $\mathrm{K}$ rapidly from the rock. Once levels of these cations increase in the fluid, the rate of alteration slows substantially. The presence of celadonite as a secondary phase replacing olivine is notable. This points to olivine as the next most reactive phase after the volcanic glass. Celadonite is found in nature as a replacement of olivine and clinopyroxene in basaltic rocks. The results from the distilled water experiments show that the release of $\mathrm{K}$ from volcanic glass, $\mathrm{Mg}$ and $\mathrm{Fe}$ from olivine, and sufficient $\mathrm{Al}$ from clinopyroxene and/or plagioclase can stabilise celadonite without addition of introduced cations in the fluid.

$\mathrm{Na} / \mathrm{K}$ geothermometry results show temperatures close to the experimental value when quartz is supersaturated at $400^{\circ} \mathrm{C}$ while at $350^{\circ} \mathrm{C}$, temperatures are close to the experiment value only when $\mathrm{K}$ is elevated after glass dissolution.

\subsubsection{Basalt-geothermal brine interactions (BGB1, BGB2)}

Two experiments simulated the interaction of geothermal brine from the Nga Awa Purua geothermal power station, New Zealand, with basalt at supercritical (BGB1, $400^{\circ} \mathrm{C} / 483$ bar) and subcritical (BGB2, $350^{\circ} \mathrm{C} / 486$ bar) conditions (red lines, Fig. 7.1). These experiments were undertaken to study the effect of re-injection of a geothermal brine, containing elevated cation concentrations, on fluid and rock chemistry. Unlike distilled water, the brine contains initial high concentrations of $\mathrm{SiO}_{2}, \mathrm{~K}, \mathrm{SO}_{4}, \mathrm{Na}, \mathrm{Cl}$ and has an acidic $\mathrm{pH}$ $(\sim 4)$.

Fluid chemistry results show that in situ pH stabilises at $\sim 7.0\left(400^{\circ} \mathrm{C}\right)$ and $6.8\left(350^{\circ} \mathrm{C}\right)$ over the experiments. At $400^{\circ} \mathrm{C}$, the quench $\mathrm{pH}$ is low ( 2.9) while glass dissolution was occurring. At $350^{\circ} \mathrm{C}$, the quench $\mathrm{pH}$ is initially low ( $\left.\sim 3.4\right)$ and gradually rises to 7.9 . The low quench $\mathrm{pH}$ values are attributed to the precipitation of anhydrite which releases $\mathrm{H}^{+}$to the fluid. At high temperature $\mathrm{H}^{+}$is held in protonated species such as $\mathrm{HSO}_{4}^{-}$but is released on cooling leading to acidic quench $\mathrm{pH}$ values.

At $400^{\circ} \mathrm{C}, \mathrm{SiO}_{2}$ concentration remains oversaturated with respect to quartz for approximately two weeks after temperature increase. This is due to the dissolution of the volcanic glass which took longer than with distilled water due to the higher input $\mathrm{SiO}_{2}$ concentration in the brine. At $350^{\circ} \mathrm{C}, \mathrm{SiO}_{2}$ concentration is initially elevated after the 
temperature increase, however, it gradually decreases in concentration back to the input value over the experiment. This is attributed to onset of precipitation of secondary phases immediately after the increase in temperature.

At $400^{\circ} \mathrm{C}$, other notable changes in fluid chemistry are: a sharp rise in $\mathrm{K}$ after temperature increase, followed by higher concentrations than the input value while glass is dissolving; and elevated $\mathrm{Al}$ concentrations after the glass is removed due to lower $\mathrm{SiO}_{2}$ concentrations. At $350^{\circ} \mathrm{C}$, the above changes are similar except for $\mathrm{K}$ which decreases back to the input values immediately after the initial rise. At both temperatures $\mathrm{H}_{2} \mathrm{~S}$ is detected during glass dissolution and $\mathrm{Ca}, \mathrm{Mg}$, and $\mathrm{Fe}$ concentrations are detectable but low.

Many trace element concentrations are higher in the unreacted geothermal brine and during fluid-rock interaction through the initial room temperature period. At higher temperature, many trace elements are undetected except $\mathrm{Mo}, \mathrm{Ba}$, and $\mathrm{Au}$. The presence of $\mathrm{Cu}$ sulfide as a secondary phase suggests removal of trace elements from the fluid and fixation in the rock.

SEM examination of the basalt reacted at $400^{\circ} \mathrm{C}$ shows intense alteration to biotite and anhydrite immediately adjacent to the entry point of the brine. At the top of the Reactor, anhydrite and smectite are found as the secondary minerals. At $350^{\circ} \mathrm{C}$, the alteration assemblage found at the bottom of the Reactor consists of smectite (with two distinct textures) and anhydrite. At the top of the Reactor only smectite is found as a secondary phase.

Mass balance results show significant uptake of $\mathrm{SiO}_{2}$ and $\mathrm{K}$ by the fluid at $400^{\circ} \mathrm{C}$ but only $\mathrm{SiO}_{2}$ at $350^{\circ} \mathrm{C}$. This suggests greater secondary mineral precipitation at the lower temperature. $\mathrm{SO}_{4}$ shows significant losses from the fluid due to anhydrite precipitation. All other elements are essentially conservative meaning that any $\mathrm{Ca}, \mathrm{Mg}$, or Fe released from the rock was precipitated as anhydrite and smectite.

\subsubsection{Seawater-only experiments (SW1, SW2)}

The seawater-only experiments were carried out to determine the behaviour of seawater in the absence of basalt and to provide the input solution compositions for the seawater-basalt experiments. These are essentially control experiments that used the Preheater only, without the Reactor.

Effluent chemistry results show in situ $\mathrm{pH}$ values of $5.3-5.4\left(377^{\circ} \mathrm{C}\right)$ and 5.5 $\left(342^{\circ} \mathrm{C}\right)$. Quench $\mathrm{pH}$ values are highly acidic at $3.2-3.9\left(377^{\circ} \mathrm{C}\right)$ and $2.9-3.7\left(342^{\circ} \mathrm{C}\right)$. These low quench $\mathrm{pH}$ values are due to retrograde solubility phases that release $\mathrm{H}^{+}$during precipitation. The $\mathrm{H}^{+}$is ion-paired at high temperature but upon cooling these complexes 
deprotonate resulting in acidic solutions. Fluid chemistry and mass balance results from both experiments show significant decreases in $\mathrm{Mg}, \mathrm{Ca}$, and $\mathrm{SO}_{4} . \mathrm{Na}, \mathrm{K}$ and $\mathrm{Cl}$ are conservative. Elevated concentrations of $\mathrm{SiO}_{2}, \mathrm{Al}$, and $\mathrm{Fe}$, which cannot be sourced from seawater, are derived from the $\mathrm{ZrO}_{2}$ beads used in the Preheater. Trace element concentrations above blank seawater values are found including $\mathrm{V}, \mathrm{Cr}, \mathrm{Mn}, \mathrm{Co}, \mathrm{Cu}, \mathrm{Ni}, \mathrm{Zn}, \mathrm{Cd}, \mathrm{Ba}$, and $\mathrm{Au}$. These must also derived from the $\mathrm{ZrO}_{2}$ beads.

The mineral precipitates from both seawater-only experiments were the same. They consisted of anhydrite, caminite and brucite. These phases have retrograde solubility and hence precipitated during the heating of the seawater.

\subsubsection{Basalt-seawater interactions (BSW1, BSW2)}

The seawater-basalt experiments provide the first example of flow-through experiments using preheated seawater and rock. They were performed to simulate (at a much smaller scale) the descent of seawater into the recharge zone and its reaction with basaltic rocks in the reaction zone at mid-ocean ridges.

The results from both experiments (green lines, Fig. 7.1) indicate that seawater reacted aggressively with the basalt. Fluid chemistry results show calculated in situ $\mathrm{pH}$ values of $\sim 5.8\left(400^{\circ} \mathrm{C}\right)$ and $5.3\left(350^{\circ} \mathrm{C}\right)$ while quench $\mathrm{pH}$ values are acidic at $3.6-4.7\left(400^{\circ} \mathrm{C}\right)$ and $3.1-4.4\left(350^{\circ} \mathrm{C}\right)$.

Major changes in fluid chemistry due fluid-rock interaction are observed in both experiments. $\mathrm{SiO}_{2}$ concentrations increase substantially, and are above quartz saturation, but are not specifically elevated during glass dissolution due to immediate precipitation of secondary minerals. Ca concentrations greatly increase while there are smaller increases in Fe. Most Mg concentrations decrease to near or below detection limit (at $1 \mathrm{ml} \mathrm{hr}^{-1}$ ). $\mathrm{Na}, \mathrm{K}$ and $\mathrm{Cl}$ are generally conservative. Increased flow rate results in decreases in $\mathrm{Ca}$ concentration and increases in $\mathrm{Mg}$ and $\mathrm{Fe}$ concentrations. This is attributed to the effect of shorter fluid residence time on plagioclase dissolution (resulting in less $\mathrm{Ca}$ ) and chlorite precipitation (resulting in higher $\mathrm{Mg}$ and $\mathrm{Fe}$ ). $\mathrm{SiO}_{2}$ concentration is independent of flow rate showing that it is buffered by opposing mineral reactions.

Mass balance calculations show the highest uptake of $\mathrm{Mg}$ occurred in the bottom third to half of the Reactor at $400^{\circ} \mathrm{C}$ and only in the bottom portion of the rock at $350^{\circ} \mathrm{C}$. This is attributed to a shorter experiment time and the lower temperature. Complete chloritization occurs and results in a maximum uptake $\sim 9 \mathrm{~g} 100 \mathrm{~g}^{-1}$ rock of $\mathrm{Mg}$ at both temperatures. 
Maximum uptake of $\mathrm{S}$ occurs approximately halfway up the Reactor at $400^{\circ} \mathrm{C}$ and at the bottom of the Reactor at $350^{\circ} \mathrm{C}$. The uptake of $\mathrm{S}$ is due to the precipitation of anhydrite.

SEM examination of the reacted basalt from the $400^{\circ} \mathrm{C}$ experiment shows that the dominant secondary phase at the bottom of the Reactor is chlorite. Further up the Reactor, complete chloritization of the rock is found. At approximately halfway up the Reactor the dominant secondary mineral changes from chlorite to smectite. This change is accompanied by the highest anhydrite content. At the top of the Reactor, smectite occurs as the dominant secondary phase, albeit only as thin coatings on the surface of relatively unreacted grains. At $350^{\circ} \mathrm{C}$, the observed distribution of minerals is similar, however, the alteration only proceeded within the very bottom of the Reactor near the entry point of the fluid. This is attributed to the lower temperature and shorter time of the experiment.

The results indicate that at least three alteration fronts occurred during seawater-basalt interaction in the experiments: the dissolution of volcanic glass; a chloritization front replacing all the primary minerals (excluding Fe-Ti oxides); and an accompanying peak in anhydrite precipitation which moves with the chloritization front.

Trace element results are perhaps informative. During the distilled water experiments, some trace elements are released during glass dissolution. In the seawater-only experiments, some trace elements are released from the $\mathrm{ZrO}_{2}$ beads. However, the trace element concentrations measured from the BSW experiments show in general lower values. The suggestion is that if these elements are entering the rock or released during glass dissolution, they are fixed during alteration of the rock.

As $\mathrm{Na}$ and $\mathrm{K}$ are essentially conservative during fluid-rock interaction, the $\mathrm{Na} / \mathrm{K}$ ratio in the fluid remains unchanged. As a result, estimated temperatures using common $\mathrm{Na} / \mathrm{K}$ geothermometers are inaccurate and reflect solely the input seawater composition. 
Table 7.1. Parameters and results from the experiments of this study.

\begin{tabular}{|c|c|c|c|c|c|c|c|c|}
\hline Parameter & $\begin{array}{c}\text { BW1 } \\
400^{\circ} \mathrm{C} / 502 \text { bar }\end{array}$ & $\begin{array}{c}\text { BW2 } \\
350^{\circ} \mathrm{C} / 490 \text { bar }\end{array}$ & $\begin{array}{c}\text { BGB1 } \\
400^{\circ} \mathrm{C} / 483 \mathrm{bar}\end{array}$ & $\begin{array}{c}\text { BGB2 } \\
350^{\circ} \mathrm{C} / 486 \text { bar }\end{array}$ & $\begin{array}{c}\text { SW1 } \\
377^{\circ} \mathrm{C} / 488 \text { bar }\end{array}$ & $\begin{array}{c}\mathrm{SW} 2 \\
342^{\circ} \mathrm{C} / 488 \text { bar }\end{array}$ & $\begin{array}{c}\text { BSW1 } \\
400^{\circ} \mathrm{C} / 488 \text { bar }\end{array}$ & $\begin{array}{c}\text { BSW2 } \\
350^{\circ} \mathrm{C} / 488 \text { bar }\end{array}$ \\
\hline Fluid & Water (distilled) & Water (distilled) & Geothermal Brine & Geothermal Brine & Seawater (natural) & Seawater (natural) & Seawater (natural) & Seawater (natural) \\
\hline Rock & Basalt & Basalt & Basalt & Basalt & No Rock & No Rock & Basalt & Basalt \\
\hline Total time / hrs & 913.5 & 1144.7 & 853.2 & 907.8 & 546.7 & 381.2 & 659 & 311 \\
\hline Pressure Vessels used & Reactor & Reactor & Reactor & Reactor & Preheater & Preheater & Preheater and Reactor & Preheater and Reactor \\
\hline Weight of Rock / $\mathrm{g}$ & 26.2 & 26.6 & 27 & 26.4 & - & - & 26.5 & 26.3 \\
\hline Total Fluid Flux / L & 0.77 & 1.02 & 0.69 & 0.75 & 0.40 & 0.33 & 1.48 & 1.15 \\
\hline Flow-rate / $\mathrm{ml} \mathrm{hr}^{-1}$ & $1-0.5$ & $1-0.5$ & $1-0.5$ & 1 & 1 & 1 & $1-1.5-10-7.5-5$ & $1-10-5-2.5-1$ \\
\hline Glass dissolution Time / hr & 314 & 288 & 407 & 550 & - & - & Cannot be determined & Cannot be determined \\
\hline Estimate of Glass / $\mathbf{m g}$ & 620 & 600 & 530 & 330 & - & - & Cannot be determined & Cannot be determined \\
\hline $\begin{array}{c}\Sigma \mathrm{SiO}_{2} \text { Input flux / } \mathrm{mg} \\
\Sigma \mathrm{SiO}_{2} \text { Output flux / } \mathrm{mg}\end{array}$ & $\begin{array}{c}0 \\
+769\end{array}$ & $\begin{array}{c}0 \\
+894\end{array}$ & $\begin{array}{c}525 \\
+504\end{array}$ & $\begin{array}{c}661 \\
+226\end{array}$ & $\begin{array}{r}2.7 \\
+17\end{array}$ & $\begin{array}{c}1.9 \\
+3.8\end{array}$ & $\begin{array}{c}80 \\
+2427\end{array}$ & $\begin{array}{c}17 \\
+2180\end{array}$ \\
\hline $\begin{array}{l}\Sigma \mathrm{H}_{2} \mathrm{~S} \text { Input flux } / \mathrm{mg} \\
\Sigma \mathrm{H}_{2} \mathrm{~S} \text { Output flux / } \mathrm{mg}\end{array}$ & $\begin{array}{c}0 \\
+1\end{array}$ & $\begin{array}{c}0 \\
+1\end{array}$ & $\begin{array}{l}0.14 \\
+0.7\end{array}$ & $\begin{array}{c}0 \\
+0.3\end{array}$ & $\begin{array}{l}\text { n.a. } \\
\text { n.a. }\end{array}$ & $\begin{array}{l}\text { n.a. } \\
\text { n.a. }\end{array}$ & $\begin{array}{c}0 \\
+0.34\end{array}$ & $\begin{array}{c}0 \\
+0.13\end{array}$ \\
\hline$\Sigma \mathrm{SO}_{4}$ Input flux / mg & 0 & 0 & 280 & 305 & 856 & 746 & 171 & 298 \\
\hline$\Sigma \mathrm{SO}_{4}$ Output flux / $\mathrm{mg}$ & +0.6 & +2.1 & -45 & -58 & -814 & -669 & -143 & -285 \\
\hline$\Sigma$ Ca Input flux / mg & 0 & 0 & 2 & 5 & 152 & 107 & 125 & 64 \\
\hline$\Sigma$ Ca Output flux / mg & +0.4 & +0.6 & +0.2 & -4 & -121 & -89 & +876 & +725 \\
\hline$\Sigma$ Fe Input flux / mg & 0 & 0 & 0.06 & 0 & 0.04 & 0.03 & 108 & 109 \\
\hline$\Sigma F e$ Output flux / mg & +0.2 & +0.4 & +0.009 & +0.07 & +25 & +23 & +317 & +159 \\
\hline$\Sigma \mathrm{K}$ Input flux / mg & 0 & 0 & 80 & 87 & - & - & 487 & 377 \\
\hline$\Sigma K$ Output flux / mg & +5 & +9 & +4 & +15 & - & - & -5.4 & +17 \\
\hline$\Sigma$ Mg Input flux / mg & 0 & 0 & 0.1 & 0.7 & 450 & 297 & 832 & 602 \\
\hline$\Sigma$ Mg Output flux / mg & +0.1 & +0.1 & +0.1 & -0.5 & -235 & -130 & -657 & -537 \\
\hline$\Sigma \mathrm{Na}$ Input flux / mg & 0 & 0 & 502 & 543 & - & - & 12278 & 9512 \\
\hline$\Sigma \mathrm{Na}$ Output flux / mg & +24 & +38 & -18 & -5 & - & - & -51 & -114 \\
\hline Maximum $\mathrm{pH}^{2}{ }^{\circ} \mathrm{T}$ & 6.76 & 6.37 & 7.12 & 6.84 & 5.39 & 5.53 & 5.82 & 5.31 \\
\hline Minimum $\mathrm{pH}$ at ${ }^{\circ} \mathrm{T}$ & 5.66 & 5.30 & 7.00 & 6.66 & 5.25 & 5.51 & 5.73 & 5.22 \\
\hline Maximum quench pH & 9.47 & 9.66 & 7.76 & 7.91 & 3.85 & 3.72 & 4.65 & 4.36 \\
\hline Minimum quench pH & 5.04 & 5.50 & 2.87 & 3.39 & 3.19 & 2.92 & 3.58 & 3.11 \\
\hline $\begin{array}{l}\text { Secondary } \\
\text { Mineralogy }\end{array}$ & $\begin{array}{c}\text { Anorthite } \\
\text { Chlorite } \\
\text { Wollastonite } \\
\text { Grossular } \\
\text { Celadonite } \\
\text { Sphene } \\
\text { Magnetite }\end{array}$ & $\begin{array}{l}\text { Anorthite } \\
\text { Chlorite } \\
\text { Sphene } \\
\text { Celadonite }\end{array}$ & $\begin{array}{l}\text { Anhydrite } \\
\text { Biotite } \\
\text { Smectite } \\
\text { Cu-sulfide } \\
\text { Magnetite }\end{array}$ & $\begin{array}{l}\text { Anhydrite } \\
\text { Smectite } \\
\text { Cu-sulfidid }\end{array}$ & $\begin{array}{l}\text { Anhydrite } \\
\text { Caminite } \\
\text { Brucite }\end{array}$ & $\begin{array}{l}\text { Anhydrite } \\
\text { Caminite } \\
\text { Brucite }\end{array}$ & $\begin{array}{c}\text { Anhydrite } \\
\text { Caminite } \\
\text { Chlorite } \\
\text { Calcite } \\
\text { Ankerite } \\
\text { Smectite } \\
\text { Hematite } \\
\text { Maghemite }\end{array}$ & $\begin{array}{l}\text { Anhydrite } \\
\text { Chlorite } \\
\text { Calcite } \\
\text { Ankerite } \\
\text { Smectite } \\
\text { Magnetite }\end{array}$ \\
\hline
\end{tabular}


Figure 7.1. Summary of the $\mathrm{pH}$ and major species concentrations in the water, geothermal brine and seawater experiments.
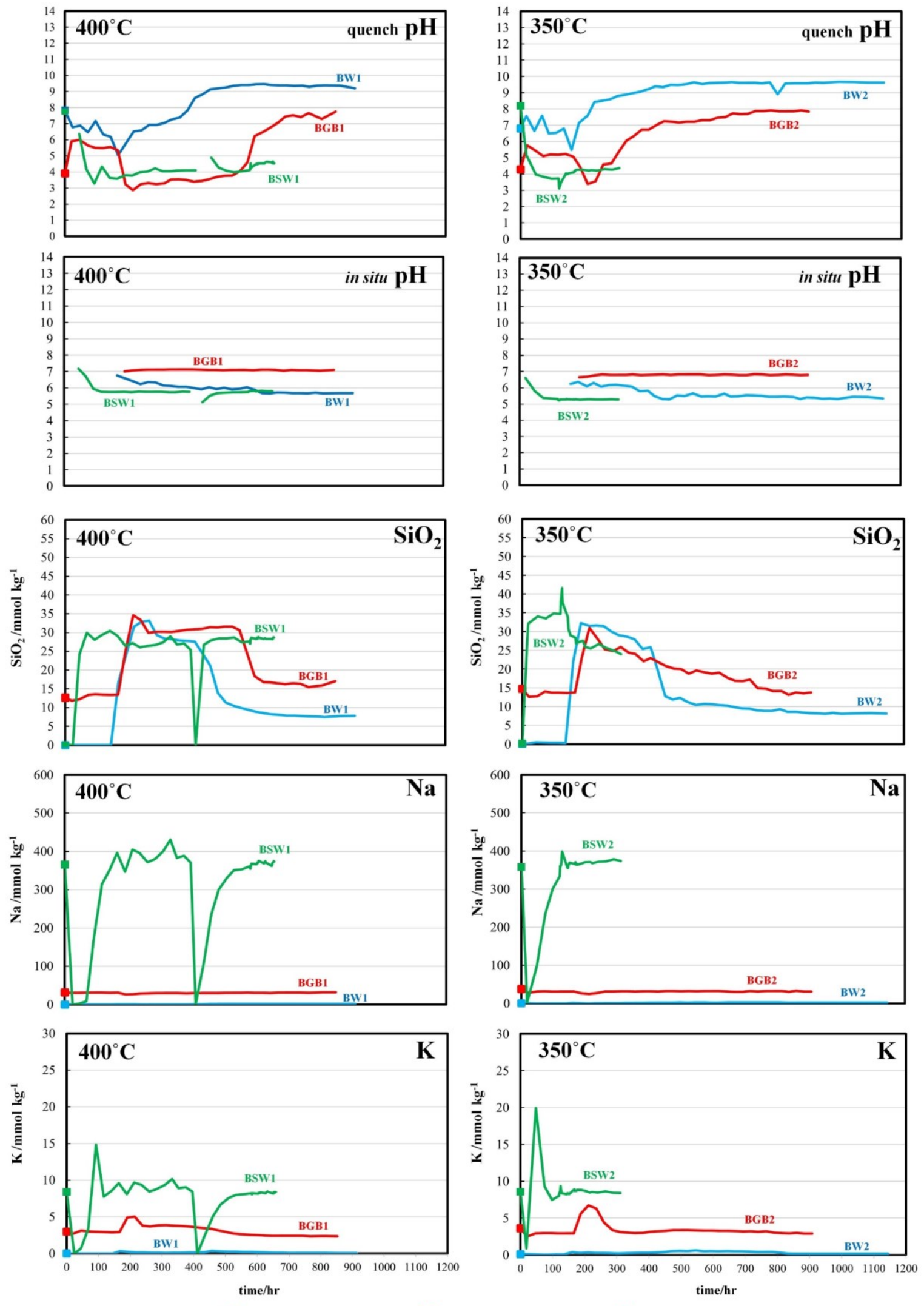

blank BW experiments

blank BGB experiments

blank BSW experiments 

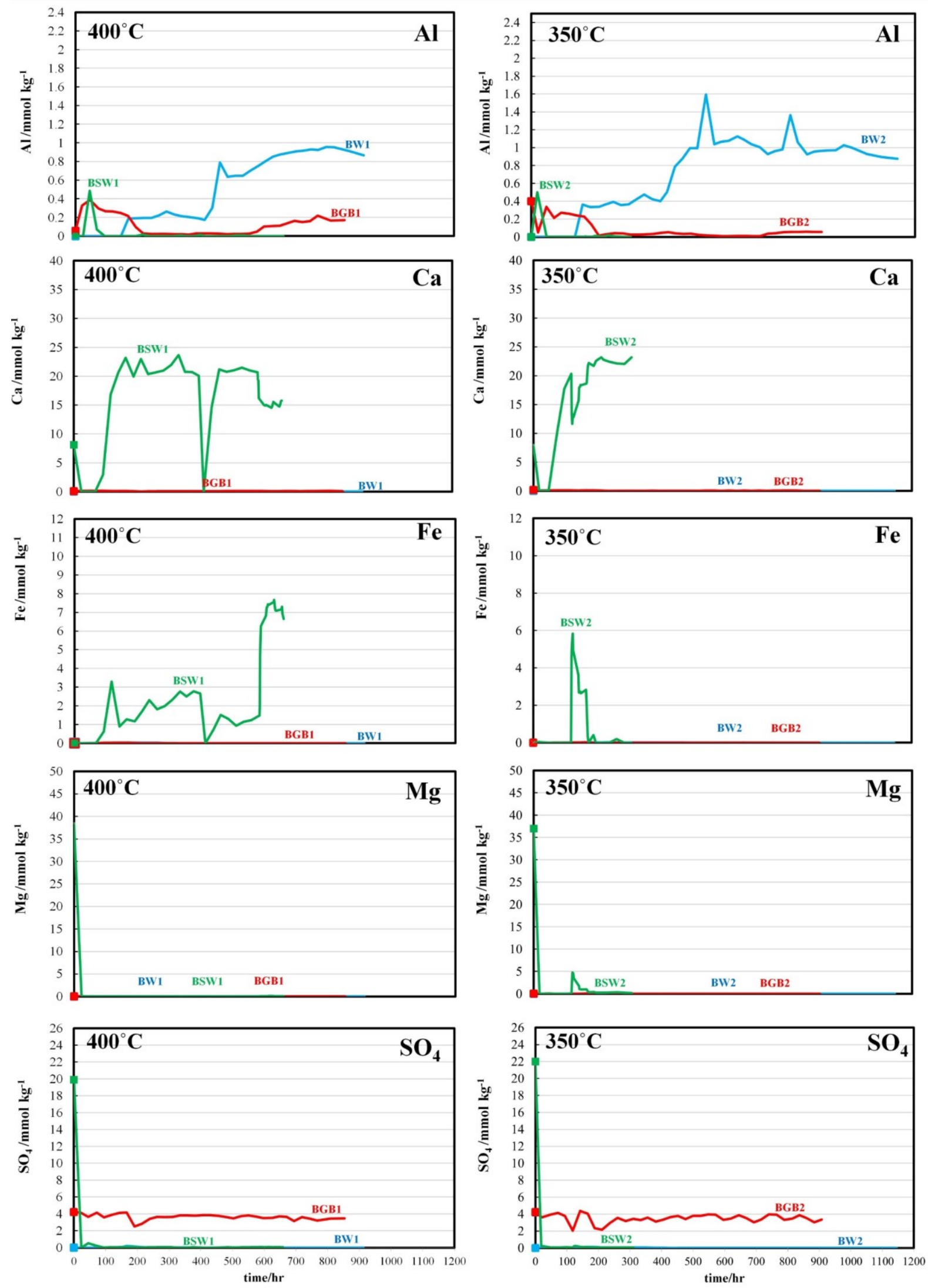

blank BW experiments

blank BGB experiments

blank BSW experiments 

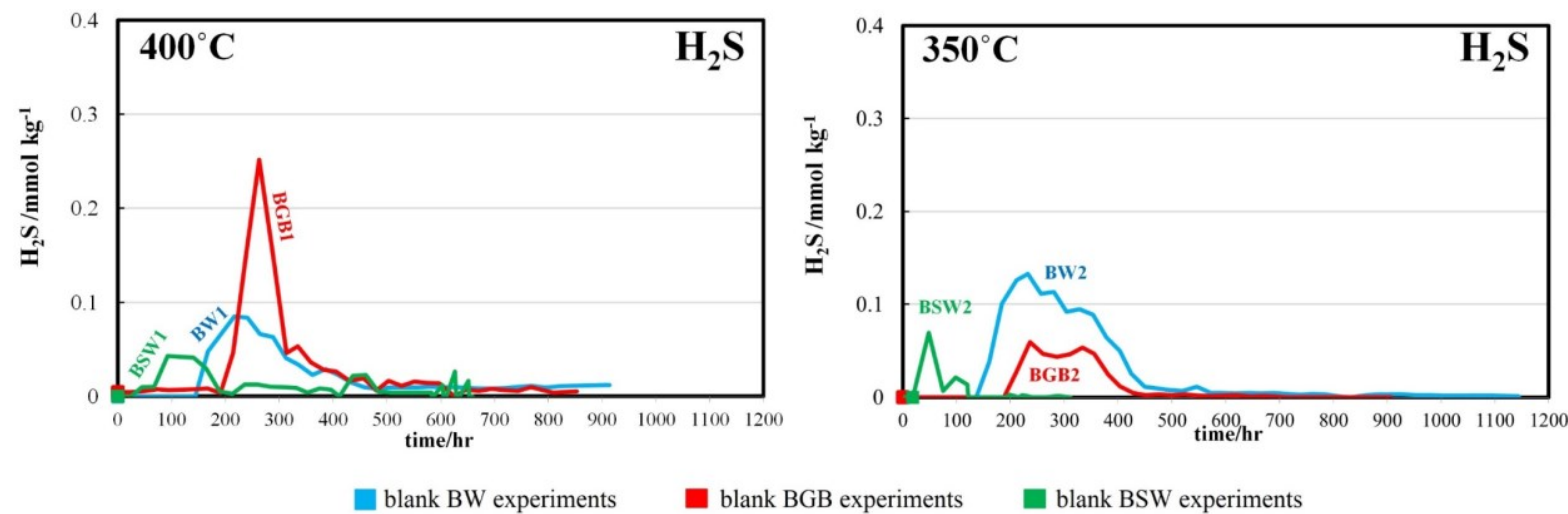


\subsection{Conclusions}

Eight experiments have been conducted to investigate the interaction of three different fluids with basalt at subcritical, near-supercritical, and supercritical conditions. From the results of this study, the following conclusions can be made.

\section{Experimental Method}

1. A novel experimental method has been developed to allow continuous flow experiments between seawater and rock substrates without the hinderance of retrograde mineral precipitation.

II. Distilled Water - basalt

1. A skarn-like Ca-silicate assemblage can result from the extraction of alkali cations from basalt by pure water at high temperature.

2. The precipitation of celadonite can occur in basalt with K-bearing glass without the addition of outside components.

3. At $400^{\circ} \mathrm{C}$ reaction rates are extremely fast and result in the growth of phases such as garnet even on the time scale of a short experiment.

4. The alteration mineralogy is determined by the rock.

5. There is some evidence of $\mathrm{Cu}, \mathrm{Co}$, and $\mathrm{Mo}$ release during devitrification of volcanic glass.

III. Geothermal brine - basalt

1. The injection of $\mathrm{SO}_{4}$-containing geothermal brine into basalt results in the precipitation of anhydrite at both temperatures.

2. The precipitation of biotite occurred immediately upon entry of the fluid at $400^{\circ} \mathrm{C}$ while smectite was found at $350^{\circ} \mathrm{C}$. This is due to the faster precipitation rate of biotite at higher temperature.

3. The precipitation of K-bearing secondary phases is due to the higher $\mathrm{K}$ concentrations in the geothermal brine.

4. Hence, the alteration mineralogy is largely determined by the fluid composition.

5. The presence of metal sulfides as precipitates suggests fixation from the fluid rather than release from the rock. 
IV. Seawater - only

1. The progressive heating of seawater results in the precipitation of anhydrite, caminite and brucite.

2. The preheated seawater is in equilibrium with anhydrite, caminite and brucite upon exit from the Preheater.

3. Preheated seawater has a near-neutral $\mathrm{pH}$ at $350-400^{\circ} \mathrm{C}$, however, this becomes highly acidic upon cooling.

4. Many trace elements were released from the $\mathrm{ZrO}_{2}$ beads used in the Preheater. They are not necessarily ideal for trace element experiments.

V. Seawater - basalt

1. The seawater-basalt experiments provide the first example of flow-through experiments using natural seawater and basalt.

2. In situ $\mathrm{pH}$ values were near-neutral in the effluent samples.

3. Mass balance calculations show a maximum uptake of $\sim 9 \mathrm{~g} 100 \mathrm{~g}^{-1}$ rock of $\mathrm{Mg}$ after complete chloritization of the basalt, at both temperatures.

4. The alteration mineralogy shows at least three alteration fronts: dissolution of volcanic glass (which passed completely through the rock in all experiments); intense chloritization which switches to smectitization and results in consumption of all $\mathrm{Mg}$ in the fluid; and an anhydrite precipitation front that coincides with the switch between chlorite and smectite.

5. The alteration is driven by the high $\mathrm{Mg}$ concentration in the fluid thus alteration mineralogy is controlled by the fluid until $\mathrm{Mg}$ is consumed.

6. The rate of reaction is extremely fast at both temperatures with an estimate of a few hours to fix essentially all $\mathrm{Mg}$ from the seawater by the rock.

7. The relative resistance of phases to alteration, from lowest to highest, is glass - olivine clinopyroxene - plagioclase - Fe-Ti oxides. For the silicate phases this is related to their relative $\mathrm{Al}$ contents (except glass which is an amorphous phase and highly soluble).

8. The trace element results show that they are fixed in the altered rock and not released. This suggests that chloritization of the basalt is not the source of metals for the generation of volcanogenic massive sulfide deposits. 


\subsection{Further Work}

The experimental method developed for this study can be applied to many geochemical problems. It is specifically applicable to fluid-rock interactions experiments using seawater as the experimental fluid due to the problem of retrograde mineral solubility. The apparatus can be used to study the thermodynamic parameters for retrograde solubility phases.

In terms of basalt - seawater experiments, further experiments for a longer period of time would greatly contribute to the understanding of how fast the alteration fronts progress through the rock. The computer modelling of fluid-rock interactions in the Reactor using geochemical/hydrological modelling software such as CHEMTOUGH would greatly enhance the understanding of the chemical gradients during alteration and confirm the results found in our experiments. 


\section{APPENDICES}


Appendices Doctoral Thesis: "Basalt - fluid interactions at subcritical and supercritical conditions: An experimental study" University of Victoria Wellington and GNS Science, Wairakei, New Zealand

Appendix A - (Chapter 2) 


\section{Chapter 2: Experimental Method}

\subsubsection{Unreacted basalt: mineralogy, texture and mineral chemistry}

Figure A.2.1. SEM photographs of the petrographic thin section points analysed by EMPA (Fig. 2.4, Area A-E in the thesis). (a) SEM picture of point A analysed by EMPA (red rectangle); (b) enlargement of picture in (a) showing plagioclase (darker grey), clinopyroxene (lighter grey) and olivine. Oxides appear in bright white

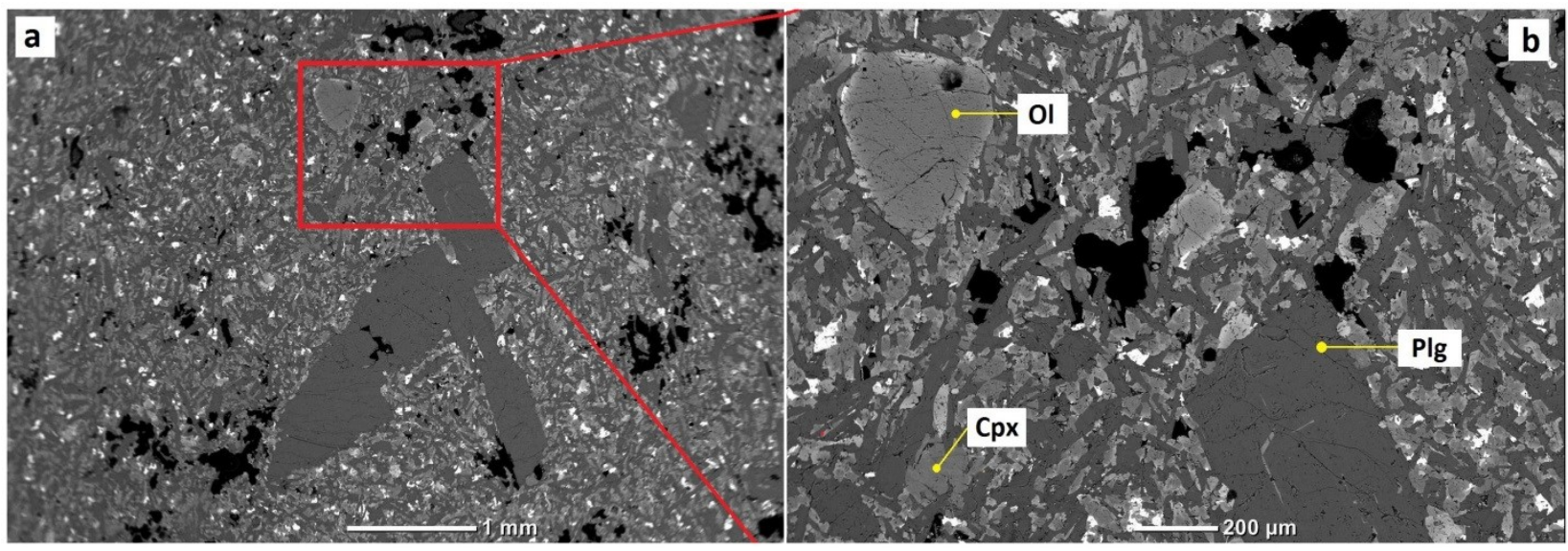

Figure A.2.2. SEM picture of point B. Photograph shows the presence of plagioclase, clinopyroxene and olivine. Oxides appear in a bright white

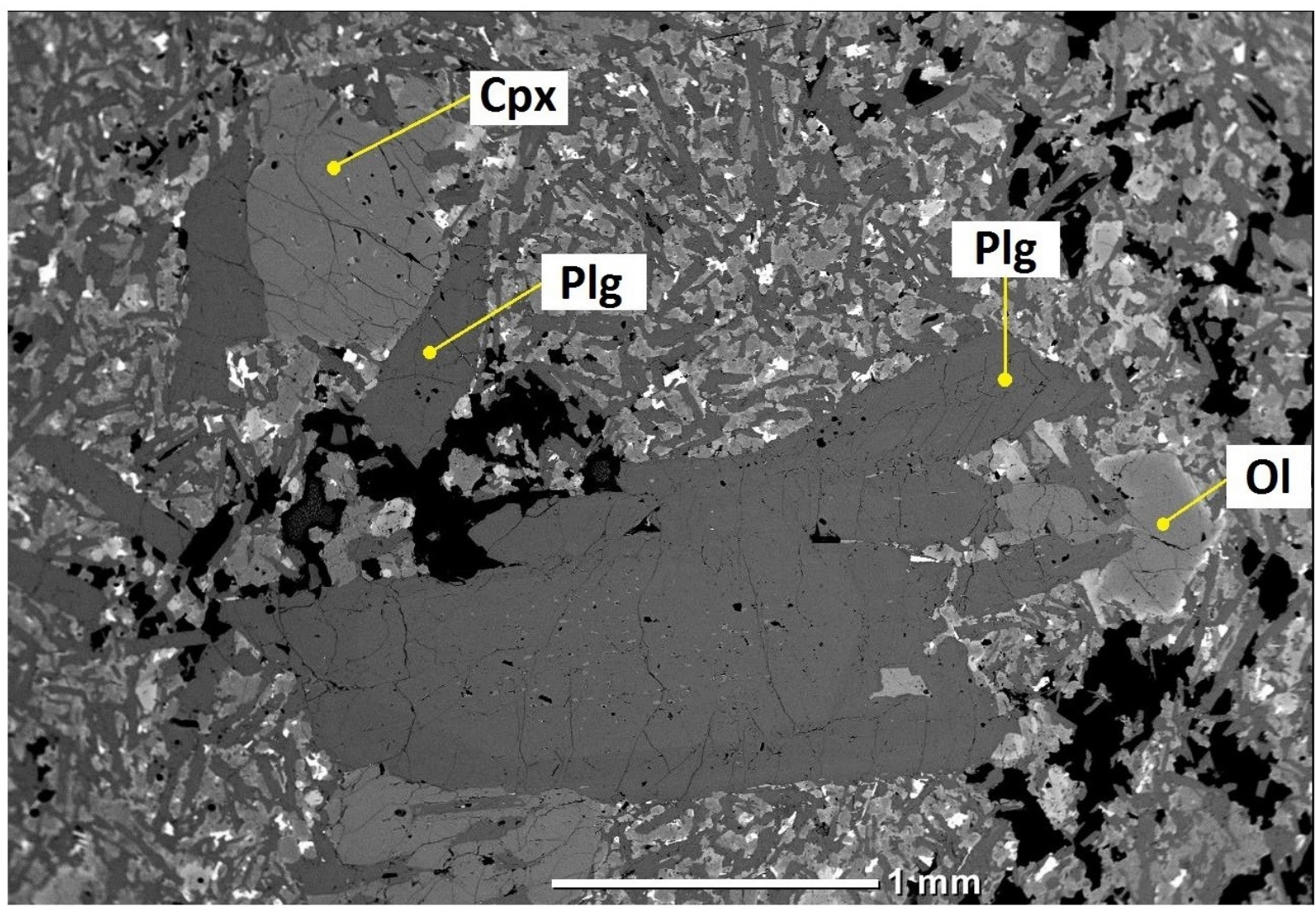


Figure A.2.3. Point D. SEM photographs. (a) glass area for chemical analysis marked in red rectangle; (b) enlargement of picture in (a) showing the areas (yellows lines) with presence of glass. In (c) composite colour image of picture in (b) shows plagioclase (in green), clinopyroxene (in light red), glass (in dark red), oxides (in white) and apatite (in blue-violet) trapped within the glass

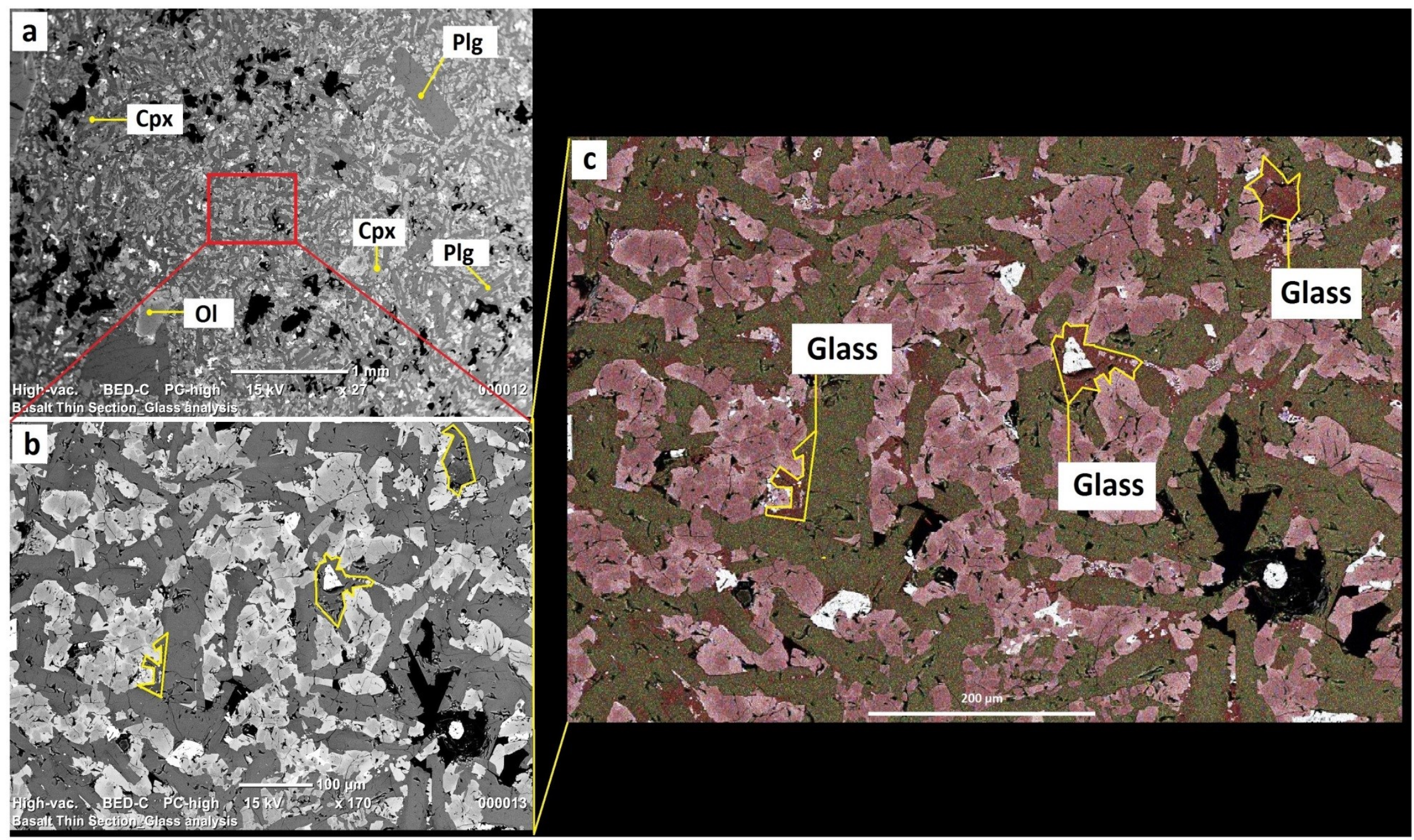


Figure A.2.4. SEM-EDS elemental map off Point D for glass analysis. d) grey scale image. In e) composite colour image combining maps for a) Al, b) Si and c) P shows plagioclase (in green), clinopyroxene (in wine colour), glass (in reddish), oxides (in white) and apatite (in blue-violet) trapped within the glass

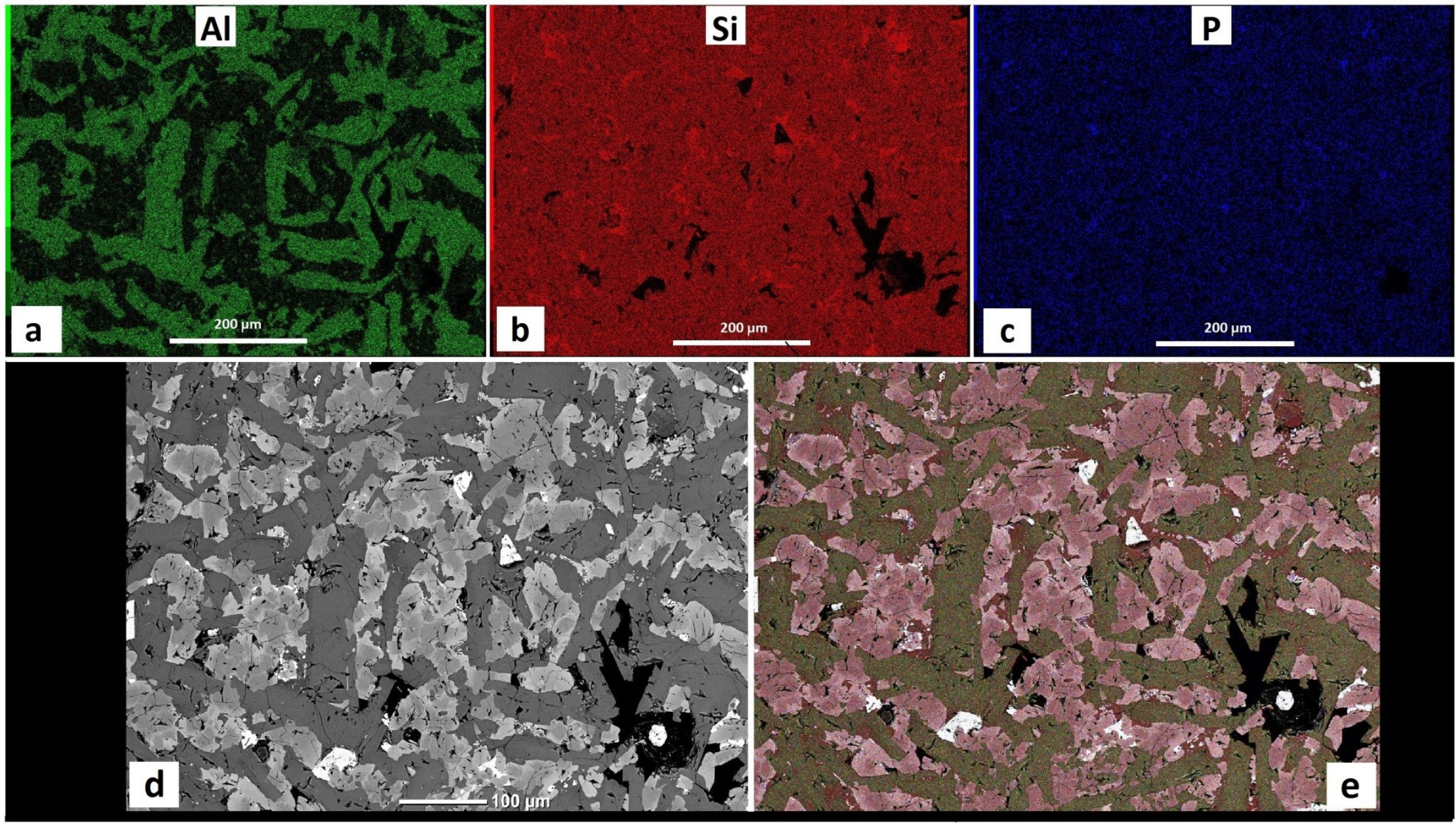


Figure A.2.5. Point E. SEM photographs. (a) glass area for chemical analysis marked in red rectangle; (b) enlargement of picture in (a) showing areas (yellow lines) with the presence of glass; In (c) composite colour image of picture in (b) shows plagioclase (in green), clinopyroxene (in light red), glass (in dark red), oxides (in white) and apatite (in blue-violet) trapped within the glass

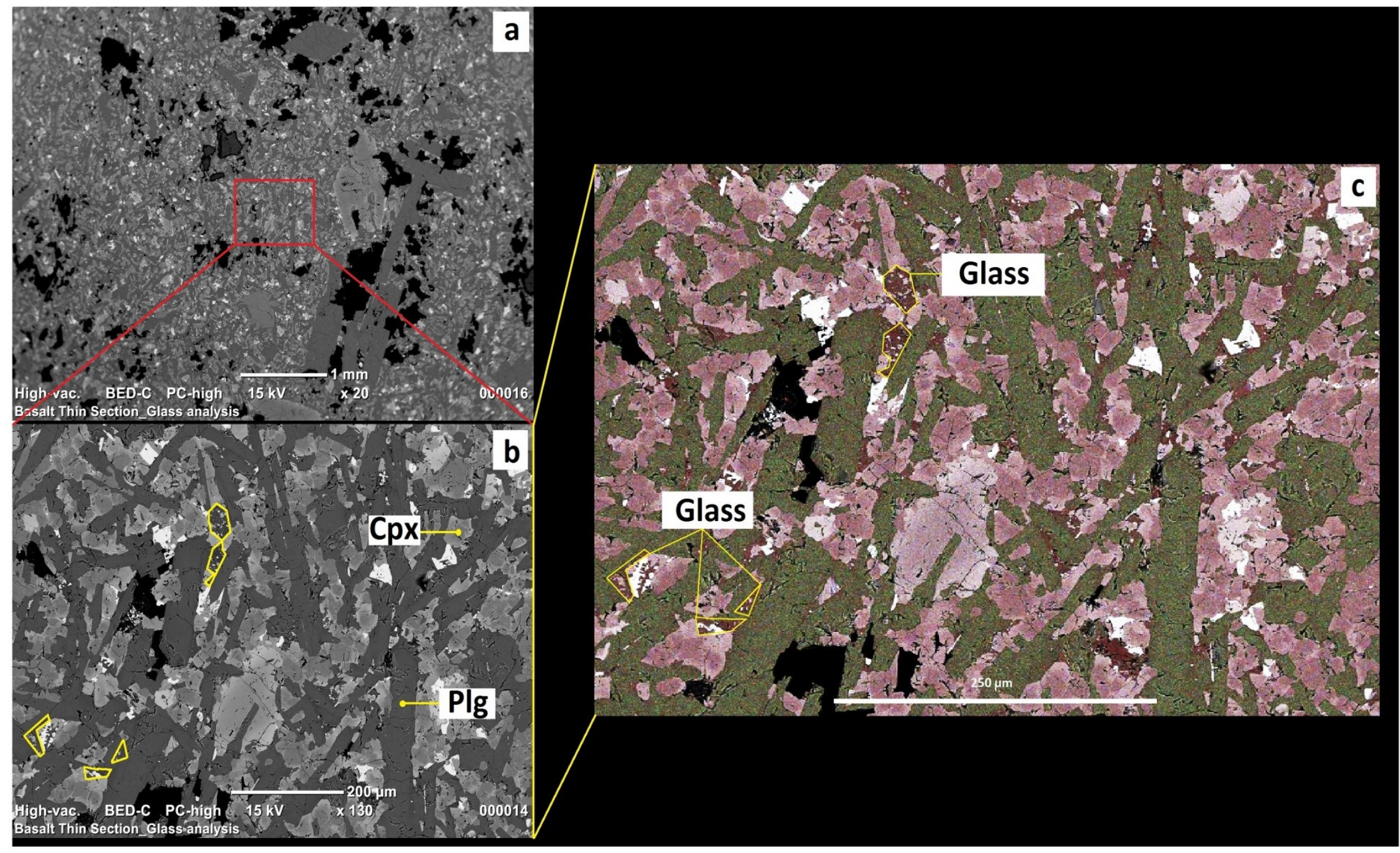


Figure A.2.6. SEM-EDS elemental map of Point $\mathrm{E}$ for glass analysis. d) grey scale image. In e) composite colour image combining maps for a) Al, b) Si and c) P shows plagioclase (in green), clinopyroxene (in wine colour), glass (in reddish), oxides (in white) and apatite (in blue-violet) trapped within the glass

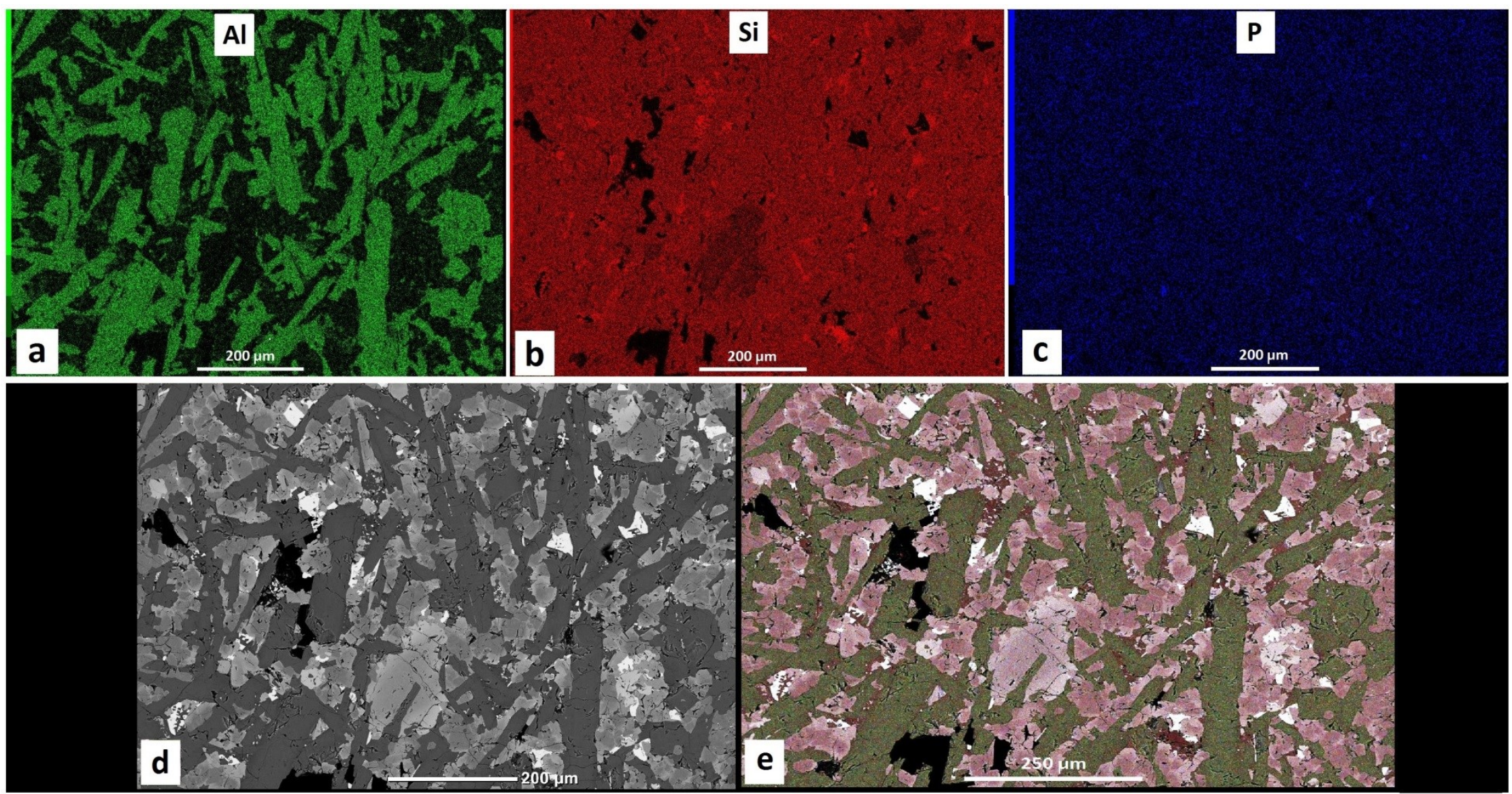


Table A.2.1. Electron Microprobe Analysis (EMPA) of the petrographic thin section (Fig. 2.4. - Area A-E)

$\begin{array}{cc}\text { Plg } & \text { Analysis } \\ \text { Point B } & \text { Point } \\ & 1 \\ & 2 \\ & 3 \\ & 4 \\ & 5 \\ & 6 \\ & 7 \\ & 8 \\ & 9 \\ & 10 \\ & 11 \\ & 12 \\ & 13 \\ \text { Point C } & 14 \\ & 15 \\ & 16 \\ & 17 \\ & 18 \\ & 19 \\ & 20 \\ & 21 \\ & 22 \\ & 23 \\ & 24\end{array}$

$\begin{array}{llllllll}\mathrm{Na}_{2} \mathrm{O} & \mathrm{MgO} & \mathrm{SiO}_{2} & \mathrm{Al}_{2} \mathrm{O}_{3} & \mathrm{FeO} & \mathrm{CaO} & \mathrm{K}_{2} \mathrm{O} & \mathrm{TiO}_{2}\end{array}$

$\begin{array}{lllllllll}2.50 & 0.25 & 49.80 & 32.15 & 0.64 & 15.77 & 0.03 & 0.03\end{array}$ $\begin{array}{lllllllll}2.52 & 0.27 & 49.51 & 31.87 & 0.72 & 15.45 & 0.03 & 0.05\end{array}$ $\begin{array}{llllllllll}2.69 & 0.25 & 40.25 & 1.62 & 0.58 & 14.92 & 0.04 & 0.04\end{array}$ $\begin{array}{llllllll}1.29 & 0.25 & 45.93 & 34.46 & 0.48 & 18.11 & 0.01 & 0.00\end{array}$ $\begin{array}{lllllllll}1.21 & 0.25 & 45.71 & 34.48 & 0.46 & 18.14 & 0.01 & 0.01 \\ 1.82 & 0.20 & 47.53 & 33.55 & 0.61 & 17.01 & 0.02 & 0.03\end{array}$ $\begin{array}{llllllll}2.17 & 0.23 & 48.43 & 32.90 & 0.62 & 16.22 & 0.02 & 0.02\end{array}$ $\begin{array}{lllllllll}2.93 & 0.27 & 50.11 & 31.49 & 0.68 & 14.94 & 0.03 & 0.05\end{array}$ $\begin{array}{llllllll}3.19 & 0.24 & 50.77 & 31.08 & 1.02 & 14.10 & 0.07 & 0.06 \\ 2.83 & 0.19 & 50.04 & 31.49 & 0.91 & 14.73 & 0.07 & 0.05 \\ 3 & 0.02 & 50.58 & 3.00 & 0.90 & 14.52 & 0.03 & 0.07\end{array}$ $\begin{array}{lllllllll}3.01 & 0.29 & 50.58 & 31.00 & 0.90 & 14.52 & 0.03 & 0.07\end{array}$ $\begin{array}{lllllllll}1.98 & 0.22 & 47.60 & 33.44 & 0.65 & 16.54 & 0.02 & 0.03\end{array}$ $\begin{array}{llllllll}2.48 & 0.24 & 48.36 & 33.46 & 0.66 & 15.58 & 0.05 & 0.04 \\ 2.07 & 0.23 & 48.11 & 32.95 & 0.59 & 16.15 & 0.03 & 0.03\end{array}$ $\begin{array}{llllllll}2.07 & 0.23 & 48.11 & 32.95 & 0.59 & 16.15 & 0.03 & 0.03 \\ 2.73 & 0.26 & 50.27 & 31.88 & 0.62 & 15.14 & 0.04 & 0.05\end{array}$ $\begin{array}{lllllllll}2.58 & 0.26 & 49.44 & 32.14 & 0.64 & 15.45 & 0.03 & 0.04\end{array}$ $\begin{array}{llllllllll}259 & 0.27 & 49.09 & 31.76 & 0.62 & 15.20 & 0.04 & 0.04\end{array}$ $\begin{array}{lllllllll}3.28 & 0.21 & 50.68 & 30.42 & 0.88 & 13.64 & 0.08 & 0.11\end{array}$ $\begin{array}{llllllll}4.41 & 0.14 & 53.48 & 28.85 & 0.93 & 11.59 & 0.14 & 0.11 \\ 3.49 & 0.20 & 5.80 & 30.28 & 0.98 & 13.60 & 0.07 & 0.09\end{array}$ $\begin{array}{lllllllll}.49 & 0.20 & 50.80 & 30.28 & 0.98 & 13.60 & 0.07 & 0.09 \\ & 0.25 & 5.14 & 31.79 & 1.03 & 1.84 & 0.05 & 0.06\end{array}$ $\begin{array}{lllllllll}3.58 & 0.24 & 51.43 & 31.79 & 1.20 & 14.89 & 0.05 & 0.06 \\ 3 & 0.03 & 13.64 & 0.08 & 0.09\end{array}$ $\begin{array}{llllllll}3.12 & 0.27 & 50.11 & 31.02 & 0.88 & 14.37 & 0.05 & 0.06 \\ \mathbf{2 . 6 7} & \mathbf{0 . 2 4} & \mathbf{4 9 . 4 4} & \mathbf{3 1 . 8 8} & \mathbf{0 . 7 5} & \mathbf{1 5 . 2 0} & \mathbf{0 . 0 4} & \mathbf{0 . 0 5}\end{array}$

Total

101.16

100.41

100.49

00.53

100.27

100.60

00.51

100.30

100.41

100.48

9.87

10.15

9931

99.66

100.28

$\mathbf{1 0 0 . 2 8}$

average

Cpx

Point A

Analysis
Point

$\begin{array}{llllllllllll}\mathrm{SiO}_{2} & \mathrm{Al}_{2} \mathrm{O}_{3} & \mathrm{~K}_{2} \mathrm{O} & \mathrm{FeO} & \mathrm{Na}_{2} \mathrm{O} & \mathrm{MgO} & \mathrm{Cr}_{2} \mathrm{O}_{3} & \mathrm{TiO}_{2} & \mathrm{CaO} & \mathrm{NiO} & \text { MnO } & \text { Total }\end{array}$

$\begin{array}{llllllllllll}49.97 & 2.14 & 0.01 & 20.80 & 0.23 & 11.62 & 0.07 & 0.97 & 14.93 & 0.00 & 0.37 & 101.12\end{array}$ $\begin{array}{llllllllllll}51.57 & 2.04 & 0.00 & 11.58 & 0.16 & 15.94 & 0.11 & 0.52 & 17.39 & 0.06 & 0.28 & 99.67\end{array}$ $\begin{array}{llllllllllllll}51.64 & 3.85 & 0.01 & 11.70 & 0.21 & 15.04 & 0.11 & 0.52 & 1.75 & 0.78 & 15.83 & 0.07 & 0.23 & 100.72\end{array}$ $\begin{array}{lllllllllllll}51.86 & 7.50 & 0.02 & 11.01 & 1.42 & 12.88 & 0.21 & 0.66 & 15.01 & 0.06 & 0.23 & 100.85\end{array}$ $\begin{array}{lllllllllllll}51.97 & 3.60 & 0.01 & 7.40 & 0.22 & 17.64 & 0.47 & 0.50 & 18.13 & 0.00 & 0.14 & 100.07 \\ 51.47 & 3.66 & 0.01 & 7.70 & 0.17 & 17.50 & 0.52 & 0.55 & 18.13 & 0.01 & 0.21 & 99.93\end{array}$ $\begin{array}{lllllllllllll}51.47 & 3.66 & 0.01 & 7.70 & 0.17 & 17.50 & 0.52 & 0.55 & 18.13 & 0.01 & 0.21 & 99.93 \\ 52.58 & 2.00 & 0.00 & 7.15 & 0.23 & 18.83 & 0.32 & 0.36 & 17.67 & 0.00 & 0.14 & 99.27\end{array}$ $\begin{array}{llllllllllllll}52.82 & 3.38 & 0.00 & 7.68 & 0.21 & 18.10 & 0.44 & 0.41 & 17.46 & 0.02 & 0.14 & 100.59\end{array}$ $\begin{array}{llllllllllllll}52.65 & 3.10 & 0.00 & 7.24 & 0.22 & 18.03 & 0.40 & 0.40 & 18.16 & 0.04 & 0.16 & 100.39\end{array}$ $\begin{array}{lllllllllllll}52.42 & 2.86 & 0.02 & 7.24 & 0.22 & 18.03 & 0.40 & 0.40 & 18.16 & 0.04 & 0.16 & 100.39 \\ 52.57 & 2.82 & 0.03 & 72 & 0.23 & 18.02 & 0.42 & 0.38 & 18.46 & 0.02 & 0.21 & 100.15\end{array}$ $\begin{array}{llllllllllll}52.57 & 2.82 & 0.03 & 7.27 & 0.23 & 1824 & 0.48 & 0.37 & 17.94 & 0.04 & 0.10 & 100.08\end{array}$ $\begin{array}{llllllllllllll}51.68 & 3.97 & 0.01 & 7.62 & 0.22 & 17.30 & 0.56 & 0.61 & 18.13 & 0.00 & 0.20 & 100.30\end{array}$ $\begin{array}{llllllllllll}52.62 & 2.81 & 0.01 & 7.07 & 0.22 & 18.13 & 0.40 & 0.35 & 18.32 & 0.01 & 0.12 & 100.06 \\ \mathbf{5 1 . 9 8} & \mathbf{3 . 3 7} & \mathbf{0 . 0 1} & \mathbf{9 . 4 1} & \mathbf{0 . 3 0} & \mathbf{1 6 . 7 1} & \mathbf{0 . 3 7} & \mathbf{0 . 5 3} & \mathbf{1 7 . 3 5} & \mathbf{0 . 0 3} & \mathbf{0 . 1 9} & \mathbf{1 0 0 . 2 4}\end{array}$ $\begin{array}{llllllllllllllll}\text { Glass } & \text { Analysis } & \mathrm{SiO}_{2} & \mathrm{Al}_{2} \mathrm{O}_{3} & \mathrm{Na}_{2} \mathrm{O} & \mathrm{MgO} & \mathrm{TiO}_{2} & \mathrm{Cl} & \mathrm{SO}_{2} & \mathrm{~K}_{2} \mathrm{O} & \mathrm{CaO} & \mathrm{MnO} & \mathrm{FeO}_{(\mathrm{n}} & \mathrm{P}_{2} \mathrm{O}_{5} & \text { Total }\end{array}$ $\begin{array}{lllllllllllll}54.94 & 29.23 & 7.00 & 0.12 & 0.11 & 0.00 & 0.00 & 0.12 & 12.26 & 0.02 & 1.01 & 0.00 & 104.81\end{array}$

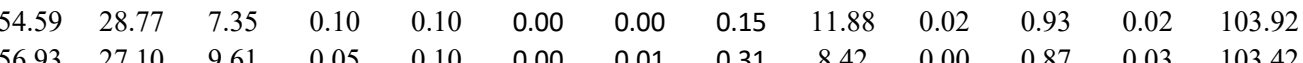
$\begin{array}{llllllllllllll}52.63 & 30.68 & 5.97 & 0.12 & 0.09 & 0.00 & 0.01 & 0.31 & 8.42 & 0.00 & 0.87 & 0.02 & 103.42\end{array}$ $\begin{array}{lllllllllllllll}53.70 & 29.72 & 6.38 & 0.11 & 0.10 & 0.00 & 0.00 & 0.12 & 12.89 & 0.01 & 0.96 & 0.00 & 103.98\end{array}$ $\begin{array}{llllllllllllll}57.28 & 27.27 & 9.19 & 0.06 & 0.12 & 0.00 & 0.01 & 0.28 & 9.65 & 0.00 & 0.86 & 0.01 & 104.73\end{array}$

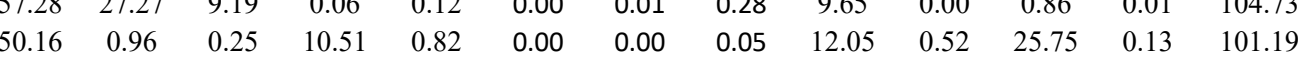
$\begin{array}{lllllllllllll}73.38 & 14.68 & 6.51 & 0.10 & 0.72 & 0.07 & 0.04 & 3.21 & 2.78 & 0.03 & 1.17 & 0.61 & 103.30\end{array}$ $\begin{array}{lllllllllllll}54.79 & 28.82 & 7.72 & 0.09 & 0.13 & 0.00 & 0.00 & 0.15 & 11.67 & 0.00 & 0.96 & 0.02 & 104.35 \\ 59.42 & 3.63 & 1.62 & 6.04 & 0.40 & 0.21 & 0.01 & 0.60 & 4.87 & 0.51 & 25.14 & 0.25 & 102.70\end{array}$ $\begin{array}{ccccccccccccc}59.42 & 3.63 & 1.62 & 6.04 & 0.40 & 0.21 & 0.01 & 0.60 & 4.87 & 0.51 & 25.14 & 0.25 & 102.70 \\ 59.77 & 25.61 & 10.63 & 0.04 & 0.10 & 0.01 & 0.00 & 0.32 & 7.76 & 0.00 & 0.90 & 0.04 & 105.18\end{array}$ $\begin{array}{llllllllllllll}76.23 & 11.71 & 6.68 & 0.03 & 0.57 & 0.15 & 0.01 & 2.14 & 2.64 & 0.00 & 0.90 & 0.04 & 105.18 \\ 7.13 & 1.19 & 102.50\end{array}$ $\begin{array}{lllllllllllll}60.25 & 24.49 & 10.34 & 0.09 & 0.16 & 0.07 & 0.01 & 0.32 & 8.01 & 0.00 & 1.04 & 0.66 & 105.42 \\ 75.53 & 12.19 & 2.21 & 0.02 & 0.90 & 0.21 & 0.01 & 5.33 & 0.58 & 0.05 & 1.67 & 0.10 & 99.31\end{array}$ $\begin{array}{lllllllllllll}76.81 & 10.93 & 2.05 & 0.05 & 0.85 & 0.29 & 0.03 & 5.55 & 0.54 & 0.02 & 2.42 & 0.13 & 99.66\end{array}$ $\begin{array}{lllllllllllll}67.42 & 10.20 & 2.61 & 0.22 & 3.86 & 0.12 & 0.05 & 4.23 & 1.26 & 0.16 & 11.95 & 0.13 & 102.21\end{array}$ $\begin{array}{lllllllllllll}60.39 & 25.40 & 10.99 & 0.04 & 0.10 & 0.00 & 0.00 & 0.41 & 7.26 & 0.03 & 0.84 & 0.02 & 105.47\end{array}$ $\begin{array}{lllllllllllll}68.93 & 11.32 & 6.18 & 0.02 & 0.29 & 0.17 & 0.01 & 2.88 & 4.33 & 0.01 & 1.10 & 1.85 & 97.09\end{array}$ $\begin{array}{lllllllllllll}87.32 & 5.68 & 3.13 & 0.00 & 0.15 & 0.08 & 0.01 & 0.15 & 0.93 & 0.00 & 0.47 & 0.01 & 97.93\end{array}$ $\begin{array}{lllllllllllll}63.31 & 24.11 & 12.38 & 0.00 & 0.07 & 0.01 & 0.00 & 0.75 & 5.29 & 0.01 & 0.52 & 0.00 & 106.46 \\ 93.83 & 3.29 & 1.51 & 0.01 & 0.18 & 0.01 & 0.00 & 0.11 & 0.43 & 0.00 & 0.59 & 0.00 & 99.96\end{array}$ $\begin{array}{llllllllllllll}93.83 & 3.29 & 1.51 & 0.01 & 0.18 & 0.01 & 0.00 & 0.11 & 0.43 & 0.00 & 0.59 & 0.00 & 99.96\end{array}$ $\begin{array}{llllllllllllll}80.65 & 1.11 & 1.09 & 0.00 & 0.23 & 0.01 & 0.01 & 0.01 & 0.11 & 0.03 & 0.62 & 0.00 & 99.96 \\ 57.28 & 26.37 & 9.59 & 0.04 & 0.66 & 0.03 & 0.01 & 0.56 & 2.07 & 0.00 & 0.99 & 0.11 & 102.58\end{array}$ $\begin{array}{lllllllllllll}57.28 & 26.37 & 9.59 & 0.05 & 0.36 & 0.01 & 0.00 & 0.27 & 8.92 & 0.00 & 1.43 & 0.02 & 104.30\end{array}$ $\begin{array}{lllllllllllll}68.38 & 23.56 & 8.62 & 0.04 & 0.37 & 0.01 & 0.00 & 1.31 & 6.63 & 0.04 & 1.22 & 0.06 & 110.23\end{array}$ $\begin{array}{lllllllllllll}61.23 & 8.97 & 4.37 & 0.10 & 7.43 & 0.12 & 0.10 & 0.68 & 0.98 & 0.12 & 14.63 & 0.03 & 98.76\end{array}$ $\begin{array}{lllllllllllll}73.50 & 12.62 & 8.82 & 0.02 & 0.74 & 0.04 & 0.02 & 0.68 & 1.90 & 0.00 & 2.59 & 0.00 & 100.92\end{array}$ $\begin{array}{lllllllllllll}71.88 & 10.70 & 6.87 & 0.04 & 0.47 & 0.21 & 0.83 & 0.67 & 6.57 & 0.05 & 2.13 & 4.34 & 104.77\end{array}$ $\begin{array}{llllllllllllll}77.64 & 14.01 & 9.66 & 0.01 & 0.39 & 0.23 & 0.03 & 1.43 & 1.74 & 0.03 & 0.90 & 0.11 & 106.17 \\ 80.89 & 12.17 & 1.60 & 0.02 & 0.61 & 0.27 & 0.25 & 0.67 & 2.13 & 0.02 & 1.25 & 0.32 & 10.04\end{array}$ $\begin{array}{llllllllllllll}80.89 & 1.1 .17 & 1.60 & 0.02 & 0.61 & 0.27 & 0.25 & 0.67 & 2.13 & 0.02 & 1.25 & 0.32 & 100.19 \\ 75.89 & 14.39 & 6.91 & 0.01 & 0.33 & 0.06 & 0.03 & 0.64 & 2.90 & 0.00 & 0.83 & 0.05 & 10.04\end{array}$ $\begin{array}{llllllllllllll}7.89 & 14.39 & 6.91 & 0.01 & 0.33 & 0.06 & 0.03 & 0.64 & 2.90 & 0.00 & 0.83 & 0.05 & 102.04 \\ 70.85 & 11.43 & 1.77 & 0.53 & 0.42 & 0.29 & 0.04 & 537 & 220 & 0.05 & 2.76 & 0.54 & 06.26\end{array}$ $\begin{array}{lllllllllllll}55.00 & 1.95 & 1.37 & 9.03 & 0.59 & 0.07 & 0.02 & 0.23 & 6.55 & 0.51 & 30.67 & 0.33 & 10633\end{array}$ $\begin{array}{lllllllllllll}73.91 & 16.66 & 9.91 & 0.02 & 0.23 & 0.24 & 0.00 & 2.60 & 1.84 & 0.03 & 0.79 & 0.01 & 106.25\end{array}$ $\begin{array}{lllllllllllll}74.29 & 16.36 & 7.21 & 0.01 & 0.11 & 0.08 & 0.01 & 4.93 & 1.26 & 0.02 & 0.64 & 0.01 & 104.92 \\ \mathbf{6 7 . 8 8} & \mathbf{1 6 . 2 2} & \mathbf{6 . 1 3} & \mathbf{0 . 7 9} & \mathbf{0 . 6 5} & \mathbf{0 . 0 9} & \mathbf{0 . 0 4} & \mathbf{1 . 3 7} & \mathbf{5 . 2 9} & \mathbf{0 . 0 7} & \mathbf{4 . 0 8} & \mathbf{0 . 3 2} & \mathbf{1 0 2 . 9 1}\end{array}$ 
Table A.2.2. Average mineral compositions determined by EMPA from Tabbe A2.1

$\begin{array}{cc}\text { Oxides } & \text { average wt \% } \\ \mathrm{Na}_{2} \mathrm{O} & 2.67 \\ \mathrm{MgO} & 0.24 \\ \mathrm{SiO}_{2} & 49.44 \\ \mathrm{Al}_{2} \mathrm{O}_{3} & 31.88 \\ \mathrm{FeO}_{(\mathrm{T})} & 0.75 \\ \mathrm{CaO} & 15.20 \\ \mathrm{~K}_{2} \mathrm{O} & 0.04 \\ \mathrm{TiO}_{2} & 0.05 \\ \mathrm{Cr}_{2} \mathrm{O}_{3} & \\ \mathrm{MnO} & \\ \mathrm{NiO} & \\ \mathrm{Cl} & \\ \mathrm{SO}_{2} & \\ \mathrm{P}_{2} \mathrm{O}_{5} & \end{array}$

Total

100.28

Mineral $\quad \mathrm{K}_{0.002} \mathrm{Ca}_{0.74} \mathrm{Na}_{0.24} \mathrm{Fe}^{2+}{ }_{0.025} \mathrm{Mg}_{0.016} \mathrm{Fe}^{3+}{ }_{0.004} \mathrm{Ti}_{0.002} \mathrm{Al}_{1.72} \mathrm{Si}_{2.26} \mathrm{O}_{8}$

Composition

Phase and ID average $\mathrm{wt} \%$

0.30

16.71

16.71

51.98

9.41

17.35

0.01

0.53

0.37

0.19

100.22

99.28

average wt \%

0.01

36.14

37.27

0.04

0.28

0.01

0.35

0.13

$\mathrm{Ca}_{0.008} \mathrm{Mn}_{0.008} \mathrm{Fe}^{2+}{ }_{0.54} \mathrm{Mg}_{1.43} \mathrm{Fe}^{3+}{ }_{0.015} \mathrm{Al}_{0.001} \mathrm{Si}_{0.99} \mathrm{O}_{4}$ $\left(\mathrm{Fo}_{72}-\mathrm{Fa}_{28}\right)$

Mg-Olivine

Clinopyroxene average $\mathrm{wt} \%$

6.13

0.79

67.88

5.29

0.65

101.56
$\mathrm{Na}_{0.02} \mathrm{Ca}_{0.68} \mathrm{Mg}_{0.92} \mathrm{Fe}_{0.29} \mathrm{Mn}_{0.006} \mathrm{Cr}_{0.011} \mathrm{Ti}_{0.015} \mathrm{Al}_{0.07} \mathrm{Si}_{1.91} \mathrm{Al}_{0.09} \mathrm{O}_{6}$ 


\section{SEM-EDS analysis of unreacted polished basalt grains}

Figure A.2.7. Unreacted basalt grain. a) grey scale image. In b) composite colour image combining maps for c) Mg, d) Ca and e) Na shows plagioclase (violet), pyroxene (in turquoise), olivine (light green) and titanomagnetite (white)
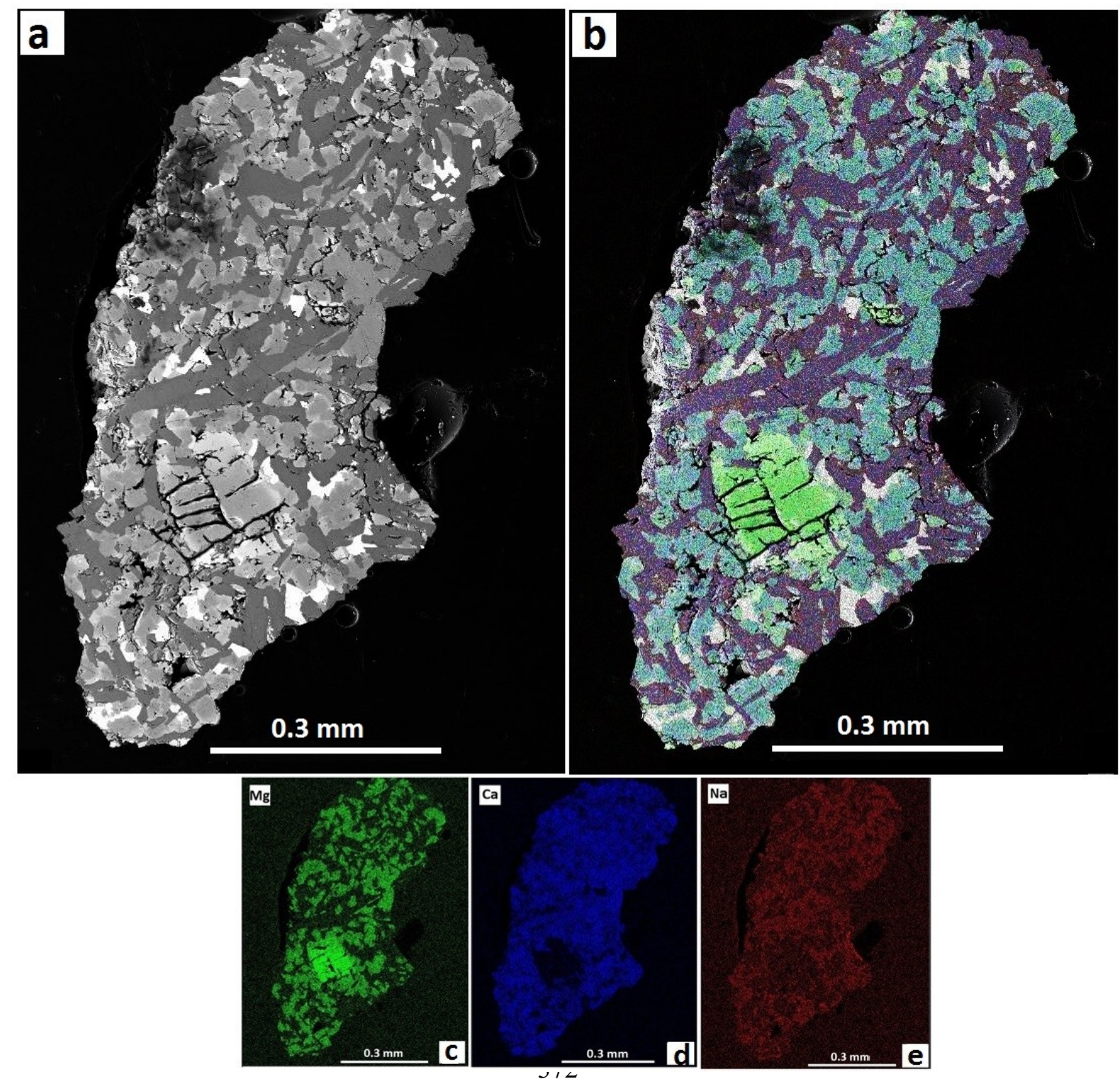
Figure A.2.8. (a-c) SEM photographs of unreacted basalt grains in Fig. (A.8) and in Fig. (A.9); b-d) enlargements of pictures in (a) and (c) (red rectangles), respectively, showing plagioclase, clinopyroxene, olivine and Fe-Ti oxides
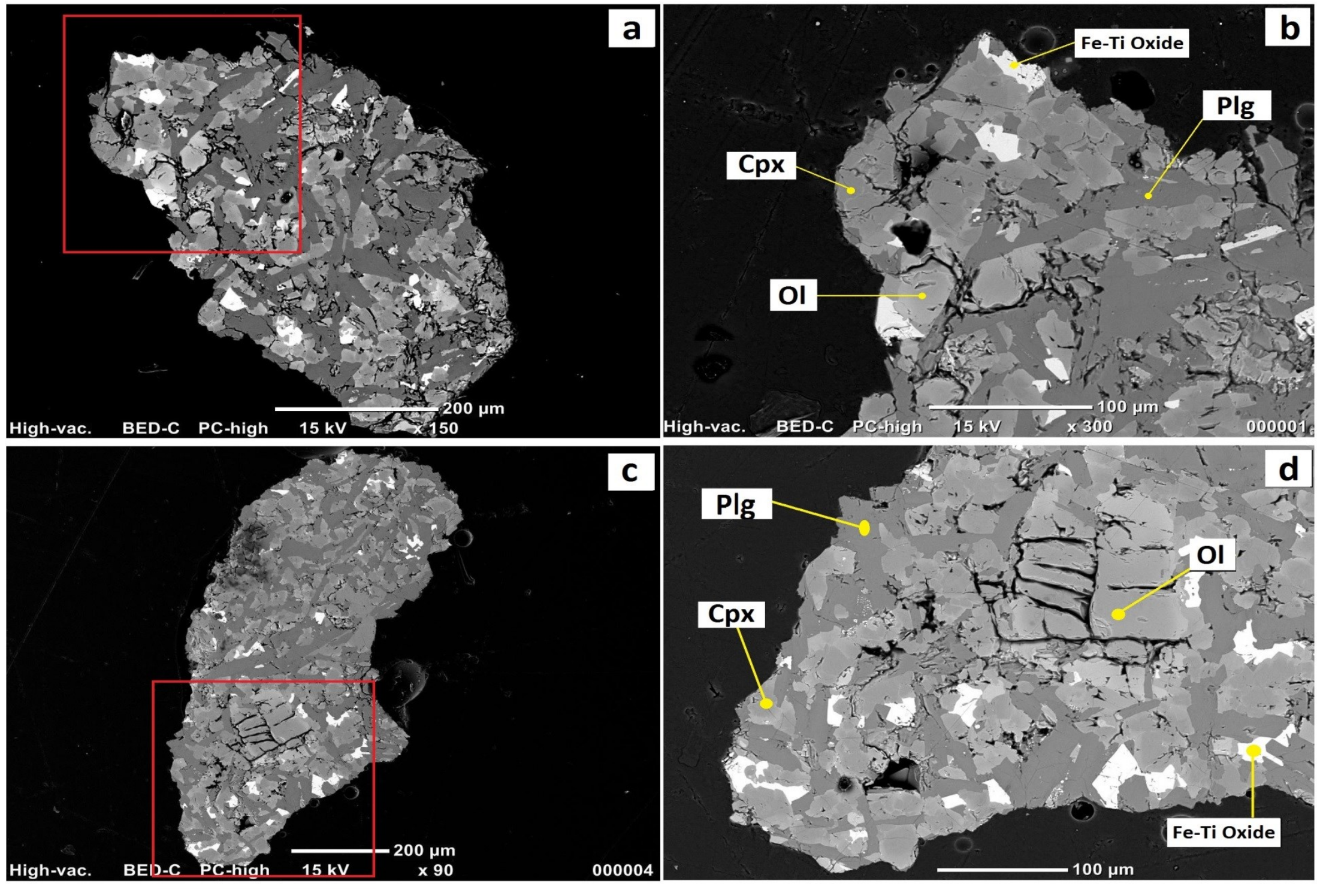

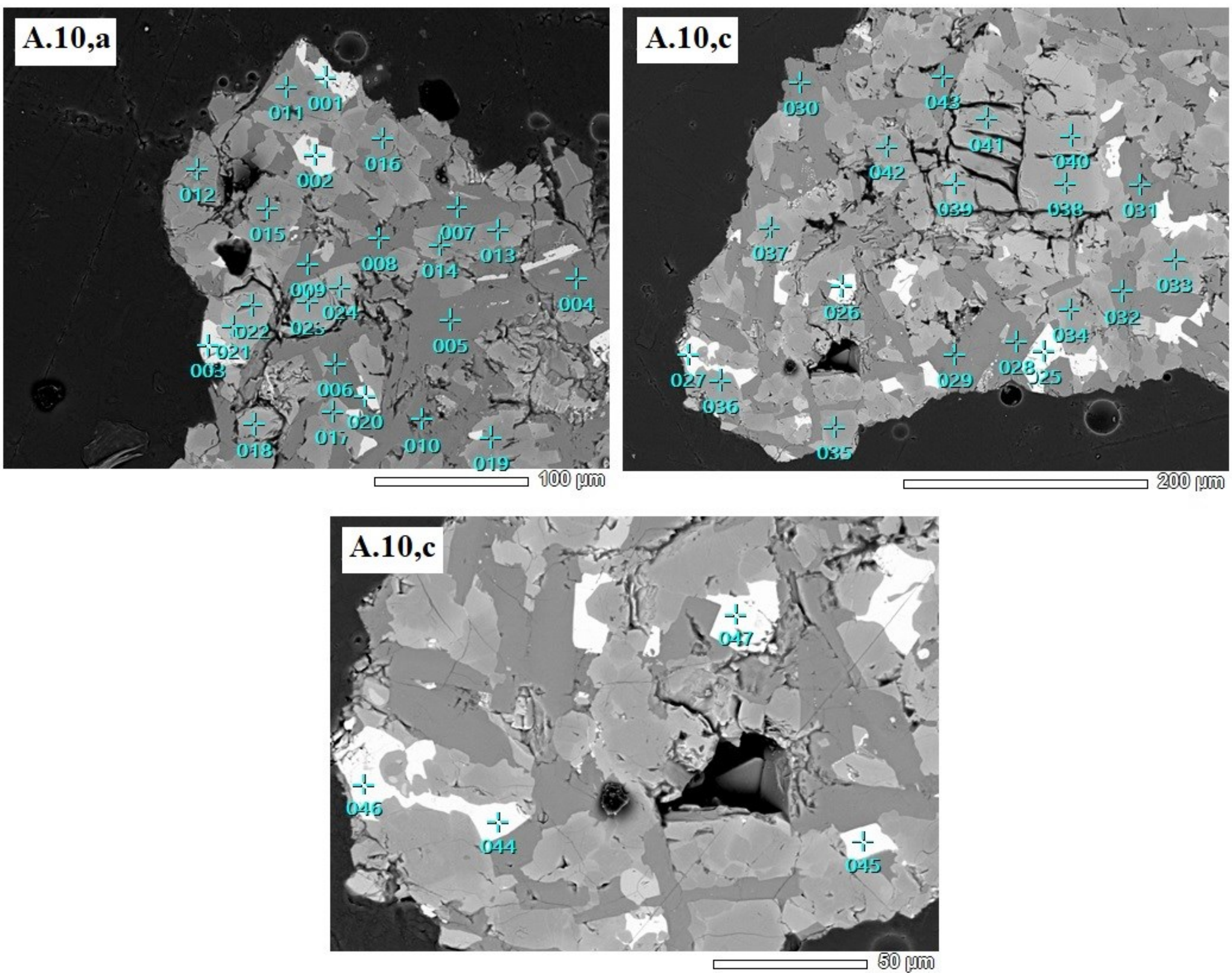
Table A.2.3. SEM-EDS analysis of unreacted basalt grains in Fig. A.2.9(A.10,a) and Fig. A.2.9(A.10,c)

\begin{tabular}{|c|c|c|c|c|c|c|c|c|c|c|c|c|c|c|c|c|c|c|c|}
\hline \multirow[t]{7}{*}{$\begin{array}{l}\text { Plg } \\
\text { Fig. A.10,a }\end{array}$} & $\begin{array}{c}\text { Analysis } \\
\text { Point }\end{array}$ & $\mathrm{Na}_{2} \mathrm{O}$ & MgO & $\mathrm{Al}_{2} \mathrm{O}_{3}$ & $\mathrm{SiO}_{2}$ & $\mathrm{CaO}$ & $\mathrm{TiO}_{2}$ & $\mathrm{FeO}$ & Total & $\begin{array}{c}\mathrm{Ol} \\
\text { Fig. A.10,a }\end{array}$ & $\begin{array}{c}\text { Analysis } \\
\text { Point }\end{array}$ & $\mathrm{Na}_{2} \mathrm{O}$ & MgO & $\mathrm{Al}_{2} \mathrm{O}_{3}$ & $\mathrm{SiO}_{2}$ & $\mathrm{CaO}$ & $\mathrm{TiO}_{2}$ & FeO & Total \\
\hline & $\begin{array}{l}4 \\
5\end{array}$ & 3.85 & & 29.78 & 53.15 & 13.22 & & & 100.00 & & 21 & & 21.22 & & 34.40 & & & 44.38 & 100.00 \\
\hline & 5 & 3.25 & & 30.84 & 51.97 & 13.95 & & & 100.01 & & 22 & & 20.77 & & 32.13 & & & 47.10 & 100.00 \\
\hline & $\begin{array}{l}6 \\
7\end{array}$ & $\begin{array}{l}5.29 \\
3.28\end{array}$ & & $\begin{array}{l}26.86 \\
33.52\end{array}$ & $\begin{array}{l}57.78 \\
5.57\end{array}$ & $\begin{array}{l}10.07 \\
13.63\end{array}$ & & & $\begin{array}{l}100.00 \\
1000\end{array}$ & & $\begin{array}{l}23 \\
24\end{array}$ & & $\begin{array}{l}29.47 \\
27.77\end{array}$ & & $\begin{array}{l}37.35 \\
35.80\end{array}$ & & & $\begin{array}{l}33.18 \\
36.43\end{array}$ & $\begin{array}{l}100.00 \\
100.00\end{array}$ \\
\hline & 8 & 3.06 & & 30.55 & 52.27 & 14.12 & & & 100.00 & $\mathrm{Ol}$ & Analysis & & & & & & & & \\
\hline & 9 & 3.46 & & 30.50 & 52.50 & 13.54 & & & 100.00 & Fig. A. $10, \mathrm{c}$ & Point & $\mathrm{Na}_{2} \mathrm{O}$ & MgO & $\mathrm{Al}_{2} \mathrm{O}_{3}$ & $\mathrm{SiO}_{2}$ & $\mathrm{CaO}$ & $\mathrm{TiO}_{2}$ & $\mathrm{FeO}$ & Total \\
\hline & 10 & 3.67 & & 30.58 & 52.83 & 12.93 & & & 100.01 & & 38 & & 35.62 & & 38.29 & & & 26.08 & 100.00 \\
\hline \multirow{7}{*}{$\begin{array}{l}\text { Plg } \\
\text { Fig. A.10,c }\end{array}$} & $\begin{array}{l}\text { Analysis } \\
\text { Povins }\end{array}$ & $\mathrm{Na}_{2} \mathrm{O}$ & MgO & $\mathrm{Al}_{2} \mathrm{O}_{3}$ & $\mathrm{SiO}_{2}$ & $\mathrm{CaO}$ & $\mathrm{TiO}_{2}$ & $\mathrm{FeO}$ & Total & & $\begin{array}{l}39 \\
40\end{array}$ & & $\begin{array}{l}30.68 \\
33.67\end{array}$ & & $\begin{array}{l}37.13 \\
38.06\end{array}$ & & & $\begin{array}{l}32.19 \\
2827\end{array}$ & $\begin{array}{l}100.00 \\
10000\end{array}$ \\
\hline & $\begin{array}{c}\text { Point } \\
28\end{array}$ & 3.61 & & 29.91 & 53.30 & 13.18 & & & 100.00 & & 41 & & 36.01 & & 38.55 & & & 25.44 & 100.00 \\
\hline & 29 & 4.63 & & 28.02 & 56.39 & 10.97 & & & 100.01 & average & & & 29.40 & & 36.46 & & & 34.13 & 100.00 \\
\hline & 30 & 3.21 & & 30.15 & 52.51 & 14.13 & & & 100.00 & & & & & & & & & & \\
\hline & 31 & 3.09 & & 30.70 & 52.29 & 13.92 & & & 100.00 & Ox & $\begin{array}{c}\text { Analysis } \\
\text { Point }\end{array}$ & $\mathrm{Na}_{2} \mathrm{O}$ & MgO & $\mathrm{Al}_{2} \mathrm{O}_{3}$ & $\mathrm{SiO}_{2}$ & $\mathrm{CaO}$ & $\mathrm{TiO}_{2}$ & FeO & Total \\
\hline & 32 & 3.15 & & 30.47 & 52.35 & 14.03 & & & 100.00 & Fig. A.10,a & Point & & & & & & & & \\
\hline & 43 & $\begin{array}{l}3.09 \\
\mathbf{3 . 5 9}\end{array}$ & & $\begin{array}{l}30.82 \\
\mathbf{2 9 . 9 8}\end{array}$ & $\begin{array}{l}52.43 \\
\mathbf{5 3 . 2 6}\end{array}$ & $\begin{array}{l}13.67 \\
\mathbf{1 3 . 1 8}\end{array}$ & & & $\begin{array}{l}100.01 \\
\mathbf{1 0 0 . 0 0}\end{array}$ & & $\begin{array}{l}1 \\
2\end{array}$ & & & & & & $\begin{array}{l}20.497 \\
26.21\end{array}$ & 73.79 & $\begin{array}{l}100.00 \\
100.00\end{array}$ \\
\hline average & & & & & & & & & & & 3 & & & & & & 27.36 & 72.64 & 100.00 \\
\hline \multirow{9}{*}{$\begin{array}{l}\text { Cpx } \\
\text { Fig. A.10,a }\end{array}$} & $\begin{array}{l}\text { Analysis } \\
\text { Point }\end{array}$ & $\mathrm{Na}_{2} \mathrm{O}$ & MgO & $\mathrm{Al}_{2} \mathrm{O}_{3}$ & $\mathrm{SiO}_{2}$ & $\mathrm{CaO}$ & $\mathrm{TiO}_{2}$ & $\mathrm{FeO}$ & Total & & 20 & & & & & & 26.61 & 73.39 & 100.00 \\
\hline & 11 & & 15.74 & 2.34 & 53.15 & 18.25 & & 10.52 & 100.00 & Ox & Analysis & $\mathrm{Na}_{2} \mathrm{O}$ & MgO & $\mathrm{Al}_{2} \mathrm{O}_{3}$ & $\mathrm{SiO}_{2}$ & $\mathrm{CaO}$ & $\mathbf{T i O}_{2}$ & $\mathrm{FeO}$ & Total \\
\hline & $\begin{array}{l}12 \\
13\end{array}$ & & $\begin{array}{l}13.52 \\
14.65\end{array}$ & $\begin{array}{l}3.58 \\
2.46\end{array}$ & $\begin{array}{l}49.98 \\
528\end{array}$ & $\begin{array}{l}17.55 \\
1846\end{array}$ & & 15.37 & 100.00 & Fig. A. $10, \mathrm{c}$ & Point & & & & & & 2664 & & \\
\hline & $\begin{array}{l}13 \\
14\end{array}$ & & $\begin{array}{l}14.65 \\
15.93\end{array}$ & $\begin{array}{l}2.46 \\
2.96\end{array}$ & $\begin{array}{l}52.89 \\
5.25\end{array}$ & $\begin{array}{l}18.46 \\
18.33\end{array}$ & & $\begin{array}{l}11.54 \\
10.23\end{array}$ & $\begin{array}{l}100.00 \\
100.00\end{array}$ & & 25 & & & & & & 26.64 & $\begin{array}{l}73.36 \\
73.69\end{array}$ & $\begin{array}{l}100.00 \\
10000\end{array}$ \\
\hline & 15 & & 15.89 & 2.95 & 52.31 & 18.05 & & 10.81 & 100.00 & & $\begin{array}{l}26 \\
27\end{array}$ & & & & & & $\begin{array}{l}26.31 \\
27.21\end{array}$ & $\begin{array}{l}13.09 \\
72.79\end{array}$ & $\begin{array}{l}100.00 \\
100.00\end{array}$ \\
\hline & 16 & & 15.75 & 2.21 & 53.36 & 18.56 & & 10.12 & 100.00 & & 44 & & & & & & 27.16 & 72.84 & 100.00 \\
\hline & 17 & & 15.54 & 2.62 & 52.80 & 17.72 & & 11.31 & 100.00 & & 45 & & & & & & 26.58 & 73.42 & 100.00 \\
\hline & 18 & & 9.88 & 1.38 & 50.87 & 12.97 & & 24.89 & 100.00 & & 46 & & & & & & 26.62 & 73.38 & 100.00 \\
\hline & 19 & & 15.74 & 2.29 & 53.38 & 18.81 & & 9.77 & 100.00 & & 47 & & & & & & 26.66 & 73.34 & 100.00 \\
\hline \multirow{6}{*}{$\begin{array}{l}\text { Cpx } \\
\text { Fig. A.10,c }\end{array}$} & Analysis & $\mathrm{Na}_{2} \mathrm{O}$ & $\mathrm{MgO}$ & $\mathrm{Al}_{2} \mathbf{O}_{3}$ & $\mathrm{SiO}_{2}$ & $\mathrm{CaO}$ & $\mathrm{TiO}_{2}$ & $\mathrm{FeO}$ & Total & average & & & & & & & 26.71 & 73.29 & 100.00 \\
\hline & $\begin{array}{l}\text { Point } \\
33\end{array}$ & & & 2.46 & 52.15 & 17.18 & & 12.66 & & & & & & & & & & & \\
\hline & 34 & & 14.79 & 2.47 & 52.82 & 16.83 & & 13.09 & 100.00 & & & & & & & & & & \\
\hline & 35 & & 15.83 & 1.80 & 53.56 & 19.00 & & 9.81 & 100.00 & & & & & & & & & & \\
\hline & 36 & & 15.18 & 2.40 & 53.18 & 19.02 & & 10.22 & 100.00 & & & & & & & & & & \\
\hline & 37 & & 15.57 & 2.68 & 52.49 & 18.81 & & 10.45 & & & & & & & & & & & \\
\hline av & & & 14.97 & 2.47 & 52.54 & 17.82 & & 12.20 & 100.00 & & & & & & & & & & \\
\hline
\end{tabular}

Table A.2.4. Average mineral compositions determined by EDS from Table A.2.3

\begin{tabular}{|c|c|c|c|c|}
\hline Oxides & average $w t \%$ & average $w t \%$ & average $w t \%$ & average wt $\%$ \\
\hline $\mathrm{Na}_{2} \mathrm{O}$ & 3.59 & & & \\
\hline $\mathrm{MgO}$ & & 14.97 & 29.40 & \\
\hline $\mathrm{SiO}_{2}$ & 53.26 & 52.54 & 36.46 & \\
\hline $\mathrm{Al}_{2} \mathrm{O}_{3}$ & 29.98 & 2.47 & & \\
\hline $\mathrm{FeO}_{(\mathrm{T})}$ & & 12.20 & 34.13 & 73.29 \\
\hline $\mathrm{CaO}$ & 13.18 & 17.82 & & \\
\hline $\mathrm{K}_{2} \mathrm{O}$ & & & & \\
\hline $\mathrm{TiO}_{2}$ & & & & 26.71 \\
\hline Total & 100.01 & 100.00 & 99.99 & 100.00 \\
\hline $\begin{array}{c}\text { Mineral } \\
\text { Composition }\end{array}$ & $\begin{array}{c}\mathrm{Ca}_{0.7} \mathrm{Na}_{0.3} \mathrm{Al}_{1.6} \mathrm{Si}_{2.4} \mathrm{O}_{8} \\
\left(\mathrm{An}_{70}-\mathrm{Ab}_{30}\right)\end{array}$ & $\mathrm{Ca}_{0.71} \mathrm{Mg}_{0.83} \mathrm{Fe}_{0.38} \mathrm{Al}_{0.8} \mathrm{Si}_{1.97} \mathrm{Al}_{0.03} \mathrm{O}_{6}$ & $\begin{array}{c}\mathrm{Mg}_{1.2} \mathrm{Fe}_{0.8} \mathrm{SiO}_{4} \\
\left(\mathrm{Fo}_{60}-\mathrm{Fa}_{40}\right)\end{array}$ & $\mathrm{Fe}^{2+}\left(\mathrm{Fe}^{3+}, \mathrm{Ti}_{2} \mathrm{O}_{2}\right.$ \\
\hline hase and ID & $\begin{array}{c}\text { Plagioclase } \\
\text { (bytownite) }\end{array}$ & $\begin{array}{c}\text { Clinopyroxene } \\
\text { (augite) }\end{array}$ & $\begin{array}{c}\text { Mg-olivine } \\
\text { (forsterite) }\end{array}$ & Titanomagnetite \\
\hline
\end{tabular}



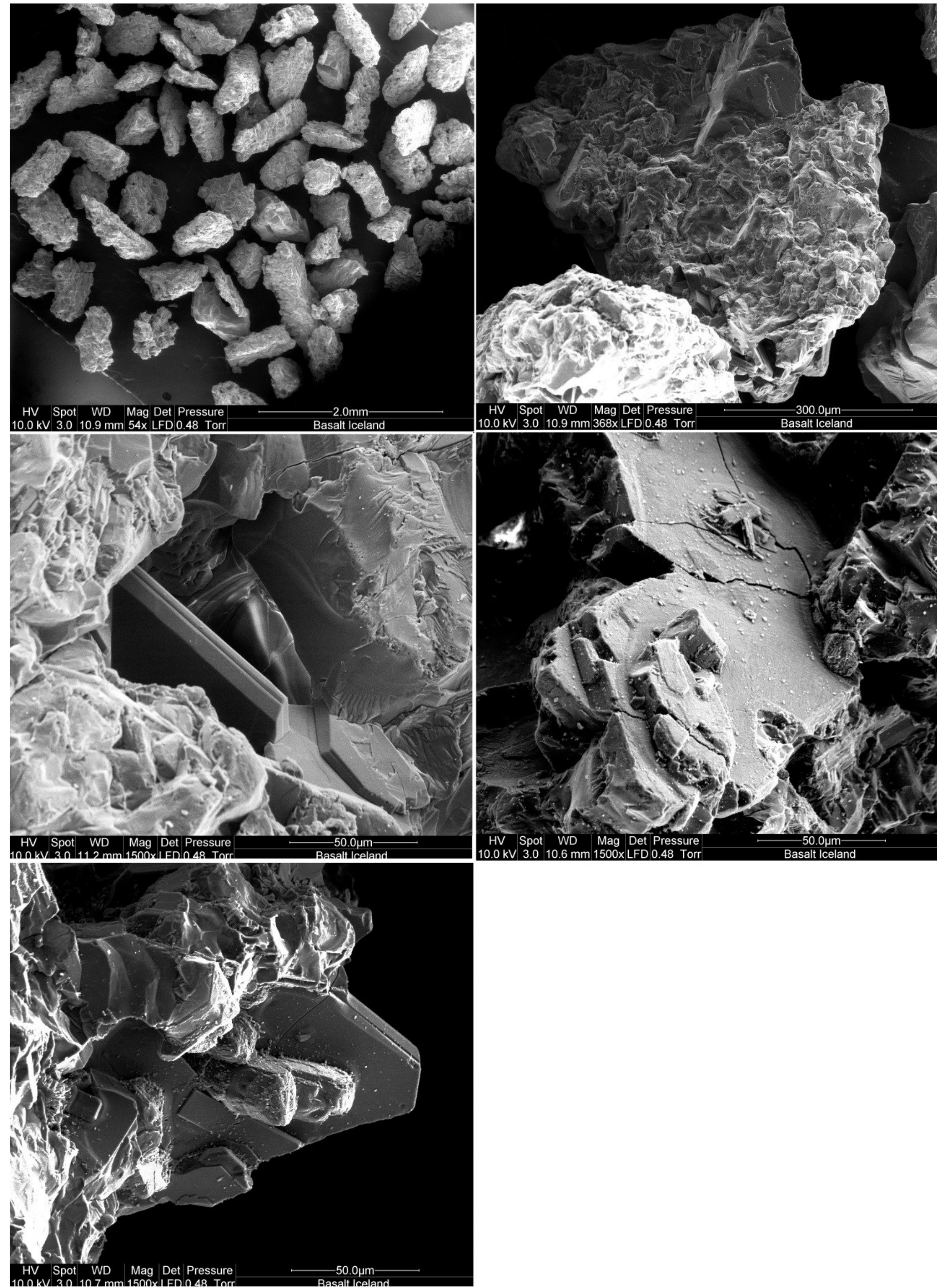

HV Spot WD Mag Det Pressure $50.0 \mu \mathrm{m}$ 
Appendices Doctoral Thesis: "Basalt - fluid interactions at subcritical and supercritical conditions: An experimental study" University of Victoria Wellington and GNS Science, Wairakei, New Zealand by Mauro Passarella

Appendix B - (Chapter 3) 


\section{Chapter 3: Basalt-Water Reaction under Hydrothermal Conditions}

\subsection{Results}

BW1: Basalt - water at $400^{\circ} \mathrm{C} / 502$ bar

Table B.3.1. Major ions compositions and complete experimental parameters (number of samples collected, T, P, time, flow rate and pH) for the $\mathrm{BW} 1 \mathrm{at} 400^{\circ} \mathrm{C} / 502$ bar. In situ $\mathrm{pH}$ is the calculated $\mathrm{pH}$ at temperature. Analysis of major ions are reported both in mg kg ${ }^{-1}$ and in mmol $\mathrm{kg}^{-1}$. n...: not calculated

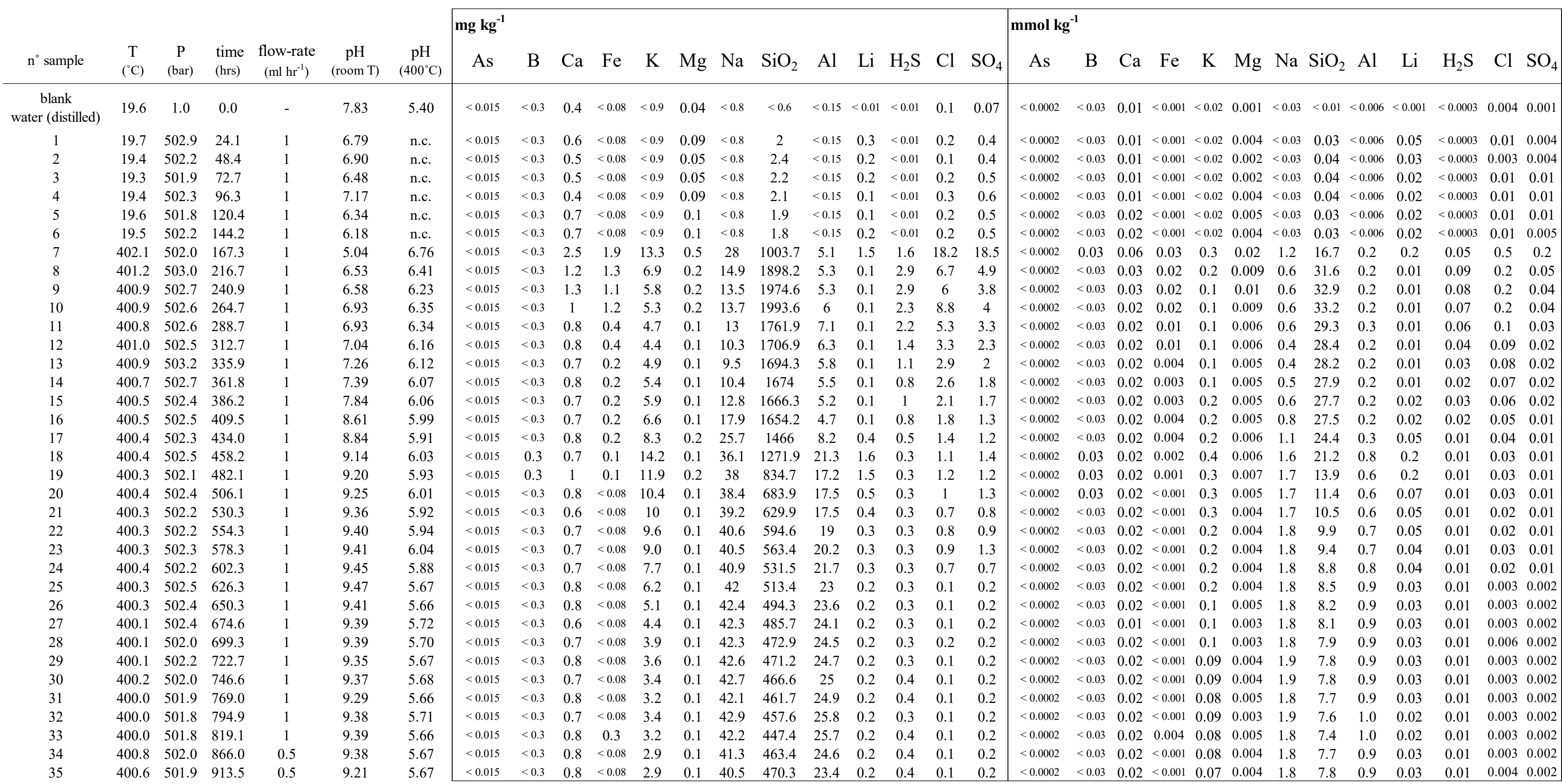




\begin{tabular}{|c|c|c|c|c|c|c|c|c|c|c|c|c|c|c|c|c|c|c|c|c|}
\hline & & & & & & & $\mu \mathrm{mol} \mathrm{kg}{ }^{-1}$ & & & & & & & & & & & & & \\
\hline $\mathrm{n}^{\circ}$ sample & $\begin{array}{c}\mathrm{T} \\
\left({ }^{\circ} \mathrm{C}\right)\end{array}$ & $\begin{array}{c}\mathrm{P} \\
\text { (bar) }\end{array}$ & $\begin{array}{l}\text { time } \\
\text { (hrs) }\end{array}$ & $\begin{array}{l}\text { flow-rate } \\
\left(\mathrm{ml} \mathrm{hr}{ }^{-1}\right)\end{array}$ & $\underset{\text { (room T) }}{\mathrm{pH}}$ & $\begin{array}{c}\mathrm{pH} \\
\left(400^{\circ} \mathrm{C}\right)\end{array}$ & $\mathrm{V}$ & $\mathrm{Cr}$ & $\mathrm{Co}$ & $\mathrm{Ni}$ & $\mathrm{Cu}$ & $\mathrm{Zn}$ & $\mathrm{Rb}$ & Mo & $\mathrm{Ag}$ & $\mathrm{Cd}$ & $\mathrm{Ba}$ & $\mathrm{Au}$ & $\mathrm{Pb}$ & $\mathrm{Mn}$ \\
\hline $\begin{array}{c}\text { blank } \\
\text { water (distilled) }\end{array}$ & 19.6 & 1 & 0.0 & - & 7.83 & 5.40 & $<0.002$ & $<0.004$ & $<0.002$ & $<0.003$ & $<0.0009$ & $<0.008$ & $<0.001$ & $<0.002$ & $<0.0005$ & $<0.0009$ & $<0.001$ & $<0.001$ & $<0.001$ & $<0.13$ \\
\hline 1 & 19.7 & 502.9 & 24.1 & 1 & 6.79 & n.c. & n.a. & n.a. & n.a. & n.a. & n.a. & n.a. & n.a. & n.a. & n.a. & n.a. & n.a. & n.a. & n.a. & n.a. \\
\hline 2 & 19.4 & 502.2 & 48.4 & 1 & 6.90 & n.c. & $<0.002$ & 0.1 & 0.01 & 0.6 & 0.2 & 31.5 & 0.05 & 0.3 & $<0.0005$ & 0.02 & 0.06 & $<0.001$ & $<0.001$ & $<0.13$ \\
\hline 3 & 19.3 & 501.9 & 72.7 & 1 & 6.48 & n.c. & $<0.002$ & 0.003 & 0.01 & 0.3 & 0.2 & 41.6 & 0.1 & 0.2 & $<0.0005$ & 0.001 & 0.003 & 0.01 & 0.02 & $<0.13$ \\
\hline 4 & 19.4 & 502.3 & 96.3 & 1 & 7.17 & n.c. & $<0.002$ & 0.04 & 0.01 & 0.3 & 0.003 & 55.5 & 0.04 & 0.1 & $<0.0005$ & $<0.0009$ & 0.1 & $<0.001$ & $<0.001$ & $<0.13$ \\
\hline 5 & 19.6 & 501.8 & 120.4 & 1 & 6.34 & n.c. & $<0.002$ & 0.1 & 0.01 & 0.5 & 0.3 & 43.1 & 0.02 & 0.1 & $<0.0005$ & $<0.0009$ & 0.2 & $<0.001$ & $<0.001$ & $<0.13$ \\
\hline 6 & 19.5 & 502.2 & 144.2 & 1 & 6.18 & n.c. & $<0.002$ & 0.05 & 0.01 & 0.2 & 0.2 & 37.2 & 0.03 & 0.1 & $<0.0005$ & $<0.0009$ & 0.2 & 0.02 & $<0.001$ & $<0.13$ \\
\hline 7 & 402.1 & 502.0 & 167.3 & 1 & 5.04 & 6.76 & 0.7 & 0.7 & 0.2 & 4.4 & 5.2 & 55.8 & 2.1 & 1 & $<0.0005$ & 0.02 & 13.4 & 0.03 & 0.06 & 0.4 \\
\hline 8 & 401.2 & 503.0 & 216.7 & 1 & 6.53 & 6.41 & 1 & 0.6 & 0.1 & 2.4 & 15.3 & 37.9 & 1.5 & 0.7 & $<0.0005$ & 0.1 & 1.1 & 0.01 & 0.03 & 0.3 \\
\hline 9 & 400.9 & 502.7 & 240.9 & 1 & 6.58 & 6.23 & 1.2 & 0.4 & 0.08 & 2.6 & 12.5 & 23.5 & 1.4 & 0.7 & $<0.0005$ & 0.2 & 0.9 & 0.03 & 0.03 & 0.2 \\
\hline 10 & 400.9 & 502.6 & 264.7 & 1 & 6.93 & 6.35 & 3 & 0.3 & 0.1 & 0.9 & 7.9 & 22.5 & 1.3 & 1 & $<0.0005$ & 0.04 & 1 & 0.03 & 0.01 & 0.2 \\
\hline 11 & 400.8 & 502.6 & 288.7 & 1 & 6.93 & 6.34 & 2.3 & 0.2 & 0.09 & 0.6 & 8.7 & 6.7 & 1.1 & 1.1 & $<0.0005$ & 0.03 & 2 & 0.02 & 0.01 & $<0.13$ \\
\hline 12 & 401.0 & 502.5 & 312.7 & 1 & 7.04 & 6.16 & 1.7 & 0.1 & 0.07 & 1.1 & 9.1 & 53 & 1.1 & 0.9 & $<0.0005$ & 0.04 & 3.9 & $<0.001$ & 0.09 & $<0.13$ \\
\hline 13 & 400.9 & 503.2 & 335.9 & 1 & 7.26 & 6.12 & 1.1 & 0.2 & 0.04 & 0.3 & 7.3 & 13.2 & 1.4 & 0.8 & $<0.0005$ & 0.001 & 4.2 & 0.01 & 0.08 & $<0.13$ \\
\hline 14 & 400.7 & 502.7 & 361.8 & 1 & 7.39 & 6.07 & 0.8 & 0.2 & 0.04 & 0.7 & 6.3 & 19.1 & 1.9 & 0.7 & $<0.0005$ & 0.04 & 3.1 & 0.01 & 0.08 & $<0.13$ \\
\hline 15 & 400.5 & 502.4 & 386.2 & 1 & 7.84 & 6.06 & 1.3 & 0.1 & 0.04 & 0.6 & 4.3 & 17.8 & 2.4 & 0.6 & $<0.0005$ & $<0.0009$ & 1.9 & 0.02 & 0.05 & $<0.13$ \\
\hline 16 & 400.5 & 502.5 & 409.5 & 1 & 8.61 & 5.99 & 3.5 & 0.1 & 0.03 & 1 & 4 & 16.6 & 3 & 0.6 & $<0.0005$ & $<0.0009$ & 1.2 & $<0.001$ & 0.04 & $<0.13$ \\
\hline 17 & 400.4 & 502.3 & 434.0 & 1 & 8.84 & 5.91 & 4.6 & 0.1 & 0.03 & 0.8 & 5.6 & 26 & 3.8 & 0.5 & $<0.0005$ & 0.03 & 0.8 & $<0.001$ & 0.02 & $<0.13$ \\
\hline 18 & 400.4 & 502.5 & 458.2 & 1 & 9.14 & 6.03 & 0.5 & 0.1 & $<0.002$ & 0.4 & 0.1 & 2.9 & 1 & 0.1 & $<0.0005$ & $<0.0009$ & 0.05 & $<0.001$ & $<0.001$ & $<0.13$ \\
\hline 19 & 400.3 & 502.1 & 482.1 & 1 & 9.20 & 5.93 & 0.4 & 0.1 & $<0.002$ & 0.3 & 0.004 & 2.3 & 0.4 & 0.1 & $<0.0005$ & $<0.0009$ & 0.001 & $<0.001$ & $<0.001$ & $<0.13$ \\
\hline 20 & 400.4 & 502.4 & 506.1 & 1 & 9.25 & 6.01 & 2.8 & 0.2 & 0.02 & 0.9 & 0.5 & 47.4 & 1.8 & 0.6 & $<0.0005$ & 0.07 & 0.2 & 0.02 & 0.5 & $<0.13$ \\
\hline 21 & 400.3 & 502.2 & 530.3 & 1 & 9.36 & 5.92 & 2.9 & 0.1 & 0.04 & 1 & 0.4 & 38.4 & 1.3 & 0.5 & $<0.0005$ & 0.04 & 0.1 & 0.001 & 0.1 & $<0.13$ \\
\hline 22 & 400.3 & 502.2 & 554.3 & 1 & 9.40 & 5.94 & 6.3 & 0.2 & 0.02 & 0.6 & 0.2 & 37.6 & 1 & 0.3 & $<0.0005$ & 0.01 & 3.2 & 0.02 & 0.2 & $<0.13$ \\
\hline 23 & 400.3 & 502.3 & 578.3 & 1 & 9.41 & 6.04 & 15.8 & 0.1 & 0.02 & 0.4 & 0.002 & 28.7 & 0.9 & 0.3 & $<0.0005$ & 0.03 & 0.2 & $<0.001$ & 0.04 & $<0.13$ \\
\hline 24 & 400.4 & 502.2 & 602.3 & 1 & 9.45 & 5.88 & 17.5 & 0.1 & 0.01 & 0.3 & $<0.0009$ & 21.2 & 0.8 & 0.3 & $<0.0005$ & $<0.0009$ & 0.06 & $<0.001$ & 0.06 & $<0.13$ \\
\hline 25 & 400.3 & 502.5 & 626.3 & 1 & 9.47 & 5.67 & 18.5 & 0.4 & 0.02 & 0.7 & $<0.0009$ & 21.6 & 0.7 & 0.3 & $<0.0005$ & $<0.0009$ & 0.05 & 0.01 & 0.1 & $<0.13$ \\
\hline 26 & 400.3 & 502.4 & 650.3 & 1 & 9.41 & 5.66 & 15.8 & 0.1 & 0.02 & 0.5 & $<0.0009$ & 18.2 & 0.6 & 0.2 & $<0.0005$ & $<0.0009$ & 0.001 & $<0.001$ & 0.1 & $<0.13$ \\
\hline 27 & 400.1 & 502.4 & 674.6 & 1 & 9.39 & 5.72 & 10.6 & 0.3 & 0.01 & 0.5 & 2.3 & 27.8 & 0.4 & 0.2 & $<0.0005$ & $<0.0009$ & $<0.001$ & $<0.001$ & 0.1 & $<0.13$ \\
\hline 28 & 400.1 & 502.0 & 699.3 & 1 & 9.39 & 5.70 & 10.9 & 0.1 & 0.01 & 0.2 & 0.04 & 29.3 & 0.5 & 0.2 & $<0.0005$ & 0.01 & 0.9 & $<0.001$ & 0.2 & $<0.13$ \\
\hline 29 & 400.1 & 502.2 & 722.7 & 1 & 9.35 & 5.67 & 12.9 & 0.1 & 0.01 & 3.9 & $<0.0009$ & 21.8 & 0.5 & 0.2 & $<0.0005$ & 0.02 & 0.03 & $<0.001$ & 0.06 & $<0.13$ \\
\hline 30 & 400.2 & 502.0 & 746.6 & 1 & 9.37 & 5.68 & 11.7 & 0.1 & 0.01 & 0.3 & $<0.0009$ & 18.1 & 0.5 & 0.2 & $<0.0005$ & 0.01 & 0.02 & $<0.001$ & 0.06 & $<0.13$ \\
\hline
\end{tabular}



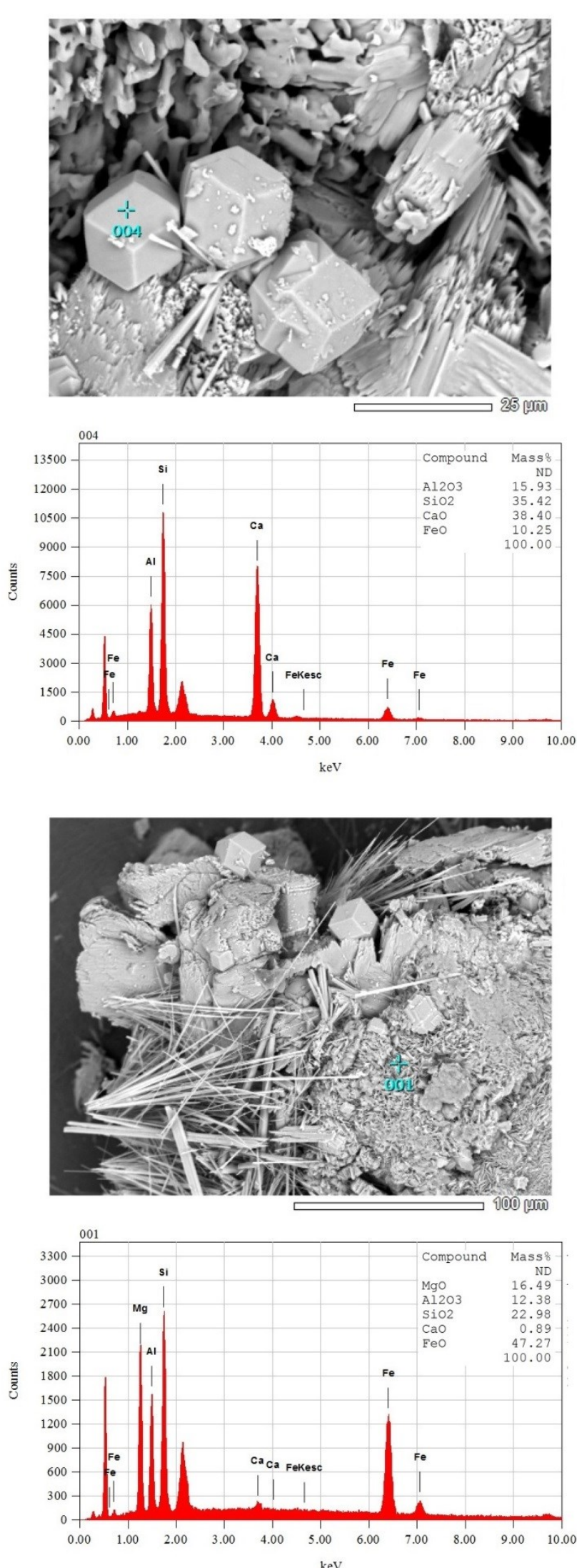
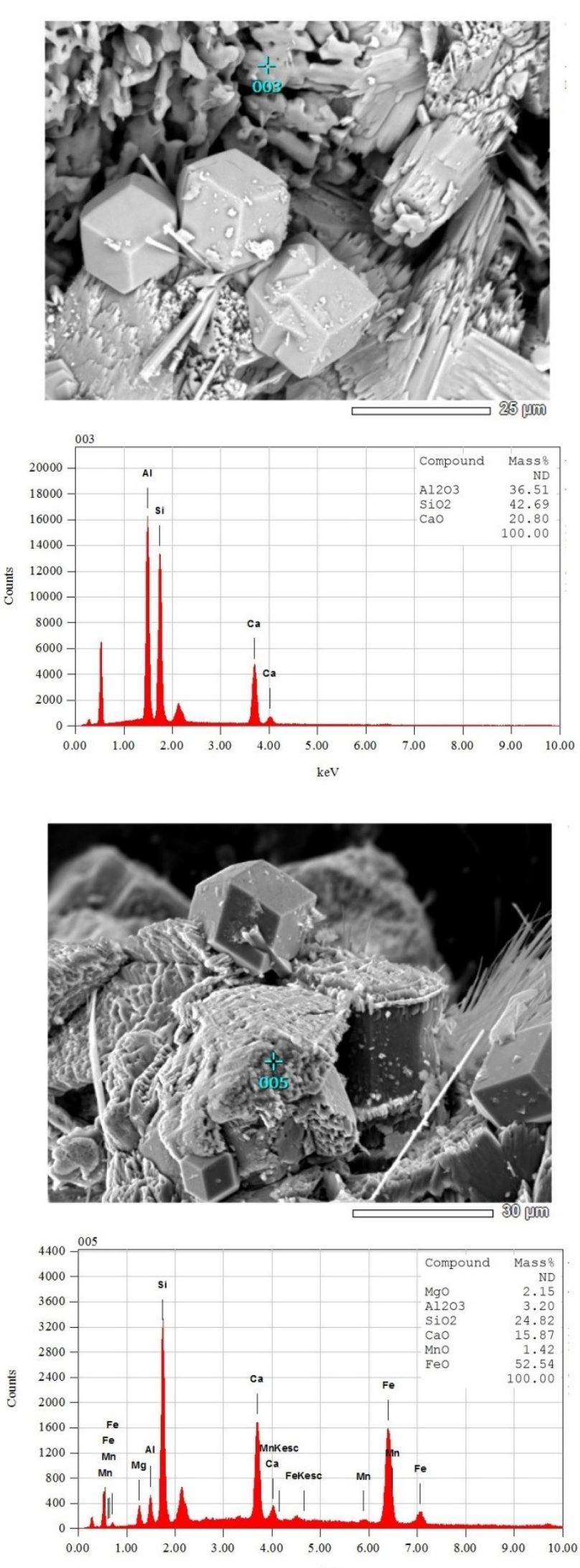
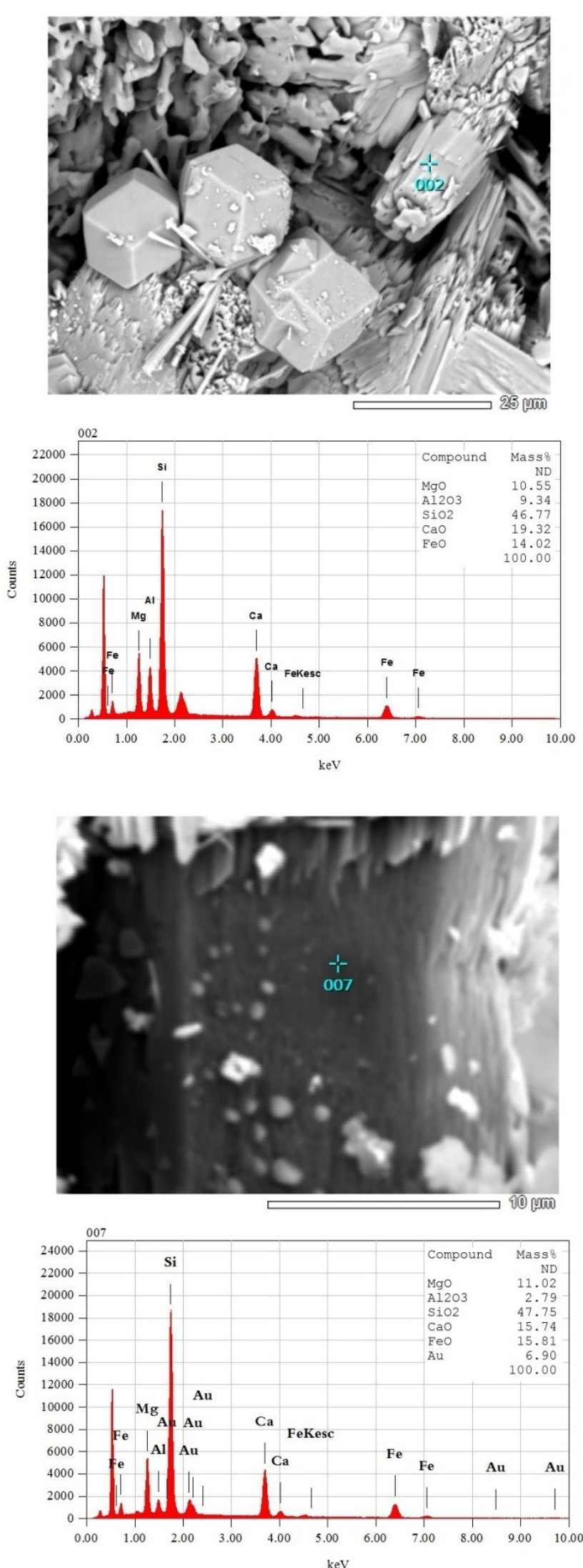
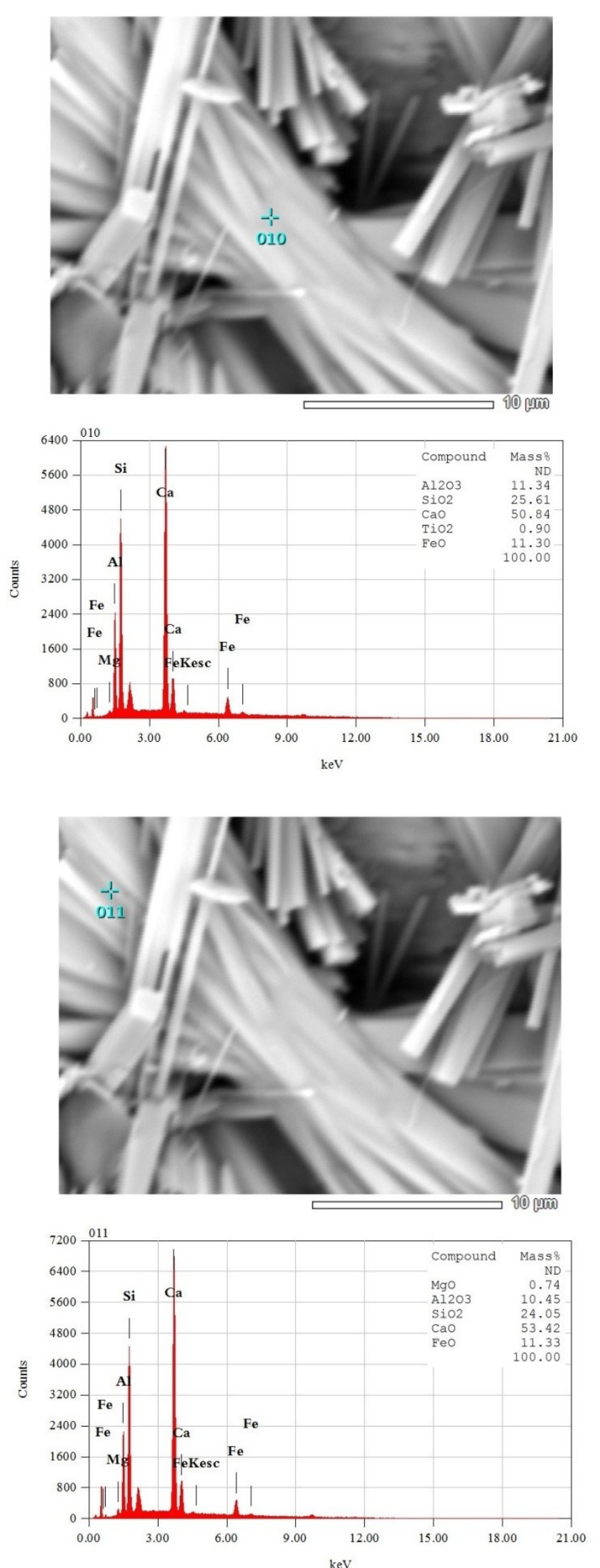

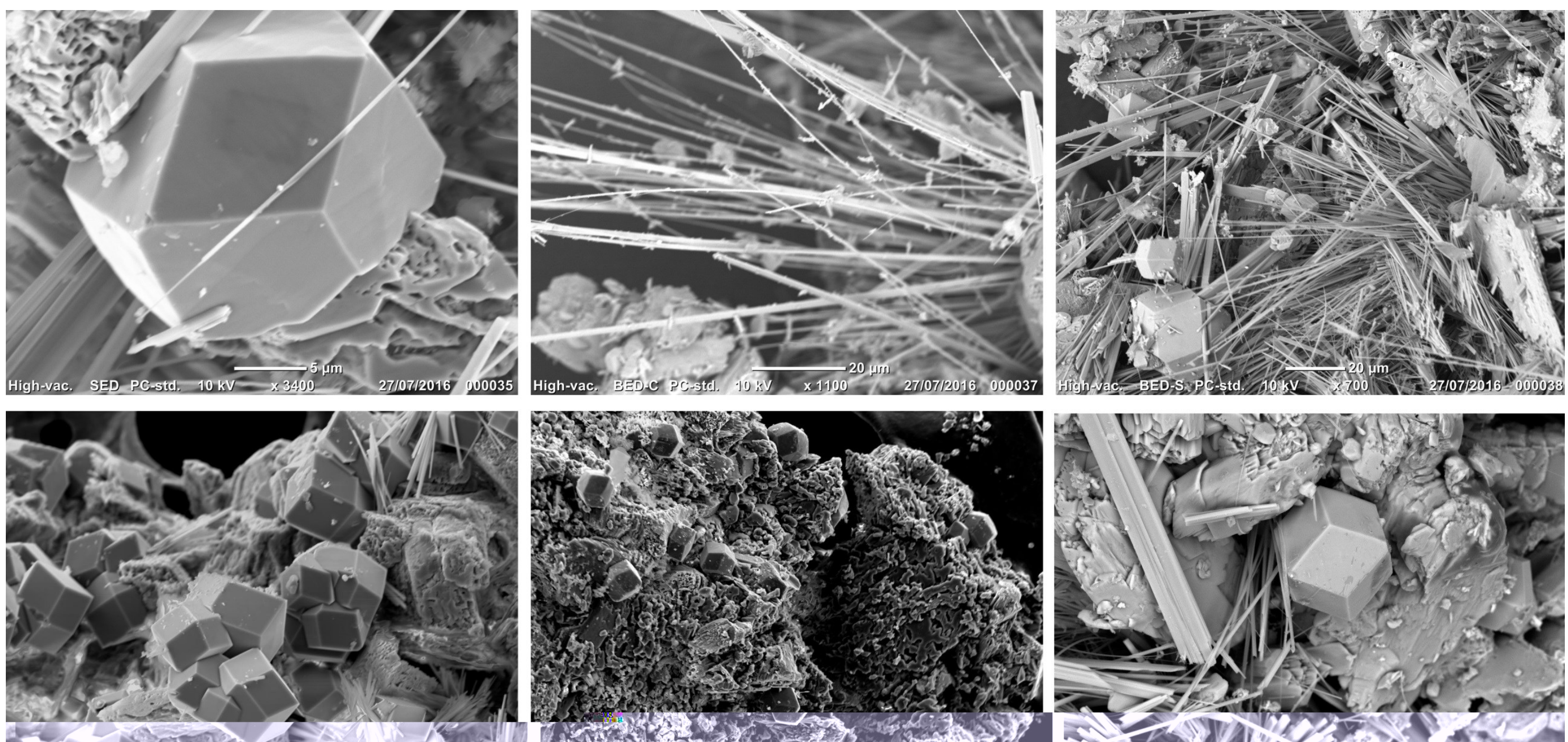

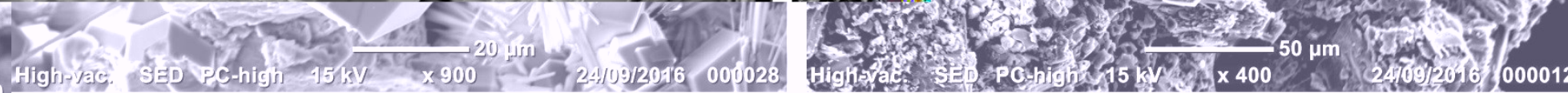
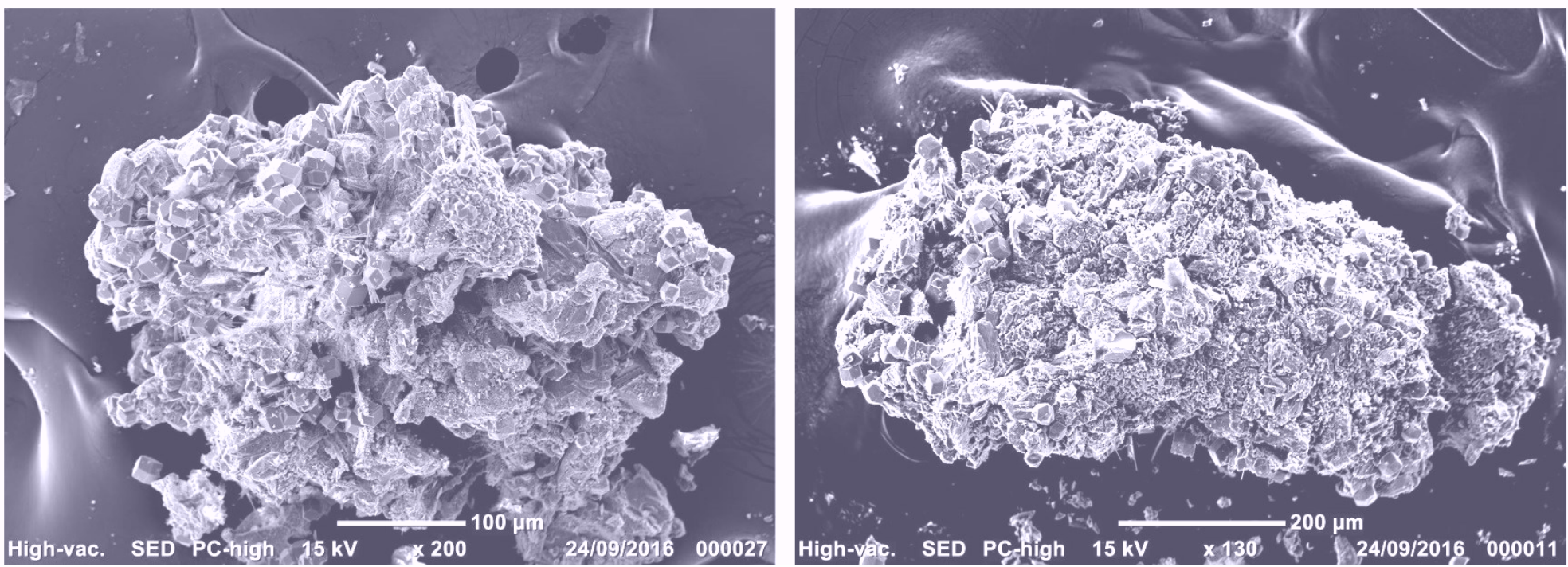
Figure B.3.3. SEM photographs (epoxy-mounted) of reacted grains collected from the bottom (Portion 1) of Rector fer the BW1 experiment for EMPA examination. Analysis points are marted in red numbers
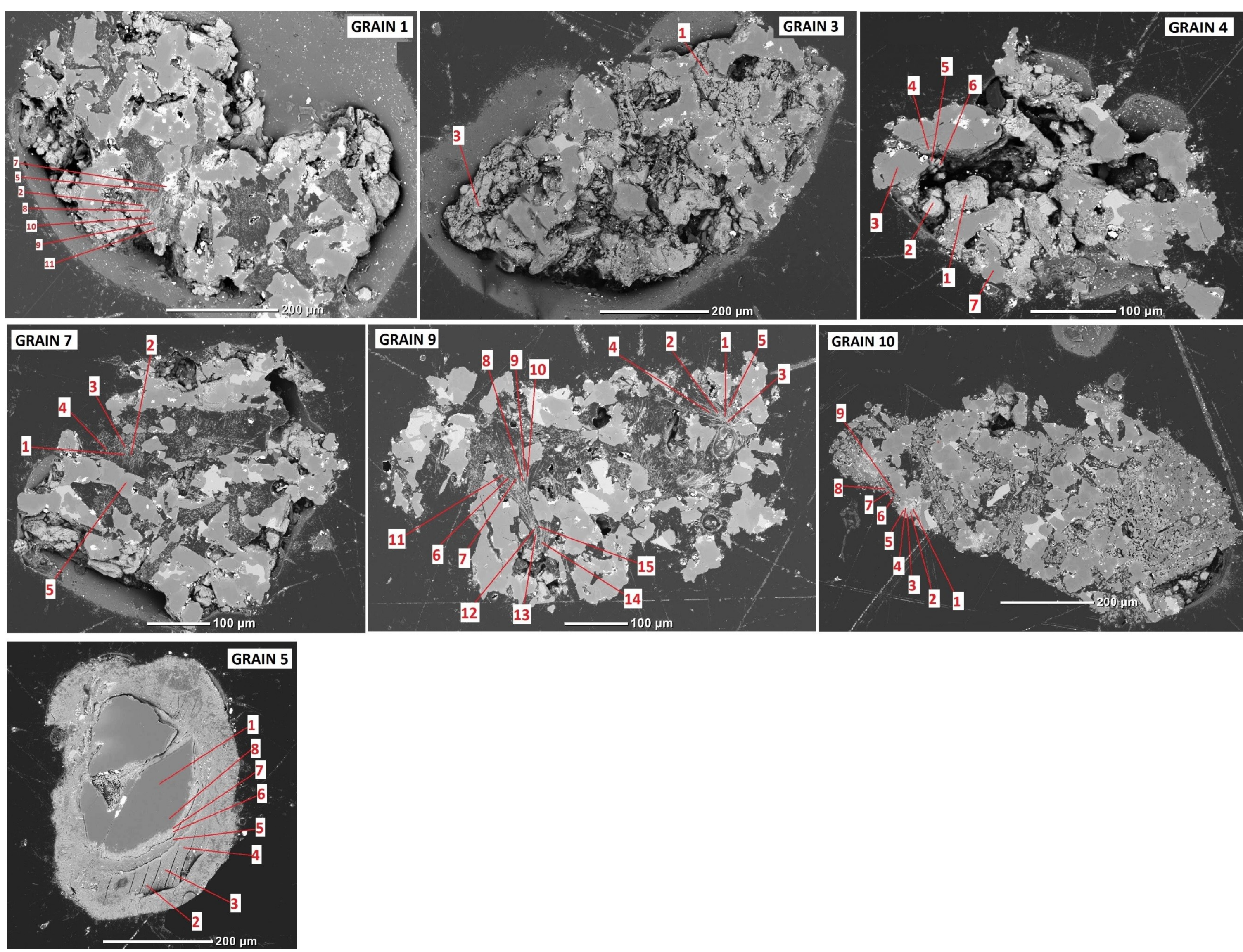
Table B.3.3. EMPA analysis of reacted grains 1-3-4-5-7-9-10 in Figure B.3.3.

\begin{tabular}{|c|c|c|c|c|c|c|c|c|c|c|c|c|c|c|}
\hline $\begin{array}{c}\text { Analysis } \\
\text { Point }\end{array}$ & Grain 1 & $\mathrm{Na}_{2} \mathrm{O}$ & MgO & $\mathrm{SiO}_{2}$ & $\mathbf{K}_{2} \mathbf{O}$ & $\mathrm{CaO}$ & $\mathrm{TiO}_{2}$ & $\mathrm{FeO}$ & MnO & $\mathrm{Cl}$ & $\mathbf{A l}_{2} \mathbf{O}_{3}$ & $\mathrm{SO}_{2}$ & $\mathbf{P}_{2} \mathbf{O}_{5}$ & Total \\
\hline 2 & Wo & 0.03 & 0.04 & 29.02 & 0.00 & 25.92 & 0.01 & 0.85 & 0.04 & 0.29 & 0.56 & 0.09 & 0.04 & 56.91 \\
\hline 5 & Wo & 0.00 & 0.04 & 18.54 & 0.00 & 16.17 & 0.01 & 0.52 & 0.00 & 0.36 & 0.25 & 0.06 & 0.01 & 35.97 \\
\hline 7 & Ox & 0.00 & 0.62 & 0.16 & 0.00 & 0.35 & 19.94 & 71.01 & 0.43 & 0.01 & 1.45 & 0.02 & 0.00 & 94.00 \\
\hline 8 & Wo & 0.02 & 0.38 & 29.48 & 0.01 & 26.61 & 0.17 & 2.01 & 0.06 & 0.28 & 1.01 & 0.08 & 0.04 & 60.14 \\
\hline 9 & Wo & 0.01 & 0.05 & 32.29 & 0.00 & 31.80 & 0.03 & 1.05 & 0.03 & 0.24 & 0.49 & 0.05 & 0.01 & 66.05 \\
\hline 10 & Wo & 0.03 & 0.04 & 28.51 & 0.00 & 26.57 & 0.00 & 0.92 & 0.02 & 0.27 & 0.53 & 0.13 & 0.30 & 57.32 \\
\hline 11 & Wo & 0.00 & 0.03 & 31.73 & 0.02 & 30.45 & 0.01 & 1.11 & 0.01 & 0.25 & 0.48 & 0.07 & 0.01 & 64.16 \\
\hline $\begin{array}{c}\text { Analysis } \\
\text { Point }\end{array}$ & Grain 3 & $\mathrm{Na}_{2} \mathrm{O}$ & MgO & $\mathrm{SiO}_{2}$ & $\mathbf{K}_{2} \mathbf{O}$ & $\mathrm{CaO}$ & $\mathrm{TiO}_{2}$ & $\mathrm{FeO}$ & MnO & $\mathrm{Cl}$ & $\mathrm{Al}_{2} \mathrm{O}_{3}$ & $\mathrm{SO}_{2}$ & $\mathbf{P}_{2} \mathbf{O}_{5}$ & Total \\
\hline 1 & Plg & 0.03 & 0.20 & 34.33 & 0.01 & 14.39 & 0.05 & 0.73 & 0.01 & 0.02 & 28.94 & 0.25 & 0.03 & 78.99 \\
\hline 3 & Plg & 0.00 & 0.01 & 9.34 & 0.01 & 5.10 & 0.02 & 0.67 & 0.02 & 0.00 & 8.10 & 0.01 & 0.01 & 23.30 \\
\hline $\begin{array}{c}\text { Analysis } \\
\text { Point }\end{array}$ & Grain 4 & $\mathrm{Na}_{2} \mathrm{O}$ & MgO & $\mathrm{SiO}_{2}$ & $\mathbf{K}_{2} \mathbf{O}$ & $\mathrm{CaO}$ & $\mathrm{TiO}_{2}$ & $\mathrm{FeO}$ & MnO & $\mathrm{Cl}$ & $\mathrm{Al}_{2} \mathrm{O}_{3}$ & $\mathrm{SO}_{2}$ & $\mathbf{P}_{2} \mathbf{O}_{5}$ & Total \\
\hline 1 & Cpx & 0.11 & 10.31 & 43.97 & 0.06 & 16.02 & 0.49 & 14.10 & 0.50 & 0.07 & 1.52 & 0.26 & 0.04 & 87.43 \\
\hline 2 & Grt & 0.06 & 0.44 & 21.55 & 0.19 & 19.52 & 1.49 & 10.07 & 0.12 & 0.07 & 4.56 & 1.06 & 0.08 & 59.21 \\
\hline 3 & Cpx & 0.20 & 19.15 & 53.48 & 0.01 & 17.02 & 0.33 & 9.11 & 0.29 & 0.01 & 1.71 & 0.01 & 0.02 & 101.33 \\
\hline 4 & Cpx & 0.00 & 5.51 & 36.38 & 0.02 & 6.79 & 0.17 & 6.33 & 0.27 & 0.13 & 2.79 & 0.30 & 0.07 & 58.75 \\
\hline 5 & Grt & 0.00 & 0.26 & 18.42 & 0.06 & 18.31 & 0.78 & 4.29 & 0.03 & 0.09 & 4.94 & 0.48 & 0.03 & 47.67 \\
\hline 6 & Grt & 0.00 & 7.22 & 18.40 & 0.04 & 9.39 & 0.41 & 21.91 & 0.55 & 0.05 & 1.66 & 0.35 & 0.03 & 60.02 \\
\hline 7 & Cpx & 0.10 & 12.87 & 40.45 & 0.01 & 17.72 & 0.55 & 10.76 & 0.20 & 0.03 & 1.64 & 0.09 & 0.03 & 84.45 \\
\hline $\begin{array}{c}\text { Analysis } \\
\text { Point }\end{array}$ & Grain 5 & $\mathrm{Na}_{2} \mathrm{O}$ & MgO & $\mathrm{SiO}_{2}$ & $\mathbf{K}_{2} \mathbf{O}$ & $\mathrm{CaO}$ & $\mathrm{TiO}_{2}$ & $\mathrm{FeO}$ & MnO & $\mathrm{Cl}$ & $\mathrm{Al}_{2} \mathbf{O}_{3}$ & $\mathrm{SO}_{2}$ & $\mathbf{P}_{2} \mathbf{O}_{5}$ & Total \\
\hline 1 & OI & 0.02 & 42.54 & 39.81 & 0.00 & 0.30 & 0.02 & 20.11 & 0.29 & 0.00 & 0.04 & 0.02 & 0.02 & 103.18 \\
\hline 2 & Chl & 0.05 & 20.86 & 27.67 & 0.05 & 0.24 & 0.01 & 11.16 & 0.10 & 0.06 & 7.79 & 0.69 & 0.07 & 68.74 \\
\hline 3 & Chl & 0.06 & 26.92 & 34.78 & 0.06 & 0.20 & 0.02 & 13.27 & 0.08 & 0.02 & 9.63 & 0.20 & 0.04 & 85.27 \\
\hline 4 & Chl & 0.00 & 18.55 & 29.30 & 0.07 & 0.27 & 0.02 & 11.32 & 0.11 & 0.07 & 9.26 & 0.75 & 0.02 & 69.74 \\
\hline 5 & Chl & 0.03 & 18.59 & 26.80 & 0.04 & 0.09 & 0.02 & 10.31 & 0.10 & 0.06 & 7.11 & 0.56 & 0.01 & 63.71 \\
\hline 6 & Chl & 0.00 & 27.97 & 35.67 & 0.00 & 0.19 & 0.02 & 16.01 & 0.24 & 0.01 & 1.07 & 0.11 & 0.02 & 81.31 \\
\hline 7 & OI & 0.01 & 43.46 & 43.62 & 0.00 & 0.31 & 0.01 & 19.38 & 0.33 & 0.01 & 0.08 & 0.00 & 0.02 & 107.22 \\
\hline 8 & OI & 0.01 & 42.49 & 39.85 & 0.00 & 0.30 & 0.00 & 19.87 & 0.27 & 0.00 & 0.04 & 0.00 & 0.02 & 102.86 \\
\hline $\begin{array}{c}\text { Analysis } \\
\text { Point }\end{array}$ & Grain 7 & $\mathrm{Na}_{2} \mathrm{O}$ & MgO & $\mathrm{SiO}_{2}$ & $\mathbf{K}_{2} \mathbf{O}$ & $\mathrm{CaO}$ & $\mathrm{TiO}_{2}$ & $\mathrm{FeO}$ & MnO & $\mathrm{Cl}$ & $\mathbf{A l}_{2} \mathbf{O}_{3}$ & $\mathrm{SO}_{2}$ & $\mathbf{P}_{2} \mathbf{O}_{5}$ & Total \\
\hline 1 & Wo & 0.00 & 0.08 & 29.36 & 0.01 & 28.50 & 0.00 & 0.64 & 0.04 & 0.29 & 0.47 & 0.07 & 0.02 & 59.49 \\
\hline 2 & Wo & 0.01 & 0.11 & 24.84 & 0.00 & 22.86 & 0.02 & 0.67 & 0.07 & 0.31 & 0.38 & 0.08 & 0.01 & 49.37 \\
\hline 3 & Wo & 0.03 & 0.08 & 18.72 & 0.00 & 18.30 & 0.01 & 0.48 & 0.03 & 0.40 & 0.32 & 0.10 & 0.05 & 38.54 \\
\hline 4 & Wo & 0.00 & 0.13 & 12.98 & 0.00 & 11.41 & 0.04 & 0.52 & 0.00 & 0.47 & 0.36 & 0.13 & 0.05 & 26.09 \\
\hline 5 & Cpx & 0.16 & 16.88 & 52.61 & 0.00 & 18.80 & 0.48 & 10.00 & 0.24 & 0.01 & 2.04 & 0.00 & 0.03 & 101.26 \\
\hline $\begin{array}{c}\text { Analysis } \\
\text { Point }\end{array}$ & Grain 9 & $\mathrm{Na}_{2} \mathrm{O}$ & MgO & $\mathrm{SiO}_{2}$ & $\mathrm{~K}_{2} \mathrm{O}$ & $\mathrm{CaO}$ & $\mathrm{TiO}_{2}$ & $\mathrm{FeO}$ & MnO & $\mathrm{Cl}$ & $\mathrm{Al}_{2} \mathrm{O}_{3}$ & $\mathrm{SO}_{2}$ & $\mathbf{P}_{2} \mathbf{O}_{5}$ & Total \\
\hline 1 & Wo & 0.00 & 0.04 & 30.58 & 0.00 & 29.50 & 0.03 & 0.91 & 0.06 & 0.24 & 0.53 & 0.09 & 0.02 & 62.01 \\
\hline 2 & Wo & 0.00 & 0.05 & 39.24 & 0.01 & 37.83 & 0.03 & 1.17 & 0.04 & 0.15 & 0.70 & 0.05 & 0.02 & 79.29 \\
\hline 3 & Wo & 0.03 & 0.06 & 27.94 & 0.00 & 26.91 & 0.04 & 1.11 & 0.01 & 0.27 & 1.31 & 0.12 & 1.00 & 58.82 \\
\hline 4 & Wo & 0.00 & 0.04 & 29.08 & 0.02 & 29.42 & 0.02 & 0.99 & 0.04 & 0.24 & 0.64 & 0.09 & 0.02 & 60.60 \\
\hline 5 & Wo & 0.00 & 0.03 & 17.10 & 0.01 & 17.29 & 4.49 & 1.55 & 0.00 & 0.31 & 5.08 & 0.19 & 0.03 & 46.09 \\
\hline 6 & Wo & 0.04 & 0.04 & 26.87 & 0.01 & 25.85 & 0.02 & 0.84 & 0.05 & 0.22 & 0.53 & 0.26 & 0.03 & 54.74 \\
\hline 7 & Wo & 0.01 & 0.05 & 40.14 & 0.02 & 38.79 & 0.03 & 1.06 & 0.05 & 0.12 & 0.68 & 0.05 & 0.04 & 81.02 \\
\hline 8 & Wo & 0.02 & 0.05 & 32.27 & 0.00 & 31.45 & 0.02 & 0.89 & 0.05 & 0.21 & 0.56 & 0.08 & 0.04 & 65.65 \\
\hline 9 & Wo & 0.04 & 0.04 & 28.01 & 0.00 & 28.91 & 0.02 & 0.91 & 0.02 & 0.24 & 0.44 & 0.08 & 0.04 & 58.74 \\
\hline 10 & Wo & 0.00 & 0.05 & 34.10 & 0.00 & 33.97 & 0.01 & 1.04 & 0.05 & 0.19 & 0.51 & 0.06 & 0.00 & 69.97 \\
\hline 11 & Wo & 0.01 & 0.14 & 14.68 & 0.00 & 14.62 & 0.03 & 0.71 & 0.00 & 0.35 & 0.35 & 0.16 & 0.01 & 31.06 \\
\hline 12 & Wo & 0.02 & 0.12 & 19.37 & 0.00 & 21.07 & 0.01 & 0.77 & 0.01 & 0.28 & 0.49 & 0.15 & 0.02 & 42.31 \\
\hline 13 & Wo & 0.01 & 0.23 & 15.85 & 0.00 & 15.43 & 0.03 & 0.85 & 0.00 & 0.35 & 0.58 & 0.17 & 0.01 & 33.51 \\
\hline 14 & Wo & 0.00 & 0.06 & 32.47 & 0.00 & 29.85 & 0.02 & 1.00 & 0.03 & 0.20 & 0.60 & 0.12 & 0.03 & 64.37 \\
\hline 15 & Wo & 0.01 & 0.05 & 24.64 & 0.03 & 15.91 & 0.05 & 0.83 & 0.00 & 0.23 & 0.64 & 0.62 & 0.27 & 43.28 \\
\hline $\begin{array}{c}\text { Analysis } \\
\text { Point }\end{array}$ & Grain 10 & $\mathrm{Na}_{2} \mathrm{O}$ & MgO & $\mathrm{SiO}_{2}$ & $\mathrm{~K}_{2} \mathrm{O}$ & $\mathrm{CaO}$ & $\mathrm{TiO}_{2}$ & $\mathrm{FeO}$ & MnO & $\mathrm{Cl}$ & $\mathrm{Al}_{2} \mathbf{O}_{3}$ & $\mathrm{SO}_{2}$ & $\mathbf{P}_{2} \mathbf{O}_{5}$ & Total \\
\hline 1 & Chl & 0.05 & 16.56 & 26.31 & 0.02 & 0.38 & 0.07 & 20.30 & 0.40 & 0.12 & 15.12 & 0.37 & 0.06 & 79.78 \\
\hline 2 & Chl & 0.02 & 11.96 & 20.00 & 0.04 & 0.28 & 0.04 & 15.00 & 0.27 & 0.27 & 12.07 & 0.14 & 0.04 & 60.11 \\
\hline 3 & Chl & 0.00 & 0.17 & 0.35 & 0.02 & 0.10 & 0.02 & 0.28 & 0.00 & 0.66 & 0.33 & 0.11 & 0.00 & 2.03 \\
\hline 4 & Chl & 0.00 & 3.90 & 6.48 & 0.03 & 0.59 & 0.02 & 5.08 & 0.07 & 0.52 & 4.62 & 0.24 & 0.02 & 21.57 \\
\hline 5 & Chl & 0.01 & 0.01 & 0.05 & 0.00 & 0.03 & 0.00 & 0.14 & 0.00 & 0.79 & 0.02 & 0.16 & 0.00 & 1.22 \\
\hline 6 & Plg & 0.25 & 0.02 & 42.82 & 0.00 & 19.65 & 0.02 & 0.41 & & & 36.16 & & & 99.33 \\
\hline 7 & Plg & 0.39 & 0.00 & 43.27 & 0.00 & 19.30 & 0.02 & 0.41 & & & 36.24 & & & 99.63 \\
\hline 8 & Plg & 0.20 & 0.00 & 42.07 & 0.01 & 19.67 & 0.00 & 0.39 & & & 36.57 & & & 98.91 \\
\hline \multirow[t]{9}{*}{9} & Plg & 0.06 & 0.00 & 42.86 & 0.00 & 20.21 & 0.38 & 0.01 & & & 36.99 & & & 100.52 \\
\hline & average & $\mathrm{Na}_{2} \mathrm{O}$ & MgO & $\mathrm{SiO}_{2}$ & $\mathbf{K}_{2} \mathbf{O}$ & $\mathrm{CaO}$ & $\mathrm{TiO}_{2}$ & $\mathrm{FeO}$ & MnO & $\mathrm{Cl}$ & $\mathrm{Al}_{2} \mathbf{O}_{3}$ & $\mathrm{SO}_{2}$ & $\mathbf{P}_{2} \mathbf{O}_{5}$ & \\
\hline & Plg & 0.16 & 0.04 & 35.78 & 0.01 & 16.39 & 0.08 & 0.44 & & & 30.50 & & & \\
\hline & Cpx & 0.12 & 12.94 & 45.38 & 0.02 & 15.27 & 0.40 & 10.06 & 0.30 & 0.05 & 1.94 & 0.13 & 0.04 & \\
\hline & Grt & 0.03 & 0.35 & 19.99 & 0.12 & 18.91 & 1.14 & 7.18 & 0.08 & 0.08 & 4.75 & 0.77 & 0.05 & \\
\hline & Wo & 0.01 & 0.08 & 26.71 & 0.01 & 25.41 & 0.21 & 0.94 & 0.03 & 0.27 & 0.74 & 0.13 & 0.09 & \\
\hline & Chl & 0.02 & 14.55 & 20.74 & 0.03 & 0.24 & 0.02 & 10.29 & 0.14 & 0.26 & 6.70 & 0.33 & 0.03 & \\
\hline & Ox & 0.00 & 0.62 & 0.16 & 0.00 & 0.35 & 19.94 & 71.01 & 0.43 & 0.01 & 1.45 & 0.02 & 0.00 & \\
\hline & 01 & 0. & 4283 & 4111 & 0 & 0 & 0.01 & 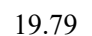 & 030 & n & 005 & 001 & 002 & \\
\hline
\end{tabular}


Table B.3.4. Average mineral compositions determined by EMPA analysis from Table B.3.3

$\begin{array}{ccc}\text { Oxides } & \text { average wt \% } & \text { average wt } \% \\ \mathrm{Na}_{2} \mathrm{O} & 0.16 & 0.12 \\ \mathrm{MgO} & & 12.94 \\ \mathrm{SiO}_{2} & 35.78 & 45.38 \\ \mathrm{~K}_{2} \mathrm{O} & 0.01 & 0.02 \\ \mathrm{CaO} & 16.39 & 15.27 \\ \mathrm{TiO}_{2} & 0.08 & 0.40 \\ \mathrm{FeO}_{(\mathrm{T})} & 0.44 & 10.06 \\ \mathrm{MnO} & & 0.30 \\ \mathrm{Cl} & & 0.05 \\ \mathrm{Al}_{2} \mathrm{O}_{3} & 30.50 & 1.94 \\ \mathrm{SO}_{2} & & 0.13 \\ \mathrm{P}_{2} \mathrm{O}_{5} & & 0.04 \\ & & \\ \text { Total } & 83.36 & 86.64\end{array}$

average wt $\%$
0.01
42.83
41.10

0.30
0.01
19.79
0.30

0.05
0.01
0.02

average $w t \%$

0.62

0.16

0.35

19.94

71.01

0.43

0.0

1.45
0.02

104.39

94.00

\begin{tabular}{|c|c|c|c|c|}
\hline $\begin{array}{l}\text { Mineral } \\
\text { Composition }\end{array}$ & $\begin{array}{c}\mathrm{Ca}_{0.975} \mathrm{Na}_{0.017} \mathrm{Fe}^{3+}{ }_{0.02} \mathrm{Al}_{1.996} \mathrm{Si}_{1.987} \mathrm{O}_{8} \\
\left(\mathrm{An}_{98}-\mathrm{Ab}_{2}\right)\end{array}$ & $\mathrm{Na}_{0.01} \mathrm{Ca}_{0.70} \mathrm{Mg}_{0.83} \mathrm{Fe}^{2+}{ }_{0.36} \mathrm{Mn}_{0.01} \mathrm{Ti}_{0.01} \mathrm{Al}_{0.01} \mathrm{Si}_{1.96} \mathrm{O}_{6}$ & $\begin{array}{c}\mathrm{Ca}_{0.008} \mathrm{Mn}_{0.008} \mathrm{Fe}^{2+}{ }_{0.542} \mathrm{Mg}_{1.56} \mathrm{Fe}^{3+}{ }_{0.015} \mathrm{Si}_{0.99} \mathrm{O}_{4} \\
\left(\mathrm{Fo}_{72}-\mathrm{Fa}_{28}\right)\end{array}$ & $\mathrm{Fe}^{2+}\left(\mathrm{Fe}^{3+}, \mathrm{Ti}_{2} \mathrm{O}_{4}\right.$ \\
\hline Phase and ID & $\begin{array}{c}\text { Plagioclase } \\
\text { (anorthite) }\end{array}$ & $\begin{array}{l}\text { Clinopyroxene } \\
\text { (augite) }\end{array}$ & $\begin{array}{l}\text { Mg-olivine } \\
\text { (forsterite) }\end{array}$ & $\begin{array}{c}\text { Oxide } \\
\text { (titanomagnetite) }\end{array}$ \\
\hline Oxides & average wt \% & average wt \% & average wt \% & \\
\hline $\mathrm{Na}_{2} \mathrm{O}$ & 0.02 & 0.01 & 0.03 & \\
\hline $\mathrm{MgO}$ & 14.55 & 0.08 & 0.35 & \\
\hline $\mathrm{SiO}_{2}$ & 20.74 & 26.71 & 19.99 & \\
\hline $\mathrm{K}_{2} \mathrm{O}$ & 0.03 & 0.01 & 0.12 & \\
\hline $\mathrm{CaO}$ & 0.24 & 25.41 & 18.91 & \\
\hline $\mathrm{TiO}_{2}$ & 0.02 & 0.21 & 1.14 & \\
\hline $\mathrm{FeO}_{(\mathrm{T})}$ & 10.29 & 0.94 & 7.18 & \\
\hline $\mathrm{MnO}$ & 0.14 & 0.03 & 0.08 & \\
\hline $\mathrm{Cl}$ & 0.26 & 0.27 & 0.08 & \\
\hline $\mathrm{Al}_{2} \mathrm{O}_{3}$ & 6.70 & 0.74 & 4.75 & \\
\hline $\mathrm{SO}_{2}$ & 0.33 & 0.13 & 0.77 & \\
\hline $\mathrm{P}_{2} \mathrm{O}_{5}$ & 0.03 & 0.09 & 0.05 & \\
\hline Total & 53.35 & 54.62 & 53.44 & \\
\hline $\begin{array}{c}\text { Mineral } \\
\text { Composition }\end{array}$ & $\begin{array}{c}\mathrm{K}_{0.01} \mathrm{Na}_{0.01} \mathrm{Ca}_{0.09} \mathrm{Mn}_{0.04} \mathrm{Mg}_{7.22} \mathrm{Fe}_{2.87} \mathrm{Ti}_{0.01} \mathrm{Al}_{1.54} \mathrm{Si}_{6.91} \mathrm{Al}_{1.09} \mathrm{O}_{20}(\mathrm{OH})_{16} \\
\text { (on the basis of } 28 \text { oxygen equivalents, ignoring } \mathrm{H}_{2} \mathrm{O} \text { ) }\end{array}$ & $\begin{array}{l}\mathrm{K}_{0.001} \mathrm{Na}_{0.004} \mathrm{Ca}_{5.89} \mathrm{Mn}_{0.005} \mathrm{Mg}_{0.026} \mathrm{Fe} \mathrm{Fe}_{0.17} \mathrm{Ti}_{0.034} \mathrm{Si}_{5.77} \mathrm{Al}_{0.19} \mathrm{O}_{18} \\
\text { (on the basis of } 18 \text { oxygen equivalents) }\end{array}$ & $\begin{array}{l}\mathrm{Ca}_{6.32} \mathrm{Mn}_{0.02} \mathrm{Fe}_{1.874} \mathrm{Mg}_{0.163} \mathrm{Ti}_{0.267} \mathrm{Si}_{6.235} \mathrm{Al}_{1.747} \mathrm{O}_{24} \\
\text { (on the basis of } 24 \text { oxygen equivalent) }\end{array}$ & \\
\hline Phase and ID & Chlorite & Wollastonite & $\begin{array}{l}\text { Garnet } \\
\text { (grossular) }\end{array}$ & \\
\hline
\end{tabular}



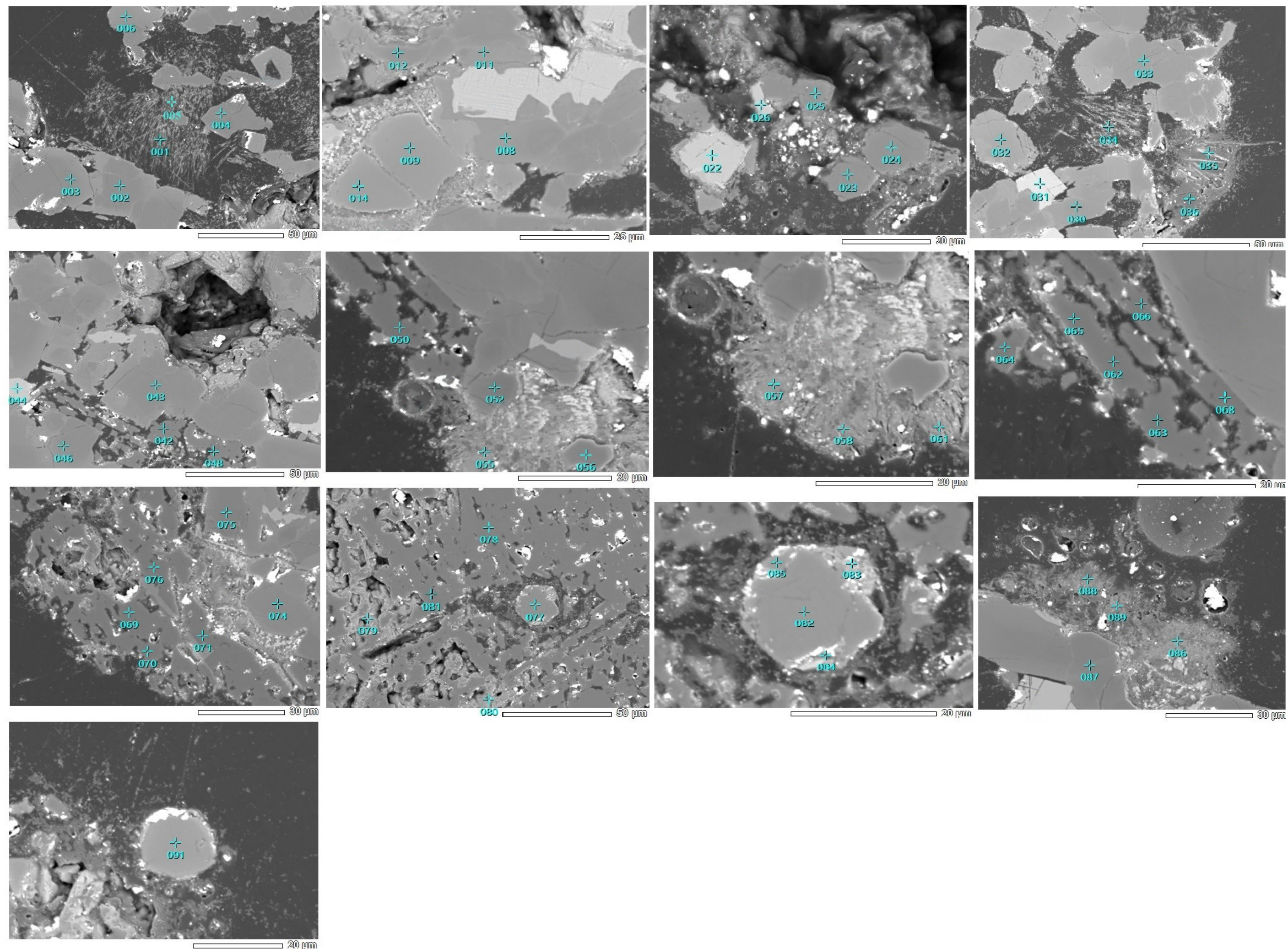
Table B.3.5. EDS analysis of reacted grains in Figure B.3.4

\begin{tabular}{|c|c|c|c|c|c|c|c|}
\hline & $\begin{array}{l}\text { Analysis } \\
\text { Point }\end{array}$ & $\mathrm{Na}_{2} \mathrm{O}$ & $\mathbf{A l}_{2} \mathbf{O}_{3}$ & $\mathrm{SiO}_{2}$ & $\mathrm{CaO}$ & & Total \\
\hline \multirow[t]{17}{*}{ Plg } & 42 & 0.40 & 39.00 & 41.42 & 19.18 & & 100.00 \\
\hline & 48 & 0.30 & 36.37 & 43.57 & 19.77 & & 100.00 \\
\hline & 50 & 0.00 & 36.72 & 43.07 & 20.21 & & 100.00 \\
\hline & 62 & 0.00 & 36.40 & 44.22 & 19.38 & & 100.00 \\
\hline & 63 & 0.00 & 36.87 & 43.43 & 19.70 & & 100.00 \\
\hline & 64 & 0.29 & 39.51 & 41.27 & 18.93 & & 100.00 \\
\hline & 65 & 0.00 & 36.52 & 43.21 & 20.28 & & 100.00 \\
\hline & 66 & 0.00 & 39.89 & 42.07 & 18.04 & & 100.00 \\
\hline & 68 & 0.33 & 36.30 & 41.67 & 20.67 & & 100.00 \\
\hline & 69 & 0.32 & 38.94 & 40.96 & 19.78 & & 100.00 \\
\hline & 70 & 0.00 & 39.78 & 40.18 & 20.04 & & 100.00 \\
\hline & 71 & 0.00 & 36.70 & 43.19 & 20.11 & & 100.00 \\
\hline & 76 & 0.00 & 39.37 & 40.81 & 19.83 & & 100.00 \\
\hline & 78 & 0.00 & 36.77 & 43.02 & 20.21 & & 100.00 \\
\hline & 79 & 0.00 & 37.13 & 43.50 & 19.37 & & 100.00 \\
\hline & 80 & 0.00 & 39.25 & 41.87 & 18.88 & & 100.00 \\
\hline & 81 & 1.05 & 36.50 & 45.40 & 17.06 & & 100.00 \\
\hline \multirow[t]{2}{*}{ average } & & 0.16 & 37.77 & 42.52 & 19.50 & & \\
\hline & $\begin{array}{c}\text { Analysis } \\
\text { Point }\end{array}$ & $\mathrm{MgO}$ & $\mathrm{Al}_{2} \mathbf{O}_{3}$ & $\mathrm{SiO}_{2}$ & $\mathrm{CaO}$ & $\mathrm{FeO}$ & Total \\
\hline \multirow[t]{21}{*}{$\mathrm{Cpx}$} & 2 & 15.04 & 3.65 & 50.79 & 18.34 & 12.18 & 100.00 \\
\hline & 3 & 15.59 & 2.40 & 52.78 & 19.32 & 9.91 & 100.00 \\
\hline & 4 & 12.26 & 2.57 & 55.32 & 18.37 & 11.48 & 100.00 \\
\hline & 6 & 13.13 & 1.94 & 51.30 & 11.37 & 22.27 & 100.00 \\
\hline & 8 & 15.97 & 1.59 & 50.38 & 5.31 & 26.76 & 100.00 \\
\hline & 11 & 16.40 & 0.80 & 51.76 & 4.44 & 26.59 & 100.00 \\
\hline & 12 & 16.02 & 2.46 & 52.82 & 18.71 & 9.99 & 100.00 \\
\hline & 23 & 13.91 & 6.50 & 49.75 & 19.50 & 10.33 & 100.00 \\
\hline & 24 & 16.26 & 1.98 & 53.17 & 19.50 & 9.08 & 100.00 \\
\hline & 25 & 16.07 & 2.10 & 52.89 & 17.92 & 11.03 & 100.00 \\
\hline & 30 & 14.08 & 2.15 & 55.88 & 20.11 & 7.78 & 100.00 \\
\hline & 32 & 15.39 & 1.59 & 51.46 & 8.28 & 23.27 & 100.00 \\
\hline & 33 & 15.92 & 2.77 & 51.70 & 18.71 & 10.89 & 100.00 \\
\hline & 43 & 14.12 & 2.11 & 56.03 & 20.40 & 7.35 & 100.00 \\
\hline & 46 & 13.45 & 2.28 & 55.28 & 20.26 & 8.74 & 100.00 \\
\hline & 52 & 16.18 & 2.27 & 52.55 & 19.86 & 9.14 & 100.00 \\
\hline & 56 & 11.59 & 1.92 & 54.70 & 13.59 & 18.20 & 100.00 \\
\hline & 67 & 12.20 & 2.29 & 55.67 & 20.21 & 9.63 & 100.00 \\
\hline & 74 & 14.77 & 1.04 & 51.35 & 4.44 & 28.40 & 100.00 \\
\hline & 75 & 13.46 & 2.33 & 55.27 & 20.01 & 8.94 & 100.00 \\
\hline & 87 & 13.62 & 2.21 & 51.00 & 17.00 & 16.17 & 100.00 \\
\hline & & 14.54 & 2.33 & 52.95 & 15.98 & 14.20 & \\
\hline
\end{tabular}

\begin{tabular}{|c|c|c|c|c|c|c|c|}
\hline & $\begin{array}{c}\text { Analysis } \\
\text { Point }\end{array}$ & MgO & $\mathrm{SiO}_{2}$ & $\mathrm{FeO}$ & $\mathrm{Al}_{3} \mathrm{O}_{3}$ & & Total \\
\hline \multirow[t]{2}{*}{$\mathrm{Ol}$} & 14 & 30.48 & 36.81 & 32.70 & 0.00 & & 100.00 \\
\hline & 9 & 30.38 & 36.19 & 32.84 & 0.59 & & 100.00 \\
\hline \multirow[t]{2}{*}{ average } & & 30.43 & 36.50 & 32.77 & 0.30 & & \\
\hline & $\begin{array}{c}\text { Analysis } \\
\text { Point }\end{array}$ & $\mathbf{A l}_{2} \mathbf{O}_{3}$ & $\mathrm{SiO}_{2}$ & $\mathrm{CaO}$ & & & Total \\
\hline \multirow[t]{4}{*}{ Wo } & 5 & 0.91 & 53.86 & 45.23 & & & 100.00 \\
\hline & 1 & 1.74 & 52.03 & 46.23 & & & 100.00 \\
\hline & 34 & 1.26 & 52.76 & 45.98 & & & 100.00 \\
\hline & 35 & 0.00 & 50.69 & 49.31 & & & 100.00 \\
\hline \multirow[t]{2}{*}{ average } & & 0.98 & 52.34 & 46.69 & & & \\
\hline & $\begin{array}{c}\text { Analysis } \\
\text { Point }\end{array}$ & $\mathbf{A l}_{2} \mathbf{O}_{3}$ & $\mathrm{SiO}_{2}$ & $\mathrm{CaO}$ & $\mathrm{TiO}_{2}$ & $\mathrm{FeO}$ & Total \\
\hline \multirow[t]{6}{*}{ Grt } & 77 & 15.79 & 35.19 & 38.69 & 0.00 & 10.33 & 100.00 \\
\hline & 82 & 15.70 & 34.73 & 38.30 & 1.58 & 9.69 & 100.00 \\
\hline & 83 & 18.48 & 37.13 & 36.28 & 0.00 & 8.11 & 100.00 \\
\hline & 84 & 11.76 & 35.04 & 39.79 & 0.00 & 13.41 & 100.00 \\
\hline & 85 & 17.89 & 35.44 & 38.86 & 0.00 & 7.81 & 100.00 \\
\hline & 91 & 14.90 & 34.83 & 38.84 & 0.00 & 11.44 & 100.00 \\
\hline \multirow[t]{2}{*}{ average } & & 15.75 & 35.39 & 38.46 & 0.26 & 10.13 & \\
\hline & $\begin{array}{c}\text { Analysis } \\
\text { Point }\end{array}$ & MgO & $\mathbf{A l}_{2} \mathbf{O}_{3}$ & $\mathrm{SiO}_{2}$ & $\mathrm{FeO}$ & & Total \\
\hline \multirow[t]{7}{*}{ Chl } & 55 & 20.68 & 19.21 & 35.27 & 24.84 & & 100.00 \\
\hline & 57 & 20.94 & 19.73 & 34.40 & 24.93 & & 100.00 \\
\hline & 58 & 21.32 & 18.73 & 35.84 & 24.11 & & 100.00 \\
\hline & 61 & 22.72 & 20.04 & 35.23 & 22.01 & & 100.00 \\
\hline & 86 & 19.54 & 16.40 & 38.00 & 26.05 & & 100.00 \\
\hline & 88 & 16.10 & 18.60 & 36.05 & 29.24 & & 100.00 \\
\hline & 89 & 21.06 & 19.69 & 35.00 & 24.24 & & 100.00 \\
\hline \multirow[t]{2}{*}{ average } & & 20.34 & 18.91 & 35.68 & 25.06 & & \\
\hline & $\begin{array}{c}\text { Analysis } \\
\text { Point }\end{array}$ & $\mathbf{T i O}_{2}$ & $\mathrm{FeO}$ & & & & Total \\
\hline \multirow[t]{4}{*}{ Ox } & 22 & 30.39 & 69.61 & & & & 100.00 \\
\hline & 26 & 28.62 & 71.38 & & & & 100.00 \\
\hline & 31 & 28.62 & 71.38 & & & & 100.00 \\
\hline & 44 & 25.73 & 74.27 & & & & 100.00 \\
\hline average & & 28.34 & 71.66 & & & & \\
\hline
\end{tabular}


Table B.3.6. Average mineral compositions determined by EDS from Table B.3.5

\begin{tabular}{|c|c|c|c|c|c|c|c|}
\hline Oxides & average wt $\%$ & average wt $\%$ & average wt $\%$ & average wt $\%$ & average wt $\%$ & average wt $\%$ & average wt $\%$ \\
\hline $\mathrm{MgO}$ & & 14.54 & 30.43 & & 20.34 & & \\
\hline $\mathrm{Na}_{2} \mathrm{O}$ & 0.16 & & & & & & \\
\hline $\mathrm{Al}_{2} \mathrm{O}_{3}$ & 37.77 & 2.33 & 0.30 & & 18.91 & 0.98 & 15.75 \\
\hline $\mathrm{SiO}_{2}$ & 42.52 & 52.95 & 36.50 & & 35.68 & 52.34 & 35.39 \\
\hline $\mathrm{CaO}$ & 19.50 & 15.98 & & & & 46.69 & 38.46 \\
\hline $\mathrm{FeO}_{(\mathrm{T})}$ & & 14.20 & 32.77 & 71.66 & 25.06 & & 10.13 \\
\hline $\mathrm{TiO}_{2}$ & & & & 28.34 & & & 0.26 \\
\hline Total & 99.94 & 100.00 & 100.00 & 100.00 & 99.99 & 100.01 & 100.00 \\
\hline $\begin{array}{l}\text { Mineral } \\
\text { Composition }\end{array}$ & $\begin{array}{l}\mathrm{Ca}_{0.97} \mathrm{Na}_{0.01} \mathrm{Al}_{2.06} \mathrm{Si}_{1.97} \mathrm{O}_{8} \\
\quad\left(\mathrm{An}_{99}-\mathrm{Ab}_{1}\right)\end{array}$ & $\mathrm{Ca}_{0.64} \mathrm{Mg}_{0.88} \mathrm{Fe}_{0.44} \mathrm{Al}_{0.1} \mathrm{Si}_{1.98} \mathrm{O}_{6}$ & $\underset{\left(\mathrm{Fo}_{62}-\mathrm{Fa}_{38}\right)}{\mathrm{Mg}_{1.24} \mathrm{Fe}_{0.7} \mathrm{SiO}_{4}}$ & $\mathrm{Fe}^{2+}\left(\mathrm{Fe}^{3+}, \mathrm{Ti}_{2}\right)_{4} \mathrm{O}_{4}$ & $\begin{array}{c}\mathrm{Mg}_{5.44} \mathrm{Fe}_{3.76} \mathrm{Al}_{2.4} \mathrm{Si}_{6.4} \mathrm{Al}_{1.6} \mathrm{O}_{20}(\mathrm{OH})_{16} \\
\text { (on the basis of } 28 \text { oxygen equivalents, ignoring } \mathrm{H}_{2} \mathrm{O} \text { ) }\end{array}$ & $\begin{array}{c}\mathrm{Ca}_{5.77} \mathrm{~S}_{6.02} \mathrm{~A}_{2} \mathrm{Al}_{13} \mathrm{O}_{18} \\
\text { (on the basis of } 18 \text { oxygen equivalents) }\end{array}$ & 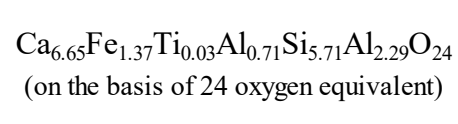 \\
\hline Phase nd ID & $\begin{array}{c}\text { Plagioclase } \\
\text { (anorthite) }\end{array}$ & $\begin{array}{c}\text { Clinopyroxene } \\
\text { (augite) }\end{array}$ & $\begin{array}{l}\text { Mg-olivine } \\
\text { (forsterite) }\end{array}$ & $\begin{array}{c}\text { Oxide } \\
\text { (titanomagnetite) }\end{array}$ & Chlorite & Wollastonite & $\begin{array}{l}\text { Garnet } \\
\text { (grossular) }\end{array}$ \\
\hline
\end{tabular}


Figure B.3.5. EDS analysis of grains collected from the bottom (Portion 1) of the Reactor
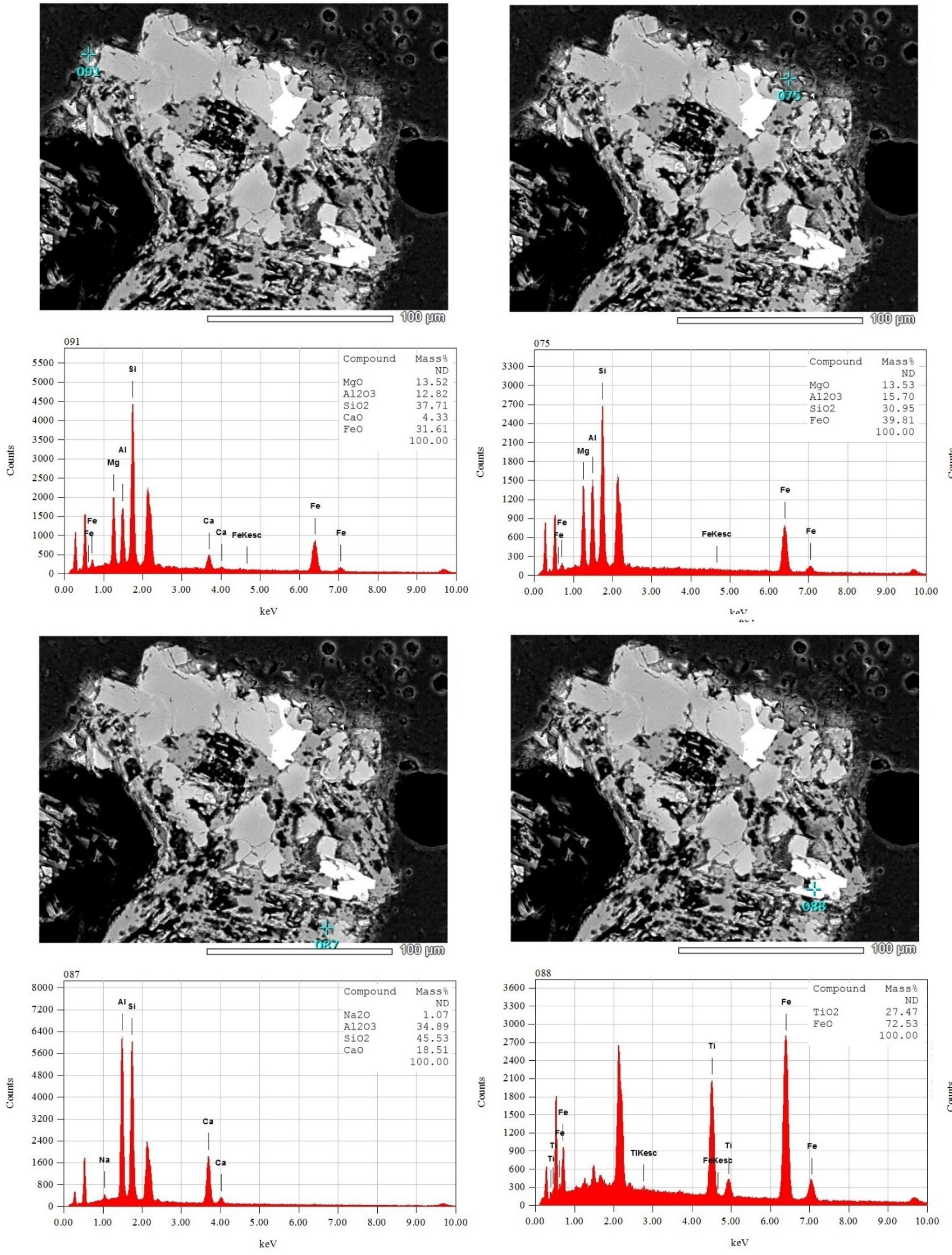
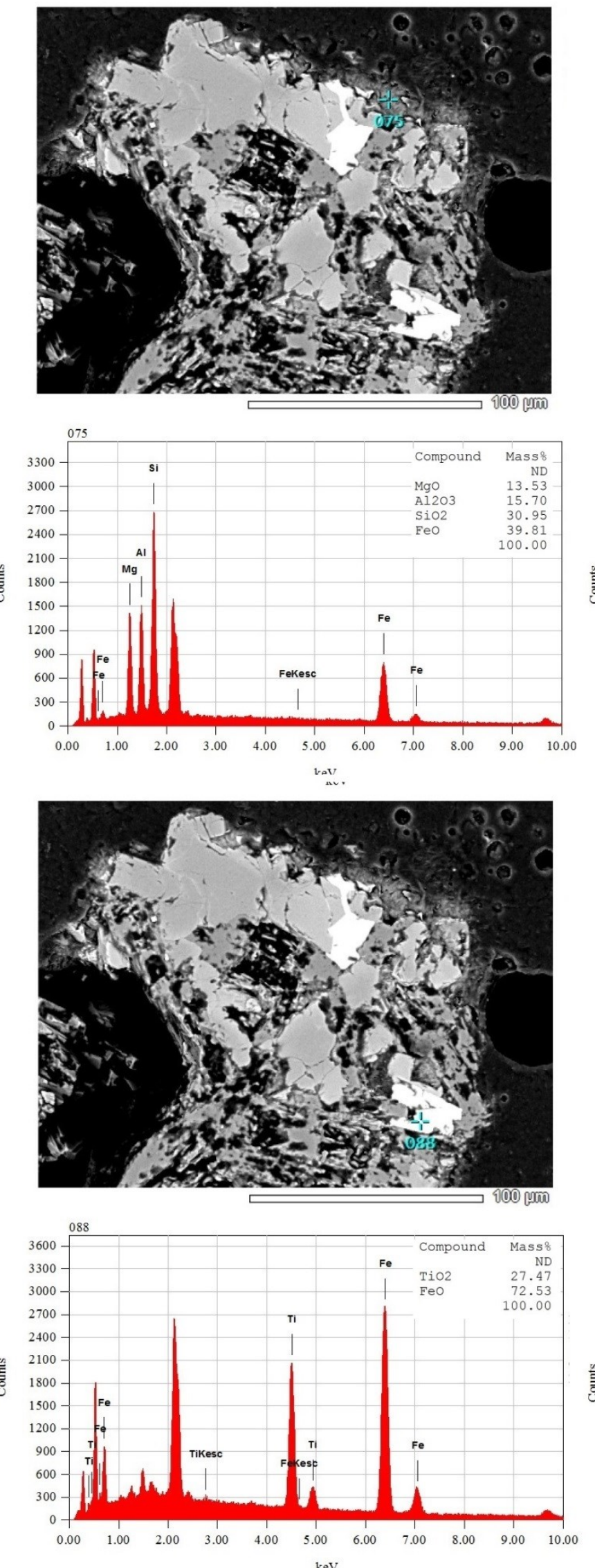
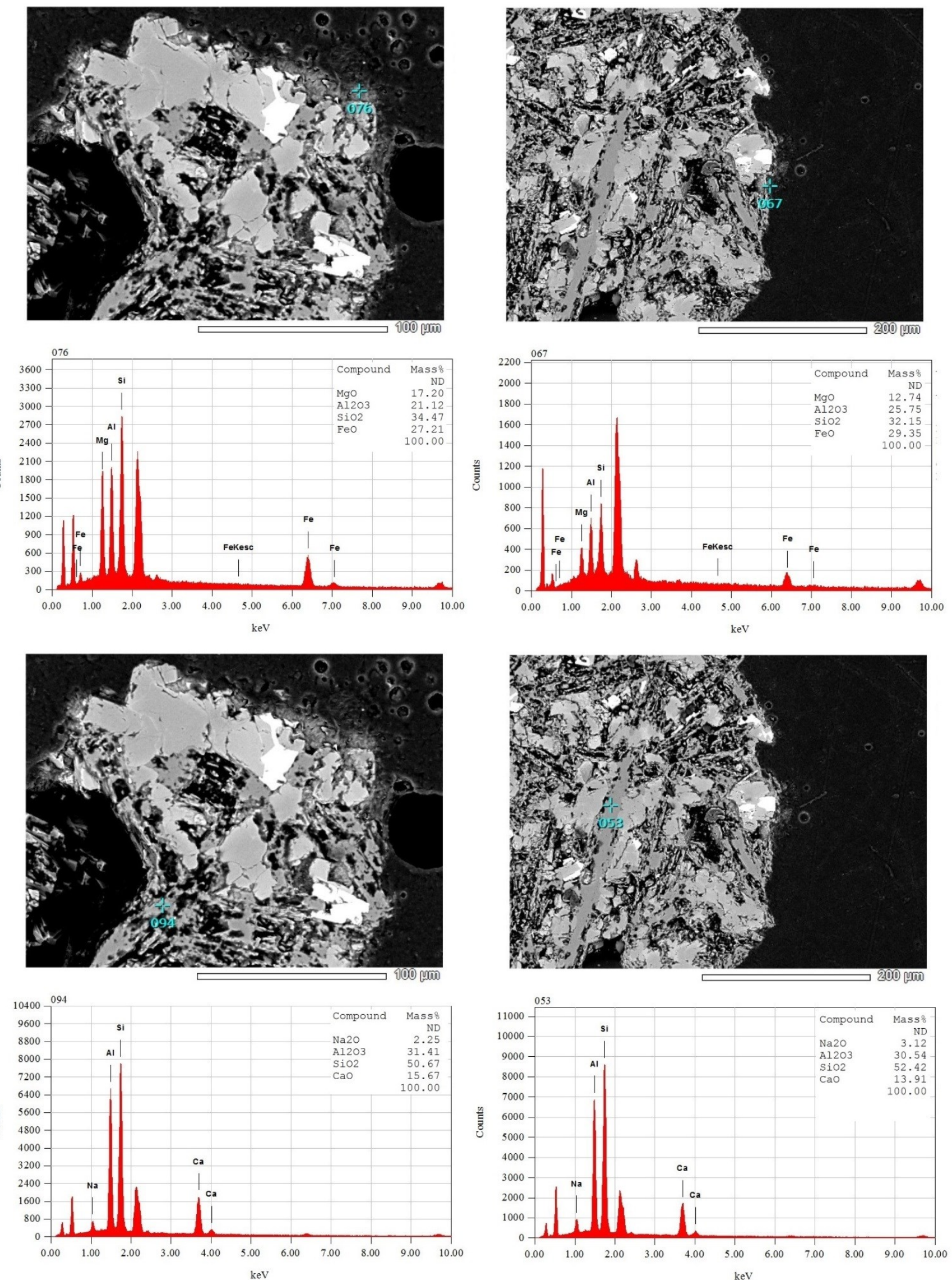
Figure B.3.6. FDS analysis of grains collected from the bottom (Portion 1) of the Reactor
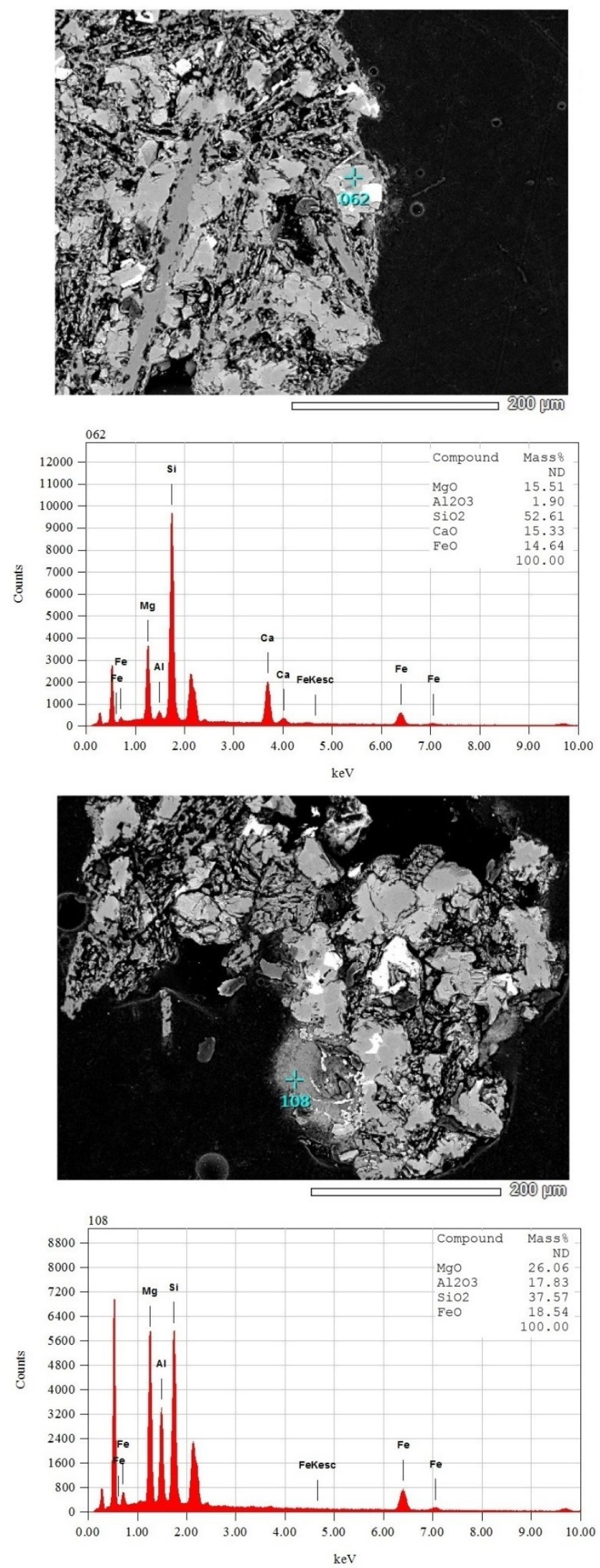
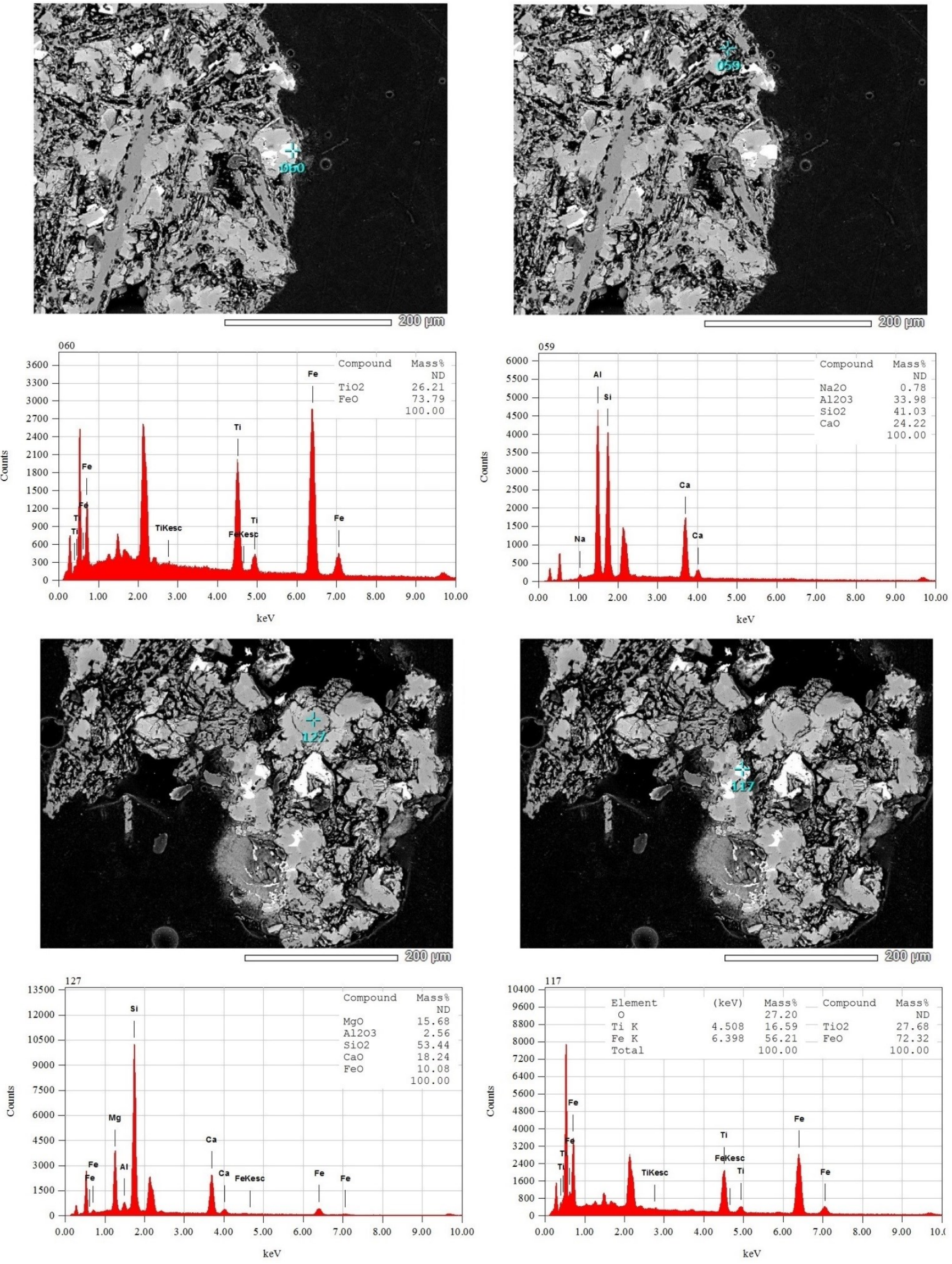
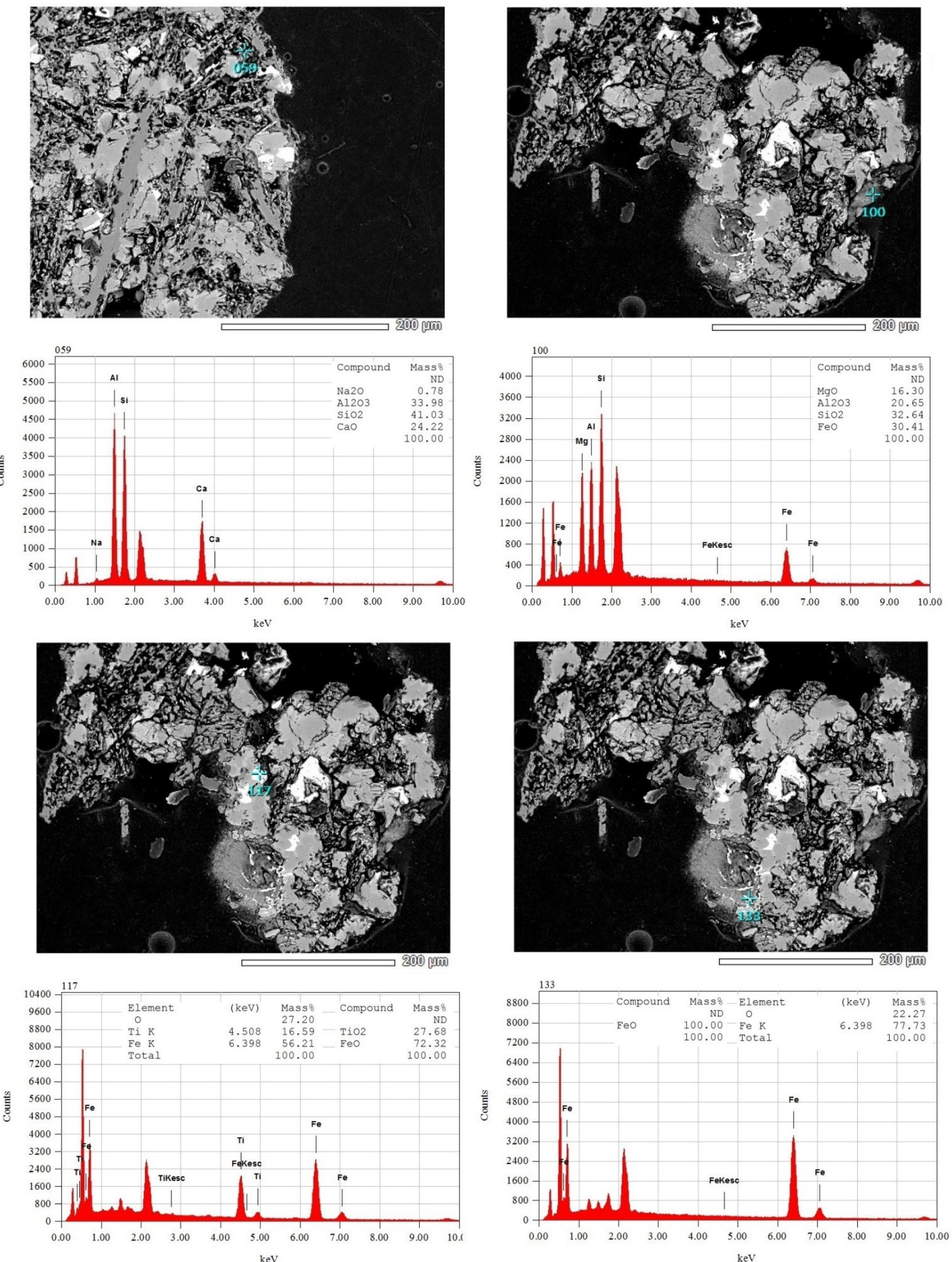
Figure B.3.7. EDS analysis of grains collected from the bottom (Portion 1) of the Reactor
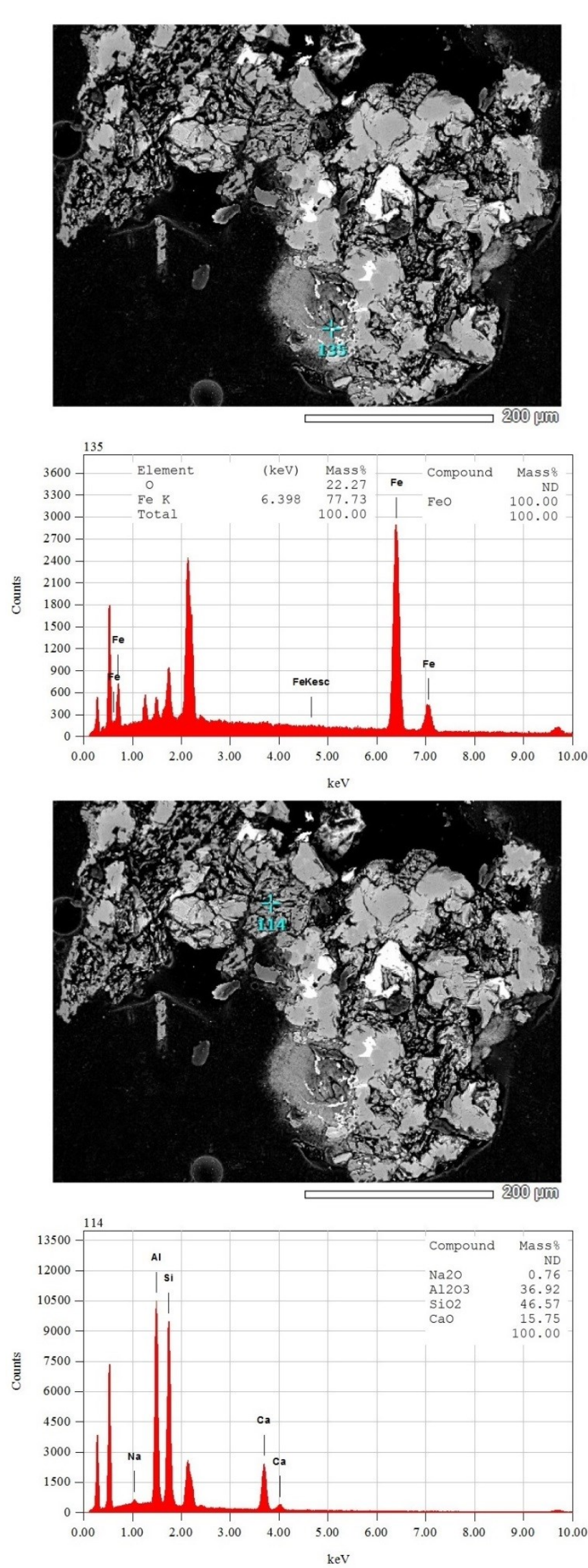
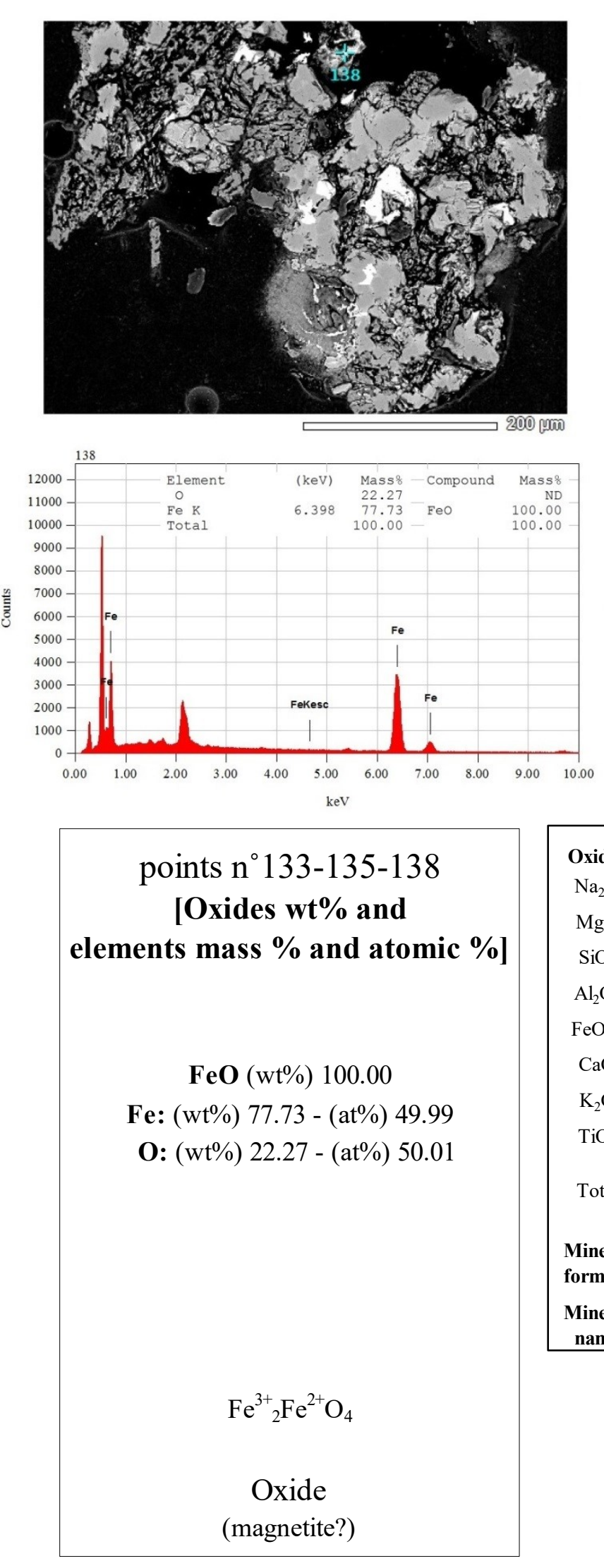
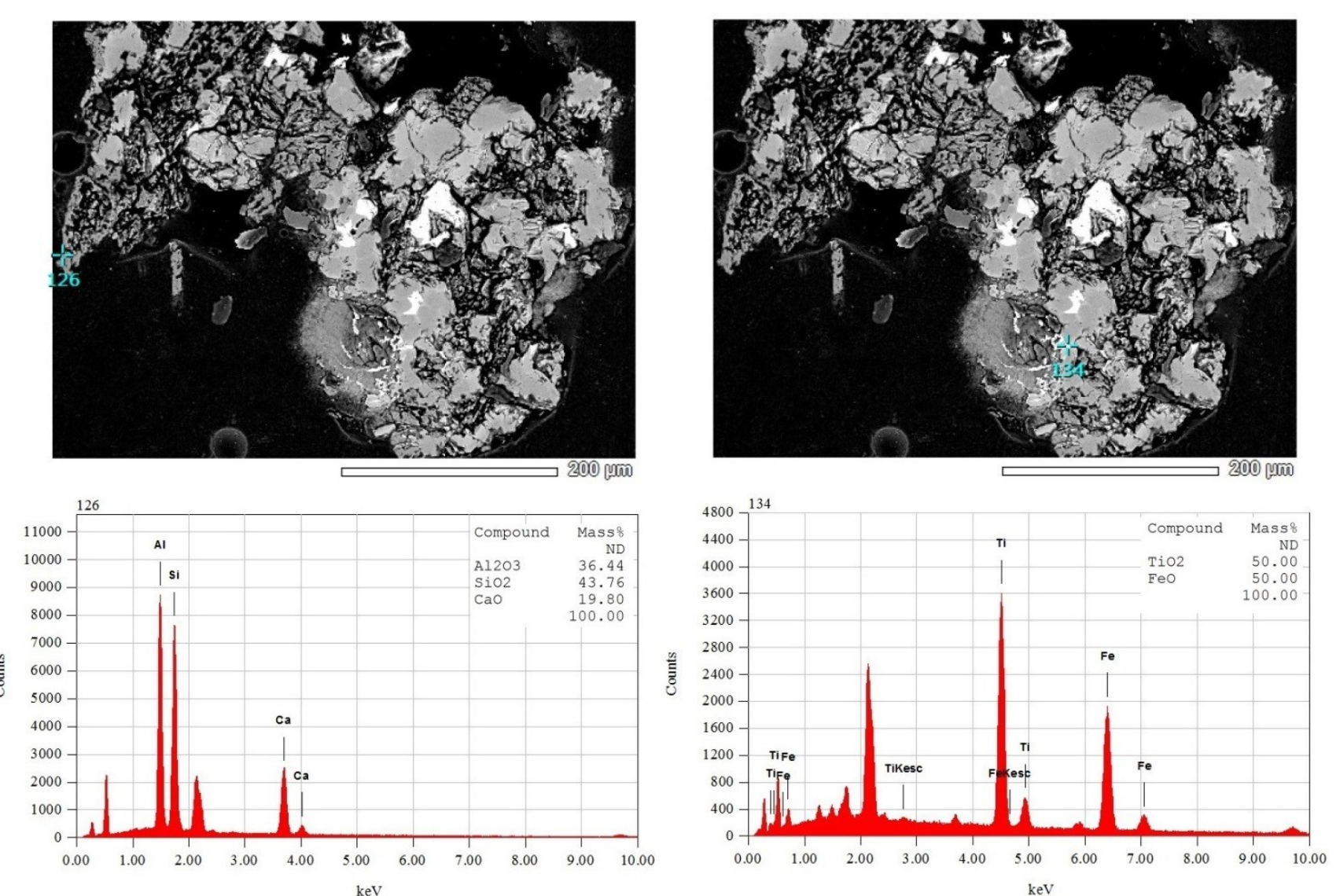

$\begin{array}{lc}\text { Oxides } & \text { average } \\ \mathrm{Na}_{2} \mathrm{O} & 1.42\end{array}$

$\mathrm{MgO}$

$\mathrm{SiO}_{2}$

$\mathrm{Al}_{2} \mathrm{O}_{3}$

$\mathrm{FeO}_{(\mathrm{T})}$

$\mathrm{CaO}$

$\mathrm{K}_{2} \mathrm{O}$

Total

average

average

average

$\begin{array}{lllll}\text { Mineral } & \mathrm{Ca}_{0.88} \mathrm{Na}_{0.13} \mathrm{Al}_{1.85} \mathrm{Si}_{2.13} \mathrm{O}_{8} & \mathrm{Fe}_{2} & \left.{ }^{3}{ }_{2} \mathrm{Fe}^{2+} \mathrm{O}_{4}\right) & \mathrm{Mg}_{5.88} \mathrm{Fe}_{4.12} \mathrm{Al}_{1.9} \mathrm{Si}_{6.31} \mathrm{Al}_{1.69} \mathrm{O}_{20}(\mathrm{OH})_{8}\end{array}$

$\left(\mathrm{Fe}^{2+} \mathrm{O}_{3}\right) \quad$ (on the basis of 28 oxygen equivalents, ignoring

Mineral
name Plagioclase
(Bytownite)

Clinopyroxene
(Augite)

Titanomagnetite Magnetite(?) Chlorite

21.63

16.70

$\begin{array}{lll}72.67 & 100.00 & 27.05\end{array}$

7.33 Hematite(?) 


\section{Quantitative XRD Analysis}

Sample Identification: BW1 Experiment-Bottom

Laboratory Reference No: 2015005879

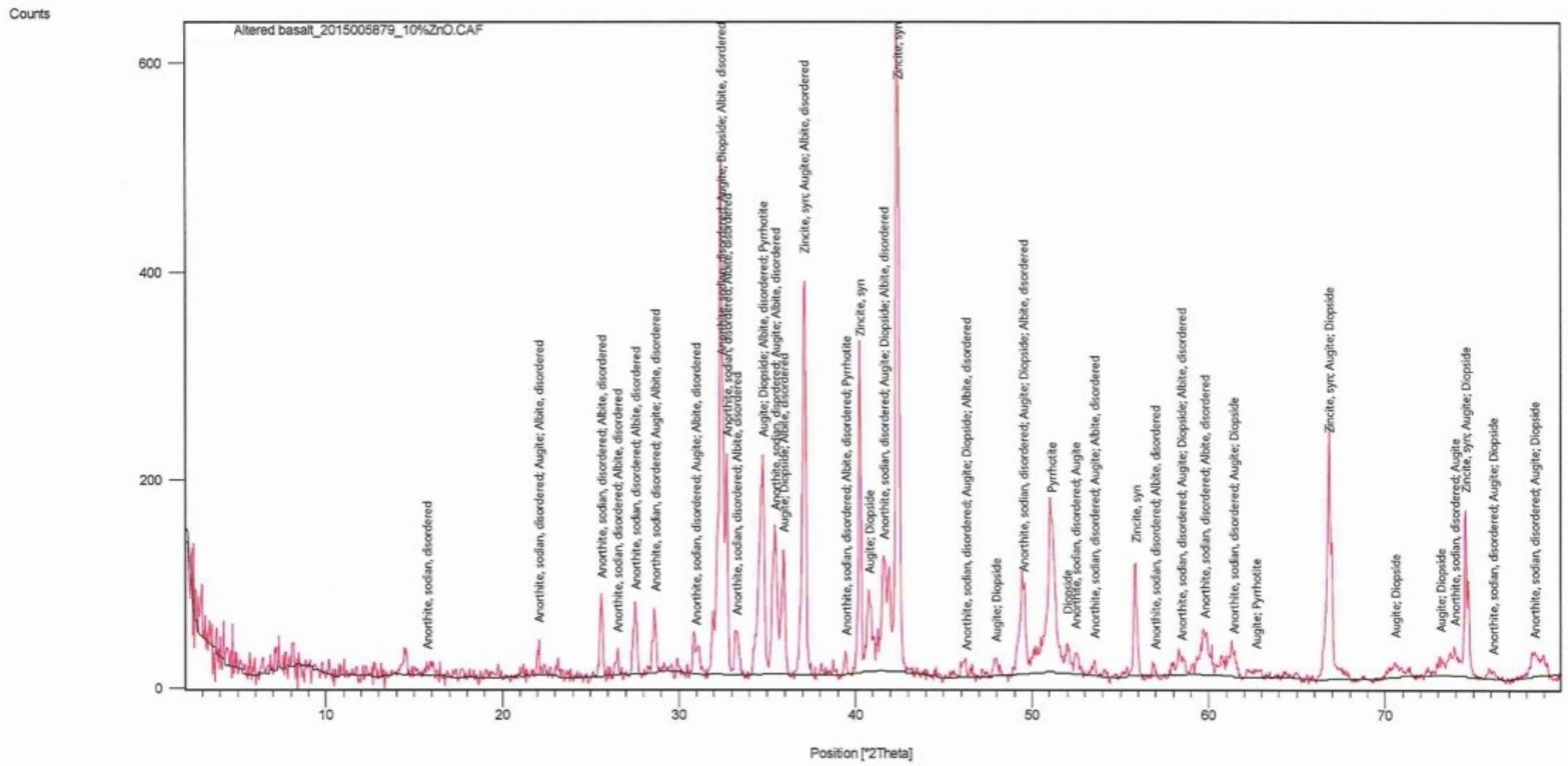

Figure 2. XRD scan showing the mineralogy of sample BW1 Altered Basalt as indicated by the labelled scan peaks

Disclaimer: 1. GNS Science accepts no responsibility for reports reproduced except in full. 2 . The results pertain to the samples as received. 
Report Number: 201508250

Report Date: $28 / 08 / 2015$
NEW ZEALAND GEOTHERMAL

ANALYTICAL LABORATORY

Private Bag 2000, Taupo

Phone: (07) 3748211

Email: w.labmanager@gns.cri.nz

\section{Sample Composition}

\section{Quantitative XRD Analysis}

Table 1. Mineral percentages for $\mathbf{B W 1}$ sample:

\begin{tabular}{l|c}
\hline \multirow{2}{*}{} & \multicolumn{2}{|c}{ Abundance \% } \\
\cline { 2 - 3 } & $\begin{array}{c}\text { Altered Basalt } \\
2015005879\end{array}$ \\
\hline Anorthite & 44 \\
Augite & 46 \\
Pyrrhotite & $(1) ?$ \\
Albite & 3 \\
Diopside & 6 \\
\hline
\end{tabular}

Margin of Error: Abundance estimates are determined through successive refinement of cell parameters; the position, width and orientation of each mineral. Values are given to the nearest whole number. The margin of error for phase concentration is proposed as follows: $0-10 \% \pm 10 \% ; 10-50 \% \pm 5 \% ; 50-100 \% \pm 2 \%$

Disclaimer: 1. GNS Science accepts no responsibility for reports reproduced except in full. 2. The results pertain to the samples as received. 

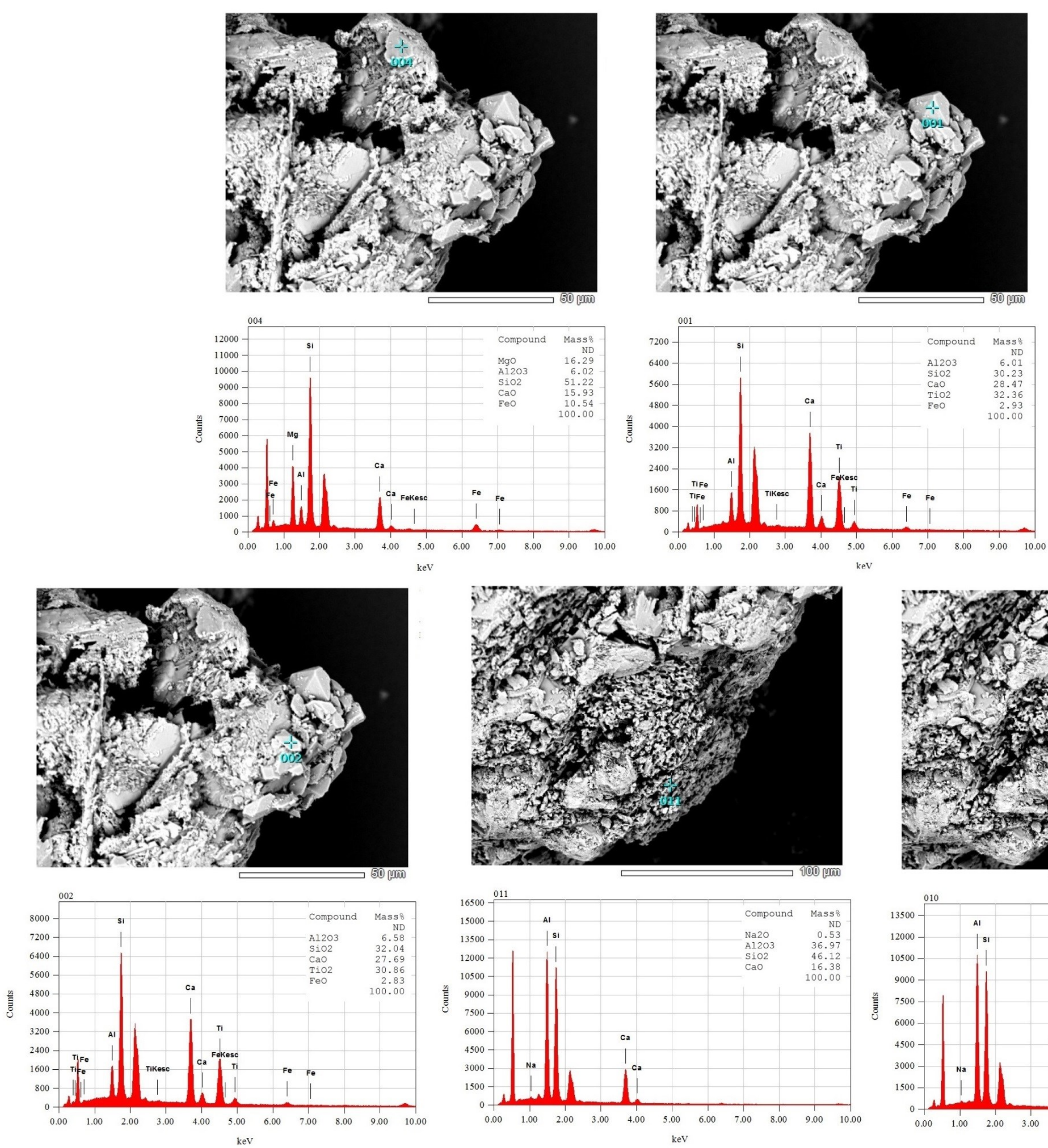
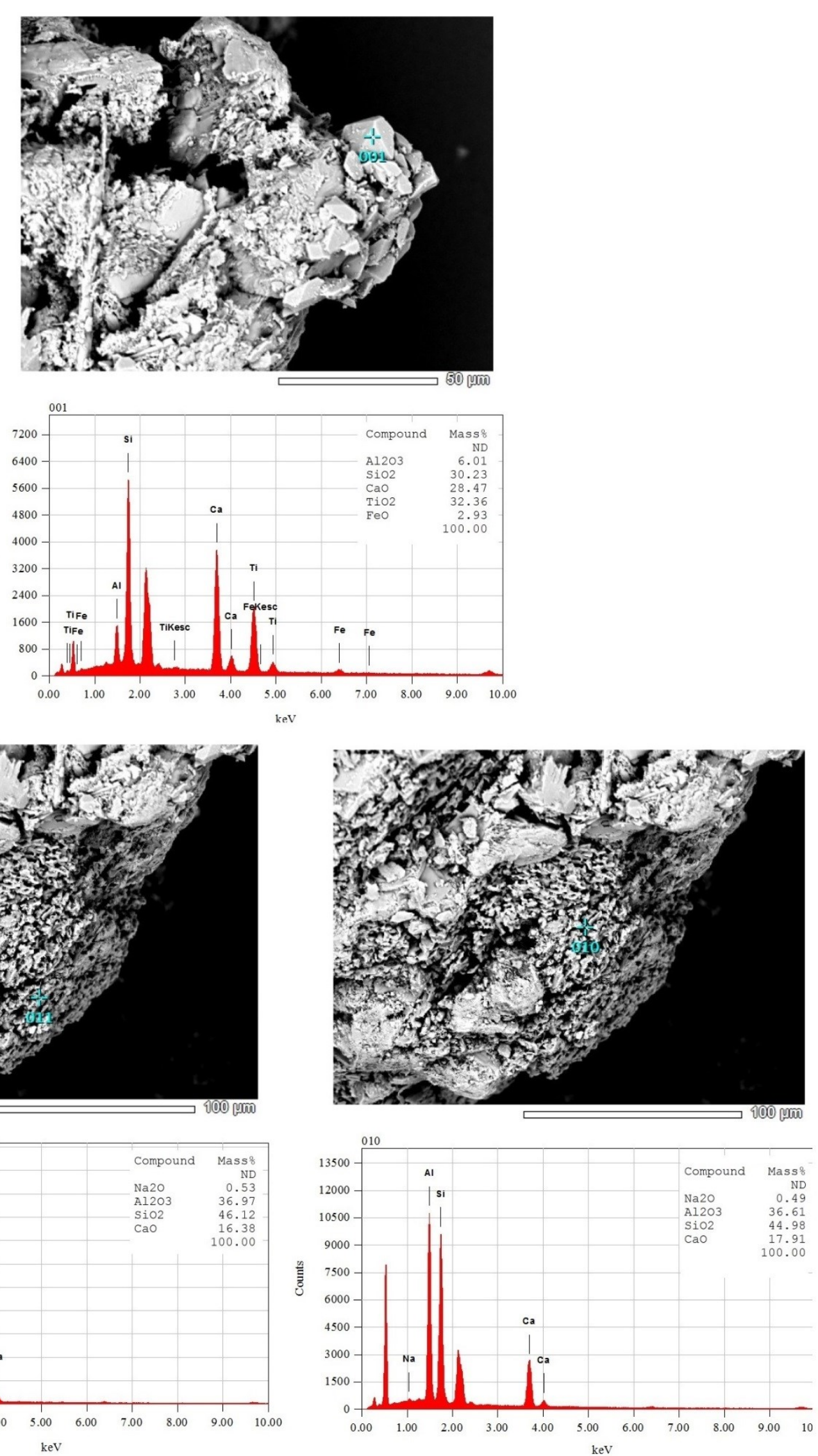
Figure B.3.11. SEM-EDS morphology analysis of grains collected from the top (Portion 2) of the Reactor
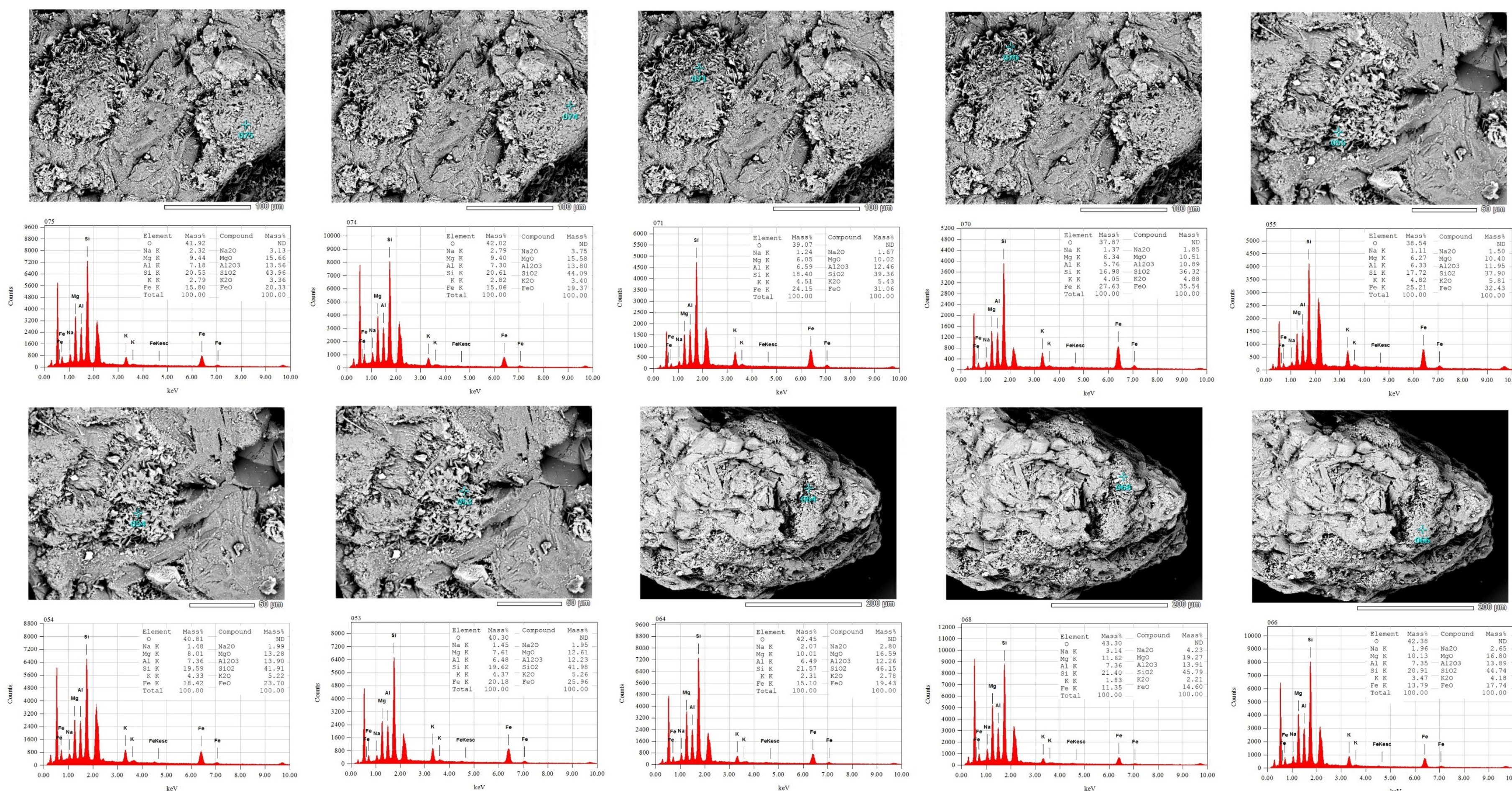
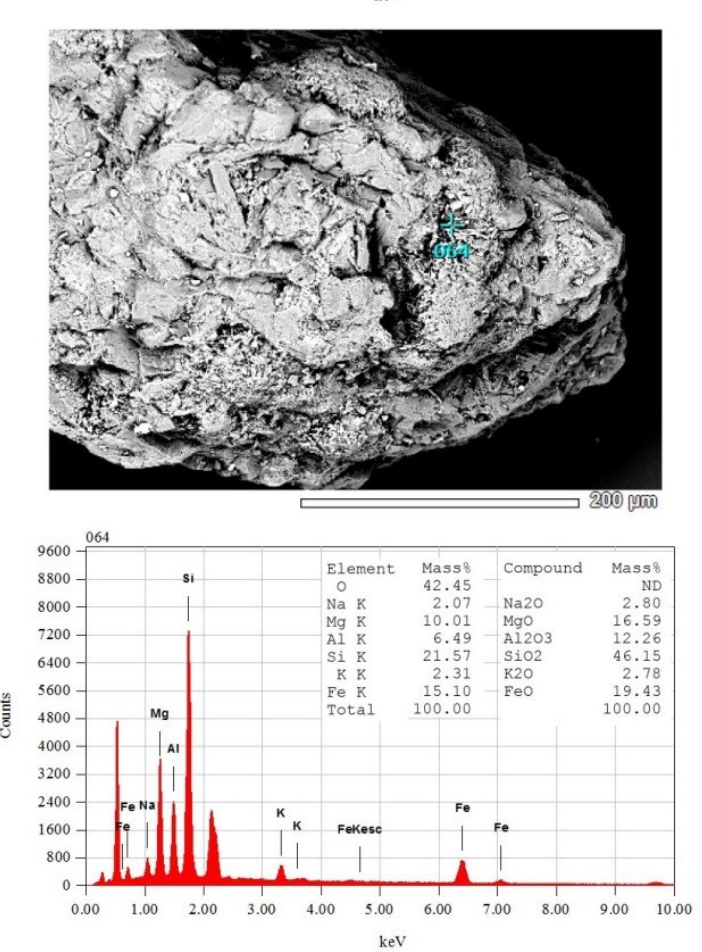
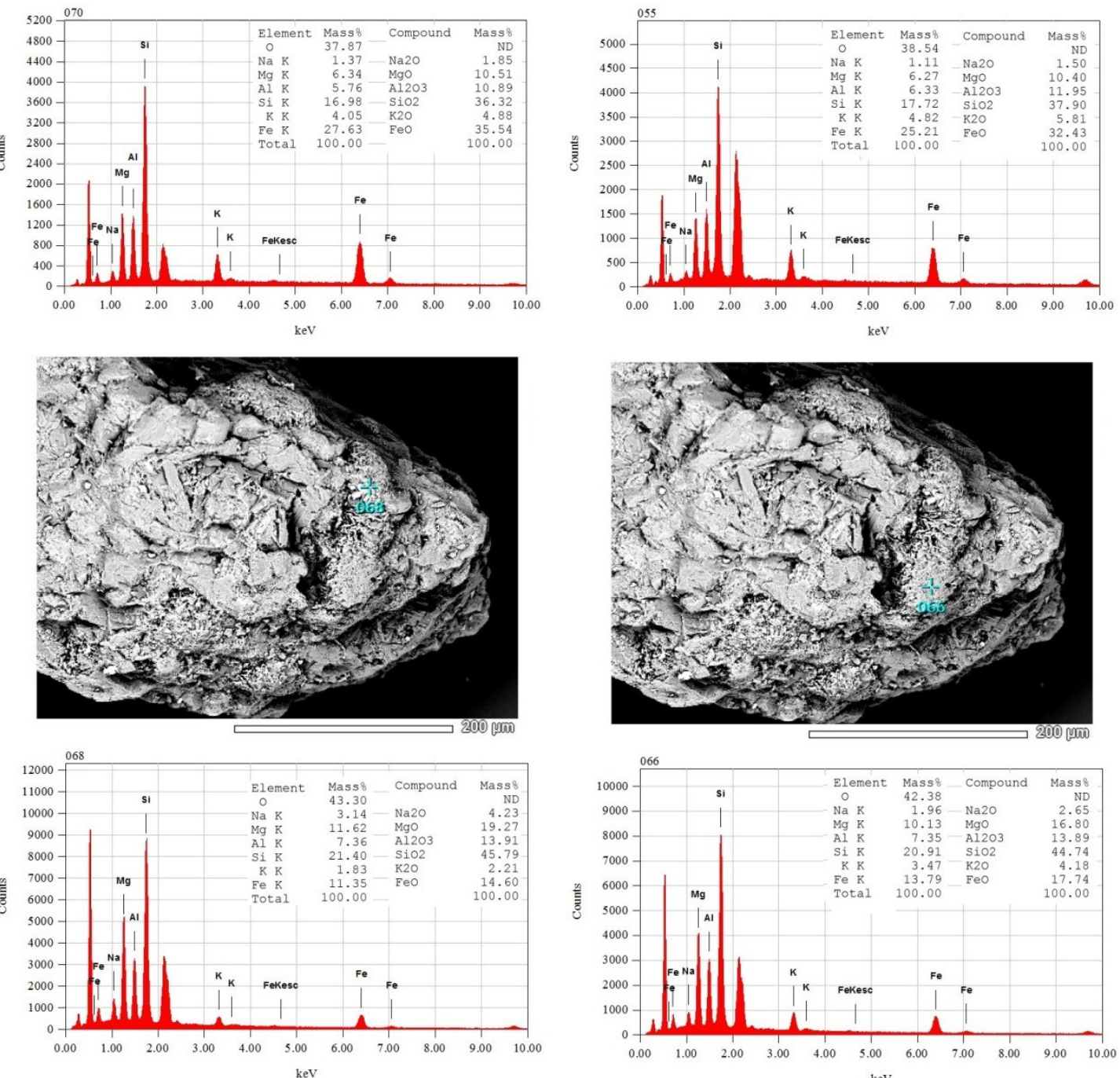
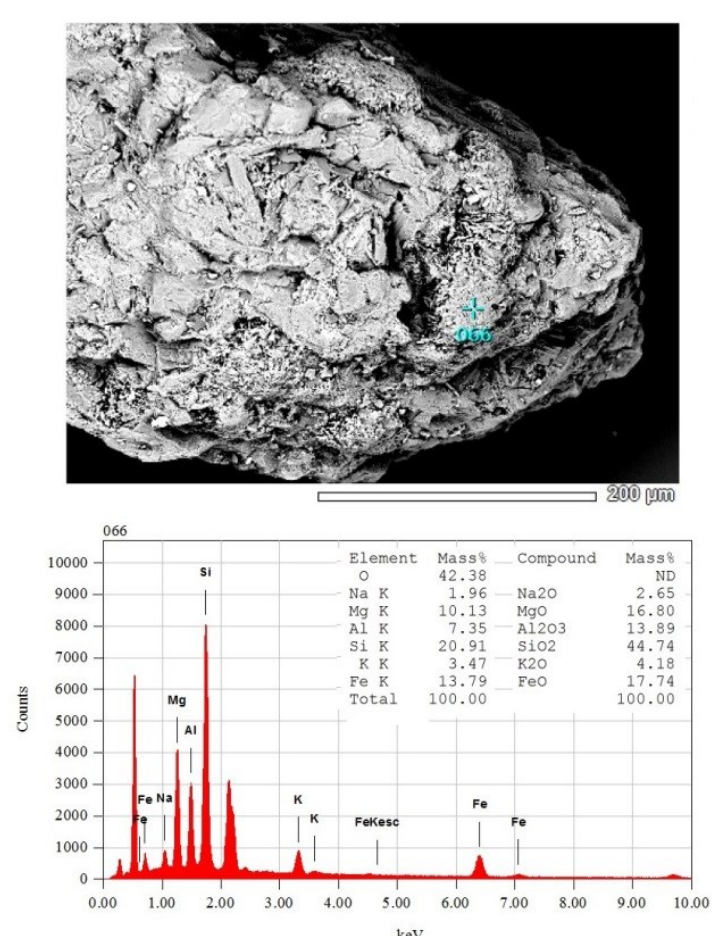
Table B.3.7. EDS analysis and average mineral compositions of grains in Figure B.3.11 for the celadonite

\begin{tabular}{|ccccccccc|}
\hline $\begin{array}{c}\text { Cel } \\
\text { (Grains Morphology Study) }\end{array}$ & $\begin{array}{c}\text { Analysis } \\
\text { Point }\end{array}$ & $\mathbf{N a}_{\mathbf{2}} \mathbf{O}$ & $\mathbf{M g O}$ & $\mathbf{A l}_{\mathbf{2}} \mathbf{O}_{\mathbf{3}}$ & $\mathbf{S i O}_{\mathbf{2}}$ & $\mathbf{K}_{\mathbf{2}} \mathbf{O}$ & $\mathbf{F e O}$ & Total \\
& 53 & 1.95 & 12.61 & 12.23 & 41.98 & 5.26 & 25.96 & 99.99 \\
& 54 & 1.99 & 13.28 & 13.9 & 41.91 & 5.22 & 23.7 & 100.00 \\
& 55 & 1.50 & 10.40 & 11.95 & 37.90 & 5.81 & 32.43 & 99.99 \\
& 64 & 2.80 & 16.59 & 12.26 & 46.15 & 2.78 & 19.43 & 100.01 \\
& 66 & 2.65 & 16.80 & 13.89 & 44.74 & 4.18 & 17.74 & 100.00 \\
& 68 & 4.23 & 19.27 & 13.91 & 45.79 & 2.21 & 14.60 & 100.01 \\
& 70 & 1.85 & 10.51 & 10.89 & 36.32 & 4.88 & 35.54 & 99.99 \\
& 71 & 1.67 & 10.02 & 12.46 & 39.36 & 5.43 & 31.06 & 100.00 \\
average & 74 & 3.75 & 15.58 & 13.80 & 44.09 & 3.40 & 19.47 & 100.09 \\
$\mathbf{\pm \sigma}$ & 75 & 3.13 & 15.66 & 13.56 & 43.96 & 3.36 & 20.33 & 100.00 \\
& & $\mathbf{2 . 5 5}$ & $\mathbf{1 4 . 0 7}$ & $\mathbf{1 2 . 8 9}$ & $\mathbf{4 2 . 2 2}$ & $\mathbf{4 . 2 5}$ & $\mathbf{2 4 . 0 3}$ & $\mathbf{1 0 0 . 0 1}$ \\
& & 0.93 & 3.18 & 1.07 & 3.38 & 1.25 & 7.00 & \\
\hline
\end{tabular}

\begin{tabular}{cc|}
\hline Oxides & average wt\% \\
$\mathrm{Na}_{2} \mathrm{O}$ & 2.55 \\
$\mathrm{MgO}$ & 14.07 \\
$\mathrm{SiO}_{2}$ & 42.22 \\
$\mathrm{Al}_{2} \mathrm{O}_{3}$ & 12.89 \\
$\mathrm{FeO}_{(\mathrm{T})}$ & 24.03 \\
& \\
$\mathrm{~K}_{2} \mathrm{O}$ & 4.25 \\
Total & 100.02 \\
Mineral & \\
Composition & $\mathrm{K}_{0.78} \mathrm{Na}_{0.71} \mathrm{Mg}_{3.0} \mathrm{Fe}_{2.9} \mathrm{Al}_{0.23} \mathrm{Si}_{6.05} \mathrm{Al}_{1.95} \mathrm{O}_{20}(\mathrm{OH})_{4}$ \\
& $\left(\right.$ on the basis of 22 oxygen equivalents, ignoring $\left.\mathrm{H}_{2} \mathrm{O}\right)$ \\
Phase and ID & Celadonite \\
& (grains morphology study) \\
\hline
\end{tabular}




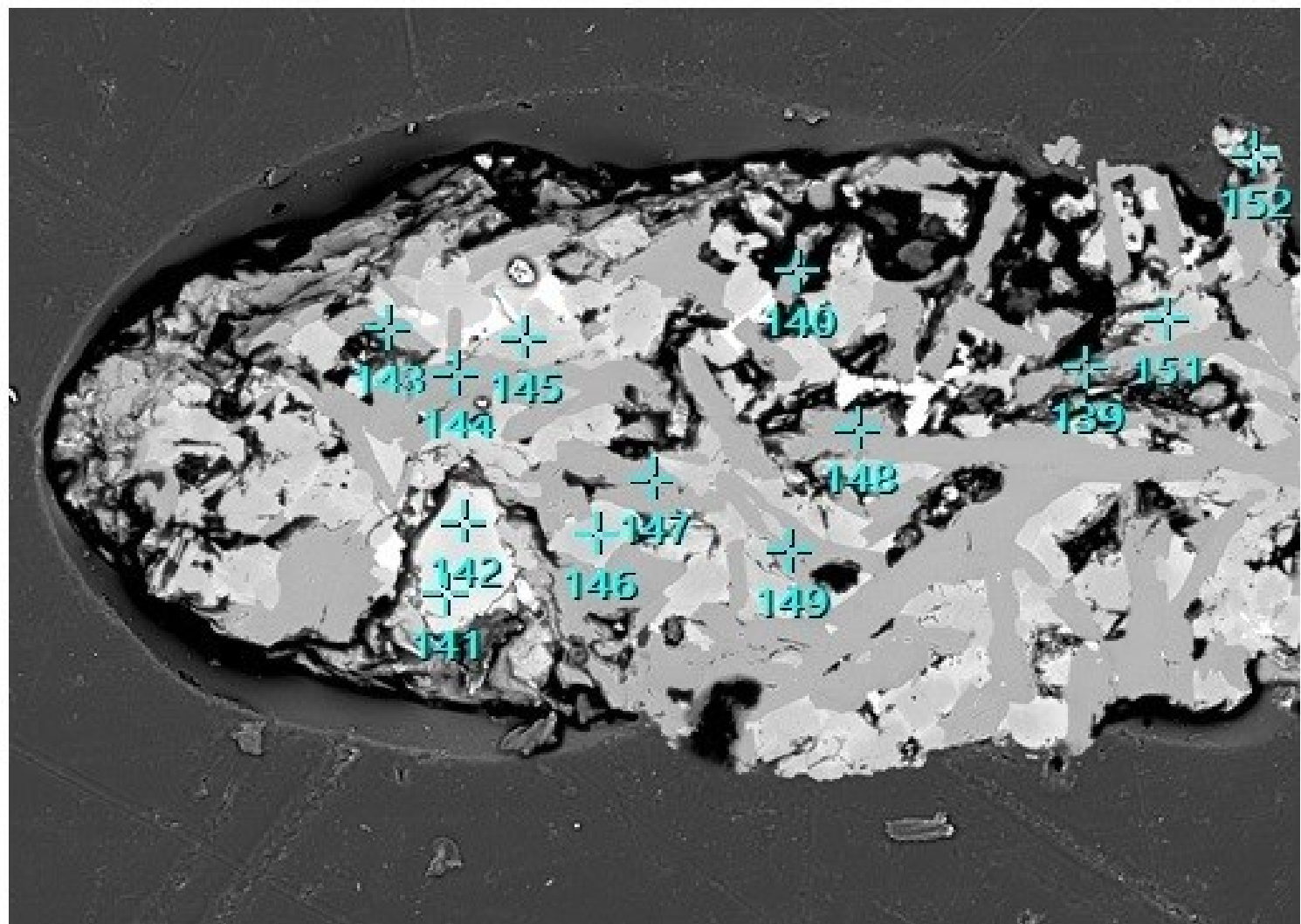

20000000
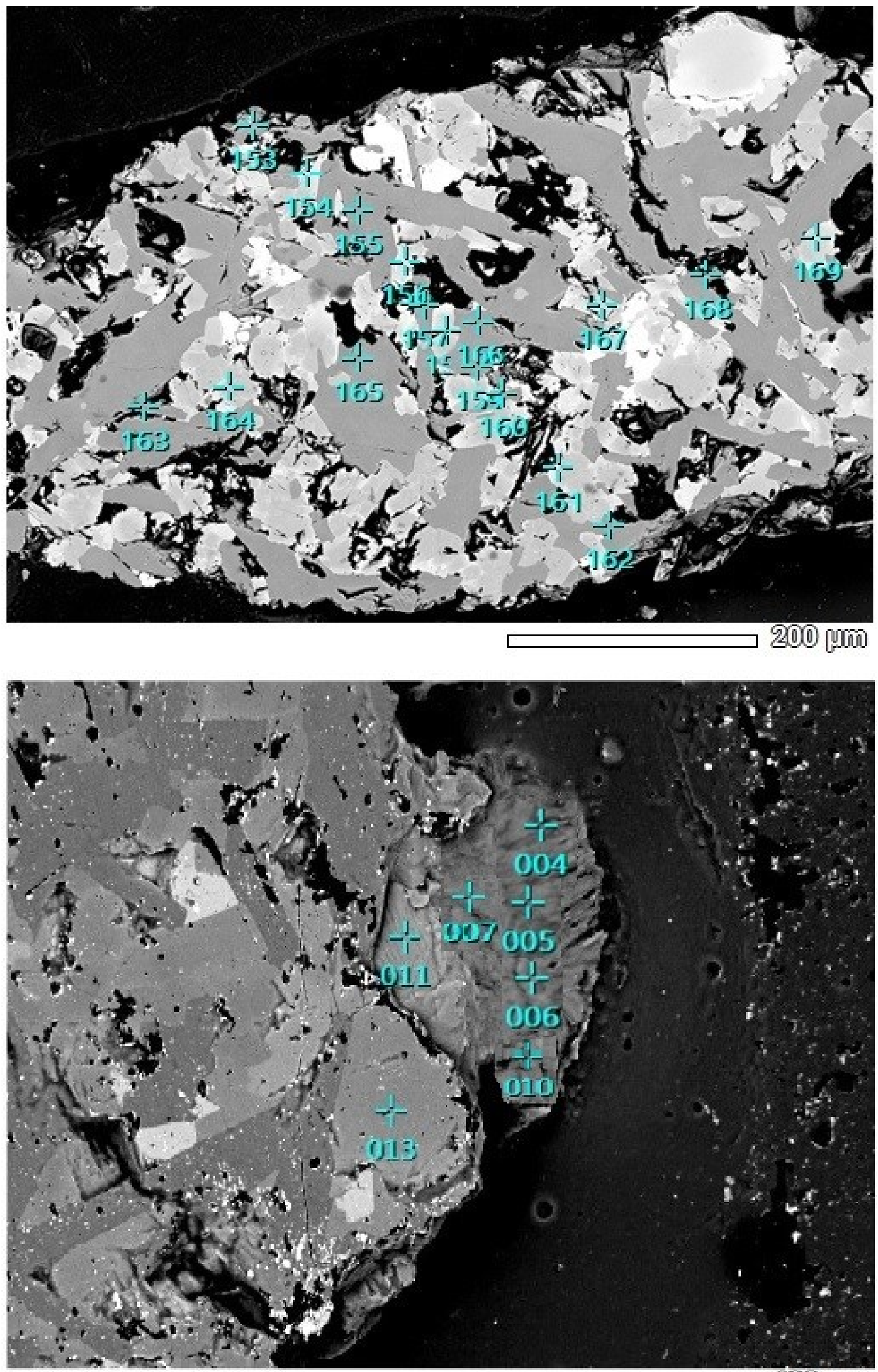
Figure B.3.13. SEM-EDS of an epoxy-mount polished grain collected from the top (Portion 2) of the Reactor for the mineral celadonite (points 4-5-6 in Table B.3.7b)
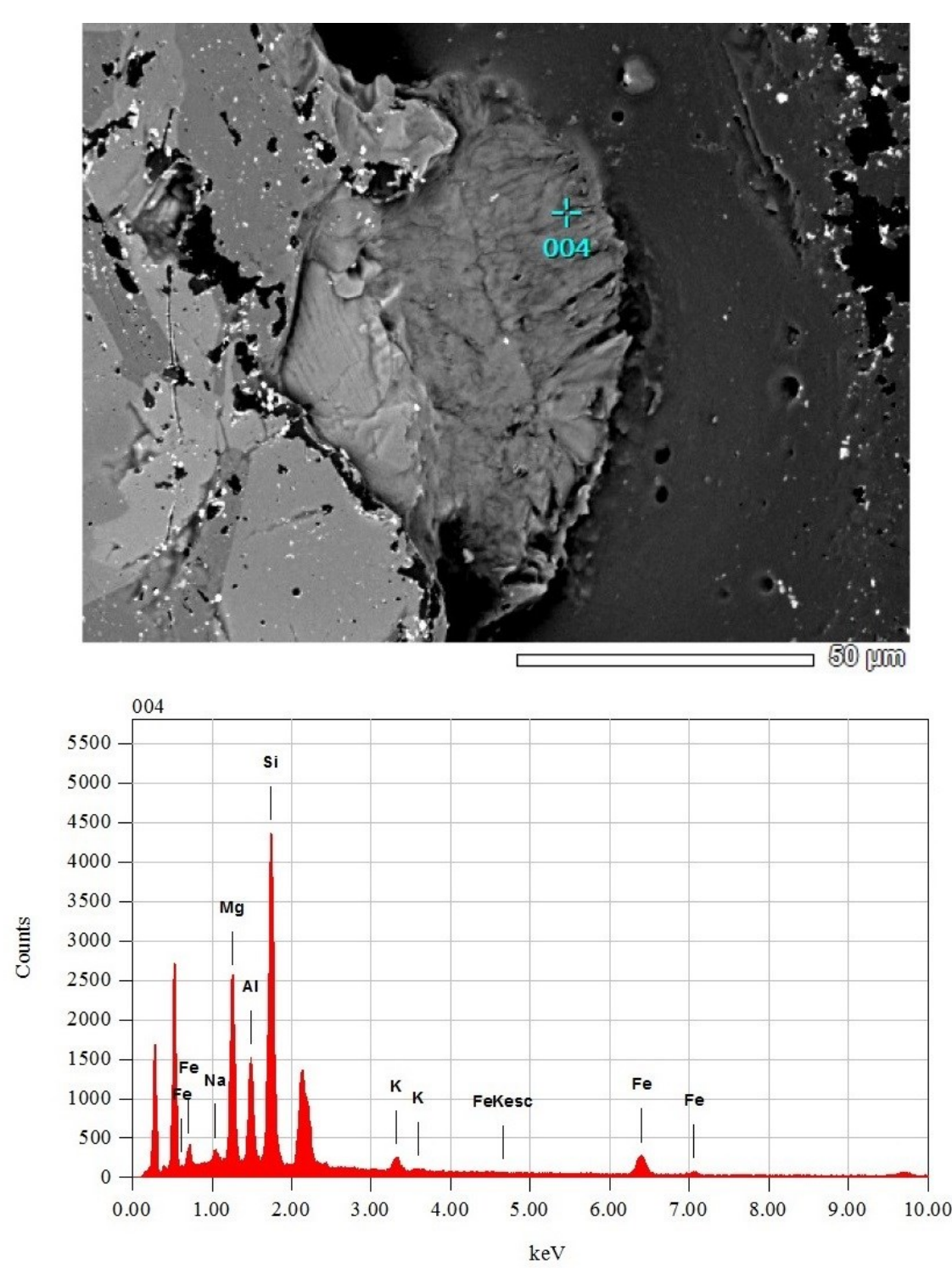

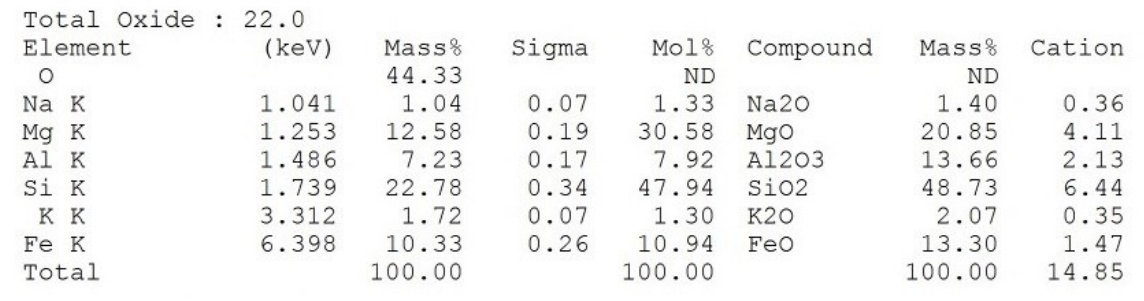
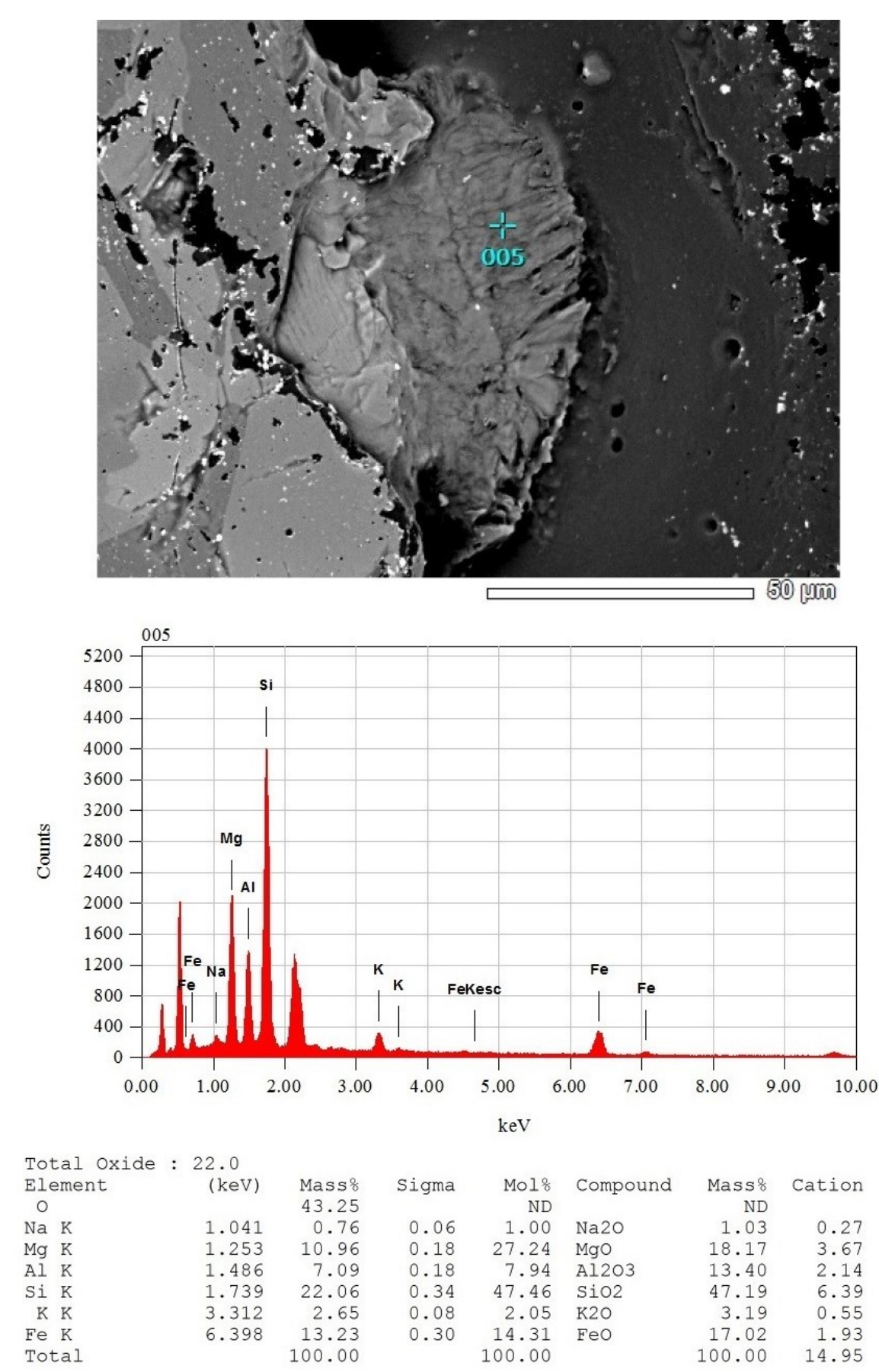
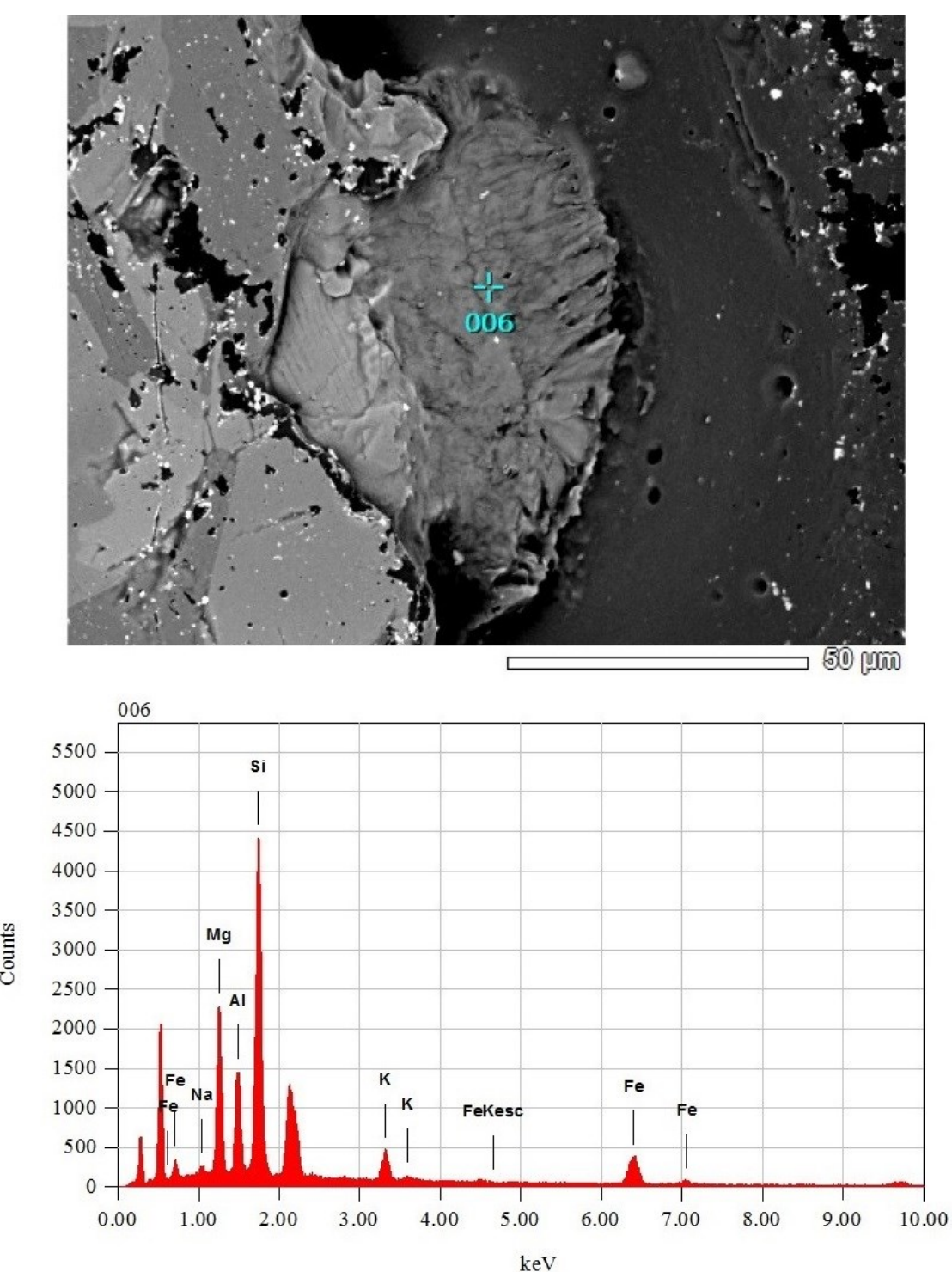

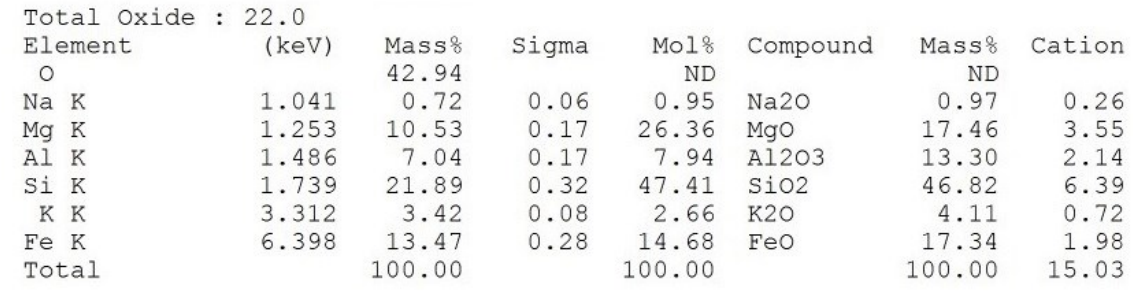


Figure B.3.14. SEM-EDS of an epoxy-mount polished grain collected from the top (Portion 2) of the Reactor for the mineral celadonite (points 4-5-6 in Table B.3.7b)
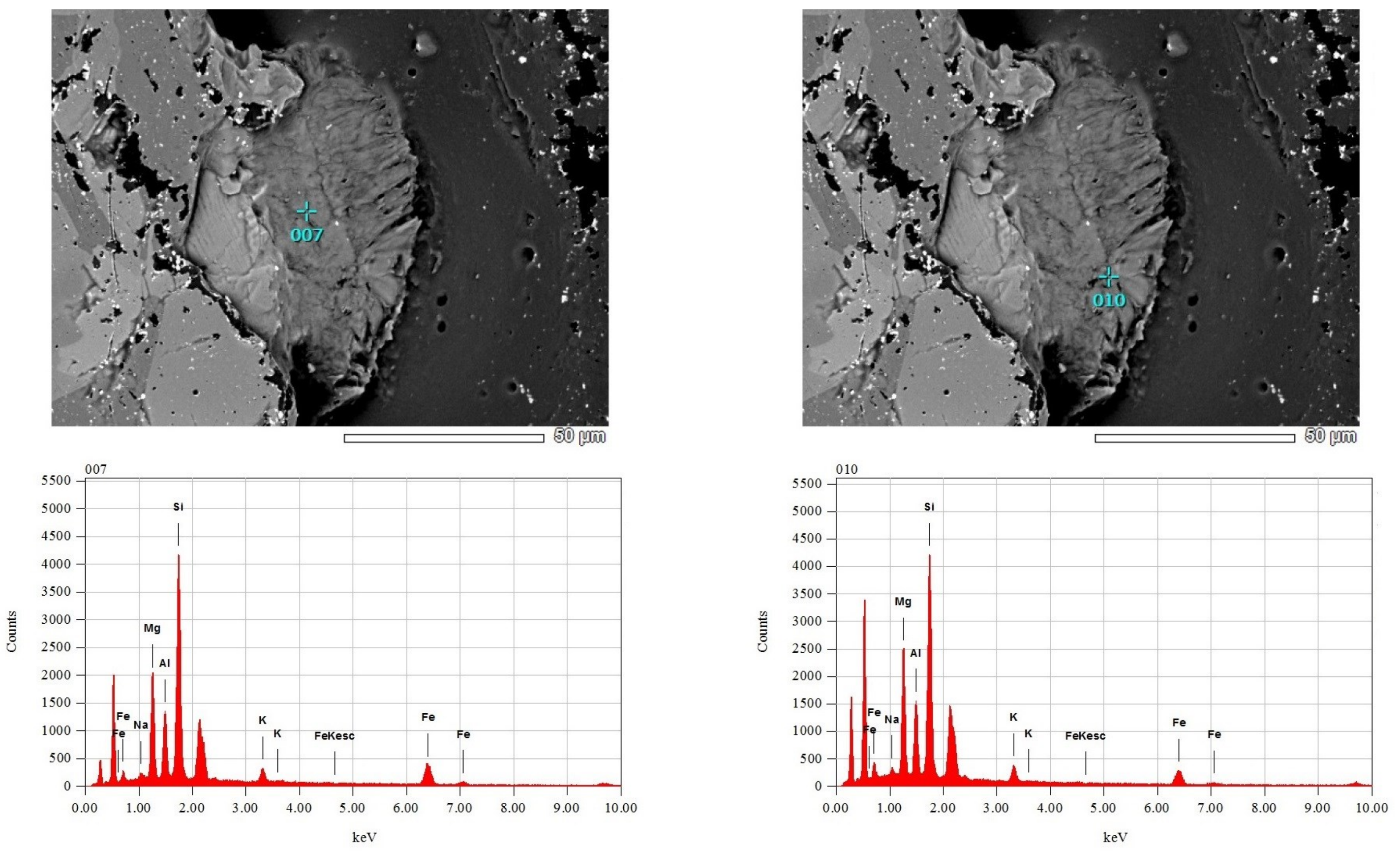

ZAF Method Standardless Quantitative Analysis (Oxide)
Fitting Coefficient : 0.3715

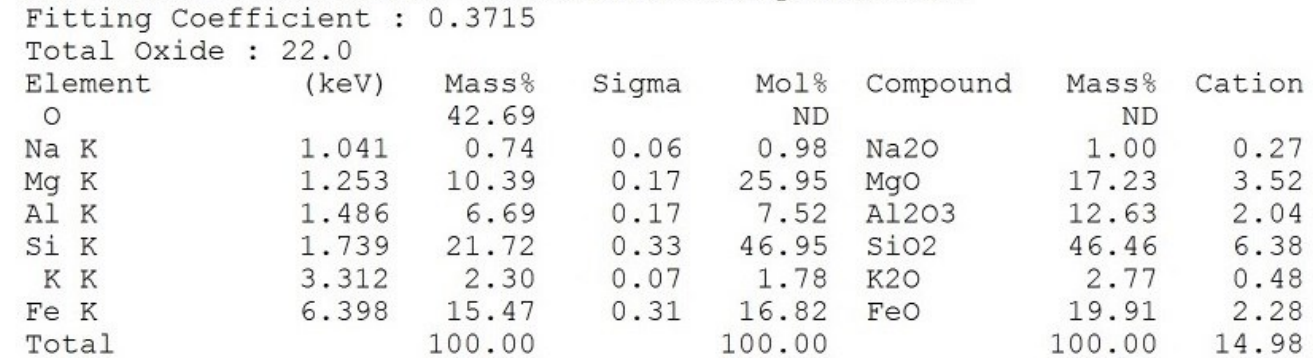

ZAF Method Standardless Quantitative Analysis (Oxide)

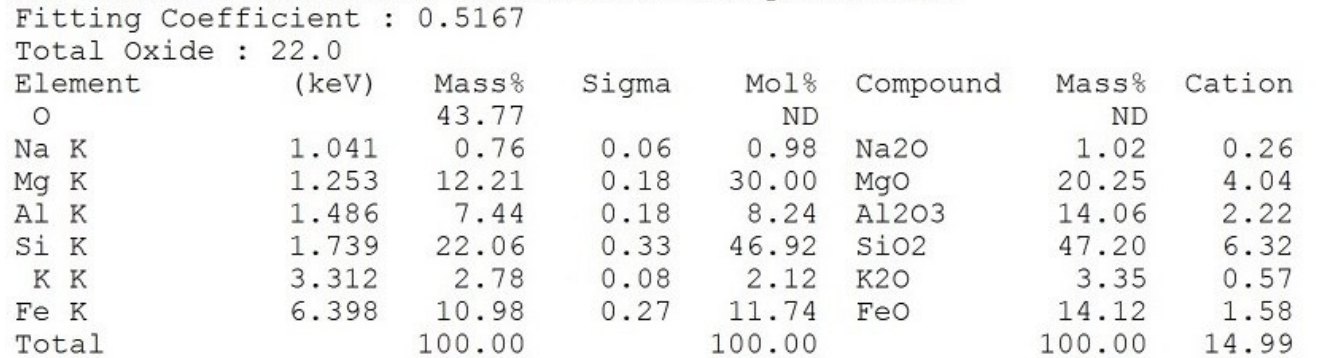


Table B.3.7b. EDS analysis and average mineral compositions of grains in Figure B.3.12

\begin{tabular}{|c|c|c|c|c|c|c|c|c|c|c|c|c|c|}
\hline \multirow[t]{15}{*}{$\mathrm{Plg}$} & $\begin{array}{l}\text { Analysis } \\
\text { Point }\end{array}$ & $\mathrm{Na}_{2} \mathrm{O}$ & MgO & $\mathrm{Al}_{2} \mathrm{O}_{3}$ & $\mathrm{SiO}_{2}$ & $\mathrm{CaO}$ & $\mathrm{TiO}_{2}$ & Total & $\begin{array}{l}\text { Oxides } \\
\mathrm{Na}_{2} \mathrm{O}\end{array}$ & $\begin{array}{c}\text { average wt\% } \\
3.87\end{array}$ & average wt $\%$ & average wt\% & $\begin{array}{c}\text { average wt } \% \\
1.08\end{array}$ \\
\hline & 139 & 2.10 & & 30.52 & $\begin{array}{l}50.40 \\
57.52\end{array}$ & $\begin{array}{l}16.98 \\
9.15\end{array}$ & & $\begin{array}{l}100.00 \\
10000\end{array}$ & $\mathrm{MgO}$ & & 15.59 & 27.15 & 18.81 \\
\hline & $\begin{array}{l}140 \\
143\end{array}$ & $\begin{array}{l}5.91 \\
4.45\end{array}$ & & $\begin{array}{l}27.42 \\
26.97\end{array}$ & $\begin{array}{l}57.52 \\
58.27\end{array}$ & $\begin{array}{l}9.15 \\
10.32\end{array}$ & & $\begin{array}{l}100.00 \\
100.01\end{array}$ & $\mathrm{SiO}_{2}$ & 54.82 & 52.80 & 36.23 & 47.28 \\
\hline & 144 & 3.75 & & 29.16 & 54.20 & 12.90 & & 100.01 & $\mathrm{Al}_{2} \mathrm{O}_{3}$ & 28.94 & 2.24 & & 13.41 \\
\hline & 147 & 3.27 & & 30.00 & 52.88 & 13.85 & & 100.00 & $\mathrm{FeO}_{(\mathrm{T})}$ & & 14.90 & 36.62 & 16.34 \\
\hline & 148 & 3.53 & & 29.78 & 53.61 & 13.08 & & 100.00 & $\mathrm{CaO}$ & 12.37 & 14.47 & & \\
\hline & $\begin{array}{l}149 \\
153\end{array}$ & $\begin{array}{l}4.40 \\
3.90\end{array}$ & & $\begin{array}{l}28.07 \\
2837\end{array}$ & $\begin{array}{l}56.65 \\
55.97\end{array}$ & $\begin{array}{l}10.88 \\
11.76\end{array}$ & & $\begin{array}{l}100.00 \\
100.00\end{array}$ & $\mathrm{~K}_{2} \mathrm{O}$ & & & & 3.10 \\
\hline & 155 & 3.18 & & 30.41 & 52.64 & 13.77 & & 100.00 & & & & & \\
\hline & 157 & 3.79 & & 29.06 & 54.58 & 12.57 & & 100.00 & Total & 100.00 & 100.00 & 100.00 & 100.02 \\
\hline & 159 & 4.25 & & 28.33 & 55.87 & 11.54 & & 99.99 & & & & & \\
\hline & 160 & 4.38 & & 27.25 & 57.86 & 10.51 & & 100.00 & Mineral & $\mathrm{Ca}_{0.66} \mathrm{Na}_{0.34} \mathrm{Al}_{1.5} \mathrm{Si}_{2.5} \mathrm{O}_{8}$ & & $\mathrm{Mg}_{1.2} \mathrm{Fe}_{0.8} \mathrm{SiO}_{4}$ & $\mathrm{~K}_{0.53} \mathrm{Na}_{0.28} \mathrm{Mg}_{3.79} \mathrm{Fe}_{1.84} \mathrm{Al}_{0.51} \mathrm{Si}_{6.38} \mathrm{Al}_{1.62} \mathrm{O}_{20}(\mathrm{OH})_{4}$ \\
\hline & $\begin{array}{l}162 \\
163\end{array}$ & $\begin{array}{l}3.35 \\
3.18\end{array}$ & & $\begin{array}{l}29.97 \\
29.72\end{array}$ & $\begin{array}{l}53.32 \\
52.88\end{array}$ & $\begin{array}{l}13.36 \\
14.22\end{array}$ & & $\begin{array}{l}100.00 \\
100.00\end{array}$ & Composition & $\left(\mathrm{An}_{64}-\mathrm{Ab}_{36}\right)$ & $\mathrm{Ca}_{0.58} \mathrm{Mg}_{0.87} \mathrm{Fe}_{0.47} \mathrm{Al}_{0.1} \mathrm{Si}_{2} \mathrm{O}_{6}$ & $\left(\mathrm{Fo}_{60}-\mathrm{Fa}_{40}\right)$ & (on the basis of 22 oxygen equivalents, ignoring $\mathrm{H}_{2} \mathrm{O}$ ) \\
\hline & 165 & 3.54 & & 29.62 & 53.98 & 12.86 & & 100.00 & & & & & \\
\hline & 166 & 3.55 & & 29.62 & 54.46 & 12.38 & & 100.01 & Phase and ID & Plagioclase & Climopyroxene & $\begin{array}{l}\text { Mg-olivine } \\
\text { (fortarite }\end{array}$ & Celadonite \\
\hline & 168 & 5.20 & & 27.78 & 56.84 & 10.18 & & 100.00 & & & & & \\
\hline average & & 3.87 & & 28.94 & 54.82 & 12.37 & & 100.00 & & & & & \\
\hline \multirow[t]{12}{*}{ Cpx } & $\begin{array}{c}\text { Analysis } \\
\text { Point }\end{array}$ & $\mathrm{Na}_{2} \mathrm{O}$ & Mgo & $\mathrm{Al}_{2} \mathrm{O}_{3}$ & $\mathrm{SiO}_{2}$ & $\mathrm{CaO}$ & $\mathrm{FeO}$ & Total & & & & & \\
\hline & 145 & & 15.89 & 3.41 & 52.39 & 18.26 & 10.05 & 100.00 & & & & & \\
\hline & 146 & & 15.77 & 2.10 & 53.47 & 18.11 & 10.55 & 100.00 & & & & & \\
\hline & 151 & & 14.89 & 4.36 & 52.07 & 19.65 & 9.04 & 100.01 & & & & & \\
\hline & 152 & & 16.50 & 1.65 & 53.95 & 12.43 & 15.47 & 100.00 & & & & & \\
\hline & 154 & & 17.70 & 0.99 & 52.64 & 4.30 & 24.38 & 100.01 & & & & & \\
\hline & 156 & & 12.62 & 1.72 & 50.97 & 10.30 & 24.39 & 100.00 & & & & & \\
\hline & 158 & & 14.79 & 1.82 & 53.11 & 16.81 & 13.48 & 100.01 & & & & & \\
\hline & 161 & & 15.06 & 2.41 & 52.99 & 19.27 & 10.28 & 100.01 & & & & & \\
\hline & 164 & & 15.89 & 2.63 & 53.02 & 18.49 & 9.96 & 99.99 & & & & & \\
\hline & 167 & & 13.51 & 2.40 & 52.47 & 16.22 & 15.40 & 100.00 & & & & & \\
\hline & 169 & & 18.89 & 1.16 & 53.71 & 5.32 & 20.92 & 100.00 & & & & & \\
\hline average & & & 15.59 & 2.24 & 52.80 & 14.47 & 14.90 & 100.00 & & & & & \\
\hline \multirow[t]{5}{*}{$\mathrm{Ol}$} & $\begin{array}{c}\text { Analysis } \\
\text { Point }\end{array}$ & $\mathrm{Na}_{2} \mathrm{O}$ & Mgo & $\mathrm{Al}_{2} \mathrm{O}_{3}$ & $\mathrm{SiO}_{2}$ & $\mathrm{CaO}$ & $\mathrm{FeO}$ & Total & & & & & \\
\hline & 141 & & 25.92 & & 35.90 & & 38.18 & 100.00 & & & & & \\
\hline & 142 & & 28.38 & & 36.56 & & 35.06 & 100.00 & & & & & \\
\hline & 13 & & 33.40 & & 38.44 & & 28.16 & 100.00 & & & & & \\
\hline & 11 & & 30.76 & & 38.55 & & 30.70 & 100.01 & & & & & \\
\hline average & & & 29.62 & & 37.36 & & 33.03 & 100.00 & & & & & \\
\hline \multirow{6}{*}{$\begin{array}{c}\text { Cel } \\
\text { (Epoxy-Mount Polished } \\
\text { Grains Study) }\end{array}$} & $\begin{array}{c}\text { Analysis } \\
\text { Point }\end{array}$ & $\mathrm{Na}_{2} \mathrm{O}$ & MgO & $\mathrm{Al}_{2} \mathrm{O}_{3}$ & $\mathrm{SiO}_{2}$ & $\mathrm{~K}_{2} \mathrm{O}$ & $\mathrm{FeO}$ & Total & & & & & \\
\hline & 4 & 1.40 & 20.85 & 13.66 & 48.73 & 2.07 & 13.30 & 100.01 & & & & & \\
\hline & 10 & 1.02 & 20.25 & 14.06 & 47.20 & 3.35 & 14.12 & 100.00 & & & & & \\
\hline & 7 & 1.00 & 17.23 & 12.63 & 46.46 & 2.77 & 19.91 & 100.00 & & & & & \\
\hline & 6 & 0.97 & 17.46 & 13.30 & 46.82 & 4.11 & 17.34 & 100.00 & & & & & \\
\hline & 5 & 1.03 & 18.27 & 13.40 & 47.19 & 3.19 & 17.02 & 100.10 & & & & & \\
\hline average & & 1.08 & 18.81 & 13.41 & 47.28 & 3.10 & 16.34 & 100.02 & & & & & \\
\hline$\pm \sigma$ & & 0.18 & 1.65 & 0.53 & 0.87 & 0.75 & 2.66 & 0.04 & & & & & \\
\hline
\end{tabular}


Figure B.3.15. SEM backscatter image of the UNREACTED basalt block surface by assembling singular photographs (mosaic composition)

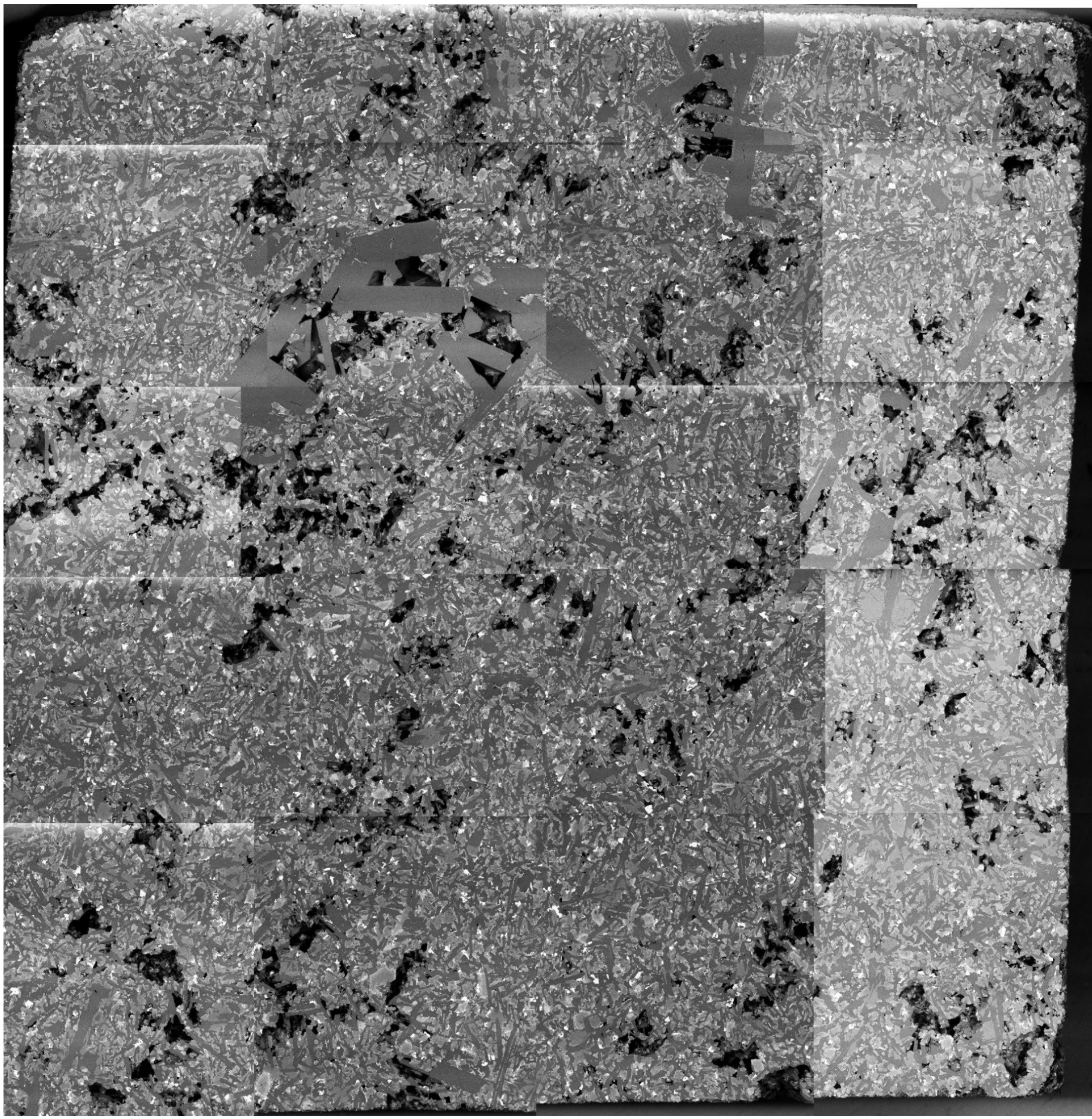




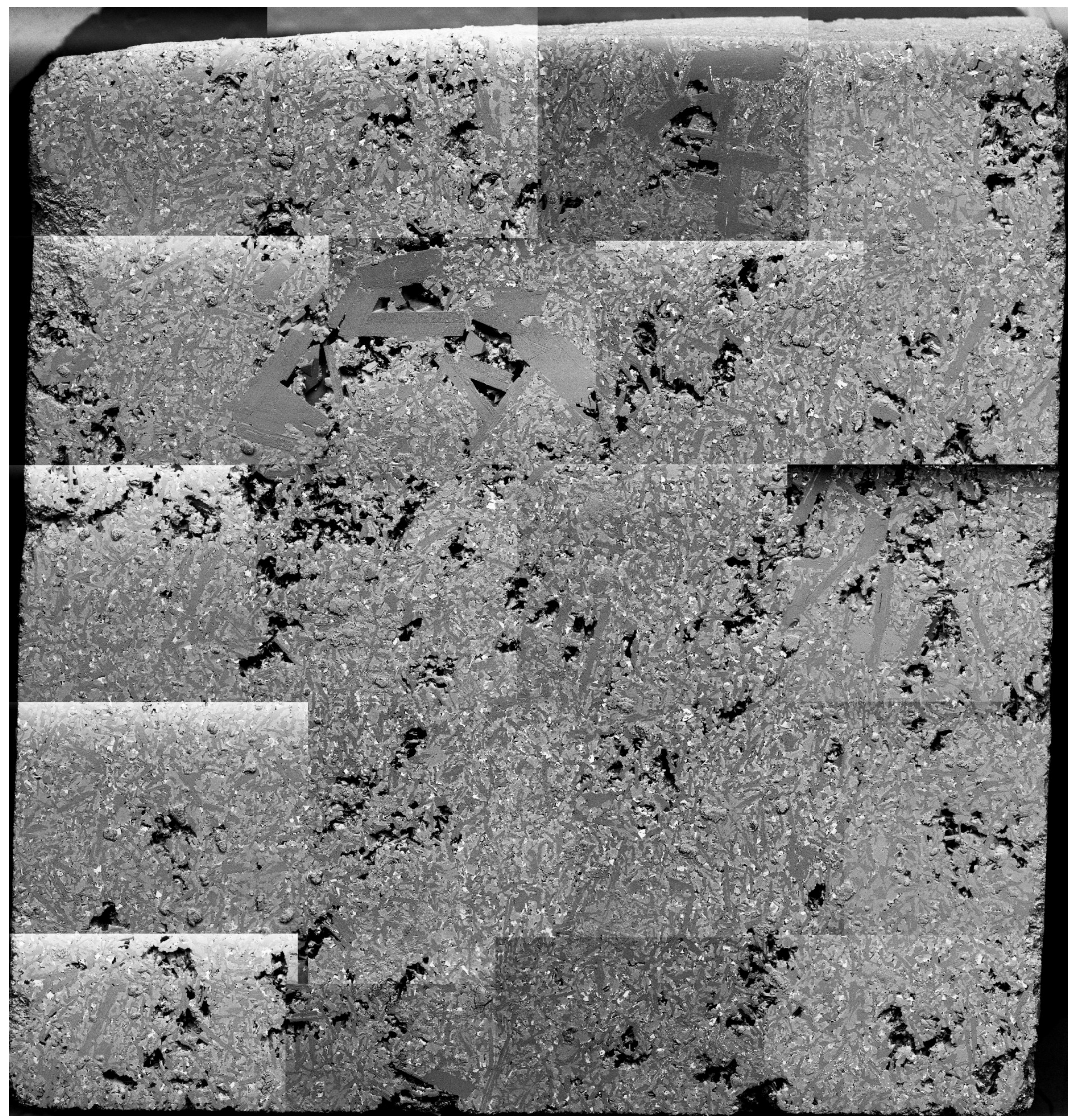



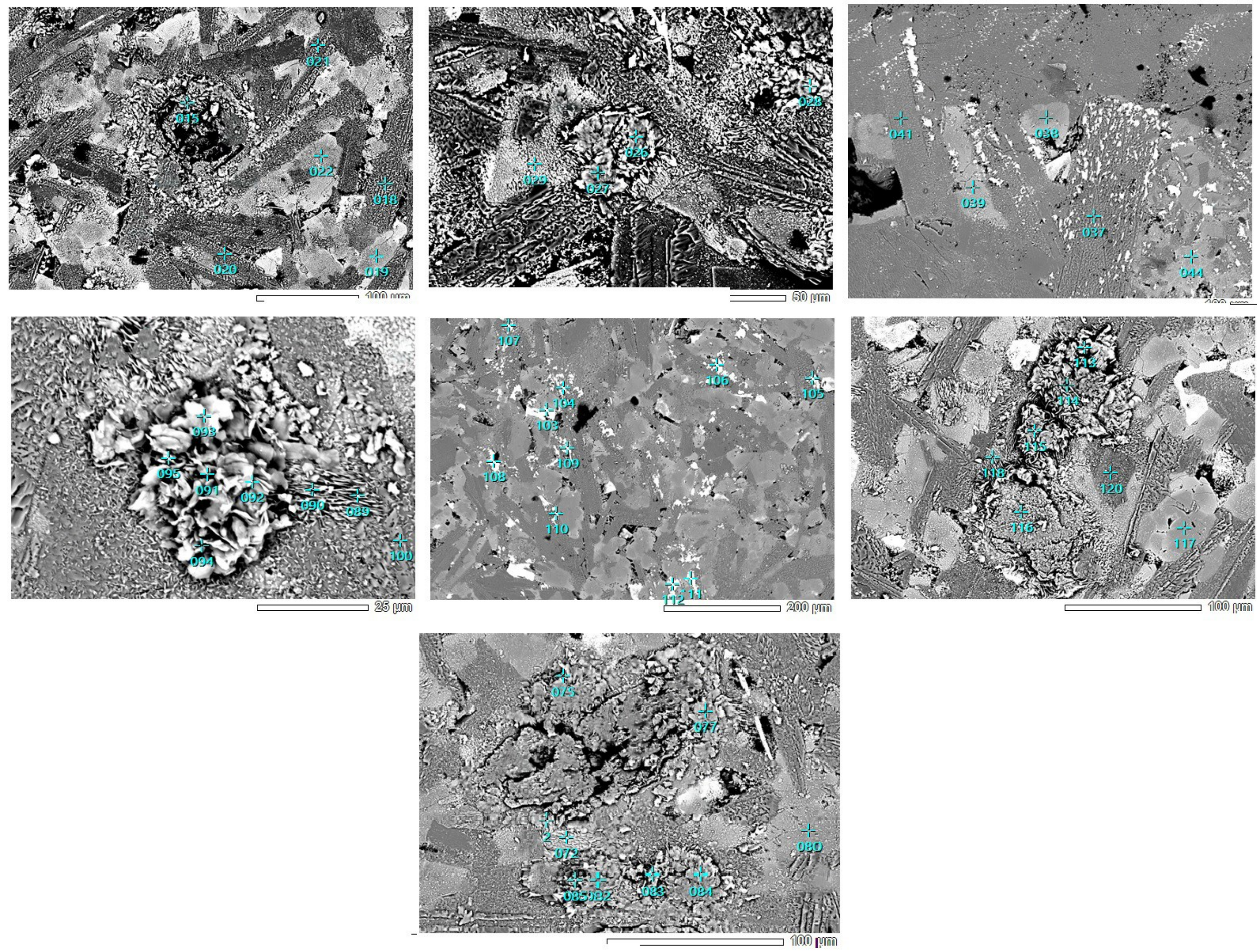
Table B.3.8. EDS analysis and average mineral compositions of pictures in Figure B.3.17.

\begin{tabular}{|c|c|c|c|c|c|c|c|c|c|c|c|c|}
\hline \multirow[t]{6}{*}{ Plg } & $\begin{array}{l}\text { Analysis } \\
\text { Point }\end{array}$ & $\mathrm{Na}_{2} \mathrm{O}$ & $\mathrm{Al}_{2} \mathrm{O}_{3}$ & $\mathrm{SiO}_{2}$ & $\mathrm{CaO}$ & & & Total & Oxides & average wt \% & average wt \% & average wt $\%$ \\
\hline & & 3.93 & 26.47 & 55.04 & 14.56 & & & 100.00 & $\mathrm{MgO}$ & & 14.46 & 12.81 \\
\hline & 20 & 6.56 & 27.14 & $\begin{array}{l}56.77 \\
5.17\end{array}$ & $\begin{array}{r}9.53 \\
1500\end{array}$ & & & 100.00 & $\mathrm{Na}_{2} \mathrm{O}$ & 4.69 & & 2.28 \\
\hline & $\begin{array}{l}21 \\
37\end{array}$ & $\begin{array}{l}3.3 \\
5.32\end{array}$ & $\begin{array}{l}26.55 \\
27.32\end{array}$ & $\begin{array}{l}55.12 \\
55.66\end{array}$ & $\begin{array}{l}\begin{array}{l}51.00 \\
11.71\end{array} \\
-\end{array}$ & & & $\begin{array}{l}1000.00 \\
1000\end{array}$ & $\mathrm{Al}_{2} \mathrm{O}_{3}$ & 28.12 & 3.69 & 13.16 \\
\hline & 41 & 2.15 & 33.06 & $\begin{array}{l}48.03 \\
5582\end{array}$ & $\begin{array}{l}16.76 \\
0.67\end{array}$ & & & 100.00 & $\mathrm{SiO}_{2}$ & 54.60 & 51.79 & 40.00 \\
\hline & 120 & $\begin{array}{l}6.30 \\
5.30\end{array}$ & $\begin{array}{l}28.22 \\
28.10\end{array}$ & $\begin{array}{l}55.82 \\
55.76\end{array}$ & $\begin{array}{l}9.67 \\
10.83\end{array}$ & & & 100.00 & $\mathrm{CaO}$ & 12.58 & 16.14 & \\
\hline average & & 4.69 & 28.12 & 54.60 & 12.58 & & & 100.00 & $\mathrm{~K}_{2} \mathrm{O}$ & & & 4.91 \\
\hline \multirow[t]{7}{*}{ Cpx } & $\begin{array}{c}\text { Analysis } \\
\text { Point }\end{array}$ & MgO & $\mathrm{Al}_{2} \mathrm{O}_{3}$ & $\mathrm{SiO}_{2}$ & CaO & FeO & & Total & $\mathrm{FeO}_{(\mathrm{T})}$ & & 13.92 & 26.85 \\
\hline & & 13.64 & 3.44 & 53.83 & 18.21 & 10.88 & & 100.00 & & & & \\
\hline & 22 & 16.27 & 4.45 & 51.73 & 16.37 & 11.18 & & 100.00 & Total & 99.99 & 100.00 & 100.01 \\
\hline & 29 & $\begin{array}{l}12.39 \\
16.69\end{array}$ & $\begin{array}{r}4.25 \\
3.31\end{array}$ & $\begin{array}{r}49.98 \\
5522\end{array}$ & $\begin{array}{l}14.74 \\
155\end{array}$ & 18.64 & & $\begin{array}{l}100.00 \\
10000\end{array}$ & & & & \\
\hline & $\begin{array}{l}38 \\
39\end{array}$ & $\begin{array}{l}16.19 \\
12.94\end{array}$ & $\begin{array}{l}3.31 \\
3.77\end{array}$ & $\begin{array}{l}52.22 \\
50.55\end{array}$ & $\begin{array}{l}15.25 \\
11.73\end{array}$ & 13.03 & & & & & & \\
\hline & 44 & 12.67 & 3.70 & 50.83 & 16.54 & $\begin{array}{l}21.01 \\
16.27\end{array}$ & & 100.00 & Mineral & $\mathrm{Ca}_{0.6} \mathrm{Na}_{0.4} \mathrm{Al}_{1.5} \mathrm{Si}_{2.5} \mathrm{O}_{8}$ & 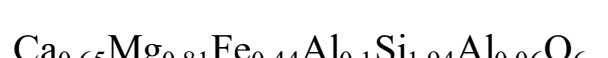 & $\mathrm{K}_{0.92} \mathrm{Na}_{0.65} \mathrm{Mg}_{2.80} \mathrm{Fe}_{3.29} \mathrm{Al}_{0.13} \mathrm{Si}_{5.86} \mathrm{Al}_{2.14} \mathrm{O}_{20}(\mathrm{OH})_{4}$ \\
\hline & 80 & 15.72 & 2.50 & 52.80 & 17.79 & 11.19 & & 100.00 & formula & $\left(\mathrm{An}_{59}-\mathrm{Ab}_{41}\right)$ & $\mathrm{a}_{0.65} \mathrm{MI}_{0.81} \mathrm{Fe}_{0.44} \mathrm{Al}_{0.1} \mathrm{~S}_{1.94} \mathrm{Al}_{0.06} \mathrm{U}_{6}$ & (on the basis of 22 oxygen equivalents, ignoring $\mathrm{H}_{2} \mathrm{O}$ ) \\
\hline \multirow{2}{*}{ average } & 117 & 15.89 & 4.11 & 52.39 & 18.47 & 9.13 & & 100.00 & & & & \\
\hline & & 14.46 & 3.69 & & 16.14 & 13.92 & & & Mineral & Plagioclase & Clinopyroxene & Celadonite \\
\hline \multirow{25}{*}{$\begin{array}{c}\mathrm{Cel} \\
\text { (reacted basalt } \\
\text { block) }\end{array}$} & $\begin{array}{c}\text { Analysis } \\
\text { Point }\end{array}$ & $\mathrm{Na}_{2} \mathrm{O}$ & MgO & $\mathrm{Al}_{2} \mathrm{O}_{3}$ & $\mathrm{SiO}_{2}$ & $\mathrm{~K}_{2} \mathrm{O}$ & $\mathrm{FeO}$ & Total & name & & (augite) & 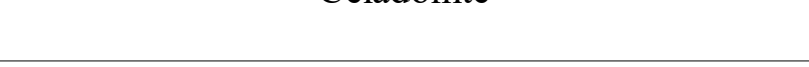 \\
\hline & 15 & 3.46 & 17.38 & 10.51 & 39.10 & 1.55 & 27.99 & 100.00 & & & & \\
\hline & 26 & 2.42 & 14.93 & 13.80 & 42.93 & 3.57 & 22.35 & 100.00 & & & & \\
\hline & 27 & 2.65 & 13.58 & 13.22 & 42.29 & 4.07 & 24.18 & 100.00 & & & & \\
\hline & 28 & 3.15 & 16.14 & 14.17 & 44.20 & 3.76 & 18.58 & 100.00 & & & & \\
\hline & 72 & 1.67 & 13.45 & 15.34 & 40.36 & 7.32 & 21.86 & 100.00 & & & & \\
\hline & 2 & 1.96 & 12.71 & 14.67 & 40.81 & 6.92 & 22.94 & 100.00 & & & & \\
\hline & 75 & 3.02 & 14.58 & 13.92 & 43.42 & 4.00 & 21.05 & 100.00 & & & & \\
\hline & 77 & 2.39 & 12.19 & 12.24 & 38.80 & 4.35 & 30.03 & 100.00 & & & & \\
\hline & 82 & 3.68 & 15.91 & 15.47 & 43.34 & 3.13 & 18.47 & 100.00 & & & & \\
\hline & 83 & 2.76 & 14.98 & 13.77 & 42.87 & 4.34 & 21.29 & 100.00 & & & & \\
\hline & 84 & 2.75 & 15.51 & 14.60 & 43.40 & 4.61 & 19.13 & 100.00 & & & & \\
\hline & 85 & 1.78 & 10.86 & 13.36 & 38.94 & 5.27 & 29.80 & 100.00 & & & & \\
\hline & 89 & 1.47 & 13.58 & 15.06 & 41.73 & 7.25 & 20.91 & 100.00 & & & & \\
\hline & 90 & 1.07 & 12.05 & 13.55 & 40.00 & 8.38 & 24.95 & 100.00 & & & & \\
\hline & 91 & 0.49 & 5.29 & 7.69 & 29.40 & 6.50 & 50.63 & 100.00 & & & & \\
\hline & 92 & 3.85 & 16.56 & 16.01 & 43.59 & 3.52 & 16.48 & 100.00 & & & & \\
\hline & 93 & 2.20 & 12.48 & 13.83 & 41.18 & 4.78 & 25.53 & 100.00 & & & & \\
\hline & 94 & 1.00 & 6.03 & 10.41 & 31.05 & 7.24 & 44.26 & 100.00 & & & & \\
\hline & 95 & 3.14 & 10.66 & 13.59 & 33.62 & 5.35 & 33.65 & 100.00 & & & & \\
\hline & 113 & 2.20 & 13.96 & 13.07 & 43.76 & 4.38 & 22.62 & 100.00 & & & & \\
\hline & 114 & 3.26 & 12.36 & 13.85 & 40.40 & 2.98 & 27.15 & 100.00 & & & & \\
\hline & 115 & 1.75 & 8.78 & 11.53 & 31.81 & 5.78 & 40.35 & 100.00 & & & & \\
\hline & 116 & 1.67 & 11.46 & 9.24 & 40.67 & 1.26 & 35.71 & 100.00 & & & & \\
\hline & 118 & 0.86 & 11.95 & 12.99 & 42.23 & 7.58 & 24.40 & 100.00 & & & & \\
\hline \multirow{2}{*}{\multicolumn{2}{|c|}{$\begin{array}{c}\text { average } \\
\pm \sigma \\
\end{array}$}} & 2.28 & 12.81 & 13.16 & 40.00 & 4.91 & 26.85 & 100.00 & & & & \\
\hline & & 0.93 & 3.02 & 2.01 & 4.25 & 1.90 & 8.59 & & & & & \\
\hline \multirow{11}{*}{$\begin{array}{c}\text { Ox } \\
\begin{array}{c}\text { (reacted basalt } \\
\text { block) }\end{array}\end{array}$} & $\begin{array}{c}\text { Analysis } \\
\text { Point }\end{array}$ & $\mathrm{TiO}_{2}$ & $\mathrm{Cr}_{2} \mathrm{O}_{3}$ & FeO & $\mathrm{NiO}$ & & & Total & & & & \\
\hline & 103 & 23.58 & & 76.42 & & & & 1000.00 & & & & \\
\hline & 104 & & 20.48 & 70.57 & 8.95 & & & 100.00 & & & & \\
\hline & 105 & & 20.81 & 70.79 & 8.40 & & & 100.00 & & & & \\
\hline & 106 & & 21.16 & 70.04 & 8.80 & & & 100.00 & & & & \\
\hline & 107 & 27.85 & & 70.69 & & & & 100.00 & & & & \\
\hline & 108 & & 20.02 & 71.21 & 8.77 & & & 100.00 & & & & \\
\hline & 109 & 3.46 & 20.11 & 67.68 & 8.75 & & & 100.00 & & & & \\
\hline & 110 & & 20.25 & 69.76 & 9.99 & & & 100.00 & & & & \\
\hline & 111 & & 20.60 & $\begin{array}{l}71.39 \\
7\end{array}$ & $\begin{array}{l}8.00 \\
020\end{array}$ & & & 100.00 & & & & \\
\hline & 112 & & 20.20 & 70.57 & 9.23 & & & 100.00 & & & & \\
\hline
\end{tabular}


Figure B.3.18. EDS analysis for oxides. Reacted basalt-block surface
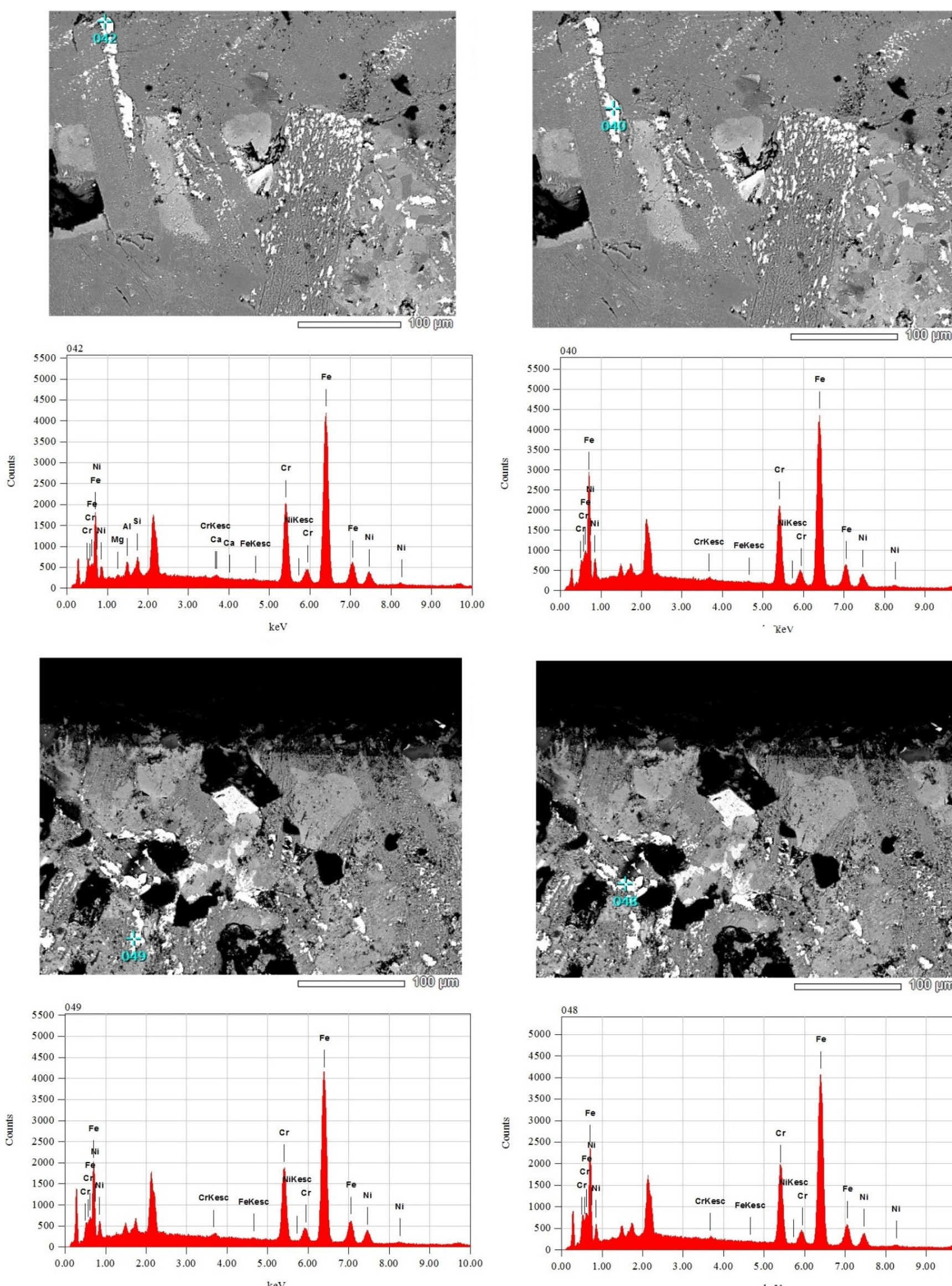
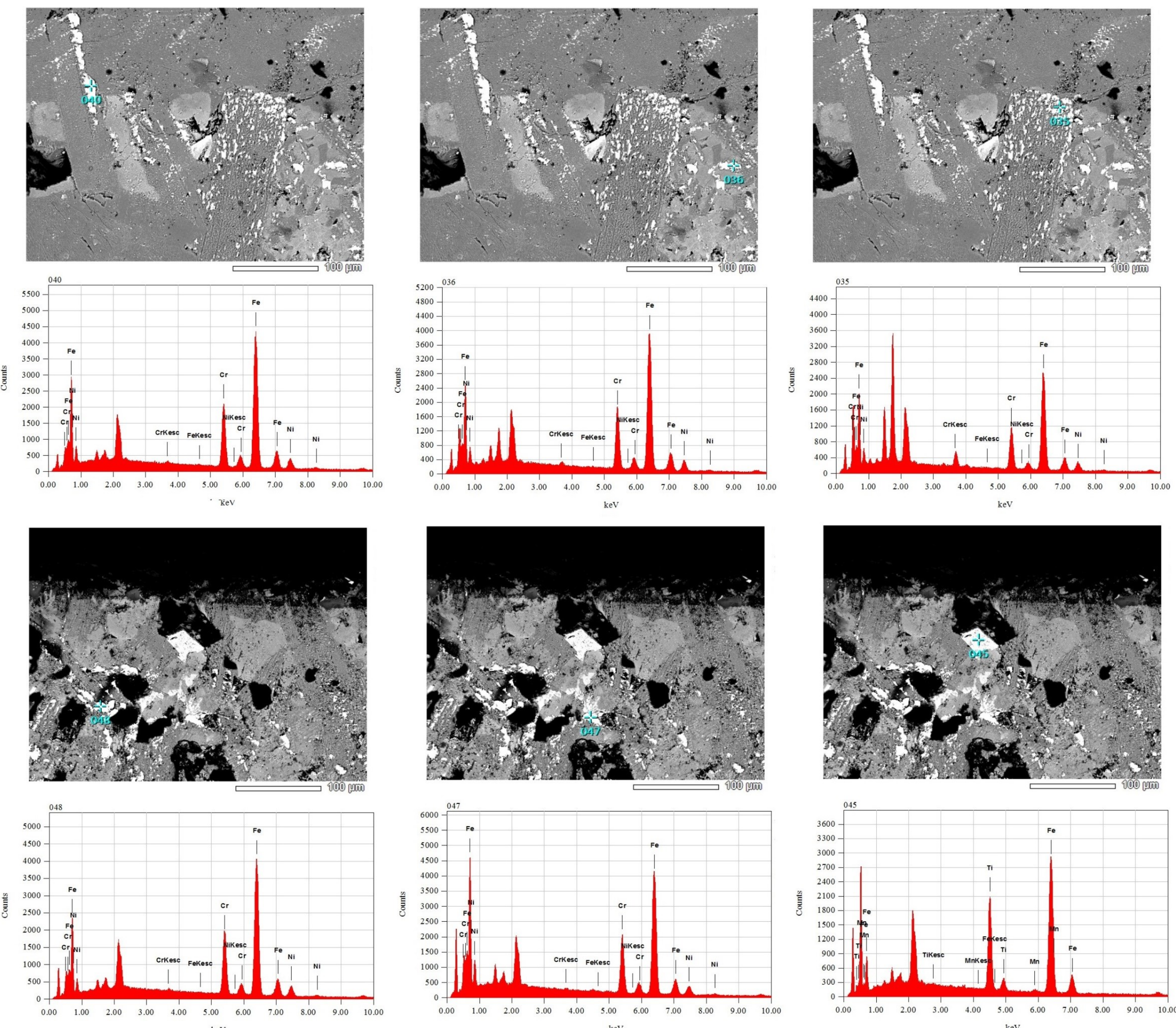
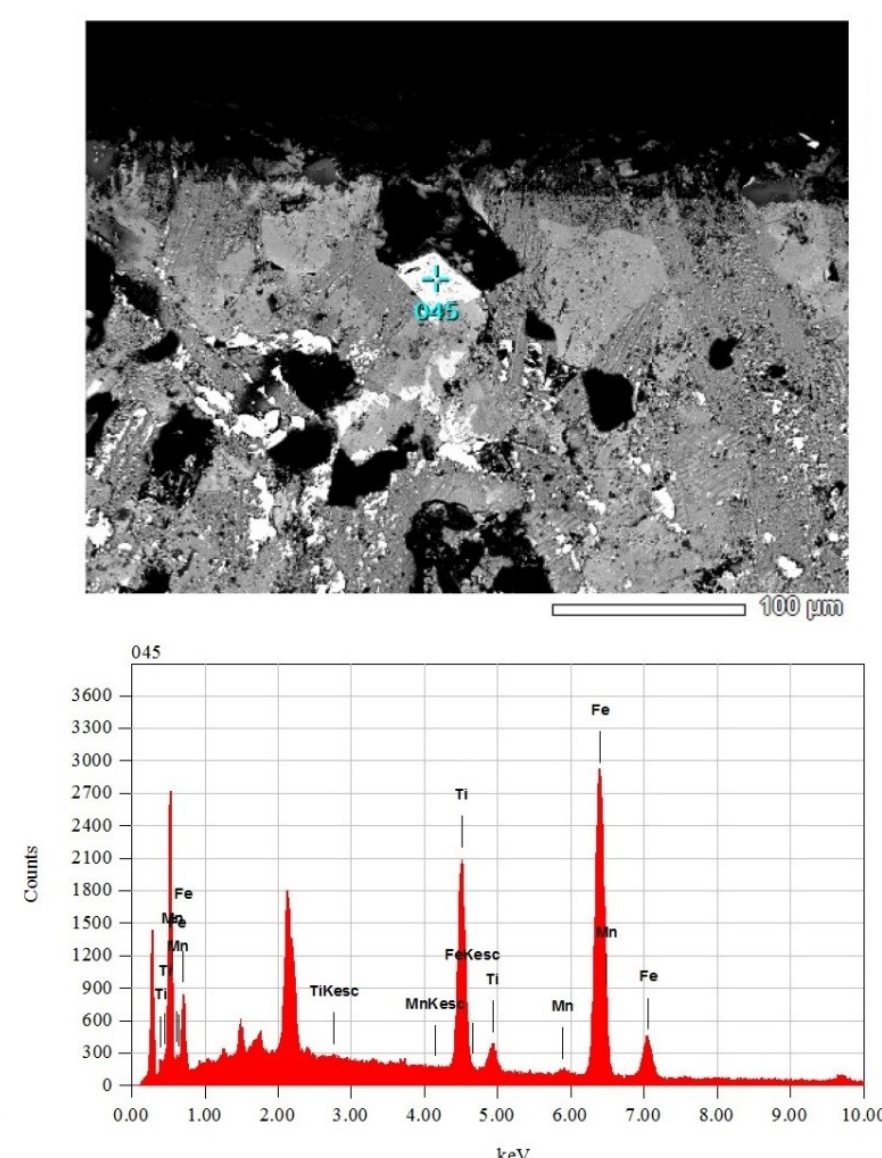
Figure B.3.19. XRD scan showing the mineralogy of reacted grains collected from the top (Portion 2) of the Reactor

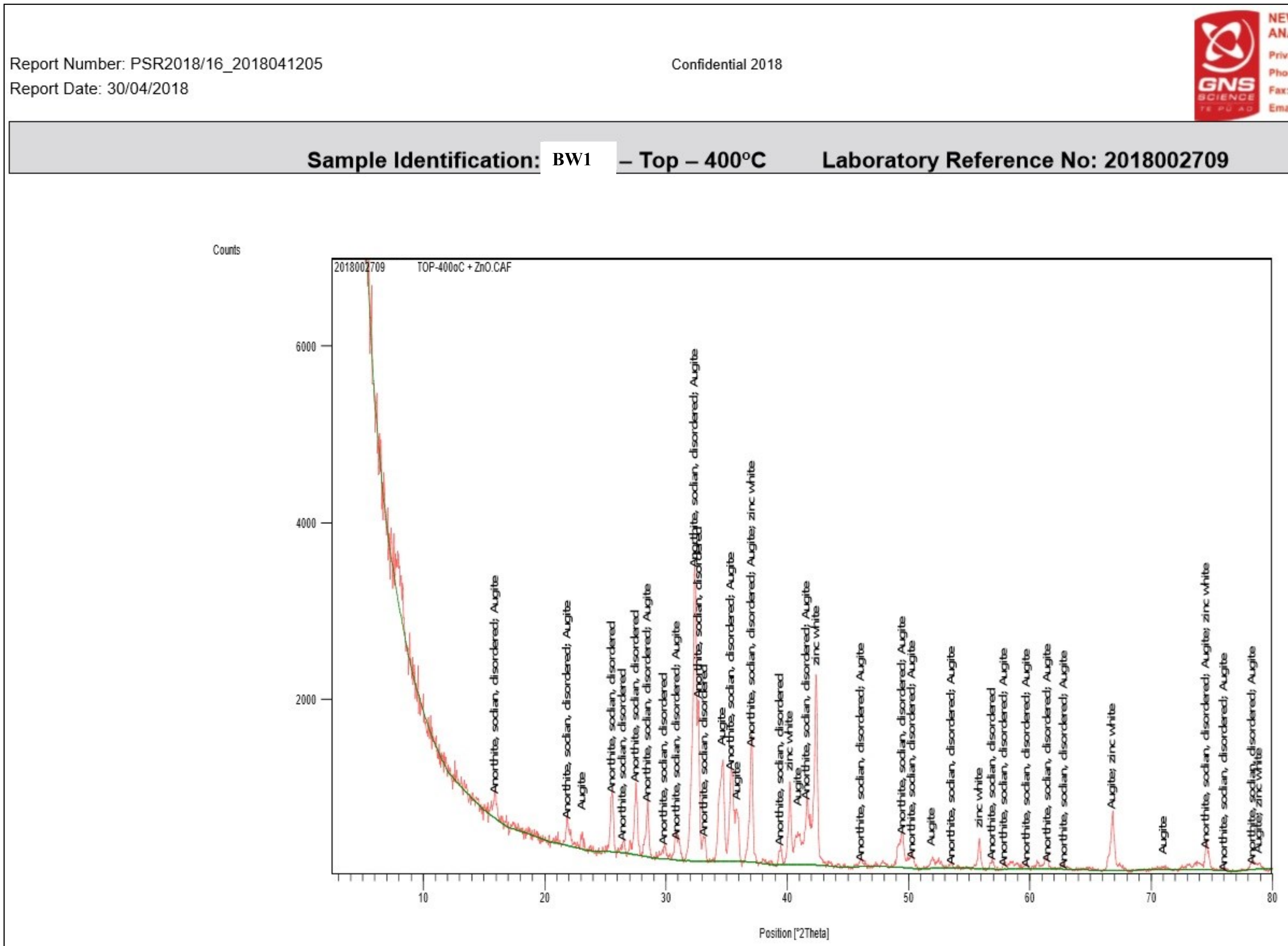

Figure 11 . XRD scan showing the mineralogy of $\mathbf{B W 1}-\mathrm{Top}-400^{\circ} \mathrm{C}$ as indicated by the labelled scan peaks 


\section{Sample Composition}

Table 1. Mineral percentages for BW1 sample was determined and then normalized to exclude zinc oxide:

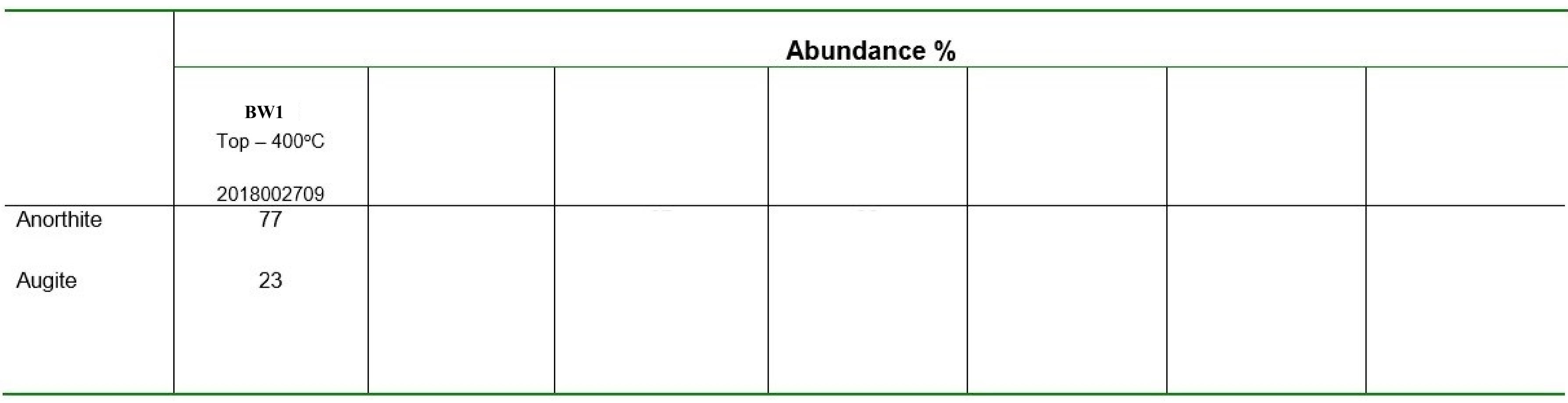

Margin of Error: Abundance estimates are determined through successive refinement of cell parameters; the position, width and orientation of each mineral. Values are given to the nearest whole number. The margin of error for phase concentration is proposed as follows: $0-10 \% \pm 10 \% ; 10-50 \% \pm 5 \% ; 50-100 \% \pm 2 \%$ 


\subsection{Results}

\section{BW2: Basalt - water at $350^{\circ} \mathrm{C} / 490$ bar}

Table B.3.9. Major ions compositions and complete experimental parameters (number of samples collected, $\mathrm{T}, \mathrm{P}$, time, flow rate and $\mathrm{pH}$ ) for the $\mathrm{BW} 2 \mathrm{at} 350^{\circ} \mathrm{C} / 490 \mathrm{bar}$. In situ $\mathrm{pH}$ is the calculated $\mathrm{pH}$ at temperature. Analysis of major ions are reported both in $\mathrm{mg} \mathrm{kg}^{-1}$ and in mmol $\mathrm{kg}^{-1}$. n.c.. not calculated

\begin{tabular}{|c|c|c|c|c|c|c|c|c|c|c|c|c|c|c|c|c|c|c|c|c|c|c|c|c|c|c|c|c|c|c|c|c|c|}
\hline & \multirow[b]{2}{*}{$\mathrm{n}^{\circ}$ sample } & \multirow[b]{2}{*}{$\begin{array}{l}\mathrm{T} \\
\left({ }^{\circ} \mathrm{C}\right)\end{array}$} & \multirow[b]{2}{*}{$\underset{\text { (bar) }}{\mathrm{P}}$} & \multirow[b]{2}{*}{$\begin{array}{l}\text { time } \\
\text { (hrs) }\end{array}$} & \multirow[b]{2}{*}{$\begin{array}{c}\text { flow-rate } \\
\left(\mathrm{ml} \mathrm{hr}^{-1}\right)\end{array}$} & \multirow[b]{2}{*}{$\underset{\text { (room T) }}{\mathrm{pH}}$} & \multirow[b]{2}{*}{$\begin{array}{c}\mathrm{pH} \\
\left(350^{\circ} \mathrm{C}\right)\end{array}$} & \multicolumn{13}{|c|}{$\mathbf{m g} \mathbf{~ k g}^{-1}$} & $\mathrm{mmol} \mathrm{kg}^{-1}$ & & & & & & & & & & & & \\
\hline & & & & & & & & As & B & $\mathrm{Ca}$ & $\mathrm{Fe}$ & K & $\mathrm{Mg}$ & $\mathrm{Na}$ & $\mathrm{SiO}_{2}$ & $\mathrm{Al}$ & $\mathrm{Li}$ & $\mathrm{H}_{2} \mathrm{~S}$ & $\mathrm{Cl}$ & $\mathrm{SO}_{4}$ & As & B & $\mathrm{Ca}$ & $\mathrm{Fe}$ & K & $\mathrm{Mg}$ & $\mathrm{Na}$ & $\mathrm{SiO}_{2}$ & $2 \mathrm{Al}$ & $\mathrm{Li}$ & $\mathrm{H}_{2} \mathrm{~S}$ & $\mathrm{Cl}$ & $\mathrm{SO}_{4}$ \\
\hline & $\begin{array}{c}\text { blank } \\
\text { water (distilled) }\end{array}$ & 19.6 & 1 & 0.0 & - & 6.8 & 5. & 0.04 & 2.5 & 1 & 8 & 3.2 & 0.1 & 6.7 & 2.3 & $<0.15$ & $<0.01$ & $<0.01$ & $<0.1$ & .1 & 1 & 0.2 & 0.02 & $<0.001$ & 0.08 & 0.004 & 0.3 & 0.04 & 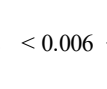 & 1 & 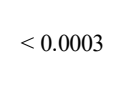 & 3 & $<0.001$ \\
\hline & 1 & 19.4 & 489.5 & 18.3 & 1 & 7.56 & n.c. & 0.02 & 2.1 & 1.2 & 0.08 & 4.3 & 0.3 & 12.5 & 7.8 & $<0.15$ & 0.02 & $<0.01$ & 5.9 & 1.9 & 0.0002 & 0.2 & 0.03 & 0.001 & 0.1 & 0.01 & 0.5 & 0.1 & $<0.006$ & 50.003 & $<0.0003$ & 0.2 & 0.02 \\
\hline & 2 & 19.7 & 488.9 & 43.3 & 1 & 6.65 & n.c. & 0.2 & 1.6 & 1.1 & $<0.08$ & 2.5 & 0.2 & 7.3 & 27.4 & $<0.15$ & $<0.01$ & $<0.01$ & 0.7 & 0.3 & 0.003 & 0.1 & 0.03 & $<0.001$ & 0.06 & 0.01 & 0.3 & 0.5 & $<0.006$ & $5<0.001$ & $<0.0003$ & 0.02 & 0.003 \\
\hline & 3 & 19.5 & 488.9 & 67.6 & 1 & 7.58 & n.c. & 0.3 & 1.3 & 1 & $<0.08$ & 1.8 & 0.1 & 6.2 & 23.1 & $<0.15$ & $<0.01$ & $<0.01$ & 0.3 & $<0.1$ & 0.004 & 0.1 & 0.02 & $<0.001$ & 0.05 & 0.004 & 0.3 & 0.4 & $<0.006$ & $6<0.001$ & $<0.0003$ & 0.01 & $<0.001$ \\
\hline & 4 & 19.6 & 488.8 & 88.5 & 1 & 6.50 & n.c. & 0.2 & 1.4 & 1 & $<0.08$ & 1.9 & 0.1 & 5.8 & 19.8 & $<0.15$ & $<0.01$ & $<0.01$ & 0.2 & $<0.1$ & 0.002 & 0.1 & 0.02 & $<0.001$ & 0.05 & 0.005 & 0.3 & 0.3 & $<0.006$ & $5<0.001$ & $<0.0003$ & 0.005 & $<0.001$ \\
\hline & 5 & 19.3 & 488.8 & 112.4 & 1 & 6.53 & n.c. & 0.1 & 0.7 & 1 & 0.09 & 3.1 & 0.2 & $<0.8$ & 18.8 & $<0.15$ & $<0.01$ & $<0.01$ & 0.2 & $<0.1$ & 0.002 & 0.06 & 0.02 & 0.002 & 0.08 & 0.01 & $<0.03$ & $\begin{array}{ll}3 & 0.3\end{array}$ & $<0.006$ & $6<0.001$ & $<0.0003$ & 0.005 & $<0.001$ \\
\hline & 6 & 19.5 & 488.8 & 136.4 & 1 & 6.80 & n.c. & 0.1 & 0.6 & 1 & 0.09 & 2.6 & 0.2 & $<0.8$ & 17.5 & $<0.15$ & $<0.01$ & $<0.01$ & 0.2 & $<0.1$ & 0.002 & 0.05 & 0.02 & 0.002 & 0.07 & 0.01 & $<0.03$ & $\begin{array}{ll}3 & 0.3\end{array}$ & $<0.006$ & $6<0.001$ & $<0.0003$ & 0.01 & $<0.001$ \\
\hline & 7 & 351.8 & 488.8 & 160.5 & 1 & 5.50 & 6.24 & 0.2 & 0.7 & 2.0 & 1.5 & 14.3 & 0.7 & 25.6 & 1330.1 & 9.7 & 0.09 & 1.3 & 19.9 & 11.6 & 0.003 & 0.07 & 0.05 & 0.03 & 0.4 & 0.03 & 1.1 & 22.1 & 0.4 & 0.01 & 0.04 & 0.6 & 0.1 \\
\hline & 8 & 350.4 & 488.9 & 184.3 & 1 & 7.13 & 6.37 & 0.1 & 0.7 & 1.5 & 1.2 & 11.2 & 0.4 & 17.5 & 1937.5 & 9 & 0.08 & 3.4 & 10.6 & 10.9 & 0.002 & 0.06 & 0.04 & 0.02 & 0.3 & 0.02 & 0.8 & 32.2 & 0.3 & 0.01 & 0.1 & 0.3 & 0.1 \\
\hline & 9 & 350.6 & 488.9 & 211.6 & 1 & 7.59 & 6.09 & 0.06 & 1.2 & 2.5 & 1 & 12.8 & 0.4 & 7.6 & 1891.2 & 9.1 & 0.08 & 4.3 & 7.6 & 8.1 & 0.001 & 0.1 & 0.06 & 0.02 & 0.3 & 0.02 & 0.3 & 31.5 & 0.3 & 0.01 & 0.1 & 0.2 & 0.08 \\
\hline & 10 & 350.2 & 488.9 & 232.8 & 1 & 8.41 & 6.31 & \begin{tabular}{|l|l}
0.07 \\
\end{tabular} & 0.6 & 1.1 & 1.2 & 10.3 & 0.2 & 20.3 & 1902.4 & 9.9 & 0.09 & 4.5 & 6.2 & 7.7 & 0.001 & 0.06 & 0.03 & 0.02 & 0.3 & 0.01 & (n) & 31.7 & 0.4 & 0.01 & 0.1 & 0.2 & .08 \\
\hline & 11 & 350.6 & 489.0 & 256.5 & 1 & 8.50 & 6. & 0.05 & 0.7 & 1.9 & 1.1 & 10.7 & 0.3 & 19.6 & 1889.0 & 10.6 & 0.09 & 3.8 & 5.6 & 6.4 & 0.001 & .07 & 0.05 & 0.02 & 0.3 & 0.01 & 0.9 & 31.4 & 0.4 & 0.01 & 0.1 & 0.2 & .07 \\
\hline & 12 & 350.7 & 488.9 & 280.5 & 1 & 8.59 & 6.16 & 0.05 & 0.7 & 1.7 & 0.9 & 9.6 & 0.2 & 16.8 & 1802.9 & 9.6 & 0.09 & 3.9 & 5.4 & 6.4 & 0.001 & 0.07 & 0.04 & 0.02 & 0.2 & 0.01 & 0.7 & 30 & 0.4 & 0.01 & 0.1 & 0.2 & 0.07 \\
\hline & 13 & 350.6 & 489.0 & 304.0 & 1 & 8.78 & 6.18 & 0.05 & 0.7 & 1.7 & 0.9 & 8.1 & 0.3 & 20.4 & 1743.3 & 9.9 & 0.1 & 3.1 & 4.5 & 7.1 & 0.001 & 0.06 & 0.04 & 0.02 & 0.2 & 0.01 & 0.9 & 29 & 0.4 & 0.01 & 0.09 & 0.1 & .07 \\
\hline & 14 & 350.2 & 489.0 & & 1 & 88 & & 66 & 0.9 & 1.7 & 0.7 & 8.9 & 0.2 & 25.6 & 1721.3 & 11.4 & 0.1 & 3.2 & 12 & 6.2 & 000 & 0.08 & $0 . c$ & 001 & 0.2 & 0.01 & 11 & 28.7 & 04 & 02 & .09 & & 66 \\
\hline & 15 & 350.4 & 488.9 & 353.0 & 1 & 8.9 & 6. & 0.05 & 1.2 & 2.1 & 0.5 & 10.1 & 0.2 & 24.1 & 1678.5 & 12.9 & 0.1 & 3 & 3.5 & 6.1 & 0.001 & 0.1 & 0.05 & 0.01 & 0.3 & 0.01 & 1 & 7.9 & 0.5 & 0.02 & 09 & 0.1 & .06 \\
\hline & 16 & 350.8 & 489.1 & 378.2 & 1 & 9.07 & 5.79 & 0.04 & 1.4 & 2.9 & 0.5 & 12.1 & 0.3 & 32.6 & 1522.5 & 11.4 & 0.09 & 2.2 & 2.5 & 3.9 & 0.0005 & 0.1 & 0.07 & 0.01 & 0.3 & 0.01 & 1.4 & 5.3 & 0.4 & 0.01 & 0.06 & 0.07 & 0.04 \\
\hline & 17 & 350.7 & 488.9 & 403.6 & 1 & 9.22 & 5.82 & 0.02 & 0.9 & 2.2 & 0.4 & 12 & 0.2 & 38.4 & 1553.3 & 10.8 & 0.05 & 1.7 & 1.9 & 2 & 0.0003 & 0.08 & 0.05 & 0.01 & 0.3 & 0.01 & 1.7 & 5.9 & 0.4 & 0.01 & 0.05 & 0.05 & 0.03 \\
\hline & 18 & 350.6 & 489.0 & & 1 & 9. & & $<0.015$ & 0.9 & 2 & 0.4 & 13.7 & 0.3 & 45.6 & 1212.3 & 13.6 & 0.03 & 0 & & 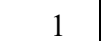 & $<0.0002$ & 08 & & & 3 & & 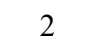 & 2 & .5 & & 3 & 02 & .01 \\
\hline & 19 & 350.4 & 488.9 & 449.2 & 1 & 9.35 & 5.31 & 0.02 & 0.7 & 1.7 & 0.4 & 15.9 & 0.3 & 50.3 & 766.2 & 21.3 & 0.02 & 0.4 & 0.3 & $<0.1$ & 0.0003 & 0.07 & 0.04 & 0.01 & 0.4 & 0.01 & 2.2 & 2.8 & 0.8 & 0.003 & 0.01 & 0.01 & $<0.001$ \\
\hline & 20 & 350.6 & 489.1 & 472.5 & 1 & 9.48 & 5.30 & 0.06 & 1.8 & 2.2 & 0.3 & 19.9 & 0.3 & 51.7 & 715.1 & 23.7 & 0.02 & 0.3 & 0.2 & $<0.1$ & 0.001 & 0.2 & 0.05 & 0.01 & 0.5 & 0.01 & 2.2 & 1.9 & 0.9 & 0.003 & 0.01 & 0.01 & $<0.001$ \\
\hline & 21 & 350.8 & 488.9 & 496.3 & 1 & 9.47 & 5.52 & $<0.015$ & 1.5 & 1.5 & 0.3 & 20.8 & 0.3 & 57.5 & 739.6 & 26.8 & $<0.01$ & 0.3 & 0.6 & 0.7 & $<0.0002$ & 0.1 & 0.04 & 0.005 & 0.5 & 0.01 & 2.5 & 2.3 & 1 & $<0.001$ & 0.01 & 0.02 & 0.01 \\
\hline & 22 & 350.7 & 488.9 & & 1 & 9 & & 0.02 & 1.4 & 1.8 & 0 & 19.9 & 0.2 & 51.1 & 676.8 & 26.8 & $<0.01$ & 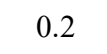 & & & 00003 & 0.1 & 0.05 & 0.01 & 5 & & & & 1 & $<0.001$ & & 01 & \\
\hline & 23 & 350.5 & 489.6 & 546.3 & 1 & 9.6 & 5.6 & 0.02 & 1.2 & 0.5 & 0.2 & 24.3 & 0.03 & 64.7 & 628.9 & 43 & 0.01 & 0.4 & 0.3 & 0.4 & 0.0002 & 0.1 & 0.01 & 0.004 & 0.6 & 0.001 & 2.8 & 0.5 & 1.6 & 0.001 & 0.01 & 0.01 & 0.005 \\
\hline & 24 & 350.5 & 489.6 & 572.4 & 1 & 9.53 & 5. & 0.02 & 1.1 & 1.6 & 0.2 & 19 & 0.2 & 53.1 & 645.3 & 28 & 0.01 & 0.2 & 0.3 & 0.4 & 0.0003 & 0.1 & 0.04 & 0.004 & 0.5 & 0.01 & 2.3 & 0.7 & 1 & 0.001 & 0.005 & 0.01 & 0.004 \\
\hline & 25 & 350.7 & 489.5 & 592.6 & 1 & 9.5 & 5. & 0.04 & 1.1 & 1.6 & 0.2 & 19.7 & 0.2 & 50.3 & 638.6 & 28.8 & 0.01 & 0.2 & 0.3 & & 0.0005 & 0.1 & 0.04 & 0.004 & 0.5 & & 2 & .6 & 1.1 & 0.002 & 0.005 & 01 & 0.005 \\
\hline & 26 & 350.9 & 489.5 & & 1 & & & $<0.015$ & 1 & 1 & 0. & 18.8 & 0.2 & 51 & 626.7 & 29 & & & & & $<0.0002$ & 0.09 & 0.04 & 0.002 & 5 & & 2.2 & 4 & 1.1 & 0.003 & 0.004 & 01 & 0.004 \\
\hline & 27 & 350.7 & 488.1 & 644.5 & 1 & 9. & 5.6 & 0.02 & 0.8 & 0.8 & 0. & 20 & 0.1 & 62.7 & 615.2 & 30.4 & 0.01 & 0.2 & 3 & 0.6 & 0.0003 & 07 & 0.02 & 0.003 & 0.5 & 0.002 & 2.7 & 0.2 & 1.1 & 0.002 & 0.005 & 01 & .01 \\
\hline & 28 & 350.4 & 488.6 & 664.5 & 1 & 9. & 5. & $<0.015$ & 0.8 & 1.7 & 0.3 & 19.2 & 0.3 & 61.7 & 596.6 & 29.4 & 0.01 & 0.1 & 0.3 & 0. & $<0.0002$ & 07 & 0.04 & 0.01 & 0.5 & 0.01 & 2.7 & 9.9 & 1.1 & 0.002 & 0.004 & 0.01 & 0.01 \\
\hline & 29 & 350.6 & 489.5 & & 1 & 9. & & 0.01 & 0.6 & 1.5 & 0.2 & 18.2 & 0.2 & 58 & 573.7 & 28 & 0.02 & 0. & 0.2 & & 0.0002 & 06 & 0.04 & 0.004 & 5 & 0.01 & 5 & 9.5 & 1 & 0.002 & 0.004 & 0.005 & 0.005 \\
\hline & 30 & 350.5 & 489.5 & 71 & 1 & 9. & & $<0.015$ & 0.6 & 0.9 & 0. & 17.5 & 0.1 & 58.2 & 566.2 & 27.1 & 3 & 0.1 & & & $<0.0002$ & 06 & 0.02 & 0.002 & 4 & 0.005 & 2.5 & 9.4 & 1 & 0.005 & 0.004 & 0.01 & 0.005 \\
\hline & 31 & 350.7 & 489.6 & 739.1 & 1 & 9. & 5. & $<0.015$ & 0.6 & 1.4 & 0. & 16.5 & 0.1 & 59.4 & 539.1 & 25 & 0.02 & 0.1 & $<0.1$ & 0. & $<0.0002$ & 06 & 0.04 & 0.002 & 0.4 & 0.005 & 2.6 & 9 & 0.9 & 0.002 & 0.003 & $<0.003$ & 0.005 \\
\hline & 32 & 350.4 & 489.5 & 761.1 & 1 & 9. & 5. & $<0.015$ & 0.7 & 1.4 & 0. & 16.2 & 0.1 & 57.6 & 533.3 & 26 & & 0 & 0.2 & 0 & $<0.0002$ & 06 & 0.04 & 0.001 & 0.4 & 0.004 & - & 8.9 & 1 & 0.005 & 0.004 & 0.01 & 0.004 \\
\hline & & 350.5 & 488.0 & 785.2 & 1 & 9. & & $<0.015$ & 0.6 & 1.9 & 0.2 & 16.2 & 0.2 & 60.9 & 530.3 & 26.4 & $<0.01$ & 0.1 & 0.2 & 0.4 & $<0.0002$ & 06 & 0.05 & 0.003 & 0.4 & 0.01 & 2.6 & 8.8 & 1 & $<0.001$ & 0.003 & 0.01 & 0.004 \\
\hline re-filling & 34 & 19.6 & 1 & 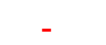 & 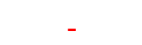 & 6. & & $<0.015$ & 0.3 & 1.4 & 0. & 2.2 & 2 & 6.1 & 2.7 & $<0.15$ & $<0.01$ & $<0.01$ & 2 & & $<0.0002$ & 03 & 0.03 & & 1 & 0.01 & 0.3 & 0.05 & $<0.006$ & $6<0.001$ & $<0.0003$ & 0.01 & 0.005 \\
\hline & 35 & 350.2 & 489.5 & 809.8 & 1 & 8. & 5. & $<0.015$ & 0.4 & 1.9 & 0.3 & 11.9 & 0.2 & 64.7 & 561.4 & 36.8 & $<0.01$ & 0.03 & 0.1 & 0 & $<0.0002$ & 04 & 0.05 & 0.005 & 3 & 0.01 & 2.8 & 9.3 & 1.4 & $<0.001$ & 0.001 & 0.003 & 0.004 \\
\hline & 36 & 350.5 & 489.5 & 833.0 & 1 & 9.5 & & $<0.015$ & 0.8 & 1.5 & $<0.08$ & 6.8 & 0.2 & 47.2 & 515.4 & 28.6 & 0.04 & $<0.01$ & 0.5 & 0.5 & & 08 & 0.04 & $<0.001$ & 0.2 & 0.01 & 2. & 8.6 & 1.1 & 0.01 & $<0.0003$ & 0.01 & 01 \\
\hline & 37 & 350.6 & 489.6 & 862.3 & 1 & 9. & 5. & $<0.015$ & 0.6 & 0.8 & 0.1 & 5.3 & 0.1 & 43.4 & 514.9 & 25 & 0.04 & 0.08 & 0.4 & 0.1 & $<$ & 06 & 0.02 & 0.003 & 0.1 & 0.004 & 1 & 8.6 & 0.9 & 01 & 0.002 & 0.01 & 0.001 \\
\hline & 38 & 350.4 & 489.6 & 88 & 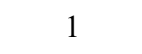 & 9. & & $<0.015$ & 0.7 & 1.5 & 0. & 5. & 0. & & 505 & 25.8 & & 0. & & & $<0.0002$ & 07 & 0.04 & & & & & & 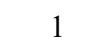 & 11 & 003 & 02 & $<0.001$ \\
\hline & 39 & 350 & 489.6 & & 1 & 9. & & $<0$. & 0.5 & 1 & 0. & 5. & 0. & & 497 & 26 & & 0. & & $<01$ & & & 0.03 & & 1 & 0.00 & 2 & 5 & 1 & & & & $<0.001$ \\
\hline & 40 & 350.7 & 489.5 & 928.3 & 1 & 9.62 & 5. & $<0.015$ & 0.5 & 1.3 & 0.1 & 5.3 & 0.1 & 48.5 & 493.2 & 26.1 & 0.03 & 0.1 & 0.4 & 0.1 & $<1$ & 0.04 & 0.03 & 0.002 & 0.1 & 0.01 & 2.1 & 8.2 & 1 & 0.005 & 0.003 & 01 & 0.004 \\
\hline & 41 & 350.4 & 489.5 & 952.3 & 1 & 9.61 & 5. & $<0.015$ & 0.5 & 1.5 & 0.1 & 5.3 & 0.2 & 48.7 & 485.3 & 26.2 & 0.04 & 0.08 & 0.4 & $<0.1$ & $<0.0002$ & 0.04 & 0.04 & 0.003 & 0.1 & 0.01 & 2.1 & .1 & 1 & 01 & 0.002 & 1 & $<0.001$ \\
\hline & 42 & 350 & 48 & 976.7 & 1 & & & $<0.0$ & 0.4 & 1. & 0. & 5. & & 49.3 & 49 & 27.7 & & & & 0 & $<0.0002$ & 0.04 & & & & & 2.1 & & 1 & 0.005 & 0.002 & 01 & $<0.001$ \\
\hline & 43 & 350 & 489 & & 1 & 9.6 & 5. & & 2.1 & 1.1 & 0.1 & 5.5 & 0.3 & 45.5 & 48 & 27 & 0.04 & 0.06 & 0.5 & $<0.1$ & & 0.2 & 0.03 & 0.002 & 0.1 & 0.01 & 2 & 8.1 & 1 & 0.01 & 0.002 & 01 & $<0.001$ \\
\hline & 44 & 350.5 & 489.5 & 1049.8 & 0.5 & 9.65 & 5.45 & 0.03 & 1.6 & 0.8 & 0.1 & 5.5 & 0.1 & 48.1 & 493.6 & 25 & 0.02 & 0.06 & 0.5 & $<0.1$ & 0.0004 & 0.1 & 0.02 & 0.002 & 0.1 & 0.003 & 2.1 & 8.2 & 0.9 & 0.003 & 0.002 & 01 & $<0.001$ \\
\hline & 45 & 350.4 & 489.5 & 1096.5 & 0.5 & 9.62 & 5.43 & 0.03 & 1.5 & 1.1 & 0.1 & 5 & 0.1 & 45.8 & 495.7 & 24.1 & 0.04 & 0.07 & 0.7 & 0.1 & 0.0003 & 0.1 & 0.03 & 0.001 & 0.1 & 0.003 & 2 & 8.3 & 0.9 & 0.01 & 0.002 & 0.02 & 0.001 \\
\hline & 46 & 350.4 & 489.4 & 1144.7 & 0.5 & 9.62 & 5.35 & 0.04 & 1.4 & 1.3 & 0.2 & & 0.1 & 45.8 & 490.5 & 23.6 & 0.03 & 0.03 & 0.5 & $<0.1$ & 0.001 & 0.1 & 0.03 & 0.003 & 0.1 & 0.01 & 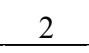 & 8.2 & 0.9 & 0.005 & 0.001 & 0.01 & 0.001 \\
\hline
\end{tabular}




\begin{tabular}{|c|c|c|c|c|c|c|c|c|c|c|c|c|c|c|c|c|c|c|c|c|}
\hline \multirow[b]{2}{*}{$\mathrm{n}^{\circ}$ sample } & \multirow[b]{2}{*}{$\begin{array}{c}\mathrm{T} \\
\left({ }^{\circ} \mathrm{C}\right)\end{array}$} & \multirow[b]{2}{*}{$\begin{array}{c}\mathrm{P} \\
\text { (bar) }\end{array}$} & \multirow[b]{2}{*}{$\begin{array}{l}\text { time } \\
\text { (hrs) }\end{array}$} & \multirow[b]{2}{*}{$\begin{array}{l}\text { flow-rate } \\
\left(\mathrm{ml} \mathrm{hr}{ }^{-1}\right)\end{array}$} & \multirow[b]{2}{*}{$\begin{array}{c}\mathrm{pH} \\
(\operatorname{room~T)}\end{array}$} & \multirow[b]{2}{*}{$\begin{array}{c}\mathrm{pH} \\
\left(350^{\circ} \mathrm{C}\right)\end{array}$} & \multicolumn{14}{|c|}{$\mu \mathrm{mol} \mathrm{kg}{ }^{-1}$} \\
\hline & & & & & & & V & $\mathrm{Cr}$ & $\mathrm{Co}$ & $\mathrm{Ni}$ & $\mathrm{Cu}$ & $\mathrm{Zn}$ & $\mathrm{Rb}$ & Mo & $\mathrm{Ag}$ & $\mathrm{Cd}$ & $\mathrm{Ba}$ & $\mathrm{Au}$ & $\mathrm{Pb}$ & $\mathrm{Mn}$ \\
\hline $\begin{array}{c}\text { blank } \\
\text { water (distilled) }\end{array}$ & 19.6 & 1 & 0.0 & - & 6.80 & 5.29 & $<0.001$ & $<0.004$ & $<0.002$ & $<0.003$ & $<0.0009$ & $<0.008$ & $<0.001$ & $<0.002$ & $<0.0005$ & $<0.0009$ & $<0.001$ & $<0.001$ & $<0.001$ & $<0.13$ \\
\hline 1 & 19.4 & 489.5 & 18.3 & 1 & 7.56 & n.c. & $<0.001$ & 0.07 & $<0.002$ & n.a. & 0.2 & 1.7 & 0.05 & 0.3 & $<0.0005$ & $<0.0009$ & $<0.001$ & n.a. & 0.006 & $<0.13$ \\
\hline 2 & 19.7 & 488.9 & 43.3 & 1 & 6.65 & n.c. & $<0.001$ & 0.1 & $<0.002$ & 0.2 & $<0.0009$ & 12.9 & 0.02 & 0.3 & $<0.0005$ & $<0.0009$ & $<0.001$ & n.a. & 0.008 & $<0.13$ \\
\hline 3 & 19.5 & 488.9 & 67.6 & 1 & 7.58 & n.c. & $<0.001$ & 0.05 & $<0.002$ & 0.1 & n.a. & 16.3 & 0.01 & 0.2 & $<0.0005$ & $<0.0009$ & $<0.001$ & n.a. & 0.04 & $<0.13$ \\
\hline 4 & 19.6 & 488.8 & 88.5 & 1 & 6.50 & n.c. & $<0.001$ & 1.2 & $<0.002$ & 0.2 & $<0.0009$ & 5.6 & 0.02 & 0.2 & $<0.0005$ & $<0.0009$ & $<0.001$ & n.a. & $<0.001$ & $<0.13$ \\
\hline 5 & 19.3 & 488.8 & 112.4 & 1 & 6.53 & n.c. & $<0.001$ & 0.05 & $<0.002$ & 0.2 & $<0.0009$ & 16.8 & 0.01 & 0.1 & $<0.0005$ & $<0.0009$ & $<0.001$ & n.a. & $<0.001$ & $<0.13$ \\
\hline 6 & 19.5 & 488.8 & 136.4 & 1 & 6.80 & n.c. & 0.01 & 0.06 & $<0.002$ & 0.04 & $<0.0009$ & 5.4 & 0.01 & 0.1 & $<0.0005$ & $<0.0009$ & $<0.001$ & n.a. & $<0.001$ & $<0.13$ \\
\hline 7 & 351.8 & 488.8 & 160.5 & 1 & 5.50 & 6.24 & $<0.001$ & 0.08 & 0.006 & 0.4 & $<0.0009$ & 17.2 & 0.3 & 1 & 0.003 & $<0.0009$ & $<0.001$ & 0.02 & 0.006 & 0.3 \\
\hline 8 & 350.4 & 488.9 & 184.3 & 1 & 7.13 & 6.37 & 0.1 & 0.06 & 0.01 & 0.1 & $<0.0009$ & 14.6 & 0.2 & 0.8 & $<0.0005$ & $<0.0009$ & $<0.001$ & 0.04 & 0.01 & 0.1 \\
\hline 9 & 350.6 & 488.9 & 211.6 & 1 & 7.59 & 6.09 & 0.8 & 0.05 & $<0.002$ & 0.1 & $<0.0009$ & 7.8 & 0.2 & 0.5 & $<0.0005$ & $<0.0009$ & $<0.001$ & 0.04 & $<0.001$ & $<0.13$ \\
\hline 10 & 350.2 & 488.9 & 232.8 & 1 & 8.41 & 6.31 & 0.8 & 0.04 & 0.007 & 0.2 & $<0.0009$ & 1.4 & 0.2 & 0.3 & $<0.0005$ & $<0.0009$ & 0.09 & 0.03 & $<0.001$ & 0.2 \\
\hline 11 & 350.6 & 489.0 & 256.5 & 1 & 8.50 & 6.08 & 1.5 & 0.06 & 0.009 & 0.3 & $<0.0009$ & 1.7 & 0.3 & 0.4 & $<0.0005$ & $<0.0009$ & 0.1 & 0.02 & $<0.001$ & $<0.13$ \\
\hline 12 & 350.7 & 488.9 & 280.5 & 1 & 8.59 & 6.16 & 1.1 & 0.04 & 0.005 & 0.1 & $<0.0009$ & 16.6 & 0.2 & 0.3 & 0.004 & $<0.0009$ & 0.03 & 0.01 & $<0.001$ & $<0.13$ \\
\hline 13 & 350.6 & 489.0 & 304.0 & 1 & 8.78 & 6.18 & 1.5 & 0.02 & $<0.002$ & n.a. & $<0.0009$ & 3 & 0.2 & 0.2 & $<0.0005$ & $<0.0009$ & $<0.001$ & 0.05 & $<0.001$ & $<0.13$ \\
\hline 14 & 350.2 & 489.0 & 328.3 & 1 & 8.88 & 6.14 & 1.7 & $<0.004$ & $<0.002$ & 0.1 & $<0.0009$ & 1 & 0.2 & 0.2 & $<0.0005$ & $<0.0009$ & $<0.001$ & 0.02 & $<0.001$ & 0.1 \\
\hline 15 & 350.4 & 488.9 & 353.0 & 1 & 8.96 & 6.08 & 1.5 & 0.03 & $<0.002$ & 0.1 & $<0.0009$ & 1.1 & 0.2 & 0.2 & $<0.0005$ & $<0.0009$ & $<0.001$ & 0.04 & 0.008 & $<0.13$ \\
\hline 16 & 350.8 & 489.1 & 378.2 & 1 & 9.07 & 5.79 & 1.6 & 0.04 & $<0.002$ & 0.003 & $<0.0009$ & 1.1 & 0.2 & 0.2 & $<0.0005$ & $<0.0009$ & $<0.001$ & 0.02 & $<0.001$ & $<0.13$ \\
\hline 17 & 350.7 & 488.9 & 403.6 & 1 & 9.22 & 5.82 & 2 & 0.04 & 0.02 & 0.03 & $<0.0009$ & 0.4 & 0.4 & 0.1 & $<0.0005$ & $<0.0009$ & 0.05 & 0.01 & $<0.001$ & 0.2 \\
\hline 18 & 350.6 & 489.0 & 424.3 & 1 & 9.39 & 5.50 & 2.3 & $<0.004$ & $<0.002$ & $<0.003$ & $<0.0009$ & 2.1 & 1 & 0.2 & 0.007 & $<0.0009$ & 0.02 & 0.01 & $<0.001$ & $<0.13$ \\
\hline 19 & 350.4 & 488.9 & 449.2 & 1 & 9.35 & 5.31 & 2.8 & $<0.004$ & $<0.002$ & 0.04 & $<0.0009$ & 1.4 & 1.5 & 0.2 & $<0.0005$ & 0.006 & 0.03 & 0.01 & $<0.001$ & 0.1 \\
\hline 20 & 350.6 & 489.1 & 472.5 & 1 & 9.48 & 5.30 & 3.3 & $<0.004$ & $<0.002$ & 0.002 & $<0.0009$ & 0.9 & 0.7 & 0.1 & $<0.0005$ & $<0.0009$ & $<0.001$ & 0.003 & $<0.001$ & 0.1 \\
\hline 21 & 350.8 & 488.9 & 496.3 & 1 & 9.47 & 5.52 & 3.2 & 0.03 & $<0.002$ & 0.01 & $<0.0009$ & 10.4 & 0.4 & 0.1 & 0.003 & $<0.0009$ & 0.04 & 0.02 & 0.33 & $<0.13$ \\
\hline 22 & 350.7 & 488.9 & 519.3 & 1 & 9.52 & 5.49 & 3.1 & 0.06 & $<0.002$ & 0.1 & $<0.0009$ & 20.5 & 0.4 & 0.1 & 0.004 & $<0.0009$ & 0.02 & 0.01 & n.a. & $<0.13$ \\
\hline 23 & 350.5 & 489.6 & 546.3 & 1 & 9.64 & 5.65 & 0.6 & 0.02 & 0.005 & 0.1 & $<0.0009$ & 0.4 & 0.03 & 0.004 & 0.003 & $<0.0009$ & $<0.001$ & 0.005 & $<0.001$ & $<0.13$ \\
\hline 24 & 350.5 & 489.6 & 572.4 & 1 & 9.53 & 5.46 & 3.7 & $<0.004$ & 0.005 & 0.04 & $<0.0009$ & 9.6 & 0.2 & 0.1 & $<0.0005$ & $<0.0009$ & $<0.001$ & 0.01 & 0.007 & $<0.13$ \\
\hline 25 & 350.7 & 489.5 & 592.6 & 1 & 9.59 & 5.48 & 3.7 & $<0.004$ & 0.005 & 0.03 & $<0.0009$ & 12.2 & 0.2 & 0.1 & 0.004 & 0.005 & $<0.001$ & 0.02 & 0.03 & $<0.13$ \\
\hline 26 & 350.9 & 489.5 & 616.8 & 1 & 9.60 & 5.46 & 3.6 & $<0.004$ & 0.01 & 0.1 & $<0.0009$ & 10.2 & 0.2 & 0.1 & 0.004 & $<0.0009$ & 0.03 & 0.01 & 0.02 & $<0.13$ \\
\hline 27 & 350.7 & 488.1 & 644.5 & 1 & 9.62 & 5.64 & 4 & $<0.004$ & $<0.002$ & 0.1 & 1.7 & 9.6 & 0.2 & 0.1 & $<0.0005$ & $<0.0009$ & 0.005 & 0.01 & 0.03 & 0.1 \\
\hline 28 & 350.4 & 488.6 & 664.5 & 1 & 9.65 & 5.46 & 3.8 & $<0.004$ & 0.007 & $<0.003$ & $<0.0009$ & 7.5 & 0.2 & 0.1 & $<0.0005$ & 0.009 & 0.02 & 0.01 & 0.007 & $<0.13$ \\
\hline 29 & 350.6 & 489.5 & 688.3 & 1 & 9.61 & 5.48 & 3.9 & $<0.004$ & 0.01 & $<0.003$ & $<0.0009$ & 7.4 & 0.2 & 0.1 & $<0.0005$ & $<0.0009$ & $<0.001$ & 0.02 & $<0.001$ & $<0.13$ \\
\hline
\end{tabular}



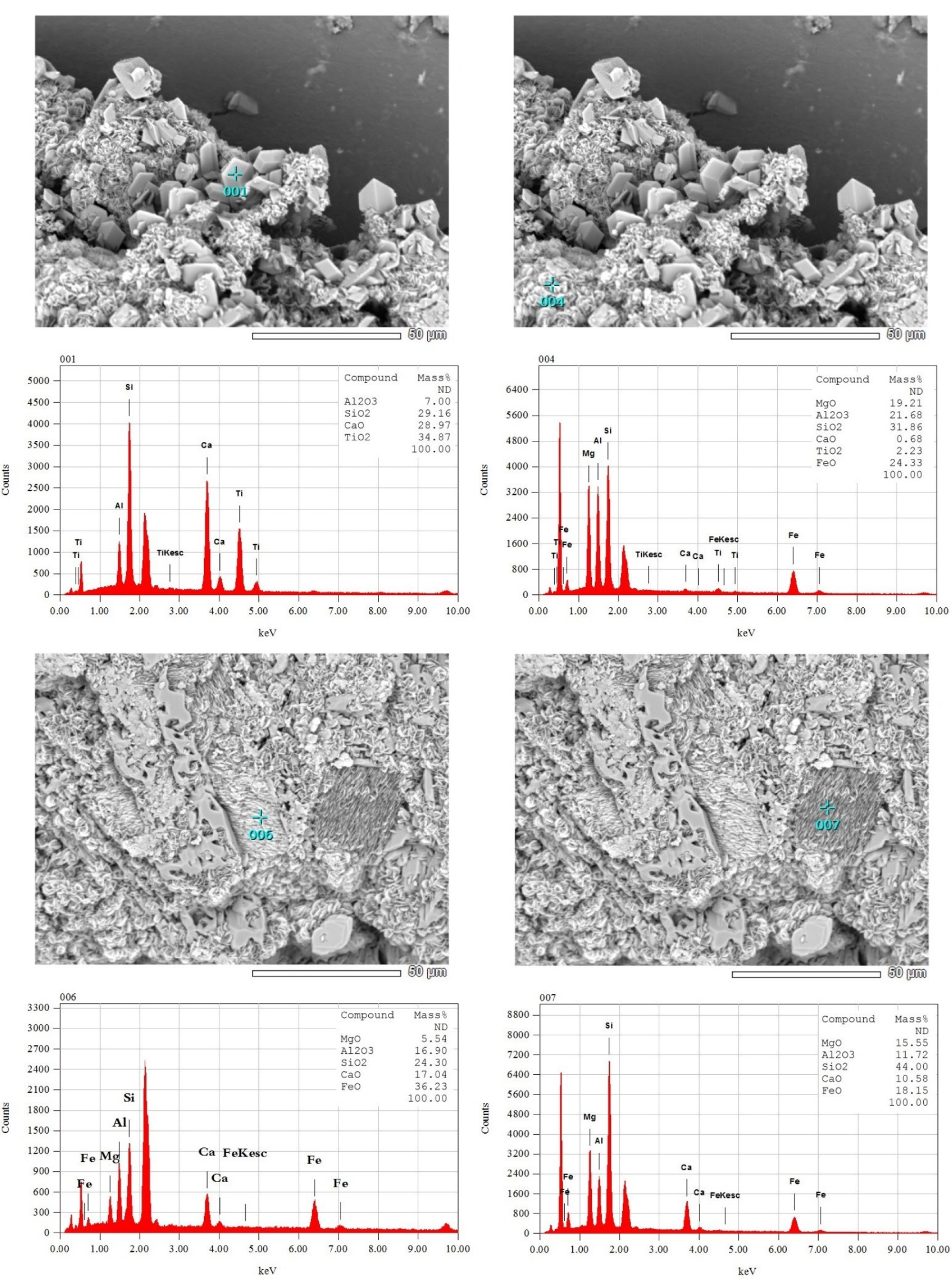
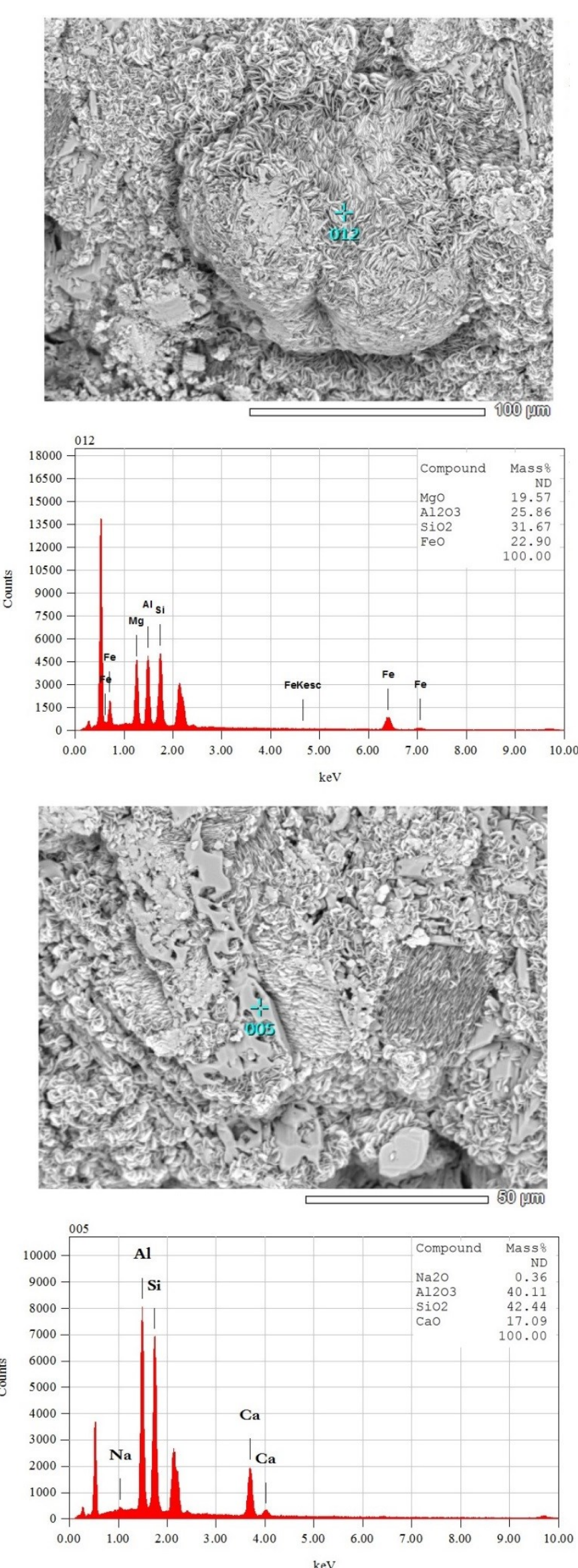
Figure B.3.22. EDS analysis for the study of morphology of reacted grains collected from the bottom portion of Reactor
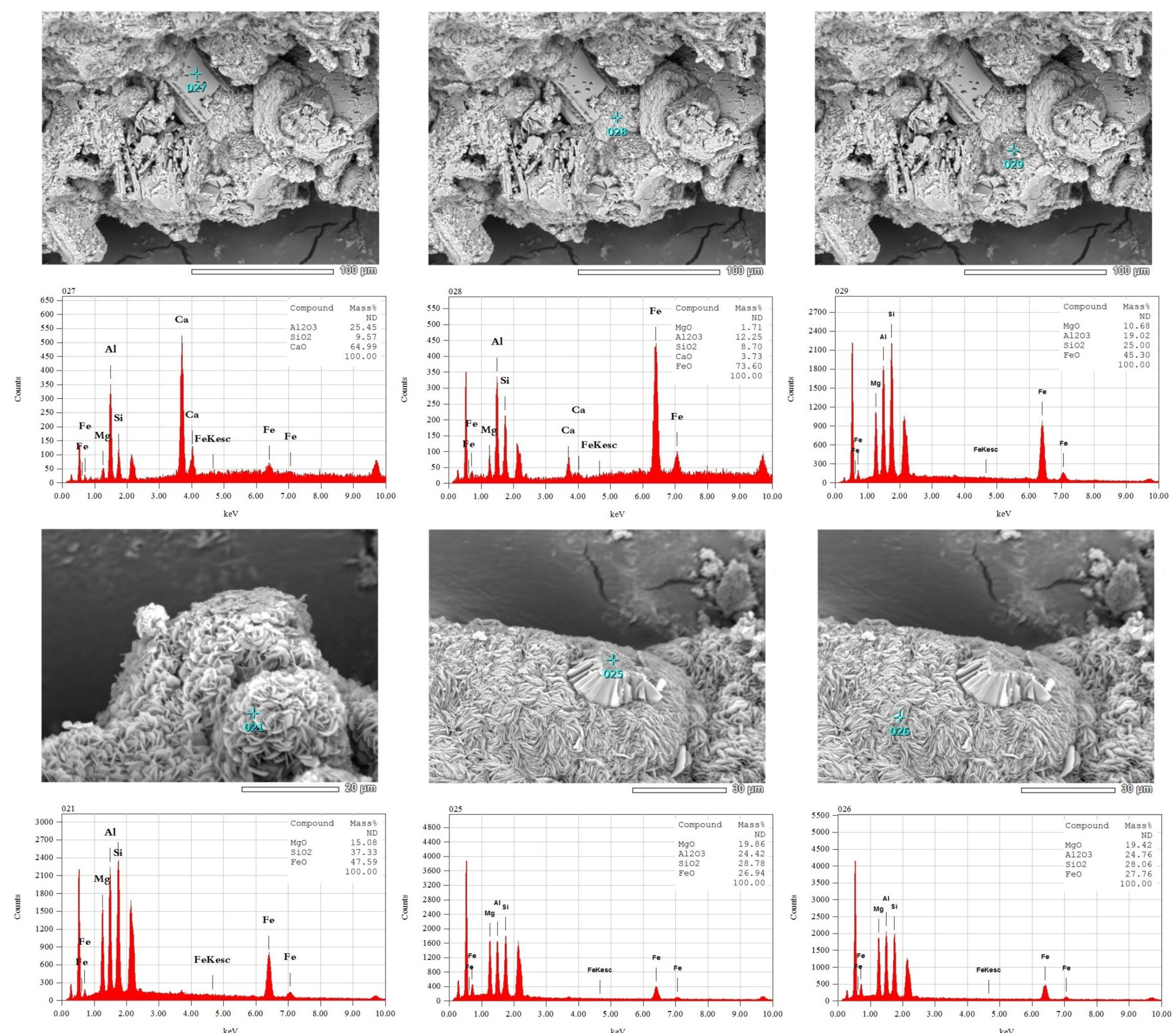


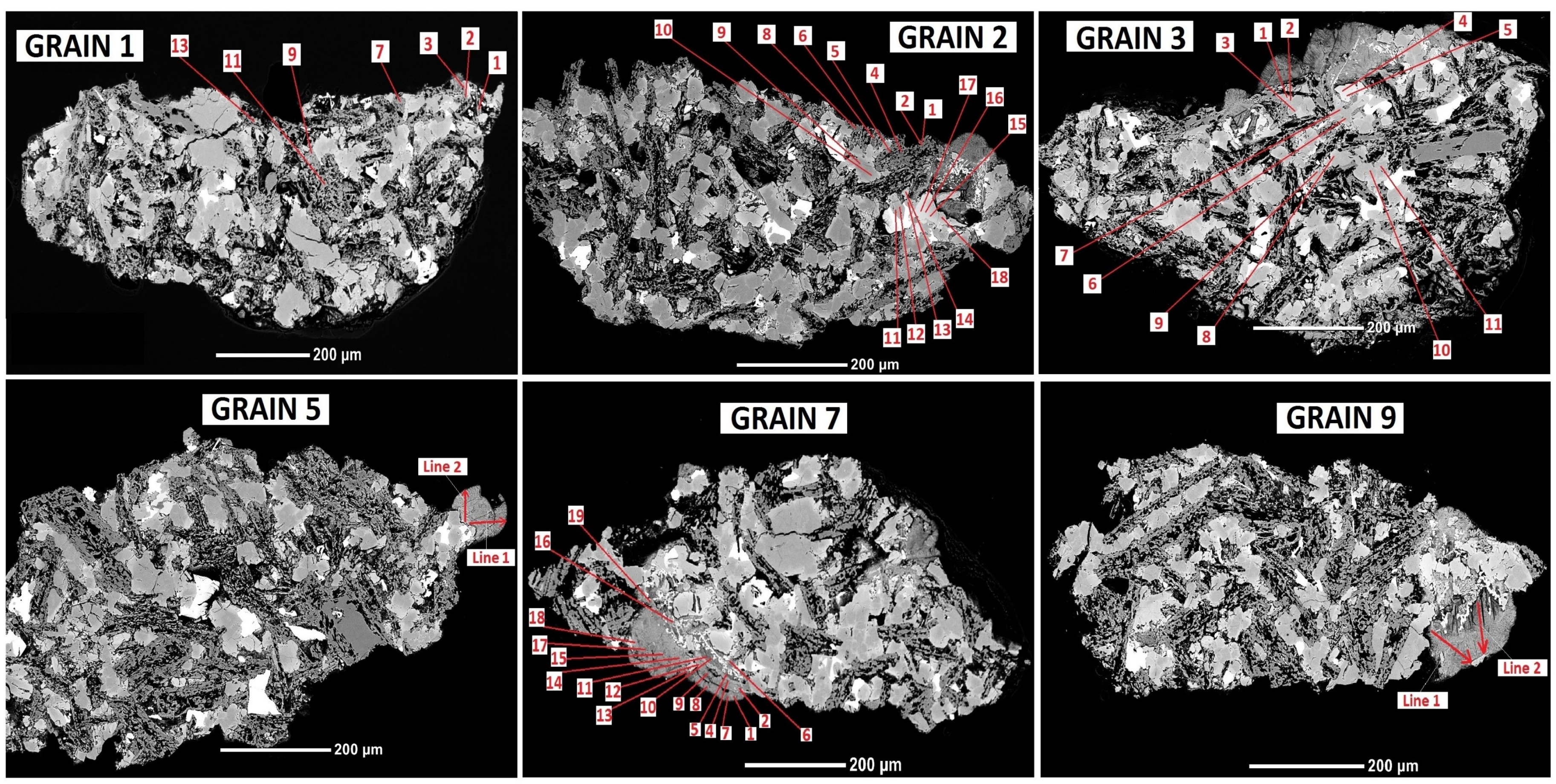


Table B.3.11. EMPA analysis of grains 1-3-4-5-7-9-10 in Figure B.3.23

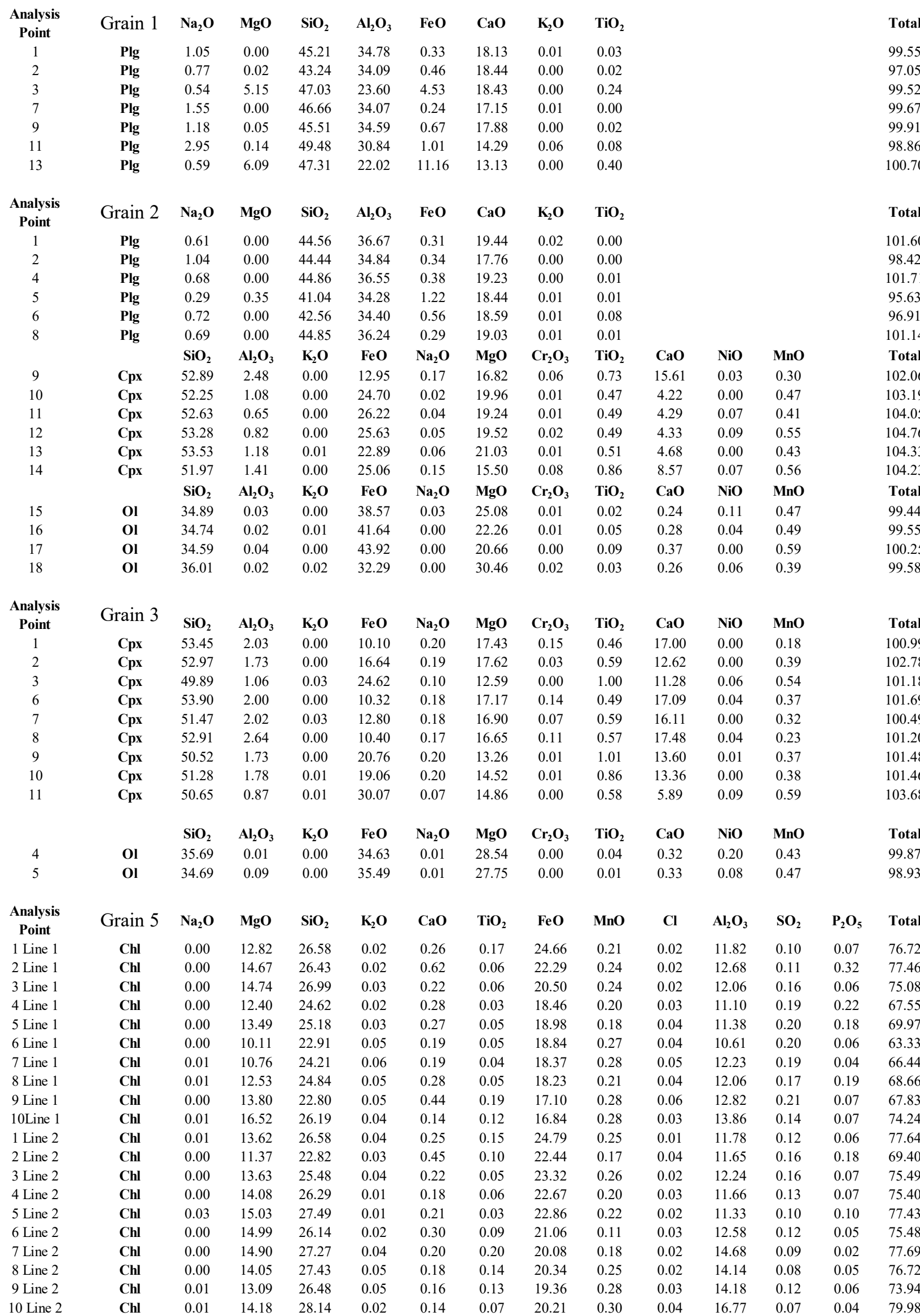

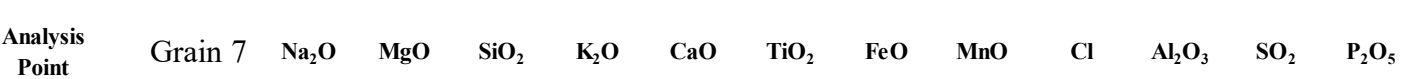
$\begin{array}{lllllllllllll}\mathrm{Chl} & 0.00 & 15.10 & 24.16 & 0.02 & 0.11 & 0.10 & 18.71 & 0.32 & 0.04 & 14.91 & 0.17 & 0.03 \\ \mathrm{Chl} & 0.00 & 16.82 & 27.36 & 0.02 & 0.58 & 0.11 & 20.20 & 0.27 & 0.03 & 14.91 & 0.11 & 0.05\end{array}$ $\begin{array}{lllllllllllll}\mathrm{Chl} & 0.00 & 13.95 & 22.69 & 0.00 & 0.29 & 0.25 & 17.20 & 0.23 & 0.05 & 14.88 & 0.18 & 0.03 \\ \mathrm{Chl} & 0.00 & 20.75 & 28.38 & 0.00 & 0.19 & 0.02 & 14.21 & 0.19 & 0.05 & 9.90 & 0.20 & 0.03\end{array}$ $\begin{array}{lllllllllllll}\text { Chl } & 0.00 & 17.82 & 27.78 & 0.02 & 0.18 & 0.03 & 17.64 & 0.22 & 0.04 & 9.84 & 0.14 & 0.04 \\ \mathrm{Chl} & 0.00 & 20.83 & 29.20 & 0.02 & 0.16 & 0.09 & 1.52 & 0.34 & 0.02 & 15.97 & 0.09 & 0.02\end{array}$ $\begin{array}{lllllllllllll}\mathrm{Chl} & 0.00 & 20.83 & 29.20 & 0.02 & 0.16 & 0.09 & 12.52 & 0.34 & 0.02 & 15.97 & 0.09 & 0.02 \\ \mathrm{Chl} & 0.00 & 17.01 & 25.66 & 0.00 & 0.06 & 0.08 & 17.21 & 0.27 & 0.07 & 15.85 & 0.14 & 0.03\end{array}$

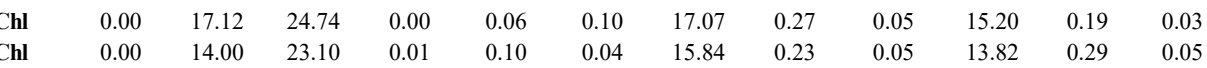
$\begin{array}{lllllllllllll}\mathrm{Chl} & 0.01 & 21.05 & 33.31 & 0.03 & 0.24 & 0.02 & 21.78 & 0.24 & 0.02 & 12.91 & 0.05 & 0.01 \\ \mathrm{Chl} & 0.00 & 1716 & 2.30 & 0.02 & 0.202 & 0.00 & 1047 & 0.09 & 0.03 & 374 & 07 & 0.03\end{array}$

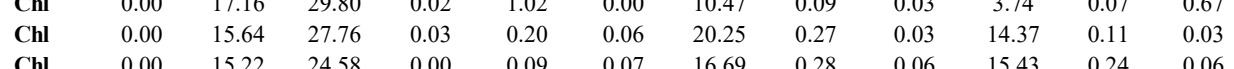
$\begin{array}{lllllllllllll}\mathrm{Chl} & 0.00 & 15.22 & 24.58 & 0.00 & 0.09 & 0.07 & 16.69 & 0.28 & 0.06 & 15.43 & 0.24 & 0.06 \\ \mathrm{Chl} & 0.00 & 15.07 & 25.20 & 0.00 & 0.14 & 0.04 & 18.76 & 0.27 & 0.03 & 13.58 & 0.15 & 0.05\end{array}$

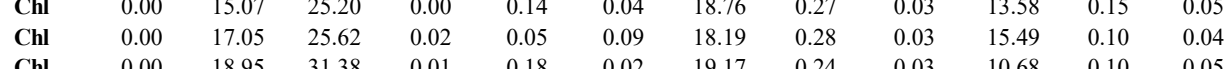
$\begin{array}{lllllllllllll}\text { Chl } & 0.00 & 18.95 & 31.38 & 0.01 & 0.18 & 0.02 & 19.17 & 0.24 & 0.03 & 10.68 & 0.10 & 0.05 \\ \mathrm{Chl} & 0.00 & 15.18 & 2.55 & 0.01 & 0.13 & 0.06 & 18.05 & 0.25 & 0.05 & 14.14 & 0.17 & 0.07\end{array}$

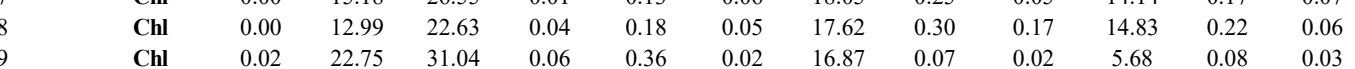

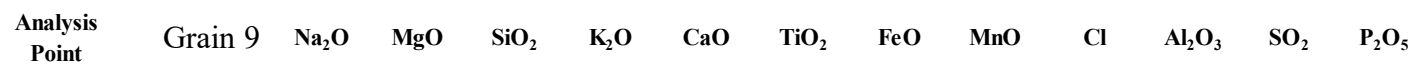
$\begin{array}{llllllllllllll}\begin{array}{l}\text { Point } \\ 1 \text { Line 1 }\end{array} & \text { Chl } & 0.00 & 17.97 & 27.21 & 0.01 & 0.24 & 0.05 & 16.18 & 0.29 & 0.02 & 13.85 & 0.11 & 0.00 \\ 2 \text { Line } 1 & \text { Chl } & 0.00 & 1735 & 30.48 & 0.02 & 0.47 & 0.03 & 1723 & 0.24 & 0.03 & 1098 & 0.09 & 0.11\end{array}$ $\begin{array}{llllllllllllll}2 \text { Line 1 } & \text { Chl } & 0.00 & 17.35 & 30.48 & 0.02 & 0.47 & 0.03 & 17.23 & 0.24 & 0.03 & 10.98 & 0.09 & 0.11 \\ 3 \text { Line 1 } & \text { Chl } & 0.00 & 18.35 & 30.45 & 0.02 & 0.49 & 0.05 & 19.01 & 0.19 & 0.03 & 11.24 & 0.08 & 0.11\end{array}$

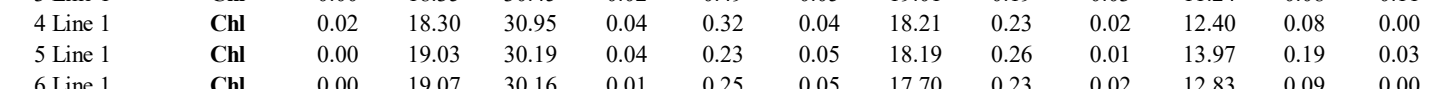
$\begin{array}{llllllllllllll}6 \text { L Line 1 } & \text { Chl } & 0.00 & 19.07 & 30.16 & 0.01 & 0.25 & 0.05 & 17.70 & 0.23 & 0.02 & 12.83 & 0.09 & 0.00 \\ 7 \text { Line 1 } & \text { Chl } & 0.00 & 16.83 & 27.87 & 0.04 & 0.34 & 0.18 & 16.09 & 0.21 & 0.01 & 12.27 & 0.13 & 0.03\end{array}$

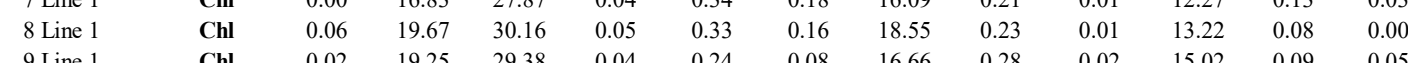
$\begin{array}{llllllllllllll}9 \text { Linn 1 } & \text { Chl } & 0.02 & 19.25 & 29.38 & 0.04 & 0.24 & 0.08 & 16.66 & 0.28 & 0.02 & 15.02 & 0.09 & 0.05 \\ 10 \text { Line 1 } & \text { Chl } & 0.00 & 16.26 & 25.34 & 0.02 & 0.24 & 0.34 & 20.08 & 0.26 & 0.02 & 14.62 & 0.11 & 0.03\end{array}$ 11 Line 1
12 Line 1

1 Line 2
2 Line 2
3 Line 2

4 Line 2
5 Line 2
6 Line 2

6 Line 2
7 Line 2
8 Line 2
9 Line 2

9 Line 2
10 Line 2

11 Line 2
13 Line 2
13 Line 2

14 Line 2
15 Line 2
16 Line 2

17 Line 2

$\begin{array}{llllllllllllllll}\mathrm{Na}_{2} \mathrm{O} & \mathrm{MgO} & \mathrm{SiO}_{2} & \mathrm{~K}_{2} \mathrm{O} & \mathrm{CaO} & \mathrm{TiO}_{2} & \mathrm{FeO} & \mathrm{Al}_{2} \mathrm{O}_{3} & \mathrm{MnO} & \mathrm{NiO} & \mathrm{Cr}_{2} \mathrm{O}_{3} & \mathrm{Cl} & \mathrm{SO}_{2} & \mathrm{P}_{2} \mathrm{O}_{5}\end{array}$ $\begin{array}{llllllllllll}\mathrm{Plg} & 0.97 & 0.91 & 45.13 & 0.01 & 17.69 & 0.07 & 1.65 & 32.84 & & & \\ \mathrm{Cpx} & 0.13 & 16.87 & 52.24 & 0.01 & 11.07 & 0.65 & 19.48 & 1.56 & 0.41 & 0.03 & 0.05 \\ \mathrm{Ol} & 0.01 & 25.79 & 35.10 & 0.01 & 0.30 & 0.04 & 37.76 & 0.04 & 0.47 & 0.08 & 0.01\end{array}$

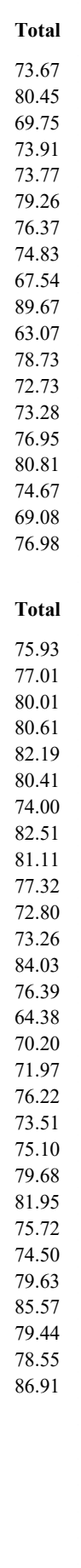


Table B.3.12. Average mineral compositions determined by EMPA from Table B.3.11

\begin{tabular}{|c|c|c|c|c|}
\hline Oxides & average $w t \%$ & average $w t \%$ & average $w t \%$ & average wt $\%$ \\
\hline $\mathrm{Na}_{2} \mathrm{O}$ & 0.97 & 0.13 & 0.01 & 0.03 \\
\hline $\mathrm{MgO}$ & 0.91 & 16.87 & 25.79 & 16.16 \\
\hline $\mathrm{SiO}_{2}$ & 45.13 & 52.24 & 35.10 & 28.44 \\
\hline $\mathrm{K}_{2} \mathrm{O}$ & 0.01 & 0.01 & 0.01 & 0.04 \\
\hline $\mathrm{CaO}$ & 17.69 & 11.07 & 0.30 & 0.99 \\
\hline $\mathrm{TiO}_{2}$ & 0.07 & 0.65 & 0.04 & 0.15 \\
\hline $\mathrm{FeO}_{(\mathrm{T})}$ & 1.65 & 19.48 & 37.76 & 17.57 \\
\hline $\mathrm{MnO}$ & & 0.41 & 0.47 & 0.23 \\
\hline $\mathrm{Cl}$ & & & & 0.03 \\
\hline $\mathrm{Al}_{2} \mathrm{O}_{3}$ & 32.84 & 1.56 & 0.04 & 11.81 \\
\hline $\mathrm{NiO}$ & & 0.03 & 0.08 & \\
\hline $\mathrm{Cr}_{2} \mathrm{O}_{3}$ & & 0.05 & 0.01 & \\
\hline $\mathrm{SO}_{2}$ & & & & 0.13 \\
\hline $\mathrm{P}_{2} \mathrm{O}_{5}$ & & & & 0.07 \\
\hline Total & 99.28 & 102.50 & 99.61 & 75.65 \\
\hline $\begin{array}{l}\text { Mineral } \\
\text { Oomposition }\end{array}$ & $\begin{array}{r}\mathrm{Ca}_{0.88} \mathrm{Na}_{0.09} \mathrm{Mg}_{0.06} \mathrm{Fe}^{3+}{ }_{0.06} \mathrm{Ti}_{0.002} \mathrm{Al}_{1.8} \mathrm{Si}_{2.1} \mathrm{O}_{8} \\
\left(\mathrm{An}_{91}-\mathrm{Ab}_{9}\right)\end{array}$ & $\mathrm{Na}_{0.09} \mathrm{Ca}_{0.44} \mathrm{Mg}_{0.93} \mathrm{Fe}_{0.60} \mathrm{Mn}_{0.01} \mathrm{Cr}_{0.001} \mathrm{Ti}_{0.18} \mathrm{Si}_{1.93} \mathrm{Al}_{0.07} \mathrm{O}_{6}$ & $\begin{array}{c}\mathrm{Ca}_{0.008} \mathrm{Mn}_{0.008} \mathrm{Fe}^{2+}{ }_{0.542} \mathrm{Mg}_{1.434} \mathrm{Fe}^{3+}{ }_{0.015} \mathrm{Si}_{0.99} \mathrm{Al}_{0.001} \mathrm{O}_{4} \\
\left(\mathrm{Fo}_{72}-\mathrm{Fa}_{28}\right)\end{array}$ & $\begin{array}{r}\mathrm{Ca}_{0.25} \mathrm{~K}_{0.01} \mathrm{Na}_{0.01} \mathrm{Mn}_{0.05} \mathrm{Mg}_{5.77} \mathrm{Fe}_{3.49} \mathrm{Ti}_{0.03} \mathrm{Al}_{2.00} \mathrm{Si}_{6.75} \mathrm{Al}_{1.25} \mathrm{O}_{20}(\mathrm{OH})_{16} \\
\text { (on the basis of } 28 \text { oxygen equivalents, ignoring } \mathrm{H}_{2} \mathrm{O} \text { ) }\end{array}$ \\
\hline hase and ID & $\begin{array}{c}\text { Plagioclase } \\
\text { (anorthite) }\end{array}$ & $\begin{array}{c}\text { Clinopyroxene } \\
\text { (augite) }\end{array}$ & $\begin{array}{c}\text { Mg-olivine } \\
\text { (forsterite) }\end{array}$ & Chlorite \\
\hline
\end{tabular}



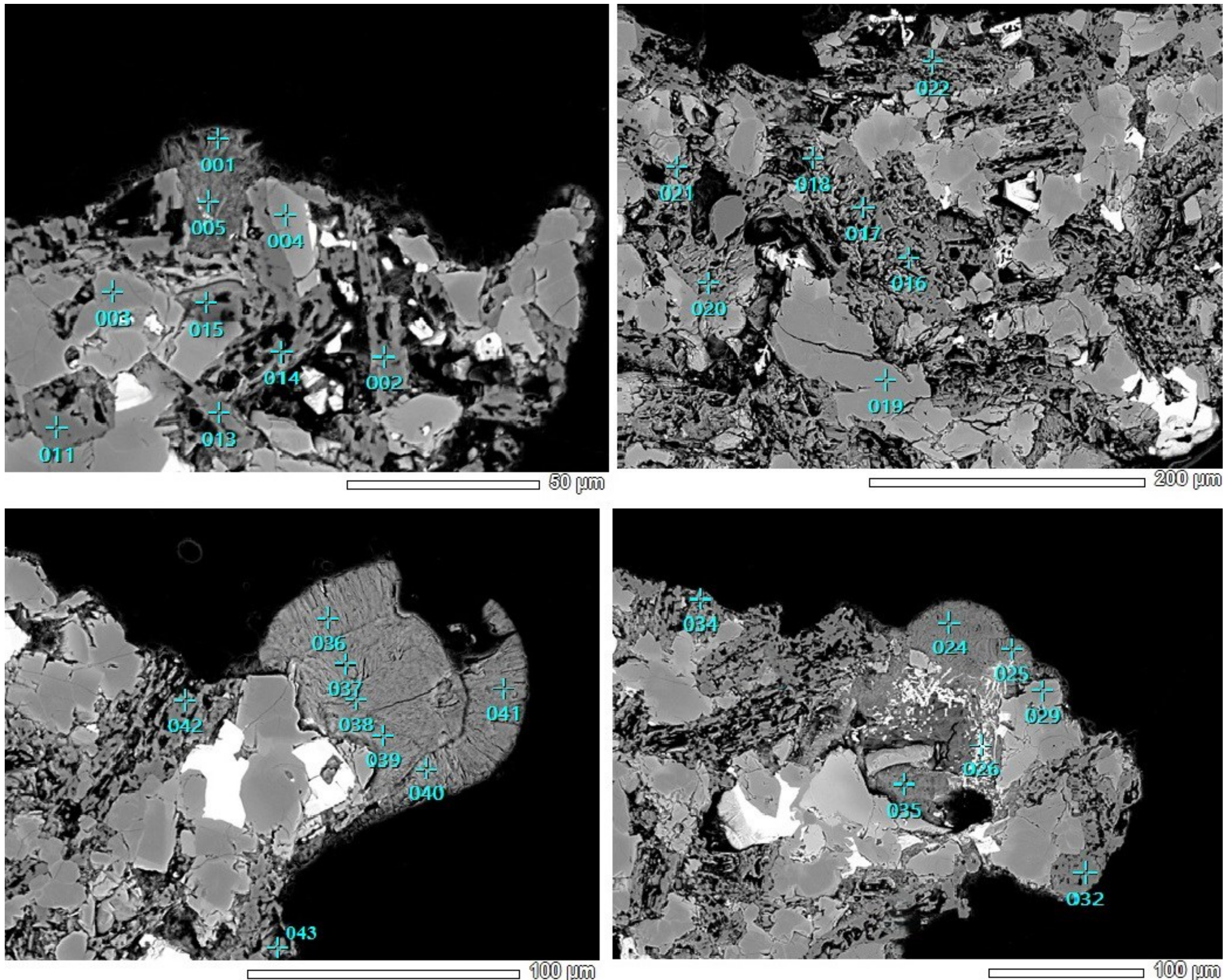
Table B.3.13. EDS analysis and average mineral compositions of grains in Figure B.3.24

\begin{tabular}{|c|c|c|c|c|c|c|c|c|c|c|c|}
\hline & $\begin{array}{c}\text { Analysis } \\
\text { Point }\end{array}$ & $\mathrm{Na}_{2} \mathrm{O}$ & $\mathbf{A l}_{2} \mathbf{O}_{3}$ & $\mathrm{SiO}_{2}$ & $\mathrm{CaO}$ & & Total & Oxides & average $w t \%$ & average $w t \%$ & average $\mathrm{wt} \%$ \\
\hline \multirow[t]{15}{*}{ Plg } & 2 & 0.94 & 37.31 & 44.18 & 17.58 & & 100.00 & $\mathrm{Na}_{2} \mathrm{O}$ & 0.63 & & \\
\hline & 11 & 0.83 & 37.86 & 43.15 & 18.16 & & 100.00 & $\mathrm{MgO}$ & & 13.56 & 18.48 \\
\hline & 13 & 0.48 & 39.18 & 42.05 & 18.29 & & 100.00 & $\mathrm{SiO}_{2}$ & 42.41 & 55.52 & 36.76 \\
\hline & 14 & 0.67 & 38.74 & 42.95 & 17.63 & & 100.00 & $\mathrm{Al}_{2} \mathrm{O}_{3}$ & 38.51 & 2.65 & 17.13 \\
\hline & 15 & 0.70 & 38.62 & 42.88 & 17.81 & & 100.00 & $\mathrm{FeO}_{\text {(T) }}$ & & 10.09 & 27.63 \\
\hline & 16 & 0.30 & 38.37 & 40.52 & 20.81 & & 100.00 & $\begin{array}{l}\mathrm{CaO} \\
\mathrm{K}_{2} \mathrm{O}\end{array}$ & 18.45 & 18.19 & \\
\hline & 17 & 0.51 & 38.79 & 42.48 & 18.22 & & 100.00 & $\begin{array}{l}\mathrm{N}_{2} \mathrm{U} \\
\mathrm{TiO}_{2}\end{array}$ & & & \\
\hline & 18 & 0.35 & 39.25 & 39.96 & 20.44 & & 100.00 & 1102 & & & \\
\hline & 20 & 1.46 & 37.31 & 45.54 & 15.69 & & 100.00 & Total & 100 & 100 & 100 \\
\hline & 21 & 0.66 & 39.80 & 43.40 & 16.14 & & 100.00 & & & & \\
\hline & 22 & 0.61 & 37.95 & 42.25 & 19.19 & & 100.00 & Mineral & $\mathrm{Ca}_{0.91} \mathrm{Na}_{0.06} \mathrm{Al}_{2.09} \mathrm{Si}_{1.95} \mathrm{O}_{8}$ & 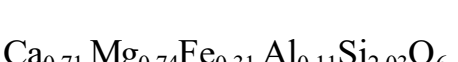 & $\mathrm{Mg}_{4.99} \mathrm{Fe}_{4.19} \mathrm{Al}_{2.32} \mathrm{Si}_{6.66} \mathrm{Al}_{1.34} \mathrm{O}_{20}(\mathrm{OH})_{16}$ \\
\hline & 32 & 0.55 & 38.84 & 41.80 & 18.81 & & 100.00 & Composition & $\left(\mathrm{An}_{94}-\mathrm{Ab}_{6}\right)$ & $\mathfrak{a}_{0.71}+\operatorname{lig}_{0.741} \mathfrak{L}_{0.31}$ & (on the basis of 28 oxygen equivalents, ignoring $\mathrm{H}_{2} \mathrm{O}$ ) \\
\hline & 34 & 0.35 & 37.91 & 39.84 & 21.90 & & 100.00 & & & & \\
\hline & 42 & 0.30 & 39.02 & 41.68 & 19.00 & & 100.00 & Phase and ID & (anorthite) & (limopyroxente & Chlorite \\
\hline & 43 & 0.68 & 38.71 & 43.47 & 17.13 & & 100.00 & & & & \\
\hline \multirow[t]{2}{*}{ average } & & 0.63 & 38.51 & 42.41 & 18.45 & & & & & & \\
\hline & $\begin{array}{c}\text { Analysis } \\
\text { Point }\end{array}$ & MgO & $\mathrm{Al}_{2} \mathbf{O}_{3}$ & $\mathrm{SiO}_{2}$ & $\mathrm{CaO}$ & $\mathrm{FeO}$ & Total & & $\begin{array}{c}\text { point } \mathrm{n}^{\circ} 26 \\
\text { [Oxides wt } \% \text { and }\end{array}$ & & \\
\hline \multirow[t]{4}{*}{ Cpx } & 3 & 14.02 & 2.14 & 55.62 & 20.07 & 8.14 & 100.00 & & elements mass $\%$ and atomic $\%]$ & & \\
\hline & 4 & 13.51 & 1.78 & 56.30 & 11.96 & 16.45 & 100.00 & & & & \\
\hline & 19 & 13.40 & 4.26 & 54.64 & 20.80 & 6.90 & 100.00 & & & & \\
\hline & 29 & 13.30 & 2.40 & 55.50 & 19.93 & 8.87 & 100.00 & & & & \\
\hline \multirow[t]{2}{*}{ average } & & 13.56 & 2.65 & 55.52 & 18.19 & 10.09 & & & $\begin{array}{c}\mathbf{F e O}(\mathrm{wt} \%) 95.10 \\
\text { Fe: }(\mathrm{wt} \%) 73.93-(\mathrm{at} \%) 47.34\end{array}$ & & \\
\hline & $\begin{array}{c}\text { Analysis } \\
\text { Point }\end{array}$ & $\mathrm{TiO}_{2}$ & $\mathrm{FeO}$ & & & & Total & & O: (wt\%) 23.55 - (at\%) 52.66 & & \\
\hline \multirow[t]{2}{*}{$\mathrm{Ox}$} & 26 & & 100.00 & & & & 100.00 & & & & \\
\hline & $\begin{array}{c}\text { Analysis } \\
\text { Point }\end{array}$ & MgO & $\mathrm{Al}_{3} \mathrm{O}_{3}$ & $\mathrm{SiO}_{2}$ & $\mathrm{FeO}$ & & Total & & & & \\
\hline \multirow[t]{11}{*}{ Chl } & 1 & 11.14 & 19.64 & 32.89 & 36.33 & & 100.00 & & $\mathrm{Fe}^{3+}{ }_{2} \mathrm{Fe}^{2+} \mathrm{O}_{4}$ & & \\
\hline & 5 & 13.45 & 15.73 & 33.65 & 37.18 & & 100.00 & & & & \\
\hline & 24 & 25.39 & 20.77 & 37.27 & 16.56 & & 100.00 & & Oxide & & \\
\hline & 25 & 18.30 & 19.21 & 34.96 & 27.53 & & 100.00 & & (magnetite?) & & \\
\hline & 35 & 27.09 & 12.71 & 43.02 & 17.17 & & 100.00 & & & & \\
\hline & 36 & 17.41 & 19.05 & 36.30 & 27.24 & & 100.00 & & & & \\
\hline & 37 & 16.32 & 13.94 & 37.20 & 32.54 & & 100.00 & & & & \\
\hline & 38 & 17.71 & 14.87 & 38.14 & 29.28 & & 100.00 & & & & \\
\hline & 39 & 18.29 & 15.14 & 39.04 & 27.53 & & 100.00 & & & & \\
\hline & 40 & 18.71 & 19.03 & 34.94 & 27.32 & & 100.00 & & & & \\
\hline & 41 & 19.50 & 18.35 & 36.93 & 25.22 & & 100.00 & & & & \\
\hline average & & 18.48 & 17.13 & 36.76 & 27.63 & & 100.00 & & & & \\
\hline
\end{tabular}



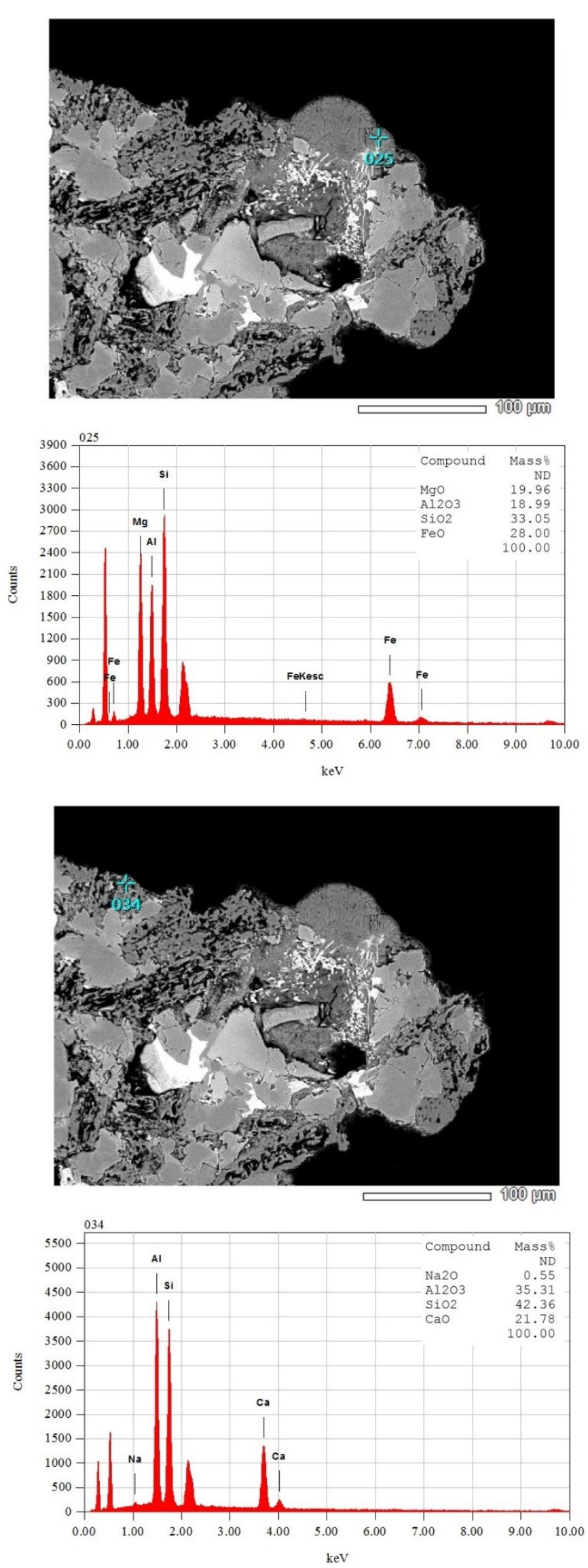
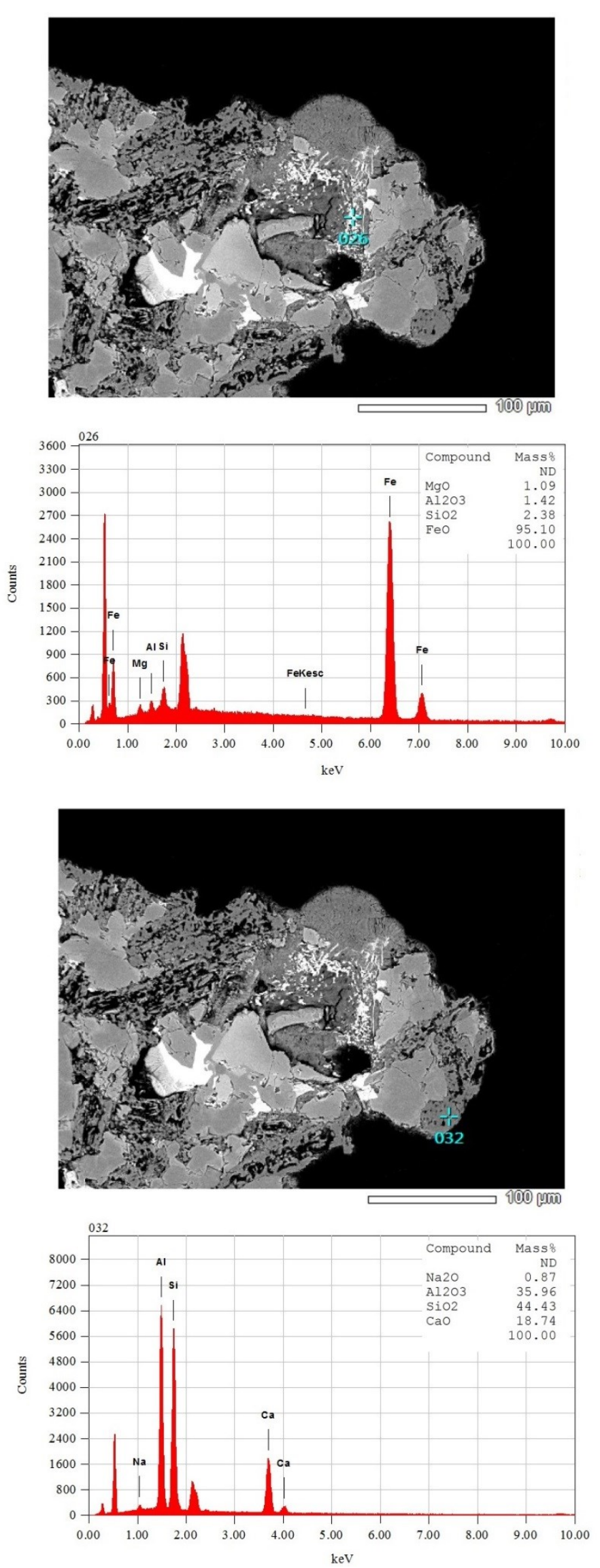
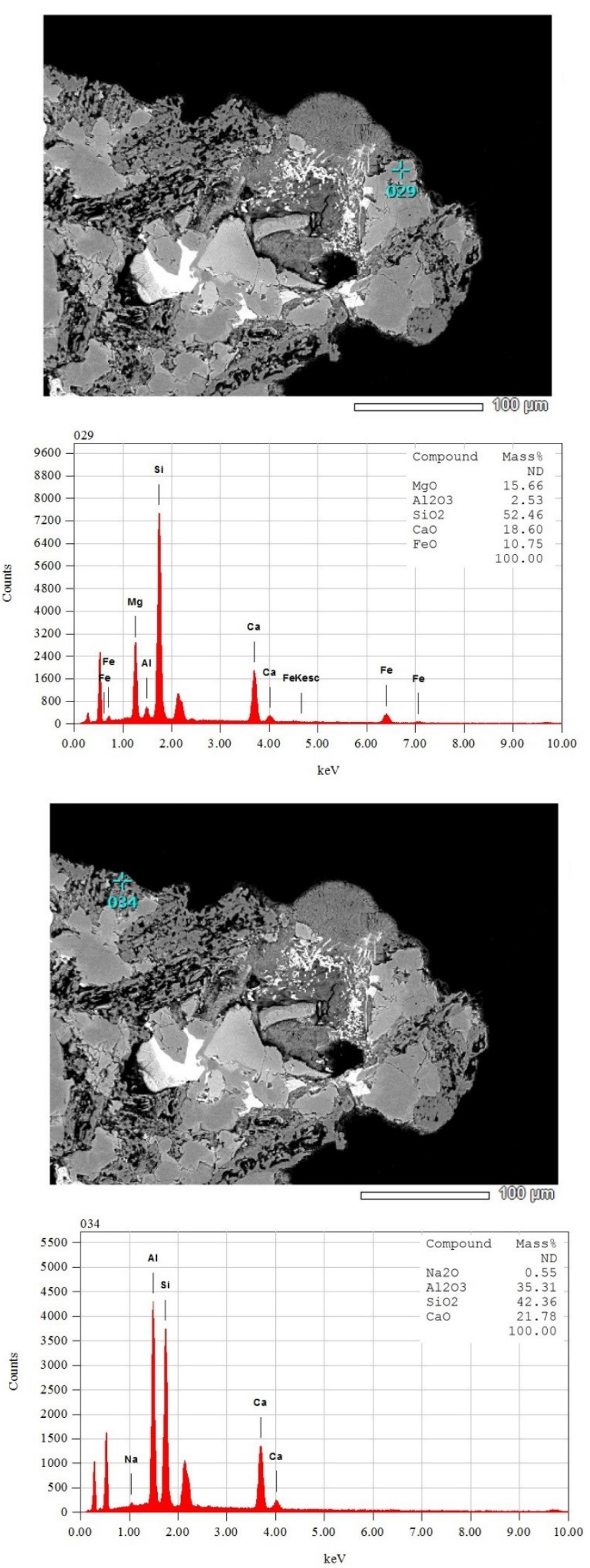


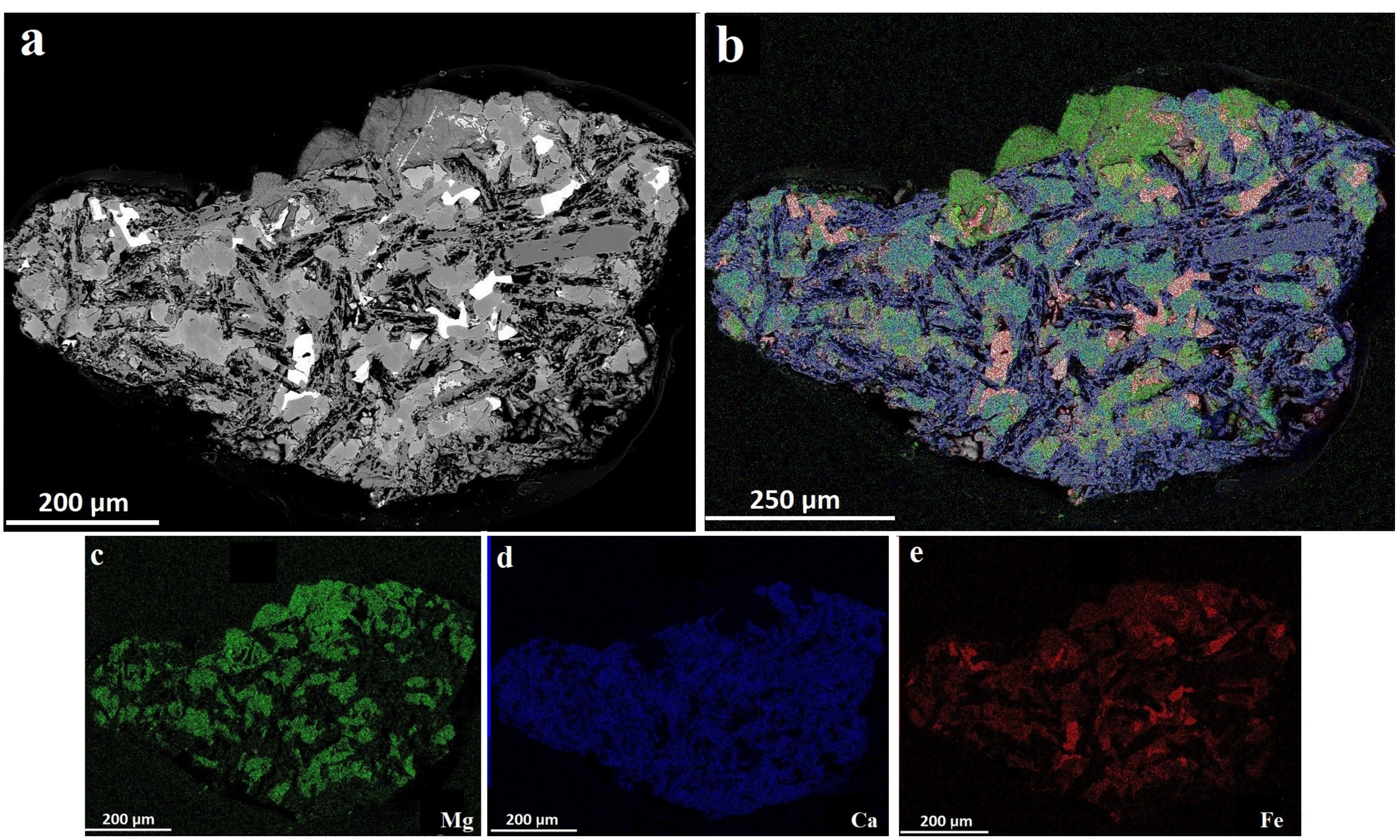


Figure B.3.27. XRD scan showing the mineralogy of reacted grains collected from the bottom portion of Reactor

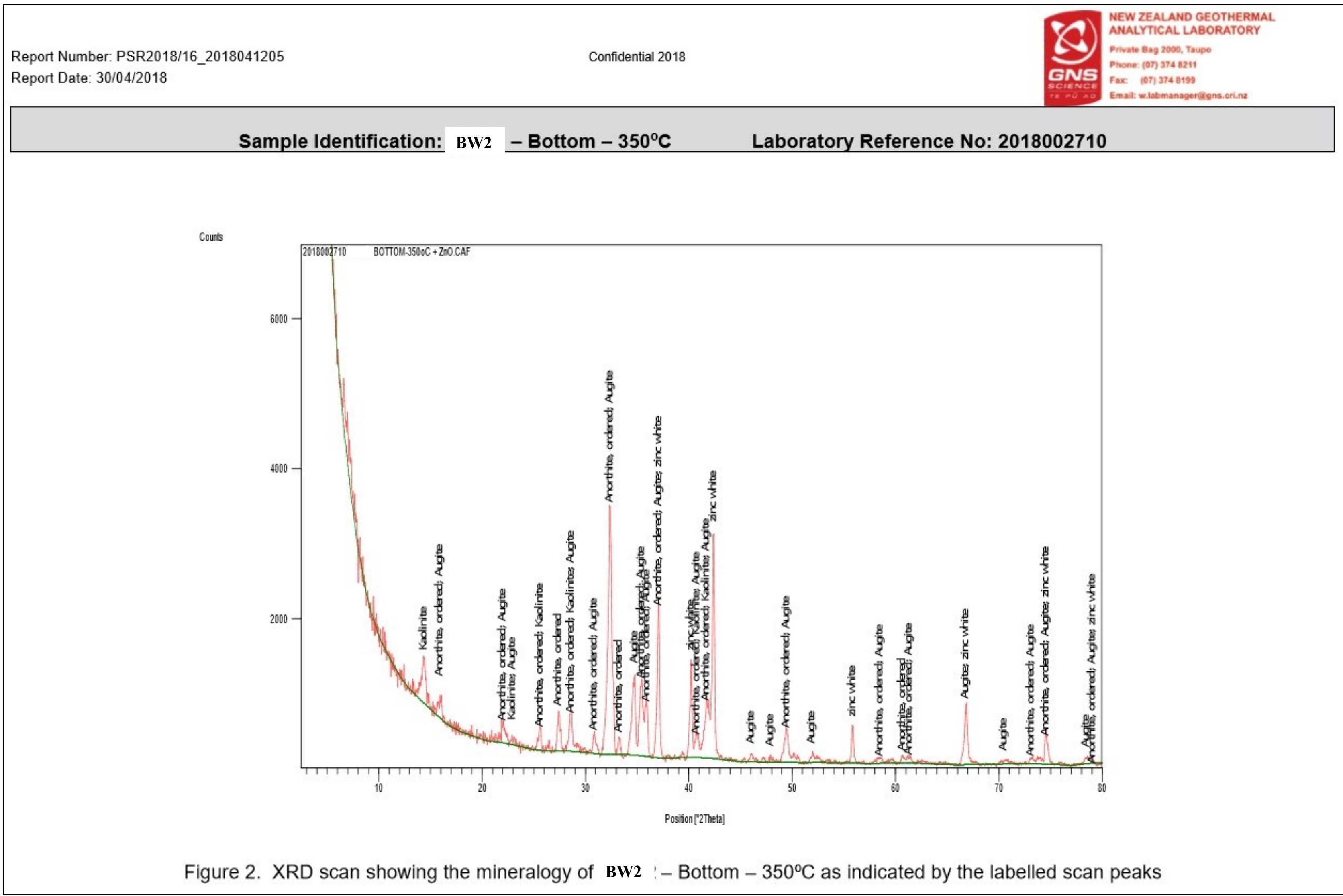


Figure B.3.28. Quantitative XRD analysis of reacted grains collected from the bottom portion of Reactor

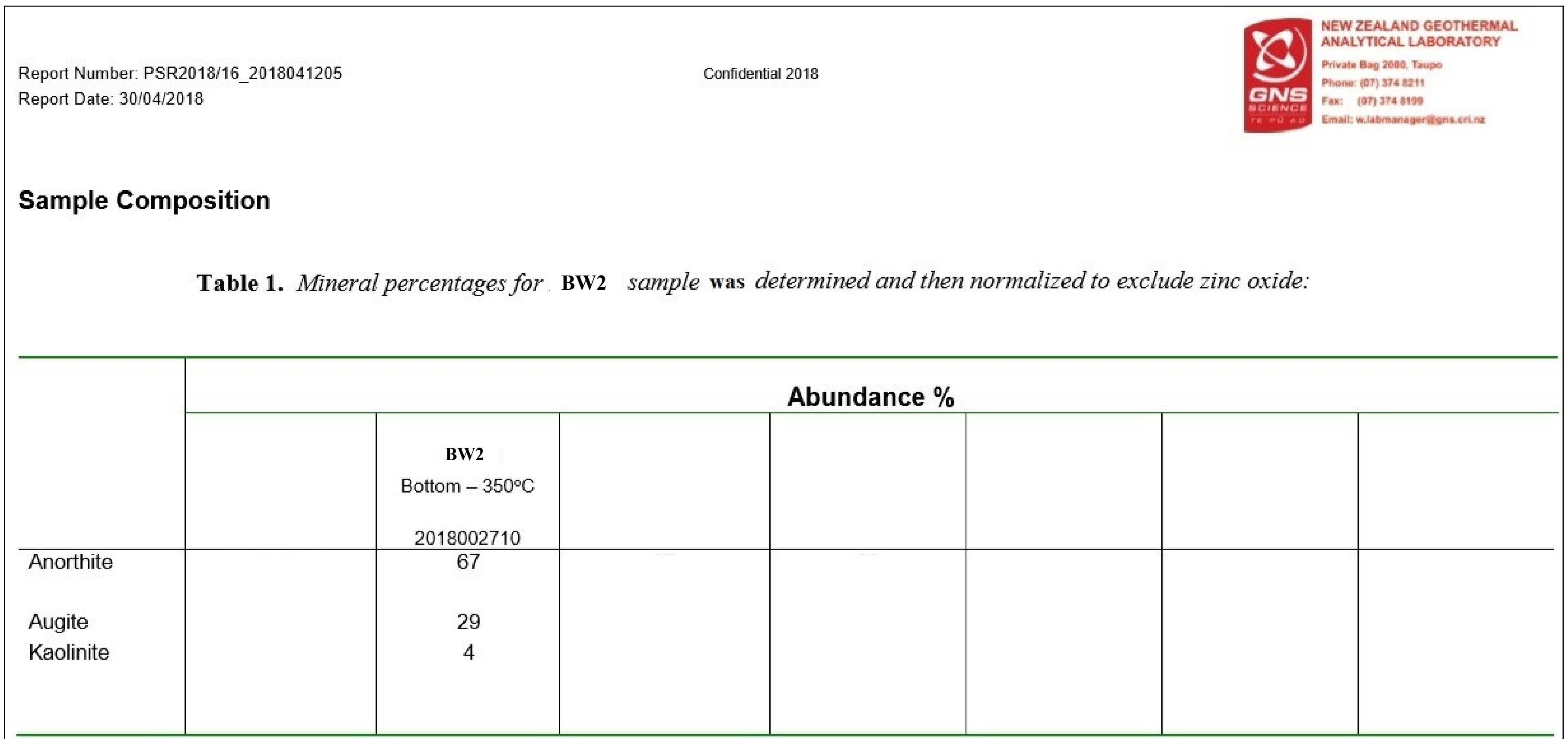

Margin of Error: Abundance estimates are determined through successive refinement of cell parameters; the position, width and orientation of each mineral. Values are given to the nearest whole number. The margin of error for phase concentration is proposed as follows: $0-10 \% \pm 10 \% ; 10-50 \% \pm 5 \% ; 50-100 \% \pm 2 \%$ 

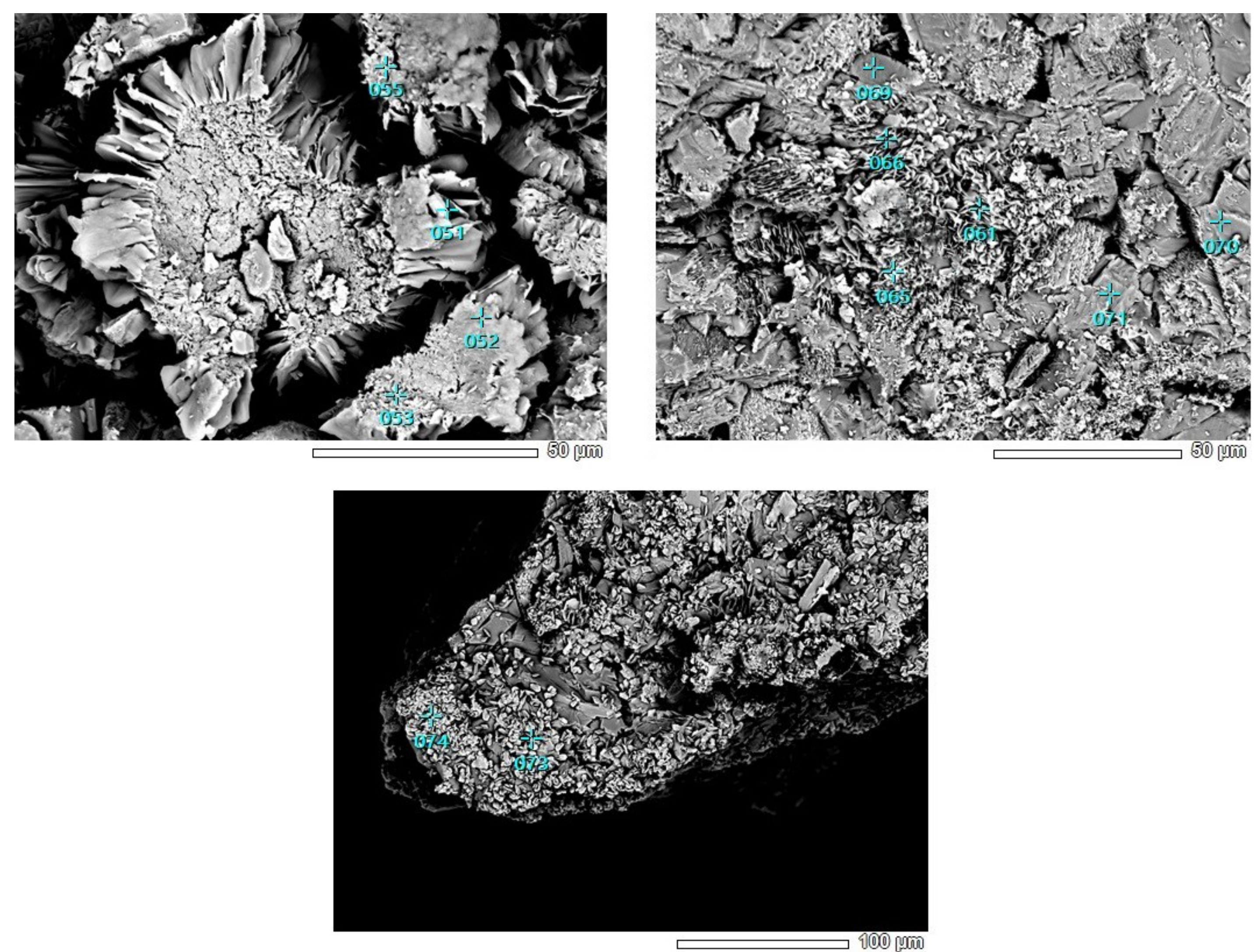
Table B.3.14. EDS analysis and average mineral compositions of grains in Figure B.3.29

\begin{tabular}{|c|c|c|c|c|c|c|c|c|}
\hline \multirow[t]{4}{*}{ Plg } & $\begin{array}{c}\text { Analysis } \\
\text { Point }\end{array}$ & $\mathrm{Na}_{2} \mathrm{O}$ & $\mathrm{Al}_{2} \mathbf{O}_{3}$ & $\mathrm{SiO}_{2}$ & $\mathrm{CaO}$ & & & Total \\
\hline & 69 & 5.27 & 24.92 & 59.96 & 9.85 & & & 100.00 \\
\hline & 70 & 2.41 & 31.26 & 51 & 15.33 & & & 100.00 \\
\hline & 71 & 5.72 & 28.31 & 56.17 & 9.8 & & & 100.00 \\
\hline average & & 4.47 & 28.16 & 55.71 & 11.66 & & & 100.00 \\
\hline \multirow{8}{*}{$\begin{array}{c}\text { Cel } \\
\text { (Grains Morphology } \\
\text { Study) }\end{array}$} & $\begin{array}{c}\text { Analysis } \\
\text { Point }\end{array}$ & $\mathrm{Na}_{2} \mathrm{O}$ & MgO & $\mathrm{Al}_{2} \mathbf{O}_{3}$ & $\mathrm{SiO}_{2}$ & $\mathbf{K}_{2} \mathbf{O}$ & $\mathrm{FeO}$ & Total \\
\hline & 51 & 4.21 & 14.98 & 15.64 & 43.98 & 0.00 & 21.18 & 99.99 \\
\hline & 52 & 1.47 & 11.16 & 16.38 & 41.31 & 2.82 & 26.86 & 100.00 \\
\hline & 53 & 1.64 & 14.01 & 14.55 & 43.76 & 4.47 & 21.57 & 100.00 \\
\hline & 55 & 2.24 & 14.33 & 13.25 & 45.86 & 1.46 & 22.86 & 100.00 \\
\hline & 61 & 0.00 & 7.19 & 12.44 & 35.63 & 8.38 & 36.37 & 100.01 \\
\hline & 65 & 0.00 & 10.18 & 18.49 & 39.46 & 6.19 & 25.68 & 100.00 \\
\hline & 66 & 0.48 & 7.76 & 12.60 & 38.05 & 8.26 & 32.84 & 99.99 \\
\hline average & & 1.43 & 11.37 & 14.76 & 41.15 & 4.51 & 26.77 & 100.00 \\
\hline$\pm \boldsymbol{\sigma}$ & & 1.38 & 3.18 & 2.22 & 3.65 & 2.85 & 5.83 & \\
\hline \multirow[t]{3}{*}{ Ttn } & $\begin{array}{c}\text { Analysis } \\
\text { Point }\end{array}$ & MgO & $\mathrm{Al}_{2} \mathbf{O}_{3}$ & $\mathrm{SiO}_{2}$ & $\mathrm{CaO}$ & $\mathrm{TiO}_{2}$ & $\mathrm{FeO}$ & Total \\
\hline & 73 & 0.62 & 4.85 & 23.74 & 33.83 & 30.94 & 6.03 & 100.01 \\
\hline & 74 & 0.7 & 6.65 & 29.1 & 28.49 & 32.18 & 2.89 & 100.01 \\
\hline average & & 0.66 & 5.75 & 26.42 & 31.16 & 31.56 & 4.46 & 100.01 \\
\hline
\end{tabular}

\begin{tabular}{|c|c|c|c|}
\hline Oxides & average $w t \%$ & average $w t \%$ & average $w t \%$ \\
\hline $\mathrm{Na}_{2} \mathrm{O}$ & 4.47 & 1.43 & \\
\hline $\mathrm{MgO}$ & & 11.37 & 0.66 \\
\hline $\mathrm{SiO}_{2}$ & 55.71 & 41.15 & 26.42 \\
\hline $\mathrm{Al}_{2} \mathrm{O}_{3}$ & 28.16 & 14.76 & 5.75 \\
\hline $\mathrm{FeO}_{(\mathrm{T})}$ & & 26.77 & 4.46 \\
\hline $\mathrm{CaO}$ & 11.66 & & 31.16 \\
\hline $\mathrm{K}_{2} \mathrm{O}$ & & 4.51 & \\
\hline $\mathrm{TiO}_{2}$ & & & 31.56 \\
\hline Total & 100.00 & 99.99 & 100.01 \\
\hline $\begin{array}{c}\text { Mineral } \\
\text { Composition }\end{array}$ & $\begin{array}{c}\mathrm{Ca}_{0.57} \mathrm{Na}_{0.39} \mathrm{Al}_{1.51} \mathrm{Si}_{2.53} \mathrm{O}_{8} \\
\quad\left(\mathrm{An}_{59}-\mathrm{Ab}_{41}\right)\end{array}$ & $\begin{array}{l}\mathrm{K}_{0.83} \mathrm{Na}_{0.40} \mathrm{Mg}_{2.45} \mathrm{Fe}_{3.24} \mathrm{Al}_{0.49} \mathrm{Si}_{5.96} \mathrm{Al}_{2.03} \mathrm{O}_{20}(\mathrm{OH})_{4} \\
\text { (on the basis of } 22 \text { oxygen equivalents, ignoring } \mathrm{H}_{2} \mathrm{O} \text { ) }\end{array}$ & $\mathrm{Ca}_{1.13} \mathrm{Fe}_{0.13} \mathrm{Ti}_{0.80} \mathrm{Al}_{0.23} \mathrm{Si}_{0.9} \mathrm{O}_{5}$ \\
\hline Phase and ID & Plagioclase & Celadonite & $\begin{array}{l}\text { Titanite } \\
\text { (sphene) }\end{array}$ \\
\hline
\end{tabular}




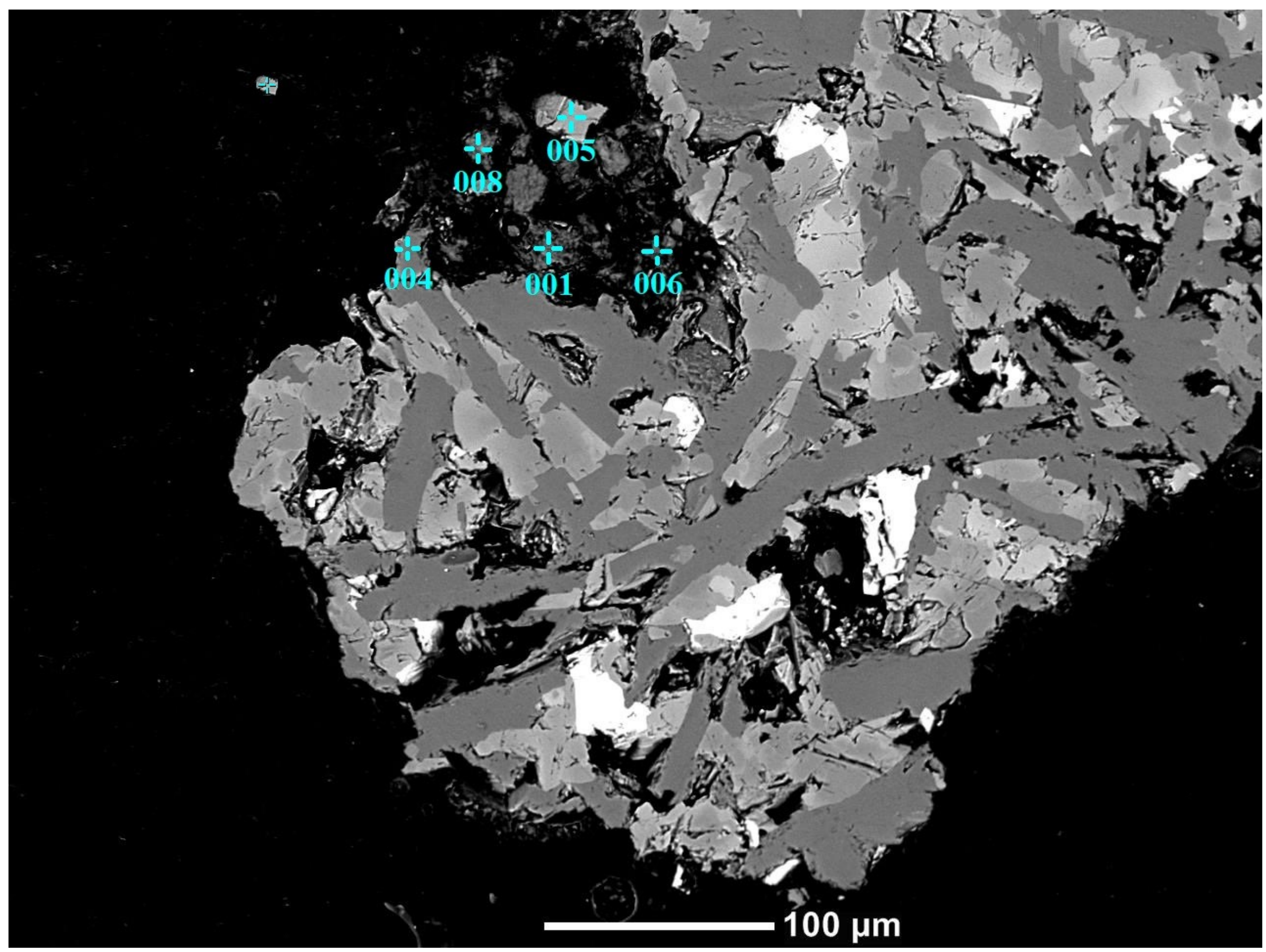


Table B.3.15. EDS analysis and average mineral compositions of grain in Figure B.3.30

\begin{tabular}{|c|c|c|c|c|c|c|c|}
\hline Plg & $\begin{array}{c}\text { Analysis } \\
\text { Point }\end{array}$ & $\mathrm{Na}_{2} \mathrm{O}$ & $\mathbf{A l}_{2} \mathbf{O}_{3}$ & $\mathrm{SiO}_{2}$ & $\mathrm{CaO}$ & & Total \\
\hline & 4 & 4.07 & 29.05 & 55.11 & 11.77 & & 100.00 \\
\hline $\mathrm{Ol}$ & $\begin{array}{c}\text { Analysis } \\
\text { Point }\end{array}$ & MgO & $\mathrm{SiO}_{2}$ & $\mathrm{FeO}$ & & & Total \\
\hline & 5 & 27.51 & 36.18 & 36.3 & & & 99.99 \\
\hline $\begin{array}{l}\text { Cel } \\
\text {-Mount Study) }\end{array}$ & $\begin{array}{c}\text { Analysis } \\
\text { Point }\end{array}$ & MgO & $\mathbf{A l}_{2} \mathbf{O}_{3}$ & $\mathrm{SiO}_{2}$ & $\mathbf{K}_{2} \mathbf{O}$ & $\mathrm{FeO}$ & Total \\
\hline & 1 & 13.08 & 15.35 & 44.76 & 3.13 & 23.68 & 100.00 \\
\hline & 6 & 15.48 & 13.28 & 47.12 & 1.72 & 22.40 & 100.00 \\
\hline & 8 & 14.64 & 13.01 & 48.33 & 0.73 & 23.29 & 100.00 \\
\hline average & & 14.40 & 13.88 & 46.74 & 1.86 & 23.12 & 100.00 \\
\hline L & & 1.22 & 1.28 & 1.82 & 1.21 & 0.66 & \\
\hline
\end{tabular}

\begin{tabular}{|c|c|c|c|}
\hline Oxides & average $w t \%$ & average $w t \%$ & average $w t \%$ \\
\hline $\mathrm{Na}_{2} \mathrm{O}$ & 4.07 & & \\
\hline $\mathrm{MgO}$ & & 27.51 & 14.40 \\
\hline $\mathrm{SiO}_{2}$ & 55.11 & 36.18 & 46.74 \\
\hline $\mathrm{Al}_{2} \mathrm{O}_{3}$ & 29.05 & & 13.88 \\
\hline $\mathrm{FeO}_{(\mathrm{T})}$ & & 36.30 & 23.12 \\
\hline $\mathrm{CaO}$ & 11.77 & & \\
\hline $\mathrm{K}_{2} \mathrm{O}$ & & & 1.86 \\
\hline Total & 100.00 & 99.99 & 100.00 \\
\hline $\begin{array}{c}\text { Mineral } \\
\text { Composition }\end{array}$ & $\begin{array}{c}\mathrm{Ca}_{0.60} \mathrm{Na}_{0.34} \mathrm{Al}_{1.5} \mathrm{Si}_{2.5} \mathrm{O}_{8} \\
\left(\mathrm{An}_{64}-\mathrm{Ab}_{46}\right)\end{array}$ & $\begin{array}{l}\mathrm{Mg}_{1.14} \mathrm{Fe}_{0.85} \mathrm{SiO}_{4} \\
\left(\mathrm{Fo}_{57}-\mathrm{Fa}_{43}\right)\end{array}$ & $\begin{array}{l}\mathrm{K}_{0.33} \mathrm{Mg}_{2.95} \mathrm{Fe}_{2.65} \mathrm{Al}_{0.68} \mathrm{Si}_{6.43} \mathrm{Al}_{1.57} \mathrm{O}_{20}(\mathrm{OH})_{4} \\
\text { (on the basis of } 22 \text { oxygen equivalents, ignoring } \mathrm{H}_{2} \mathrm{O} \text { ) }\end{array}$ \\
\hline Phase and ID & Plagioclase & $\begin{array}{l}\text { Mg-olivine } \\
\text { (forsterite) }\end{array}$ & Celadonite \\
\hline
\end{tabular}


Figure B.3.31. XRD scan showing the mineralogy of reacted grains collected from the top portion of Reactor

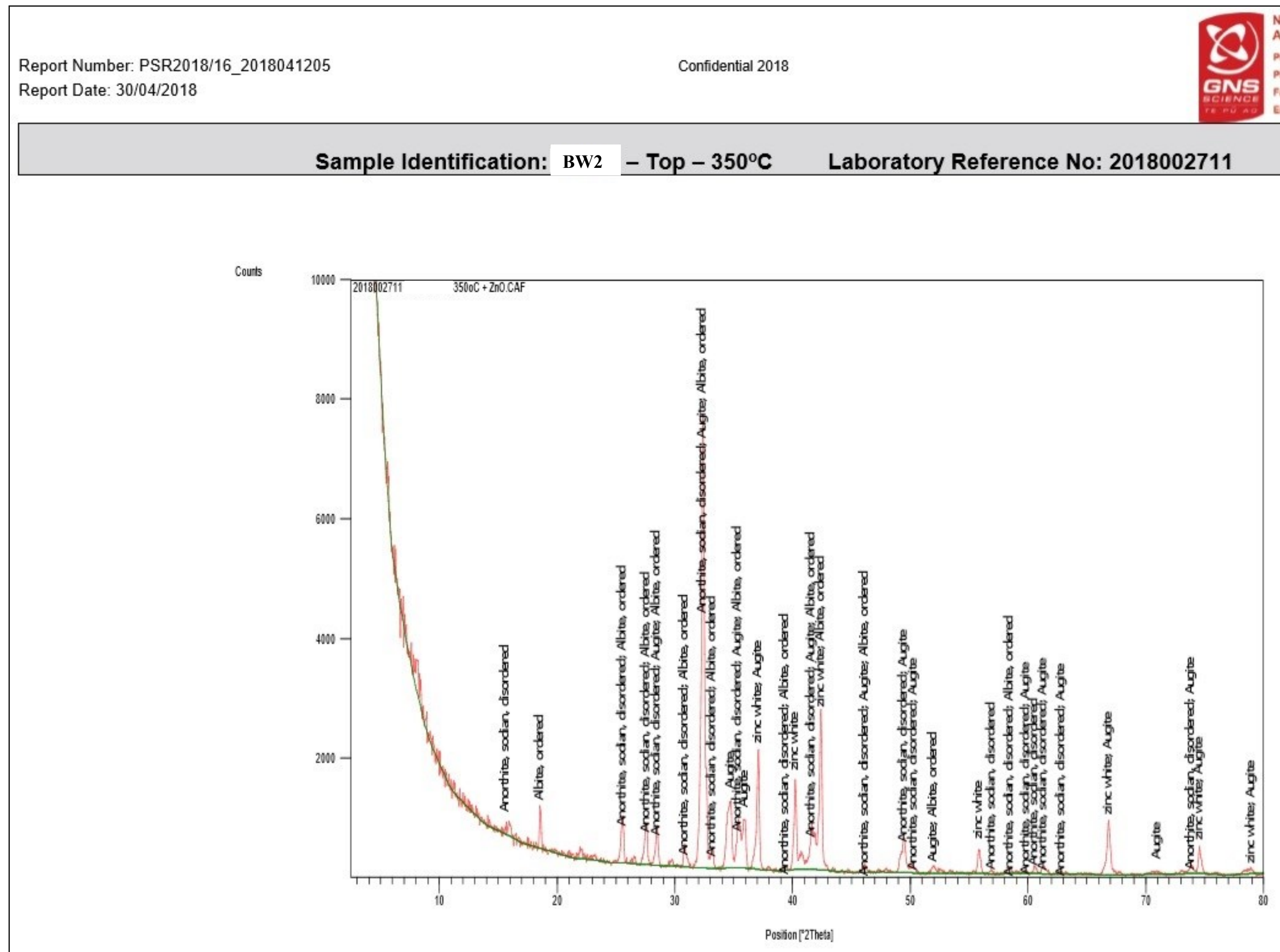

NEW ZEALAND GEOTHERMAL

Privato Bag 2000, Taupo

Phene: (077) 374 8211

Gnail: w.labmanageratense.crine

Figure 3. XRD scan showing the mineralogy of BW2 $-\mathrm{Top}-350^{\circ} \mathrm{C}$ as indicated by the labelled scan peaks 


\section{Sample Composition}

Table 1. Mineral percentages for BW2 sample was determined and then normalized to exclude zinc oxide:

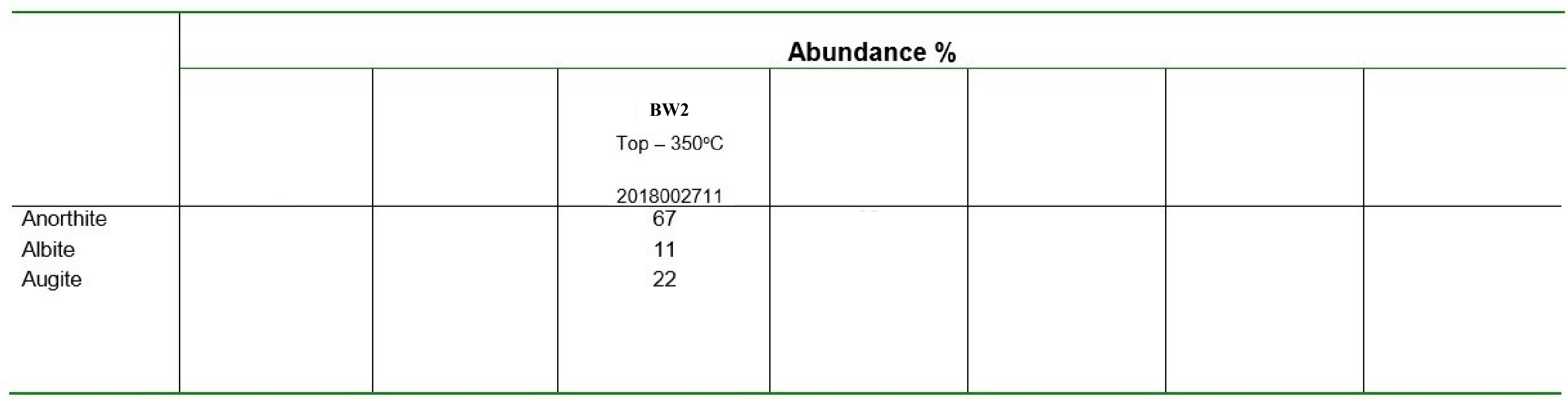

Margin of Error: Abundance estimates are determined through successive refinement of cell parameters; the position, width and orientation of each mineral. Values are given to the nearest whole number. The margin of error for phase concentration is proposed as follows: $0-10 \% \pm 10 \% ; 10-50 \% \pm 5 \% ; 50-100 \% \pm 2 \%$ 


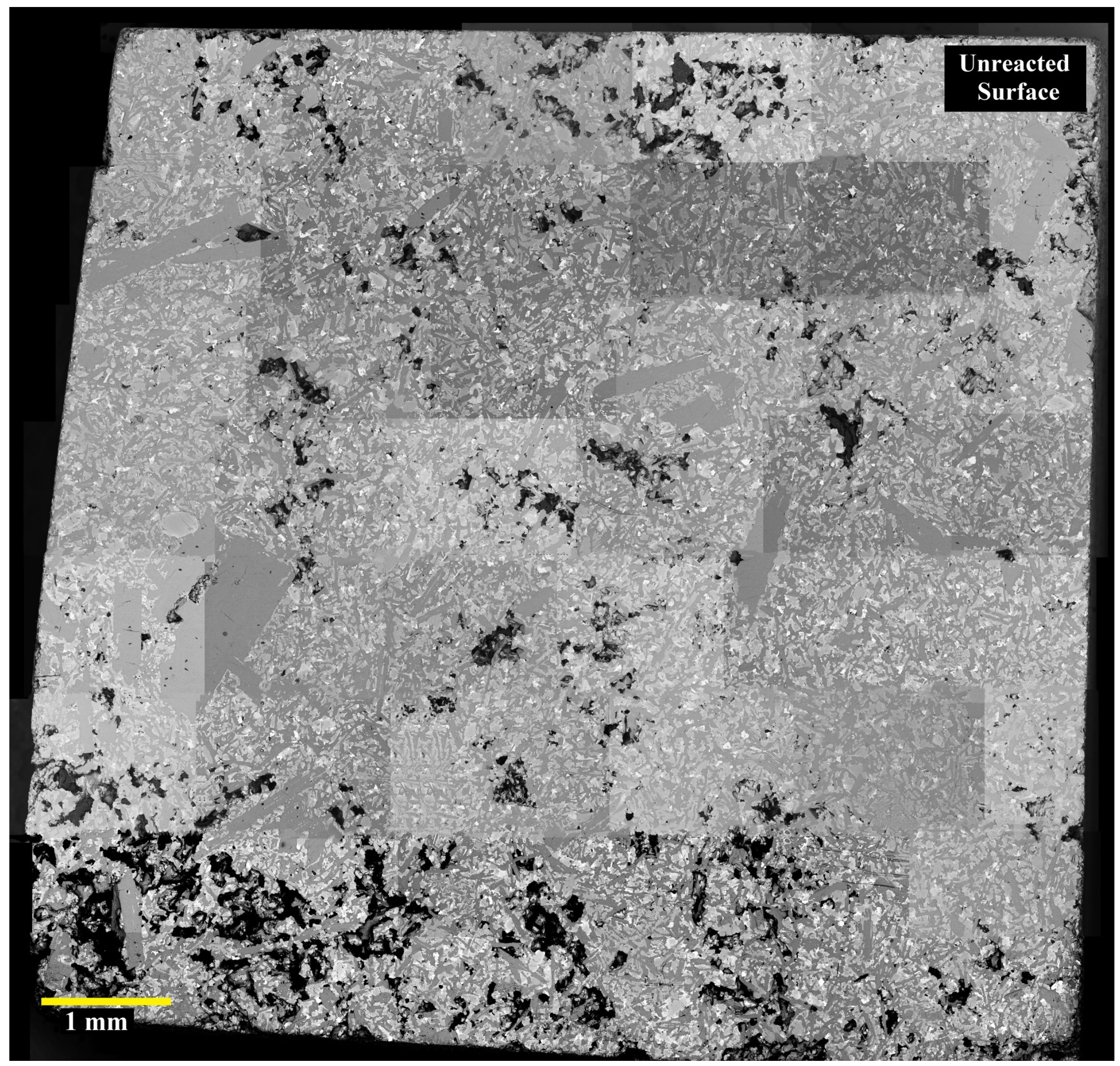




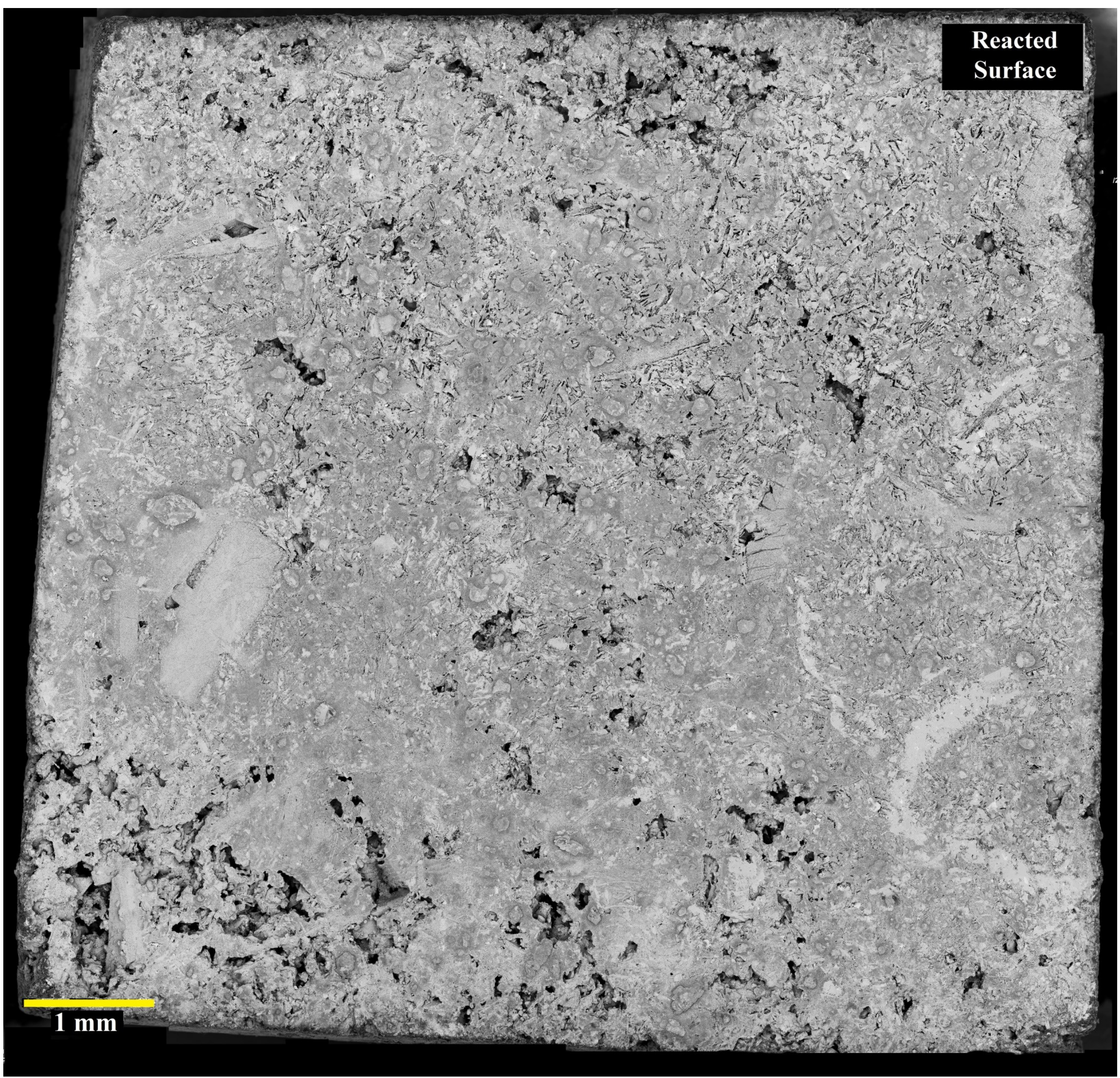


Figure B.3.35. SEM photographs of different areas of the reacted basalt block surfece
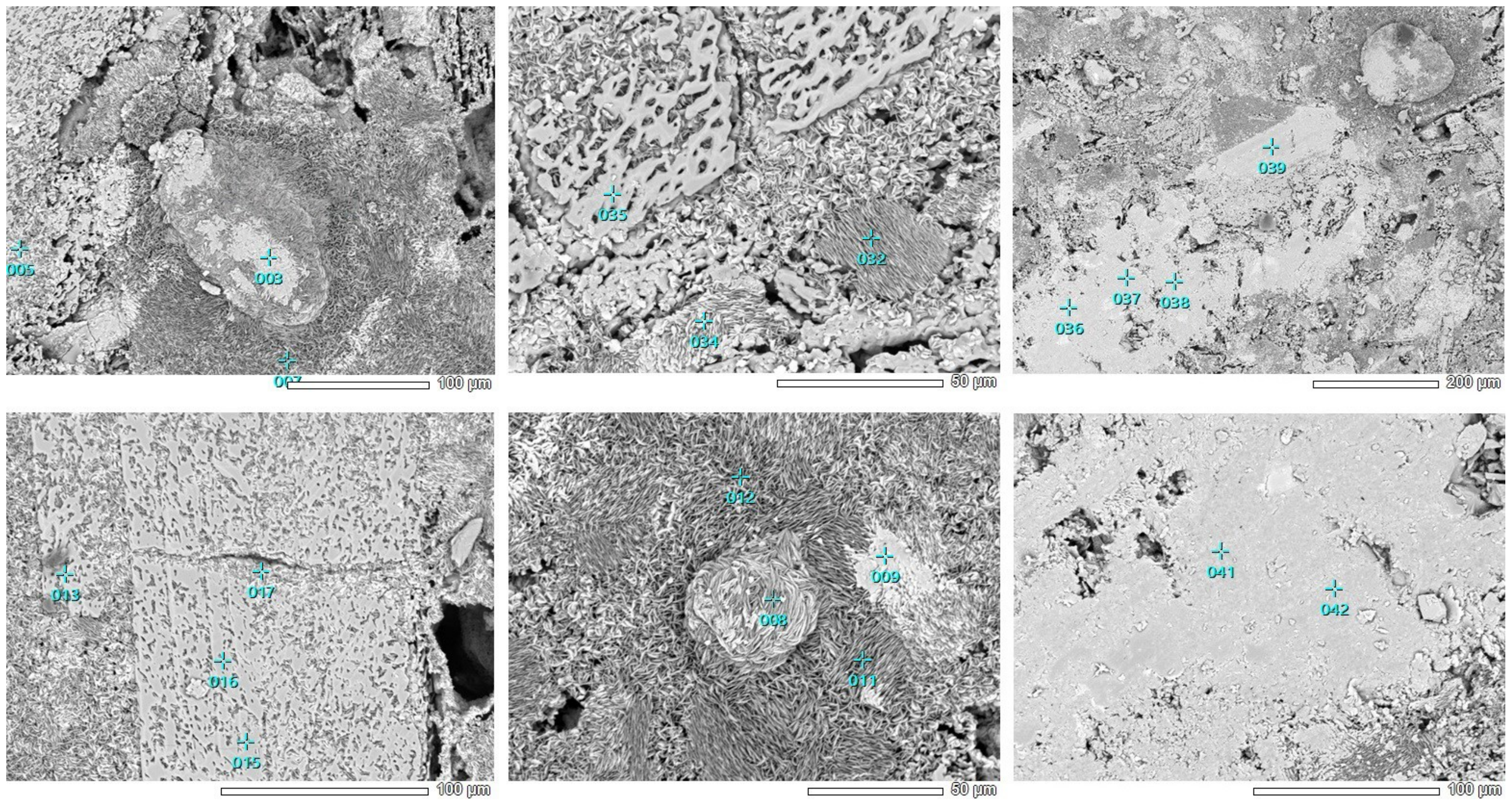
Table B.3.16. EDS analysis of points in Figure B.3.35

\begin{tabular}{|c|c|c|c|c|c|c|c|c|}
\hline \multirow[t]{7}{*}{ Plg } & \multicolumn{2}{|l|}{ Analysis Point } & $\mathbf{A l}_{2} \mathbf{O}_{3}$ & $\mathrm{SiO}_{2}$ & \multicolumn{3}{|l|}{$\mathrm{CaO}$} & Total \\
\hline & \multicolumn{2}{|l|}{5} & 38.47 & 41.07 & 20.46 & & & 100.00 \\
\hline & \multicolumn{2}{|l|}{13} & 36.06 & 44.59 & 19.35 & & & 100.00 \\
\hline & \multicolumn{2}{|l|}{15} & 35.64 & 44.70 & 19.65 & & & 99.99 \\
\hline & \multicolumn{2}{|l|}{16} & 36.64 & 43.82 & 19.54 & & & 100.00 \\
\hline & \multicolumn{2}{|l|}{17} & 36.65 & 43.98 & 19.36 & & & 99.99 \\
\hline & \multicolumn{2}{|l|}{35} & 37.07 & 43.37 & 19.57 & & & 100.01 \\
\hline \multirow{7}{*}{$\mathrm{Cpx}$} & Analysis Point & MgO & $\mathbf{A l}_{2} \mathbf{O}_{3}$ & $\mathrm{SiO}_{2}$ & $\mathrm{CaO}$ & $\mathrm{FeO}$ & & Total \\
\hline & 36 & 9.60 & 8.88 & 46.90 & 16.33 & 18.28 & & 99.99 \\
\hline & 37 & 9.80 & 20.82 & 30.23 & 3.15 & 36.00 & & 100.00 \\
\hline & 38 & 10.68 & 4.21 & 53.61 & 20.12 & 11.37 & & 99.99 \\
\hline & 39 & 12.86 & 5.83 & 53.46 & 16.08 & 11.78 & & 100.01 \\
\hline & 41 & 11.57 & 21.92 & 28.11 & 0.00 & 38.40 & & 100.00 \\
\hline & 42 & 15.45 & 19.16 & 31.92 & 0.00 & 33.46 & & 99.99 \\
\hline \multirow[t]{9}{*}{ Chl } & Analysis Point & MgO & $\mathrm{Al}_{3} \mathbf{O}_{3}$ & $\mathrm{SiO}_{2}$ & $\mathrm{CaO}$ & $\mathrm{FeO}$ & $\mathrm{TiO}_{2}$ & Total \\
\hline & 3 & 16.82 & 24.21 & 32.10 & & 26.88 & & 100.01 \\
\hline & 7 & 11.97 & 16.25 & 22.74 & & 43.81 & 5.24 & 94.77 \\
\hline & 8 & 11.14 & 22.84 & 29.80 & & 36.21 & & 99.99 \\
\hline & 9 & 14.39 & 23.34 & 32.13 & & 30.14 & & 100.00 \\
\hline & 11 & 15.92 & 22.70 & 28.96 & & 32.43 & & 100.01 \\
\hline & 12 & 14.58 & 21.32 & 28.42 & & 35.68 & & 100.00 \\
\hline & 32 & 15.43 & 23.60 & 29.86 & 0.83 & 30.28 & & 100.00 \\
\hline & 34 & 11.87 & 21.79 & 29.25 & & 37.09 & & 100.00 \\
\hline
\end{tabular}



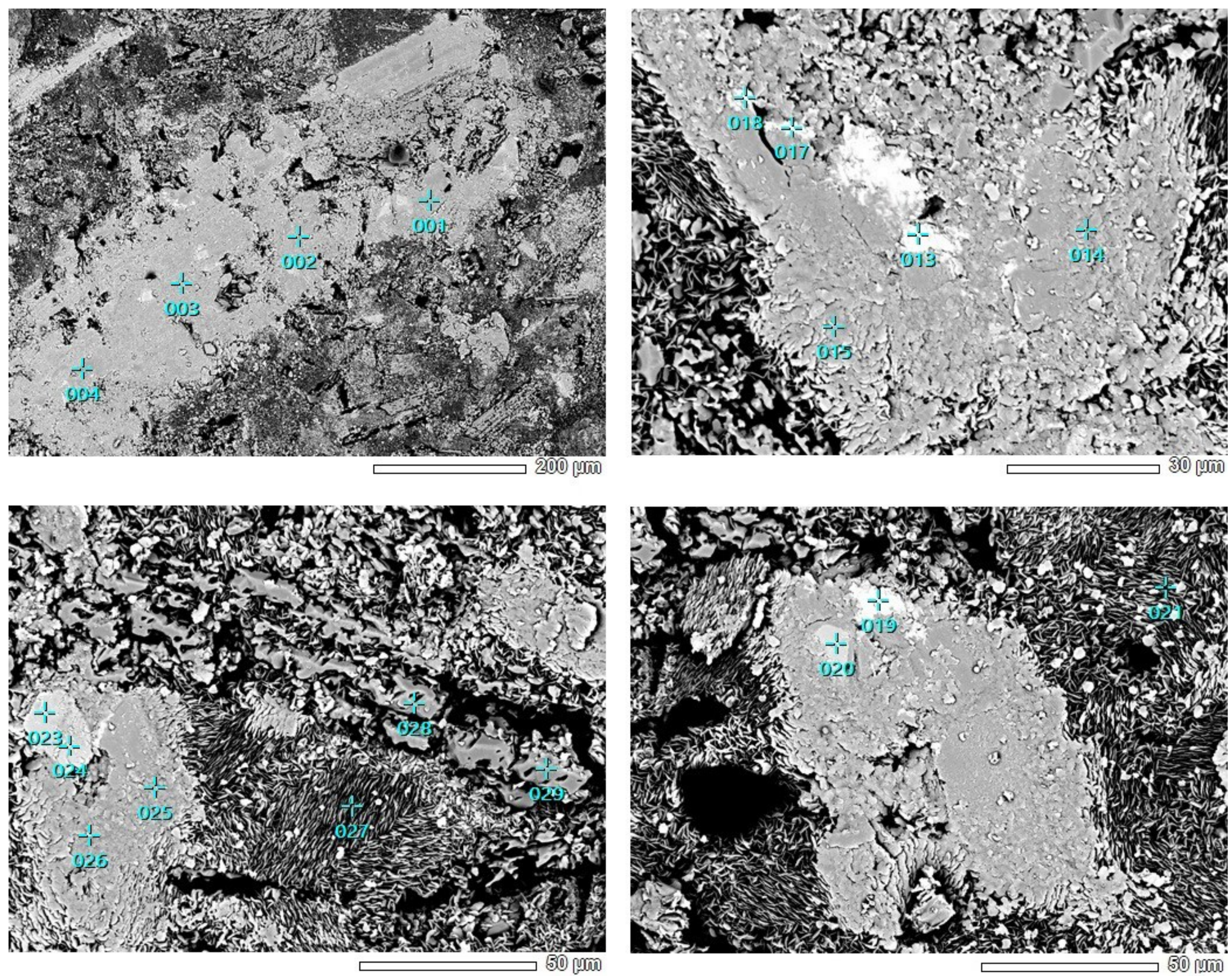


\begin{tabular}{|c|c|c|c|c|c|c|c|}
\hline \multirow[t]{3}{*}{ Plg } & Analysis Point & $\mathrm{NaO}$ & $\mathbf{A l}_{2} \mathbf{O}_{3}$ & $\mathrm{SiO}_{2}$ & \multicolumn{2}{|l|}{$\mathrm{CaO}$} & Total \\
\hline & 28 & 0.58 & 35.12 & 42.24 & 22.06 & & 100.00 \\
\hline & 29 & 0.74 & 34.79 & 42.63 & 21.84 & & 100.00 \\
\hline \multirow[t]{9}{*}{ Cpx } & Analysis Point & $\mathrm{MgO}$ & $\mathbf{A l}_{2} \mathbf{O}_{3}$ & $\mathrm{SiO}_{2}$ & $\mathrm{CaO}$ & $\mathrm{FeO}$ & Total \\
\hline & 1 & 10.24 & 11.56 & 37.66 & 13.89 & 26.66 & 100.01 \\
\hline & 2 & 7.62 & 23.40 & 32.32 & 6.38 & 30.28 & 100.00 \\
\hline & 3 & 12.62 & 20.87 & 29.18 & 1.09 & 36.24 & 100.00 \\
\hline & 4 & 13.28 & 3.83 & 51.79 & 17.79 & 13.31 & 100.00 \\
\hline & 14 & 9.42 & 13.96 & 31.79 & 9.20 & 35.63 & 100.00 \\
\hline & 15 & 13.12 & 21.41 & 31.96 & 3.05 & 30.45 & 99.99 \\
\hline & 25 & 9.47 & 14.25 & 34.15 & 10.15 & 31.98 & 100.00 \\
\hline & 26 & 10.90 & 10.17 & 40.96 & 13.75 & 24.22 & 100.00 \\
\hline \multirow[t]{8}{*}{$\mathrm{Ox}$} & Analysis Point & $\mathrm{Cr}_{2} \mathrm{O}_{3}$ & $\mathrm{FeO}$ & $\mathrm{NiO}$ & $\mathrm{TiO}_{2}$ & $\mathrm{FeO}$ & Total \\
\hline & 13 & 19.73 & 71.91 & 8.35 & & & 99.99 \\
\hline & 17 & 20.01 & 71.89 & 8.10 & & & 100.00 \\
\hline & 18 & 19.54 & 71.30 & 9.15 & & & 99.99 \\
\hline & 19 & 20.48 & 71.21 & 8.31 & & & 100.00 \\
\hline & 20 & & & & 23.72 & 76.28 & 100.00 \\
\hline & 23 & & & & 23.02 & 76.98 & 100.00 \\
\hline & 24 & & & & 21.98 & 78.02 & 100.00 \\
\hline \multirow[t]{3}{*}{ Chl } & Analysis Point & MgO & $\mathrm{Al}_{3} \mathrm{O}_{3}$ & $\mathrm{SiO}_{2}$ & $\mathrm{CaO}$ & $\mathrm{FeO}$ & Total \\
\hline & 21 & 12.38 & 19.94 & 30.30 & 3.15 & 34.23 & 100.00 \\
\hline & 27 & 12.84 & 19.68 & 30.00 & & 37.48 & 100.00 \\
\hline
\end{tabular}


Table B.3.18. Average of EDS analysis from Table B.3.16 and Table B.3.17

$\begin{array}{ccccccc}\text { average } & \mathbf{N a O} & \mathbf{M g O} & \mathbf{A l}_{\mathbf{3}} \mathbf{O}_{\mathbf{3}} & \mathbf{S i O}_{\mathbf{2}} & \mathbf{C a O} & \mathbf{F e O} \\ \mathrm{Plg} & 0.66 & & 36.31 & 43.30 & 20.23 & \\ \mathrm{Cpx} & & 11.19 & 14.31 & 38.15 & 9.36 & 27.00 \\ \mathrm{Chl} & & 13.94 & 22.27 & 30.09 & & 33.70\end{array}$

Oxides

$\mathrm{Na}_{2} \mathrm{O}$

$\mathrm{MgO}$

$\mathrm{SiO}_{2}$

$\mathrm{Al}_{2} \mathrm{O}_{3}$

$\mathrm{FeO}_{(\mathrm{T})}$

$\mathrm{CaO}$

Total

Mineral

Composition

Phase and ID

\section{average $w t \%$}

0.66

43.30

36.31

20.23

100.50

\section{average $w t \%$}

11.19

38.15

14.31

27.00

9.36

100.01

\section{average $w t \%$}

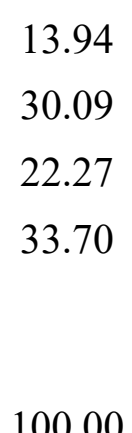

30.09

00.00

$\mathrm{Mg}_{3.79} \mathrm{Fe}_{5.58} \mathrm{Al}_{2.36} \mathrm{Si}_{5.66} \mathrm{Al}_{2.34} \mathrm{O}_{20}(\mathrm{OH})_{16}$ (on the basis of 28 oxygen equivalents, ignoring $\mathrm{H}_{2} \mathrm{O}$ )

Plagioclase (anorthite)
Clinopyroxene

(augite)

$\mathrm{Ca}_{0.399} \mathrm{Mg}_{0.663} \mathrm{Fe}_{0.898} \mathrm{Al}_{0.188} \mathrm{Si}_{1.517} \mathrm{Al}_{0.483} \mathrm{O}_{6}$
Chlorite 
3.3. Discussion

\section{Elements Flux Calculation}

Table B.3.20. BW1 experiment $\left(400^{\circ} \mathrm{C} / 502\right.$ bar). Elements flux calculation and amount of glass dissolved

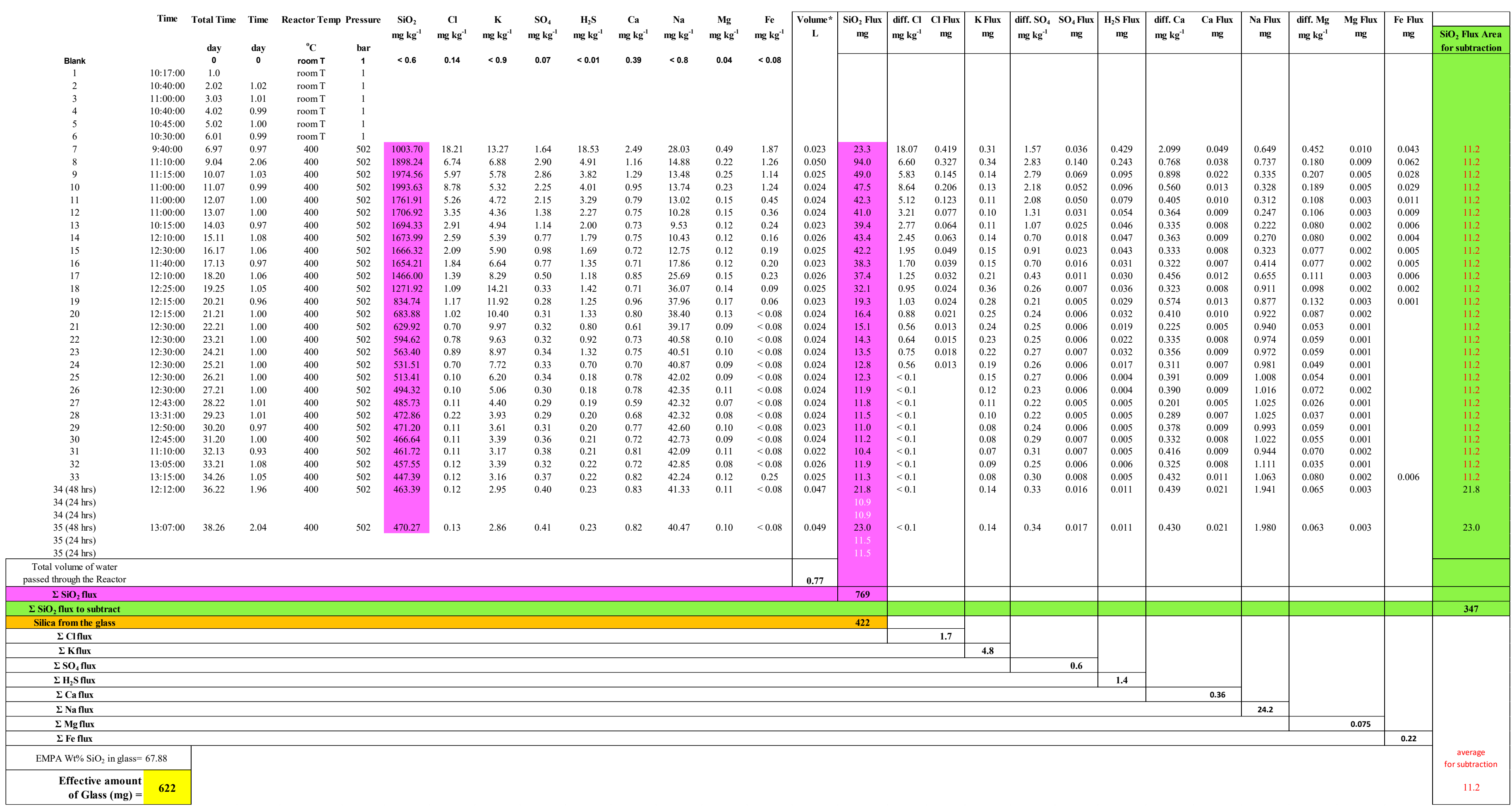




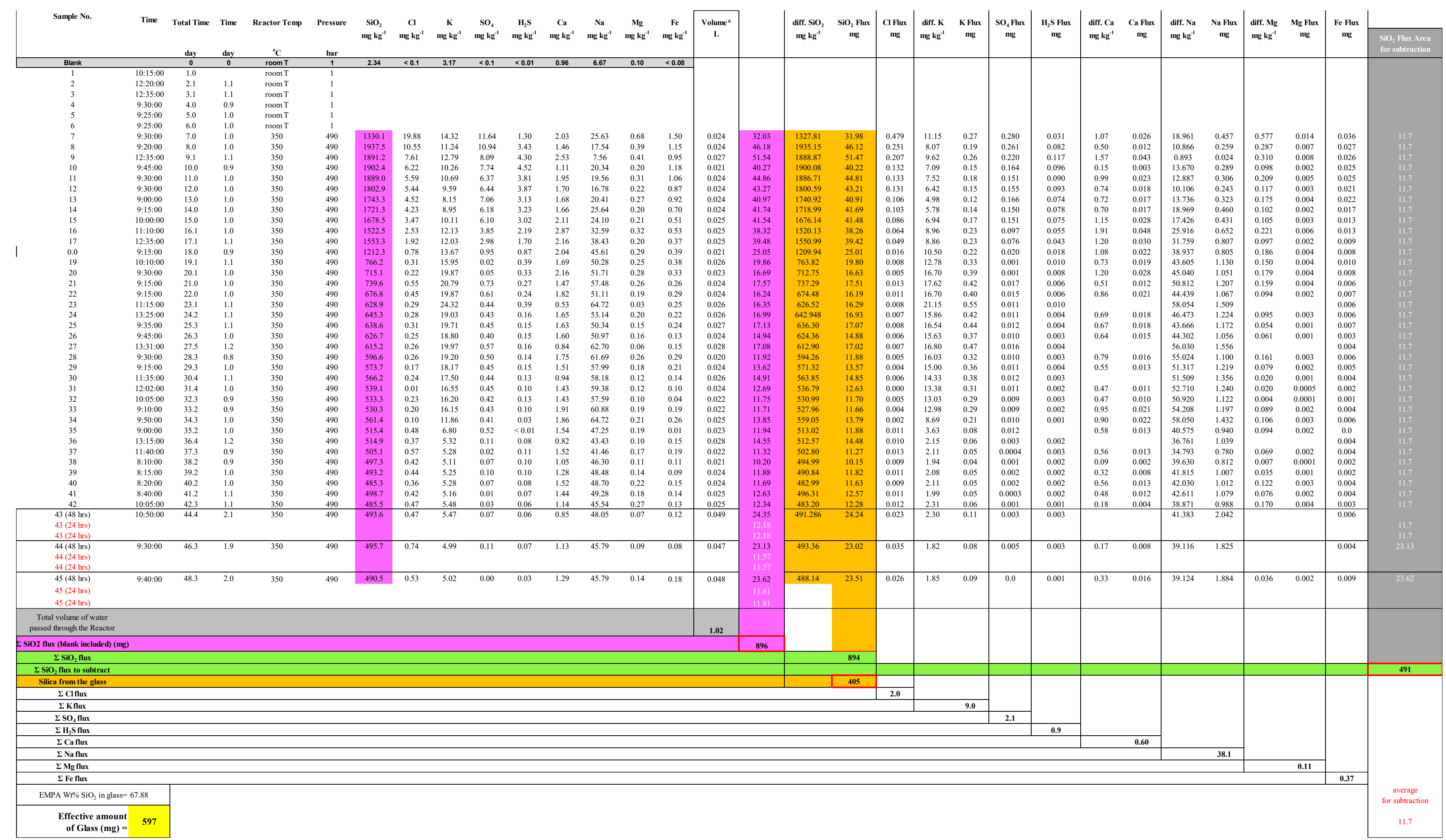


Table B.3.22. Major elements estimated in the unaltered volcanic glass, and $\Sigma$ major elements flux calculation from fluid samples compositions, both for the BW1 and BW2

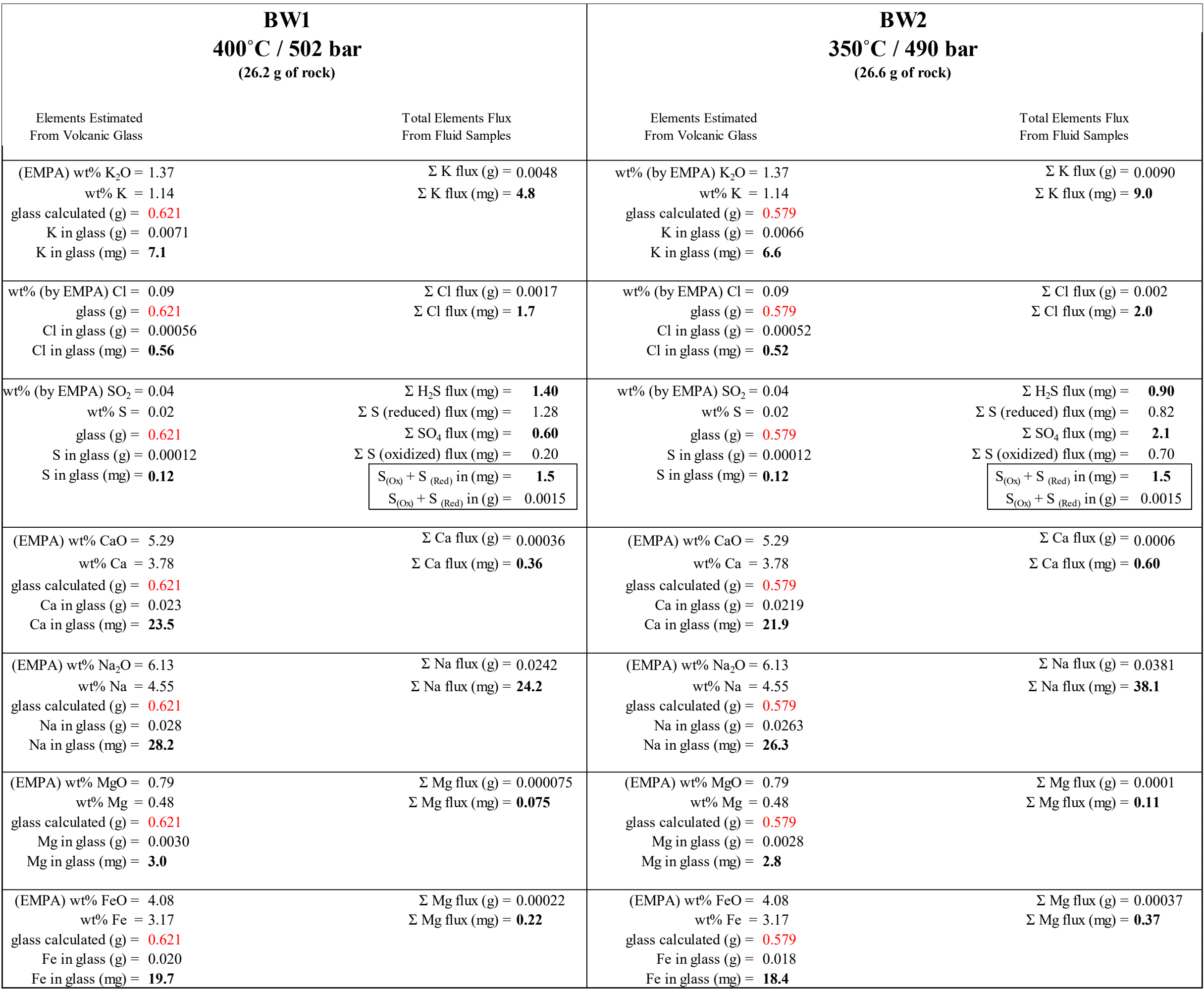


Activity calculation

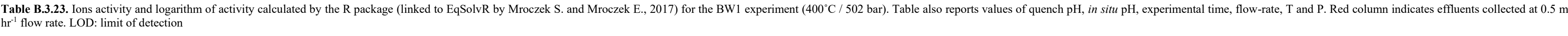

\begin{tabular}{|c|c|c|c|c|c|c|c|c|c|c|c|c|c|c|c|c|c|c|c|c|c|c|c|c|c|c|c|c|c|c|}
\hline samples & $\begin{array}{c}\text { water } \\
\text { (distilited) } \\
\text { bank }\end{array}$ & 7 & 8 & 9 & 10 & 11 & 12 & 13 & 14 & 15 & 16 & 17 & 18 & 19 & 20 & 21 & 22 & 23 & 24 & 25 & 26 & 27 & 28 & 29 & 30 & 31 & 32 & 33 & 34 & 35 \\
\hline 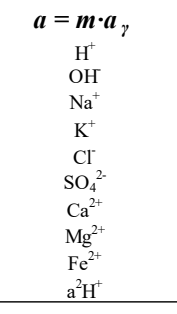 & 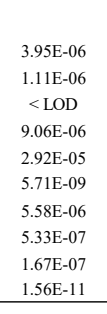 & 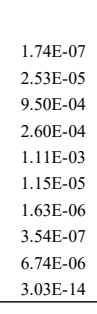 & 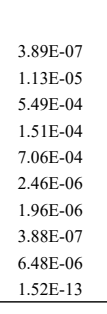 & 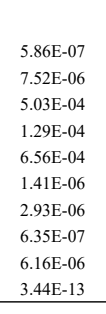 & 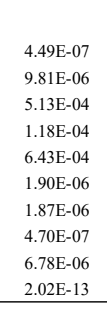 & 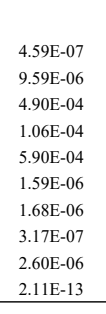 & 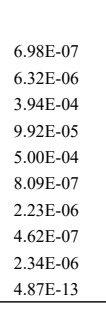 & 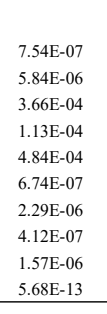 & 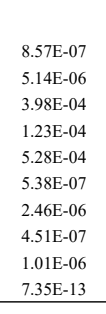 & 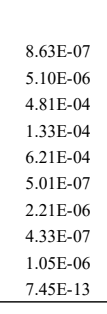 & 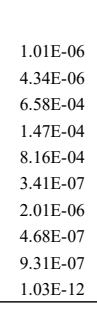 & 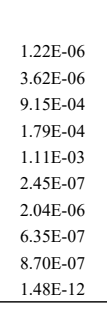 & 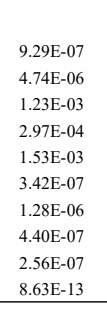 & 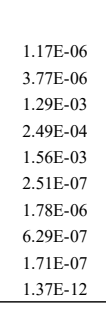 & 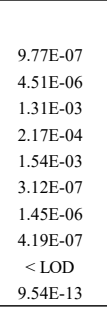 & 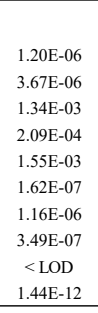 & 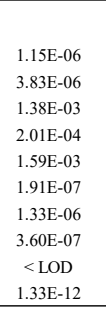 & 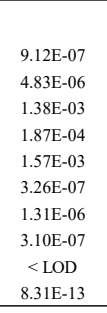 & 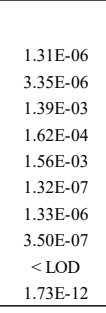 & 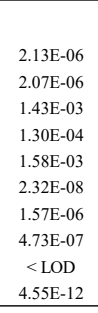 & 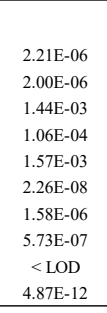 & 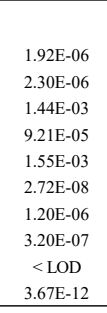 & 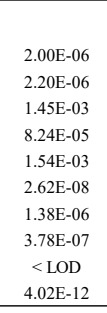 & 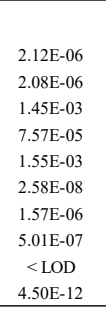 & 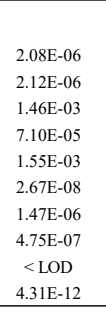 & 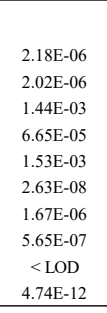 & 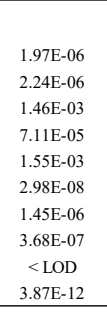 & 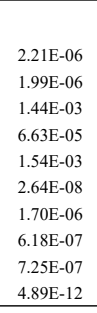 & 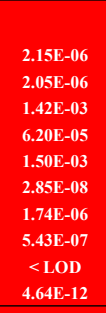 & 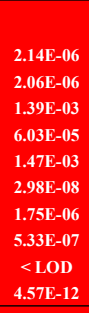 \\
\hline $\log \left(a \mathrm{SiO}_{2}\right)$ & -5.8 & -1.5 & -1.5 & -1.5 & -1.5 & -1.5 & -1.5 & -1.6 & -1.6 & -1.6 & -1.6 & -1.7 & -1.9 & -1.9 & -20 & -2.0 & -2 & -21 & 21 & -21 & 11 & 2 & 2 & 23 & 2 & 2 & 21 & -2.1 & -2.1 & -2.1 \\
\hline $\log \left(a_{\mathrm{K} \downarrow} / a\right.$ & 0.4 & 3. & 2.6 & 2.3 & 2. & 2. & 2 & 2. & 2 & 2. & 2. & 2. & 2 & 2. & 2 & 2. & 2. & 2 & 2 & 1 & & & & & & & & 1.5 & & 1.4 \\
\hline $\log \left(a_{\mathrm{Na}} / a_{\mathrm{HH}}\right)$ & $<$ LOD & 3.7 & 3.1 & 2.9 & 3.1 & 3.0 & 2.8 & 2.7 & 2.7 & 2.7 & 2.8 & 2.9 & 3.1 & 3.0 & 3.1 & 3.0 & 3.1 & 3.2 & 3.0 & 2.8 & 2.8 & 2.9 & 2. & 2.8 & 2.8 & 2.8 & 2.9 & 2.8 & 2.8 & 2.8 \\
\hline $\log \left(a_{\mathrm{C} 2+} / a_{\mathrm{HH}}^{2}\right)$ & 5.6 & 7.7 & 7.1 & 6.9 & 7.0 & 6.9 & 6.7 & 6.6 & 6.5 & 6.5 & 6.3 & 6.1 & 6.2 & 6.1 & 6.2 & 5.9 & 6.0 & 6.2 & 5.9 & 5. & 5. & 5.5 & 5.8 & 5.5 & 5. & 5.5 & & 5.5 & & 5.6 \\
\hline & 4.0 & 83 & 7.6 & 7.3 & 7.5 & 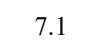 & 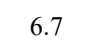 & 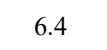 & 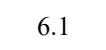 & 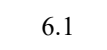 & 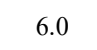 & 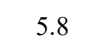 & & 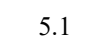 & $<$ LOD & $<L O D$ & $<10$ & $<$ LOD & $<$ LOD & $<\mathrm{LC}$ & $<$ LOI & $<\mathrm{LC}$ & $<\mathrm{LC}$ & $<$ LOD & $<1$ & $<$ LOD & $<\mathrm{LO}$ & 5.2 & OD & $<\angle O D$ \\
\hline$\left(a_{\mathrm{Mg}_{2}+}+a_{\mathrm{H}}^{2}\right.$ & 4.5 & 7.1 & 6.4 & 6.3 & 6.4 & 6.2 & 6.0 & 5.9 & 5.8 & 5.8 & 5.7 & 5.6 & 5.7 & 5.7 & 5.6 & 5.4 & 5.4 & 5.6 & 5.3 & 5.0 & 5.1 & 4.9 & 5.0 & 5.0 & 5.0 & 5.1 & 5.0 & 5.1 & 5.1 & 5.1 \\
\hline & $<\angle 00$ & & -3.3 & -3.3 & & & & & & & & & & & & & & & & & & & & & & & & & & .9 \\
\hline & $\begin{array}{l}-5 . \\
-4 .\end{array}$ & $\begin{array}{l}-3 \\
-3 \\
-3\end{array}$ & -3 & $\begin{array}{c}-3 \\
-3\end{array}$ & & $\begin{array}{l}-4 \\
-3 \\
-3\end{array}$ & & & & & & & & & & & & & & & & & & & & & & & & .2 \\
\hline & -4. & $\begin{array}{l}-3 . \\
-4 . \\
\text {. }\end{array}$ & & $\begin{array}{l}-5 \\
-5 \\
-5\end{array}$ & $\begin{array}{l}-3 \\
-5 \\
-5\end{array}$ & $e^{-3}$ & & & & & & & & & -6 & & & & & & & & & & & & & & & $\begin{array}{l}-2.8 \\
-7.5\end{array}$ \\
\hline & & & & -5 & & & & & & & & & & & & & & & -5 & & & & & & & & & & & -5.8 \\
\hline & & & & -6 & & & & & & & & & & & & & & & & & & & & & & & & & & 3 \\
\hline & & & & & & -5 & & & & & & & & & & & & & & & & & & & & & & & & 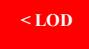 \\
\hline${ }_{\mathrm{p}}^{\mathrm{T}}$ & 400 & 402 & 44 & $4 c$ & 4 & 40 & 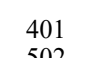 & 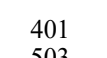 & 40 & 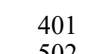 & 401 & 4 & & & 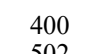 & 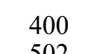 & & & $\begin{array}{l}400 \\
500\end{array}$ & 400 & 400 & 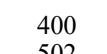 & & & & & & 0 & 101 & 401 \\
\hline in situ pH & $\begin{array}{l}500 \\
5.4\end{array}$ & & & $\begin{array}{l}5 \\
6\end{array}$ & & & & & & & & & & 5. & & & $\begin{array}{l}502 \\
5.94\end{array}$ & & s. & & 3. & J. & s. & 3. & & 5.66 & 5.71 & 5.66 & $\begin{array}{l}502 \\
5.67\end{array}$ & 5.67 \\
\hline Th & 7.8. & 5.04 & 6.53 & 6.58 & 6.93 & 6.93 & 7.04 & 7.26 & 7.39 & 7.84 & 8.61 & 8.84 & 9.14 & $i$ & 9.23 & 9.3 & 9.4 & 9.41 & 9.45 & 9. & 9.41 & 9.3 & 9.39 & 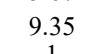 & 9.37 & 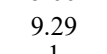 & 1 & $\begin{array}{r}9.39 \\
\end{array}$ & & 9.21 \\
\hline e(hrs) & 0.00 & $\begin{array}{c}1 \\
167.3\end{array}$ & $\begin{array}{c}1 \\
216.7\end{array}$ & $\begin{array}{c}1 \\
240.9\end{array}$ & $\begin{array}{c}1 \\
264.7\end{array}$ & $\begin{array}{c}1 \\
288.7\end{array}$ & $\begin{array}{c}1 \\
312.7\end{array}$ & 335.9 & $\begin{array}{r}1 \\
361.8\end{array}$ & $\begin{array}{c}1 \\
386.2\end{array}$ & $\begin{array}{c}1 \\
409.5\end{array}$ & $\begin{array}{c}1 \\
434.0\end{array}$ & 458. & 482. & 506. & $\begin{array}{r}1 \\
530 .\end{array}$ & 554.3 & $\begin{array}{l}1 \\
578.3\end{array}$ & 602.3 & 626.3 & 650.3 & 674.6 & 699.3 & 722.7 & 746.6 & 769.0 & 794.9 & 819.1 & 866.0 & 913.5 \\
\hline
\end{tabular}


sample

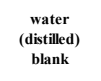
$\mathbf{H}^{+} \quad \mathrm{OH}^{-} \mathrm{Na}^{+}$

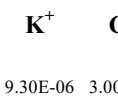

$a_{t} \quad 9.74 \mathrm{E}-01 \quad 9.74 \mathrm{E}-01$

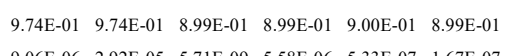

\author{
$6.45 E-07 \quad 4.21 E-10$
}

$9.74-01 \quad 9.74 E-01$

$\begin{array}{ccc}4.56 E-09 & 5.64 E-08 & 2.82 E-10 \\ 1.00 E+00 & 1.00 E+00 & 1.00 E+00\end{array}$

$\begin{array}{lll}1.00 \mathrm{E}+00 & 1.00 \mathrm{E}+00 & 1.00 \mathrm{E}+00 \\ 4.56 \mathrm{E}-09 & 5.64 \mathrm{E}-08 & 2.82 \mathrm{E}-10\end{array}$

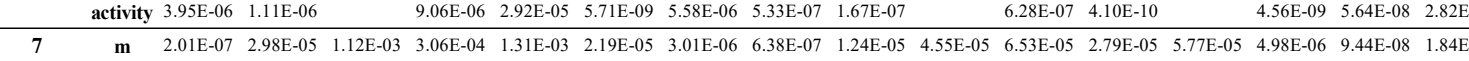

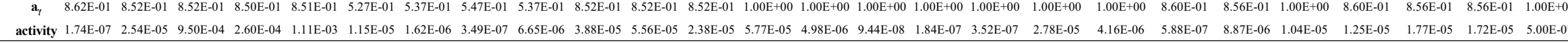

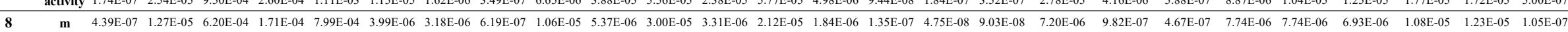

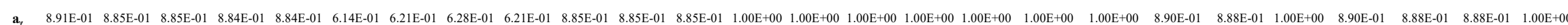

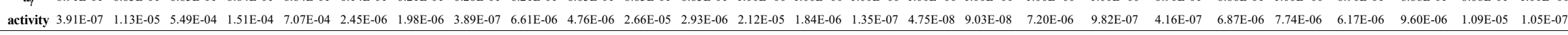

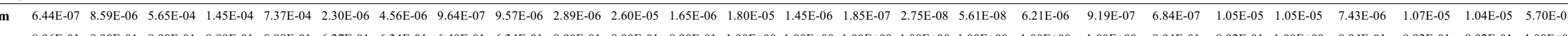

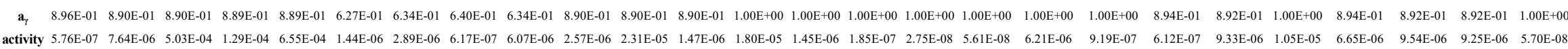

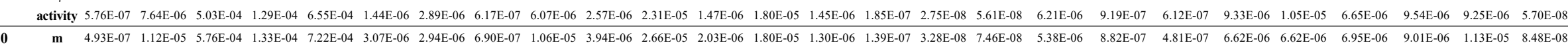

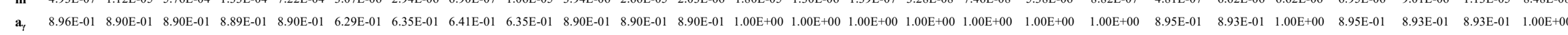

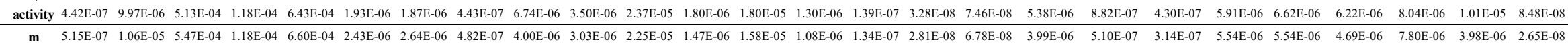

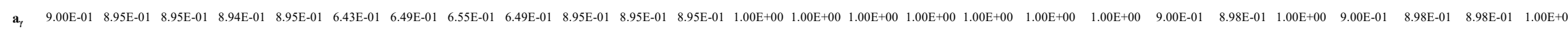

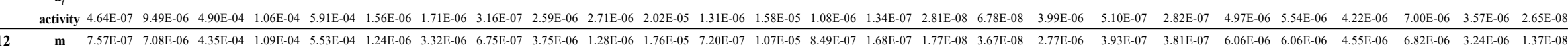

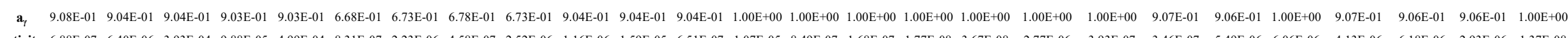

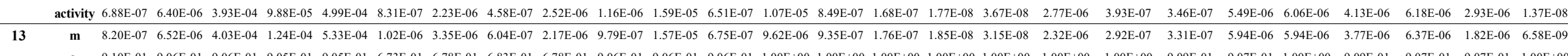

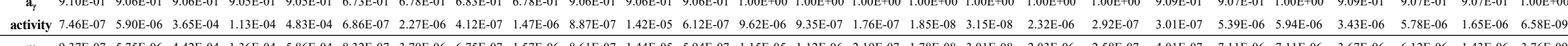

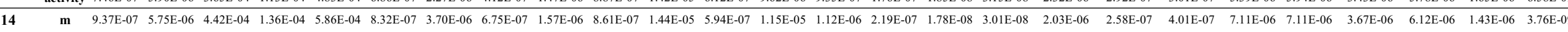

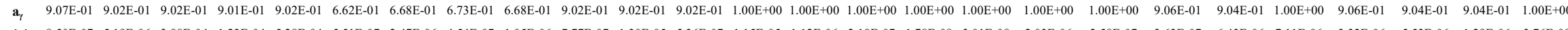

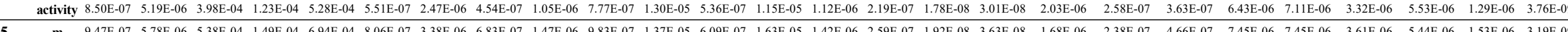

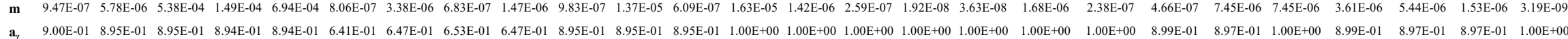

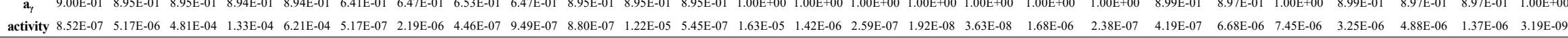

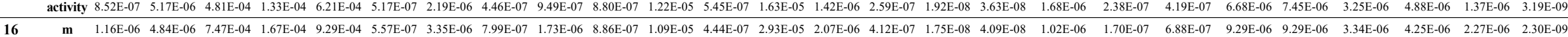

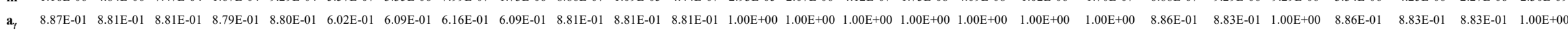

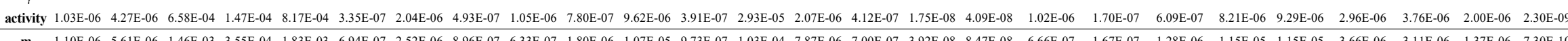

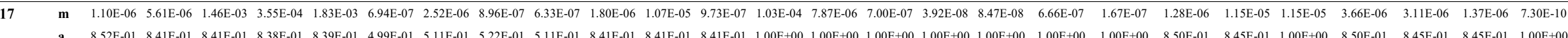

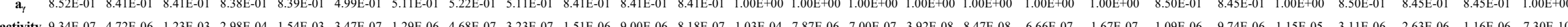

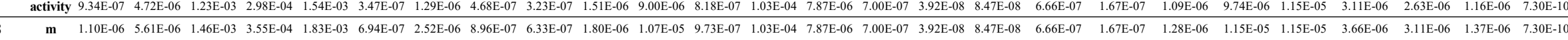

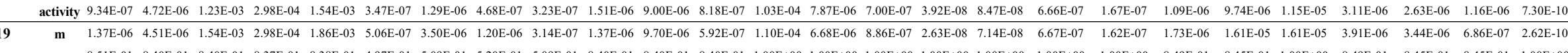

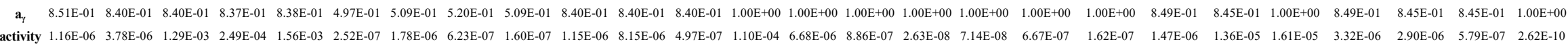

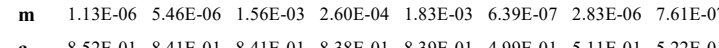

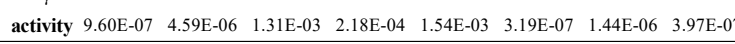

$\begin{array}{lllllllll}\mathbf{m} & 1.45 \mathrm{E}-06 & 4.25 \mathrm{E}-06 & 1.59 \mathrm{E}-03 & 2.49 \mathrm{E}-04 & 1.85 \mathrm{E}-03 & 3.06 \mathrm{E}-07 & 2.23 \mathrm{E}-06 & 7.14 \mathrm{E}-07\end{array}$

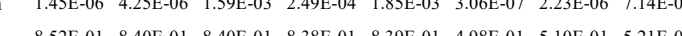

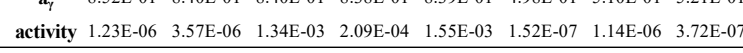

$\begin{array}{lllllllllll} & 1.31 \mathrm{E}-06 & 4.70 \mathrm{E}-06 & 1.64 \mathrm{E}-03 & 2.40 \mathrm{E}-04 & 1.90 \mathrm{E}-03 & 4.12 \mathrm{E}-07 & 2.59 \mathrm{E}-06 & 6.71 \mathrm{E}-07\end{array}$

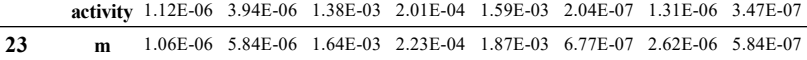

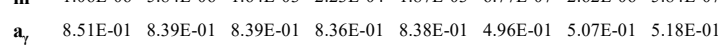

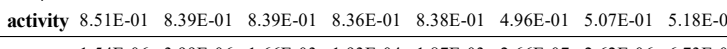

$\begin{array}{llllllllllllllll}24 & \mathbf{m} & 1.54 \mathrm{E}-06 & 3.99 \mathrm{E}-06 & 1.66 \mathrm{E}-03 & 1.93 \mathrm{E}-04 & 1.87 \mathrm{E}-03 & 2.66 \mathrm{E}-07 & 2.62 \mathrm{E}-06 & 6.73 \mathrm{E}-07\end{array}$

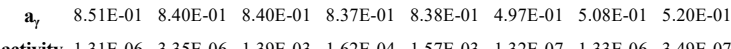

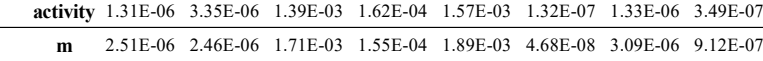

\begin{tabular}{lllllllll}
$a_{7}$ & $8.51 \mathrm{E}-01$ & $8.39 \mathrm{E}-01$ & $8.39 \mathrm{E}-01$ & $8.37 \mathrm{E}-01$ & $8.38 \mathrm{E}-01$ & $4.96 \mathrm{E}-01$ & $5.07 \mathrm{E}-01$ & $5.19 \mathrm{E}-01$ \\
\hline
\end{tabular}

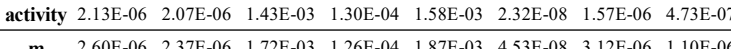

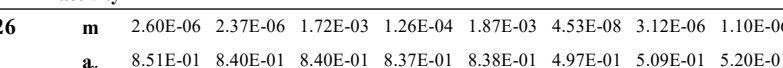

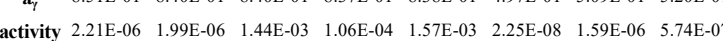

$\begin{array}{llllllllll}27 & \mathbf{m} & 2.25 \mathrm{E}-06 & 2.74 \mathrm{E}-06 & 1.72 \mathrm{E}-03 & 1.10 \mathrm{E}-04 & 1.85 \mathrm{E}-03 & 5.44 \mathrm{E}-08 & 2.33 \mathrm{E}-06 & 6.14 \mathrm{E}-07\end{array}$

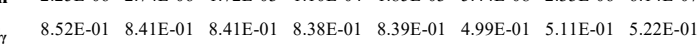

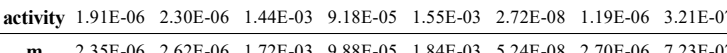

$\begin{array}{lllllllll}\mathbf{m} & 2.35 \mathrm{E}-06 & 2.62 \mathrm{E}-06 & 1.72 \mathrm{E}-03 & 9.88 \mathrm{E}-05 & 1.84 \mathrm{E}-03 & 5.24 \mathrm{E}-08 & 2.70 \mathrm{E}-06 & 7.23 \mathrm{E}-07\end{array}$

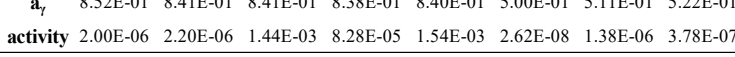

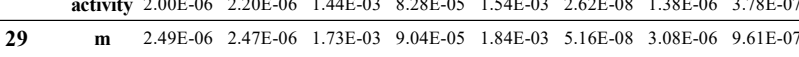

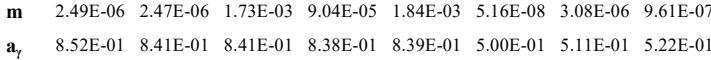
$\begin{array}{llllllllll}\text { activity } & 2.12 \mathrm{E}-06 & 2.07 \mathrm{E}-06 & 1.45 \mathrm{E}-03 & 7.57 \mathrm{E}-05 & 1.55 \mathrm{E}-03 & 2.58 \mathrm{E}-08 & 1.57 \mathrm{E}-06 & 5.01 \mathrm{E}-07\end{array}$

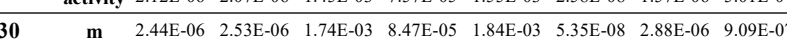

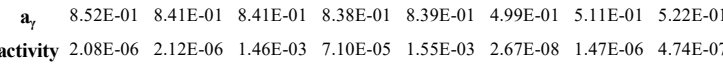

$\begin{array}{lllllllllll}\mathbf{m} & 2.55 \mathrm{E}-06 & 2.40 \mathrm{E}-06 & 1.71 \mathrm{E}-03 & 7.92 \mathrm{E}-05 & 1.82 \mathrm{E}-03 & 5.24 \mathrm{E}-08 & 3.25 \mathrm{E}-06 & 1.08 \mathrm{E}-06\end{array}$

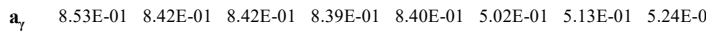

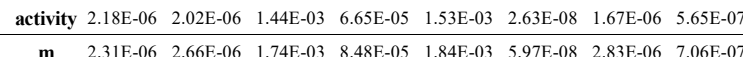

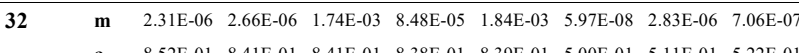

$\begin{array}{llllllllll}\mathbf{a}_{f} & 8.52 \mathrm{E}-01 & 8.41 \mathrm{E}-01 & 8.41 \mathrm{E}-01 & 8.38 \mathrm{E}-01 & 8.39 \mathrm{E}-01 & 5.00 \mathrm{E}-01 & 5.11 \mathrm{E}-01 & 5.22 \mathrm{E}-0 .\end{array}$

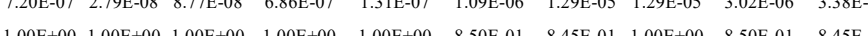

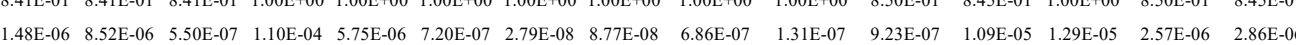

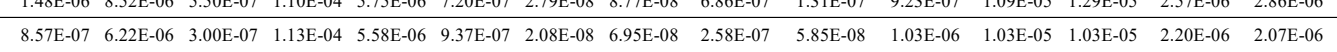

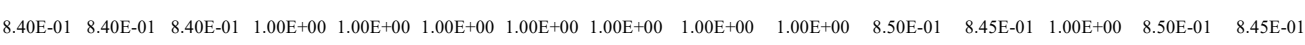

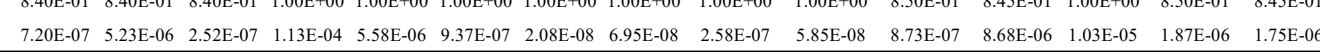

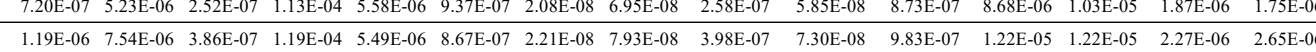

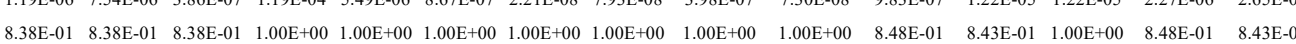

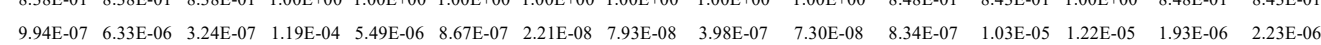

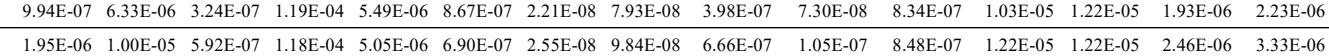

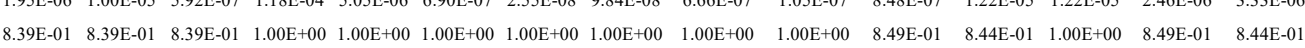

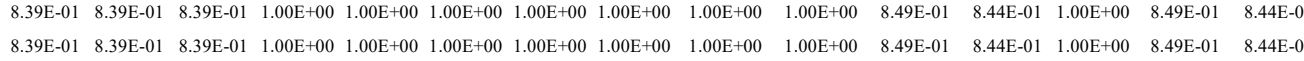

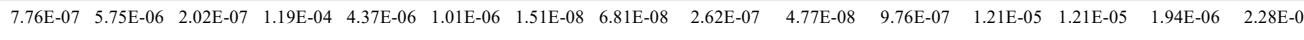

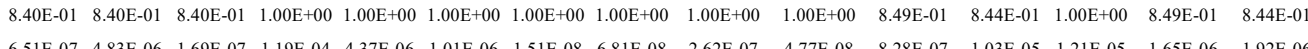

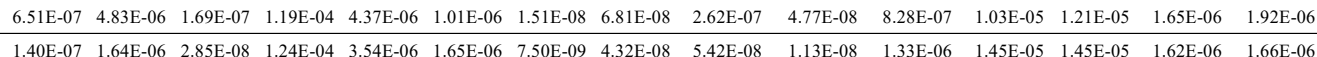

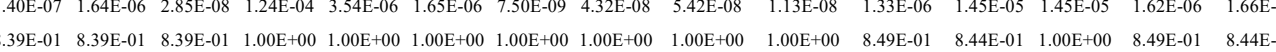

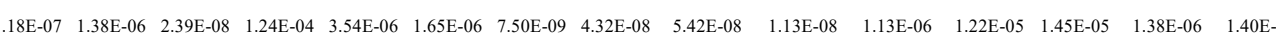

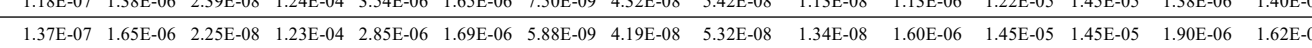

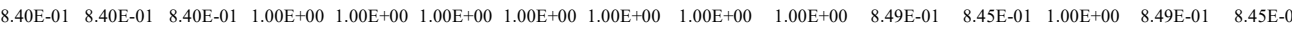

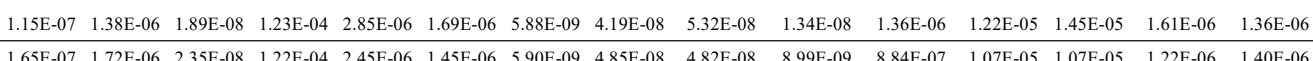

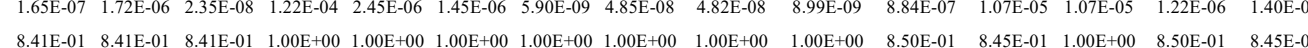

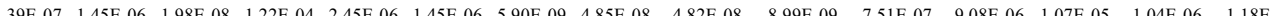

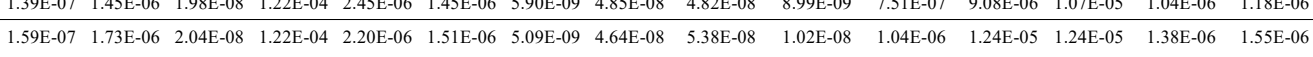

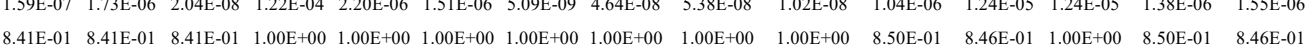

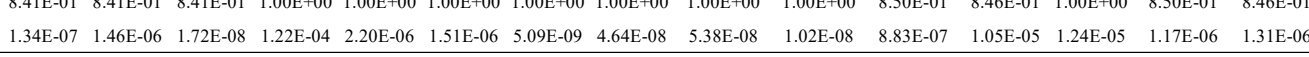

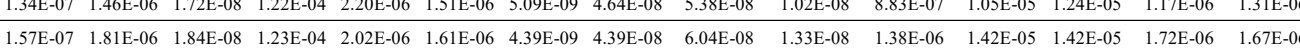

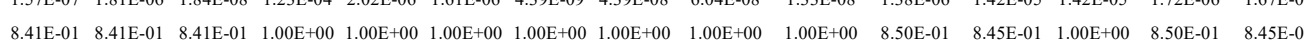

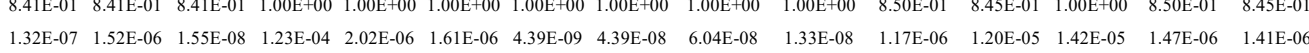

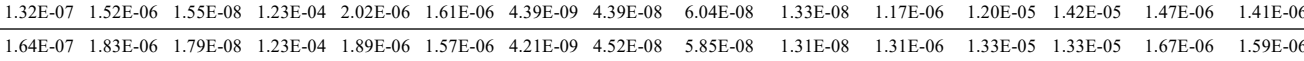

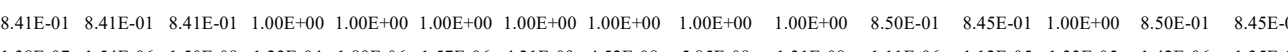

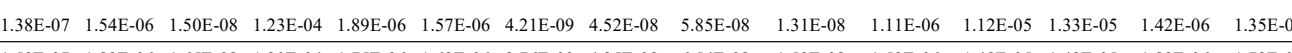

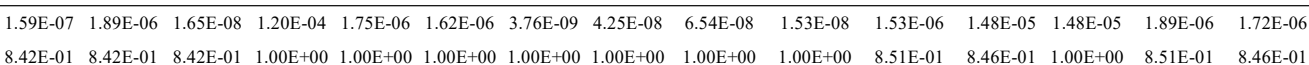

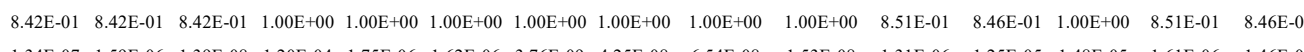

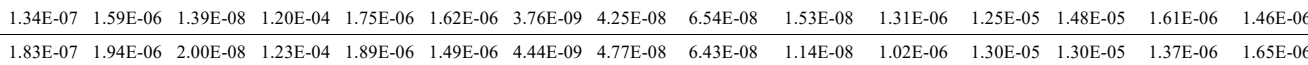

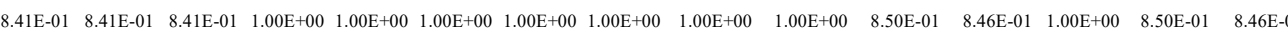

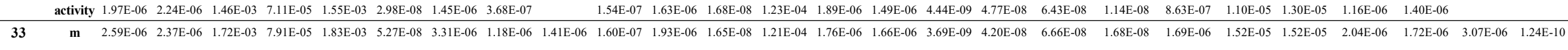

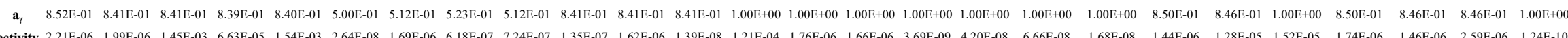

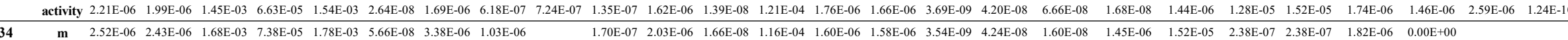

$\begin{array}{lllllllll}\text { activity } & 2.15 \mathrm{E}-06 & 2.05 \mathrm{E}-06 & 1.42 \mathrm{E}-03 & 6.20 \mathrm{E}-05 & 1.50 \mathrm{E}-03 & 2.85 \mathrm{E}-08 & 1.74 \mathrm{E}-06 & 5.43 \mathrm{E}-07\end{array}$

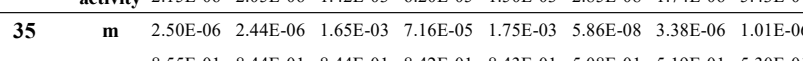

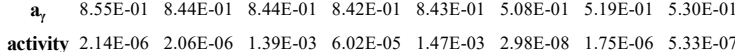

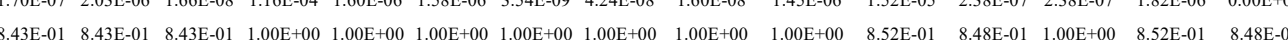

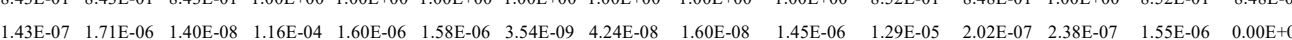

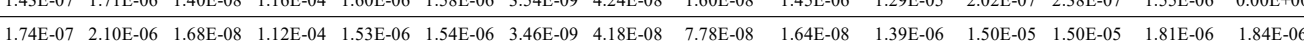

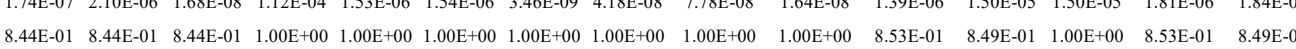

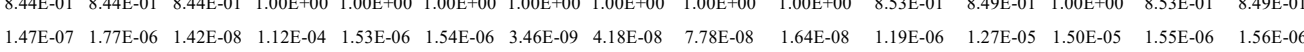


Table B.3.25. Ions activity and logarithm of activity calculate by the R package (linked to EqSolvR by Mroczek S. and Mroczek E., 2017) for the BW2 experiment $\left(350^{\circ} \mathrm{C} / 490\right.$ bar). Table also reports values of quench pH, in situ $\mathrm{pH}$, experimental time, flow-rate, $\mathrm{T}$ and $\mathrm{P}$

\begin{tabular}{|c|c|c|c|c|c|c|c|c|c|c|c|c|c|c|c|c|c|c|c|c|c|}
\hline samples & $\begin{array}{c}\text { water } \\
\text { (distilled) } \\
\text { blank }\end{array}$ & 7 & 8 & 9 & 10 & 11 & 12 & 13 & 14 & 15 & 16 & 17 & 18 & 19 & 20 & 21 & 22 & 23 & 24 & 25 & 26 \\
\hline $\boldsymbol{a}=\underset{\mathrm{H}^{+}}{\boldsymbol{m} \cdot \boldsymbol{a}}$ & $5.14 \mathrm{E}-06$ & $5.74 \mathrm{E}-07$ & $4.29 \mathrm{E}-07$ & $8.11 E-07$ & $4.88 \mathrm{E}-07$ & $8.23 \mathrm{E}-07$ & $6.94 \mathrm{E}-07$ & $6.58 \mathrm{E}-07$ & $7.17 \mathrm{E}-07$ & $8.29 \mathrm{E}-07$ & $1.61 \mathrm{E}-06$ & $1.51 \mathrm{E}-06$ & $3.14 \mathrm{E}-06$ & $4.88 \mathrm{E}-06$ & $5.04 \mathrm{E}-06$ & $2.99 \mathrm{E}-06$ & $3.23 \mathrm{E}-06$ & $2.24 \mathrm{E}-06$ & 3.49E-06 & $3.32 \mathrm{E}-06$ & $3.44 \mathrm{E}-06$ \\
\hline OH & 1.50E-06 & $1.35 \mathrm{E}-05$ & $1.80 \mathrm{E}-05$ & $9.53 \mathrm{E}-06$ & $1.58 \mathrm{E}-05$ & 9.39E-06 & $1.11 \mathrm{E}-05$ & $1.17 \mathrm{E}-05$ & $1.08 \mathrm{E}-05$ & $9.32 \mathrm{E}-06$ & 4.79E-06 & $5.13 \mathrm{E}-06$ & $2.46 \mathrm{E}-06$ & $1.58 \mathrm{E}-06$ & $1.53 \mathrm{E}-06$ & $2.58 \mathrm{E}-06$ & $2.39 \mathrm{E}-06$ & 3.45E-06 & $2.22 E-06$ & $2.32 \mathrm{E}-06$ & $2.25 \mathrm{E}-06$ \\
\hline $\mathrm{Na}^{+}$ & $2.71 \mathrm{E}-04$ & $9.58 \mathrm{E}-04$ & $6.70 \mathrm{E}-04$ & $2.98 \mathrm{E}-04$ & $7.79 \mathrm{E}-04$ & $7.53 \mathrm{E}-04$ & $6.50 \mathrm{E}-04$ & 7.85E-04 & $9.81 \mathrm{E}-04$ & $9.22 \mathrm{E}-04$ & $1.23 \mathrm{E}-03$ & $1.43 \mathrm{E}-03$ & $1.68 \mathrm{E}-03$ & $1.84 \mathrm{E}-03$ & $1.88 \mathrm{E}-03$ & $2.07 \mathrm{E}-03$ & $1.86 \mathrm{E}-03$ & $2.31 \mathrm{E}-03$ & $1.93 \mathrm{E}-03$ & $1.83 \mathrm{E}-03$ & $1.86 \mathrm{E}-03$ \\
\hline $\mathrm{K}^{+}$ & $7.61 \mathrm{E}-05$ & $3.15 \mathrm{E}-04$ & $2.49 \mathrm{E}-04$ & $2.95 \mathrm{E}-04$ & $2.29 \mathrm{E}-04$ & $2.42 \mathrm{E}-04$ & $2.18 \mathrm{E}-04$ & $1.84 \mathrm{E}-04$ & $2.01 \mathrm{E}-04$ & $2.28 \mathrm{E}-04$ & $2.71 \mathrm{E}-04$ & $2.67 \mathrm{E}-04$ & $3.02 \mathrm{E}-04$ & $3.49 \mathrm{E}-04$ & $4.33 \mathrm{E}-04$ & $4.50 \mathrm{E}-04$ & $4.33 \mathrm{E}-04$ & $5.22 \mathrm{E}-04$ & 4.15E-04 & $4.30 \mathrm{E}-04$ & 4.11E-04 \\
\hline $\mathrm{Cl}$ & $3.95 \mathrm{E}-04$ & $1.25 \mathrm{E}-03$ & $8.60 \mathrm{E}-04$ & $6.13 \mathrm{E}-04$ & $9.73 \mathrm{E}-04$ & $1.01 E-03$ & $8.67 \mathrm{E}-04$ & $9.62 \mathrm{E}-04$ & $1.18 \mathrm{E}-03$ & $1.16 \mathrm{E}-03$ & $1.57 \mathrm{E}-03$ & $1.74 \mathrm{E}-03$ & $2.05 E-03$ & $2.26 \mathrm{E}-03$ & $2.40 \mathrm{E}-03$ & $2.57 \mathrm{E}-03$ & $2.35 \mathrm{E}-03$ & $2.85 \mathrm{E}-03$ & $2.40 \mathrm{E}-03$ & $2.32 \mathrm{E}-03$ & $2.32 \mathrm{E}-03$ \\
\hline $\mathrm{SO}_{4}^{2 \cdot}$ & $<$ LOD & $1.40 \mathrm{E}-05$ & $1.80 \mathrm{E}-05$ & $8.51 \mathrm{E}-06$ & $1.23 \mathrm{E}-05$ & $6.80 \mathrm{E}-06$ & $8.08 \mathrm{E}-06$ & $9.00 \mathrm{E}-06$ & $7.29 \mathrm{E}-06$ & $6.34 \mathrm{E}-06$ & $2.42 \mathrm{E}-06$ & $2.06 \mathrm{E}-06$ & $4.04 \mathrm{E}-07$ & $6.22 \mathrm{E}-09$ & $1.48 \mathrm{E}-08$ & $3.19 \mathrm{E}-07$ & $2.54 \mathrm{E}-07$ & $2.43 \mathrm{E}-07$ & $1.71 \mathrm{E}-07$ & $1.86 \mathrm{E}-07$ & $1.62 \mathrm{E}-07$ \\
\hline $\mathrm{Ca}^{2+}$ & 1.21E-05 & $5.64 \mathrm{E}-06$ & $3.62 \mathrm{E}-06$ & $1.08 \mathrm{E}-05$ & $3.32 \mathrm{E}-06$ & $8.09 E-06$ & $6.64 \mathrm{E}-06$ & $6.10 \mathrm{E}-06$ & $6.27 \mathrm{E}-06$ & $8.62 \mathrm{E}-06$ & 1.42E- -05 & $1.02 \mathrm{E}-05$ & $1.03 \mathrm{E}-05$ & $8.41 \mathrm{E}-06$ & $1.03 \mathrm{E}-05$ & 6.34E-06 & $8.45 \mathrm{E}-06$ & $2.10 \mathrm{E}-06$ & $7.63 \mathrm{E}-06$ & $7.69 \mathrm{E}-06$ & $7.56 \mathrm{E}-06$ \\
\hline $\mathrm{Mg}^{2+}$ & $1.95 \mathrm{E}-06$ & $2.31 \mathrm{E}-06$ & $1.07 \mathrm{E}-06$ & $2.07 \mathrm{E}-06$ & $6.61 \mathrm{E}-07$ & $1.59 \mathrm{E}-06$ & $9.91 \mathrm{E}-07$ & $1.18 \mathrm{E}-06$ & $9.34 \mathrm{E}-07$ & $1.06 E-06$ & $2.57 \mathrm{E}-06$ & $1.52 \mathrm{E}-06$ & $3.07 E-06$ & $2.97 \mathrm{E}-06$ & $3.25 \mathrm{E}-06$ & $2.52 \mathrm{E}-06$ & $2.01 E-06$ & $2.66 \mathrm{E}-07$ & $2.05 E-06$ & $1.62 \mathrm{E}-06$ & $1.71 \mathrm{E}-06$ \\
\hline $\mathrm{Fe}^{2+}$ & $5.47 \mathrm{E}-07$ & $1.09 \mathrm{E}-05$ & $9.77 \mathrm{E}-06$ & $9.37 \mathrm{E}-06$ & $9.67 \mathrm{E}-06$ & $8.63 \mathrm{E}-06$ & $7.59 \mathrm{E}-06$ & 7.67E-06 & $5.33 \mathrm{E}-06$ & $3.90 \mathrm{E}-06$ & $3.55 \mathrm{E}-06$ & $2.33 \mathrm{E}-06$ & $2.22 \mathrm{E}-06$ & $2.04 \mathrm{E}-06$ & $1.71 \mathrm{E}-06$ & $1.30 \mathrm{E}-06$ & $1.51 \mathrm{E}-06$ & $1.15 E-06$ & $1.13 \mathrm{E}-06$ & $1.29 \mathrm{E}-06$ & $6.89 \mathrm{E}-07$ \\
\hline$a^{2} H^{+}$ & $2.64 \mathrm{E}-11$ & $3.29 \mathrm{E}-13$ & $1.84 \mathrm{E}-13$ & $6.57 \mathrm{E}-13$ & $2.38 \mathrm{E}-13$ & $6.77 \mathrm{E}-13$ & $4.81 \mathrm{E}-13$ & $4.33 \mathrm{E}-13$ & $5.14 \mathrm{E}-13$ & $6.87 \mathrm{E}-13$ & $2.60 \mathrm{E}-12$ & $2.27 \mathrm{E}-12$ & $9.88 \mathrm{E}-12$ & $2.38 \mathrm{E}-11$ & $2.54 \mathrm{E}-11$ & $8.95 \mathrm{E}-12$ & $1.04 \mathrm{E}-11$ & $5.03 \mathrm{E}-12$ & $1.21 \mathrm{E}-11$ & $1.11 \mathrm{E}-11$ & 1.18E-11 \\
\hline $\log \left(a \mathrm{SiO}_{2}\right)$ & -4.4 & -1.7 & -1.5 & -1.5 & -1.5 & -1.5 & -1.5 & -1.5 & -1.5 & -1.6 & -1.6 & -1.6 & -1.7 & -1.9 & -1.9 & -1.9 & -1.9 & -2.0 & -2.0 & -2.0 & -2.0 \\
\hline $\log \left(a_{\mathrm{K}+} / a_{\mathrm{H}+}\right)$ & 1.2 & 2.7 & 2.8 & 2.6 & 2.7 & 2.5 & 2.5 & 2.4 & 2.4 & 2.4 & 2.2 & 2.2 & 2.0 & 1.9 & 1.9 & 2.2 & 2.1 & 2.4 & 2.1 & 2.1 & 2.1 \\
\hline $\log \left(a_{\mathrm{Na}+} / a_{\mathrm{H}+}\right)$ & 2.4 & 3.2 & 3.2 & 2.6 & 3.2 & 3.0 & 3.0 & 3.1 & 3.1 & 3.0 & 2.9 & 3.0 & 2.7 & 2.6 & 2.6 & 2.8 & 2.8 & 3.0 & 2.7 & 2.7 & 2.7 \\
\hline $\log \left(a_{\mathrm{Ca} 2} / a_{\mathrm{H}+}^{2}\right)$ & 5.7 & 7.2 & 7.3 & 7.2 & 7.1 & 7.1 & 7.1 & 7.1 & 7.1 & 7.1 & 6.7 & 6.7 & 6.0 & 5.5 & 5.6 & 5.9 & 5.9 & 5.6 & 5.8 & 5.8 & 5.8 \\
\hline $\log \left(a_{\mathrm{Fe} 2} / a_{\mathrm{H}+}^{2}\right)$ & 4.3 & 7.5 & 7.7 & 7.2 & 7.6 & 7.1 & 7.2 & 7.2 & 7.0 & 6.8 & 6.1 & 6.0 & 5.4 & 4.9 & 4.8 & 5.2 & 5.2 & 5.4 & 5.0 & 5.1 & 4.8 \\
\hline $\log \left(a_{\mathrm{Mg} 2+} / a_{\mathrm{H}+}^{2}\right)$ & 4.9 & 6.8 & 6.8 & 6.5 & 6.4 & 6.4 & 6.3 & 6.4 & 6.3 & 6.2 & 6.0 & 5.8 & 5.5 & 5.1 & 5.1 & 5.5 & 5.3 & 4.7 & 5.2 & 5.2 & 5.2 \\
\hline $\log a \mathrm{Na}^{+}$ & -3.6 & -3.0 & -3.2 & -3.5 & -3.1 & -3.1 & -3.2 & -3.1 & -3.0 & -3.0 & -2.9 & -2.8 & -2.8 & -2.7 & -2.7 & -2.7 & -2.7 & -2.6 & -2.7 & -2.7 & -2.7 \\
\hline & -4.1 & -3.5 & -3.6 & -3.5 & -3.6 & -3.6 & -3.7 & -3.7 & -3.7 & -3.6 & -3.6 & -3.6 & -3.5 & -3.5 & -3.4 & -3.3 & -3.4 & -3.3 & -3.4 & -3.4 & -3.4 \\
\hline $\log a \mathrm{Cl}$ & -3.4 & -2.9 & -3.1 & -3.2 & -3.0 & -3.0 & -3.1 & -3.0 & -2.9 & -2.9 & -2.8 & -2.8 & -2.7 & -2.6 & -2. & -2 & -2.6 & -2.5 & -2.6 & -2.6 & -2.6 \\
\hline $\log a \mathrm{SO}_{4}^{2-}$ & $<$ LOD & -4.9 & -4.7 & -5.1 & -4.9 & -5.2 & -5.1 & -5.0 & -5.1 & -5.2 & -5.6 & -5.7 & -6.4 & -8.2 & -7.8 & -6.5 & -6.6 & -6.6 & -6.8 & -6.7 & -6.8 \\
\hline $\log a \mathrm{Ca}^{2+}$ & -4.9 & -5.2 & -5.4 & -5.0 & -5.5 & -5.1 & -5.2 & -5.2 & -5.2 & -5.1 & -4.8 & -5.0 & -5.0 & -5.1 & -5.0 & -5.2 & -5.1 & -5.7 & -5.1 & -5.1 & -5.1 \\
\hline $\log a \mathrm{Mg}^{2+}$ & -5.7 & -5.6 & -6.0 & -5.7 & -6.2 & -5.8 & -6.0 & -5.9 & -6.0 & -6.0 & -5.6 & -5.8 & -5.5 & -5.5 & -5.5 & -5.6 & -5.7 & -6.6 & -5.7 & -5.8 & -5.8 \\
\hline $\log a \mathrm{Fe}^{2+}$ & -6.3 & -5.0 & -5.0 & -5.0 & -5.0 & -5.1 & -5.1 & -5.1 & -5.3 & -5.4 & -5.4 & -5.6 & -5.7 & -5.7 & -5.8 & -5.9 & -5.8 & -5.9 & -5.9 & -5.9 & -6.2 \\
\hline $\mathrm{T}$ & 350 & 352 & 350 & 351 & 350 & 351 & 351 & 351 & 350 & 350 & 351 & 351 & 351 & 350 & 351 & 351 & 351 & 351 & 351 & 351 & 351 \\
\hline P & 500 & 489 & 489 & 489 & 489 & 489 & 489 & 489 & 489 & 489 & 489 & 489 & 489 & 489 & 489 & 489 & 489 & 490 & 490 & 490 & 490 \\
\hline in situ $\mathrm{pH}_{\left(350^{\circ} \mathrm{C}\right)}$ & 5.29 & 6.24 & 6.37 & 6.09 & 6.31 & 6.08 & 6.16 & 6.18 & 6.14 & 6.08 & 5.79 & 5.82 & 5.50 & 5.31 & 5.30 & 5.52 & 5.49 & 5.65 & 5.46 & 5.48 & 5.46 \\
\hline room T pH & 6.8 & 5.50 & 7.13 & 7.59 & 8.41 & 8.50 & 8.59 & 8.78 & 8.88 & 8.96 & 9.07 & 9.22 & 9.39 & 9.35 & 9.48 & 9.47 & 9.52 & 9.64 & 9.53 & 9.59 & 9.60 \\
\hline flow rate $\left(\mathrm{ml} \mathrm{hr} \mathrm{r}^{-1}\right)$ & - & 1 & 1 & 1 & 1 & 1 & 1 & 1 & 1 & 1 & 1 & 1 & 1 & 1 & 1 & 1 & 1 & 1 & 1 & 1 & 1 \\
\hline time (hrs) & 0.0 & 160.5 & 184.3 & 211.6 & 232.8 & 256.5 & 280.5 & 304.0 & 328.3 & 353.0 & 378.2 & 403.6 & 424.3 & 449.2 & 472.5 & 496.3 & 519.3 & 546.3 & 572.4 & 592.6 & 616.8 \\
\hline
\end{tabular}


Table B.3.26. Ions activity and logarithm of activity calculate by the R package (linked to EqSolvR by Mroczek S. and Mroczek E., 2017) for the BW2 experiment $\left(350^{\circ} \mathrm{C} / 490\right.$ bar). Table also reports values of quench pH, in situ $\mathrm{pH}$, experimental time, flow-rate, $\mathrm{T}$ and $\mathrm{P}$

\begin{tabular}{|c|c|c|c|c|c|c|c|c|c|c|c|c|c|c|c|c|c|c|c|c|}
\hline & 27 & 28 & 29 & 30 & 31 & 32 & 33 & 34 & 35 & 36 & 37 & 38 & 39 & 40 & 41 & 42 & 43 & 44 & 45 & 46 \\
\hline \multicolumn{21}{|l|}{$a=\boldsymbol{m} \cdot \boldsymbol{a}_{y}$} \\
\hline $\begin{array}{c}\mathrm{H}^{+} \\
\mathrm{OH}\end{array}$ & $\begin{array}{l}2.31 \mathrm{E}-06 \\
3.35 \mathrm{E}-06\end{array}$ & $\begin{array}{l}3.50 \mathrm{E}-06 \\
2.21 \mathrm{E}-06\end{array}$ & $\begin{array}{l}3.28 \mathrm{E}-06 \\
2.36 \mathrm{E}-06\end{array}$ & $\begin{array}{l}2.80 \mathrm{E}-06 \\
2.76 \mathrm{E}-06\end{array}$ & $\begin{array}{l}3.04 \mathrm{E}-06 \\
2.54 \mathrm{E}-06\end{array}$ & $\begin{array}{l}3.06 \mathrm{E}-06 \\
2.52 \mathrm{E}-06\end{array}$ & $\begin{array}{l}3.53 \mathrm{E}-06 \\
2.19 \mathrm{E}-06\end{array}$ & $\begin{array}{l}\text { refilling } \\
\text { refilling }\end{array}$ & $\begin{array}{l}3.58 \mathrm{E}-06 \\
2.16 \mathrm{E}-06\end{array}$ & $\begin{array}{l}3.38 \mathrm{E}-06 \\
2.29 \mathrm{E}-06\end{array}$ & $\begin{array}{l}3.60 \mathrm{E}-06 \\
2.15 \mathrm{E}-06\end{array}$ & $\begin{array}{l}4.75 \mathrm{E}-06 \\
1.63 \mathrm{E}-06\end{array}$ & $\begin{array}{l}3.92 \mathrm{E}-06 \\
1.97 \mathrm{E}-06\end{array}$ & $\begin{array}{l}4.06 \mathrm{E}-06 \\
1.90 \mathrm{E}-06\end{array}$ & $\begin{array}{l}4.66 \mathrm{E}-06 \\
1.66 \mathrm{E}-06\end{array}$ & $\begin{array}{l}4.62 \mathrm{E}-06 \\
1.67 \mathrm{E}-06\end{array}$ & $\begin{array}{l}4.81 \mathrm{E}-06 \\
1.61 \mathrm{E}-06\end{array}$ & $\begin{array}{l}3.57 \mathrm{E}-06 \\
2.17 \mathrm{E}-06\end{array}$ & $\begin{array}{l}3.76 \mathrm{E}-06 \\
2.06 \mathrm{E}-06\end{array}$ & $\begin{array}{l}4.45 \mathrm{E}-06 \\
1.73 \mathrm{E}-06\end{array}$ \\
\hline $\begin{array}{l}\mathrm{OH} \\
\mathrm{Na}^{+}\end{array}$ & $\begin{array}{l}3.325-00 \\
2.25 \mathrm{E}-03\end{array}$ & $\begin{array}{l}2.21 \mathrm{E}-\mathrm{U} 0 \\
2.21 \mathrm{E}-03\end{array}$ & $2.09 \mathrm{E}-03$ & $2.10 \mathrm{E}-03$ & $\begin{array}{l}2.54 \mathrm{E}-00 \\
2.14 \mathrm{E}-03\end{array}$ & $2.08 \mathrm{E}-03$ & $2.19 \mathrm{E}-03$ & $\begin{array}{l}\text { refilling } \\
\text { to }\end{array}$ & $2.33 \mathrm{E}-03$ & $1.75 \mathrm{E}-03$ & $1.62 \mathrm{E}-03$ & $1.55 \mathrm{E}-03$ & $1.72 \mathrm{E}-03$ & $1.80 \mathrm{E}-03$ & $1.80 \mathrm{E}-03$ & $1.82 \mathrm{E}-03$ & $1.69 \mathrm{E}-03$ & $1.78 \mathrm{E}-03$ & $1.70 \mathrm{E}-03$ & $1.70 \mathrm{E}-03$ \\
\hline $\mathrm{K}^{+}$ & $4.31 \mathrm{E}-04$ & $4.14 \mathrm{E}-04$ & $3.94 \mathrm{E}-04$ & $3.80 \mathrm{E}-04$ & $3.58 \mathrm{E}-04$ & $3.52 \mathrm{E}-04$ & $3.49 \mathrm{E}-04$ & refilling & $2.56 \mathrm{E}-04$ & $1.51 \mathrm{E}-04$ & $\begin{array}{l}1.19 \mathrm{E}-04 \\
\end{array}$ & $1.18 \mathrm{E}-04$ & $1.14 \mathrm{E}-04$ & $1.16 \mathrm{E}-04$ & $1.17 \mathrm{E}-04$ & $1.14 \mathrm{E}-04$ & $1.22 \mathrm{E}-04$ & $1.21 \mathrm{E}-04$ & $1.11 \mathrm{E}-04$ & $1.12 \mathrm{E}-04$ \\
\hline $\mathrm{Cl}^{-}$ & $2.70 \mathrm{E}-03$ & $2.69 \mathrm{E}-03$ & $2.54 \mathrm{E}-03$ & $2.51 \mathrm{E}-03$ & $2.54 \mathrm{E}-03$ & $2.47 \mathrm{E}-03$ & $2.60 \mathrm{E}-03$ & refilling & $2.65 \mathrm{E}-03$ & $1.95 \mathrm{E}-03$ & $1.77 \mathrm{E}-03$ & $1.73 \mathrm{E}-03$ & $1.87 \mathrm{E}-03$ & $1.96 \mathrm{E}-03$ & $1.98 \mathrm{E}-03$ & $1.99 \mathrm{E}-03$ & $1.87 \mathrm{E}-03$ & $1.93 \mathrm{E}-03$ & $1.85 \mathrm{E}-03$ & $1.87 \mathrm{E}-03$ \\
\hline $\mathrm{SO}_{4}^{2-}$ & $3.09 \mathrm{E}-07$ & $1.93 \mathrm{E}-07$ & $1.87 \mathrm{E}-07$ & $2.12 \mathrm{E}-07$ & $1.99 \mathrm{E}-07$ & $1.86 \mathrm{E}-07$ & $1.66 \mathrm{E}-07$ & refilling & $1.57 \mathrm{E}-07$ & $2.21 \mathrm{E}-07$ & 4.79E- 08 & 6.67E-09 & $2.78 \mathrm{E}-08$ & $3.78 \mathrm{E}-08$ & $2.33 \mathrm{E}-08$ & $3.38 \mathrm{E}-09$ & 9.91E-09 & $3.03 \mathrm{E}-08$ & $4.53 \mathrm{E}-08$ & $0.00 \mathrm{E}+00$ \\
\hline $\mathrm{Ca}^{2+}$ & $3.46 \mathrm{E}-06$ & 7.43E-06 & $6.67 \mathrm{E}-06$ & $4.11 \mathrm{E}-06$ & $6.30 \mathrm{E}-06$ & $6.42 \mathrm{E}-06$ & $8.32 \mathrm{E}-06$ & refilling & $8.00 \mathrm{E}-06$ & $8.22 \mathrm{E}-06$ & $4.73 \mathrm{E}-06$ & $9.13 \mathrm{E}-06$ & $5.87 \mathrm{E}-06$ & 6.96E-06 & $8.30 \mathrm{E}-06$ & $7.83 \mathrm{E}-06$ & $6.47 \mathrm{E}-06$ & 4.61E-06 & $6.36 \mathrm{E}-06$ & $7.32 \mathrm{E}-06$ \\
\hline $\mathrm{Mg}^{2+}$ & $5.17 \mathrm{E}-07$ & $2.61 \mathrm{E}-06$ & $1.81 \mathrm{E}-06$ & $1.16 \mathrm{E}-06$ & $1.18 \mathrm{E}-06$ & $1.04 \mathrm{E}-06$ & $1.93 \mathrm{E}-06$ & refilling & $2.10 \mathrm{E}-06$ & $2.19 \mathrm{E}-06$ & $1.15 \mathrm{E}-06$ & $2.22 \mathrm{E}-06$ & $1.30 \mathrm{E}-06$ & $1.63 \mathrm{E}-06$ & $2.75 \mathrm{E}-06$ & $2.18 \mathrm{E}-06$ & 3.46E-06 & $7.95 \mathrm{E}-07$ & $1.02 \mathrm{E}-06$ & $1.71 \mathrm{E}-06$ \\
\hline $\mathrm{Fe}^{2+}$ & $7.03 \mathrm{E}-07$ & $1.41 \mathrm{E}-06$ & $1.04 \mathrm{E}-06$ & $6.83 \mathrm{E}-07$ & $4.82 \mathrm{E}-07$ & $2.01 \mathrm{E}-07$ & $9.26 \mathrm{E}-07$ & refilling & $1.26 \mathrm{E}-06$ & $<\mathrm{LOD}$ & $9.19 \mathrm{E}-07$ & $1.18 \mathrm{E}-06$ & $6.64 \mathrm{E}-07$ & $5.23 \mathrm{E}-07$ & $8.55 \mathrm{E}-07$ & $8.36 \mathrm{E}-07$ & $8.01 \mathrm{E}-07$ & $6.84 \mathrm{E}-07$ & $4.80 \mathrm{E}-07$ & $1.12 \mathrm{E}-06$ \\
\hline$a^{2} H^{+}$ & $5.33 \mathrm{E}-12$ & $1.23 \mathrm{E}-11$ & $1.07 \mathrm{E}-11$ & $7.82 \mathrm{E}-12$ & $9.26 \mathrm{E}-12$ & $9.39 \mathrm{E}-12$ & $1.24 \mathrm{E}-11$ & refilling & $1.28 \mathrm{E}-11$ & $1.14 \mathrm{E}-11$ & $1.30 \mathrm{E}-11$ & $2.26 \mathrm{E}-11$ & $1.53 \mathrm{E}-11$ & $1.65 \mathrm{E}-11$ & $2.17 \mathrm{E}-11$ & $2.13 \mathrm{E}-11$ & $2.32 \mathrm{E}-11$ & $1.27 \mathrm{E}-11$ & $1.41 \mathrm{E}-11$ & $1.98 \mathrm{E}-11$ \\
\hline $\log \left(a \mathrm{SiO}_{2}\right)$ & -2.0 & -2.0 & -2.0 & -2.0 & -2.0 & -2.1 & -2.1 & refilling & -2.0 & -2.1 & -2.1 & -2.1 & -2.1 & -2.1 & -2.1 & -2.1 & -2.1 & -2.1 & -2.1 & -2.1 \\
\hline $\log \left(a_{\mathrm{K}+} / a_{\mathrm{H}+}\right)$ & 2.3 & 2.1 & 2.1 & 2.1 & 2.1 & 2.1 & 2.0 & refilling & 1.9 & 1.6 & 1.5 & 1.4 & 1.5 & 1.5 & 1.4 & 1.4 & 1.4 & 1.5 & 1.5 & 1.4 \\
\hline $\log \left(a_{\mathrm{Na}+} / a_{\mathrm{H}+}\right)$ & 3.0 & 2.8 & 2.8 & 2.9 & 2.8 & 2.8 & 2.8 & refilling & 2.8 & 2.7 & 2.7 & 2.5 & 2.6 & 2.6 & 2.6 & 2.6 & 2.5 & 2.7 & 2.7 & 2.6 \\
\hline $\log \left(a_{\mathrm{Ca} 2+} / a_{\mathrm{H}+}^{2}\right)$ & 5.8 & 5.8 & 5.8 & 5.7 & 5.8 & 5.8 & 5.8 & refilling & 5.8 & 5.9 & 5.6 & 5.6 & 5.6 & 5.6 & 5.6 & 5.6 & 5.4 & 5.6 & 5.7 & 5.6 \\
\hline $\log \left(a_{\mathrm{Fe} 2+} / a_{\mathrm{H}+}^{2}\right)$ & 5.1 & 5.1 & 5.0 & 4.9 & 4.7 & 4.3 & 4.9 & refilling & 5.0 & & 4.9 & 4.7 & 4.6 & 4.5 & 4.6 & 4.6 & 4.5 & 4.7 & 4.5 & 4.8 \\
\hline $\log \left(a_{\mathrm{Mg} 2+} / a^{2}{ }^{2}\right)$ & 5.0 & 5.3 & 5.2 & 5.2 & 5.1 & 5.0 & 5.2 & refilling & 5.2 & 5.3 & 4.9 & 5.0 & 4.9 & 5.0 & 5.1 & 5.0 & 5.2 & 4.8 & 4.9 & 4.9 \\
\hline $\log a \mathrm{Na}^{+}$ & -2.6 & -2.7 & -2.7 & -2.7 & -2.7 & -2.7 & -2.7 & refilling & -2.6 & -2.8 & -2.8 & -2.8 & -2.8 & -2.7 & -2.7 & -2.7 & -2.8 & -2.7 & -2.8 & -2.8 \\
\hline $\log a \mathrm{~K}^{+}$ & -3.4 & -3.4 & -3.4 & -3.4 & -3.4 & -3.5 & -3.5 & refilling & -3.6 & -3.8 & -3.9 & -3.9 & -3.9 & -3.9 & -3.9 & -3.9 & -3.9 & -3.9 & -4.0 & -4.0 \\
\hline $\log a \mathrm{Cl}^{-}$ & -2.6 & -2.6 & -2.6 & -2.6 & -2.6 & -2.6 & -2.6 & refilling & -2.6 & -2.7 & -2.8 & -2.8 & -2.7 & -2.7 & -2.7 & -2.7 & -2.7 & -2.7 & -2.7 & -2.7 \\
\hline $\log a \mathrm{SO}_{4}^{2-}$ & -6.5 & -6.7 & -6.7 & -6.7 & -6.7 & -6.7 & -6.8 & refilling & -6.8 & -6.7 & -7.3 & -8.2 & -7.6 & -7.4 & -7.6 & -8.5 & -8.0 & -7.5 & -7.3 & \\
\hline $\log a \mathrm{Ca}^{2+}$ & -5.5 & -5.1 & -5.2 & -5.4 & -5.2 & -5.2 & -5.1 & refilling & -5.1 & -5.1 & -5.3 & -5.0 & -5.2 & -5.2 & -5.1 & -5.1 & -5.2 & -5.3 & -5.2 & -5.1 \\
\hline $\log a \mathrm{Mg}^{2+}$ & -6.3 & -5.6 & -5.7 & -5.9 & -5.9 & -6.0 & -5.7 & refilling & -5.7 & -5.7 & -5.9 & -5.7 & -5.9 & -5.8 & -5.6 & -5.7 & -5.5 & -6.1 & -6.0 & -5.8 \\
\hline $\log a \mathrm{Fe}^{2+}$ & -6.2 & -5.9 & -6.0 & -6.2 & -6.3 & -6.7 & -6.0 & refilling & -5.9 & & -6.0 & -5.9 & -6.2 & -6.3 & -6.1 & -6.1 & -6.1 & -6.2 & -6.3 & -6.0 \\
\hline $\mathrm{T}$ & 351 & 350 & 351 & 351 & 351 & 350 & 351 & refilling & 350 & 351 & 351 & 350 & 351 & 351 & 350 & 350 & 351 & 351 & 350 & 350 \\
\hline $\mathrm{P}$ & 488 & 489 & 490 & 490 & 490 & 489 & 488 & refilling & 490 & 490 & 490 & 490 & 490 & 489 & 489 & 490 & 490 & 490 & 489 & 489 \\
\hline in situ $\mathrm{pH}_{\left(350^{\circ} \mathrm{C}\right)}$ & 5.64 & 5.46 & 5.48 & 5.55 & 5.52 & 5.51 & 5.45 & refilling & 5.45 & 5.47 & 5.44 & 5.32 & 5.41 & 5.39 & 5.33 & 5.34 & 5.32 & 5.45 & 5.43 & 5.35 \\
\hline room $\mathrm{TpH}$ & 9.62 & 9.65 & 9.61 & 9.61 & 9.60 & 9.57 & 9.63 & refilling & 8.91 & 9.56 & 9.57 & 9.57 & 9.58 & 9.62 & 9.61 & 9.64 & 9.66 & 9.65 & 9.62 & 9.62 \\
\hline flow rate $\left(\mathrm{ml} \mathrm{hr} \mathrm{r}^{-1}\right)$ & 1 & 1 & 1 & 1 & 1 & 1 & 1 & refilling & 1 & 1 & 1 & 1 & 1 & 1 & 1 & 1 & 1 & 0.5 & 0.5 & 0.5 \\
\hline time (hrs) & 644.5 & 664.5 & 688.3 & 714.6 & 739.1 & 761.1 & 785.2 & refilling & 809.8 & 833.0 & 862.3 & 883.7 & 904.2 & 928.3 & 952.3 & 976.7 & 1002.1 & 1049.8 & 1096.5 & 1144.7 \\
\hline
\end{tabular}


Table B.3.27. Molal (m), activity coefficients ( $\mathrm{a}_{y}$ ) and activity of the ions species in solution calculated by the R package for the BW2

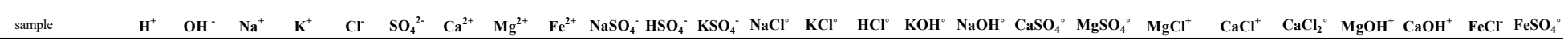

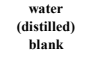

$1.54 \mathrm{-05} 2$ 2.48E-06 6.98E-07

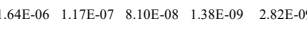

$\begin{array}{llllll}3.21 \mathrm{E}-07 & 5.83 \mathrm{E}-06 & 8.09 \mathrm{E}-09 & 1.27 \mathrm{E}-06 & 2.66 \mathrm{E}-06 & 1.39 \mathrm{E}-07\end{array}$

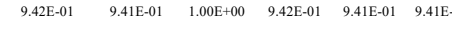

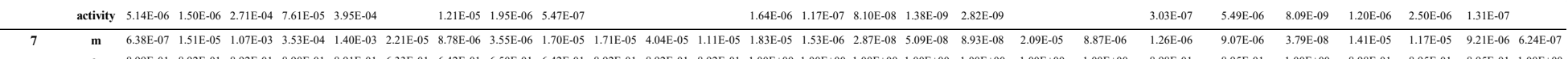

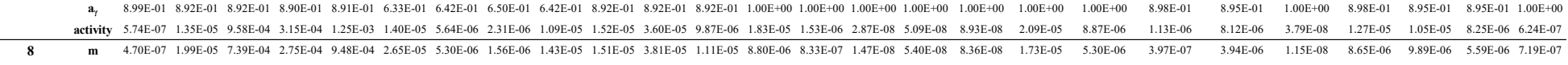

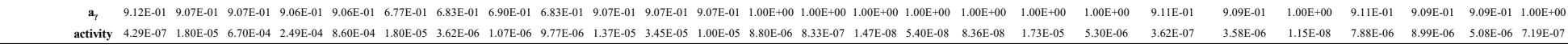

\begin{tabular}{llllllllllllll} 
& $\mathrm{m}$ & $8.76-07$ \\
\hline
\end{tabular}

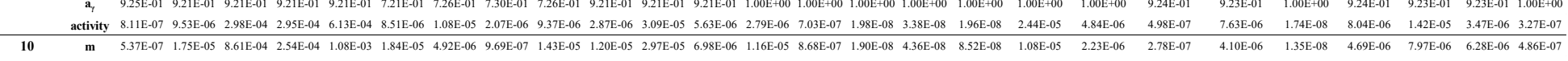

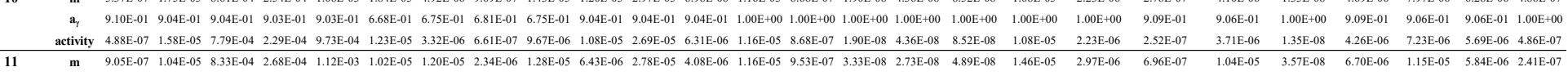

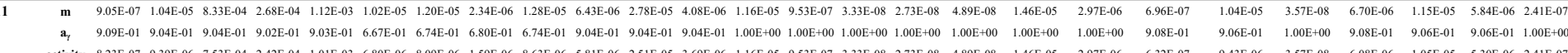

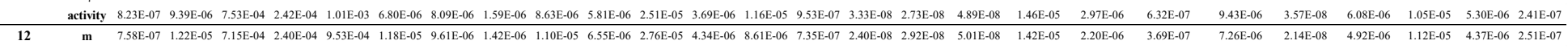

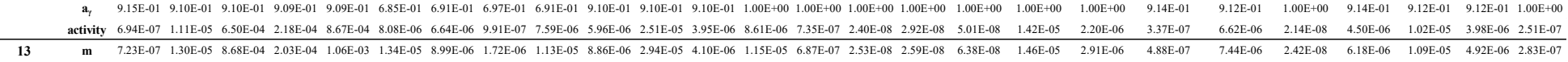

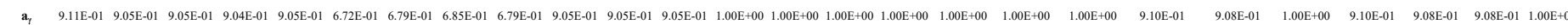

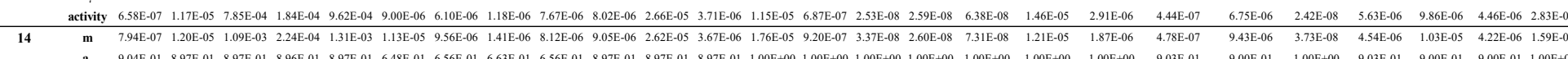

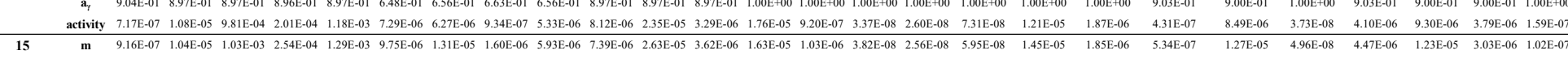

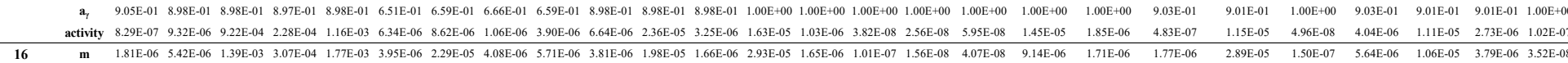

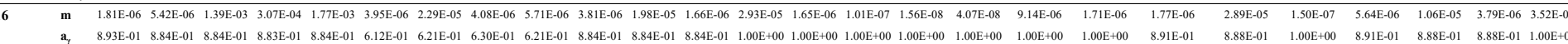

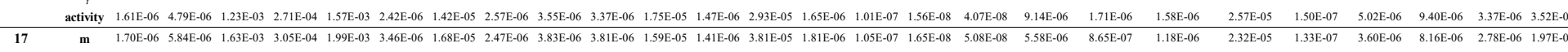

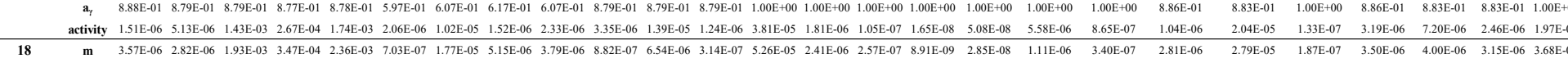

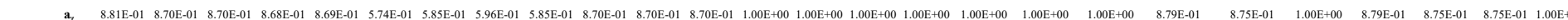

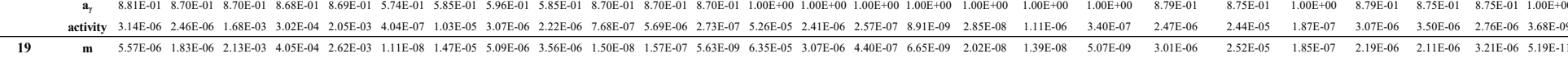

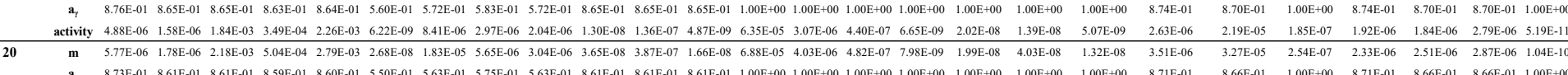

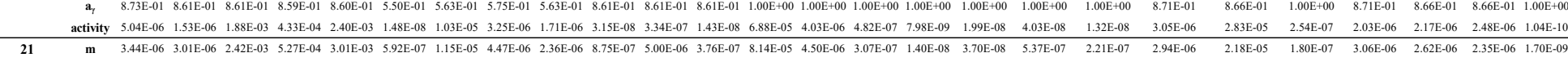

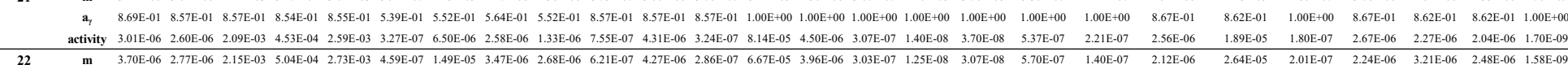

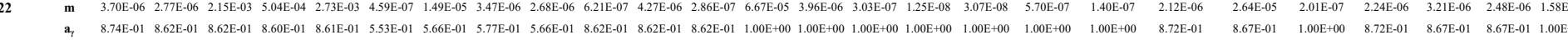

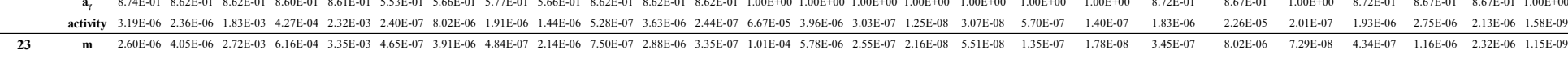

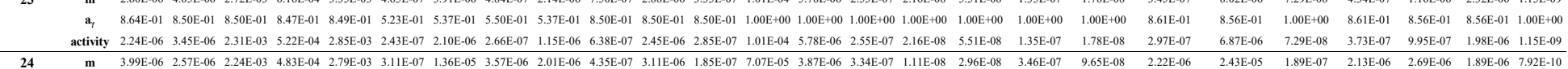

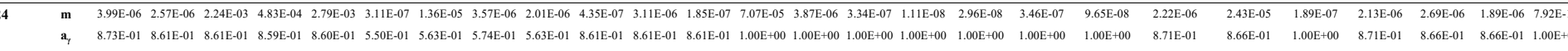

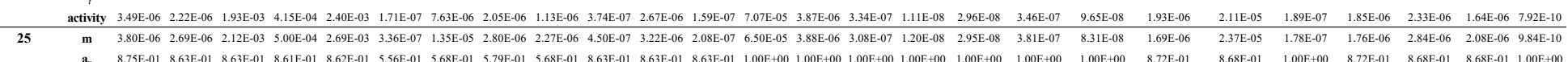

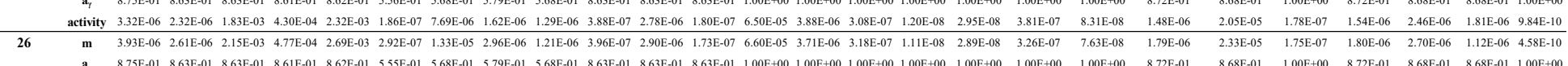

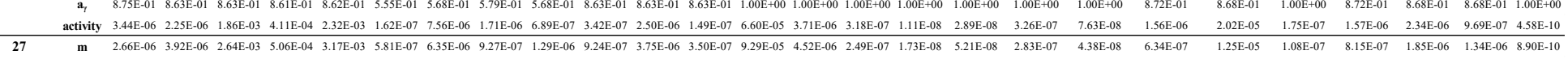

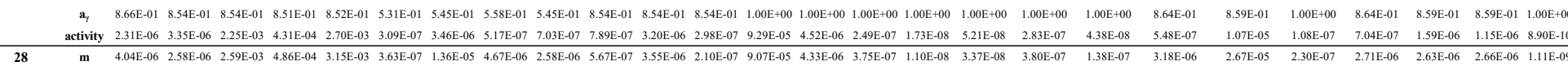

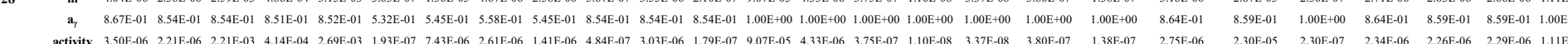

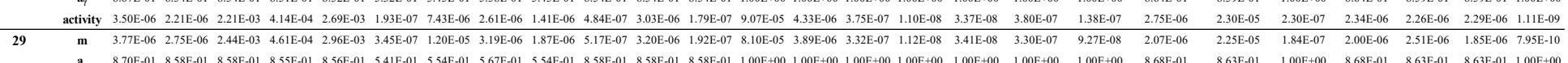

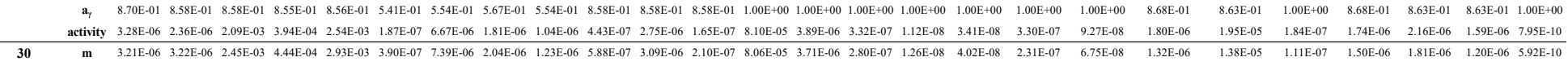

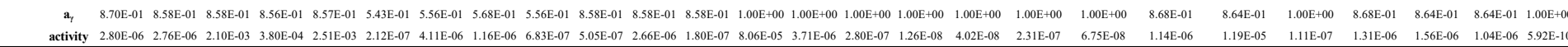

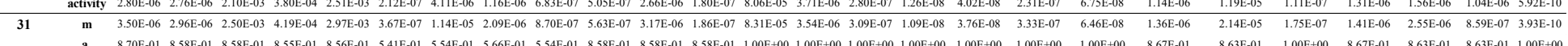

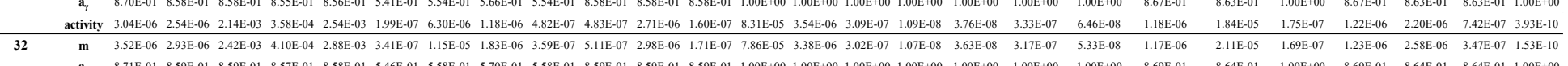

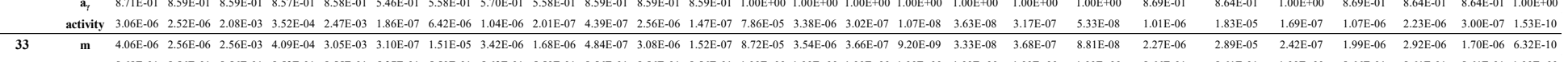

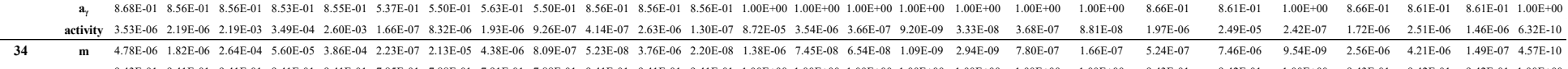

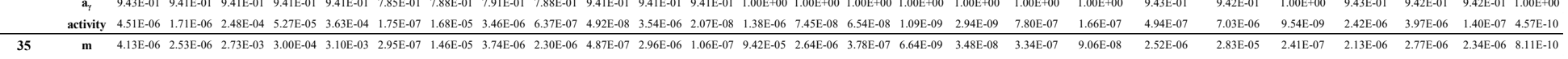

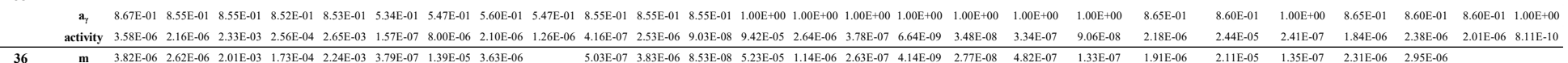

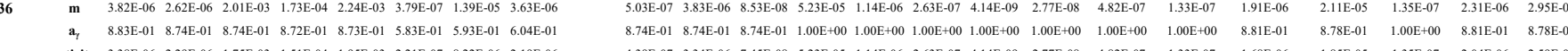

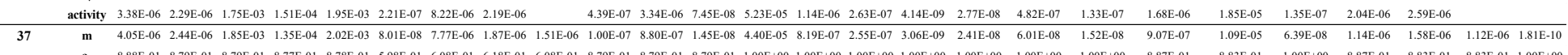

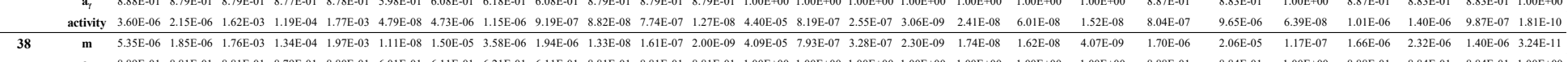

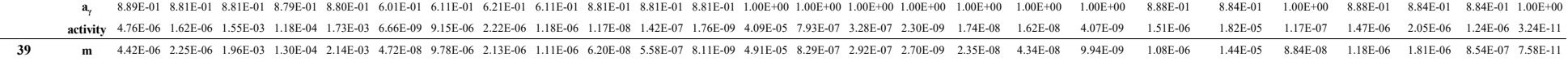

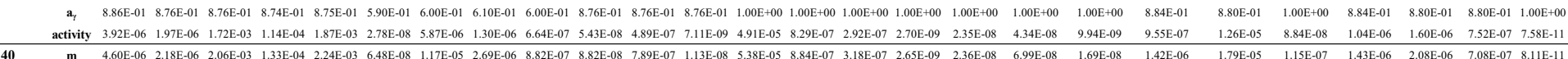

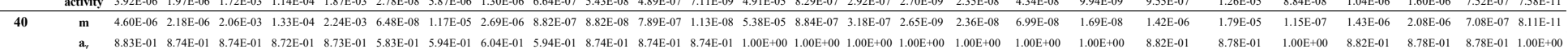

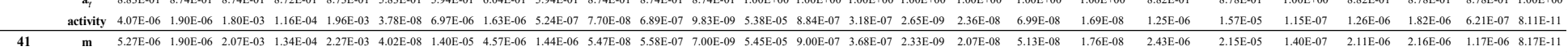

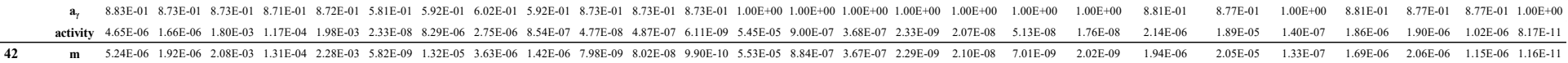

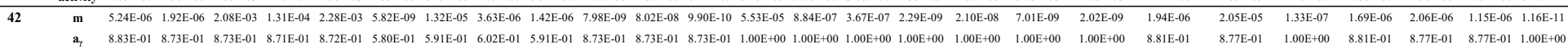

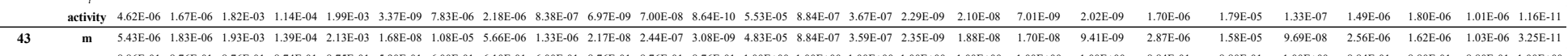

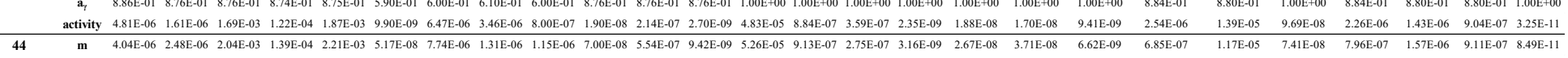

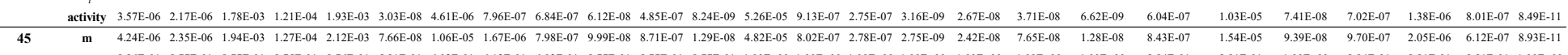

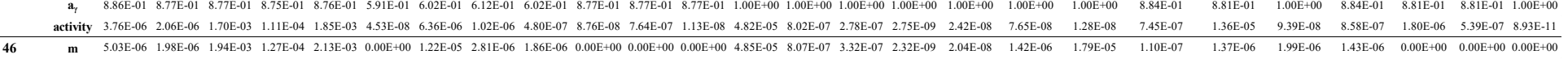

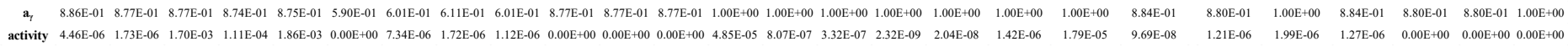




\section{Activity-activity diagrams}

Figure B.3.37. Activity diagrams for the $\mathrm{BW} 1$ showing mineral stability fields in the $\mathrm{CaO}-\mathrm{MgO}-\mathrm{Al}_{2} \mathrm{O}_{3}-\mathrm{H}_{2} \mathrm{O}$. Diagrams were constructed on the base of two different silica averages, during and after glass dissolution. Black and red crosses show position of effluent samples collected at 1.0 and $0.5 \mathrm{ml} \mathrm{hr}^{-1}$ flow rate, respectively. Yellow circles show position of the unreacted fluid (water) at $400^{\circ} \mathrm{C} / 500$ bar. Blue arrows show the path of reacted fluids over the time of the experiments.
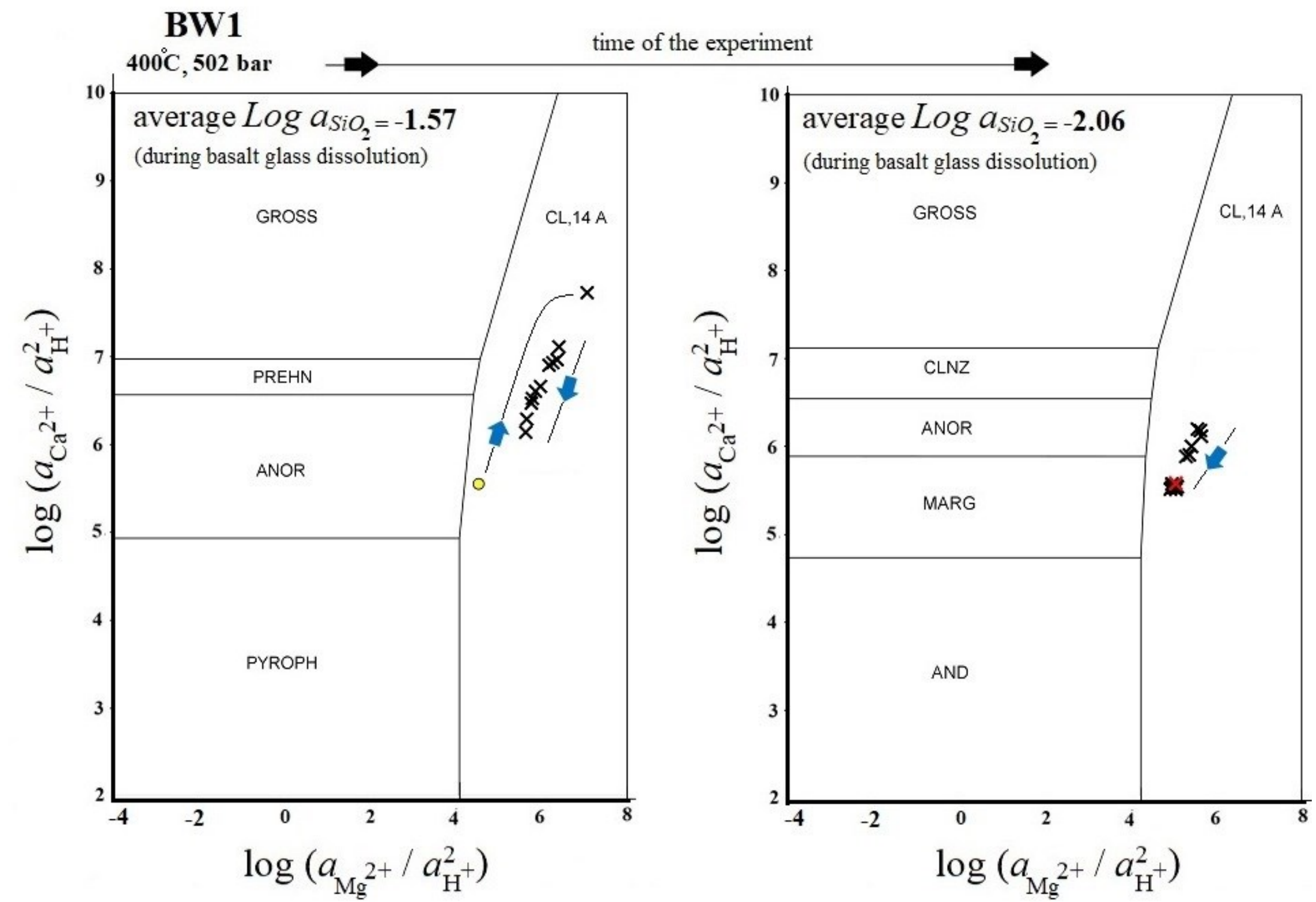

Figure B.3.38. Activity diagrams for the $\mathrm{BW} 2$ showing mineral stability fields in the $\mathrm{CaO}-\mathrm{MgO}-\mathrm{Al}_{2} \mathrm{O}_{3}-\mathrm{H}_{2} \mathrm{O}$. Diagrams were constructed on the base of two different silica averages, during and after glass dissolution process. Black and red crosses show position of effluent samples collected at 1.0 and $0.5 \mathrm{ml} \mathrm{hr}^{-1}$ flow rate, respectively. Yellow circles show position of the unreacted fluid (water) at $350^{\circ} \mathrm{C} / 490$ bar. Blue arrows show the path of reacted fluids over the time of the experiments.

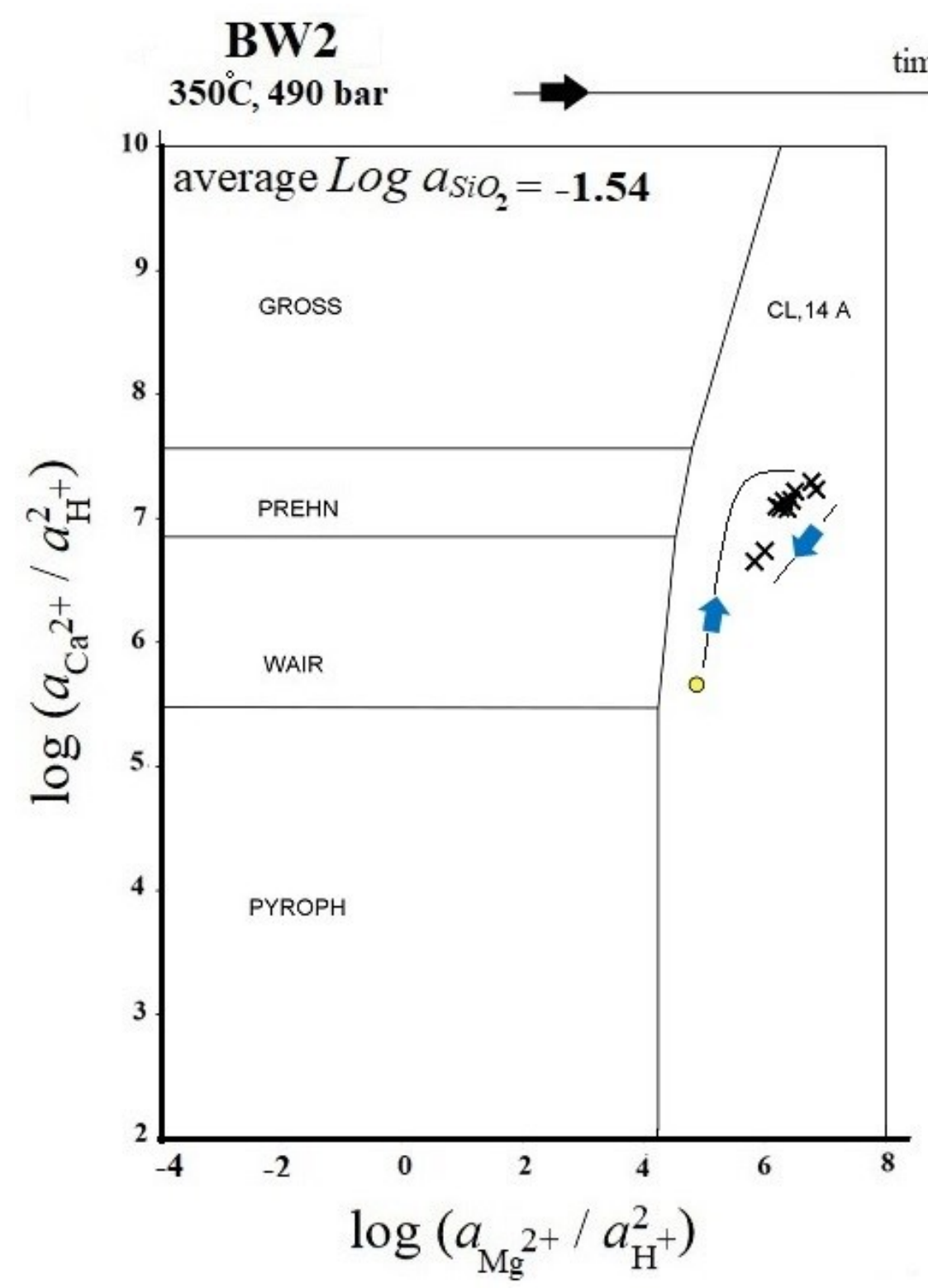

time of the experiment

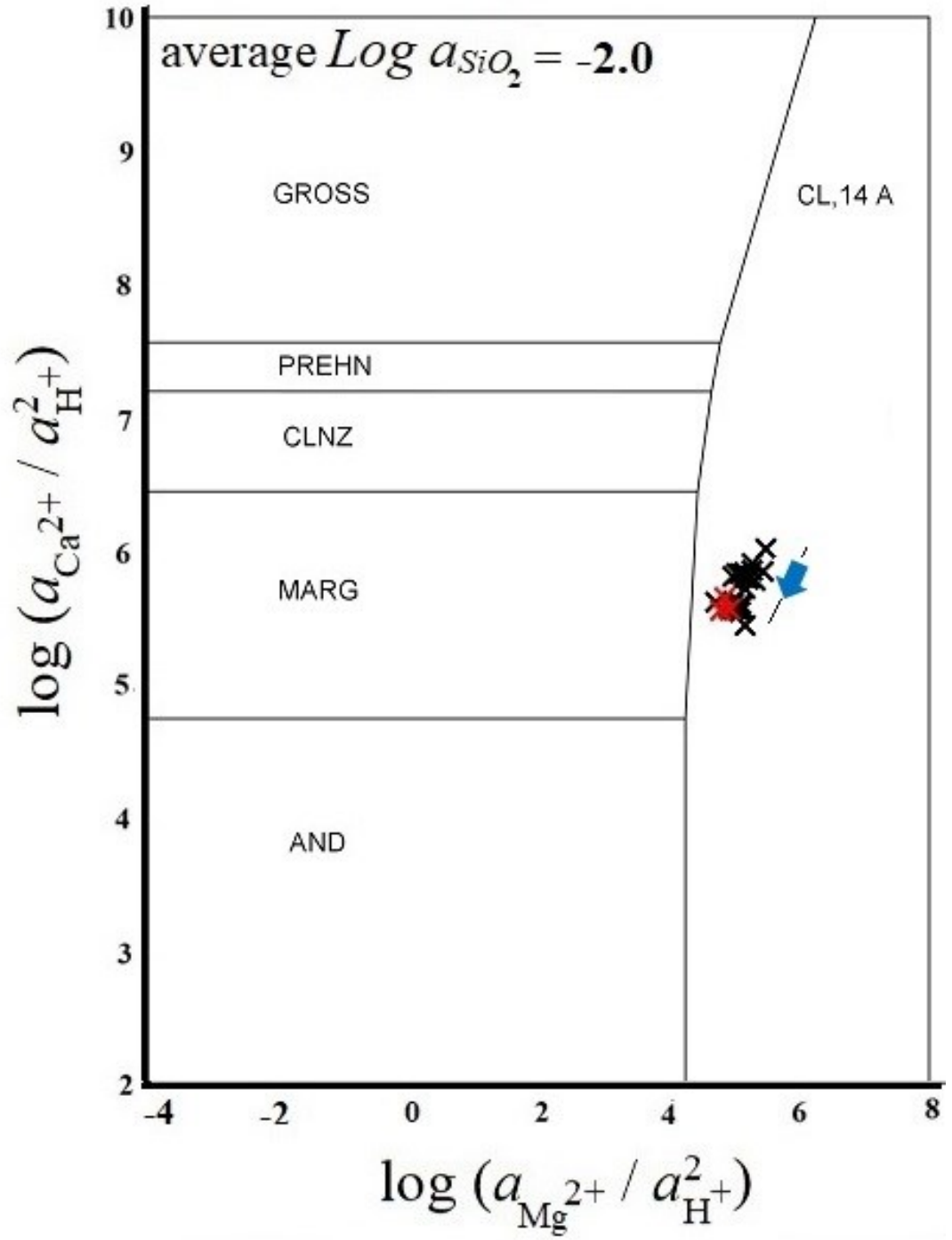


Figure B.3.39. Activity diagrams for the $\mathrm{BW} 1$ and $\mathrm{BW} 2$ showing mineral stability fields in the $\mathrm{CaO}-\mathrm{FeO}-\mathrm{Al}_{2} \mathrm{O}_{3}-\mathrm{H}_{2} \mathrm{O}$. Diagrams for each experiment were constructed on the base of two different silica averages, during and after glass dissolution. Black and red crosses show position of effluent samples collected at 1.0 and $0.5 \mathrm{ml}^{2} \mathrm{hr}^{-1}$ flow rate, respectively. Yellow circles show position of the unreacted fluid (water) at $400-$ $350^{\circ} \mathrm{C} / 500 \mathrm{bar}$. Blue arrows show the path of reacted fluids over the time of the experiments

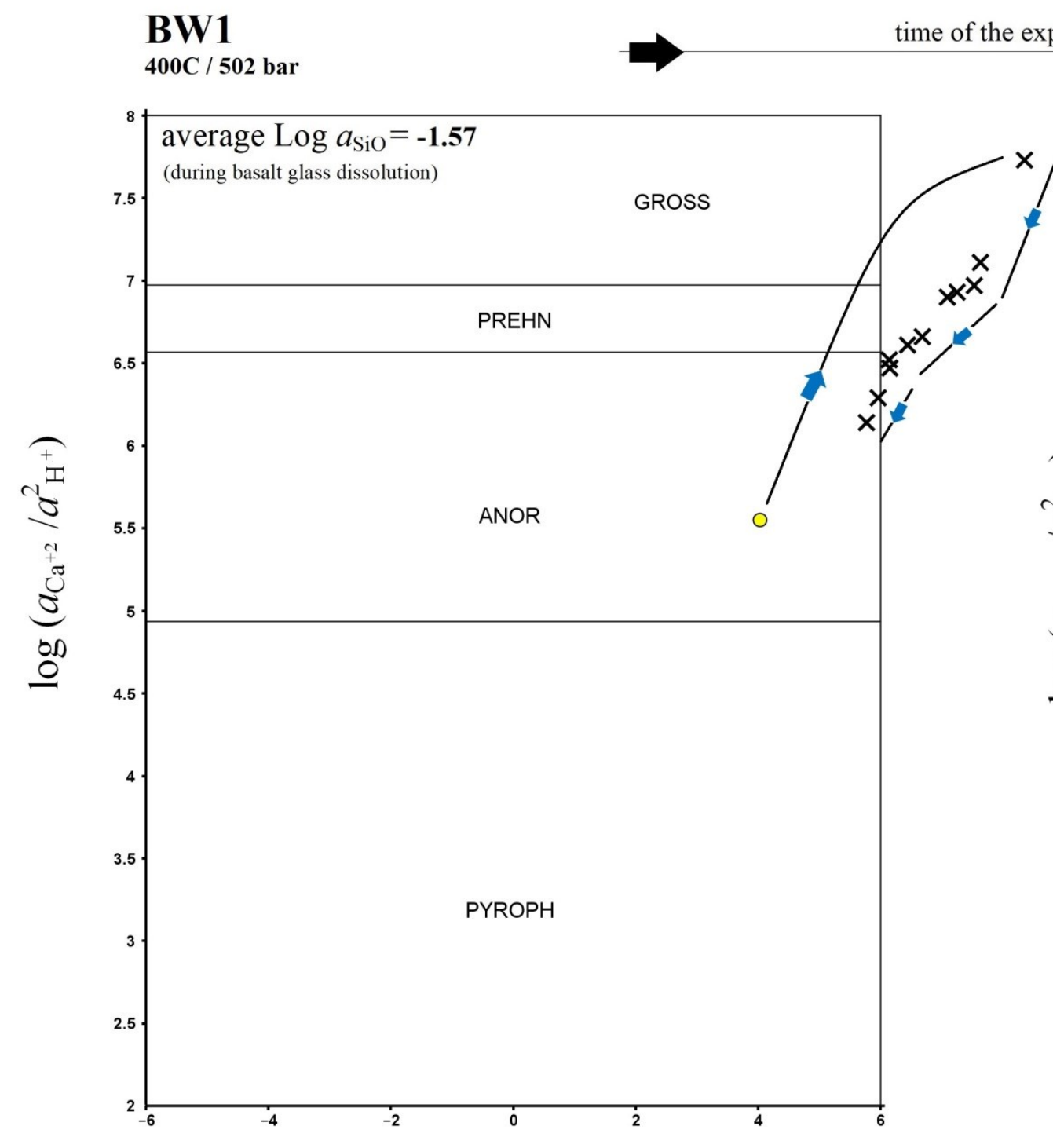

$\log \left(a_{\mathrm{Fe}}^{+2} / a_{\mathrm{H}^{+}}^{2}\right)$

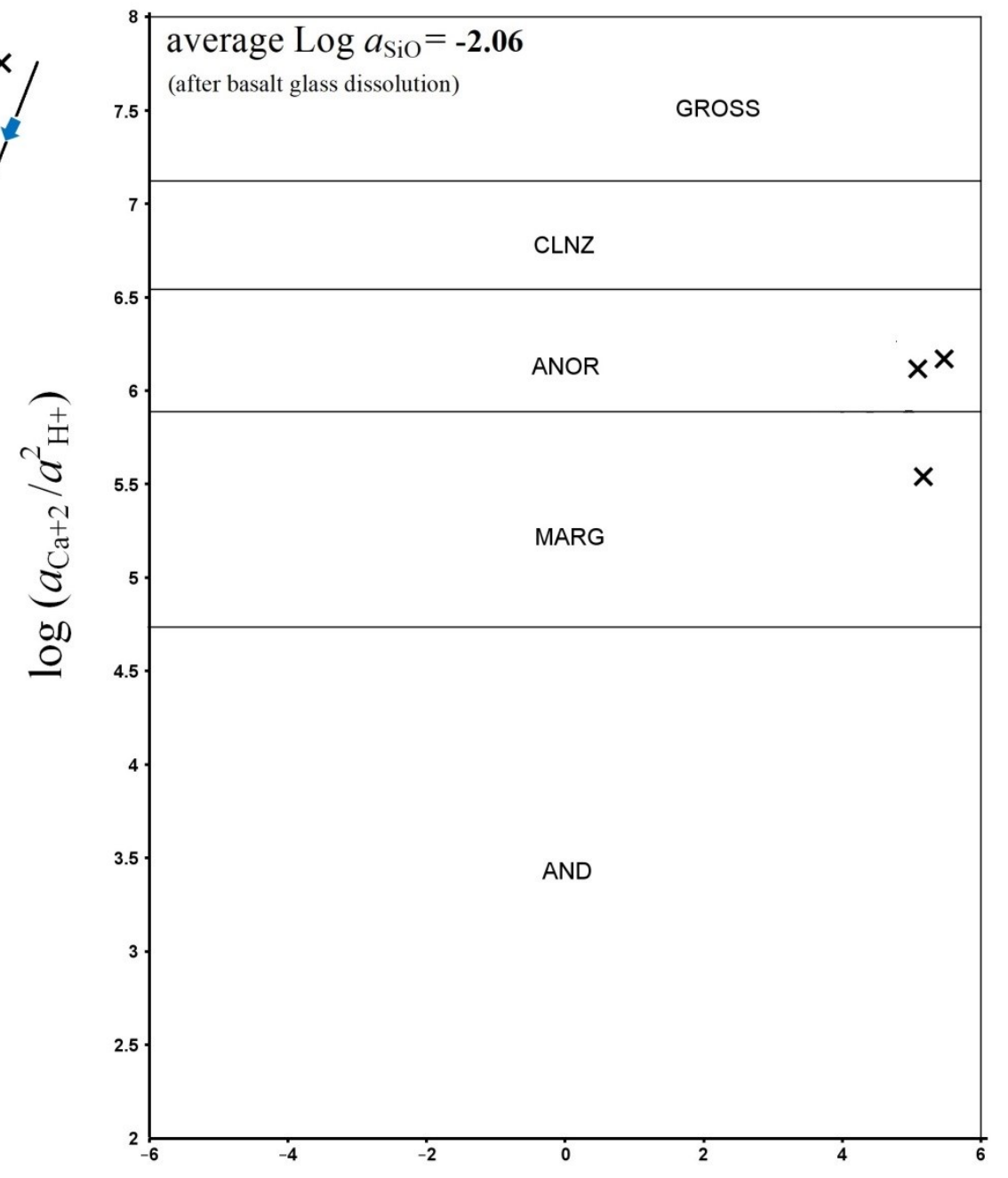

$\log \left(a_{\mathrm{Fe}^{+2}} / a_{\mathrm{H}^{+}}^{2}\right)$

\section{BW2}

$350 \mathrm{C} / 490$ bar

average $\log a_{\mathrm{SiO}}=\mathbf{- 1 . 5 4}$

(during basalt glass dissolution)

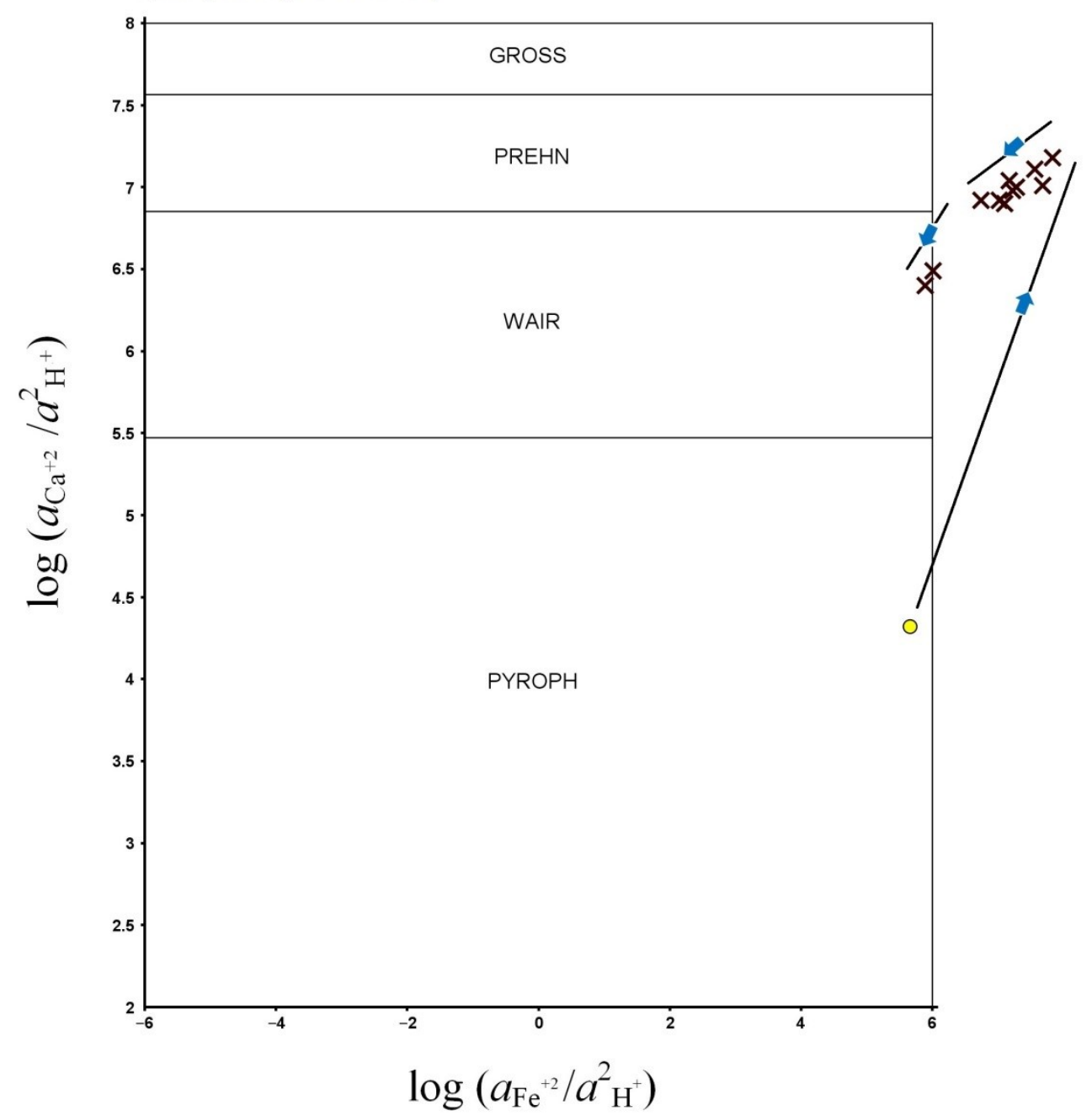

time of the experiment

$$
\text { average } \log a_{\mathrm{SiO}}=\mathbf{- 2 . 0}
$$

(after basalt glass dissolution)

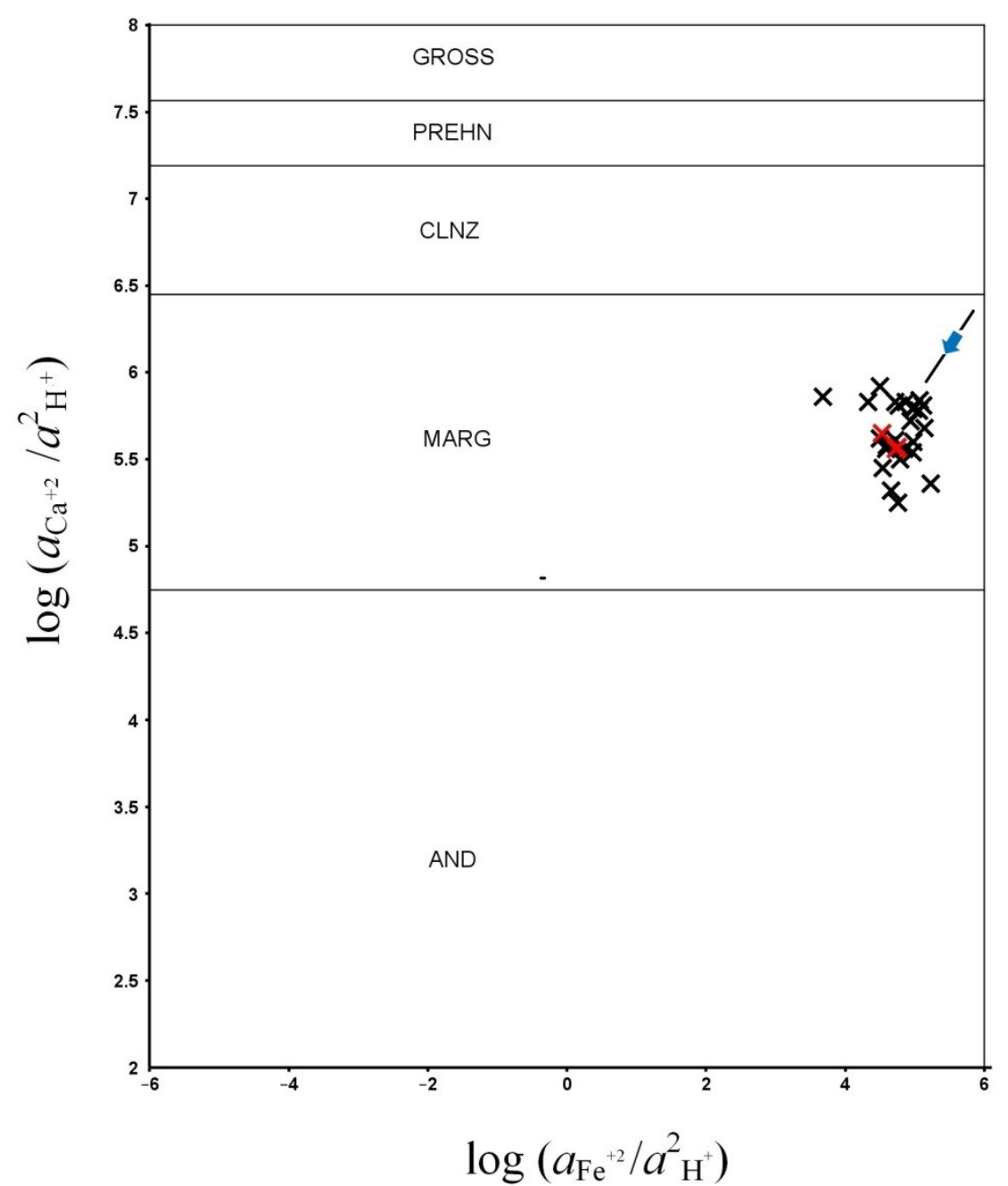


Figure B.3.40. Activity diagrams for the $\mathrm{BW} 1$ and $\mathrm{BW} 2$ showing mineral stability fields in the $\mathrm{CaO}-\mathrm{K}_{2} \mathrm{O}-\mathrm{Al}_{2} \mathrm{O}_{3}-\mathrm{H}_{2} \mathrm{O}$. Diagrams for each experiment were constructed on the base of two different silica averages, during and after glass dissolution. Black and red crosses show position of effluent samples collected at 1.0 and $0.5 \mathrm{ml} \mathrm{hr}^{-1}$ flow rate, respectively. Yellow circles show position of the unreacted fluid (water) at $400-$ $350^{\circ} \mathrm{C} / 500$ bar. Blue arrows show the path of reacted fluids over the time of the experiments

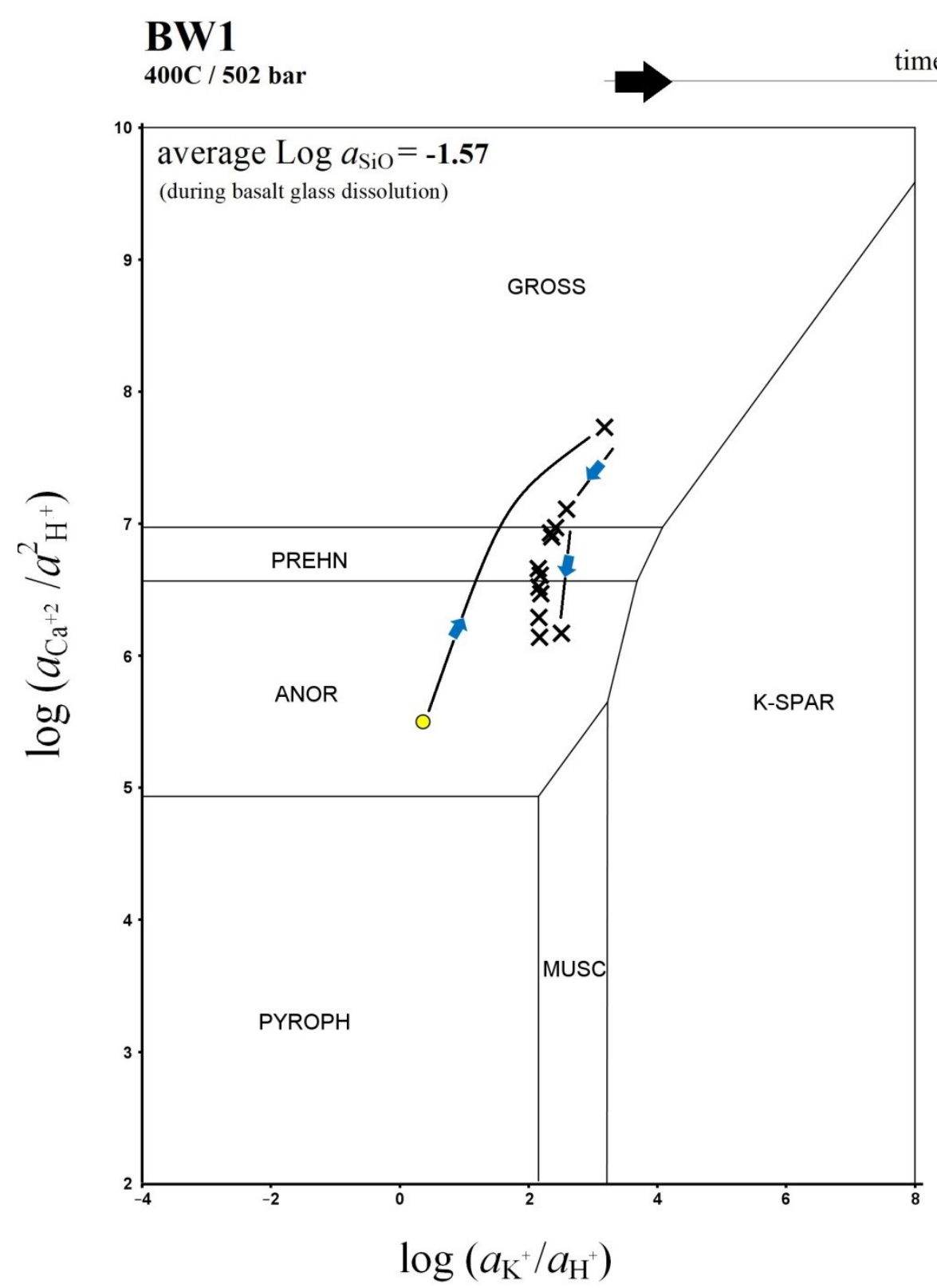

time of the experiment

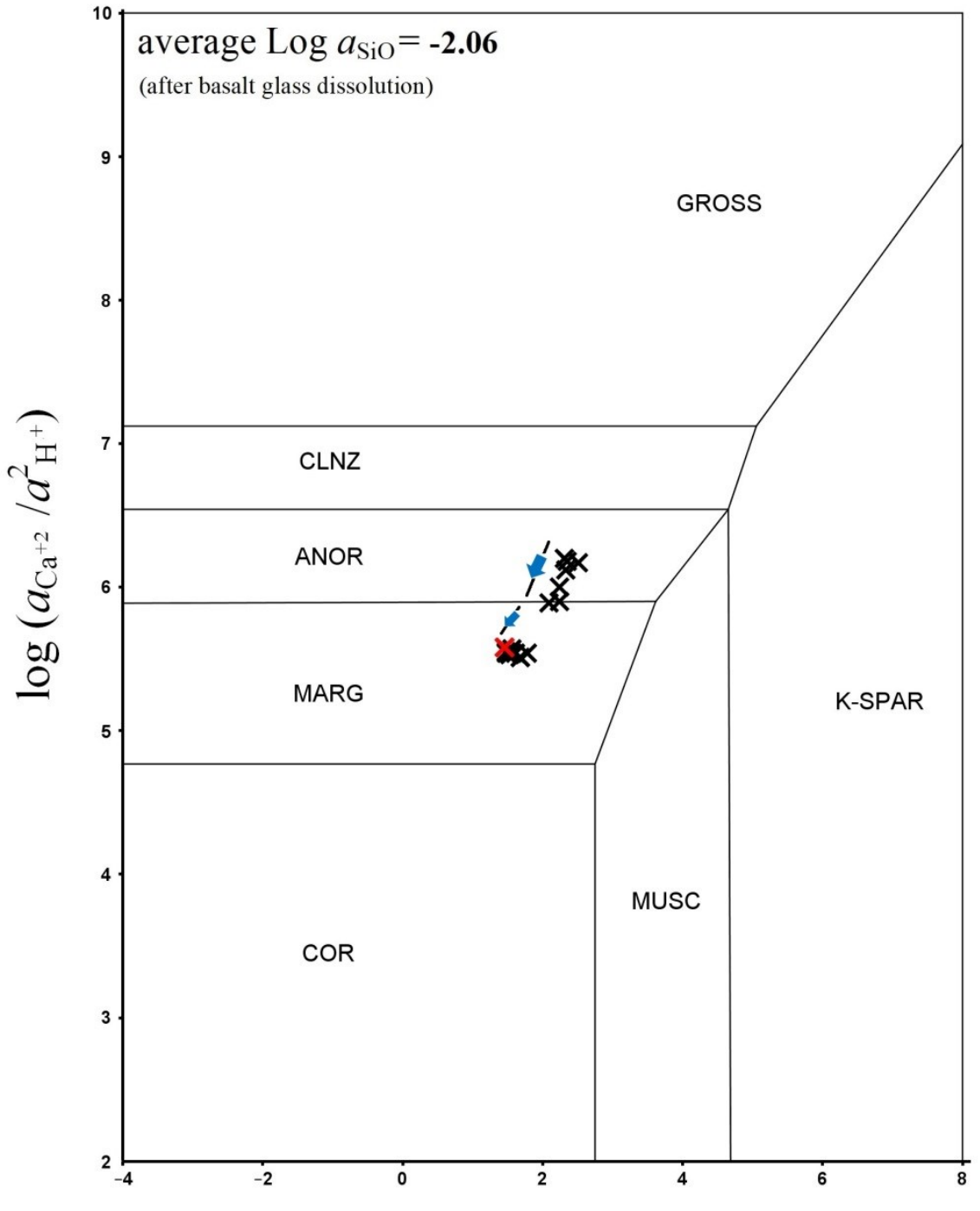

$\log \left(a_{\mathrm{K}^{+}} / a_{\mathrm{H}^{+}}\right)$

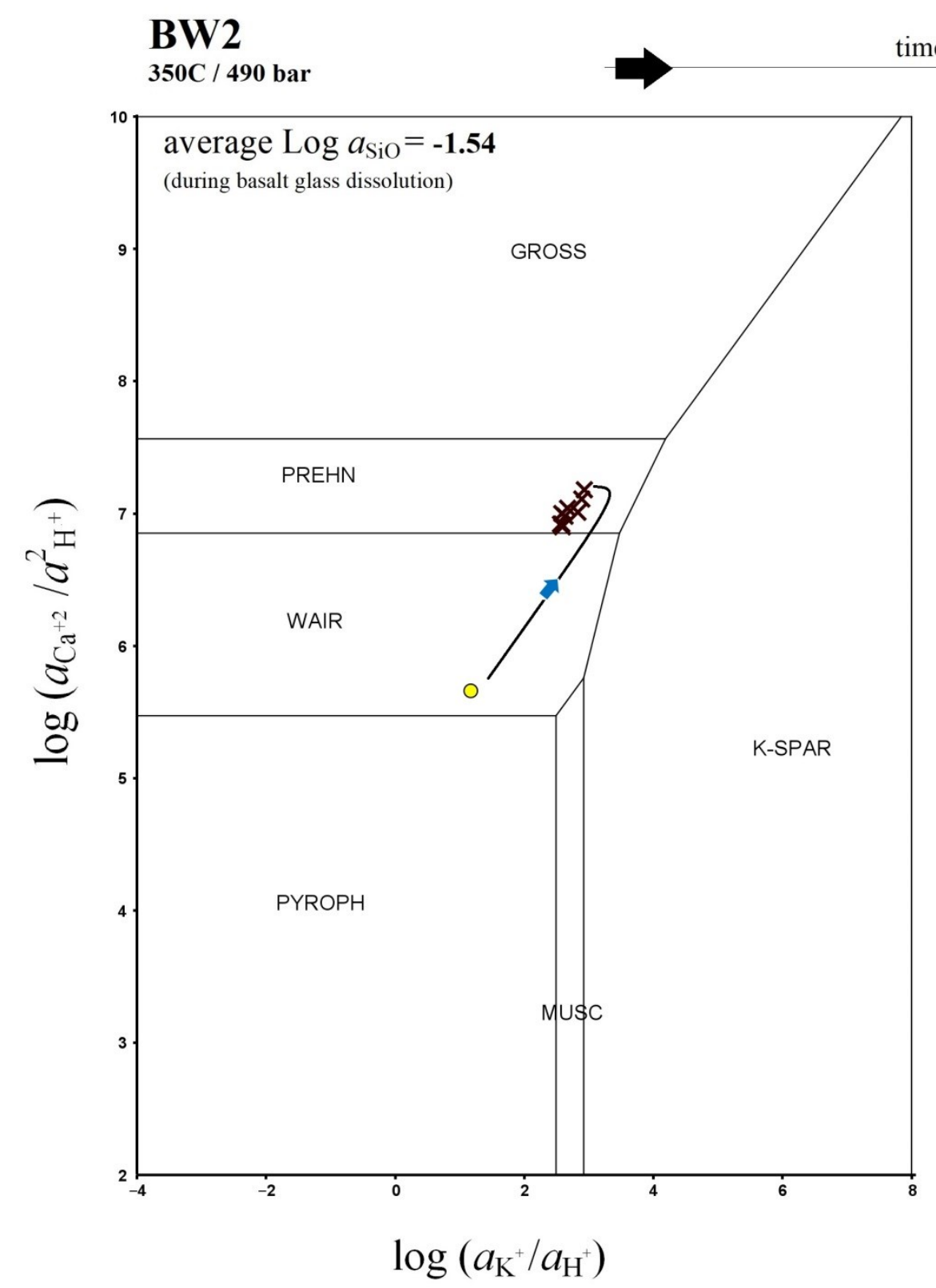

time of the experiment

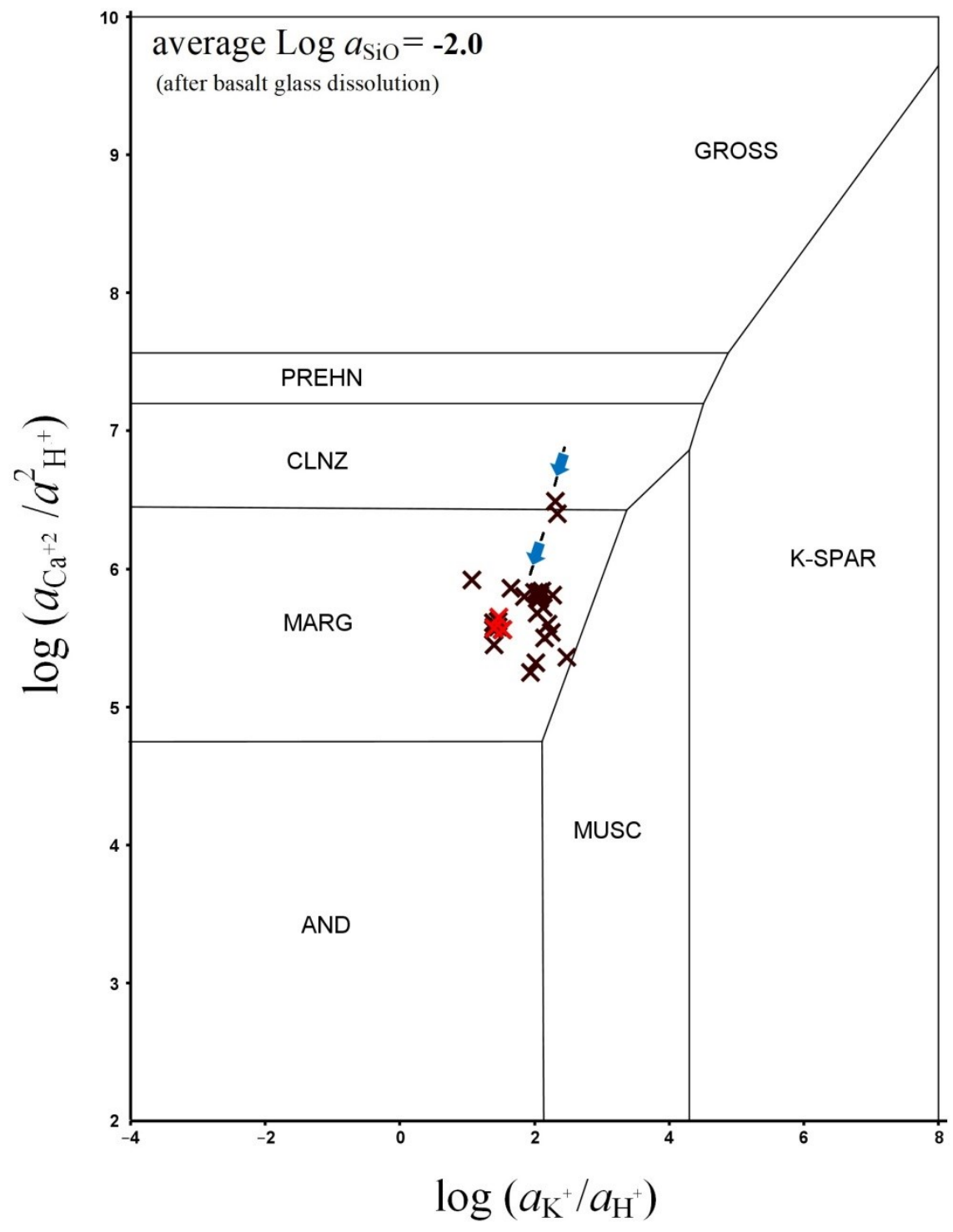


Figure B.3.41. Activity diagrams for the $\mathrm{BW} 1$ and $\mathrm{BW} 2$ showing mineral stability fields in the $\mathrm{CaO}-\mathrm{Na}_{2} \mathrm{O}-\mathrm{Al}_{2} \mathrm{O}_{3}-\mathrm{H}_{2} \mathrm{O}$. Diagrams for each experiment were constructed on the base of two different silica averages, during and after lass dissolution. Black and red crosses show position of effluent samples collected at 1.0 and $0.5 \mathrm{ml} \mathrm{hr}^{-1}$ flow rate, respectively. Yellow circles show position of the unreacted fluid (water) at $400-$ $350^{\circ} \mathrm{C} / 500 \mathrm{bar}$. Blue arrows show the path of reacted fluids over the time of the experiments

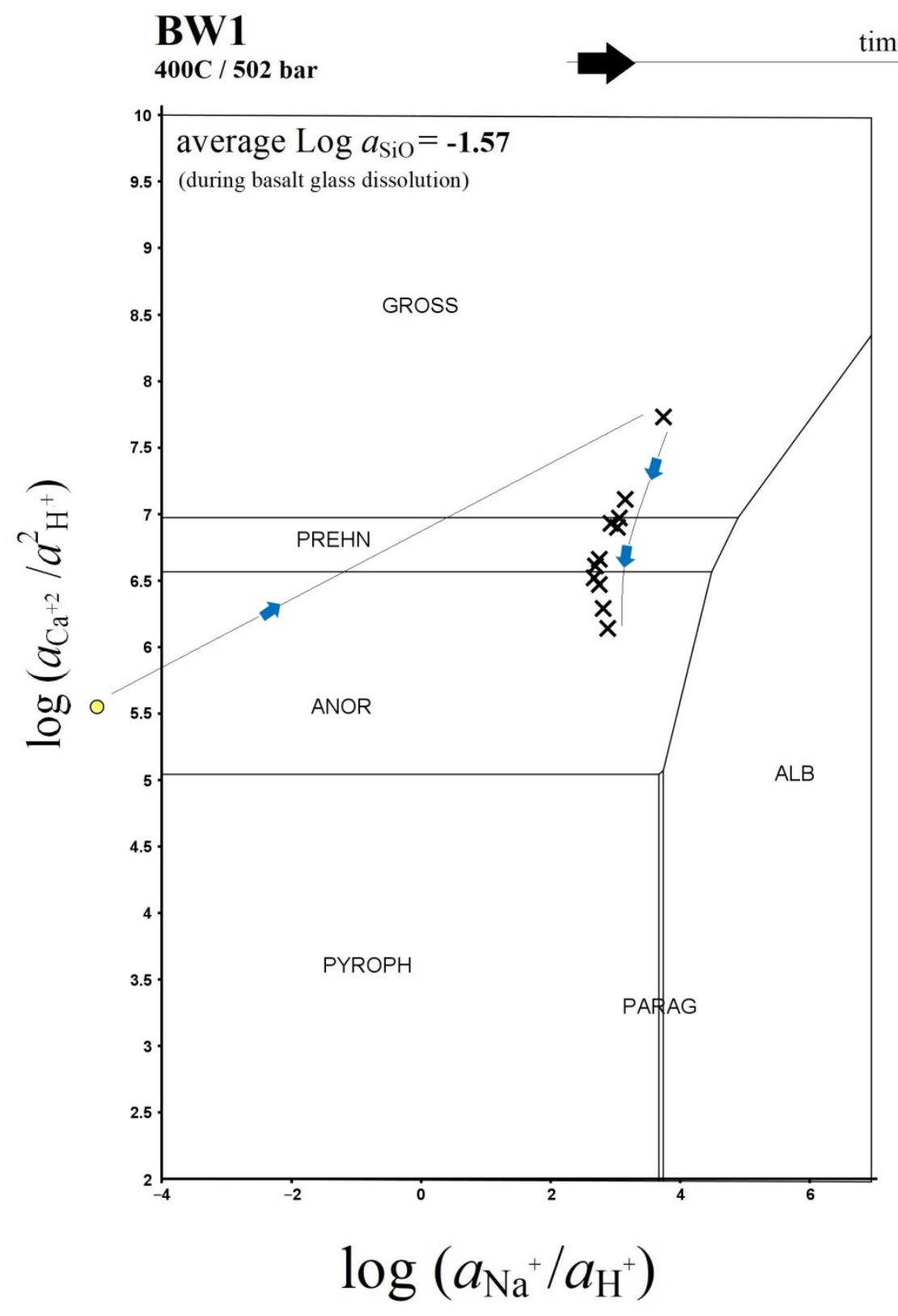

me of the experiment
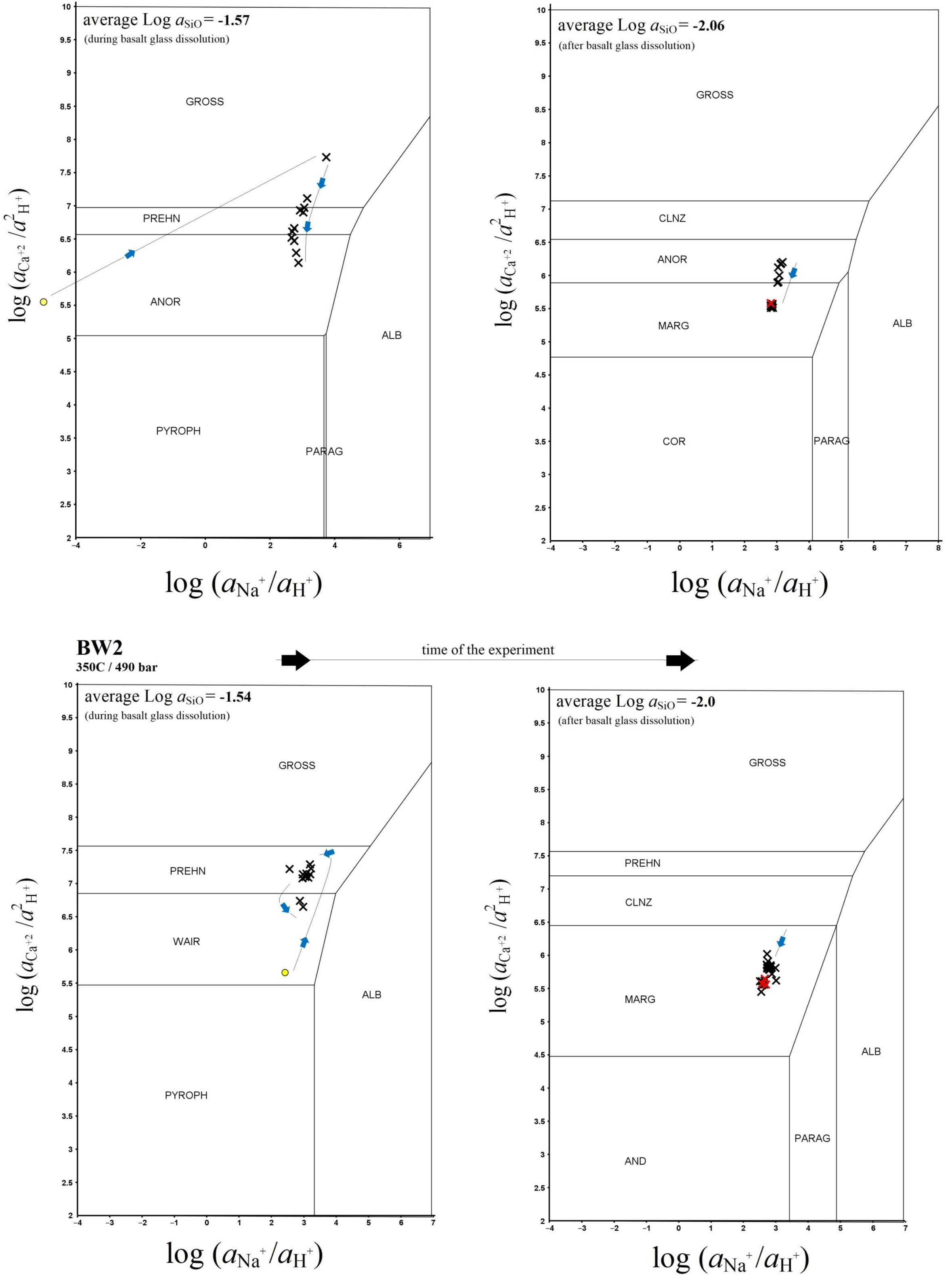

me of the experiment

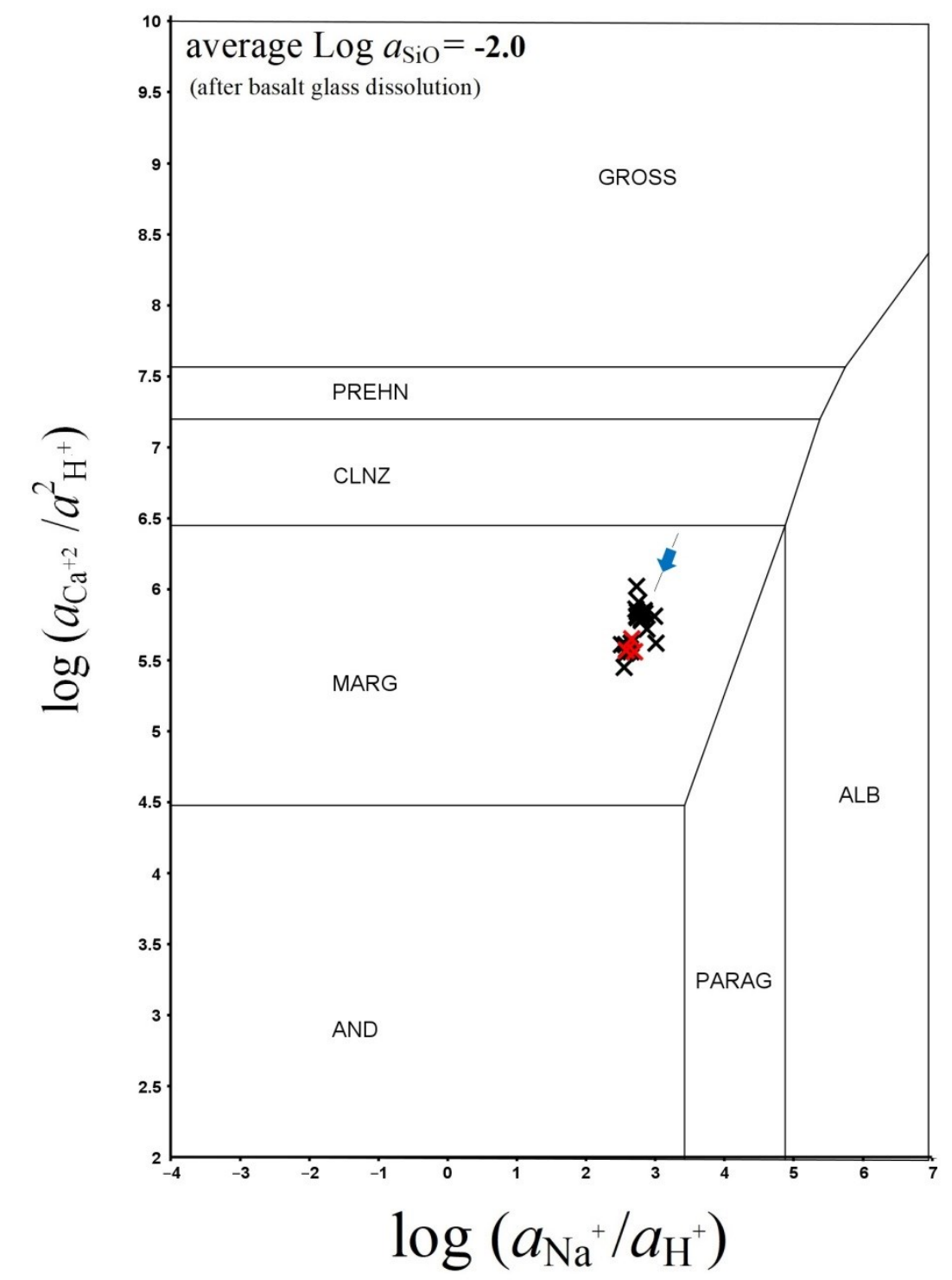


Figure B.3.42. Activity diagrams for the $\mathrm{BW} 1$ and $\mathrm{BW} 2$ showing mineral stability fields in the $\mathrm{FeO}-\mathrm{MgO}-\mathrm{Al}_{2} \mathrm{O}_{3}-\mathrm{H}_{2} \mathrm{O}$. Diagrams for each experiment were constructed on the base of two different silica averages, during and after glass dissolution. Black and red crosses show position of effluent samples collected at 1.0 and $0.5 \mathrm{ml} \mathrm{hr}^{-1}$ flow rate, respectively. Yellow circles show position of the unreacted fluid (water) at $400-$ $350^{\circ} \mathrm{C} / 500 \mathrm{bar}$. Blue arrows show the path of reacted fluids over the time of the experiments
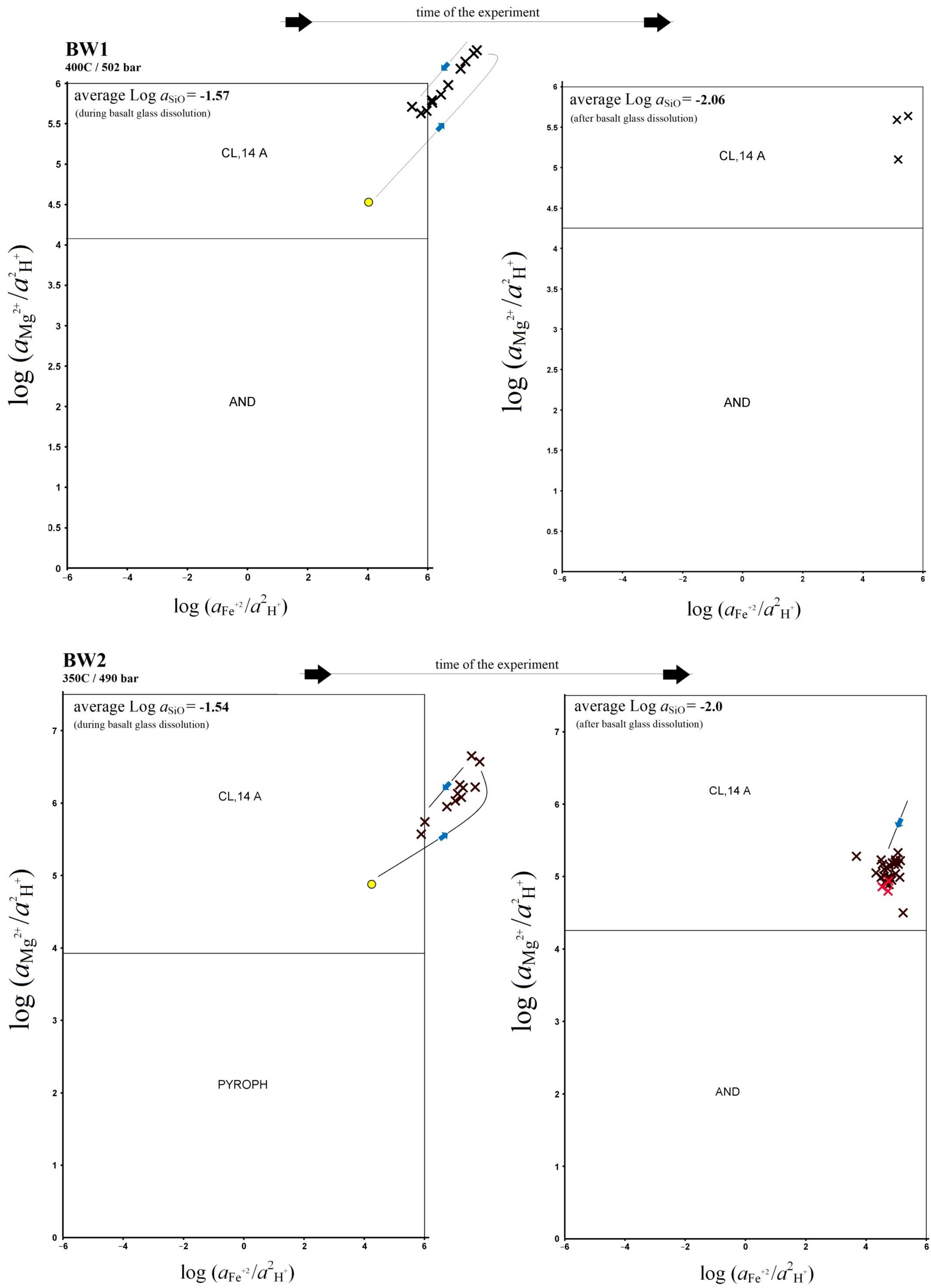
Figure B.3.43. Activity diagrams for the BW1 and BW2 showing mineral stability fields in the $\mathrm{K}_{2} \mathrm{O}-\mathrm{MgO}-\mathrm{Al}_{2} \mathrm{O}_{3}-\mathrm{H}_{2} \mathrm{O}$. Diagrams for each experiment were constructed on the base of two different silica averages, during and after glass dissolution. Black and red crosses show position of effluent samples collected at 1.0 and $0.5 \mathrm{ml} \mathrm{hr}^{-1}$ flow rate, respectively. Yellow circles show position of the unreacted fluid (water) at 400 $350^{\circ} \mathrm{C} / 500$ bar. Blue arrows show the path of reacted fluids over the time of the experiments

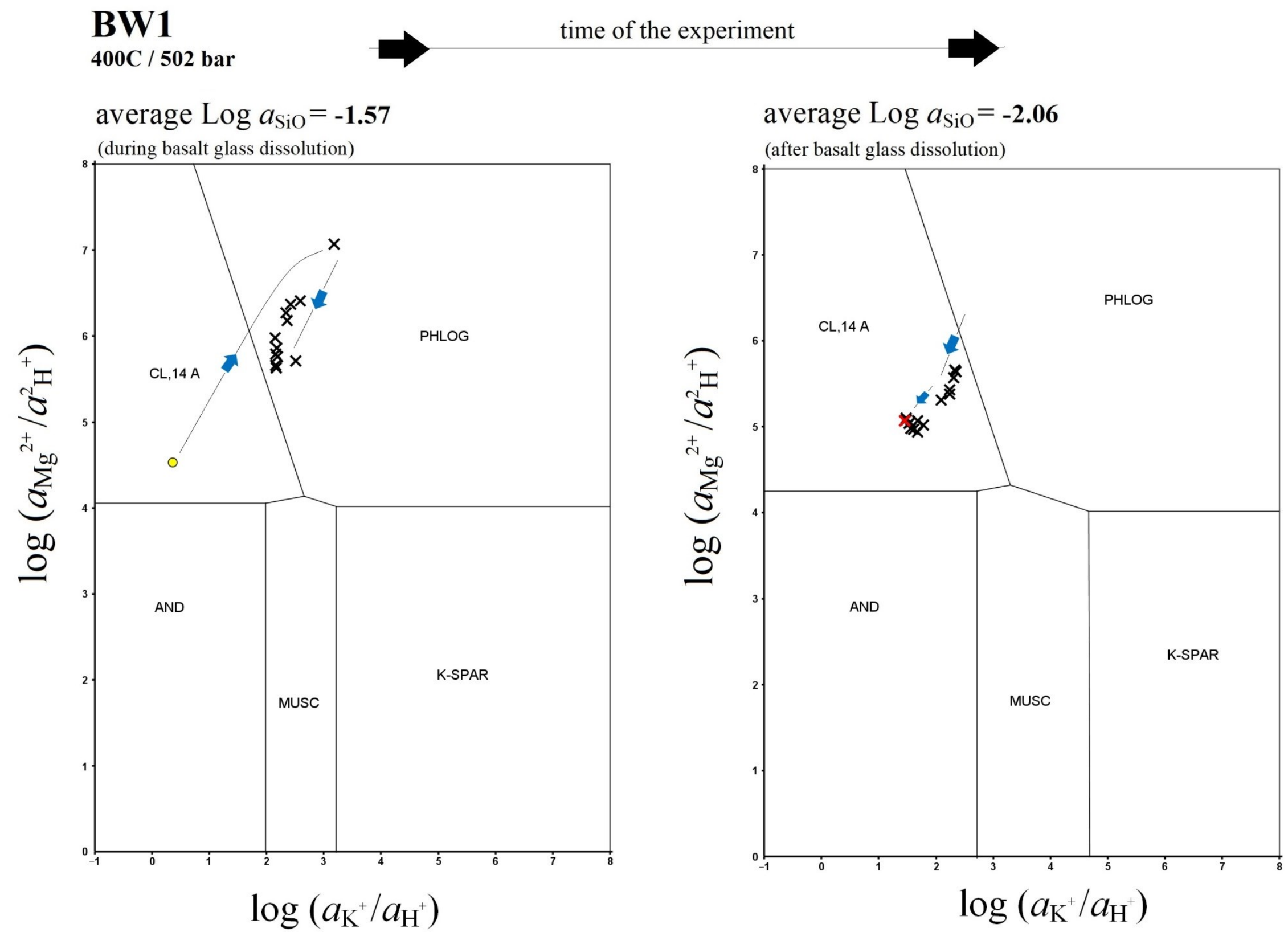

BW2

$350 \mathrm{C} / 490$ bar

time of the experiment

average $\log a_{\mathrm{SiO}}=\mathbf{- 1 . 5 4}$

(during basalt glass dissolution)

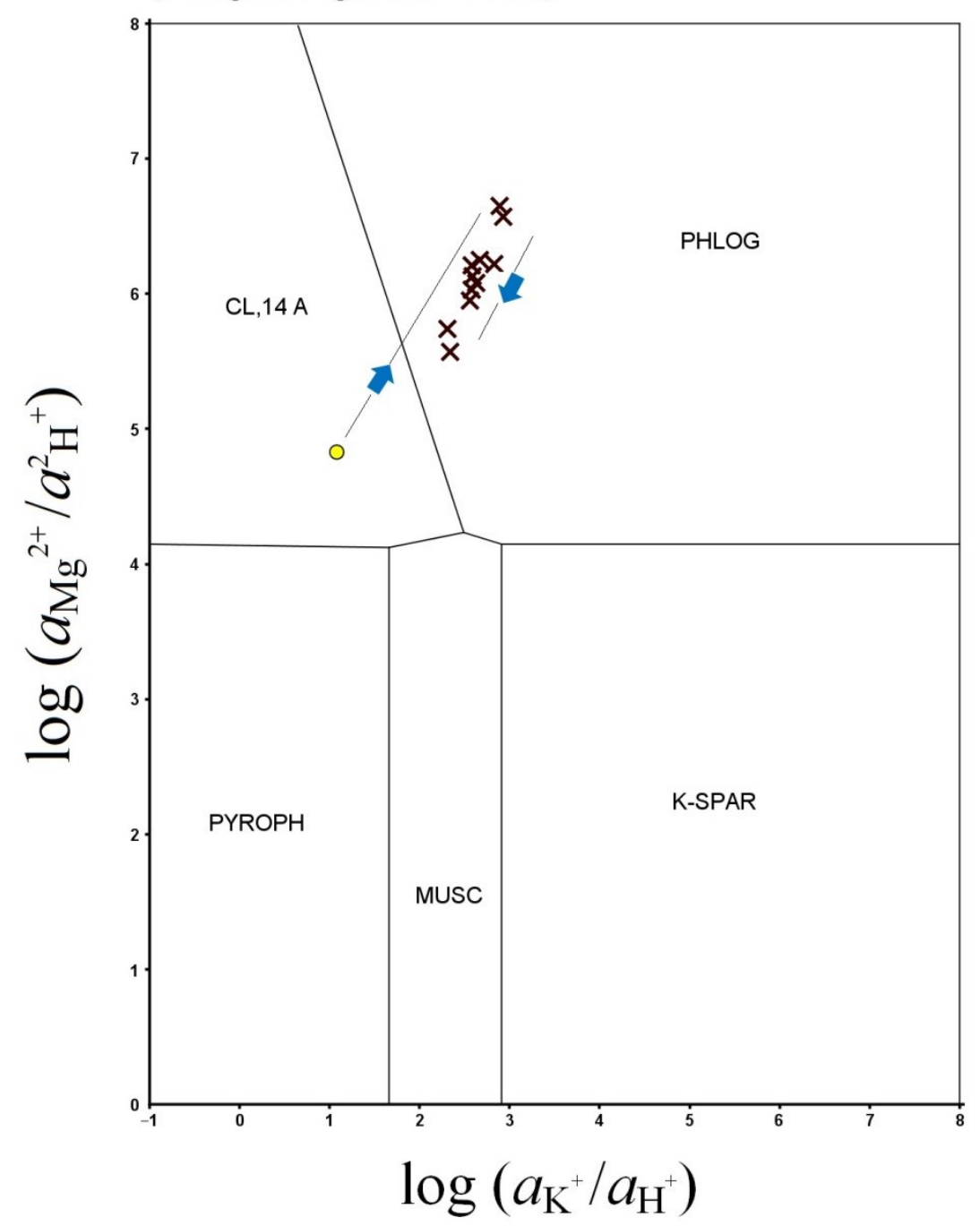

average $\log a_{\mathrm{SiO}}=\mathbf{- 2 . 0}$

(after basalt glass dissolution)

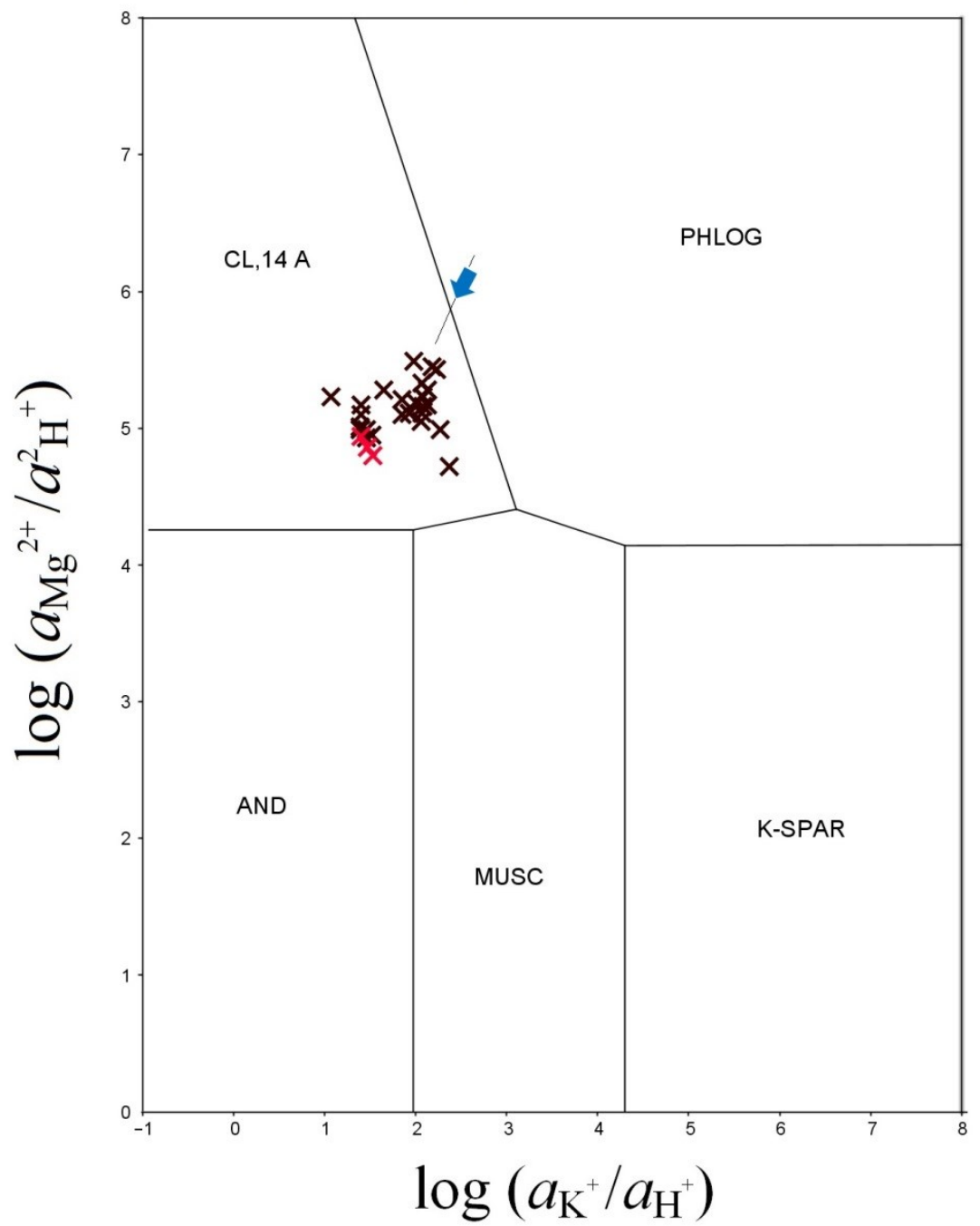


Figure B.3.44. Activity diagrams for the $\mathrm{BW} 1$ and $\mathrm{BW} 2$ showing mineral stability fields in the $\mathrm{SiO}_{2}-\mathrm{MgO}-\mathrm{Al}_{2} \mathrm{O}_{3}-\mathrm{H}_{2} \mathrm{O}$. Diagrams for each experiment were constructed on the base of two different silica averages, during and after glass dissolution. Black and red crosses show position of effluent samples collected at 1.0 and $0.5 \mathrm{ml} \mathrm{hr}^{-1}$ flow rate, respectively. Yellow circles show position of the unreacted fluid (water) at $400-$ $350^{\circ} \mathrm{C} / 500 \mathrm{bar}$. Blue arrows show the path of reacted fluids over the time of the experiments.

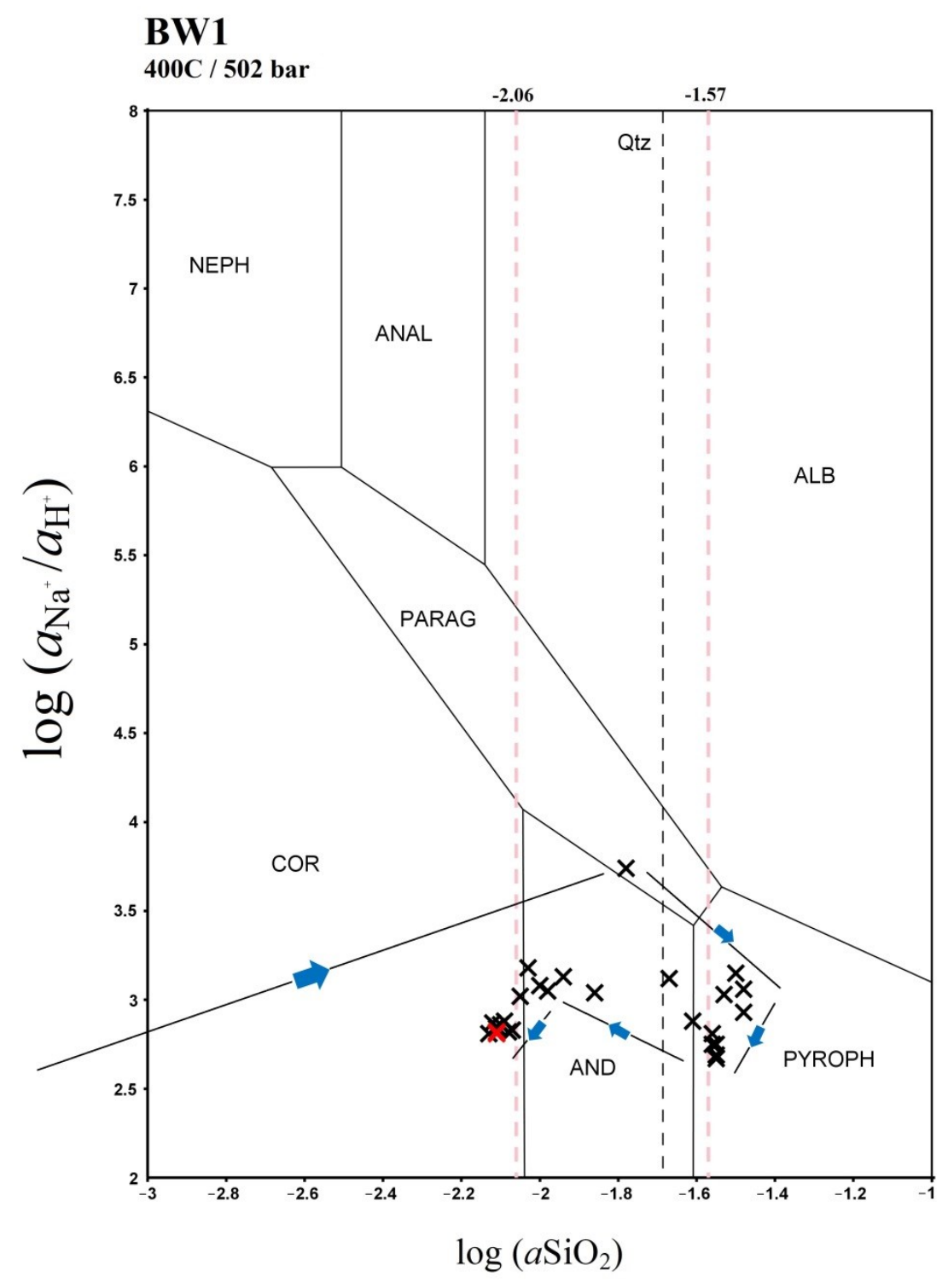

BW2

$350 \mathrm{C} / 490 \mathrm{bar}$

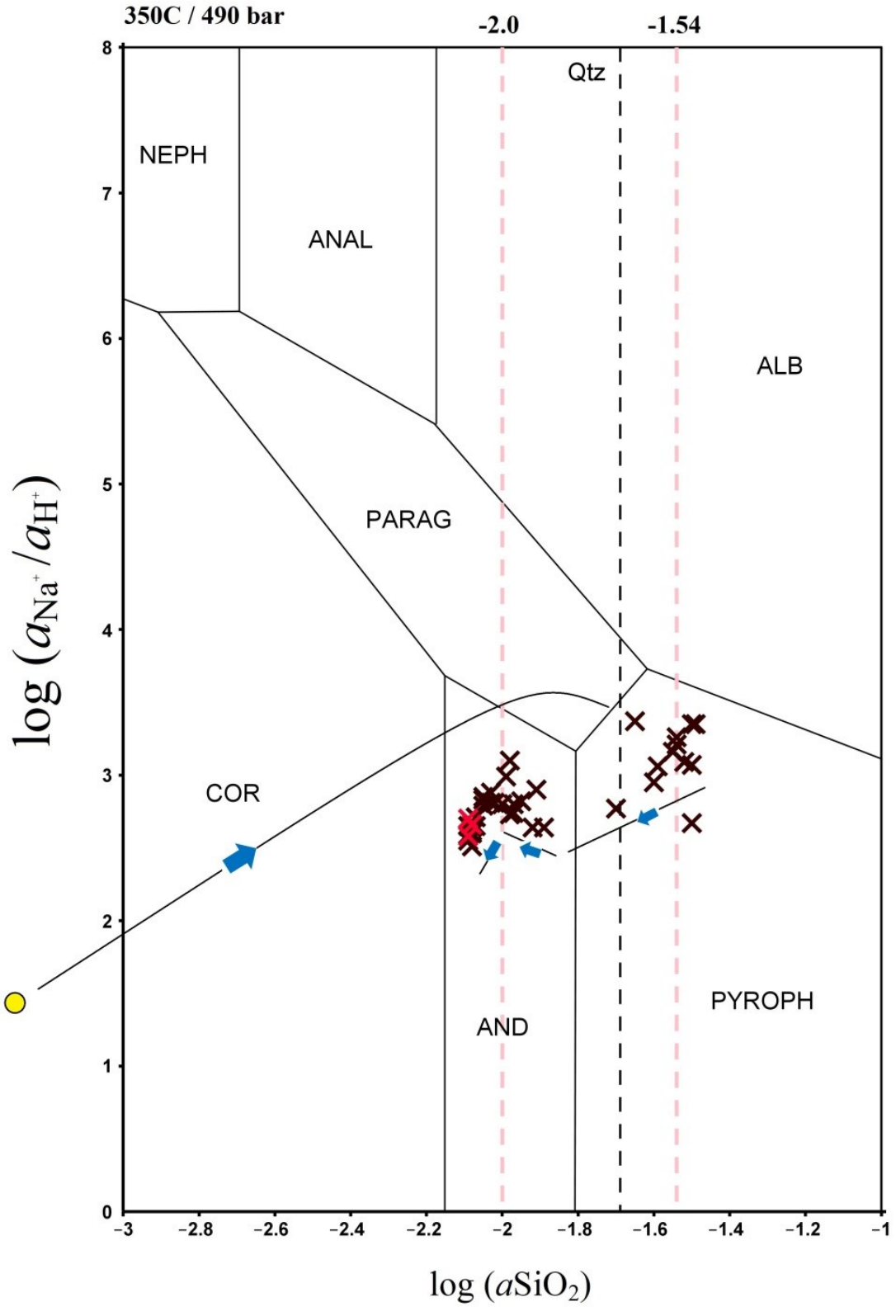


$\mathrm{Na} /$ K geothermometers

Table B.3.28. Values of the estimate temperatures for the BW1 calculated with the geothermometers equations by Fournier (1979), Truesdell (1976), Fournier and Truesdell (1973), Santoyo and Díaz-González (2009), Arnorsson (1983), Tonani (1980), Nieva and Nieva (1987) and Giggenbach (1988) $B W 1-400^{\circ} \mathrm{C}$

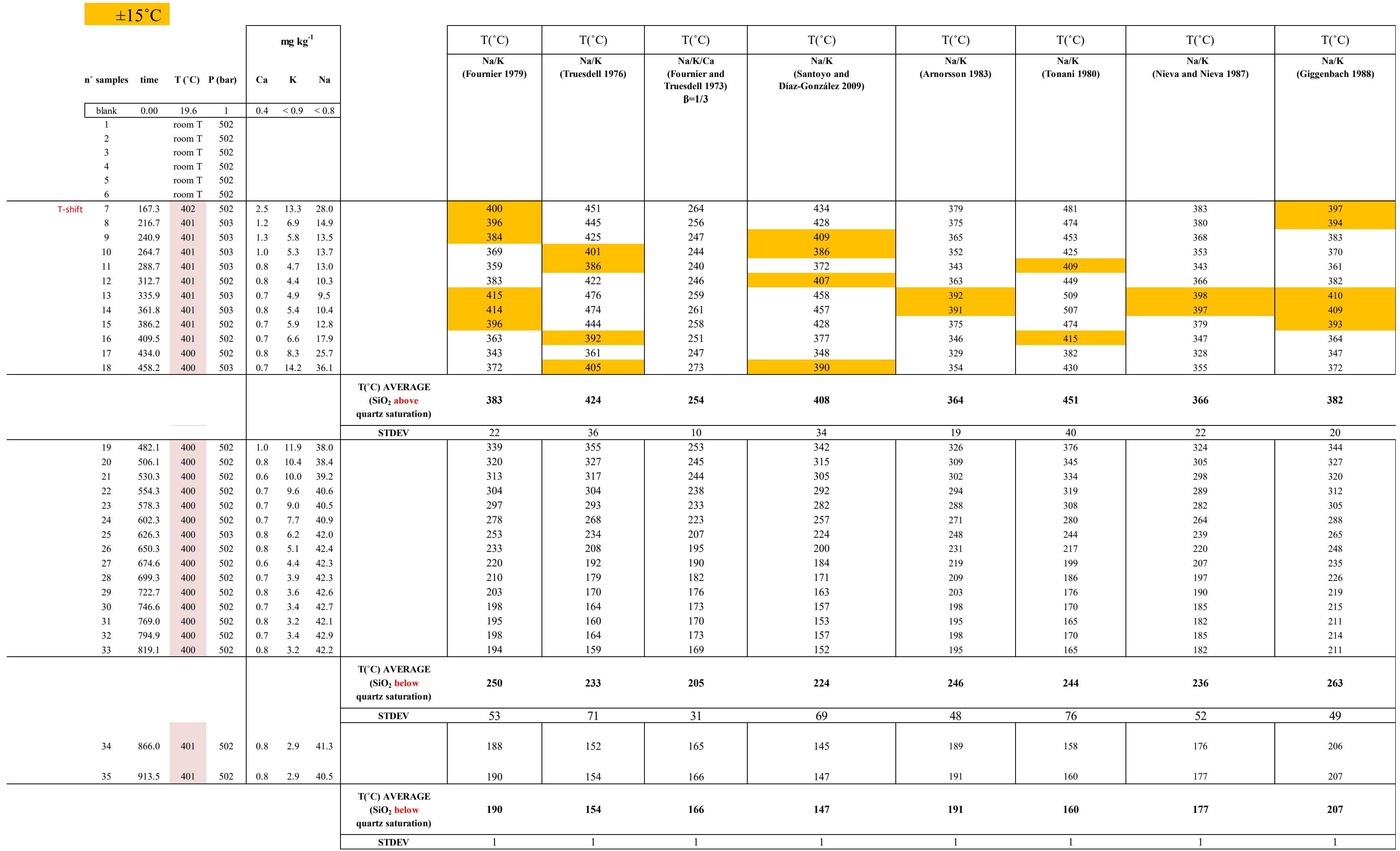


Table B.3.29. Values of the estimate temperatures for the BW2 calculated with the geothermometers equations by Fournier (1979), Truesdell (1976), Fournier and Truesdell (1973), Santoyo and Díaz-González (2009), Arnorsson (1983), Tonani (1980), Nieva and Nieva (1987) and Giggenbach (1988)

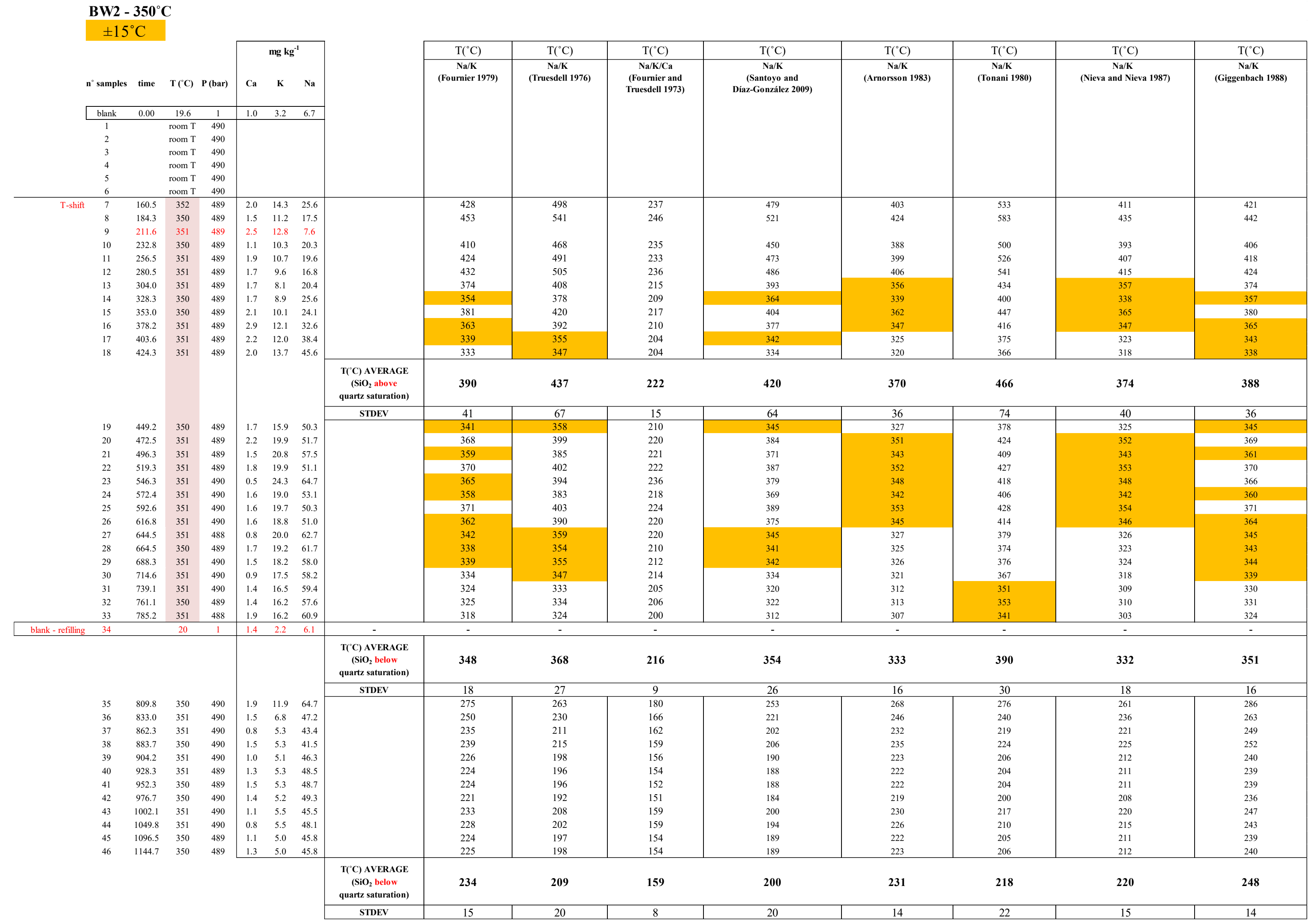


$\mathrm{Na} / \mathrm{K}$ : Fournier (1979)

$\mathrm{Na} / \mathrm{K}:$ Truesdell (1976)

$\mathrm{Na} / \mathrm{K}$ : Santoyo and

Gonzalez (2009)

$\mathrm{Na} / \mathrm{K}:$ Arnorsson (1983)

$\mathrm{Na} / \mathrm{K}$ : Tonani (1980)

$\mathrm{Na} / \mathrm{K}$ : Nieva

and Nieva (1987)

$\mathrm{Na} / \mathrm{K}$ : Giggenbach (1988)

$\mathrm{Na} / \mathrm{K} / \mathrm{Ca}:$ Fournier and Truesdall (1973)

$$
T\left({ }^{\circ} \mathrm{C}\right)=\frac{1217}{1.438+\log \left(\frac{N a}{K}\right)}-273,15\left({ }^{\circ} \mathrm{K}\right)
$$

$T\left({ }^{\circ} \mathrm{C}\right)=\frac{855,6}{0.8573+\log \left(\frac{N a}{K}\right)}-273,15\left({ }^{\circ} \mathrm{K}\right)$

$T\left({ }^{\circ} \mathrm{C}\right)=\frac{876.3( \pm 26.26)}{0.8775( \pm 0.0508)+\log \left(\frac{N a}{K}\right)}-273,15\left({ }^{\circ} \mathrm{K}\right)$

$T\left({ }^{\circ} \mathrm{C}\right)=\frac{1319}{1.699+\log \left(\frac{N a}{K}\right)}-273,15\left({ }^{\circ} \mathrm{K}\right)$

$T\left({ }^{\circ} \mathrm{C}\right)=\frac{883}{0.78+\log \left(\frac{N a}{K}\right)}-273,15\left({ }^{\circ} \mathrm{K}\right)$

$T\left({ }^{\circ} \mathrm{C}\right)=\frac{1178}{1.483+\log \left(\frac{N a}{K}\right)}-273,15\left({ }^{\circ} \mathrm{K}\right)$

$T\left({ }^{\circ} \mathrm{C}\right)=\frac{1390}{1.75+\log \left(\frac{N a}{K}\right)}-273,15\left({ }^{\circ} \mathrm{K}\right)$

$T\left({ }^{\circ} \mathrm{C}\right)=\frac{1647}{\log \left(\frac{N a}{K}\right)+\beta[\log (\sqrt{C a} / N a)+2.06]+2.47}-273,15\left({ }^{\circ} \mathrm{K}\right)$ 
Appendices Doctoral Thesis: "Basalt - fluid interactions at subcritical and supercritical conditions: An experimental study" University of Victoria Wellington and GNS Science, Wairakei, New Zealan
by Mauro Passarella

Appendix C - (Chapter 4) 


\section{Chapter 4: Basalt - Geothermal Brine Interactions Under Hydrothermal Conditions}

4.2. Results

4.2.1. BGB1: Basalt - geothermal brine at $400^{\circ} \mathrm{C} / 483$ bar

Table C.4.1. Major ions compositions and complete experimental parameters (n- of samples collected, $\mathrm{T}$, $\mathrm{P}$, experimental time, flow rate and $\mathrm{pH})$ for the $\mathrm{BGBl}\left(400^{\circ} \mathrm{C} / 483 \mathrm{bar}\right)$. In situ $\mathrm{pH}$ is the calculated $\mathrm{pH}$ at temperature. Analysis of major ions are reported both in $\mathrm{mg} \mathrm{kg} \mathrm{kg}^{-1}$ and in $\mathrm{mmol} \mathrm{kg}^{-1}$. n.c.: not calculated

\begin{tabular}{|c|c|c|c|c|c|c|c|c|c|c|c|c|c|c|c|c|c|c|c|c|c|c|c|c|c|c|c|c|c|c|c|c|}
\hline \multirow[b]{2}{*}{$\mathrm{n}^{\circ}$ sample } & \multirow[b]{2}{*}{$\begin{array}{c}\mathrm{T} \\
\left({ }^{\circ} \mathrm{C}\right)\end{array}$} & \multirow[b]{2}{*}{$\begin{array}{c}\mathrm{P} \\
\text { (bar) }\end{array}$} & \multirow[b]{2}{*}{$\begin{array}{l}\text { time } \\
\text { (hrs) }\end{array}$} & \multirow[b]{2}{*}{$\begin{array}{l}\text { flow-rate } \\
\left(\mathrm{ml} \mathrm{hr}^{-1}\right)\end{array}$} & \multirow[b]{2}{*}{$\begin{array}{c}\mathrm{pH} \\
\text { (room T) }\end{array}$} & \multirow[b]{2}{*}{$\begin{array}{c}\mathrm{pH} \\
\left(400^{\circ} \mathrm{C}\right)\end{array}$} & \multicolumn{13}{|c|}{$\mathrm{mg} \mathrm{kg}^{-1}$} & \multicolumn{13}{|c|}{$\mathbf{m m o l ~ k g}{ }^{-1}$} \\
\hline & & & & & & & As & B & $\mathrm{Ca}$ & $\mathrm{Fe}$ & K & $\mathrm{Mg}$ & $\mathrm{Na}$ & $\mathrm{SiO}_{2}$ & $\mathrm{Al}$ & $\mathrm{Li}$ & $\mathrm{H}_{2} \mathrm{~S}$ & $\mathrm{Cl}$ & $\mathrm{SO}_{4}$ & As & B & $\mathrm{Ca}$ & $\mathrm{Fe}$ & $\mathrm{K}$ & $\mathrm{Mg}$ & $\mathrm{Na}$ & $\mathrm{SiO}_{2}$ & $\mathrm{Al}$ & $\mathrm{Li}$ & $\mathrm{H}_{2} \mathrm{~S}$ & $\mathrm{Cl}$ & $\mathrm{SO}_{4}$ \\
\hline $\begin{array}{l}\text { blank } \\
\text { geothrmal brine }\end{array}$ & 20.1 & 1 & 0.0 & - & 3.91 & 7.14 & 1.8 & 48.2 & 3.4 & 0.08 & 116.2 & 0.2 & 725.3 & 758.7 & 1.5 & 5.7 & 0.2 & 941 & 404.9 & 0.02 & 4.5 & 0.08 & 0.001 & 3 & 0.01 & 31.6 & 12.6 & 0.06 & 0.8 & 0.004 & 26.5 & 4.2 \\
\hline 1 & 20.4 & 485.8 & 20.6 & 1 & 5.90 & n.c. & 0.4 & 48.2 & 7.1 & 0.2 & 106.7 & 1.2 & 710.5 & 710.6 & 8.8 & 5.6 & 0.1 & 935.6 & 401.3 & 0.01 & 4.5 & 0.2 & 0.004 & 2.7 & 0.05 & 30.9 & 11.8 & 0.3 & 0.8 & 0.004 & 26.5 & 4.2 \\
\hline 2 & 20.2 & 483.4 & 45.6 & 1 & 6.00 & n.c. & 0.2 & 48.2 & 5.9 & 0.4 & 122.3 & 0.8 & 710.9 & 733.9 & 10.5 & 5.6 & 0.2 & 842.7 & 350.4 & 0.003 & 4.5 & 0.1 & 0.01 & 3.1 & 0.03 & 30.9 & 12.2 & 0.4 & 0.8 & 0.01 & 26.4 & 3.6 \\
\hline 3 & 20.7 & 484.0 & 72.8 & 1 & 5.64 & n.c. & 0.2 & 48.2 & 6.1 & 0.9 & 117.2 & 0.6 & 720 & 803.8 & 8 & 5.7 & 0.3 & 963.6 & 397.6 & 0.003 & 4.5 & 0.2 & 0.02 & 3 & 02 & 31.3 & 13.4 & 3 & .8 & 0.01 & 27.2 & 4.1 \\
\hline 4 & 20.6 & 483.5 & 94.8 & 1 & 5.50 & n.c. & 0.2 & 48.2 & 5.6 & 1.3 & 116 & 0.6 & 724.5 & 815.1 & 7.2 & 5.7 & 0.2 & 824.1 & 345.1 & 0.003 & 4.5 & 0.1 & 0.02 & 3 & 0.03 & 31.5 & 13.6 & 0.3 & 0.8 & 0.01 & 23.2 & 3.6 \\
\hline 5 & 20.5 & 484.2 & 118.9 & 1 & 5.49 & n.c. & 0.3 & 48.2 & 5.1 & 1.5 & 115 & 0.7 & 716.9 & 804.9 & 7.1 & 5.7 & 0.2 & 891.8 & 373.9 & 0.004 & 4.5 & 0.1 & 0.03 & 2.9 & 0.03 & 31.2 & 13.4 & 0.3 & 0.8 & 0.01 & 25.2 & 3.9 \\
\hline 6 & 20.7 & 485.4 & 143.1 & 1 & 5.55 & n.c. & 0.4 & 48.2 & 5.2 & 1.6 & 113.8 & 0.8 & 712 & 802.1 & 6.7 & 5.6 & 0.3 & 951.7 & 394.7 & 0.005 & 4.5 & 0.1 & 0.03 & 2.9 & 0.03 & 31 & 13.3 & 0.2 & 0.8 & 0.01 & 26.8 & 4.1 \\
\hline 7 & 20.4 & 484.5 & 166.7 & 1 & 5.35 & n.c. & 0.4 & 48.2 & 4.9 & 1.3 & 114.6 & 0.8 & 716.9 & 807.9 & 5.8 & 5.7 & 0.3 & 970.5 & 400 & 0.01 & 4.5 & 0.1 & 0.02 & 2.9 & 0.03 & 31.2 & 13.4 & 0.2 & 0.8 & 0.01 & 27.4 & 4.2 \\
\hline 8 & 397.6 & 478.9 & 190.9 & 1 & 3. & 7.00 & 2.1 & 48.2 & 3.2 & 0.5 & 192.5 & 0.4 & 597.7 & 1531.1 & 2.6 & 4.4 & 0.1 & 900.9 & 239.8 & 0.03 & 4.5 & 0.08 & 0.01 & 4.9 & 0.02 & 26 & 25.5 & .1 & 0.6 & 003 & 25.4 & 2.5 \\
\hline 9 & 400.1 & 483.1 & 214.7 & 1 & 2. & 7.0 & 1 & 48.2 & 2 & 0.1 & 196.5 & 0.2 & 623.5 & 2081.2 & 0.8 & 5 & 1.6 & 934.4 & 272.7 & 0.01 & 4.5 & 0.05 & 0.001 & 5 & 0.01 & 27.1 & 34.6 & 0.03 & 0.7 & 0.05 & 26.4 & 2.8 \\
\hline 10 & 400.4 & 483.5 & 239.3 & 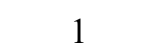 & 3. & 7.1 & 0.8 & 48.2 & 2.2 & 0.1 & 149.5 & 0.2 & 666.1 & 2000.7 & 0.6 & 5.4 & 5.3 & 964.6 & 326.8 & 0.01 & 4.5 & 0.06 & 0.002 & 3.8 & 0.01 & 29 & 33.3 & 0.02 & .8 & 0.2 & 27.2 & 3.4 \\
\hline 11 & 400.7 & 483.8 & 262.6 & 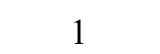 & 3.32 & 7. & 0.7 & 48.2 & 2.8 & $<0.08$ & 144.8 & 0.3 & 684.6 & 1798.4 & 0.6 & 5.3 & 8.6 & 969.2 & 350.2 & 0.01 & 4.5 & 0.07 & $<0.001$ & 3.7 & 0.01 & 29.8 & 29.9 & 0.02 & .8 & .3 & 27.3 & 3.6 \\
\hline 12 & 400.8 & 484.1 & 287.9 & 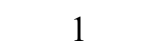 & 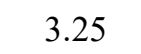 & 7.1 & 1 & 48.2 & 2.6 & $<0.08$ & 150.9 & 0.2 & 692.5 & 1813.4 & 0.6 & 5.1 & 5.2 & 906.1 & 347.9 & 0.01 & 4.5 & 0.06 & $<0.001$ & 3.9 & 0.01 & 30.1 & 30.2 & 0.02 & 0.7 & 0.2 & 25.6 & 3.6 \\
\hline 13 & 400.4 & 484.4 & 313.4 & 1 & 3. & 7.1 & 1.2 & 48.2 & 2.3 & $<0.08$ & 151.5 & 0.1 & 697.6 & 1814.9 & 0.5 & 5.1 & 1.6 & 903.4 & 351.1 & 0.02 & 4.5 & 0.06 & $<0.001$ & 3.9 & 0.01 & 30.3 & 30.2 & 0.02 & 0.7 & 0.05 & 25.5 & 3.7 \\
\hline 14 & 400.4 & 484.3 & 334.4 & 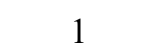 & 0 & 7.1 & 1.4 & 48.2 & 2.5 & $<0.08$ & 148.7 & 0.2 & 689.8 & 1810.1 & 0.6 & 5 & 1.8 & 938.8 & 366 & 0.02 & 4.5 & 0.06 & $<0.001$ & 3.8 & 0.01 & 30 & 30.1 & 0.02 & .7 & 0.05 & 26.5 & 3.8 \\
\hline 15 & 400.8 & 484.4 & 359.0 & 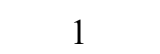 & 3.5 & 7.1 & 1.5 & 48.2 & 2.7 & $<0.08$ & 147.9 & 0.2 & 696.9 & 1829.5 & 0.5 & 5.1 & 1.2 & 921 & 367.4 & 0.02 & 4.5 & 0.07 & $<0.001$ & 3.8 & 0.01 & 30.3 & 30.5 & 0.02 & 0.7 & 0.04 & 26 & 3.8 \\
\hline 16 & 400.6 & 484.2 & 382.7 & 1 & 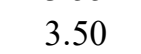 & 7. & 1.6 & 48.2 & 2.7 & $<0.08$ & 145.3 & 0.2 & 681.6 & 1844.5 & 0.8 & 5.1 & 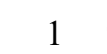 & 914.3 & 364.1 & 0.02 & 4.5 & 0.07 & $<0.001$ & 3.7 & 0.01 & 29.6 & 30.7 & 0.03 & 0.7 & 0.03 & 25.8 & 3.8 \\
\hline 17 & 400.7 & 483.5 & 406.0 & 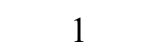 & 3.40 & 7.1 & 1.7 & 48.2 & 3 & 0.1 & 141.6 & 0.2 & 684.8 & 1852.9 & 0.8 & 5.1 & 0.9 & 923.4 & 368.8 & 0.02 & 4.5 & 0.07 & 0.001 & 3.6 & 0.01 & 29.8 & 30.8 & 0.03 & 0.7 & 0.03 & 26 & 3.8 \\
\hline 18 & 400.9 & 483.6 & 430.6 & 1 & & 7. & 1.7 & 48.2 & 3.8 & $<0.08$ & 136.2 & 0.2 & 688.8 & 1859.6 & 0.8 & 5.1 & 0.6 & 928.6 & 369.1 & 0.02 & 4.5 & 0.09 & $<0.001$ & 3.5 & 0.01 & 30 & 31 & 0.03 & 0.7 & 0.02 & 26.2 & 3.8 \\
\hline 19 & 400.7 & 483.8 & 457.3 & 1 & & 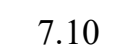 & 1. & 48.2 & 3.7 & $<0.08$ & 132.1 & 0.4 & 694.3 & 1887.6 & 0. & 5.1 & 0.7 & 894.6 & 361.5 & 0.02 & 4.5 & 0.09 & $<0.001$ & 3.4 & 0.02 & 30.2 & 31.4 & 0.03 & .7 & 0.02 & 25.2 & 3.8 \\
\hline 20 & 400.6 & 483.8 & 480.7 & 1 & 3.7 & 7.0 & 1.7 & 48.2 & 4.3 & $<0.08$ & 122.6 & 0.4 & 693.2 & 1886.4 & 0.6 & 5.1 & 0.2 & 883.8 & 348.4 & 0.02 & 4.5 & 0.1 & $<0.001$ & 3.1 & 0.02 & 30.2 & 31.4 & 0.02 & .7 & 0.01 & 24.9 & 3.6 \\
\hline 21 & 400.6 & 1847 & 503.3 & 1 & & & 1.7 & 48.2 & 4 & 01 & 114.4 & 0.4 & 710.1 & 1898.7 & 0.7 & 5.2 & 0.6 & 822.2 & 333.8 & 0.02 & 4.5 & 0.1 & 0.001 & 2.9 & 0.02 & 30.9 & 31.6 & 0.02 & .7 & 0.02 & 23.2 & 3.5 \\
\hline 22 & 400.9 & 484.2 & 527.7 & 1 & 3.78 & 7.1 & 1.6 & 48.2 & 4.3 & $<0.08$ & 106.3 & 0.5 & 706 & 1897.8 & 0.7 & 5.1 & 0.4 & 907.7 & 360.2 & 0.02 & 4.5 & 0.1 & $<0.001$ & 2.7 & 0.02 & 30.7 & 31.6 & 0.02 & 0.7 & 0.01 & 25.6 & 3.8 \\
\hline 23 & 400.5 & 483 & 550.4 & 1 & & & 1 & 48.2 & 4.9 & 0.1 & & 0.5 & 713.4 & & 0.7 & 5.1 & 0.5 & 918.7 & 366.9 & 0.02 & 4.5 & 0.1 & 0.002 & 2.6 & 2 & 31 & 6 & 0.03 & 0.7 & 0.02 & 25.9 & 3.8 \\
\hline 2 & 400.7 & 483.5 & 574.8 & 1 & 4 & 7 & 1. & 48.2 & 3.9 & $<0.08$ & 100.4 & 0.4 & 714.8 & 1463.6 & 1.2 & 5 & 0.5 & 920.1 & 352.7 & 0.02 & 4.5 & 0.1 & $<0.001$ & 2.6 & 0.02 & 31.1 & 4 & 0.05 & .7 & 0.01 & 26 & 3.7 \\
\hline 25 & 400.6 & 483.9 & 597.6 & 1 & 6.23 & 7.0 & 1.7 & 48.2 & 4.2 & $<0.08$ & 98.8 & 0.5 & 701.6 & 1101.8 & 2.8 & 4.8 & 0.5 & 893.8 & 337.1 & 0.02 & 4.5 & 0.1 & $<0.001$ & 2.5 & 0.02 & 30.5 & 18.3 & 0.1 & 0.7 & 0.01 & 25.2 & 3.5 \\
\hline 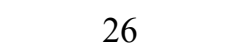 & 400.5 & 484.0 & 625.7 & 1 & & & 1. & 48.2 & 3.3 & $<0.08$ & 96.3 & 0.3 & 699.7 & & 2.9 & 4.8 & $<0.01$ & 925.3 & 338.3 & 0.02 & 4.5 & 0.1 & $<0.001$ & 2.5 & 0.01 & 30.4 & & & 0.7 & $<0.0003$ & 26.1 & 3.5 \\
\hline 27 & 400.7 & 483.9 & 647.5 & 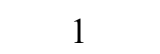 & 6.77 & 7.1 & 1.7 & 48.2 & 3.8 & $<0.08$ & 95.1 & 0.4 & 694.6 & 1004.2 & 3 & 4.8 & 0.2 & 933.1 & 354.8 & 0.02 & 4.5 & 0.1 & $<0.001$ & 2.4 & 0.02 & 30.2 & 16.7 & 0.1 & .7 & 0.01 & 26.3 & 3.7 \\
\hline & 400.4 & 483.6 & 670.8 & 1 & 7.0 & & & 48 & 4.4 & $<0.08$ & 95. & 0.5 & 727.2 & & 3.7 & 4.9 & 0.2 & 942.6 & 351.8 & 0.02 & 4.5 & 0.1 & $<0.001$ & 2.4 & 0.02 & 31.6 & 4 & & .7 & 01 & 6.6 & 3.7 \\
\hline 29 & 400.5 & 483.6 & 694.4 & 1 & 7.44 & 7.0 & 1.6 & 48.2 & 4.4 & $<0.08$ & 95.4 & 0.5 & 718.4 & 976.9 & 4.4 & 4.9 & 0.3 & 828.4 & 303.2 & 0.02 & 4.5 & 0.1 & $<0.001$ & 2.4 & 0.02 & 31.2 & 16.3 & 0.2 & 0.7 & 0.01 & 3.4 & 3.2 \\
\hline 30 & 400.2 & 483.4 & 718.8 & 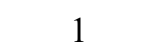 & 7.52 & 7.1 & 1.7 & 48.2 & 3.8 & $<0.08$ & 95.1 & 0.4 & 724.5 & 987.2 & 4 & 5 & 0.2 & 916.1 & 346.4 & 0.02 & 4.5 & 0.1 & $<0.001$ & 2.4 & 0.02 & 31.5 & 16.4 & 0.1 & .7 & 0.01 & 25.8 & 3.6 \\
\hline 3 & 40 & & 743.4 & 1 & 1.4 & & 1. & 48.2 & 4 & & 94.8 & 0.4 & 722.1 & & 4.3 & 3 & .2 & 874.2 & 332 & 0.02 & 4.5 & 0.1 & $<0.001$ & 2.4 & 0.02 & 31.4 & 10.3 & 2 & .7 & 01 & 4.7 & 3.5 \\
\hline 32 & 400.6 & 483.1 & 767.5 & 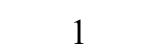 & 7.66 & 7.08 & 1.5 & 48.2 & 4 & $<0.08$ & 92.3 & 0.3 & 711.8 & 930.3 & 5.9 & 5 & 0.3 & 891.4 & 309.2 & 0.02 & 4.5 & 0.1 & $<0.001$ & 2.4 & 0.01 & 31 & 15.5 & 0.2 & 0.7 & 0.01 & 25.1 & 3.2 \\
\hline 33 & 400.7 & 477.0 & 809.2 & 0.5 & 7.30 & 7.0 & 2 & 48.2 & 5.7 & $<0.08$ & 93.3 & 0.7 & 741.6 & 954.2 & 4.5 & 5.2 & 0.1 & 918.3 & 330.2 & 0.03 & 4.5 & 0.1 & $<0.001$ & 2.4 & 0.03 & 32.3 & 15.9 & 0.2 & 0.8 & 0.00 & 25.9 & 3.4 \\
\hline 34 & 400.5 & 482.3 & 853.2 & 0.5 & 7.76 & 7.09 & 1.9 & 48.2 & 3.9 & $<0.08$ & 92.1 & 0.4 & 735.9 & 1023.2 & 4.6 & 5.1 & 0.2 & 915.2 & 333.3 & 0.03 & 4.5 & 0.1 & $<0.001$ & 2.4 & 0.01 & 32 & 17 & 0.2 & 0.7 & 0.01 & 25.8 & 3.5 \\
\hline
\end{tabular}




\begin{tabular}{|c|c|c|c|c|c|c|c|c|c|c|c|c|c|c|c|c|c|c|c|c|}
\hline \multirow[b]{2}{*}{$\mathrm{n}^{\circ}$ sample } & \multirow[b]{2}{*}{$\begin{array}{c}\mathrm{T} \\
\left({ }^{\circ} \mathrm{C}\right)\end{array}$} & \multirow[b]{2}{*}{$\begin{array}{c}\mathrm{P} \\
\text { (bar) }\end{array}$} & \multirow[b]{2}{*}{$\begin{array}{l}\text { time } \\
\text { (hrs) }\end{array}$} & \multirow[b]{2}{*}{$\begin{array}{l}\text { flow-rate } \\
\left(\mathrm{ml} \mathrm{hr}{ }^{-1}\right)\end{array}$} & \multirow[b]{2}{*}{$\begin{array}{c}\mathrm{pH} \\
(\operatorname{room~T})\end{array}$} & \multirow[b]{2}{*}{$\begin{array}{c}\mathrm{pH} \\
\left(400^{\circ} \mathrm{C}\right)\end{array}$} & \multicolumn{14}{|c|}{$\mu \mathrm{mol} \mathrm{kg}{ }^{-1}$} \\
\hline & & & & & & & V & $\mathrm{Cr}$ & $\mathrm{Co}$ & $\mathrm{Ni}$ & $\mathrm{Cu}$ & $\mathrm{Zn}$ & $\mathrm{Rb}$ & Mo & $\mathrm{Ag}$ & $\mathrm{Cd}$ & $\mathrm{Ba}$ & $\mathrm{Au}$ & $\mathrm{Pb}$ & $\mathrm{Mn}$ \\
\hline $\begin{array}{l}\text { blank } \\
\text { geothrmal brine }\end{array}$ & 20.1 & 1 & 0.0 & - & 3.91 & 7.14 & 0.04 & 0.06 & $<0.002$ & 0.1 & 0.3 & 1.9 & 8.5 & 0.1 & 0.006 & 0.6 & $<0.001$ & 1 & 0.01 & $<0.13$ \\
\hline 1 & 20.4 & 485.8 & 20.6 & 1 & 5.90 & n.c. & 0.02 & 0.3 & 0.2 & 4.7 & 0.1 & 23.3 & 6.2 & 0.1 & 0.004 & 0.03 & 0.1 & 0.8 & 0.3 & 3.1 \\
\hline 2 & 20.2 & 483.4 & 45.6 & 1 & 6.00 & n.c. & 0.02 & 0.6 & 0.2 & 4.4 & 12.7 & 23.1 & 8.5 & 0.07 & 0.002 & 0.04 & 0.3 & 0.5 & 0.2 & 3.5 \\
\hline 3 & 20.7 & 484.0 & 72.8 & 1 & 5.64 & n.c. & 0.01 & 2.3 & 0.4 & 5.8 & 36.3 & 13.4 & 8.3 & 0.09 & $<0.0005$ & 0.02 & 0.4 & 0.4 & 0.8 & 3.7 \\
\hline 4 & 20.6 & 483.5 & 94.8 & 1 & 5.50 & n.c. & 0.02 & 3.7 & 0.3 & 5.5 & 29.4 & 20.3 & 7.5 & 0.1 & 0.003 & 0.05 & 0.5 & 0.3 & 1.1 & 3.0 \\
\hline 5 & 20.5 & 484.2 & 118.9 & 1 & 5.49 & n.c. & 0.03 & 5 & 0.3 & 6.1 & 31 & 14.5 & 7.2 & 0.2 & $<0.0005$ & 0.03 & 0.4 & 0.3 & 1.1 & 2.5 \\
\hline 6 & 20.7 & 485.4 & 143.1 & 1 & 5.55 & n.c. & 0.05 & 5 & 0.3 & 5.6 & 23.1 & 26.9 & 7 & 0.1 & 0.003 & 0.03 & 0.3 & 0.2 & 1.4 & 2.2 \\
\hline 7 & 20.4 & 484.5 & 166.7 & 1 & 5.35 & n.c. & 0.07 & 6.2 & 0.4 & 6.8 & 27.6 & 35.4 & 9.7 & 0.3 & 0.003 & 0.03 & 0.4 & 0.3 & 1.1 & 1.6 \\
\hline 8 & 397.6 & 478.9 & 190.9 & 1 & 3.23 & 7.00 & 0.1 & 0.6 & 0.04 & 1.0 & 7.9 & 30.2 & 6.7 & 0.06 & $<0.0005$ & 0.04 & 0.09 & 0.1 & 0.3 & 0.2 \\
\hline 9 & 400.1 & 483.1 & 214.7 & 1 & 2.87 & 7.06 & 0.003 & 0.1 & 0.01 & 0.6 & 0.3 & 37.1 & 5.8 & 0.2 & $<0.0005$ & 0.01 & 0.01 & 0.1 & 0.8 & $<0.13$ \\
\hline 10 & 400.4 & 483.5 & 239.3 & 1 & 3.25 & 7.10 & 0.01 & 0.1 & 0.005 & 0.5 & 0.2 & 42.6 & 6 & 0.2 & $<0.0005$ & 0.04 & $<0.001$ & 0.1 & 1.3 & $<0.13$ \\
\hline 11 & 400.7 & 483.8 & 262.6 & 1 & 3.32 & 7.11 & 0.04 & $<0.004$ & $<0.002$ & 0.7 & 1.7 & 42 & 10.9 & 0.3 & $<0.0005$ & 0.01 & $<0.001$ & 0.1 & 0.2 & $<0.13$ \\
\hline 12 & 400.8 & 484.1 & 287.9 & 1 & 3.25 & 7.11 & 0.03 & 0.1 & $<0.002$ & 0.4 & 0.1 & 33 & 11.4 & 0.1 & $<0.0005$ & 0.01 & $<0.001$ & 0.1 & 1 & $<0.13$ \\
\hline 13 & 400.4 & 484.4 & 313.4 & 1 & 3.31 & 7.11 & 0.05 & 0.02 & $<0.002$ & 0.6 & 0.1 & 39.4 & 7.5 & 0.1 & $<0.0005$ & 0.03 & $<0.001$ & 0.1 & 0.3 & $<0.13$ \\
\hline 14 & 400.4 & 484.3 & 334.4 & 1 & 3.53 & 7.12 & 0.08 & 0.02 & $<0.002$ & 0.6 & 0.1 & 33.1 & 6.1 & 0.1 & $<0.0005$ & 0.03 & $<0.001$ & 0.1 & 0.1 & $<0.13$ \\
\hline 15 & 400.8 & 484.4 & 359.0 & 1 & 3.55 & 7.12 & 0.08 & 0.03 & $<0.002$ & 0.6 & 0.1 & 30.1 & 5.5 & 0.1 & $<0.0005$ & 0.003 & $<0.001$ & 0.1 & 0.1 & $<0.13$ \\
\hline 16 & 400.6 & 484.2 & 382.7 & 1 & 3.50 & 7.12 & 0.07 & 0.03 & 0.005 & 0.6 & 0.2 & 38.1 & 5.1 & 0.1 & $<0.0005$ & 0.02 & $<0.001$ & 0.1 & 0.1 & $<0.13$ \\
\hline 17 & 400.7 & 483.5 & 406.0 & 1 & 3.40 & 7.12 & 0.07 & 0.03 & $<0.002$ & 0.7 & 0.2 & 34.1 & 4.5 & 0.1 & $<0.0005$ & 0.02 & $<0.001$ & 0.1 & 0.1 & $<0.13$ \\
\hline 18 & 400.9 & 483.6 & 430.6 & 1 & 3.45 & 7.11 & 0.05 & 0.03 & $<0.002$ & 0.3 & 0.1 & 30.8 & 4.1 & 0.1 & $<0.0005$ & 0.03 & $<0.001$ & 0.1 & 0.3 & $<0.13$ \\
\hline 19 & 400.7 & 483.8 & 457.3 & 1 & 3.57 & 7.10 & 0.03 & 0.04 & $<0.002$ & 0.2 & 0.1 & 21.1 & 3.8 & 0.09 & $<0.0005$ & 0.03 & 0.02 & 0.03 & 0.4 & $<0.13$ \\
\hline 20 & 400.6 & 483.8 & 480.7 & 1 & 3.71 & 7.09 & 0.03 & 0.04 & $<0.002$ & 0.6 & 0.2 & 34.7 & 3.1 & 0.1 & $<0.0005$ & 0.03 & $<0.001$ & 0.1 & 0.5 & 0.2 \\
\hline 21 & 400.6 & 484.7 & 503.3 & 1 & 3.76 & 7.08 & 0.06 & 0.03 & 0.008 & 0.9 & 0.1 & 38.5 & 3.5 & 0.1 & $<0.0005$ & 0.03 & $<0.001$ & 0.04 & 0.2 & $<0.13$ \\
\hline 22 & 400.9 & 484.2 & 527.7 & 1 & 3.78 & 7.10 & 0.03 & 0.03 & 0.006 & 0.6 & 0.1 & 35.7 & 2.7 & 0.08 & $<0.0005$ & 0.04 & $<0.001$ & 0.04 & 0.2 & $<0.13$ \\
\hline 23 & 400.5 & 483.5 & 550.4 & 1 & 4.05 & 7.09 & 0.03 & 0.04 & 0.005 & 0.5 & 0.3 & 26.4 & 2.4 & 0.07 & $<0.0005$ & 0.03 & $<0.001$ & 0.03 & 0.5 & $<0.13$ \\
\hline 24 & 400.7 & 483.5 & 574.8 & 1 & 4.60 & 7.10 & 0.08 & $<0.004$ & $<0.002$ & 0.2 & 0.1 & 17.1 & 2.3 & 0.09 & $<0.0005$ & 0.04 & $<0.001$ & 0.03 & 0.1 & $<0.13$ \\
\hline 25 & 400.6 & 483.9 & 597.6 & 1 & 6.23 & 7.08 & 0.3 & 0.1 & $<0.002$ & 0.2 & 0.1 & 11.7 & 2 & 0.3 & $<0.0005$ & 0.03 & $<0.001$ & 0.03 & 0.03 & $<0.13$ \\
\hline 26 & 400.5 & 484.0 & 625.7 & 1 & 6.51 & 7.11 & 0.3 & 0.04 & $<0.002$ & 0.3 & 0.2 & 8.4 & 2 & 0.1 & $<0.0005$ & 0.02 & $<0.001$ & 0.03 & 0.03 & 0.2 \\
\hline 27 & 400.7 & 483.9 & 647.5 & 1 & 6.77 & 7.11 & 0.2 & 0.1 & $<0.002$ & 0.2 & 0.3 & 16.2 & 1.8 & 0.1 & $<0.0005$ & 0.03 & $<0.001$ & 0.02 & 0.2 & $<0.13$ \\
\hline 28 & 400.4 & 483.6 & 670.8 & 1 & 7.07 & 7.09 & 0.3 & 0.1 & $<0.002$ & 0.4 & 0.3 & 15.5 & 1.8 & 0.1 & 0.003 & 0.03 & $<0.001$ & 0.03 & 0.3 & 0.14 \\
\hline 29 & 400.5 & 483.6 & 694.4 & 1 & 7.44 & 7.05 & 0.3 & 0.03 & 0.004 & 0.2 & 0.2 & 11.4 & 1.6 & 0.1 & $<0.0005$ & 0.02 & $<0.001$ & 0.02 & 0.2 & $<0.13$ \\
\hline 30 & 400.2 & 483.4 & 718.8 & 1 & 7.52 & 7.10 & 0.2 & 0.02 & $<0.002$ & 0.2 & 0.1 & 14.4 & 1.5 & 0.1 & $<0.0005$ & 0.01 & $<0.001$ & 0.02 & 0.3 & $<0.13$ \\
\hline
\end{tabular}



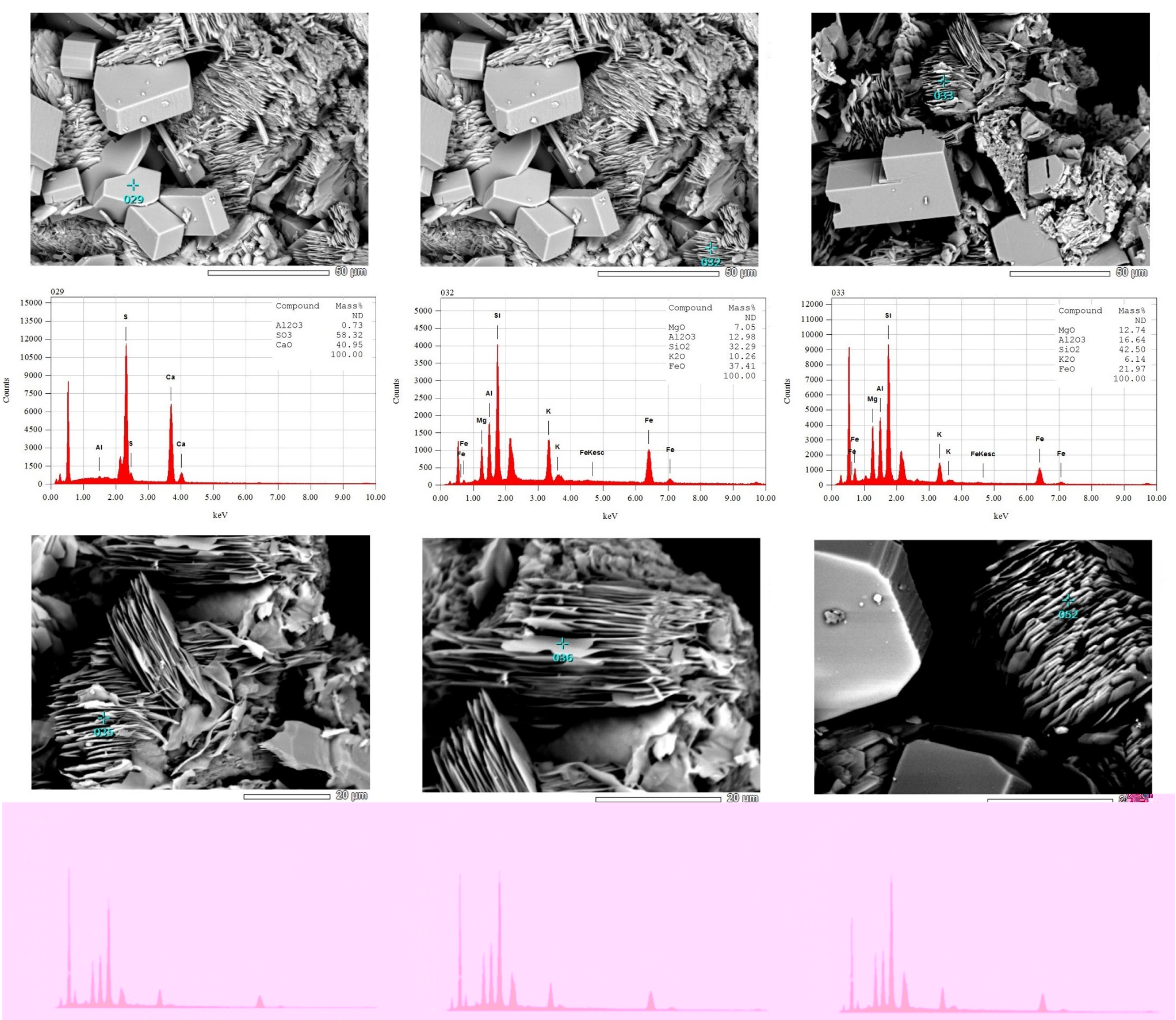
Figure C.4.2. EDS analysis for the study of the morphology of reacted grains collected from the bottom (Portion 1) of the Reactor after the BGB1 experiment
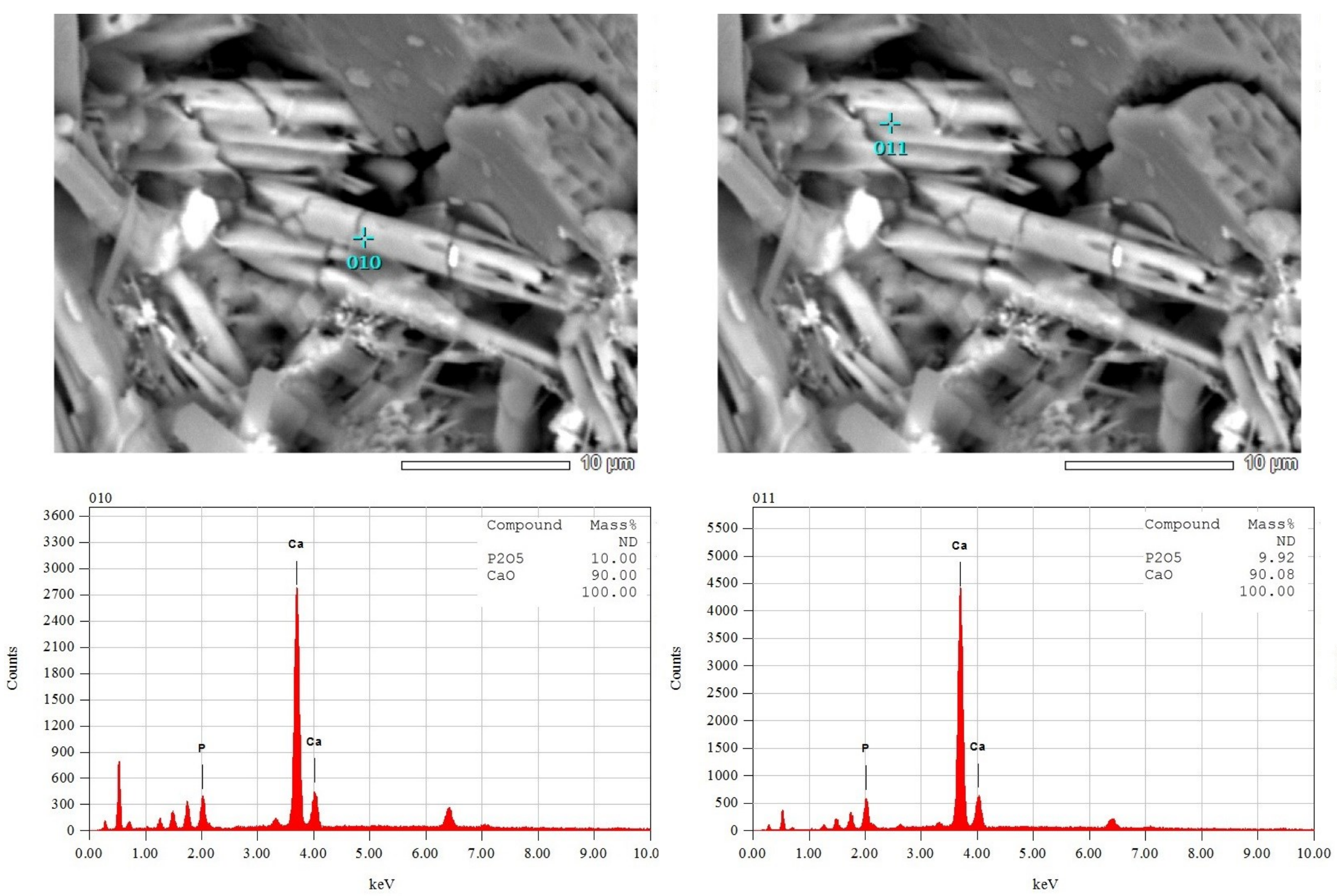
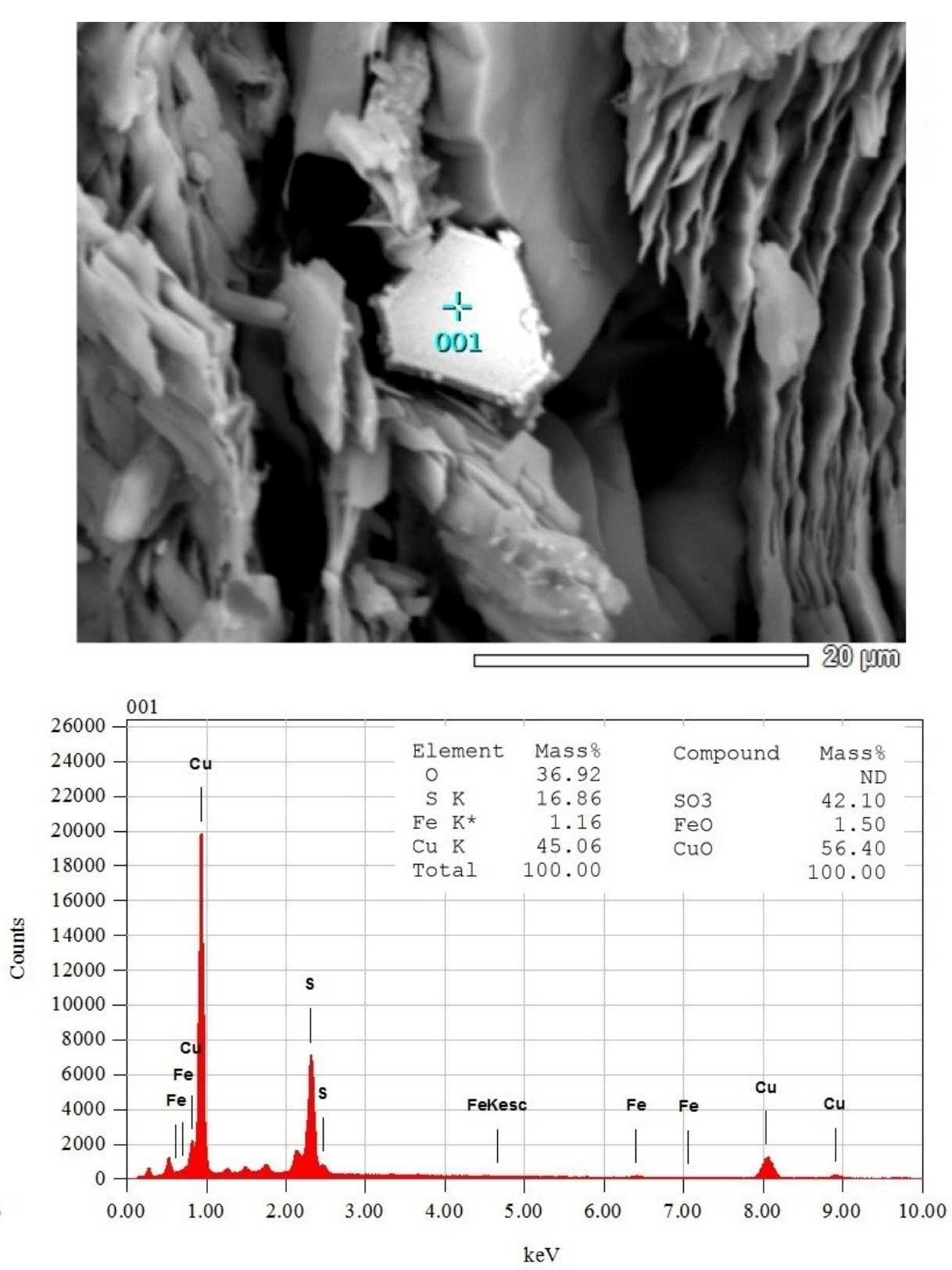
Figure C.4.3. SEM photographs (epoxy-mount) of reacted grains collected from the bottom (Portion 1) of Reactor for EMPA examination. Analysis points are marked in red number

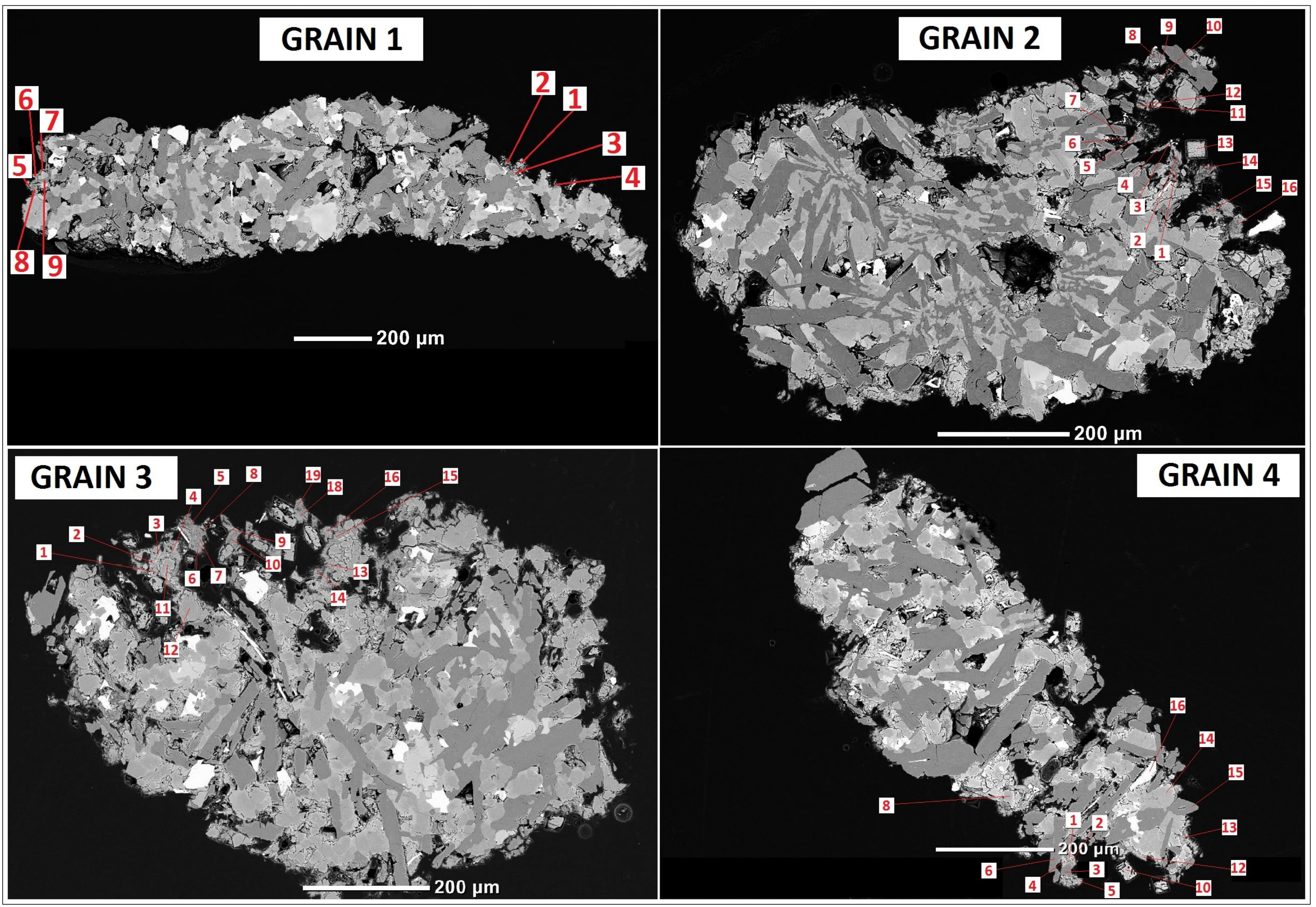


Table C.4.3. EMPA analysis of grains 1-2-3-4 in Fig. C.4.3

\begin{tabular}{|c|c|c|c|c|c|c|c|c|c|c|c|c|c|c|}
\hline $\begin{array}{c}\text { Analysis } \\
\text { Point }\end{array}$ & Grain 1 & $\mathrm{Na}_{2} \mathrm{O}$ & $\mathrm{MgO}$ & $\mathrm{SiO}_{2}$ & $\mathbf{K}_{2} \mathbf{O}$ & $\mathrm{CaO}$ & $\mathrm{TiO}_{2}$ & $\mathrm{FeO}$ & MnO & Cl & $\mathrm{Al}_{2} \mathrm{O}_{3}$ & $\mathrm{SO}_{2}$ & $\mathbf{P}_{2} \mathbf{O}_{5}$ & Total \\
\hline 1 & Mca & 0.13 & 6.16 & 19.74 & 3.07 & 0.23 & 0.12 & 10.81 & 0.18 & 0.34 & 7.23 & 0.11 & & 48.12 \\
\hline 2 & Mca & 0.45 & 8.17 & 25.12 & 2.03 & 0.82 & 0.38 & 20.88 & 0.18 & 0.13 & 8.50 & 0.19 & 0.06 & 66.92 \\
\hline 3 & Mca & 0.49 & 11.00 & 29.51 & 0.26 & 0.63 & 0.09 & 12.88 & 0.10 & 0.19 & 5.61 & 0.25 & 0.07 & 61.07 \\
\hline 4 & Mca & 0.22 & 5.57 & 21.21 & 3.28 & 0.95 & 0.17 & 11.50 & 0.14 & 0.17 & 8.03 & 0.40 & 0.02 & 51.64 \\
\hline 5 & Mca & 0.42 & 10.90 & 35.51 & 5.19 & 0.98 & 0.32 & 20.05 & 0.35 & 0.06 & 12.69 & 0.09 & 0.29 & 86.84 \\
\hline 6 & Mca & 0.38 & 10.02 & 31.50 & 4.86 & 0.61 & 0.21 & 18.67 & 0.32 & 0.10 & 10.52 & 0.14 & 0.04 & 77.37 \\
\hline 7 & Mca & 0.23 & 9.17 & 32.45 & 6.25 & 0.40 & 0.26 & 19.24 & 0.27 & 0.09 & 11.63 & 0.06 & 0.02 & 80.06 \\
\hline 8 & PIg & 3.87 & 0.19 & 52.35 & 0.09 & 13.79 & 0.06 & 1.02 & 0.01 & & 30.86 & & 0.02 & 102.25 \\
\hline 9 & Cpx & 0.21 & 16.09 & 51.69 & & 18.50 & 0.64 & 11.45 & 0.30 & & 2.17 & 0.01 & 0.02 & .08 \\
\hline
\end{tabular}

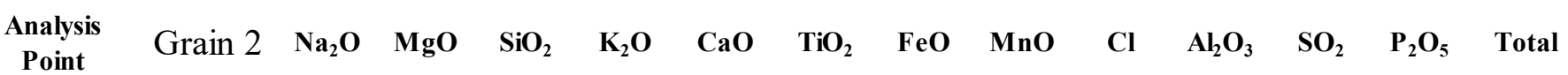

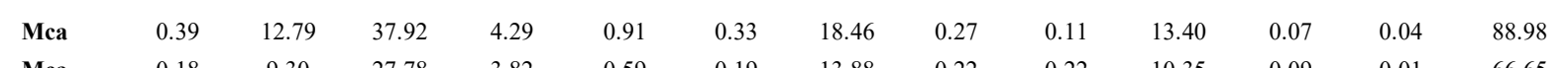
$\begin{array}{llllllllllllll}\text { Mca } & 0.18 & 9.30 & 27.78 & 3.82 & 0.59 & 0.19 & 13.88 & 0.22 & 0.22 & 10.35 & 0.09 & 0.01 & 66.65 \\ & 0.07 & 3.31 & 87.79 & 3.28 & 0.59 & 0.30 & 13.64 & 0.20 & 0.22 & 10.30 & 0.06 & 0.39 & 5380\end{array}$ $\begin{array}{llllllllllllll}\text { Mca } & 0.07 & 3.31 & 8.74 & 1.06 & 0.69 & 13.28 & 21.27 & 1.14 & 0.32 & 3.47 & 0.07 & 0.39 & 53.80 \\ \text { Mca } & 0.19 & 9.39 & 27.79 & 3.28 & 0.59 & 0.30 & 13.64 & 0.20 & 0.22 & 10.30 & 0.06 & 0.01 & 65.96\end{array}$ $\begin{array}{llllllllllllll}\text { Mca } & 0.36 & 10.99 & 33.53 & 4.17 & 0.92 & 0.46 & 17.33 & 0.20 & 0.10 & 12.71 & 0.11 & 0.05 & 80.92\end{array}$ $\begin{array}{llllllllllllll}\text { Mca } & 0.06 & 3.44 & 13.98 & 2.12 & 0.48 & 1.27 & 9.50 & 0.18 & 0.29 & 5.90 & 0.15 & 0.19 & 37.55 \\ \text { Mca } & 0.30 & 10.48 & 33.89 & 3.78 & 0.64 & 0.23 & 17.46 & 0.27 & 0.16 & 11.02 & 0.11 & 0.02 & 77.34\end{array}$

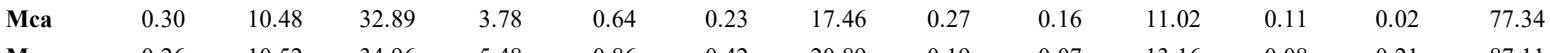

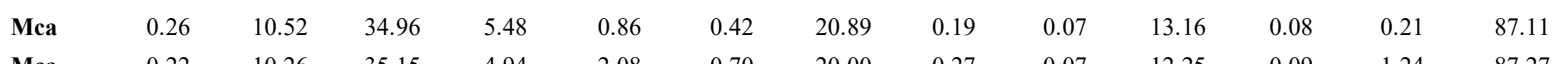
$\begin{array}{llllllllllllll}\text { Mca } & 0.11 & 8.92 & 30.90 & 4.84 & 0.69 & 0.47 & 16.76 & 0.24 & 0.08 & 11.77 & 0.17 & 0.02 & 74.96\end{array}$ $\begin{array}{llllllllllllll}\text { Mca } & 0.15 & 7.55 & 22.43 & 2.99 & 4.14 & 0.20 & 10.89 & 0.18 & 0.15 & 9.07 & 2.39 & 0.03 & 60.17 \\ \text { Mca } & 0.27 & 12.68 & 3737 & 3.88 & 0.96 & 0.13 & 1.95 & 0.25 & 0.08 & 13.76 & 0.05 & 0.02 & 89.22\end{array}$ $\begin{array}{llllllllllllll}\text { Mca } & 0.40 & 13.19 & 38.78 & 4.81 & 0.84 & 0.34 & 19.75 & 0.20 & 0.04 & 13.67 & 0.05 & 0.05 & 92.12\end{array}$ $\begin{array}{llllllllllllll}\text { Mca } & 0.29 & 12.79 & 36.73 & 3.35 & 0.72 & 0.41 & 18.38 & 0.19 & 0.06 & 12.47 & 0.09 & 0.05 & 85.53\end{array}$ $\begin{array}{llllllllllll}\text { Plg } & 4.51 & 0.17 & 52.79 & 0.11 & 13.11 & 0.09 & 0.96 & 0.01 & 30.51 & 0.01 & 102.28\end{array}$
$\mathrm{Anh}$
$0.03 \quad 0.01 \quad 38.31$
0.07
$\begin{array}{lllll}0.03 & 0.03 & 34.87 & 0.03 & 73.38\end{array}$

$\begin{array}{lllllllllllllll}\text { Analysis } & \text { Grain } 4 & \mathrm{Na}_{2} \mathbf{O} & \mathbf{M g O} & \mathrm{SiO}_{2} & \mathrm{~K}_{2} \mathrm{O} & \mathrm{CaO} & \mathrm{TiO}_{2} & \mathrm{FeO} & \mathbf{M n O} & \mathrm{Cl}_{2} & \mathrm{Al}_{2} \mathrm{O}_{3} & \mathrm{SO}_{2} & \mathrm{P}_{2} \mathrm{O}_{5} & \text { Total }\end{array}$ $\begin{array}{llllllllllllll}\text { Mca } & 0.38 & 10.86 & 35.91 & 6.38 & 0.49 & 0.51 & 20.98 & 0.31 & 0.03 & 14.53 & 0.07 & 0.03 & 90.48\end{array}$

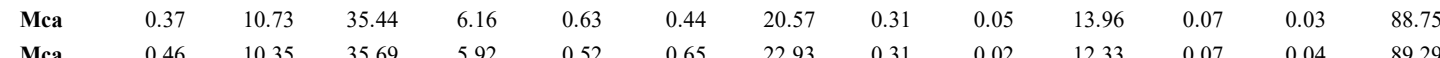
$\begin{array}{llllllllllllll}\text { Mca } & 0.33 & 11.80 & 38.07 & 6.84 & 0.39 & 0.36 & 22.80 & 0.29 & 0.04 & 13.99 & 0.01 & 0.02 & 94.95\end{array}$ $\begin{array}{llllllllllllll}\text { Mca } & 0.17 & 7.13 & 21.24 & 2.54 & 0.68 & 0.20 & 12.65 & 0.25 & 0.27 & 9.55 & 0.06 & 0.01 & 54.74 \\ \text { Mca } & 0.39 & 9.78 & 31.08 & 4.63 & 0.79 & 0.68 & 18.90 & 0.29 & 0.16 & 12.05 & 0.09 & 0.03 & 78.86\end{array}$ $\begin{array}{llllllllllllll}\text { Cpx } & 0.26 & 16.71 & 49.37 & 0.60 & 15.00 & 0.53 & 12.33 & 0.28 & 0.02 & 3.89 & 0.03 & 0.02 & 99.04\end{array}$

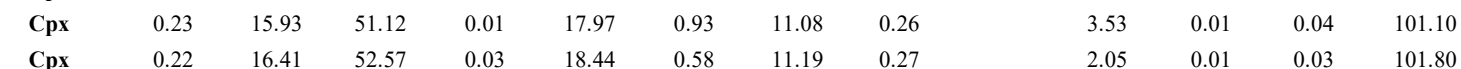

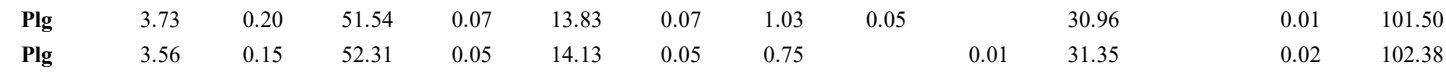

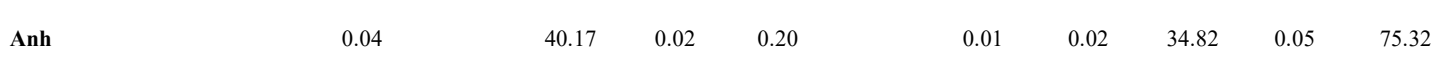
ox $\begin{array}{lllllllll}1.06 & 0.02 & 0.01 & 0.17 & 42.96 & 47.20 & 0.60 & 0.01 & 0.09\end{array}$ $0.01 \quad 92.12$

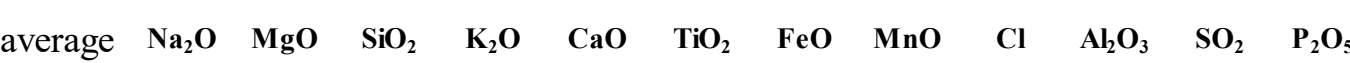
$\begin{array}{lllllllllllll}\text { Mca } & 0.35 & 9.99 & 31.10 & 4.11 & 1.04 & 0.76 & 17.86 & 0.25 & 0.12 & 11.18 & 0.16 & 0.28\end{array}$ $\begin{array}{lllllllllllll}\text { Cpx } & 0.22 & 1589 & 50.01 & 0.16 & 17.04 & 0.62 & 1146 & 026 & 0.02 & 258 & 0.93 & 0.09\end{array}$ $\begin{array}{cccccccccccc}\mathbf{O x} & 1.06 & 0.02 & 0.01 & 0.17 & 42.96 & 47.20 & 0.60 & 0.01 & 0.09 & & 0.01 \\ \mathbf{O n h} & & 0.03 & 0.01 & 39.24 & 0.02 & 0.14 & & 0.02 & 0.02 & 34.84 & 0.04\end{array}$

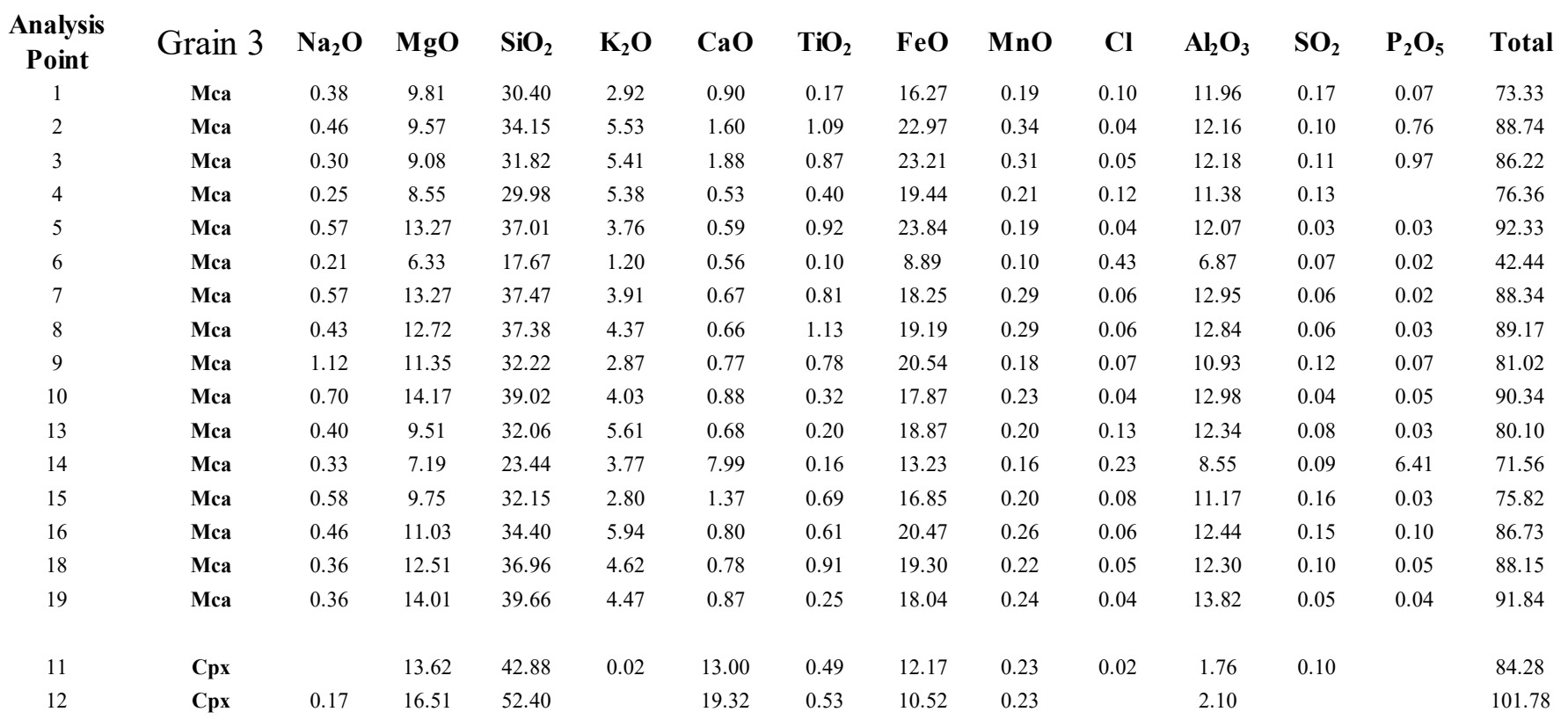


Appendices Doctoral Thesis: “Basalt - fluid interactions at subcritical and supercritical conditions: An experimental study"
University of Victoria Wellington and GNS Science, Wairakei, NewZ Zealand
by Mauro Passarella

Table C.4.4. Average mineral compositions from Table C.4.J

$\begin{array}{cc}\text { Oxides } & \text { average wt\% } \\ \mathrm{Na}_{2} \mathrm{O} & 0.18 \\ \mathrm{MgO} & 15.88 \\ \mathrm{SiO}_{2} & 50.01 \\ \mathrm{~K}_{2} \mathrm{O} & 0.11 \\ \mathrm{CaO} & 17.04 \\ \mathrm{TiO}_{2} & 0.62 \\ \mathrm{FeO}_{(\mathrm{T})} & 11.46 \\ \mathrm{MnO} & 0.26 \\ \mathrm{Cl} & 0.01 \\ \mathrm{Al}_{2} \mathrm{O}_{3} & 2.58 \\ \mathrm{SO}_{2} & 0.03 \\ \mathrm{P}_{2} \mathrm{O}_{5} & 0.02 \\ \text { Total } & 98.18\end{array}$

Mineral Compositio

Phase and ID
$\mathrm{Na}_{0.013} \mathrm{Ca}_{0.70} \mathrm{Mg}_{0.90} \mathrm{Fe}_{0.37} \mathrm{Mn}_{0.01} \mathrm{Ti}_{0.02} \mathrm{Al}_{0.03} \mathrm{Si}_{1.91} \mathrm{Al}_{0.09} \mathrm{O}_{6}$

Clinopyroxene ge wt\%

15.88

50.01
0.11
17.04

0.62

11.46
0.26
0.01

18

average wt\%
0.35
9.99
31.10
4.11
1.04
0.76
17.86
0.25
0.12
11.18
0.16
0.27
77.19

$\mathrm{K}_{0.98} \mathrm{Ca}_{0.21} \mathrm{Na}_{0.13} \mathrm{Mg}_{2.80} \mathrm{Fe}_{2.80} \mathrm{Mn}_{0.04} \mathrm{Ti}_{0.11} \mathrm{Al}_{0.31} \mathrm{Si}_{5.84} \mathrm{Al}_{2.16} \mathrm{O}_{20}(\mathrm{OH})_{4}$ (on the basis of 22 oxygen equivalents, ignoring $\mathrm{H}_{2} \mathrm{O}$ )

$$
\begin{gathered}
\text { Mica } \\
\text { (biotite) }
\end{gathered}
$$

average wt $\%$

1.06

0.02
0.01
0.17

0.17

42.96

47.20

0.60

0.09

0.01

92.12
Oxide
(titanomagnetite)

average $\mathbf{w t} \%$

0.02

34.84

74.35

$\mathrm{CaSO}_{4}$

Sulphate
(anhydrite) 

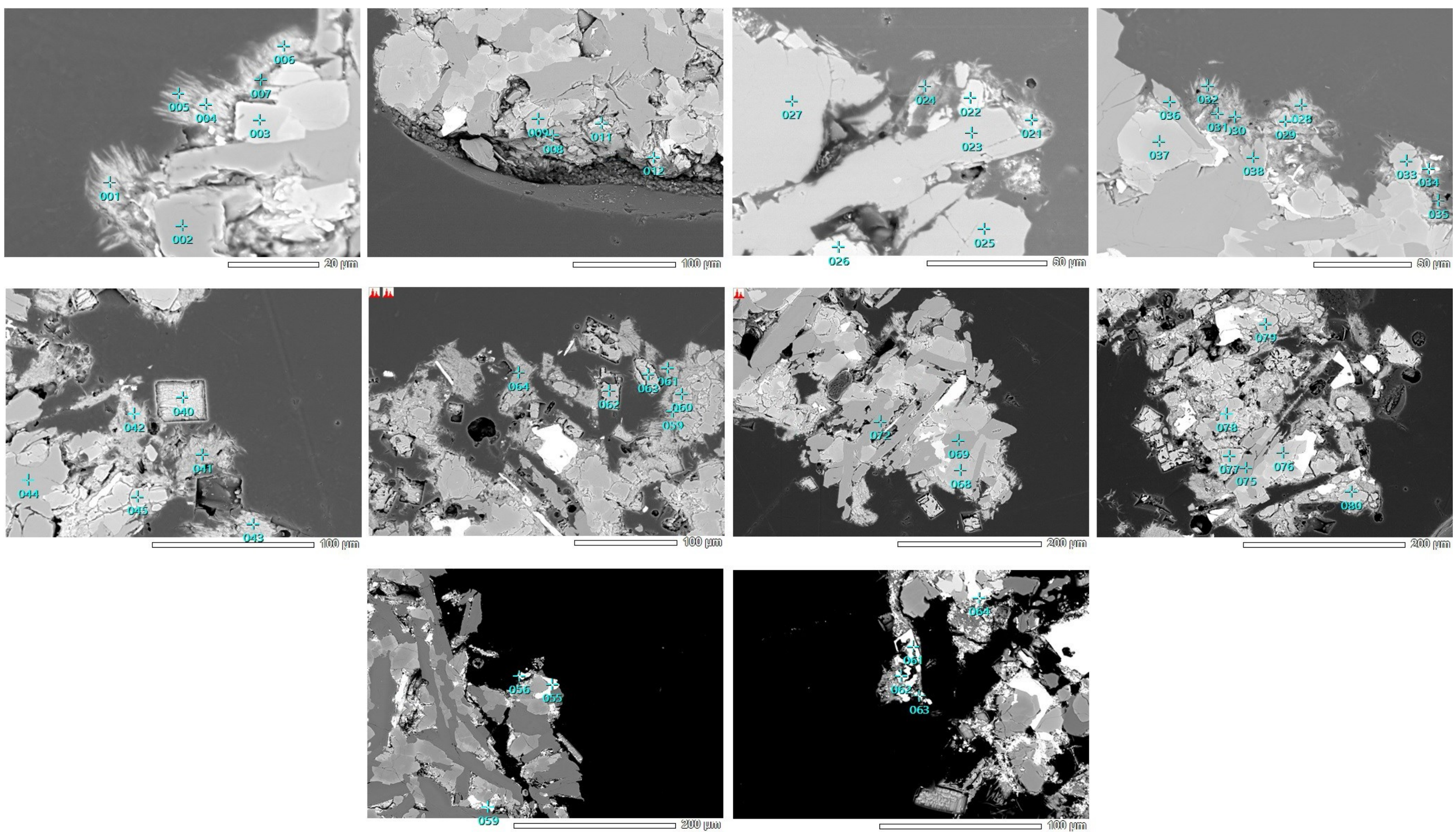
Figure C.4.5. SEM backscatter and EDS compositional maps of further epoxy-mounted, polished grain collected from the bottom (Portion 1) of Reactor after the BGB1 experiment: (a) backscatter image; (b) composite colour image combining the backscatter image and elemental maps for c) $\mathrm{K}$ in green, d) Ca in blue, and e) $\mathrm{S}$ in red. The composite image shows the anhydrite crystals (pink), biotite (green), the primary plagioclase (darker blue) and clinopyroxene (lighter blue), primary olivine and Fe-Ti oxides (grey)
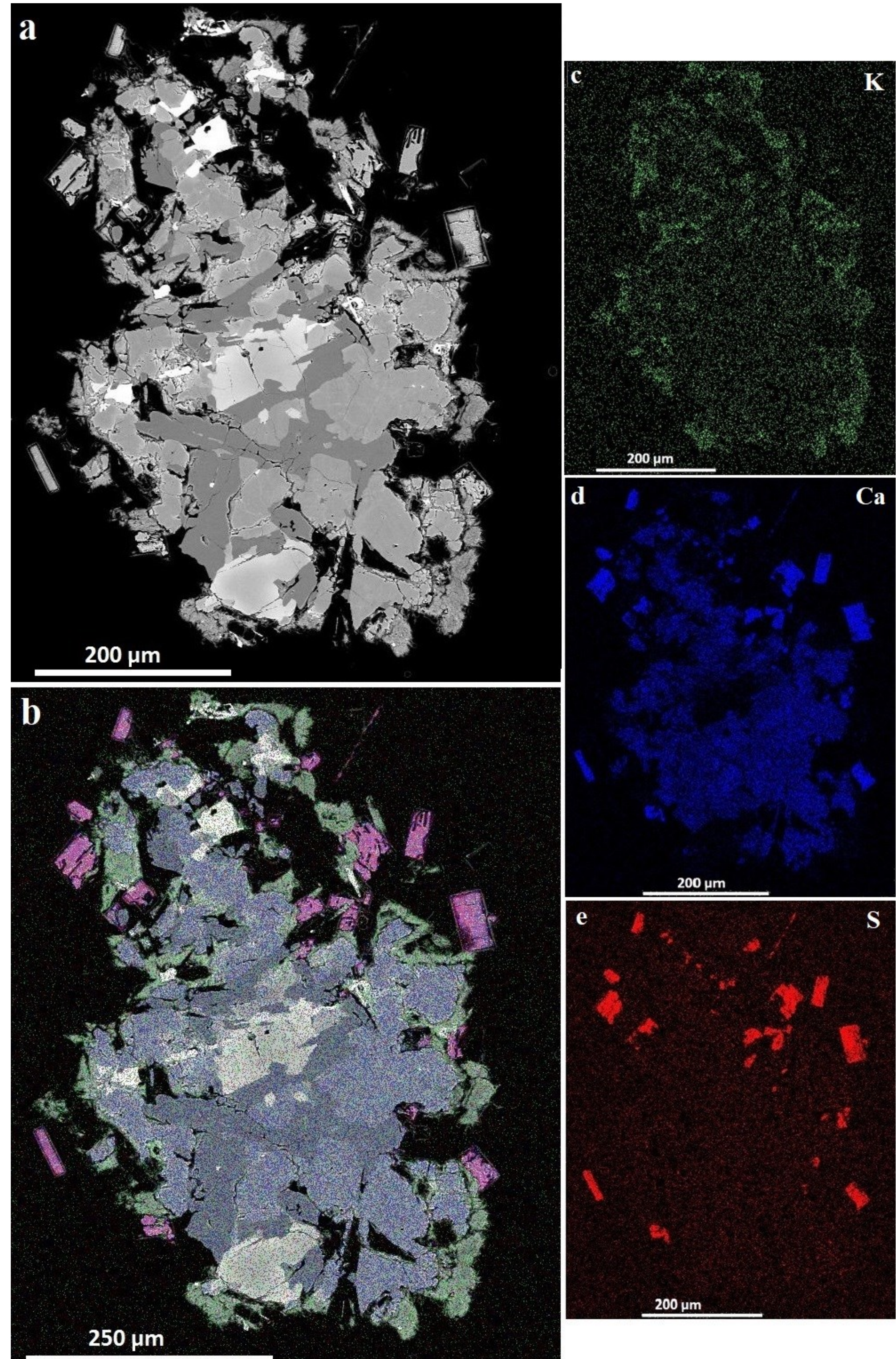
Table C.4.5. EDS analysis of grains in Fig. C.4.4

\begin{tabular}{|c|c|c|c|c|c|c|c|c|c|c|c|c|c|c|c|}
\hline Plg & $\begin{array}{c}\text { Analysis } \\
\text { Point }\end{array}$ & $\mathrm{Na}_{2} \mathrm{O}$ & $\mathrm{Al}_{2} \mathrm{O}_{3}$ & $\mathrm{SiO}_{2}$ & $\mathrm{CaO}$ & $\mathrm{FeO}$ & Total & Mca & $\begin{array}{c}\text { Analysis } \\
\text { Point }\end{array}$ & MgO & $\mathrm{Al}_{2} \mathbf{O}_{3}$ & $\mathrm{SiO}_{2}$ & $\mathbf{K}_{2} \mathbf{O}$ & $\mathrm{FeO}$ & Total \\
\hline & 2 & 2.21 & 32.77 & 50.32 & 13.78 & 0.93 & 100.00 & & 1 & 12.06 & 15.34 & 46.06 & 7.02 & 19.53 & 100.00 \\
\hline & 8 & 2.54 & 32.01 & 52.11 & 13.34 & 0.00 & 100.00 & & 4 & 11.00 & 14.12 & 45.45 & 7.43 & 22.00 & 100.00 \\
\hline & 23 & 2.09 & 33.09 & 49.97 & 14.85 & 0.00 & 100.00 & & 5 & 10.90 & 15.84 & 45.22 & 7.81 & 20.23 & 100.00 \\
\hline & 25 & 2.13 & 33.35 & 50.11 & 14.41 & 0.00 & 100.00 & & 6 & 10.58 & 14.54 & 44.83 & 8.12 & 21.93 & 100.00 \\
\hline & 27 & 2.25 & 34.06 & 49.61 & 14.07 & 0.00 & 100.00 & & 21 & 12.01 & 14.51 & 46.58 & 6.54 & 20.36 & 100.00 \\
\hline & 36 & 2.17 & 33.61 & 49.60 & 13.52 & 1.10 & 100.00 & & 24 & 10.19 & 13.73 & 46.16 & 7.86 & 22.06 & 100.00 \\
\hline & 38 & 2.37 & 32.58 & 51.98 & 13.07 & 0.00 & 100.00 & & 28 & 10.20 & 14.34 & 43.94 & 7.55 & 23.97 & 100.00 \\
\hline & 44 & 1.83 & 34.01 & 48.89 & 15.27 & 0.00 & 100.00 & & 30 & 11.34 & 12.78 & 46.70 & 3.87 & 25.32 & 100.00 \\
\hline & 72 & 2.10 & 32.59 & 50.61 & 14.71 & 0.00 & 100.00 & & 31 & 12.90 & 11.69 & 41.97 & 1.63 & 31.81 & 100.00 \\
\hline & 75 & 2.09 & 33.10 & 50.16 & 14.65 & 0.00 & 100.00 & & 32 & 9.85 & 13.47 & 44.65 & 5.69 & 26.33 & 100.00 \\
\hline \multirow[t]{2}{*}{ average } & & 2.18 & 33.12 & 50.34 & 14.17 & 0.20 & 100.00 & & 35 & 8.45 & 14.40 & 46.04 & 8.32 & 22.79 & 100.00 \\
\hline & & & & & & & & & 41 & 12.70 & 17.27 & 47.51 & 1.92 & 20.61 & 100.00 \\
\hline \multirow{21}{*}{ Cpx } & Analysis & $\mathrm{MgO}$ & $\mathrm{Al}_{2} \mathbf{O}_{3}$ & $\mathrm{SiO}_{2}$ & $\mathrm{CaO}$ & $\mathrm{FeO}$ & Total & & 42 & 12.45 & 15.53 & 46.67 & 6.97 & 18.38 & 100.00 \\
\hline & Point & Nige & $\mathrm{N}_{2} \mathrm{O}_{3}$ & $10_{2}$ & Cav & 100 & & & 43 & 11.09 & 15.74 & 44.90 & 7.18 & 21.09 & 100.00 \\
\hline & 3 & 12.01 & 2.20 & 55.18 & 19.04 & 11.57 & 100.00 & & 59 & 10.66 & 15.64 & 44.66 & 7.52 & 21.52 & 100.00 \\
\hline & 7 & 3.80 & 6.09 & 33.06 & 26.02 & 31.03 & 100.00 & & 61 & 12.09 & 15.13 & 45.78 & 7.47 & 19.53 & 100.00 \\
\hline & 9 & 14.08 & 2.06 & 55.77 & 20.50 & 7.60 & 100.00 & & 64 & 12.15 & 14.78 & 46.34 & 6.14 & 20.59 & 100.00 \\
\hline & 11 & 9.32 & 2.69 & 54.66 & 13.22 & 20.11 & 100.00 & average & & 11.21 & 14.64 & 45.50 & 6.41 & 22.24 & 100.00 \\
\hline & 12 & 5.98 & 1.64 & 42.98 & 17.94 & 31.47 & 100.00 & & & & & & & & \\
\hline & 22 & 10.61 & 2.06 & 54.88 & 17.77 & 14.68 & 100.00 & & Analysis & $\mathrm{CaO}$ & so & & & & Total \\
\hline & 26 & 9.35 & 1.89 & 55.28 & 17.95 & 15.53 & 100.00 & Ann & Point & $\mathrm{COO}$ & $\mathrm{SO}_{3}$ & & & & Total \\
\hline & 29 & 13.87 & 2.24 & 55.83 & 19.90 & 8.16 & 100.00 & & 40 & 42.16 & 57.84 & & & & 100.00 \\
\hline & 33 & 13.66 & 2.74 & 55.66 & 19.64 & 8.30 & 100.00 & & 62 & 37.07 & 62.77 & & & & 100.00 \\
\hline & 37 & 12.90 & 4.13 & 53.77 & 20.65 & 8.55 & 100.00 & & 63 & 39.10 & 60.90 & & & & 100.00 \\
\hline & 45 & 13.61 & 3.62 & 54.86 & 20.14 & 7.78 & 100.00 & average & & 39.44 & 60.50 & & & & 99.95 \\
\hline & 60 & 14.09 & 2.18 & 56.28 & 19.27 & 8.18 & 100.00 & & & & & & & & \\
\hline & 68 & 9.58 & 2.16 & 54.45 & 17.42 & 16.40 & 100.00 & & & & & & & & \\
\hline & 69 & 9.53 & 2.45 & 53.70 & 17.81 & 16.52 & 100.00 & & & & & & & & \\
\hline & 76 & 13.09 & 2.48 & 55.22 & 19.99 & 9.22 & 100.00 & & & & & & & & \\
\hline & 77 & 13.22 & 4.56 & 53.54 & 19.95 & 8.73 & 100.00 & & & & & & & & \\
\hline & 78 & 13.15 & 2.38 & 55.23 & 20.54 & 8.70 & 100.00 & & & & & & & & \\
\hline & 79 & 12.82 & 4.72 & 53.01 & 19.38 & 10.07 & 100.00 & & & & & & & & \\
\hline & 80 & 13.62 & 3.31 & 54.67 & 18.43 & 9.97 & 100.00 & & & & & & & & \\
\hline average & & 11.49 & 2.93 & 53.05 & 19.24 & 13.29 & 100.00 & & & & & & & & \\
\hline \multirow[t]{3}{*}{ Ox } & $\begin{array}{c}\text { Analysis } \\
\text { Point }\end{array}$ & $\mathrm{FeO}$ & $\mathrm{TiO}_{2}$ & & & & Total & & & & & & & & \\
\hline & 55 & 52.10 & 47.90 & & & & 100.00 & & & & & & & & \\
\hline & 56 & 98.77 & 1.23 & & & & 100.00 & & & & & & & & \\
\hline \multirow[t]{6}{*}{ Tnt } & 34 & 70.26 & 29.74 & & & & 100.00 & & & & & & & & \\
\hline & 59 & 69.96 & 30.04 & & & & 100.00 & & & & & & & & \\
\hline & 61 & 74.44 & 25.56 & & & & 100.00 & & & & & & & & \\
\hline & 62 & 66.47 & 33.53 & & & & 100.00 & & & & & & & & \\
\hline & 63 & 75.83 & 24.17 & & & & 100.00 & & & & & & & & \\
\hline & 64 & 73.15 & 26.85 & & & & 100.00 & & & & & & & & \\
\hline average & & 71.69 & 28.32 & & & & 100.00 & & & & & & & & \\
\hline
\end{tabular}




\begin{tabular}{|c|c|c|c|c|c|c|}
\hline Oxides & average $w t \%$ & average $w t \%$ & average $w t \%$ & average $w t \%$ & average $\mathrm{wt} \%$ & point $n^{\circ} 56 \mathrm{w}$ \\
\hline $\mathrm{Na}_{2} \mathrm{O}$ & 2.18 & & & & & \\
\hline $\mathrm{Al}_{2} \mathrm{O}_{3}$ & 33.12 & 2.93 & 14.64 & & & \\
\hline $\mathrm{SiO}_{2}$ & 50.34 & 53.05 & 45.50 & & & \\
\hline $\mathrm{CaO}$ & 14.17 & 19.24 & & 39.44 & & \\
\hline $\mathrm{FeO}$ & 0.20 & 13.29 & 22.24 & & 71.69 & 98.77 \\
\hline $\mathrm{MgO}$ & & 11.49 & 11.21 & & & \\
\hline $\mathrm{K}_{2} \mathrm{O}$ & & & 6.41 & & & \\
\hline $\mathrm{TiO}_{2}$ & & & & & 28.32 & 1.23 \\
\hline $\mathrm{SO}_{3}$ & & & & 60.50 & & \\
\hline Total & 100.00 & 100.00 & 100.00 & 99.94 & 100.01 & 100.00 \\
\hline $\begin{array}{l}\text { Mineral } \\
\text { omposition }\end{array}$ & $\begin{array}{c}\mathrm{Ca}_{0.70} \mathrm{Na}_{0.19} \mathrm{Al}_{1.79} \mathrm{Si}_{2.31} \mathrm{O}_{8} \\
\left(\mathrm{An}_{78}-\mathrm{Ab}_{22}\right)\end{array}$ & $\mathrm{Ca}_{0.77} \mathrm{Mg}_{0.64} \mathrm{Fe}_{0.42} \mathrm{Al}_{0.12} \mathrm{Si}_{1.99} \mathrm{Al}_{0.01} \mathrm{O}_{6}$ & $\begin{array}{l}\mathrm{K}_{1.15} \mathrm{Mg}_{2.35} \mathrm{Fe}_{2.62} \mathrm{Al}_{0.84} \mathrm{Si}_{6.41} \mathrm{Al}_{1.59} \mathrm{O}_{20}(\mathrm{OH})_{4} \\
\text { (on the basis of } 22 \text { oxygen equivalents, ignoring } \mathrm{H}_{2} \mathrm{O} \text { ) }\end{array}$ & $\mathrm{CaSO}_{4}$ & $\mathrm{Fe}^{2+}\left(\mathrm{Fe}^{3+}, \mathrm{Ti}\right)_{2} \mathrm{O}_{4}$ & \\
\hline lase and ID & $\begin{array}{l}\text { Plagioclase } \\
\text { (bytownite) }\end{array}$ & $\begin{array}{l}\text { Clinopyroxene } \\
\text { (augite) }\end{array}$ & $\begin{array}{c}\text { Mica } \\
\text { (biotite) }\end{array}$ & $\begin{array}{l}\text { Sulphate } \\
\text { (anhydrite) }\end{array}$ & $\begin{array}{c}\text { Oxide } \\
\text { (titanomagnetite) }\end{array}$ & Oxide \\
\hline
\end{tabular}


Figure C.4.6. XRD scan showing the mineralogy of reacted grains collected from the bottom (Portion 1) of the Reactor after the BGBl experiment

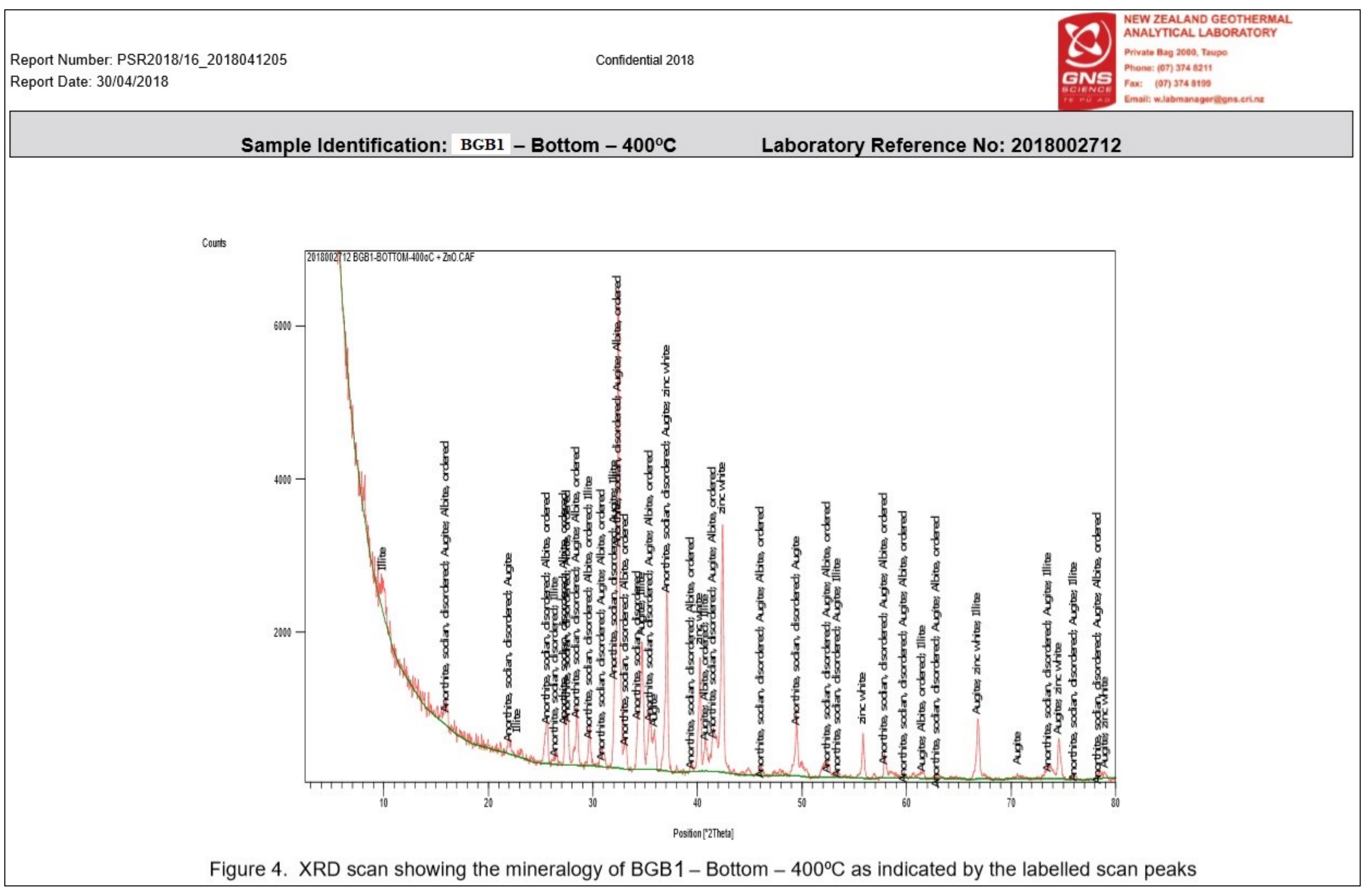




\section{Sample Composition}

Table 1. Mineral percentages for BGB1 sample was determined and then normalized to exclude zinc oxide:

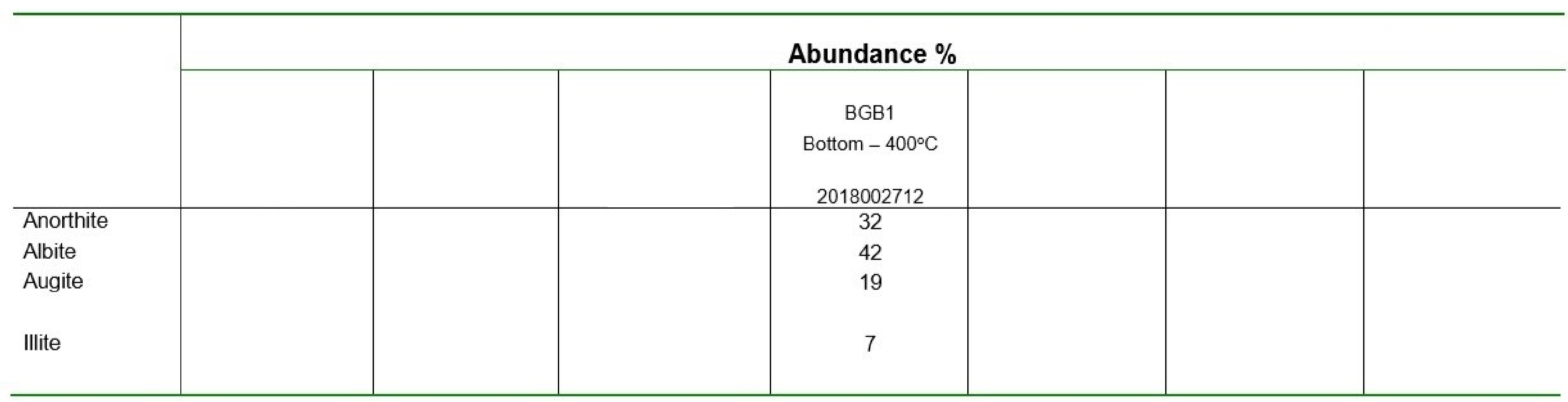

Margin of Error: Abundance estimates are determined through successive refinement of cell parameters; the position, width and orientation of each mineral. Values are given to the nearest whole number. The margin of error for phase concentration is proposed as follows: $0-10 \% \pm 10 \% ; 10-50 \% \pm 5 \% ; 50-100 \% \pm 2 \%$ 
Figure C.4.8. SEM photographs for EDS analysis of epoxy-mounted polished grains collected from the top portion of Reactor. Analysis points are marked in blue
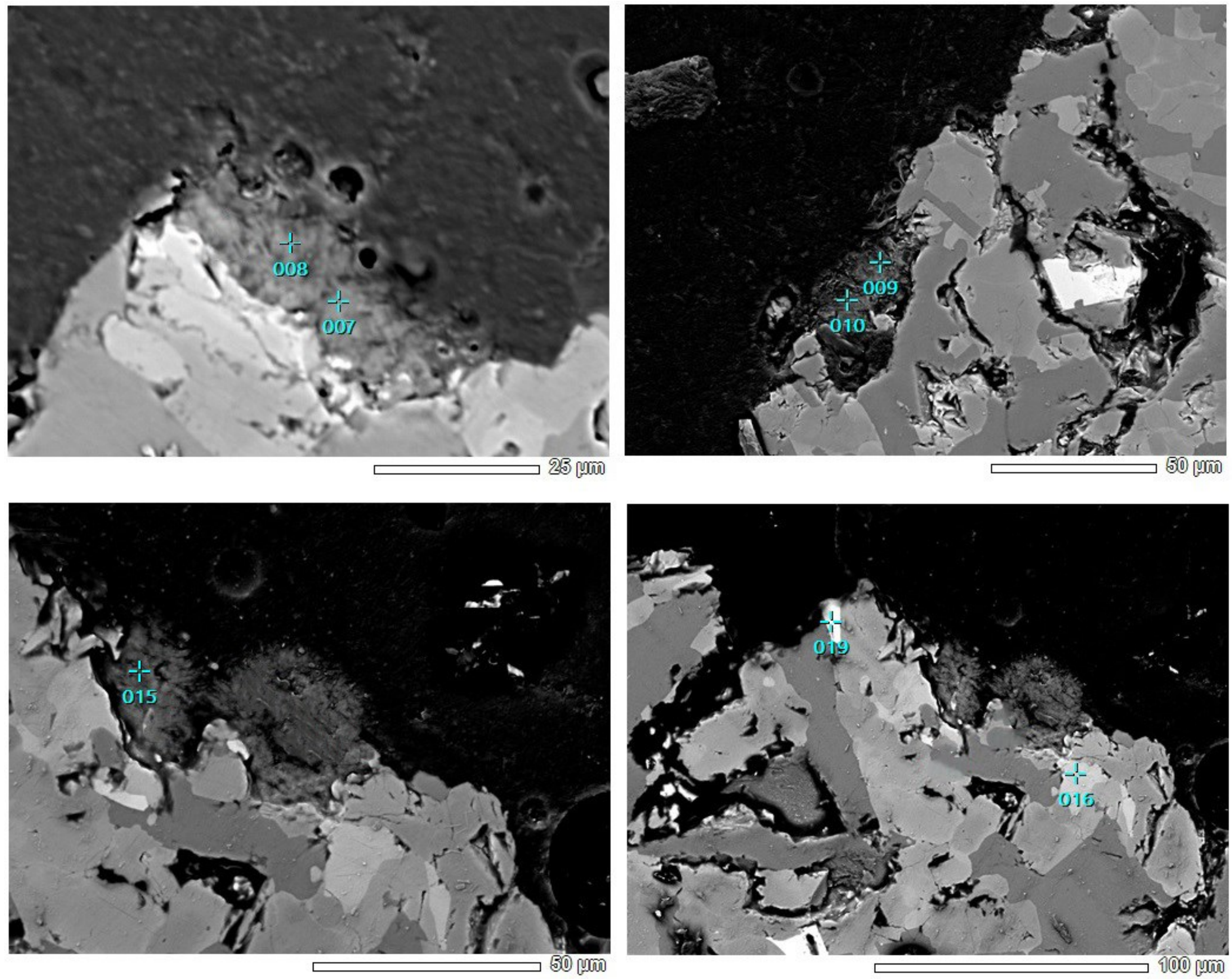


\section{$\mathrm{Ol} \quad \begin{gathered}\text { Analysis } \\ \mathrm{MgO}\end{gathered} \mathrm{Al}_{2} \mathrm{O}_{3} \mathrm{SiO}_{2} \quad \mathrm{CaO} \quad \mathrm{FeO}$ Total}

$\begin{array}{llllll}5.75 & 1.18 & 33.14 & 0.54 & 49.4 & 100.00\end{array}$

\begin{tabular}{|c|c|c|c|c|c|c|c|}
\hline \multirow[t]{2}{*}{$\mathrm{Ox}$} & $\begin{array}{c}\text { Analysis } \\
\text { Point }\end{array}$ & $\mathrm{TiO}_{2}$ & $\mathrm{FeO}$ & & & & Total \\
\hline & 19 & 25.6 & 74.4 & & & & 100.00 \\
\hline \multirow[t]{6}{*}{ Smc } & $\begin{array}{c}\text { Analysis } \\
\text { Point }\end{array}$ & $\mathrm{MgO}$ & $\mathrm{Al}_{2} \mathbf{O}_{3}$ & $\mathrm{SiO}_{2}$ & $\mathrm{~K}_{2} \mathrm{O}$ & $\mathrm{FeO}$ & Total \\
\hline & 7 & 13.73 & 11.12 & 48.05 & 1.07 & 26.03 & 100.00 \\
\hline & 8 & 15.83 & 10.97 & 50.43 & 0.38 & 22.39 & 100.00 \\
\hline & 9 & 16.07 & 12.64 & 47.57 & 1.50 & 22.22 & 100.00 \\
\hline & 10 & 14.88 & 10.73 & 48.95 & 1.50 & 23.94 & 100.00 \\
\hline & 15 & 15.57 & 11.62 & 49.13 & 0.68 & 23.00 & 100.00 \\
\hline age & & 15.22 & 11.42 & 48.83 & 1.03 & 23.52 & 100.00 \\
\hline$\pm \sigma$ & & 0.94 & 0.76 & 1.10 & 0.50 & 1.56 & \\
\hline
\end{tabular}

Table C.4.8. Average mineral compositions from Table (A.4.7)

\begin{tabular}{|c|c|c|c|}
\hline Oxides & average $w t \%$ & average wt $\%$ & average $w t \%$ \\
\hline $\mathrm{Na}_{2} \mathrm{O}$ & & & \\
\hline $\mathrm{Al}_{2} \mathrm{O}_{3}$ & 1.18 & 11.42 & \\
\hline $\mathrm{SiO}_{2}$ & 33.14 & 48.83 & \\
\hline $\mathrm{CaO}$ & 0.54 & & \\
\hline $\mathrm{FeO}$ & 49.39 & 23.52 & 74.41 \\
\hline $\mathrm{MgO}$ & 15.75 & 15.22 & \\
\hline $\mathrm{TiO}_{2}$ & & & 25.59 \\
\hline $\mathrm{K}_{2} \mathrm{O}$ & & 1.03 & \\
\hline Total & 100.00 & 100.02 & 100.00 \\
\hline $\begin{array}{l}\text { Mineral } \\
\text { Composition }\end{array}$ & $\begin{array}{l}\mathrm{Mg}_{0.7} \mathrm{Fe}_{1.2} \mathrm{SiO}_{4} \\
\left(\mathrm{Fo}_{37}-\mathrm{Fa}_{63}\right)\end{array}$ & $\begin{array}{l}\mathrm{K}_{0.1} \mathrm{Mg}_{1.5} \mathrm{Fe}_{1.3} \mathrm{Al}_{0.2} \mathrm{Si}_{3.3} \mathrm{Al}_{0.7} \mathrm{O}_{10}(\mathrm{OH})_{2} \\
\text { (on the basis of } 11 \text { oxygen equivalents, ignoring } \mathrm{H}_{2} \mathrm{O} \text { ) }\end{array}$ & $\mathrm{Fe}^{2+}\left(\mathrm{Fe}^{3+}, \mathrm{Ti}_{2} \mathrm{O}_{4}\right.$ \\
\hline Phase and ID & $\begin{array}{c}\text { Fe-olivine } \\
\text { (fayalite) }\end{array}$ & $\begin{array}{c}\text { Smectite } \\
\text { (epoxy-mount) }\end{array}$ & $\begin{array}{c}\text { Oxide } \\
\text { (titanomagnetite) }\end{array}$ \\
\hline
\end{tabular}


Figure C.4.9. XRD scan showing the mineralogy of reacted grains collected from the top (Portion 2) of the Reactor after the BGB1 experiment

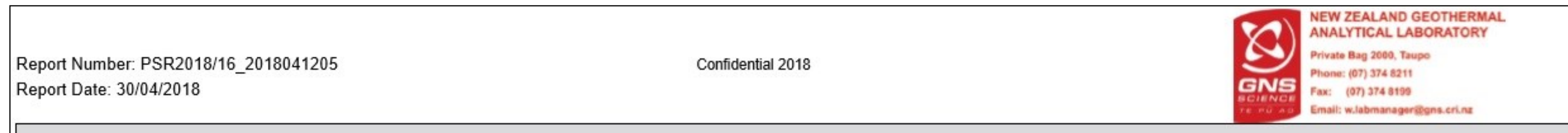

\section{Sample Identification: BGBI - Top $-400^{\circ} \mathrm{C} \quad$ Laboratory Reference No: 2018002713}

Courts

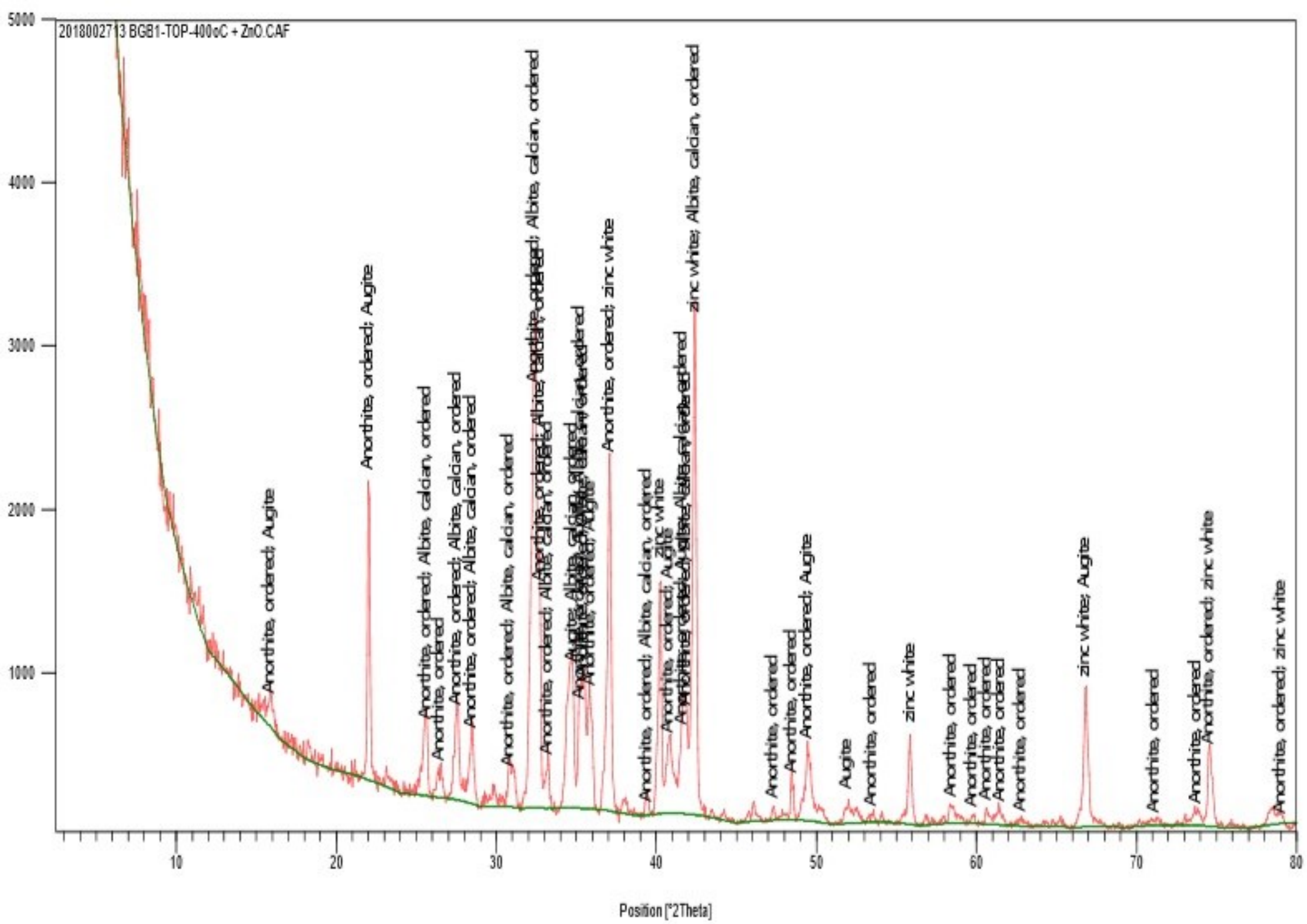

Figure 5. XRD scan showing the mineralogy of BGB1 $-\mathrm{Top}-400^{\circ} \mathrm{C}$ as indicated by the labelled scan peaks 


\section{Sample Composition}

Table 1. Mineral percentages for BGB1 sample was determined and then normalized to exclude zinc oxide:

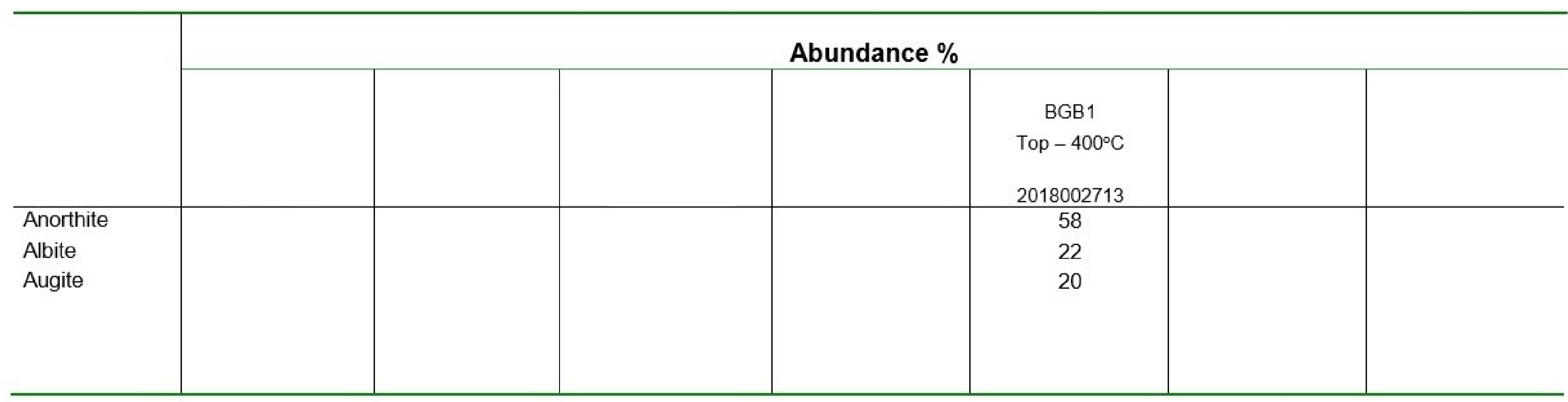

Margin of Error: Abundance estimates are determined through successive refinement of cell parameters; the position, width and orientation of each mineral. Values are given to the nearest whole number. The margin of error for phase concentration is proposed as follows: $0-10 \% \pm 10 \% ; 10-50 \% \pm 5 \% ; 50-100 \% \pm 2 \%$ 


\subsection{Results}

4.2.2. BGB2: Basalt - geothermal brine at $350^{\circ} \mathrm{C} / 486$ bar

Table C.4.9. Major ions compositions and complete experimental parameters (n' of samples collected, T, P, time, flow rate and $\mathrm{pH}$ ) for the $\mathrm{BGB2}$ at $350^{\circ} \mathrm{C}$ and 486 bar. In situ $\mathrm{pH}$ is the calculated pH at temperature. Analysis of major ions are reported both in $\mathrm{mg}$ kg-1 and in mmol $\mathrm{kg}^{-1}$. n.c.:. not calculated

\begin{tabular}{|c|c|c|c|c|c|c|c|c|c|c|c|c|c|c|c|c|c|c|c|c|c|c|c|c|c|c|c|c|c|c|c|c|}
\hline \multirow[b]{2}{*}{$\mathrm{n}^{\circ}$ sample } & \multirow[b]{2}{*}{$\begin{array}{l}\mathrm{T} \\
\left({ }^{\circ} \mathrm{C}\right)\end{array}$} & \multirow[b]{2}{*}{$\begin{array}{c}\mathrm{P} \\
\text { (bar) }\end{array}$} & \multirow[b]{2}{*}{$\begin{array}{l}\text { time } \\
\text { (hrs) }\end{array}$} & \multirow[b]{2}{*}{$\begin{array}{c}\text { flow-rate } \\
\left(\mathrm{ml} \mathrm{hr}^{-1}\right)\end{array}$} & \multirow[b]{2}{*}{$\underset{\text { (room T) }}{\mathrm{pH}}$} & \multirow[b]{2}{*}{$\begin{array}{c}\mathrm{pH} \\
\left(350^{\circ} \mathrm{C}\right)\end{array}$} & \multicolumn{13}{|c|}{$\mathrm{mg} \mathrm{kg}^{-1}$} & \multicolumn{13}{|c|}{$\mathrm{mmol} \mathrm{kg}^{-1}$} \\
\hline & & & & & & & As & B & $\mathrm{Ca}$ & $\mathrm{Fe}$ & K & $\mathrm{Mg}$ & $\mathrm{Na}$ & $\mathrm{SiO}_{2}$ & $\mathrm{Al}$ & $\mathrm{Li}$ & $\mathrm{H}_{2} \mathrm{~S}$ & $\mathrm{Cl}$ & $\mathrm{SO}_{4}$ & As & B & $\mathrm{Ca}$ & $\mathrm{Fe}$ & K & $\mathrm{Mg}$ & $\mathrm{Na}$ & $\mathrm{SiO}_{2}$ & $\mathrm{Al}$ & $\mathrm{Li}$ & $\mathrm{H}_{2} \mathrm{~S}$ & $\mathrm{Cl}$ & $\mathrm{SO}_{4}$ \\
\hline $\begin{array}{c}\text { blank } \\
\text { geothrmal brine }\end{array}$ & 20.1 & 1 & 0.0 & - & 4.28 & 6.75 & 0.1 & 55.4 & 7.2 & $<0.08$ & 116 & 0.9 & 725.1 & 883.3 & 9.6 & 6.7 & $<0.01$ & 962.1 & 406.3 & 0.002 & 5.1 & 0.2 & $<0.001$ & 3 & 0.04 & 31.6 & 14.7 & 0.4 & 1 & $<0.0003$ & 27.1 & 4.2 \\
\hline 1 & 20.4 & 488.3 & 21.2 & 1 & 5.77 & n.c. & 1.5 & 41.2 & 2.9 & 0.1 & 97.4 & 0.2 & 647 & 760.3 & 1.4 & 4.8 & $<0.01$ & 899.2 & 348.2 & 0.02 & 3.8 & 0.07 & 0.001 & 2.5 & 0.01 & 28.1 & 12.7 & 0.1 & 0.7 & $<0.0003$ & 27.1 & 3.6 \\
\hline 2 & 20.3 & 488.0 & 47.3 & 1 & 5.43 & n.c. & 0.1 & 46.8 & 5.4 & 0.1 & 115.1 & 0.8 & 723.6 & 766.7 & 9.1 & 5.6 & $<0.01$ & 901.4 & 377.4 & 0.0009 & 4.3 & 0.1 & 0.001 & 2.9 & 0.03 & 31.5 & 12.8 & 0.3 & 0.8 & $<0.0003$ & 25.4 & 3.9 \\
\hline 3 & 20.6 & 488.0 & 71.4 & 1 & 5.10 & n.c. & 0.5 & 48.4 & 4.3 & 0.3 & 115.9 & 0.5 & 733.3 & 840 & 5.8 & 5.7 & $<0.01$ & 951.1 & 398.3 & 0.01 & 4.5 & 0.1 & 0.01 & 3 & 0.02 & 31.9 & 14 & 0.2 & 0.8 & $<0.0003$ & 26.8 & 4.1 \\
\hline 4 & 20.5 & 487.8 & 93.7 & 1 & 5.20 & n.c. & 0.4 & 46.4 & 4.1 & 0.3 & 115.2 & 0.6 & 723.2 & 821.4 & 7.3 & 5.6 & $<0.01$ & 892.2 & 363 & 0.01 & 4.3 & 0.1 & 0.01 & 2.9 & 0.02 & 31.5 & 13.7 & 0.3 & 0.8 & $<0.0003$ & 25.2 & 3.8 \\
\hline 5 & 20.5 & 487.9 & 118.2 & 1 & 5.19 & n.c. & 0.4 & 46.3 & 4.2 & 0.6 & 115 & 0.7 & 724.8 & 821.9 & 7 & 5.6 & $<0.01$ & 498.1 & 195.6 & 0.01 & 4.3 & 0.1 & 0.01 & 2.9 & 03 & 31.5 & 13.7 & 0.3 & 0.8 & $<0.0003$ & 4.1 & 2 \\
\hline 6 & 20.1 & 487.9 & 141.8 & 1 & 5.23 & n.c. & 0.5 & 46.4 & 3.7 & 0.9 & 114.8 & 0.6 & 722 & 819.8 & 6.5 & 5.6 & $<0.01$ & 990.6 & 421.2 & 0.01 & 4.3 & 0.1 & 0.02 & 2.9 & 0.03 & 31.4 & 13.6 & 0.2 & 0.8 & $<0.0003$ & 27.9 & 4.4 \\
\hline 7 & 20.4 & 487.8 & 165.7 & 1 & 5.06 & n.c. & 0.7 & 46.2 & 4.1 & 1.1 & 114.9 & 0.9 & 721.7 & 823.8 & 6.2 & 5.6 & $<0.01$ & 965.3 & 388.2 & 0.01 & 4.3 & 0.1 & 0.02 & 2.9 & 0.04 & 31.4 & 13.7 & 0.2 & 0.8 & $<0.0003$ & 27.2 & 4 \\
\hline 8 & 352.3 & 486.3 & 187.8 & 1 & 4.43 & 6.66 & 0.9 & 46.3 & 4.2 & 0.3 & 218.3 & 0.6 & 620.2 & 1395 & 3.7 & 4 & $<0.01$ & 990.3 & 225.4 & 0.01 & 4.3 & 0.1 & 0.005 & 5.6 & 0.02 & 27 & 23.2 & 0.1 & 0.6 & $<0.0003$ & 7.9 & 2.3 \\
\hline 9 & 350.4 & 486.2 & 211.4 & 1 & 3.39 & 6.68 & 2 & 47.8 & 2.2 & 0.1 & 263.5 & 0.2 & 574.2 & 1860.4 & 0.4 & 4.3 & 0.9 & 957.2 & 207.5 & 0.03 & 4.4 & 0.06 & 0.002 & 6.7 & 0.01 & 25 & 31 & 0.01 & 0.6 & 0.03 & 27 & 2.2 \\
\hline 10 & 350.5 & 486.3 & 236.2 & 1 & 3.56 & 6.76 & 0.6 & 45.9 & 1.7 & 0.1 & 246.3 & 0.1 & 634.7 & 1690 & 0.8 & 4.8 & 2 & 885.1 & 283.4 & 0.01 & 4.2 & 0.04 & 0.003 & 6.3 & 0.002 & 27.6 & 28.1 & 0.03 & 0.7 & 0.06 & 25 & 2.9 \\
\hline 11 & 350.7 & 486.2 & 260.3 & 1 & 4.58 & 6.82 & 1.1 & 47.6 & 1 & 0.1 & 172.9 & 0.01 & 713.7 & 1516.8 & 1.1 & 5.4 & 1.6 & 980 & 341.5 & 0.01 & 4.4 & 0.02 & 0.001 & 4.4 & 0.000 & 31 & 25.2 & 0.04 & 0.8 & 0.05 & 27.6 & 3.6 \\
\hline 12 & 350.6 & 486.2 & 286.3 & 1 & 4.65 & 6.80 & 1 & 46.8 & 1.2 & 0.1 & 131.4 & 0.04 & 710.3 & 1491.7 & 1.1 & 5.3 & 1.5 & 909.3 & 304.1 & 0.01 & 4.3 & 0.03 & 0.001 & 3.4 & 0.002 & 30.9 & 24.8 & 0.04 & 0.8 & 0.04 & 5.7 & 3.2 \\
\hline 13 & 350.8 & 486.2 & 310.3 & 1 & 5.40 & 6.80 & 0.8 & 47.7 & 2.1 & 0.1 & 121.1 & 0.1 & 726.9 & 1554.1 & 0.7 & 5.4 & 1.6 & 961 & 331.5 & 0.01 & 4.4 & 0.05 & 0.002 & 3.1 & 0.01 & 31.6 & 25.9 & 0.03 & 0.8 & 0.05 & 7.1 & 3.5 \\
\hline 14 & 350.7 & 486.2 & 334.0 & 1 & 6.05 & 6.80 & 1.6 & 46.2 & 1.6 & 0.1 & 118.1 & 0.1 & 730.9 & 1463.1 & 0.7 & 5.4 & 1.8 & 914.3 & 315.6 & 0.02 & 4.3 & 0.04 & 0.001 & 3 & 0.003 & 31.8 & 24.4 & 0.03 & 0.8 & 0.05 & 5.8 & 3.3 \\
\hline 15 & 350.4 & 486.3 & 355.5 & 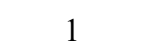 & 631 & 6.82 & 1.6 & 47.1 & 1.9 & 0.1 & 116.2 & 0.1 & 715.8 & 1443.3 & 0.8 & 5.3 & 16 & 972.3 & 345 & 0.02 & 4.4 & 0.05 & 0.001 & 2 & 0.005 & 31.1 & 24 & 0.03 & 0.8 & 0.05 & 7.4 & 3.6 \\
\hline 16 & 350.6 & 486.2 & 381.8 & 1 & 6.72 & 6.7 & 1.7 & 46.8 & 1.9 & 0.1 & 117 & 0.2 & 725.3 & 1325 & 0.9 & 5.6 & 0.8 & 878.3 & 299.2 & 0.02 & 4.3 & 0.05 & 0.001 & 3 & 0.01 & 31.5 & 22.1 & 0.03 & 0.8 & 0.02 & 24.8 & 3.1 \\
\hline 17 & 350.8 & 486.4 & 403.3 & 1 & 6.72 & 6.79 & 1.7 & 47.5 & 2 & 0.1 & 122 & 0.2 & 734.1 & 1377.3 & 1.3 & 5.6 & 0.4 & 908 & 320.5 & 0.02 & 4.4 & 0.05 & 0.001 & 3.1 & 0.01 & 31.9 & 22.9 & 0.05 & 0.8 & 0.01 & 25.6 & 3.3 \\
\hline 18 & 350.6 & 486.2 & 428.1 & 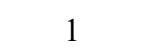 & & 6.81 & 1.7 & 46 & 2.1 & 0 & 124.6 & 0.2 & 718.8 & 1308.3 & 1.4 & 5.5 & 0 & 925.3 & 349 & & 4.3 & 0.05 & 0.001 & 3.2 & 0.01 & 31.3 & 21.8 & 0.05 & 0.8 & 0.005 & 5.1 & 3.6 \\
\hline 19 & 350.7 & 486.2 & 451.8 & 1 & 7.25 & 6.8 & 1.7 & 47.2 & 1.9 & 0.1 & 127.3 & 0.1 & 743.1 & 1250.1 & 1.1 & 5.6 & 0. & 930.1 & 363.2 & 0.02 & 4.4 & 0.05 & 0.001 & 3.3 & 0.01 & 32.3 & 20.8 & 0.04 & 0.8 & 0.002 & 26.2 & 3.8 \\
\hline 20 & 350.8 & 486.1 & 475.8 & 1 & 7 & 6.7 & 1.7 & 48.4 & 2.1 & 0.1 & 131.9 & 0.1 & 746.9 & 1211.6 & 0.9 & 5.6 & 0. & 896.4 & 327.1 & 007 & 4.5 & 0.05 & 0.002 & 3.4 & 0.01 & 32.5 & 20.2 & 0.03 & 0.8 & 003 & 5.3 & 3.4 \\
\hline 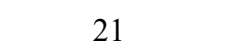 & 350.3 & 486.2 & 498.9 & 1 & & 6 & 7 & 45.9 & 1.6 & $<0.08$ & 131.1 & 0.04 & 725.9 & 1200.9 & 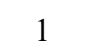 & & 0 & 952.1 & & & 4.2 & 0.04 & $<0.001$ & 3.4 & 02 & 31.6 & 20 & 0.04 & 0.8 & 002 & 5.9 & 3.8 \\
\hline 22 & 350.5 & 486.3 & 523.6 & 1 & 7.21 & 6.8 & 1.7 & 48.1 & 2.1 & $<0.08$ & 131.6 & 0.2 & 743.7 & 1125.9 & 0.6 & 5.3 & 0.1 & 947.4 & 364.3 & 0.02 & 4.5 & 0.05 & $<0.001$ & 3.4 & 0.01 & 32.3 & 18.7 & 0.02 & 0.8 & 0.003 & 26.7 & 3.8 \\
\hline 23 & 350.5 & 486.3 & 547.8 & 1 & & 6.8 & 1.7 & 48.2 & 2.4 & $<0.08$ & 130.8 & 0.2 & 739.4 & 1179.8 & 0.4 & 5.3 & 0. & 996.3 & 381.4 & & 4.5 & 0.06 & $<0.001$ & 3.3 & 0.01 & 32.2 & 19.6 & 0.02 & 0.8 & 002 & 28.1 & 4 \\
\hline 24 & 350.4 & 486.2 & 571 & 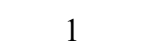 & & & 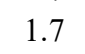 & 48.3 & 2.3 & $<0.08$ & 129.3 & 0.2 & 747.4 & 1149.7 & 0.4 & 5 & 0 & 956.4 & 379.3 & 0. & 4. & 0.06 & $<0.001$ & 3.3 & .01 & 32.5 & 19.1 & 0.01 & 0.8 & 001 & 27 & 3.9 \\
\hline 25 & 350.6 & 486.2 & 595.7 & 1 & 7. & 6.7 & 1.7 & 47.9 & 2.2 & $<0.08$ & 128.4 & 0.2 & 747 & 1126.4 & 0.3 & 5.3 & 0. & 881.2 & 318.5 & 0. & 4.4 & 0.05 & $<0.001$ & 3.3 & 0.01 & 32.5 & 18.7 & 0.01 & 0.8 & .002 & 24.9 & 3.3 \\
\hline 26 & 350.8 & 486.2 & 619.5 & 1 & & 6. & 17 & 48.2 & 2.3 & $<0.08$ & 127.6 & 0.2 & 751.1 & 1142 & 0.3 & 5.2 & 0. & 870.4 & 332.5 & & 4.5 & 0.06 & $<0.001$ & 3.3 & 0.01 & 32.7 & 19 & 0.01 & 0.8 & 02 & 1.6 & 3.5 \\
\hline 27 & 350.7 & 486.2 & 645.3 & 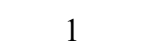 & & 6. & 1.7 & 46.1 & 2 & 0.2 & 127.3 & 0.2 & 716.7 & 1061.5 & 0.3 & 5.3 & 0.04 & 943.2 & 373.1 & 0. & 4.3 & 0.05 & 0.003 & 3.3 & 0.01 & 31.2 & 17.7 & 0.01 & 0.8 & 001 & 6.6 & 3.9 \\
\hline 28 & 350.7 & 486.2 & 668.7 & 1 & 7. & 6. & 1.7 & 45.8 & 2.2 & 0. & 125.8 & 0.3 & 704.2 & 1011.4 & 0 & 5 & 0.05 & 950.1 & 338.2 & & 4.2 & 0.06 & 0.001 & 3.2 & 01 & 30.6 & 16.8 & 0.01 & 0.8 & 001 & 6.8 & 3.5 \\
\hline 29 & 350.4 & 486.2 & 692.9 & 1 & 7.69 & & 1.7 & 46 & 2.2 & $<0.08$ & 124.4 & 0.2 & 709.1 & 1009.1 & 0.2 & 5.3 & 0.04 & 872.2 & 291 & 0.0 & 4.3 & 0.05 & $<0.001$ & 3.2 & 0.01 & 30.8 & 16.8 & 0.01 & 0.8 & 0.001 & 1.6 & 3 \\
\hline 30 & 350.6 & 486.3 & 715.6 & 1 & 7.70 & 6.7 & 1.7 & 48.3 & 2.7 & 0.1 & 125 & 0.3 & 746 & 1031.6 & 0.3 & 5.4 & $<0.01$ & 901.5 & 321.1 & 0.0 & 4.5 & 0.07 & 0.002 & 3.2 & 0.01 & 32.4 & 17.2 & 0.01 & 0.8 & $<0.0003$ & 5.4 & 3.3 \\
\hline 31 & 350.6 & 486.2 & 739.8 & 1 & & & 1.7 & 46.1 & 1.8 & 0.1 & 122.4 & 0.2 & 712.2 & 899.1 & 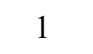 & & $<0.01$ & 996.3 & & & 4. & 0.04 & 0.001 & 3.1 & 0.01 & 31 & 15 & 0.04 & 0.8 & $<0.0003$ & 28.1 & \\
\hline 32 & 350.5 & 486.2 & 764.8 & 1 & 7.87 & 6.8 & 1. & 48.7 & 2.6 & $<0.08$ & 125.3 & 0.3 & 749.2 & 889.3 & 1.2 & 5.6 & $<0.01$ & 956.4 & 379.3 & 0.6 & 4.5 & 0.06 & $<0.001$ & 3.2 & 0.01 & 32.6 & 14.8 & 0.04 & 0.8 & $<0.0003$ & 27 & 3.9 \\
\hline 33 & 350.7 & 486.2 & 788.5 & 1 & 7.91 & 6.7 & 1.7 & 48.3 & 2.3 & 0.1 & 118.7 & 0.3 & 751.3 & 847.7 & 1.5 & 5.4 & $<0.01$ & 881.2 & 318.5 & 0.0 & 4.5 & 0.06 & 0.002 & 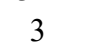 & 0.01 & 32.7 & 14.1 & 0.05 & 0.8 & $<0.0003$ & 24.9 & 3.3 \\
\hline 34 & 350.8 & 486.3 & 81 & 1 & & 6. & 1.7 & 48 & 2.5 & 0. & 116.3 & 0.3 & 747.2 & $84 \varepsilon$ & 1.5 & & $<0$ & 870.4 & 332.5 & $0 .($ & 4.4 & 0.06 & 0.002 & 3 & 01 & 32.5 & 14.1 & 0.06 & 0.8 & & 4.6 & 3.5 \\
\hline 35 & 350.5 & 486.2 & 837.58 & 1 & 7.85 & 6.83 & 1.7 & 45.5 & 2.5 & 0.1 & 114.3 & 0.3 & 705.7 & 790.6 & 1.5 & 5.4 & $<0.01$ & 943.2 & 373.1 & 0.02 & 4.2 & 0.06 & 0.001 & 2.9 & 0.01 & 30.7 & 13.2 & 0.06 & 0.8 & $<0.0003$ & 6.6 & 3.9 \\
\hline 36 & 350.3 & 486.3 & 860.17 & 1 & 7.85 & 6.81 & 1.8 & 48.9 & 1.9 & 0.1 & 117.8 & 0.1 & 756.3 & 827.4 & 1.6 & 5.5 & $<0.01$ & 950.1 & 338.2 & & 4. & 0.05 & 0.002 & 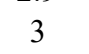 & 0.004 & 32.9 & 13.8 & 0.06 & 0.8 & $<0.0003$ & 6.8 & 3.5 \\
\hline 31 & 350.6 & 486.2 & & $1+$ & 1.91 & 6.7 & 1.7 & 47.7 & 2 & 0.1 & 113.2 & 0.2 & 724.1 & 813.4 & 1.5 & 5.4 & $<0.0$ & 872.2 & 29 & 0.02 & 4.4 & 0.05 & 0.001 & 2.9 & 0.01 & 31.5 & 13.5 & 0.06 & 0.8 & $<0.0003$ & 24.6 & \\
\hline 38 & 350.4 & 486.3 & 907.75 & 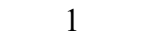 & 7.84 & 6.80 & 1.7 & 47 & 2.1 & 0.1 & 113.3 & 0.1 & 712.3 & 827.6 & 1.5 & 5.4 & $<0.01$ & 901.5 & 321.1 & 0.02 & 4.4 & 0.05 & 0.001 & 2.9 & 0.01 & 31 & 13.8 & 0.06 & 0.8 & $<0.0003$ & 25.4 & 3.3 \\
\hline
\end{tabular}




\section{$\mu \mathrm{mol} \mathrm{kg}{ }^{-1}$}

\begin{tabular}{|c|c|c|c|c|c|c|c|c|c|c|c|c|c|c|c|c|c|}
\hline $\mathrm{n}^{\circ}$ sample & $\begin{array}{c}\mathrm{T} \\
\left({ }^{\circ} \mathrm{C}\right)\end{array}$ & $\begin{array}{c}\mathrm{P} \\
\text { (bar) }\end{array}$ & $\begin{array}{l}\text { time } \\
\text { (hrs) }\end{array}$ & $\begin{array}{l}\text { flow-rate } \\
\left(\mathrm{ml} \mathrm{hr}{ }^{-1}\right)\end{array}$ & $\begin{array}{c}\mathrm{pH} \\
\text { (room T) }\end{array}$ & $\begin{array}{c}\mathrm{pH} \\
\left(350^{\circ} \mathrm{C}\right)\end{array}$ & $\mathrm{Co}$ & $\mathrm{Ni}$ & $\mathrm{Cu}$ & $\mathrm{Zn}$ & Mo & $\mathrm{Ag}$ & $\mathrm{Cd}$ & $\mathrm{Ba}$ & $\mathrm{Au}$ & $\mathrm{Pb}$ & $\mathrm{Mn}$ \\
\hline $\begin{array}{l}\text { blank } \\
\text { geothrmal brine }\end{array}$ & 20.1 & 1 & 0.0 & - & 4.28 & 6.75 & 0.001 & 0.2 & 0.8 & 2.9 & 0.03 & 0.003 & 0.002 & 0.05 & 0.04 & 0.02 & 2.5 \\
\hline 1 & 20.4 & 488.3 & 21.2 & 1 & 5.77 & n.c. & 0.07 & 3.1 & 73.3 & 11.9 & 0.04 & $<0.0005$ & 0.01 & 0.6 & 0.005 & 0.001 & 1.8 \\
\hline 2 & 20.3 & 488.0 & 47.3 & 1 & 5.43 & n.c. & 0.02 & 0.6 & 38.7 & 3.5 & 0.02 & $<0.0005$ & 0.006 & 0.4 & 0.003 & 0.001 & 0.5 \\
\hline 3 & 20.6 & 488.0 & 71.4 & 1 & 5.10 & n.c. & 0.05 & 0.9 & 37.9 & 2.2 & 0.01 & $<0.0005$ & 0.005 & 0.3 & 0.002 & $<0.001$ & 1 \\
\hline 4 & 20.5 & 487.8 & 93.7 & 1 & 5.20 & n.c. & 0.04 & 0.6 & 36.8 & 1.6 & 0.02 & $<0.0005$ & 0.005 & 0.3 & 0.002 & $<0.001$ & 0.9 \\
\hline 5 & 20.5 & 487.9 & 118.2 & 1 & 5.19 & n.c. & 0.04 & 0.6 & 37.5 & 1.3 & 0.01 & $<0.0005$ & 0.004 & 0.2 & 0.002 & $<0.001$ & 0.8 \\
\hline 6 & 20.1 & 487.9 & 141.8 & 1 & 5.23 & n.c. & 0.04 & 0.5 & 28.7 & 0.9 & 0.01 & $<0.0005$ & 0.007 & 0.2 & 0.002 & $<0.001$ & 0.8 \\
\hline 7 & 20.4 & 487.8 & 165.7 & 1 & 5.06 & n.c. & 0.03 & 2 & 23.2 & 2.8 & 1.1 & $<0.0005$ & 0.001 & 0.1 & 0.001 & 0.007 & 0.7 \\
\hline 8 & 352.3 & 486.3 & 187.8 & 1 & 4.43 & 6.66 & 0.002 & 0.1 & 2.3 & 0.7 & 0.07 & $<0.0005$ & $<0.0009$ & 0.1 & 0.001 & $<0.001$ & $<0.13$ \\
\hline 9 & 350.4 & 486.2 & 211.4 & 1 & 3.39 & 6.68 & $<0.002$ & 0.2 & 0.1 & 0.3 & 0.2 & $<0.0005$ & $<0.0009$ & 0.03 & 0.001 & $<0.001$ & $<0.13$ \\
\hline 10 & 350.5 & 486.3 & 236.2 & 1 & 3.56 & 6.76 & 0.01 & 0.02 & 0.2 & 0.1 & 0.5 & $<0.0005$ & $<0.0009$ & 0.03 & 0.001 & $<0.001$ & $<0.13$ \\
\hline 11 & 350.7 & 486.2 & 260.3 & 1 & 4.58 & 6.82 & 0.01 & 0.008 & 0.04 & 0.1 & 0.6 & $<0.0005$ & $<0.0009$ & 0.03 & 0.001 & $<0.001$ & $<0.13$ \\
\hline 12 & 350.6 & 486.2 & 286.3 & 1 & 4.65 & 6.80 & 0.01 & 0.01 & 0.1 & 0.1 & 0.9 & $<0.0005$ & $<0.0009$ & 0.04 & 0.001 & $<0.001$ & $<0.13$ \\
\hline 13 & 350.8 & 486.2 & 310.3 & 1 & 5.40 & 6.80 & 0.01 & $<0.003$ & 0.04 & 0.1 & 0.9 & $<0.0005$ & $<0.0009$ & 0.05 & 0.001 & $<0.001$ & $<0.13$ \\
\hline 14 & 350.7 & 486.2 & 334.0 & 1 & 6.05 & 6.80 & 0.01 & 0.008 & 0.1 & 0.1 & 1 & $<0.0005$ & $<0.0009$ & 0.1 & 0.001 & $<0.001$ & $<0.13$ \\
\hline 15 & 350.4 & 486.3 & 355.5 & 1 & 6.31 & 6.82 & 0.002 & $<0.003$ & 0.1 & 0.2 & 1.1 & $<0.0005$ & 0.001 & 0.1 & 0.001 & $<0.001$ & $<0.13$ \\
\hline 16 & 350.6 & 486.2 & 381.8 & 1 & 6.72 & 6.78 & $<0.002$ & 0.04 & 0.1 & 0.3 & 0.8 & $<0.0005$ & 0.002 & 0.1 & 0.001 & $<0.001$ & $<0.13$ \\
\hline 17 & 350.8 & 486.4 & 403.3 & 1 & 6.72 & 6.79 & $<0.002$ & $<0.003$ & 0.1 & 0.4 & 1 & $<0.0005$ & $<0.0009$ & 0.1 & 0.001 & $<0.001$ & $<0.13$ \\
\hline 18 & 350.6 & 486.2 & 428.1 & 1 & 7.01 & 6.81 & $<0.002$ & 0.02 & 0.1 & 5.7 & 0.9 & $<0.0005$ & $<0.0009$ & 0.1 & 0.001 & 0.001 & $<0.13$ \\
\hline 19 & 350.7 & 486.2 & 451.8 & 1 & 7.25 & 6.82 & $<0.002$ & 0.02 & 0.1 & 2 & 0.7 & $<0.0005$ & $<0.0009$ & 0.1 & 0.001 & 0.004 & $<0.13$ \\
\hline 20 & 350.8 & 486.1 & 475.8 & 1 & 7.21 & 6.79 & $<0.002$ & 0.03 & 1.2 & 1.9 & 0.7 & $<0.0005$ & $<0.0009$ & 0.1 & 0.001 & 0.003 & $<0.13$ \\
\hline 21 & 350.3 & 486.2 & 498.9 & 1 & 7.17 & 6.83 & $<0.002$ & $<0.003$ & 0.1 & 1.6 & 0.6 & $<0.0005$ & $<0.0009$ & 0.1 & 0.001 & 0.001 & $<0.13$ \\
\hline 22 & 350.5 & 486.3 & 523.6 & 1 & 7.21 & 6.82 & $<0.002$ & $<0.003$ & 0.1 & 2.7 & 0.6 & $<0.0005$ & $<0.0009$ & 0.1 & 0.001 & 0.005 & $<0.13$ \\
\hline 23 & 350.5 & 486.3 & 547.8 & 1 & 7.21 & 6.82 & $<0.002$ & 0.004 & 0.2 & 2.9 & 0.5 & $<0.0005$ & $<0.0009$ & 0.1 & $<0.001$ & 0.001 & $<0.13$ \\
\hline 24 & 350.4 & 486.2 & 571.4 & 1 & 7.30 & 6.82 & $<0.002$ & $<0.003$ & 0.04 & 1.1 & 0.4 & $<0.0005$ & $<0.0009$ & 0.05 & 0.001 & 0.002 & $<0.13$ \\
\hline 25 & 350.6 & 486.2 & 595.7 & 1 & 7.31 & 6.78 & $<0.002$ & $<0.003$ & 0.03 & 2.4 & 0.5 & $<0.0005$ & $<0.0009$ & 0.1 & 0.001 & $<0.001$ & $<0.13$ \\
\hline 26 & 350.8 & 486.2 & 619.5 & 1 & 7.46 & 6.79 & $<0.002$ & 0.03 & 0.1 & 1.4 & 0.5 & $<0.0005$ & $<0.0009$ & 0.1 & 0.001 & 0.02 & $<0.13$ \\
\hline 27 & 350.7 & 486.2 & 645.3 & 1 & 7.51 & 6.83 & $<0.002$ & 0.02 & 0.04 & 1.5 & 0.5 & $<0.0005$ & $<0.0009$ & 0.1 & $<0.001$ & 0.02 & $<0.13$ \\
\hline 28 & 350.7 & 486.2 & 668.7 & 1 & 7.73 & 6.81 & $<0.002$ & $<0.003$ & 0.05 & 3.6 & 0.4 & $<0.0005$ & $<0.0009$ & 0.1 & $<0.001$ & 0.004 & $<0.13$ \\
\hline 29 & 350.4 & 486.2 & 692.9 & 1 & 7.69 & 6.77 & $<0.002$ & $<0.003$ & 0.1 & 2.9 & 0.4 & $<0.0005$ & $<0.0009$ & 0.1 & $<0.001$ & 0.005 & $<0.13$ \\
\hline
\end{tabular}



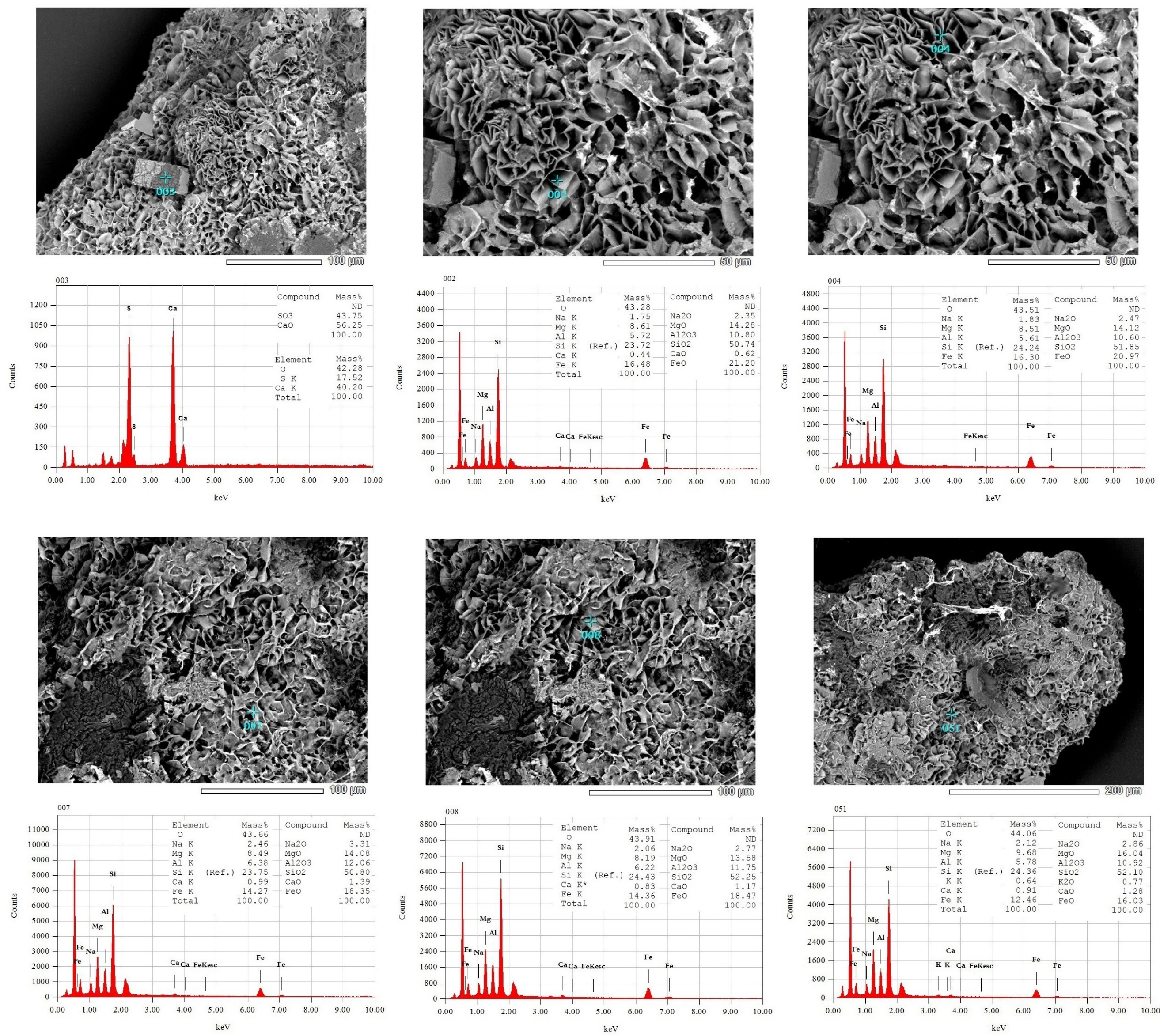

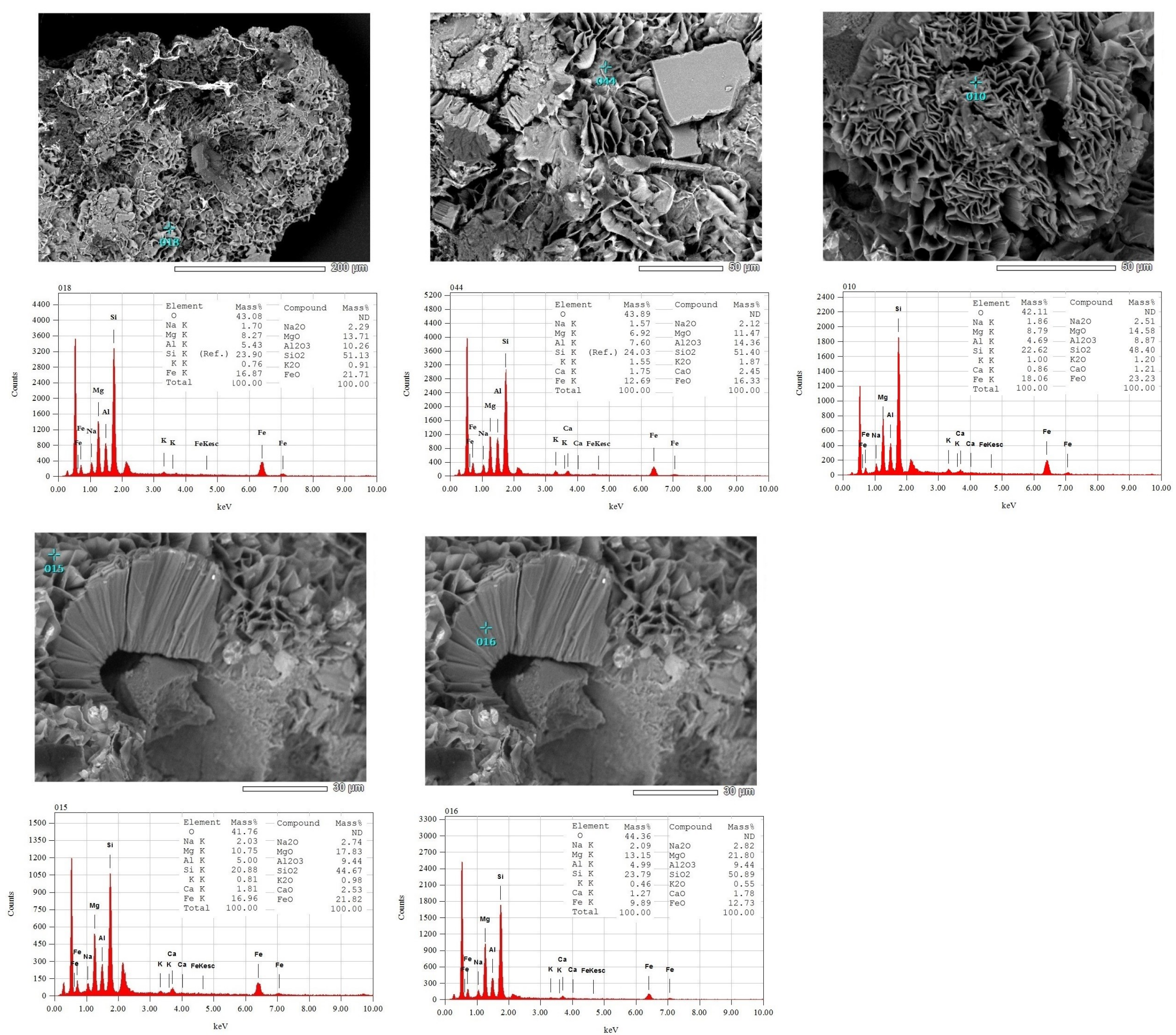

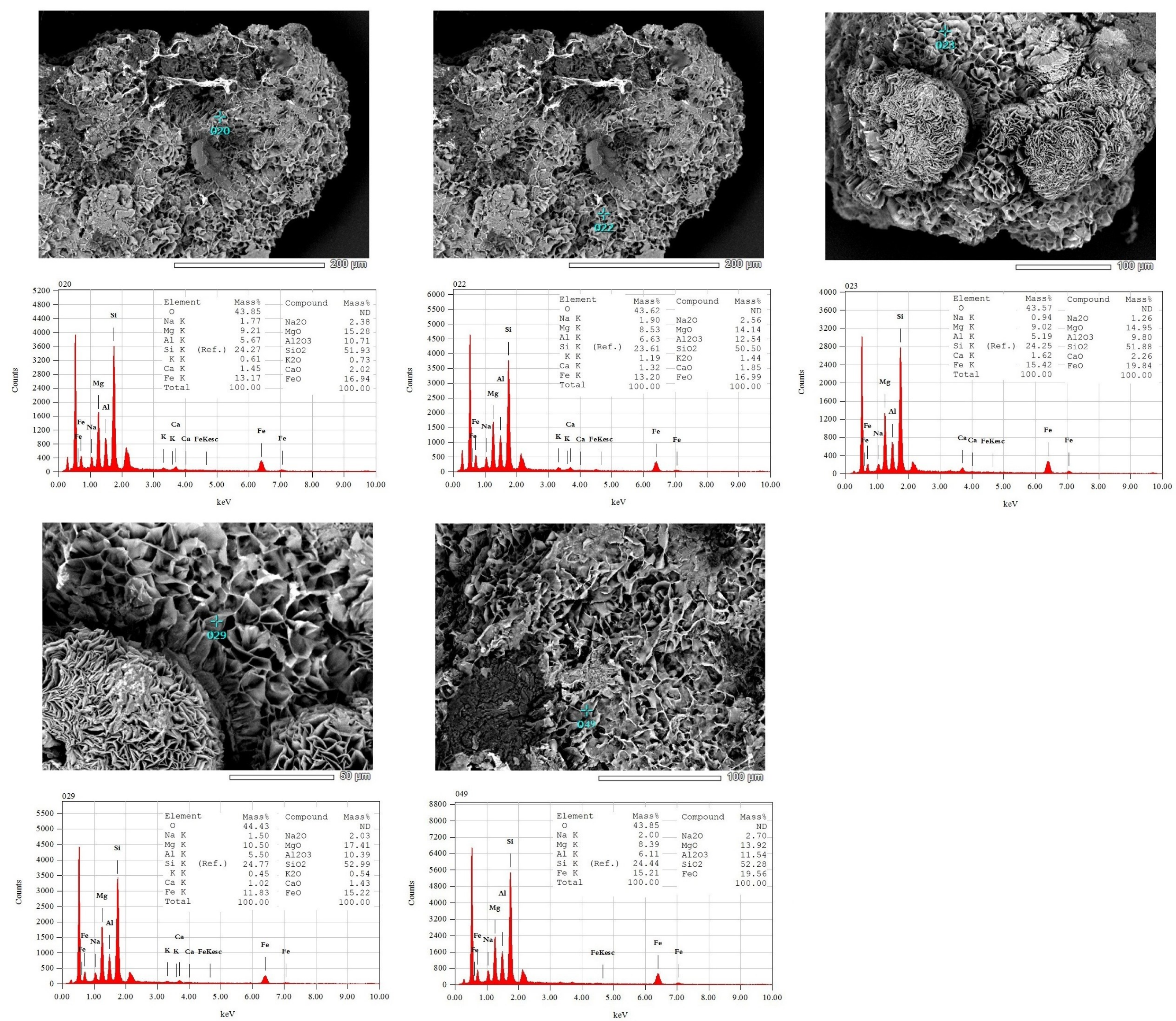

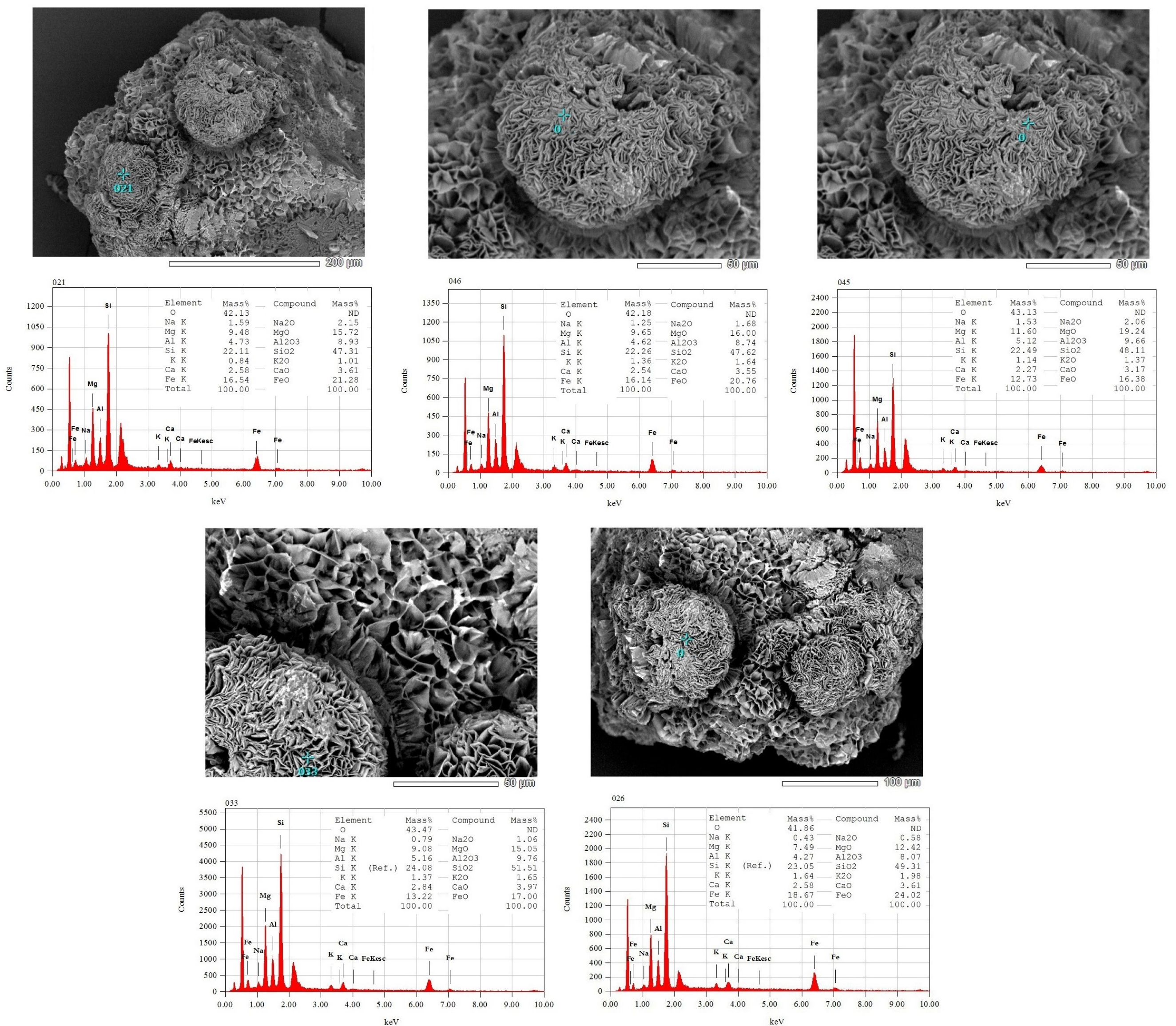
Figure C.4.13. EDS analysis of the Cu-sulfide from the study of the morphology (Portion 1, BGB2)
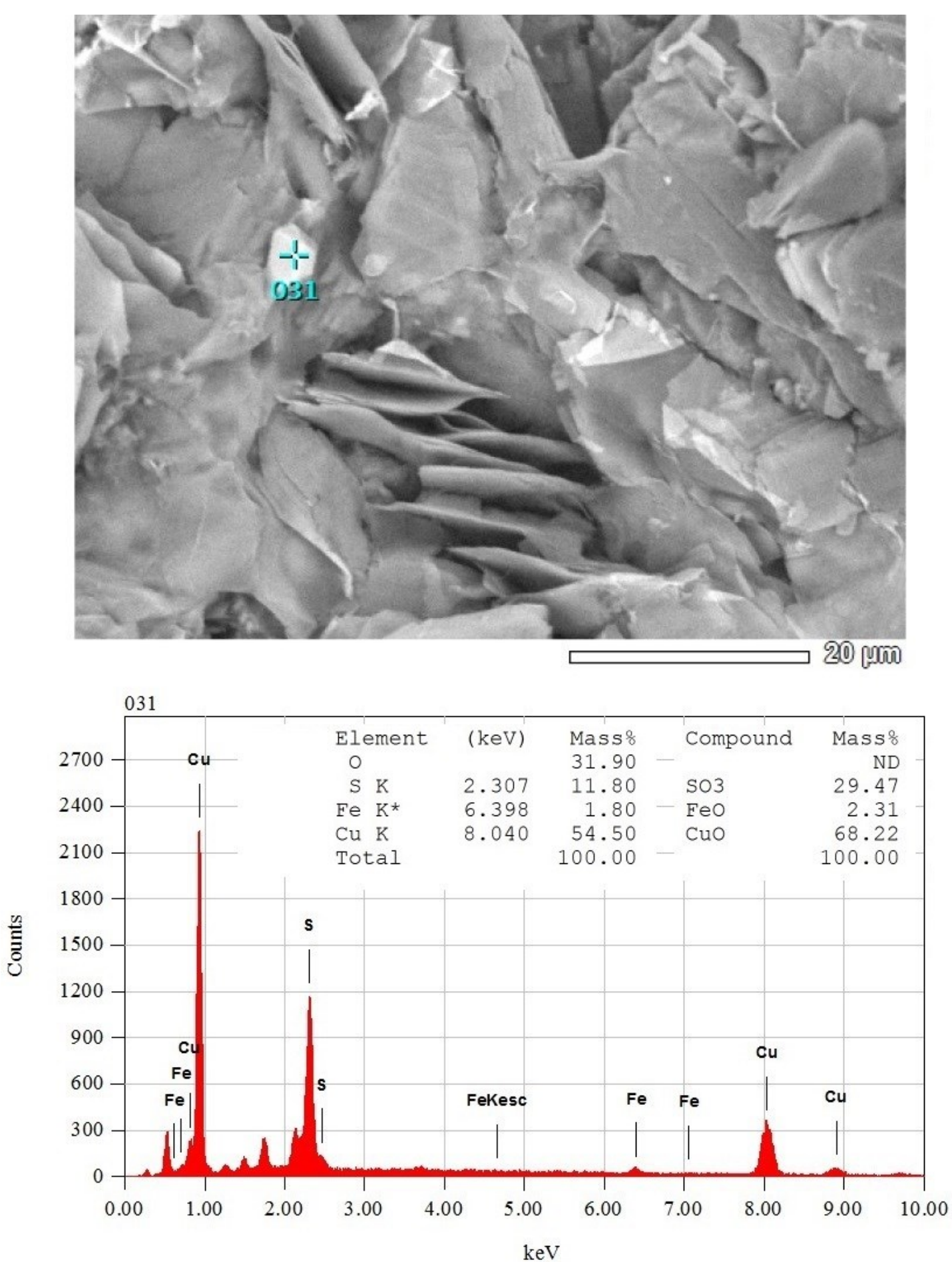
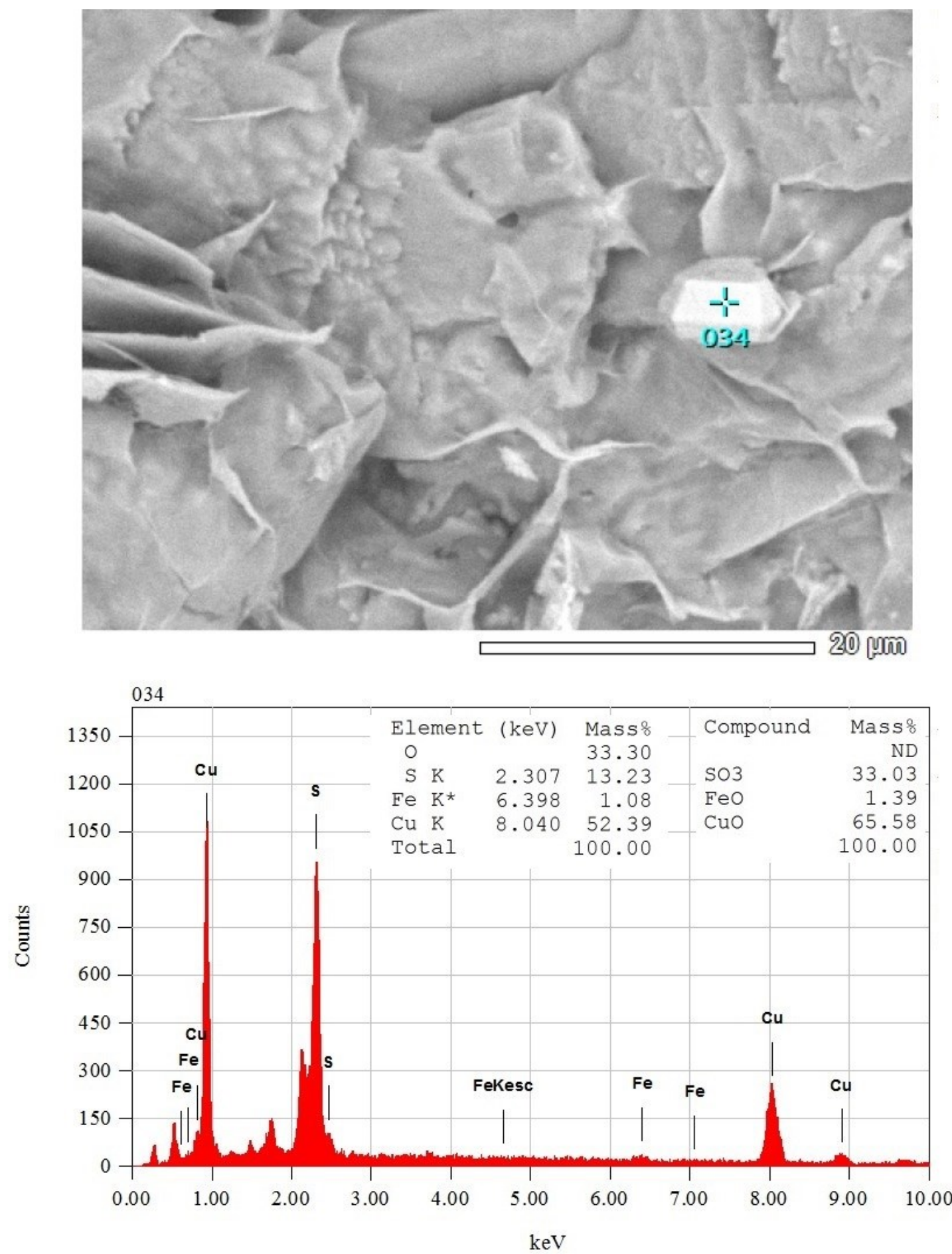
Table C.4.11. EDS analysis from Fig. C.4.11-13

\begin{tabular}{|c|c|c|c|c|c|c|c|c|c|}
\hline Anh & $\begin{array}{c}\text { Analysis } \\
\text { Point } \\
3\end{array}$ & $\begin{array}{l}\mathbf{S O}_{3} \\
43.75\end{array}$ & & & & \multicolumn{3}{|c|}{$\mathrm{CaO}$} & $\begin{array}{r}\text { Total } \\
100.00\end{array}$ \\
\hline \multirow[t]{4}{*}{$\mathrm{Cu}$-sulfide } & $\begin{array}{c}\text { Analysis } \\
\text { Point }\end{array}$ & $\mathrm{SO}_{3}$ & $\mathrm{CuO}$ & & & & & $\mathrm{FeO}$ & Total \\
\hline & 31 & 29.47 & 68.22 & & & & & 2.31 & 100.00 \\
\hline & 34 & 33.03 & 65.68 & & & & & 1.39 & 100.10 \\
\hline & & 31.25 & 66.95 & & & & & 1.85 & 100.05 \\
\hline \multirow[t]{16}{*}{$\begin{array}{c}\text { Smc } 2 \\
\text { (morphology) }\end{array}$} & $\begin{array}{l}\text { Analysis } \\
\text { Point }\end{array}$ & $\mathrm{Na}_{2} \mathbf{O}$ & MgO & $\mathrm{Al}_{2} \mathrm{O}_{3}$ & $\mathrm{SiO}_{2}$ & $\mathbf{K}_{2} \mathbf{O}$ & $\mathrm{CaO}$ & $\mathrm{FeO}$ & Total \\
\hline & 2 & 2.35 & 14.28 & 10.80 & 50.74 & 0.00 & 0.62 & 21.20 & 99.99 \\
\hline & 4 & 2.47 & 14.12 & 10.60 & 51.85 & 0.00 & 0.00 & 20.27 & 99.31 \\
\hline & 7 & 3.31 & 14.08 & 12.06 & 50.80 & 0.00 & 1.39 & 18.35 & 99.99 \\
\hline & 8 & 2.77 & 13.58 & 11.75 & 52.25 & 0.00 & 1.17 & 18.47 & 99.99 \\
\hline & 10 & 2.51 & 14.58 & 8.87 & 48.40 & 1.20 & 1.21 & 23.20 & 99.97 \\
\hline & 15 & 2.74 & 17.83 & 9.44 & 44.67 & 0.98 & 2.53 & 21.82 & 100.01 \\
\hline & 16 & 2.82 & 21.80 & 9.44 & 50.89 & 0.55 & 1.78 & 12.73 & 100.01 \\
\hline & 18 & 2.29 & 13.71 & 10.26 & 51.13 & 0.91 & 0.00 & 21.71 & 100.01 \\
\hline & 20 & 2.38 & 15.28 & 10.71 & 51.93 & 0.73 & 2.02 & 16.94 & 99.99 \\
\hline & 22 & 2.56 & 14.14 & 12.54 & 50.50 & 1.44 & 1.85 & 16.99 & 100.02 \\
\hline & 23 & 1.26 & 14.95 & 9.80 & 51.88 & 0.00 & 2.26 & 19.84 & 99.99 \\
\hline & 29 & 2.03 & 17.41 & 10.39 & 52.99 & 0.54 & 1.43 & 15.22 & 100.01 \\
\hline & 44 & 2.12 & 11.47 & 14.36 & 51.40 & 1.87 & 2.45 & 16.33 & 100.00 \\
\hline & 49 & 2.70 & 13.92 & 11.54 & 52.28 & 0.00 & 0.00 & 19.56 & 100.00 \\
\hline & 51 & 2.86 & 16.04 & 10.92 & 52.10 & 0.77 & 1.28 & 16.03 & 100.00 \\
\hline average & & 2.48 & 15.15 & 10.90 & 50.92 & 0.60 & 1.33 & 18.58 & 99.95 \\
\hline$\pm \sigma$ & & 0.47 & 2.41 & 1.40 & 2.04 & 0.44 & 0.58 & 2.88 & \\
\hline \multirow[t]{6}{*}{$\begin{array}{l}\text { Smc 1 } \\
\text { (morphology) }\end{array}$} & $\begin{array}{c}\text { Analysis } \\
\text { Point }\end{array}$ & $\mathrm{Na}_{2} \mathrm{O}$ & MgO & $\mathrm{Al}_{2} \mathrm{O}_{3}$ & $\mathrm{SiO}_{2}$ & $\mathbf{K}_{2} \mathbf{O}$ & $\mathrm{CaO}$ & $\mathrm{FeO}$ & Total \\
\hline & 21 & 2.15 & 15.72 & 8.93 & 47.31 & 1.01 & 3.61 & 21.28 & 100.01 \\
\hline & 26 & 0.58 & 12.42 & 8.07 & 49.31 & 1.98 & 3.61 & 24.02 & 99.99 \\
\hline & 33 & 1.06 & 15.05 & 9.76 & 51.51 & 1.65 & 3.97 & 17.00 & 100.00 \\
\hline & 45 & 2.06 & 19.24 & 9.66 & 48.11 & 1.37 & 3.17 & 16.38 & 99.99 \\
\hline & 46 & 1.68 & 16.00 & 8.74 & 47.62 & 1.64 & 3.55 & 20.76 & 99.99 \\
\hline average & & 1.51 & 15.69 & 9.03 & 48.77 & 1.53 & 3.58 & 19.89 & 100.00 \\
\hline$\pm \sigma$ & & 0.67 & 2.44 & 0.70 & 1.71 & 0.36 & 0.28 & 3.18 & \\
\hline
\end{tabular}


Table C.4.12. Average mineral compositions from Table C.4.11

\begin{tabular}{|c|c|c|c|c|}
\hline Oxides & Point $n^{\circ} 3$ & average $w t \%$ & average $w t \%$ & average $w t \%$ \\
\hline $\mathrm{Na}_{2} \mathrm{O}$ & & & 2.48 & 1.51 \\
\hline $\mathrm{Al}_{2} \mathrm{O}_{3}$ & & & 10.90 & 9.03 \\
\hline $\mathrm{SiO}_{2}$ & & & 50.92 & 48.77 \\
\hline $\mathrm{CaO}$ & 56.25 & & 1.33 & 3.58 \\
\hline $\mathrm{FeO}$ & & 1.85 & 18.58 & 19.89 \\
\hline $\mathrm{MgO}$ & & & 15.15 & 15.69 \\
\hline $\mathrm{K}_{2} \mathrm{O}$ & & & 0.60 & 1.53 \\
\hline $\mathrm{SO}_{3}$ & 43.75 & 31.25 & & \\
\hline $\mathrm{CuO}$ & & 66.95 & & \\
\hline Total & 100.00 & 100.05 & 99.96 & 100.00 \\
\hline al Composition & $\mathrm{CaSO}_{4}$ & $\mathrm{CuS}$ & $\begin{array}{c}\mathrm{K}_{0.1} \mathrm{Na}_{0.3} \mathrm{Ca}_{0.1} \mathrm{Mg}_{1.5} \mathrm{Fe}_{1.1} \mathrm{Al}_{0.29} \mathrm{Si}_{3.43} \mathrm{Al}_{0.57} \mathrm{O}_{10}(\mathrm{OH})_{2} \\
\left.\text { (11 oxygen equivalents, ignoring } \mathrm{H}_{2} \mathrm{O}\right)\end{array}$ & $\begin{array}{c}\mathrm{K}_{0.1} \mathrm{Na}_{0.2} \mathrm{Ca}_{0.3} \mathrm{Mg}_{1.6} \mathrm{Fe}_{1.2} \mathrm{Al}_{0.1} \mathrm{Si}_{3.4} \mathrm{Al}_{0.6} \mathrm{O}_{10}(\mathrm{OH})_{2} \\
\left.\text { (11 oxygen equivalents, ignoring } \mathrm{H}_{2} \mathrm{O}\right)\end{array}$ \\
\hline lase and ID & Sulfate & $\mathrm{Cu}$-sulfide & Smectite 1 & Smectite 2 \\
\hline
\end{tabular}




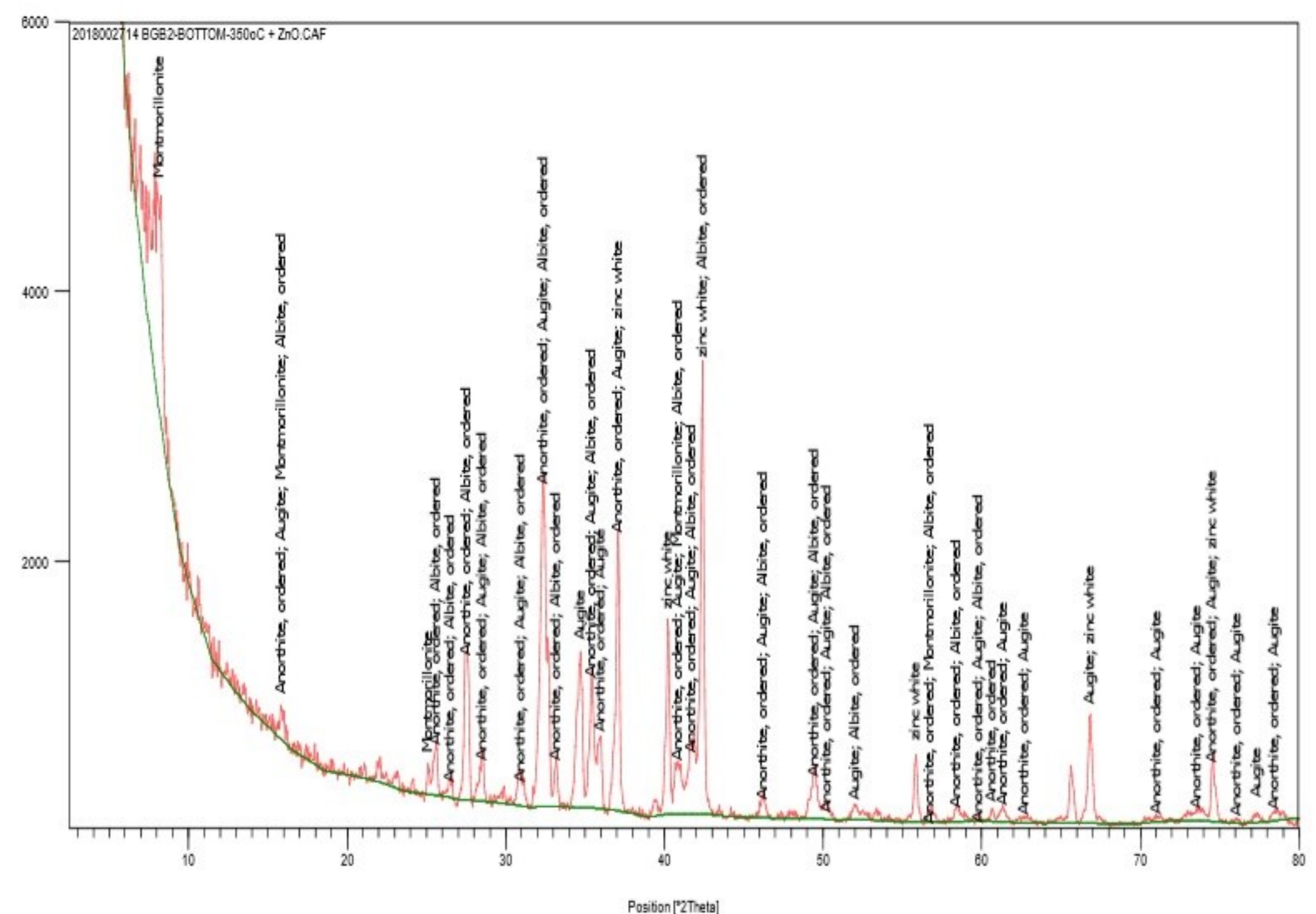

Figure 6. XRD scan showing the mineralogy of $\mathrm{BGB} 2-\mathrm{Bottom}-350^{\circ} \mathrm{C}$ as indicated by the labelled scan peaks 


\section{Sample Composition}

Table 1. Mineral percentages for BGB2 sample was determined and then normalized to exclude zinc oxide:

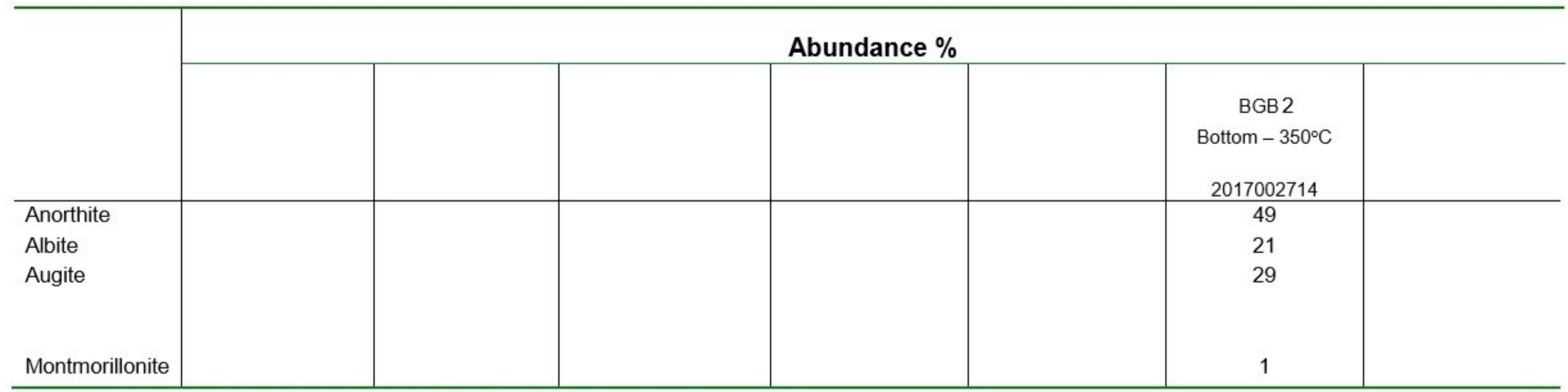

Margin of Error: Abundance estimates are determined through successive refinement of cell parameters; the position, width and orientation of each mineral. Values are given to the nearest whole number. The margin of error for phase concentration is proposed as follows: $0-10 \% \pm 10 \% ; 10-50 \% \pm 5 \% ; 50-100 \% \pm 2 \%$ 

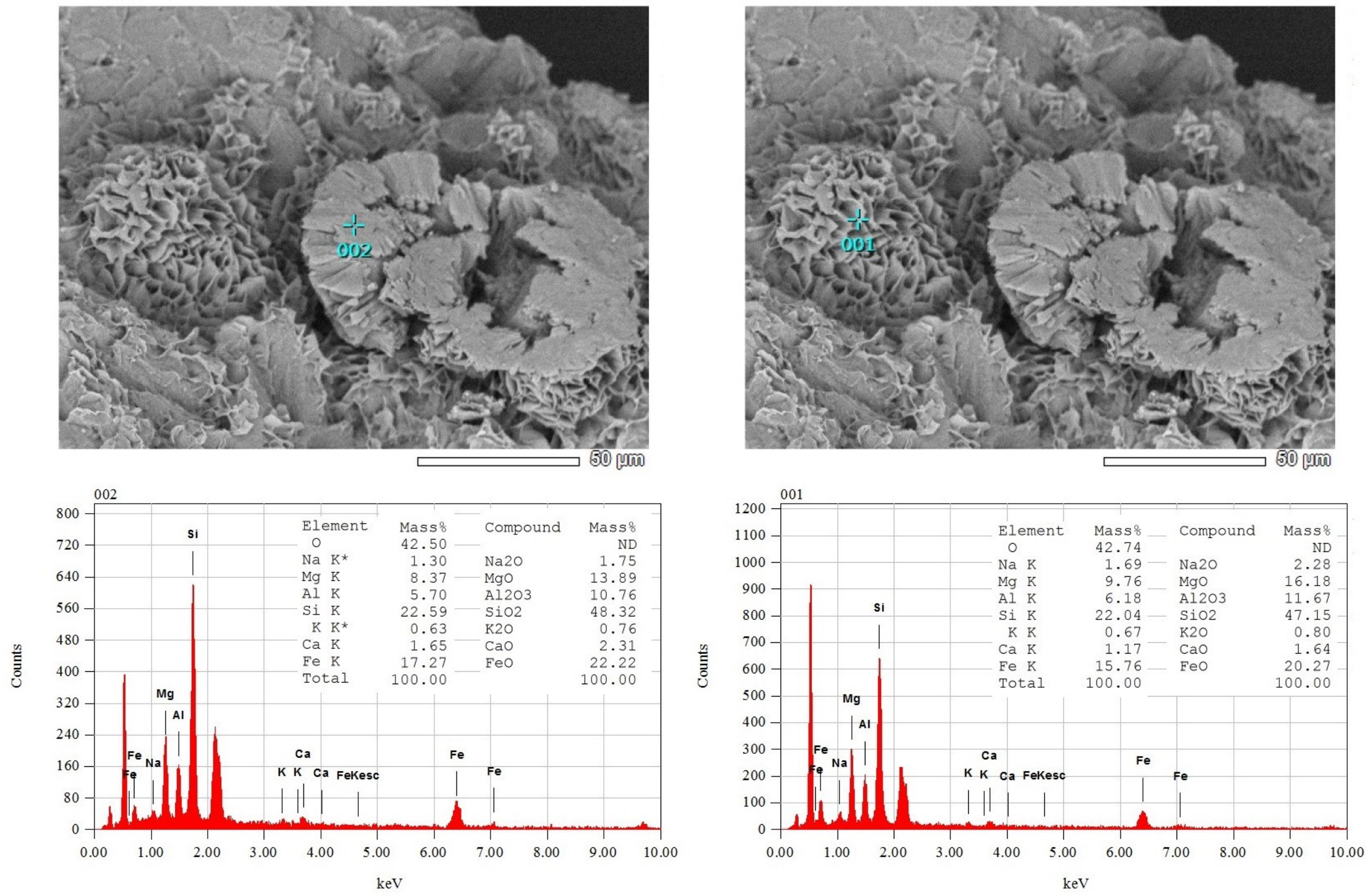
Table C.4.13. EDS analysis of grains in Fig. C.4.16

$\begin{array}{cccccccccc}\begin{array}{c}\text { Smc } \\ \text { (morphology) }\end{array} & \begin{array}{c}\text { Analysis } \\ \text { Point }\end{array} & \mathbf{N a}_{\mathbf{2}} \mathbf{O} & \mathbf{M g O} & \mathbf{A l}_{\mathbf{2}} \mathbf{O}_{\mathbf{3}} & \mathbf{S i O}_{\mathbf{2}} & \mathbf{K}_{\mathbf{2}} \mathbf{O} & \mathbf{C a O} & \mathbf{F e O} & \text { Total } \\ & 1 & 2.28 & 16.18 & 11.67 & 47.15 & 0.80 & 1.64 & 20.27 & 99.99 \\ & 2 & 1.75 & 13.89 & 10.76 & 48.32 & 0.76 & 2.31 & 22.22 & 100.01 \\ \text { average } & & \mathbf{2 . 0 2} & \mathbf{1 5 . 0 4} & \mathbf{1 1 . 2 2} & \mathbf{4 7 . 7 4} & \mathbf{0 . 7 8} & \mathbf{1 . 9 8} & \mathbf{2 1 . 2 5} & \mathbf{1 0 0 . 0 0} \\ \pm \sigma & & 0.37 & 1.62 & 0.64 & 0.83 & 0.03 & 0.47 & 1.38 & \end{array}$

Table C.4.14. Average mineral compositions from Table C.4.13

$\begin{array}{cc}\text { Oxides } & \text { average wto } \\ \mathrm{Na}_{2} \mathrm{O} & 2.02 \\ \mathrm{Al}_{2} \mathrm{O}_{3} & 11.22 \\ \mathrm{SiO}_{2} & 47.74 \\ \mathrm{CaO} & 1.98 \\ \mathrm{FeO} & 21.25 \\ \mathrm{MgO} & 15.04 \\ \mathrm{~K}_{2} \mathrm{O} & 0.78\end{array}$

Mineral Composition

Phase and ID
$\mathrm{K}_{0.05} \mathrm{Na}_{0.25} \mathrm{Ca}_{0.15} \mathrm{Mg}_{1.6} \mathrm{Fe}_{1.2} \mathrm{Al}_{0.2} \mathrm{Si}_{3.3} \mathrm{Al}_{0.7} \mathrm{O}_{10}(\mathrm{OH})_{2}$

(11 oxygen equivalents, ignoring $\mathrm{H}_{2} \mathrm{O}$ )

$$
\text { Smectite }
$$

(morphology study) 

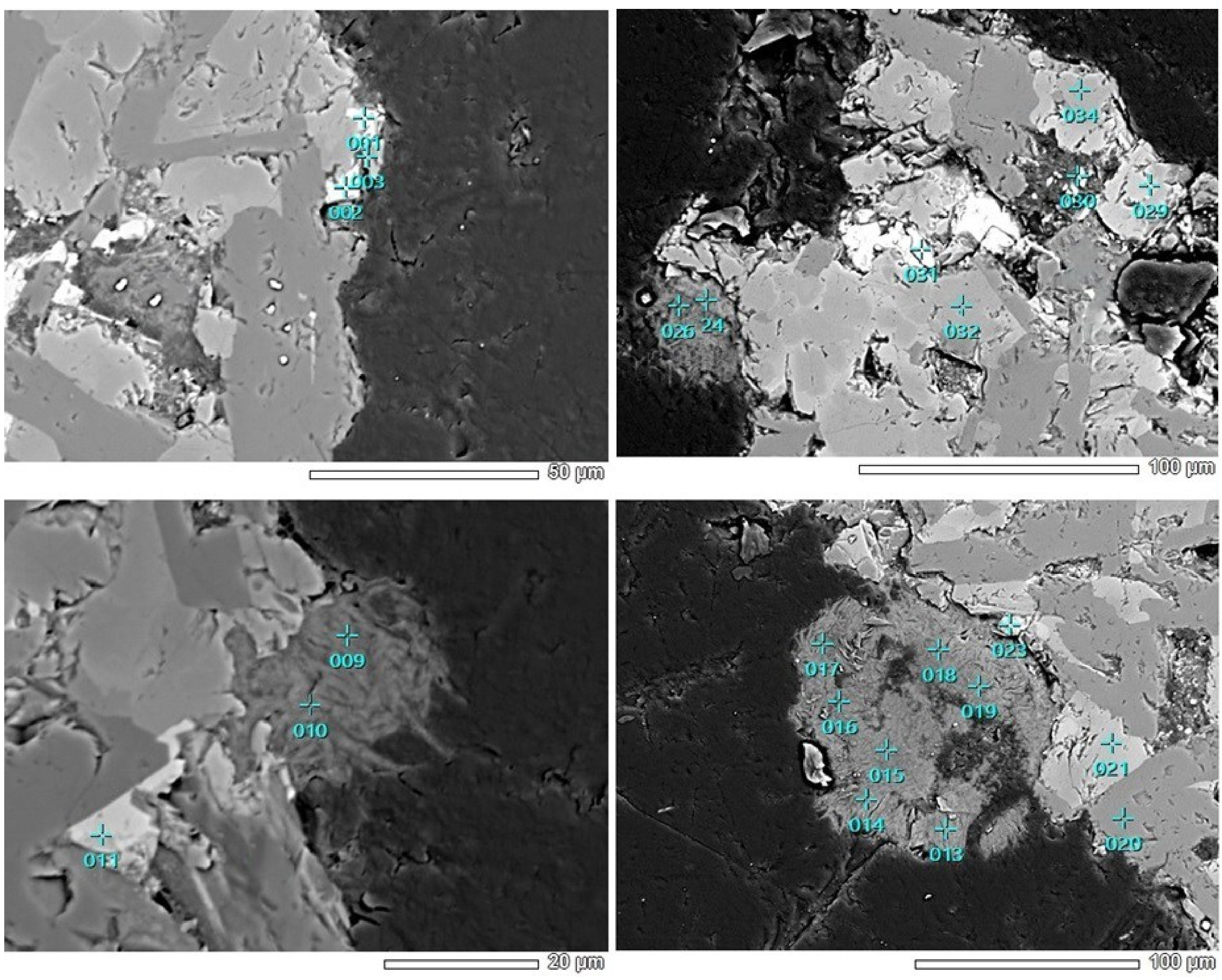
Table C.4.14. EDS analysis of grains in Fig. C.4.17

$\begin{array}{cc}\text { Plg } & \begin{array}{c}\text { Analysis } \\ \text { Point } \\ 20\end{array} \\ \text { Cpx } & \begin{array}{c}\text { Analysis } \\ \text { Point } \\ 3 \\ \end{array} \\ 21 \\ 29 \\ 30 \\ 32 \\ 34\end{array}$

average

Ol

$$
\begin{gathered}
\text { Analysis } \\
\text { Point }
\end{gathered}
$$

23

$\mathrm{Ox}$

\section{Analysis Point}

average

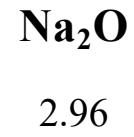

27.18
$\mathrm{CaO}$

Total

14.43

100.00

\begin{tabular}{|c|c|c|c|c|c|c|c|c|c|}
\hline \multirow[t]{12}{*}{$\begin{array}{c}\text { Smc } \\
\text { (epoxy-mount) }\end{array}$} & $\begin{array}{c}\text { Analysis } \\
\text { Point }\end{array}$ & $\mathrm{Na}_{2} \mathrm{O}$ & MgO & $\mathbf{A l}_{2} \mathbf{O}_{3}$ & $\mathrm{SiO}_{2}$ & $\mathbf{K}_{2} \mathbf{O}$ & $\mathrm{CaO}$ & $\mathrm{FeO}$ & Total \\
\hline & 9 & 0.00 & 14.46 & 9.78 & 50.17 & 0.62 & 1.07 & 23.90 & 100.00 \\
\hline & 10 & 0.00 & 12.59 & 8.75 & 48.43 & 0.38 & 1.35 & 28.51 & 100.00 \\
\hline & 13 & 1.52 & 15.68 & 8.35 & 51.14 & 0.79 & 0.50 & 22.01 & 100.00 \\
\hline & 14 & 2.02 & 16.70 & 8.84 & 51.06 & 0.74 & 0.38 & 19.69 & 100.00 \\
\hline & 15 & 0.96 & 15.78 & 8.46 & 51.28 & 0.68 & 0.81 & 22.03 & 100.00 \\
\hline & 16 & 0.89 & 15.29 & 8.40 & 52.88 & 0.00 & 0.65 & 21.89 & 100.00 \\
\hline & 17 & 0.57 & 13.78 & 7.90 & 51.20 & 0.20 & 1.60 & 24.76 & 100.00 \\
\hline & 18 & 3.16 & 17.04 & 7.99 & 50.21 & 0.37 & 1.22 & 20.02 & 100.00 \\
\hline & 19 & 0.80 & 18.93 & 9.03 & 52.28 & 0.30 & 0.37 & 18.29 & 100.00 \\
\hline & 24 & 0.00 & 11.32 & 8.79 & 48.86 & 1.50 & 0.78 & 28.74 & 100.00 \\
\hline & 26 & 0.95 & 14.04 & 9.14 & 50.19 & 0.89 & 0.76 & 24.04 & 100.00 \\
\hline average & & 0.99 & 15.06 & 8.68 & 50.70 & 0.59 & 0.86 & 23.08 & 99.95 \\
\hline 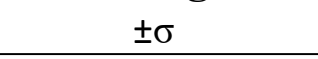 & & 0.86 & 2.14 & 0.54 & 1.32 & 0.38 & 0.40 & 3.37 & \\
\hline
\end{tabular}

$\begin{array}{ccc}\text { CaO } & \text { FeO } & \text { Total } \\ 11.99 & 21.46 & 100.00 \\ 4.71 & 29.11 & 100.00 \\ 10.71 & 30.47 & 100.00 \\ 11.64 & 30.15 & 100.00 \\ 18.55 & 10.89 & 100.00 \\ 18.13 & 10.63 & 100.00 \\ \mathbf{1 2 . 6 2} & \mathbf{2 2 . 1 2} & \mathbf{1 0 0 . 0 0} \\ & & \\ & \text { FeO } & \text { Total } \\ & & 100.00 \\ & 50.77 & \\ & & \text { Total } \\ & \text { FeO } & 100.00 \\ & 72.41 & 100.00 \\ & 71.82 & 100.00 \\ & 73.06 & 100.00 \\ & 73.99 & \mathbf{1 0 0 . 0 0}\end{array}$




$\begin{array}{cc}\text { Oxides } & \text { Point } \mathbf{n}^{\circ} \mathbf{2 0} \\ \mathrm{Na}_{2} \mathrm{O} & 2.96 \\ \mathrm{Al}_{2} \mathrm{O}_{3} & 30.31 \\ \mathrm{SiO}_{2} & 52.30 \\ \mathrm{CaO} & 14.43 \\ \mathrm{FeO} & \\ \mathrm{MgO} & \\ \mathrm{K}_{2} \mathrm{O} & \\ \mathrm{Cl} & \\ \mathrm{TiO}_{2} & \end{array}$

\section{Total}

\subsection{0}

Mineral

Composition

Phase and ID
$\mathrm{Ca}_{0.71} \mathrm{Na}_{0.26} \mathrm{Al}_{1.64} \mathrm{Si}_{2.39} \mathrm{O}_{8}$ $\left(\mathrm{An}_{73}-\mathrm{Ab}_{27}\right)$

Plagioclase (bytownite)

\section{Point $n^{\circ} 23$}

32.66

50.77

16.57 average $w t \%$

2.20

51.60

12.62

22.12

11.45

99.99

$\mathrm{Mg}_{0.74} \mathrm{Fe}_{1.24} \mathrm{Si}_{0.98} \mathrm{O}_{4}$ $\left(\mathrm{Fo}_{37}-\mathrm{Fa}_{63}\right)$

Fe-olivine (fayalite) average $w t \%$

$$
\begin{gathered}
0.99 \\
8.68 \\
50.70 \\
0.86 \\
23.08 \\
15.06 \\
0.59 \\
0.05
\end{gathered}
$$

average $w t \%$

27.18

100.00

100.01
$\mathrm{Ca}_{0.52} \mathrm{Mg}_{0.66} \mathrm{Fe}_{0.71} \mathrm{Al}_{0.8} \mathrm{Si}_{1.98} \mathrm{Al}_{0.02} \mathrm{O}_{6}$

Clinopyroxene

(augite)
$\mathrm{Fe}^{2+}\left(\mathrm{Fe}^{3+}, \mathrm{Ti}_{2}\right)_{4}$

Oxide

(titanomagnetite)
$\mathrm{K}_{0.05} \mathrm{Na}_{0.15} \mathrm{Ca}_{0.05} \mathrm{Mg}_{1.5} \mathrm{Fe}_{1.3} \mathrm{Al}_{0.2} \mathrm{Si}_{3,5} \mathrm{Al}_{0.5} \mathrm{O}_{10}(\mathrm{OH})_{2}$ (11 oxygen equivalents, ignoring $\mathrm{H}_{2} \mathrm{O}$ )

\section{Smectite}

(epoxy study) 
Courts

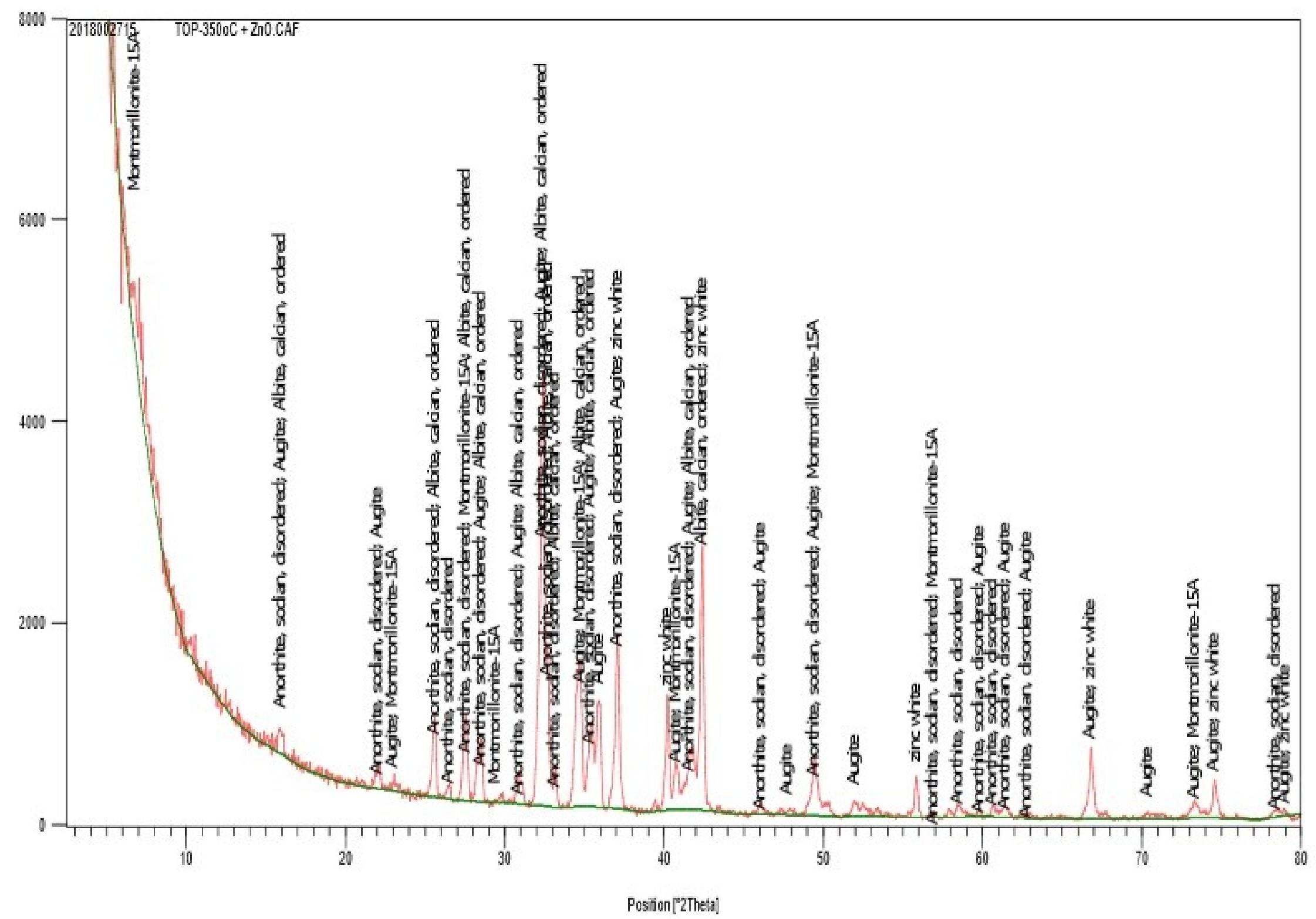

Figure 7. XRD scan showing the mineralogy of $B G B 2-T o p-350^{\circ} \mathrm{C}$ as indicated by the labelled scan peaks 


\section{Sample Composition}

Table 1. Mineral percentages for BGB2 sample was determined and then normalized to exclude zinc oxide:

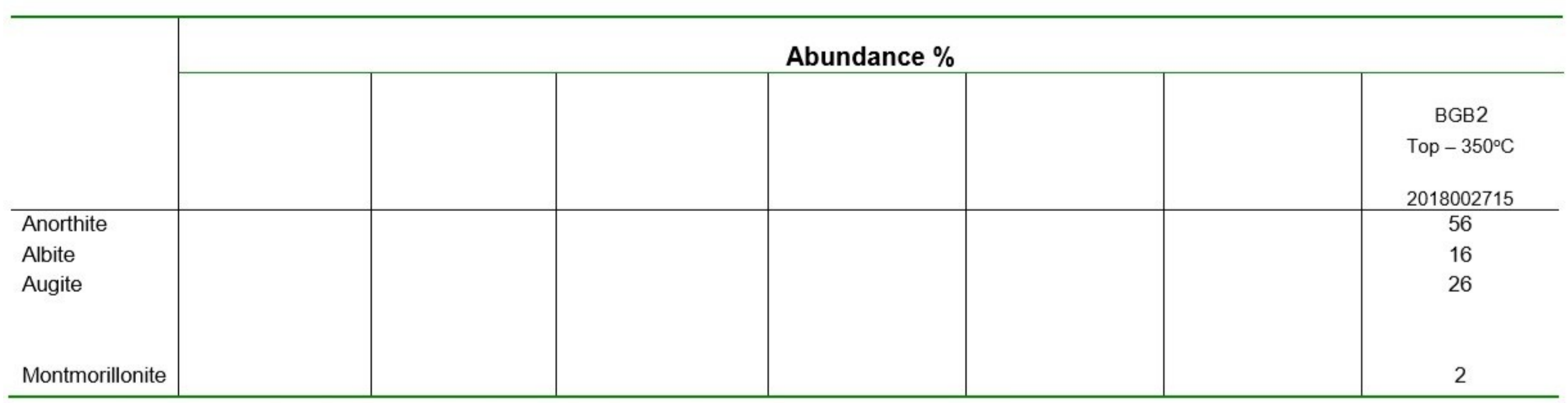

Margin of Error: Abundance estimates are determined through successive refinement of cell parameters; the position, width and orientation of each mineral. Values are given to the nearest whole number. The margin of error for phase concentration is proposed as follows: $0-10 \% \pm 10 \% ; 10-50 \% \pm 5 \% ; 50-100 \% \pm 2 \%$ 


\section{Reacted Basalt Block}

Figure C.4.20. EDS analysis of the reacted basalt block surface from the bottom (Portion 1) of the reactor after the BGB2 experiment
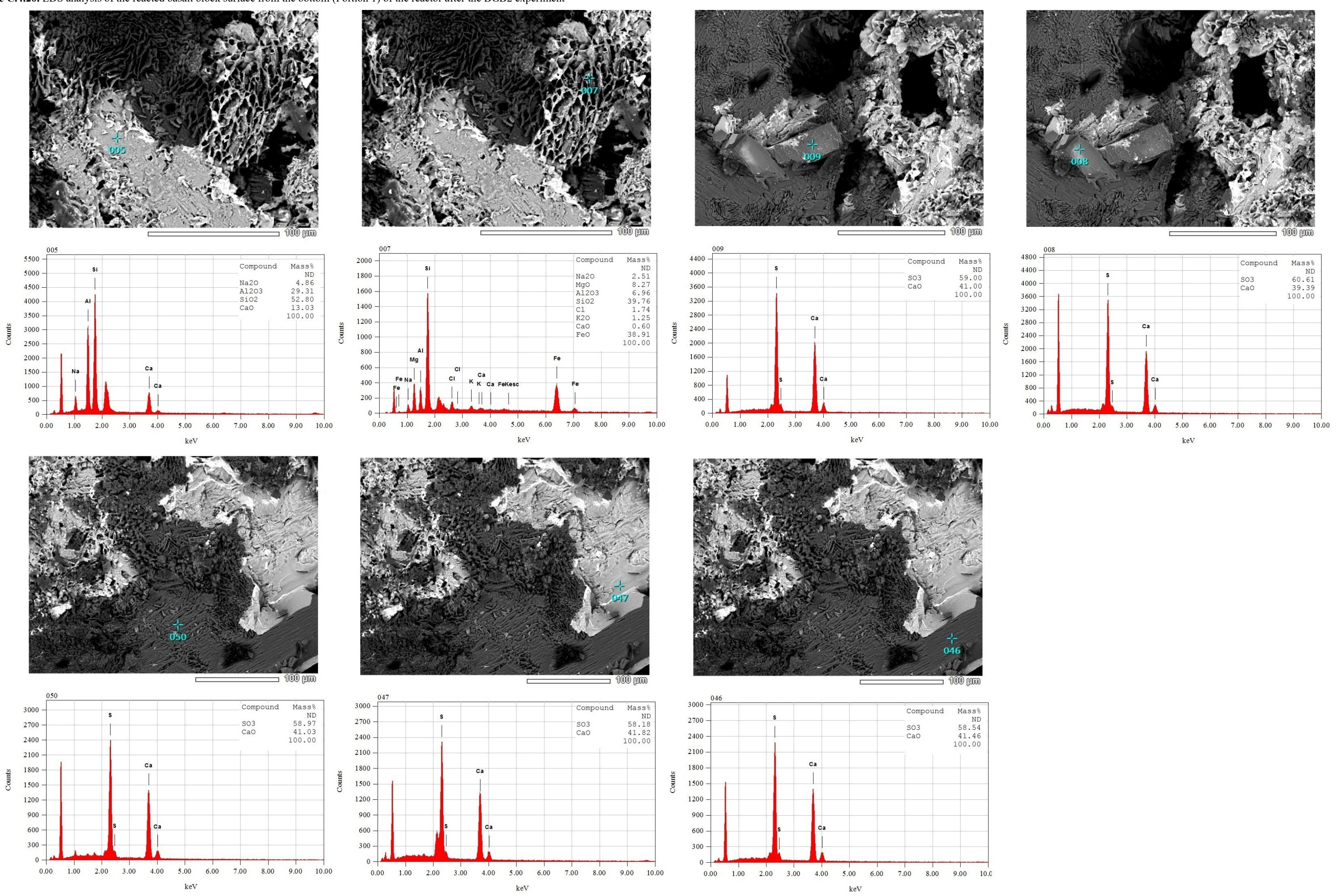


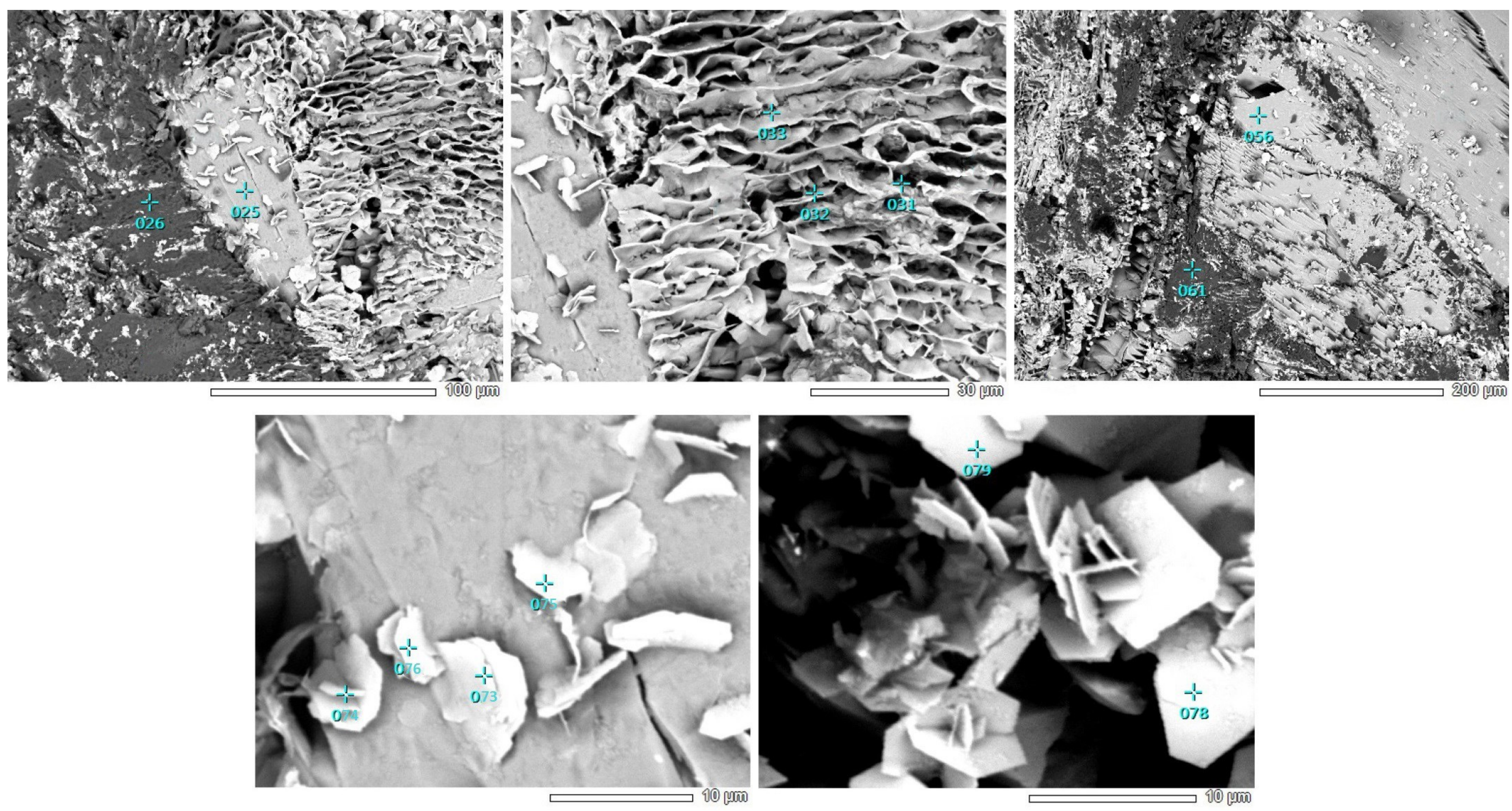


Table C.4.16. EDS analysis of points from Fig. C.4.20-21.

\begin{tabular}{|c|c|c|c|c|c|c|c|c|c|c|c|c|}
\hline \multirow[t]{3}{*}{ Plg } & $\begin{array}{l}\text { Analysis } \\
\text { Point }\end{array}$ & $\mathrm{Na}_{2} \mathrm{O}$ & $\mathbf{A l}_{2} \mathbf{O}_{3}$ & $\mathrm{SiO}_{2}$ & $\mathrm{CaO}$ & & & & & & & Total \\
\hline & 25 & 3.19 & 29.67 & 52.45 & 14.69 & & & & & & & 100.00 \\
\hline & 56 & 2.45 & 30.92 & 51.23 & 15.51 & & & & & & & 100.11 \\
\hline average & & 2.82 & 30.30 & 51.84 & 15.10 & & & & & & & 100.06 \\
\hline \multirow[t]{7}{*}{ Anh } & $\begin{array}{l}\text { Analysis } \\
\text { Point }\end{array}$ & $\mathrm{SO}_{3}$ & $\mathrm{CaO}$ & & & & & & & & & Total \\
\hline & 8 & 60.61 & 39.39 & & & & & & & & & 100.00 \\
\hline & 9 & 59.00 & 41.00 & & & & & & & & & 100.00 \\
\hline & 50 & 58.97 & 41.03 & & & & & & & & & 100.00 \\
\hline & 47 & 58.18 & 41.82 & & & & & & & & & 100.00 \\
\hline & 46 & 58.54 & 41.46 & & & & & & & & & 100.00 \\
\hline & & 59.06 & 40.94 & & & & & & & & & 100.00 \\
\hline \multirow[t]{9}{*}{ Smc } & $\begin{array}{l}\text { Analysis } \\
\text { Point }\end{array}$ & $\mathrm{Na}_{2} \mathrm{O}$ & MgO & $\mathrm{Al}_{2} \mathbf{O}_{3}$ & $\mathrm{SiO}_{2}$ & SO3 & Cl & $\mathbf{K}_{2} \mathbf{O}$ & $\mathrm{CaO}$ & $\mathrm{TiO}_{2}$ & $\mathrm{FeO}$ & Total \\
\hline & 26 & 4.77 & 16.29 & 9.00 & 47.54 & 2.04 & 1.12 & 0.89 & 3.18 & 0.00 & 15.17 & 100.00 \\
\hline & 31 & 6.85 & 11.25 & 7.29 & 37.32 & & 1.00 & 1.10 & 3.01 & 0.00 & 23.54 & 91.36 \\
\hline & 33 & 3.68 & 11.14 & 7.33 & 33.73 & & 0.00 & 1.35 & 3.14 & 0.00 & 39.63 & 100.00 \\
\hline & 7 & 2.51 & 8.27 & 6.96 & 39.76 & & 1.74 & 1.25 & 0.60 & 0.00 & 38.91 & 100.00 \\
\hline & 15 & 5.93 & 16.81 & 10.69 & 46.96 & & 1.12 & 0.65 & 0.77 & 0.00 & 17.08 & 100.01 \\
\hline & 32 & 4.16 & 10.94 & 6.12 & 37.29 & 0.16 & 0.89 & 0.65 & 4.50 & 2.87 & 32.41 & 99.99 \\
\hline & 61 & 3.05 & 16.81 & 6.94 & 50.17 & & 0.54 & 0.71 & 11.77 & 0.00 & 10.01 & 100.00 \\
\hline & & 4.42 & 13.07 & 7.76 & 41.82 & & 0.92 & 0.94 & 3.86 & 0.41 & 25.25 & 98.77 \\
\hline \multirow[t]{7}{*}{$\begin{array}{l}\mathrm{Na}-\mathrm{Ca}-\mathrm{Mg}-\mathrm{Fe}-\mathrm{Mn}-\mathrm{Ti} \\
\text { aluminosilicate }\end{array}$} & $\begin{array}{l}\text { Analysis } \\
\text { Point }\end{array}$ & $\mathrm{Na}_{2} \mathrm{O}$ & MgO & $\mathrm{Al}_{2} \mathbf{O}_{3}$ & $\mathrm{SiO}_{2}$ & $\mathrm{CaO}$ & $\mathrm{TiO}_{2}$ & MnO & $\mathrm{FeO}$ & & & Total \\
\hline & 76 & 4.30 & 1.51 & 6.74 & 11.48 & 2.55 & 36.25 & 1.86 & 35.31 & & & 100.00 \\
\hline & 75 & 3.23 & 1.12 & 10.76 & 18.57 & 3.80 & 30.92 & 0.00 & 31.61 & & & 100.01 \\
\hline & 74 & 3.76 & 0.92 & 13.94 & 21.67 & 4.63 & 26.51 & 0.00 & 28.56 & & & 99.99 \\
\hline & 73 & 1.97 & 1.16 & 7.84 & 11.50 & 2.18 & 36.95 & 0.00 & 38.41 & & & 100.01 \\
\hline & 79 & 2.77 & 0.00 & 17.71 & 22.68 & 7.63 & 24.07 & 0.00 & 25.14 & & & 100.00 \\
\hline & 78 & 0.80 & 0.00 & 5.75 & 6.75 & 3.85 & 38.61 & 2.47 & 41.77 & & & 100.00 \\
\hline average & & 2.81 & 0.79 & 10.46 & 15.44 & 4.11 & 32.22 & 0.72 & 33.47 & & & 100.00 \\
\hline$\pm \sigma$ & & 1.27 & 0.64 & 4.64 & 6.45 & 1.95 & 6.00 & 1.13 & 6.22 & & & \\
\hline
\end{tabular}




$\begin{array}{cc}\text { Oxides } & \text { average wt\% } \\ \mathrm{Na}_{2} \mathrm{O} & 2.82 \\ \mathrm{Al}_{2} \mathrm{O}_{3} & 30.30 \\ \mathrm{SiO}_{2} & 51.84 \\ \mathrm{CaO} & 15.10 \\ \mathrm{TiO}_{2} & \\ \mathrm{SO}_{3} & \\ \mathrm{FeO} & \\ \mathrm{MgO} & \\ \mathrm{K}_{2} \mathrm{O} & \\ \mathrm{Cl} & \\ \text { Total } & \\ \text { Mineral } & \mathrm{Ca}_{0.74} \mathrm{Na}_{0.25} \mathrm{Al}_{1.64} \mathrm{Si}_{2.37} \mathrm{O}_{8} \\ \text { Composition } & \left(\mathrm{An}_{75}-\mathrm{Ab}_{25}\right) \\ & \mathrm{Plagioclase} \\ \text { Phase and ID } & (\text { bytownite })\end{array}$

average $\mathrm{wt} \%$

4.42
7.76
41.82
4.84

59.06

100.00

$\mathrm{CaSO}_{4}$

Sulphate

(anhydrite) average $\mathrm{wt} \%$

$$
\begin{aligned}
& 4.42 \\
& 7.76 \\
& 41.82 \\
& 3.86
\end{aligned}
$$$$
\text { (25.25 }
$$$$
13.07
$$$$
0.94
$$$$
0.92
$$$$
98.45
$$

$\mathrm{K}_{0.1} \mathrm{Na}_{0.65} \mathrm{Ca}_{0.3} \mathrm{Mg}_{1.45} \mathrm{Fe}_{1.55} \mathrm{Si}_{3.1} \mathrm{Al}_{0.7} \mathrm{O}_{10}(\mathrm{OH})_{2}$

$$
\text { (11 oxygen equivalents, ignoring } \mathrm{H}_{2} \mathrm{O} \text { ) }
$$

\section{Smectite}




\subsection{Discussion}

\section{Elements Flux Calculation}

Table C.4.18. Elements flux calculation and amount of glass dissolved during the BGB1 experiment $\left(400^{\circ} \mathrm{C} / 483 \mathrm{bar}\right)$

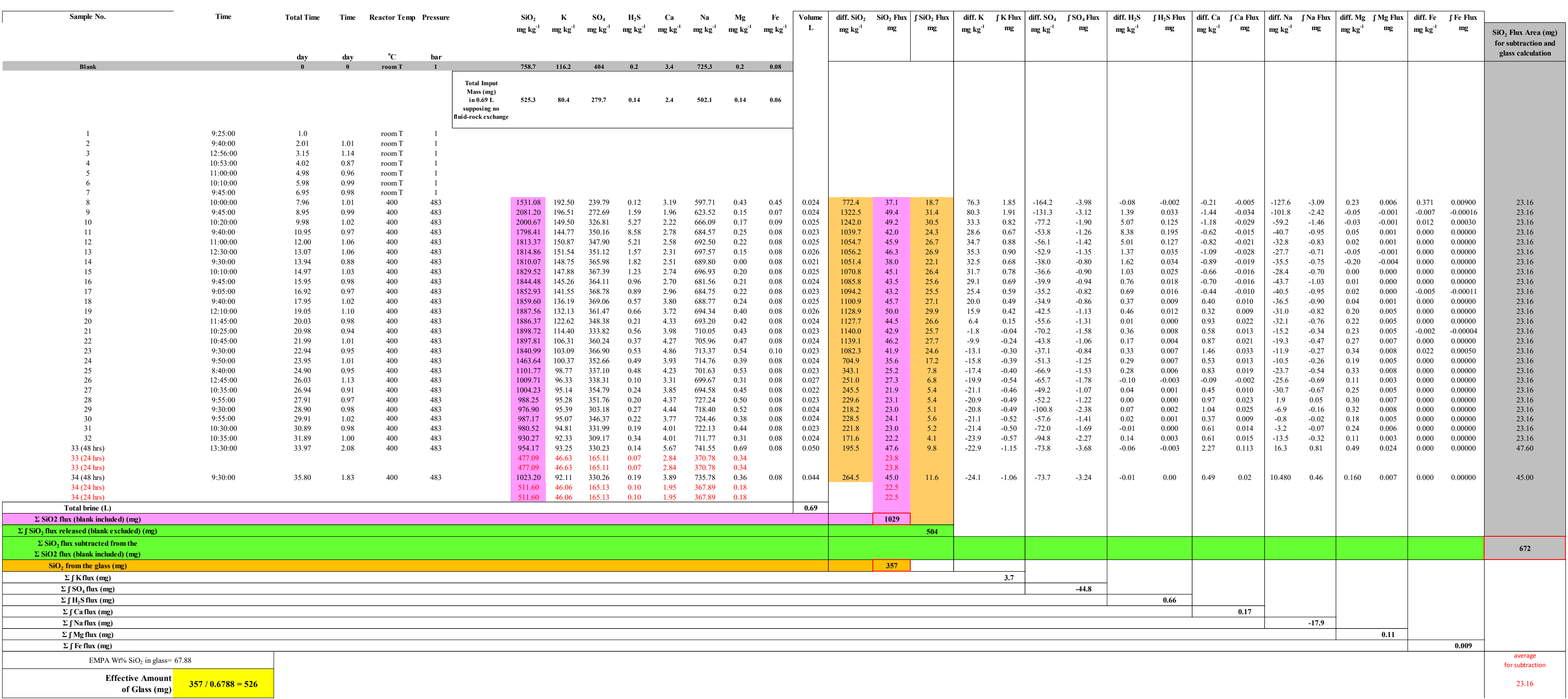


Table C.4.19. Elements flux calculation and amount of glass dissolved during the BGB2 experiment $\left(350^{\circ} \mathrm{C} / 486 \mathrm{bar}\right)$

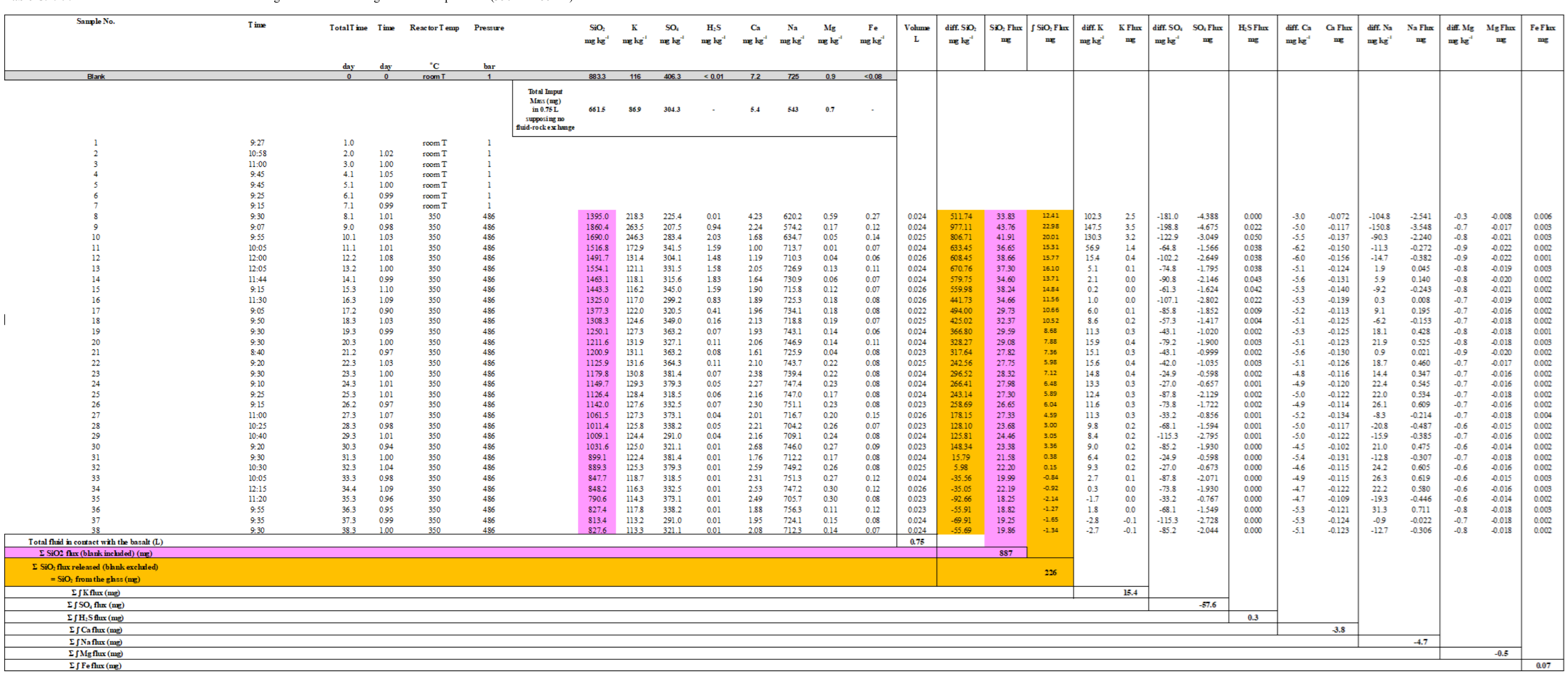


Table C.4.20. Amount of major elements estimated in the unaltered volcanic glass and $\Sigma$ major elements flux calculated from the fluid samples compositions, for the BGB1 and BGB2

\begin{tabular}{|c|c|c|c|c|c|c|c|}
\hline \multicolumn{4}{|l|}{ BGB1 } & \multirow{2}{*}{$\begin{array}{c}\text { BGB2 } \\
\mathbf{3 5 0}^{\circ} \mathbf{C} / \mathbf{4 8 6} \text { bar } \\
(26.4 \text { g of rock })\end{array}$} & & & \\
\hline $\begin{array}{c}\mathbf{4 0 0}^{\circ} \mathbf{C} / \mathbf{4 8 3} \text { bar } \\
(27.0 \mathrm{~g} \text { of rock })\end{array}$ & $\begin{array}{l}\text { Amount of major elements } \\
\text { estimated in the } \\
\text { unaltered volcanic glass }\end{array}$ & $\begin{array}{l}\Sigma \text { major elements flux } \\
\text { calculated from } \\
\text { the fluid samples } \\
\text { compositions: }\end{array}$ & & & $\begin{array}{l}\text { Amount of major elements } \\
\text { estimated in the } \\
\text { unaltered volcanic glass }\end{array}$ & \multicolumn{2}{|l|}{$\begin{array}{l}\Sigma \text { major elements flux } \\
\text { calculated from } \\
\text { the fluid samples } \\
\text { compositions: }\end{array}$} \\
\hline \multirow{2}{*}{\multicolumn{2}{|c|}{$\begin{aligned} \text { EMPA w } \mathrm{w}^{2} \mathrm{SO}_{2} & =0.04 \\
\mathrm{wt} \% \mathrm{~S} & =0.02 \\
\text { glass }(\mathrm{g}) & =0.527 \\
\mathrm{~S} \mathrm{in} \mathrm{glass}(\mathrm{g}) & =0.00011 \\
\mathrm{~S} \text { in glass }(\mathrm{mg}) & =\mathbf{0 . 1 1}\end{aligned}$}} & $\begin{array}{l}\Sigma \mathrm{H}_{2} \mathrm{~S} \text { flux }(\mathrm{mg})= \\
\Sigma \mathrm{S}(\text { reduced) flux }(\mathrm{mg})= \\
\Sigma \mathrm{SO}_{4} \text { flux }(\mathrm{mg})= \\
\Sigma \mathrm{S} \text { (oxidized) flux }(\mathrm{mg})=\end{array}$ & $\begin{array}{l}0.66 \\
0.60 \\
- \\
-\end{array}$ & \multirow{2}{*}{\multicolumn{2}{|c|}{$\begin{aligned} \text { EMPA wt } \% \mathrm{SO}_{2} & =0.04 \\
\mathrm{wt} \% \mathrm{~S} & =0.02 \\
\text { glass }(\mathrm{g}) & =0.408 \\
\mathrm{~S} \text { in glass }(\mathrm{g}) & =0.00008 \\
\mathrm{~S} \text { in glass }(\mathrm{mg}) & =\mathbf{0 . 0 8}\end{aligned}$}} & $\begin{array}{l}\Sigma \mathrm{H}_{2} \mathrm{~S} \text { flux }(\mathrm{mg})= \\
\Sigma \mathrm{S} \text { (reduced) flux (mg) = } \\
\Sigma \mathrm{SO}_{4} \text { flux }(\mathrm{mg})= \\
\Sigma \mathrm{S} \text { (oxidized) flux }(\mathrm{mg})=\end{array}$ & $\begin{array}{l}0.30 \\
0.27 \\
- \\
-\end{array}$ \\
\hline & & $\begin{array}{l}\mathrm{S}_{(\mathrm{Oxx}}+\mathrm{S}_{(\mathrm{Red})} \mathrm{in}(\mathrm{mg})= \\
\mathrm{S}_{(\mathrm{Ox})}+\mathrm{S}_{(\mathrm{Red})} \text { in }(\mathrm{g})=\end{array}$ & $\begin{array}{l}\mathbf{0 . 6 0} \\
0.00060 \\
\end{array}$ & & & $\begin{array}{l}\mathrm{S}_{(\mathrm{Oxx})}+\mathrm{S}_{(\mathrm{Red})} \text { in }(\mathrm{mg})= \\
\mathrm{S}_{(\mathrm{Ox})}+\mathrm{S}_{(\mathrm{Red})} \text { in }(\mathrm{g})=\end{array}$ & $\begin{array}{l}\mathbf{0 . 2 7} \\
0.00027 \\
\end{array}$ \\
\hline
\end{tabular}


Activity calculation

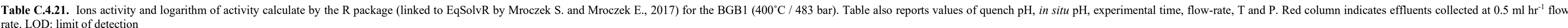

\begin{tabular}{|c|c|c|c|c|c|c|c|c|c|c|c|c|c|c|c|c|c|c|c|c|c|c|c|c|c|c|c|c|}
\hline samples & $\begin{array}{l}\text { blank } \\
\text { thermal brine }\end{array}$ & 8 & 9 & 10 & 11 & 12 & 13 & 14 & 15 & 16 & 17 & 18 & 19 & 20 & 21 & 22 & 23 & 24 & 25 & 26 & 27 & 28 & 29 & 30 & 31 & 32 & 33 & 34 \\
\hline $\begin{array}{c}a=m \cdot a_{y} \\
H^{t}\end{array}$ & $7.21 \mathrm{E}-08$ & & & & $7.798-08$ & & $7.7 \mathrm{E}-08$ & $7.55 \mathrm{E}-08$ & $7.61 \mathrm{E}-08$ & $7.5 \mathrm{~F}-08$ & $7.55 \mathrm{E}-08$ & $7.69 \mathrm{E}-08$ & & & $828=08$ & & & & & & & & & & & & & \\
\hline $\mathrm{OH}$ & $6.11 \mathrm{E}-05$ & 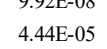 & $5.01 \mathrm{E}-05$ & $5.58 \mathrm{E}-05$ & $5.66 \mathrm{E}-05$ & $5.02 \mathrm{E}-05$ & $5.72 E-05$ & $5.83 \mathrm{E}-05$ & $5.79 \mathrm{E}-05$ & $5.825-05$ & $5.83 \mathrm{E}-05$ & $5.73 \mathrm{E}-05$ & $\begin{array}{l}5.960-08 \\
5.58-05\end{array}$ & 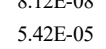 & 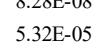 & $\begin{array}{l}5.95 \mathrm{E}-0 \mathrm{0} \\
5.5 \mathrm{~s}\end{array}$ & 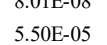 & 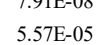 & 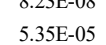 & $\begin{array}{l}7.8 .4 E=-08 \\
5.62 \mathrm{E}-05\end{array}$ & $\begin{array}{l}7.8 .80 E-08 \\
5.65 E-05\end{array}$ & $\begin{array}{l}8.1 .4 E-08 \\
553 E-05\end{array}$ & $\begin{array}{l}8.82 E-08 \\
4.99 E-05\end{array}$ & $\begin{array}{l}7.96 \mathrm{E} E-08 \\
.53 \mathrm{E}-05\end{array}$ & $\begin{array}{l}8.23 E-08 \\
5.35 E-05\end{array}$ & $\begin{array}{l}8.40 E-08 \\
5.24 E-05\end{array}$ & $\begin{array}{l}8.85 \mathrm{BS}-08 \\
4.98 \mathrm{E}-05\end{array}$ & $\begin{array}{l}8.177-08 \\
5.39 E-05\end{array}$ \\
\hline $\mathrm{Na}^{+}$ & 50 & E-02 & $1.10 \mathrm{E}-02$ & $\mathrm{E}-02$ & $1.19 \mathrm{E}-02$ & $1.20 \mathrm{E}-02$ & $1.21 \mathrm{E}-02$ & $1.20 \mathrm{E}-02$ & $1.21 \mathrm{E}-02$ & פE-02 & $1.19 \mathrm{E}-02$ & $1.20 \mathrm{E}-02$ & $1.21 \mathrm{E}-02$ & $1.21 \mathrm{E}-02$ & $1.23 E-02$ & 1.233E-02 & $1.24=-02$ & $1.24 \mathrm{E}-02$ & $1.22 \mathrm{E}-02$ & 1.222E-02 & $1.22 E-02$ & $1.26 \mathrm{E}-02$ & 1.25E -02 & 1.25E- 02 & 1.25E -02 & $1.24 \mathrm{E}-02$ & $1.28 \mathrm{E}-02$ & $1.27 \mathrm{E}-02$ \\
\hline $\mathrm{K}^{+}$ & & E-03 & $2.21 \mathrm{E}-03$ & -03 & $1.54 \mathrm{E}-03$ & $1.61 \mathrm{E}-03$ & $1.61 \mathrm{E}-03$ & $1.57 \mathrm{E}-03$ & 03 & $\mathrm{E}-03$ & $1.50 \mathrm{E}-03$ & -03 & $\mathrm{E}-03$ & $1.31 \mathrm{E}-03$ & $1.23 \mathrm{E}-03$ & 2E-03 & $1.098-03$ & $1.066-03$ & $\mathrm{E}-03$ & $1.03 \mathrm{E}-03$ & $1.01 E-03$ & $\mathrm{E}-03$ & 1.04E-03 & $1 \mathrm{EE}-03$ & $=03$ & $=03$ & 9.99E-04 & $9.8 \mathrm{~EB}-04$ \\
\hline $\mathrm{Cr}$ & & 02 & 1.1 & 02 & 1.10E-02 & & 02 & 02 & 02 & E-02 & 1.6 & 02 & -02 & -02 & $1.12 \mathrm{E}-02$ & $\mathrm{E}-02$ & -02 & 0E-02 & $: 02$ & $=02$ & $1.07 \mathrm{E}-02$ & 02 & -02 & -02 & .02 & $=02$ & i.02 & $1.14 \mathrm{E}-02$ \\
\hline $\mathrm{SO}_{4}{ }^{2}$ & & -05 & $\begin{array}{l}2.64 \mathrm{E}-05 \\
-20.07\end{array}$ & -05 & $3.50 \mathrm{E}-05$ & $\begin{array}{l}3.42 E-05 \\
3.2007\end{array}$ & $3.43 \mathrm{E}-05$ & $\begin{array}{l}3.63 \mathrm{E}-05 \\
.30 \mathrm{n}\end{array}$ & 05 & E-05 & $3.71 \mathrm{E}-05$ & .05 & -05 & $3.54 \mathrm{E}-05$ & $3.37 \mathrm{E}-05$ & E-05 & -05 & $3.63 \mathrm{E}-05$ & .05 & -05 & $3.77 \mathrm{E}-05$ & -05 & -05 & -05 & -05 & -05 & $3.30 \mathrm{E}-05$ & 39E-05 \\
\hline $\mathrm{Ca}$ & & E- -07 & $\begin{array}{l}2.75 E-07 \\
3.765 .08\end{array}$ & $8=07$ & $\begin{array}{l}3.60 \mathrm{E}-07 \\
5.070 .08\end{array}$ & $\begin{array}{l}3.33 \mathrm{E}-07 \\
3070.09\end{array}$ & $2.97 \mathrm{E}-07$ & $\begin{array}{l}3.20 \mathrm{E}-07 \\
3.0000\end{array}$ & $\begin{array}{l}3.49 E-07 \\
.1400 .08\end{array}$ & $3.47 E-07$ & 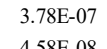 & $4.86 \mathrm{E}-07$ & $4.80 E=07$ & $5.65 E-07$ & $5.21 E=07$ & $5.47 \mathrm{E}=07$ & $6.22 E-07$ & $5.06 \mathrm{E}-07$ & $5.59 \mathrm{E}-07$ & $4.31 E-07$ & 4.998-07 & $2 \mathrm{E}-07$ & $5.97 \mathrm{E}-07$ & 1.85E-07 & 3E-07 & $\begin{array}{c}8-07 \\
0\end{array}$ & $7.46 \mathrm{E}-07$ & $\begin{array}{c}5.045-07 \\
-05600\end{array}$ \\
\hline $\begin{array}{l}\mathrm{Mg}^{2}{ }^{2} \\
\mathrm{Fe}^{2}\end{array}$ & $\begin{array}{l}3.80 \mathrm{E}-08 \\
\leq \mathrm{TD}\end{array}$ & 6E-07 & $\begin{array}{l}3.766-08 \\
2.688-08 \\
\end{array}$ & $\begin{array}{l}3.76-.08 \\
3.46-08\end{array}$ & $\begin{array}{l}5.40 \mathrm{E}-08 \\
\leq 10 \mathrm{D}\end{array}$ & $\begin{array}{l}4.87 \mathrm{E}-08 \\
\leq 0 \mathrm{D}\end{array}$ & $\begin{array}{l}3.13 \mathrm{BZ}-08 \\
\leq 0 \mathrm{P}\end{array}$ & $\begin{array}{l}3.99 \mathrm{E}-08 \\
\leq 0 \mathrm{D}\end{array}$ & $\begin{array}{l}4.18 E-08 \\
\leq 00\end{array}$ & $\begin{array}{l}4.51 E-08 \\
\text { STOD }\end{array}$ & $\begin{array}{l}4.588-08 \\
2844-0.08\end{array}$ & $\begin{array}{l}4.98 \mathrm{E}-08 \\
\leq 0 \mathrm{C}\end{array}$ & $\begin{array}{l}8.73 E-08 \\
\leq 00 \\
S 00\end{array}$ & $\begin{array}{l}9.41 E-08 \\
ك=08\end{array}$ & $\begin{array}{l}9.74 E-08 \\
285 F-08\end{array}$ & $\begin{array}{l}1.01 E-07 \\
\leq 100\end{array}$ & $\begin{array}{l}1.177-07 \\
3.81 E-08\end{array}$ & $\begin{array}{l}8.36 \mathrm{E}-08 \\
50 \mathrm{P}\end{array}$ & $\begin{array}{l}1.196-07 \\
<100\end{array}$ & $\begin{array}{l}6.64 \mathrm{E}-08 \\
50 \mathrm{D}\end{array}$ & $\begin{array}{l}9.65 \mathrm{E}-08 \\
\leq 0 \mathrm{D}\end{array}$ & $\begin{array}{l}1.100-07 \\
\leq 00\end{array}$ & $\begin{array}{l}1.24 E-07 \\
\end{array}$ & 8.36E-08 & $\begin{array}{l}9.80 \mathrm{E}-08 \\
\end{array}$ & 7.04E-08 & $\begin{array}{l}1.61 \mathrm{E}-07 \\
<\mathrm{TOD}\end{array}$ & $\begin{array}{l}7.95 \mathrm{E}-08 \\
<\mathbf{1 0 0}\end{array}$ \\
\hline 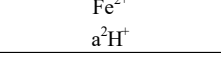 & & $\begin{array}{l}1.6 \mathrm{E}-07 \\
9.84 \mathrm{E}-15 \\
\end{array}$ & $\begin{array}{l}\begin{array}{l}2.6888-08 \\
7.73 \mathrm{E}-15\end{array} \\
\end{array}$ & $\begin{array}{l}3.4 .2 E E-08 \\
6.23 E-15 \\
\end{array}$ & $\begin{array}{l}\text { CLD } \\
6.07 E-15 \\
\end{array}$ & $\begin{array}{l}<\text { LDD } \\
6.14 E-15 \\
\end{array}$ & $\begin{array}{l}<\text { LDD } \\
5.94 \mathrm{E}-15 \\
\end{array}$ & $\begin{array}{l}<\text { LDD } \\
5.70 \mathrm{E}-15\end{array}$ & $\begin{array}{l}<.0 \mathrm{DD} \\
5.79 \mathrm{E}-15 \\
\end{array}$ & $\begin{array}{l}\text { loD } \\
5.73 \mathrm{E}-15 \\
\end{array}$ & $\begin{array}{l}2.84 \mathrm{E}-08 \\
5.71 \mathrm{E}-15 \\
\end{array}$ & & $\begin{array}{l}<\text { LDD } \\
6.24 \mathrm{E}-15\end{array}$ & $\begin{array}{l}<\text { LDD } \\
6.60 \mathrm{E}-15\end{array}$ & $\begin{array}{l}2.8856-08 \\
6.86 \mathrm{E}-15\end{array}$ & $\begin{array}{l}<\text { <DD } \\
6.29 \mathrm{E}-15\end{array}$ & 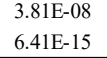 & $\begin{array}{l}<\text { LDD } \\
6.26 \mathrm{E}-15\end{array}$ & $\begin{array}{l}<\text { LDD } \\
6.77 \mathrm{E}-15\end{array}$ & $\begin{array}{l}<\text { <DD } \\
6.14 E-15\end{array}$ & $\begin{array}{l}<\text { <LD } \\
6.09 E-15\end{array}$ & $\begin{array}{l}<\text { LIDD } \\
6.57 \mathrm{E}-15\end{array}$ & $\begin{array}{c}<\text { cLD } \\
7.78 \mathrm{E}-15\end{array}$ & 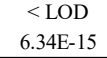 & $\begin{array}{l}<\text { <LD } \\
6.78 \mathrm{E}-15\end{array}$ & $\begin{array}{c}<\text { LDD } \\
7.06 \mathrm{E}-15\end{array}$ & 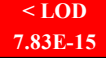 & $\begin{array}{l}<\text { LoD } \\
6.688-15\end{array}$ \\
\hline $\log \left(a \mathrm{SiO}_{2}\right)$ & -1.9 & -1.6 & -1.5 & -1.5 & -1.5 & -1.5 & -1.5 & -1.5 & -1.5 & -1.5 & -1.5 & -1.5 & -1.5 & -1.5 & -1.5 & -1.5 & -1.5 & -1.6 & -1.7 & -1.8 & -1.8 & -1.8 & -1.8 & -1.8 & -1.8 & -1.8 & -1.8 & -1.8 \\
\hline $\log \left(a_{\mathrm{K}}+c\right.$ & 4. & 4.3 & 4.4 & 4.3 & 4.3 & 4.3 & 4.3 & 4.3 & 4. & 4.3 & 4. & 4.3 & 4.2 & 4.2 & 4.2 & 4. & 4.1 & 4. & 4. & 4.1 & 4. & 4. & 4.1 & 4. & 4. & 4.1 & 4.1 & 4.1 \\
\hline $\log \left(a_{\left.\mathrm{Na}_{2} / a_{\mathrm{H}}\right)}\right)$ & 5.2 & 5.0 & 5.1 & 5.2 & 5.2 & 5.2 & 5.2 & 5.2 & 5.2 & 5.2 & 5.2 & 5.2 & 5.2 & 5.2 & 5.2 & 5.2 & 5.2 & 5.2 & 5.2 & 5.2 & 5.2 & 5.2 & 5.2 & 5.2 & 5.2 & 5.2 & 5.2 & 5.2 \\
\hline $\log \left(a_{\mathrm{Ca2}+} / a_{\mathrm{H}+}^{2}\right)$ & 7.9 & 7.7 & 7.6 & 7.7 & 7.8 & 7.7 & 7.7 & 7.7 & 7.8 & 7.8 & 7.8 & 7.9 & 7.9 & 7.9 & 7.9 & 7.9 & 8.0 & 7.9 & 7.9 & 7.8 & 7.9 & 7.9 & 7.9 & 7.9 & 1.9 & 7.9 & 8.0 & 7.9 \\
\hline $\log \left(a_{\mathrm{Fe} 2} / a_{\mathrm{H}+}^{2}\right)$ & $<$ LOD & 7.2 & 6.5 & 6.7 & $<$ LOD & $<$ LOD & $<$ LOD & $<$ LOD & $<$ LOD & $<$ LOD & 6.7 & $<$ LOD & $<$ LOD & $<$ LOD & 6.6 & $<$ LOD & 6.8 & $<$ LOD & $<$ LOD & $<$ LOD & $<$ LOD & $<$ LOD & $<$ LOD & $<$ LOD & $<$ LOD & $<$ LOD & $<$ LOD & $<$ LOD \\
\hline $\log \left(a_{\mathrm{Mg}_{2}+} / a_{\mathrm{H}+}^{2}\right)$ & 6.9 & 7.1 & 6.7 & 6.8 & 6.9 & 6.9 & 6.7 & 6.8 & 6.9 & 6.9 & 6.9 & 6.9 & 7.1 & 7.2 & 7.2 & 7.2 & 7.3 & 7.1 & 7.2 & 7.0 & 7.2 & 7.2 & 7.2 & 7.1 & 7.2 & 7.0 & 7.3 & 7.1 \\
\hline $\log a \mathrm{Na}^{+}$ & -1.9 & -2.0 & -2.0 & -1.9 & -1.9 & -1.9 & -1.9 & -1.9 & -1.9 & -1 & -1.9 & -1.9 & -1.9 & -1.9 & -1.9 & -1. & -1.9 & -1.9 & -1.9 & -1.9 & -1.9 & -1.9 & -1.9 & -1.9 & -1.9 & -1.9 & -1.9 & -1.9 \\
\hline $\log a \mathrm{~K}^{+}$ & -2.9 & -2.7 & -2.7 & -2.8 & -2.8 & -2.8 & -2.8 & -2.8 & -2.8 & -2.8 & -2.8 & -2.8 & -2. & -2.9 & -2 & -2. & -3.1 & -3 & -3 & -3.0 & -3. & -3 & -3.0 & -3.0 & -3 & -3.0 & -3.0 & -3.0 \\
\hline $\log a \mathrm{Cl}$ & -2.0 & -1.9 & -1.9 & -2.0 & -2.0 & -2.0 & -1.9 & -2.0 & -2.0 & -2.0 & -2. & -2.0 & -2 & -2.0 & -1 . & -2 & -2. & -2 & -2 & -2.0 & -2 & -2 & -1.9 & -2 & 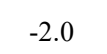 & -1.9 & -1.9 & -1.9 \\
\hline $\log a \mathrm{SO}_{4}^{2-}$ & -4.4 & -4.6 & -4.6 & -4.5 & -4. & -4.5 & -4 & -4. & -4. & -4. & -4. & -4.4 & -4 & -4 & . & -4 & -4. & -4 & -4 & -4 & -4 & -4 & -4 & -4. & -4 & -4.5 & -4.5 & -4.5 \\
\hline $\log a \mathrm{Ca}^{2+}$ & -6.4 & -6.3 & -6.6 & -6.5 & -6.4 & -6.5 & -6.5 & -6.5 & -6.5 & -6.5 & -6.4 & -6.3 & -6.3 & -6.2 & -6.3 & -6.3 & -6.2 & -6.3 & -6.3 & -6.4 & -6.3 & -6.2 & -6.2 & -6.3 & -6.3 & -6.3 & -6.1 & -6.3 \\
\hline $\log a \mathrm{Mg}^{2+}$ & -7.4 & -6.9 & -7.4 & -7.4 & -7.3 & -7.3 & -7.5 & -7.4 & -7.4 & -7.3 & -7.3 & -7.3 & -7.1 & -7.0 & -7.0 & -7.0 & -6.9 & -7.1 & -6.9 & -7.2 & -7.0 & -7.0 & -6.9 & -7.1 & -7.0 & -7.2 & -6.8 & -7.1 \\
\hline $\log a \mathrm{Fe}^{2+}$ & $<$ LOD & -6.78 & -7.57 & -7.46 & $<$ LOD & $<$ LOD & $<$ LOD & $<$ LOD & $<$ LOD & $<$ LOD & -7.55 & $<$ LOD & $<$ LOD & $<$ LOD & -7.54 & $<$ LOD & -7.42 & $<$ LOD & $<$ LOD & $<$ LOD & $<$ LOD & $<$ LOD & $<$ LOD & $<$ LOD & $<$ LOD & $<$ LOD & $<$ LOD & $<$ LOD \\
\hline $\mathrm{T}(\mathrm{C})$ & 400 & 397.6 & 4 & 40 & 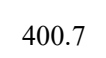 & 40 & 400.4 & 46 & 4 & 400.6 & 400.7 & 400.9 & 400.7 & 400.6 & 40 & 400.9 & 400.5 & 40 & 400.6 & 400.5 & 40 & 400.4 & 400.5 & 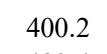 & 0.4 & 400.6 & 400.7 & 400.5 \\
\hline & & & & & & & & & & & & & & & & & & & & & & & & & & & 477.0 & 482.3 \\
\hline in situ $\mathrm{pt}$ & 7.14 & 7.0 & 7.06 & 7.10 & 7.1 & 7.11 & 7. & 7.12 & 7.12 & 7.12 & 7.12 & 7. & 7. & 7.09 & 7 & 7. & .10 & 7.10 & 7.08 & 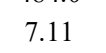 & 7.11 & 7.09 & 7.05 & 10 & 7.08 & 08 & 7.05 & 7.09 \\
\hline $\operatorname{room} \mathrm{TP}_{\mathrm{p}}$ & 3.91 & 3.23 & 2.87 & 3.25 & 3.32 & 3.25 & 3.31 & 3.53 & 3.55 & 3.5 & 3.4 & 3.45 & 3.57 & 3.71 & 3.76 & 3.78 & 4.05 & 4.6 & 6.23 & 6.51 & 6.77 & 7.07 & 7.44 & 7.52 & 7.41 & 7.66 & .3 & 7.76 \\
\hline fllow rate (m hl hr') & - & 1 & 1 & 1 & 1 & 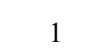 & 1 & 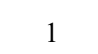 & 1 & 1 & 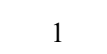 & 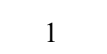 & 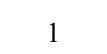 & 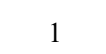 & 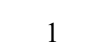 & 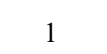 & 1 & 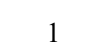 & 1 & 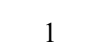 & 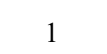 & 1 & 1 & 1 & 1 & 1 & 0.5 & 0.5 \\
\hline time (hrs) & 0.0 & 190.9 & 214.7 & 239.3 & 262.6 & 287.9 & 313.4 & 334.4 & 359.0 & 382.7 & 406.0 & 430.6 & 457.3 & 480.7 & 503.3 & 527.7 & 550.4 & 574.8 & 597.6 & 625.7 & 647.5 & 670.8 & 694.4 & 718.8 & 743.4 & 767.5 & 809.2 & 853.2 \\
\hline Anhydri & & & & & & & & & & & & & & & & & & & & & & & & & & & & \\
\hline Log Ksp (Supcrt9 & & 4.27 & 4.27 & 4.2 & 4.27 & 4.27 & 4.2 & 4.2 & 4. & 4.2 & 4.2 & 4 & 4. & 4.2 & 4. & 4.2 & 4.2 & 4. & 4.2 & 4.2 & 4.2 .45 & 4.2 & 4.2 & 4.27 & 4.27 & 4.27 & 4.27 & 4.27 \\
\hline $\log Q$ (IAP & & 3.51 & 3.69 & 3.57 & 3.45 & 3.50 & 3.55 & 3.49 & 3.45 & 3.45 & 3.41 & 3.30 & 3.32 & 3.26 & 3.31 & 3.25 & 3.18 & 3.29 & 3.27 & 3.37 & 3.28 & 3.25 & 3.29 & 3.32 & 3.31 & 3.32 & 3.17 & 3.32 \\
\hline $\log S I$ & & -0.76 & -0.58 & -0.70 & -0.82 & -0.77 & -0.72 & -0.78 & -0.82 & -0.82 & -0.86 & -0.97 & -0.95 & -1.01 & -0.96 & -1.02 & -1.09 & -0.98 & -1.00 & -0.90 & -0.99 & -1.02 & -0.98 & -0.95 & -0.96 & -0.95 & -1.10 & -0.95 \\
\hline
\end{tabular}


Table C.4.22. Values of the activity coefficients $\left(a_{y}\right)$ calculate by the R package for the BGB1

\begin{tabular}{|c|c|c|c|c|c|c|c|c|c|c|c|c|c|}
\hline sample & & $\mathbf{H}^{+}$ & $\mathrm{OH}^{-}$ & $\mathrm{Na}^{+}$ & $\mathbf{K}^{+}$ & $\mathrm{Cl}^{-}$ & $\mathrm{SO}_{4}{ }^{2-}$ & $\mathrm{Ca}^{2+}$ & $\mathbf{M g}^{2+}$ & $\mathrm{Fe}^{2+}$ & $\mathrm{NaSO}_{4}^{-}$ & $\mathrm{HSO}_{4}^{-}$ & $\mathrm{KSO}_{4}^{-}$ \\
\hline $\begin{array}{l}\text { Dhank } \\
\text { eermal }\end{array}$ & m & $1.10 \mathrm{E}-07$ & $1.04 \mathrm{E}-04$ & $2.11 \mathrm{E}-02$ & $2.09 \mathrm{E}-03$ & $1.86 \mathrm{E}-02$ & $3.38 \mathrm{E}-04$ & $2.82 \mathrm{E}-06$ & $2.19 \mathrm{E}-07$ & & $3.06 \mathrm{E}-03$ & $1.39 \mathrm{E}-04$ & $6.58 \mathrm{E}-04$ \\
\hline & & $6.58 \mathrm{E}-01$ & $5.90 \mathrm{E}-01$ & $5.90 \mathrm{E}-01$ & $5.74 \mathrm{E}-01$ & $5.82 \mathrm{E}-01$ & $1.21 \mathrm{E}-01$ & $1.48 \mathrm{E}-01$ & $1.74 \mathrm{E}-01$ & & $5.90 \mathrm{E}-01$ & $5.90 \mathrm{E}-01$ & $5.90 \mathrm{E}-01$ \\
\hline & & $7.21 \mathrm{E}-08$ & $6.11 \mathrm{E}-05$ & $1.24 \mathrm{E}-02$ & $1.20 \mathrm{E}-03$ & $1.08 \mathrm{E}-02$ & $4.10 \mathrm{E}-05$ & $4.17 \mathrm{E}-07$ & $3.80 \mathrm{E}-08$ & & $1.80 \mathrm{E}-03$ & $8.21 \mathrm{E}-05$ & $3.89 \mathrm{E}-04$ \\
\hline 8 & $\mathbf{m}$ & $1.49 \mathrm{E}-07$ & $7.42 \mathrm{E}-05$ & $1.79 \mathrm{E}-02$ & $3.80 \mathrm{E}-03$ & $1.91 \mathrm{E}-02$ & $1.84 \mathrm{E}-04$ & $3.06 \mathrm{E}-06$ & $6.39 \mathrm{E}-07$ & $1.08 \mathrm{E}-06$ & $1.50 \mathrm{E}-03$ & $1.09 \mathrm{E}-04$ & $6.91 \mathrm{E}-04$ \\
\hline & tivity & $6.64 \mathrm{E}-01$ & $5.99 \mathrm{E}-01$ & $5.99 \mathrm{E}-01$ & $5.83 \mathrm{E}-01$ & $5.91 \mathrm{E}-01$ & $1.29 \mathrm{E}-01$ & $1.55 \mathrm{E}-01$ & $1.81 \mathrm{E}-01$ & $1.55 \mathrm{E}-01$ & $5.99 \mathrm{E}-01$ & $5.99 \mathrm{E}-01$ & $5.99 \mathrm{E}-01$ \\
\hline & & & $4.44 \mathrm{E}-05$ & & & & & & & & & & $4.14 \mathrm{E}-04$ \\
\hline 9 & $\mathbf{m}$ & $1.33 \mathrm{E}-07$ & $8.42 \mathrm{E}-05$ & $1.85 \mathrm{E}-02$ & $3.82 \mathrm{E}-03$ & $1.93 \mathrm{E}-02$ & $2.10 \mathrm{E}-04$ & $1.81 \mathrm{E}-06$ & $2.11 \mathrm{E}-07$ & $1.76 \mathrm{E}-07$ & $1.73 \mathrm{E}-03$ & $1.08 \mathrm{E}-04$ & $7.77 \mathrm{E}-04$ \\
\hline & $\mathbf{a}_{r}$ & $6.61 \mathrm{E}-01$ & $5.95 \mathrm{E}-01$ & $5.95 \mathrm{E}-01$ & $5.79 \mathrm{E}-01$ & $5.87 \mathrm{E}-01$ & $1.26 \mathrm{E}-01$ & $1.52 \mathrm{E}-01$ & $1.78 \mathrm{E}-01$ & $1.52 \mathrm{E}-01$ & $5.95 \mathrm{E}-01$ & $5.95 \mathrm{E}-01$ & $5.95 \mathrm{E}-01$ \\
\hline & activity & $8.79 \mathrm{E}-08$ & $5.01 E-05$ & $1.10 \mathrm{E}-02$ & $2.21 \mathrm{E}-03$ & $1.13 \mathrm{E}-02$ & $2.64 \mathrm{E}-05$ & $2.75 \mathrm{E}-07$ & $3.76 \mathrm{E}-08$ & $2.68 \mathrm{E}-08$ & $1.03 \mathrm{E}-03$ & $6.45 \mathrm{E}-05$ & $4.63 \mathrm{E}-04$ \\
\hline 10 & $\mathbf{m}$ & $1.19 \mathrm{E}-07$ & $9.39 \mathrm{E}-05$ & $1.97 \mathrm{E}-02$ & $2.80 \mathrm{E}-03$ & $1.88 \mathrm{E}-02$ & $2.63 \mathrm{E}-04$ & $1.95 \mathrm{E}-06$ & $2.12 \mathrm{E}-07$ & $2.28 \mathrm{E}-07$ & $2.29 \mathrm{E}-03$ & $1.21 \mathrm{E}-04$ & $7.10 \mathrm{E}-04$ \\
\hline & & $6.61 \mathrm{E}-01$ & $5.94 \mathrm{E}-01$ & $5.94 \mathrm{E}-01$ & $5.78 \mathrm{E}-01$ & $5.86 \mathrm{E}-01$ & $1.25 \mathrm{E}-01$ & $1.51 \mathrm{E}-01$ & $1.77 \mathrm{E}-01$ & $1.51 \mathrm{E}-01$ & $5.94 \mathrm{E}-01$ & $5.94 \mathrm{E}-01$ & $5.94 \mathrm{E}-01$ \\
\hline & & $7.89 \mathrm{E}-08$ & $5.58 \mathrm{E}-05$ & $1.17 \mathrm{E}-02$ & $1.62 \mathrm{E}-03$ & $1.10 \mathrm{E}-02$ & $3.29 \mathrm{E}-05$ & $.95 \mathrm{E}-07$ & $3.76 \mathrm{E}-08$ & $3.44 \mathrm{E}-08$ & $1.36 \mathrm{E}-03$ & $7.21 \mathrm{E}-05$ & $4.22 \mathrm{E}-04$ \\
\hline 11 & $\mathbf{m}$ & $1.18 \mathrm{E}-07$ & $9.55 \mathrm{E}-05$ & $2.01 \mathrm{E}-02$ & $2.68 \mathrm{E}-03$ & $1.89 \mathrm{E}-02$ & $2.84 \mathrm{E}-04$ & $2.40 \mathrm{E}-06$ & $3.07 \mathrm{E}-07$ & & $2.49 \mathrm{E}-03$ & $1.28 \mathrm{E}-04$ & $7.23 \mathrm{E}-04$ \\
\hline & $a_{r}$ & $6.59 \mathrm{E}-01$ & $5.92 \mathrm{E}-01$ & $5.92 \mathrm{E}-01$ & $5.76 \mathrm{E}-01$ & $5.84 \mathrm{E}-01$ & $1.23 \mathrm{E}-01$ & $1.50 \mathrm{E}-01$ & $1.76 \mathrm{E}-01$ & & $2 \mathrm{E}-01$ & $5.92 \mathrm{E}-01$ & $5.92 \mathrm{E}-01$ \\
\hline & activity & $7.79 \mathrm{E}-08$ & $5.66 \mathrm{E}-05$ & $1.19 \mathrm{E}-02$ & $1.54 \mathrm{E}-03$ & $\begin{array}{l}1.10 \mathrm{E}-02 \\
\end{array}$ & $3.50 \mathrm{E}-05$ & $3.60 \mathrm{E}-07$ & $5.40 \mathrm{E}-08$ & & $1.48 \mathrm{E}-03$ & $7.58 \mathrm{E}-05$ & $4.28 \mathrm{E}-04$ \\
\hline 12 & 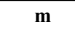 & $1.19 \mathrm{E}-07$ & $9.51 \mathrm{E}-05$ & $2.03 \mathrm{E}-02$ & $2.81 \mathrm{E}-03$ & $1.92 \mathrm{E}-02$ & $2.80 \mathrm{E}-04$ & $2.25 \mathrm{E}-06$ & $2.79 \mathrm{E}-07$ & & $2.46 \mathrm{E}-03$ & $1.26 \mathrm{E}-04$ & $7.39 \mathrm{E}-04$ \\
\hline & & $6.58 \mathrm{E}-01$ & $5.91 \mathrm{E}-01$ & $5.91 \mathrm{E}-01$ & $5.74 \mathrm{E}-01$ & $5.83 \mathrm{E}-01$ & $1.22 \mathrm{E}-01$ & $1.48 \mathrm{E}-01$ & $1.75 \mathrm{E}-01$ & & $5.91 \mathrm{E}-01$ & $5.91 \mathrm{E}-01$ & $5.91 \mathrm{E}-01$ \\
\hline & & $7.84 \mathrm{E}-08$ & $5.62 \mathrm{E}-05$ & $1.20 \mathrm{E}-02$ & $1.61 \mathrm{E}-03$ & $1.12 \mathrm{E}-02$ & $3.42 \mathrm{E}-05$ & $3.33 \mathrm{E}-07$ & $4.87 \mathrm{E}-08$ & & $1.45 \mathrm{E}-03$ & 7.44E- -05 & $4.37 \mathrm{E}-04$ \\
\hline 13 & m & $1.17 \mathrm{E}-07$ & $9.70 \mathrm{E}-05$ & $2.04 \mathrm{E}-02$ & $2.82 \mathrm{E}-03$ & $1.93 \mathrm{E}-02$ & $2.84 \mathrm{E}-04$ & $2.01 \mathrm{E}-06$ & $1.80 \mathrm{E}-07$ & & $2.49 \mathrm{E}-03$ & $1.25 \mathrm{E}-04$ & $7.47 \mathrm{E}-04$ \\
\hline & & $6.58 \mathrm{E}-01$ & $5.90 \mathrm{E}-01$ & $5.90 \mathrm{E}-01$ & $5.74 \mathrm{E}-01$ & $5.82 \mathrm{E}-01$ & $1.21 \mathrm{E}-01$ & $1.48 \mathrm{E}-01$ & $1.74 \mathrm{E}-01$ & & $5.90 \mathrm{E}-01$ & $5.90 \mathrm{E}-01$ & $5.90 \mathrm{E}-01$ \\
\hline & activity & $7.70 \mathrm{E}-08$ & $5.72 \mathrm{E}-05$ & $1.21 \mathrm{E}-02$ & $1.62 \mathrm{E}-03$ & $1.12 \mathrm{E}-02$ & $3.44 \mathrm{E}-05$ & $2.97 \mathrm{E}-07$ & $3.13 \mathrm{E}-08$ & & $1.47 \mathrm{E}-03$ & 7.37E-05 & 4.41E-04 \\
\hline 14 & $\mathbf{m}$ & $1.15 \mathrm{E}-07$ & $9.86 \mathrm{E}-05$ & $2.02 \mathrm{E}-02$ & $2.73 \mathrm{E}-03$ & $1.88 \mathrm{E}-02$ & $2.97 \mathrm{E}-04$ & $2.15 \mathrm{E}-06$ & $2.28 \mathrm{E}-07$ & & -03 & $1.29 \mathrm{E}-04$ & $7.65 \mathrm{E}-04$ \\
\hline & & $6.59 \mathrm{E}-01$ & $5.92 \mathrm{E}-01$ & $5.92 \mathrm{E}-01$ & $5.75 \mathrm{E}-01$ & $5.84 \mathrm{E}-01$ & $1.23 \mathrm{E}-01$ & $1.49 \mathrm{E}-01$ & $1.75 \mathrm{E}-01$ & & $5.92 \mathrm{E}-01$ & $5.92 \mathrm{E}-01$ & $5.92 \mathrm{E}-01$ \\
\hline & & $7.55 \mathrm{E}-08$ & $5.83 \mathrm{E}-05$ & $1.20 \mathrm{E}-02$ & $1.57 \mathrm{E}-03$ & $1.10 \mathrm{E}-02$ & $3.63 \mathrm{E}-05$ & $3.20 \mathrm{E}-07$ & $3.99 \mathrm{E}-08$ & & $1.54 \mathrm{E}-03$ & $7.63 \mathrm{E}-05$ & $4.53 \mathrm{E}-04$ \\
\hline 15 & & & & $2.04 \mathrm{E}-02$ & $2.72 \mathrm{E}-03$ & $1.90 \mathrm{E}-02$ & $2.97 \mathrm{E}-04$ & $2.35 \mathrm{E}-06$ & $2.40 \mathrm{E}-07$ & & $2.61 \mathrm{E}-03$ & $1.30 \mathrm{E}-04$ & $7.59 \mathrm{E}-04$ \\
\hline & & $6.58 \mathrm{E}-01$ & $5.91 \mathrm{E}-01$ & 91E-01 & $5.74 \mathrm{E}-01$ & $5.83 \mathrm{E}-01$ & $1.22 \mathrm{E}-01$ & $1.48 \mathrm{E}-01$ & $1.74 \mathrm{E}-01$ & & $5.91 \mathrm{E}-01$ & $5.91 \mathrm{E}-01$ & 91E-01 \\
\hline & activity & $7.61 \mathrm{E}-08$ & $5.79 \mathrm{E}-05$ & & -03 & & & & $4.18 \mathrm{E}-08$ & & $1.54 \mathrm{E}-03$ & $\begin{array}{c}\mathrm{E}=\mathrm{OS} \\
\mathrm{n}\end{array}$ & \\
\hline 16 & $\mathrm{~m}$ & $1.15 \mathrm{E}-07$ & $9.81 \mathrm{E}-05$ & $2.00 \mathrm{E}-02$ & $2.67 \mathrm{E}-03$ & $1.85 \mathrm{E}-02$ & $2.96 \mathrm{E}-04$ & $2.31 \mathrm{E}-06$ & $2.56 \mathrm{E}-07$ & & $2.59 \mathrm{E}-03$ & $1.30 \mathrm{E}-04$ & $7.55 \mathrm{E}-04$ \\
\hline & $a_{t}$ & $6.60 \mathrm{E}-01$ & $5.93 \mathrm{E}-01$ & $5.93 \mathrm{E}-01$ & $5.77 \mathrm{E}-01$ & $5.85 \mathrm{E}-01$ & $1.24 \mathrm{E}-01$ & $1.50 \mathrm{E}-01$ & $1.76 \mathrm{E}-01$ & & $5.93 \mathrm{E}-01$ & $5.93 \mathrm{E}-01$ & $5.93 \mathrm{E}-01$ \\
\hline & activity & $7.57 \mathrm{E}-08$ & $5.82 \mathrm{E}-05$ & $1.19 \mathrm{E}-02$ & $1.54 \mathrm{E}-03$ & $1.09 \mathrm{E}-02$ & $3.66 \mathrm{E}-05$ & $3.47 \mathrm{E}-07$ & $4.51 \mathrm{E}-08$ & & $1.54 \mathrm{E}-03$ & $7.70 \mathrm{E}-05$ & $4.48 \mathrm{E}-04$ \\
\hline 17 & $\mathrm{~m}$ & $1.15 \mathrm{E}-07$ & $9.84 \mathrm{E}-05$ & $2.01 \mathrm{E}-02$ & $2.60 \mathrm{E}-03$ & $1.85 \mathrm{E}-02$ & $3.00 E-04$ & $2.52 \mathrm{E}-06$ & $2.60 \mathrm{E}-07$ & & $2.64 \mathrm{E}-03$ & $1.32 \mathrm{E}-04$ & $7.43 \mathrm{E}-04$ \\
\hline & & $6.59 \mathrm{E}-01$ & $5.93 \mathrm{E}-01$ & $5.93 \mathrm{E}-01$ & $5.76 \mathrm{E}-01$ & $5.85 \mathrm{E}-01$ & $1.24 \mathrm{E}-01$ & $1.50 \mathrm{E}-01$ & $1.76 \mathrm{E}-01$ & & $5.93 \mathrm{E}-01$ & $5.93 \mathrm{E}-01$ & $5.93 \mathrm{E}-01$ \\
\hline & activity & $7.55 \mathrm{E}-08$ & $5.83 \mathrm{E}-05$ & $1.19 \mathrm{E}-02$ & $1.50 \mathrm{E}-03$ & $1.08 \mathrm{E}-02$ & $3.71 \mathrm{E}-05$ & $3.78 \mathrm{E}-07$ & $4.58 \mathrm{E}-08$ & & $1.57 \mathrm{E}-03$ & $7.80 \mathrm{E}-05$ & $4.40 \mathrm{E}-04$ \\
\hline 18 & $\mathrm{~m}$ & $1.17 \mathrm{E}-07$ & $9.67 \mathrm{E}-05$ & $2.02 \mathrm{E}-02$ & $2.49 \mathrm{E}-03$ & $1.86 \mathrm{E}-02$ & $3.01 \mathrm{E}-04$ & $3.24 \mathrm{E}-06$ & $2.83 \mathrm{E}-07$ & & $2.66 \mathrm{E}-03$ & $1.34 \mathrm{E}-04$ & $7.15 \mathrm{E}-04$ \\
\hline & $\mathbf{a}_{t}$ & $6.59 \mathrm{E}-01$ & $5.93 \mathrm{E}-01$ & $5.93 \mathrm{E}-01$ & $5.76 \mathrm{E}-01$ & $5.85 \mathrm{E}-01$ & $1.23 \mathrm{E}-01$ & $1.50 \mathrm{E}-01$ & $1.76 \mathrm{E}-01$ & & $3 \mathrm{E}-01$ & $5.93 \mathrm{E}-01$ & $5.93 \mathrm{E}-01$ \\
\hline & activity & $7.69 \mathrm{E}-08$ & $5.73 \mathrm{E}-05$ & $1.20 \mathrm{E}-02$ & $1.44 \mathrm{E}-03$ & $1.09 \mathrm{E}-02$ & $3.72 \mathrm{E}-05$ & $4.86 \mathrm{E}-07$ & $4.98 \mathrm{E}-08$ & & $8 E-03$ & $7.94 \mathrm{E}-05$ & $4.24 \mathrm{E}-04$ \\
\hline 19 & -1 & $1.20 \mathrm{E}-07$ & $9.41 \mathrm{E}-05$ & $2.04 \mathrm{E}-02$ & $2.43 \mathrm{E}-03$ & $1.88 \mathrm{E}-02$ & $2.95 \mathrm{E}-04$ & $3.21 \mathrm{E}-06$ & $4.97 \mathrm{E}-07$ & & $2.62 \mathrm{E}-03$ & $1.35 \mathrm{E}-04$ & $6.81 \mathrm{E}-04$ \\
\hline & & & $5.92 \mathrm{E}-01$ & $5.92 \mathrm{E}-01$ & $5.76 \mathrm{E}-01$ & $5.84 \mathrm{E}-01$ & $1.23 \mathrm{E}-0$ & $1.50 \mathrm{E}-01$ & $1.76 \mathrm{E}-01$ & & $5.92 \mathrm{E}-01$ & $5.92 \mathrm{E}-01$ & $5.92 \mathrm{E}-01$ \\
\hline & ty & $7.90 \mathrm{E}-08$ & $5.58 \mathrm{E}-05$ & 1E-02 & 40E-03 & & $3.63 \mathrm{E}-05$ & $4.80 \mathrm{E}-07$ & $8.73 \mathrm{E}-08$ & & $1.55 \mathrm{E}-03$ & $7.98 \mathrm{E}-05$ & $4.03 \mathrm{E}-04$ \\
\hline 20 & $\mathbf{m}$ & $1.23 \mathrm{E}-07$ & $9.15 \mathrm{E}-05$ & $2.04 \mathrm{E}-02$ & $2.27 \mathrm{E}-03$ & $1.88 \mathrm{E}-02$ & $2.86 \mathrm{E}-04$ & $3.76 \mathrm{E}-06$ & $5.34 \mathrm{E}-07$ & & $2.56 \mathrm{E}-03$ & $1.35 \mathrm{E}-04$ & $6.20 \mathrm{E}-04$ \\
\hline & $a_{t}$ & $6.60 \mathrm{E}-01$ & $5.93 \mathrm{E}-01$ & $5.93 \mathrm{E}-01$ & $5.77 \mathrm{E}-01$ & $5.85 \mathrm{E}-01$ & $1.24 \mathrm{E}-01$ & $1.50 \mathrm{E}-01$ & $1.76 \mathrm{E}-01$ & & $5.93 \mathrm{E}-01$ & $5.93 \mathrm{E}-01$ & $5.93 \mathrm{E}-01$ \\
\hline & activity & $8.12 \mathrm{E}-08$ & $\begin{array}{r}5.42 \mathrm{E}-05 \\
\end{array}$ & $1.21 \mathrm{E}-02$ & $1.31 \mathrm{E}-03$ & $1.10 \mathrm{E}-02$ & $3.54 \mathrm{E}-05$ & $5.65 \mathrm{E}-07$ & $9.41 \mathrm{E}-08$ & & $1.52 \mathrm{E}-03$ & $8.00 \mathrm{E}-05$ & $3.67 \mathrm{E}-04$ \\
\hline 21 & m & $1.26 \mathrm{E}-07$ & $8.99 \mathrm{E}-05$ & $2.08 \mathrm{E}-02$ & $2.14 \mathrm{E}-03$ & $1.93 \mathrm{E}-02$ & $2.76 \mathrm{E}-04$ & $3.50 \mathrm{E}-06$ & $5.57 \mathrm{E}-07$ & $1.92 \mathrm{E}-07$ & $2.49 \mathrm{E}-03$ & $1.31 \mathrm{E}-04$ & $5.55 \mathrm{E}-04$ \\
\hline & & $6.58 \mathrm{E}-01$ & $5.91 \mathrm{E}-01$ & $5.91 \mathrm{E}-01$ & $5.75 \mathrm{E}-01$ & $5.83 \mathrm{E}-01$ & $1.22 \mathrm{E}-01$ & $1.49 \mathrm{E}-01$ & $1.75 \mathrm{E}-01$ & & $5.91 \mathrm{E}-01$ & $5.91 \mathrm{E}-01$ & $5.91 \mathrm{E}-01$ \\
\hline & & 3.28E- 08 & $5.32 \mathrm{E}-05$ & $1.23 \mathrm{E}-02$ & $1.23 \mathrm{E}-03$ & .12E-02 & $3.37 \mathrm{E}-05$ & $5.21 \mathrm{E}-07$ & $9.74 \mathrm{E}-08$ & $2.85 \mathrm{E}-08$ & $1.47 \mathrm{E}-03$ & $7.76 \mathrm{E}-05$ & $3.28 \mathrm{E}-04$ \\
\hline 22 & m & $1.20 \mathrm{E}-07$ & $9.36 \mathrm{E}-05$ & $2.07 \mathrm{E}-02$ & $1.95 \mathrm{E}-03$ & $1.86 \mathrm{E}-02$ & $3.00 \mathrm{E}-04$ & $3.64 \mathrm{E}-06$ & $5.75 \mathrm{E}-07$ & & $2.72 \mathrm{E}-03$ & $1.38 \mathrm{E}-04$ & $5.58 \mathrm{E}-04$ \\
\hline & & & $5.93 \mathrm{E}-01$ & 5 & $5.77 \mathrm{E}-01$ & $5.85 \mathrm{E}-01$ & E-01 & $1.50 \mathrm{E}-01$ & $1.76 \mathrm{E}-01$ & & 1 & $5.93 \mathrm{E}-01$ & $5.93 \mathrm{E}-01$ \\
\hline & & $7.93 \mathrm{E}-08$ & 5E-05 & $1.23 \mathrm{E}-02$ & $1.12 \mathrm{E}-03$ & $1.09 \mathrm{E}-02$ & $\mathrm{E}-\mathrm{C}_{0}$ & 47E-07 & $1.01 \mathrm{E}-07$ & & $1.61 \mathrm{E}-03$ & $8.19 \mathrm{E}-05$ & $.31 \mathrm{E}-04$ \\
\hline 23 & $\mathrm{~m}$ & $1.21 \mathrm{E}-07$ & $9.29 \mathrm{E}-05$ & 2.09E-02 & $1.89 \mathrm{E}-03$ & $1.87 \mathrm{E}-02$ & $3.06 \mathrm{E}-04$ & $4.16 \mathrm{E}-06$ & $6.65 \mathrm{E}-07$ & $2.55 \mathrm{E}-07$ & $2.78 \mathrm{E}-03$ & 1.42E-04 & $5.48 \mathrm{E}-04$ \\
\hline & $\mathbf{a}_{\gamma}$ & 6.59 & $5.92 \mathrm{E}-01$ & $5.92 \mathrm{E}-01$ & $5.76 \mathrm{E}-01$ & $5.84 \mathrm{E}-01$ & $1.23 \mathrm{E}-01$ & $1.50 \mathrm{E}-01$ & $1.76 \mathrm{E}-01$ & & $5.92 \mathrm{E}-01$ & $5.92 \mathrm{E}-01$ & $5.92 \mathrm{E}-01$ \\
\hline & activity & $8.01 \mathrm{E}-08$ & $5.50 \mathrm{E}-05$ & $1.24 \mathrm{E}-02$ & $1.09 \mathrm{E}-03$ & $1.09 \mathrm{E}-02$ & $3.77 \mathrm{E}-05$ & $6.22 \mathrm{E}-07$ & $1.17 \mathrm{E}-07$ & $3.81 \mathrm{E}-08$ & $1.65 \mathrm{E}-03$ & $8.39 \mathrm{E}-05$ & $3.25 \mathrm{E}-04$ \\
\hline 24 & $\mathrm{~m}$ & $1.20 \mathrm{E}-07$ & $9.40 \mathrm{E}-05$ & 2.09E-02 & $1.85 \mathrm{E}-03$ & $1.88 \mathrm{E}-02$ & $2.95 \mathrm{E}-04$ & $3.39 \mathrm{E}-06$ & $4.76 \mathrm{E}-07$ & & $2.69 \mathrm{E}-03$ & $1.35 \mathrm{E}-04$ & $5.17 \mathrm{E}-04$ \\
\hline & & & $5.92 \mathrm{E}-01$ & $5.92 \mathrm{E}-01$ & $5.76 \mathrm{E}-01$ & $5.84 \mathrm{E}-01$ & $1.23 \mathrm{E}-01$ & $1.50 \mathrm{E}-01$ & $1.76 \mathrm{E}-01$ & & & $5.92 \mathrm{E}-01$ & $5.92 \mathrm{E}-01$ \\
\hline & & $7.91 \mathrm{E}-08$ & $5.57 \mathrm{E}-05$ & $1.24 \mathrm{E}-02$ & $1.06 \mathrm{E}-03$ & $1.10 \mathrm{E}-02$ & $3.63 \mathrm{E}-05$ & $5.06 \mathrm{E}-07$ & $8.36 \mathrm{E}-08$ & & 1.5 & $7.99 \mathrm{E}-05$ & $3.06 \mathrm{E}-04$ \\
\hline 25 & $\mathrm{~m}$ & $1.25 \mathrm{E}-07$ & $9.01 \mathrm{E}-05$ & $2.06 \mathrm{E}-02$ & $1.83 \mathrm{E}-03$ & $1.87 \mathrm{E}-02$ & $2.82 \mathrm{E}-04$ & $3.70 \mathrm{E}-06$ & 6.72 & & & $1.35 \mathrm{E}-04$ & $4.96 \mathrm{E}-04$ \\
\hline & $\mathbf{a}_{\gamma}$ & & $5.94 \mathrm{E}-01$ & $5.94 \mathrm{E}-01$ & $5.78 \mathrm{E}-01$ & $5.86 \mathrm{E}-01$ & $1.25 \mathrm{E}-01$ & $1.51 \mathrm{E}-01$ & 1.77 & & & 5.94E- 01 & $5.94 \mathrm{E}-01$ \\
\hline & activity & 8.2 & $5.35 \mathrm{E}-05$ & $1.22 \mathrm{E}-02$ & $1.06 \mathrm{E}-03$ & 1.10 & $3.51 \mathrm{E}$ & $5.59 \mathrm{E}-07$ & $1.19 \mathrm{E}-07$ & & 1.5 & $8.04 \mathrm{E}-05$ & $2.95 \mathrm{E}-04$ \\
\hline 26 & & $1.19 \mathrm{E}-07$ & $9.45 \mathrm{E}-05$ & $2.05 \mathrm{E}-02$ & $1.78 \mathrm{E}-03$ & $1.85 \mathrm{E}-02$ & $2.84 \mathrm{E}-04$ & $2.84 \mathrm{E}-06$ & $3.73 \mathrm{E}-07$ & & $2.59 \mathrm{E}-03$ & $1.30 \mathrm{E}-04$ & $4.88 \mathrm{E}-04$ \\
\hline & & $6.61 \mathrm{Y}$ & $5.95 \mathrm{E}-01$ & $5.95 \mathrm{E}-01$ & $5.79 \mathrm{E}-01$ & $5.87 \mathrm{E}-01$ & $1.25 \mathrm{E}-01$ & $1.52 \mathrm{E}-01$ & $1.78 \mathrm{E}-01$ & & $5.95 \mathrm{E}-01$ & $5.95 \mathrm{E}-01$ & $5.95 \mathrm{E}-01$ \\
\hline & & $7.84 \mathrm{E}-08$ & $5.62 \mathrm{E}-05$ & $1.22 \mathrm{E}-02$ & $1.03 \mathrm{E}$ & 02 & 05 & 7 & $6.64 \mathrm{E}-08$ & & 1.5 & $7.76 \mathrm{E}-05$ & $2.90 \mathrm{E}-04$ \\
\hline 27 & $\mathbf{m}$ & 1.18 & $9.47 \mathrm{E}-05$ & $2.04 \mathrm{E}-02$ & $1.74 \mathrm{E}-03$ & 1.8 & 2. & $3.27 \mathrm{E}-06$ & 5.40 & & 3 & $1.37 \mathrm{E}-04$ & $5.05 \mathrm{E}-04$ \\
\hline & & & $5.96 \mathrm{E}-01$ & 01 & 5.80 & $5.88 \mathrm{E}-01$ & $126 \mathrm{E}$ & .01 & 1.79 & & & $66 \mathrm{E}-01$ & \\
\hline & activity & 7.8 & $5.65 \mathrm{E}-05$ & $1.22 \mathrm{E}-02$ & $1.01 \mathrm{E}-03$ & 2 & 3 & .07 & $9.65 \mathrm{E}-08$ & & 1.6 & $8.17 \mathrm{E}-05$ & $3.01 \mathrm{E}-04$ \\
\hline 28 & & 1.23 & & $2.13 \mathrm{E}-02$ & $1.76 \mathrm{E}-03$ & 1.91 & & $3.79 \mathrm{E}-06$ & $6.32 \mathrm{E}-07$ & & & & \\
\hline & & & & 5.91 & & & & 1.49 & 1.75 & & & $5.91 \mathrm{E}-01$ & $5.91 \mathrm{E}-01$ \\
\hline & & & $5.43 \mathrm{E}-05$ & $1.26 \mathrm{E}-02$ & $1.01 \mathrm{E}-03$ & & & & & & & & 2.88 \\
\hline 29 & $\mathbf{m}$ & $1.34 \mathrm{E}-07$ & $8.44 \mathrm{E}-05$ & $2.11 \mathrm{E}-02$ & $1.80 \mathrm{E}-03$ & $1.95 \mathrm{E}-02$ & $2.53 \mathrm{E}-04$ & $4.01 \mathrm{E}-06$ & $7.05 \mathrm{E}-07$ & & $2.32 \mathrm{E}-03$ & $1.28 \mathrm{E}-04$ & $4.31 \mathrm{E}-04$ \\
\hline & & $6.5 \mathrm{E}-01$ & $5.92 \mathrm{E}-01$ & 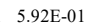 & $5.75 \mathrm{E}-01$ & $84 \mathrm{E}-01$ & $1.23 \mathrm{E}-01$ & 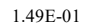 & 1.751 & & $5.92 \mathrm{E}-01$ & 5.92E-01 & $22 \mathrm{E}-01$ \\
\hline & ty & 8.82E-08 & $1.99 \mathrm{E}-05$ & $5 \mathrm{E}-02$ & $1.04 \mathrm{E}-03$ & & & & $24 \mathrm{E}-07$ & & $1.37 \mathrm{E}-03$ & $7.60 \mathrm{E}-05$ & 55E-04 \\
\hline 30 & & 1.2 & $\mathrm{E}-05$ & -02 & 1.7 & & 2. & 6 & 4 & & & 1 & 4 \\
\hline & & & & & & & & & & & & & \\
\hline & & & & & 1.011 & & & & & & & & \\
\hline 31 & & $1.25 \mathrm{E}-07$ & $9.04 \mathrm{E}-05$ & $2.12 \mathrm{E}-02$ & $1.76 \mathrm{E}-03$ & $1.92 \mathrm{E}-02$ & $2.78 \mathrm{E}-04$ & $3.51 \mathrm{E}-06$ & $5.59 \mathrm{E}-07$ & & $2.56 \mathrm{E}-03$ & $1.32 \mathrm{E}-04$ & $4.63 \mathrm{E}-04$ \\
\hline & & & & & (1) & & & 1.49E-01 & $1.75 \mathrm{E}-01$ & & & $5.92 \mathrm{E}-01$ & $5.92 \mathrm{E}-01$ \\
\hline & ity & $.08 \quad$ & E-05 & SE-02 & $1 \mathrm{E}-03$ & $\mathrm{E}-02$ & 1E- -05 & $\mathrm{E}-07$ & .08 & & 03 & $\mathrm{E}-0$ & 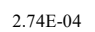 \\
\hline 32 & & $1.27 \mathrm{E}-07$ & $8.84 \mathrm{E}-05$ & $2.10 \mathrm{E}-02$ & $1.74 \mathrm{E}-03$ & 02 & 2 & $3.56 \mathrm{E}-06$ & $3.99 \mathrm{E}-07$ & & -03 & $1.26 \mathrm{E}-04$ & 4.29 \\
\hline & & & & & & & & & & & & & \\
\hline & activ & & & & & & & & & & & & \\
\hline 33 & $\mathbf{m}$ & 1.35 & $8.46 \mathrm{E}-05$ & $2.17 \mathrm{E}-02$ & $1.75 \mathrm{E}-03$ & 1.98 & 2.75 & $5.09 \mathrm{E}-06$ & 9.32 & & 2. & $1.38 \mathrm{E}-04$ & 4.44 \\
\hline & & & 5.89 & $5.89 \mathrm{I}$ & 5.72 & 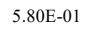 & 12 & 1.4 & 1.7 & & $5.89 \mathrm{E}-01$ & $5.89 \mathrm{E}-01$ & 5.89 \\
\hline & activity & 85E-08 & $8 \mathrm{E}-05$ & $88 \mathrm{E}-02$ & $99 \mathrm{e}-04$ & & E- 05 & 46E-07 & .61E-07 & & 1.50E-03 & 13E-05 & $62 \mathrm{E}-04$ \\
\hline 34 & & & & & & & & & & & & & \\
\hline & & & & & & & & & & & & & \\
\hline & & .17E- 08 & 39E-05 & 2 27E-02 & $.85 \mathrm{E}-04$ & $-02 \quad$ & $8-05$ & 04E-07 & $.95 \mathrm{E}-08$ & & $1.22 \mathrm{E}-03$ & $10 \mathrm{E}-05$ & $64 \mathrm{E}-04$ \\
\hline
\end{tabular}


Table C.4.23. Ions activity and logarithm of activity calculate by the R package (linked to EqSolvR by Mroczek S. and Mroczek E., 2017) for the BGB2 experiment (350 $\mathrm{C} / 486$ bar). Table also reports values of quench pH, in situ pH, experimental time, flow-rate, $\mathrm{T}$ and $\mathrm{P}$. LOD: limit of detection

\begin{tabular}{|c|c|c|c|c|c|c|c|c|c|c|c|c|c|c|c|c|c|c|c|c|c|c|c|c|c|c|c|c|c|c|c|c|}
\hline sanples & $\begin{array}{l}\text { bank } \\
\text { ermal br }\end{array}$ & 8 & 9 & 10 & 11 & 12 & 13 & 14 & 15 & 16 & 17 & 18 & 19 & 20 & 21 & 22 & 23 & 24 & 25 & 26 & 27 & 28 & 29 & 30 & 31 & 32 & 33 & 34 & 35 & 36 & 37 & 38 \\
\hline 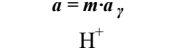 & 1.79E-07 & $2.19 \mathrm{E}-07$ & $\mathrm{EE}-07$ & $1.74-07$ & $1.53 \mathrm{E}=07$ & $\mathrm{BE}-07$ & $1.57-077$ & $1.59 E-07$ & $1.51 \mathrm{E}=07 \mathrm{7}$ & $\mathrm{E}-07$ & 1.61E-07 & 4E-07 & IE-07 & $=07$ & 1.47E-07 & $1.53-07$ & $=07$ & & & $E_{-07}$ & & & & & & & & & & $1.5 \mathrm{E}-07$ & & \\
\hline ОH & $4.32 \mathrm{E}-05$ & 3.53E-05 & $3.698-05$ & 4.4AE-05 & $5.066-05$ & 4.855-05 & $\begin{array}{l}4.92 E-05 \\
\end{array}$ & 4.866-05 & OE-05 & SE-05 & 4.800-05 & BE-05 & 2E-05 & 9E-05 & SE-05 & $66-05$ & 7E-05 & SE-05 & E-05 & 76E-05 & $5.238-05$ & E-05 & 1.44-05 & $4.63 \mathrm{E}-05$ & $5.38 \mathrm{E}-05$ & $5.10 E-05$ & $\begin{array}{l}4.65 E-05 \\
\end{array}$ & 4.75E-05 & $5.21 \mathrm{E}-05$ & 4.944-05 & OEE-05 & $4.89 \mathrm{E}=0 \mathrm{03}$ \\
\hline $\mathrm{Na}^{+}$ & $1.92 \mathrm{E}-02$ & E.02 & E-02 & $\mathrm{E}-02$ & E-02 & E-02 & E-02 & E-02 & E-02 & $\mathrm{E}-02$ & $\mathrm{E} \cdot 02$ & E-02 & E-02 & E-02 & E-02 & E-02 & $\mathrm{E}-02$ & $\mathrm{E}-02$ & $\mathrm{E}-02$ & $1.72 \mathrm{E}-02$ & $=02$ & $=02$ & .02 & $=02$ & E-02 & EE-02 & $\mathrm{E}-02$ & EE-022 & $\mathrm{E}_{02}$ & 02 & 02 & $1.65 \mathrm{E}=02$ \\
\hline $\mathrm{K}^{+}$ & $1.82 \mathrm{E}-03$ & $3.15 \mathrm{EE}-03$ & $3.86 \mathrm{E}-03$ & $3.46 E-03$ & $2.34 \mathrm{E}-03$ & E-03 & E.03 & 2E-03 & E.03 & $1.61 \mathrm{E}-03$ & $1.67 \mathrm{E}-03$ & 0.03 & .03 & E-03 & E.03 & E.03 & 4E-03 & $1.72 \mathrm{E}-03$ & E-03 & $1.73 E-03$ & $1.70 \mathrm{E}-03$ & E.03 & $1.73 \mathrm{E}=03$ & $1.71 \mathrm{E}-03$ & $1.63 \mathrm{E}-03$ & $1.67 \mathrm{E}=03$ & $1.62 \mathrm{E}-03$ & $1.58 \mathrm{SE}-03$ & E-03 & $=03$ & EE-03 & $1.55 \mathrm{E}-03$ \\
\hline $\mathrm{Cr}^{-}$ & $1.79 \mathrm{E}-02$ & $1.61 \mathrm{E}-02$ & $1.59 \mathrm{E}-02$ & $1.600-02$ & $1.59 \mathrm{E}-02$ & $1.58 \mathrm{E}-02$ & $1.57 \mathrm{E}-02$ & $1.59 \mathrm{E}-02$ & $1.53 \mathrm{E}-02$ & $1.600-02$ & $1.600-02$ & 4E-02 & $1.57 \mathrm{E}-02$ & $1.63 \mathrm{E}-02$ & $1.54 \mathrm{E}-02$ & $1.58 \mathrm{E}-02$ & $1.55 \mathrm{E}-02$ & $1.57 \mathrm{E}-02$ & $1.63 \mathrm{E}-02$ & $1.62 \mathrm{E}-02$ & $1.51 \mathrm{E}-02$ & $1.53 \mathrm{E}-02$ & $1.59 \mathrm{E}-02$ & $1.62 \mathrm{E}-02$ & $1.49 \mathrm{E}-02$ & $1.57 \mathrm{E}-02$ & $1.63 \mathrm{E}-02$ & $1.60 \mathrm{E}-02$ & $1.48 \mathrm{E}-02$ & $1.61 \mathrm{E}-02$ & $0 \mathrm{E}-02$ & $1.544-02$ \\
\hline $\mathrm{SO}_{4}^{2^{2}}$ & $8.92 \mathrm{E}-05$ & $5.522-05$ & 5.060 .055 & $6.838=05$ & 8.46E-05 & 7.8.58-05 & $8.54=05$ & $8.11 \mathrm{E}=05$ & 9.098-05 & 7.700-05 & 8.18E-05 & 9.066-05 & 9,200E-05 & $8.14 \mathrm{E}-05$ & $9,34 \mathrm{E}-05$ & $9.18 E-05$ & $9.67 \mathrm{E}-05$ & 9.57E-05 & $7.95 \mathrm{E}-05$ & $8.28 \mathrm{E}-05$ & $9.74 \mathrm{E}-05$ & $8.88 \mathrm{E}-05$ & $7.522-05$ & $8.03 \mathrm{E}-05$ & $1.01 \mathrm{E}-04$ & $9.58 \mathrm{E}-05$ & $7.98 \mathrm{E}-05$ & $8.41 \mathrm{E}=05$ & $\begin{array}{l}1.00 E-04 \\
\end{array}$ & $8.50 \mathrm{E}-05$ & $7.52 \mathrm{E}-05$ & $8.47 \mathrm{E}-05$ \\
\hline $\mathrm{Ca}^{2+}$ & $2.63 \mathrm{E}-06$ & $\mathrm{BE}-06$ & $1.07=-06$ & $7.100-07$ & $E_{0.07}$ & $4.788-07$ & $8.038-07$ & $6.500=077$ & $7.33 \mathrm{E}-07$ & 7.65E-07 & 7.74E-07 & $8.19 \mathrm{E}-07$ & $7.299-077$ & $8.05 E-07$ & $6.066-07$ & $7.91 \mathrm{E}-07$ & $8.86 \mathrm{E}-07$ & $8.43 E-07$ & $8.33 \mathrm{E}-07$ & $8.95 \mathrm{E}-07$ & $7.55 \mathrm{E}-07$ & $8.638-077$ & $8.91 \mathrm{E}-07$ & $1.06 \mathrm{E}-06$ & $6.525-077$ & $9.63 \mathrm{E}=07$ & $9.15 E-07$ & $9.88=07$ & $9.38 \mathrm{E}-07$ & $7.25 \mathrm{E}-07$ & $7.98 \mathrm{E}-07$ & $8.25 \mathrm{E}-07$ \\
\hline $\mathrm{Mg}^{2}$ & & E-07 & $1.49 E-07$ & $3.795-08$ & $3.82 E-09$ & $2.47 \mathrm{E}=08$ & $8.122 \mathrm{E}-08$ & 4.21E-08 & 7.35E E.08 & $\begin{array}{l}1.238-07 \\
-26-0\end{array}$ & 1.1.6E:-07 & $1.211 E-07$ & $8.51 E-08$ & 9.138-08 & $2.36 \mathrm{E}-0.08$ & $1.37 E-07$ & $1.34 \mathrm{E}-07$ & $1.37 E-07$ & 1.12E-07 & $1.51 E-07$ & $1.22 E-07$ & 67E-07 & $1.66 \mathrm{E}-07$ & $1.83 E-07$ & $9.688 \mathrm{E}-08$ & $1.60 \mathrm{E}-07$ & $181 E-07$ & $1.95 E-07$ & $1.78 \mathrm{E}-07$ & $6.92 \mathrm{E}-08$ & SE-07 & 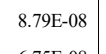 \\
\hline & & E-07 & $0.1 .15-07$ & & 15-08 & E-08 & E-07 & 6E-08 & 6.79E-08 & $7.85 \mathrm{E}-08$ & 0E-08 & $6.68 \mathrm{E}-08$ & $5.68 \mathrm{E}-08$ & $1.05 \mathrm{E}-07$ & $<$ LOD & $<$ LOD & $<$ LOD & $<$ LOD & $<$ LOD & $<$ <OD & $1.500-07$ & 41E-08 & $<$ LOD & .80E-08 & 14E-08 & <LOD & $17 E_{-07}$ & $\mathrm{E}-07$ & $\mathrm{EE}-08$ & & Fon & \\
\hline$a^{2} H$ & 3.20E-14 & $.80 E-14$ & $4.33 E-14$ & $3.03 \mathrm{E}-14$ & .33E-14 & $2.54 \mathrm{E}-14$ & $47 \mathrm{E}-14$ & $2.52 \mathrm{E}-14$ & $2.29 \mathrm{E}-14$ & $2.76 \mathrm{E}-14$ & $2.60 \mathrm{E}-14$ & $2.36 \mathrm{E}-14$ & $2.288-14$ & $2.60 \mathrm{E}-14$ & $2.17 E-14$ & $2.34 \mathrm{E}-14$ & $2.248-14$ & $2.25 \mathrm{E}-14$ & $2.70 \mathrm{E}-14$ & $2.63 \mathrm{E}-1$ & $2.18 E-14$ & 2.45E-14 & $2.90 E_{-14}$ & 2.78E-14 & $2.066-14$ & $2.29 E_{-14}$ & $2.76 E-14$ & $2.64 E-14$ & $2.20 \mathrm{E}-14$ & $2.45 \mathrm{E}-1$ & $2.82 \mathrm{E}-1$ & $2.50 \mathrm{E}-$ \\
\hline$(a \mathrm{SiC}$ & -1.83 & -1.63 & -1.51 & -1.55 & -1.60 & -1.61 & -1.59 & -1.61 & -1.62 & -1.66 & -1.64 & -1.66 & -1.68 & -1.70 & -1.70 & -1.73 & -1.71 & -1.72 & -1.73 & -1.72 & $\begin{array}{l}-1.75 \\
\end{array}$ & -1.77 & -1.77 & -1.77 & -1.82 & -1.83 & -1.85 & -1.85 & 1.88 & -1.86 & 1.8 & -1.86 \\
\hline & & & & & & & & & & & & & & & & & & & & & & & & & & & & & & & & \\
\hline & & & & & & & & & & & & & & & & & & & & & & & & & & & & & & & & \\
\hline & & & & & & & & & & & & & & & & & & & & & & & & & & & & & & & & \\
\hline & $<\mathrm{LS}$ & & & & & & & & & & & & & & $<\mathrm{LO}$ & $<\mathrm{LC}$ & $<\mathrm{LC}$ & $<\mathrm{LC}$ & $<\mathrm{LC}$ & & & & & & & & & & & & & \\
\hline $\log$ & 7.25 & 7.02 & 6.53 & 6.10 & 5.2 & 5.99 & 0.32 & 0.2 & 0.31 & 6.6 & 0.0 & 0. & 6.57 & 6.55 & 6.04 & 6.77 & 6.78 & 6.78 & 6.62 & 6.7 & 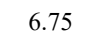 & 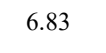 & 6.76 & 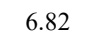 & 0.07 & 0.07 & 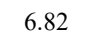 & (. & .911 & 6.45 & ol & 6.55 \\
\hline & & & & & & -1 & -1.77 & & & & & & -1.77 & -1.77 & -1.78 & -177 & 177 & 1 & -17 & 1. & & 170 & -1.78 & -1.77 & -1.79 & -1.77 & -1.76 & -1.76 & .79 & .76 & 77 & \\
\hline & & & & & & & & & & & & & & & & & & & & & & & & & & & & & & & & \\
\hline & & & & & & & & & & & & & & & & & & & & & & & & & & & & & & 79 & 80 & \\
\hline & & & & & & & & & & & & & & & & & & & & & & & & & & & & & & 07 & 12 & 07 \\
\hline & & & & & & & & & & & & & & & & & & & & & & & & & & & & & & 14 & 10 & 00 \\
\hline & -6. & & & & & & & & & & & & & & & & & & & & & & & & & & & & & & 98 & \\
\hline $\log a \mathrm{Fe}^{2}$ & $<10 D$ & -0.09 & -6.94 & -6.87 & -7.15 & -7.26 & -6.99 & -7.16 & -7.17 & -7.11 & -7.10 & -7.18 & -7.2 & -6.98 & $<$ LOD & $<$ LOD & $<$ LOD & $<1$ & $<$ LOD & $<$ LOD & -6.82 & & & & -7.1 & < LOD & -6.93 & 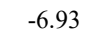 & 10 & -6.93 & -7.11 & 17 \\
\hline $\mathrm{T}(\mathrm{C})$ & 350 & 352.3 & 350.4 & 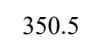 & 350.7 & 350.6 & 350.8 & 07 & 350.4 & & & 350.6 & 350.7 & 350.8 & 350.3 & 350.5 & 350.5 & 350.4 & 3506 & 350 & 350. & 350.7 & 350.4 & 350.6 & 350.6 & 350.5 & 350.7 & 350.8 & 0.5 & 0.3 & 0.6 & 350.4 \\
\hline 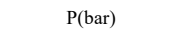 & 54 & & & 48 & 48 & 48 & 70 & & & & & & & & & & 48 & & & & & 700 & tis & 486.3 & 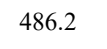 & 0.2 & 0.2 & . & 6.2 & 6.3 & 6.2 & 6.3 \\
\hline in situp $\mathrm{H}_{(35}$ & 6.75 & 6.66 & 6.68 & 6.76 & 6.82 & 6.80 & 6.80 & 6.80 & 6.82 & 6.78 & 6.79 & 6.81 & 6.82 & 6.79 & 6.83 & 6.82 & 6.83 & 6.82 & 6.78 & 6.79 & 6.83 & 6.81 & 6.77 & 6.78 & 6.84 & 6.82 & 6.78 & 6.79 & 6.83 & 5.81 & 5.77 & 6.80 \\
\hline $\operatorname{room} \mathrm{T}$ & 4.28 & & & & & & & & & & & & & & 7 & . & t. & 1.00 & . & 1.4 & & $\ldots$ & 1.05 & 1.10 & or & $7.0 r$ & 1 & 1.00 & 1.85 & 7.85 & 7.91 & 7.84 \\
\hline flow rate $\mathrm{n}$ & & 1 & 1 & 1 & 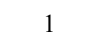 & 1 & 1 & 1 & 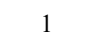 & 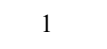 & & & 1 & & 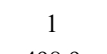 & 1 & & & & & & & & & & 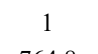 & & 1 & & 1 & 1 & 1 \\
\hline time (hrs & 0.0 & 187.8 & 211.4 & 236.2 & 260.3 & 86.3 & 10.3 & 334.0 & 55.5 & 81.8 & 403.3 & 28.1 & 51.8 & 5.8 & 98.9 & 23.6 & 47.8 & 1.4 & 595.7 & 19.5 & 45.3 & 8.7 & 692.9 & 5.6 & 9.8 & 54.8 & 8.5 & 4.5 & 837.58 & 360.1 & 83. & \\
\hline & & & & & & & & & & & & & & & & & & & & & & & & & & & & & & & & \\
\hline & & & & & & & & & & & & & & & & & & & & & & & & & & & & & & & 80 & 3.86 \\
\hline $\log Q$ & & 3. & 3.6 & 3. & 3. & 3. & 3. & I & 3. & & & & . & 3. & 3.6 & 3. & 3. & 3. & 3.5 & 3. & & 3. & 3. & 3. & & & & 3.43 & 80 & 55 & .57 & 3.51 \\
\hline Log SI & & -0.55 & -0.25 & -0.20 & -0.03 & -0.09 & -0.34 & -0.23 & -0.34 & -0.28 & -0.31 & -0.38 & -0.34 & -0.33 & -0.26 & -0.38 & -0.45 & -0.42 & -0.34 & -0.38 & -0.38 & -0.40 & -0.34 & -0.44 & -0.33 & -0.48 & -0.38 & -0.43 & -0.48 & -0.31 & -0.29 & -0.3 \\
\hline
\end{tabular}


Table C.4.24. Values of the activity coefficients $\left(a_{y}\right)$ calculate by the R package for the BGB2

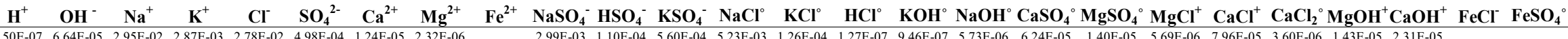

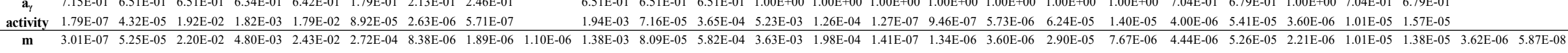

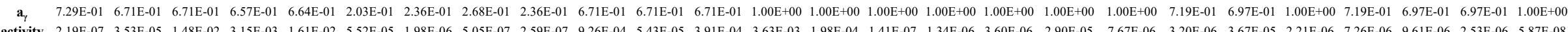

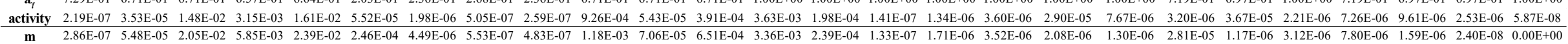

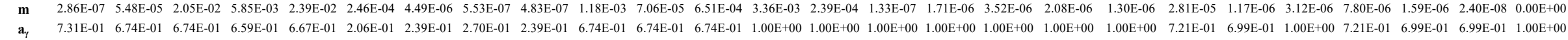

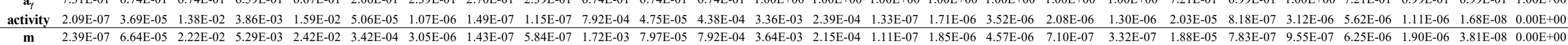

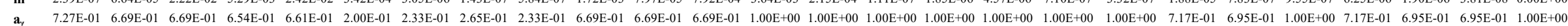

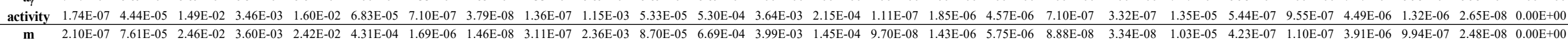

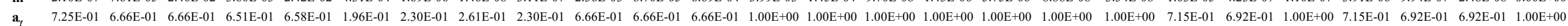

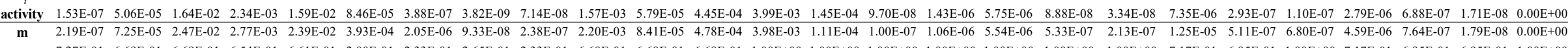

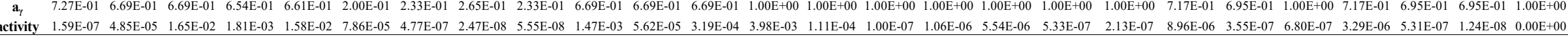

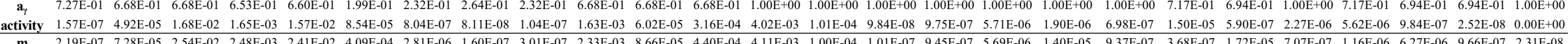

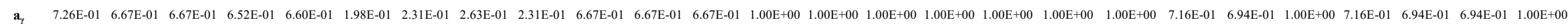

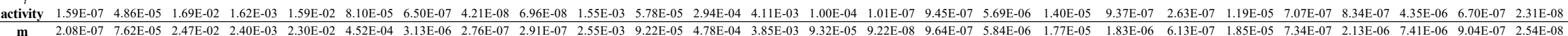

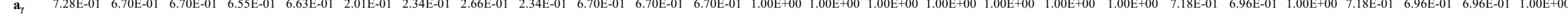

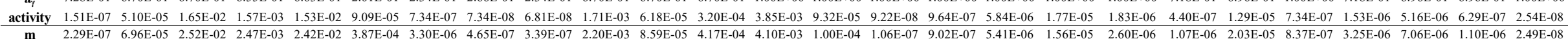

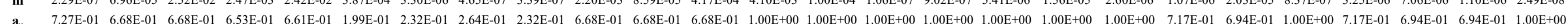

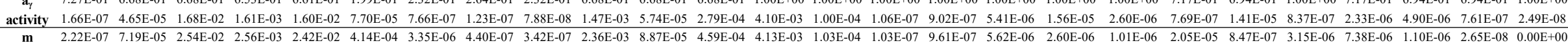

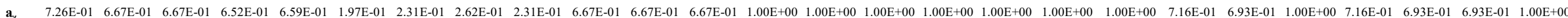

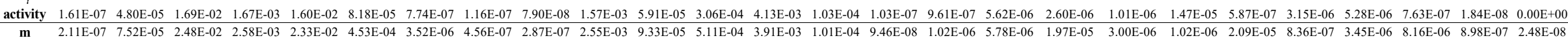

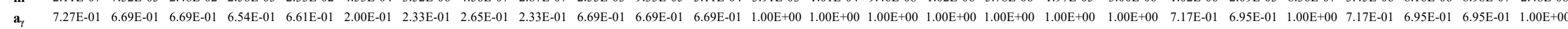

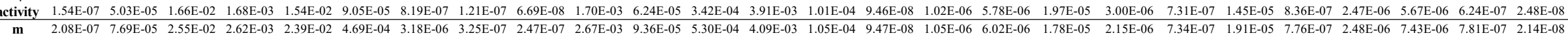

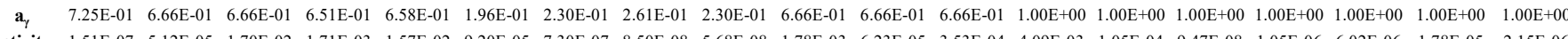

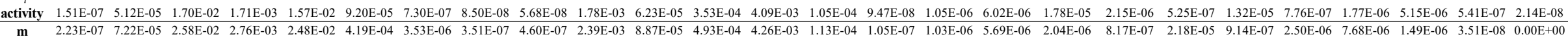

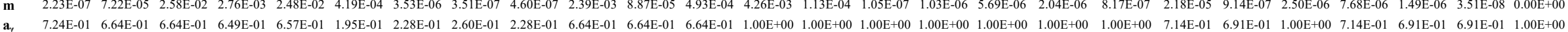

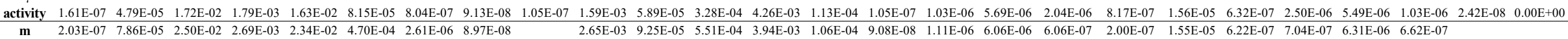

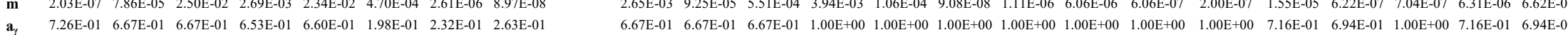

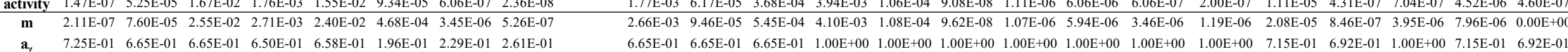

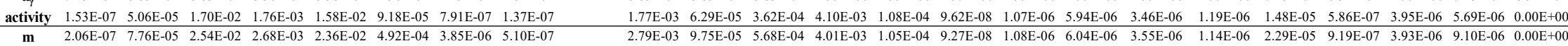

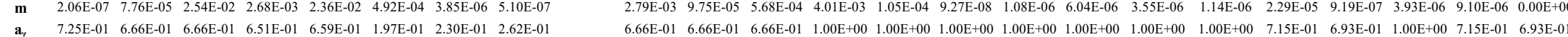

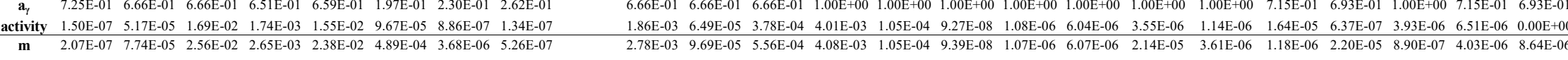

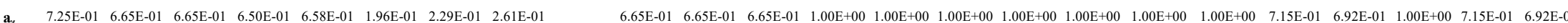

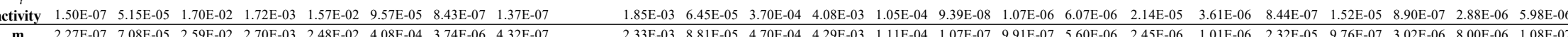

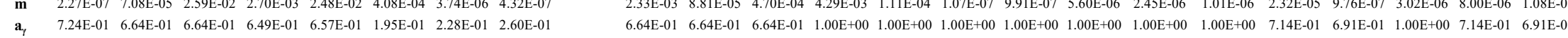

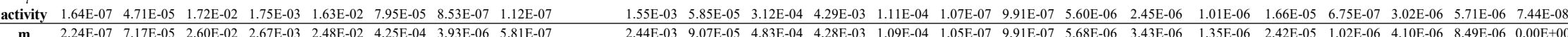

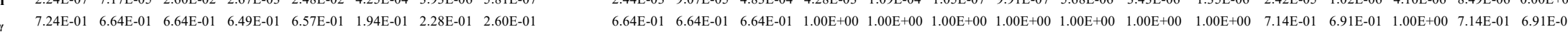

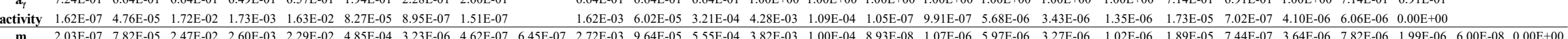

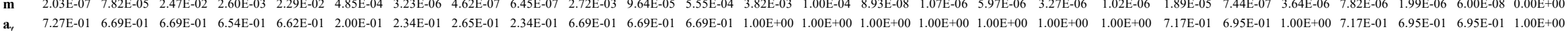

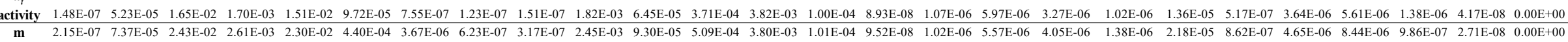

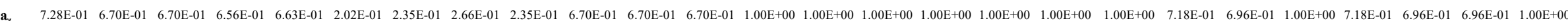

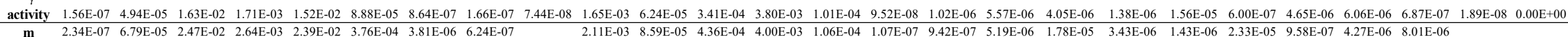

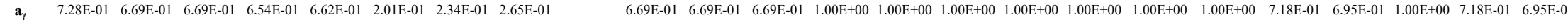

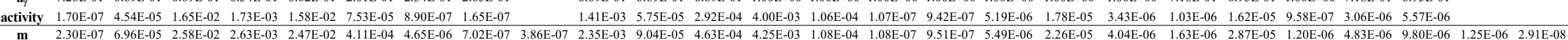

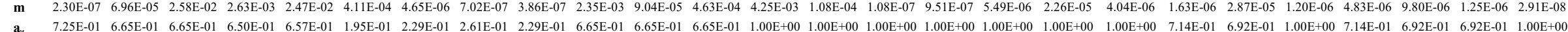

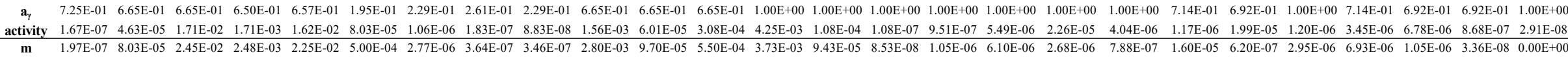

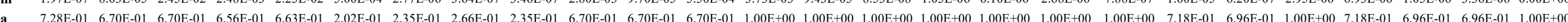

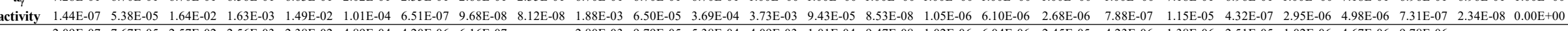

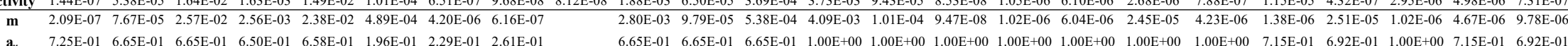

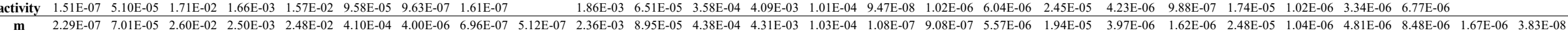

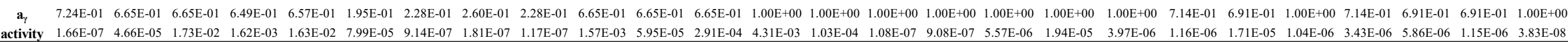
$\begin{array}{lllllllllllllllll} & & \end{array}$

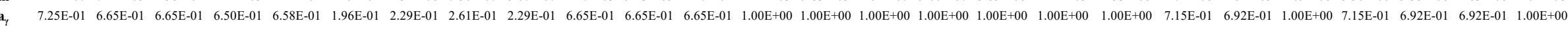

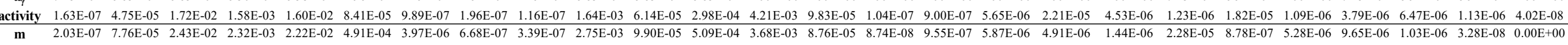

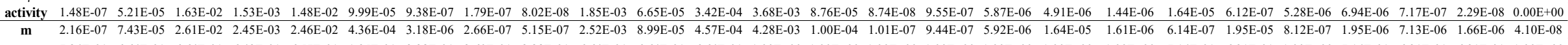

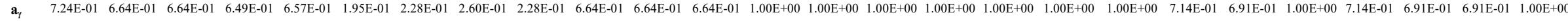

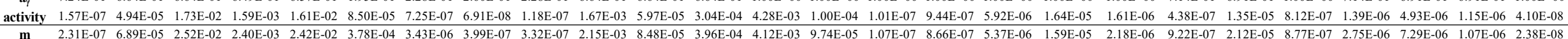

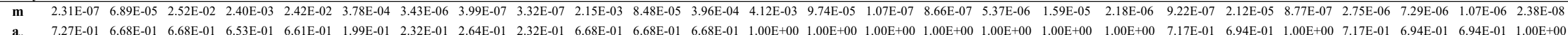

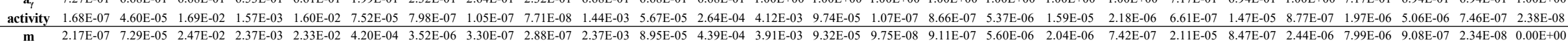

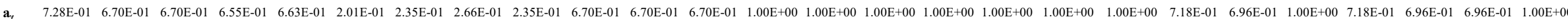

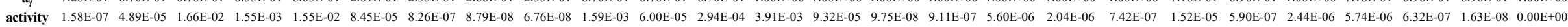




\section{Activity-activity diagrams}

Figure C.4.22. Activity diagrams for the $\mathrm{BGB} 1$ showing mineral stability fields in the $\mathrm{CaO}-\mathrm{MgO}-\mathrm{Al}_{2} \mathrm{O}_{3}-\mathrm{H}_{2} \mathrm{O}$. Diagrams were constructed on the base of two different silica averages, during and after glass dissolution. Black and red crosses show position of effluent samples collected at 1.0 and $0.5 \mathrm{ml} \mathrm{hr}^{-1}$ flow rate, respectively. Yellow circles show position of the unreacted fluid (water) at $400^{\circ} \mathrm{C} / 483 \mathrm{bar}$

\section{BGB1}

$400 \mathrm{C} / 483 \mathrm{bar}$

average $\log a_{\mathrm{SiO}}=\mathbf{- 1 . 5 2}$

(during basalt glass dissolution)
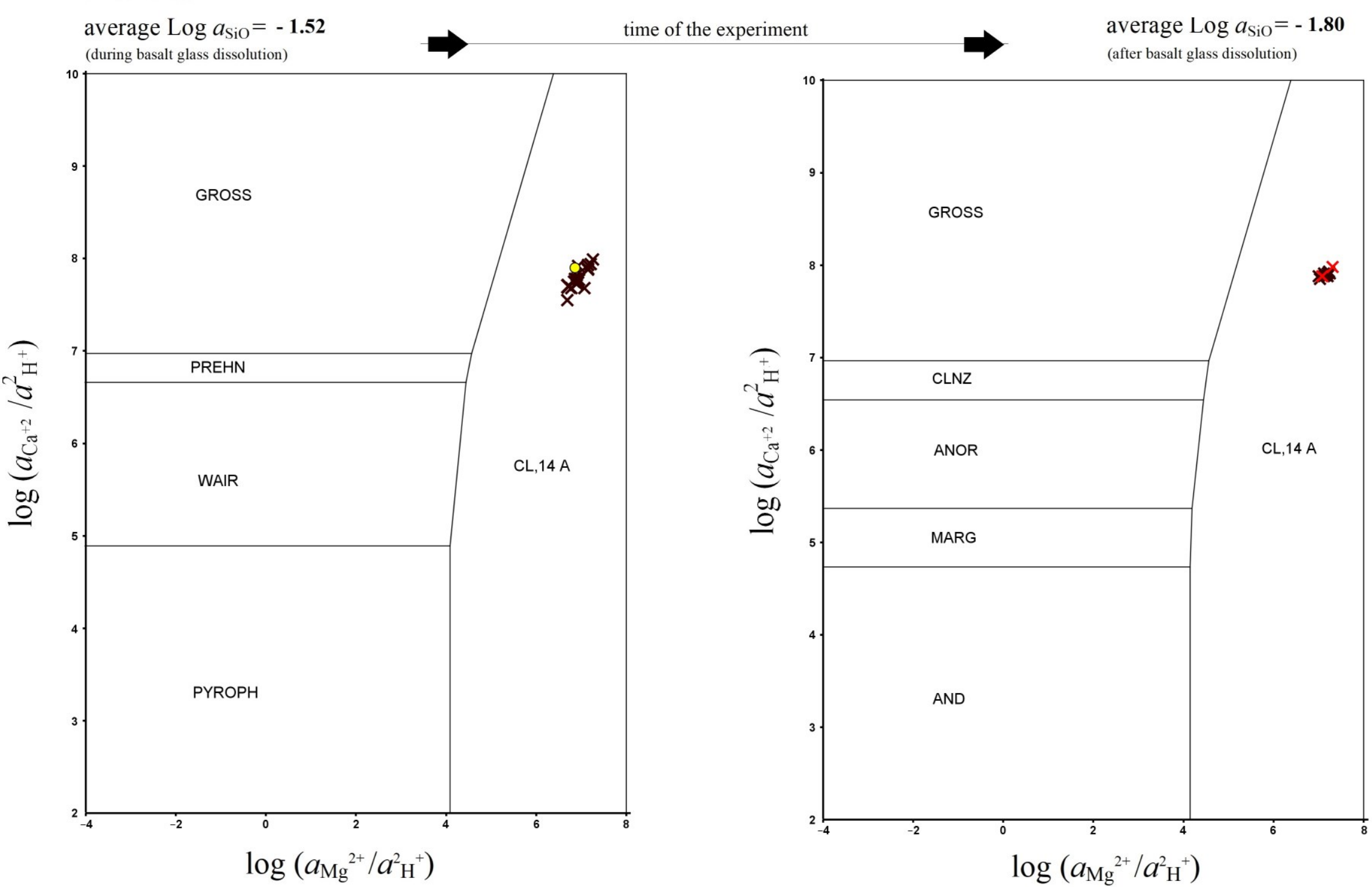

Figure C.4.23. Activity diagrams for the $\mathrm{BGB} 1$ showing mineral stability fields in the $\mathrm{CaO}-\mathrm{MgO}-\mathrm{Al}_{2} \mathrm{O}_{3}-\mathrm{H}_{2} \mathrm{O}$. Diagrams were constructed on the base of two different silica averages, during and after glass dissolution. Black and red crosses show position of effluent samples collected at 1.0 . Yellow circles show position of the unreacted fluid (water) at $350^{\circ} \mathrm{C} / 500 \mathrm{bar}$

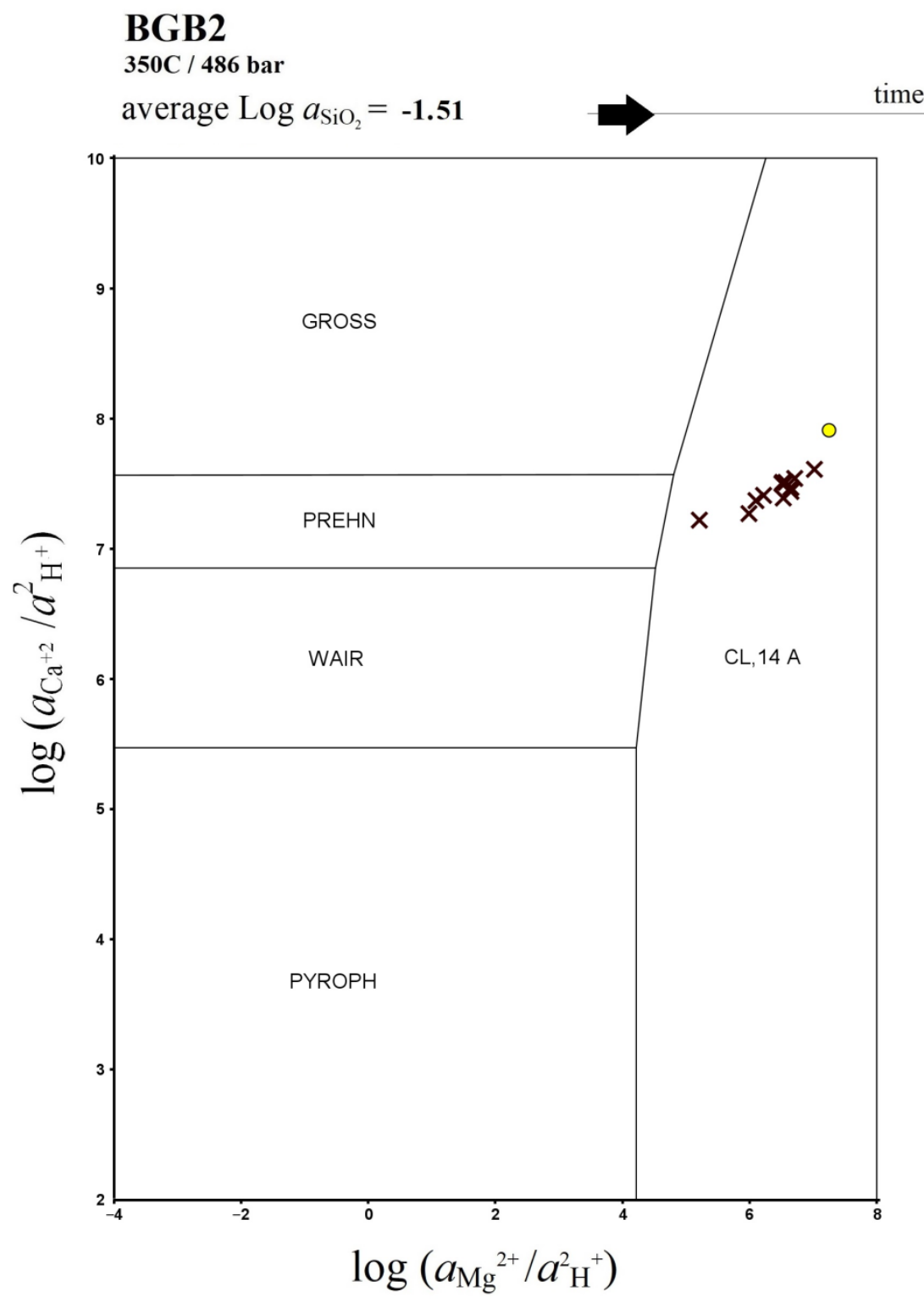

time of the experiment $\Rightarrow \quad$ average $\log a_{\mathrm{SiO}_{2}}=\mathbf{- 1 . 8 7}$

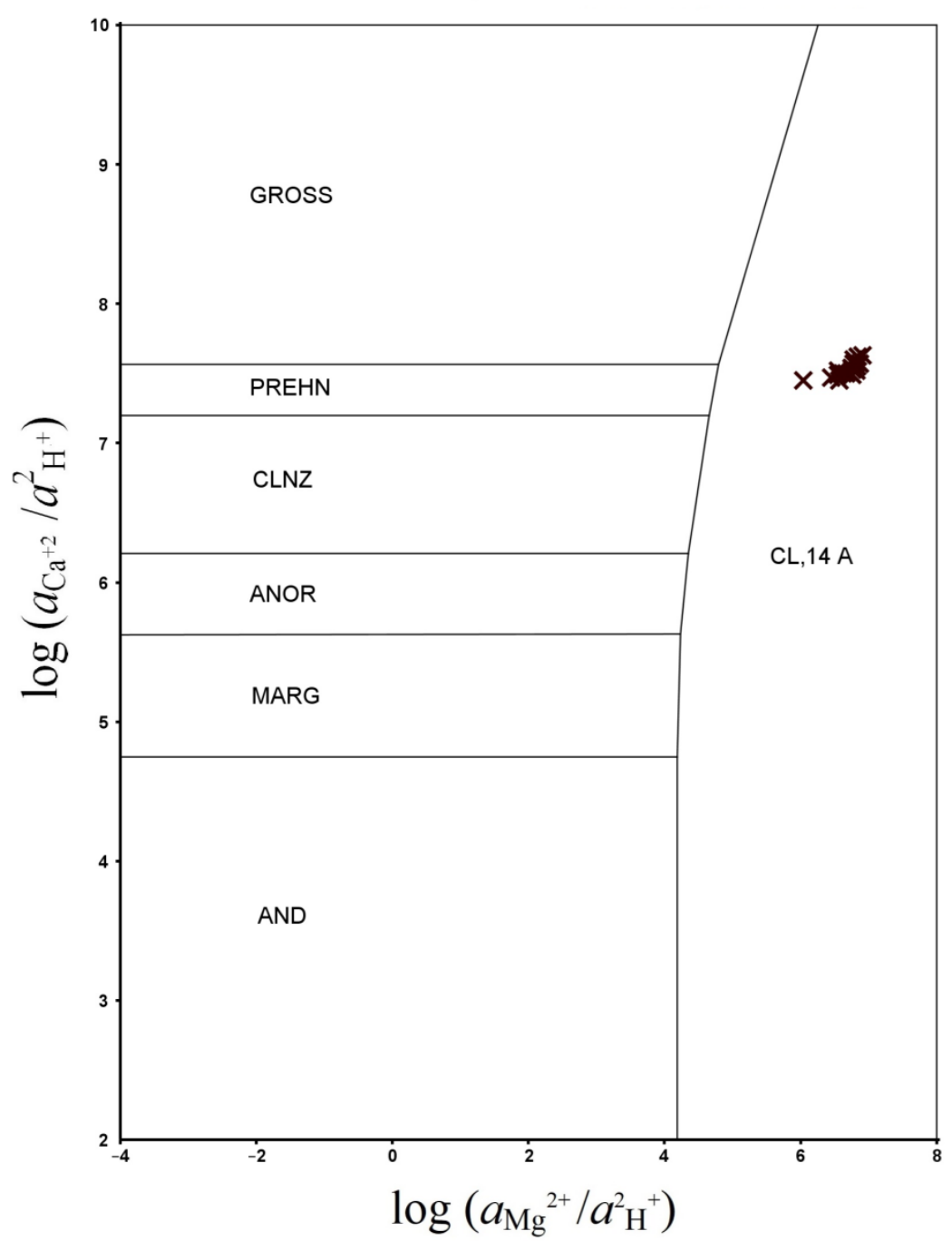


Figure C.4.24. Activity diagrams for the $\mathrm{BGB} 1$ showing mineral stability fields in the $\mathrm{CaO}-\mathrm{FeO}-\mathrm{Al}_{2} \mathrm{O}_{3}-\mathrm{H}_{2} \mathrm{O}$. Diagrams for each experiment were constructed on the base of two different silica averages, during and after glass dissolution. Black and red crosses show position of effluent samples collected at 1.0 and $0.5 \mathrm{ml} \mathrm{hr}^{-1}$ flow rate, respectively. Yellow circles show position of the unreacted fluid (water) at $400^{\circ} \mathrm{C} / 500$ bar. Blue arrows show the path of reacted fluids over the time of the experiments

\section{BGB1}

400C / 483 bar

average $\log a_{\mathrm{SiO}}=\mathbf{- 1 . 5 2}$

(during basalt glass dissolution)

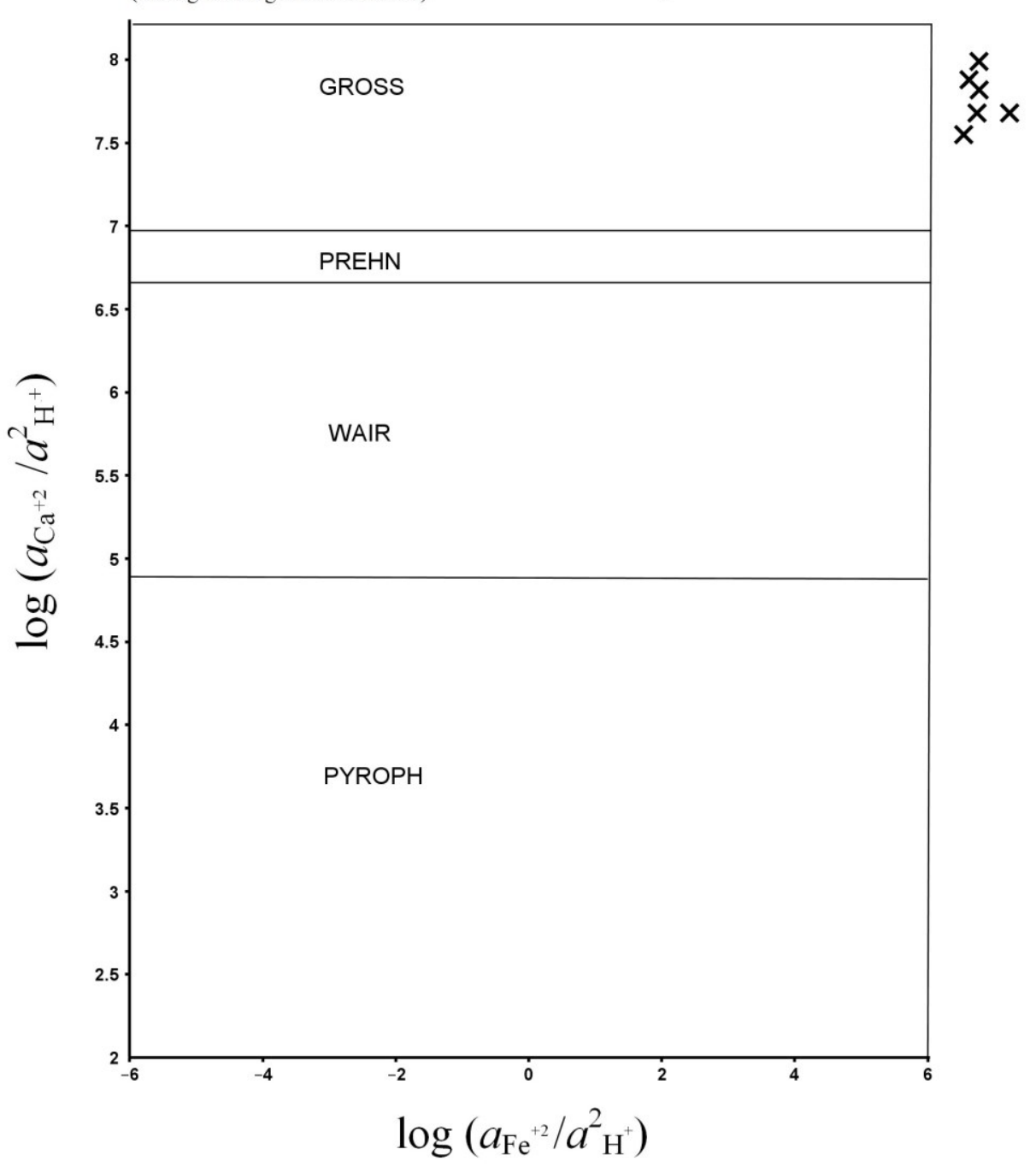

$\mathrm{Fe}<$ LOD

average $\log a_{\mathrm{SiO}}=\mathbf{- 1 . 8 0}$

(after basalt glass dissolution)

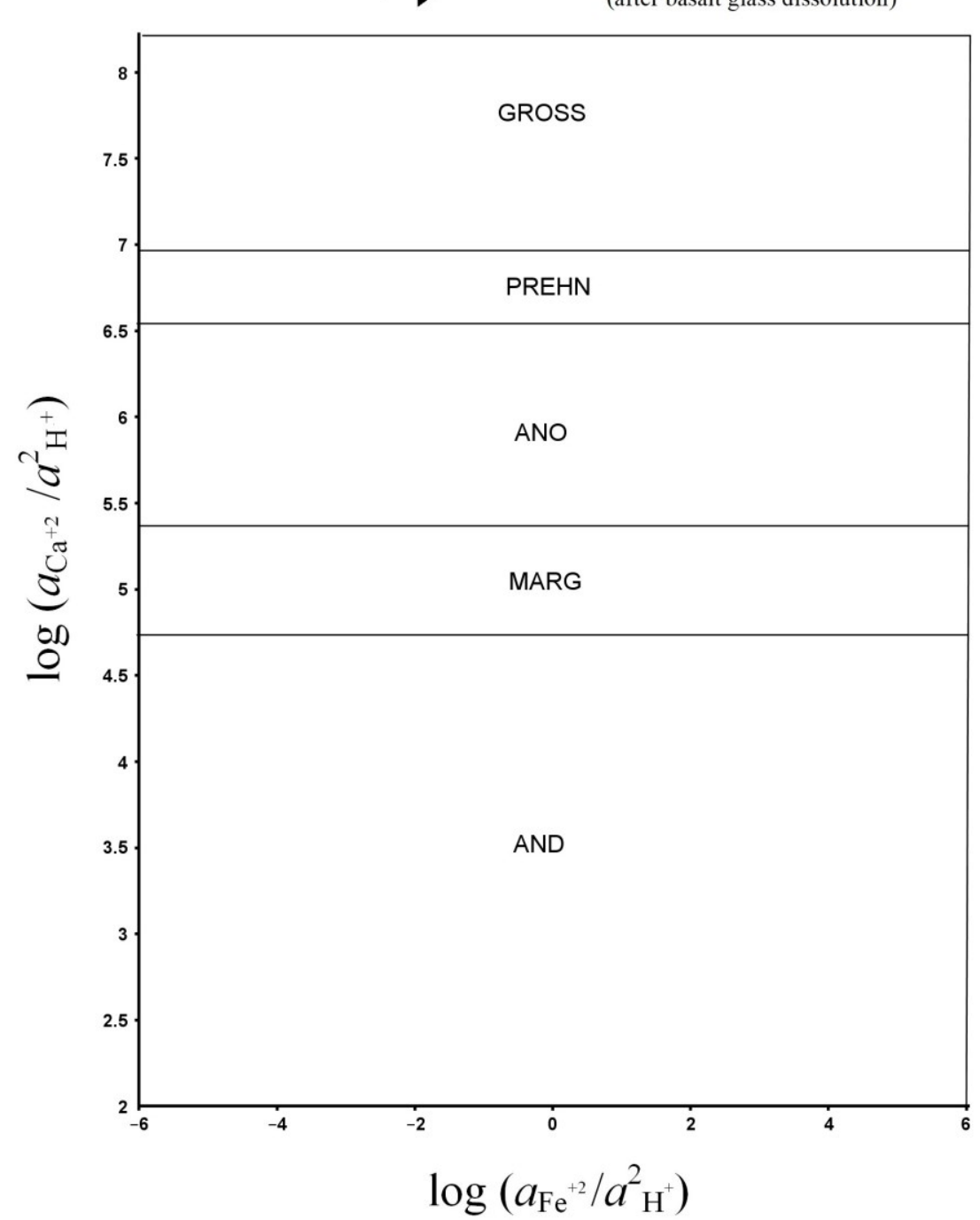

Figure C.4.25. Activity diagrams for the $\mathrm{BGB} 2$ showing mineral stability fields in the $\mathrm{CaO}-\mathrm{FeO}-\mathrm{Al}_{2} \mathrm{O}_{3}-\mathrm{H}_{2} \mathrm{O}$. Diagrams for each experiment were constructed on the base of two different silica averages, during and after glass dissolution. Black and red crosses show position of effluent samples collected at 1.0. Yellow circles show position of the unreacted fluid (water) at $350^{\circ} \mathrm{C} / 500 \mathrm{bar}$. Blue arrows show the path of reacted fluids over the time of the experiment

\section{BGB2}

350C / 486 bar

average $\log a_{\mathrm{SiO}_{2}}=\mathbf{- 1 . 5 1}$

time of the experiment

average $\log a_{\mathrm{SiO}_{2}}=\mathbf{- 1 . 8 7}$

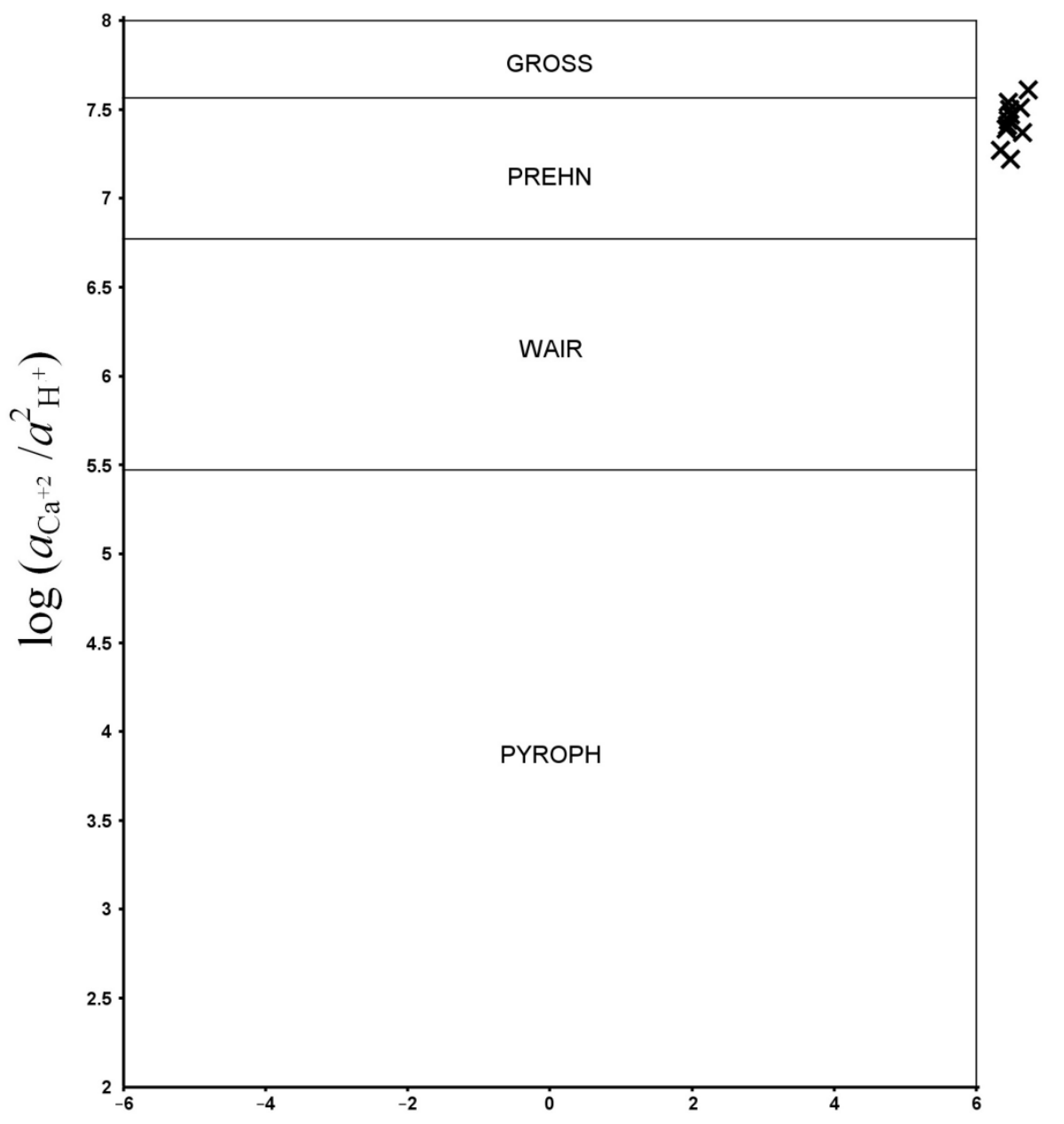

$\log \left(a_{\mathrm{Fe}}^{+2} / a_{\mathrm{H}^{+}}^{2}\right)$

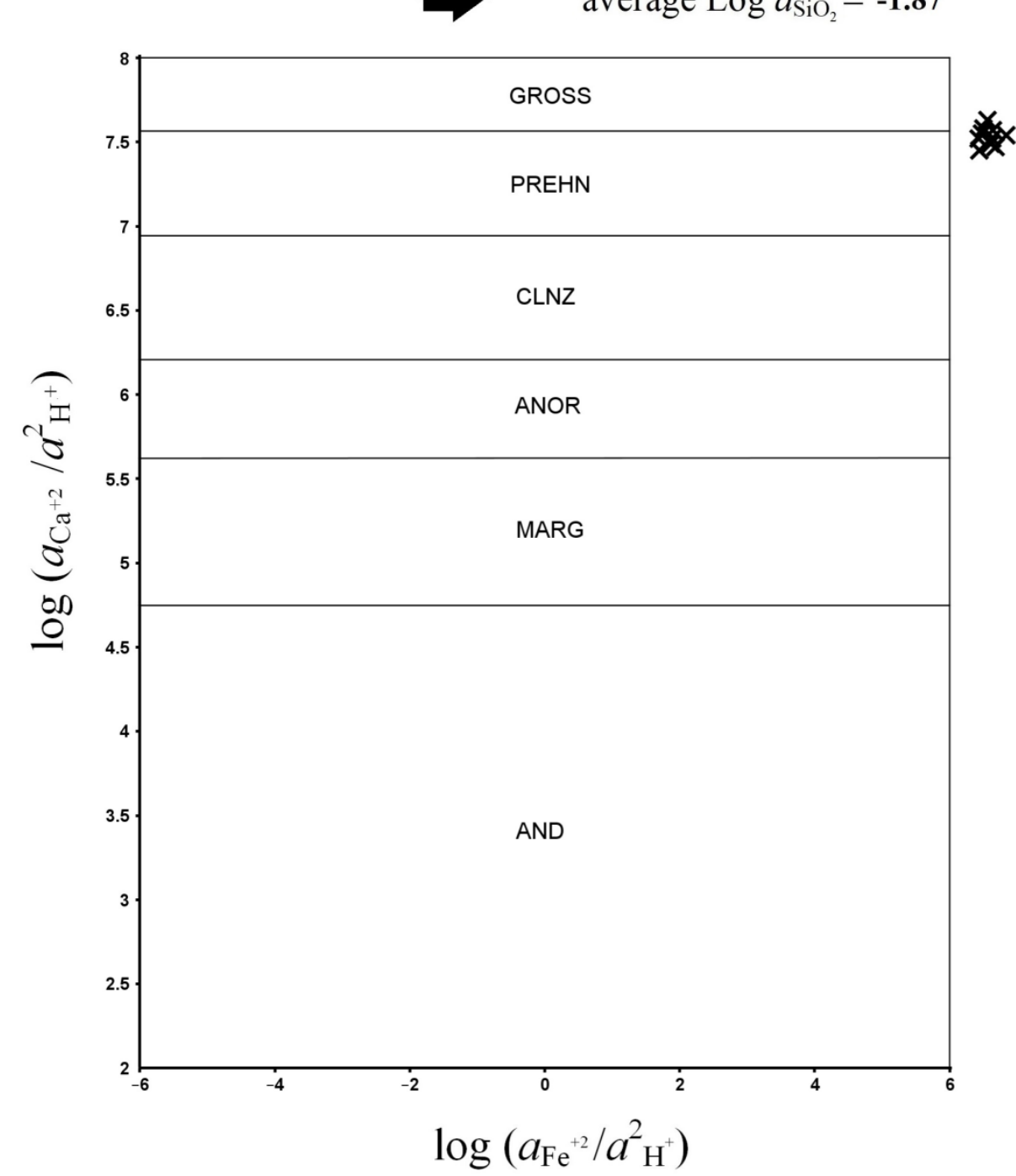


Figure C.4.26. Activity diagrams for the $\mathrm{BGB} 1$ showing mineral stability fields in the $\mathrm{CaO}-\mathrm{K}_{2} \mathrm{O}-\mathrm{Al}_{2} \mathrm{O}_{3}-\mathrm{H}_{2} \mathrm{O}$. Diagrams for each experiment were constructed on the base of two different silica averages, during and after glass dissolution. Black and red crosses show position of effluent samples collected at 1.0 and $0.5 \mathrm{ml} \mathrm{hr}^{-1}$ flow rate, respectively. Yellow circles show position of the unreacted fluid (water) at $400^{\circ} \mathrm{C} / 500$ bar. Blue arrows show the path of reacted fluids over the time of the experiments
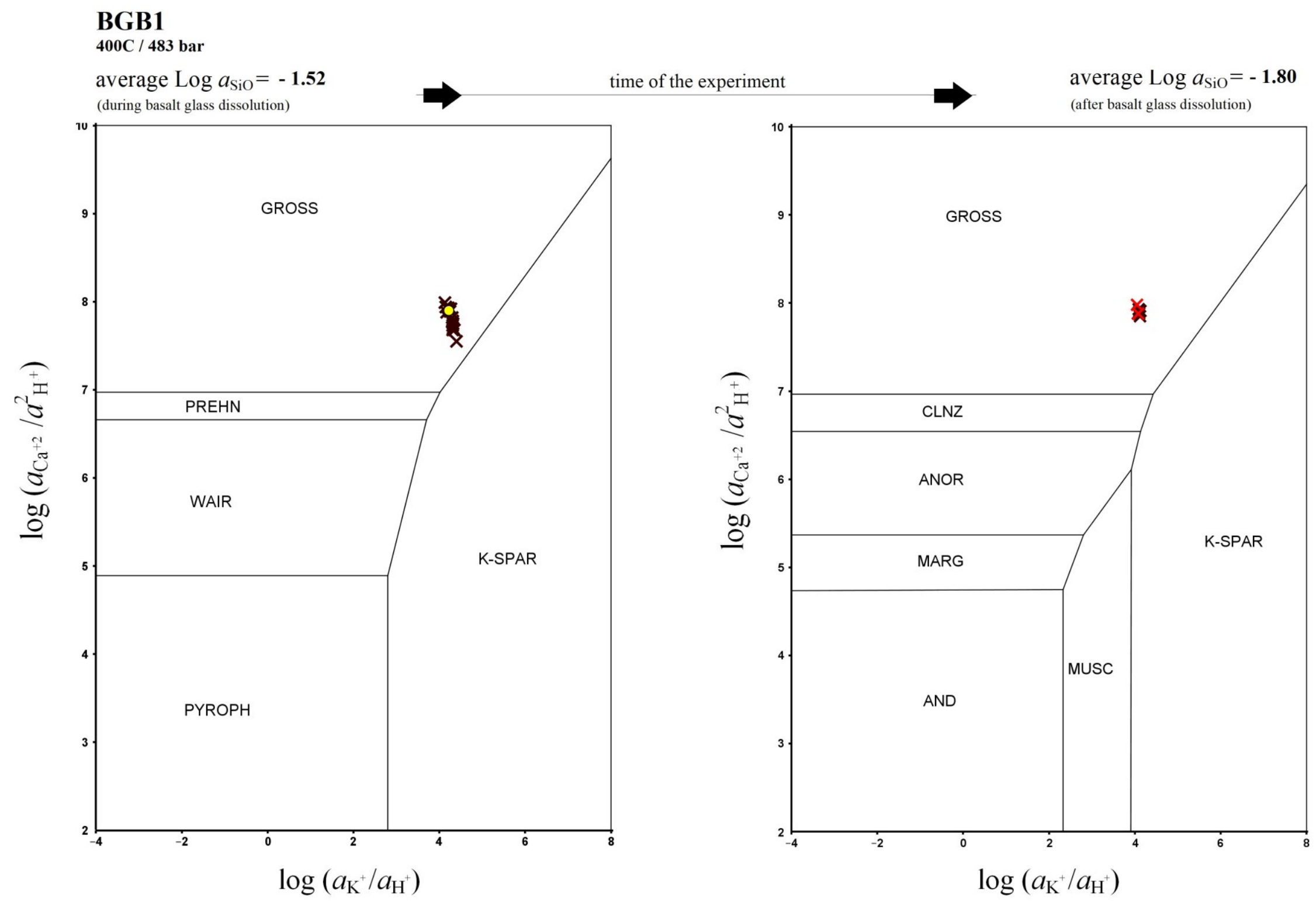

Figure C.4.27. Activity diagrams for the BGB2 showing mineral stability fields in the $\mathrm{CaO}-\mathrm{K}_{2} \mathrm{O}-\mathrm{Al}_{2} \mathrm{O}_{3}-\mathrm{H}_{2} \mathrm{O}$. Diagrams for each experiment were constructed on the base of two different silica averages, during and after glass dissolution. Black and red crosses show position of effluent samples collected at 1.0. Yellow circles show position of the unreacted fluid (water) at $350^{\circ} \mathrm{C} / 500 \mathrm{bar}$. Blue arrows show the path of reacted fluids over the time of the experiments
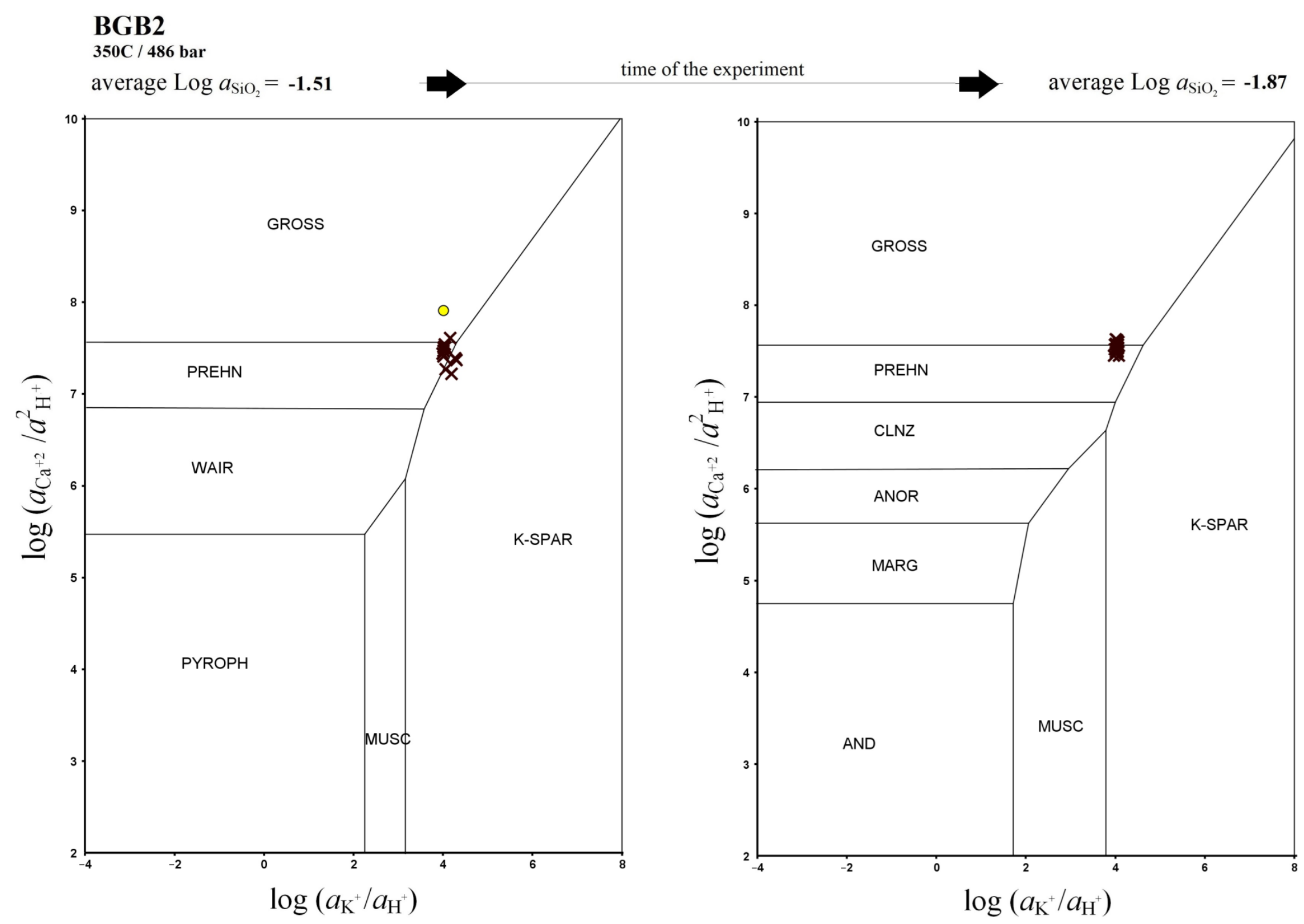

$\log \left(a_{\mathrm{K}^{+}} / a_{\mathrm{H}^{+}}\right)$ 
Figure C.4.28. Activity diagrams for the $\mathrm{BGB} 1$ showing mineral stability fields in the $\mathrm{CaO}-\mathrm{Na}_{2} \mathrm{O}-\mathrm{Al}_{2} \mathrm{O}_{3}-\mathrm{H}_{2} \mathrm{O}$. Diagrams for each experiment were constructed on the base of two different silica averages, during and after glass dissolution. Black and red crosses show position of effluent samples collected at 1.0 and $0.5 \mathrm{ml} \mathrm{hr}^{-1}$ flow rate, respectively. Yellow circles show position of the unreacted fluid (water) at $400^{\circ} \mathrm{C} / 500$ bar. Blue arrows show the path of reacted fluids over the time of the experiments

\section{BGB1}

$400 \mathrm{C} / 483 \mathrm{bar}$

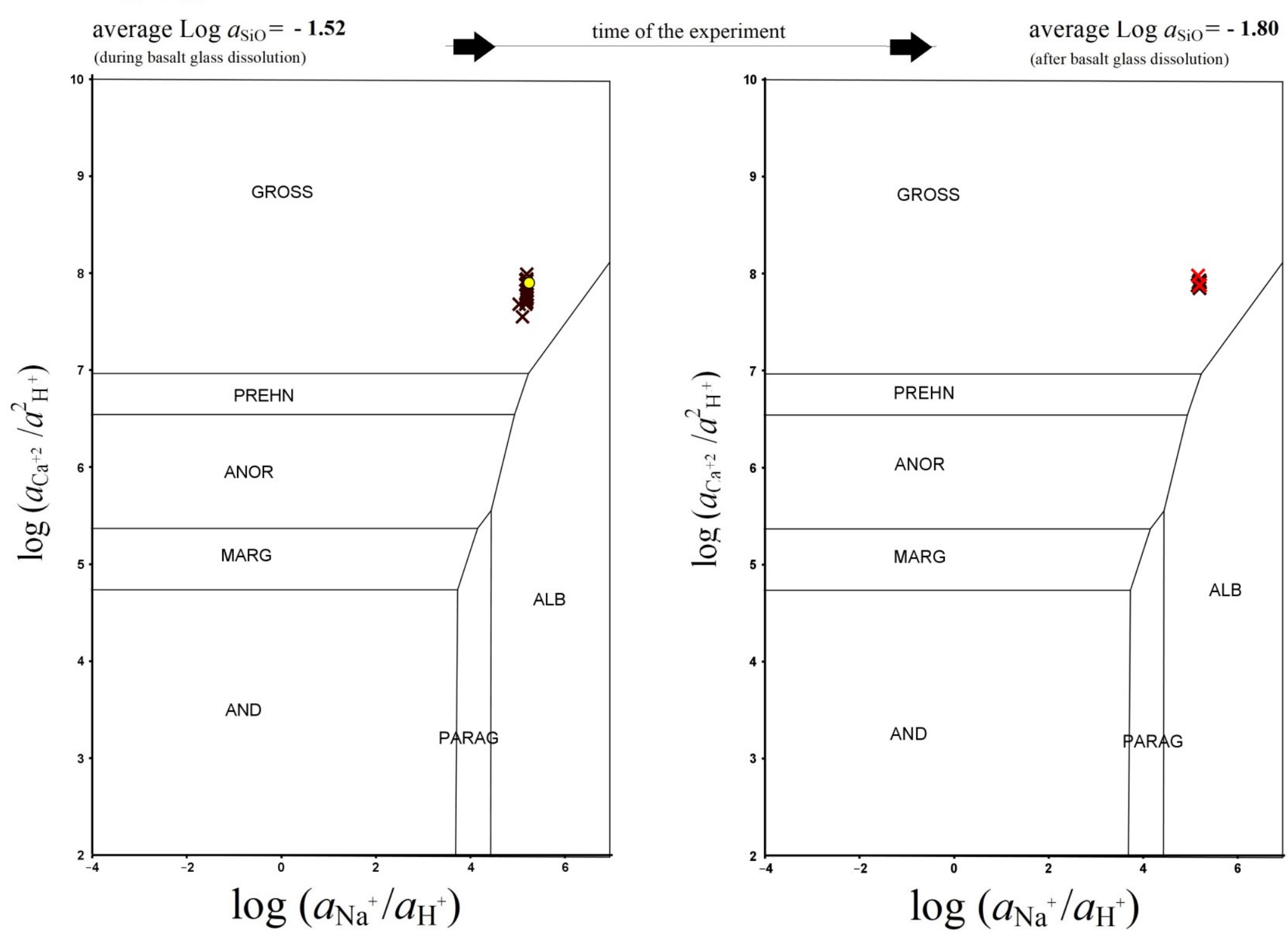

Figure C.4.29. Activity diagrams for the $\mathrm{BGB} 2$ showing mineral stability fields in the $\mathrm{CaO}-\mathrm{Na}_{2} \mathrm{O}-\mathrm{Al}_{2} \mathrm{O}_{3}-\mathrm{H}_{2} \mathrm{O}$. Diagrams for each experiment were constructed on the base of two different silica averages, during and after glass dissolution. Black and red crosses show position of effluent samples collected at 1.0 . Yellow circles show position of the unreacted fluid (water) at $350^{\circ} \mathrm{C} / 500$ bar. Blue arrows show the path of reacted fluids over the time of the experiments

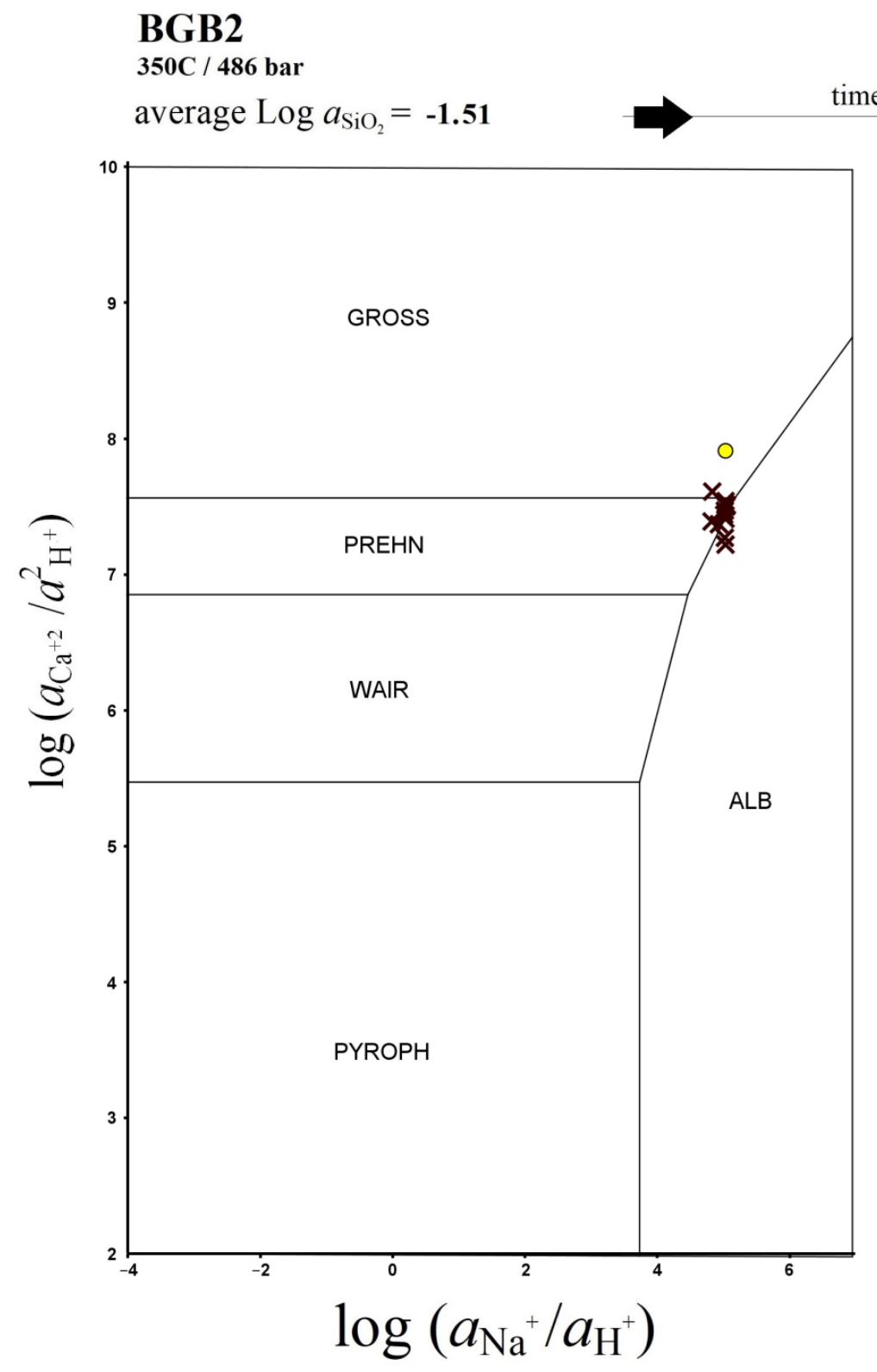

time of the experiment

average $\log a_{\mathrm{SiO}_{2}}=\mathbf{- 1 . 8 7}$

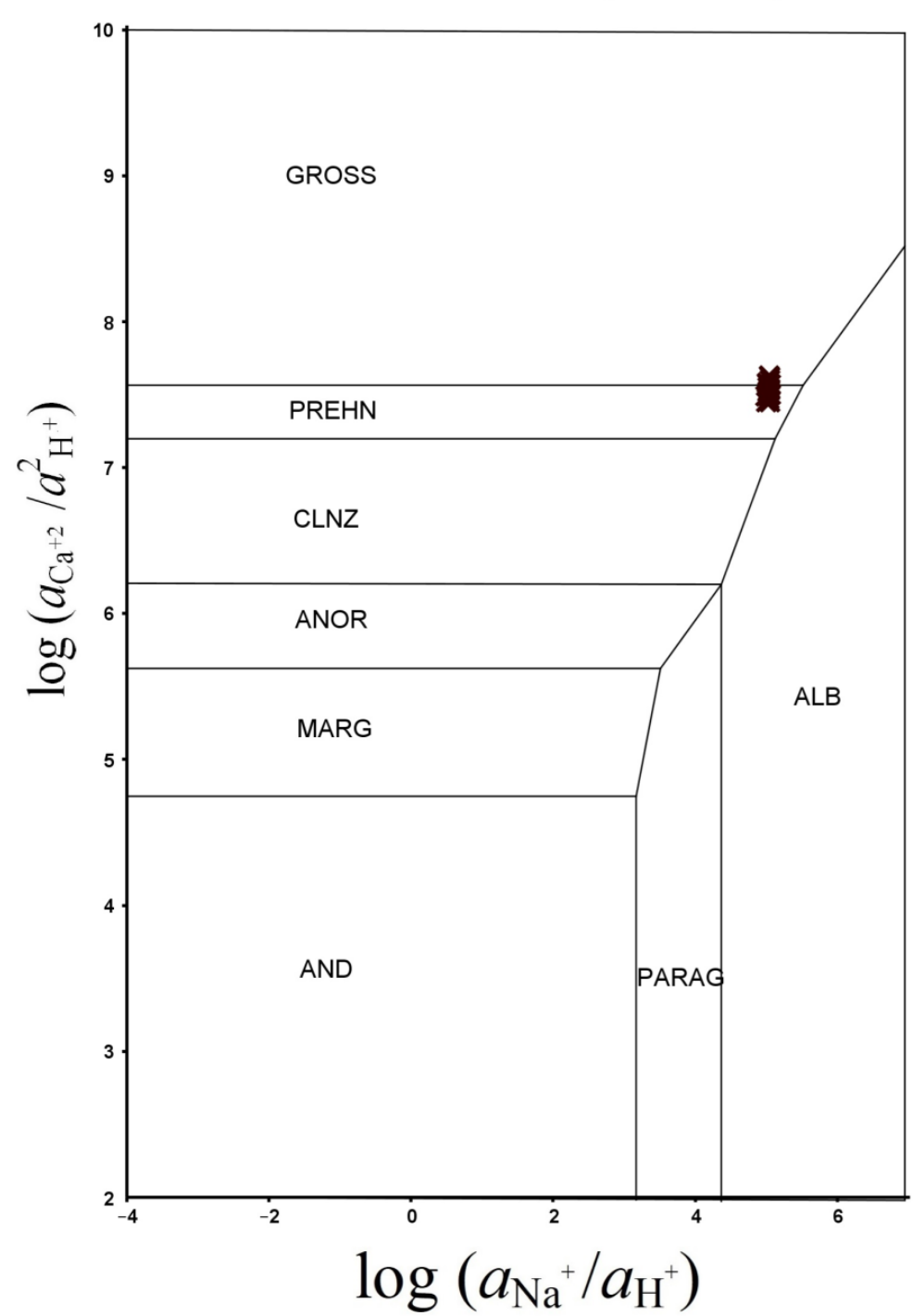


Figure C.4.30. Activity diagrams for the $\mathrm{BGB} 1$ showing mineral stability fields in the $\mathrm{FeO}-\mathrm{MgO}-\mathrm{Al}_{2} \mathrm{O}_{3}-\mathrm{H}_{2} \mathrm{O}$. Diagrams for each experiment were constructed on the base of two different silica averages, during and after glass dissolution. Black and red crosses show position of effluent samples collected at 1.0 . Yellow circles show position of the unreacted fluid (water) at $400^{\circ} \mathrm{C} / 500 \mathrm{bar}$. Blue arrows show the path of reacted fluids over the time of the experiments

\section{BGB1}

400C/ 483 bar

average $\log a_{\mathrm{SiO}}=\mathbf{- 1 . 5 2}$

(during basalt glass dissolution)

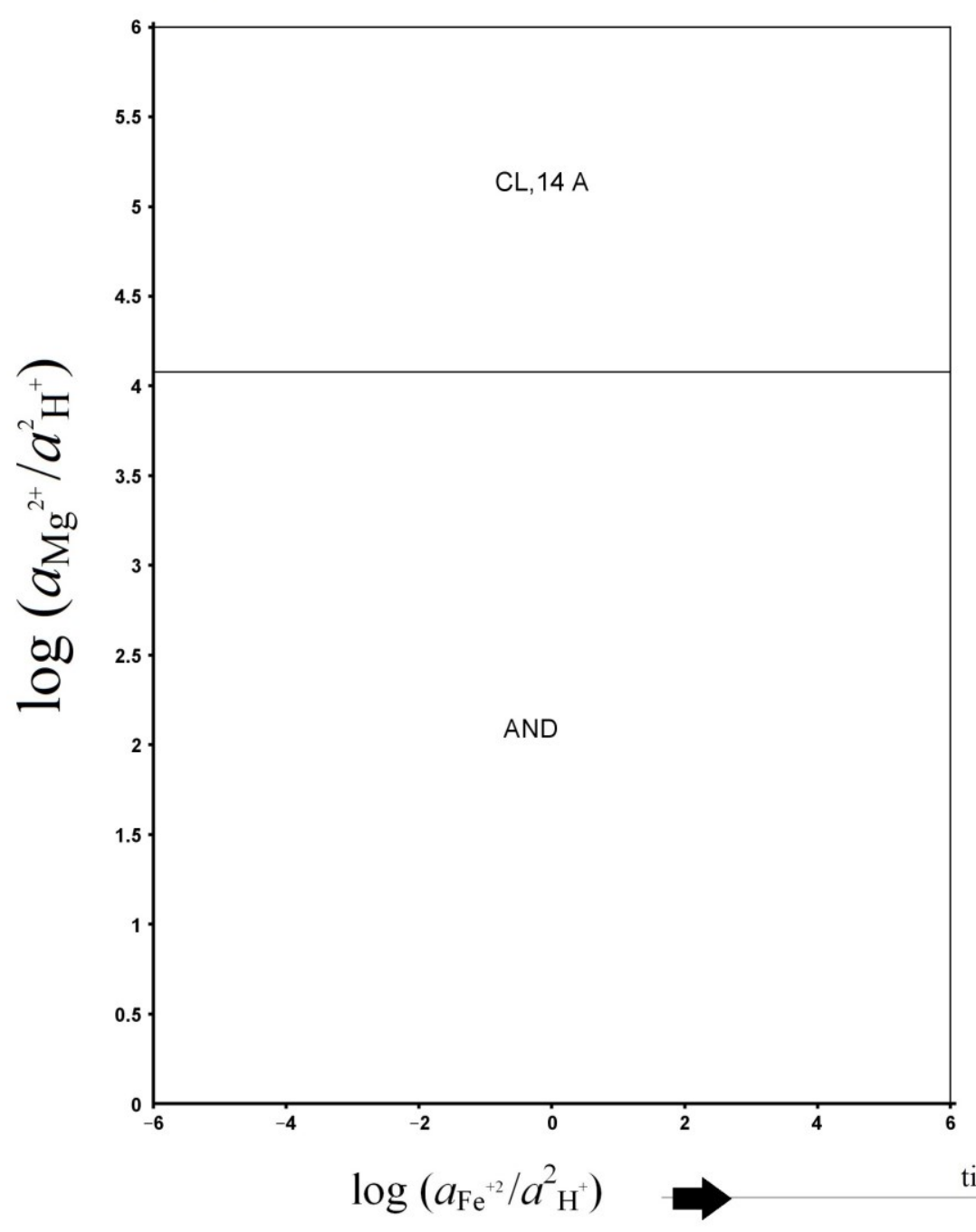

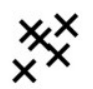

$\mathrm{Fe}<$ LOD

average $\log a_{\mathrm{SiO}}=\mathbf{- 1 . 8 0}$

(after basalt glass dissolution)

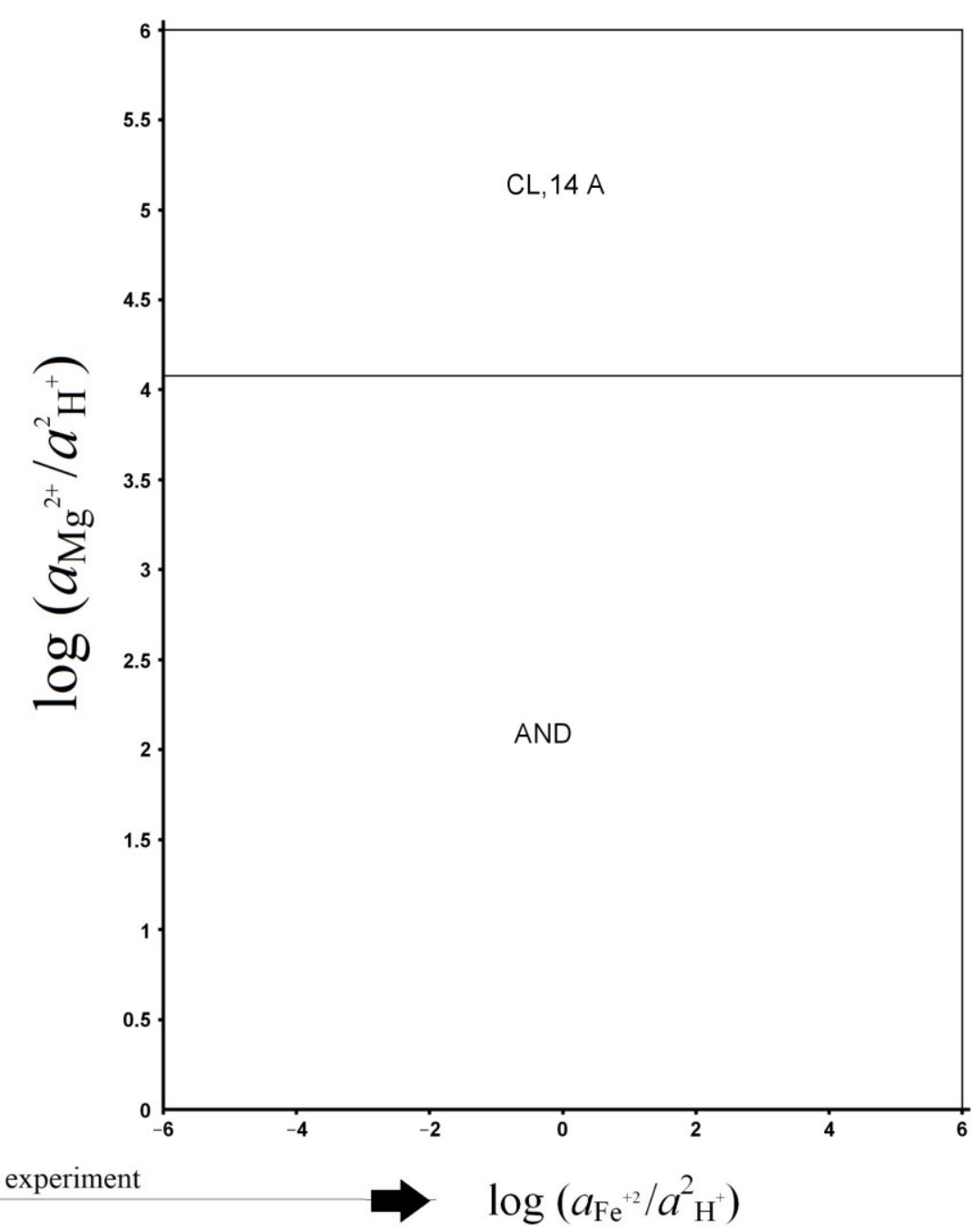

Figure C.4.31. Activity diagrams for the $\mathrm{BGB} 2$ showing mineral stability fields in the $\mathrm{FeO}-\mathrm{MgO}-\mathrm{Al}_{2} \mathrm{O}_{3}-\mathrm{H}_{2} \mathrm{O}$. Diagrams for each experiment were constructed on the base of two different silica averages, during and after glass dissolution. Black and red crosses show position of effluent samples collected at 1.0. Yellow circles show position of the unreacted fluid (water) at $350^{\circ} \mathrm{C} / 500 \mathrm{bar}$. Blue arrows show the path of reacted fluids over the time of the experiments

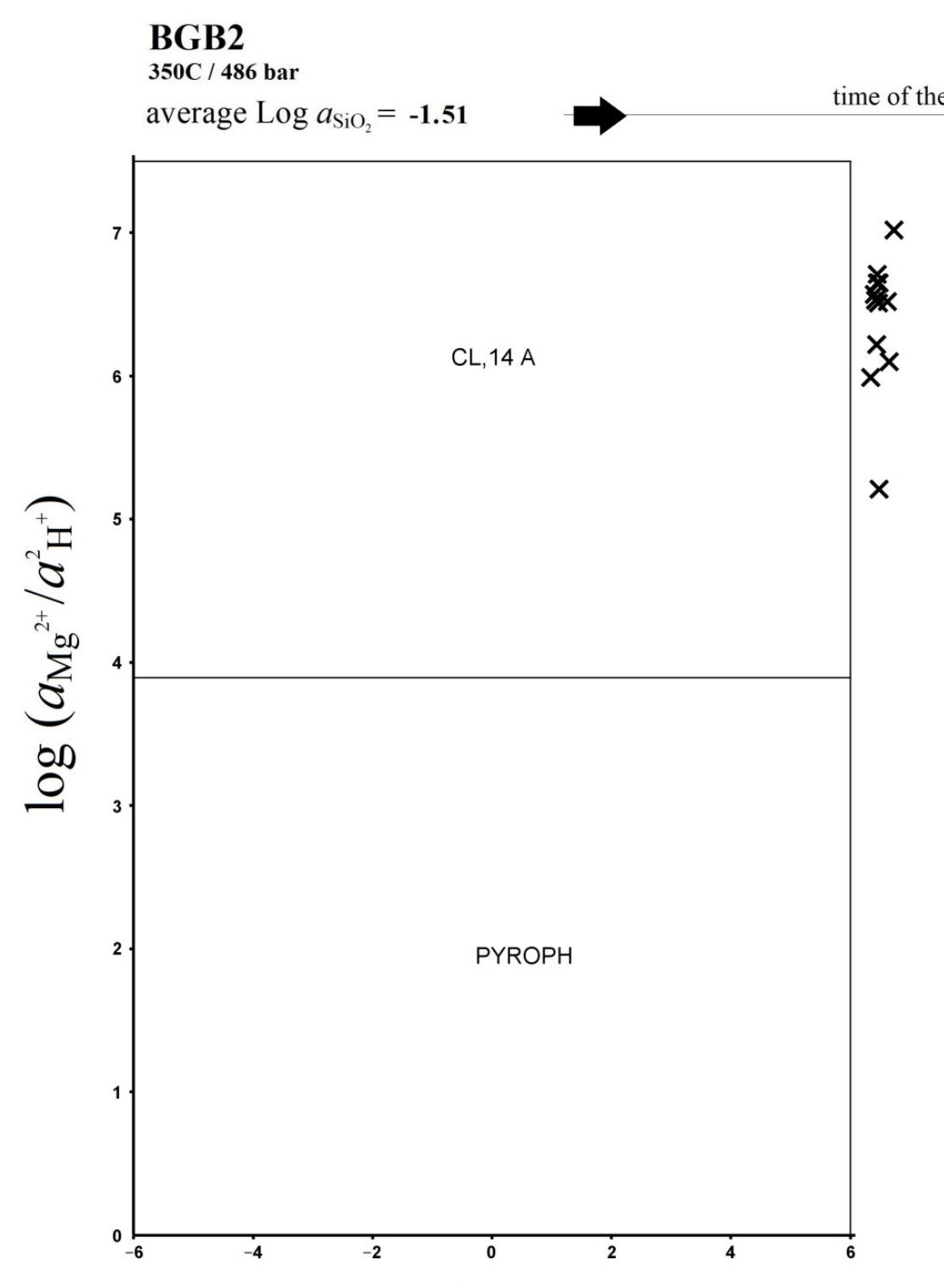

$\log \left(a_{\mathrm{Fe}^{+2}} / a_{\mathrm{H}^{+}}^{2}\right)$
$\Rightarrow \quad$ average $\log a_{\mathrm{SiO}_{2}}=\mathbf{- 1 . 8 7}$

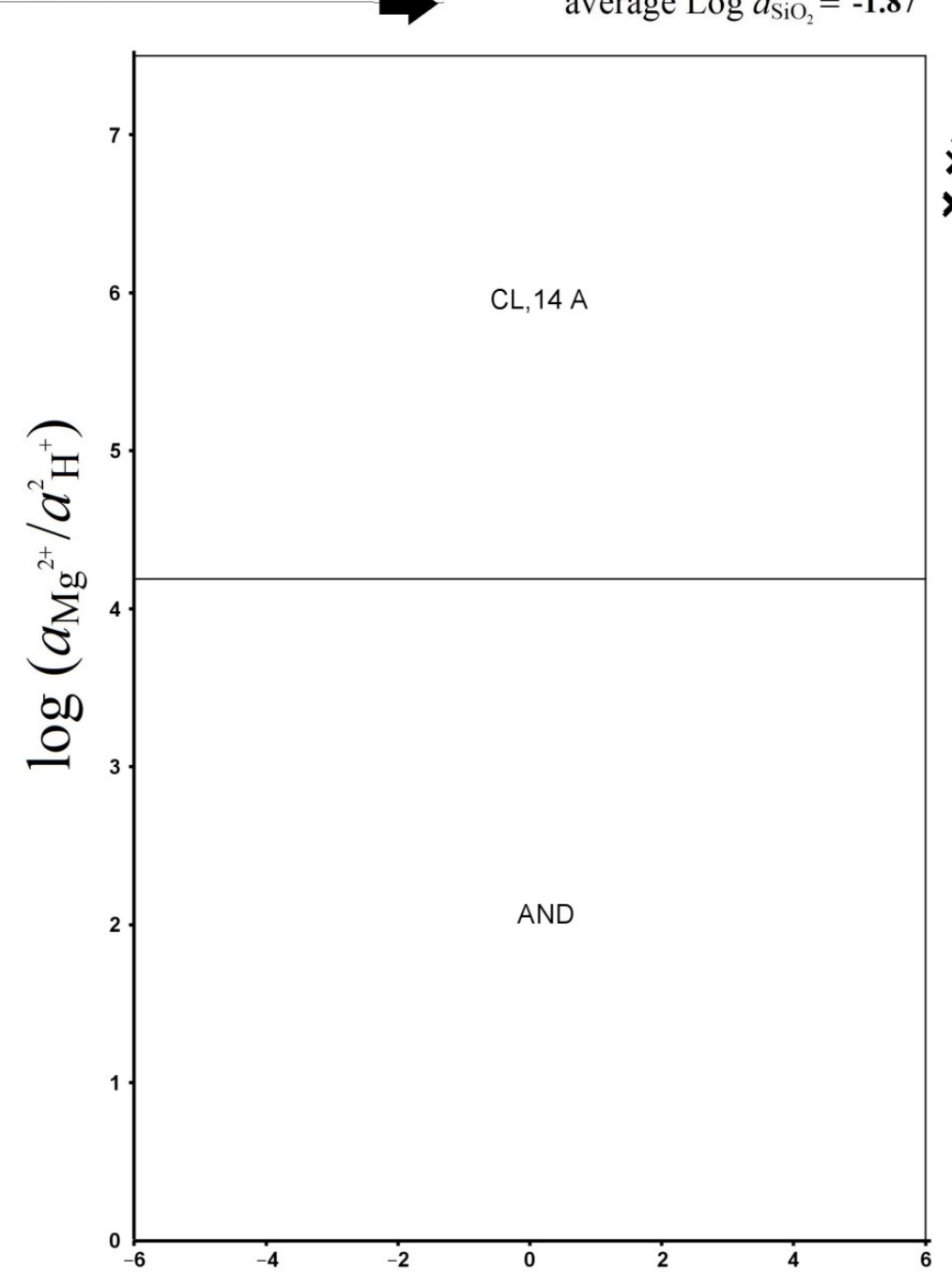

$\log \left(a_{\mathrm{Fe}^{+2}} / a_{\mathrm{H}^{+}}^{2}\right)$ 
Figure C.4.32. Activity diagrams for the $\mathrm{BGB} 1$ and $\mathrm{BGB} 2$ showing mineral stability fields in the $\mathrm{MgO}-\mathrm{SiO}_{2}-\mathrm{Al}_{2} \mathrm{O}_{3}-\mathrm{H}_{2} \mathrm{O}$. Diagrams for each experiment were constructed on the base of two different silica averages, during and after glass dissolution. Black and red crosses show position of effluent samples collected at $1.0 \mathrm{and} 0.5 \mathrm{ml} \mathrm{hr} \mathrm{hr}^{-1}$ flow rate, respectively. Yellow circles show position of the unreacted fluid (water) at $400-350^{\circ} \mathrm{C} / 500$ bar. Blue arrows show the path of reacted fluids over the time of the experiments
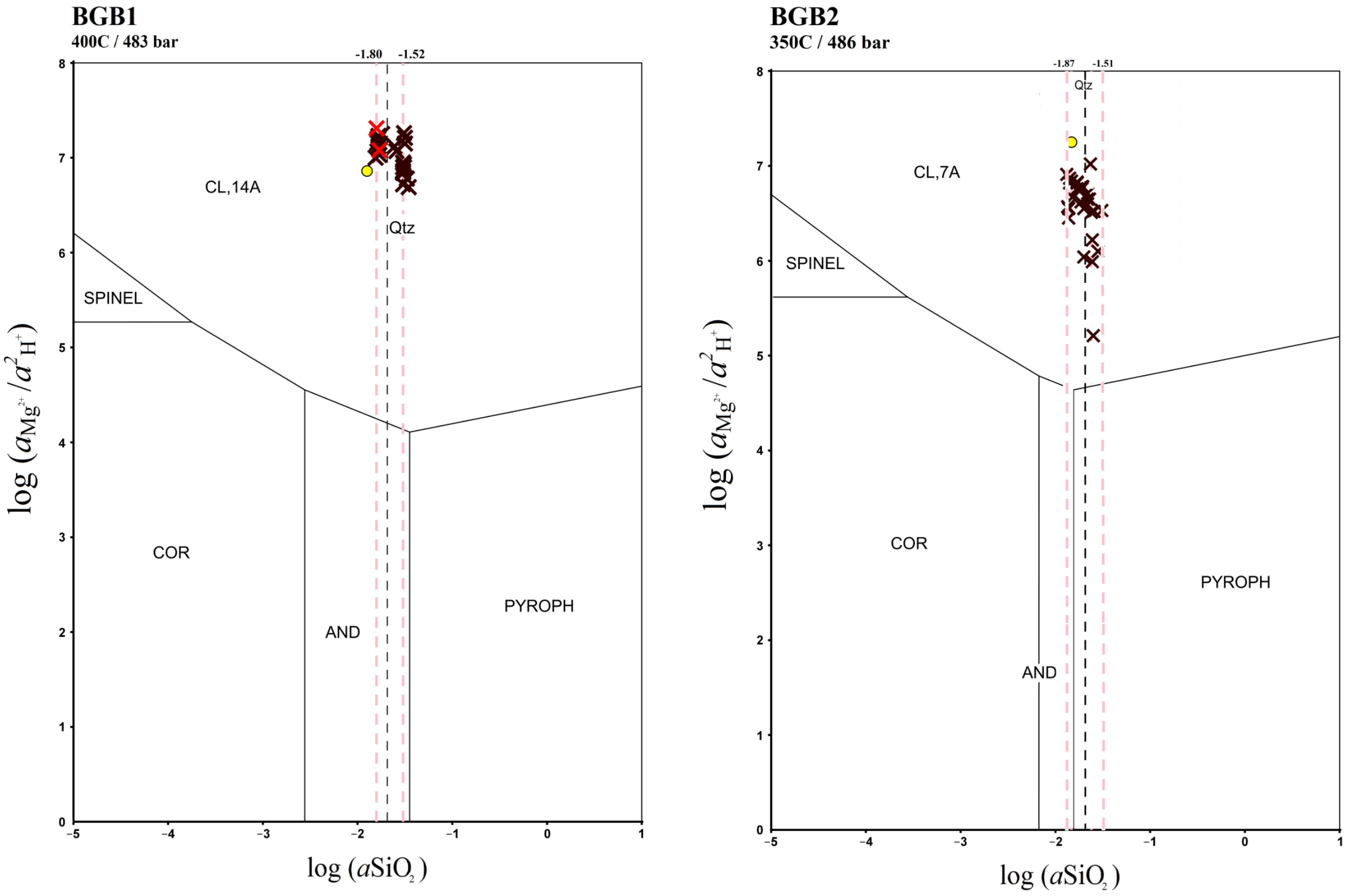

Figure C.4.33. Activity diagrams for the $\mathrm{BGB} 1$ and $\mathrm{BGB} 2$ showing mineral stability fields in the $\mathrm{Na}_{2} \mathrm{O}-\mathrm{SiO}_{2}-\mathrm{Al}_{2} \mathrm{O}_{3}-\mathrm{H}_{2} \mathrm{O}$. Diagrams for each experiment were constructed on the base of two different silica averages, during and after glass dissolution. Black and red crosses show position of effluent samples collected at 1.0 and $0.5 \mathrm{ml} \mathrm{hr}^{-1}$ flow rate, respectively. Yellow circles show position of the unreacted fluid (water) at $400-350^{\circ} \mathrm{C} / 500$ bar. Blue arrows show the path of reacted fluids over the time of the experiments

\section{BGB1}

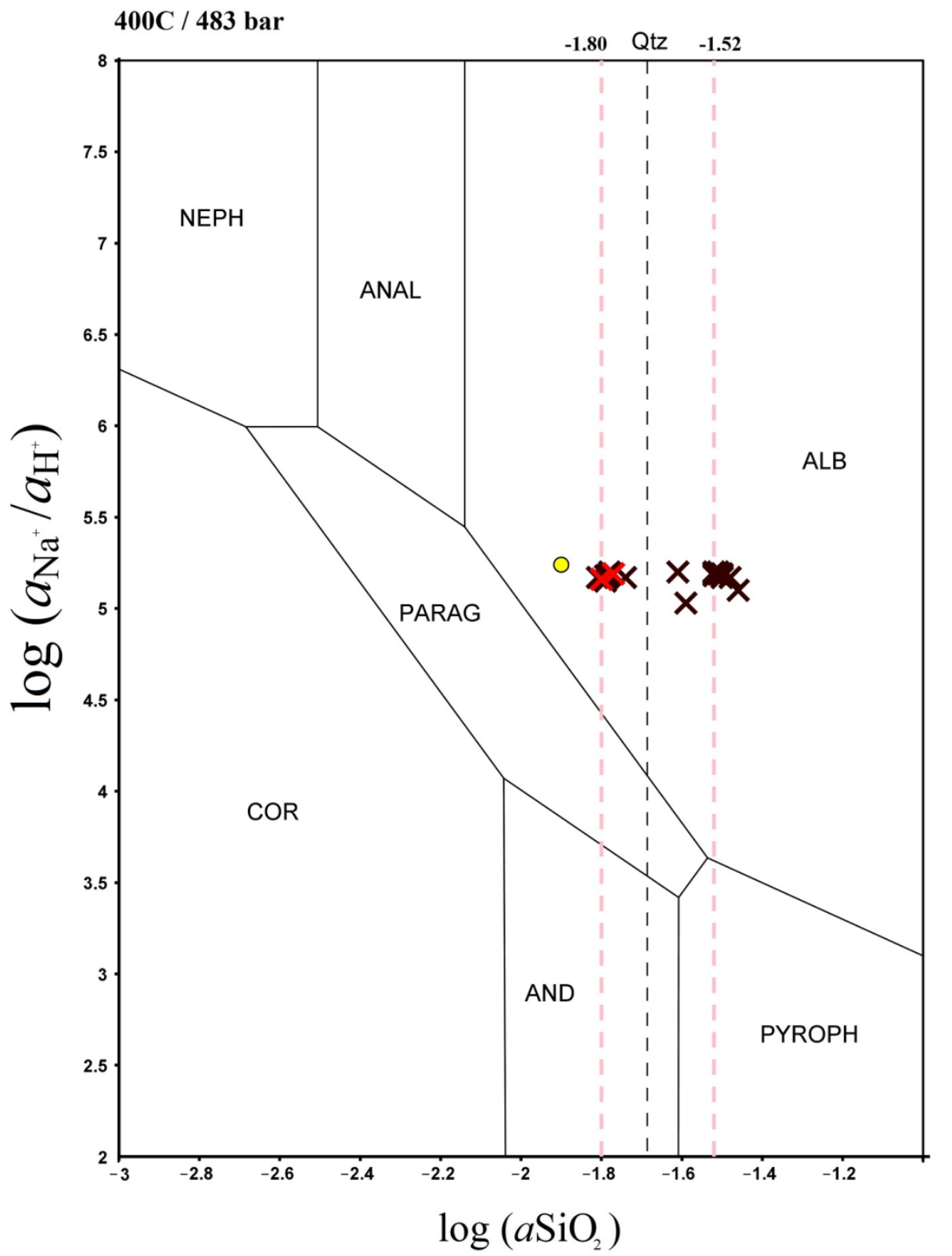

BGB2

$350 \mathrm{C} / 486$ bar

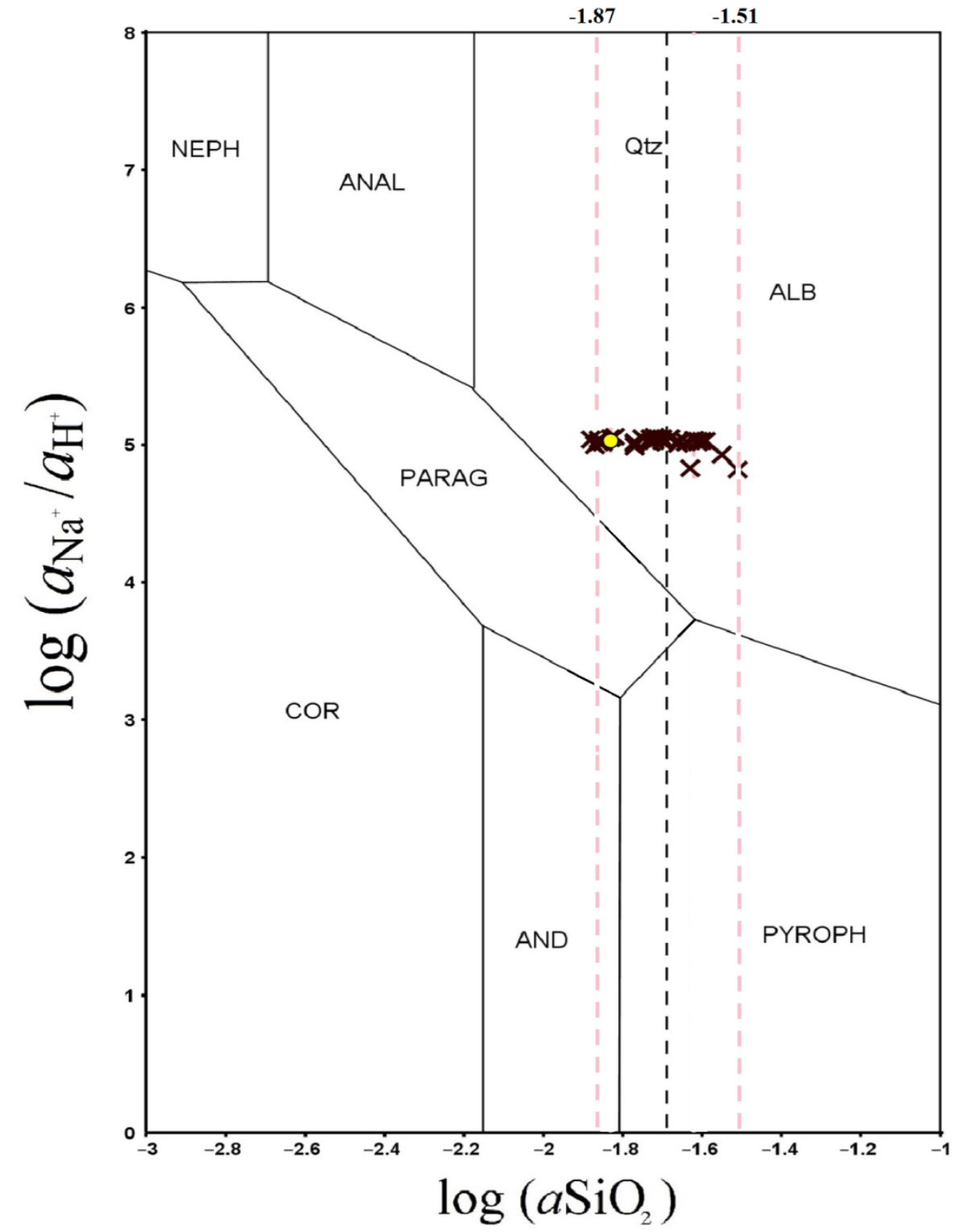


Figure C.4.34. Activity diagrams for the $\mathrm{BGB} 1$ and $\mathrm{BGB} 2$ showing mineral stability fields in the $\mathrm{CaO}-\mathrm{SiO}_{2}-\mathrm{Al}_{2} \mathrm{O}_{3}-\mathrm{H}_{2} \mathrm{O}$. Diagrams for each experiment were constructed on the base of two different silica averages, during and after glass dissolution. Black and red crosses show position of effluent samples collected at 1.0 and $0.5 \mathrm{ml} \mathrm{hr}^{-1}$ flow rate, respectively. Yellow circles show position of the unreacted fluid (water) at $400-$ $350^{\circ} \mathrm{C} / 500$ bar. Blue arrows show the path of reacted fluids over the time of the experiments
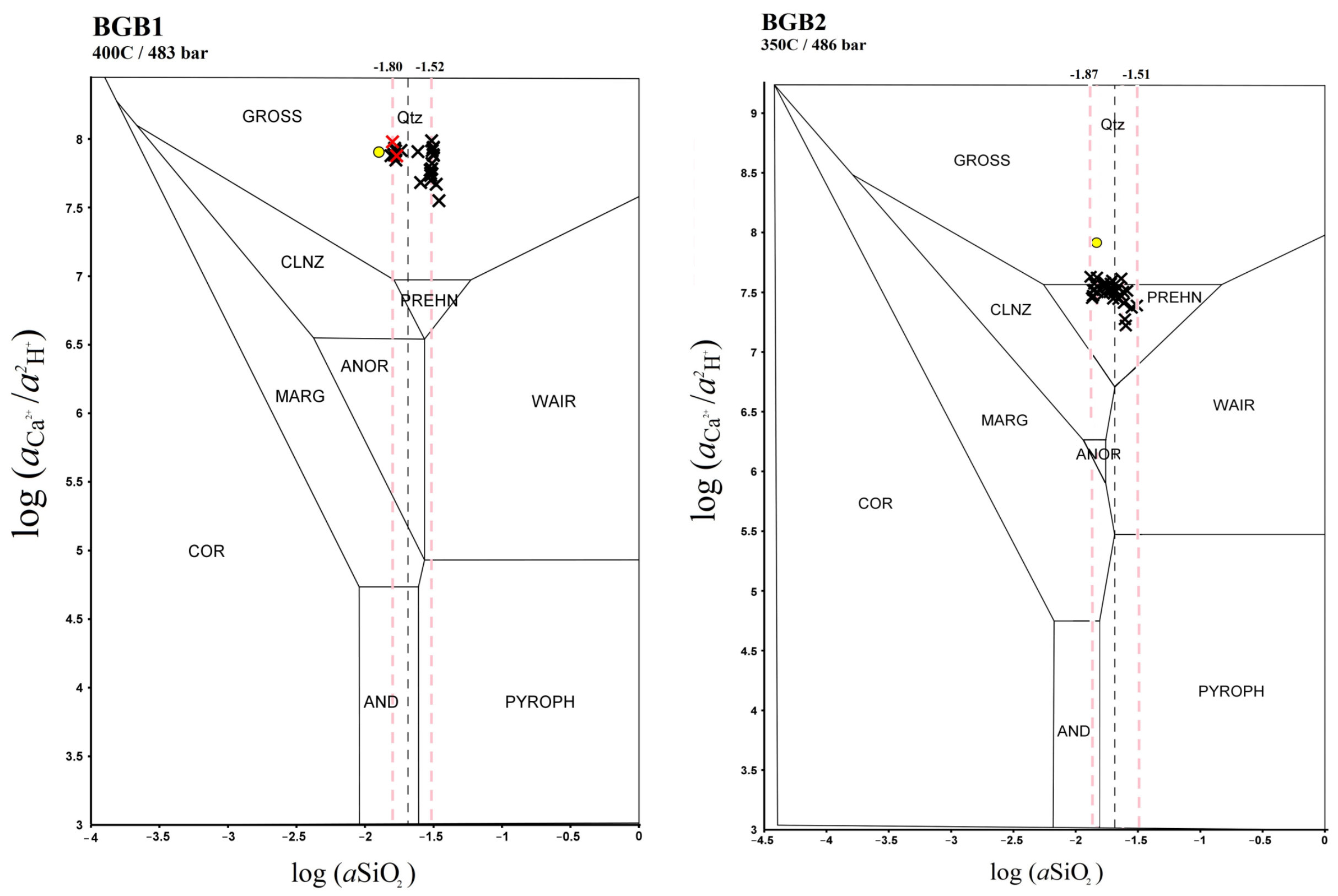
Table C.4.25. Values of the estimate temperatures for the BGBl calculated with the geothermometers equations by Fournier (1979), Truesdell (1976), Fournier and Truesdell (1973), Santoyo and Díaz-Gonzalez (2009), Arnorsson (1983), Tonani (1980), Nieva and Nieva (1987) and Giggenbach (1988)

BGB1 - 400 ${ }^{\circ} \mathrm{C} / 483$ bar

\begin{tabular}{|c|c|c|c|c|c|c|c|c|c|c|c|c|c|c|c|c|}
\hline \multirow{2}{*}{\multicolumn{2}{|c|}{$\mathrm{n}^{\circ}$ samples }} & \multirow[b]{2}{*}{ time } & \multirow[b]{2}{*}{$\mathbf{T}\left({ }^{\circ} \mathbf{C}\right)$} & \multirow[b]{2}{*}{ P (bar) } & \multicolumn{3}{|c|}{$\mathbf{m g ~ k \mathbf { ~ g } ^ { - 1 }}$} & & \multirow{2}{*}{$\begin{array}{c}\mathrm{T}\left({ }^{\circ} \mathrm{C}\right) \\
\mathbf{N a / K} \\
\text { (Fournier 1979) }\end{array}$} & \multirow{2}{*}{$\begin{array}{c}\mathrm{T}\left({ }^{\circ} \mathrm{C}\right) \\
\mathbf{N a / K} \\
\text { (Truesdell 1976) }\end{array}$} & \multirow{2}{*}{$\begin{array}{c}\mathrm{T}\left({ }^{\circ} \mathrm{C}\right) \\
\mathbf{N a / K / C a} \\
\text { (Fournier and } \\
\text { Truesdell 1973) } \\
\boldsymbol{\beta}=\mathbf{1 / 3}\end{array}$} & \multirow{2}{*}{$\begin{array}{c}\mathrm{T}\left({ }^{\circ} \mathrm{C}\right) \\
\begin{array}{c}\mathbf{N a} / \mathbf{K} \\
\text { (Santoyo and } \\
\text { Díaz-González 2009) }\end{array}\end{array}$} & \multirow{2}{*}{$\begin{array}{c}\mathrm{T}\left({ }^{\circ} \mathrm{C}\right) \\
\mathbf{N a / K} \\
\text { (Arnorsson 1983) }\end{array}$} & \multirow{2}{*}{$\begin{array}{c}\mathrm{T}\left({ }^{\circ} \mathrm{C}\right) \\
\mathbf{N a / K} \\
\text { (Tonani 1980) }\end{array}$} & \multirow{2}{*}{$\begin{array}{c}\mathrm{T}\left({ }^{\circ} \mathrm{C}\right) \\
\mathbf{N a} / \mathbf{K} \\
\text { (Nieva and Nieva 1987) }\end{array}$} & \multirow{2}{*}{$\begin{array}{c}\mathrm{T}\left({ }^{\circ} \mathrm{C}\right) \\
\mathbf{N a / K} / \mathbf{K} \\
\text { (Giggenbach 1988) }\end{array}$} \\
\hline & & & & & $\mathrm{Ca}$ & $\mathbf{K}$ & $\mathrm{Na}$ & & & & & & & & & \\
\hline & blank & 0.0 & room $\mathrm{T}$ & 1 & 3.4 & 116.2 & 725.3 & & 261 & 245 & 260 & 235 & 256 & 256 & 247 & 273 \\
\hline & 1 & 20.6 & room T & 1 & 7.1 & 106.73 & 710.52 & & & & & & & & & \\
\hline & 2 & 45.6 & room $\mathrm{T}$ & 1 & 5.9 & 122.32 & 710.95 & & & & & & & & & \\
\hline & 3 & 72.8 & room $\mathrm{T}$ & 1 & 6.1 & 117.18 & 720.04 & & & & & & & & & \\
\hline & 4 & 94.8 & room $\mathrm{T}$ & 1 & 5.6 & 115.97 & 724.53 & & & & & & & & & \\
\hline & 5 & 118.9 & room T & 1 & 5.1 & 114.99 & 716.89 & & & & & & & & & \\
\hline & 6 & 143.1 & room $\mathrm{T}$ & 1 & 5.2 & 113.79 & 711.96 & & & & & & & & & \\
\hline & 7 & 166.7 & room $\mathrm{T}$ & 1 & 4.9 & 114.6 & 716.9 & & & & & & & & & \\
\hline \multirow{31}{*}{ T-shift } & 8 & 190.9 & 400 & 483 & 3.2 & $\begin{array}{l}192.5 \\
\end{array}$ & 597.7 & & 343 & 361 & 314 & 348 & 329 & 382 & 327 & 347 \\
\hline & 9 & 214.7 & 400 & 483 & 2.0 & 196.5 & 623.5 & & 340 & 357 & 320 & 343 & 326 & 377 & 324 & 344 \\
\hline & 10 & 239.3 & 400 & 483 & 2.2 & 149.5 & 666.1 & & 298 & 295 & 290 & 284 & 289 & 310 & 283 & 306 \\
\hline & 11 & 262.6 & 400 & 483 & 2.8 & 144.8 & 684.6 & & 291 & 285 & 283 & 274 & 283 & 299 & 276 & 300 \\
\hline & 12 & 287.9 & 400 & 483 & 2.6 & 150.9 & 692.5 & & 294 & 290 & 287 & 279 & 286 & 305 & 279 & 303 \\
\hline & 13 & 313.4 & 400 & 483 & 2.3 & 151.5 & 697.6 & & 294 & 290 & 288 & 279 & 285 & 304 & 279 & 303 \\
\hline & 14 & 334.4 & 400 & 483 & 2.5 & 148.7 & 689.8 & & 293 & 288 & 286 & 277 & 285 & 303 & 278 & 302 \\
\hline & 15 & 359.0 & 400 & 483 & 2.7 & 147.9 & 696.9 & & 291 & 286 & 284 & 275 & 283 & 300 & 276 & 300 \\
\hline & 16 & 382.7 & 400 & 483 & 2.7 & 145.3 & 681.6 & & 292 & 287 & 284 & 276 & 283 & 301 & 277 & 301 \\
\hline & 17 & 406.0 & 400 & 483 & 3.0 & 141.6 & 684.8 & & 288 & 282 & 281 & 271 & 280 & 296 & 274 & 298 \\
\hline & 18 & 430.6 & 400 & 483 & 3.8 & 136.2 & 688.8 & & 283 & 275 & 274 & 264 & 276 & 288 & 269 & 293 \\
\hline & 19 & 457.3 & 400 & 483 & 3.7 & 132.1 & 694.3 & & 279 & 269 & 271 & 259 & 272 & 282 & 265 & 289 \\
\hline & 20 & 480.7 & 400 & 483 & 4.3 & 122.6 & 693.2 & & 271 & 258 & 264 & 248 & 265 & 270 & 257 & 282 \\
\hline & 21 & 503.3 & 400 & 483 & 4.0 & 114.4 & 710.1 & & 262 & 245 & 258 & 236 & 256 & 256 & 247 & 273 \\
\hline & 22 & 527.7 & 400 & 483 & 4.3 & 106.3 & 706.0 & & 255 & 236 & 252 & 227 & 250 & 247 & 241 & 267 \\
\hline & 23 & 550.4 & 400 & 483 & 4.9 & 103.1 & 713.4 & & 251 & 231 & 248 & 222 & 246 & 241 & 237 & 264 \\
\hline & \multirow[t]{3}{*}{24} & \multirow[t]{3}{*}{574.8} & \multirow[t]{3}{*}{400} & \multirow[t]{3}{*}{483} & \multirow[t]{3}{*}{3.9} & \multirow[t]{3}{*}{100.4} & 714.8 & & 248 & 227 & 249 & 218 & 244 & 237 & 234 & 261 \\
\hline & & & & & & & & $\begin{array}{c}\text { T( }\left(^{\circ} \text { C) AVERAGE }\right. \\
\text { ( } \mathrm{SiO}_{2} \text { above } \\
\text { quartz saturation) }\end{array}$ & 287 & 280 & 278 & 269 & 279 & 294 & 272 & 296 \\
\hline & & & & & & & & $1 \sigma$ & 26 & 37 & 20 & 36 & 24 & 40 & 26 & 24 \\
\hline & 25 & 597.6 & 400 & 483 & 4.2 & 98.8 & 701.6 & & 248 & 228 & 247 & 218 & 244 & 237 & 234 & 261 \\
\hline & 26 & 625.7 & 400 & 483 & 3.3 & 96.3 & 699.7 & & 246 & 225 & 249 & 216 & 242 & 234 & 232 & 259 \\
\hline & 27 & 647.5 & 400 & 483 & 3.8 & 95.1 & 694.6 & & 246 & 224 & 246 & 215 & 242 & 234 & 232 & 259 \\
\hline & 28 & 670.8 & 400 & 483 & 4.4 & 95.3 & 727.2 & & 241 & 219 & 243 & 210 & 238 & 228 & 228 & 255 \\
\hline & 29 & 694.4 & 400 & 483 & 4.4 & 95.4 & 718.4 & & 243 & 220 & 243 & 211 & 239 & 230 & 229 & 256 \\
\hline & 30 & 718.8 & 400 & 483 & 3.8 & 95.1 & 724.5 & & 241 & 219 & 245 & 210 & 238 & 228 & 228 & 255 \\
\hline & 31 & 743.4 & 400 & 483 & 4.0 & 94.8 & 722.1 & & 241 & 219 & 244 & 210 & 238 & 228 & 228 & 255 \\
\hline & 32 & 767.5 & 400 & 483 & 4.0 & 92.3 & 711.8 & & 240 & 217 & 243 & 209 & 237 & 227 & 227 & 254 \\
\hline & 33 & 809.2 & 400 & 483 & 5.7 & 93.3 & 741.6 & & 237 & 214 & 237 & 205 & 234 & 223 & 224 & 251 \\
\hline & 34 & 853.2 & 400 & 483 & 3.9 & 92.1 & 735.9 & & 237 & 213 & 241 & 204 & 234 & 222 & 223 & 251 \\
\hline & & & & & & & & $\begin{array}{c}\mathrm{T}\left({ }^{\circ} \mathrm{C}\right) \text { AVERAGE } \\
\text { ( } \mathrm{SiO}_{2} \text { below } \\
\text { quartz saturation) }\end{array}$ & 242 & 220 & 244 & 211 & 239 & 229 & 228 & 256 \\
\hline & & & & & & & & $1 \sigma$ & 4 & 5 & 3 & 5 & 3 & 5 & 4 & 3 \\
\hline
\end{tabular}




\section{$\mathrm{BGB2}-350^{\circ} \mathrm{C} / 486 \mathrm{bar}$}

\begin{tabular}{|c|c|c|c|c|c|c|c|c|c|c|c|c|c|c|c|}
\hline \multirow[b]{3}{*}{$\mathbf{n}^{\circ}$ samples } & \multirow[b]{3}{*}{ time } & \multirow[b]{3}{*}{$\mathrm{T}\left({ }^{\circ} \mathrm{C}\right)$} & \multirow[b]{3}{*}{ P (bar) } & \multicolumn{3}{|c|}{$\mathrm{mg} \mathrm{kg}^{-1}$} & & \multirow{3}{*}{$\begin{array}{c}\mathrm{T}\left({ }^{\circ} \mathrm{C} \text { ) }\right. \\
\mathbf{N a / K} \\
\text { (Fournier 1979) }\end{array}$} & \multirow{3}{*}{$\begin{array}{c}\mathrm{T}\left({ }^{\circ} \mathrm{C} \text { ) }\right. \\
\begin{array}{c}\text { Na/K } \\
\text { (Truesdell 1976) }\end{array}\end{array}$} & \multirow{3}{*}{$\begin{array}{c}\mathrm{T}\left({ }^{\circ} \mathrm{C}\right) \\
\mathbf{N a} / \mathrm{K} / \mathbf{C a} \\
\text { (Fournier and } \\
\text { Truesdell 1973) } \\
\boldsymbol{\beta}=\mathbf{1} / \mathbf{3}\end{array}$} & \multirow{3}{*}{$\begin{array}{c}\mathrm{T}\left({ }^{\circ} \mathrm{C}\right) \\
\text { Na/K } \\
\text { (Santoyo and } \\
\text { Diaz-González 2009) }\end{array}$} & \multirow{3}{*}{$\begin{array}{c}\mathrm{T}\left({ }^{\circ} \mathrm{C}\right) \\
\mathrm{Na} / \mathrm{K} \\
\text { (Arnorsson 1983) }\end{array}$} & \multirow{3}{*}{$\begin{array}{c}\mathrm{T}\left({ }^{\circ} \mathrm{C}\right) \\
\mathbf{N a / K} \\
\text { (Tonani 1980) }\end{array}$} & \multirow{3}{*}{$\begin{array}{c}\mathrm{T}\left({ }^{\circ} \mathrm{C}\right) \\
\text { Na/K } \\
\text { (Nieva and Nieva 1987) }\end{array}$} & \multirow{3}{*}{$\begin{array}{c}\mathrm{T}\left({ }^{\circ} \mathrm{C}\right) \\
\text { Na/K } \\
\text { (Giggeabach 1988) }\end{array}$} \\
\hline & & & & & & & & & & & & & & & \\
\hline & & & & $\mathrm{Ca}$ & $\mathbf{K}$ & $\mathbf{N a}$ & & & & & & & & & \\
\hline blank & 0.0 & room $T$ & 1 & 7.2 & 116.0 & 725.0 & & 261 & 244 & 182 & 235 & 256 & 255 & 247 & 273 \\
\hline 1 & 21.2 & room T & 1 & & & & & & & & & & & & \\
\hline 2 & 47.3 & room T & 1 & & & & & & & & & & & & \\
\hline 3 & 71.4 & room $\mathrm{T}$ & 1 & & & & & & & & & & & & \\
\hline 4 & 93.7 & room $T$ & 1 & & & & & & & & & & & & \\
\hline 5 & 118.2 & room $\mathrm{T}$ & 1 & & & & & & & & & & & & \\
\hline $\begin{array}{l}6 \\
7\end{array}$ & $\begin{array}{l}141.8 \\
165.7\end{array}$ & $\begin{array}{l}\text { room } \mathrm{T} \\
\text { room } \mathrm{T}\end{array}$ & $\begin{array}{l}1 \\
1\end{array}$ & & & & & & & & & & & & \\
\hline 8 & 187.8 & 350 & 486 & 4.2 & 218.3 & 620.2 & & 395 & 442 & 259 & 426 & 374 & 472 & 378 & 392 \\
\hline 9 & 211.4 & 350 & 486 & 2.2 & 263.5 & 574.2 & & 395 & 442 & 259 & 426 & 374 & 472 & 378 & 392 \\
\hline 10 & 236.2 & 350 & 486 & 1.7 & 246.3 & 634.7 & & 369 & 401 & 252 & 387 & 352 & 426 & 353 & 370 \\
\hline 11 & 260.3 & 350 & 486 & 1.0 & 172.9 & 713.7 & & 307 & 308 & 226 & 296 & 297 & 324 & 292 & 314 \\
\hline 12 & 286.3 & 350 & 486 & 1.2 & 131.4 & 710.3 & & 276 & 265 & 207 & 255 & 269 & 277 & 262 & 287 \\
\hline 13 & 310.3 & 350 & 486 & 2.1 & 121.1 & 726.9 & & 265 & 250 & 196 & 240 & 259 & 261 & 251 & 277 \\
\hline 14 & 334.0 & 350 & 486 & 1.6 & 118.1 & 730.9 & & 262 & 246 & 197 & 236 & 256 & 257 & 248 & 274 \\
\hline 15 & 355.5 & 350 & 486 & 1.9 & 116.2 & 715.8 & & 262 & 246 & 195 & 237 & 257 & 258 & 248 & 274 \\
\hline 16 & 381.8 & 350 & 486 & 1.9 & 117.0 & 725.3 & & 262 & 245 & 195 & 236 & 256 & 257 & 248 & 274 \\
\hline 17 & 403.3 & 350 & 486 & 2.0 & 122.0 & 734.1 & & 265 & 250 & 196 & 240 & 259 & 261 & 251 & 276 \\
\hline 18 & 428.1 & 350 & 486 & 2.1 & 124.6 & 718.8 & & 269 & 256 & 198 & 246 & 263 & 267 & 255 & 280 \\
\hline 19 & 451.8 & 350 & 486 & 1.9 & 127.3 & 743.1 & & 268 & 254 & 198 & 244 & 262 & 266 & 254 & 279 \\
\hline 20 & 475.8 & 350 & 486 & 2.1 & 131.9 & 746.9 & & 271 & 258 & 200 & 248 & 265 & 270 & 257 & 282 \\
\hline 21 & 498.9 & 350 & 486 & 1.6 & 131.1 & 725.9 & & 273 & 261 & 203 & 251 & 267 & 274 & 259 & 284 \\
\hline 22 & 523.6 & 350 & 486 & 2.1 & 131.6 & 743.7 & & 271 & 258 & 200 & 248 & 265 & 270 & 257 & 282 \\
\hline 23 & 547.8 & 350 & 486 & 2.4 & 130.8 & 739.4 & & 271 & 258 & 198 & 248 & 265 & 271 & 257 & 282 \\
\hline 24 & 571.4 & 350 & 486 & 2.3 & 129.3 & 747.4 & & 269 & 255 & 198 & 245 & 263 & 267 & 255 & 280 \\
\hline 25 & 595.7 & 350 & 486 & 2.2 & 128.4 & 747.0 & & 268 & 254 & 198 & 244 & 262 & 266 & 254 & 280 \\
\hline 26 & 619.5 & 350 & 486 & 2.3 & 127.6 & 751.1 & & 267 & 253 & 196 & 243 & 261 & 264 & 253 & 278 \\
\hline 27 & 645.3 & 350 & 486 & 2.0 & 127.3 & 716.7 & & 272 & 259 & 200 & 249 & 265 & 271 & 257 & 283 \\
\hline 28 & 668.7 & 350 & 486 & 2.2 & 125.8 & 704.2 & & 272 & 260 & 199 & 250 & 266 & 272 & 258 & 283 \\
\hline 29 & 692.9 & 350 & 486 & 2.2 & 124.4 & 709.1 & & 270 & 257 & 198 & 247 & 264 & 269 & 256 & 282 \\
\hline \multirow[t]{3}{*}{30} & \multirow[t]{3}{*}{715.6} & \multirow[t]{3}{*}{350} & \multirow[t]{3}{*}{486} & \multirow[t]{3}{*}{2.7} & 125.0 & 746.0 & & 266 & 251 & 194 & 241 & 260 & 262 & 251 & 277 \\
\hline & & & & & & & 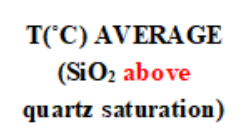 & 286 & 280 & 207 & 269 & 277 & 294 & 271 & 295 \\
\hline & & & & & & & $1 \sigma$ & 41 & 61 & 21 & 59 & 36 & 66 & 40 & 37 \\
\hline 31 & 739.8 & 350 & 486 & 1.8 & 122.4 & 712.2 & & 268 & 254 & 199 & 244 & 262 & 266 & 254 & 280 \\
\hline 32 & 764.8 & 350 & 486 & 2.6 & 125.3 & 749.2 & & 265 & 250 & 194 & 241 & 260 & 262 & 251 & 277 \\
\hline 33 & 788.5 & 350 & 486 & 2.3 & 118.7 & 751.3 & & 260 & 243 & 192 & 233 & 254 & 254 & 245 & 272 \\
\hline 34 & 814.5 & 350 & 486 & 2.5 & 116.3 & 747.2 & & 258 & 241 & 190 & 231 & 253 & 251 & 244 & 270 \\
\hline 35 & 837.6 & 350 & 486 & 2.5 & 114.3 & 705.7 & & 262 & 246 & 192 & 236 & 257 & 257 & 248 & 274 \\
\hline 36 & 860.2 & 350 & 486 & 1.9 & 117.8 & 756.3 & & 258 & 241 & 193 & 231 & 253 & 252 & 244 & 270 \\
\hline 37 & 883.8 & 350 & 486 & 2.0 & 113.2 & 724.1 & & 259 & 241 & 193 & 232 & 253 & 252 & 244 & 271 \\
\hline 38 & 907.8 & 350 & 486 & 2.1 & 113.3 & 712.3 & & 260 & 244 & 193 & 234 & 255 & 255 & 246 & 272 \\
\hline & & & & & & & $\begin{array}{c}\mathrm{T}\left({ }^{\mathrm{C} C)} \text { ) AVERAGE }\right. \\
\text { ( } \mathrm{Si \textrm {O } _ { 2 } \text { below }} \\
\text { quarts saturation) }\end{array}$ & 261 & 245 & 193 & 235 & 256 & 256 & 247 & 273 \\
\hline & & & & & & & $1 \sigma$ & 4 & 5 & 3 & 5 & 3 & 5 & 4 & 3 \\
\hline
\end{tabular}


$\mathrm{Na} / \mathrm{K}$ : Fournier (1979)

$\mathrm{Na} / \mathrm{K}:$ Truesdell (1976)

$\mathrm{Na} / \mathrm{K}$ : Santoyo and Gonzalez (2009)

$\mathrm{Na} / \mathrm{K}:$ Arnorsson (1983)

$\mathrm{Na} / \mathrm{K}$ : Tonani (1980)

$\mathrm{Na} / \mathrm{K}$ : Nieva and Nieva (1987)

$\mathrm{Na} / \mathrm{K}$ : Giggenbach (1988)

$\mathrm{Na} / \mathrm{K} / \mathrm{Ca}:$ Fournier and Truesdall (1973)

$$
T\left({ }^{\circ} \mathrm{C}\right)=\frac{1217}{1.438+\log \left(\frac{N a}{K}\right)}-273,15\left({ }^{\circ} \mathrm{K}\right)
$$

$$
T\left({ }^{\circ} \mathrm{C}\right)=\frac{855,6}{0.8573+\log \left(\frac{N a}{K}\right)}-273,15\left({ }^{\circ} \mathrm{K}\right)
$$

$$
T\left({ }^{\circ} \mathrm{C}\right)=\frac{876.3( \pm 26.26)}{0.8775( \pm 0.0508)+\log \left(\frac{N a}{K}\right)}-273,15\left({ }^{\circ} \mathrm{K}\right)
$$

$$
T\left({ }^{\circ} \mathrm{C}\right)=\frac{1319}{1.699+\log \left(\frac{N a}{K}\right)}-273,15\left({ }^{\circ} K\right)
$$

$$
T\left({ }^{\circ} \mathrm{C}\right)=\frac{883}{0.78+\log \left(\frac{N a}{K}\right)}-273,15\left({ }^{\circ} \mathrm{K}\right)
$$

$$
T\left({ }^{\circ} \mathrm{C}\right)=\frac{1178}{1.483+\log \left(\frac{N a}{K}\right)}-273,15\left({ }^{\circ} \mathrm{K}\right)
$$

$$
T\left({ }^{\circ} \mathrm{C}\right)=\frac{1390}{1.75+\log \left(\frac{N a}{K}\right)}-273,15\left({ }^{\circ} \mathrm{K}\right)
$$

$$
T\left({ }^{\circ} \mathrm{C}\right)=\frac{1647}{\log \left(\frac{N a}{K}\right)+\beta[\log (\sqrt{C a} / N a)+2.06]+2.47}-273,15\left({ }^{\circ} K\right)
$$


Appendices Doctoral Thesis: "Basalt - fluid interactions at subcritical and supercritical conditions: An experimental study" University of Victoria Wellington and GNS Science, Wairakei, New Zealand
by Mauro Passarella

Appendix D - (Chapter 5) 


\section{Chapter 5: The Experimental Behaviour of Seawater}

\subsection{Results}

5.2.1. Method development test $\left(377^{\circ} \mathrm{C} / 490 \mathrm{bar}\right)$

Figure D.5.1. EDS analysis of texture of the solid layer extracted from the bottom portion of the Preheater after the efficiency test with synthetic seawater and zirconia beads excluded
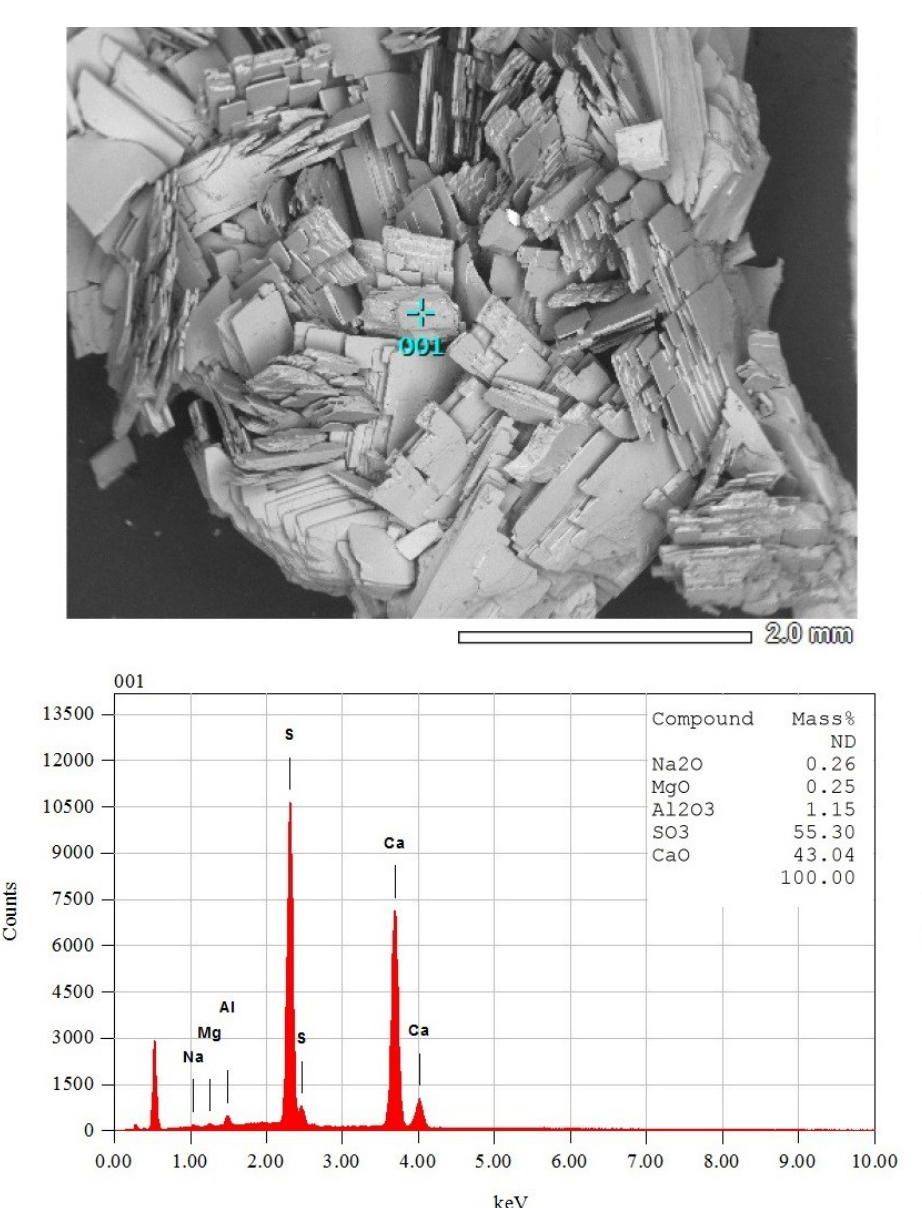
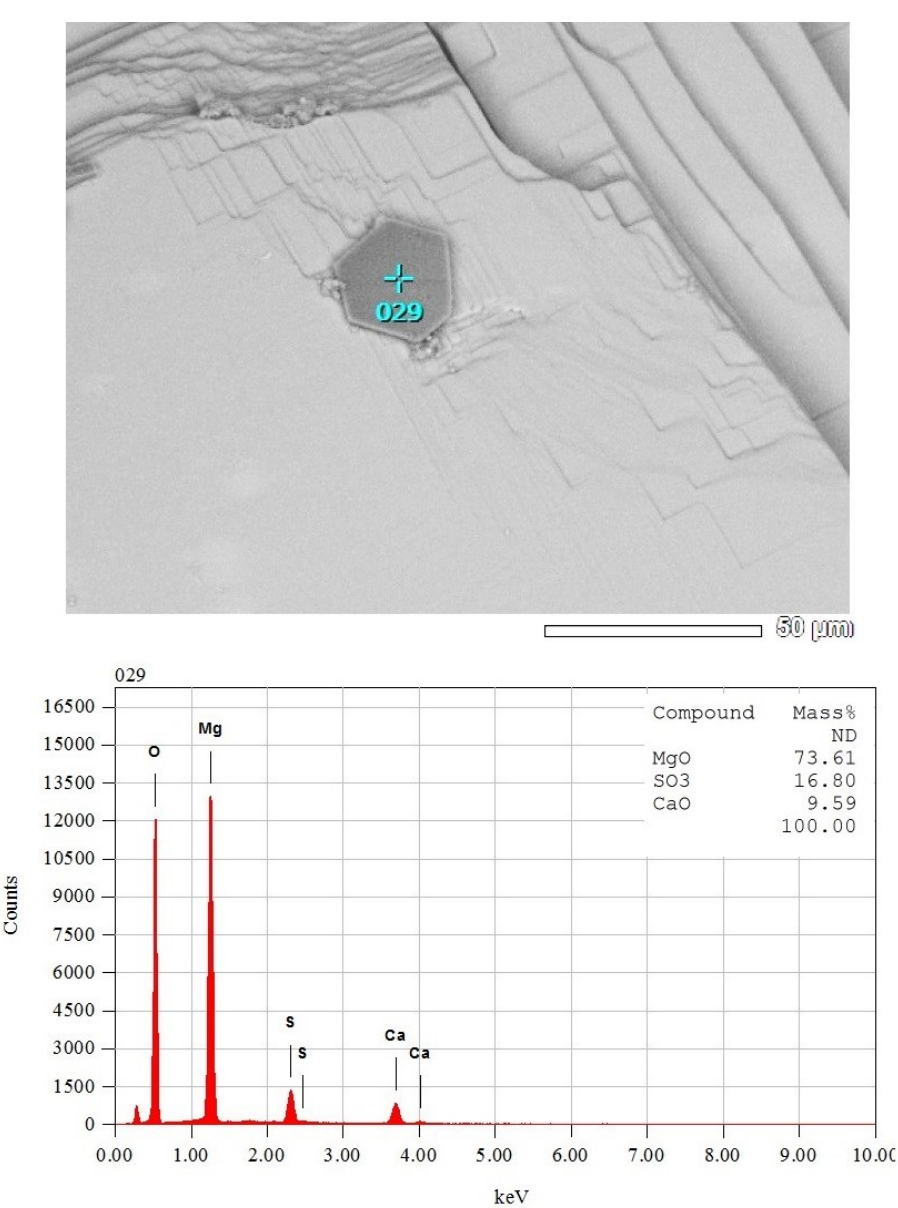
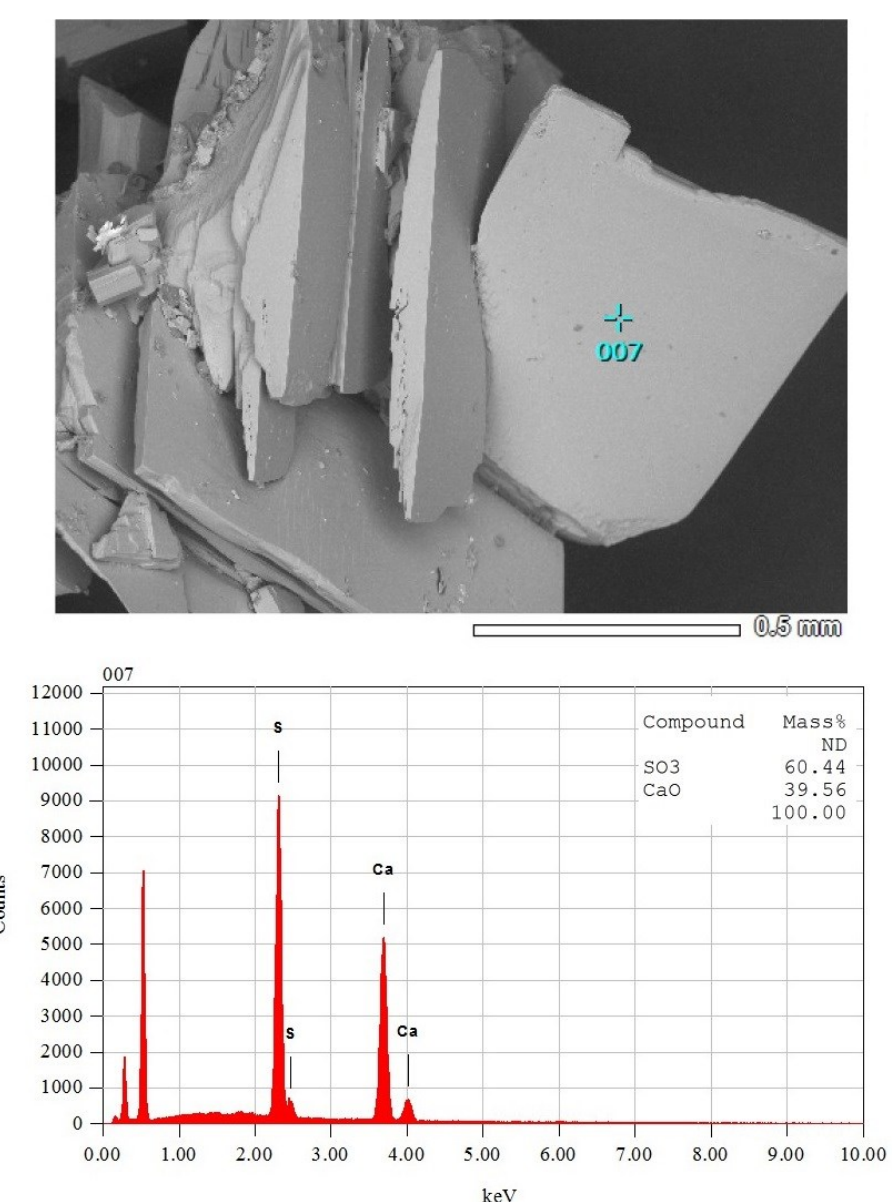
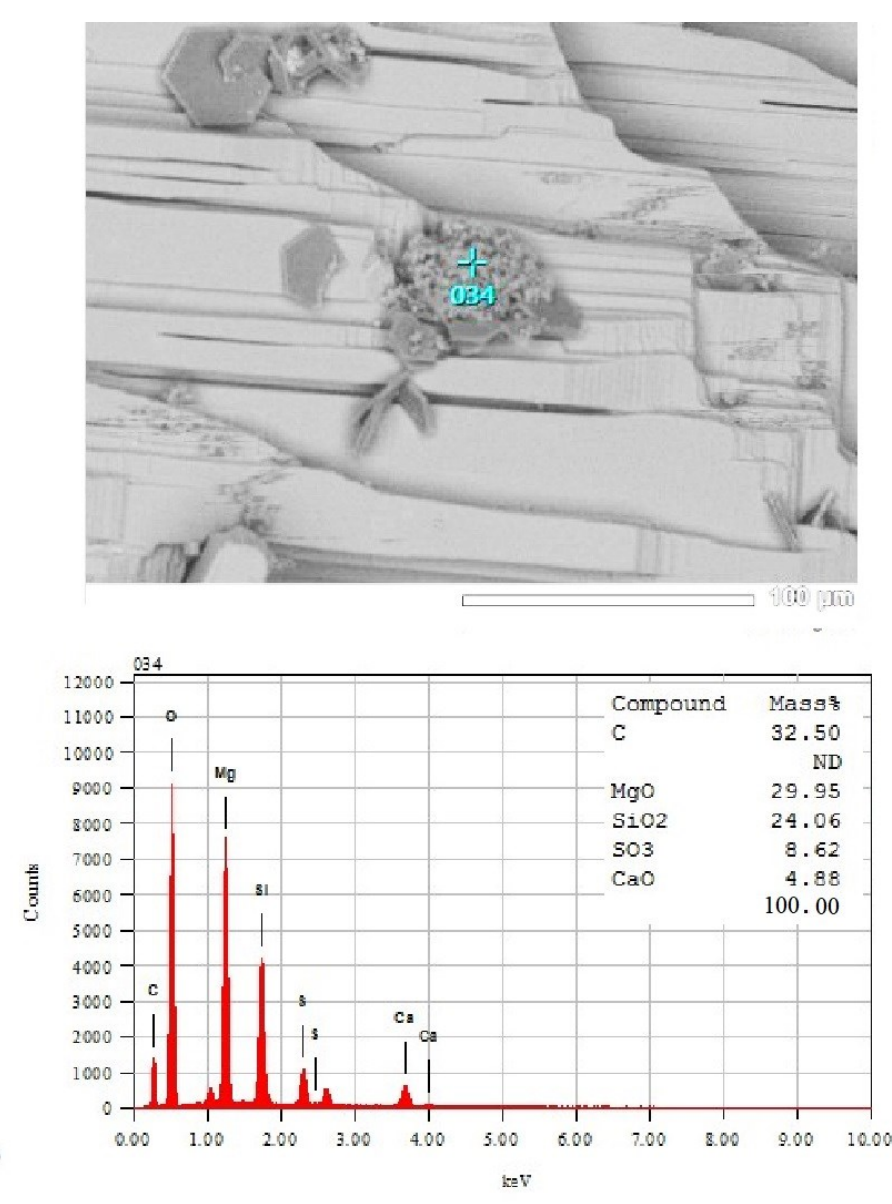
5.2.1. SW1: Natural seawater at $377^{\circ} \mathrm{C} / 488$ bar

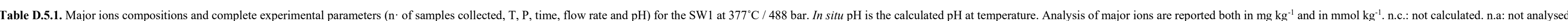

\begin{tabular}{|c|c|c|c|c|c|c|c|c|c|c|c|c|c|c|c|c|c|c|c|c|c|c|c|c|c|c|c|c|c|c|c|c|}
\hline \multirow[b]{2}{*}{$\mathrm{n}^{\circ}$ sample } & \multirow[b]{2}{*}{$\begin{array}{l}\mathrm{T} \\
\left({ }^{\circ} \mathrm{C}\right)\end{array}$} & \multirow[b]{2}{*}{$\begin{array}{c}\mathrm{P} \\
\text { (bar) }\end{array}$} & \multirow[b]{2}{*}{$\begin{array}{l}\text { time } \\
\text { (hrs) }\end{array}$} & \multirow[b]{2}{*}{$\begin{array}{l}\text { flow-rate } \\
\left(\mathrm{ml} \mathrm{hr}^{-1}\right)\end{array}$} & \multirow[b]{2}{*}{$\underset{\text { (room T) }}{\mathrm{pH}}$} & \multirow[b]{2}{*}{$\begin{array}{c}\mathrm{pH} \\
\left(375^{\circ} \mathrm{C}\right)\end{array}$} & \multicolumn{13}{|c|}{$\mathrm{mg} \mathrm{kg}^{-1}$} & \multicolumn{13}{|c|}{$\mathrm{mmol} \mathrm{kg}^{-1}$} \\
\hline & & & & & & & As & B & $\mathrm{Ca}$ & $\mathrm{Fe}$ & K & $\mathrm{Mg}$ & $\mathrm{Na}$ & $\mathrm{SiO}_{2}$ & Al & $\mathrm{Li}$ & $\mathrm{H}_{2} \mathrm{~S}$ & $\mathrm{Cl}$ & $\mathrm{SO}_{4}$ & As & B & $\mathrm{Ca}$ & $\mathrm{Fe}$ & $\mathrm{K}$ & $\mathrm{Mg}$ & $\mathrm{Na}$ & $\mathrm{SiO}_{2}$ & Al & $\mathrm{Li}$ & $\mathrm{H}_{2} \mathrm{~S}$ & $\mathrm{Cl}$ & $\mathrm{SO}_{4}$ \\
\hline $\begin{array}{c}\text { blank } \\
\text { water (distilled) }\end{array}$ & 19.6 & 1 & & - & 6.78 & n.c. & 0.03 & $<0.3$ & $<0.05$ & 0.1 & 4.7 & $<$ & 9. & 5.1 & 0.2 & 0.02 & n.a. & 1.1 & $<0.1$ & 0004 & $<0.03$ & $<0.001$ & 0.002 & 0.12 & .0004 & 0.4 & .1 & 0.01 & 0.002 & n.a. & 0.03 & $<0.001$ \\
\hline $\begin{array}{c}\text { blank } \\
\text { seawater (natural) }\end{array}$ & 19.6 & 1 & 0.0 & - & 7. & n.c. & 15 & 2.2 & 376.7 & 0.1 & 365.4 & 1112.1 & 96 & 6. & 0. & 0.2 & $<0.01$ & .4 & 2117.3 & $<0.002$ & 0.2 & 9.4 & 0.002 & 9.4 & 8 & 20 & 0.1 & 0.01 & 0.02 & $<0.0003$ & 432 & 22 \\
\hline 1 & 377 & 487.1 & 24.2 & 1 & 6.70 & 5.32 & 0.03 & $<0.3$ & $<0.05$ & $<0.08$ & 7.0 & 5.0 & 43.9 & 5.4 & 0.5 & 0.01 & $<0.01$ & 26.6 & 6.5 & 0.0004 & $<0.03$ & $<0.001$ & $<0.001$ & 0.18 & 0.20 & 1.9 & 0.1 & 0.02 & 0.002 & $<0.0003$ & 0.7 & 0.07 \\
\hline 2 & 377 & 487.7 & 44.5 & 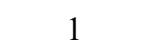 & & & $<0.015$ & $<0.3$ & 0.4 & 0.08 & 4.3 & & & & 0.1 & 0.02 & $<0.01$ & 14. & 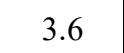 & $<0.0002$ & $<0.03$ & 0.01 & 0.001 & 0.11 & & 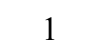 & & 0.005 & 0.003 & $<0.0003$ & 0.4 & 0.04 \\
\hline 3 & 377 & 486.8 & 68.9 & 1 & & 6.49 & $<0.015$ & $<0.3$ & $<0.05$ & $<0.08$ & 2.2 & $<0$ & 13. & 6. & 0. & 0.01 & $<0.01$ & 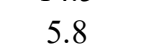 & 3.1 & $<0.0002$ & $<0.03$ & $<0.001$ & $<0.001$ & 0.06 & $<0.0004$ & 0.6 & 0.1 & .01 & 0.002 & $<0.0003$ & 0.2 & 0.03 \\
\hline 4 & 37 & 486.5 & 93.0 & 1 & & 6. & 0.04 & $<0.3$ & $<0.05$ & 0.1 & 0.8 & $<0.01$ & 4. & 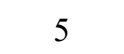 & 0.2 & $<0.01$ & $<0.01$ & 6 & 9 & 0.0005 & $<0.03$ & $<0.001$ & 0.003 & 0.02 & $<0.0004$ & 0.2 & & 0.01 & $<0.001$ & $<0.0003$ & 0.2 & 0.02 \\
\hline 5 & 37 & 486.8 & 115.8 & 1 & & 6 & 0.05 & $<0.3$ & $<0.05$ & $<0.08$ & 0.4 & $<0.01$ & 9 & 0 & 0. & 0.02 & $<0.01$ & 2.6 & 3 & 0007 & $<0.03$ & $<0.001$ & $<0.001$ & 0.01 & $<0.0004$ & 0.4 & 1 & 0.01 & 0.003 & $<0.0003$ & 0.1 & 0.01 \\
\hline 6 & 3 & & & 1 & & & $<0.015$ & $<0.3$ & $<0.05$ & 0.4 & 5. & & & & & 0.01 & $<0.01$ & 198 & & 002 & $<0.03$ & $<0.001$ & 0.008 & 0.13 & 0.32 & & & & & $<0.0003$ & 5.6 & 0.03 \\
\hline 7 & 37 & 487.6 & 163.4 & 1 & & 5.25 & 0.03 & $<0.3$ & 36.3 & 7.0 & 90.7 & 170.3 & 2553.8 & & 0. & 0.1 & $<0.01$ & 4793.1 & 22 & 0004 & $<0.03$ & 0.9 & 0.1 & 2.3 & 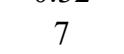 & 111.1 & .1 & .02 & 0.008 & $<0.0003$ & 135.2 & 0.2 \\
\hline 8 & 37 & & 186.6 & 1 & & 5.33 & 0.02 & $<0.3$ & 76.5 & 40.7 & 194.6 & 356.3 & 5322.4 & 5. & & 0.1 & $<0.01$ & 9832.7 & & 03 & $<0.03$ & 1.9 & & & 4.7 & 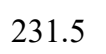 & & & 0.01 & $<0.0003$ & 277.4 & 0.6 \\
\hline 9 & 37 & 487.2 & 211.0 & 1 & & 5. & 0.03 & $<0.3$ & 80.7 & 59.4 & 242.7 & 434.1 & 6620.9 & 8 & 0 & 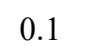 & $<0.01$ & 12226.4 & & 04 & $<0.03$ & & & 6.2 & & 288 & & 2 & 2 & $<0.0003$ & 344.9 & 0.9 \\
\hline 10 & & & & 1 & & & 002 & $<0.3$ & 79.1 & 51.3 & & & & & & & & & & & $<0$. & & & & 4 & & & & & $<0.0003$ & 381.8 & 1 \\
\hline 11 & 37 & & & 1 & & & & $<0.3$ & 79.9 & 54.1 & 305.0 & & & & & 0.2 & $<0.01$ & & & & & & & & & & & & 02 & $<0.0003$ & 410.5 & 1.1 \\
\hline 12 & 37 & 6 & 2 & 1 & & & $<0.015$ & $<0.3$ & 79.5 & 56.7 & 301.8 & & & & & ? & $<0.01$ & 15074.7 & 10 & .0002 & $<0$ & & & & 3 & & & & & $<0.0003$ & 425.2 & 1.1 \\
\hline 13 & & & & 1 & & & & $<0.3$ & 83.5 & 60.2 & 324.0 & & & & 0 & 0.2 & & & & & $<0$ & & & & & & & & & . 0003 & 414.2 & 1.2 \\
\hline 14 & 37 & 487.7 & 33 & 1 & & & $<0.015$ & $<0.3$ & 80.6 & 62.5 & 321.0 & & & & & 0.2 & $<0.01$ & 7.4 & & 002 & $<0.0$ & & & & & 368 & & & 03 & & 414.3 & 1.2 \\
\hline & & & & 1 & & & & $<0.3$ & & 63.9 & & & & & & & & & & & $<0$ & & & & & & & & & 03 & & 1.2 \\
\hline 1 & 31 & 487.4 & 378.1 & 1 & & & $<0.015$ & 5.2 & 7 & 66.3 & 343.8 & 585.6 & & 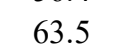 & 0 & 0.2 & $<0.01$ & & & 0002 & 0.49 & 1. & & & & 4 & 1.1 & 02 & 2 & .0003 & 440.3 & 1.2 \\
\hline $1^{\prime}$ & 37 & 487.8 & & 1 & & & $<0.015$ & 4.3 & & 72.0 & 369.1 & & & & $<0.006$ & 0.2 & $<0.01$ & & & & & & & & & & & & & & & 1.2 \\
\hline 1 & 37 & 487.9 & 428.4 & 1 & & & $<0.015$ & 3.8 & 83 & 74.7 & 372.2 & 62 & 901 & 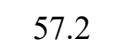 & 0 & 0.1 & $<0$ & & 11 & & 0.36 & 2.1 & & 9.5 & 25.8 & 392.3 & 1 & 0.01 & 0.02 & 3 & .7 & 1.2 \\
\hline & 37 & & & & & & & 3. & & 73.1 & & & & & & & & & & & & & & & & & & & & & & \\
\hline 2 & Jו & 487.6 & & 1 & & & & 3.4 & 77.7 & 72.6 & 347.5 & & & נכנ & 0 & 0. & $<0.01$ & & & & & 1. & 1 & 8.9 & 24.2 & & 0. & 0.01 & 0.02 & $<0.0003$ & 427.5 & 1.1 \\
\hline 2 & 37 & 487.9 & 498.5 & 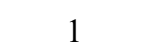 & & 5.3 & $<0.015$ & 3.2 & 76.1 & 73.6 & 346.3 & 591.2 & 8503.8 & 53.6 & $<0.006$ & 0.1 & $<0.01$ & 15391.5 & 11 & $<0.0002$ & 0.30 & 1.9 & & 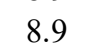 & 24.3 & 369.9 & 0.9 & $<0.005$ & 0.02 & $<0.0003$ & 434.2 & 1.2 \\
\hline 22 & 37 & 487.3 & & 1 & & & $<0.015$ & 3.0 & 81.9 & 79.5 & & & & 53 & 0.5 & 0. & & & & & & 2 & 1. & 9.2 & 25.9 & & 0.9 & 0.02 & 0.02 & & & \\
\hline 23 & 377 & 487.5 & 546.7 & 1 & 3.22 & 5.38 & $<0.015$ & 2.9 & 83.7 & 74.6 & 345.9 & 593.3 & 8530.3 & 52.1 & 0.2 & 0.1 & 0.01 & 15586.5 & 119.7 & $<0.0002$ & 0.26 & 2.1 & 1.3 & 8.8 & 24.4 & 371 & 0.9 & 0.01 & 0.01 & $<0.0003$ & 439.7 & 1.2 \\
\hline
\end{tabular}




\begin{tabular}{|c|c|c|c|c|c|c|c|c|c|c|c|c|c|c|c|c|c|c|c|}
\hline & & & & & & & $\mu \mathrm{mol} k g$ & & & & & & & & & & & & $\mathrm{mmol} \mathrm{kg}^{-1}$ \\
\hline $\mathrm{n}^{\circ}$ sample & $\begin{array}{c}\mathrm{T} \\
\left({ }^{\circ} \mathrm{C}\right)\end{array}$ & $\begin{array}{c}\mathrm{P} \\
\text { (bar) }\end{array}$ & $\begin{array}{l}\text { time } \\
\text { (hrs) }\end{array}$ & $\begin{array}{c}\text { flow-rate } \\
\left(\mathrm{ml} \mathrm{hr}^{-1}\right)\end{array}$ & $\begin{array}{c}\mathrm{pH} \\
\text { (room T) }\end{array}$ & $\begin{array}{c}\mathrm{pH} \\
\left(375^{\circ} \mathrm{C}\right)\end{array}$ & V & $\mathrm{Cr}$ & $\mathrm{Co}$ & $\mathrm{Ni}$ & $\mathrm{Cu}$ & $\mathrm{Zn}$ & $\mathrm{Rb}$ & $\mathrm{Ag}$ & $\mathrm{Cd}$ & $\mathrm{Ba}$ & $\mathrm{Au}$ & $\mathrm{Pb}$ & Mn \\
\hline $\begin{array}{c}\text { blank } \\
\text { water (distilled) }\end{array}$ & 20.1 & 1 & - & - & 6.78 & n.c. & $<0.002$ & $<0.004$ & $<0.002$ & $<0.003$ & $<0.0009$ & $<0.008$ & $<0.001$ & $<0.0005$ & $<0.0009$ & $<0.001$ & $<0.001$ & $<0.001$ & $<0.13$ \\
\hline $\begin{array}{c}\text { blank } \\
\text { seawater (natural) }\end{array}$ & 20.1 & 1 & 0.0 & - & 7.75 & n.c. & 0.04 & $<0.004$ & $<0.002$ & $<0.003$ & $<0.0009$ & $<0.008$ & 0.1 & $<0.0005$ & $<0.0009$ & $<0.001$ & 0.01 & $<0.001$ & $<0.13$ \\
\hline 1 & 377 & 487.1 & 24.2 & 1 & 6.70 & 5.32 & 0.2 & 0.2 & 0.02 & 0.4 & 1.6 & 10 & 0.03 & $<0.0005$ & $<0.0009$ & 0.4 & $<0.001$ & 0.01 & $<0.0001$ \\
\hline 2 & 377 & 487.7 & 44.5 & 1 & 5.96 & 5.95 & 0.2 & 0.09 & 0.02 & 0.3 & 1.6 & 10.7 & 0.03 & $<0.0005$ & 0.01 & 0.5 & $<0.001$ & 0.002 & 0.0001 \\
\hline 3 & 377 & 486.8 & 68.9 & 1 & 5.56 & 6.49 & 0.02 & 0.2 & 0.03 & 0.9 & 0.2 & 1.8 & 0.02 & $<0.0005$ & $<0.0009$ & 0.4 & $<0.001$ & 0.002 & 0.0007 \\
\hline 4 & 377 & 486.5 & 93.0 & 1 & 5.21 & 6.38 & 0.01 & 0.1 & 0.02 & 0.6 & 1 & 2.1 & 0.01 & $<0.0005$ & 0.01 & 0.3 & $<0.001$ & $<0.001$ & 0.0005 \\
\hline 5 & 377 & 486.8 & 115.8 & 1 & 5.53 & 6.21 & 0.004 & 0.1 & 0.02 & 0.4 & 0.2 & 1.9 & 0.01 & $<0.0005$ & $<0.0009$ & 0.3 & $<0.001$ & 0.002 & 0.0003 \\
\hline 6 & 377 & 488.2 & 138.8 & 1 & 4.69 & 5.21 & 0.01 & 0.1 & 0.05 & 0.9 & 0.2 & 7.2 & 0.02 & $<0.0005$ & $<0.0009$ & 0.5 & $<0.001$ & 0.01 & 0.003 \\
\hline 7 & 377 & 487.6 & 163.4 & 1 & 3.85 & 5.25 & 0.06 & 0.2 & 0.4 & 1.5 & 0.2 & 15.3 & 0.3 & $<0.0005$ & 0.01 & 7 & 0.06 & 0.02 & 0.02 \\
\hline 8 & 377 & 487.6 & 186.6 & 1 & 3.42 & 5.33 & 0.4 & 0.2 & 3.3 & 14.4 & 0.1 & 6.3 & 0.6 & $<0.0005$ & 0.05 & 4.8 & 0.06 & $<0.001$ & 0.03 \\
\hline 9 & 377 & 487.2 & 211.0 & 1 & 3.45 & 5.37 & 0.5 & 0.2 & 2.2 & 7.4 & 1 & 5.3 & 0.8 & $<0.0005$ & 0.08 & 3 & 0.06 & $<0.001$ & 0.02 \\
\hline 10 & 377 & 487.7 & 238.6 & 1 & 3.47 & 5.37 & 0.5 & 0.2 & 1.6 & 4.7 & 0.2 & 4.5 & 0.9 & $<0.0005$ & $<0.0009$ & 1.8 & 0.06 & $<0.001$ & 0.02 \\
\hline 11 & 377 & 487.4 & 261.8 & 1 & 3.40 & 5.37 & 0.8 & 0.2 & 2.3 & 8.1 & 0.1 & 3.8 & 0.9 & $<0.0005$ & 0.03 & 1.1 & 0.06 & $<0.001$ & 0.02 \\
\hline 12 & 377 & 487.6 & 283.2 & 1 & 3.37 & 5.38 & 0.9 & 0.1 & 2.5 & 9.3 & 0.3 & 16.3 & 0.9 & $<0.0005$ & 0.02 & 0.8 & 0.06 & $<0.001$ & 0.02 \\
\hline 13 & 377 & 487.7 & 309.0 & 1 & 3.36 & 5.38 & 1 & 0.1 & 2.8 & 11.1 & 0.1 & 11.3 & 1 & $<0.0005$ & 0.05 & 0.6 & 0.06 & $<0.001$ & 0.02 \\
\hline 14 & 377 & 487.7 & 331.0 & 1 & 3.31 & 5.38 & 1 & 0.1 & 3.1 & 13.1 & 0.1 & 2.5 & 0.9 & $<0.0005$ & 0.02 & 0.4 & 0.05 & $<0.001$ & 0.02 \\
\hline 15 & 377 & 487.7 & 354.3 & 1 & 3.30 & 5.39 & 1.1 & 1 & 3.5 & 14.9 & 33.1 & 41.3 & 0.9 & $<0.0005$ & 0.06 & 0.5 & 0.06 & 0.02 & 0.02 \\
\hline 16 & 377 & 487.4 & 378.1 & 1 & 3.29 & 5.37 & 1.2 & 0.2 & 3.8 & 16.8 & 0.1 & 5.7 & 1 & $<0.0005$ & $<0.0009$ & 0.4 & 0.05 & $<0.001$ & 0.02 \\
\hline 17 & 377 & 487.8 & 405.2 & 1 & 3.27 & 5.37 & 1.3 & 0.1 & 4.4 & 19.8 & 0.1 & 14.6 & 1 & $<0.0005$ & 0.03 & 0.4 & 0.05 & 0.03 & 0.02 \\
\hline 18 & 377 & 487.9 & 428.4 & 1 & 3.25 & 5.37 & 1.3 & 0.1 & 4.7 & 23.6 & 0.2 & 52.9 & 0.9 & $<0.0005$ & 0.03 & 0.5 & 0.05 & 0.05 & 0.02 \\
\hline 19 & 377 & 487.7 & 450.4 & 1 & 3.24 & 5.38 & 1.3 & 0.1 & 5 & 25.2 & 0.2 & 14.4 & 1 & $<0.0005$ & 0.01 & 0.4 & 0.05 & 0.04 & 0.02 \\
\hline 20 & 377 & 487.6 & 474.5 & 1 & 3.22 & 5.36 & n.a. & n.a. & n.a. & n.a. & n.a. & n.a. & n.a. & n.a. & n.a. & n.a. & n.a. & n.a. & 0.02 \\
\hline 21 & 377 & 487.9 & 498.5 & 1 & 3.21 & 5.38 & 1.5 & 0.1 & 5.4 & 29.1 & 0.2 & 19.6 & 1 & $<0.0005$ & 0.06 & 0.5 & 0.06 & 0.05 & 0.02 \\
\hline 22 & 377 & 487.3 & 522.6 & 1 & 3.19 & 5.35 & n.a. & n.a. & n.a. & n.a. & n.a. & n.a. & n.a. & n.a. & n.a. & n.a. & n.a. & n.a. & 0.02 \\
\hline 23 & 377 & 487.5 & 546.7 & 1 & 3.22 & 5.38 & 1.2 & 0.09 & 5.9 & 31.5 & 0.3 & 20.5 & 1 & $<0.0005$ & 0.06 & 0.4 & 0.04 & 0.05 & 0.02 \\
\hline
\end{tabular}


Figure D.5.2. EDS analysis of texture of the mineral phases and zirconia beads extracted from the bottom portion of the Preheater after the SW1 experiment $\left(377^{\circ} \mathrm{C} / 488 \mathrm{bar}\right)$
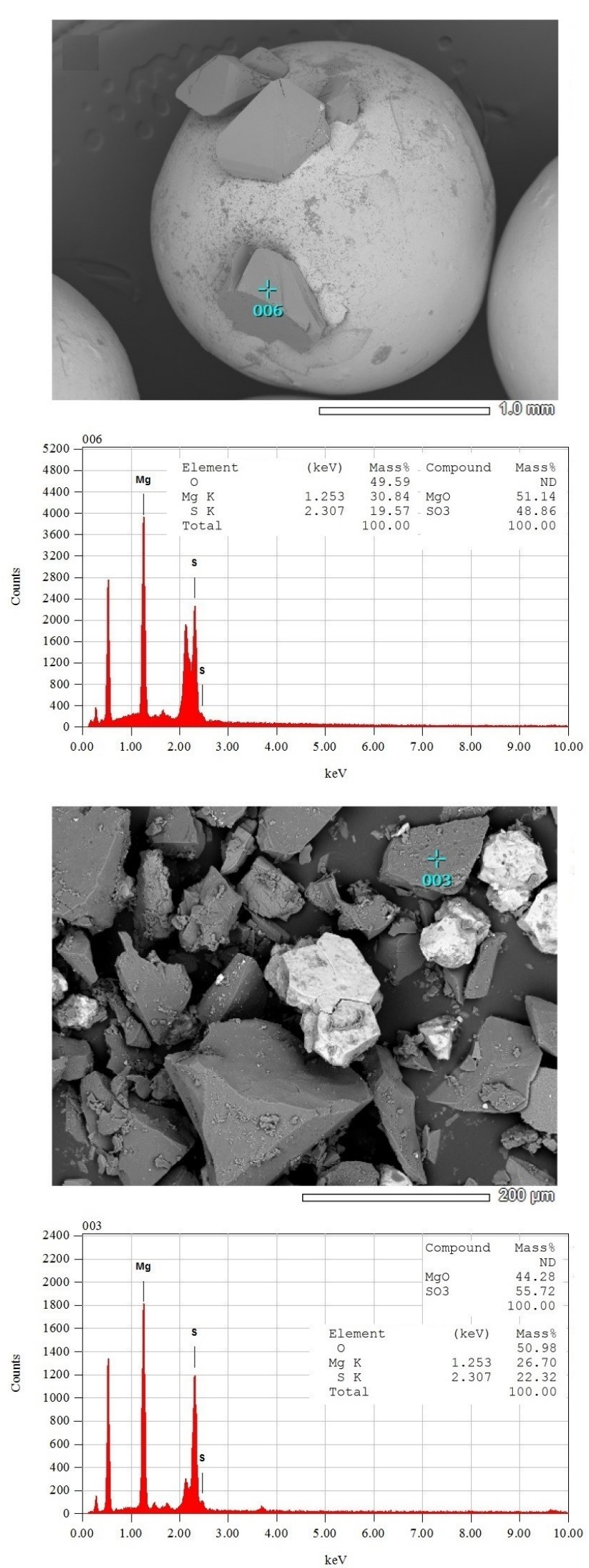
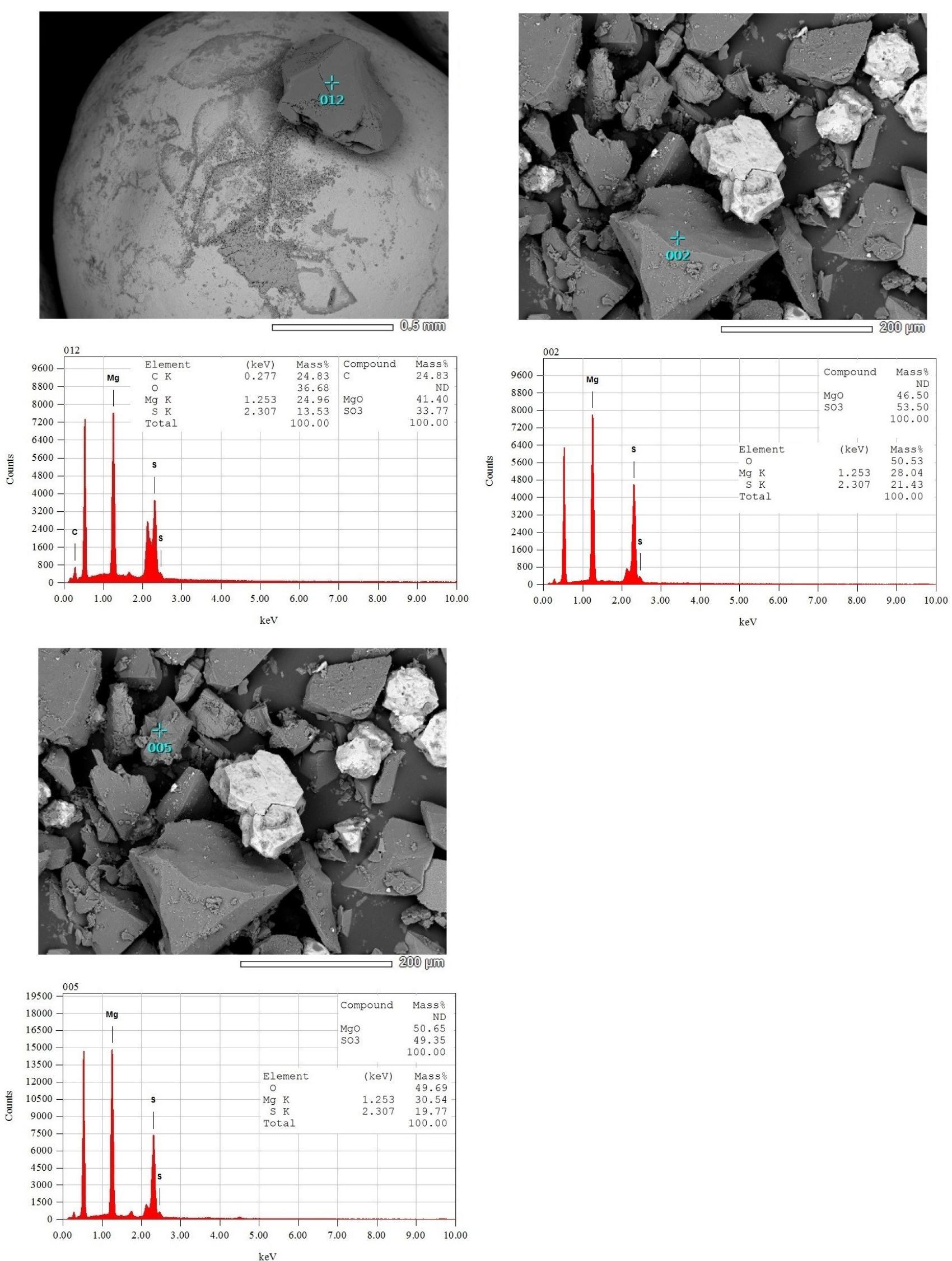
Figure D.5.3. EDS analysis of texture of zirconia beads extracted from the bottom portion of the Preheater after the $\mathrm{SW} 1$ experiment $\left(377^{\circ} \mathrm{C} / 488 \mathrm{bar}\right)$
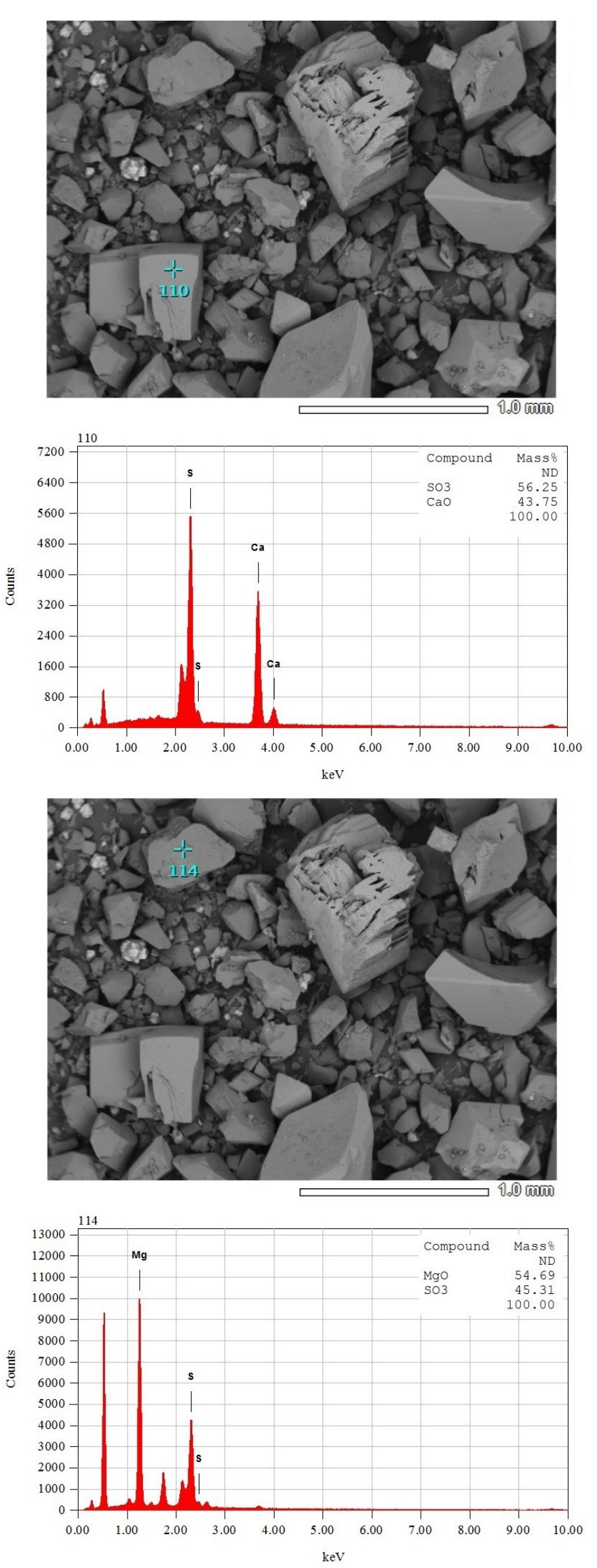
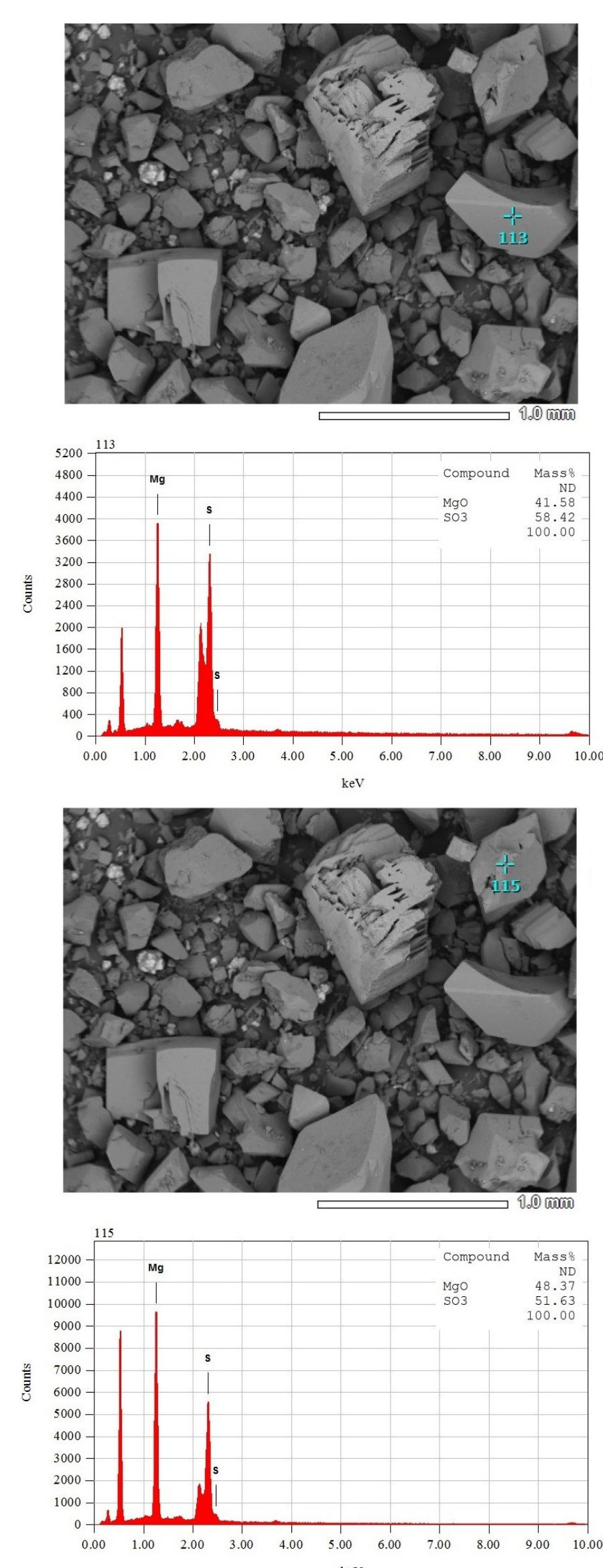
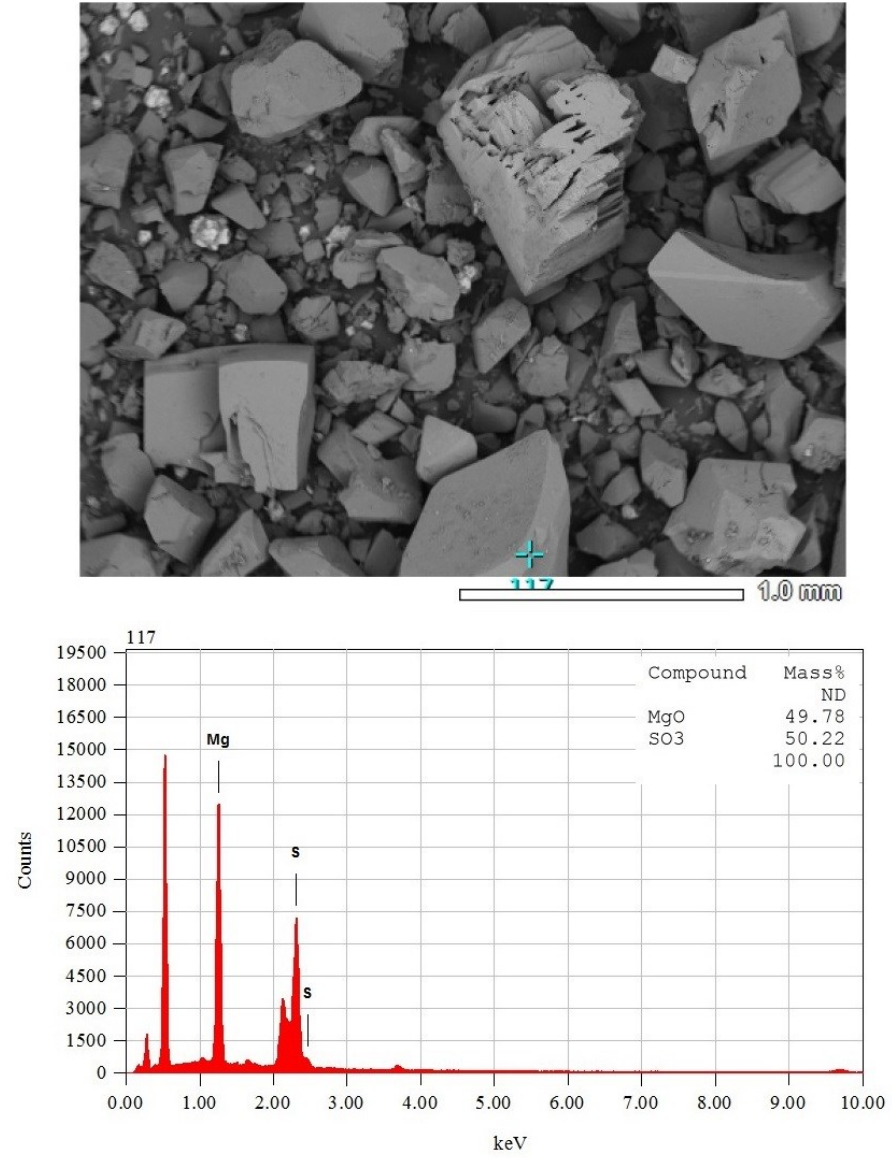
Figure D.5.4. SEM backscatter and EDS compositional maps of the polygonal shape found on a zirconia bead surface collected from the bottom (Portion 3) of Preheater after the SW1 experiment (377 ${ }^{\circ} \mathrm{C} / 488$ bar): (a) backscatter image; (b) composite colour image combining the backscatter image and elemental map for c) Mg in red
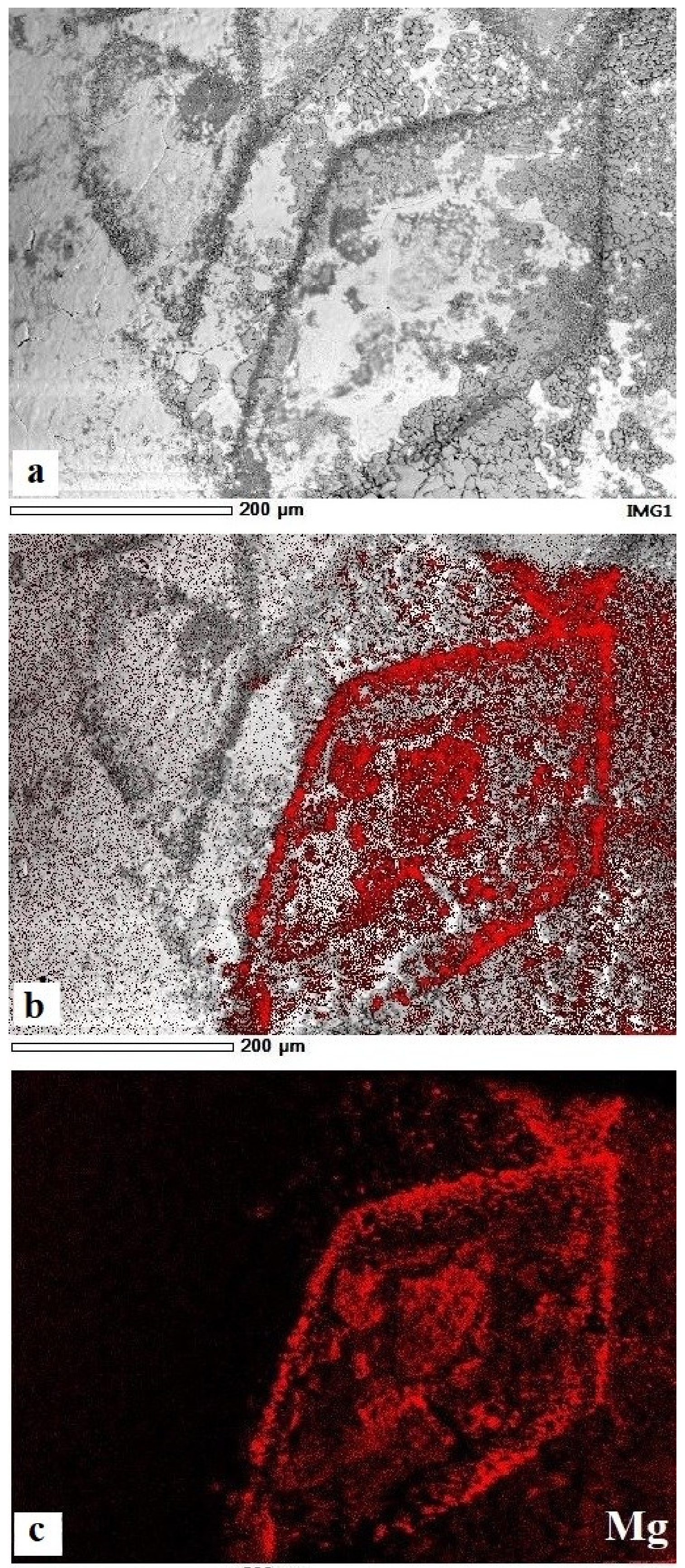
5.2.2. SW2: Natural seawater at $342^{\circ} \mathrm{C} / 488$ bar

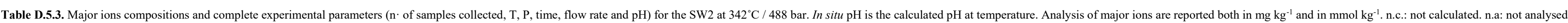

\begin{tabular}{|c|c|c|c|c|c|c|c|c|c|c|c|c|c|c|c|c|c|c|c|c|c|c|c|c|c|c|c|c|c|c|c|c|}
\hline \multirow[b]{2}{*}{$\mathrm{n}^{\circ}$ sample } & \multirow[b]{2}{*}{$\begin{array}{l}\mathrm{T} \\
\left({ }^{\circ} \mathrm{C}\right)\end{array}$} & \multirow[b]{2}{*}{$\begin{array}{c}\mathrm{P} \\
\text { (bar) }\end{array}$} & \multirow[b]{2}{*}{$\begin{array}{l}\text { time } \\
\text { (hrs) }\end{array}$} & \multirow[b]{2}{*}{$\begin{array}{l}\text { flow-rate } \\
\left(\mathrm{ml} \mathrm{hr}^{-1}\right)\end{array}$} & \multirow[b]{2}{*}{$\begin{array}{l}\mathrm{pH} \\
\text { (room } \\
\text { T) }\end{array}$} & \multirow[b]{2}{*}{$\begin{array}{c}\mathrm{pH} \\
\left(340^{\circ} \mathrm{C}\right)\end{array}$} & \multicolumn{13}{|c|}{$\mathbf{m g ~ k g}^{-1}$} & \multicolumn{13}{|c|}{$\mathbf{m m o l ~ k g} \mathrm{kg}^{-1}$} \\
\hline & & & & & & & As & B & $\mathrm{Ca}$ & $\mathrm{Fe}$ & K & $\mathrm{Mg}$ & $\mathrm{Na}$ & $\mathrm{SiO}_{2}$ & $\mathrm{Al}$ & $\mathrm{Li}$ & $\mathrm{H}_{2} \mathrm{~S}$ & $\mathrm{Cl}$ & $\mathrm{SO}_{4}$ & As & B & $\mathrm{Ca}$ & $\mathrm{Fe}$ & $\mathrm{K}$ & $\mathrm{Mg}$ & $\mathrm{Na}$ & $\mathrm{SiO}_{2}$ & $\mathrm{Al}$ & $\mathrm{Li}$ & $\mathrm{H}_{2} \mathrm{~S}$ & $\mathrm{Cl}$ & $\mathrm{SO}_{4}$ \\
\hline $\begin{array}{c}\text { blank } \\
\text { water (distilled) }\end{array}$ & 20.1 & 1 & - & - & 7.65 & n.c. & 0.02 & $<0.3$ & $<0.05$ & $<0.08$ & 3.8 & 0.1 & 6.8 & $<0.6$ & 0.2 & $<0.01$ & n.a. & $<0.1$ & 0.2 & 0.0003 & $<0.03$ & $<0.001$ & $<0.001$ & 0.1 & 0.005 & 0.3 & $<0.01$ & 0.007 & $<0.001$ & n.a. & $<0.003$ & 0.00 \\
\hline $\begin{array}{c}\text { blank } \\
\text { seawater (natural) }\end{array}$ & 20.1 & 1 & 0.0 & - & 7.65 & n.c. & $<0.015$ & 5.3 & 321.3 & 0.1 & 335.5 & 891.5 & 8308.5 & 5.8 & 0.2 & 0.2 & $<0.01$ & 15556.1 & 2236.7 & $<0.0002$ & 0.5 & 8 & 0.002 & 8.6 & 36.7 & 361 & 0.1 & 0.007 & 0.02 & $<0.0003$ & 439 & 23 \\
\hline 1 & 342 & 486.4 & 21.3 & 1 & 5.83 & 4.81 & 0.015 & 0.2 & 0.5 & 1.6 & 5.5 & 5.6 & 9.9 & 2.4 & 0.2 & 3 & $<0.01$ & 2.3 & 3 & $<0.0002$ & 0.02 & 0.01 & & 1 & & 0.4 & 0.04 & 7 & 0.004 & $<0.0003$ & 07 & 0.0 \\
\hline 2 & 342 & 486.8 & 45.3 & 1 & 5.24 & 5.5 & $<0.015$ & $<0.3$ & $<0.05$ & 0 & 2. & 0.1 & 3. & $<0.6$ & $<0.15$ & 0.02 & $<0.01$ & 1.9 & 0.1 & $<0.0002$ & $<0.03$ & $<0.001$ & 0.004 & 0.06 & 0.003 & 0.3 & 0.01 & $<0.006$ & 0.003 & $<0.0003$ & 0.05 & 0.001 \\
\hline 3 & 342 & 486.9 & 67.0 & 1 & 5.05 & 5.3 & 0.02 & $<0.3$ & 11 & 1.6 & 47 & 87.6 & 1198.1 & $<0.6$ & 0.6 & 0.04 & $<0.01$ & 1933.6 & 27.1 & 0.0003 & $<0.03$ & 0.3 & 0.03 & 1.2 & 3.6 & 52.1 & $<0.01$ & 0.02 & 0.006 & $<0.0003$ & 54.5 & 0.3 \\
\hline 4 & 342 & 487.1 & 92.1 & & & & & 0.4 & $20 ?$ & 10.2 & & & & 7 & 0 & 0.1 & $<0.01$ & 8925.8 & 102 & 0.0004 & 004 & & & & & & & & 000 & $<0.0003$ & 251.8 & 1.1 \\
\hline 5 & 32 & 487.3 & 11 & 1 & & & & 0.9 & & 3 & & & & & & & & & & $<0$. & & & & & & & & & & & & 1.8 \\
\hline 6 & 342 & 487.4 & 14 & 1 & 3.12 & 5. & $<0.015$ & 1 & 0 & 54.3 & & 52 & 7 & 4. & & 1 & $<0.01$ & 14511.4 & 214.2 & $<0.0002$ & 0.09 & 1 & 1 & 7.4 & 21.4 & 320.2 & 97 & 0.008 & 0.02 & 03 & 409.3 & 2.2 \\
\hline 7 & 342 & & & 1 & & & 15 & 1.2 & & 6 & & & & & & & & & & $<0$. & & & & 8 & & & & & & & & 2.6 \\
\hline 8 & & 487.2 & & & & & & 1.4 & & 7 & & & & 1 & $<$ & 1 & $<0.01$ & 4.5 & & $<0$ & & & & 8.2 & & & & & & 003 & 422.4 & 2.9 \\
\hline 9 & 34 & 487.4 & & & & & & 1.3 & 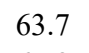 & 8 & & & & & & & $<0.01$ & & 2 & $<0$. & & & & & & & & & & 13 & 425.8 & \\
\hline 10 & 34 & 487.3 & & 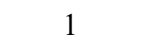 & & & $<1<$ & 1 & 6 & & & & & & & 2 & & & & $<0$. & & & & & & & 3 & & & & & 3 \\
\hline 1 & & 48 & & 1 & & & & 0. & 59 & & & & & & & & & & & & & & & & & & 3 & & & & 436.5 & 2.9 \\
\hline 12 & 342 & 487.2 & & 1 & 2.73 & 5 & $<0.015$ & 0.6 & 57.9 & 95.1 & 336.9 & 565.8 & 8462.2 & 16.1 & $<0.15$ & 2 & $<0.01$ & 15383.1 & 274.9 & $<0.0002$ & 0 & 1.4 & 1 & & 23.3 & 368.1 & 0.3 & $<0.006$ & 12 & 1003 & 433.9 & 2.9 \\
\hline 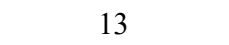 & 342 & 487.3 & & 1 & 2.75 & & $<0.015$ & 0.7 & 55.4 & -0 & 325.9 & 542.3 & 41.4 & 156 & $<0.15$ & .2 & $<0.01$ & 15465.7 & 270.2 & $<0.0002$ & 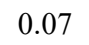 & 1 & & & 22 & 3541 & (2) & $<0.006$ & 02 & .0003 & 436.3 & 2.8 \\
\hline 1 & & 487 & & & & & $<0.015$ & 0.1 & 57 & 98.6 & & & & $1:$ & & & $<0.01$ & & & $<0.0002$ & & & & & & 37 & & & & 0003 & & \\
\hline & & 487.3 & & 1 & & & 15 & 0.1 & 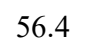 & 96 & & & & & & 1 & $<0.01$ & & & & & & 1. & & & 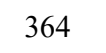 & 0.2 & 0.006 & 02 & .0003 & 434.2 & .8 \\
\hline & 342 & 487.2 & .2 & 1 & 2.72 & 552 & $<0.015$ & 0.1 & 56 & 94.5 & .9 & 554.4 & 8353 & 146 & $<0.15$ & 0.1 & $<0.01$ & 15238.3 & 260.2 & $<0.0002$ & 0.01 & 14 & 17 & 85 & 2.8 & 363. & 0.2 & $<0.006$ & 02 & 0.0003 & 429.9 & 7 \\
\hline
\end{tabular}




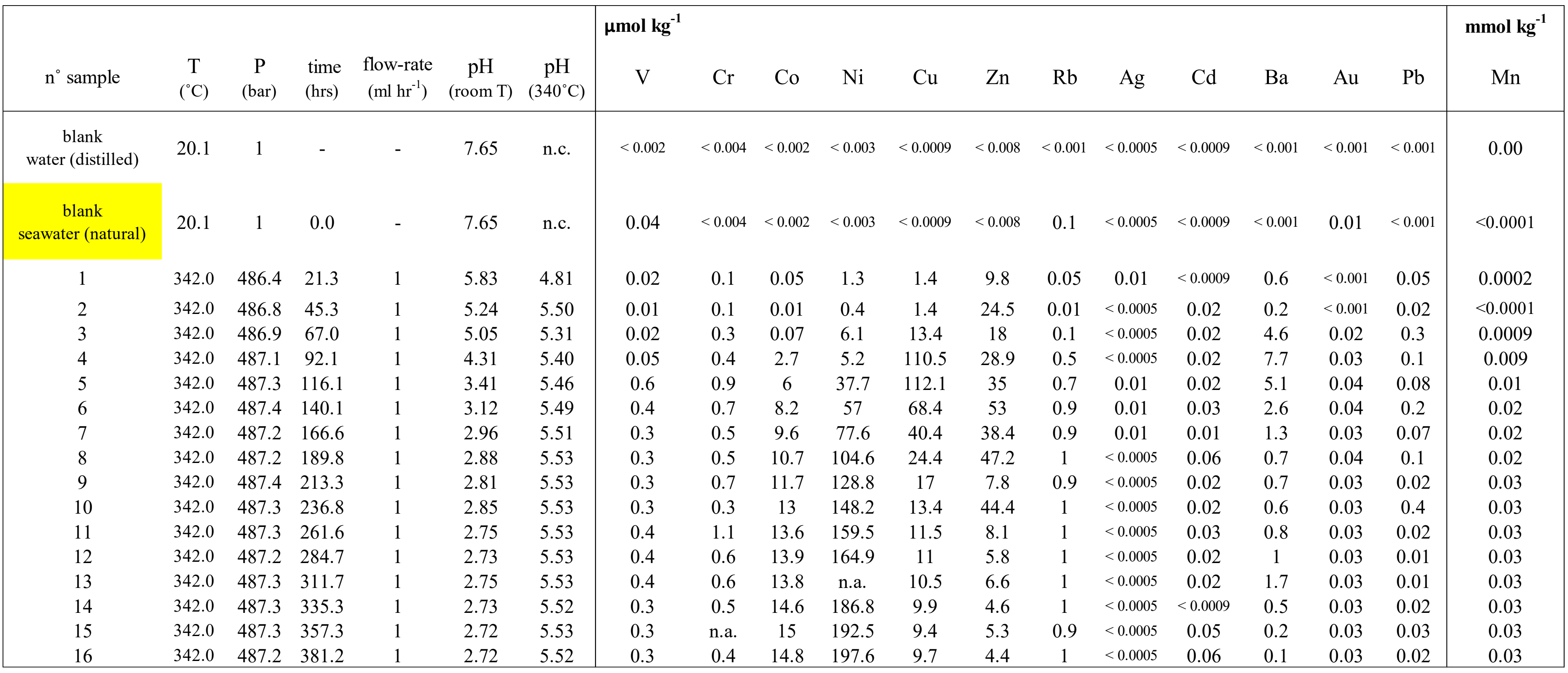


Figure D.5.5. EDS analysis of the precipitate collected from the bottom portion of the Preheater after the SW2 experiment $\left(342^{\circ} \mathrm{C} / 488 \mathrm{bar}\right)$
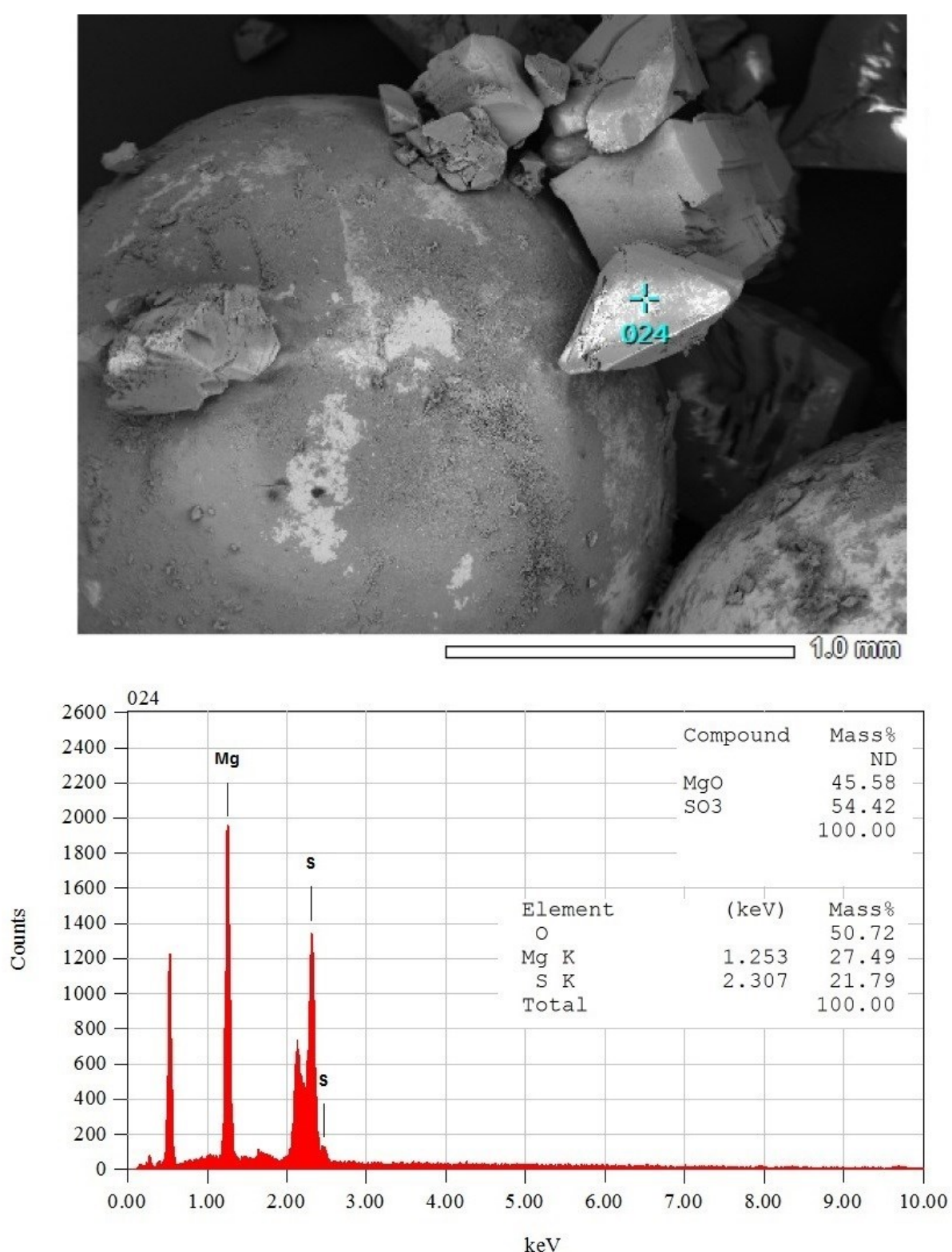
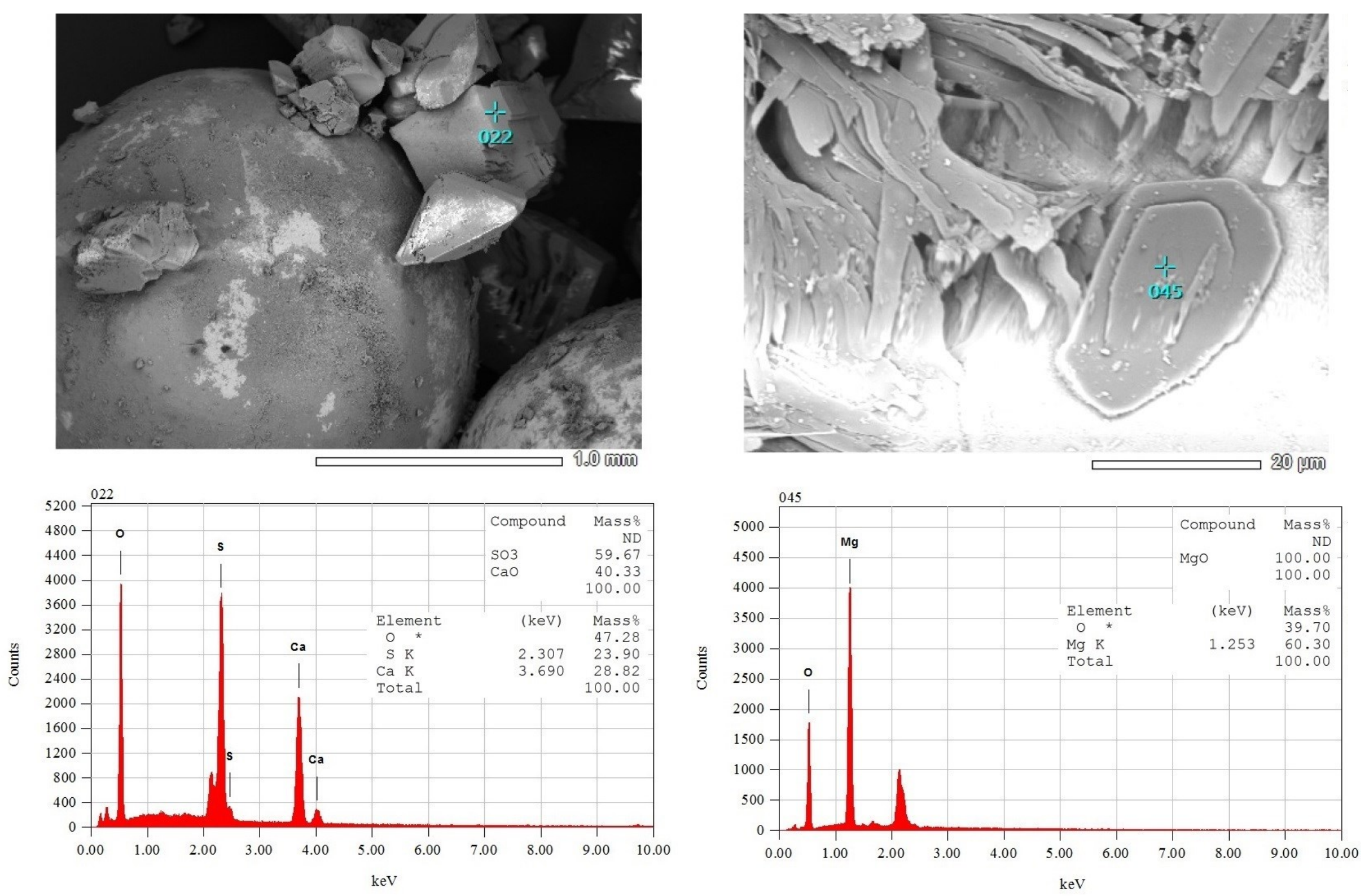
Elements Flux Calculation

Table D.5.5. Elements flux calculation for the SW1 experiment $\left(377^{\circ} \mathrm{C} / 488 \mathrm{bar}\right)$

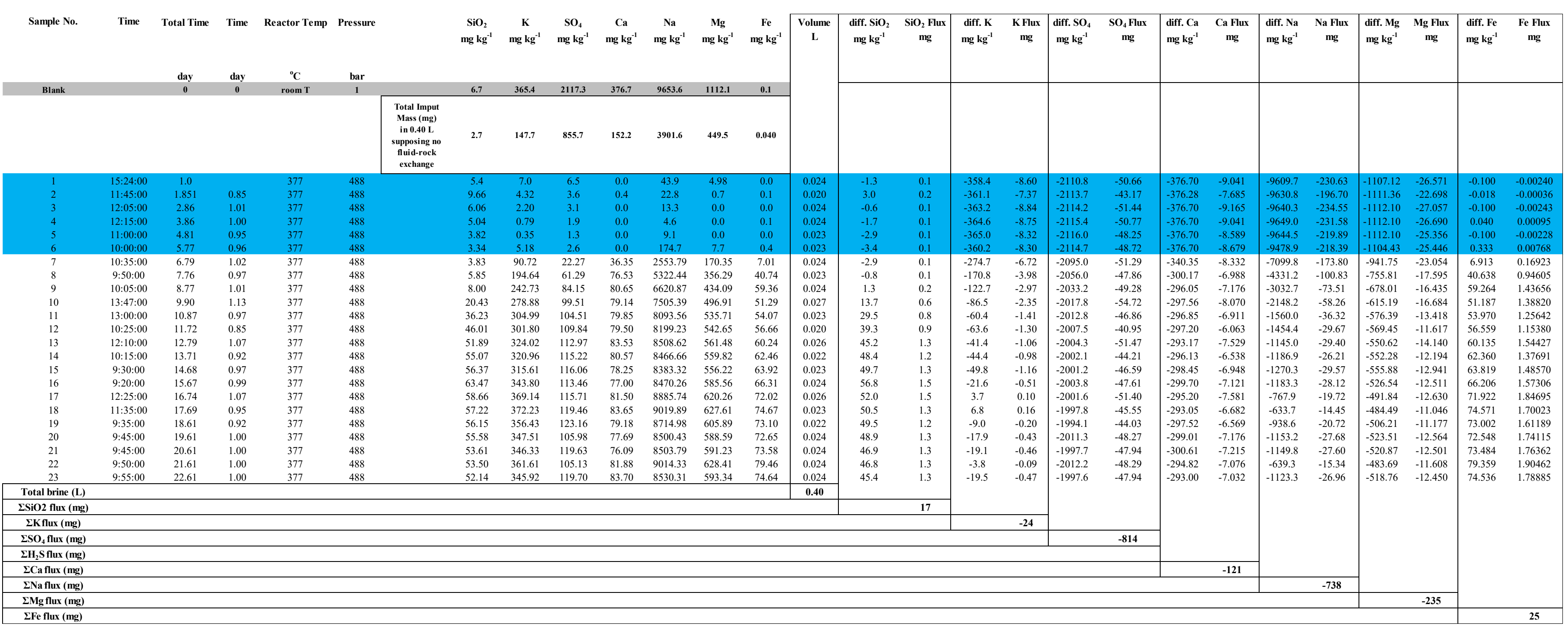


Table D.5.6. Elements flux calculation for the SW2 experiment $\left(342^{\circ} \mathrm{C} / 488 \mathrm{bar}\right)$

\begin{tabular}{|c|c|c|c|c|c|c|c|c|c|c|c|c|c|c|c|c|c|c|c|c|c|c|c|c|}
\hline Reactor Temp & Pressure & & $\begin{array}{c}\mathrm{SiO}_{2} \\
\mathrm{mg} \mathrm{kg}^{-1}\end{array}$ & $\underset{\mathbf{m g ~ k g}^{-1}}{\mathbf{K}}$ & $\begin{array}{c}\mathrm{SO}_{4} \\
\mathrm{mg} \mathrm{kg}^{-1}\end{array}$ & $\begin{array}{c}\mathrm{Ca} \\
\mathrm{mg} \mathrm{kg}^{-1}\end{array}$ & $\underset{\mathrm{mg} \mathrm{kg}^{\mathrm{Na}}}{\mathrm{Na}}$ & $\begin{array}{c}\mathbf{M g} \\
\mathrm{mg} \mathrm{kg}^{-1}\end{array}$ & $\begin{array}{c}\mathbf{F e} \\
\mathrm{mg} \mathrm{kg}^{-1}\end{array}$ & $\begin{array}{c}\text { Volume } \\
\text { L }\end{array}$ & $\begin{array}{c}\text { diff. } \mathrm{SiO}_{2} \\
\mathrm{mg} \mathrm{kg}^{-1}\end{array}$ & $\begin{array}{c}\mathrm{SiO}_{2} \text { Flux } \\
\text { mg }\end{array}$ & $\begin{array}{c}\text { diff. } \mathbf{K} \\
\mathrm{mg} \mathrm{kg}^{-1}\end{array}$ & $\begin{array}{c}\text { K Flux } \\
\text { mg }\end{array}$ & \begin{tabular}{|l} 
diff. $\mathrm{SO}_{4}$ \\
$\mathrm{mg} \mathrm{kg}^{-1}$
\end{tabular} & $\begin{array}{c}\mathrm{SO}_{4} \mathrm{Fllux} \\
\mathrm{mg}\end{array}$ & $\begin{array}{l}\text { diff. Ca } \\
\text { mg kg }^{-1}\end{array}$ & $\begin{array}{c}\text { Ca Flux } \\
\text { mg }\end{array}$ & $\begin{array}{l}\text { diff. Na } \\
\text { mg kg }^{-1}\end{array}$ & $\begin{array}{c}\text { Na Flux } \\
\text { mg }\end{array}$ & \begin{tabular}{|l|} 
diff. $\mathbf{M g}$ \\
$\mathbf{m g ~ k g}^{-1}$
\end{tabular} & $\begin{array}{c}\text { Mg Flux } \\
\text { mg }\end{array}$ & 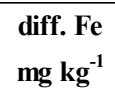 & $\begin{array}{c}\text { Fe Flux } \\
\text { mg }\end{array}$ \\
\hline${ }^{\circ} \mathrm{C}$ & bar & & & & & & & & & & & & & & & & & & & & & & & \\
\hline room T & 1 & $\begin{array}{c}\text { Total Imput } \\
\text { Mass (mg) } \\
\text { in 0.33 L } \\
\text { supposing no } \\
\text { fluid-rock } \\
\text { exchange }\end{array}$ & 1.9 & 112 & 2237 & 321 & 8309 & 892 & 0.03 & & & & & & & & & & & & & & & \\
\hline $\begin{array}{l}342 \\
342 \\
\end{array}$ & $\begin{array}{l}488 \\
488 \\
\end{array}$ & & $\begin{array}{l}2.4 \\
0.0\end{array}$ & $\begin{array}{l}5.5 \\
2.2 \\
\end{array}$ & $\begin{array}{l}3.0 \\
0.1\end{array}$ & $\begin{array}{l}0.5 \\
0.0\end{array}$ & $\begin{array}{l}9.9 \\
5.8 \\
\end{array}$ & $\begin{array}{l}5.6 \\
0.1\end{array}$ & $\begin{array}{l}1.6 \\
0.2\end{array}$ & $\begin{array}{l}0.024 \\
0.024\end{array}$ & $\begin{array}{l}-3.4 \\
-5.8 \\
\end{array}$ & $\begin{array}{l}0.1 \\
0.0\end{array}$ & $\begin{array}{r}-330.0 \\
-333.3 \\
\end{array}$ & $\begin{array}{l}-7.92 \\
-8.00 \\
\end{array}$ & \begin{tabular}{|l|}
-2233.8 \\
-2236.6 \\
\end{tabular} & $\begin{array}{l}-53.61 \\
-53.68 \\
\end{array}$ & $\begin{array}{r}-320.83 \\
-321.30 \\
\end{array}$ & $\begin{array}{r}-7.700 \\
-7.711 \\
\end{array}$ & $\begin{array}{l}-8298.6 \\
-8302.7\end{array}$ & $\begin{array}{r}-199.17 \\
-199.26 \\
\end{array}$ & \begin{tabular}{|l|}
-885.89 \\
-891.42 \\
\end{tabular} & $\begin{array}{r}-21.261 \\
-21.394 \\
\end{array}$ & $\begin{array}{l}1.527 \\
0.125\end{array}$ & $\begin{array}{l}0.03665 \\
0.00300\end{array}$ \\
\hline 342 & 488 & & 0.0 & 47.0 & 27.1 & 11.0 & 1198.1 & 87.6 & 1.6 & 0.022 & -5.8 & 0.0 & -288.5 & -6.30 & -2209.6 & -48.26 & -310.34 & -6.778 & -7110.4 & -155.29 & \begin{tabular}{|l|l|} 
& -803.90 \\
\end{tabular} & -17.557 & 1.526 & 0.03333 \\
\hline 342 & 488 & & 0.7 & 166.3 & 102.3 & 39.2 & 4224.1 & 317.4 & 10.2 & 0.025 & -5.1 & 0.0 & -169.2 & -4.22 & $\mid-2134.4$ & -53.27 & -282.09 & -7.041 & -4084.4 & -101.95 & \begin{tabular}{|l|l|} 
& -574.11
\end{tabular} & -14.330 & 10.068 & 0.25130 \\
\hline 342 & 488 & & 1.8 & 251.5 & 168.8 & 58.9 & 6414.3 & 455.5 & 39.0 & 0.023 & -4.0 & 0.0 & -84.0 & -1.94 & $\mid-2067.9$ & -47.64 & -262.41 & -6.046 & -1894.2 & -43.64 & \begin{tabular}{|l|l|}
-436.04 \\
\end{tabular} & -10.046 & 38.877 & 0.89573 \\
\hline 342 & 488 & & 4.2 & 291.1 & 214.2 & 64.2 & 7362.2 & 520.0 & 54.3 & 0.024 & -1.6 & 0.1 & -44.4 & -1.07 & -2022.5 & -48.54 & -257.14 & -6.171 & -946.3 & -22.71 & \begin{tabular}{|l|l|} 
& -371.49 \\
\end{tabular} & -8.916 & 54.222 & 1.30133 \\
\hline 342 & 488 & & 9.6 & 312.2 & 250.1 & 61.8 & 7850.7 & 552.1 & 64.0 & 0.02 & 3.8 & 0.3 & -23.3 & -0.61 & -1986.7 & -52 & -259.52 & -6.851 & -457.8 & -12.09 & \begin{tabular}{|l|}
-339.45 \\
\end{tabular} & -8.961 & 63.933 & 1.68784 \\
\hline 342 & 488 & & 14.4 & 322.0 & 282.4 & 63.9 & 8062.7 & 559.2 & 73.0 & 0.023 & 8.6 & 0.3 & -13.5 & -0.31 & -1954.3 & -45.03 & -257.36 & -5.930 & -245.8 & -5.66 & \begin{tabular}{|l|}
-332.33 \\
\end{tabular} & -7.657 & 72.915 & 1.67997 \\
\hline 342 & 488 & & 16.4 & 333.1 & 286.7 & 63.7 & 8340.8 & 572.2 & 81.2 & 0.024 & 10.6 & 0.4 & -2.4 & -0.06 & $\mid-1950.0$ & -45.86 & -257.62 & -6.059 & 32.3 & 0.76 & \begin{tabular}{|l|l|} 
& -319.31 \\
\end{tabular} & -7.510 & 81.070 & 1.90678 \\
\hline 342 & 488 & & 17.4 & 333.7 & 286.1 & 67.8 & 8447.7 & 572.3 & 89.8 & 0.024 & 11.6 & 0.4 & -1.8 & -0.04 & -1950.6 & -45.88 & -253.48 & -5.962 & 139.2 & 3.27 & \begin{tabular}{|l|}
$\mid-319.16$ \\
\end{tabular} & -7.507 & 89.694 & 2.10959 \\
\hline 342 & 488 & & 16.7 & 335.3 & 275.3 & 59.0 & 8415.8 & 564.9 & 93.5 & 0.025 & 10.9 & 0.4 & -0.2 & 0.00 & \begin{tabular}{|l|} 
\\
\end{tabular} & -48.49 & -262.33 & -6.485 & 107.3 & 2.65 & \begin{tabular}{|l|} 
\\
\end{tabular} & -8.074 & 93.396 & 2.30876 \\
\hline 342 & 488 & & 16.1 & 336.9 & 274.9 & 57.9 & 8462.2 & 565.8 & 95.1 & 0.023 & 10.3 & 0.4 & 1.4 & 0.03 & \begin{tabular}{|l|l|} 
& -1961.8 \\
\end{tabular} & -45.20 & -263.38 & -6.068 & 153.7 & 3.54 & \begin{tabular}{|l}
-325.71 \\
\end{tabular} & -7.504 & 94.997 & 2.18873 \\
\hline 342 & 488 & & 15.6 & 325.9 & 270.2 & 55.4 & 8141.4 & 542.3 & 90.0 & 0.026 & 9.8 & 0.4 & -9.6 & -0.25 & \begin{tabular}{|l|l} 
& -1966.5 \\
\end{tabular} & -50.97 & $\begin{array}{l}-265.89 \\
\end{array}$ & -6.892 & -167.1 & -4.33 & -349.15 & -9.050 & 89.867 & 2.32935 \\
\hline 342 & 488 & & 15.2 & 340.2 & 262.7 & 57.9 & 8610.8 & 572.5 & 98.6 & 0.024 & 9.4 & 0.4 & 4.7 & 0.11 & -1974.0 & -46 & -263.38 & -6.1 & 302.3 & 7.11 & \begin{tabular}{|l|} 
\\
\end{tabular} & -7.502 & 98.457 & 2.31570 \\
\hline 342 & 488 & & 14.5 & 332.6 & 271.7 & 56.4 & 8367.9 & 557.6 & 96.0 & 0.022 & 8.7 & 0.3 & -2.9 & -0.06 & -1965.0 & -43.39 & -264.93 & -5.850 & 59.4 & 1.31 & \begin{tabular}{|l|l|} 
& -333.86 \\
\end{tabular} & -7.372 & 95.944 & 2.11845 \\
\hline 342 & 488 & & 14.6 & 333.9 & 260.2 & 56.0 & 8353.0 & 554.4 & 94.5 & 0.024 & 8.8 & 0.3 & -1.6 & -0.04 & \begin{tabular}{|l|l|} 
& -1976.5 \\
\end{tabular} & -47.44 & -265.34 & -6.368 & 44.5 & 1.07 & \begin{tabular}{|l|l|}
-337.10 \\
\end{tabular} & -8.090 & 94.364 & 2.26474 \\
\hline & & & & & & & & & & 0.33 & & & & & & & & & & & & & & \\
\hline & & & & & & & & & & & & 3.8 & & & & & & & & & & & & \\
\hline & & & & & & & & & & & & & & -15 & & & & & & & & & & \\
\hline & & & & & & & & & & & & & & & & -669 & & & & & & & & \\
\hline & & & & & & & & & & & & & & & & & & -89 & & & & & & \\
\hline & & & & & & & & & & & & & & & & & & & & -326 & & & & \\
\hline & & & & & & & & & & & & & & & & & & & & & & -130 & & \\
\hline
\end{tabular}


Activity calculation

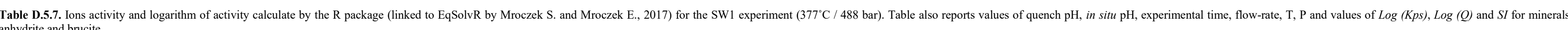

\begin{tabular}{|c|c|c|c|c|c|c|c|c|c|c|c|c|c|c|c|c|c|c|c|c|c|c|c|}
\hline samples & 1 & 2 & 3 & 4 & 5 & 6 & 7 & 8 & 9 & 10 & 11 & 12 & 13 & 14 & 15 & 16 & 17 & 18 & 19 & 20 & 21 & 22 & 23 \\
\hline $\boldsymbol{a}=\underset{\mathrm{H}^{+}}{\boldsymbol{m} \cdot \boldsymbol{a}_{y}}$ & & $1.16 \mathrm{E}-06$ & & & & & & & & & & & & & & & & & & & & & \\
\hline $\begin{array}{c}\mathrm{H} \\
\mathrm{OH}\end{array}$ & $\begin{array}{l}4.31 \mathrm{E}-06 \\
1.61 \mathrm{E}-06\end{array}$ & $\begin{array}{l}1.16 \mathrm{E}-06 \\
6.00 \mathrm{E}-06\end{array}$ & $\begin{array}{l}3.78 \mathrm{E}-07 \\
1.83 \mathrm{E}-05\end{array}$ & $\begin{array}{l}4.73 \mathrm{E}-07 \\
1.47 \mathrm{E}-05\end{array}$ & $\begin{array}{l}6.8 \mathrm{BZE}-07 \\
1.02 \mathrm{E}-05\end{array}$ & $\begin{array}{l}6.8 \mathrm{OUE}-06 \\
1.02 \mathrm{E}-06\end{array}$ & $\begin{array}{l}7.13 \mathrm{E}-06 \\
9.73 \mathrm{E}-07\end{array}$ & $\begin{array}{l}5.82 \mathrm{E}-06 \\
1.19 \mathrm{E}-06\end{array}$ & $\begin{array}{l}5.40 \mathrm{E}-06 \\
1.28 \mathrm{E}-06\end{array}$ & $\begin{array}{l}5.28 E-06 \\
1.31 E-06\end{array}$ & $\begin{array}{l}5.31 \mathrm{E}-06 \\
1.30 \mathrm{E}-06\end{array}$ & $\begin{array}{l}5.22 \mathrm{E}-06 \\
1.33 \mathrm{E}-06\end{array}$ & $\begin{array}{l}5.22 \mathrm{E}-06 \\
1.33 \mathrm{E}-06\end{array}$ & $\begin{array}{l}5.17 \mathrm{E}-06 \\
1.34 \mathrm{E}-06\end{array}$ & $\begin{array}{l}5.14 \mathrm{E}-06 \\
1.35 \mathrm{E}-06\end{array}$ & $\begin{array}{l}5.3 \mathrm{E}=-06 \\
1.30 \mathrm{E}-06\end{array}$ & $\begin{array}{l}5.4 \mathrm{E}-06 \\
1.28 \mathrm{E}-06\end{array}$ & $\begin{array}{l}5.36 \mathrm{E}-06 \\
1.29 \mathrm{E}-06\end{array}$ & $\begin{array}{l}5.21 \mathrm{E}-06 \\
1.33 \mathrm{E}-06\end{array}$ & $\begin{array}{l}5.51 \mathrm{E}-06 \\
1.26 \mathrm{E}-06\end{array}$ & $\begin{array}{l}5.23 \mathrm{E}-06 \\
1.33 \mathrm{E}-06\end{array}$ & $\begin{array}{l}5.67 \mathrm{E}-06 \\
1.22 \mathrm{E}-06\end{array}$ & $\begin{array}{l}5.24 \mathrm{E}-06 \\
1.32 \mathrm{E}-06\end{array}$ \\
\hline $\mathrm{Na}^{+}$ & $1.56 \mathrm{E}-03$ & $8.65 \mathrm{E}-04$ & $5.21 \mathrm{E}-04$ & $1.89 \mathrm{E}-04$ & $3.65 \mathrm{E}-04$ & $5.25 \mathrm{E}-03$ & $3.68 \mathrm{E}-02$ & $5.85 \mathrm{E}-02$ & $6.70 \mathrm{E}-02$ & $7.24 \mathrm{E}-02$ & $7.59 \mathrm{E}-02$ & $7.65 \mathrm{E}-02$ & $7.82 \mathrm{E}-02$ & $7.80 \mathrm{E}-02$ & $7.75 \mathrm{E}-02$ & $7.78 \mathrm{E}-02$ & $8.00 \mathrm{E}-02$ & $8.07 \mathrm{E}-02$ & $7.91 \mathrm{E}-02$ & $7.79 \mathrm{E}-02$ & 7.79E- 02 & $8.07 \mathrm{E}-02$ & $7.80 \mathrm{E}-02$ \\
\hline $\mathrm{K}^{+}$ & $1.51 \mathrm{E}-04$ & $9.72 \mathrm{E}-05$ & $5.05 \mathrm{E}-05$ & $1.90 \mathrm{E}-05$ & $8.33 \mathrm{E}-06$ & 9.72E-05 & $9.48 \mathrm{E}-04$ & $1.61 \mathrm{E}-03$ & $1.87 \mathrm{E}-03$ & $2.06 \mathrm{E}-03$ & $2.20 \mathrm{E}-03$ & $2.17 \mathrm{E}-03$ & $2.30 \mathrm{E}-03$ & $2.28 \mathrm{E}-03$ & $2.25 \mathrm{E}-03$ & $2.44 E-03$ & $2.57 \mathrm{E}-03$ & $2.58 \mathrm{E}-03$ & $2.50 \mathrm{E}-03$ & $2.46 \mathrm{E}-03$ & $2.45 \mathrm{E}-03$ & IE-03 & $2.44 E-03$ \\
\hline $\mathrm{Cl}$ & $1.90 \mathrm{E}-03$ & $9.67 \mathrm{E}-04$ & $5.19 \mathrm{E}-04$ & $1.76 \mathrm{E}-04$ & $3.52 \mathrm{E}-04$ & $5.63 \mathrm{E}-03$ & $4.09 \mathrm{E}-02$ & $6.50 \mathrm{E}-02$ & $7.41 \mathrm{E}-02$ & $7.98 \mathrm{E}-02$ & $8.35 \mathrm{E}-02$ & $8.42 \mathrm{E}-02$ & $8.61 \mathrm{E}-02$ & $8.58 \mathrm{E}-02$ & $8.53 \mathrm{E}-02$ & $8.62 \mathrm{E}-02$ & $8.88 \mathrm{E}-02$ & $8.96 \mathrm{E}-02$ & 02 & 8.6 & 02 & 02 & $8.66 \mathrm{E}-02$ \\
\hline $\mathrm{SO}_{4}^{2-}$ & $9.78 \mathrm{E}-07$ & $2.08 \mathrm{E}-06$ & $5.05 \mathrm{E}-06$ & $3.18 \mathrm{E}-06$ & $1.47 \mathrm{E}-06$ & $2.42 E-07$ & $6.96 \mathrm{E}-07$ & $1.36 \mathrm{E}-06$ & $1.67 \mathrm{E}-06$ & $1.83 \mathrm{E}-06$ & $1.83 \mathrm{E}-06$ & $1.91 \mathrm{E}-06$ & $1.92 \mathrm{E}-06$ & $1.97 \mathrm{E}-06$ & $2.00 \mathrm{E}-06$ & $1.91 \mathrm{E}-06$ & $1.88 \mathrm{E}-06$ & $1.93 \mathrm{E}-06$ & $2.05 \mathrm{E}-06$ & $1.77 \mathrm{E}-06$ & $2.02 \mathrm{E}-06$ & $1.68 \mathrm{E}-06$ & $2.01 E-06$ \\
\hline $\mathrm{Ca}^{2+}$ & $<$ LOD & $1.75 \mathrm{E}-06$ & $<$ LOD & $<$ LOD & $<$ LOD & $<$ LOD & $5.04 \mathrm{E}-06$ & $5.75 \mathrm{E}-06$ & $5.07 \mathrm{E}-06$ & $4.50 \mathrm{E}-06$ & $4.27 \mathrm{E}-06$ & $4.20 \mathrm{E}-06$ & $4.28 \mathrm{E}-06$ & 4.15E-06 & $4.06 \mathrm{E}-06$ & $3.94 \mathrm{E}-06$ & $\begin{array}{l}4.00 E-06 \\
\end{array}$ & $4.06 \mathrm{E}-06$ & $3.95 \mathrm{E}-06$ & $3.96 \mathrm{E}-06$ & $3.88 \mathrm{E}-06$ & $3.98 \mathrm{E}-06$ & $4.25 \mathrm{E}-06$ \\
\hline $\mathrm{Mg}^{2+}$ & $4.29 \mathrm{E}-05$ & $4.20 \mathrm{E}-06$ & $<$ LOD & $<$ LOD & $<$ LOD & $3.88 \mathrm{E}-05$ & $1.28 \mathrm{E}-04$ & $1.60 \mathrm{E}-04$ & $1.68 \mathrm{E}-04$ & $1.77 \mathrm{E}-04$ & $1.82 \mathrm{E}-04$ & $1.82 \mathrm{E}-04$ & $1.84 \mathrm{E}-04$ & $1.84 \mathrm{E}-04$ & $1.84 \mathrm{E}-04$ & $1.92 \mathrm{E}-04$ & $1.96 \mathrm{E}-04$ & $1.97 \mathrm{E}-04$ & $1.94 \mathrm{E}-04$ & $1.92 \mathrm{E}-04$ & $1.93 \mathrm{E}-04$ & $1.97 \mathrm{E}-04$ & $1.93 \mathrm{E}-04$ \\
\hline $\mathrm{Fe}^{2+}$ & $2.71 \mathrm{E}-07$ & $5.68 \mathrm{E}-07$ & $4.02 \mathrm{E}-07$ & $1.75 \mathrm{E}-06$ & $6.49 E-07$ & $7.81 E-07$ & $1.46 \mathrm{E}-06$ & $4.83 \mathrm{E}-06$ & $5.99 \mathrm{E}-06$ & $4.72 \mathrm{E}-06$ & $4.71 \mathrm{E}-06$ & 4.89E-06 & $5.06 \mathrm{E}-06$ & $5.26 \mathrm{E}-06$ & $5.43 \mathrm{E}-06$ & $5.56 \mathrm{E}-06$ & $5.82 \mathrm{E}-06$ & $5.97 \mathrm{E}-06$ & $6.00 \mathrm{E}-06$ & $6.07 \mathrm{E}-06$ & $6.14 \mathrm{E}-06$ & $6.35 \mathrm{E}-06$ & $6.22 E-06$ \\
\hline$a^{2}{ }_{H+}$ & $1.85 \mathrm{E}-11$ & $1.33 \mathrm{E}-12$ & $1.43 \mathrm{E}-13$ & $2.24 \mathrm{E}-13$ & $4.67 \mathrm{E}-13$ & 4.63E-11 & $5.08 \mathrm{E}-11$ & $3.39 \mathrm{E}-11$ & $2.92 \mathrm{E}-11$ & $2.79 \mathrm{E}-11$ & $2.82 \mathrm{E}-11$ & $2.73 \mathrm{E}-11$ & $2.73 \mathrm{E}-11$ & $2.67 \mathrm{E}-11$ & 2.65E-11 & $2.84 \mathrm{E}-11$ & $2.93 \mathrm{E}-11$ & $2.87 \mathrm{E}-11$ & $2.72 \mathrm{E}-11$ & $3.03 \mathrm{E}-11$ & $2.74 \mathrm{E}-11$ & $3.21 \mathrm{E}-11$ & 2.74E-11 \\
\hline $\log \left(a \mathrm{SiO}_{2}\right)$ & -4.0 & -3.8 & -4.0 & -4.1 & -4.2 & -4.3 & -4.2 & -4.0 & -3.9 & -3.5 & -3.2 & -3.1 & -3.1 & -3.0 & -3.0 & -3.0 & -3.0 & -3.0 & -3.0 & -3.0 & -3.0 & -3.1 & -3.1 \\
\hline $\log \left(a_{\mathrm{K}} / a_{\mathrm{H}+}\right)$ & 1.5 & 1.9 & 2.1 & 1.6 & 1.1 & 1.2 & 2.1 & 2.4 & 2.5 & 2.6 & 2.6 & 2.6 & 2.6 & 2.6 & 2.6 & 2.7 & 2.7 & 2.7 & 2.7 & 2.6 & 2.7 & 2.6 & 2.7 \\
\hline $\log \left(a_{\mathrm{Na}+} / a_{\mathrm{H}+}\right)$ & 2.6 & 2.9 & 3.1 & 2.6 & 2.7 & 2.9 & 3.7 & 4.0 & 4.1 & 4.1 & 4.2 & 4.2 & 4.2 & 4.2 & 4.2 & 4.2 & 4.2 & 4.2 & 4.2 & 4.2 & 4.2 & 4.2 & 4.2 \\
\hline $\log \left(a_{\mathrm{Ca}+} / a_{\mathrm{HH}}^{2}\right)$ & $<$ LOD & 6.1 & $<$ LOD & $<$ LOD & $<$ LOD & $<$ LOD & 5.0 & 5.2 & 5.2 & 5.2 & 5.2 & 5.2 & 5.2 & 5.2 & 5.2 & 5.1 & 5.1 & 5.2 & 5.2 & 5.1 & 5.2 & 5.1 & 5.2 \\
\hline $\log \left(a_{\mathrm{Fe} 2} / a_{\mathrm{H}+}^{2}\right)$ & 4.2 & 5.6 & 6.4 & 6.9 & 6.1 & 4.2 & 4.5 & 5.2 & 5.3 & 5.2 & 5.2 & 5.3 & 5.3 & 5.3 & 5.3 & 5.3 & 5.3 & 5.3 & 5.3 & 5.3 & 5.4 & 5.3 & 5.4 \\
\hline $\log \left(a_{\mathrm{Mg} 2} / a_{\mathrm{H}+}^{2}\right)$ & 6.4 & 6.5 & $<$ LOD & $<$ LOD & $<$ LOD & 5.9 & 6.4 & 6.7 & 6.8 & 6.8 & 6.8 & 6.8 & 6.8 & 6.8 & 6.8 & 6.8 & 6.8 & 6.8 & 6.9 & 6.8 & 6.8 & 6.8 & 6.8 \\
\hline $\log a_{\mathrm{Na}+}$ & -2.8 & -3.1 & -3.3 & -3.7 & -3.4 & -2.3 & -1.4 & -1.2 & -1.2 & -1.1 & -1.1 & -1.1 & -1.1 & -1.1 & -1.1 & -1.1 & -1.1 & -1.1 & -1.1 & -1.1 & -1.1 & -1.1 & -1.1 \\
\hline $\log a_{\mathrm{K}+}$ & -3.8 & -4.0 & -4.3 & -4.7 & -5.1 & -4.0 & -3.0 & -2.8 & -2.7 & -2.7 & -2.7 & -2.7 & -2.6 & -2.6 & -2.6 & -2.6 & -2.6 & -2.6 & -2.6 & -2.6 & -2.6 & -2.6 & -2.6 \\
\hline $\log a_{\mathrm{Cl}-}$ & -2.7 & -3.0 & -3.3 & -3.8 & -3.5 & -2.2 & -1.4 & -1.2 & -1.1 & -1.1 & -1.1 & -1.1 & -1.1 & -1.1 & -1.1 & -1.1 & -1.1 & -1.0 & -1.1 & -1.1 & -1.1 & -1.0 & -1.1 \\
\hline $\log a_{\text {SO42- }}$ & -6.0 & -5.7 & -5.3 & -5.5 & -5.8 & -6.6 & -6.2 & -5.9 & -5.8 & -5.7 & -5.7 & -5.7 & -5.7 & -5.7 & -5.7 & -5.7 & -5.7 & -5.7 & -5.7 & -5.8 & -5.7 & -5.8 & -5.7 \\
\hline $\log a_{\mathrm{Ca} 2+}$ & $<$ LOD & -5.8 & $<$ LOD & $<$ LOD & $<$ LOD & $<$ LOD & -5.3 & -5.2 & -5.3 & -5.3 & -5.4 & -5.4 & -5.4 & -5.4 & -5.4 & -5.4 & -5.4 & -5.4 & -5.4 & -5.4 & -5.4 & -5.4 & -5.4 \\
\hline $\log a_{\mathrm{Mg} 2+}$ & -4.4 & -5.4 & $<$ LOD & $<$ LOD & $<$ LOD & -4.4 & -3.9 & -3.8 & -3.8 & -3.8 & -3.7 & -3.7 & -3.7 & -3.7 & -3.7 & -3.7 & -3.7 & -3.7 & -3.7 & -3.7 & -3.7 & -3.7 & -3.7 \\
\hline $\log a_{\mathrm{Fe} 2+}$ & -6.6 & -6.2 & -6.4 & -5.8 & -6.2 & -6.1 & -5.8 & -5.3 & -5.2 & -5.3 & -5.3 & -5.3 & -5.3 & -5.3 & -5.3 & -5.3 & -5.2 & -5.2 & -5.2 & -5.2 & -5.2 & -5.2 & -5.2 \\
\hline $\mathrm{T}\left({ }^{\circ} \mathrm{C}\right)$ & 377.0 & 377.0 & 377.0 & 377.0 & 377.0 & 377.0 & 377.0 & 377.0 & 377.0 & 377.0 & 377.0 & 377.0 & 377.0 & 377.0 & 377.0 & 377.0 & 377.0 & 377.0 & 377.0 & 377.0 & 377.0 & 377.0 & 377.0 \\
\hline $\mathrm{P}$ (bar) & 487.1 & 487.7 & 486.8 & 486.5 & 486.8 & 488.2 & 487.6 & 487.6 & 487.2 & 487.7 & 487.4 & 487.6 & 487.7 & 487.7 & 487.7 & 487.4 & 487.8 & 487.9 & 487.7 & 487.6 & 487.9 & 487.3 & 487.5 \\
\hline in situ $\mathrm{pH}_{\left(375^{\circ} \mathrm{C}\right.}$ & 5.32 & 5.94 & 6.42 & 6.33 & 6.17 & 5.17 & 5.15 & 5.23 & 5.27 & 5.28 & 5.27 & 5.28 & 5.28 & 5.29 & 5.29 & 5.27 & 5.27 & 5.27 & 5.28 & 5.26 & 5.28 & 5.25 & 5.28 \\
\hline $\operatorname{room~TpH}$ & 5.37 & 5.96 & 5.56 & 5.21 & 5.53 & 4.69 & 3.85 & 3.42 & 3.45 & 3.47 & 3.40 & 3.37 & 3.36 & 3.31 & 3.30 & 3.29 & 3.27 & 3.25 & 3.24 & 3.22 & 3.21 & 3.19 & 3.22 \\
\hline flow rate $\left(\mathrm{ml} \mathrm{hr}^{-1}\right)$ & 1 & 1 & 1 & 1 & 1 & 1 & 1 & 1 & 1 & 1 & 1 & 1 & 1 & 1 & 1 & 1 & 1 & 1 & 1 & 1 & 1 & 1 & 1 \\
\hline time (hr) & 24.2 & 44.5 & 68.9 & 93.0 & 115.8 & 138.8 & 163.4 & 186.6 & 211.0 & 238.6 & 261.8 & 283.2 & 309.0 & 331.0 & 354.3 & 378.1 & 405.2 & 428.4 & 450.4 & 474.5 & 498.5 & 522.6 & 546.7 \\
\hline Anhydrite & & & & & & & & & & & & & & & & & & & & & & & \\
\hline Log Ksp (Supcrt92)@375 C & & 3.98 & & & & & 3.98 & 3.98 & 3.98 & 3.98 & 3.98 & 3.98 & 3.98 & 3.98 & 3.98 & 3.98 & 3.98 & 3.98 & 3.98 & 3.98 & 3.98 & 3.98 & 3.98 \\
\hline $\log Q$ & & 4.46 & & & & & 4.48 & 4.14 & 4.09 & 4.11 & 4.14 & 4.12 & 4.11 & 4.11 & 4.11 & 4.15 & 4.15 & 4.13 & 4.12 & 4.18 & 4.13 & 4.20 & 4.09 \\
\hline $\log (Q / K)$ & & 0.48 & & & & & 0.50 & 0.16 & 0.11 & 0.13 & 0.16 & 0.14 & 0.13 & 0.13 & 0.13 & 0.17 & 0.17 & 0.15 & 0.14 & 0.20 & 0.15 & 0.22 & 0.11 \\
\hline Drutce & & & & & & & & & & & & & & & & & & & & & & & \\
\hline Log Ksp (Supcrt92) @375 C & & -6.51 & & & & -6.51 & -6.51 & -6.51 & -6.51 & -6.51 & -6.51 & -6.51 & -6.51 & -6.51 & -6.51 & -6.51 & -6.51 & -6.51 & -6.51 & -6.51 & -6.51 & -6.51 & -6.51 \\
\hline $\log Q$ & & -6.50 & & & & -5.92 & -6.40 & -6.67 & -6 . & -6.80 & -6.8 & -6.83 & -6 & -6.84 & -6.84 & -6.83 & -6.83 & -6.84 & -6 & -6.80 & -6.8 & -6.79 & -6.85 \\
\hline $\log (Q / K)$ & & 0.01 & & & & 0.59 & 0.11 & -0.16 & -0.25 & -0.29 & -0.30 & -0.32 & -0.32 & -0.33 & -0.33 & -0.32 & -0.32 & -0.33 & -0.34 & -0.29 & -0.34 & -0.28 & -0.34 \\
\hline inite (M & & & & & & & & & & & & & & & & & & & & & & & \\
\hline$o g k s p=L$ & 8.81 & 9.43 & & & & 9.55 & 8.45 & 8.00 & 7.86 & 7.79 & 7.78 & 7.75 & 7.75 & 7.73 & 7.72 & 7.73 & 7.72 & 7.71 & 7.69 & 7.77 & 7.70 & 7.78 & 7.70 \\
\hline
\end{tabular}


Table D.5.8. Values of the activity coefficients $\left(\mathrm{a}_{r}\right)$ calculated by the R package for the SW1 experiment $\left(377^{\circ} \mathrm{C} / 488 \mathrm{bar}\right)$

\begin{tabular}{|c|c|c|c|c|c|c|c|c|c|c|c|c|c|c|c|c|c|c|c|c|c|c|c|c|c|c|c|}
\hline sample & $\begin{array}{c}\mathbf{m} \\
\mathrm{a}_{\mathrm{t}} \\
\text { activity }\end{array}$ & $\begin{array}{c}\mathbf{H}^{+} \\
4.99 \mathrm{E}-06 \\
8.63 \mathrm{E}-01 \\
4.31 \mathrm{E}-06\end{array}$ & $\begin{array}{c}\text { OH }^{-} \\
1.89 \mathrm{E}-06 \\
8.52 \mathrm{E}-01 \\
1.61 \mathrm{E}-06\end{array}$ & $\begin{array}{c}\mathbf{N a}^{+} \\
1.83 \mathrm{E}-03 \\
8.52 \mathrm{E}-01 \\
1.56 \mathrm{E}-03 \\
\end{array}$ & $\begin{array}{c}\mathbf{K}^{+} \\
1.78 \mathrm{E}-04 \\
8.49 \mathrm{E}-01 \\
1.51 \mathrm{E}-04 \\
\end{array}$ & $\begin{array}{c}\mathbf{C r} \\
2.23 \mathrm{E}-03 \\
8.51 \mathrm{E}-01 \\
1.90 \mathrm{E}-03 \\
\end{array}$ & $\begin{array}{l}\mathbf{S O}_{4}{ }^{2-} \\
1.86 \mathrm{E}-06 \\
5.26 \mathrm{E}-01 \\
9.78 \mathrm{E}-07\end{array}$ & $\mathrm{Ca}^{2+}$ & $\begin{array}{c}\mathbf{M g}^{\mathbf{2}^{+}} \\
7.80 \mathrm{E}-05 \\
5.50 \mathrm{E}-01 \\
4.29 \mathrm{E}-05\end{array}$ & $\begin{array}{c}\mathbf{F e}^{\mathbf{F}^{2+}} \mathbf{r} \\
5.03 \mathrm{E}-07 \\
5.39 \mathrm{E}-01 \\
2.71 \mathrm{E}-07\end{array}$ & $\begin{array}{l}\mathrm{NaSO}_{4}^{-} \\
2.97 \mathrm{E}-06 \\
8.52 \mathrm{E}-01 \\
2.53 \mathrm{E}-06\end{array}$ & $\begin{array}{l}\mathrm{HSO}_{4}^{-} \\
4.67 \mathrm{E}-05 \\
8.52 \mathrm{E}-01 \\
3.97 \mathrm{E}-05\end{array}$ & $\begin{array}{l}\mathbf{K S O}_{4}^{-} \\
6.022-07 \\
8.52 \mathrm{E}-01 \\
5.13 \mathrm{E}-07\end{array}$ & $\begin{array}{l}\mathrm{NaCl}^{\circ} \\
7.16 \mathrm{E}-05 \\
1.00 \mathrm{E}+00 \\
7.16 \mathrm{E}-05 \\
\end{array}$ & $\begin{array}{c}\mathbf{K C l}^{\circ} \\
1.99 \mathrm{E}-06 \\
1.00 \mathrm{E}+00 \\
1.99 \mathrm{E}-06\end{array}$ & 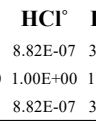 & $\begin{array}{l}\mathbf{K O H}^{\circ} \\
3.74 \mathrm{E}-09 \\
1.00 \mathrm{E}+00 \\
3.74 \mathrm{E}-09\end{array}$ & $\begin{array}{l}\mathbf{N a O H}^{\circ} \\
2.10 \mathrm{O}-08 \\
0.00 \mathrm{1}+00 \\
2.10 \mathrm{E}-08\end{array}$ & $\mathrm{CaSO}_{4}{ }^{\circ}$ & $\begin{array}{c}\mathbf{M g S O}_{4}{ }^{\circ} \\
-\end{array}$ & $\begin{array}{c}\mathbf{M g C l}^{+} \\
\vdots\end{array}$ & $\mathrm{CaCl}^{+}$ & $\mathrm{CaCl}_{2}^{\circ}$ & $\mathrm{MgOH}^{+}$ & $\mathrm{CaOH}^{+}$ & $\begin{array}{l}\mathrm{FeCr} \\
1.38 \mathrm{E}-09 \\
8.57 \mathrm{E}-01 \\
1.18 \mathrm{E}-09\end{array}$ & $\begin{array}{l}\mathbf{F e S O}_{4}{ }^{\circ} \\
0.000 \mathrm{E}+00 \\
1.00 \mathrm{E}+00 \\
0.00 \mathrm{E}+00\end{array}$ \\
\hline \multirow[t]{2}{*}{2} & $\begin{array}{l}\mathrm{m} \\
\mathrm{a}_{\mathrm{r}}\end{array}$ & $\begin{array}{l}1.29 \mathrm{E}-06 \\
8.99 \mathrm{E}-01\end{array}$ & $\begin{array}{l}6.73 \mathrm{E}-06 \\
8.92 \mathrm{E}-01\end{array}$ & $\begin{array}{l}9.69 \mathrm{E}-04 \\
8.92 \mathrm{E}-01\end{array}$ & $\begin{array}{l}1.09 \mathrm{E}-04 \\
8.91 \mathrm{E}-01\end{array}$ & $\begin{array}{l}1.08 \mathrm{E}-03 \\
8.92 \mathrm{E}-01\end{array}$ & $\begin{array}{l}3.29 \mathrm{E}-06 \\
6.34 \mathrm{E}-01\end{array}$ & $\begin{array}{l}2.74 E-06 \\
6.41 \mathrm{E}-01\end{array}$ & $\begin{array}{l}6.47 \mathrm{E}-06 \\
6.49 \mathrm{E}-01\end{array}$ & $\begin{array}{l}8.85 \mathrm{E}-07 \\
6.41 \mathrm{E}-01 \\
\end{array}$ & $\begin{array}{l}3.34 \mathrm{E}-06 \\
8.92 \mathrm{E}-01\end{array}$ & $\begin{array}{l}2.55 \mathrm{E}-05 \\
8.92 \mathrm{E}-01\end{array}$ & $\begin{array}{l}7.89 \mathrm{EE}-07 \mathrm{2} \\
8.92 \mathrm{E}-011\end{array}$ & $\begin{array}{l}2.02 \mathrm{E}-05 \\
1.00 \mathrm{E}+00\end{array}$ & $\begin{array}{l}6.52 \mathrm{E}-07 \\
1.00 \mathrm{E}+00\end{array}$ & $\begin{array}{l}1.20 \mathrm{E}-078 \\
1.00 \mathrm{E}+000.1\end{array}$ & $\begin{array}{l}8.98 \mathrm{E}-09 \\
1.00 \mathrm{E}+00\end{array}$ & $\begin{array}{l}4.34 \mathrm{E}-08 \\
0 \\
0.00 \mathrm{E}+00\end{array}$ & $\begin{array}{l}1.59 \mathrm{E}-06 \\
1.00 \mathrm{E}+00\end{array}$ & $\begin{array}{l}3.2 \mathrm{E}-06 \\
1.00 \mathrm{E}+00\end{array}$ & $\begin{array}{l}2.91 \mathrm{E}-06 \\
8.97 \mathrm{E}-01\end{array}$ & $\begin{array}{l}3.76 \mathrm{E}-06 \\
8.95 \mathrm{E}-01\end{array}$ & $\begin{array}{l}1.83 \mathrm{E}-08 \\
1.00 \mathrm{E}+00\end{array}$ & \begin{tabular}{|l|}
$1.77 \mathrm{E}-05$ \\
$8.97 \mathrm{E}-01$
\end{tabular} & $\begin{array}{l}2.39 \mathrm{E}-06 \\
8.95 \mathrm{E}-01\end{array}$ & $\begin{array}{l}6.09 \mathrm{E}-07 \\
8.95 \mathrm{E}-01\end{array}$ & $\begin{array}{l}6.14 \mathrm{E}-09 \\
1.00 \mathrm{E}+00\end{array}$ \\
\hline & & & & $8.65 \mathrm{E}-04$ & $9.72 \mathrm{E}-05$ & $9.67 \mathrm{E}-04$ & $2.08 \mathrm{E}-06$ & $1.75 \mathrm{E}-06$ & $4.20 \mathrm{E}-06$ & $5.68 \mathrm{E}-072$ & $2.98 \mathrm{E}-06$ & $2.27 \mathrm{E}-05$ & $7.04 E-072$ & $2.02 \mathrm{E}-05$ & $6.52 \mathrm{E}-07$ & $1.20 \mathrm{E}-078$ & $8.98 \mathrm{E}-09$ & $4.34 \mathrm{E}-08$ & & & & & & & & & $6.14 \mathrm{E}-09$ \\
\hline \multirow[t]{2}{*}{3} & $\begin{array}{l}\mathrm{m} \\
\mathrm{a}\end{array}$ & $\begin{array}{l}4.10 \mathrm{E}-07 \\
9.21 \mathrm{E}-01\end{array}$ & $\begin{array}{l}2.00 \mathrm{E}-05 \\
9.18 \mathrm{E}-01\end{array}$ & $\begin{array}{l}5.68 \mathrm{E}-04 \\
9.18 \mathrm{E}-01\end{array}$ & $\begin{array}{l}5.50 \mathrm{E}-05 \\
9.17 \mathrm{E}-01\end{array}$ & $\begin{array}{l}5.65 \mathrm{E}-04 \\
9.17 \mathrm{E}-01\end{array}$ & $\begin{array}{l}7.12 \mathrm{E}-06 \\
7.09 \mathrm{E}-01\end{array}$ & & & $\begin{array}{l}5.64 \mathrm{E}-07 \\
7.14 \mathrm{E}-01 \\
\end{array}$ & $\begin{array}{l}4.75 \mathrm{E}-06 \\
9.18 \mathrm{E}-01\end{array}$ & $\begin{array}{l}1.96 \mathrm{E}-05 \\
9.18 \mathrm{E}-01\end{array}$ & $\begin{array}{l}9.65 \mathrm{E}-07 \\
9.18 \mathrm{E}-01 \\
\end{array}$ & $\begin{array}{l}6.53 \mathrm{E}-06 \\
1.00 \mathrm{E}+00\end{array}$ & $\begin{array}{l}1.81 \mathrm{E}-07 \\
1.00 \mathrm{E}+00\end{array}$ & $\begin{array}{l}2.122-081 \\
1.00 E+00 \\
1\end{array}$ & $\begin{array}{l}1.42 \mathrm{E}-08 \\
1.00 \mathrm{E}+00\end{array}$ & $\begin{array}{l}7.99 \mathrm{E}-08 \\
0.00 \mathrm{~B}+00\end{array}$ & & & & & & & & $\begin{array}{l}0.00 \mathrm{E} \mp+00 \\
9.19 \mathrm{E}-01\end{array}$ & $\begin{array}{l}0.00 \mathrm{E}+00 \\
1.00 \mathrm{E}+00\end{array}$ \\
\hline & activity & $3.78 \mathrm{E}-07$ & $1.83 \mathrm{E}-05$ & $5.21 \mathrm{E}-04$ & $5.05 E-05$ & $5.19 \mathrm{E}-04$ & $5.05 E-06$ & & & $4.02 \mathrm{E}-07$ & $4.36 \mathrm{E}-06$ & $1.80 \mathrm{E}-05$ & $8.86 \mathrm{E}-07 \mathrm{G}$ & $6.53 \mathrm{E}-06$ & $1.81 \mathrm{E}-07$ & $\begin{array}{l}2.12 E-08 \\
\end{array}$ & $1.42 \mathrm{E}-08$ & $37.99 E-08$ & & & & & & & & $0.00 E+00$ & $0.00 \mathrm{E}+00$ \\
\hline \multirow[t]{2}{*}{4} & s & $4.98 \mathrm{E}-07$ & $1.55 \mathrm{E}-05$ & $1.99 \mathrm{E}-04$ & $2.01 \mathrm{E}-05$ & $1.85 \mathrm{E}-04$ & $3.93 \mathrm{E}-06$ & & & $2.15 \mathrm{E}-06$ & $1.05 E-06$ & $1.50 \mathrm{E}-05$ & $2.22 \mathrm{E}-078$ & $8.02 \mathrm{E}-07$ & $2.31 \mathrm{E}-08$ & $8.96 \mathrm{E}-094$ & $4.29 \mathrm{E}-09$ & $2.32 \mathrm{E}-08$ & & & & & & & & $0.00 \mathrm{E}+00$ & $0.00 \mathrm{E}+00$ \\
\hline & $\underset{\text { activity }}{a_{4}}$ & $\begin{array}{l}9.50 \mathrm{E}-01 \\
473 \mathrm{E}-07\end{array}$ & $\begin{array}{l}9.49 \mathrm{E}-01 \\
14 \mathrm{~F}-05\end{array}$ & $\begin{array}{l}9.49 \mathrm{E}-01 \\
1.89 \mathrm{E}-04\end{array}$ & $\begin{array}{l}9.48 E-01 \\
180 \mathrm{E}-05\end{array}$ & $\begin{array}{l}9.48 \mathrm{E}-01 \\
1.6 \mathrm{E}-04\end{array}$ & $\begin{array}{l}8.10 \mathrm{E}-01 \\
3.1 \mathrm{EE}-06\end{array}$ & & & $\begin{array}{l}8.122 \mathrm{E}-01, \\
1.7 \mathrm{E}-06\end{array}$ & $\begin{array}{l}9.49 \mathrm{E}-01 \\
.96 \mathrm{P}-07\end{array}$ & $\begin{array}{l}9.49 \mathrm{E}-01 \\
1.42-05\end{array}$ & $\begin{array}{l}9.49 E-011 \\
2.10-07\end{array}$ & $\begin{array}{l}1.00 \mathrm{E}+00 \\
8.02 \mathrm{E}-07\end{array}$ & $\begin{array}{l}1.00 \mathrm{E}+00 \\
2.31 \mathrm{E}-08\end{array}$ & $\begin{array}{l}1.000=001 \\
896 E-09 \\
896\end{array}$ & $\begin{array}{l}1.00 \mathrm{E}+00 \\
429 \mathrm{E}-09\end{array}$ & $\begin{array}{l}1.00 E+00 \\
1.32 E-08 \\
2.328\end{array}$ & & & & & & & & $\begin{array}{l}9.49 E-01 \\
0.0 E E+00\end{array}$ & $\begin{array}{l}1.00 \mathrm{E}+00 \\
0.0 \mathrm{E}+00\end{array}$ \\
\hline \multirow[t]{3}{*}{5} & $\mathrm{~m}$ & $7.30 \mathrm{E}-07$ & $1.098-05$ & $3.91 \mathrm{E}-04$ & $8.93 \mathrm{E}-06$ & $3.77 \mathrm{E}-04$ & $1.94 \mathrm{E}-06$ & & & $8.52 \mathrm{E}-079$ & $9.52 \mathrm{E}-07$ & $1.02 \mathrm{E}-05$ & $4.56 \mathrm{E}-083$ & $3.10 \mathrm{E}-06$ & $2.03 \mathrm{E}-08$ & $2.59 \mathrm{E}-08$ & $1.30 \mathrm{E}-09$ & $3.10 \mathrm{E}-08$ & & & & & & & & $0.00 \mathrm{E}+00$ & $0.00 \mathrm{E}+00$ \\
\hline & & $9.35 \mathrm{E}-01$ & 9.33E-01 & $9.33 \mathrm{E}-01$ & 9.32E-01 & 9.33E-01 & 7.57E-01 & & & $\begin{array}{ll}7.61 \mathrm{E}-01 \\
\end{array}$ & $9.33 \mathrm{E}-01$ & $9.33 \mathrm{E}-01$ & $\begin{array}{l}9.33 \mathrm{E}-01 \\
1\end{array}$ & $1.00 \mathrm{E}+00$ & $1.00 E+00$ & $\begin{array}{l}1.00 \mathrm{E}+00 \mathrm{a} \\
\end{array}$ & $1.00 E+00$ & $0.1 .00 E+00$ & & & & & & & & $9.34 \mathrm{E}-01$ & $\begin{array}{l}1.00 \mathrm{E}+00 \\
0\end{array}$ \\
\hline & $\frac{\text { activity }}{\mathrm{m}}$ & $\begin{array}{l}\frac{6.838-\mathrm{E}-7}{8.60 \mathrm{E}-06} \\
\end{array}$ & $\begin{array}{l}1.02 \mathrm{E}-05 \\
1.34 \mathrm{E}-06\end{array}$ & $\begin{array}{l}3.6 \mathrm{ES}-04 \\
6.88 \mathrm{E}-03 \\
\end{array}$ & $\begin{array}{l}8.35 \mathrm{E}-06 \\
1.29 \mathrm{E}-04\end{array}$ & \begin{tabular}{|l|}
$.3 .22 \mathrm{E}-04$ \\
$7.42 \mathrm{E}-03$
\end{tabular} & $\frac{1.4 \mathrm{TE}-06}{7.15 \mathrm{E}-07}$ & & $1.02 \mathrm{E}-04$ & $\frac{6.496-078}{2.16 E-06}$ & $\begin{array}{l}8.88 \mathrm{E}-07 \\
2.76 \mathrm{E}-06\end{array}$ & $\begin{array}{l}\frac{9.488-06}{2.04 \mathrm{E}-05} \\
\end{array}$ & $\begin{array}{l}4.25 \mathrm{E}-083 \\
1.07 \mathrm{E}-07 \\
\end{array}$ & $\begin{array}{l}3.10 \mathrm{E}-06 \\
7.14 \mathrm{E}-04\end{array}$ & $\begin{array}{l}2.03 \mathrm{E}-08 \\
380 \mathrm{E}-06\end{array}$ & $\begin{array}{l}\frac{2.59 E-08}{4.13 E-06} \\
4\end{array}$ & \begin{tabular}{|l|l}
$1.30 \mathrm{E}-09$ \\
$1.52 \mathrm{E}-09$
\end{tabular} & \begin{tabular}{|l}
$3.10 \mathrm{E}-08$ \\
$447 \mathrm{E}-08$
\end{tabular} & & & & & & & & $\begin{array}{l}0.00 E \mp+00 \\
5.64 \mathrm{E}-06\end{array}$ & $\begin{array}{l}0.00 \mathrm{E}+00 \\
.98 \mathrm{E}-10\end{array}$ \\
\hline${ }^{6}$ & $\mathbf{m}$ & $\begin{array}{l}8.000-500 \\
7.91 \mathrm{E}-01\end{array}$ & $\begin{array}{l}1.56 \mathrm{E}-00 \\
7.63 \mathrm{E}-01\end{array}$ & 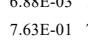 & 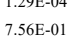 & $\begin{array}{l}7.424 \mathrm{E}-03 \\
7.00 \mathrm{E}-01\end{array}$ & 3. & & $\begin{array}{l}3.022-044 \\
3.82 \mathrm{E}-01\end{array}$ & $\begin{array}{l}3.16 \mathrm{E}-0 \mathrm{C}-1 \\
3.6 \mathrm{E}-01\end{array}$ & 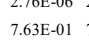 & $\begin{array}{l}2.044-53 \\
7.63 \mathrm{E}-01\end{array}$ & $\begin{array}{l}7.06 \mathrm{E}-01 \\
7\end{array}$ & $\begin{array}{l}1.144-5=4 \\
1.00 E+00\end{array}$ & 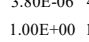 & 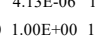 & 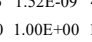 & 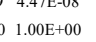 & $\begin{array}{l}\quad .54-5=0 \\
1.00 E+00\end{array}$ & $\begin{array}{l}3.4 .0 E-v 60 \\
1.00 E+00\end{array}$ & $\begin{array}{l}1.199-5 \mathrm{E} / 4 \\
7.86 \mathrm{E}-01\end{array}$ & & & 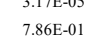 & & $\begin{array}{l}3.045-60 \\
7.75 \mathrm{E}-01\end{array}$ & $\begin{array}{l}9.88 \mathrm{E}-10 \\
1.00 \mathrm{E}+00\end{array}$ \\
\hline & activity & $6.80 \mathrm{E}-06$ & $1.022-06$ & $5.25 \mathrm{E}-03$ & $9.72 \mathrm{E}-05$ & $5.63 \mathrm{E}-03$ & $2.42 \mathrm{E}-07$ & & $3.88 \mathrm{E}-05$ & $7.81 \mathrm{E}-072$ & $2.10 \mathrm{E}-06$ & $1.55 \mathrm{E}-05$ & $8.18 E-087$ & $7.14 \mathrm{E}-04$ & $3.80 \mathrm{E}-06$ & $4.13 \mathrm{E}-06 \quad 1$ & $1.52 \mathrm{E}-09$ & 4.47₹-08 & $1.54 E-30$ & $3.45 \mathrm{E}-06$ & $1.411 \mathrm{E}-04$ & & & $2.49 \mathrm{E}-05$ & & $4.37 \mathrm{E}-06$ & $9.81 \mathrm{E}-10$ \\
\hline 7 & $\mathbf{m}$ & $1.18 \mathrm{E}-05$ & $1.97 \mathrm{E}-06$ & $7.46 \mathrm{E}-02$ & $2.05 \mathrm{E}-03$ & $8.56 \mathrm{E}-02$ & $1.18 \mathrm{E}-05$ & $5.74 \mathrm{E}-05$ & $1.08 \mathrm{E}-03$ & $1.66 \mathrm{E}-05$ & 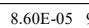 & $9.50 \mathrm{E}-05$ & $4.65 \mathrm{E}-063$ & $3.64 \mathrm{E}-02$ & \begin{tabular}{|l|l|}
$2.69 \mathrm{E}-04$ \\
\end{tabular} & $3.15 \mathrm{E}-051$ & $\begin{array}{l}11.42 \mathrm{E}-08 \\
\end{array}$ & $32.99 \mathrm{E}-07$ & $3.28 \mathrm{E}-05$ & $5.76 \mathrm{E}-03$ & $7.52 \mathrm{E}-04$ & $\begin{array}{l}9.42 \mathrm{E}-05 \\
\end{array}$ & $1.34 \mathrm{E}-04$ & $1.83 \mathrm{E}-06$ & $1.09 \mathrm{E}-04$ & \begin{tabular}{|l|l|l|l|l|} 
\\
\end{tabular} & $0.00 \mathrm{E}+00$ \\
\hline & & $6.05 \mathrm{E}-01$ & $4.93 \mathrm{E}-01$ & $4.93 \mathrm{E}-01$ & 4.63E-01 & $4.78 \mathrm{E}-01$ & $5.90 \mathrm{E}-02$ & $8.78 \mathrm{E}-02$ & $1.18 \mathrm{E}-01$ & $8.78 \mathrm{E}-02$ & $4.93 \mathrm{E}-01$ & $4.93 \mathrm{E}-01$ & $4.93 \mathrm{E}-01 \quad$ & & $1.00 \mathrm{E}+00$ & $1.00 E+00$ & $1.00 E+00$ & $01.00 E+00$ & $1.00 \mathrm{E}+00$ & $1.00 \mathrm{E}+00$ & $5.87 \mathrm{E}-01$ & $5.44 \mathrm{E}-01$ & $1.00 \mathrm{E}+00$ & $5.87 \mathrm{E}-01$ & $5.44 \mathrm{E}-01$ & $5.44 E-01$ & $1.00 \mathrm{E}+00$ \\
\hline & activity & $7.13 \mathrm{E}-06$ & $9.73 \mathrm{E}-07$ & $3.68 \mathrm{E}-02$ & 9.48E-04 & $4.09 \mathrm{E}-02$ & $6.96 \mathrm{E}-07$ & $5.04 \mathrm{E}-06$ & $1.28 \mathrm{E}-04$ & $1.46 \mathrm{E}-06$ & $4.24 \mathrm{E}-05$ & $4.68 \mathrm{E}-05$ & $2.29 \mathrm{E}-06$ & $3.64 \mathrm{E}-02$ & $2.69 \mathrm{E}-04$ & 3.15E-05 I & $1.42 \mathrm{E}-08$ & 2.99E -07 & $3.28 \mathrm{E}-05$ & $5.76 \mathrm{E}-03$ & $4.41 \mathrm{E}-04$ & $5.13 \mathrm{E}-05$ & $1.34 \mathrm{E}-04$ & $1.07 \mathrm{E}-06$ & $5.93 \mathrm{E}-05$ & $2.87 \mathrm{E}-09$ & $0.00 \mathrm{E}+00$ \\
\hline 8 & & $1.04 \mathrm{E}-05$ & $2.83 \mathrm{E}-06$ & $1.39 \mathrm{E}-01$ & $4.23 \mathrm{E}-03$ & $1.62 \mathrm{E}-01$ & $4.37 \mathrm{TE}-05$ & $1.04 \mathrm{E}-04$ & $1.91 \mathrm{E}-03$ & $8.70 \mathrm{E}-05$ & $3.14 \mathrm{E}-04$ & $1.78 \mathrm{E}-04$ & $1.82 \mathrm{E}-059$ & $9.19 \mathrm{E}-02$ & $7.28 \mathrm{E}-04$ & $4.09 \mathrm{E}-052$ & $2.96 \mathrm{E}-08$ & $8.82 \mathrm{E}-07$ & $8.00 \mathrm{E}-05$ & $1.24 \mathrm{E}-02$ & $1.53 \mathrm{E}-03$ & & & & & & $0.00 \mathrm{E}+00$ \\
\hline & & & & $4.20 \mathrm{E}-01$ & 3.82E-01 & & & $5.55 \mathrm{E}$ & & $5.55 \mathrm{E}-02$ & $4.20 \mathrm{E}$ & & & & & & & 0.00 & & & $5.38 \mathrm{E}-01$ & & & & & & $1.00 \mathrm{E}+00$ \\
\hline & & $5.82 \mathrm{E}-06$ & 1.19E-06 & $5.85 \mathrm{E}-02$ & $1.611-03$ & $6.50 \mathrm{E}-\mathrm{T}$ & $1.36 \mathrm{E}-06$ & $5.75 \mathrm{E}-06$ & $1.60 \mathrm{E}-04$ & $4.83 \mathrm{E}-06$ & $1.32 E-04$ & 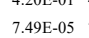 & $\begin{array}{l}7.204=01 \\
7.64-06\end{array}$ & $9.19 \mathrm{E}-02$ & $\begin{array}{l}7.28 \mathrm{E}-04 \\
\end{array}$ & $\begin{array}{l}4.09 E-05 \\
4\end{array}$ & $2.96 \mathrm{E}-08$ & $5.82 \mathrm{E}-07$ & $8.00 \mathrm{E}-05$ & $1.24 \mathrm{E}-02$ & $8.23 \mathrm{E}-04$ & 1. & $2.23 \mathrm{E}-04$ & $1.54 \mathrm{E}-06$ & 2E-04 & 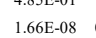 & $0.00 \mathrm{E}+00$ \\
\hline 9 & $\mathrm{~m}$ & $9.84 \mathrm{E}-06$ & $3.21 \mathrm{E}-06$ & $1.68 \mathrm{E}-01$ & $5.22 \mathrm{E}-03$ & $1.95 \mathrm{E}-01$ & $6.52 \mathrm{E}-05$ & $1.04 \mathrm{E}-04$ & $2.21 \mathrm{E}-03$ & $1.23 \mathrm{E}-04$ & $4.64 \mathrm{E}-04$ & $2.13 \mathrm{E}-04$ & $2.72 \mathrm{E}-05$ & $1.20 \mathrm{E}-01$ & $9.63 \mathrm{E}-04$ & $4.32 \mathrm{E}-053$ & $3.70 \mathrm{E}-08$ & $\begin{array}{l}7.0219 \mathrm{E}-07 \\
\end{array}$ & $1.03 \mathrm{E}-04$ & $1.53 \mathrm{E}-02$ & $1.59 \mathrm{E}-03$ & $3.111-04$ & $2.59 \mathrm{E}-04$ & $2.82 \mathrm{E}-06$ & $9.40 \mathrm{E}-04$ & $5.20 \mathrm{E}-08$ & $0.00 \mathrm{E}+00$ \\
\hline & 7. & $5.49 \mathrm{E}-01$ & $4.00 \mathrm{E}-01$ & $4.00 \mathrm{E}-01$ & $3.59 \mathrm{E}-01$ & $3.80 \mathrm{E}-01$ & $2.56 \mathrm{E}-02$ & $4.86 \mathrm{E}-02$ & $7.61 \mathrm{E}-02$ & $4.86 \mathrm{E}-02$ & $4.00 \mathrm{E}-01$ & $4.00 \mathrm{E}-01$ & $\begin{array}{l}4.00 \mathrm{E}-01 \quad 1 \\
\end{array}$ & $1.00 \mathrm{E}+00$ & $1.00 E+00$ & $1.00 E+001$ & $1.00 \mathrm{E}+00$ & $01.00 \mathrm{E}+00$ & 1.0 & $1.00 \mathrm{E}+00$ & $5.25 \mathrm{E}-01$ & $4.69 \mathrm{E}-01$ & $1.00 \mathrm{E}+00$ & 5.25E-01 & $4.69 \mathrm{E}-01$ & $4.69 \mathrm{E}-01$ & $1.00 \mathrm{E}+00$ \\
\hline & activity & $5.40 \mathrm{E}-06$ & $1.28 \mathrm{E}-06$ & $6.70 \mathrm{E}-02$ & $1.87 \mathrm{E}-03$ & $7.41 \mathrm{E}-02$ & $1.67 \mathrm{EE}-06$ & $5.07 \mathrm{E}-06$ & $1.68 \mathrm{E}-04$ & $5.99 \mathrm{E}-06$ & $1.86 \mathrm{E}-04$ & $8.53 \mathrm{E}-05$ & $1.09 E-05$ & $1.20 \mathrm{E}-01$ & $9.63 \mathrm{E}-04$ & $4.32 E-05 \quad 3$ & $3.70 \mathrm{E}-08$ & $\begin{array}{l}37.19 E-07 \\
\end{array}$ & $1.03 \mathrm{E}-04$ & $1.53 \mathrm{E}-02$ & $8.35 \mathrm{E}-04$ & $1.46 \mathrm{E}-04$ & $2.59 \mathrm{E}-04$ & 1.48E-06 & $4.41 \mathrm{E}-04$ & $2.44 \mathrm{E}-08$ & $0.00 \mathrm{E}+00$ \\
\hline 10 & $\mathrm{~m}$ & $9.73 \mathrm{E}-06$ & $3.38 \mathrm{E}-06$ & $1.86 \mathrm{E}-01$ & $5.96 \mathrm{E}-03$ & $2.17 \mathrm{E}-01$ & $8.00 \mathrm{E}-05$ & $1.00 \mathrm{E}-04$ & $2.46 \mathrm{E}-03$ & $1.05 E-045$ & $5.65 \mathrm{E}-04$ & $2.35 \mathrm{E}-04$ & $3.38 \mathrm{E}-051$ & $1.40 \mathrm{E}-01$ & $1.14 \mathrm{E}-03$ & $4.55 \mathrm{E}-05 \quad 4$ & $4.17 \mathrm{E}-08$ & $87.95 \mathrm{E}-07$ & $\begin{array}{l}1.19 \mathrm{E}-04 \\
\end{array}$ & $1.76 \mathrm{E}-02$ & $1.55 \mathrm{E}-03$ & $3.20 \mathrm{E}-04$ & $2.83 \mathrm{E}-04$ & $2.61 \mathrm{E}-06$ & $8.13 \mathrm{E}-04$ & $\begin{array}{l}4.49 E-08 \\
\end{array}$ & $0.00 \mathrm{E}+00$ \\
\hline & & $5.43 \mathrm{E}-01$ & $3.89 \mathrm{E}-01$ & $3.89 \mathrm{E}-01$ & $3.47 \mathrm{E}-01$ & & $2.29 \mathrm{E}-02$ & $4.50 \mathrm{E}-02$ & $7.20 \mathrm{E}-02$ & $4.50 \mathrm{E}-023$ & $3.89 \mathrm{E}-01$ & $3.89 \mathrm{E}-01$ & $\begin{array}{lll}3.89 \mathrm{E}-01 & 1\end{array}$ & & $1.00 E+00$ & & & $01.00 E+00$ & $1.00 \mathrm{E}+00$ & $1.00 \mathrm{E}+00$ & $5.18 \mathrm{E}-01$ & $4.61 \mathrm{E}-01$ & $1.00 \mathrm{E}+00$ & $5.18 E-01$ & $4.61 \mathrm{E}-01$ & $4.61 \mathrm{E}-01$ & $1.00 \mathrm{E}+00$ \\
\hline & activity & $5.28 \mathrm{E}-06$ & $1.31 \mathrm{E}-06$ & $7.24 \mathrm{E}-02$ & $2.06 \mathrm{E}-03$ & $7.98 \mathrm{E}-02$ & $1.83 \mathrm{E}-06$ & $4.50 \mathrm{E}-06$ & $1.77 \mathrm{E}-04$ & $4.72 E-062$ & $2.20 \mathrm{E}-04$ & $9.13 \mathrm{E}-05$ & $1.31 E-05$ & $1.40 \mathrm{E}-01$ & $1.14 \mathrm{E}-03$ & $4.55 \mathrm{E}-05 \quad 4$ & $4.17 \mathrm{E}-08$ & 7.95E-07 & 1.19E-04 & $1.76 \mathrm{E}-02$ & $8.02 E-04$ & $1.47 \mathrm{E}-04$ & $2.83 \mathrm{E}-04$ & $1.35 \mathrm{E}-06$ & $3.75 \mathrm{E}-04$ & $2.07 E-08$ & $0.00 \mathrm{E}+00$ \\
\hline 11 & & $9.87 \mathrm{E}-06$ & $3.41 \mathrm{E}-06$ & $1.98 \mathrm{E}-01$ & $6.49 \mathrm{E}-03$ & $2.31 \mathrm{E}-01$ & $8.55 \mathrm{E}-05$ & $9.93 \mathrm{E}-05$ & $2.61 \mathrm{E}-03$ & $1.10 \mathrm{E}-04$ & $6.01 \mathrm{E}-04$ & $2.40 \mathrm{E}-04$ & $3.66 \mathrm{E}-05$ & $1.53 \mathrm{E}-01$ & $1.28 \mathrm{E}-03$ & $4.79 \mathrm{E}-054$ & $4.42 \mathrm{E}-08$ & $8.27 \mathrm{E}-07$ & $1.22 \mathrm{E}-04$ & $1.90 \mathrm{E}-02$ & $1.55 \mathrm{E}-03$ & $3.33 \mathrm{E}-04$ & $2.91 \mathrm{E}-04$ & $2.48 \mathrm{E}-06$ & $8.58 \mathrm{E}-04$ & $4.47 \mathrm{E}-08$ & $0.00 \mathrm{E}+00$ \\
\hline & & $5.39 \mathrm{E}-01$ & $3.82 \mathrm{E}-01$ & $3.82 \mathrm{E}-01$ & 3.39E-01 & & & 4.291 & $6.96 \mathrm{~F}$ & $4.29 \mathrm{~F}$ & 3.82 & $3.82 \mathrm{E}-01$ & $3.82 \mathrm{E}-01 \mathrm{I}$ & & $1.00 \mathrm{E}+00$ & 1.00 & & 0 & $1.00 \mathrm{E}+00$ & $1.00 \mathrm{E}+00$ & $5.14 \mathrm{E}-01$ & $4.5 \mathrm{E}-01$ & $1.00 \mathrm{E}+00$ & $5.14 \mathrm{E}-01$ & $4.55 \mathrm{E}-01$ & $4.55 \mathrm{E}-01$ & $1.00 \mathrm{E}+00$ \\
\hline & $\begin{array}{l}\text { activity } \\
\text { at }\end{array}$ & $5.31 \mathrm{E}-06$ & $1.30 \mathrm{E}-06$ & $7.59 \mathrm{E}-02$ & $2.20 \mathrm{E}-03$ & $8.35 \mathrm{E}-0.2$ & $1.83 \mathrm{E}-06$ & $4.27 \mathrm{E}-06$ & $1.82 \mathrm{E}-04$ & $4.71 E-062$ & $2.30 \mathrm{E}-04$ & $9.17 \mathrm{E}-05$ & 1.40E-05 & $1.53 \mathrm{E}-01$ & $1.28 \mathrm{E}-03$ & $4.79 E-054$ & $4.42 \mathrm{E}-08$ & $8.27 \mathrm{E}-07$ & 1.22E-04 & $1.90 \mathrm{E}-02$ & $7.99 \mathrm{E}-04$ & $1.51 \mathrm{E}-04$ & $2.91 \mathrm{E}-04$ & $1.28 \mathrm{E}-06$ & $3.91 \mathrm{E}-04$ & $2.04 \mathrm{E}-08$ & $0.00 \mathrm{E}+00$ \\
\hline 12 & $\mathrm{~m}$ & $9.71 \mathrm{E}-06$ & $3.488=-06$ & $2.01 \mathrm{E}-01$ & $6.42 \mathrm{E}-03$ & $2.34 \mathrm{E}-01$ & $9.06 \mathrm{E}-05$ & $9.86 \mathrm{E}-05$ & $2.63 \mathrm{E}-03$ & $1.15 \mathrm{E}-04$ & $6.36 \mathrm{E}-04$ & $2.48 \mathrm{E}-04$ & $3.78 \mathrm{E}-05$ & $1.55 \mathrm{E}-01$ & & & & $8.49 \mathrm{E}-07$ & & & $1.55 \mathrm{E}-03$ & & & & & $86 \mathrm{E}-08$ & $E+00$ \\
\hline & & $5.38 \mathrm{E}-01$ & & $3.81 \mathrm{E}-01$ & $3.38 \mathrm{E}-01$ & & & & $6.93 \mathrm{E}-02$ & $4.26 \mathrm{E}-023$ & $3.81 \mathrm{E}-01$ & & & & & & & & & & & & & & & & \\
\hline & activity & $5.22 \mathrm{E}-06$ & $1.33 \mathrm{E}-06$ & $7.65 \mathrm{E}-02$ & $2.17 \mathrm{E}-03$ & $8.42 \mathrm{E}-02$ & $1.91 \mathrm{E}-06$ & $4.20 \mathrm{E}-06$ & $1.82 \mathrm{E}-04$ & $4.89 \mathrm{E}-062$ & $2.42 \mathrm{E}-04$ & $9.44 \mathrm{E}-05$ & 1.44E-05 & $1.55 \mathrm{E}-01$ & $1.27 \mathrm{E}-03$ & $4.74 \mathrm{E}-054$ & $4.43 \mathrm{E}-088$ & $8.49 \mathrm{E}-07$ & 1.28E-04 & $1.93 \mathrm{E}-02$ & $7.93 \mathrm{E}-04$ & $1.51 \mathrm{E}-04$ & $2.98 \mathrm{E}-04$ & $1.28 \mathrm{E}-06$ & $9 \mathrm{EE}-04$ & $2.21 \mathrm{E}-08$ & $0.00 \mathrm{E}+00$ \\
\hline 13 & $\mathrm{~m}$ & $9.74 \mathrm{E}-06$ & $3.51 \mathrm{E}-06$ & $2.07 \mathrm{E}-01$ & $6.87 \mathrm{E}-03$ & $2.41 \mathrm{E}-01$ & $9.40 \mathrm{E}-05$ & $1.03 \mathrm{E}-04$ & $2.70 \mathrm{E}-03$ & $1.21 \mathrm{E}-04$ & $6.58 \mathrm{E}-04$ & $2.50 \mathrm{E}-04$ & \begin{tabular}{|l|l|l}
$4.06 E-05$ \\
\end{tabular} & $1.63 \mathrm{E}-01$ & $1.37 \mathrm{E}-03$ & $4.8 \mathrm{EE}-05 \quad 4$ & $4.69 \mathrm{E}-08 \quad 8$ & $8.68 \mathrm{E}-07$ & $1.30 \mathrm{E}-04$ & $2.00 \mathrm{E}-02$ & $1.62 \mathrm{E}-03$ & $3.54 \mathrm{E}-04$ & $3.02 \mathrm{E}-04$ & $2.56 \mathrm{E}-06$ & $9.57 \mathrm{E}-04$ & \begin{tabular}{|l|l|}
$5.04 E-08$ \\
\end{tabular} & $0.00 \mathrm{E}+00$ \\
\hline & & $5.36 \mathrm{E}-01$ & 3.788-01 & $3.78 \mathrm{E}-01$ & $3.34 \mathrm{E}-01$ & $3.57 \mathrm{E}-01$ & $2.04 \mathrm{E}-02$ & $4.16 \mathrm{E}-02$ & $6.81 \mathrm{E}-02$ & $4.16 \mathrm{E}-023$ & $3.78 E-01$ & $3.78 \mathrm{E}-01$ & $\begin{array}{lll}3.78 E-01 & 1\end{array}$ & & & & & $01.00 E+00$ & $1.00 \mathrm{E}+00$ & $1.00 \mathrm{E}+00$ & $5.111-01$ & $4.52 \mathrm{E}-01$ & & $5.11 E-01$ & $4.52 \mathrm{E}-01$ & $4.52 \mathrm{E}-01$ & $1.00 \mathrm{E}+00$ \\
\hline & activity & $5.22 \mathrm{E}-06$ & $1.33 \mathrm{E}-06$ & $7.82 \mathrm{E}-02$ & $2.30 \mathrm{E}-03$ & $8.61 \mathrm{E}-02$ & $1.92 \mathrm{E}-06$ & $4.28 \mathrm{E}-06$ & $1.84 \mathrm{E}-04$ & $5.066-062$ & $2.49 \mathrm{E}-04$ & $9.47 \mathrm{E}-05$ & $1.53 \mathrm{E}-05$ & $1.63 \mathrm{E}-01$ & $1.37 \mathrm{E}-03$ & $4.85 \mathrm{E}-05 \quad 4$ & $4.69 \mathrm{E}$ & $8.68 \mathrm{E}-07$ & $1.30 E-04$ & $2.00 \mathrm{E}-02$ & $8.28 \mathrm{E}-04$ & $1.60 \mathrm{E}-04$ & $3.02 \mathrm{E}-04$ & $1.31 E-06$ & $4.32 \mathrm{E}-04$ & $2.28 \mathrm{E}-08$ & $0.00 \mathrm{E}+00$ \\
\hline 14 & $\mathrm{~m}$ & $9.64 \mathrm{E}-06$ & $3.54 \mathrm{E}-06$ & $2.06 \mathrm{E}-01$ & $6.81 \mathrm{E}-03$ & $2.40 \mathrm{E}-01$ & $\begin{array}{l}9.600 \mathrm{E}-05 \\
\end{array}$ & $9.93 \mathrm{E}-05$ & $2.70 \mathrm{E}-03$ & $1.26 \mathrm{E}-04 \mathrm{C}$ & $6.72 \mathrm{E}-04$ & $2.54 \mathrm{E}-04$ & $4.12 \mathrm{E}-05 \mathrm{I}$ & $1.62 \mathrm{E}-01$ & $1.36 \mathrm{E}-03$ & $4.79 \mathrm{E}-05 \quad 4$ & $4.70 \mathrm{E}-08 \&$ & $88.74 \mathrm{E}-07$ & $1.33 \mathrm{E}-04$ & $1.99 \mathrm{E}-02$ & $1.56 \mathrm{E}-03$ & $3.41 \mathrm{E}-04$ & $3.05 \mathrm{E}-04$ & $2.50 \mathrm{E}-06$ & $9.92 \mathrm{E}-04$ & $\begin{array}{l}5.38 \mathrm{E}-08 \\
\end{array}$ & $0.00 \mathrm{E}+00$ \\
\hline & & $5.36 \mathrm{E}-01$ & 3.78E-01 & $3.78 \mathrm{E}-01$ & $3.35 \mathrm{E}-01$ & $3.57 \mathrm{E}-01$ & $2.05 \mathrm{E}-02$ & $4.18 \mathrm{E}-02$ & $6.83 \mathrm{E}-02$ & $4.18 \mathrm{E}-023$ & $3.78 \mathrm{E}-01$ & $3.78 \mathrm{E}-01$ & $3.78 \mathrm{E}-01 \quad 1$ & $1.00 \mathrm{E}+00$ & $1.00 \mathrm{E}+00$ & $1.00 \mathrm{E}$ & $1.00 E+001$ & $01.00 E+00$ & $1.00 E+00$ & $1.00 \mathrm{E}+00$ & $5.111 \mathrm{E}-01$ & $4.52 \mathrm{E}-01$ & & 5.11E-01 & $4.52 \mathrm{E}-01$ & $4.52 \mathrm{E}-01$ & $1.00 \mathrm{E}+00$ \\
\hline & activity & $5.17 \mathrm{E}-06$ & 1.34E- 06 & $7.80 \mathrm{E}-02$ & $2.28 \mathrm{E}-03$ & $8.58 \mathrm{E}-02$ & $1.97 \mathrm{E}-06$ & $4.15 \mathrm{E}-06$ & $1.84 \mathrm{E}-04$ & $5.26 \mathrm{E}-062$ & $2.54 \mathrm{E}-04$ & $9.61 \mathrm{E}-05$ & $1.56 \mathrm{E}-05$ & $1.62 \mathrm{E}-01$ & $1.36 \mathrm{E}-03$ & $4.79 \mathrm{E}-05 \quad 4$ & $4.70 \mathrm{E}-088$ & $8.74 \mathrm{E}-07$ & $1.33 \mathrm{E}-04$ & $1.99 \mathrm{E}-02$ & $7.99 \mathrm{E}-04$ & $1.54 \mathrm{E}-04$ & $3.05 \mathrm{E}-04$ & $1.28 \mathrm{E}-06$ & 4.49E- 04 & $2.43 E-08$ & $0.00 \mathrm{E}+00$ \\
\hline 15 & & $9.58 \mathrm{E}-06$ & $3.55 \mathrm{E}-06$ & $2.04 \mathrm{E}-01$ & $6.70 \mathrm{E}-03$ & $2.38 \mathrm{E}-01$ & $9.66 \mathrm{E}-05$ & $9.66 \mathrm{E}-05$ & $2.68 \mathrm{E}-03$ & $1.29 \mathrm{E}-04$ & $6.76 \mathrm{E}-04$ & $2.56 \mathrm{E}-04$ & $4.12 \mathrm{E}-05$ & $1.60 \mathrm{E}-01$ & $1.33 \mathrm{E}-03$ & $4.73 \mathrm{E}-054$ & $4.66 \mathrm{E}-088$ & $8.73 \mathrm{E}-07$ & $1.35 \mathrm{E}-04$ & $1.98 \mathrm{E}-02$ & $1.52 \mathrm{E}-03$ & $3.30 \mathrm{E}-04$ & $3.06 \mathrm{E}-04$ & $2.46 \mathrm{E}-06$ & $1.02 \mathrm{E}-03$ & $5.63 \mathrm{E}-08$ & $0.00 \mathrm{E}+00$ \\
\hline & & $5.37 \mathrm{E}-01$ & 3.79E-01 & $3.79 \mathrm{E}-01$ & $3.36 \mathrm{E}-01$ & $3.58 \mathrm{E}-01$ & $2.07 \mathrm{E}-02$ & $4.20 \mathrm{E}-02$ & $6.86 \mathrm{E}-02$ & $4.20 \mathrm{E}-02$ & $3.79 \mathrm{E}-01$ & $3.79 \mathrm{E}-01$ & 3.79E-01 । & $\begin{array}{l}1.00 \mathrm{E}+00 \\
\end{array}$ & $1.00 \mathrm{E}+00$ & $1.00 \mathrm{E}+00$ & $1.00 \mathrm{E}+00$ & 0 & $1.00 \mathrm{E}+00$ & $1.00 \mathrm{E}+00$ & $5.12 \mathrm{E}-01$ & $4.53 \mathrm{E}-01$ & $1.00 \mathrm{E}+00$ & $5.12 \mathrm{E}-01$ & $4.53 \mathrm{E}-01$ & $4.53 \mathrm{E}-01$ & $1.00 \mathrm{E}+00$ \\
\hline & & $5.14 \mathrm{E}-06$ & & -02 & $2.25 \mathrm{E}-03$ & & $2.00 \mathrm{E}-06$ & $4.06 \mathrm{E}-06$ & $1.84 \mathrm{E}-04$ & $5.43 \mathrm{E}-06$ & $2.56 \mathrm{E}-04$ & $9.70 \mathrm{E}-05$ & | & $1.60 \mathrm{E}-01$ & $1.33 \mathrm{E}-03$ & $\begin{array}{l}4.73 \mathrm{E}-05 \\
4\end{array}$ & $4.66 \mathrm{E}-08 \quad 8$ & $8.73 \mathrm{E}-07$ & $1.35 \mathrm{E}-04$ & $1.98 \mathrm{E}-02$ & $7.78 \mathrm{E}-04$ & 1.49E- -4 & $3.06 \mathrm{E}-04$ & $1.26 \mathrm{E}-06$ & $4.60 \mathrm{E}-04$ & $2.55 \mathrm{E}-08$ & $0.00 \mathrm{E}+00$ \\
\hline 16 & $\mathrm{~m}$ & $9.95 \mathrm{E}-06$ & $3.44 \mathrm{E}-06$ & $2.06 \mathrm{E}-01$ & $7.29 \mathrm{E}-03$ & 2.42 & $9.39 \mathrm{E}-05$ & $9.48 \mathrm{E}-05$ & $2.82 \mathrm{E}-03$ & $1.34 \mathrm{E}-04$ & $6.52 \mathrm{E}-04$ & $2.55 \mathrm{E}-04$ & $4.29 \mathrm{E}-05$ & $1.62 \mathrm{E}-01$ & & & & & & & $1.49 \mathrm{E}-03$ & & & & & & \\
\hline & & & 3.78E-01 & $3.78 \mathrm{E}-01$ & $3.34 \mathrm{E}-01$ & $3.56 \mathrm{E}-01$ & $2.04 \mathrm{E}-02$ & 4.1 & 6.80 & $4.16 \mathrm{E}-023$ & $3.78 \mathrm{E}-01$ & 3.78 & 3.78 & & 1.00 & 1.00 & & & & & 5.1 & & & & & 4.5 & \\
\hline & activity & 5.3 & $1.30 \mathrm{E}-06$ & $7.78 \mathrm{E}-02$ & $2.44 \mathrm{E}-03$ & & $1.91 \mathrm{EE}-06$ & $3.94 \mathrm{E}-06$ & 1.92 & $5.56 \mathrm{E}-062$ & $2.46 \mathrm{E}-04$ & $9.63 \mathrm{E}-05$ & $05 \quad 1$ & 1.6 & 1.46 & 4.96 & & 8.45 & 1. & 02 & $7.63 \mathrm{E}-04$ & $1.48 \mathrm{E}-04$ & 3.08 & 06 & .04 & $2.49 \mathrm{E}-08$ & $0.00 \mathrm{E}+00$ \\
\hline 17 & & $1.01 \mathrm{E}-05$ & $3.43 \mathrm{E}-06$ & $2.14 \mathrm{E}-01$ & $7.81 \mathrm{E}-03$ & $2.52 \mathrm{E}-01$ & $9.67 \mathrm{EE}-05$ & $9.93 \mathrm{E}-05$ & $2.95 \mathrm{E}-03$ & $1.44 \mathrm{E}-04$ & $6.67 \mathrm{E}-04$ & $2.57 \mathrm{E}-04$ & $4.50 \mathrm{E}-05 \mathrm{I}$ & $1.72 \mathrm{E}-01$ & 1.581 & 5.191 & 5.07 & $8.56 \mathrm{E}-07$ & $1.36 \mathrm{E}-04$ & $2.21 \mathrm{E}-02$ & $1.58 \mathrm{E}-03$ & $3.53 \mathrm{E}-04$ & $3.13 \mathrm{E}-04$ & $2.33 \mathrm{E}-06$ & $1.15 \mathrm{E}-03$ & $\begin{array}{l}5.68 \mathrm{E}-08 \\
\end{array}$ & $0.00 \mathrm{E}+00$ \\
\hline & & & & $3.73 \mathrm{E}-01$ & $3.29 \mathrm{E}-01$ & $3.52 \mathrm{E}-$ & $1.94 \mathrm{E}$ & 4.03E & $6.66 \mathrm{E}$ & $4.03 \mathrm{E}-\mathrm{T}$ & $3.73 \mathrm{E}$ & 3.731 & $3.73 \mathrm{E}-$ & & & & & $01.00 \mathrm{E}+00$ & 1.0 & & $5.08 \mathrm{E}-01$ & 4.48E-01 & & & $4.48 \mathrm{E}-01$ & $4.48 \mathrm{E}-01$ & \\
\hline & $\mathrm{ac}$ & $5.41 \mathrm{E}-06$ & $1.28 \mathrm{E}$ & 8.00 & $2.57 \mathrm{E}$ & $8.88 \mathrm{E}-02$ & $1.88 \mathrm{E}-06$ & $4.00 \mathrm{E}-06$ & $1.96 \mathrm{E}-04$ & $5.82 \mathrm{E}-06$ & $2.49 \mathrm{E}-04$ & $9.60 \mathrm{E}-05$ & $1.68 \mathrm{E}-05$ & $1.72 \mathrm{E}$ & $1.58 \mathrm{E}-03$ & $5.19 \mathrm{E}-055$ & $5.07 \mathrm{E}-08 \&$ & $8.56 \mathrm{E}-07$ & $1.36 \mathrm{E}-$ & $2.21 \mathrm{E}-02$ & $8.00 \mathrm{E}-04$ & $1.58 \mathrm{E}-04$ & $3.13 \mathrm{E}-04$ & 1.1.18E-06 & $5.13 \mathrm{E}-04$ & $2.55 \mathrm{E}-08$ & $0.00 \mathrm{E}+00$ \\
\hline 18 & & $1.01 \mathrm{E}-05$ & $3.48 \mathrm{E}-06$ & $2.17 \mathrm{E}-01$ & $7.87 \mathrm{E}-03$ & $2.56 \mathrm{E}-01$ & $1.00 \mathrm{E}-04$ & $1.02 \mathrm{E}-04$ & $2.97 \mathrm{E}-03$ & $1.49 \mathrm{E}-04$ & $6.92 \mathrm{E}-04$ & $2.62 \mathrm{E}-04$ & \begin{tabular}{|l|l|l}
$4.64 \mathrm{E}-05$ & \\
\end{tabular} & $1.75 \mathrm{E}-01$ & $1.60 \mathrm{E}-03$ & $5.18 \mathrm{E}-055$ & $5.14 \mathrm{E}-088$ & $8.73 \mathrm{E}-07$ & $1.39 E-04$ & $2.24 \mathrm{E}-02$ & $1.62 \mathrm{E}-03$ & $3.64 \mathrm{E}-04$ & $3.17 \mathrm{E}-04$ & $2.39 \mathrm{E}-06$ & $1.19 \mathrm{E}-03$ & \begin{tabular}{|c|}
$5.97 \mathrm{E}-08$ \\
\end{tabular} & $0.00 \mathrm{E}+00$ \\
\hline & & & $3.72 \mathrm{E}-01$ & $3.72 \mathrm{E}-01$ & $3.28 \mathrm{E}-01$ & $3.51 \mathrm{E}-01$ & $1.92 \mathrm{E}-02$ & $4.00 \mathrm{E}-02$ & $6.61 \mathrm{E}-02$ & $4.00 \mathrm{E}-02$ & $3.72 \mathrm{E}-01$ & $3.72 \mathrm{E}-01$ & $3.72 \mathrm{E}-01 \quad 1$ & & $1.00 \mathrm{E}+00$ & 1.001 & & $01.00 E+00$ & & & $5.07 \mathrm{E}-01$ & $4.47 \mathrm{E}-01$ & $1.00 \mathrm{E}+00$ & $5.07 \mathrm{E}-01$ & 4.47E- 01 & $4.47 \mathrm{E}-01$ & $1.00 \mathrm{E}+00$ \\
\hline & activity & $5.36 \mathrm{E}-06$ & 1.29E- -06 & $8.07 \mathrm{E}-02$ & $2.58 \mathrm{E}-03$ & $8.96 \mathrm{E}-02$ & $1.93 \mathrm{E}-06$ & $4.06 \mathrm{E}-06$ & $1.97 \mathrm{E}-04$ & $5.97 \mathrm{E}-062$ & $2.58 \mathrm{E}-04$ & $9.74 \mathrm{E}-05$ & $1.73 \mathrm{E}-05$ & $1.75 \mathrm{E}-01$ & $1.60 \mathrm{E}-03$ & $5.18 \mathrm{E}-055$ & $5.14 E-088$ & $8.73 \mathrm{E}-07$ & $1.39 \mathrm{E}-04$ & $2.24 \mathrm{E}-02$ & $8.19 \mathrm{E}-04$ & $1.63 \mathrm{E}-04$ & $3.17 \mathrm{E}-04$ & $1.21 \mathrm{E}-06$ & $5.31 \mathrm{E}-04$ & $2.67 \mathrm{E}-08$ & $0.00 \mathrm{E}+00$ \\
\hline & & $9.75 \mathrm{E}-06$ & $3.55 \mathrm{E}-06$ & $2.11 \mathrm{E}-01$ & $7.55 \mathrm{E}-03$ & $2.48 \mathrm{E}-01$ & $1.03 \mathrm{E}-04$ & $9.69 \mathrm{E}-05$ & $2.89 \mathrm{E}-03$ & $1.47 \mathrm{E}-04$ & $7.14 \mathrm{E}-04$ & $2.68 \mathrm{E}-04$ & $4.74 \mathrm{E}-05 \mathrm{I}$ & $1.68 \mathrm{E}-01$ & $1.52 \mathrm{E}-03$ & $4.93 \mathrm{~B}-055$ & $5.12 \mathrm{E}-088$ & $8.79 \mathrm{E}-07$ & $1.46 \mathrm{E}-04$ & $2.16 \mathrm{E}-02$ & $1.53 \mathrm{E}-03$ & $3.40 \mathrm{E}-04$ & $3.20 \mathrm{E}-04$ & $.38 \mathrm{E}-06$ & 3 & $6.37 \mathrm{E}-08$ & $0.00 \mathrm{E}+00$ \\
\hline & & & & $3.75 \mathrm{E}-01$ & & & & & & & $3.75 \mathrm{E}-01$ & & & & & & & & & & & & & & & $4.49 \mathrm{E}-01$ & 1 \\
\hline & & & & $7.91 \mathrm{E}-02$ & $2.50 \mathrm{E}-03$ & & $2.05 E-06$ & & & $6.00 \mathrm{E}-062$ & & $1.01 \mathrm{E}-04$ & | & $1.68 \mathrm{E}-01$ & 03 . & $\begin{array}{l}4.93 \mathrm{E}-05 \\
4\end{array}$ & & $\begin{array}{l}8.79 \mathrm{E}-07 \\
8\end{array}$ & $1.46 \mathrm{E}-04$ & $6 \mathrm{E}-02$ & $7.80 \mathrm{E}-04$ & $\begin{array}{l}-.445-51 \\
1.53 \mathrm{E}-04\end{array}$ & $3.20 \mathrm{E}-04$ & & -04 & 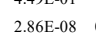 & $0.00 \mathrm{E}+00$ \\
\hline 20 & & 15 & 3.3 & $2.06 \mathrm{E}-01$ & $7.37 \mathrm{E}-03$ & 2.4 & $8.72 \mathrm{E}-05$ & $9.55 \mathrm{E}-05$ & $2.83 \mathrm{E}-03$ & $1.46 \mathrm{E}-04$ & $6.04 \mathrm{E}-04$ & $2.44 \mathrm{E}-04$ & & & $1.47 \mathrm{E}-03$ & $5.14 \mathrm{E}$ & & $8.19 \mathrm{E}-07$ & & & 1.51 & $3.31 \mathrm{E}-04$ & & & & & \\
\hline & & & & $3.77 \mathrm{E}-01$ & 3.34 & & & & & & 3.77 & & 3.77 & & & & & & & & 5.1 & & & & & 4.5 & \\
\hline & activity & & $1.26 \mathrm{E}$ & $7.79 \mathrm{E}-02$ & 2.46 & & 1.771 & 3.96 & 1.92 & $6.07 \mathrm{E}-062$ & 2.28 & 9.26 & 1.51 & & 1.47 & & & & & & 7.69 & 1.49 & & 1.15 & & & \\
\hline 21 & & $9.76 \mathrm{E}-06$ & $3.51 \mathrm{E}-06$ & $2.07 \mathrm{E}-01$ & $7.34 \mathrm{E}-03$ & $2.43 \mathrm{E}-01$ & $\begin{array}{l}9.96 \mathrm{E}-05 \\
\end{array}$ & $9.36 \mathrm{E}-05$ & $2.84 \mathrm{E}-03$ & $1.48 \mathrm{E}-04$ & $6.90 \mathrm{E}-04$ & $2.64 \mathrm{E}-04$ & $4.55 \mathrm{E}-05 \mathrm{I}$ & 1.63 & $1.47 \mathrm{E}-03$ & 4.88 & $4.99 \mathrm{E}-08 \quad 8$ & $88.63 \mathrm{E}-07$ & 1.43 & $2.10 \mathrm{E}-02$ & $1.48 \mathrm{E}-03$ & $3.24 \mathrm{E}-04$ & $3.16 \mathrm{E}-04$ & $2.32 \mathrm{E}-06$ & $1.17 \mathrm{E}-03$ & \begin{tabular}{|c|}
$6.44 \mathrm{E}-08$ \\
\end{tabular} & $0.00 \mathrm{E}+00$ \\
\hline & & & & $3.77 \mathrm{E}-01$ & & & $2.03 \mathrm{~F}$ & 4.14 & & 4.145 & $3.77 \mathrm{E}-01$ & & $\begin{array}{l}3.77 E-01 \quad 1 \\
\end{array}$ & & 1.001 & & & & & $1.00 \mathrm{E}+00$ & 5.10 & $4.51 \mathrm{E}-01$ & & $5.10 \mathrm{~F}$ & $4.51 \mathrm{E}-01$ & $4.51 \mathrm{E}-01$ & 1. \\
\hline & activity & $5.23 \mathrm{E}-06$ & $1.33 \mathrm{E}-06$ & $7.79 \mathrm{E}-02$ & $2.45 \mathrm{E}-03$ & $8.64 \mathrm{E}-02$ & $2.02 \mathrm{E}-06$ & $3.88 \mathrm{E}-06$ & $1.93 \mathrm{E}-04$ & $6.14 \mathrm{E}-062$ & $2.60 \mathrm{E}-04$ & $9.96 \mathrm{E}-05$ & $1.72 \mathrm{E}-05$ & $1.63 \mathrm{E}-01$ & $1.47 \mathrm{E}-03$ & $4.88 \mathrm{E}-05 \quad 4$ & $4.99 \mathrm{E}-088$ & $8.63 \mathrm{E}-07$ & $1.43 \mathrm{E}-04$ & $2.10 \mathrm{E}-02$ & $7.53 \mathrm{E}-04$ & $1.46 \mathrm{E}-04$ & $3.16 \mathrm{E}-04$ & 1.18E-06 & $5.28 \mathrm{E}-04$ & $2.91 \mathrm{E}-08$ & $0.00 \mathrm{E}+00$ \\
\hline 22 & $\mathrm{~m}$ & $1.06 \mathrm{E}-05$ & $3.29 \mathrm{E}-06$ & $2.17 \mathrm{E}-01$ & $7.65 \mathrm{E}-03$ & $2.56 \mathrm{E}-01$ & $8.74 \mathrm{E}-05$ & $9.94 \mathrm{E}-05$ & $2.98 \mathrm{E}-03$ & $1.59 \mathrm{E}-04$ & $6.02 \mathrm{E}-04$ & $2.41 \mathrm{E}-04$ & $3.93 \mathrm{E}-05$ & $1.75 \mathrm{E}-01$ & $1.56 \mathrm{E}-03$ & $5.48 \mathrm{E}-054$ & $4.72 \mathrm{E}-088$ & $8.25 \mathrm{E}-07$ & 1.2 & SE-02 & $1.58 \mathrm{E}-03$ & $3.56 \mathrm{E}-04$ & $3.00 \mathrm{E}-04$ & $2.21 E-06$ & $26 \mathrm{E}-03$ & $5.53 \mathrm{E}-08$ & $0.00 \mathrm{E}+00$ \\
\hline & & & $3.72 \mathrm{E}-01$ & $3.72 \mathrm{E}-01$ & $3.28 \mathrm{E}-01$ & $3.51 \mathrm{E}-01$ & $1.92 \mathrm{E}-02$ & 4. & & $4.00 \mathrm{E}-02$ & 3.721 & $3.72 \mathrm{E}-01$ & $\begin{array}{l}3.72 \mathrm{E}-01 \quad \mathrm{I} \\
\end{array}$ & & $1.00 \mathrm{E}+00$ & & & $01.00 E+00$ & $1.00 \mathrm{E}+00$ & $1.00 \mathrm{E}+00$ & $5.07 \mathrm{E}-01$ & $4.47 \mathrm{E}-01$ & $1.00 \mathrm{E}+00$ & $5.07 \mathrm{E}-01$ & $4.47 \mathrm{E}-01$ & $4.47 \mathrm{E}-01$ & $1.00 \mathrm{E}+00$ \\
\hline & vity & $5.67 \mathrm{E}-06$ & & & & (E-02 & $1.68 \mathrm{E}-06$ & $3.98 \mathrm{E}-06$ & -04 & $6.35 \mathrm{E}-062$ & $2.24 \mathrm{E}-04$ & $8.98 \mathrm{E}-05$ & | & $1.75 \mathrm{E}-01$ & $1.56 \mathrm{E}-03$ & $5.48 \mathrm{E}-054$ & $4.72 \mathrm{E}-08 \quad 8$ & $8.25 \mathrm{E}-07$ & $1.22 \mathrm{E}-04$ & $2.25 \mathrm{E}-02$ & $8.02 \mathrm{E}-04$ & $1.59 \mathrm{E}-04$ & $3.00 \mathrm{E}-04$ & $1.12 \mathrm{E}-06$ & $5.65 \mathrm{E}-04$ & $2.47 \mathrm{E}-08$ & $0.00 \mathrm{E}+00$ \\
\hline & & & & & & & & & & & & & & & & & & & & & $1.62 \mathrm{E}-03$ & & & & & $\begin{array}{ll}6.50 \mathrm{E}-08 \\
\end{array}$ & \\
\hline & & & & & & & 2014 & & & & & & & & & & & $\begin{array}{l}0.00 E+00 \\
3\end{array}$ & $1.00 \mathrm{E}+00$ & $1.00 \mathrm{E}+00$ & $5.10 \mathrm{E}-0.1$ & $\begin{array}{l}4.51 \mathrm{E}-01 \\
\end{array}$ & $\begin{array}{l}1.00 \mathrm{E}+00 \\
3.1 .6-14\end{array}$ & $5.10 \mathrm{E}-01$ & $\begin{array}{l}4.51 \mathrm{E}-01 \\
5.35-04\end{array}$ & 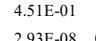 & $\begin{array}{l}1.00 \mathrm{E}+00 \\
0.0 \mathrm{E}+00\end{array}$ \\
\hline & & & & & & & & & & & & & & & & & & $8.63 \mathrm{E}-07$ & 1.433E-04 & & & & & $.29 \mathrm{E}-06$ & $5,35 \mathrm{E}-04$ & $2.93 \mathrm{E}-0\}$ & \\
\hline
\end{tabular}




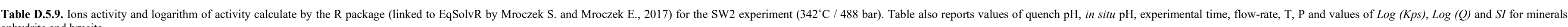

\begin{tabular}{|c|c|c|c|c|c|c|c|c|c|c|c|c|c|c|c|c|}
\hline samples & 1 & 2 & 3 & 4 & 5 & 6 & 7 & 8 & 9 & 10 & 11 & 12 & 13 & 14 & 15 & 16 \\
\hline \multicolumn{17}{|l|}{$a=\boldsymbol{m} \cdot \boldsymbol{a}_{\gamma}$} \\
\hline $\mathrm{H}^{+}$ & 1.132E-05 & $3.014 \mathrm{E}-06$ & $6.925 \mathrm{E}-06$ & $5.838 \mathrm{E}-06$ & $5.239 \mathrm{E}-06$ & 4.923E-06 & 4.675E-06 & 4.415E-06 & 4.421E- 06 & 4.419E-06 & 4.471E-06 & 4.476E-06 & 4.427E-06 & $4.599 \mathrm{E}-06$ & 4.470E-06 & 4.554E-06 \\
\hline $\mathrm{OH}$ & $6.823 \mathrm{E}-07$ & $2.563 \mathrm{E}-06$ & $1.116 \mathrm{E}-06$ & $1.324 \mathrm{E}-06$ & $1.475 \mathrm{E}-06$ & $1.569 \mathrm{E}-06$ & $1.653 \mathrm{E}-06$ & $1.750 \mathrm{E}-06$ & $1.748 \mathrm{E}-06$ & 1.749E-06 & $1.728 \mathrm{E}-06$ & $1.726 \mathrm{E}-06$ & $1.745 \mathrm{E}-06$ & $1.680 \mathrm{E}-06$ & $1.729 \mathrm{E}-06$ & $1.697 \mathrm{E}-06$ \\
\hline $\mathrm{Na}^{+}$ & $3.857 \mathrm{E}-04$ & $2.400 \mathrm{E}-04$ & $2.515 \mathrm{E}-02$ & $5.964 \mathrm{E}-02$ & $7.825 \mathrm{E}-02$ & $8.543 \mathrm{E}-02$ & $8.899 \mathrm{E}-02$ & $9.053 \mathrm{E}-02$ & $9.252 \mathrm{E}-02$ & $9.329 \mathrm{E}-02$ & $9.311 \mathrm{E}-02$ & $9.345 \mathrm{E}-02$ & $9.121 \mathrm{E}-02$ & $9.450 \mathrm{E}-02$ & $9.280 \mathrm{E}-02$ & $9.271 \mathrm{E}-02$ \\
\hline $\mathrm{K}^{+}$ & $1.269 \mathrm{E}-04$ & $5.401 \mathrm{E}-05$ & $6.635 \mathrm{E}-04$ & $1.704 \mathrm{E}-03$ & 2.285E- 03 & $2.536 \mathrm{E}-03$ & $2.666 \mathrm{E}-03$ & $2.726 \mathrm{E}-03$ & $2.791 \mathrm{E}-03$ & 2.787E- 03 & $2.806 \mathrm{E}-03$ & $2.815 \mathrm{E}-03$ & $2.754 \mathrm{E}-03$ & $2.829 \mathrm{E}-03$ & $2.788 \mathrm{E}-03$ & $2.803 \mathrm{E}-03$ \\
\hline $\mathrm{Cl}$ & $9.000 \mathrm{E}-04$ & $3.048 \mathrm{E}-04$ & $2.806 \mathrm{E}-02$ & $6.636 \mathrm{E}-02$ & $8.646 \mathrm{E}-02$ & 9.422E-02 & $9.796 \mathrm{E}-02$ & 9.945E-02 & $1.015 \mathrm{E}-01$ & $1.023 \mathrm{E}-01$ & $1.020 \mathrm{E}-01$ & $1.024 \mathrm{E}-01$ & 9.989E-02 & $1.035 \mathrm{E}-01$ & $1.016 \mathrm{E}-01$ & $1.016 \mathrm{E}-01$ \\
\hline $\mathrm{SO}_{4}^{2-}$ & 3.498E-07 & 6.139E-08 & $1.846 \mathrm{E}-06$ & $3.712 \mathrm{E}-06$ & $4.876 \mathrm{E}-06$ & $5.716 \mathrm{E}-06$ & $6.447 \mathrm{E}-06$ & 7.222E-06 & 7.180E-06 & $7.120 \mathrm{E}-06$ & $6.871 \mathrm{E}-06$ & $6.839 \mathrm{E}-06$ & $6.913 \mathrm{E}-06$ & $6.446 \mathrm{E}-06$ & $6.817 \mathrm{E}-06$ & $6.524 \mathrm{E}-06$ \\
\hline $\mathrm{Ca}^{2+}$ & 4.187E-06 & $<\mathrm{LOD}$ & 4.565E-06 & $5.697 \mathrm{E}-06$ & $6.093 \mathrm{E}-06$ & $5.933 \mathrm{E}-06$ & $5.425 \mathrm{E}-06$ & $5.501 \mathrm{E}-06$ & $5.333 \mathrm{E}-06$ & $5.624 \mathrm{E}-06$ & $4.909 \mathrm{E}-06$ & $4.801 \mathrm{E}-06$ & $4.742 \mathrm{E}-06$ & 4.735E-06 & $4.717 \mathrm{E}-06$ & 4.689E-06 \\
\hline $\mathrm{Mg}^{2+}$ & $1.024 \mathrm{E}-04$ & $1.251 \mathrm{E}-06$ & $1.615 \mathrm{E}-04$ & $2.416 \mathrm{E}-04$ & 2.613E-04 & $2.715 \mathrm{E}-04$ & $2.757 \mathrm{E}-04$ & $2.740 \mathrm{E}-04$ & 2.744E-04 & $2.723 \mathrm{E}-04$ & $2.698 \mathrm{E}-04$ & 2.694E-04 & $2.648 \mathrm{E}-04$ & $2.699 \mathrm{E}-04$ & $2.675 \mathrm{E}-04$ & 2.665E-04 \\
\hline $\mathrm{Fe}^{2+}$ & 1.400E- 05 & 2.793E-06 & $9.068 \mathrm{E}-07$ & 2.141E-06 & $6.026 \mathrm{E}-06$ & 7.592E-06 & $8.547 \mathrm{E}-06$ & $9.573 \mathrm{E}-06$ & 1.039E- 05 & 1.139E-05 & 1.190E-05 & $1.205 \mathrm{E}-05$ & $1.174 \mathrm{E}-05$ & $1.233 \mathrm{E}-05$ & $1.228 \mathrm{E}-05$ & $1.209 \mathrm{E}-05$ \\
\hline$a_{H^{+}}^{2}$ & $1.282 \mathrm{E}-10$ & $9.086 \mathrm{E}-12$ & 4.796E-11 & 3.408E-11 & 2.744E-11 & 2.424E-11 & 2.185E-11 & 1.949E-11 & 1.954E-11 & 1.953E-11 & 1.999E-11 & 2.003E-11 & 1.960E-11 & 2.115E-11 & $1.998 \mathrm{E}-11$ & 2.074E-11 \\
\hline $\log \left(a \mathrm{SiO}_{2}\right)$ & -4.4 & $<$ LOD & $<\mathrm{LOD}$ & -4.9 & -4.5 & -4.2 & -3.8 & -3.6 & -3.6 & -3.5 & -3.6 & -3.6 & -3.6 & -3.6 & -3.6 & -3.6 \\
\hline $\log \left(a_{\mathrm{K}^{+}} / a_{\mathrm{H}^{+}}\right)$ & 1.0 & 1.3 & 2.0 & 2.5 & 2.6 & 2.7 & 2.8 & 2.8 & 2.8 & 2.8 & 2.8 & 2.8 & 2.8 & 2.8 & 2.8 & 2.8 \\
\hline $\log \left(a_{\mathrm{Na}+} / a_{\mathrm{H}+}\right)$ & 1.5 & 1.9 & 3.6 & 4.0 & 4.2 & 4.2 & 4.3 & 4.3 & 4.3 & 4.3 & 4.3 & 4.3 & 4.3 & 4.3 & 4.3 & 4.3 \\
\hline $\log \left(a_{\mathrm{Ca} 2} / a_{\mathrm{H}+}^{2}\right)$ & 4.5 & $<$ LOD & 5.0 & 5.2 & 5.3 & 5.4 & 5.4 & 5.5 & 5.4 & 5.5 & 5.4 & 5.4 & 5.4 & 5.3 & 5.4 & 5.4 \\
\hline $\log \left(a_{\mathrm{Fe} 2} / a_{\mathrm{H}}^{2}\right)$ & 5.0 & 5.5 & 4.3 & 4.8 & 5.3 & 5.5 & 5.6 & 5.7 & 5.7 & 5.8 & 5.8 & 5.8 & 5.8 & 5.8 & 5.8 & 5.8 \\
\hline $\log \left(a_{\mathrm{Mg} 2} / a_{\mathrm{H}}^{2}\right)$ & 5.9 & 5.1 & 6.5 & 6.9 & 7.0 & 7.0 & 7.1 & 7.1 & 7.1 & 7.1 & 7.1 & 7.1 & 7.1 & 7.1 & 7.1 & 7.1 \\
\hline $\log a_{\mathrm{Na}+}$ & -3.4 & -3.6 & -1.6 & -1.2 & -1.1 & -1.1 & -1.1 & -1.0 & -1.0 & -1.0 & -1.0 & -1.0 & -1.0 & -1.0 & -1.0 & -1.0 \\
\hline $\log a_{\mathrm{K}+}$ & -3.9 & -4.3 & -3.2 & -2.8 & -2.6 & -2.6 & -2.6 & -2.6 & -2.6 & -2.6 & -2.6 & -2.6 & -2.6 & -2.5 & -2.6 & -2.6 \\
\hline $\log a_{\mathrm{Cl}}$ & -3.0 & -3.5 & -1.6 & -1.2 & -1.1 & -1.0 & -1.0 & -1.0 & -1.0 & -1.0 & -1.0 & -1.0 & -1.0 & -1.0 & -1.0 & -1.0 \\
\hline $\log a_{\text {SO42- }}$ & -6.5 & -7.2 & -5.7 & -5.4 & -5.3 & -5.2 & -5.2 & -5.1 & -5.1 & -5.1 & -5.2 & -5.2 & -5.2 & -5.2 & -5.2 & -5.2 \\
\hline $\log a_{\mathrm{Ca} 2+}$ & -5.4 & $<$ LOD & -5.3 & -5.2 & -5.2 & -5.2 & -5.3 & -5.3 & -5.3 & -5.2 & -5.3 & -5.3 & -5.3 & -5.3 & -5.3 & -5.3 \\
\hline $\log a_{\mathrm{Mg} 2+}$ & -4.0 & -5.9 & -3.8 & -3.6 & -3.6 & -3.6 & -3.6 & -3.6 & -3.6 & -3.6 & -3.6 & -3.6 & -3.6 & -3.6 & -3.6 & -3.6 \\
\hline $\log a_{\mathrm{Fe} 2+}$ & -4.9 & -5.6 & -6.0 & -5.7 & -5.2 & -5.1 & -5.1 & -5.0 & -5.0 & -4.9 & -4.9 & -4.9 & -4.9 & -4.9 & -4.9 & -4.9 \\
\hline $\mathrm{T}\left({ }^{\circ} \mathrm{C}\right)$ & 340 & 340 & 340 & 340 & 340 & 340 & 340 & 340 & 340 & 340 & 340 & 340 & 340 & 340 & 340 & 340 \\
\hline $\mathrm{P}$ (bar) & 486.4 & 486.8 & 486.9 & 487.1 & 487.3 & 487.4 & 487.2 & 487.2 & 487.4 & 487.3 & 487.3 & 487.2 & 487.3 & 487.3 & 487.3 & 487.2 \\
\hline in situ $\mathrm{pH}_{\left(340^{\circ} \mathrm{C}\right)}$ & 4.94 & 5.52 & 5.16 & 5.23 & 5.28 & 5.31 & 5.33 & 5.36 & 5.35 & 5.35 & 5.35 & 5.35 & 5.35 & 5.34 & 5.35 & 5.34 \\
\hline $\operatorname{room~} \mathrm{TpH}$ & 5.83 & 5.24 & 5.05 & 4.31 & 3.41 & 3.12 & 2.96 & 2.88 & 2.81 & 2.85 & 2.75 & 2.73 & 2.75 & 2.73 & 2.72 & 2.72 \\
\hline flow rate $\left(\mathrm{ml} \mathrm{hr}^{-1}\right)$ & 1 & 1 & 1 & 1 & 1 & 1 & 1 & 1 & 1 & 1 & 1 & 1 & 1 & 1 & 1 & 1 \\
\hline time (hr) & 21.3 & 45.3 & 67.0 & 92.1 & 116.1 & 140.1 & 166.6 & 189.8 & 213.3 & 236.8 & 261.6 & 284.7 & 311.7 & 335.3 & 357.3 & 381.2 \\
\hline \multicolumn{17}{|l|}{ Anhydrite } \\
\hline Log Ksp (Supcrt92) @350 & 3.86 & & 3.86 & 3.86 & 3.86 & 3.86 & 3.86 & 3.86 & 3.86 & 3.86 & 3.86 & 3.86 & 3.86 & 3.86 & 3.86 & 3.86 \\
\hline $\log Q$ & 5.19 & & 4.42 & 4.03 & 3.88 & 3.82 & 3.80 & 3.74 & 3.77 & 3.75 & 3.82 & 3.83 & 3.84 & 3.86 & 3.84 & 3.86 \\
\hline $\log (Q / K)$ & 1.33 & & 0.56 & 0.17 & 0.02 & -0.04 & -0.06 & -0.12 & -0.09 & -0.11 & -0.04 & -0.03 & -0.02 & 0.00 & -0.02 & 0.00 \\
\hline \multicolumn{17}{|l|}{ Brucite } \\
\hline Log Ksp (Supcrt92) @350 & -6.60 & -6.60 & -6.60 & -6.60 & -6.60 & -6.60 & -6.60 & -6.60 & -6.60 & -6.60 & -6.60 & -6.60 & -6.60 & -6.60 & -6.60 & -6.60 \\
\hline $\log Q$ & 3.99 & 5.90 & 3.79 & 3.62 & 3.58 & 3.57 & 3.56 & 3.56 & 3.56 & 3.56 & 3.57 & 3.57 & 3.58 & 3.57 & 3.57 & 3.57 \\
\hline $\log (Q / K)$ & 10.59 & 12.50 & 10.39 & 10.22 & 10.18 & 10.17 & 10.16 & 10.16 & 10.16 & 10.16 & 10.17 & 10.17 & 10.18 & 10.17 & 10.17 & 10.17 \\
\hline \multicolumn{17}{|l|}{ Caminite (MHSH 0.625) } \\
\hline $\log K s p=\log Q$ & 8.97 & & & & & 7.05 & 6.97 & 6.91 & 6.92 & 6.93 & 6.95 & 6.95 & 6.96 & 6.98 & 6.96 & 6.98 \\
\hline
\end{tabular}




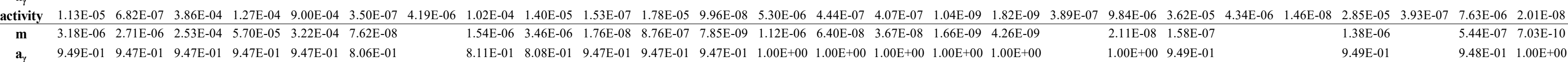

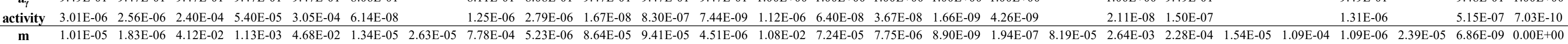

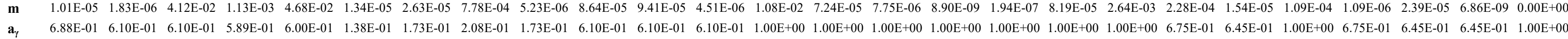

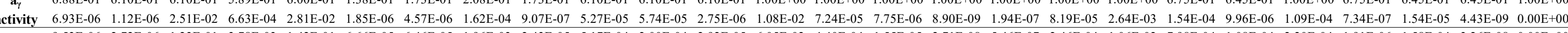

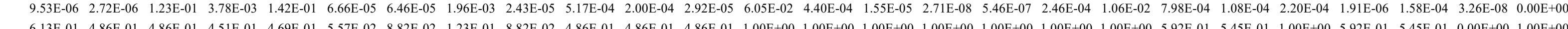

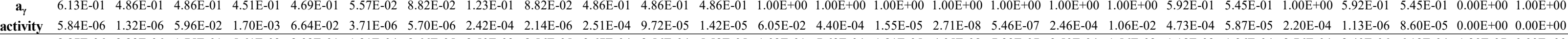

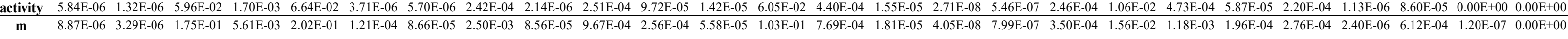

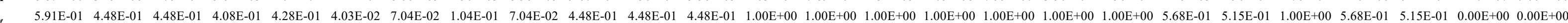

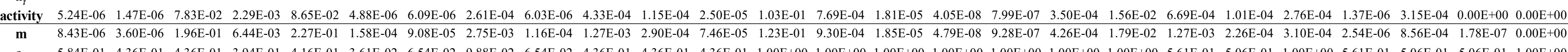

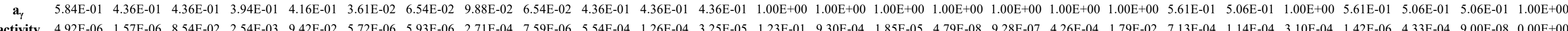

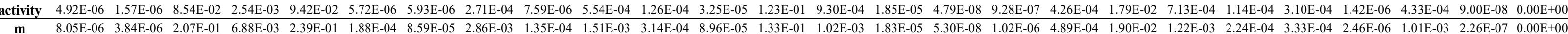

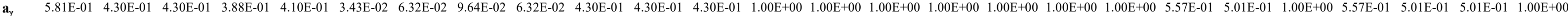

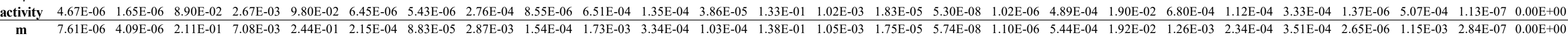

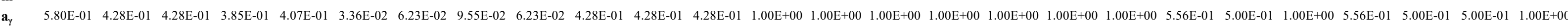

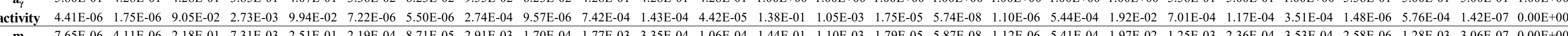

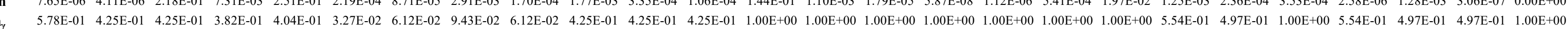

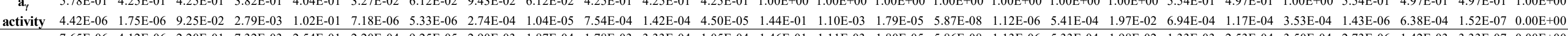

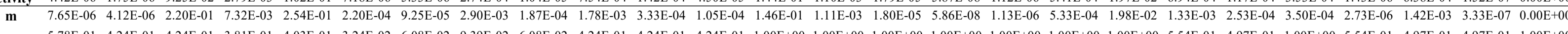

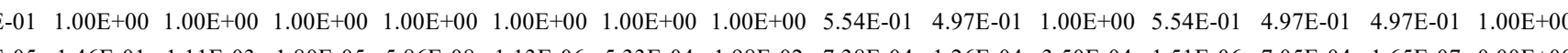

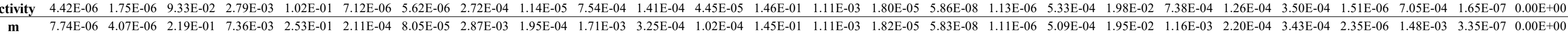

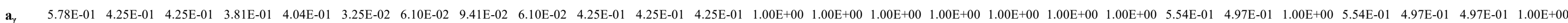

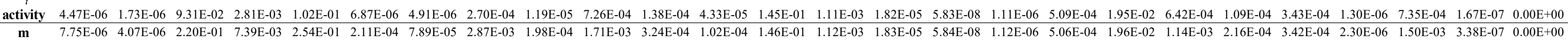

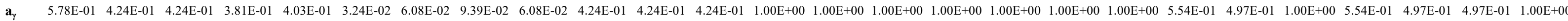

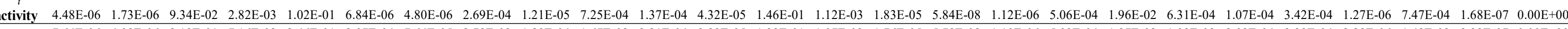

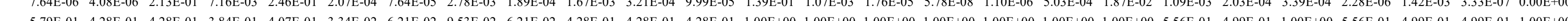

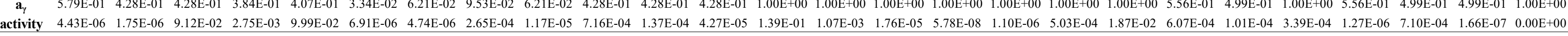

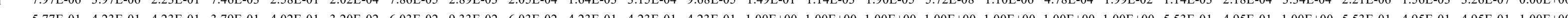

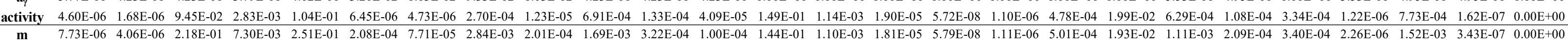

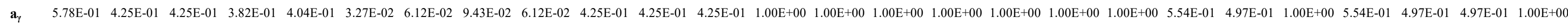

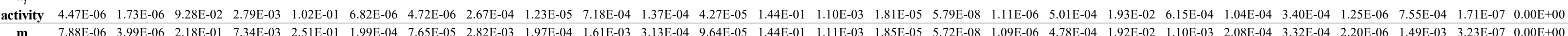

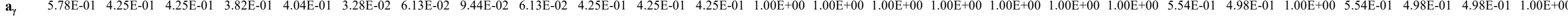

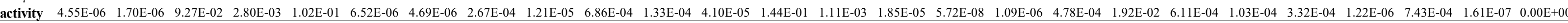


Appendices Doctoral Thesis: "Basalt - fluid interactions at subcritical and supercritical conditions: An experimental study" University of Victoria Wellington and GNS Science, Wairakei, New Zealand by Mauro Passarella

Appendix E - (Chapter 6) 


\section{Chapter 6: Basalt - Seawater Interactions under Hydrothermal Conditions}

\subsection{Results}

\subsubsection{BSW1: Basalt-seawater experiment at $400^{\circ} \mathrm{C} / 488$ bar}

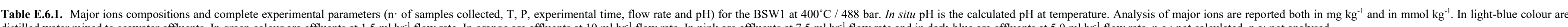

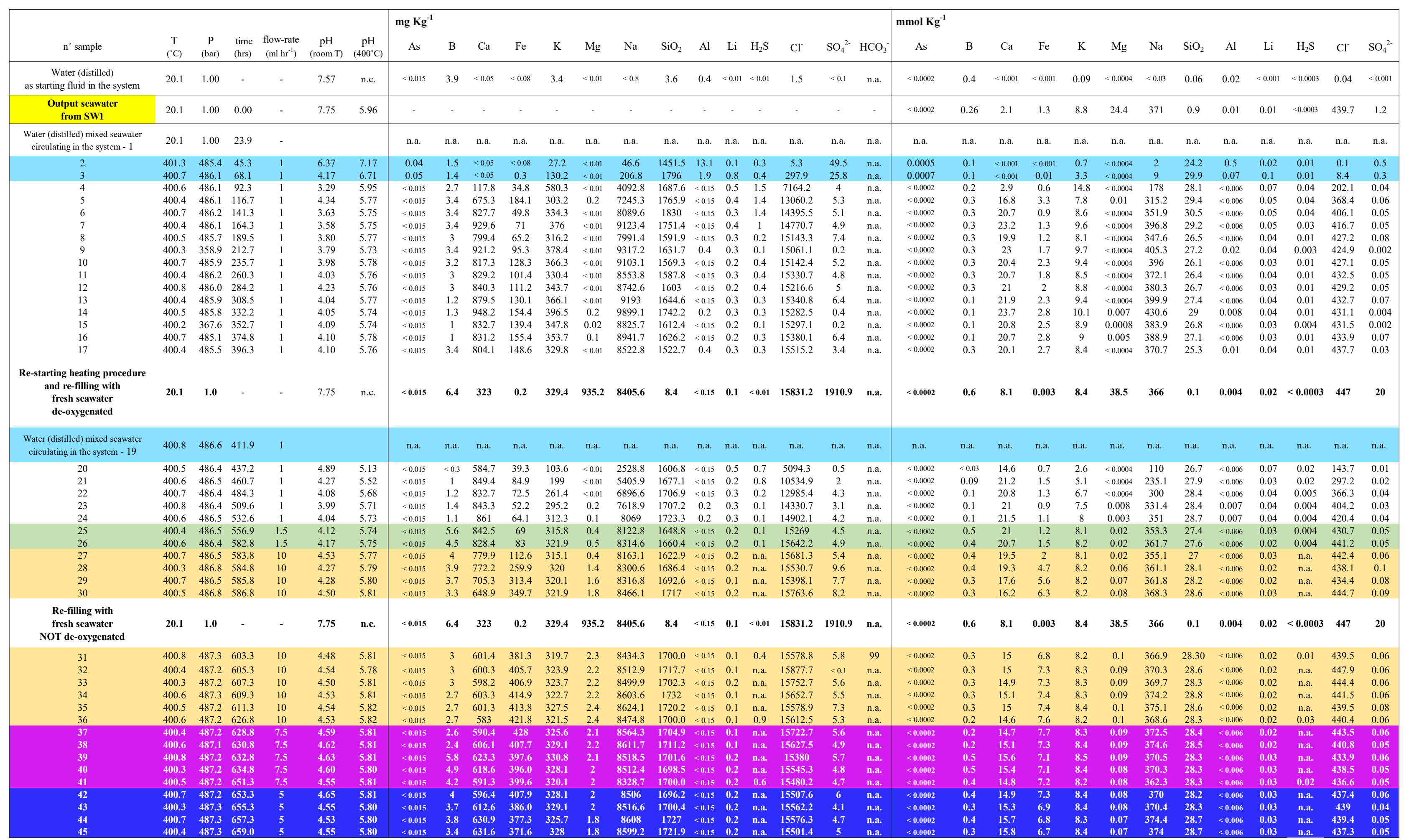




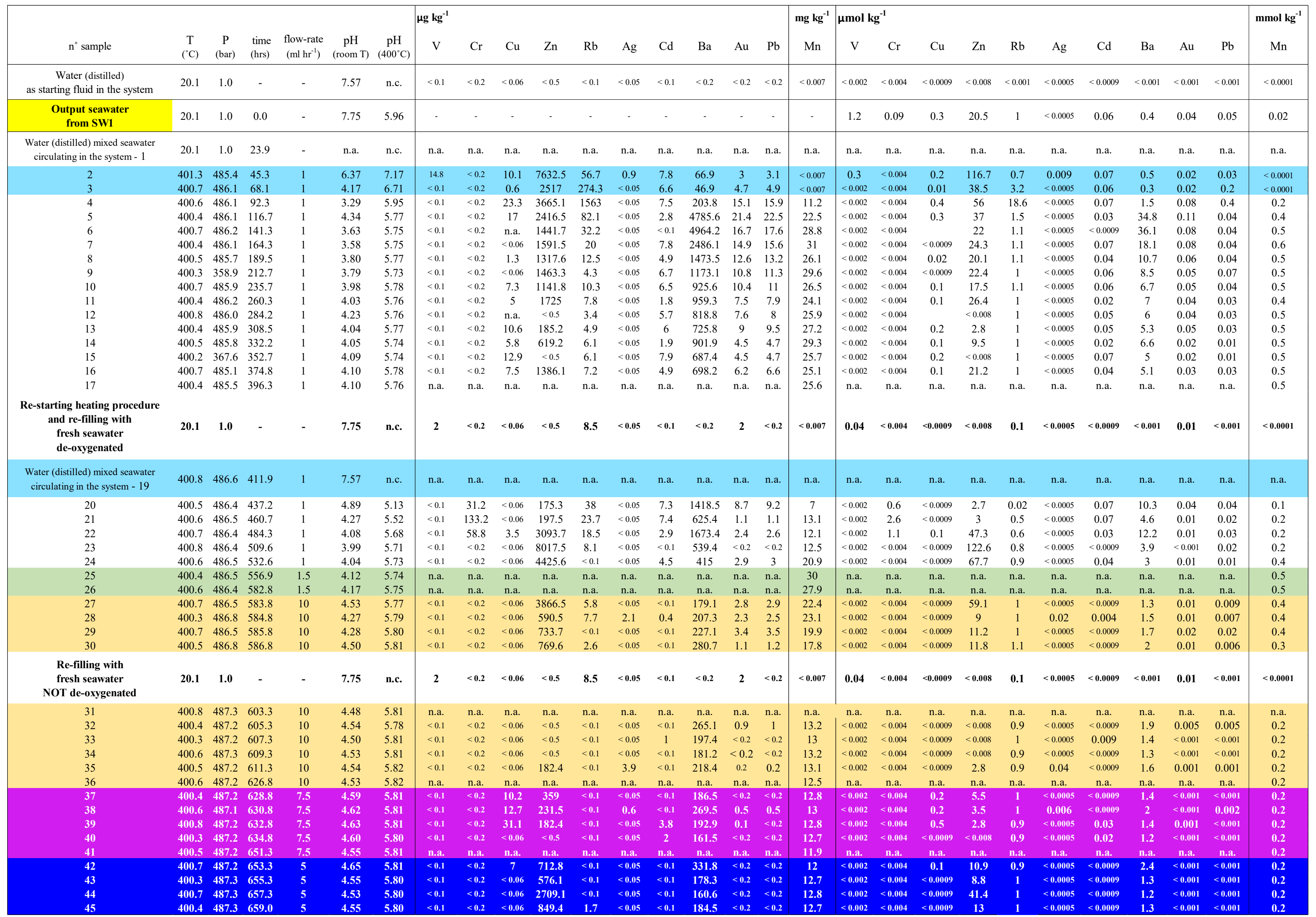


Sample Identification: BSW1 - Portion 1 Laboratory Reference No: 2017007018

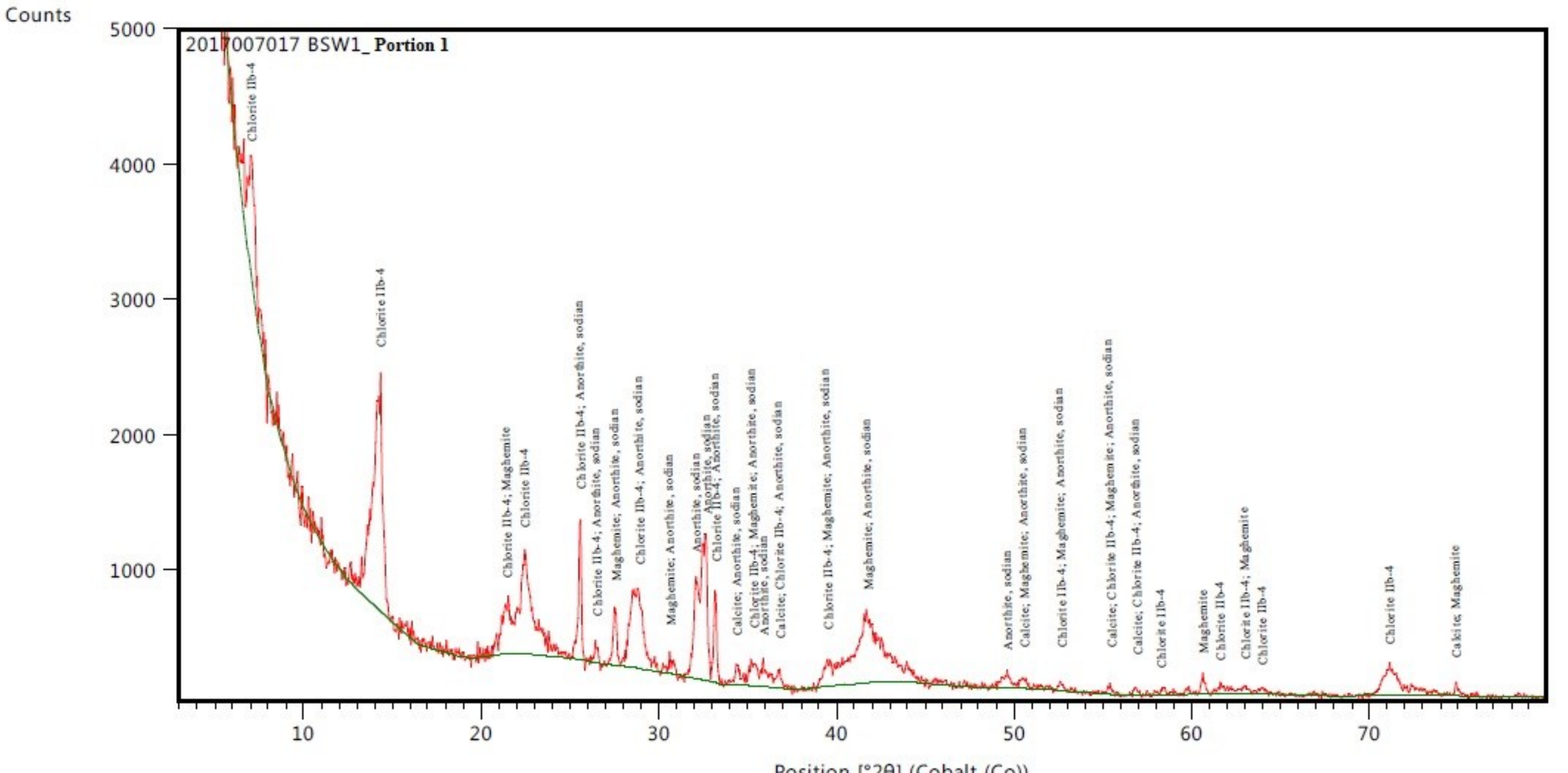

Figure 1. XRD scan showing the mineralogy of BSW1 - Portion 1 sample as indicated by the labelled scan peaks 
Counts

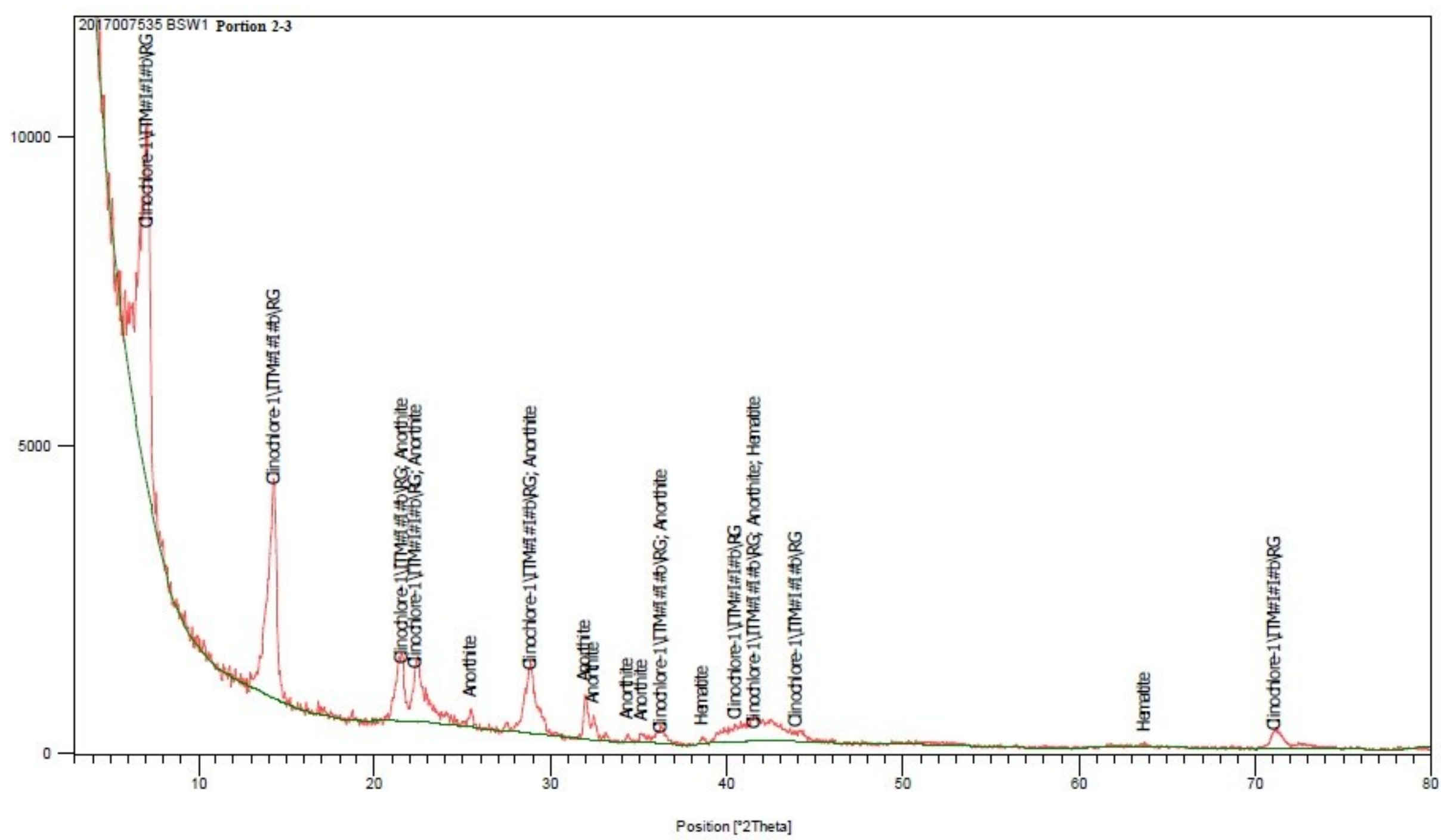

Figure 1. XRD scan showing the mineralogy of BSW1 Portion 2-3 sample as indicated by the labelled scan peaks 
Figure E.6.3. XRD scan showing the mineralogy of Portion 4

Sample Identification: BSW1 - Portion 4 Laboratory Reference No: 2017007020

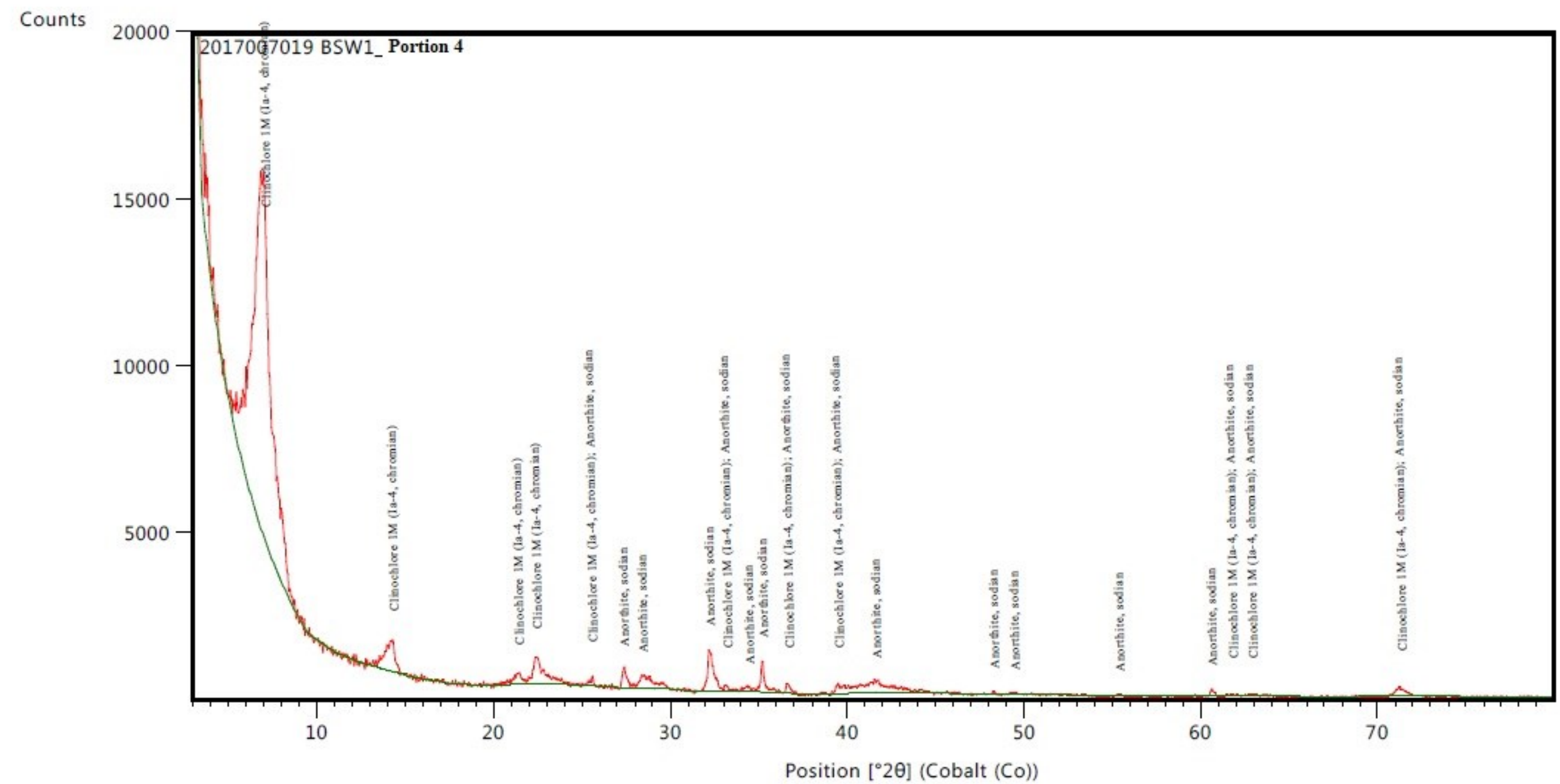

Figure 2. XRD scan showing the mineralogy of BSW1 - Portion 4 sample as indicated by the labelled scan peaks 
Sample Identification: BSW1 - Portion 7 Laboratory Reference No: 2017007022

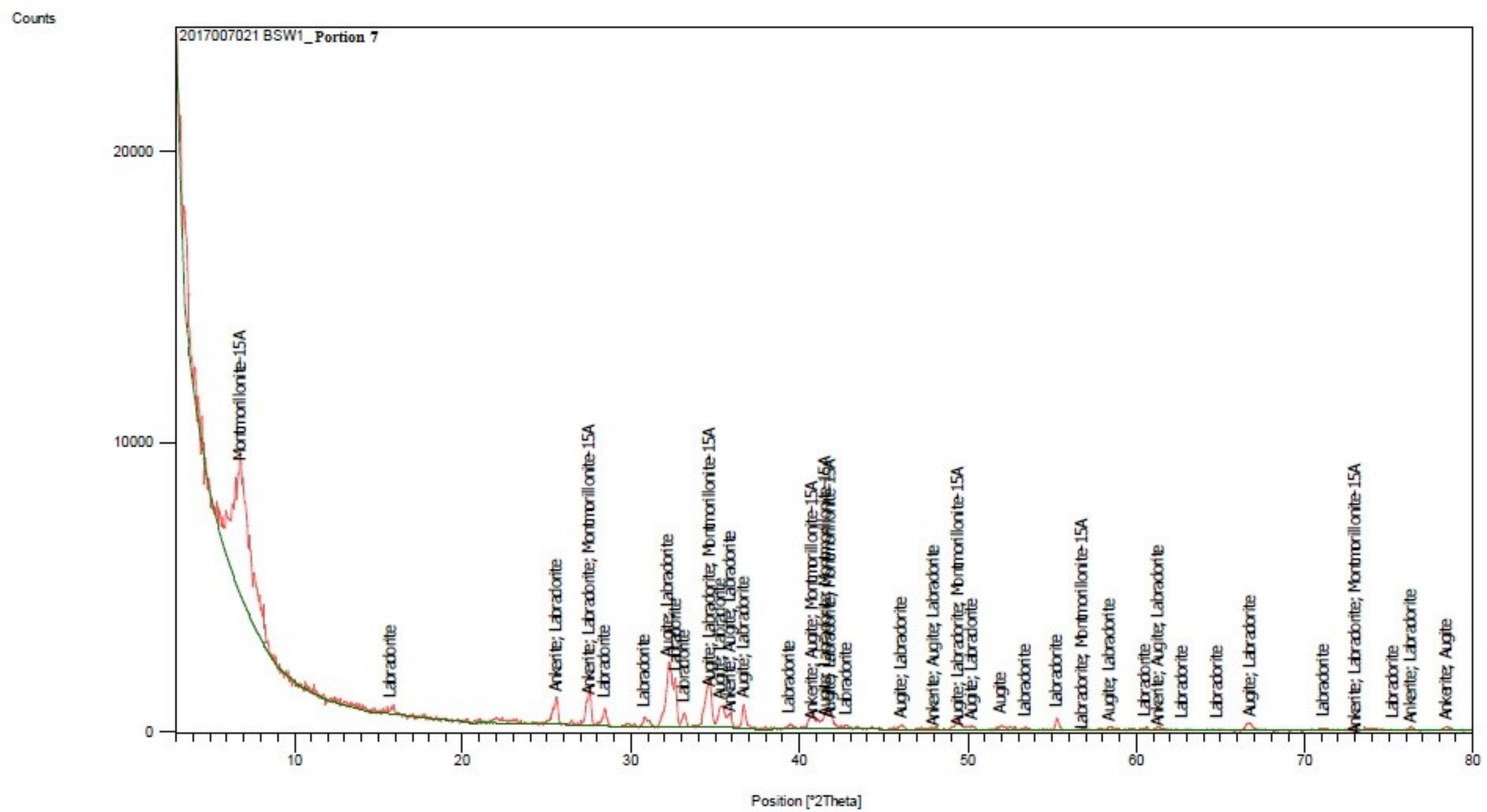

Figure 3. XRD scan showing the mineralogy of BSW1 - Portion 7 sample as indicated by the labelled scan peaks 
Figure E.6.5. Qualitative XRD analysis of Portion 1, 2-3,4 and 7

\section{Sample Composition}

Table 1. Mineralogical Composition of BSWI Samples

\begin{tabular}{l|c|c|c|c|}
\hline \multirow{2}{*}{} & \multicolumn{4}{|c|}{ Mineralogical Composition } \\
\cline { 2 - 5 } & Portion 1 & Portion 2-3 & Portion 4 & Portion 7 \\
& 2017007017 & 2017007535 & 2017007019 & \\
\hline Chlorite & $\mathrm{x}$ & $\mathrm{x}$ & $\mathrm{x}$ & $\mathrm{x}$ \\
Plagioclase & $\mathrm{x}$ & $\mathrm{x}$ & $\mathrm{x}$ & \\
Maghemite & $\mathrm{x}$ & $\mathrm{x}$ & & \\
Hematite & & & & $\mathrm{x}$ \\
Calcite & $\mathrm{x}$ & & & $\mathrm{x}$ \\
Smectite & & & & $\mathrm{x}$ \\
Ankerite & & & & \\
Augite & & & & \\
\hline
\end{tabular}




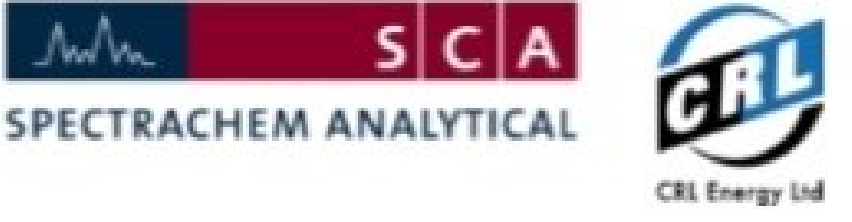

\section{Multi-element Analysis}

\begin{tabular}{|c|c|c|c|c|c|c|c|c|}
\hline $\begin{array}{l}\text { CLIENT } \\
\text { PROJECT } \\
\text { DATE } \\
\text { SAMPLE } \\
\text { COMMENTS }\end{array}$ & $\begin{array}{l}: \\
: \\
: \\
: \\
:\end{array}$ & $\begin{array}{l}\text { GNS } \\
\text { SA198 } \\
31 / 10 / 2 \\
\text { SAMPI } \\
100 \% \text { - }\end{array}$ & $\begin{array}{l}1, \text { LAB\#201 } \\
\text { = sum of ur }\end{array}$ & $\begin{array}{l}7007 \\
\text { Imea }\end{array}$ & $\begin{array}{l}\text { 018, B } \\
\text { sured }\end{array}$ & $\begin{array}{l}\text {-Portion } \\
\text { ents (i.e } \mathrm{H} \text {, }\end{array}$ & , C, & , 0) \\
\hline & $\begin{array}{l}: \\
:\end{array}$ & & & & & & & \\
\hline Carbon & c & - & Zinc & $\mathrm{Zn}$ & 0.004 & lodine & 1 & nd \\
\hline Fluorine & $\mathbf{F}$ & nd & Gallium & $\mathrm{Ga}$ & nd & Caesium & Cs & nd \\
\hline Sodium & $\mathrm{Na}$ & 0.470 & Germanium & $\mathrm{Ge}$ & nd & Barium & $\mathrm{Ba}$ & nd \\
\hline Magnesium & $\mathrm{Mg}$ & 13.9 & Arsenic & As & nd & Lanthanum & La & nd \\
\hline Aluminium & Al & 7.34 & Selenium & $\mathrm{Se}$ & nd & Cerium & $\mathrm{Ce}$ & - \\
\hline Silicon & Si & 17.9 & Bromine & $\mathrm{Br}$ & nd & Hafnium & $\mathrm{Hf}$ & - \\
\hline Phosphorus & $\mathbf{P}$ & 0.110 & Rubidium & $\mathbf{R b}$ & nd & Tantalum & $\mathrm{Ta}$ & nd \\
\hline Sulphur & s & 0.091 & Strontium & Sr & 0.006 & Tungsten & w & nd \\
\hline Chlorine & $\mathrm{Cl}$ & 0.138 & Yttrium & Y & nd & Rhenium & $\operatorname{Re}$ & - \\
\hline Potassium & K & 0.026 & Z̈rconium & $\mathrm{Zr}$ & 0.007 & Osmium & Os & - \\
\hline Calcium & $\mathrm{Ca}$ & 2.74 & Niobium & $\mathrm{Nb}$ & nd & Iridium & Ir & - \\
\hline Scandium & $\mathrm{Sc}$ & nd & Molybdenum & Mo & nd & Platinum & Pt & - \\
\hline Titanium & $\mathrm{Ti}$ & 1.18 & Rhodium & Rh & - & Gold & Au & - \\
\hline Vanadium & v & 0.039 & Palladium & Pd & - & Mercury & $\mathrm{Hg}$ & nd \\
\hline Chromium & $\mathrm{Cr}$ & 0.011 & Silver & $\mathrm{Ag}$ & - & Thallium & $\mathrm{TI}$ & nd \\
\hline Manganese & Mn & 0.016 & Cadmium & Cd & nd & Lead & $\mathrm{Pb}$ & nd \\
\hline Iron & $\mathrm{Fe}$ & 5.36 & Indium & In & - & Bismuth & $\mathrm{Bi}$ & nd \\
\hline Cobalt & Co & 0.008 & Tin & Sn & nd & Thorium & Th & nd \\
\hline Nickel & Ni & 0.043 & Antimony & Sb & nd & Uranium & u & nd \\
\hline Copper & $\mathrm{Cu}$ & nd & Tellurium & $\mathrm{Te}$ & - & Total & & 49.4 \\
\hline
\end{tabular}



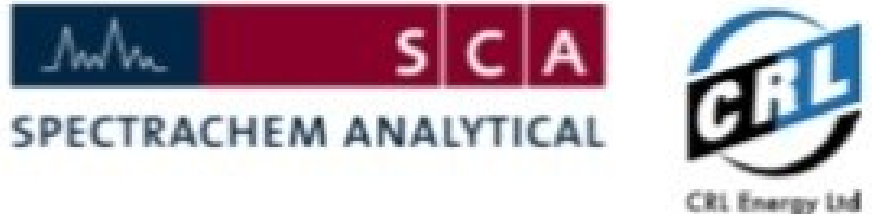

\section{$X$-ray fluorescence \\ SPECTRA plus}

Multi-element Analysis

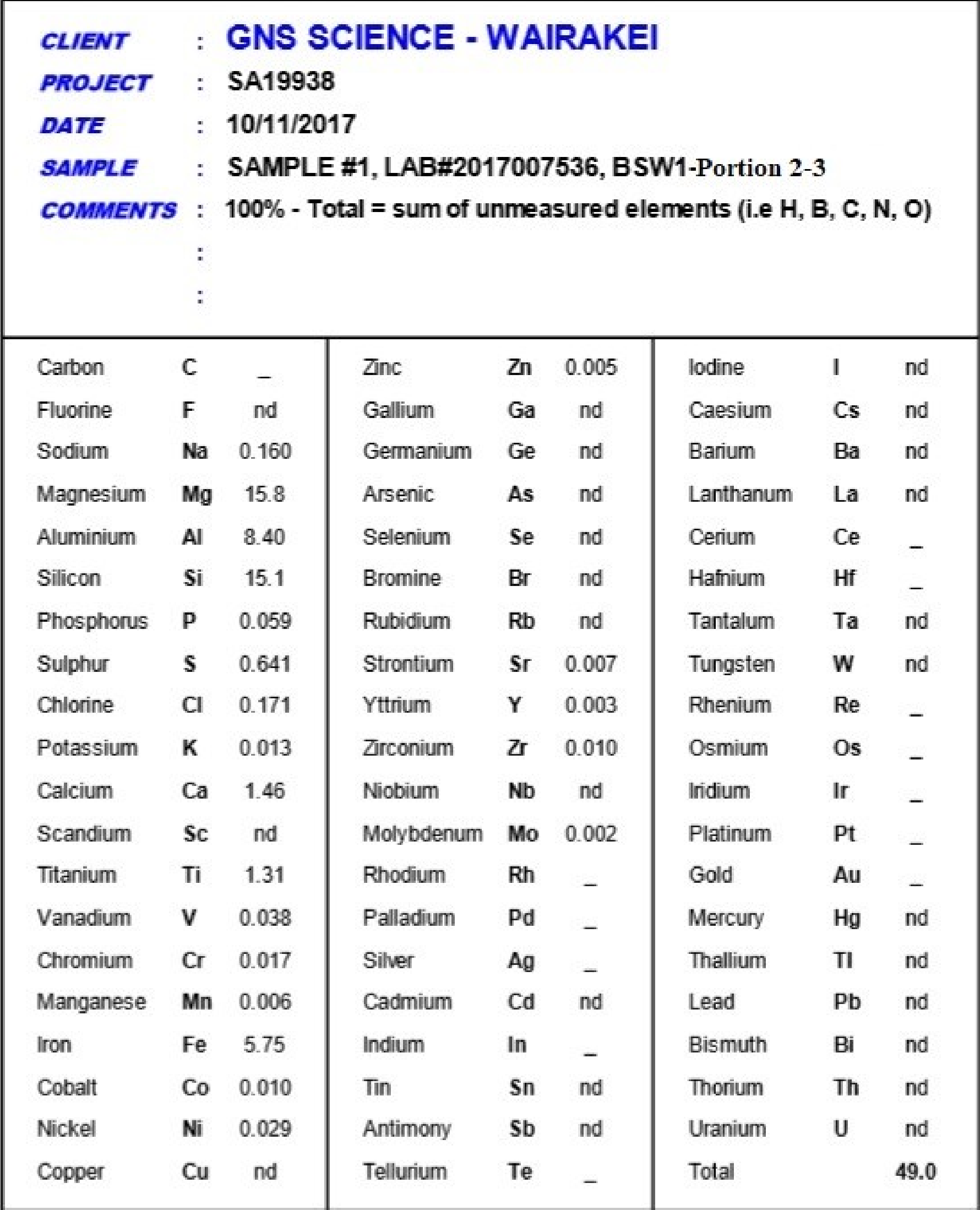




\section{Mwhe S C A \\ SPECTRACHEM ANALYTICAL}

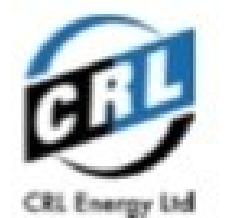

$X$-ray fluorescence

SPECTRA ${ }^{\text {plus }}$

\section{Multi-element Analysis}

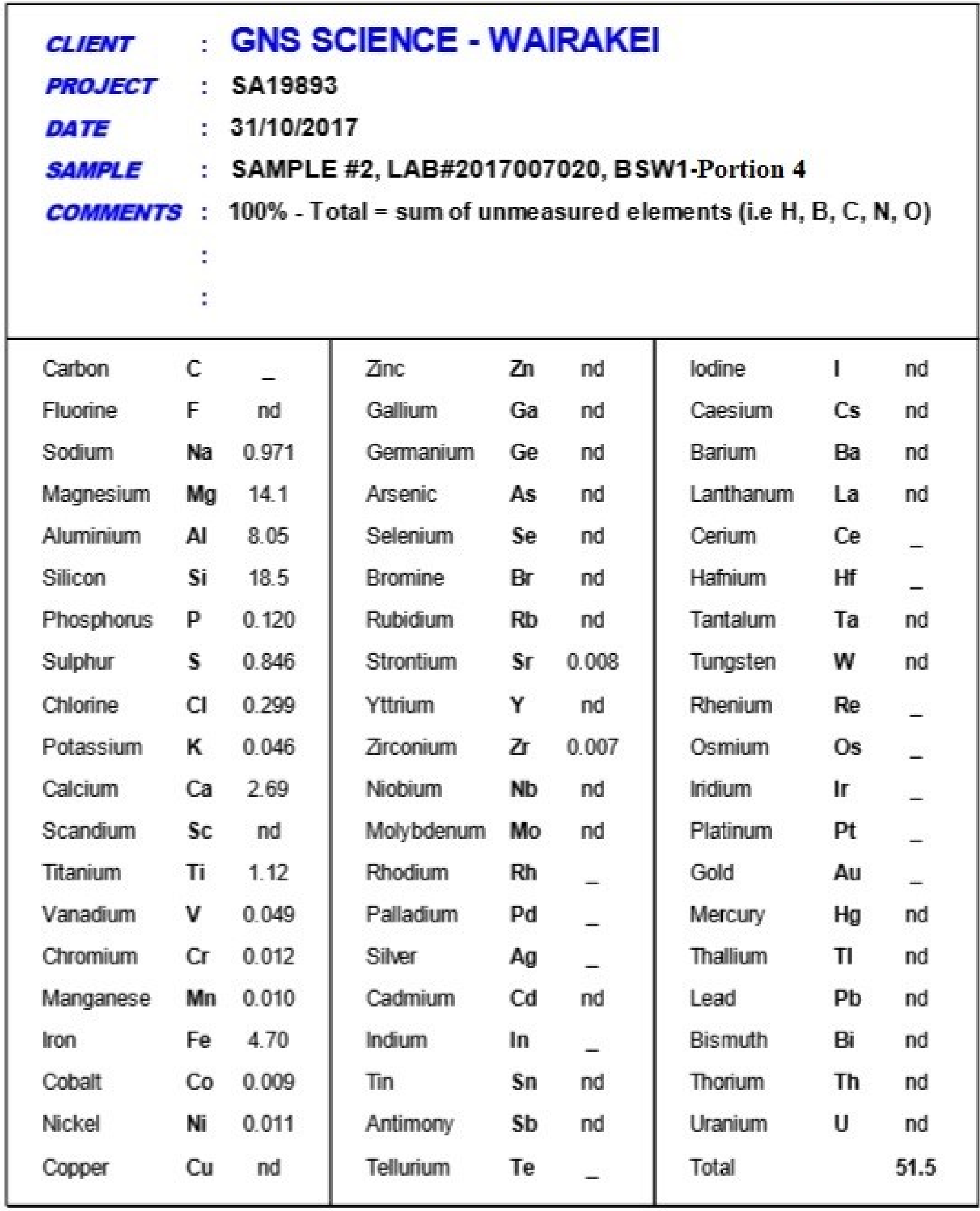




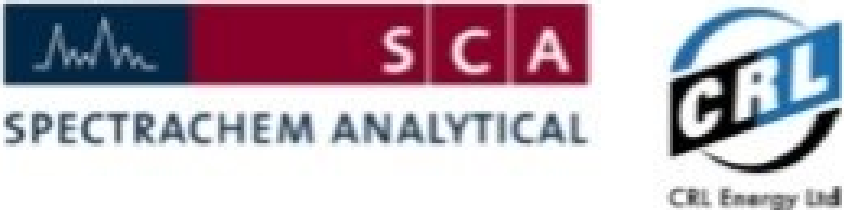

\section{$X$-ray fluorescence \\ SPECTRA ${ }^{\text {plus }}$}

\section{Multi-element Analysis}

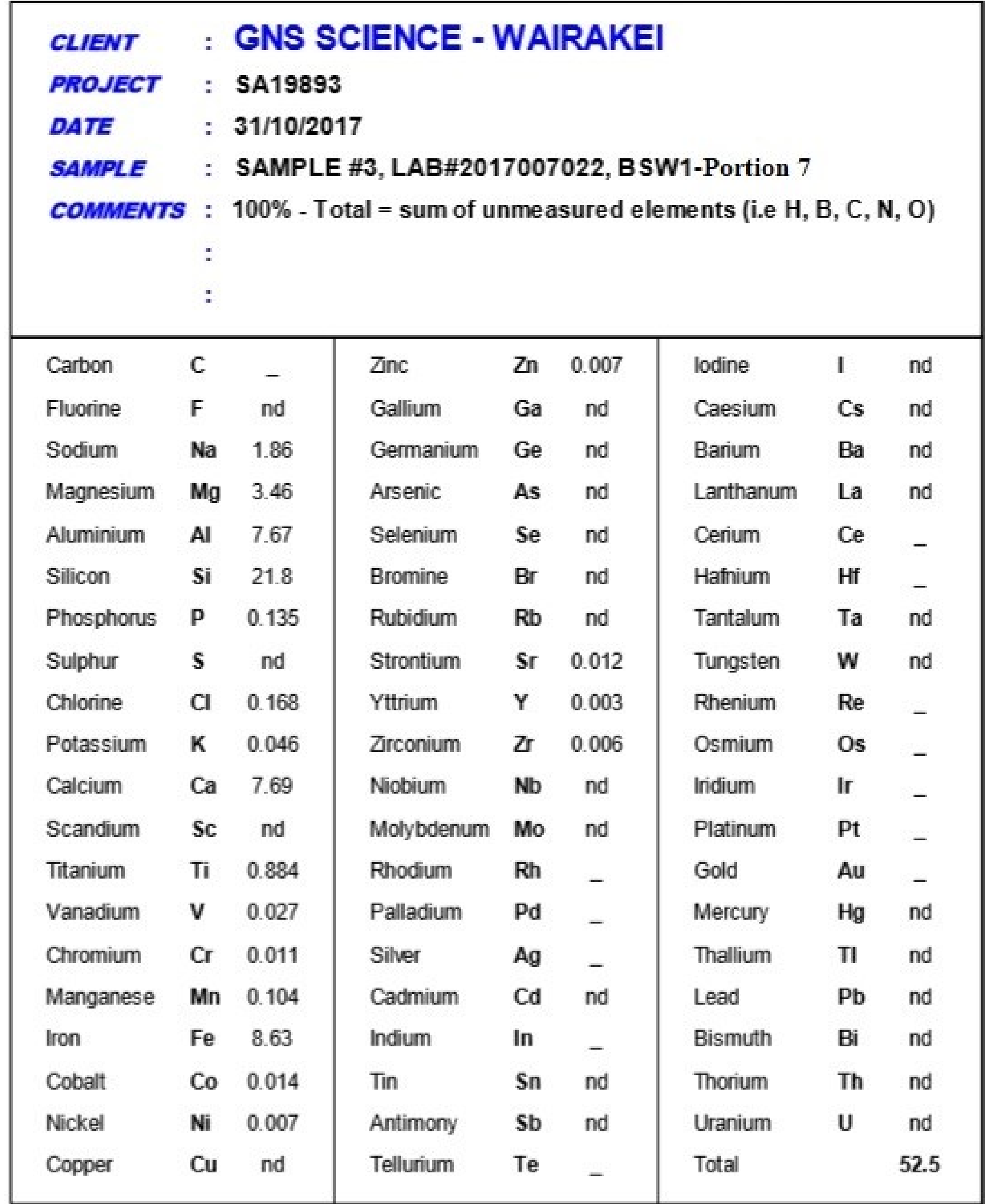


SEM results of the grains collected from the immediately adjacent fluid entry point after $\mathbf{3 9 6 . 3}$ hours of the experiment Figure E.6.10. EDS analysis of texture of reacted grains collected from the bob of the Ret
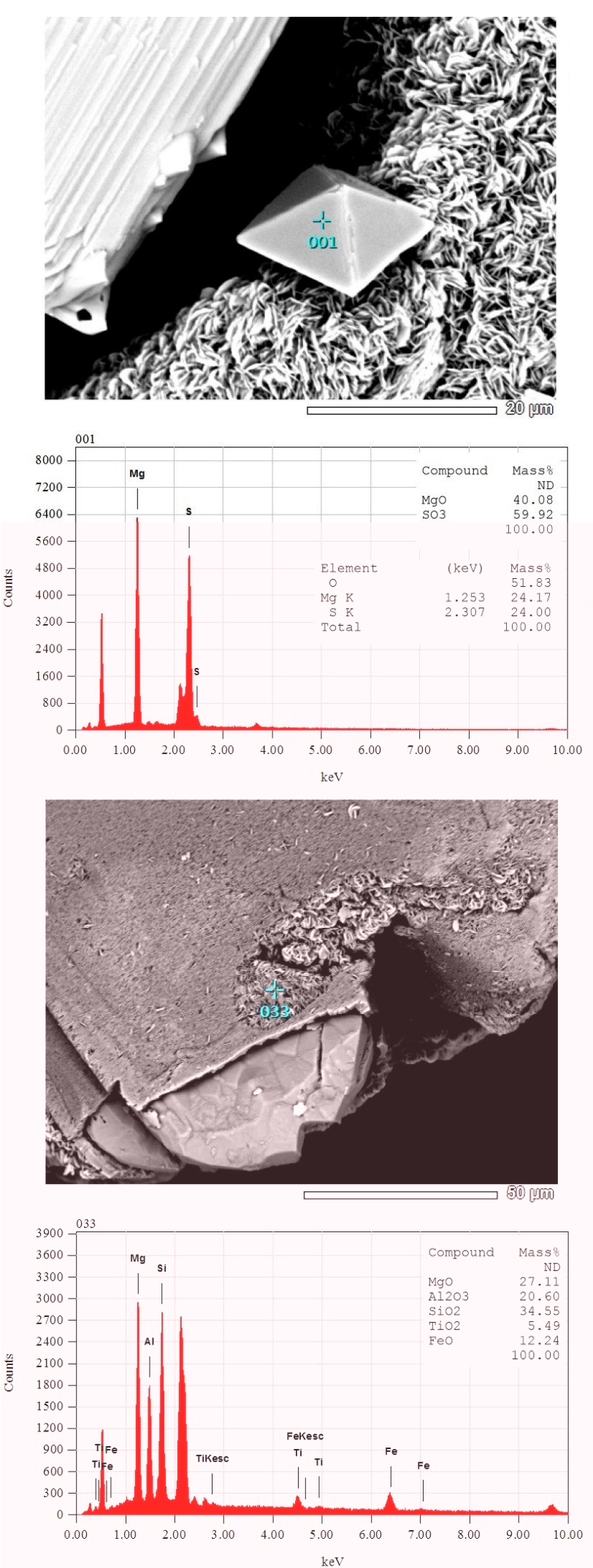
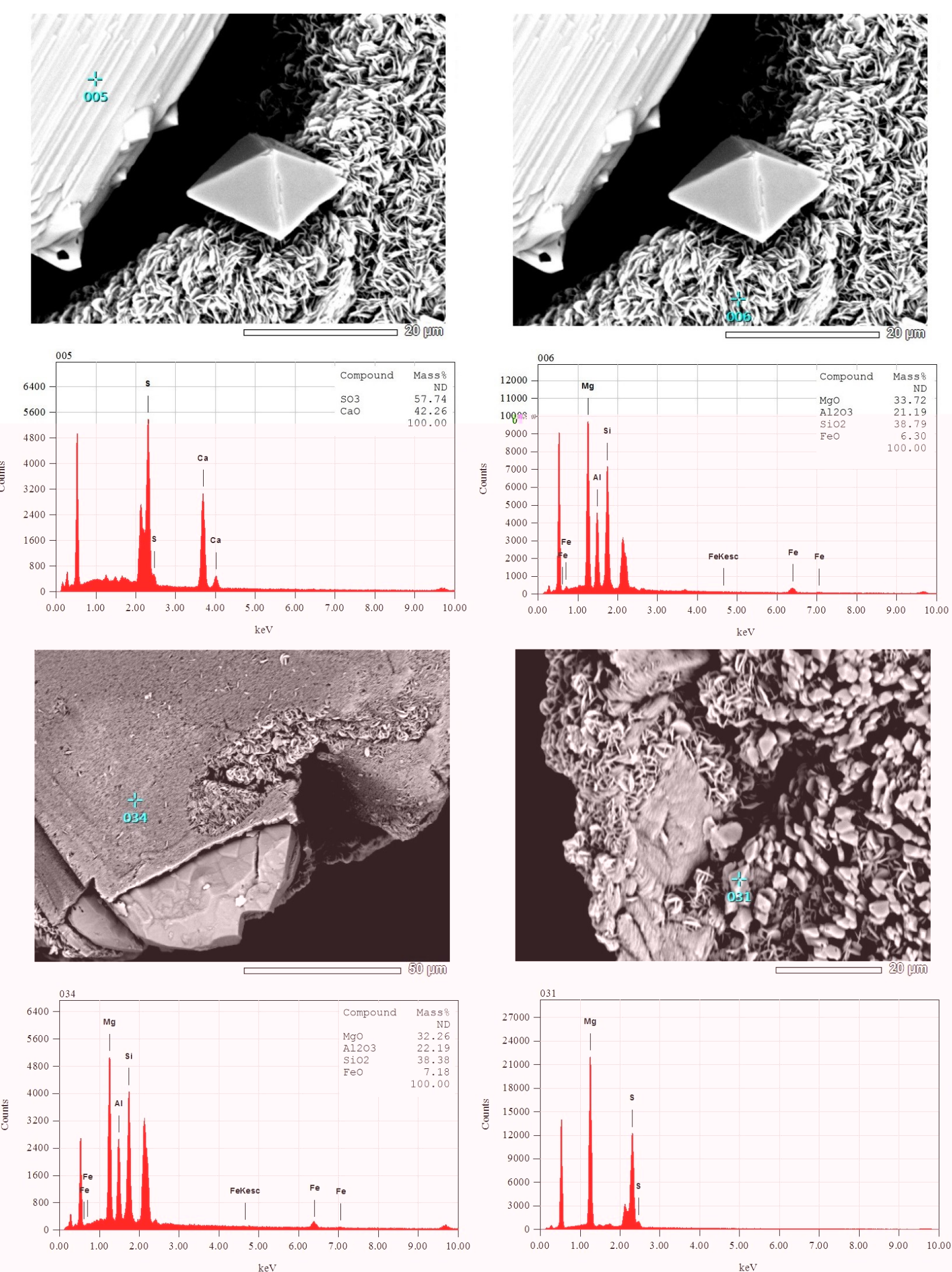
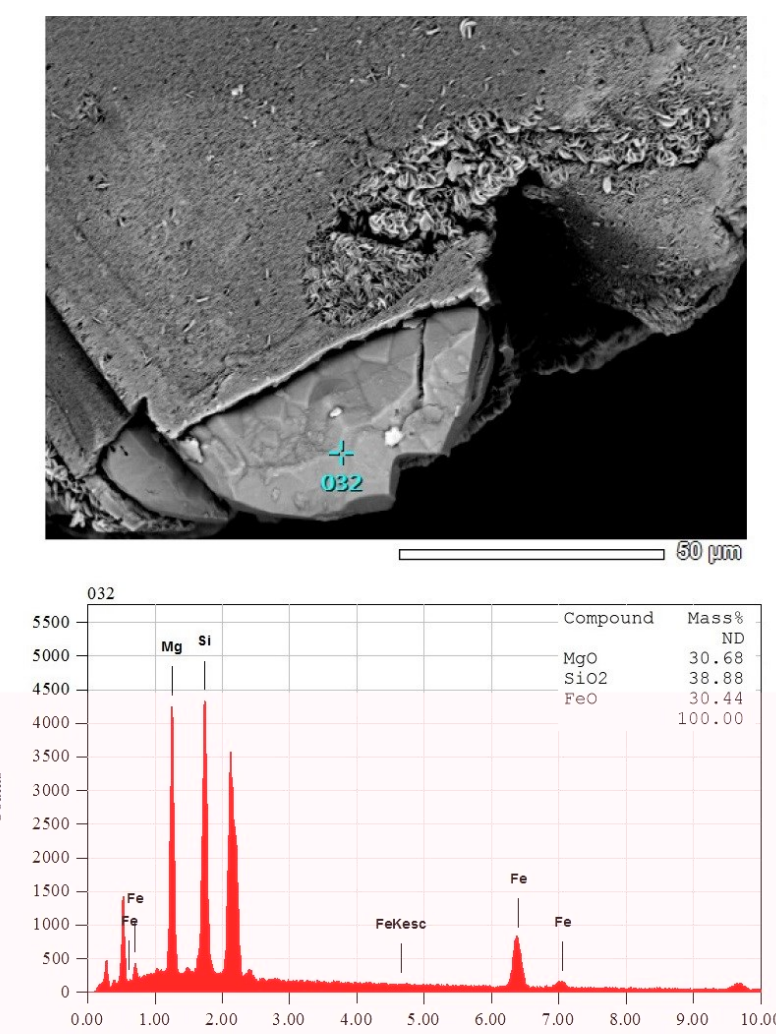
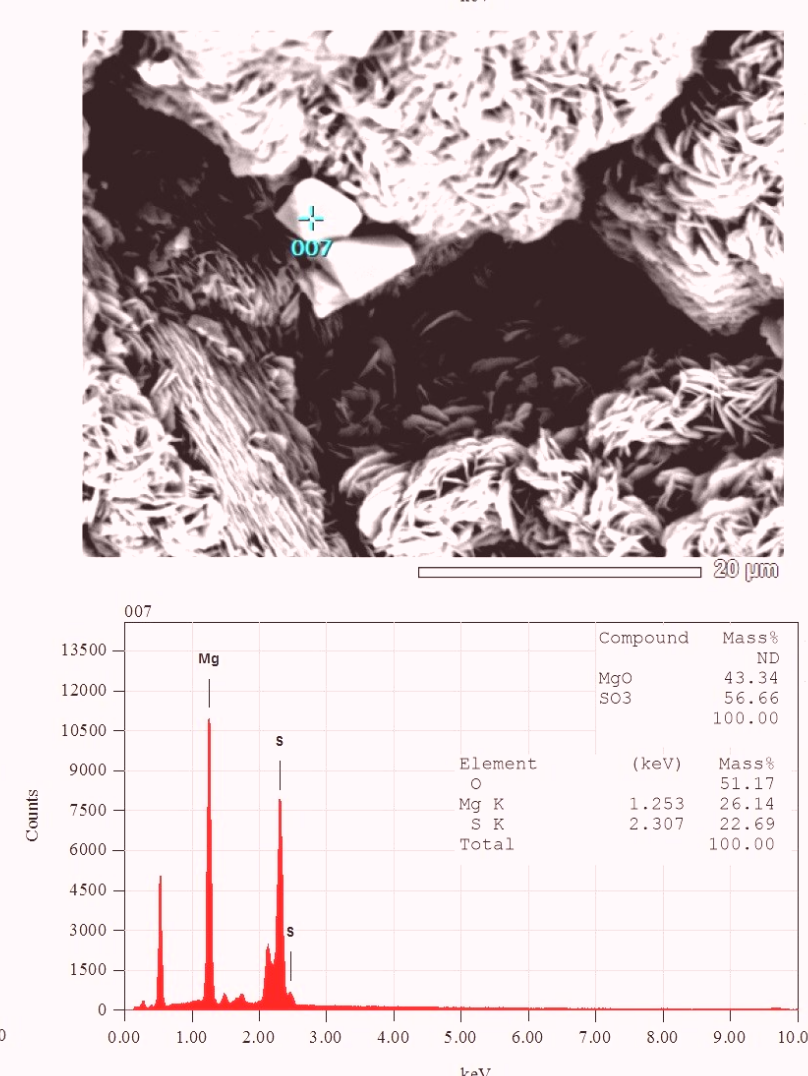

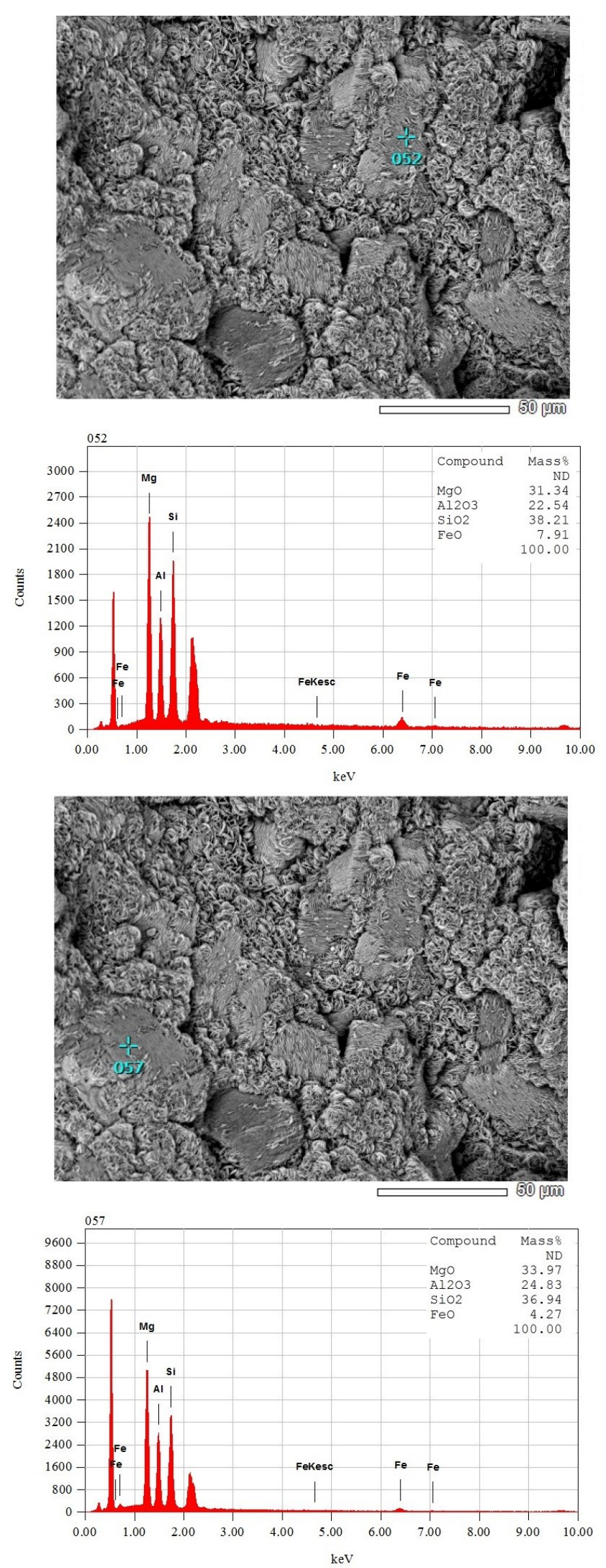
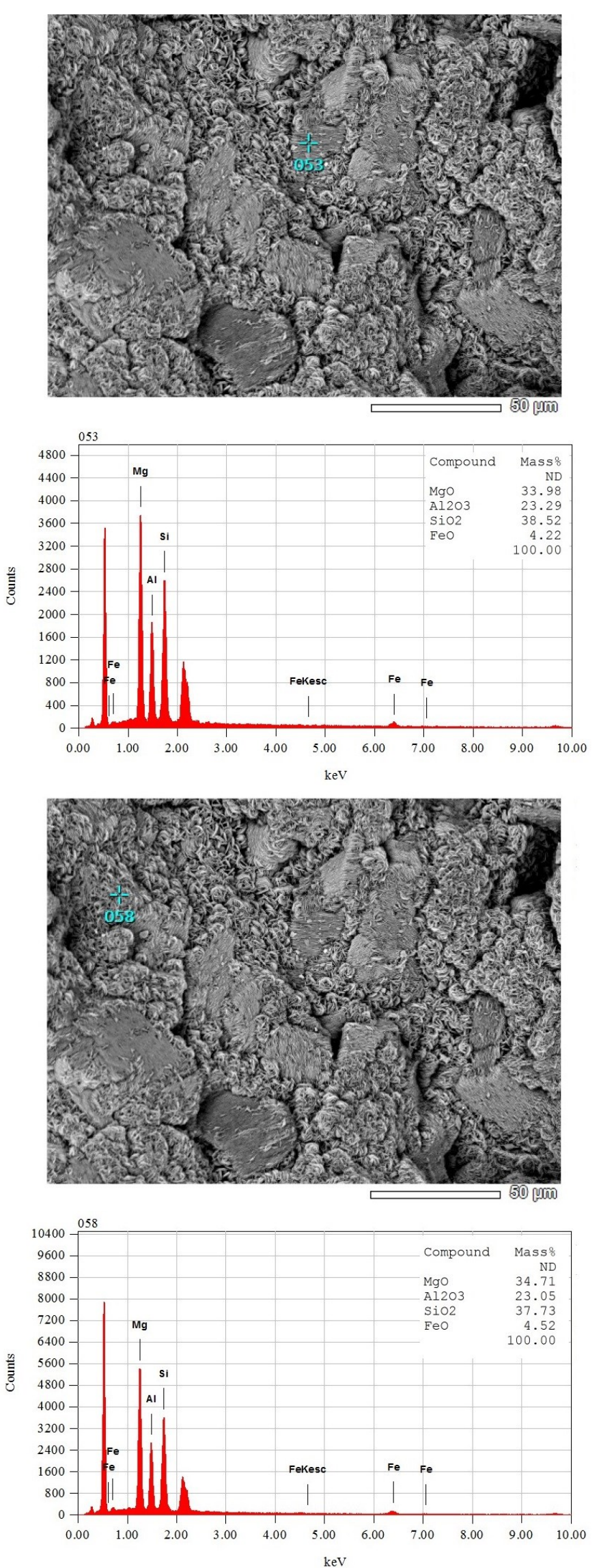
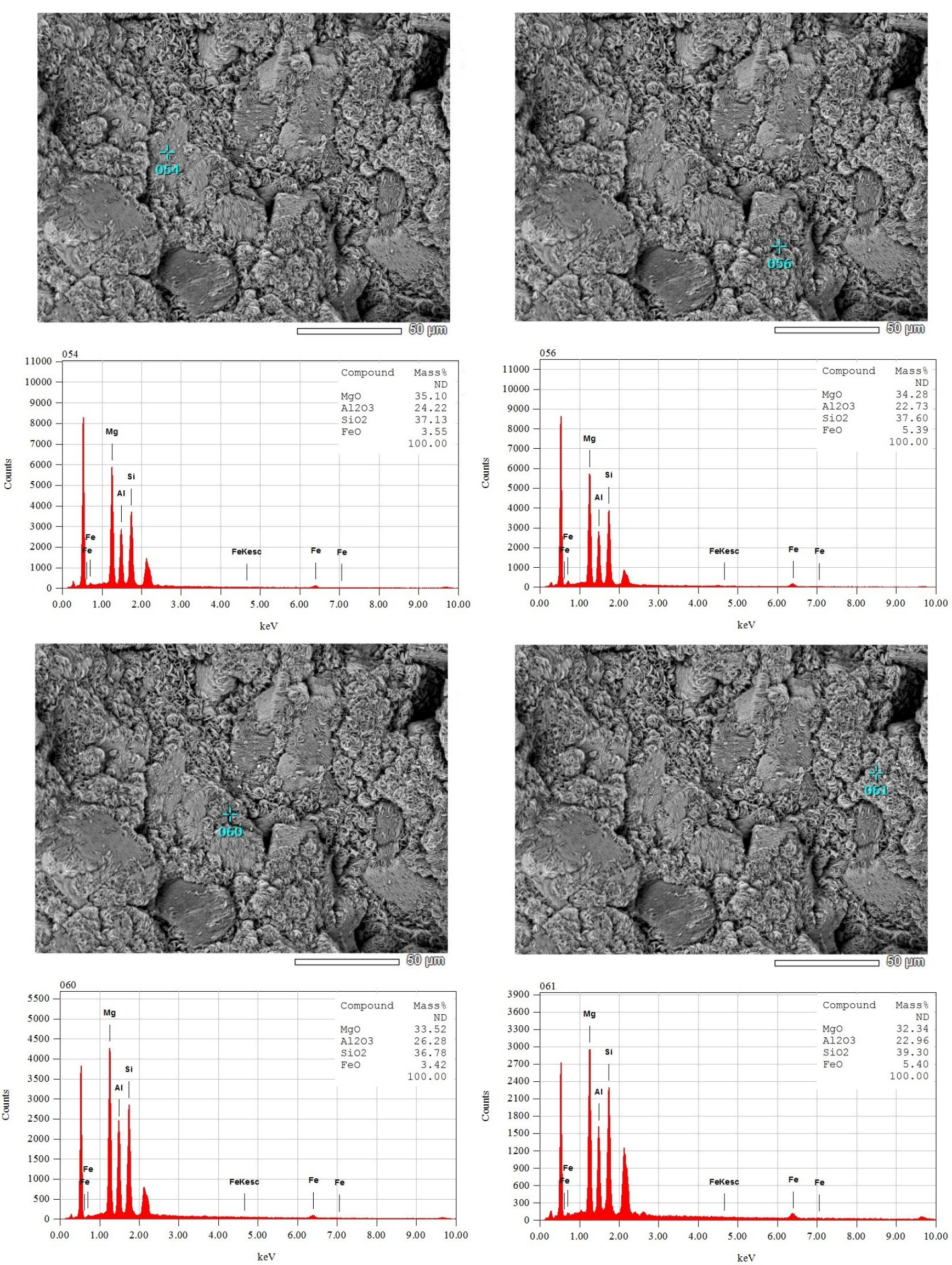
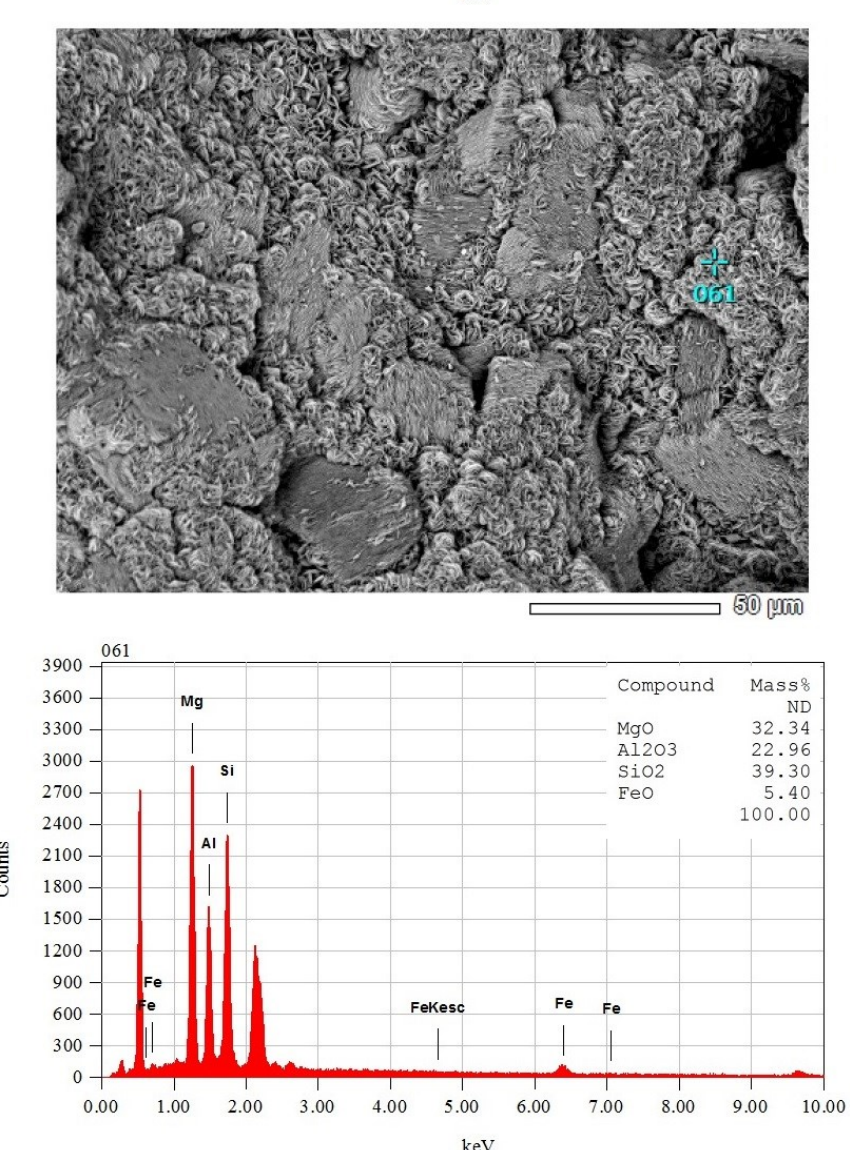
Table E.6.3. EDS analysis of reacted grains in Figures A.6.10-11

\begin{tabular}{|c|c|c|c|c|c|c|c|c|}
\hline \multirow[t]{2}{*}{ Anh } & $\begin{array}{c}\text { Analysis } \\
\text { Point }\end{array}$ & $\mathrm{CaO}$ & $\mathrm{SO}_{3}$ & & & & & Total \\
\hline & 5 & 57.74 & 42.26 & & & & & 100.00 \\
\hline \multirow[t]{3}{*}{ Sulfate } & $\begin{array}{c}\text { Analysis } \\
\text { Point }\end{array}$ & MgO & $\mathrm{SO}_{3}$ & Total & $\mathbf{O}$ & Mg & $\mathrm{S}$ & Total \\
\hline & 1 & 40.08 & 59.92 & 100.00 & 51.83 & 24.17 & 24.00 & 100.00 \\
\hline & 7 & 43.34 & 56.66 & 100.00 & 51.17 & 26.14 & 22.69 & 100.00 \\
\hline average & & 41.71 & 58.29 & & & & & 100.00 \\
\hline \multirow[t]{12}{*}{ Chl } & $\begin{array}{c}\text { Analysis } \\
\text { Point }\end{array}$ & MgO & $\mathbf{A l}_{2} \mathbf{O}_{3}$ & $\mathrm{SiO}_{2}$ & $\mathrm{FeO}$ & $\mathrm{TiO}_{2}$ & & Total \\
\hline & 6 & 33.72 & 21.19 & 38.79 & 6.30 & 0.00 & & 100.00 \\
\hline & 33 & 27.11 & 20.60 & 34.55 & 12.24 & 5.49 & & 99.99 \\
\hline & 34 & 32.26 & 22.19 & 38.38 & 7.18 & 0.00 & & 100.01 \\
\hline & 52 & 31.34 & 22.54 & 38.21 & 7.91 & 0.00 & & 100.00 \\
\hline & 53 & 33.98 & 23.29 & 38.52 & 4.22 & 0.00 & & 100.01 \\
\hline & 54 & 35.10 & 24.22 & 37.13 & 3.55 & 0.00 & & 100.00 \\
\hline & 56 & 34.28 & 22.73 & 37.60 & 5.39 & 0.00 & & 100.00 \\
\hline & 57 & 33.97 & 24.83 & 36.94 & 4.27 & 0.00 & & 100.01 \\
\hline & 58 & 34.71 & 23.05 & 37.73 & 4.52 & 0.00 & & 100.01 \\
\hline & 60 & 33.52 & 26.28 & 36.78 & 3.42 & 0.00 & & 100.00 \\
\hline & 61 & 32.34 & 22.96 & 39.30 & 5.40 & 0.00 & & 100.00 \\
\hline averag & & 32.94 & 23.08 & 37.63 & 5.85 & 0.50 & & 100.00 \\
\hline
\end{tabular}

Table E.6.4. Average mineral compositions determined by EDS from Table E.6.3

$\begin{array}{cccc}\text { Oxides } & \text { average wt\% } & \text { average wt\% } & \text { average } \mathbf{w t} \% \\ \mathrm{MgO} & & 41.71 & 32.94 \\ \mathrm{Al}_{2} \mathrm{O}_{3} & & & 23.08 \\ \mathrm{SiO}_{2} & & & 37.63 \\ \mathrm{CaO} & 57.74 & & 5.85 \\ \mathrm{FeO} & & 58.29 & 0.50 \\ \mathrm{SO}_{3} & 42.26 & & 100.00 \\ \mathrm{TiO}_{2} & & 100.00 & \\ \text { Total } & 100.00 & & \end{array}$

Mineral

Composition

$\mathrm{CaSO}_{4}$

$\mathrm{Mg}_{7}\left(\mathrm{SO}_{4}\right)_{5}(\mathrm{OH})_{4} \cdot \mathrm{H}_{2} \mathrm{O}$

Phase and ID
Anhydrite

Caminite
$\mathrm{Mg}_{80} \mathrm{Fe}_{08} \mathrm{Al}_{27} \mathrm{Ti}_{01} \mathrm{Si}_{62} \mathrm{Al}_{18} \mathrm{O}_{20}(\mathrm{OH})_{16}$

(on the basis of 28 oxygen equivalents, ignoring $\mathrm{H}_{2} \mathrm{O}$ )

Chlorite 
Figure E.6.12. SEM photographs of reacted grains collected from the bottom of the Reactor
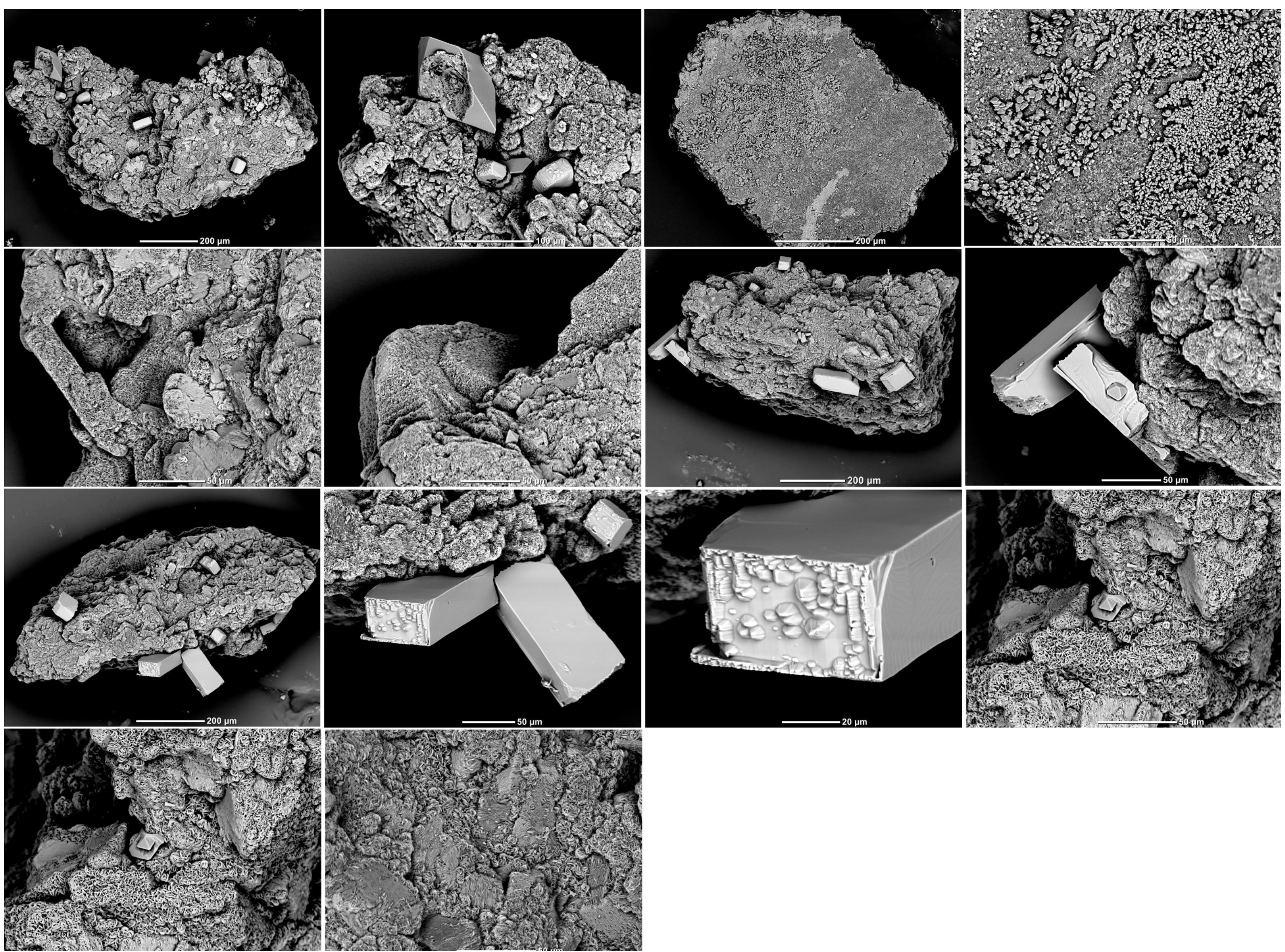
SEM results of the grains collected from the immediately adjacent fluid exit point after 396.3 hours of the experiment Figure E.6.13. EDS analysis of texture of reacted grains collected from the top of the Reactor
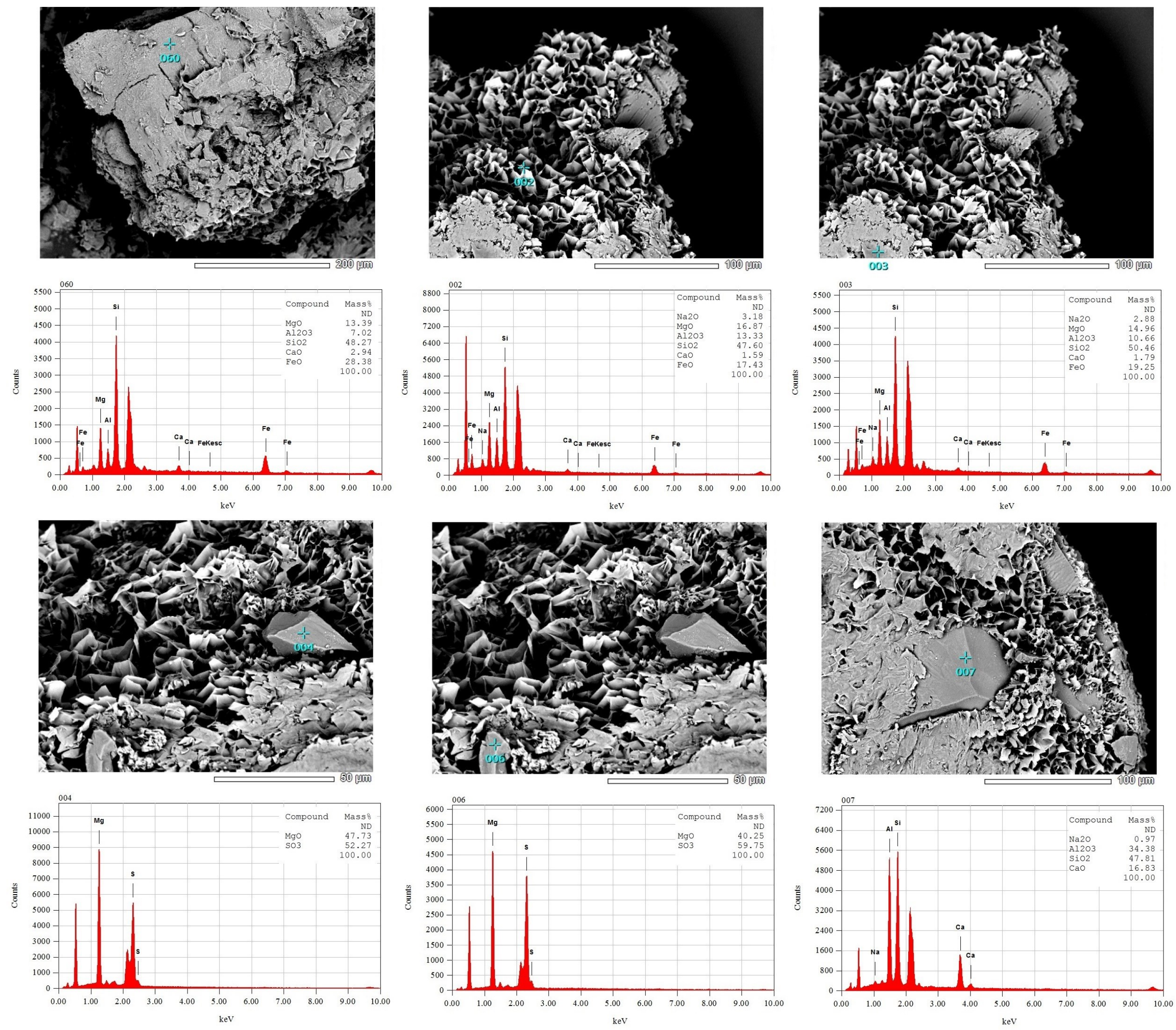
Table E.6.5. EDS analysis of reacted grains in Figure E 6.13

\begin{tabular}{|c|c|c|c|c|c|c|c|c|}
\hline \multirow[t]{3}{*}{ Plg } & $\begin{array}{c}\text { Analysis } \\
\text { Point }\end{array}$ & $\mathrm{Na}_{2} \mathrm{O}$ & $\mathrm{CaO}$ & $\mathbf{A l}_{2} \mathbf{O}_{3}$ & $\mathrm{SiO}_{2}$ & & & Total \\
\hline & 7 & 0.97 & 16.83 & 34.38 & 47.81 & & & 99.99 \\
\hline & 8 & 1.18 & 15.80 & 34.55 & 48.48 & & & 100.01 \\
\hline average & & 1.08 & 16.32 & 34.47 & 48.15 & & & 100.00 \\
\hline \multirow[t]{2}{*}{ Cpx } & $\begin{array}{c}\text { Analysis } \\
\text { Point }\end{array}$ & MgO & $\mathbf{A l}_{2} \mathbf{O}_{3}$ & $\mathrm{SiO}_{2}$ & & $\mathrm{CaO}$ & $\mathrm{FeO}$ & Total \\
\hline & 60 & 13.39 & 7.02 & 48.27 & & 2.94 & 28.38 & 100.00 \\
\hline \multirow[t]{3}{*}{ Sulfate } & $\begin{array}{c}\text { Analysis } \\
\text { Point }\end{array}$ & MgO & $\mathrm{SO}_{3}$ & Total & O & $\mathbf{M g}$ & $\mathbf{S}$ & Total \\
\hline & 4 & 47.73 & 52.27 & 100.00 & 50.28 & 28.78 & 20.94 & 100.00 \\
\hline & 6 & 40.25 & 59.75 & 100.00 & 51.80 & 24.27 & 23.93 & 100.00 \\
\hline average & & 43.99 & 56.01 & 100.00 & & & & \\
\hline \multirow[t]{3}{*}{ Smc } & $\begin{array}{c}\text { Analysis } \\
\text { Point }\end{array}$ & $\mathrm{Na}_{2} \mathrm{O}$ & MgO & $\mathbf{A l}_{2} \mathbf{O}_{3}$ & $\mathrm{SiO}_{2}$ & $\mathrm{CaO}$ & $\mathrm{FeO}$ & Total \\
\hline & 2 & 3.18 & 16.87 & 13.33 & 47.60 & 1.59 & 17.43 & 100.00 \\
\hline & 3 & 2.88 & 14.96 & 10.56 & 50.46 & 1.79 & 19.25 & 100.00 \\
\hline average & & 3.03 & 15.92 & 11.95 & 49.03 & 1.69 & 18.34 & 99.95 \\
\hline$\pm \boldsymbol{\sigma}$ & & 0.21 & 1.35 & 1.96 & 2.02 & 0.14 & 1.29 & \\
\hline
\end{tabular}

Table E.6.6. Average mineral compositions determined by EDS from Table E.6.5

$\begin{array}{ccccc}\text { Oxides } & \text { average wt\% } & \text { average } \mathbf{w t} \% & \text { average } \mathbf{w t} \% & \text { average } \mathbf{w t} \% \\ \mathrm{Na}_{2} \mathrm{O} & 1.08 & & & 3.03 \\ \mathrm{MgO} & & 13.39 & 43.99 & 15.92 \\ \mathrm{Al}_{2} \mathrm{O}_{3} & 34.47 & 7.02 & & 11.95 \\ \mathrm{SiO}_{2} & 48.15 & 48.27 & & 49.03 \\ \mathrm{CaO} & 16.32 & 2.94 & & 1.69 \\ \mathrm{FeO} & & 28.38 & 56.01 & 18.34 \\ \mathrm{SO}_{3} & & & & \\ \mathrm{TiO}_{2} & & & 100.00 & 99.96 \\ \text { Total } & 100.02 & 100.00 & \end{array}$

$\begin{array}{cccc}\text { Mineral } & \mathrm{Ca}_{0.8} \mathrm{Na}_{0.1} \mathrm{Al}_{1.9} \mathrm{Si}_{2.2} \mathrm{O}_{8} & \mathrm{Ca}_{0.1} \mathrm{Mg}_{0.8} \mathrm{Fe}_{0.9} \mathrm{Al}_{0.2} \mathrm{Si}_{1.9} \mathrm{Al}_{0.1} \mathrm{O}_{6} & \mathrm{Mg}_{7}\left(\mathrm{SO}_{4}\right)_{5}(\mathrm{OH})_{4} \cdot \mathrm{H}_{2} \mathrm{O}\end{array} \quad \begin{gathered}\mathrm{Na}_{0.8} \mathrm{Ca}_{0.2} \mathrm{Mg}_{3.2} \mathrm{Fe}_{2.1} \mathrm{Al}_{0.5} \mathrm{Si}_{6.6} \mathrm{Al}_{1.4} \mathrm{O}_{20}(\mathrm{OH})_{4} \\ \text { Composition the basis of 22 oxygen equivalents, ignoring } \mathrm{H}_{2} \mathrm{O} \text { ) }\end{gathered}$

Phase and ID

Bytownite

Augite

Caminite

Smectite 


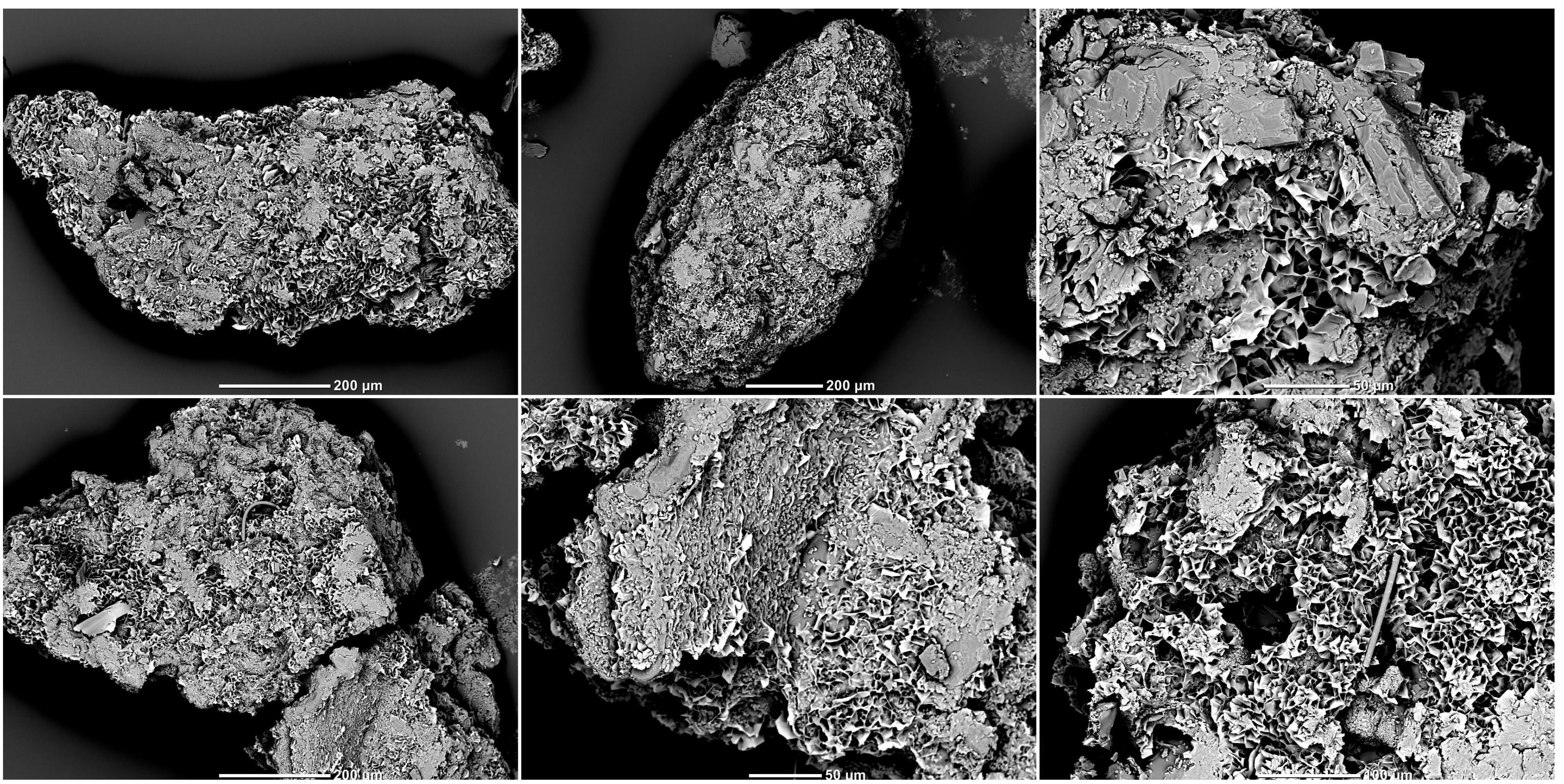


BSW1: Portion 1

Figure E.6.15. EDS analysis of texture of reacted grains from Portion 1
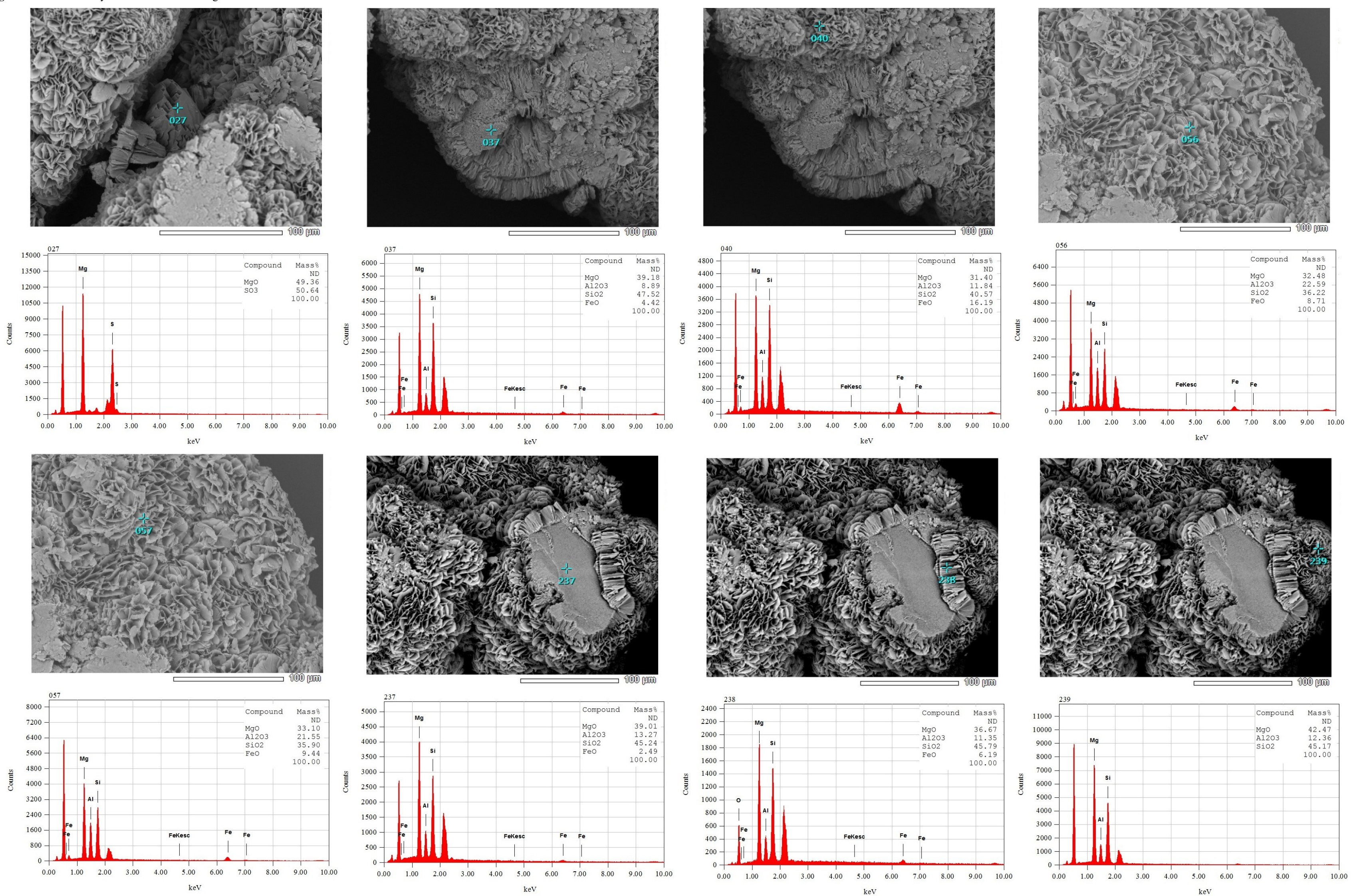

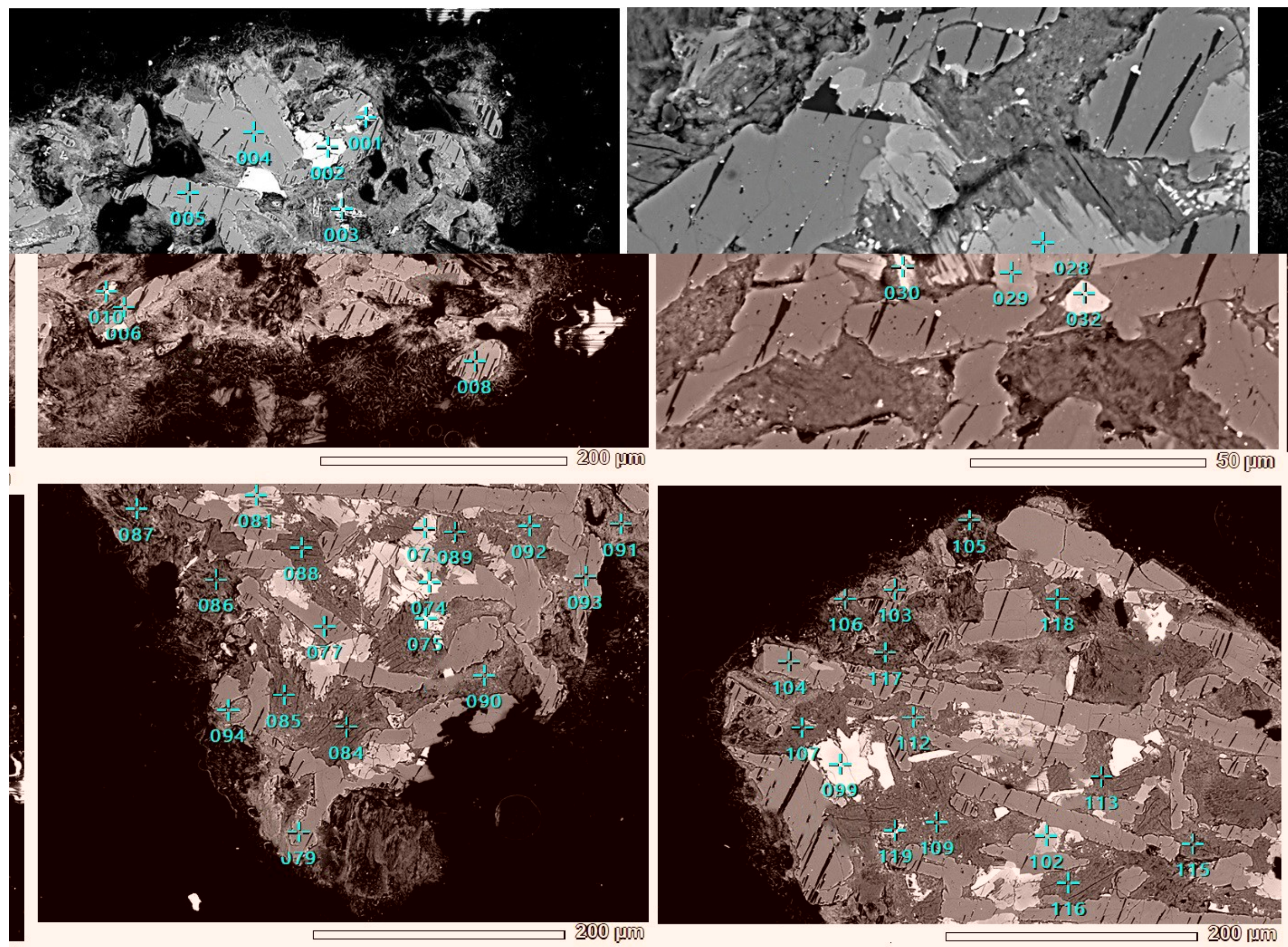
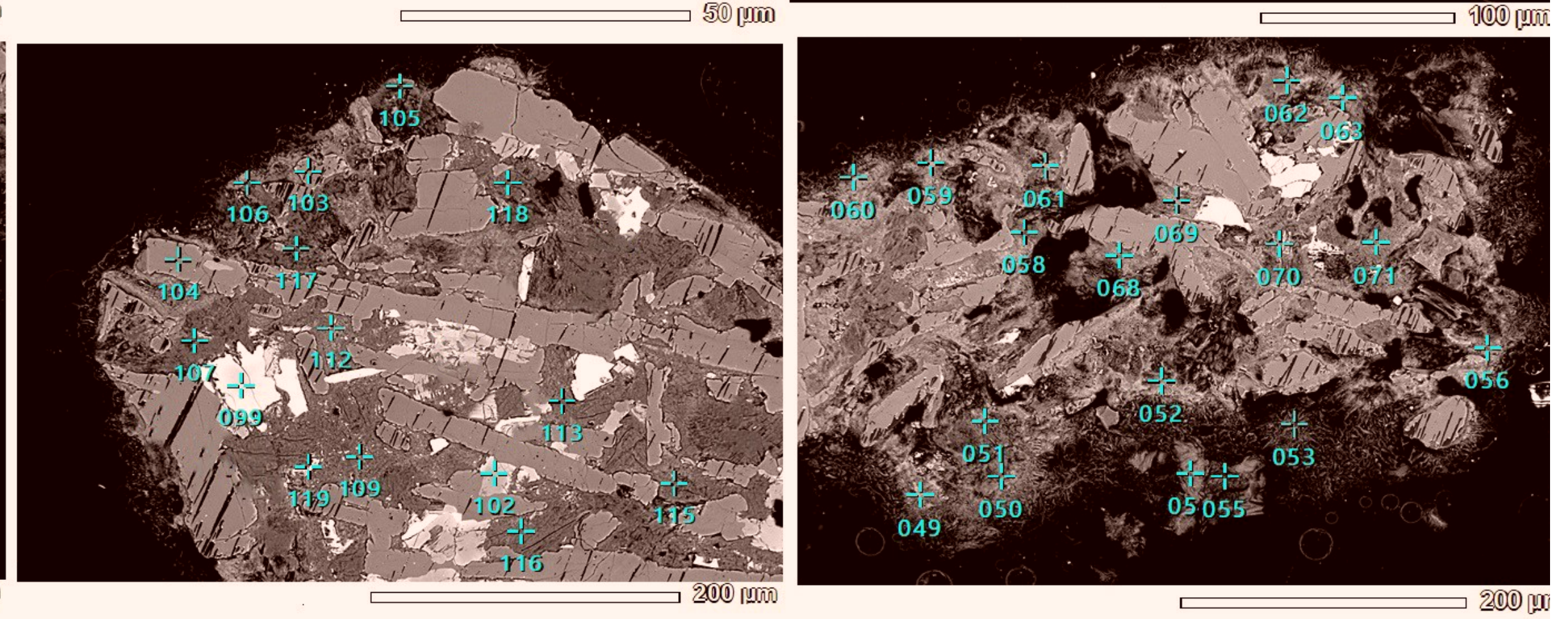


\section{$\begin{array}{llllll}\text { Point } & \mathrm{Na}_{2} \mathrm{O} & \mathrm{Al}_{2} \mathrm{O}_{3} & \mathrm{SiO}_{2} & \mathrm{CaO} & \mathrm{MgO}\end{array}$}

Plg

4
5
6
8
34
77
79
103
104

average

$\begin{array}{lllll}3.86 & 30.29 & 52.50 & 13.35 & 0.00\end{array}$

$\begin{array}{lllll}3.61 & 30.13 & 52.14 & 14.12 & 0.00\end{array}$

$\begin{array}{lllll}3.63 & 30.17 & 52.51 & 13.69 & 0.00\end{array}$

$\begin{array}{lllll}3.20 & 30.66 & 51.87 & 14.27 & 0.00\end{array}$

$\begin{array}{lllll}3.88 & 31.72 & 51.61 & 12.57 & 0.22\end{array}$

$\begin{array}{lllll}5.58 & 27.60 & 57.23 & 9.59 & 0.00\end{array}$

$\begin{array}{lllll}4.27 & 29.06 & 54.42 & 12.25 & 0.00\end{array}$

$\begin{array}{llllll}4.10 & 30.30 & 52.86 & 12.74 & 0.00\end{array}$

$\begin{array}{lllll}3.34 & 30.66 & 51.57 & 14.43 & 0.00\end{array}$

$\begin{array}{lllll}3.94 & 30.07 & 52.97 & 13.00 & 0.02\end{array}$

100.00

100.00

100.00

100.00

100.00

100.00

100.00

100.00

100.00

100.00

\section{Analysis}

Point

Cpx

28

29
73

81

average

\section{Analysis}

Point

2
32
74
99

average

Onalysis
Point
1
3
10
30
75
119

$\begin{array}{lllllll}16.97 & 2.32 & 52.97 & 15.85 & 11.88 & 0.00 & 100.00\end{array}$ $\begin{array}{llllllll}14.88 & 2.22 & 52.24 & 17.91 & 12.75 & 0.00 & 100.00\end{array}$ $\begin{array}{lllllll}18.54 & 0.73 & 53.13 & 4.40 & 23.20 & 0.00 & 100.00\end{array}$ $\begin{array}{llllllll}15.18 & 2.85 & 52.20 & 19.09 & 9.73 & 0.94 & 100.00\end{array}$ $\begin{array}{lllllll}16.49 & 1.77 & 53.41 & 18.33 & 10.01 & 0.00 & 100.00\end{array}$

$\begin{array}{lllllll}16.41 & 1.98 & 52.79 & 15.12 & 13.51 & 0.19 & 99.81\end{array}$

$\begin{array}{lll}\mathrm{MgO} & \mathrm{SiO}_{2} & \mathrm{FeO}\end{array}$

$\begin{array}{lll}25.34 & 35.60 & 39.06\end{array}$

$\begin{array}{lll}17.22 & 33.86 & 48.92\end{array}$

$\begin{array}{lll}22.25 & 35.43 & 42.32\end{array}$

$\begin{array}{lll}23.89 & 35.57 & 40.55\end{array}$

Total

100.00

100.00

100.00

100.00

100.00

$\mathrm{TiO}_{2} \quad \mathrm{FeO}$

Total

$33.94 \quad 66.06$

$41.15 \quad 58.85$

$37.92 \quad 62.08$

$\begin{array}{cc}44.9 & 55.1 \\ 27.87 & 72.13\end{array}$

$1.99 \quad 98.01$
$\begin{array}{lllllll}\mathrm{MgO} & \mathrm{Al}_{2} \mathrm{O}_{3} & \mathrm{SiO}_{2} & \mathrm{CaO} & \mathrm{FeO} & \mathrm{TiO}_{2} & \text { Total }\end{array}$
Analysis

Point

Chl

35
37
41
42
43
48
49
50
51
52
53
54
55
56
58
59
60
61
62
63
68
69
70
71
84
85
86
87
88
89
90
91
92
93
94
105
106
107
109
112
113
115
116
117
118

average
$\begin{array}{lllll}\mathrm{MgO} & \mathrm{Al}_{2} \mathrm{O}_{3} & \mathrm{SiO}_{2} & \mathrm{TiO}_{2} & \mathrm{FeO}\end{array}$

$\begin{array}{lllll}32.38 & 12.80 & 43.28 & 1.12 & 10.43\end{array}$ $\begin{array}{lllll}33.43 & 14.86 & 40.76 & 0.00 & 10.95\end{array}$ $\begin{array}{llllll}32.56 & 13.91 & 42.61 & 0.00 & 10.91\end{array}$ $\begin{array}{lllll}29.13 & 16.56 & 38.00 & 0.00 & 16.31\end{array}$ $\begin{array}{llllll}32.42 & 12.48 & 42.74 & 0.00 & 12.37 \\ 31.93 & 16.67 & 39.25 & 0.00 & 12.15\end{array}$ $\begin{array}{llllll}31.93 & 16.67 & 39.25 & 0.00 & 12.15\end{array}$ $\begin{array}{llllll}34.18 & 13.75 & 42.04 & 0.00 & 10.03\end{array}$ $\begin{array}{lllllll}34.18 & 13.75 & 42.04 & 0.00 & 10.03\end{array}$ $\begin{array}{llllll}37.01 & 13.10 & 43.65 & 0.00 & 6.25\end{array}$ $\begin{array}{lllll}32.47 & 15.11 & 40.25 & 0.00 & 12.18 \\ 31.00 & 13.49 & 42.17 & 0.00 & 13.34\end{array}$ $\begin{array}{lllll}31.21 & 16.72 & 40.00 & 0.00 & 12.07\end{array}$ $\begin{array}{lllll}31.98 & 18.18 & 41.58 & 0.00 & 8.26\end{array}$

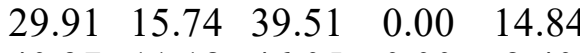
$\begin{array}{llllll}40.37 & 11.18 & 46.05 & 0.00 & 2.40\end{array}$ $\begin{array}{llllll}23.40 & 18.11 & 36.30 & 0.00 & 22.18\end{array}$ $\begin{array}{lllllll}24.49 & 16.98 & 36.50 & 0.00 & 22.03\end{array}$ $\begin{array}{llllll}19.58 & 13.94 & 31.56 & 0.00 & 34.92\end{array}$ $\begin{array}{llllll}34.02 & 22.11 & 41.83 & 0.00 & 2.04\end{array}$ $\begin{array}{lllll}31.45 & 16.81 & 38.96 & 0.00 & 12.78\end{array}$ $\begin{array}{lllll}24.98 & 11.76 & 38.21 & 0.00 & 25.05\end{array}$ $\begin{array}{lllll}25.00 & 17.00 & 37.36 & 0.00 & 20.64\end{array}$ $\begin{array}{llllll}23.91 & 17.35 & 37.81 & 0.00 & 20.93\end{array}$ $\begin{array}{llllll}35.93 & 13.00 & 41.66 & 0.00 & 9.42\end{array}$ $\begin{array}{llllll}36.94 & 4.43 & 57.47 & 0.00 & 1.16\end{array}$ $\begin{array}{lllll}34.27 & 2.01 & 62.53 & 0.00 & 1.19\end{array}$ $\begin{array}{lllll}34.10 & 3.68 & 60.65 & 0.00 & 1.56\end{array}$ $\begin{array}{lllll}35.65 & 4.24 & 59.69 & 0.42 & 0.00\end{array}$ $\begin{array}{lllll}33.29 & 4.05 & 58.76 & 1.85 & 2.05\end{array}$ $\begin{array}{llllll}35.65 & 4.24 & 59.69 & 0.42 & 0.00\end{array}$ $\begin{array}{llllll}33.29 & 4.05 & 58.76 & 1.85 & 2.05\end{array}$ $\begin{array}{llllll}25.03 & 17.39 & 36.74 & 0.00 & 20.85\end{array}$ $\begin{array}{llllll}30.01 & 15.88 & 38.46 & 0.00 & 15.65\end{array}$ $\begin{array}{llllll}25.03 & 17.39 & 36.74 & 0.00 & 20.85\end{array}$ $\begin{array}{llllll}31.76 & 15.13 & 41.18 & 0.00 & 11.93\end{array}$ $\begin{array}{llllll}39.35 & 6.79 & 52.38 & 0.00 & 1.47\end{array}$ $\begin{array}{lllll}38.18 & 9.59 & 45.52 & 1.43 & 5.28 \\ 33.38 & 2.23 & 62.92 & 0.00 & 1.46\end{array}$ $\begin{array}{llllll}33.38 & 2.23 & 62.92 & 0.00 & 1.46\end{array}$ $\begin{array}{llllll}35.29 & 12.11 & 41.01 & 2.00 & 9.59\end{array}$ $\begin{array}{lllllll}33.48 & 14.37 & 41.38 & 0.00 & 10.77\end{array}$ $\begin{array}{lllllll}36.06 & 15.60 & 42.31 & 0.00 & 6.03\end{array}$ $\begin{array}{llllll}39.95 & 12.27 & 44.19 & 0.00 & 3.59\end{array}$ $\begin{array}{llllll}34.30 & 5.79 & 55.12 & 0.92 & 3.86\end{array}$ $\begin{array}{lllll}33.63 & 3.62 & 59.16 & 0.68 & 2.91 \\ 34.09 & 2.48 & 60.07 & 1.65 & 1.70\end{array}$ $\begin{array}{llllll}32.07 & 12.13 & 45.21 & 0.27 & 10.32\end{array}$

\section{Total}

100.00 100.00 100.00 100.00 100.00 100.00 100.00 100.00 100.00 100.00 100.00 100.00 100.00 100.00 100.00 100.00 100.00 100.00 100.00 100.00 100.00 100.00 00.00 00.00 100.00 100.00 00.00 10.00 100.00 100.00 100.00 100.00 100.00 100.00 100.00 100.00 100.00 100.00 100.00 100.00 00.00 100.00 100.00 100.00 100.00 100.00 100.00 

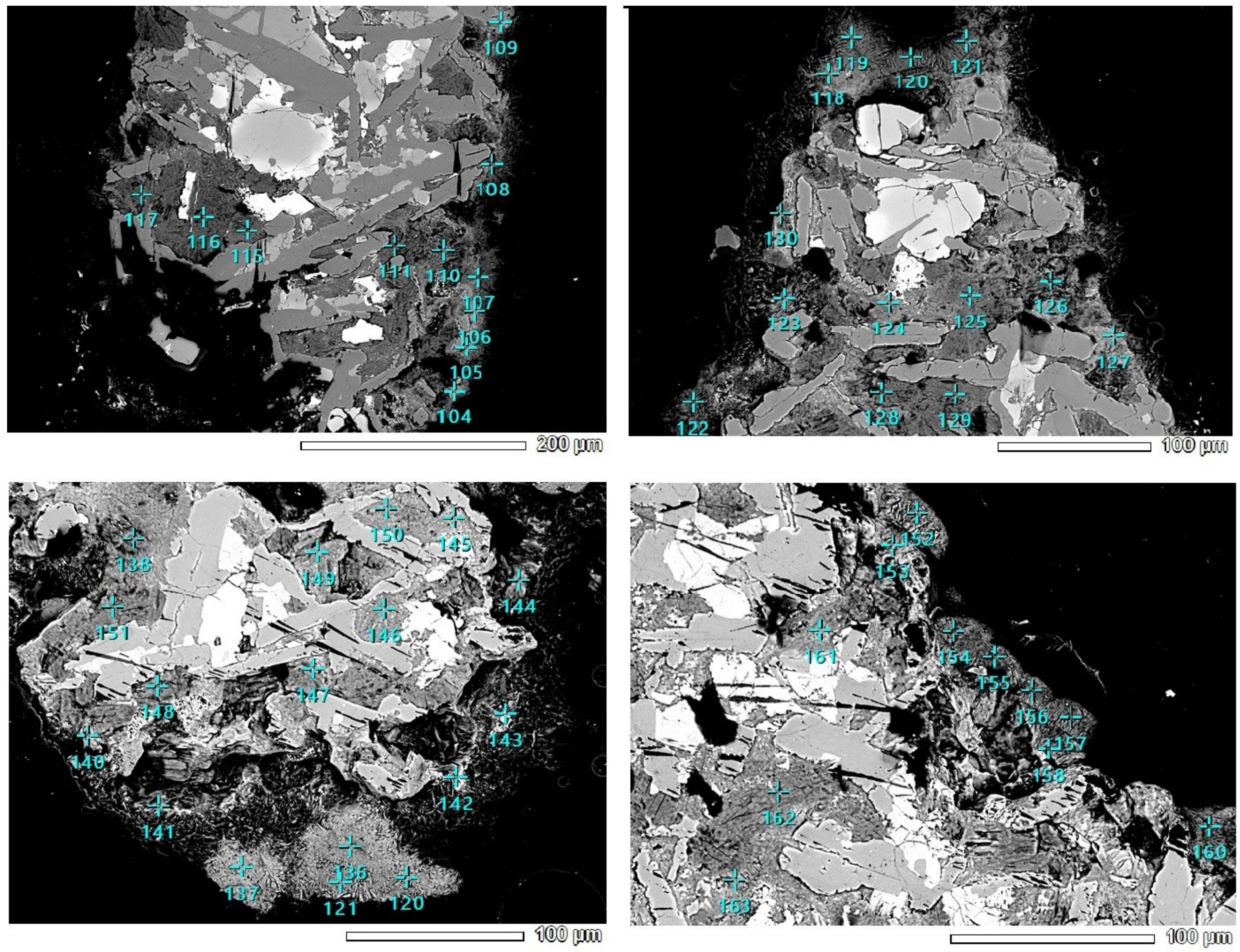


\begin{tabular}{|c|c|c|c|c|c|c|c|}
\hline & $\begin{array}{c}\text { Analysis } \\
\text { Point }\end{array}$ & MgO & $\mathbf{A l}_{2} \mathbf{O}_{3}$ & $\mathrm{SiO}_{2}$ & $\mathrm{TiO}_{2}$ & FeO & Total \\
\hline \multirow[t]{52}{*}{ Chl } & 104 & 30.23 & 18.60 & 40.29 & 0.00 & 10.88 & 100.00 \\
\hline & 105 & 29.72 & 18.38 & 39.54 & 0.00 & 12.37 & 100.00 \\
\hline & 106 & 31.31 & 16.43 & 40.30 & 0.00 & 11.96 & 100.00 \\
\hline & 107 & 36.44 & 10.48 & 45.56 & 0.00 & 7.51 & 100.00 \\
\hline & 108 & 36.40 & 13.14 & 42.92 & 0.00 & 7.55 & 100.00 \\
\hline & 109 & 25.74 & 19.82 & 36.96 & 0.00 & 17.48 & 100.00 \\
\hline & 110 & 36.99 & 11.76 & 43.60 & 0.00 & 7.64 & 100.00 \\
\hline & 111 & 35.48 & 4.37 & 58.46 & 0.00 & 1.68 & 100.00 \\
\hline & 115 & 35.23 & 10.65 & 44.39 & 2.63 & 7.09 & 100.00 \\
\hline & 116 & 40.06 & 9.86 & 46.70 & 0.00 & 3.38 & 100.00 \\
\hline & 117 & 32.68 & 4.69 & 59.29 & 0.00 & 3.33 & 100.00 \\
\hline & 118 & 31.03 & 13.68 & 40.90 & 0.00 & 14.39 & 100.00 \\
\hline & 119 & 37.30 & 12.55 & 42.86 & 0.00 & 7.29 & 100.00 \\
\hline & 120 & 38.76 & 11.07 & 45.28 & 0.00 & 4.89 & 100.00 \\
\hline & 121 & 38.31 & 11.81 & 43.63 & 0.00 & 6.25 & 100.00 \\
\hline & 122 & 40.21 & 11.37 & 43.34 & 0.00 & 5.07 & 100.00 \\
\hline & 123 & 37.38 & 10.83 & 44.38 & 0.00 & 7.41 & 100.00 \\
\hline & 124 & 35.41 & 14.09 & 42.29 & 0.00 & 8.22 & 100.00 \\
\hline & 125 & 32.13 & 1.82 & 63.87 & 0.00 & 2.19 & 100.00 \\
\hline & 126 & 33.01 & 3.06 & 62.26 & 0.00 & 1.67 & 100.00 \\
\hline & 127 & 30.92 & 15.35 & 39.65 & 0.00 & 14.08 & 100.00 \\
\hline & 128 & 33.53 & 5.49 & 57.25 & 0.00 & 3.74 & 100.00 \\
\hline & 129 & 32.97 & 3.28 & 61.90 & 0.00 & 1.84 & 100.00 \\
\hline & 130 & 32.32 & 13.23 & 41.07 & 0.00 & 13.39 & 100.00 \\
\hline & 120 & 35.47 & 12.43 & 42.85 & 0.00 & 9.25 & 100.00 \\
\hline & 121 & 38.13 & 11.63 & 44.22 & 0.00 & 6.02 & 100.00 \\
\hline & 136 & 37.70 & 12.84 & 42.57 & 0.00 & 6.89 & 100.00 \\
\hline & 137 & 37.22 & 12.39 & 42.53 & 0.00 & 7.86 & 100.00 \\
\hline & 138 & 34.76 & 4.63 & 58.85 & 0.00 & 1.76 & 100.00 \\
\hline & 140 & 33.14 & 15.59 & 41.84 & 0.00 & 9.43 & 100.00 \\
\hline & 141 & 32.58 & 13.87 & 41.17 & 0.00 & 12.38 & 100.00 \\
\hline & 142 & 30.43 & 21.75 & 38.56 & 0.00 & 9.26 & 100.00 \\
\hline & 143 & 31.52 & 17.33 & 38.92 & 0.00 & 12.23 & 100.00 \\
\hline & 144 & 38.57 & 10.54 & 47.76 & 0.00 & 3.13 & 100.00 \\
\hline & 145 & 30.36 & 15.49 & 39.38 & 0.00 & 14.77 & 100.00 \\
\hline & 146 & 33.18 & 2.30 & 58.41 & 0.00 & 6.10 & 100.00 \\
\hline & 147 & 35.96 & 4.77 & 56.88 & 0.00 & 2.39 & 100.00 \\
\hline & 148 & 37.48 & 6.12 & 54.27 & 0.00 & 2.13 & 100.00 \\
\hline & 149 & 40.56 & 8.77 & 47.50 & 0.00 & 3.18 & 100.00 \\
\hline & 150 & 34.09 & 16.19 & 40.64 & 0.00 & 9.07 & 100.00 \\
\hline & 151 & 32.34 & 3.68 & 61.42 & 0.00 & 2.56 & 100.00 \\
\hline & 152 & 41.64 & 9.93 & 45.03 & 0.00 & 3.40 & 100.00 \\
\hline & 153 & 39.63 & 11.55 & 43.51 & 0.00 & 5.30 & 100.00 \\
\hline & 154 & 42.23 & 9.99 & 44.98 & 0.00 & 2.80 & 100.00 \\
\hline & 155 & 41.96 & 9.47 & 45.70 & 0.00 & 2.86 & 100.00 \\
\hline & 156 & 41.48 & 10.03 & 45.15 & 0.00 & 3.35 & 100.00 \\
\hline & 157 & 42.50 & 9.83 & 44.81 & 0.00 & 2.86 & 100.00 \\
\hline & 158 & 40.19 & 9.94 & 45.55 & 0.00 & 4.32 & 100.00 \\
\hline & 160 & 40.52 & 10.45 & 44.33 & 0.00 & 4.69 & 100.00 \\
\hline & 161 & 34.87 & 12.40 & 41.99 & 0.00 & 10.74 & 100.00 \\
\hline & 162 & 32.03 & 2.30 & 63.20 & 0.00 & 2.46 & 100.00 \\
\hline & 163 & 36.57 & 13.79 & 43.00 & 0.00 & 6.63 & 100.00 \\
\hline aq & & 35.59 & 10.88 & 46.76 & 0.05 & 6.71 & \\
\hline
\end{tabular}


Table E.6.9. Average mineral compositions from Table E.6.7 and Table E.6.8

average $w t \%$

\section{average wt $\%$}

$$
16.41
$$$$
3.94
$$

30.07

52.97

13.00

$\mathrm{CaO}$

$\mathrm{FeO}$

$\mathrm{TiO}_{2}$

Total

100.00

99.81

100.01

$\mathrm{Mg}_{1.24} \mathrm{Fe}_{0.75} \mathrm{SiO}_{4}$

$\left(\mathrm{Fo}_{51}-\mathrm{Fa}_{49}\right)$

Mg-olivine

(forsterite) (augite)

(labradorite)

\begin{tabular}{|c|}
\hline point $\mathrm{n}^{\circ} 119$ \\
[Oxides wt\% and \\
elements mass \% and atomic \%] \\
\\
\\
FeO (wt\%) 98.01 \\
TiO 2 (wt\%) 1.99 \\
Fe: (wt\%) 76.18 - (at\%) 48.66 \\
Ti: (wt\%) 1.19 .18 - (at\%) 0.89 \\
O: (wt\%) 22.62 - (at $\%) 50.46$ \\
\\
Oxide \\
(magnetite?)
\end{tabular}

\section{average $\mathrm{wt} \%$}

33.83

11.51

45.99

8.52

0.16

100.01

$\mathrm{Mg}_{8.30} \mathrm{Fe}_{1.17} \mathrm{Al}_{1.80} \mathrm{Si}_{7.57} \mathrm{Al}_{0.43} \mathrm{O}_{20}(\mathrm{OH})_{16}$ (on the basis of 28 oxygen equivalents, ignoring $\mathrm{H}_{2} \mathrm{O}$ )

Oxide (titanomagnetite) 
Portion 2-3

Figure E.6.18. SEM pictures for EDS analysis of epoxy-mounted polished grains collected from Portion 2-3. Analysis points are marked in blue
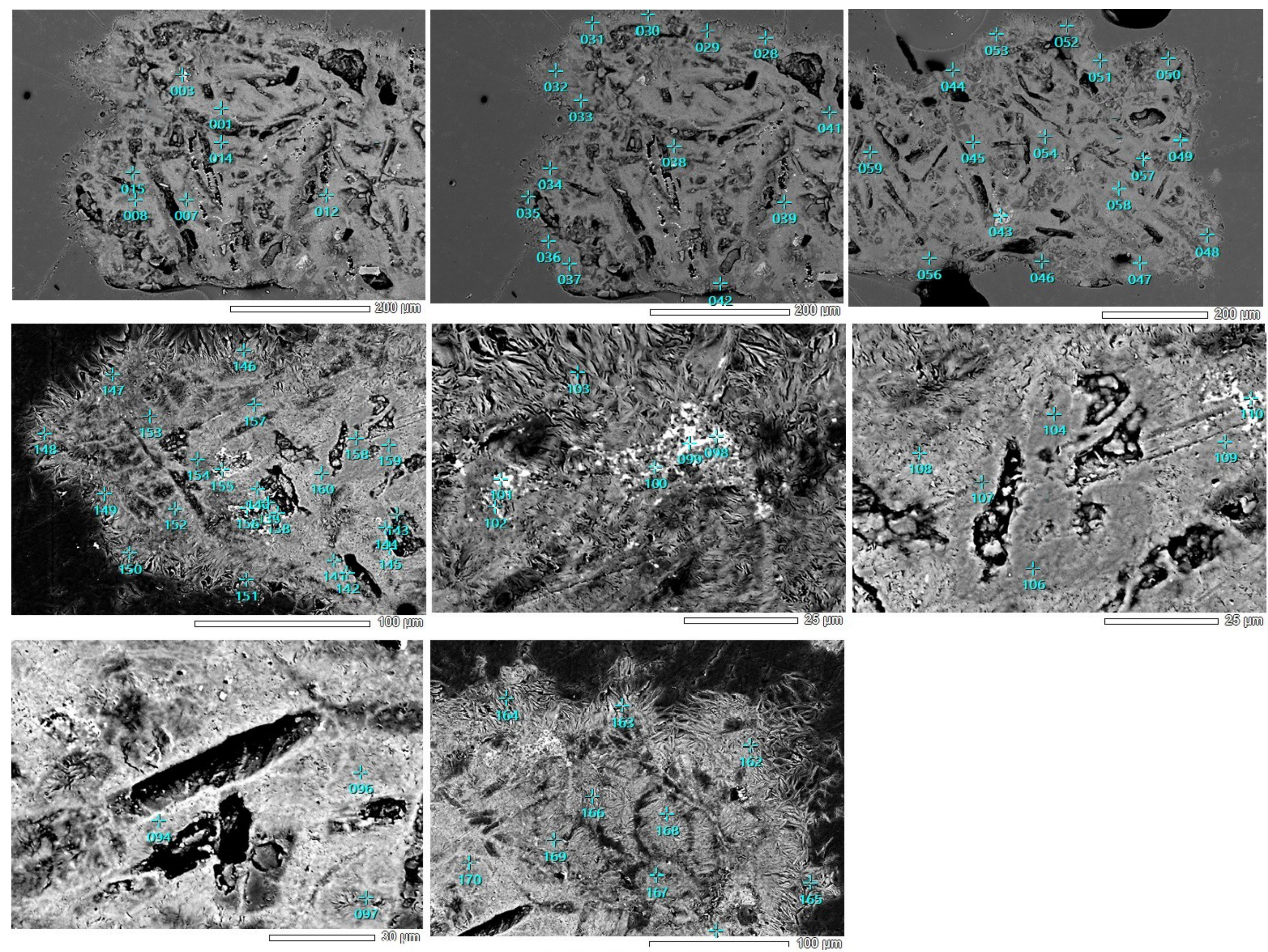
Table E.6.10. SEM-EDS analysis results of grains in Figure E.6.18

\begin{tabular}{|c|c|c|c|c|c|c|c|}
\hline Chl & $\begin{array}{c}\text { Analysis } \\
\text { Point }\end{array}$ & MgO & $\mathbf{A l}_{2} \mathbf{O}_{3}$ & $\mathrm{SiO}_{2}$ & $\mathrm{TiO}_{2}$ & $\mathrm{FeO}$ & Total \\
\hline & 1 & 28.21 & 25.01 & 37.56 & 0.00 & 9.23 & 100.01 \\
\hline & 7 & 26.34 & 22.62 & 36.86 & 0.00 & 14.18 & 100.00 \\
\hline & 8 & 24.78 & 19.08 & 36.65 & 0.00 & 19.48 & 99.99 \\
\hline & 12 & 27.07 & 21.79 & 37.70 & 0.00 & 13.44 & 100.00 \\
\hline & 14 & 27.29 & 21.55 & 37.09 & 0.00 & 14.06 & 99.99 \\
\hline & 15 & 24.97 & 25.10 & 38.25 & 0.00 & 11.68 & 100.00 \\
\hline & 28 & 26.36 & 32.22 & 35.81 & 0.00 & 5.61 & 100.00 \\
\hline & 29 & 26.06 & 21.52 & 36.51 & 0.00 & 15.90 & 99.99 \\
\hline & 30 & 27.73 & 22.03 & 38.04 & 0.00 & 12.20 & 100.00 \\
\hline & 31 & 27.87 & 21.38 & 38.51 & 0.00 & 12.24 & 100.00 \\
\hline & 32 & 24.58 & 20.11 & 35.55 & 0.00 & 19.77 & 100.01 \\
\hline & 33 & 27.75 & 21.17 & 35.57 & 0.00 & 15.51 & 100.00 \\
\hline & 34 & 28.07 & 21.32 & 37.63 & 0.00 & 12.98 & 100.00 \\
\hline & 35 & 29.17 & 21.50 & 37.97 & 0.00 & 11.37 & 100.01 \\
\hline & 36 & 28.19 & 20.78 & 37.33 & 0.00 & 13.70 & 100.00 \\
\hline & 37 & 26.39 & 21.46 & 35.56 & 0.00 & 16.60 & 100.01 \\
\hline & 38 & 27.05 & 21.23 & 36.09 & 0.00 & 15.63 & 100.00 \\
\hline & 39 & 24.25 & 21.76 & 36.30 & 0.00 & 17.70 & 100.01 \\
\hline & 41 & 27.95 & 23.92 & 36.63 & 1.79 & 9.71 & 100.00 \\
\hline & 42 & 26.50 & 22.04 & 38.92 & 0.00 & 12.53 & 99.99 \\
\hline & 44 & 27.87 & 22.80 & 37.42 & 0.00 & 11.92 & 100.01 \\
\hline & 45 & 27.38 & 35.83 & 34.04 & 0.00 & 2.75 & 100.00 \\
\hline & 46 & 27.03 & 21.36 & 37.91 & 2.31 & 11.40 & 100.01 \\
\hline & 47 & 24.15 & 19.62 & 35.78 & 0.00 & 20.45 & 100.00 \\
\hline & 48 & 25.82 & 22.33 & 36.58 & 0.00 & 15.27 & 100.00 \\
\hline & 49 & 20.89 & 17.94 & 31.11 & 10.16 & 19.91 & 100.01 \\
\hline & 50 & 26.99 & 22.50 & 37.07 & 0.00 & 13.45 & 100.01 \\
\hline & 51 & 26.94 & 23.73 & 35.78 & 0.00 & 13.56 & 100.01 \\
\hline & 52 & 26.08 & 21.22 & 37.02 & 0.00 & 15.68 & 100.00 \\
\hline & 53 & 26.06 & 20.11 & 36.91 & 0.00 & 16.92 & 100.00 \\
\hline & 54 & 29.21 & 21.84 & 38.24 & 0.00 & 10.71 & 100.00 \\
\hline & 56 & 27.47 & 22.23 & 37.11 & 0.00 & 13.19 & 100.00 \\
\hline & 58 & 28.47 & 21.02 & 38.36 & 0.00 & 12.15 & 100.00 \\
\hline & 59 & 27.85 & 21.74 & 36.39 & 0.00 & 14.02 & 100.00 \\
\hline & 94 & 30.51 & 20.58 & 39.92 & 0.00 & 8.99 & 100.00 \\
\hline & 96 & 31.62 & 20.63 & 38.90 & 0.00 & 8.85 & 100.00 \\
\hline & 97 & 32.03 & 21.51 & 40.20 & 0.00 & 6.27 & 100.01 \\
\hline & 103 & 30.88 & 19.67 & 40.34 & 0.00 & 9.10 & 100.00 \\
\hline & 104 & 25.60 & 35.45 & 35.84 & 0.00 & 3.11 & 100.00 \\
\hline & 106 & 25.03 & 37.45 & 35.87 & 0.00 & 1.65 & 100.00 \\
\hline & 107 & 26.49 & 36.44 & 35.21 & 0.00 & 1.86 & 100.00 \\
\hline & 108 & 24.61 & 18.19 & 35.15 & 4.33 & 17.72 & 100.00 \\
\hline & 109 & 27.05 & 19.75 & 37.35 & 0.00 & 15.85 & 100.00 \\
\hline & 138 & 30.45 & 36.96 & 31.44 & 0.00 & 1.14 & 99.99 \\
\hline & 139 & 29.86 & 37.00 & 31.45 & 0.00 & 1.69 & 100.00 \\
\hline
\end{tabular}

\begin{tabular}{|c|c|c|c|c|c|c|c|}
\hline & 140 & 28.79 & 36.62 & 33.41 & 0.00 & 1.18 & 100.00 \\
\hline & 141 & 29.58 & 24.94 & 36.36 & 0.00 & 9.11 & 99.99 \\
\hline & 142 & 27.49 & 24.57 & 35.69 & 0.00 & 12.25 & 100.00 \\
\hline & 143 & 29.45 & 33.11 & 34.27 & 0.00 & 3.17 & 100.00 \\
\hline & 144 & 30.36 & 28.50 & 35.94 & 0.00 & 5.20 & 100.00 \\
\hline & 145 & 30.56 & 32.27 & 34.24 & 0.00 & 2.92 & 99.99 \\
\hline & 146 & 30.42 & 20.10 & 40.07 & 0.00 & 9.40 & 99.99 \\
\hline & 147 & 30.61 & 20.69 & 39.64 & 0.00 & 9.06 & 100.00 \\
\hline & 148 & 28.69 & 20.35 & 38.61 & 0.00 & 12.35 & 100.00 \\
\hline & 149 & 31.38 & 21.22 & 38.61 & 0.00 & 8.79 & 100.00 \\
\hline & 150 & 32.84 & 21.50 & 38.99 & 0.00 & 6.68 & 100.01 \\
\hline & 151 & 24.11 & 19.01 & 37.98 & 0.00 & 18.89 & 99.99 \\
\hline & 152 & 27.09 & 19.51 & 37.62 & 0.00 & 15.78 & 100.00 \\
\hline & 153 & 25.00 & 19.22 & 37.30 & 0.00 & 18.49 & 100.01 \\
\hline & 154 & 31.66 & 20.34 & 39.01 & 2.29 & 6.71 & 100.01 \\
\hline & 157 & 28.40 & 19.24 & 38.62 & 1.76 & 11.97 & 99.99 \\
\hline & 158 & 27.63 & 38.90 & 32.23 & 0.00 & 1.25 & 100.01 \\
\hline & 159 & 31.25 & 36.71 & 30.69 & 0.00 & 1.35 & 100.00 \\
\hline & 160 & 26.37 & 34.23 & 35.41 & 0.00 & 3.99 & 100.00 \\
\hline & 162 & 31.66 & 21.16 & 38.93 & 0.00 & 8.26 & 100.01 \\
\hline & 163 & 31.88 & 20.13 & 40.18 & 0.00 & 7.81 & 100.00 \\
\hline & 164 & 31.95 & 21.62 & 40.16 & 0.00 & 6.26 & 99.99 \\
\hline & 165 & 30.69 & 21.97 & 40.81 & 0.00 & 6.53 & 100.00 \\
\hline & 166 & 33.82 & 20.78 & 40.11 & 0.00 & 5.29 & 100.00 \\
\hline & 167 & 29.78 & 20.51 & 39.09 & 0.00 & 10.62 & 100.00 \\
\hline & 168 & 30.12 & 20.43 & 40.54 & 0.00 & 8.90 & 99.99 \\
\hline & 169 & 32.29 & 21.58 & 39.07 & 0.00 & 7.06 & 100.00 \\
\hline & 170 & 30.04 & 19.97 & 38.68 & 2.08 & 9.22 & 99.99 \\
\hline & 171 & 26.59 & 18.74 & 33.15 & 0.00 & 21.52 & 100.00 \\
\hline average & & 28.15 & 23.83 & 36.99 & 0.33 & 10.69 & \\
\hline $\mathrm{Ox}$ & $\begin{array}{c}\text { Analysis } \\
\text { Point }\end{array}$ & $\mathrm{TiO}_{2}$ & $\mathrm{FeO}$ & & & & Total \\
\hline & 3 & 15.69 & 84.31 & & & & 100.00 \\
\hline & 43 & 25.54 & 74.46 & & & & 100.00 \\
\hline & 57 & 30.48 & 69.52 & & & & 100.00 \\
\hline & 98 & 29.78 & 70.22 & & & & 100.00 \\
\hline & 99 & 50.94 & 49.06 & & & & 100.00 \\
\hline & 100 & 26.75 & 73.25 & & & & 100.00 \\
\hline & 101 & 24.00 & 76.00 & & & & 100.00 \\
\hline & 102 & 45.49 & 54.51 & & & & 100.00 \\
\hline & 155 & 29.68 & 70.32 & & & & 100.00 \\
\hline & 156 & 27.24 & 72.76 & & & & 100.00 \\
\hline & & & & & & & \\
\hline
\end{tabular}



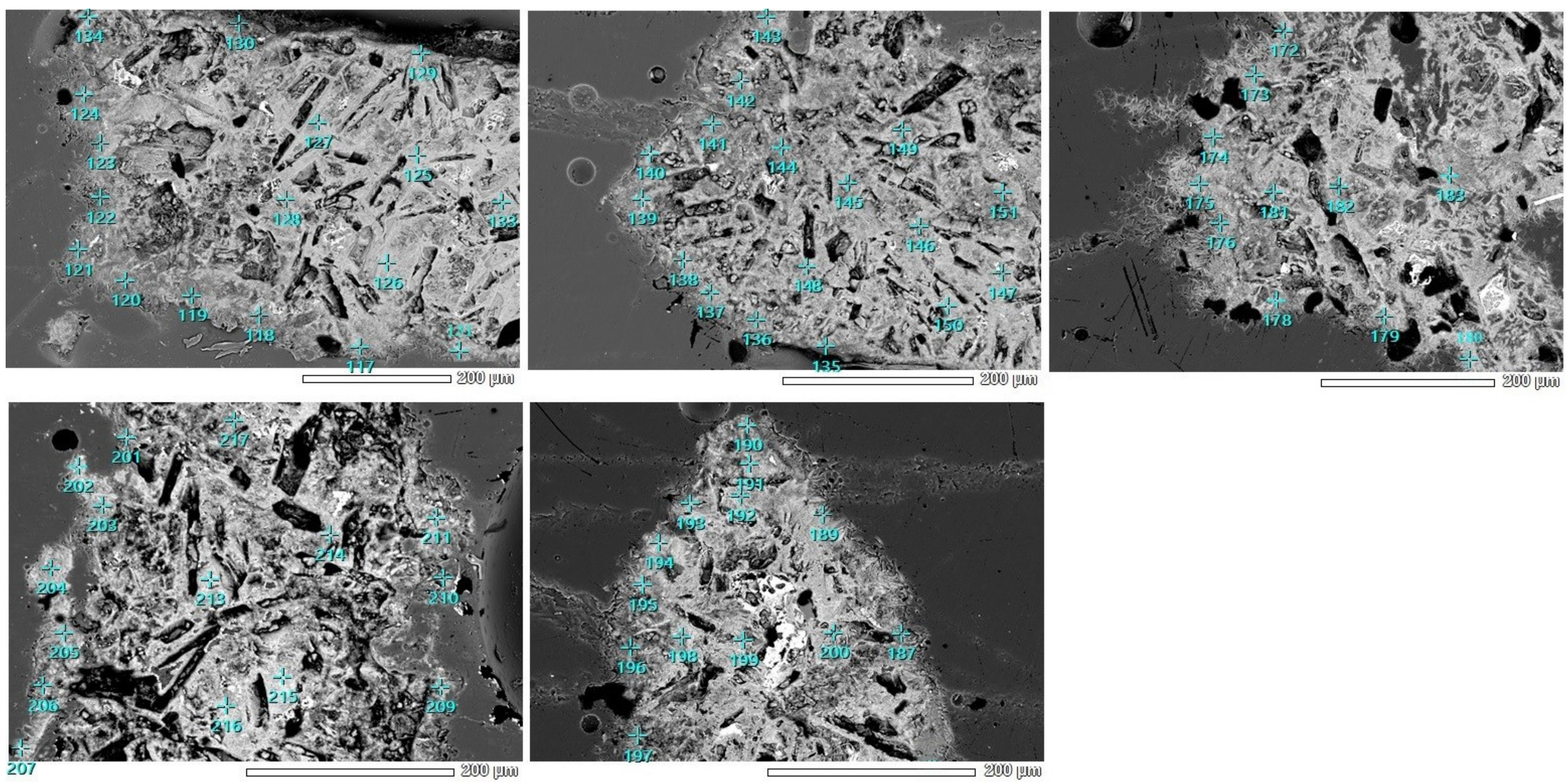
Table E.6.11. SEM-EDS analysis results of grains in Figure E.6.19

$\begin{array}{cccccc}\text { Chl Analysis } & \mathbf{M g O} & \mathbf{A l}_{\mathbf{2}} \mathbf{O}_{\mathbf{3}} & \mathbf{S i O}_{\mathbf{2}} & \mathbf{F e O} & \text { Total } \\ \text { Point } & 30.14 & 22.45 & 37.60 & 9.80 & 99.99 \\ 117 & 29.85 & 22.90 & 39.78 & 7.46 & 99.99 \\ 118 & 21.19 & 20.02 & 40.13 & 18.67 & 100.01 \\ 119 & 27.44 & 21.42 & 36.78 & 14.36 & 100.00 \\ 120 & 29.69 & 21.96 & 37.66 & 10.69 & 100.00 \\ 121 & 31.88 & 23.84 & 37.99 & 6.29 & 100.00 \\ 122 & 29.66 & 22.26 & 37.26 & 10.83 & 100.01 \\ 123 & 30.42 & 22.17 & 36.76 & 10.65 & 100.00 \\ 124 & 31.74 & 22.36 & 38.02 & 7.89 & 100.01 \\ 125 & 30.20 & 22.35 & 37.64 & 9.81 & 100.00 \\ 126 & 31.55 & 22.46 & 37.70 & 8.29 & 100.00 \\ 127 & 28.36 & 20.92 & 37.96 & 12.75 & 99.99 \\ 128 & 27.29 & 21.74 & 37.06 & 13.91 & 100.00 \\ 129 & 31.88 & 22.57 & 38.02 & 7.53 & 100.00 \\ 130 & 29.22 & 21.91 & 37.35 & 11.52 & 100.00 \\ 131 & 30.31 & 21.08 & 37.34 & 11.27 & 100.00 \\ 133 & 28.73 & 20.02 & 37.44 & 13.81 & 100.00 \\ 134 & 22.06 & 19.15 & 36.38 & 22.42 & 100.01 \\ 135 & 29.49 & 21.54 & 37.76 & 11.21 & 100.00 \\ 136 & 29.17 & 22.84 & 37.54 & 10.45 & 100.00 \\ 137 & 31.16 & 21.81 & 37.11 & 9.93 & 100.01 \\ 138 & 28.00 & 20.48 & 35.39 & 16.13 & 100.00 \\ 139 & 32.23 & 22.23 & 35.51 & 10.04 & 100.01 \\ 140 & 30.59 & 22.62 & 38.29 & 8.50 & 100.00 \\ 141 & 28.57 & 21.13 & 36.33 & 13.97 & 100.00 \\ 142 & 31.25 & 22.86 & 37.30 & 8.60 & 100.01 \\ 143 & 29.31 & 21.74 & 36.95 & 12.00 & 100.00 \\ 144 & 29.94 & 24.31 & 38.07 & 7.68 & 100.00 \\ 145 & 28.30 & 20.17 & 38.95 & 12.57 & 99.99 \\ 146 & 30.48 & 22.55 & 37.09 & 9.89 & 100.01 \\ 147 & 30.32 & 21.68 & 39.12 & 8.88 & 100.00 \\ 148 & 29.13 & 23.42 & 38.65 & 8.80 & 100.00 \\ 149 & 29.27 & 21.75 & 37.80 & 11.18 & 100.00 \\ 150 & 29.73 & 21.26 & 37.11 & 11.90 & 100.00 \\ 151 & 30.64 & 22.20 & 37.78 & 9.38 & 100.00 \\ 172 & 28.42 & 22.15 & 37.78 & 8.65 & 100.00 \\ 173 & 21.86 & 37.44 & 12.08 & 100.00 \\ 174 & 28.62 & & & \end{array}$

\begin{tabular}{ccccc}
$\mathbf{M g O}$ & $\mathbf{A l}_{\mathbf{2}} \mathbf{O}_{\mathbf{3}}$ & $\mathbf{S i O}_{\mathbf{2}}$ & $\mathbf{F e O}$ & Total \\
29.29 & 22.31 & 37.75 & 10.65 & 100.00 \\
29.82 & 22.07 & 37.04 & 11.07 & 100.00 \\
31.30 & 22.01 & 36.98 & 9.71 & 100.00 \\
32.36 & 22.65 & 37.00 & 7.99 & 100.00 \\
30.79 & 21.98 & 37.89 & 9.33 & 99.99 \\
30.43 & 21.98 & 37.29 & 10.30 & 100.00 \\
25.20 & 19.25 & 35.85 & 19.71 & 100.01 \\
28.45 & 23.40 & 36.67 & 11.48 & 100.00 \\
32.91 & 20.99 & 38.97 & 7.14 & 100.01 \\
32.10 & 20.63 & 38.90 & 8.38 & 100.01 \\
30.39 & 20.63 & 38.02 & 10.96 & 100.00 \\
28.21 & 19.46 & 38.58 & 13.76 & 100.01 \\
31.49 & 20.39 & 38.53 & 9.59 & 100.00 \\
30.05 & 19.87 & 37.65 & 12.43 & 100.00 \\
32.51 & 20.91 & 38.73 & 7.86 & 100.01 \\
31.58 & 20.48 & 38.48 & 9.47 & 100.01 \\
33.25 & 21.25 & 39.88 & 5.62 & 100.00 \\
34.89 & 21.30 & 39.32 & 4.49 & 100.00 \\
33.04 & 23.30 & 38.87 & 4.79 & 100.00 \\
36.35 & 21.78 & 39.47 & 2.40 & 100.00 \\
31.35 & 33.34 & 33.58 & 1.73 & 100.00 \\
30.03 & 21.47 & 37.27 & 11.22 & 99.99 \\
26.26 & 20.38 & 37.32 & 16.03 & 99.99 \\
30.00 & 21.85 & 37.22 & 10.93 & 100.00 \\
30.37 & 20.94 & 38.25 & 10.43 & 99.99 \\
29.97 & 21.67 & 37.36 & 11.00 & 100.00 \\
31.31 & 22.02 & 37.70 & 8.98 & 100.01 \\
31.91 & 21.31 & 37.44 & 9.35 & 100.01 \\
26.06 & 19.58 & 38.81 & 15.55 & 100.00 \\
31.68 & 20.26 & 40.88 & 7.17 & 99.99 \\
27.36 & 19.59 & 36.82 & 16.22 & 99.99 \\
29.89 & 22.28 & 36.61 & 11.23 & 100.01 \\
33.10 & 23.08 & 37.84 & 5.98 & 100.00 \\
31.56 & 22.14 & 37.11 & 9.18 & 99.99 \\
30.71 & 22.32 & 35.89 & 11.08 & 100.00 \\
29.08 & 21.78 & 38.01 & 11.13 & 100.00 \\
$\mathbf{3 0 . 0 6}$ & $\mathbf{2 1 . 7 9}$ & $\mathbf{3 7 . 6 8}$ & $\mathbf{1 0 . 4 7}$ & \\
\hline
\end{tabular}




\begin{tabular}{|c|c|c|}
\hline Oxides & average $w t \%$ & average $w t \%$ \\
\hline $\mathrm{MgO}$ & & 29.11 \\
\hline $\mathrm{Al}_{2} \mathrm{O}_{3}$ & & 22.81 \\
\hline $\mathrm{SiO}_{2}$ & & 37.34 \\
\hline $\mathrm{FeO}_{(\mathrm{T})}$ & & 10.58 \\
\hline $\mathrm{TiO}_{2}$ & & 0.17 \\
\hline Total & & 100.00 \\
\hline $\begin{array}{l}\text { Mineral } \\
\text { omposition }\end{array}$ & $\begin{array}{l}\text { Altered Compositions } \\
\quad \text { in } \mathrm{FeO}-\mathrm{TiO}_{2}\end{array}$ & $\begin{array}{l}\mathrm{Mg}_{7.25} \mathrm{Fe}_{1.48} \mathrm{Al}_{2.73} \mathrm{Si}_{6.24} \mathrm{Al}_{1.76} \mathrm{O}_{20}(\mathrm{OH})_{16} \\
\text { (on the basis of } 28 \text { oxygen equivalents, ignoring } \mathrm{H}_{2} \mathrm{O} \text { ) }\end{array}$ \\
\hline hase and ID & $\begin{array}{c}\text { Oxide } \\
\text { (titanomagnetite } \\
\text { present) }\end{array}$ & Chlorite \\
\hline
\end{tabular}




\section{Portion 4}

Figure E.6.20. SEM pictures for EDS analysis of epoxy-mounted polished grains collected from Portion 4. Analysis points are marked in blue
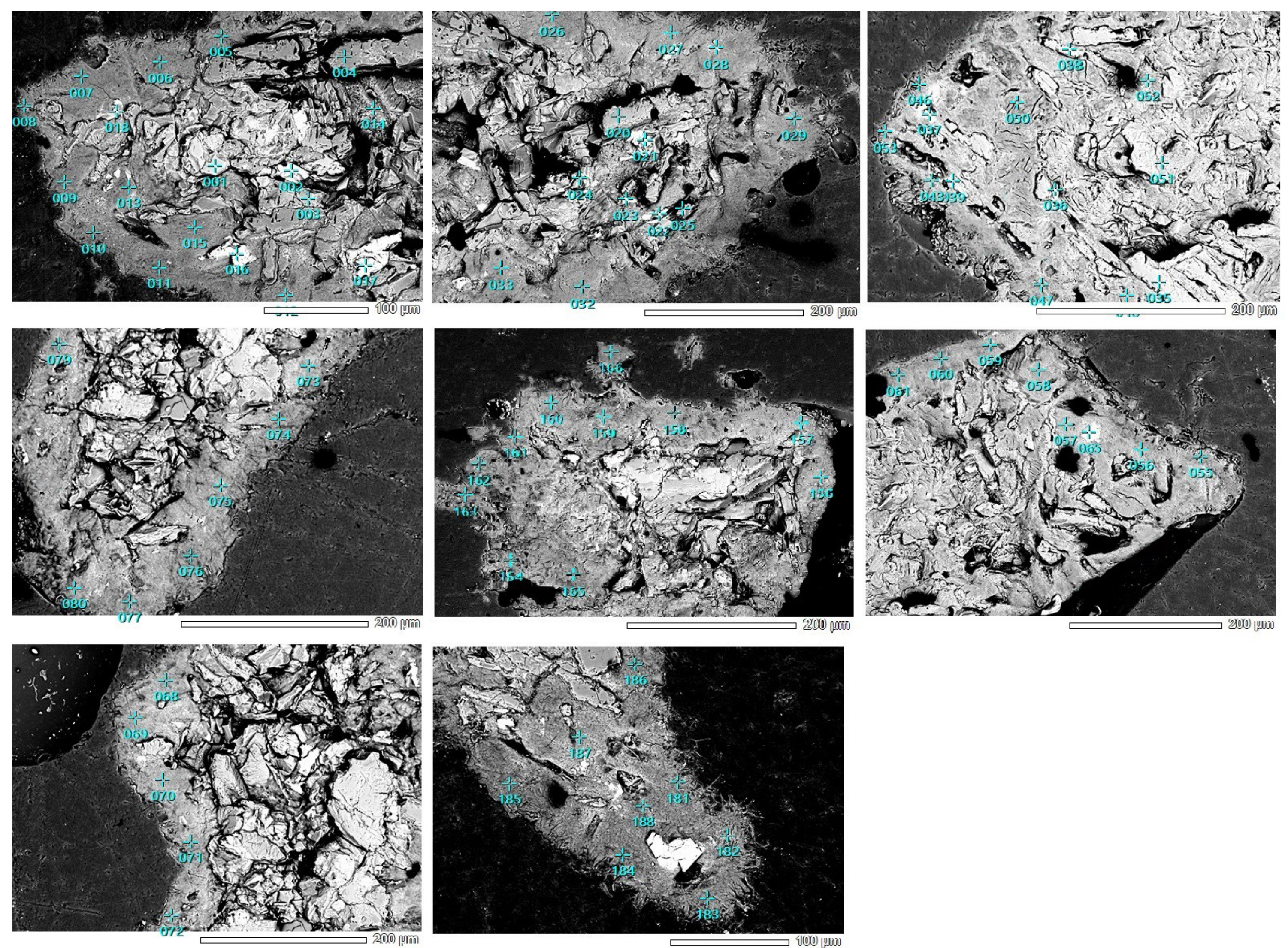
Table E.6.13. SEM-EDS analysis results of grains in Figure E.6.20

\begin{tabular}{|c|c|c|c|c|c|c|c|}
\hline & $\begin{array}{l}\text { Analysis } \\
\text { Point }\end{array}$ & $\mathrm{Na}_{2} \mathrm{O}$ & $\mathrm{Al}_{2} \mathrm{O}_{3}$ & $\mathrm{SiO}_{2}$ & CaO & & Total \\
\hline \multirow[t]{5}{*}{ Plg } & 4 & 2.96 & 30.27 & 51.89 & 14.89 & & 100.01 \\
\hline & 20 & 3.36 & 27.44 & 56.56 & 12.63 & & 99.99 \\
\hline & 25 & 4.84 & 29.18 & 55.18 & 10.79 & & 99.99 \\
\hline & 35 & $\begin{array}{l}2.59 \\
4.09\end{array}$ & $\begin{array}{c}30.54 \\
3154\end{array}$ & $\begin{array}{r}52.64 \\
5272\end{array}$ & $\begin{array}{l}14.24 \\
11.72\end{array}$ & & 100.01 \\
\hline & $\begin{array}{l}38 \\
39 \\
39\end{array}$ & $\begin{array}{l}4.07 \\
2.68\end{array}$ & $\begin{array}{r}31.51 \\
30.41\end{array}$ & $\begin{array}{l}52.71 \\
52.28\end{array}$ & $\begin{array}{l}11.72 \\
14.58\end{array}$ & & $\begin{array}{l}100.01 \\
100.00\end{array}$ \\
\hline \multirow[t]{2}{*}{ average } & & 3.42 & 29.90 & 53.54 & 13.14 & & 100.01 \\
\hline & $\begin{array}{l}\text { Analysis } \\
\text { Point }\end{array}$ & MgO & $\mathrm{Al}_{2} \mathrm{O}_{3}$ & $\mathrm{SiO}_{2}$ & CaO & $\mathrm{FeO}$ & Total \\
\hline \multirow[t]{2}{*}{$\mathrm{Cpx}$} & 3 & 12.44 & 8.96 & 47.41 & 18.41 & 12.79 & 100.01 \\
\hline & 24 & 20.17 & 4.75 & 52.97 & 13.68 & 8.42 & 99.99 \\
\hline \multirow[t]{2}{*}{ average } & & 16.31 & 6.86 & 50.19 & 16.05 & 10.61 & 99.99 \\
\hline & $\begin{array}{c}\text { Analysis } \\
\text { Point }\end{array}$ & $\mathrm{MgO}$ & $\mathrm{SiO}_{2}$ & FeO & & & Total \\
\hline \multirow[t]{2}{*}{$\mathrm{Ol}$} & 1 & 24.27 & 35.39 & 40.35 & & & 100.01 \\
\hline & $\begin{array}{c}\text { Analysis } \\
\text { Point }\end{array}$ & $\mathrm{TiO}_{2}$ & FeO & & & & Total \\
\hline \multirow[t]{10}{*}{$\mathrm{Ox}$} & 2 & 29.47 & 70.53 & & & & 100.00 \\
\hline & 16 & 38.60 & 61.40 & & & & 100.00 \\
\hline & 17 & 30.93 & 69.07 & & & & 100.00 \\
\hline & 18 & $\begin{array}{l}28.87 \\
27\end{array}$ & 71.13 & & & & 100.00 \\
\hline & 21 & $\begin{array}{l}27.96 \\
199\end{array}$ & $\begin{array}{l}72.04 \\
88029\end{array}$ & & & & 100.00 \\
\hline & $\begin{array}{l}22 \\
22\end{array}$ & $\begin{array}{l}19.71 \\
1\end{array}$ & 80.29 & & & & 100.00 \\
\hline & $\begin{array}{l}23 \\
28\end{array}$ & $\begin{array}{l}13.88 \\
27.34\end{array}$ & $\begin{array}{l}86.12 \\
72.66\end{array}$ & & & & $\begin{array}{l}100.00 \\
1000.00\end{array}$ \\
\hline & $\begin{array}{l}38 \\
36\end{array}$ & 31.55 & $\begin{array}{r}62.00 \\
68.45\end{array}$ & & & & $\begin{array}{l}100.00 \\
\end{array}$ \\
\hline & 37 & 48.81 & 51.19 & & & & \\
\hline & 65 & 40.31 & 59.69 & & & & 100.00 \\
\hline
\end{tabular}

\begin{tabular}{|c|c|c|c|c|c|c|c|c|c|}
\hline Smc & $\begin{array}{c}\text { Analysis } \\
\text { Point }\end{array}$ & $\mathrm{Na}_{2} \mathrm{O}$ & MgO & $\mathrm{Al}_{2} \mathbf{O}_{3}$ & $\mathrm{SiO}_{2}$ & $\mathrm{CaO}$ & $\mathrm{TiO}_{2}$ & FeO & Total \\
\hline & 5 & 2.60 & 23.29 & 14.54 & 49.35 & 0.54 & 0.00 & 9.69 & 100.00 \\
\hline & 6 & 1.49 & 21.89 & 14.20 & 48.70 & 0.39 & 0.91 & 12.43 & 100.00 \\
\hline & 7 & 2.00 & 20.86 & 14.11 & 51.28 & 0.50 & 0.00 & 11.24 & 100.00 \\
\hline & 8 & 1.56 & 25.32 & 15.15 & 51.48 & 0.00 & 0.00 & 6.51 & 100.00 \\
\hline & 9 & 1.82 & 25.78 & 16.95 & 47.32 & 0.00 & 0.00 & 8.14 & 100.00 \\
\hline & 10 & 1.75 & 27.16 & 14.55 & 50.75 & 0.00 & 0.00 & 5.78 & 100.00 \\
\hline & 11 & $\begin{array}{l}1.44 \\
1\end{array}$ & 24.21 & 11.65 & 53.25 & 0.00 & 0.86 & $\begin{array}{l}8.59 \\
7.27\end{array}$ & 100.00 \\
\hline & 12 & $\begin{array}{l}1.00 \\
1.30\end{array}$ & $\begin{array}{r}28.03 \\
2403\end{array}$ & $\begin{array}{r}17.13 \\
707\end{array}$ & $\begin{array}{l}46.56 \\
547\end{array}$ & $\begin{array}{l}0.00 \\
0.90\end{array}$ & $\begin{array}{l}0.00 \\
61\end{array}$ & $\begin{array}{l}7.27 \\
3.78\end{array}$ & 100.00 \\
\hline & $\begin{array}{l}13 \\
14\end{array}$ & $\begin{array}{l}1.34 \\
4.14\end{array}$ & $\begin{array}{l}24.99 \\
15.49\end{array}$ & $\begin{array}{c}7.97 \\
17.81\end{array}$ & $\begin{array}{r}54.78 \\
55.48\end{array}$ & $\begin{array}{l}0.98 \\
3.19\end{array}$ & $\begin{array}{l}6.17 \\
0.00\end{array}$ & $\begin{array}{l}3.78 \\
3.62\end{array}$ & 100.00 \\
\hline & $\begin{array}{l}14 \\
15\end{array}$ & $\begin{array}{l}4.14 \\
1.76\end{array}$ & $\begin{array}{r}53.49 \\
24.18\end{array}$ & $\begin{array}{l}17.81 \\
11.46\end{array}$ & $\begin{array}{r}55.46 \\
54.55\end{array}$ & $\begin{array}{l}3.19 \\
1.58\end{array}$ & $\begin{array}{l}0.00 \\
0.00\end{array}$ & $\begin{array}{l}3.62 \\
6.47\end{array}$ & \\
\hline & 26 & 2.59 & 22.07 & 11.49 & 51.68 & 0.48 & 0.00 & 11.68 & $\begin{array}{l}100.000 \\
10000\end{array}$ \\
\hline & 27 & 1.77 & 21.31 & 13.75 & 50.72 & 0.00 & 0.00 & 12.46 & \\
\hline & 29 & 1.41 & 22.88 & 13.61 & 55.04 & 0.00 & 0.00 & 7.06 & $\begin{array}{l}100.00 \\
100.00\end{array}$ \\
\hline & 32 & 0.99 & 23.88 & 14.56 & 49.98 & 0.00 & 0.00 & 10.60 & $\begin{array}{l}100.000 \\
100.0\end{array}$ \\
\hline & 33 & 0.99 & 20.42 & 11.53 & 48.81 & 2.74 & 3.37 & 12.15 & $\begin{array}{l}100.00 \\
100.0\end{array}$ \\
\hline & 43 & 0.46 & 29.86 & 30.35 & 37.90 & 0.00 & 0.00 & 1.42 & 100.00 \\
\hline & 46 & 0.76 & 32.17 & 19.59 & 43.51 & 0.00 & 0.00 & 3.97 & 1000 \\
\hline & 47 & 1.38 & 31.78 & 20.02 & 41.76 & 0.00 & 0.00 & 5.06 & 100.00 \\
\hline & 48 & 0.47 & 26.06 & 13.53 & 41.24 & 0.38 & 8.47 & 9.85 & 100.00 \\
\hline & 50 & 0.54 & 27.02 & 12.17 & 55.77 & 0.63 & 0.00 & 3.87 & 100.00 \\
\hline & 51 & 0.53 & 31.79 & 15.42 & 47.79 & 0.48 & 0.00 & 4.00 & 100.00 \\
\hline & 52 & 0.78 & 28.94 & 16.20 & 51.00 & 0.45 & 0.00 & 2.63 & 100.00 \\
\hline & 53 & 0.47 & 30.60 & 20.34 & 43.51 & 0.00 & 0.00 & 5.07 & 100.00 \\
\hline & 55 & 4.34 & 25.11 & 18.70 & 46.36 & 0.00 & 0.00 & 5.49 & 100.00 \\
\hline & 56 & 1.18 & 28.96 & 18.69 & 45.51 & 0.41 & 0.00 & 5.25 & 100.00 \\
\hline & 57 & 0.58 & 26.47 & 14.89 & 49.26 & 0.54 & 1.46 & 6.80 & 100.00 \\
\hline & 58 & 0.94 & 27.47 & 16.08 & 51.11 & 0.00 & 0.00 & 4.40 & 100.00 \\
\hline & 59 & 0.71 & 30.55 & 17.66 & 41.52 & 0.00 & 3.12 & 6.43 & 100.00 \\
\hline & 60 & 1.07 & 29.46 & 17.03 & 44.88 & 0.77 & 0.79 & 6.00 & 100.00 \\
\hline & 61 & 0.46 & 30.63 & 18.52 & 43.98 & 0.00 & 0.00 & 6.41 & 100.00 \\
\hline & 68 & 1.19 & 25.32 & 10.99 & 56.29 & 0.00 & 0.00 & 6.22 & 100.00 \\
\hline & 69 & 2.12 & $\begin{array}{r}21.58 \\
27\end{array}$ & $\begin{array}{l}13.27 \\
10.62\end{array}$ & $\begin{array}{l}47.61 \\
53991\end{array}$ & 0.00 & 2.65 & 12.77 & 100.00 \\
\hline & 70 & $\begin{array}{l}2.25 \\
187\end{array}$ & $\begin{array}{r}22.85 \\
23\end{array}$ & $\begin{array}{l}10.63 \\
110.43\end{array}$ & $\begin{array}{l}53.96 \\
5466\end{array}$ & 0.00 & 1.66 & $\begin{array}{l}8.65 \\
8.57\end{array}$ & 100.00 \\
\hline & $\begin{array}{l}11 \\
72\end{array}$ & $\begin{array}{l}1.87 \\
1.41\end{array}$ & $\begin{array}{l}23.49 \\
24.39\end{array}$ & $\begin{array}{l}11.41 \\
14.83\end{array}$ & $\begin{array}{l}54.66 \\
49.62\end{array}$ & $\begin{array}{l}0.00 \\
0.00\end{array}$ & $\begin{array}{l}0.00 \\
0.00\end{array}$ & $\begin{array}{l}8.57 \\
9.975\end{array}$ & 100.00 \\
\hline & 73 & $\begin{array}{l}1.41 \\
2.20\end{array}$ & $\begin{array}{l}24.39 \\
22.06\end{array}$ & $\begin{array}{l}14.85 \\
10.54\end{array}$ & $\begin{array}{l}49.02 \\
54.89\end{array}$ & 0.00 & 0.00 & $\begin{array}{l}1.13 \\
10.32\end{array}$ & $\begin{array}{l}100.00 \\
100.00\end{array}$ \\
\hline & 74 & 2.47 & 19.11 & 12.88 & 51.22 & 0.00 & 0.87 & 13.46 & 100.00 \\
\hline & 75 & 1.40 & 19.78 & 12.15 & 50.96 & 0.00 & 2.08 & 13.63 & 100.00 \\
\hline & 76 & 0.98 & 15.29 & 11.99 & 52.46 & 0.00 & 0.00 & 19.28 & 100.00 \\
\hline & 77 & 0.49 & 23.28 & 13.70 & 55.88 & 0.00 & 0.00 & 6.65 & 100.00 \\
\hline & 79 & 1.87 & 22.08 & 13.52 & 51.78 & 0.00 & 0.00 & 10.74 & 100.00 \\
\hline & 80 & 0.60 & 24.42 & 14.30 & 52.17 & 0.00 & 0.00 & 8.51 & 100.00 \\
\hline & 156 & 2.60 & 19.21 & 12.08 & 52.52 & 0.84 & 0.00 & 12.74 & 100.00 \\
\hline & $\begin{array}{l}157 \\
158\end{array}$ & 3.23 & $\begin{array}{r}24.36 \\
2272\end{array}$ & $\begin{array}{r}14.54 \\
\end{array}$ & 49.41 & 0.35 & 0.00 & 8.11 & 100.00 \\
\hline & $\begin{array}{l}158 \\
159\end{array}$ & $\begin{array}{l}2.20 \\
2.70\end{array}$ & $\begin{array}{r}22.26 \\
227.7\end{array}$ & $\begin{array}{l}13.04 \\
11204\end{array}$ & $\begin{array}{r}50.91 \\
51.61\end{array}$ & $\begin{array}{l}0.00 \\
1.1\end{array}$ & 0.00 & $\begin{array}{l}11.59 \\
8.57\end{array}$ & 100.00 \\
\hline & $\begin{array}{l}139 \\
160\end{array}$ & $\begin{array}{l}2.75 \\
1.74\end{array}$ & $\begin{array}{l}22.73 \\
22.13\end{array}$ & $\begin{array}{l}12.97 \\
12.63\end{array}$ & $\begin{array}{l}51.68 \\
54.34\end{array}$ & $\begin{array}{l}1.13 \\
0.00\end{array}$ & $\begin{array}{l}0.000 \\
0.00\end{array}$ & $\begin{array}{l}8.73 \\
9.14\end{array}$ & $\begin{array}{l}100.000 \\
100.00\end{array}$ \\
\hline & 161 & 4.51 & 23.86 & 12.62 & 50.67 & 0.00 & 0.00 & 8.34 & 100.00 \\
\hline & 162 & 5.30 & 22.96 & 10.02 & 53.87 & 0.00 & 0.00 & 7.85 & 100.00 \\
\hline & 163 & 3.75 & 21.22 & 12.38 & 52.45 & 0.00 & 0.00 & 10.20 & 100.00 \\
\hline & 164 & 1.82 & 20.63 & 11.56 & 55.11 & 0.00 & 0.00 & 10.87 & 100.00 \\
\hline & 165 & 2.68 & 25.32 & 10.85 & 53.65 & 0.60 & & 6.89 & 100.00 \\
\hline & 16 & 2.00 & 22.53 & 14.66 & 51.92 & 0.00 & 0.00 & 8.89 & 100.00 \\
\hline & 181 & 2.31 & 21.29 & 13.71 & 50.41 & 0.00 & 0.00 & 12.28 & 100.00 \\
\hline & 182 & 1.13 & 18.60 & 13.52 & 50.06 & 0.00 & 0.00 & 16.70 & 100.00 \\
\hline & 183 & 1.50 & 23.15 & 14.82 & 52.35 & 0.00 & 0.00 & 8.18 & 100.00 \\
\hline & $\begin{array}{l}184 \\
184\end{array}$ & 1.33 & 23.75 & $\begin{array}{l}12.15 \\
12.15\end{array}$ & 54.11 & 0.00 & 0.000 & 8.66 & $\begin{array}{l}100.00 \\
\end{array}$ \\
\hline & 185 & $\begin{array}{l}1.62 \\
1.52\end{array}$ & $\begin{array}{r}24.10 \\
25.10\end{array}$ & $\begin{array}{l}15.16 \\
15\end{array}$ & $\begin{array}{l}50.61 \\
47\end{array}$ & 0.000 & 0.00 & 8.52 & $\begin{array}{l}100.00 \\
\end{array}$ \\
\hline & 187 & $\begin{array}{l}1.50 \\
1.07\end{array}$ & $\begin{array}{r}25.60 \\
25.90\end{array}$ & $\begin{array}{l}16.53 \\
15.73\end{array}$ & $\begin{array}{l}47.66 \\
49.05\end{array}$ & $\begin{array}{l}0.00 \\
0.00\end{array}$ & $\begin{array}{l}0.00 \\
0.00\end{array}$ & $\begin{array}{l}8.11 \\
8.24\end{array}$ & $\begin{array}{l}100.00 \\
100.00\end{array}$ \\
\hline & 188 & 1.12 & 21.28 & 13.79 & 56.64 & 0.00 & 0.00 & 7.17 & 100.00 \\
\hline & & 72 & 24.24 & 14.40 & 50.38 & 27 & 52 & .46 & 100.00 \\
\hline & & 1.05 & 3.72 & 3.32 & 4.13 & 0.79 & 2.43 & 3.36 & \\
\hline
\end{tabular}


Table E.6.13. Average mineral compositions from Table E6 12.

\begin{tabular}{|c|c|c|c|c|c|}
\hline Oxides & average $w t \%$ & average $w t \%$ & average $w t \%$ & average $w t \%$ & average $w t \%$ \\
\hline $\mathrm{MgO}$ & & 16.31 & 24.27 & & 24.24 \\
\hline $\mathrm{Na}_{2} \mathrm{O}$ & 3.42 & & & & 1.72 \\
\hline $\mathrm{Al}_{2} \mathrm{O}_{3}$ & 29.90 & 6.86 & & & 14.40 \\
\hline $\mathrm{SiO}_{2}$ & 53.54 & 50.19 & 35.39 & & 50.38 \\
\hline $\mathrm{CaO}$ & 13.14 & 16.05 & & & 0.27 \\
\hline \multicolumn{6}{|l|}{$\mathrm{K}_{2} \mathrm{O}$} \\
\hline $\mathrm{FeO}$ & & 10.61 & 40.35 & 69.32 & 8.46 \\
\hline $\mathrm{TiO}_{2}$ & & & & 30.68 & 0.52 \\
\hline Total & 100.00 & 100.02 & 100.01 & 100.00 & 99.99 \\
\hline $\begin{array}{l}\text { Mineral } \\
\text { Composition }\end{array}$ & $\begin{array}{c}\mathrm{Ca}_{0.65} \mathrm{Na}_{0.30} \mathrm{Al}_{1.6} \mathrm{Si}_{2.4} \mathrm{O}_{8} \\
\left(\mathrm{An}_{68}-\mathrm{Ab}_{32}\right)\end{array}$ & $\mathrm{Ca}_{0.63} \mathrm{Mg}_{0.89} \mathrm{Fe}_{0.33} \mathrm{Al}_{0.14} \mathrm{Si}_{1.84} \mathrm{Al}_{0.16} \mathrm{O}_{6}$ & $\begin{array}{l}\mathrm{Mg}_{1.03} \mathrm{Fe}_{0.96} \mathrm{SiO}_{4} \\
\quad\left(\mathrm{Fo}_{52}-\mathrm{Fa}_{48}\right)\end{array}$ & $\mathrm{Fe}^{2+}\left(\mathrm{Fe}^{3+}, \mathrm{Ti}_{2} \mathrm{O}_{4}\right.$ & $\begin{array}{l}\mathrm{Na}_{0.42} \mathrm{Mg}_{4.61} \mathrm{Fe}_{0.89} \mathrm{Al}_{0.62} \mathrm{Si}_{6.40} \mathrm{Al}_{1.60} \mathrm{O}_{20}(\mathrm{OH})_{4} \\
\quad\left(22 \text { oxygen equivalents, ignoring } \mathrm{H}_{2} \mathrm{O}\right)\end{array}$ \\
\hline Phase and ID & Plagioclase & $\begin{array}{c}\text { Clinopyroxene } \\
\text { (augite) }\end{array}$ & $\begin{array}{l}\text { Mg-olivine } \\
\text { (forsterite) }\end{array}$ & $\begin{array}{c}\text { Oxide } \\
\text { (titanomagnetite) }\end{array}$ & Smectite \\
\hline
\end{tabular}


Figure E.6.21. SEM pictures for EDS analysis of epoxy-mounted polished grains collected from Portion 7. Analysis points are marked in blue
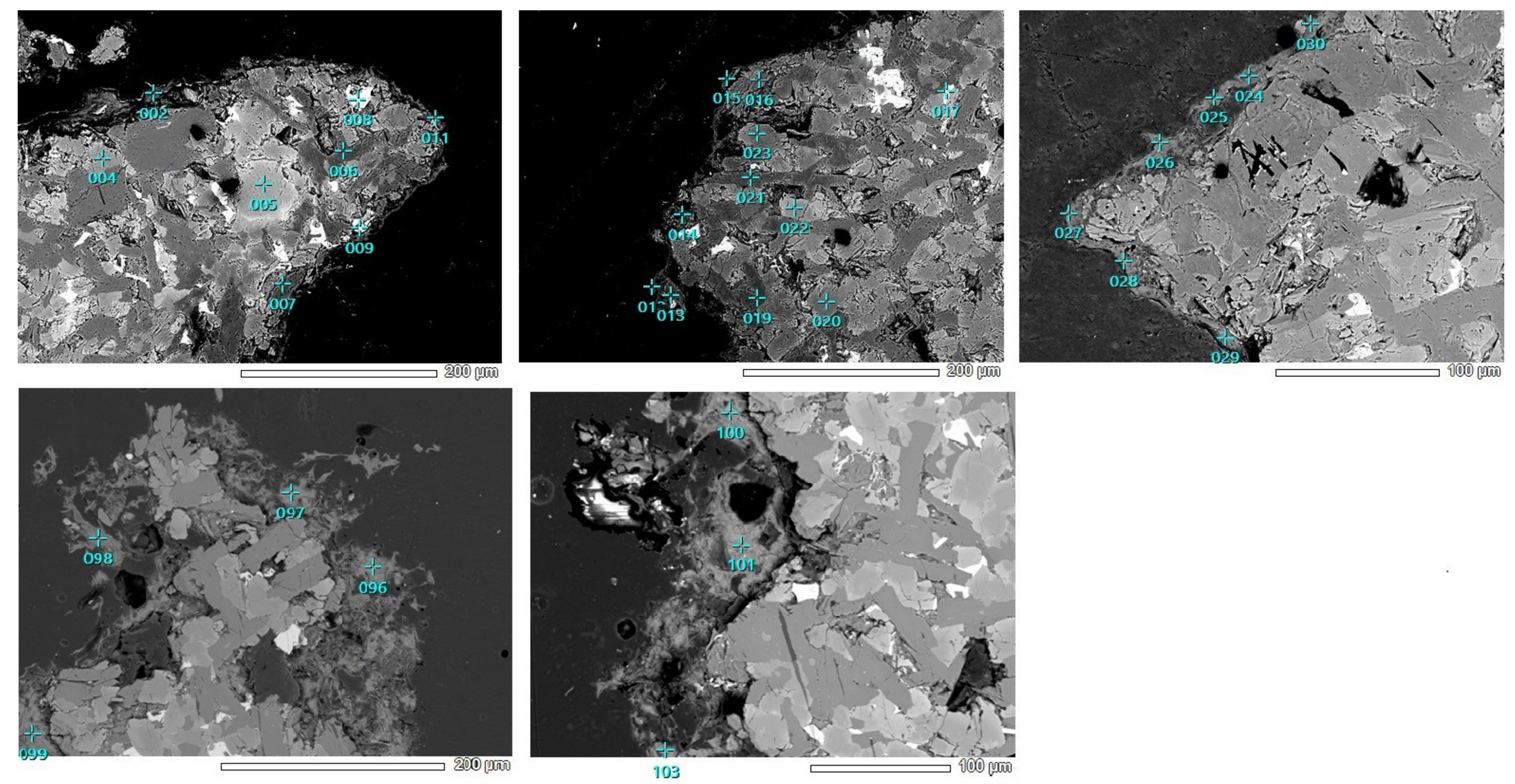
Table E.6.14. SEM-EDS analysis results of grains in Figure E.6.21

\begin{tabular}{|c|c|c|c|c|c|c|c|c|c|}
\hline \multirow[t]{7}{*}{ Plg } & $\begin{array}{l}\text { Analysis } \\
\text { Point }\end{array}$ & $\mathrm{Na}_{2} \mathrm{O}$ & $\mathbf{A l}_{2} \mathbf{O}_{3}$ & $\mathrm{SiO}_{2}$ & $\mathrm{CaO}$ & & & & Total \\
\hline & 6 & 2.81 & 29.93 & 53.22 & 14.03 & & & & 100.00 \\
\hline & 7 & 4.11 & 25.53 & 59.36 & 11.00 & & & & 100.00 \\
\hline & 13 & 2.92 & 29.95 & 52.79 & 14.34 & & & & 100.00 \\
\hline & 16 & 4.47 & 28.92 & 53.91 & 12.70 & & & & 100.00 \\
\hline & 19 & 2.60 & 30.01 & 52.51 & 14.88 & & & & 100.00 \\
\hline & 21 & 3.26 & 29.95 & 52.26 & 14.53 & & & & 100.00 \\
\hline average & & 3.36 & 29.05 & 54.01 & 13.58 & & & & 100.00 \\
\hline \multirow[t]{5}{*}{$\mathrm{Cpx}$} & $\begin{array}{c}\text { Analysis } \\
\text { Point }\end{array}$ & MgO & $\mathbf{A l}_{2} \mathbf{O}_{3}$ & $\mathrm{SiO}_{2}$ & $\mathrm{CaO}$ & $\mathrm{FeO}$ & & & Total \\
\hline & 4 & 14.68 & 2.53 & 52.84 & 18.11 & 11.85 & & & 100.00 \\
\hline & 20 & 13.24 & 3.05 & 52.79 & 19.96 & 10.95 & & & 100.00 \\
\hline & 22 & 13.41 & 3.00 & 51.64 & 17.92 & 14.02 & & & 100.00 \\
\hline & 23 & 15.42 & 2.79 & 53.54 & 16.56 & 11.70 & & & 100.00 \\
\hline average & & 14.19 & 2.84 & 52.70 & 18.14 & 12.13 & & & 100.00 \\
\hline \multirow[t]{2}{*}{$\mathrm{Ol}$} & $\begin{array}{c}\text { Analysis } \\
\text { Point }\end{array}$ & MgO & $\mathrm{SiO}_{2}$ & $\mathrm{FeO}$ & & & & & Total \\
\hline & 5 & 35.81 & 38.09 & 26.10 & & & & & 100.00 \\
\hline \multirow[t]{3}{*}{$\mathrm{Ox}$} & $\begin{array}{c}\text { Analysis } \\
\text { Point }\end{array}$ & $\mathrm{TiO}_{2}$ & $\mathrm{FeO}$ & & & & & & Total \\
\hline & 8 & 26.06 & 73.94 & & & & & & 100.00 \\
\hline & 9 & 26.04 & 73.96 & & & & & & 100.00 \\
\hline \multirow[t]{2}{*}{ average } & & 26.05 & 73.95 & & & & & & 100.00 \\
\hline & 17 & 50.29 & 49.71 & & & & & & 100.00 \\
\hline \multirow[t]{20}{*}{ Smc } & $\begin{array}{c}\text { Analysis } \\
\text { Point }\end{array}$ & $\mathrm{Na}_{2} \mathbf{O}$ & MgO & $\mathrm{Al}_{2} \mathbf{O}_{3}$ & $\mathrm{SiO}_{2}$ & $\mathbf{K}_{2} \mathbf{O}$ & $\mathrm{CaO}$ & $\mathrm{FeO}$ & Total \\
\hline & 2 & 1.59 & 13.66 & 11.46 & 50.13 & 0.00 & 0.46 & 22.70 & 100.00 \\
\hline & 11 & 1.86 & 12.06 & 10.77 & 48.43 & 0.00 & 0.00 & 26.88 & 100.00 \\
\hline & 12 & 2.06 & 12.82 & 11.04 & 47.82 & 0.31 & 0.00 & 25.95 & 100.00 \\
\hline & 14 & 1.80 & 5.10 & 6.12 & 70.58 & 0.00 & 0.00 & 16.39 & 99.99 \\
\hline & 15 & 1.94 & 9.08 & 10.00 & 47.12 & 0.00 & 0.75 & 31.11 & 100.00 \\
\hline & 24 & 2.28 & 12.11 & 10.15 & 48.67 & 0.83 & 0.00 & 25.05 & 99.09 \\
\hline & 25 & 2.06 & 10.71 & 10.69 & 47.50 & 0.69 & 0.00 & 27.43 & 99.08 \\
\hline & 26 & 2.22 & 11.45 & 10.72 & 48.08 & 0.51 & 0.00 & 27.02 & 100.00 \\
\hline & 27 & 2.11 & 10.07 & 10.10 & 47.83 & 1.19 & 0.00 & 27.81 & 99.11 \\
\hline & 28 & 1.80 & 11.87 & 10.69 & 48.74 & 0.99 & 0.00 & 25.92 & 100.01 \\
\hline & 29 & 2.93 & 14.09 & 11.31 & 50.15 & 0.00 & 0.49 & 21.04 & 100.01 \\
\hline & 30 & 1.76 & 13.12 & 11.09 & 49.41 & 0.62 & 0.00 & 23.99 & 99.99 \\
\hline & 96 & 1.19 & 13.82 & 10.48 & 49.58 & 0.78 & 0.54 & 23.63 & 100.02 \\
\hline & 97 & 0.70 & 13.33 & 10.65 & 49.85 & 0.45 & 1.03 & 23.99 & 100.00 \\
\hline & 98 & 2.72 & 13.50 & 9.95 & 48.68 & 0.33 & 0.68 & 24.14 & 100.00 \\
\hline & 99 & 2.17 & 15.09 & 10.95 & 49.45 & 0.32 & 0.63 & 21.39 & 100.00 \\
\hline & 100 & 1.95 & 13.99 & 10.59 & 49.62 & 0.56 & 0.38 & 22.92 & 100.01 \\
\hline & 101 & 1.07 & 14.44 & 11.17 & 49.91 & 0.25 & 0.86 & 22.30 & 100.00 \\
\hline & 103 & 0.85 & 14.40 & 10.74 & 49.64 & 0.44 & 0.86 & 23.07 & 100.00 \\
\hline average & & 1.85 & 12.35 & 10.46 & 50.06 & 0.44 & 0.35 & 24.35 & 99.86 \\
\hline & & 0.58 & 2.37 & 1.13 & 5.05 & 0.28 & 0.21 & 3.17 & \\
\hline
\end{tabular}


Table E.6.15. Average mineral compositions from Table E 6.14

average $w t \%$

average $\mathbf{w t} \%$

verage $w t \%$

3.36

29.05

54.01

3.58

$\mathrm{FeO}$

$\mathrm{TiO}_{2}$

Total

Miceral

Composition

$\mathrm{Ca}_{0.67} \mathrm{Na}_{0.30} \mathrm{Al}_{1.57} \mathrm{Si}_{2.47} \mathrm{O}_{8}$ $\left(\mathrm{An}_{69}-\mathrm{Ab}_{31}\right)$

Phase and ID

$$
14.19
$$

2.84

52.70

18.14

12.13

100.00

$\mathrm{Ca}_{0.72} \mathrm{Mg}_{0.79} \mathrm{Fe}_{0.38} \mathrm{Al}_{0.09} \mathrm{Si}_{1.96} \mathrm{Al}_{0.04} \mathrm{O}_{6}$

Clinopyroxene

(augite)
35.81

38.09

26.10

100.00

$\mathrm{Mg}_{1.41} \mathrm{Fe}_{0.58} \mathrm{SiO}_{4}$ $\left(\mathrm{Fo}_{71}-\mathrm{Fa}_{29}\right)$

Mg-olivine

(forsterite) average $w t \%$

Oxides wt\% and

lements mass \% and atomic \%]

$$
\mathbf{F e O}(w t \%) 49.71
$$

$\mathrm{TiO}_{2}(\mathrm{wt} \%) 50.29$

Fe: (wt\%) 38.64 - (at\%) 21.13

Ti: (wt\%) 30.14 - (at\%) 19.23

O: (wt\%) 31.22 - (at\%) 59.63

73.95

26.05

100.00

$\mathrm{Fe}^{2+}\left(\mathrm{Fe}^{3+}, \mathrm{Ti}_{2} \mathrm{O}_{4}\right.$

Oxide
(titanomagnetite)
$\mathrm{Fe}^{2+} \mathrm{TiO}_{3}$

Oxide average $w t \%$

12.35

1.85

10.46

50.06

0.35

24.35

99.86

$\mathrm{Na}_{0.49} \mathrm{Mg}_{2.53} \mathrm{Fe}_{2.80} \mathrm{Al}_{0.59} \mathrm{Si}_{6.89} \mathrm{Al}_{1.11} \mathrm{O}_{20}(\mathrm{OH})_{4}$ (on the basis of 22 oxygen equivalents, ignoring $\mathrm{H}_{2} \mathrm{O}$ )

Smectite 


\subsection{Results}

6.2.2. BSW2: Basalt-seawater experiment at $350^{\circ} \mathrm{C} / 488$ bar

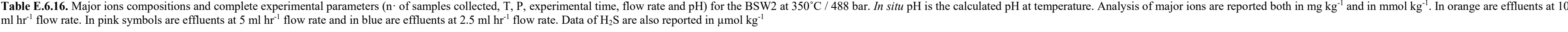

\begin{tabular}{|c|c|c|c|c|c|c|c|c|c|c|c|c|c|c|c|c|c|c|c|c|c|c|c|c|c|c|c|c|c|c|c|c|c|}
\hline \multirow[b]{2}{*}{$\mathrm{n}^{\circ}$ sample } & \multirow[b]{2}{*}{$\begin{array}{c}\mathrm{T} \\
\left.{ }^{\circ} \mathrm{C}\right)\end{array}$} & \multirow[b]{2}{*}{$\underset{\text { (bar) }}{\mathrm{P}}$} & \multirow[b]{2}{*}{$\begin{array}{l}\text { time } \\
\text { (hrs) }\end{array}$} & \multirow[b]{2}{*}{$\begin{array}{l}\text { flow-rate } \\
\left(\mathrm{m} \cdot \mathrm{hr} \mathbf{r}^{-1}\right)\end{array}$} & \multirow[b]{2}{*}{$\underset{\text { (room T) }}{\mathrm{pH}}$} & \multirow[b]{2}{*}{$\underset{\left(350^{\circ} \mathrm{C}\right)}{\mathrm{pH}}$} & \multicolumn{14}{|l|}{$\mathrm{mg} \mathrm{kg}^{-1}$} & \multicolumn{13}{|c|}{$\mathrm{mmol} \mathrm{kg}^{-1}$} \\
\hline & & & & & & & As & B & $\mathrm{Ca}$ & $\mathrm{Fe}$ & $\mathrm{K}$ & $\mathrm{Mg}$ & $\mathrm{Na}$ & $\mathrm{SiO}_{2}$ & $\mathrm{Al}$ & $\mathrm{Li}$ & $\mathrm{H}_{2} \mathrm{~S}$ & $\mathrm{Cl}^{-}$ & $\mathrm{SO}_{4}^{2-}$ & $\mathrm{HCO}_{3}$ & As & B & $\mathrm{Ca}$ & $\mathrm{Fe}$ & K & $\mathrm{Mg}$ & $\mathrm{Na}$ & $\mathrm{SiO}_{2}$ & $\mathrm{Al}$ & $\mathrm{Li}$ & $\mathrm{H}_{2} \mathrm{~S}$ & $\mathrm{Cl}^{-}$ & $\mathrm{SO}_{4}{ }^{2-}$ \\
\hline $\begin{array}{c}\text { blank } \\
\text { water (distilled) }\end{array}$ & 20.1 & 1 & & & 7.10 & n.c. & $<0.015$ & 0.7 & $<0.05$ & $<0.08$ & 2.4 & $<0.01$ & 4.2 & 0.5 & $<0.15$ & 0.006 & n.a. & 5.5 & 0.2 & n.a. & $<0.0002$ & 0.06 & $<0.001$ & $<0.001$ & 0.06 & $<0.0004$ & 0.2 & 0.01 & $<0.006$ & 0.01 & n.a. & 0.2 & 0.004 \\
\hline $\begin{array}{l}\text { Output seawater } \\
\text { from SW2 }\end{array}$ & 20.1 & 1 & 0.0 & & 8.20 & 5.70 & - & - & - & - & - & - & - & - & - & - & - & - & - & n.a. & $<0.0002$ & 0.01 & 1 & 1.7 & 8.5 & 22.8 & 363.3 & 0.2 & 0.006 & 0.02 & 0003 & 429.9 & 2.7 \\
\hline 1 & 2.4 & 487.5 & 18.5 & 1 & 5.1 & 6.61 & 0.004 & 0.7 & $<0.05$ & $<0.08$ & 33.8 & $<0.01$ & 69.5 & 1928.4 & 13.5 & 0.2 & 1.3 & 31.3 & 23.3 & n.a. & $\mid<0.0002$ & 0.07 & $<0.001$ & 0.04 & 0.9 & $<0.0004$ & 3 & 32.1 & 0.5 & 0.03 & $<0.0003$ & 0.9 & 0.2 \\
\hline 2 & 7 & 487.4 & 48.2 & 1 & & 5.78 & $<0.015$ & 1.2 & 3.2 & $<0.08$ & 780 & $<0.01$ & 2253.1 & 2041.8 & $<0.15$ & 1.1 & 2.4 & 4217.2 & 6.1 & n.a. & $<0.0002$ & 0.1 & 0.08 & $<0.001$ & 20 & $<0.0004$ & 98 & 34 & $<0.006$ & 0.2 & 0.07 & 119 & 0.06 \\
\hline 3 & 5 & 487.5 & 74 & 1 & & & $<0.015$ & 2.3 & 400.9 & $<0.08$ & 364.9 & $<0.01$ & 5390.3 & 0.6 & $<0.15$ & . & 00 & 9614.5 & & n.a. & .0002 & 0.2 & 100 & 0.001 & 9.3 & $<0.0004$ & 234.5 & 33.5 & $<0.006$ & & & 271.2 & .06 \\
\hline 4 & & 487.4 & & 1 & & & $<0.015$ & 2.6 & 712.7 & $<0.08$ & 291.7 & 0.7 & & & $<0.15$ & & 0 & 20248 & & n.a. & 0002 & 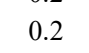 & & 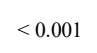 & & 0.03 & & 4.8 & $<0.006$ & & & & .1 \\
\hline 5 & 7 & 487.0 & 119.8 & 1 & & 5.31 & $<0.015$ & 2.9 & 814.5 & $<0.08$ & 313.6 & 1 & 7664.8 & 2.3 & $<0.15$ & 0.3 & 0.5 & 13274 & 6.6 & na.a. & .0002 & 0.3 & 20.3 & $<0.001$ & 8 & 0.04 & 333.4 & 34.7 & $<0.006$ & 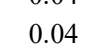 & 0.01 & 4 & 0.07 \\
\hline 6 & 6 & 487.0 & 121.3 & 10 & & 5. & $<0.015$ & 2.9 & 534.7 & 257.2 & 329.7 & 70 & 8297.2 & 2282.9 & $<0.15$ & 0.2 & n.a. & 14240 & 17 & n.a. & $<0.0002$ & 0.3 & 13.3 & 4.6 & 8.4 & 2.9 & 360.9 & 38 & $<0.006$ & 0.03 & n.a. & 401.7 & 0.2 \\
\hline 7 & 8 & 487.1 & 123.3 & 10 & & 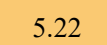 & 15 & 3.1 & 467.2 & 295 & 335.4 & 115.1 & 8511.6 & 2361.3 & $<0.15$ & 0.2 & n.a. & 14592.3 & 22 & n.a. & $<0.0003$ & 0.3 & 11. & 5.3 & 8.6 & 4.7 & 360.9 & 39.3 & $<0.006$ & 0.03 & 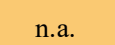 & 411.6 & 0.2 \\
\hline 8 & & & 125.3 & 10 & & & & 3.4 & 531.9 & 325.5 & 365.3 & 111.8 & 9168.5 & & $<0.15$ & 0.2 & n.a. & 14745.7 & E- & & .0004 & 0.3 & 13 & & & 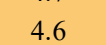 & & 41.6 & $<0.006$ & & & 416 & 0.2 \\
\hline 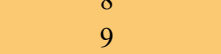 & & & 127.3 & 10 & & & & $\begin{array}{l}.4 \\
6.1\end{array}$ & 512.8 & $\begin{array}{r}274.5 \\
274.2\end{array}$ & 328.4 & $\begin{array}{l}11.8 \\
85.1\end{array}$ & 82 & & $<0.15$ & $\begin{array}{l}0.2 \\
0.2\end{array}$ & $\begin{array}{l}\text { In.a. } \\
<0.01\end{array}$ & $\begin{array}{l}14 / 4322.2 \\
1472\end{array}$ & & $\begin{array}{l}\text { n.c. } \\
\text { n.c. }\end{array}$ & 0005 & 6 & & & & & & $\begin{array}{l}41.0 \\
37.6\end{array}$ & $\begin{array}{l}0.0000 \\
<0.006\end{array}$ & & $\begin{array}{l}\text { n.a. } \\
<0.0003\end{array}$ & & $\begin{array}{l}0.2 \\
0.2\end{array}$ \\
\hline 10 & & 0 & & 1 & & & & 4.8 & & 202 & . & 42 & & & 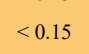 & & n.a. & 17. & & n.a. & 0006 & & & & & 1.1 & & & & & n.a. & 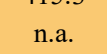 & 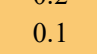 \\
\hline 11 & 5 & 487.0 & $\begin{array}{l}145.5 \\
145.3\end{array}$ & 10 & & s. & $<0.015$ & $\begin{array}{l}4.0 \\
4.2\end{array}$ & 719.4 & 150.1 & 326.7 & 25 & 8372.4 & .7 & $<0.15$ & 0.3 & $\begin{array}{l}\text { II.a. } \\
\text { n.a. }\end{array}$ & 14556.7 & 10.6 & $\begin{array}{l}\text { H.a.e. } \\
\text { n.a. }\end{array}$ & .0007 & 0.4 & 18 & 2.7 & 3.4 & 1 & 355 & 30.6 & $<0.006$ & 0.0 & n.a. & $\begin{array}{l}\text { t11.a. } \\
410 .\end{array}$ & $\begin{array}{l}0.1 \\
0.1\end{array}$ \\
\hline 12 & & 486.9 & 147.3 & 10 & & 5 & $<0.015$ & 4 & 724.9 & 153.2 & 327 & 24. & & & $<0.15$ & 0 & n.a. & n.a. & 12 & n.a. & .0008 & 0.4 & 18 & 2.7 & 4 & 1 & 364.2 & 30.1 & $<0.006$ & & n.a. & a. & 0.1 \\
\hline 13 & & 486.9 & 149.3 & 10 & & & & 3.5 & 737 & 152.2 & 323.9 & 24. & 84 & & $<0.15$ & 0 & n.a. & 14614.3 & 10.4 & $\mathrm{n}$. & .0009 & 0.3 & 18 & & & 1 & 366 & 29.7 & $<0.006$ & & n.a. & 2.3 & 0.1 \\
\hline 14 & & 486.9 & 151.1 & 10 & & & & 3.4 & 73 & 147.6 & & 23 & & & $<0.15$ & 0 & $<0.01$ & 14 & 9.6 & $\mathrm{n}$ & .0010 & 0.3 & & & & 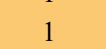 & 369.3 & 29 & $<0.006$ & 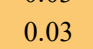 & $<0.0000$ & 411 & 0.1 \\
\hline 15 & 7 & 486.9 & 167.3 & 10 & & & $<0.015$ & 6.2 & 745.6 & 158.1 & 348.2 & 24 & 3 & 1701.2 & $<0.15$ & 0 & n.a. & 14621.3 & 9.1 & 83 & $<0.0011$ & 0.6 & & 2 & 8.9 & 1 & 366 & 28.3 & $<0.006$ & 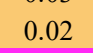 & n.a. & .4 & 0.09 \\
\hline 16 & & tou. & 16 & 5 & & & & 5.3 & & 120.2 & 339.9 & 20. & & & 0.2 & & n.a. & & 9.1 & n.a. & $<0.0002$ & 0 & & 2. & & 11 & & 26.9 & 0.006 & & & & . \\
\hline 17 & & 48 & 17 & $=$ & & & $<0$ & 5 & & 56.6 & 8 & 14 & & & $<0.15$ & 0 & n.a. & 14 & & n.a. & $\mid<0.0002$ & 0.5 & 21 & 1 & & 0 & & 27.6 & $<0.006$ & & n. & & 08 \\
\hline 18 & & 487.0 & 178 & 5 & & & & 4.6 & & 19.3 & & 10.3 & & & 0. & 0.2 & n.a. & 145 & 7. & $\mathbf{n}$ & $\mid<0.0002$ & 0.4 & & 0.3 & 7 & . & & 27.1 & $<0.006$ & & n.a. & & 08 \\
\hline 19 & & 486.9 & 175.3 & 5 & & 5.30 & $<0.015$ & 4.4 & 889.4 & 0.06 & 345.1 & 8.2 & 8457.4 & 1628.1 & $<0.15$ & 0.2 & $<0.01$ & 14543.4 & 8.3 & n. .2 & $\mid<0.0002$ & 0.4 & 22 & 0.001 & 8. & 0. & 364.2 & 27.1 & $<0.006$ & 0.1 & $<0.0003$ & .3 & .09 \\
\hline 20 & 350.7 & 487.4 & 190.8 & 5 & 4. & 5.27 & $<0.015$ & 4.3 & 870.5 & 22.7 & 344.2 & 9.9 & 8526.1 & 1654.6 & $<0.15$ & 0.2 & n.a. & 15849.6 & 4.5 & 24 & $\mid<0.0002$ & 0.4 & 21 & 0.4 & 8.8 & 0.4 & 367.9 & 27.5 & 0.002 & 0.0 & 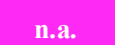 & .1 & .05 \\
\hline 21 & & 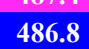 & & & & & & 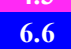 & & $<0.08$ & & 5.9 & & & 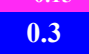 & & $\ldots$ & & & $\omega$ & . & & & & & & & & & & & & \\
\hline 2 & & & & & & & & 5.7 & & $<0$ & & 5 & & & & & & & & n. & 12 & & & & & & & & & & & & 08 \\
\hline 2 & & 487.1 & 222 & 2. & & & & 5.5 & & $<0.08$ & 333.9 & 5.2 & & & $<0.15$ & & 0.08 & & $\%$ & n. & $<0.0002$ & 0.5 & & & & 0.2 & & 25.8 & & & 0.0 & & 08 \\
\hline . & .7 & 487.1 & 240.8 & 2.5 & & 5. & $<0.015$ & 5.3 & 898.6 & $<0.08$ & 331.7 & 6.3 & 8559.2 & 160 & 0. & 0 . & n.a. & 15224.4 & 6.7 & 2 & $<0.0002$ & 0.5 & & $<0.6$ & 5 & 0.3 & 372 & 26.7 & 0.02 & 0.0 & 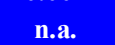 & .5 & 0.07 \\
\hline 25 & $\begin{array}{l}350.0 \\
350.5\end{array}$ & 487.2 & $\begin{array}{r}264.0 \\
264.3\end{array}$ & 2.5 & 4.31 & 5.29 & 0.016 & $\begin{array}{l}.0 .1 \\
5.1\end{array}$ & 886.1 & 10.8 & 337 & 8.1 & 8701.7 & 1538.8 & 0.2 & 0.2 & $<0.01$ & $\begin{array}{l}15189.7 \\
\end{array}$ & $\begin{array}{l}6.1 \\
6.6\end{array}$ & n.a. & $<0.0002$ & 0.5 & 22.1 & 0.2 & 8.6 & 0.3 & 372.3 & $\begin{array}{l}25.1 \\
25.6\end{array}$ & 0.007 & 03 & $<0.0003$ & 428.5 & $\begin{array}{l}0.07 \\
0.07\end{array}$ \\
\hline & & & & & & & & 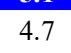 & & & & 56 & & & & & & & & & & & & & & & & & & & & & \\
\hline & 350.8 & & 1.0 & & 4 & 29 & 15 & 4.7 & 9.1 & $<0.08$ & 329.4 & 42 & 98.3 & 0.6 & $<0.15$ & & a. & 62.4 & 2 & a. & 0.0002 & 0.4 & 23.2 & $<0.001$ & 8.4 & 0.2 & 374.2 & 24 & .006 & .03 & a. & 430.5 & 06 \\
\hline
\end{tabular}




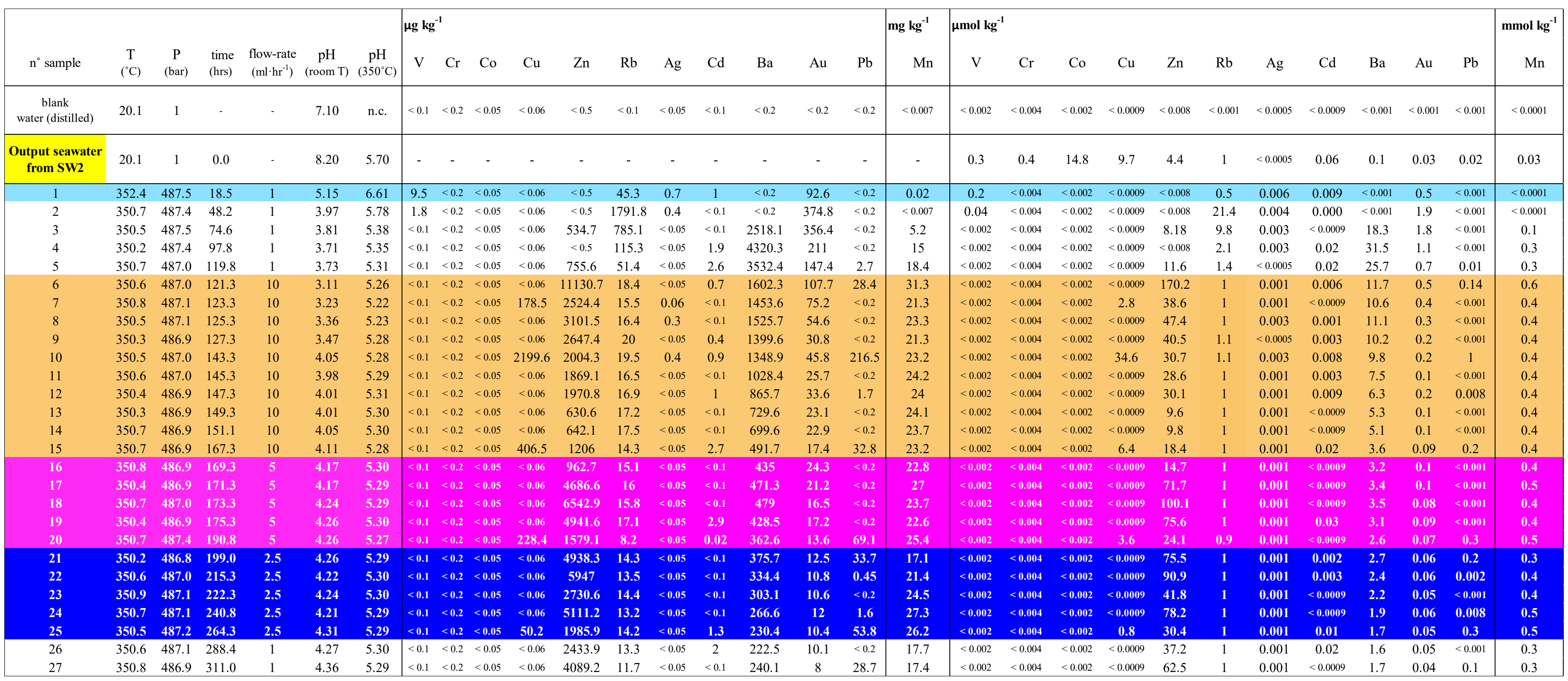




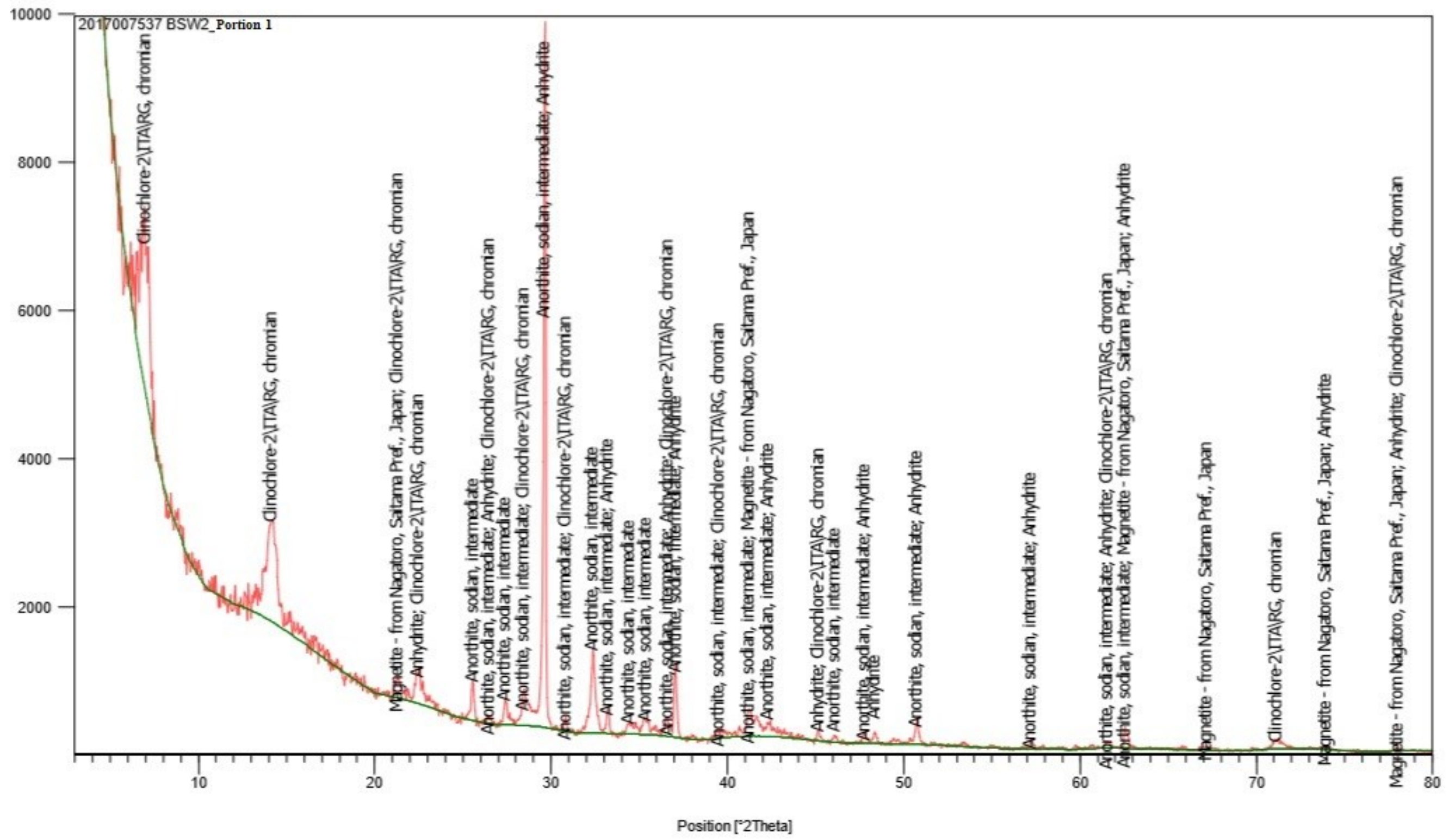


Counts

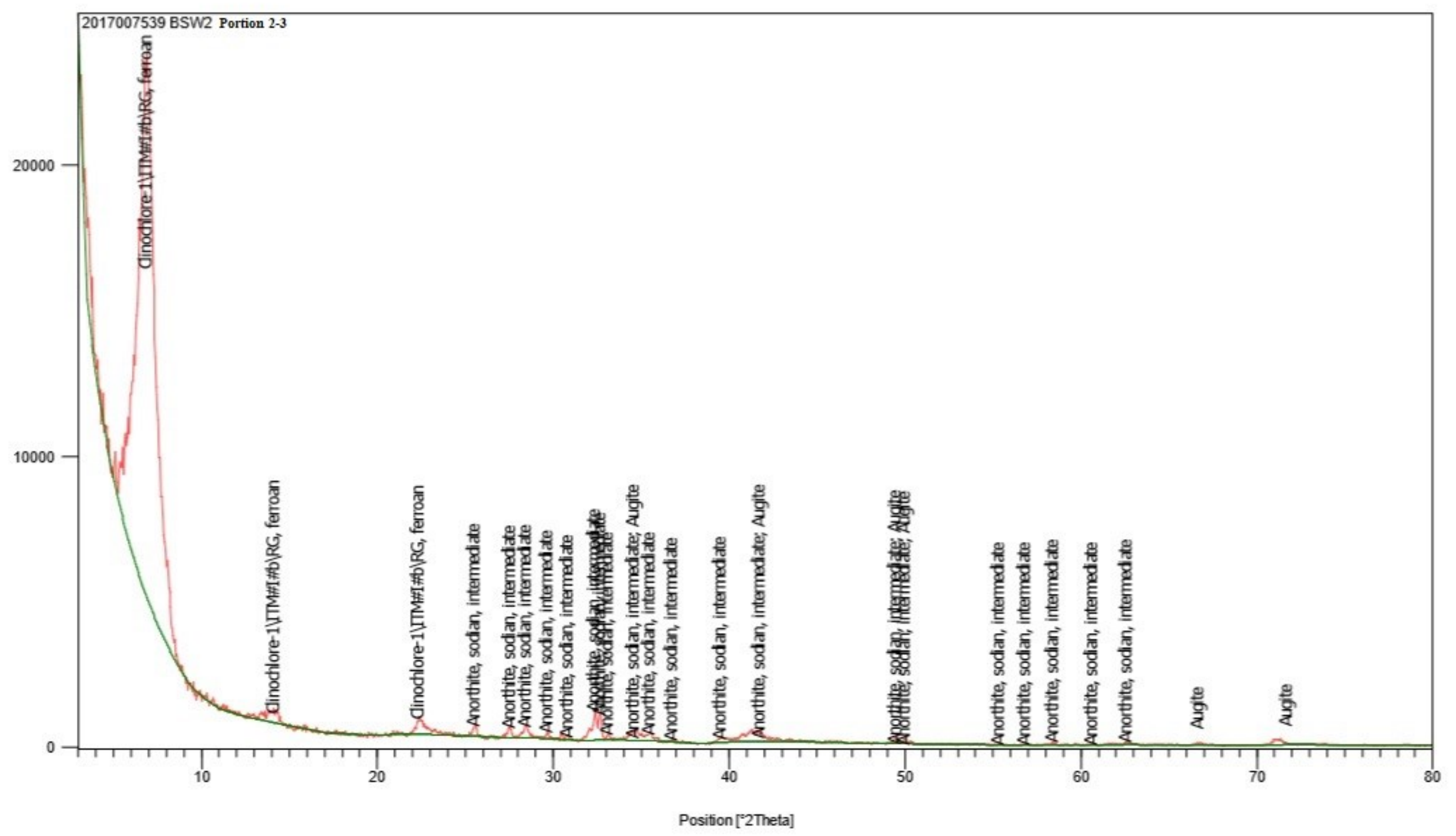




\section{Counts}

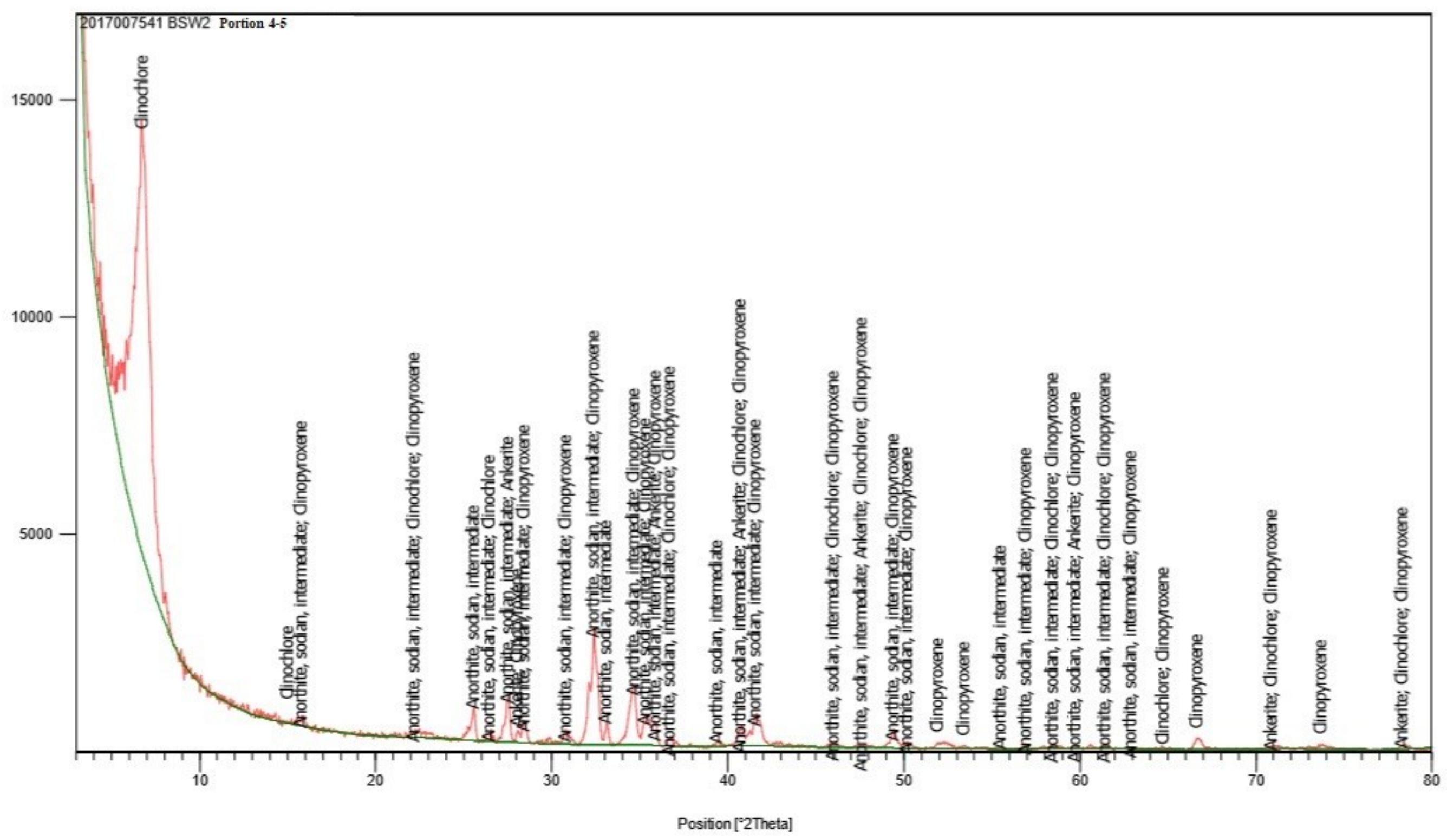


Sample Composition

Table 1. Mineralogical Composition of BSW2 Samples

\begin{tabular}{l|c|c|c}
\hline \multirow{2}{*}{} & \multicolumn{3}{|c}{ Mineralogical Composition } \\
\cline { 2 - 4 } & Portion 1 & Portion 2-3 & Portion 4-5 \\
2017007539 & 2017007541 \\
\hline Chlorite & $\mathrm{x}$ & $\mathrm{x}$ & $\mathrm{x}$ \\
Plagioclase & $\mathrm{x}$ & $\mathrm{x}$ & $\mathrm{x}$ \\
Magnetite & $\mathrm{x}$ & & \\
Anhydrite & $\mathrm{x}$ & & $\mathrm{x}$ \\
Ankerite & & $\mathrm{x}$ & $\mathrm{x}$ \\
Augite/ CPX & & & \\
\hline
\end{tabular}




\section{Anth S C A SPECTRACHEM ANALYTICAL

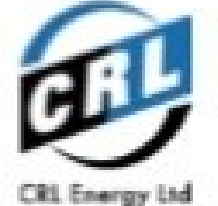 \\ $X$-ray fluorescence \\ SPECTRA ${ }^{\text {plus }}$ \\ Multi-element Analysis}

\begin{tabular}{|c|c|c|c|c|c|c|c|c|}
\hline $\begin{array}{l}\text { CLIENT } \\
\text { PROJECT } \\
\text { DATE } \\
\text { SAMPLE } \\
\text { COMMENTS }\end{array}$ & $\begin{array}{l}: \\
: \\
: \\
: \\
:\end{array}$ & $\begin{array}{l}\text { GNS } \\
\text { SA199 } \\
10 / 11 / \\
\text { SAMP } \\
100 \% \text { - }\end{array}$ & $\begin{array}{l}72, \mathrm{LAB} \# 201 \\
\mathrm{al}=\mathrm{sum} \text { of ur }\end{array}$ & $\begin{array}{l}7007 \\
\text { nmea }\end{array}$ & $\begin{array}{l}538, F \\
\text { sured }\end{array}$ & $\begin{array}{l}\text { ion } 1 \\
\text { nents (i.e H }\end{array}$ & $B, C$ & v, O) \\
\hline Carbon & c & _ & Zinc & Zn & 0.005 & lodine & I & nd \\
\hline Fluorine & $\mathbf{F}$ & nd & Gallium & $\mathrm{Ga}$ & nd & Caesium & Cs & nd \\
\hline Sodium & $\mathrm{Na}$ & 0.310 & Germanium & $\mathrm{Ge}$ & nd & Barium & $\mathrm{Ba}$ & nd \\
\hline Magnesium & $\mathbf{M g}$ & 13.6 & Arsenic & As & nd & Lanthanum & La & nd \\
\hline Aluminium & Al & 7.23 & Selenium & $\mathrm{Se}$ & nd & Cerium & $\mathrm{Ce}$ & - \\
\hline Silicon & Si & 16.3 & Bromine & $\mathrm{Br}$ & nd & Hafnium & Hf & - \\
\hline Phosphorus & $\mathbf{P}$ & 0.056 & Rubidium & $\mathbf{R b}$ & nd & Tantalum & Ta & nd \\
\hline Sulphur & s & 1.99 & Strontium & Sr & 0.016 & Tungsten & w & nd \\
\hline Chlorine & $\mathrm{Cl}$ & 0.046 & Yttrium & $Y$ & nd & Rhenium & $\operatorname{Re}$ & - \\
\hline Potassium & K & 0.022 & Zrrconium & $\mathrm{Zr}$ & 0.007 & Osmium & Os & - \\
\hline Calcium & $\mathrm{Ca}$ & 4.29 & Niobium & $\mathrm{Nb}$ & nd & Iridium & Ir & - \\
\hline Scandium & Sc & nd & Molybdenum & Mo & nd & Platinum & Pt & - \\
\hline Titanium & $\mathrm{Ti}$ & 1.08 & Rhodium & Rh & - & Gold & $\mathrm{Au}$ & - \\
\hline Vanadium & v & 0.035 & Palladium & Pd & - & Mercury & $\mathrm{Hg}$ & nd \\
\hline Chromium & $\mathrm{Cr}$ & 0.012 & Silver & $\mathrm{Ag}$ & - & Thallium & $\mathrm{TI}$ & nd \\
\hline Manganese & Mn & 0.026 & Cadmium & cd & nd & Lead & $\mathrm{Pb}$ & nd \\
\hline Iron & $\mathrm{Fe}$ & 6.35 & Indium & In & - & Bismuth & $\mathrm{Bi}$ & nd \\
\hline Cobalt & Co & 0.011 & Tin & Sn & nd & Thorium & Th & nd \\
\hline Nickel & Ni & 0.287 & Antimony & $\mathbf{S b}$ & nd & Uranium & u & nd \\
\hline Copper & $\mathrm{Cu}$ & 0.006 & Tellurium & $\mathrm{Te}$ & _ & Total & & 51.7 \\
\hline
\end{tabular}




\section{Mnlm SPECTRACHEM ANALYTICAL}

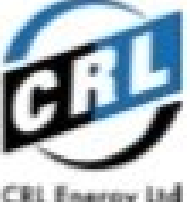

\section{$X$-ray fluorescence} SPECTRA ${ }^{\text {plus }}$

Multi-element Analysis

\begin{tabular}{|c|c|c|c|c|c|c|c|c|}
\hline & : & \multicolumn{7}{|c|}{ GNS SCIENCE - WAIRAKEI } \\
\hline PROJECT & : & \multicolumn{7}{|c|}{ SA19938 } \\
\hline DATE & : & \multicolumn{7}{|c|}{$10 / 11 / 2017$} \\
\hline SAMPLE & : & \multicolumn{7}{|c|}{ SAMPLE \#3, LAB\#2017007540, Portion 2-3 } \\
\hline COMMENTS & : & \multicolumn{7}{|c|}{$100 \%-$ Total $=$ sum of unmeasured elements (i.e $\mathrm{H}, \mathrm{B}, \mathrm{C}, \mathrm{N}, \mathrm{O}$ ) } \\
\hline Carbon & C & - & Znc & $\mathrm{Zn}$ & nd & lodine & I & nd \\
\hline Fluorine & $\mathbf{F}$ & nd & Gallium & $\mathrm{Ga}$ & nd & Caesium & Cs & nd \\
\hline Sodium & $\mathrm{Na}$ & 1.02 & Germanium & $\mathrm{Ge}$ & nd & Barium & $\mathrm{Ba}$ & nd \\
\hline Magnesium & $\mathrm{Mg}$ & 10.3 & Arsenic & As & nd & Lanthanum & La & nd \\
\hline Aluminium & Al & 7.20 & Selenium & Se & nd & Cerium & $\mathrm{Ce}$ & - \\
\hline Silicon & Si & 20.3 & Bromine & $\mathrm{Br}$ & nd & Hafnium & $\mathrm{Hf}$ & - \\
\hline Phosphorus & $\mathbf{P}$ & 0.075 & Rubidium & $\mathrm{Rb}$ & nd & Tantalum & $\mathrm{Ta}$ & nd \\
\hline Sulphur & $\mathbf{s}$ & 0.533 & Strontium & $\mathrm{Sr}$ & 0.010 & Tungsten & $\mathbf{w}$ & nd \\
\hline Chlorine & $\mathrm{Cl}$ & 0.077 & Yttrium & $\mathbf{Y}$ & nd & Rhenium & $\operatorname{Re}$ & - \\
\hline Potassium & K & 0.044 & Zrrconium & $\mathrm{Zr}$ & 0.008 & Osmium & Os & - \\
\hline Calcium & $\mathrm{Ca}$ & 3.65 & Niobium & $\mathrm{Nb}$ & nd & Iridium & Ir & - \\
\hline Scandium & Sc & nd & Molybdenum & Mo & nd & Platinum & Pt & - \\
\hline Titanium & $\mathrm{Ti}$ & 0.953 & Rhodium & Rh & - & Gold & $\mathrm{Au}$ & - \\
\hline Vanadium & v & 0.039 & Palladium & Pd & - & Mercury & $\mathrm{Hg}$ & nd \\
\hline Chromium & $\mathrm{Cr}$ & 0.015 & Silver & $\mathrm{Ag}$ & - & Thallium & TI & nd \\
\hline Manganese & Mn & 0.031 & Cadmium & $\mathrm{Cd}$ & nd & Lead & $\mathrm{Pb}$ & nd \\
\hline Iron & $\mathrm{Fe}$ & 8.00 & Indium & In & - & Bismuth & $\mathrm{Bi}$ & nd \\
\hline Cobalt & Co & 0.013 & Tin & Sn & nd & Thorium & Th & nd \\
\hline Nickel & $\mathrm{Ni}$ & 0.013 & Antimony & Sb & nd & Uranium & $\mathbf{u}$ & nd \\
\hline Copper & $\mathrm{Cu}$ & 0.007 & Tellurium & $\mathrm{Te}$ & - & Total & & 52.3 \\
\hline
\end{tabular}

Values are weight $\%$

nd $=$ not detected

- = not measured 


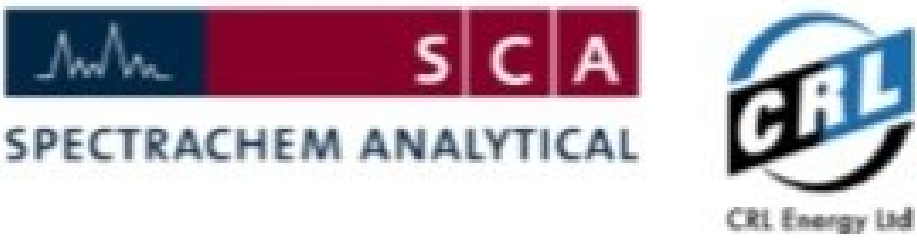

$X$-ray fluorescence

SPECTRA plus

\section{Multi-element Analysis}

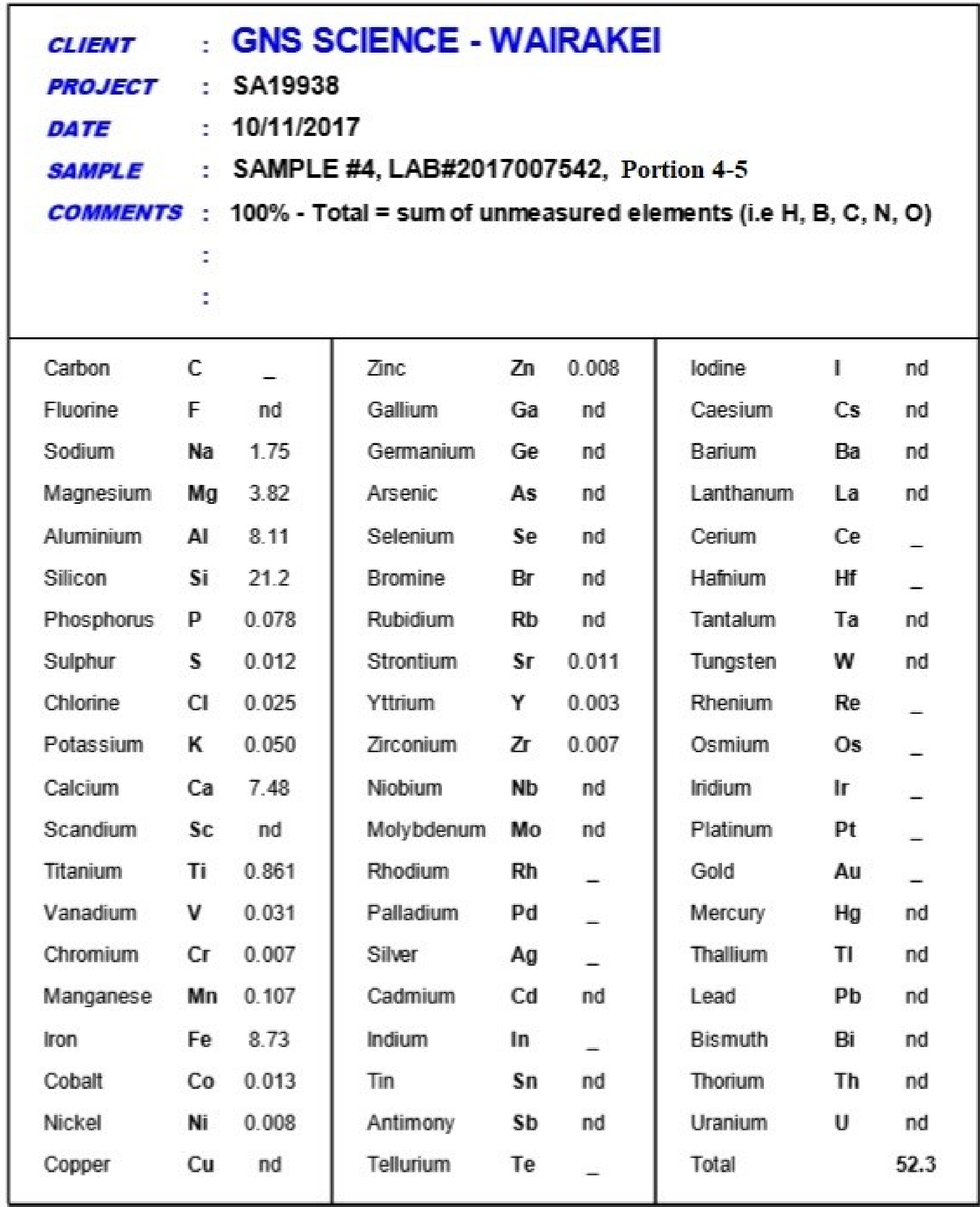


Figure E.6.29. SEM pictures for EDS analysis of epoxy-mounted polished grains collected from Portion 1. Analysis points are marked in blue
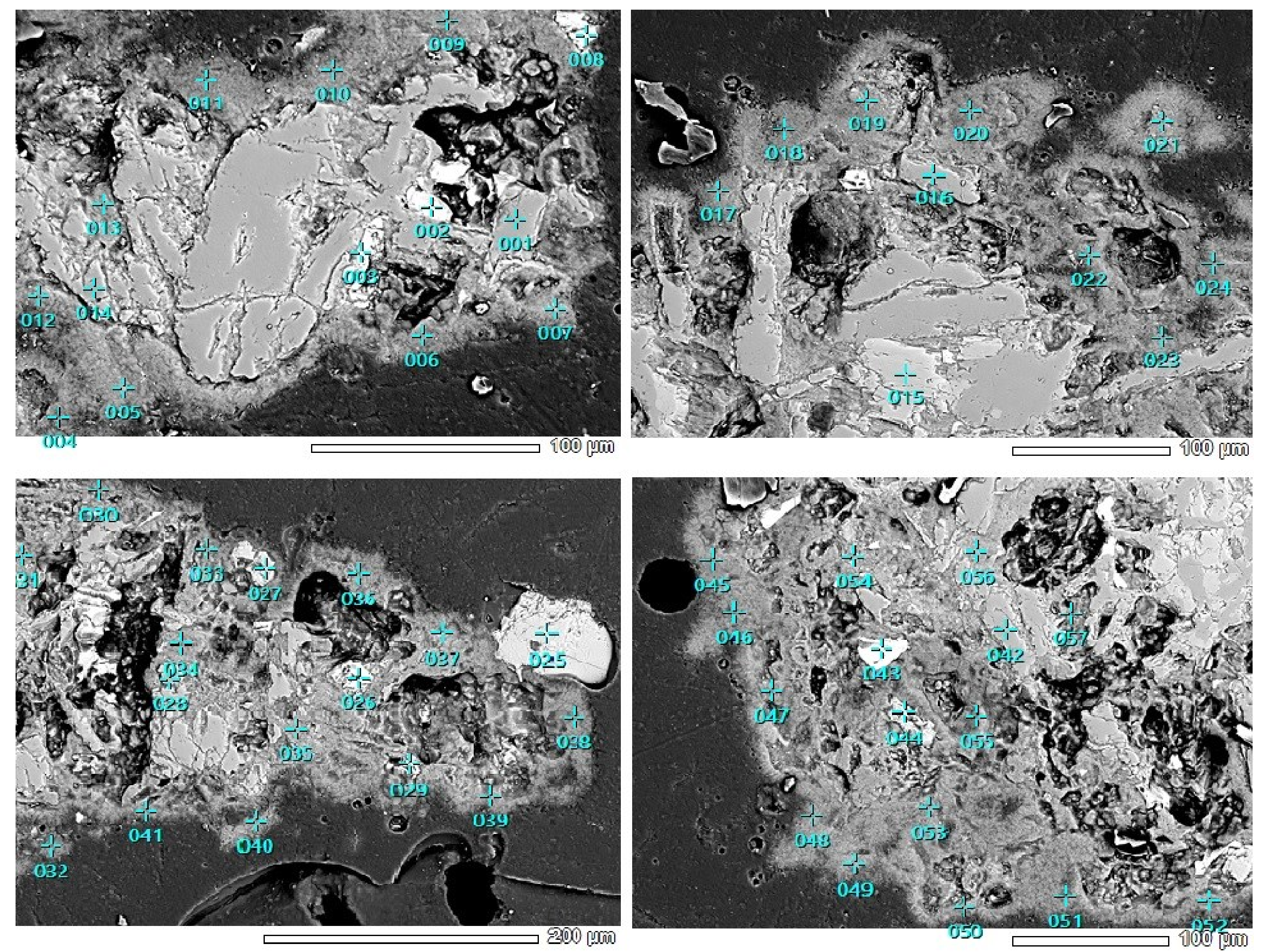
Table E.6.18. SEM-EDS analysis results of grains in Figure E.6.29

\begin{tabular}{|c|c|c|c|c|c|c|c|c|c|c|c|c|c|c|}
\hline \multirow[t]{6}{*}{ Plg } & $\begin{array}{c}\text { Analysis } \\
\text { Point }\end{array}$ & $\mathrm{Na}_{2} \mathrm{O}$ & $\mathbf{A l}_{2} \mathbf{O}_{3}$ & $\mathrm{SiO}_{2}$ & $\mathrm{CaO}$ & & Total & Chl & $\begin{array}{c}\text { Analysis } \\
\text { Point }\end{array}$ & MgO & $\mathbf{A l}_{2} \mathbf{O}_{3}$ & $\mathrm{SiO}_{2}$ & $\mathrm{FeO}$ & Total \\
\hline & 1 & 2.98 & 30.91 & 52.99 & 13.12 & & 100.00 & & 4 & 32.15 & 12.06 & 47.88 & 7.91 & 100.00 \\
\hline & 14 & 3.57 & 30.64 & 54.27 & 11.52 & & 100.00 & & 5 & 34.35 & 16.14 & 43.77 & 5.73 & 100.00 \\
\hline & 16 & 2.62 & 32.08 & 52.20 & 13.09 & & 100.00 & & 6 & 35.12 & 11.95 & 46.77 & 6.17 & 100.00 \\
\hline & 28 & 3.52 & 30.48 & 54.69 & 11.31 & & 100.00 & & 7 & 31.92 & 15.82 & 43.38 & 8.88 & 100.00 \\
\hline & 42 & 3.20 & 30.77 & 53.76 & 12.27 & & 100.00 & & 9 & 32.93 & 17.72 & 43.92 & 5.43 & 100.00 \\
\hline \multirow[t]{3}{*}{ average } & & 3.18 & 30.98 & 53.58 & 12.26 & & 100.00 & & 10 & 32.85 & 13.90 & 45.50 & 7.75 & 100.00 \\
\hline & & & & & & & & & 11 & 34.36 & 11.69 & 47.80 & 6.16 & 100.00 \\
\hline & & & & & & & & & 12 & 34.53 & 14.90 & 45.02 & 5.54 & 100.00 \\
\hline \multirow[t]{4}{*}{$\mathrm{Cpx}$} & Analysis & MgO & $\mathrm{Al}_{2} \mathbf{O}_{3}$ & $\mathrm{SiO}_{2}$ & $\mathrm{CaO}$ & $\mathrm{FeO}$ & Total & & 13 & 32.25 & 16.13 & 43.93 & 7.68 & 100.00 \\
\hline & Pont & 1636 & 282 & 5555 & 1715 & 812 & 10000 & & 17 & 30.98 & 14.89 & 45.01 & 9.12 & 100.00 \\
\hline & & 10.36 & 2.82 & 50.55 & 17.15 & 8.12 & 100.00 & & 18 & 34.34 & 12.34 & 48.56 & 4.75 & 100.00 \\
\hline & & & & & & & & & 19 & 33.78 & 15.53 & 45.15 & 5.54 & 100.00 \\
\hline \multirow{5}{*}{$\mathrm{Ol}$} & Analysis & MoO & $\mathrm{SiO}_{2}$ & $\mathrm{FeO}$ & & & Total & & 20 & 33.00 & 15.43 & 44.60 & 6.97 & 100.00 \\
\hline & Point & & $\mathrm{SiO}_{2}$ & & & & & & 21 & 26.29 & 32.56 & 34.43 & 6.71 & 100.00 \\
\hline & 2 & 21.62 & 38.34 & 40.03 & & & 100.00 & & 22 & 34.29 & 14.28 & 44.70 & 6.73 & 100.00 \\
\hline & & & & & & & & & 23 & 33.61 & 14.30 & 45.71 & 6.38 & 100.00 \\
\hline & & & & & & & & & 24 & 32.64 & 14.62 & 45.10 & 7.64 & 100.00 \\
\hline \multirow[t]{6}{*}{$\mathrm{Ox}$} & $\begin{array}{c}\text { Analysis } \\
\text { Point }\end{array}$ & $\mathrm{TiO}_{2}$ & $\mathrm{FeO}$ & & & & Total & & 30 & 27.67 & 20.27 & 42.37 & 9.70 & 100.00 \\
\hline & 3 & 29.93 & 70.07 & & & & 100.00 & & 31 & 26.02 & 18.20 & 37.98 & 17.79 & 100.00 \\
\hline & 8 & 31.46 & 68.54 & & & & 100.00 & & 32 & 34.87 & 13.44 & 47.10 & 4.59 & 100.00 \\
\hline & 26 & 29.02 & 70.98 & & & & 100.00 & & 33 & 29.97 & 16.83 & 42.67 & 10.54 & 100.00 \\
\hline & 29 & 29.53 & 70.47 & & & & 100.00 & & 34 & 35.31 & 14.04 & 45.20 & 5.44 & 100.00 \\
\hline & 43 & 15.45 & 84.55 & & & & 100.00 & & 35 & 28.30 & 34.30 & 34.32 & 3.07 & 100.00 \\
\hline \multirow[t]{3}{*}{ average } & & 27.08 & 72.92 & & & & 100.00 & & 36 & 27.96 & 19.07 & 41.76 & 11.22 & 100.00 \\
\hline & & & & & & & & & 37 & 32.49 & 19.59 & 41.97 & 5.95 & 100.00 \\
\hline & & & & & & & & & 38 & 27.82 & 17.43 & 41.94 & 12.81 & 100.00 \\
\hline \multirow{5}{*}{ Anh } & Analysis & & & & & & & & 39 & 30.69 & 16.67 & 43.05 & 9.58 & 100.00 \\
\hline & Point & $\mathrm{SO}_{3}$ & $\mathrm{CaO}$ & & & & Total & & 40 & 40.22 & 10.40 & 45.72 & 3.67 & 100.00 \\
\hline & 25 & 57.04 & 42.96 & & & & 100.00 & & 41 & 29.07 & 17.80 & 41.81 & 11.32 & 100.00 \\
\hline & 27 & 56.63 & 43.37 & & & & 100.00 & & 45 & 30.45 & 16.40 & 42.70 & 10.45 & 100.00 \\
\hline & 44 & 55.96 & 44.04 & & & & 100.00 & & 46 & 31.26 & 15.74 & 43.69 & 9.31 & 100.00 \\
\hline \multirow[t]{12}{*}{ average } & & 56.54 & 43.46 & & & & 100.00 & & 47 & 31.86 & 15.50 & 43.71 & 8.92 & 100.00 \\
\hline & & & & & & & & & 48 & 30.32 & 17.68 & 42.14 & 9.87 & 100.00 \\
\hline & & & & & & & & & 49 & 30.47 & 16.43 & 42.50 & 10.60 & 100.00 \\
\hline & & & & & & & & & 50 & 28.80 & 17.88 & 41.57 & 11.76 & 100.00 \\
\hline & & & & & & & & & 51 & 30.80 & 15.55 & 44.02 & 9.62 & 100.00 \\
\hline & & & & & & & & & 52 & 30.59 & 19.26 & 42.89 & 7.27 & 100.00 \\
\hline & & & & & & & & & 53 & 30.17 & 17.38 & 41.48 & 10.97 & 100.00 \\
\hline & & & & & & & & & 54 & 27.61 & 31.43 & 36.32 & 4.64 & 100.00 \\
\hline & & & & & & & & & 55 & 32.72 & 15.34 & 43.49 & 8.45 & 100.00 \\
\hline & & & & & & & & & 56 & 27.23 & 21.85 & 42.83 & 8.08 & 100.00 \\
\hline & & & & & & & & & 57 & 33.91 & 6.10 & 56.48 & 3.51 & 100.00 \\
\hline & & & & & & & & average & & 31.57 & 16.88 & 43.59 & 7.96 & 100.00 \\
\hline
\end{tabular}


Table E.6.19. Average mineral compositions from Table E.6.18

\begin{tabular}{|c|c|c|c|c|c|c|}
\hline & average $w t \%$ & average $w t \%$ & average wt $\%$ & average wt $\%$ & average wt $\%$ & average $w t \%$ \\
\hline \multicolumn{7}{|l|}{ Oxides } \\
\hline $\mathrm{MgO}$ & & 16.36 & 21.62 & & 31.57 & \\
\hline $\mathrm{Na}_{2} \mathrm{O}$ & 3.18 & & & & & \\
\hline $\mathrm{Al}_{2} \mathrm{O}_{3}$ & 30.98 & 2.82 & & & 16.88 & \\
\hline $\mathrm{SiO}_{2}$ & 53.58 & 55.55 & 38.34 & & 43.59 & 43.46 \\
\hline $\mathrm{CaO}$ & 12.26 & 17.15 & & & & \\
\hline $\mathrm{FeO}$ & & 8.12 & 40.03 & 72.92 & 7.96 & \\
\hline $\mathrm{TiO}_{2}$ & & & & 27.08 & & \\
\hline $\mathrm{SO}_{3}$ & & & & & & 56.64 \\
\hline Total & 100.00 & 100.00 & 99.99 & 100.00 & 100.00 & 100.10 \\
\hline $\begin{array}{l}\text { Mineral } \\
\text { Composition }\end{array}$ & $\begin{array}{c}\mathrm{Ca}_{0.60} \mathrm{Na}_{0.28} \mathrm{Al}_{1.67} \mathrm{Si}_{2.45} \mathrm{O}_{8} \\
\left(\mathrm{An}_{68}-\mathrm{Ab}_{32}\right)\end{array}$ & $\mathrm{Ca}_{0.67} \mathrm{Mg}_{0.88} \mathrm{Fe}_{0.25} \mathrm{Al}_{0.12} \mathrm{Si}_{2.01} \mathrm{O}_{6}$ & $\begin{array}{c}\mathrm{Mg}_{0.93} \mathrm{Fe}_{0.97} \mathrm{Si}_{1.1} \mathrm{O}_{4} \\
\left(\mathrm{Fo}_{49}-\mathrm{Fa}_{51}\right)\end{array}$ & $\mathrm{Fe}^{2+}\left(\mathrm{Fe}^{3+}, \mathrm{Ti}_{2}\right)_{2} \mathrm{O}_{4}$ & $\begin{array}{c}\mathrm{Mg}_{7.72} \mathrm{Fe}_{1.09} \mathrm{Al}_{3.17} \mathrm{Si}_{7.15} \mathrm{Al}_{0.85} \mathrm{O}_{20}(\mathrm{OH})_{16} \\
\text { (on the basis of } 28 \text { oxygen equivalents, ignoring } \mathrm{H}_{2} \mathrm{O} \text { ) }\end{array}$ & $\mathrm{Ca}\left(\mathrm{SO}_{4}\right)$ \\
\hline hase and ID & Plagioclase & $\begin{array}{c}\text { Clinopyroxene } \\
\text { (augite) }\end{array}$ & $\begin{array}{c}\text { Fe-olivine } \\
\text { (fayalite) }\end{array}$ & $\begin{array}{c}\text { Oxide } \\
\text { (titanomagnetite) }\end{array}$ & Chlorite & $\begin{array}{c}\text { Sulfate } \\
\text { (anhydrite) }\end{array}$ \\
\hline
\end{tabular}




\section{Portion 2-3}

Figure E.6.30. SEM pictures for EDS analysis of epoxy-mounted polished grains collected from Portion 2-3. Analysis points are marked in blue
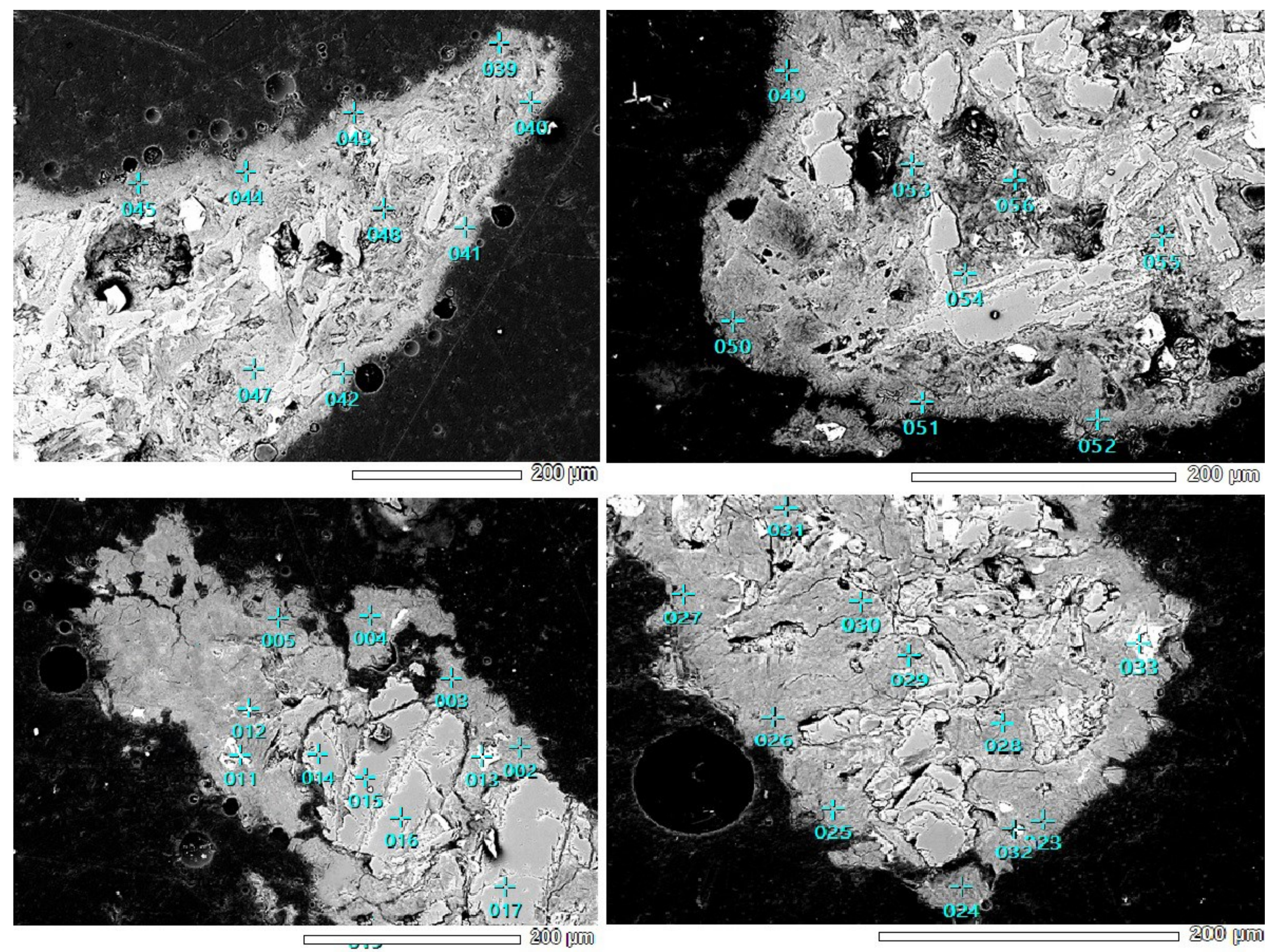


\begin{tabular}{|c|c|c|c|c|c|c|c|}
\hline \multirow[t]{5}{*}{ Plg } & $\begin{array}{l}\text { Analysis } \\
\text { Point }\end{array}$ & $\mathrm{Na}_{2} \mathrm{O}$ & $\mathbf{A l}_{2} \mathbf{O}_{3}$ & $\mathrm{SiO}_{2}$ & \multicolumn{2}{|l|}{$\mathrm{CaO}$} & Total \\
\hline & 14 & 2.72 & 30.59 & 52.23 & \multicolumn{2}{|l|}{14.46} & 100.00 \\
\hline & 15 & 2.73 & 30.14 & 51.67 & \multicolumn{2}{|l|}{15.45} & 99.99 \\
\hline & 16 & 3.20 & 30.49 & 52.71 & \multicolumn{2}{|l|}{13.60} & 100.00 \\
\hline & 17 & 2.36 & 31.14 & 51.93 & \multicolumn{2}{|l|}{14.57} & 100.00 \\
\hline average & & 2.75 & 30.59 & 52.14 & \multicolumn{2}{|l|}{14.52} & 100.00 \\
\hline \multirow[t]{19}{*}{ Chl } & $\begin{array}{c}\text { Analysis } \\
\text { Point }\end{array}$ & MgO & $\mathbf{A l}_{2} \mathbf{O}_{3}$ & $\mathrm{SiO}_{2}$ & $\mathrm{FeO}$ & $\mathrm{TiO}_{2}$ & Total \\
\hline & 39 & 28.22 & 17.31 & 43.58 & 10.89 & 0.00 & 100.00 \\
\hline & 40 & 25.91 & 17.78 & 42.29 & 14.02 & 0.00 & 100.00 \\
\hline & 41 & 27.12 & 18.00 & 43.32 & 11.56 & 0.00 & 100.00 \\
\hline & 42 & 31.51 & 19.25 & 41.72 & 7.51 & 0.00 & 100.00 \\
\hline & 43 & 29.65 & 17.82 & 43.73 & 8.80 & 0.00 & 100.00 \\
\hline & 44 & 29.16 & 17.43 & 43.95 & 9.46 & 0.00 & 100.00 \\
\hline & 45 & 31.01 & 18.31 & 43.89 & 6.78 & 0.00 & 100.00 \\
\hline & 47 & 25.75 & 24.08 & 38.27 & 11.90 & 0.00 & 100.00 \\
\hline & 48 & 31.09 & 19.48 & 41.49 & 7.93 & 0.00 & 100.00 \\
\hline & 49 & 30.06 & 19.47 & 41.78 & 8.69 & 0.00 & 100.00 \\
\hline & 50 & 29.35 & 21.37 & 41.16 & 8.12 & 0.00 & 100.00 \\
\hline & 51 & 29.60 & 18.46 & 42.63 & 9.30 & 0.00 & 100.00 \\
\hline & 52 & 26.53 & 17.12 & 41.76 & 14.58 & 0.00 & 100.00 \\
\hline & 53 & 28.13 & 19.25 & 41.59 & 11.03 & 0.00 & 100.00 \\
\hline & 54 & 26.74 & 17.30 & 38.27 & 14.98 & 2.72 & 100.00 \\
\hline & 55 & 27.98 & 19.95 & 40.71 & 11.36 & 0.00 & 100.00 \\
\hline & 56 & 26.72 & 11.78 & 49.14 & 8.01 & 4.35 & 100.00 \\
\hline & & 28.50 & 18.48 & 42.31 & 10.29 & 0.42 & 100.00 \\
\hline
\end{tabular}

\begin{tabular}{|c|c|c|c|c|c|c|c|c|c|c|}
\hline Smc & $\begin{array}{c}\text { Analysis } \\
\text { Point }\end{array}$ & $\mathrm{Na}_{2} \mathrm{O}$ & MgO & $\mathbf{A l}_{2} \mathbf{O}_{3}$ & $\mathrm{SiO}_{2}$ & $\mathbf{K}_{2} \mathbf{O}$ & $\mathrm{CaO}$ & $\mathrm{TiO}_{2}$ & $\mathrm{FeO}$ & Total \\
\hline & 2 & 0.82 & 22.52 & 12.46 & 52.68 & 0.00 & 0.00 & 0.00 & 11.52 & 100.00 \\
\hline & 3 & 1.00 & 21.64 & 12.82 & 49.87 & 0.51 & 0.00 & 0.00 & 14.16 & 100.00 \\
\hline & 4 & 1.19 & 21.76 & 12.22 & 53.67 & 0.73 & 0.00 & 0.00 & 10.43 & 100.00 \\
\hline & 5 & 0.42 & 21.68 & 11.92 & 53.39 & 0.00 & 0.00 & 0.00 & 12.59 & 100.00 \\
\hline & 23 & 0.78 & 20.21 & 11.49 & 52.64 & 0.00 & 0.00 & 0.00 & 14.87 & 100.00 \\
\hline & 24 & 0.67 & 21.45 & 13.07 & 52.87 & 0.00 & 0.00 & 0.00 & 11.94 & 100.00 \\
\hline & 25 & 0.44 & 22.92 & 11.76 & 52.77 & 0.00 & 0.00 & 0.00 & 12.10 & 100.00 \\
\hline & 26 & 0.64 & 20.86 & 11.84 & 53.62 & 0.00 & 0.00 & 0.00 & 13.04 & 100.00 \\
\hline & 27 & 0.66 & 22.81 & 12.34 & 53.21 & 0.00 & 0.00 & 0.00 & 10.98 & 100.00 \\
\hline & 28 & 0.57 & 22.19 & 10.41 & 56.03 & 0.00 & 0.00 & 0.00 & 10.80 & 100.00 \\
\hline & 29 & 0.67 & 24.11 & 10.59 & 55.27 & 0.00 & 0.40 & 0.00 & 8.95 & 100.00 \\
\hline & 30 & 0.71 & 22.94 & 11.08 & 53.48 & 0.26 & 0.39 & 1.32 & 9.81 & 100.00 \\
\hline & 31 & 0.85 & 24.11 & 10.18 & 55.40 & 0.00 & 0.00 & 0.00 & 9.46 & 100.00 \\
\hline average & & 0.72 & 22.25 & 11.71 & 53.45 & 0.12 & 0.06 & 0.10 & 11.59 & 100.00 \\
\hline$\pm \sigma$ & & 0.21 & 1.15 & 0.92 & 1.55 & 0.24 & 0.01 & & 1.78 & \\
\hline $\mathrm{Ox}$ & $\begin{array}{c}\text { Analysis } \\
\text { Point }\end{array}$ & $\mathrm{TiO}_{2}$ & $\mathrm{FeO}$ & & & & & & & Total \\
\hline & 11 & 27.26 & 72.74 & & & & & & & 100.00 \\
\hline & 12 & 26.32 & 73.68 & & & & & & & 100.00 \\
\hline & 13 & 27.15 & 72.85 & & & & & & & 100.00 \\
\hline & 32 & 30.05 & 69.95 & & & & & & & 100.00 \\
\hline & 33 & 28.51 & 71.49 & & & & & & & 100.00 \\
\hline average & & 27.86 & 72.14 & & & & & & & 100.00 \\
\hline
\end{tabular}


Table E.6.21 Average mineral compositions from Table E.6.20

average wt\%

\section{Oxides}

$\mathrm{MgO}$

$\mathrm{Na}_{2} \mathrm{O}$

$\mathrm{Al}_{2} \mathrm{O}_{3}$

$\mathrm{SiO}_{2}$

$\mathrm{CaO}$

$\mathrm{FeO}$

$\mathrm{TiO}_{2}$

$\mathrm{K}_{2} \mathrm{O}$

Total

100.00

$$
30.59
$$$$
52.14
$$$$
14.52
$$

\section{Mineral \\ Composition}
$\mathrm{Ca}_{0.71} \mathrm{Na}_{0.24} \mathrm{Al}_{1.65} \mathrm{Si}_{2.39} \mathrm{O}_{8}$
$\left(\mathrm{An}_{74}-\mathrm{Ab}_{26}\right)$

Phase and ID

Plagioclase (bytownite)

average $w t \%$$$
72.14
$$

27.86

100.00

\section{average $\mathrm{wt} \%$}

28.50

18.48

42.31

10.29

0.42

100.00

$\mathrm{Mg}_{7.04} \mathrm{Fe}_{1.43} \mathrm{Ti}_{0.05} \mathrm{Al}_{2.65} \mathrm{Si}_{7.04} \mathrm{Al}_{0.96} \mathrm{O}_{20}(\mathrm{OH})_{16}$ (on the basis of 28 oxygen equivalents, ignoring $\mathrm{H}_{2} \mathrm{O}$ )

Oxide (titanomagnetite)
Chlorite

$\mathrm{Na}_{0.18} \mathrm{Mg}_{4.26} \mathrm{Fe}_{1.24} \mathrm{Al}_{0.63} \mathrm{Si}_{6.86} \mathrm{Al}_{1.14} \mathrm{O}_{20}(\mathrm{OH})_{4}$ (on the basis of 22 oxygen equivalents, ignoring $\mathrm{H}_{2} \mathrm{O}$ )

Smectite
22.25

0.72

11.71

53.45

0.06

11.59

0.10

0.12

100.00 


\section{Portion 4-5}

Figure E.6.31. SEM pictures for EDS analysis of epoxy-mounted polished grains collected from Portion 4-5. Analysis points are marked in blue
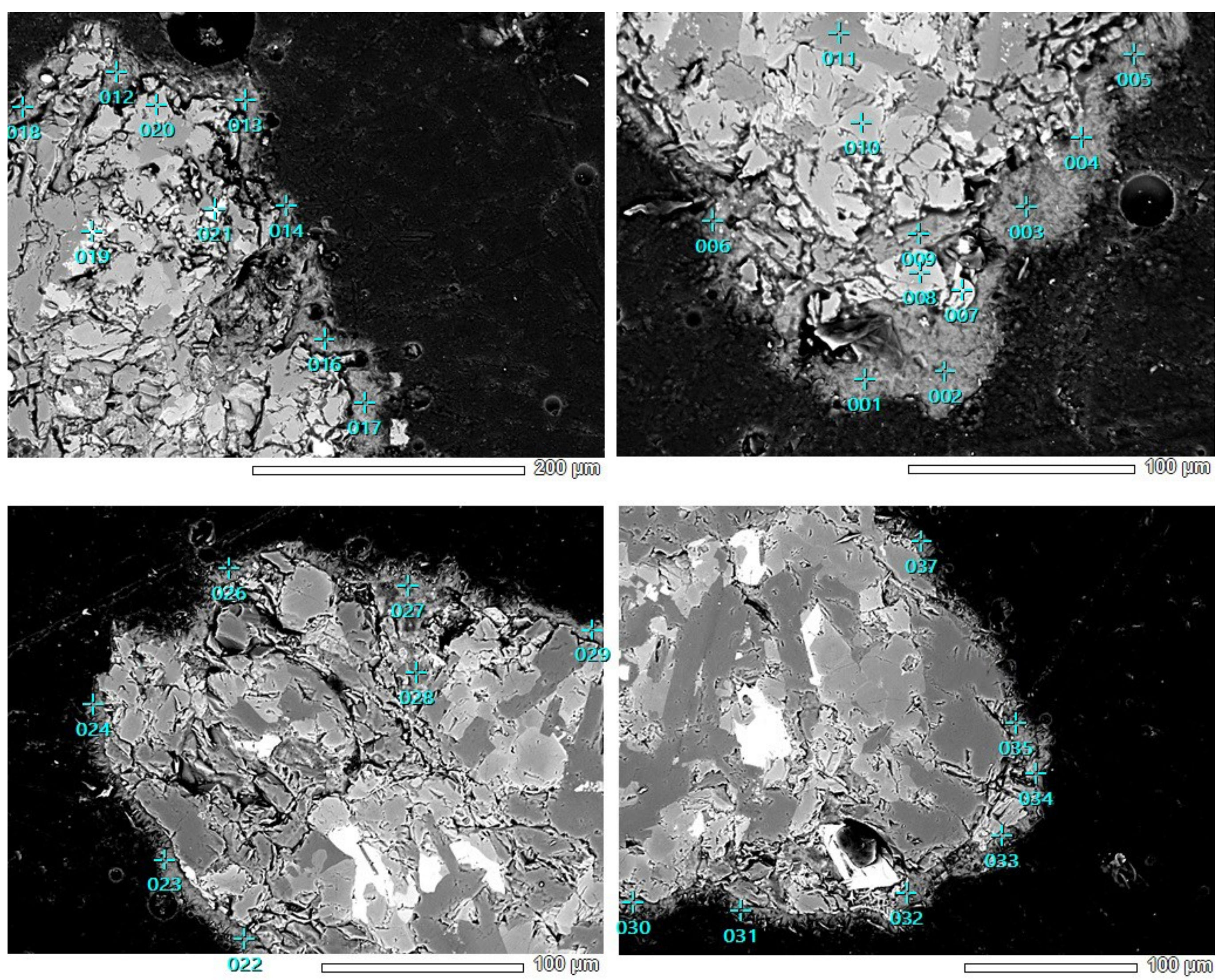


\begin{tabular}{|c|c|c|c|c|c|c|c|c|}
\hline Plg & $\begin{array}{c}\text { Analysis } \\
\text { Point }\end{array}$ & $\mathrm{Na}_{2} \mathrm{O}$ & $\mathbf{A l}_{2} \mathbf{O}_{3}$ & $\mathrm{SiO}_{2}$ & $\mathrm{CaO}$ & & & Total \\
\hline & 9 & 4.89 & 27.78 & 58.31 & 9.03 & & & 100.00 \\
\hline & 11 & 3.08 & 31.10 & 53.07 & 12.75 & & & 100.00 \\
\hline average & & 3.99 & 29.44 & 55.69 & 10.89 & & & 100.01 \\
\hline \multirow[t]{5}{*}{$\mathrm{Cpx}$} & $\begin{array}{c}\text { Analysis } \\
\text { Point }\end{array}$ & MgO & $\mathbf{A l}_{2} \mathbf{O}_{3}$ & $\mathrm{SiO}_{2}$ & $\mathrm{CaO}$ & $\mathrm{TiO}_{2}$ & $\mathrm{FeO}$ & Total \\
\hline & 20 & 16.95 & 3.23 & 55.44 & 15.47 & 0.00 & 8.90 & 99.99 \\
\hline & 7 & 17.54 & 1.85 & 54.79 & 3.67 & 0.00 & 22.15 & 100.00 \\
\hline & 8 & 14.41 & 3.16 & 52.98 & 13.47 & 0.00 & 15.97 & 99.99 \\
\hline & 10 & 14.28 & 6.13 & 52.04 & 16.00 & 1.29 & 10.26 & 100.00 \\
\hline average & & 15.80 & 3.59 & 53.81 & 12.15 & 0.32 & 14.32 & 100.00 \\
\hline \multirow[t]{3}{*}{$\mathrm{Ox}$} & $\begin{array}{c}\text { Analysis } \\
\text { Point }\end{array}$ & $\mathrm{TiO}_{2}$ & $\mathrm{FeO}$ & & & & & Total \\
\hline & 19 & 27.22 & 72.78 & & & & & 100.00 \\
\hline & 21 & 30.69 & 69.31 & & & & & 100.00 \\
\hline average & & 28.96 & 71.05 & & & & & 100.00 \\
\hline \multirow[t]{27}{*}{$\mathrm{Smc}$} & $\begin{array}{c}\text { Analysis } \\
\text { Point }\end{array}$ & $\mathrm{Na}_{2} \mathrm{O}$ & MgO & $\mathbf{A l}_{2} \mathbf{O}_{3}$ & $\mathrm{SiO}_{2}$ & $\mathrm{CaO}$ & $\mathrm{FeO}$ & Total \\
\hline & 12 & 0.78 & 12.55 & 11.60 & 50.44 & 0.75 & 23.87 & 100.00 \\
\hline & 13 & 0.51 & 11.74 & 11.79 & 48.80 & 0.38 & 26.78 & 100.00 \\
\hline & 14 & 1.47 & 6.94 & 10.77 & 44.34 & 1.43 & 35.06 & 100.00 \\
\hline & 16 & 0.85 & 11.87 & 11.09 & 50.34 & 1.01 & 24.84 & 100.00 \\
\hline & 17 & 0.00 & 12.38 & 11.22 & 50.93 & 0.99 & 24.48 & 100.00 \\
\hline & 18 & 1.86 & 15.37 & 14.25 & 50.74 & 1.15 & 16.63 & 100.00 \\
\hline & 1 & 0.91 & 17.11 & 10.67 & 53.23 & 0.34 & 17.74 & 100.00 \\
\hline & 2 & 0.92 & 15.18 & 10.21 & 52.41 & 0.87 & 20.42 & 100.00 \\
\hline & 3 & 1.12 & 15.28 & 11.67 & 52.24 & 0.87 & 18.82 & 100.00 \\
\hline & 4 & 0.83 & 10.06 & 10.65 & 48.46 & 0.88 & 29.12 & 100.00 \\
\hline & 5 & 0.75 & 13.96 & 12.07 & 51.95 & 0.50 & 20.41 & 100.00 \\
\hline & 6 & 1.59 & 15.10 & 12.30 & 50.49 & 1.42 & 19.11 & 100.00 \\
\hline & 22 & 2.42 & 16.12 & 12.43 & 51.71 & 0.60 & 16.73 & 100.00 \\
\hline & 23 & 2.93 & 12.13 & 12.07 & 49.65 & 0.73 & 22.48 & 100.00 \\
\hline & 24 & 2.49 & 14.09 & 13.01 & 51.21 & 0.49 & 18.71 & 100.00 \\
\hline & 26 & 2.59 & 14.53 & 14.04 & 50.87 & 0.91 & 17.07 & 100.00 \\
\hline & 27 & 2.06 & 12.21 & 12.06 & 49.66 & 1.37 & 22.64 & 100.00 \\
\hline & 28 & 1.87 & 11.54 & 15.06 & 48.00 & 1.67 & 21.88 & 100.00 \\
\hline & 29 & 2.02 & 12.31 & 12.43 & 48.88 & 0.67 & 23.69 & 100.00 \\
\hline & 30 & 1.96 & 13.36 & 11.80 & 50.03 & 0.73 & 21.72 & 100.00 \\
\hline & 31 & 2.33 & 14.86 & 12.37 & 50.95 & 1.08 & 18.40 & 100.00 \\
\hline & 32 & 2.32 & 15.13 & 12.58 & 50.39 & 0.66 & 18.92 & 100.00 \\
\hline & 33 & 2.09 & 12.59 & 11.78 & 49.61 & 0.72 & 23.22 & 100.00 \\
\hline & 34 & 0.81 & 7.11 & 11.29 & 49.85 & 1.48 & 29.47 & 100.00 \\
\hline & 35 & 1.70 & 12.43 & 13.11 & 51.39 & 0.84 & 20.53 & 100.00 \\
\hline & 37 & 1.52 & 12.69 & 12.50 & 50.80 & 0.00 & 22.49 & 100.00 \\
\hline average & & 1.57 & 13.02 & 12.11 & 50.28 & 0.87 & 22.12 & 99.97 \\
\hline$\pm \boldsymbol{\sigma}$ & & 0.70 & 2.43 & 1.14 & 1.73 & 0.36 & 4.38 & \\
\hline
\end{tabular}


Table E.6.23. Average mineral compositions from Table E.6.22

\begin{tabular}{|c|c|c|c|c|}
\hline & average $w t \%$ & average $w t \%$ & average $w t \%$ & average $w t \%$ \\
\hline \multicolumn{5}{|l|}{ Oxides } \\
\hline $\mathrm{MgO}$ & & 15.80 & & 13.02 \\
\hline $\mathrm{Na}_{2} \mathrm{O}$ & 3.99 & & & 1.57 \\
\hline $\mathrm{Al}_{2} \mathrm{O}_{3}$ & 29.44 & 3.59 & & 12.11 \\
\hline $\mathrm{SiO}_{2}$ & 55.69 & 53.81 & & 50.28 \\
\hline $\mathrm{CaO}$ & 10.89 & 12.15 & & 0.87 \\
\hline $\mathrm{FeO}_{(\mathrm{T})}$ & & 14.32 & 71.05 & 22.12 \\
\hline $\mathrm{TiO}_{2}$ & & 0.32 & 28.96 & \\
\hline Total & 100.01 & 99.99 & 100.01 & 99.97 \\
\hline $\begin{array}{c}\text { Mineral } \\
\text { Composition }\end{array}$ & $\begin{array}{c}\mathrm{Ca}_{0.53} \mathrm{Na}_{0.35} \mathrm{Al}_{1.58} \mathrm{Si}_{2.54} \mathrm{O}_{8} \\
\left(\mathrm{An}_{60}-\mathrm{Ab}_{40}\right)\end{array}$ & $\mathrm{Ca}_{0.48} \mathrm{Mg}_{0.87} \mathrm{Fe}_{0.44} \mathrm{Al}_{0.14} \mathrm{Si}_{1.98} \mathrm{Al}_{0.02} \mathrm{O}_{6}$ & $\mathrm{Fe}^{2+}\left(\mathrm{Fe}^{3+}, \mathrm{Ti}\right)_{2} \mathrm{O}_{4}$ & $\begin{array}{l}\mathrm{Na}_{0.41} \mathrm{Ca}_{0.13} \mathrm{Mg}_{2.63} \mathrm{Fe}_{2.51} \mathrm{Al}_{0.74} \mathrm{Si}_{6.81} \mathrm{Al}_{1.19} \mathrm{O}_{20}(\mathrm{OH})_{4} \\
\text { (on the basis of } 22 \text { oxygen equivalents, ignoring } \mathrm{H}_{2} \mathrm{O} \text { ) }\end{array}$ \\
\hline Phase and ID & Plagioclase & $\begin{array}{l}\text { Clinopyroxene } \\
\text { (augite) }\end{array}$ & $\begin{array}{c}\text { Oxide } \\
\text { (titanomagnetite) }\end{array}$ & Smectite \\
\hline
\end{tabular}


F 6.32. SEM photographs of different areas of the basal block surface after the BSW2 experiment
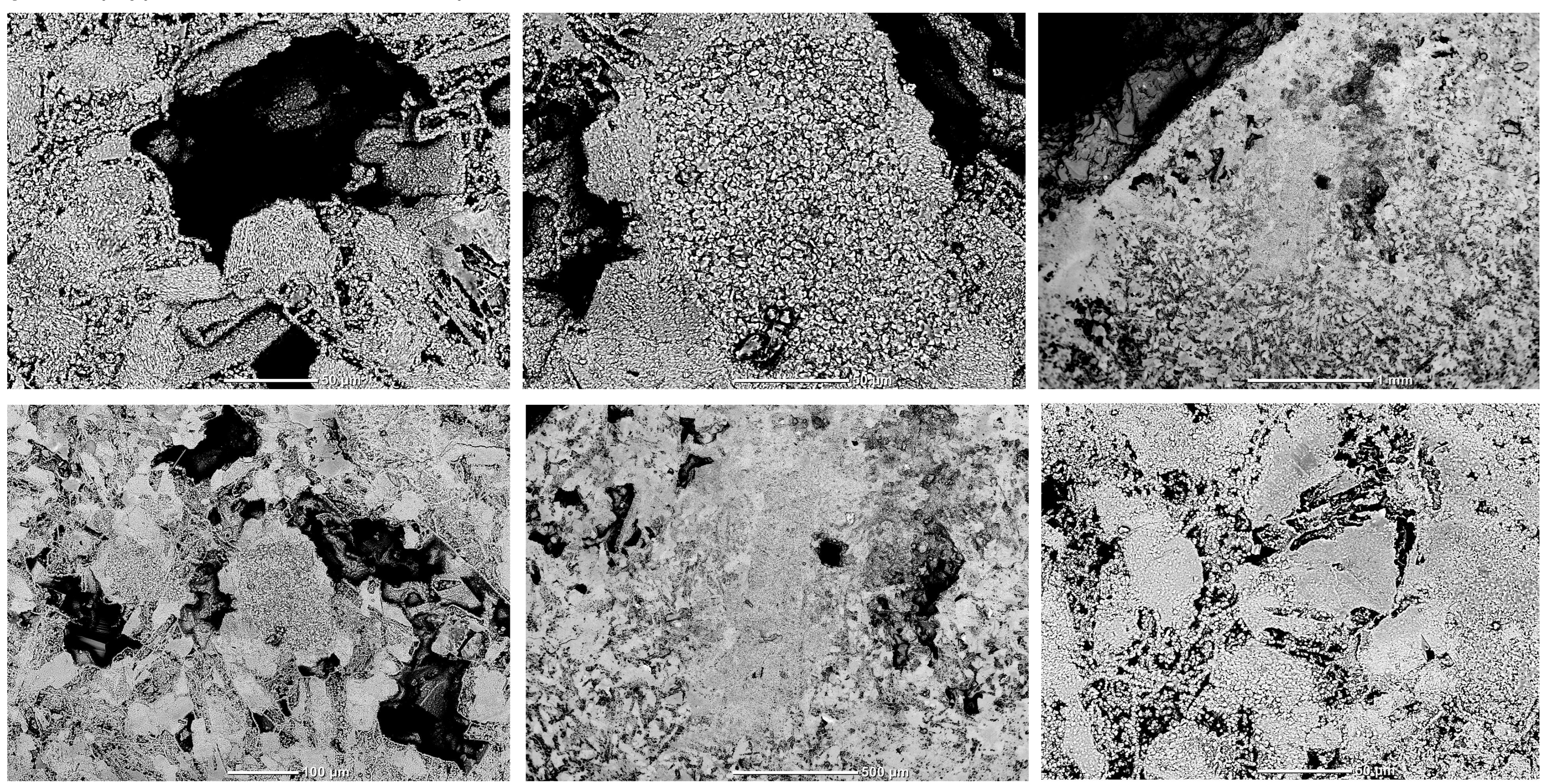
6.3. Discussion

\section{Elements Flux Calculation}

Table E.6.24. Elements flux calculation and amount of glass dissolved during the BSW1 experiment $\left(400^{\circ} \mathrm{C} / 488 \mathrm{bar}\right)$. Light blue colour indicates samples excluded from calculation

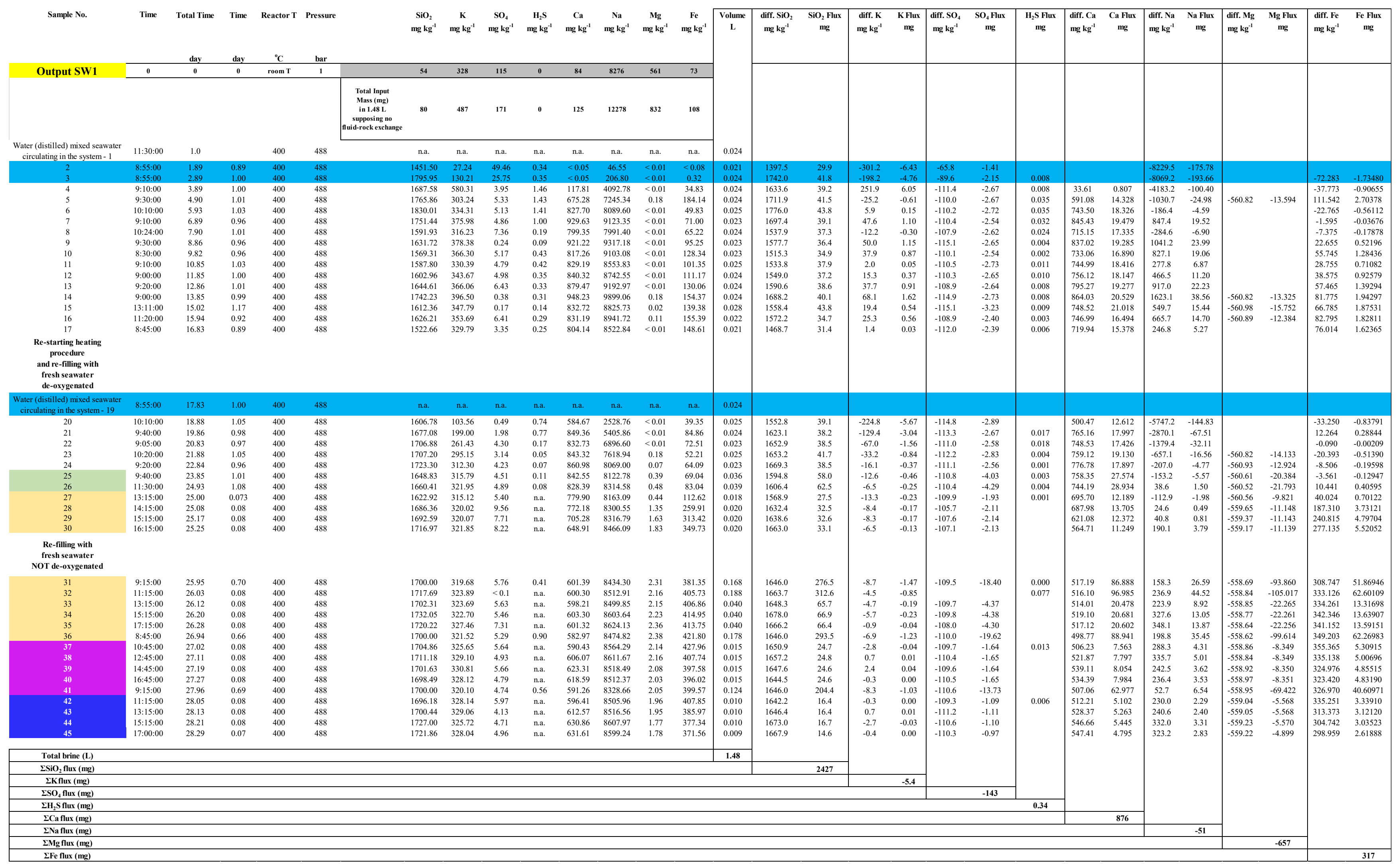


Table E.6.25. Elements flux calculation and amount of glass dissolved during the BSW2 experiment $\left(350^{\circ} \mathrm{C} / 488 \mathrm{bar}\right)$. Light blue colour indicates samples excluded from calculation

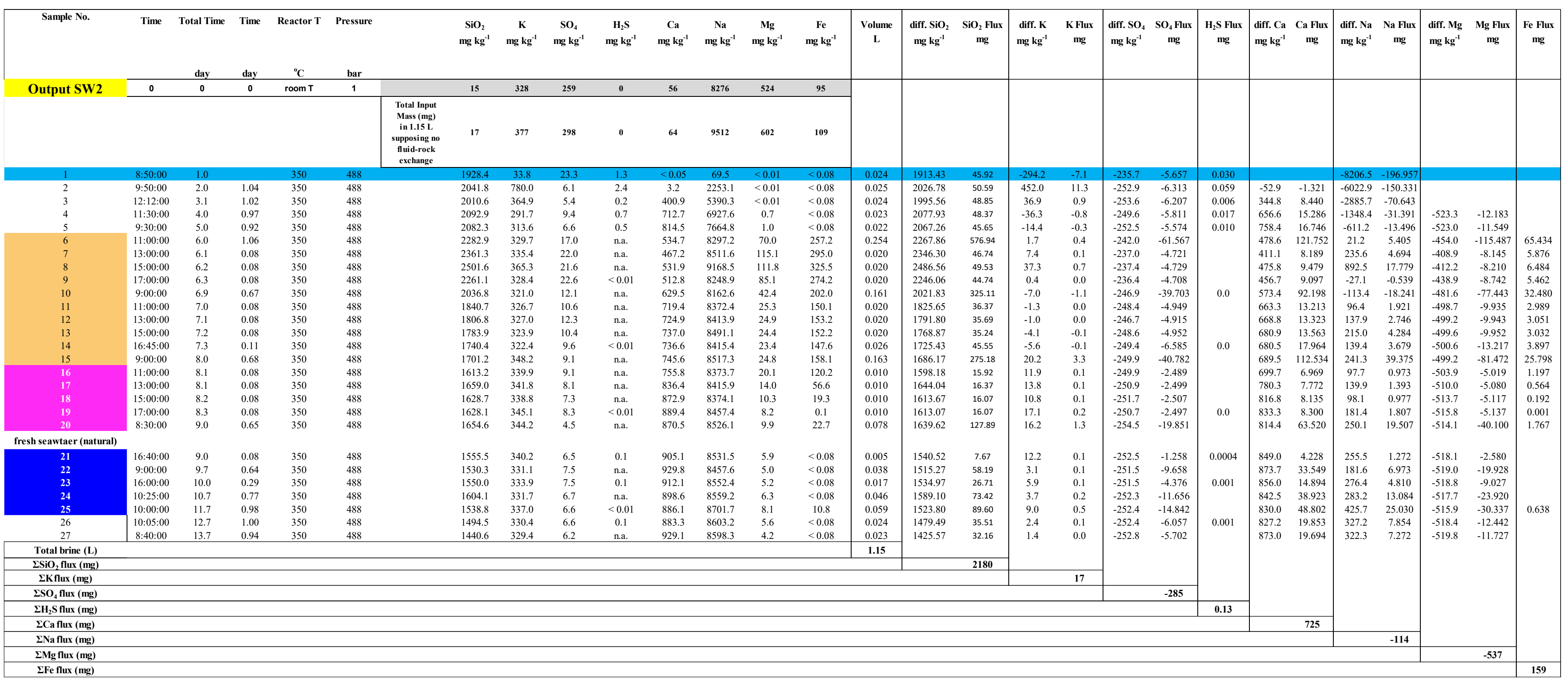




\section{Activity calculation}

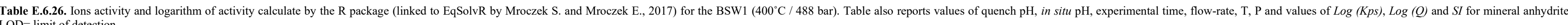

\begin{tabular}{|c|c|c|c|c|c|c|c|c|c|c|c|c|c|c|c|c|c|c|c|c|c|c|c|}
\hline samples & $\begin{array}{c}\begin{array}{c}\text { Blank seawater } \\
\text { (natural) } \\
\text { de-oxygenated }\end{array}\end{array}$ & $\begin{array}{l}\begin{array}{c}\text { Water (disitilled) mixed } \\
\text { seavater } \\
\text { circulating in the system - } \\
\text { (not considered) }\end{array} \\
\text { (nt }\end{array}$ & 2 & 3 & 4 & 5 & 6 & 7 & 8 & 9 & 10 & 11 & 12 & 13 & 14 & 15 & 16 & 17 & $\begin{array}{l}\text { Re-starting heating procedure } \\
\text { and } \\
\text { re-illing with } \\
\text { fresh seawater } \\
\text { de-oxgyenated } \\
\text { (not considered) }\end{array}$ & $\begin{array}{c}\text { Water (distilled) mixed } \\
\text { seavater } \\
\text { circulating in the system- } \\
19 \\
\text { (not considered) }\end{array}$ & 20 & 21 & 22 \\
\hline $\boldsymbol{a}=\underset{\mathrm{H}^{+}}{\boldsymbol{m} \cdot \boldsymbol{a}_{y}}$ & $1.09 \mathrm{E}-06$ & & $6.82 \mathrm{E}-08$ & $1.95 \mathrm{E}-07$ & $1.13 \mathrm{E}-06$ & $1.69 \mathrm{E}-06$ & $1.77 \mathrm{E}-06$ & $1.76 \mathrm{E}-06$ & $1.70 \mathrm{E}-06$ & $1.85 \mathrm{E}-06$ & $1.67 \mathrm{E}-00$ & $1.73 \mathrm{E}-06$ & $1.72 \mathrm{E}-06$ & $1.69 \mathrm{E}-06$ & $1.81 \mathrm{E}-06$ & $1.82 \mathrm{E}-06$ & $1.67 \mathrm{E}-06$ & & & & & & \\
\hline $\mathrm{OH}^{-}$ & $4.05 \mathrm{E}-06$ & & $6.46 \mathrm{E}-05$ & $2.26 \mathrm{E}-05$ & $3.90 \mathrm{E}-06$ & 2.61E- 06 & $2.49 \mathrm{E}-06$ & $2.50 \mathrm{E}-06$ & $2.59 \mathrm{E}-06$ & $2.39 \mathrm{E}-06$ & $2.64 \mathrm{E}-06$ & $2.54 \mathrm{E}-06$ & $2.56 \mathrm{E}-06$ & $2.61 \mathrm{E}-06$ & $2.43 \mathrm{E}-06$ & 2.42E-06 & $2.64 \mathrm{E}-06$ & $\begin{array}{l}2.145 \mathrm{E}-0.06 \\
2.56\end{array}$ & & $\begin{array}{l}3.19-0 \mathrm{D} \\
1.16 \mathrm{-0}\end{array}$ & $\begin{array}{l}.1 .06 \mathrm{E}-06 \\
5.99 \mathrm{E}-07\end{array}$ & $\begin{array}{l}0.005 \mathrm{E}=00 \\
1.45 \mathrm{E}\end{array}$ & $2.09 \mathrm{E}-06$ \\
\hline $\mathrm{Na}^{+}$ & $5.47 \mathrm{E}-02$ & & $1.41 \mathrm{E}-03$ & $4.89 \mathrm{E}-03$ & $3.74 \mathrm{E}-02$ & $5.24 \mathrm{E}-02$ & $5.61 \mathrm{E}-02$ & $6.02 \mathrm{E}-02$ & $5.58 \mathrm{E}-02$ & $6.09 \mathrm{E}-02$ & $6.02 \mathrm{E}-02$ & $5.80 \mathrm{E}-02$ & $5.87 \mathrm{E}-02$ & $6.04 \mathrm{E}-02$ & $6.30 \mathrm{E}-02$ & $5.90 \mathrm{E}-02$ & $5.95 \mathrm{E}-02$ & $5.78 \mathrm{E}-02$ & & $2.38 \mathrm{E}-03$ & $1.44 E-03$ & $2.59 \mathrm{E}-02$ & $4.34 \mathrm{E}-02$ \\
\hline $\mathrm{K}^{+}$ & $1.63 \mathrm{E}-03$ & & $4.42 \mathrm{E}-04$ & $2.03 \mathrm{E}-03$ & $4.29 \mathrm{E}-03$ & $1.82 \mathrm{E}-03$ & $1.93 \mathrm{E}-03$ & $2.07 \mathrm{E}-03$ & $1.84 \mathrm{E}-03$ & $2.07 \mathrm{E}-03$ & $2.03 \mathrm{E}-03$ & $1.87 \mathrm{E}-03$ & $1.93 \mathrm{E}-03$ & $2.01 \mathrm{E}-03$ & $2.12 \mathrm{E}-03$ & $1.94 \mathrm{E}-03$ & $1.97 \mathrm{E}-03$ & $1.87 \mathrm{E}-03$ & & $1.09 \mathrm{E}-04$ & $1.40 \mathrm{E}-03$ & $1.63 \mathrm{E}-03$ & $1.73 \mathrm{E}-03$ \\
\hline $\mathrm{Cl}^{-}$ & $6.09 \mathrm{E}-02$ & & $1.30 \mathrm{E}-03$ & $6.69 \mathrm{E}-03$ & $4.15 \mathrm{E}-02$ & $5.71 \mathrm{E}-02$ & $6.05 \mathrm{E}-02$ & $6.47 \mathrm{E}-02$ & $6.00 \mathrm{E}-02$ & $6.54 \mathrm{E}-02$ & $6.44 \mathrm{E}-02$ & $6.23 \mathrm{E}-02$ & $6.31 \mathrm{E}-02$ & $6.49 \mathrm{E}-02$ & $6.77 \mathrm{E}-02$ & $6.35 \mathrm{E}-02$ & $6.39 \mathrm{E}-02$ & $6.23 \mathrm{E}-02$ & & $2.47 \mathrm{E}-03$ & $1.188-02$ & $3.50 \mathrm{E}-02$ & $4.96 \mathrm{E}-02$ \\
\hline $\mathrm{SO}_{4}^{2-}$ & $1.98 \mathrm{E}-05$ & & $3.49 \mathrm{E}-05$ & 4.41E-06 & $7.61 \mathrm{E}-08$ & $6.84 \mathrm{E}-08$ & $6.00 \mathrm{E}-08$ & $5.19 \mathrm{E}-08$ & $8.76 \mathrm{E}-08$ & $2.51 \mathrm{E}-09$ & $5.63 \mathrm{E}-08$ & $5.42 \mathrm{E}-08$ & $5.56 \mathrm{E}-08$ & $6.91 \mathrm{E}-08$ & $3.86 \mathrm{E}-09$ & $2.11 \mathrm{E}-09$ & $7.08 \mathrm{E}-08$ & $3.81 \mathrm{E}-08$ & & $1.07 \mathrm{E}-06$ & $8.70 \mathrm{E}-09$ & 3.89E- -08 & $6.36 \mathrm{E}-08$ \\
\hline $\mathrm{Ca}^{2+}$ & $7.58 \mathrm{E}-06$ & & $<\mathrm{LOD}$ & $<$ LOD & $5.12 \mathrm{E}-06$ & $1.84 \mathrm{E}-05$ & $2.09 \mathrm{E}-05$ & $2.12 \mathrm{E}-05$ & $2.03 \mathrm{E}-05$ & $2.07 \mathrm{E}-05$ & $1.88 \mathrm{E}-05$ & $2.00 \mathrm{E}-05$ & $1.99 \mathrm{E}-05$ & $1.99 \mathrm{E}-05$ & $2.02 \mathrm{E}-05$ & $1.95 \mathrm{E}-05$ & $1.93 \mathrm{E}-05$ & $1.94 \mathrm{E}-05$ & & $<$ LOD & $1.36 \mathrm{E}-04$ & $4.70 \mathrm{E}-05$ & $2.80 \mathrm{E}-05$ \\
\hline $\mathrm{Mg}^{2+}$ & $1.48 \mathrm{E}-04$ & & $<\mathrm{LOD}$ & $<\mathrm{LOD}$ & $<\mathrm{LOD}$ & $3.51 \mathrm{E}-08$ & $<$ LOD & $<$ LOD & $<$ LOD & $<$ LOD & $<\mathrm{LOD}$ & $<$ LOD & $<$ LOD & $<\mathrm{LOD}$ & $2.72 \mathrm{E}-08$ & 4.20E-09 & $2.08 \mathrm{E}-08$ & $<\mathrm{LOD}$ & & $<$ LOD & $<$ LOD & $<\mathrm{LOD}$ & $<\mathrm{LOD}$ \\
\hline $\mathrm{Fe}^{2+}$ & $7.44 \mathrm{E}-09$ & & $<$ LOD & $2.17 \mathrm{E}-07$ & $2.69 \mathrm{E}-06$ & $9.33 \mathrm{E}-06$ & $2.34 \mathrm{E}-06$ & $3.04 \mathrm{E}-06$ & $3.10 \mathrm{E}-06$ & $4.04 \mathrm{E}-06$ & $5.54 \mathrm{E}-06$ & $4.56 \mathrm{E}-06$ & $4.93 \mathrm{E}-06$ & $5.56 \mathrm{E}-06$ & $6.24 \mathrm{E}-06$ & $6.13 \mathrm{E}-06$ & $6.77 \mathrm{E}-06$ & $6.71 \mathrm{E}-06$ & & $2.86 \mathrm{E}-06$ & $1.42 \mathrm{E}-05$ & $8.13 \mathrm{E}-06$ & 4.41E-06 \\
\hline$a^{2} H^{+}$ & $1.18 \mathrm{E}-12$ & & $4.66 \mathrm{E}-15$ & $3.81 \mathrm{E}-14$ & $1.28 \mathrm{E}-12$ & $2.86 \mathrm{E}-12$ & $3.13 \mathrm{E}-12$ & $3.11 \mathrm{E}-12$ & $2.89 \mathrm{E}-12$ & $3.41 \mathrm{E}-12$ & $2.79 \mathrm{E}-12$ & $3.01 \mathrm{E}-12$ & $2.96 \mathrm{E}-12$ & $2.84 \mathrm{E}-12$ & $3.27 \mathrm{E}-12$ & $3.31 \mathrm{E}-12$ & $2.78 \mathrm{E}-12$ & $3.04 \mathrm{E}-12$ & & $1.43 \mathrm{E}-13$ & $5.41 \mathrm{E}-11$ & $9.19 E-12$ & 4.43E- -12 \\
\hline $\log \left(a \mathrm{SiO}_{2}\right)$ & -3.95 & & -1.62 & -1.52 & -1.55 & -1.53 & -1.52 & -1.54 & -1.58 & -1.57 & -1.58 & -1.58 & -1.57 & -1.56 & -1.54 & -1.57 & -1.57 & -1.60 & & -1.60 & -1.57 & -1.55 & -1.55 \\
\hline $\log \left(a_{\mathrm{K}} / a_{\mathrm{HH}}\right)$ & 3.18 & & 3.81 & 4.02 & 3.58 & 3.03 & 3.04 & 3.07 & 3.03 & 3.05 & 3.08 & 3.03 & 3.05 & 3.08 & 3.07 & 3.03 & 3.07 & 3.03 & & 2.46 & 2.28 & 2.73 & 2.91 \\
\hline $\log \left(a_{\mathrm{Na}+} / a_{\mathrm{H}+}\right)$ & 4.70 & & 4.31 & 4.40 & 4.52 & 4.49 & 4.50 & 4.53 & 4.52 & 4.52 & 4.56 & 4.52 & 4.53 & 4.55 & 4.54 & 4.51 & 4.55 & 4.52 & & 3.80 & 2.29 & 3.93 & 4.31 \\
\hline $\log \left(a_{\mathrm{Ca}+} / a_{\mathrm{H}+}^{2}\right)$ & 6.81 & & $<\mathrm{LOD}$ & $<$ LOD & 6.60 & 6.81 & 6.82 & 6.83 & 6.85 & 6.78 & 6.83 & 6.82 & 6.83 & 6.85 & 6.79 & 6.77 & 6.84 & 6.80 & & $<$ LOD & 6.40 & 6.71 & 6.80 \\
\hline $\log \left(a_{\mathrm{Fe}+} / a_{\mathrm{H}+}^{2}\right)$ & 3.80 & & $<$ LOD & 6.76 & 6.32 & 6.51 & 5.87 & 5.99 & 6.03 & 6.07 & 6.30 & 6.18 & 6.22 & 6.29 & 6.28 & 6.27 & 6.39 & 6.34 & & 7.30 & 5.42 & 5.95 & 6.00 \\
\hline $\log \left(a_{\mathrm{Mg}_{2}+} / a_{\mathrm{H}+}^{2}\right)$ & 8.10 & & $<$ LOD & $<$ LOD & $<$ LOD & 4.09 & $<$ LOD & $<$ LOD & $<$ LOD & $<$ LOD & $<$ LOD & $<$ LOD & $<$ LOD & $<$ LOD & 3.92 & 3.10 & 3.87 & $<$ LOD & & $<$ LOD & $<$ LOD & $<$ LOD & $<$ LOD \\
\hline $\log a \mathrm{Na}^{+}$ & -1.26 & & -2.85 & -2.31 & -1.43 & -1.28 & -1.25 & -1.22 & -1.25 & -1.22 & -1.22 & -1.24 & -1.23 & -1.22 & -1.20 & -1.23 & -1.23 & -1.24 & & -2.62 & -2.84 & -1.59 & -1.36 \\
\hline $\log a \mathrm{~K}^{+}$ & -2.79 & & -3.35 & -2.69 & -2.37 & -2.74 & -2.71 & -2.68 & -2.74 & -2.68 & -2.69 & -2.73 & -2.71 & -2.70 & -2.67 & -2.71 & -2.71 & -2.73 & & -3.96 & -2.86 & -2.79 & -2.76 \\
\hline $\log a \mathrm{Cl}$ & -1.22 & & -2.89 & -2.17 & -1.38 & -1.24 & -1.22 & -1.19 & -1.22 & -1.18 & -1.19 & -1.21 & -1.20 & -1.19 & -1.17 & -1.20 & -1.19 & -1.21 & & -2.61 & -1.93 & -1.46 & -1.30 \\
\hline $\log a \mathrm{SO}_{4}^{2-}$ & -4.70 & & -4.46 & -5.36 & -7.12 & -7.16 & -7.22 & -7.28 & -7.06 & -8.60 & -7.25 & -7.27 & -7.26 & -7.16 & -8.41 & -8.68 & -7.15 & -7.42 & & -5.97 & -8.06 & -7.41 & -7.20 \\
\hline $\log a \mathrm{Ca}^{2+}$ & -5.12 & & $<\mathrm{LOD}$ & $<$ LOD & -5.29 & -4.73 & -4.68 & -4.67 & -4.69 & -4.68 & -4.73 & -4.70 & -4.70 & -4.70 & -4.69 & -4.71 & -4.71 & -4.71 & & $<$ LOD & -3.87 & -4.33 & -4.55 \\
\hline $\log a \mathrm{Mg}^{2+}$ & -3.83 & & $<\mathrm{LOD}$ & $<$ LOD & $<$ LOD & -7.45 & $<$ LOD & $<$ LOD & $<$ LOD & $<$ LOD & $<$ LOD & $<$ LOD & $<$ LOD & $<$ LOD & -7.56 & -8.38 & -7.68 & $<$ LODc & & $<$ LOD & $<\mathrm{LOD}$ & $<$ LOD & $<$ LOD \\
\hline $\log a \mathrm{Fe}^{2+}$ & -8.13 & & $<\mathrm{LOD}$ & -6.66 & -5.57 & -5.03 & -5.63 & -5.52 & -5.51 & -5.39 & -5.26 & -5.34 & -5.31 & -5.26 & -5.21 & -5.21 & -5 . & -5 & & -5 & -4.85 & -5.09 & -5.36 \\
\hline$\left.{ }^{T} \mathrm{~T}{ }^{\circ} \mathrm{C}\right)$ & 400 & & 401.3 & 400.7 & 400.6 & 400.4 & 400.7 & 400.4 & 400.5 & 400.3 & 40 & 40 & 40 & 40 & 400 & 40 & 40 & & & 400.8 & 400.5 & 400.6 & 400.7 \\
\hline $\mathrm{P}(\mathrm{bar})$ & 500 & & 485.4 & 486.1 & 486.1 & 486.1 & 486.2 & 486.1 & 485.7 & 358.9 & 485.9 & 486.2 & 486.0 & 485.9 & 485.8 & 36 & 485.1 & 48 & & 486.6 & 486.4 & 486.5 & 486.4 \\
\hline in situ $\mathrm{pl}$ & 5.96 & & 7.17 & 6.71 & 5.95 & 5.77 & 5.75 & 5.75 & 5.77 & 5.73 & 5.78 & 5.76 & 5.76 & 5.77 & 5.74 & 5. & 5.7 & 5. & & 6.42 & 5.13 & 5.52 & 5.68 \\
\hline roc & 7.75 & & 6.37 & 4.17 & 3.29 & 4.34 & 3.63 & 3.58 & 3.8 & 3.79 & 3.98 & 4.03 & 4.23 & 4.04 & 4.05 & 4.09 & 4.10 & 4.10 & & 6.27 & 4.89 & 4.27 & 4.08 \\
\hline & & & 1 & 1 & 1 & 1 & 1 & 1 & 1 & 1 & 1 & 1 & 1 & 1 & 1 & 1 & 1 & 1 & & 1 & 1 & 1 & 1 \\
\hline time (hrs) & 0.0 & & 45.3 & 68.1 & 92.3 & 116.7 & 141.3 & 164.3 & 189.5 & 212.7 & 235.7 & 260.3 & 284.2 & 308.5 & 332.2 & 352.7 & 374.8 & 396.3 & & 411.9 & 437.2 & 460.7 & 484.3 \\
\hline & & & & & & & & & & & & & & & & & & & & & & & 4.27 \\
\hline $\begin{array}{c}\log K s p \text { (Supctit92) @ } 400^{\circ} \mathrm{C} \\
\log Q(\text { or } \log \text { IAP) }\end{array}$ & & & $\begin{array}{r}4 . \\
<\mathrm{L}\end{array}$ & $<1$ & 4.96 & $\begin{array}{l}4.2 \\
4.45\end{array}$ & $\begin{array}{l}4.27 \\
4.46\end{array}$ & 4.52 & 4.3 & 5.8 & 4.5 & 4.5 & $\begin{array}{l}4.27 \\
4.52\end{array}$ & $\begin{array}{l}4.27 \\
4.42\end{array}$ & $\begin{array}{l}5.2 \\
5.6\end{array}$ & 6.2 & 4.4 & 4.6 & & $<1$ & $\begin{array}{l}4.27 \\
3.69\end{array}$ & 55 & $\begin{array}{l}4.27 \\
4.37\end{array}$ \\
\hline $\log S I$ & & & $<$ LOD & $<$ LOD & $\begin{array}{l}\quad .30 \\
0.69 \\
\end{array}$ & $\begin{array}{l}\quad+.40 \\
0.19\end{array}$ & 0.19 & 0.25 & $\begin{array}{r}0.04 \\
\end{array}$ & $\begin{array}{l}1.047 \\
1.57\end{array}$ & 0.26 & 0.25 & 0.25 & 0.15 & 1.40 & 1.73 & 0.15 & 0.42 & & $<$ LOD & $\begin{array}{l}-0.58 \\
-0.58 \\
\end{array}$ & 0.28 & 0.10 \\
\hline
\end{tabular}




\begin{tabular}{|c|c|c|c|c|c|c|c|c|c|c|c|c|c|c|c|c|c|c|c|c|c|c|c|c|}
\hline samples & 23 & 24 & 25 & 26 & 27 & 28 & 29 & 30 & $\begin{array}{c}\text { Re-filling with } \\
\text { fresh seawater } \\
\text { NoO de-oxyganated } \\
\text { (not considered) }\end{array}$ & 31 & 32 & 33 & 34 & 35 & 36 & 37 & 38 & 39 & 40 & 41 & 42 & 43 & 44 & 45 \\
\hline$a=m \cdot a_{y}$ & $1.96 \mathrm{E}-06$ & $1.86 \mathrm{E}-06$ & $1.80 \mathrm{E}-06$ & $1.78 \mathrm{E}-06$ & $1.71 \mathrm{E}-06$ & $1.63 \mathrm{E}-06$ & $1.60 \mathrm{E}-06$ & $1.54 \mathrm{E}-06$ & & $1.55 \mathrm{E}-06$ & $1.67 \mathrm{E}-06$ & $1.54 \mathrm{E}-06$ & $1.55 \mathrm{E}-06$ & $1.51 \mathrm{E}-06$ & $1.53 \mathrm{E}-06$ & $1.53 \mathrm{E}-06$ & $1.56 \mathrm{E}-06$ & $1.55 \mathrm{E}-06$ & $157 \mathrm{~F}-06$ & $155 \mathrm{E}-06$ & $154 \mathrm{E}-06$ & $158 \mathrm{E}-06$ & $158 \mathrm{E}-06$ & $157 \mathrm{E}-06$ \\
\hline $\mathrm{OH}^{-}$ & $2.25 \mathrm{E}-06$ & $2.37 \mathrm{E}-06$ & $2.44 \mathrm{E}-06$ & $2.48 \mathrm{E}-06$ & $2.58 \mathrm{E}-06$ & $2.71 \mathrm{E}-06$ & $2.75 \mathrm{E}-06$ & $2.85 \mathrm{E}-06$ & & $2.85 \mathrm{E}-06$ & $2.63 \mathrm{E}-06$ & $2.86 \mathrm{E}-06$ & $2.84 \mathrm{E}-06$ & 2.92E-06 & $2.88 \mathrm{E}-06$ & 2.88E-06 & 2.83E-06 & $2.84 \mathrm{E}-06$ & $2.80 \mathrm{E}-06$ & $2.84 \mathrm{E}-06$ & $2.86 \mathrm{E}-06$ & $2.79 \mathrm{E}-06$ & 2.79E-06 & $2.81 \mathrm{E}-06$ \\
\hline $\mathrm{Na}^{+}$ & $5.07 \mathrm{E}-02$ & $5.40 \mathrm{E}-02$ & $5.60 \mathrm{E}-02$ & $5.62 \mathrm{E}-02$ & $5.71 \mathrm{E}-02$ & $5.61 \mathrm{E}-02$ & $5.67 \mathrm{E}-02$ & $5.68 \mathrm{E}-02$ & & $5.75 \mathrm{E}-02$ & $5.73 \mathrm{E}-02$ & $5.77 \mathrm{E}-02$ & $5.76 \mathrm{E}-02$ & $5.80 \mathrm{E}-02$ & $5.82 \mathrm{E}-02$ & $5.75 \mathrm{E}-02$ & $5.79 \mathrm{E}-02$ & $5.80 \mathrm{E}-02$ & $5.77 \mathrm{E}-02$ & $5.77 \mathrm{E}-02$ & $5.69 \mathrm{E}-02$ & $5.76 \mathrm{E}-02$ & $5.77 \mathrm{E}-02$ & $5.81 \mathrm{E}-02$ \\
\hline $\mathrm{K}^{+}$ & $1.80 \mathrm{E}-03$ & $1.84 \mathrm{E}-03$ & $1.83 \mathrm{E}-03$ & $1.86 \mathrm{E}-03$ & $1.81 \mathrm{E}-03$ & $1.83 \mathrm{E}-03$ & $1.82 \mathrm{E}-03$ & $1.83 \mathrm{E}-03$ & & $1.81 \mathrm{E}-03$ & $1.84 \mathrm{E}-03$ & $1.83 \mathrm{E}-03$ & $1.83 \mathrm{E}-03$ & $1.84 \mathrm{E}-03$ & $1.81 \mathrm{E}-03$ & $1.84 \mathrm{E}-03$ & $1.86 \mathrm{E}-03$ & $1.86 \mathrm{E}-03$ & $1.85 \mathrm{E}-03$ & $1.81 \mathrm{E}-03$ & $1.87 \mathrm{E}-03$ & $1.86 \mathrm{E}-03$ & $1.84 \mathrm{E}-03$ & $1.85 \mathrm{E}-03$ \\
\hline $\mathrm{Cr}$ & $5.59 \mathrm{E}-02$ & $5.88 \mathrm{E}-02$ & $6.05 E-02$ & $6.07 \mathrm{E}-02$ & $6.13 \mathrm{E}-02$ & $6.12 \mathrm{E}-02$ & $6.16 \mathrm{E}-02$ & $6.16 \mathrm{E}-02$ & & $6.21 \mathrm{E}-02$ & $6.21 \mathrm{E}-02$ & $6.24 \mathrm{E}-02$ & $6.24 \mathrm{E}-02$ & $6.27 \mathrm{E}-02$ & $6.28 \mathrm{E}-02$ & $6.23 \mathrm{E}-02$ & $6.26 \mathrm{E}-02$ & $6.28 \mathrm{E}-02$ & $6.24 \mathrm{E}-02$ & $6.23 \mathrm{E}-02$ & $6.17 \mathrm{E}-02$ & $6.23 \mathrm{E}-02$ & $6.24 \mathrm{E}-02$ & $6.27 \mathrm{E}-02$ \\
\hline $\mathrm{SO}_{4}{ }^{2-}$ & $4.06 \mathrm{E}-08$ & $5.11 \mathrm{E}-08$ & $5.28 \mathrm{E}-08$ & $5.72 \mathrm{E}-08$ & $6.24 \mathrm{E}-08$ & $1.14 \mathrm{E}-07$ & $9.03 E-08$ & $9.76 \mathrm{E}-08$ & & $6.74 \mathrm{E}-08$ & $2.00 \mathrm{E}-28$ & $6.61 \mathrm{E}-08$ & $6.38 \mathrm{E}-08$ & $8.46 \mathrm{E}-08$ & $6.11 \mathrm{E}-08$ & $6.63 \mathrm{E}-08$ & $5.67 \mathrm{E}-08$ & $6.53 \mathrm{E}-08$ & $5.57 \mathrm{EE}-08$ & $5.49 \mathrm{E}-08$ & $7.04 \mathrm{E}-08$ & 4.79E- -08 & $5.45 E-08$ & $5.75 \mathrm{E}-08$ \\
\hline $\mathrm{Ca}^{2+}$ & $2.38 \mathrm{E}-05$ & $2.26 \mathrm{E}-05$ & $2.12 \mathrm{E}-05$ & $2.08 \mathrm{E}-05$ & $1.93 \mathrm{E}-05$ & $1.91 \mathrm{E}-05$ & $1.73 \mathrm{E}-05$ & $1.59 \mathrm{E}-05$ & & $1.45 \mathrm{E}-05$ & $1.45 \mathrm{E}-05$ & $1.44 \mathrm{E}-05$ & $1.45 \mathrm{E}-05$ & $1.43 \mathrm{E}-05$ & $1.39 \mathrm{E}-05$ & $1.42 \mathrm{E}-05$ & $1.45 \mathrm{E}-05$ & $1.48 \mathrm{E}-05$ & $1.48 \mathrm{E}-05$ & $1.42 \mathrm{E}-05$ & $1.46 \mathrm{E}-05$ & $1.47 \mathrm{E}-05$ & $1.52 \mathrm{E}-05$ & $1.51 \mathrm{E}-05$ \\
\hline $\mathrm{Mg}^{2+}$ & $3.91 \mathrm{E}-08$ & $1.38 \mathrm{E}-08$ & $7.11 \mathrm{E}-08$ & $8.85 \mathrm{E}-08$ & $7.86 \mathrm{E}-08$ & $2.44 \mathrm{E}-07$ & $2.90 \mathrm{E}-07$ & $3.24 \mathrm{E}-07$ & & $4.07 E-07$ & $3.82 \mathrm{E}-07$ & $3.79 \mathrm{E}-07$ & $3.92 \mathrm{E}-07$ & $4.10 \mathrm{E}-07$ & $4.14 \mathrm{E}-07$ & $3.75 \mathrm{E}-07$ & $3.78 \mathrm{E}-07$ & $3.59 \mathrm{E}-07$ & $3.53 \mathrm{E}-07$ & $3.58 \mathrm{E}-07$ & $3.49 \mathrm{E}-07$ & $3.41 \mathrm{E}-07$ & $3.11 \mathrm{E}-07$ & $3.09 \mathrm{E}-07$ \\
\hline $\mathrm{Fe}^{2+}$ & $2.72 \mathrm{E}-06$ & $3.12 \mathrm{E}-06$ & $3.24 \mathrm{E}-06$ & $3.88 \mathrm{E}-06$ & $5.20 \mathrm{E}-06$ & $1.20 \mathrm{E}-05$ & $1.43 \mathrm{E}-05$ & $1.60 \mathrm{E}-05$ & & $1.73 \mathrm{E}-05$ & $1.84 \mathrm{E}-05$ & $1.83 \mathrm{E}-05$ & $1.87 \mathrm{E}-05$ & $1.85 \mathrm{E}-05$ & $1.88 \mathrm{E}-05$ & $1.93 \mathrm{E}-05$ & $1.83 \mathrm{E}-05$ & $1.77 \mathrm{E}-05$ & $1.78 \mathrm{E}-05$ & $1.80 \mathrm{E}-05$ & $1.86 \mathrm{E}-05$ & $1.74 \mathrm{E}-05$ & $1.70 \mathrm{E}-05$ & $1.66 \mathrm{E}-05$ \\
\hline$a^{2} H^{+}$ & $3.84 \mathrm{E}-12$ & $3.47 \mathrm{E}-12$ & $3.25 \mathrm{E}-12$ & $3.16 \mathrm{E}-12$ & $2.92 \mathrm{E}-12$ & $2.65 \mathrm{E}-12$ & $2.57 \mathrm{E}-12$ & $2.38 \mathrm{E}-12$ & & 2.40E-12 & $2.80 \mathrm{E}-12$ & $2.37 \mathrm{E}-12$ & 2.40E-12 & $2.27 \mathrm{E}-12$ & $2.34 \mathrm{E}-12$ & $2.35 \mathrm{E}-12$ & 2.43E-12 & $2.41 \mathrm{E}-12$ & $2.47 \mathrm{E}-12$ & $2.40 \mathrm{E}-12$ & $2.37 \mathrm{E}-12$ & $2.50 \mathrm{E}-12$ & $2.50 \mathrm{E}-12$ & $2.47 \mathrm{E}-12$ \\
\hline $\log \left(a \mathrm{SiO}_{2}\right)$ & -1.55 & -1.54 & -1.56 & -1.56 & -1.57 & -1.55 & -1.55 & -1.54 & & -1.59 & -1.54 & -1.55 & -1.54 & -1.54 & -1.61 & -1.55 & -1.55 & -1.55 & -1.55 & -1.62 & -1.55 & -1.55 & -1.54 & -1.54 \\
\hline $\left.\log \left(a_{\mathrm{K}}\right\lrcorner a_{\mathrm{H}+}\right)$ & 2.96 & 2.99 & 3.01 & 3.02 & 3.02 & 3.05 & 3.06 & 3.08 & & 3.07 & 3.04 & 3.08 & 3.07 & 3.09 & 3.07 & 3.08 & 3.08 & 3.08 & 3.07 & 3.07 & 3.08 & 3.07 & 3.07 & 3.07 \\
\hline $\log \left(a_{\mathrm{Na}} / a_{\mathrm{H}}\right)$ & 4.41 & 4.46 & 4.49 & 4.50 & 4.52 & 4.54 & 4.55 & 4.57 & & 4.57 & 4.53 & 4.57 & 4.57 & 4.59 & 4.58 & 4.57 & 4.57 & 4.57 & 4.56 & 4.57 & 4.57 & 4.56 & 4.56 & 4.57 \\
\hline $\log \left(a_{\mathrm{C} 2}+/ a_{\mathrm{H}}^{2}\right)$ & 6.79 & 6.81 & 6.81 & 6.82 & 6.82 & 6.86 & 6.83 & 6.82 & & 6.78 & 6.72 & 6.78 & 6.78 & 6.80 & 6.77 & 6.78 & 6.78 & 6.79 & 6.78 & 6.77 & 6.79 & 6.77 & 6.78 & 6.79 \\
\hline $\log \left(a_{\mathrm{Fe}_{2}+} / a_{\mathrm{HH}}^{2}\right)$ & 5.85 & 5.95 & 6.00 & 6.09 & 6.25 & 6.66 & 6.75 & 6.83 & & 6.86 & 6.82 & 6.89 & 6.89 & 6.91 & 6.91 & 6.92 & 6.88 & 6.87 & 6.86 & 6.87 & 6.90 & 6.84 & 6.83 & 6.83 \\
\hline $\log \left(a_{\mathrm{Mg}_{2}+} / a_{\mathrm{H}+}^{2}\right)$ & 4.01 & 3.60 & 4.34 & 4.45 & 4.43 & 4.96 & 5.05 & 5.13 & & 5.23 & 5.14 & 5.20 & 5.21 & 5.26 & 5.25 & 5.20 & 5.19 & 5.17 & 5.16 & 5.17 & 5.17 & 5.14 & 5.09 & 5.10 \\
\hline $\log a \mathrm{Na}^{+}$ & -1.29 & -1.27 & -1.25 & -1.25 & -1.24 & -1.25 & -1.25 & -1.25 & & -1.24 & -1.24 & -1.24 & -1.24 & -1.24 & -1.24 & -1.24 & -1.24 & -1.24 & -1.24 & -1.24 & -1.25 & -1.24 & -1.24 & -1.24 \\
\hline $\log a \mathrm{~K}^{+}$ & -2.74 & -2.74 & -2.74 & -2.73 & -2.74 & -2.74 & -2.74 & -2.74 & & -2.74 & -2.74 & -2.74 & -2.74 & -2.73 & -2.74 & -2.73 & -2.73 & -2.73 & -2.73 & -2.74 & -2.73 & -2.73 & -2.73 & -2.73 \\
\hline $\log a \mathrm{Cl}^{-}$ & -1.25 & -1.23 & -1.22 & -1.22 & -1.21 & -1.21 & -1.21 & -1.21 & & -1.21 & -1.21 & -1.21 & -1.21 & -1.20 & -1.20 & -1.21 & -1.20 & -1.20 & -1.20 & -1.21 & -1.21 & -1.21 & -1.20 & -1.20 \\
\hline $\log a \mathrm{SO}_{4}^{2-}$ & -7.39 & -7.29 & -7.28 & -7.24 & -7.20 & -6.94 & -7.04 & -7.01 & & -7.17 & -27.70 & -7.18 & -7.20 & -7.07 & -7.21 & -7.18 & -7.25 & -7.19 & -7.25 & -7.26 & -7.15 & -7.32 & -7.26 & -7.24 \\
\hline $\log a \mathrm{Ca}^{2+}$ & -4.62 & -4.65 & -4.67 & -4.68 & -4.72 & -4.72 & -4.76 & -4.80 & & -4.84 & -4.84 & -4.84 & -4.84 & -4.84 & -4.86 & -4.85 & -4.84 & -4.83 & -4.83 & -4.85 & -4.84 & -4.83 & -4.82 & -4.82 \\
\hline $\log a \mathrm{Mg}^{2+}$ & -7.41 & -7.86 & -7.15 & -7.05 & -7.10 & -6.61 & -6.54 & -6.49 & & -6.39 & -6.42 & -6.42 & -6.41 & -6.39 & -6.38 & -6.43 & -6.42 & -6.44 & -6.45 & -6.45 & -6.46 & -6.47 & -6.51 & -6.51 \\
\hline $\log a \mathrm{Fe}^{2+}$ & -5.57 & -5.51 & -5.49 & -5.41 & -5.28 & -4.92 & -4.84 & -4.80 & & -4.76 & -4.74 & -4.74 & -4.73 & -4.73 & -4.73 & -4.71 & -4.74 & -4.75 & -4.75 & -4.74 & -4.73 & -4.76 & -4.77 & -4.78 \\
\hline $\mathrm{T}\left({ }^{\circ} \mathrm{C}\right)$ & 400.8 & 400.6 & 400.4 & 400.6 & 400.7 & 400.3 & 400.7 & 400.5 & & 400.8 & 400.4 & 400.3 & 400.6 & 400.50 & 400.60 & 400.40 & 400.60 & 400.80 & 400.30 & 400.50 & 400.70 & 400.30 & 400.70 & 400.40 \\
\hline P(bar) & 486.4 & 486.5 & 486.5 & 486.4 & 486.5 & 486.8 & 486.5 & 486.8 & & 487.3 & 487.2 & 487.2 & 487.3 & 487.18 & 487.20 & 487.20 & 487.15 & 487.16 & 487.20 & 487.24 & 487.24 & 487.26 & 487.28 & 487.27 \\
\hline in situ $\mathrm{pH}_{\left(400^{\circ} \mathrm{C}\right)}$ & 5.71 & 5.73 & 5.74 & 5.75 & 5.77 & 5.79 & 5.80 & 5.81 & & 5.81 & 5.78 & 5.81 & 5.81 & 5.82 & 5.82 & 5.81 & 5.81 & 5.81 & 5.80 & 5.81 & 5.81 & 5.80 & 5.80 & 5.80 \\
\hline room $\mathrm{T}_{\mathrm{P}}$ & 3.99 & 4.04 & 4.12 & 4.17 & 4.53 & 4.27 & 4.28 & 4.5 & & 4.48 & 4.54 & 4.5 & 4.53 & 4.54 & 4.53 & 4.59 & 4.62 & 4.63 & 4.6 & 4.55 & 4.65 & 4.55 & 4.53 & 4.55 \\
\hline flow rate (ml hr-1) & 1 & 1 & 1.5 & 1.5 & 10 & 10 & 10 & 10 & & 10 & 10 & 10 & 10 & 10 & 10 & 7.5 & 7.5 & 7.5 & 7.5 & 7.5 & 5 & 5 & 5 & 5 \\
\hline time (hrs) & 509.6 & 532.6 & 556.9 & 582.8 & 583.8 & 584.8 & 585.8 & 586.8 & & 603.3 & 605.3 & 607.3 & 609.3 & 611.3 & 626.8 & 628.8 & 630.8 & 632.8 & 634.8 & 651.3 & 653.3 & 655.3 & 657.3 & 659.0 \\
\hline & & & & & & & & & & & & & & & & & & & & & & & & \\
\hline Log Ksp (Supcrt92) @4400 C & 4.27 & 4.27 & 4.27 & 4.27 & 4.2 & $4.2 .2-3$. & 4.2 & 4.27 & & 4.2. & 4.2. & & 4.27 & 4. & 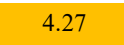 & 4.2. & $4.27-2$ & 4.27 & $4.6>3$ & 4.2 & 4.27 & 4.27 & 4.27 & 4.27 \\
\hline $\log Q($ or $\log \mathrm{I}$ & 4.3 & 4.58 & 45 & 4.51 & $4.4 .4-4$ & 4.4 & 4.25 & 4.38 & & 4.41 & 4.60 & $<\mathrm{L}$ & 4.58 & & 4.49 & 4.62 & 4.61 & & & 4.65 & 4.65 & 4.55 & 4.70 & 54 \\
\hline Log SI & 0.07 & 0.31 & 0.24 & 0.24 & 0.22 & 0.19 & -0.02 & 0.11 & & 0.14 & 0.33 & $\leq$ LOD & 0.31 & 0.32 & 0.22 & 0.35 & 0.34 & 0.36 & 0.31 & 0.38 & 0.38 & 0.28 & 0.43 & 0.37 \\
\hline
\end{tabular}




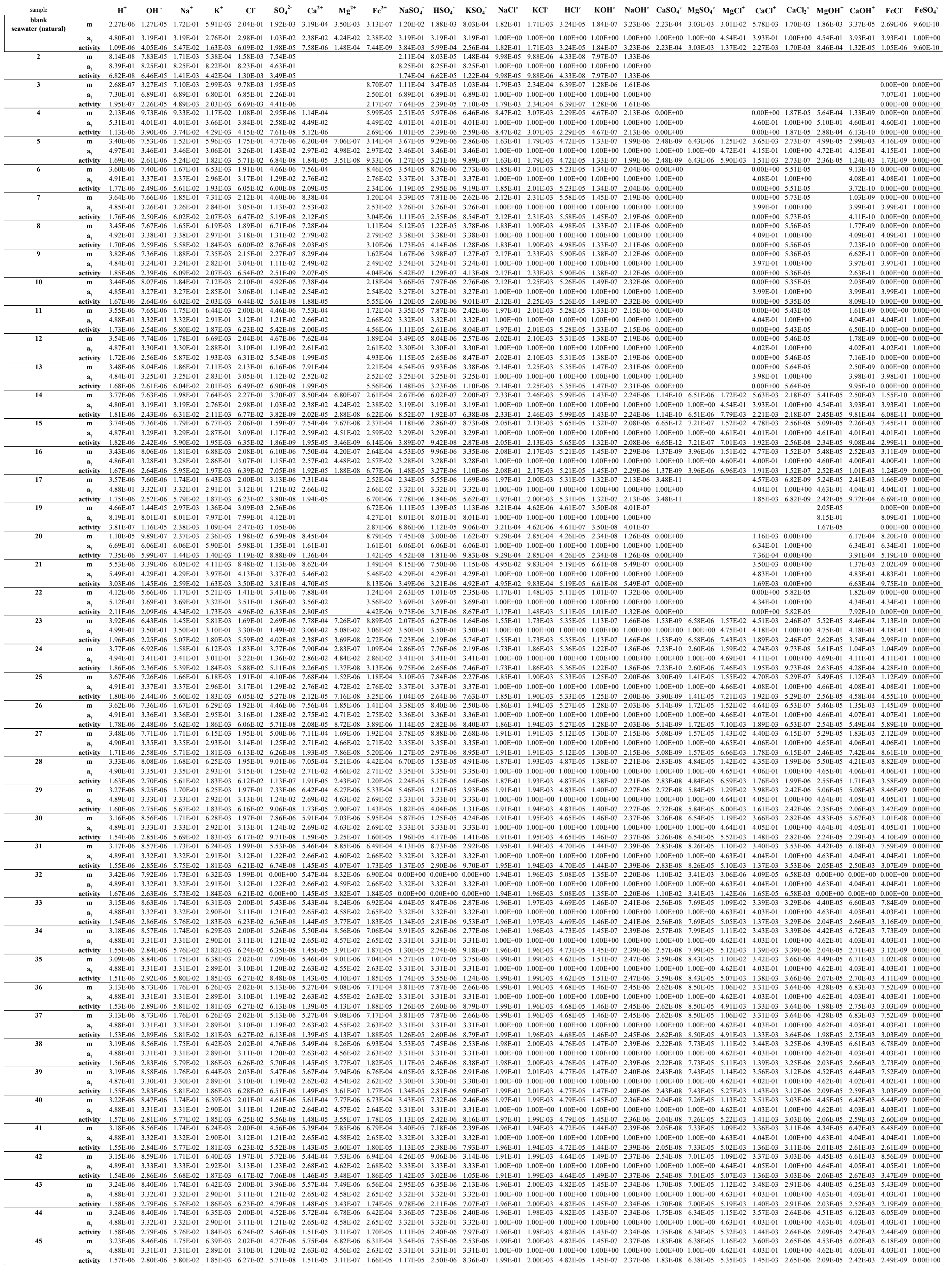




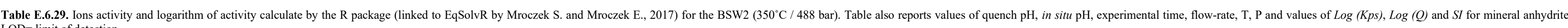

\begin{tabular}{|c|c|c|c|c|c|c|c|c|c|c|c|c|c|c|c|c|c|c|c|c|c|c|c|c|c|c|c|c|}
\hline samples & $\begin{array}{l}\text { nk seawater (natural) } \\
\text { de-oxygenated }\end{array}$ & 1 & 2 & 3 & 4 & 5 & 6 & 7 & 8 & 9 & 10 & 11 & 12 & 13 & 14 & 15 & 16 & 17 & 18 & 19 & 20 & 21 & 22 & 23 & 24 & 25 & 26 & 27 \\
\hline$a=\boldsymbol{m} \cdot \boldsymbol{a}_{\gamma}$ & & & & & & & & & & & & & & & & & & & & & & & & & & & & \\
\hline $\begin{array}{c}\mathrm{H}^{+} \\
\mathrm{OH}^{-}\end{array}$ & $\begin{array}{l}2.02 E-06 \\
3.83 E-06\end{array}$ & $2.45 E-07$ & $1.64 \mathrm{E}-06$ & $\begin{array}{l}4.20 \mathrm{E}-06 \\
.20 \mathrm{C}\end{array}$ & $4.53 \mathrm{E}-06$ & $4.92 \mathrm{E}-06$ & $5.45 E-06$ & $6.00 \mathrm{E}-06$ & $5.99 \mathrm{E}-06$ & $5.22 \mathrm{E}-06$ & $5.24 \mathrm{E}-06$ & $5.077-06$ & $4.87 \mathrm{E}-06$ & $5.03 E-06$ & $5.07 E-06$ & $5.19 \mathrm{E}-06$ & $5.05 E-06$ & $5.13 \mathrm{E}-06$ & $5.16 \mathrm{E}-06$ & $5.03 \mathrm{E}-06$ & $5.39 E-06$ & $5.10 \mathrm{E}-06$ & $5.04 \mathrm{E}-06$ & $5.01 E-06$ & $5.10 \mathrm{E}-06$ & $5.13 \mathrm{E}-06$ & $5.01 \mathrm{E}-06$ & $5.17 \mathrm{E}-06$ \\
\hline $\begin{array}{l}\mathrm{OH} \\
\mathrm{Na}^{+}\end{array}$ & $\begin{array}{l}3.834-06 \\
8.94-02\end{array}$ & 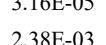 & 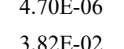 & $\begin{array}{l}1.846-060 \\
710-02\end{array}$ & $\begin{array}{l}1.711 \mathrm{E}-06 \\
8.34 \mathrm{E}-02\end{array}$ & $\begin{array}{l}1.57 \mathrm{l}-\mathrm{E}-6 \\
8.89 \mathrm{E}-02\end{array}$ & $\begin{array}{l}1.42 E-06 \\
9.35 E-02\end{array}$ & $\begin{array}{l}1.29 E-06 \\
9.33-02\end{array}$ & $\begin{array}{l}1.29 \mathrm{EE}-06 \\
0.4 \mathrm{E}-02\end{array}$ & $\begin{array}{l}1.488 E=06 \\
9.990-02\end{array}$ & $\begin{array}{l}1.47 Z-06 \\
9.325-02\end{array}$ & $\begin{array}{l}1.522-06 \\
0.25-02\end{array}$ & $\begin{array}{l}1.59 \mathrm{E}-06 \\
9.40-02\end{array}$ & $\begin{array}{l}1.544-06 \\
0.435-02\end{array}$ & $\begin{array}{l}1.52 \mathrm{E}-\mathrm{-}-6 \\
9.49-02\end{array}$ & 1.49E- -06 & $1.53 \mathrm{E}-06$ & $1.51 E-06$ & $1.50 \mathrm{E}-06$ & $1.54 E-06$ & 1.43EE-06 & $1.5 \mathrm{EE}-06$ & 1.53E-06 & $1.54 E-06$ & $1.51 \mathrm{E}-06$ & $1.51 \mathrm{E}-06$ & $1.54 \mathrm{E}-06$ & $\begin{array}{l}1.49 \mathrm{E}-06 \\
0.57-02\end{array}$ \\
\hline $\mathrm{K}^{+}$ & $2.59 \mathrm{E}-03$ & 6.75E-04 & $9.32 \mathrm{E}-03$ & $3.56 \mathrm{E}-03$ & $2.65 \mathrm{E}-03$ & $2.76 \mathrm{E}-03$ & $2.83 \mathrm{E}-03$ & $2.87 \mathrm{E}-03$ & $3.10 \mathrm{E}-03$ & $2.74 \mathrm{E}-03$ & $2.76 \mathrm{E}-03$ & $2.82 \mathrm{E}-03$ & $\begin{array}{l}9.4 \mathrm{ULV}-\mathrm{z} 2 \\
2.80 \mathrm{E}-03\end{array}$ & $\begin{array}{l}9.4 \mathrm{TL}-\mathrm{T} 2 \\
2.77 \mathrm{E}-03\end{array}$ & $\begin{array}{l}9.4 \mathrm{gEE}-02 \\
2.75 \mathrm{E}-03\end{array}$ & $\begin{array}{l}9.42 E-02 \\
2.98 E-03 \\
2\end{array}$ & $\begin{array}{l}9.50 \mathrm{9}-\mathrm{E}-22 \\
2.90-03\end{array}$ & $\begin{array}{l}9.39 \mathrm{~g}-\mathrm{E}-2 \\
2.93 \mathrm{E}-03\end{array}$ & $\begin{array}{l}9.43 E-E 2 \\
2.90-03\end{array}$ & $\begin{array}{l}9.40 E-02 \\
2.96-03\end{array}$ & $\begin{array}{l}9.46 \mathrm{f}-\mathrm{-}-22 \\
2.94-03\end{array}$ & $\begin{array}{l}9.5 \mathrm{E} \mid-02 \\
2.90 \mathrm{E}-03\end{array}$ & $\begin{array}{l}9.5 \mathrm{E} E-02 \\
2.82 \mathrm{E}-03\end{array}$ & $\begin{array}{l}9.46 \mathrm{~F}-\mathrm{E} 2 \\
2.8 \mathrm{E}-\mathrm{s}\end{array}$ & $\begin{array}{l}9.542-02 \\
2.825-03\end{array}$ & $\begin{array}{l}9.544-\mathrm{E} 2 \\
2.87 \mathrm{E}-03\end{array}$ & $\begin{array}{l}9.66 \mathrm{~g}-\mathrm{E}-2 \\
2.8 \mathrm{E}-03\end{array}$ & $\begin{array}{l}9.57 \mathrm{~g}-\mathrm{E}-2 \\
2.80-03\end{array}$ \\
\hline $\mathrm{Cr}$ & $9.77 \mathrm{E}-02$ & $2.81 \mathrm{E}-03$ & $4.68 \mathrm{E}-02$ & $7.61 \mathrm{E}-02$ & $8.94 \mathrm{E}-02$ & $9.53 \mathrm{E}-02$ & $1.00 \mathrm{E}-01$ & $1.01 \mathrm{E}-01$ & $1.03 \mathrm{E}-01$ & $1.06 \mathrm{E}-01$ & $9.98 \mathrm{E}-02$ & $9.93 \mathrm{E}-02$ & $1.01 E-01$ & $1.01 E-01$ & $1.02 E-01$ & $1.01 \mathrm{E}-01$ & $1.02 \mathrm{E}-01$ & $1.01 \mathrm{E}-01$ & $1.01 \mathrm{E}-01$ & $1.01 \mathrm{E}-01$ & $1.01 E-01$ & $1.02 E-01$ & $1.02 E-01$ & $1.01 E-01$ & $1.02 E-01$ & $1.02 \mathrm{E}-01$ & $1.03 \mathrm{E}-01$ & $1.03 \mathrm{E}-01$ \\
\hline $\mathrm{SO}_{4}^{2-}$ & $5.13 \mathrm{E}-05$ & $2.91 \mathrm{E}-05$ & $4.15 \mathrm{E}-07$ & $2.15 \mathrm{E}-07$ & $3.10 \mathrm{E}-07$ & $1.99 \mathrm{E}-07$ & $4.78 \mathrm{E}-07$ & $6.04 \mathrm{E}-07$ & $5.79 \mathrm{E}-07$ & $6.11 \mathrm{E}-07$ & $3.56 \mathrm{E}-07$ & $3.05 E-07$ & $3.57 \mathrm{E}-07$ & $3.00 E-07$ & $2.70 \mathrm{E}-07$ & $2.56 \mathrm{E}-07$ & $2.57 \mathrm{E}-07$ & $2.30 \mathrm{E}-07$ & $2.05 \mathrm{E}-07$ & $2.36 \mathrm{E}-07$ & $1.34 \mathrm{E}-07$ & $1.88 \mathrm{E}-07$ & $2.15 \mathrm{E}-07$ & $2.16 \mathrm{E}-07$ & $1.88 \mathrm{E}-07$ & $1.87 \mathrm{E}-07$ & $1.86 \mathrm{E}-07$ & $1.60 \mathrm{E}-07$ \\
\hline $\mathrm{Ca}^{2+}$ & $2.62 \mathrm{E}-05$ & $<$ LOD & $7.24 \mathrm{E}-07$ & $4.93 \mathrm{E}-05$ & $7.13 E-05$ & $7.48 \mathrm{E}-05$ & $4.59 \mathrm{E}-05$ & $4.00 \mathrm{E}-05$ & 4.45E-05 & $4.10 \mathrm{E}-05$ & $5.45 \mathrm{E}-05$ & $6.26 \mathrm{E}-05$ & $6.19 \mathrm{E}-05$ & $6.27 \mathrm{EE}-05$ & $6.24 \mathrm{E}-05$ & $6.32 \mathrm{E}-05$ & $6.39 \mathrm{E}-05$ & $7.15 E-05$ & $7.43 E-05$ & $7.60 \mathrm{E}-05$ & $7.37 \mathrm{EE}-05$ & $7.62 \mathrm{E}-05$ & $7.82 \mathrm{E}-05$ & $7.73 \mathrm{E}-05$ & $7.56 \mathrm{E}-05$ & $7.44 E-05$ & $7.35 \mathrm{E}-05$ & $7.77 \mathrm{E}-05$ \\
\hline $\mathrm{Mg}^{2+}$ & $3.80 \mathrm{E}-04$ & $<$ LOD & $<$ LOD & $<$ LOD & $3.92 \mathrm{E}-07$ & $5.09 \mathrm{E}-07$ & $3.50 \mathrm{E}-05$ & $5.74 \mathrm{E}-05$ & $5.46 \mathrm{E}-05$ & $4.00 \mathrm{E}-05$ & $2.12 \mathrm{E}-05$ & $1.28 \mathrm{E}-05$ & $1.23 \mathrm{E}-05$ & $1.20 \mathrm{E}-05$ & $1.15 \mathrm{E}-05$ & $1.23 \mathrm{E}-05$ & $9.89 \mathrm{E}-06$ & $6.93 \mathrm{E}-06$ & $5.11 \mathrm{E}-06$ & $4.09 \mathrm{E}-06$ & $4.92 E-06$ & $2.87 \mathrm{E}-06$ & $2.50 \mathrm{E}-06$ & $2.52 \mathrm{E}-06$ & $3.10 \mathrm{E}-06$ & $3.93 \mathrm{E}-06$ & $2.72 \mathrm{E}-06$ & $2.02 E-06$ \\
\hline$F_{0}$ & $<$ LOD & $<$ LOD & $<$ LOD & $<$ LOD & $<$ LOD & $<$ LOD & $3.36 \mathrm{E}-05$ & $3.83 \mathrm{E}-05$ & $4.13 \mathrm{E}-05$ & $3.35 \mathrm{E}-05$ & $2.65 \mathrm{E}-05$ & $1.98 \mathrm{E}-05$ & $1.99 \mathrm{E}-05$ & $1.97 \mathrm{E}-05$ & $1.90 \mathrm{E}-05$ & $2.04 \mathrm{E}-05$ & $1.54 \mathrm{E}-05$ & $7.31 \mathrm{E}-06$ & $2.49 \mathrm{E}-06$ & $7.75 \mathrm{E}-09$ & $2.95 \mathrm{E}-06$ & $<$ LOD & $<$ LOD & $<$ LOD & $<$ LOD & 1.36E-06 & <LOD & $<$ LOD \\
\hline$a^{2} H^{+}$ & 4.06E-12 & $5.99 \mathrm{E}-14$ & $2.70 \mathrm{E}-12$ & $1.77 \mathrm{E}-11$ & $2.05 \mathrm{E}-11$ & $2.42 E-11$ & $2.97 \mathrm{E}-11$ & 3.59E-11 & $3.59 \mathrm{E}-11$ & $2.73 \mathrm{E}-11$ & $2.75 \mathrm{E}-11$ & $2.57 \mathrm{E}-11$ & $2.37 \mathrm{E}-11$ & $2.53 \mathrm{E}-11$ & $2.57 \mathrm{E}-11$ & $2.69 \mathrm{E}-11$ & $2.55 \mathrm{E}-11$ & $2.63 \mathrm{E}-11$ & $2.66 \mathrm{E}-11$ & $2.53 \mathrm{E}-11$ & $2.90 \mathrm{E}-11$ & $2.60 \mathrm{E}-11$ & $2.54 \mathrm{E}-11$ & $2.51 \mathrm{E}-11$ & $2.60 \mathrm{E}-11$ & $2.63 \mathrm{E}-11$ & $2.51 \mathrm{E}-11$ & \\
\hline $\log \left(a \mathrm{SiO}_{2}\right.$ & -3.8 & -1.5 & -1.5 & -1.5 & -1.5 & -1.5 & -1.4 & -1.4 & -1.4 & -1.4 & -1.5 & -1.5 & -1.5 & -1.5 & -1.5 & -1.5 & -1.6 & -1.6 & -1.6 & -1.6 & -1.6 & -1.6 & -1.6 & -1.6 & -1.6 & -1.6 & -1.6 & -1.6 \\
\hline $\log \left(a_{k}\right.$ & 3.1 & 3.4 & 3.8 & 2.9 & 2.8 & 2.7 & 2.7 & 2.7 & 2.7 & 2.7 & 2.7 & 2.7 & 2.8 & 2.7 & 2.7 & 2.8 & 2.8 & 28 & 2. 7 & 2 & $-\pi$ & 2.8 & 2.7 & 2.8 & 2.7 & 2.7 & 2.7 & 2.7 \\
\hline avad & & & 4.4 & 4.2 & 4.3 & 4.3 & 4.2 & 4.2 & 4. & 4.3 & 4.2 & 4.3 & 4.3 & 4.3 & 4.3 & 4.3 & 4.3 & 4.3 & 4.3 & 4.3 & 4.2 & 4. & 4.3 & 4.3 & 4.3 & 4.3 & 4.3 & 4.3 \\
\hline $\mathrm{Ca}_{\mathrm{Ca}}$ & & & & 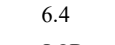 & 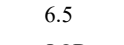 & 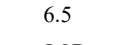 & 6.2 & 6.0 & 6.1 & 6.2 & 6.3 & 6.4 & 6.4 & 6.4 & 6.4 & 6.4 & 6.4 & 6.4 & 6.4 & 6.5 & 6.4 & & 6.5 & 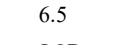 & 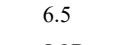 & & .5 & tron \\
\hline $\log \left(a_{\mathrm{Fe} 2}+a^{a}\right.$ & $<$ LOD & $<$ LOD & $<$ LOD & $<$ LOD & $<$ LOD & $<$ LOD & 6.1 & 6.0 & 6.1 & 6.1 & 6.0 & 5.9 & 5.9 & 5.9 & 5.9 & 5.9 & 5.8 & 5.4 & 5.0 & $<$ LOD & 5.0 & $<$ LOD & $<$ LOD & $<$ LOD & $<$ LOD & $<$ LOD & $<$ LOD & $<$ LOD \\
\hline $\log \left(a_{\mathrm{Mg}_{2}+} / a_{\mathrm{HH}}^{2}\right)$ & 8.0 & $<$ LOD & $<$ LOD & $<$ LOD & 4.3 & 4.3 & 6.1 & 6.2 & 6.2 & 6.2 & 5.9 & 5.7 & 5.7 & 5.7 & 5.7 & 5.7 & 5.6 & 5.4 & 5.3 & 5.2 & 5.2 & 5.0 & 5.0 & 5.0 & 5.1 & 5.2 & 5.0 & 4.9 \\
\hline $\log a \mathrm{Na}$ & -1.0 & -2.6 & -1.4 & -1.1 & -1.1 & -1.1 & -1.0 & -1.0 & -1.0 & -1.0 & -1.0 & -1.0 & -1.0 & -1.0 & -1.0 & -1.0 & -1.0 & -1.0 & -1.0 & -1.0 & -1.0 & -1.0 & -1.0 & -1.0 & -1.0 & -1.0 & -1.0 & -1.0 \\
\hline & -2.6 & -3.2 & -2.0 & -2.4 & -2.6 & -2.6 & -2.5 & -2.5 & -2.5 & -2.6 & -2.6 & -2.5 & -2.6 & -2.6 & -2.6 & -2.5 & -2.5 & -2.5 & -2.5 & -2.5 & -2.5 & -2.5 & -2.5 & -2.5 & -2.5 & -2.5 & -2.6 & -2.6 \\
\hline $\log a$ & -1. & -2.6 & -1.3 & -1.1 & -1.0 & -1.0 & -1.0 & -1.0 & -1.0 & -1.0 & -1.0 & -1.0 & -1. & -1.0 & -1. & -1.0 & -1. & -1.0 & -1 & -1.0 & -1.6 & -1.0 & -1.6 & -1.0 & -1.0 & -1.0 & -1.0 & -1.0 \\
\hline $\log a \mathrm{~S}$ & -4. & -4.5 & -6.4 & -6.7 & -6.5 & -6.7 & -6.3 & -6. & -6.2 & -6. & -6. & -6.5 & -6. & -6.5 & -6 & -6.6 & -6 & -6 & -6. & -6.6 & -6. & -6 & -6.7 & -6.7 & -6.7 & -6.7 & -6.7 & -6.8 \\
\hline $\log a c$ & -4 & $<$ LOD & -6. & -4. & -4. & -4 & -4. & -4 & -4. & -4 & -4 & -4 & -4 & -4 & -4 & -4 & 4 & -4 & -4 & 4 & -4. & -4 & -4 & -4 & -4.1 & 4 & 1 & -4.1 \\
\hline $\log a \mathrm{~N}$ & -3.4 & $<1$ & $<1$ & $c^{<1}$ & & t & -4. & 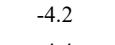 & -4. & -4 & & -4 & -4 & -4 & -4 & -4 & 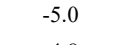 & -5 & -5 & 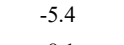 & -5.3 & & & & & & 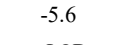 & -5.7 \\
\hline 10 & $<$ LOD & $<$ LOD & $<$ LOD & $<$ LOD & $<$ LOD & $<$ LOD & -4 & -4 & -4 & -4 & -4 & -4 & -4. & -4 & -4. & -4 & -4 & & -5. & 0 & -5 & & $<$ LOD & & LOD & & $<$ LOD & \\
\hline $\begin{array}{l}\text { T ( }{ }^{\circ} \text { C) } \\
\text { P(ar) }\end{array}$ & 50 & $\begin{array}{l}32.4 \\
487.5\end{array}$ & 487.4 & $\begin{array}{l}350.5 \\
487.5\end{array}$ & 487.4 & $\begin{array}{l}30.1 \\
487.0\end{array}$ & 487.0 & $\begin{array}{l}30.8 \\
487.1\end{array}$ & 487.1 & 486.9 & 487.0 & 487.0 & 486.9 & 486.9 & 486.9 & 486.9 & 486.9 & 486.9 & 487.0 & 486.9 & 487.4 & 486.8 & 487.0 & 487.1 & 487.1 & 37.2 & 487.1 & $\begin{array}{l}350.8 \\
436.9\end{array}$ \\
\hline in situ $\mathrm{pH}_{\left(350^{\circ} \mathrm{C}\right)}$ & 5.70 & 6.61 & 5.78 & 5.38 & 5.34 & 5.31 & 5.26 & 5.22 & 5.22 & 5.28 & 5.28 & 5.29 & 5.31 & 5.30 & 5.29 & 5.29 & 5.30 & 5.29 & 5.29 & 5.30 & 5.27 & 5.29 & 5.30 & 5.30 & 5.29 & 5.29 & 5.30 & 5.29 \\
\hline room T pH & 8.20 & 5.15 & 3.97 & 3.81 & 3.71 & 3.73 & 3.11 & 3.23 & 3.36 & 3.47 & 4.05 & 3.98 & 4.01 & 4.01 & 4.05 & 4.11 & 4.17 & 4.17 & 4.24 & 4.26 & 4.26 & 4.26 & 4.22 & 4.24 & 4.21 & 4.31 & 4.27 & 4.36 \\
\hline flow rate & & 1 & 1 & 1 & 1 & & 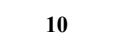 & 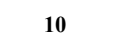 & 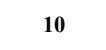 & 10 & 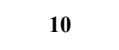 & & 10 & 10 & 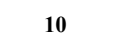 & 10 & & 5 & & & & & & & & & 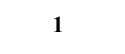 & \\
\hline tim & 0.0 & 18.5 & 48.2 & 74.6 & 97.8 & 119.8 & 121.3 & 123.3 & 125.3 & 127.3 & 143.3 & 145.3 & 147.3 & 149.3 & 151.1 & 167.3 & 169.3 & 171.3 & 173.3 & 175.3 & 190.8 & 199.0 & 215.3 & 222.3 & 240.8 & 264.3 & 288.4 & 311.0 \\
\hline 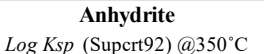 & & & & & & & & & & & & & & & & & & & & & & & & & & & & \\
\hline 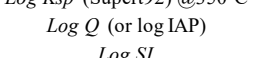 & & & $\begin{array}{l}5.86 \\
2.00\end{array}$ & $\begin{array}{l}4.32 \\
0.46\end{array}$ & 4.01 & 4.17 & $\begin{array}{l}4.01 \\
0.15\end{array}$ & 0.11 & $\begin{array}{l}3.94 \\
0.92\end{array}$ & 3.96 & 0.021 & $\begin{array}{l}4.07 \\
0.21\end{array}$ & $\begin{array}{l}4.01 \\
0.015\end{array}$ & $\begin{array}{l}4.088 \\
0.028\end{array}$ & $\begin{array}{l}-0.72 \\
-458\end{array}$ & $\begin{array}{l}4.13 \\
027\end{array}$ & $\begin{array}{l}4.13 \\
027\end{array}$ & $\begin{array}{l}4.13 \\
07\end{array}$ & $\begin{array}{l}4.16 \\
030\end{array}$ & $\begin{array}{l}4.09 \\
0.03 \\
0.3\end{array}$ & $\begin{array}{l}4.38 \\
\text { n.35 }\end{array}$ & $\begin{array}{l}4.21 \\
.23 .\end{array}$ & $\begin{array}{l}4.13 \\
0.17\end{array}$ & $\begin{array}{l}4.13 \\
4.137 \\
0.07\end{array}$ & 4.20 & $\begin{array}{l}3.21 \\
4.21 \\
0.35\end{array}$ & 4.22 & 4.22 \\
\hline
\end{tabular}


Table E.6.30. Values of the activity coefficients $\left(\mathrm{a}_{\gamma}\right)$ calculated by the R package for the $\mathrm{BSW} 2\left(350^{\circ} \mathrm{C} / 488 \mathrm{bar}\right)$

\begin{tabular}{|c|c|c|c|c|c|c|c|c|c|c|c|c|c|c|c|c|c|c|c|c|c|c|c|c|c|c|c|}
\hline mple & & $\mathbf{H}^{+}$ & $\mathrm{OH}^{-}$ & $\mathrm{Na}^{+}$ & $K^{+}$ & $\mathrm{Cr}$ & $\mathrm{SO}_{4}^{2-}$ & $\mathrm{Ca}^{2+}$ & $\mathrm{Mg}^{2+}$ & $\mathrm{Fe}^{2+}$ & $\mathrm{aSO}_{4}$ & $\mathrm{HSO}_{4}$ & $\mathrm{KSO}_{4}$ & $\mathrm{NaCl}^{\circ}$ & $\mathrm{KCl}^{\circ}$ & $\mathrm{Cl}^{1}$ & $\mathrm{KOH}^{\circ}$ & $\mathrm{NaOH}^{\circ}$ & $\mathrm{CaSO}_{4}^{\circ}$ & $\mathrm{MgSO}_{4}{ }^{\circ}$ & $\mathbf{M g C l}^{+}$ & $\mathrm{CaCl}^{+}$ & $\mathrm{CaCl}_{2}^{\circ}$ & $\mathrm{MgOH}^{+}$ & $\mathrm{CaOH}^{+}$ & $\mathrm{FeCl}$ & $\mathrm{FeSO}_{4}{ }^{\circ}$ \\
\hline blank & & 50E- 0 & $.10 \mathrm{E}-0$ & $1.12 E-1$ & $6.88 \mathrm{E}-\mathrm{C}$ & $2.44 \mathrm{E}-01$ & $1.63 \mathrm{E}-0$ & $4.39 \mathrm{E}-04$ & 4.10E-03 & & $1.24 \mathrm{E}-$ & & $7.09 \mathrm{E}$ & & & 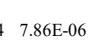 & & & & & & & & & 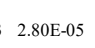 & & \\
\hline & & $5.76 \mathrm{E}-01$ & $2.21 \mathrm{E}-01$ & $4.21 \mathrm{E}-01$ & $3.77 \mathrm{E}-$ & 4.00E-01 & $1.15 \mathrm{E}-02$ & 997E-02 & $9.26 \mathrm{E}-022$ & & $4.21 \mathrm{E}-01$ & 215 & $2.21 E-011$ & & & & & & & & & & & $.52 \mathrm{E}-01$ & -01 & & \\
\hline & activity & $\begin{array}{l}2 \mathrm{EE}-06 \\
\text { S-07 }\end{array}$ & $\frac{.83 \mathrm{E}-06}{71-05}$ & & & & & & $3.80 \mathrm{E}-\mathrm{C}$ & & & & & & & & & & & & $1.46 \mathrm{E}-02$ & 2 & $07 \mathrm{CZE}-03$ & $5.93 \mathrm{E}-04$ & $1.38 \mathrm{E}-05$ & & \\
\hline 1 & & $2.85 \mathrm{E}-07$ & $3.74 \mathrm{E}-05$ & & $8.03 \mathrm{E}-04$ & $3.34 \mathrm{E}-03$ & $5.75 \mathrm{E}-05$ & & & & $9.33 \mathrm{E}-05$ & $3.79 \mathrm{E}-05$ & $5.22 \mathrm{E}-05$ & $1.02 \mathrm{E}-04$ & 7.39E-06 & & & & $\mathrm{E}+00$ & & & & & & $1.07 E-06$ & & \\
\hline & & $8.58 \mathrm{E}-01$ & $8.43 \mathrm{E}-01$ & $8.43 \mathrm{E}-01$ & $8.40 \mathrm{E}-01$ & $8.42 \mathrm{E}-01$ & $5.06 \mathrm{E}-01$ & $5.21 \mathrm{E}-01$ & & & $8.43 \mathrm{E}-01$ & $8.43 \mathrm{E}-01$ & $8.43 \mathrm{E}-01$ & $1.00 \mathrm{E}+00$ & $1.00 \mathrm{E}+00$ & $0 \quad 1.00 \mathrm{E}+00$ & $\begin{array}{lll}0 & 1.00 \mathrm{E}+00\end{array}$ & $\begin{array}{lll}0 & 1.00 \mathrm{E}+00\end{array}$ & $01.00 \mathrm{E}+00$ & & & $8.49 \mathrm{E}-01$ & $1.00 \mathrm{E}+00$ & & 8. & & \\
\hline & activit & $2.45 \mathrm{E}-07$ & $3.16 \mathrm{E}-05$ & $\begin{array}{l}2.38 \mathrm{E}-03 \\
7.07 \mathrm{E}-0.2\end{array}$ & $\begin{array}{l}6.75 \mathrm{E}-04 \\
183 \mathrm{E}-0.2\end{array}$ & $\begin{array}{r}2.81 \mathrm{E}-03 \\
880 \mathrm{E}-02\end{array}$ & $\begin{array}{l}2.91 E-05 \\
56 \text { (1) }\end{array}$ & $0.00 \mathrm{E}+00$ & & & $\begin{array}{l}7.86 \mathrm{E}-05 \\
.50 .05\end{array}$ & $\begin{array}{l}3.20 \mathrm{E}-05 \\
50 \mathrm{C}-1\end{array}$ & $4.40 \mathrm{E}-05$ & 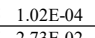 & $\begin{array}{l}7.39 E-06 \\
1770.03\end{array}$ & $52.75 \mathrm{E}-08$ & $\begin{array}{lll}82.56 \mathrm{E}-07 \\
\end{array}$ & $\begin{array}{ll}7 \quad 5.20 \mathrm{E}-07 \\
7.20\end{array}$ & & & & $0.00 E+00$ & & & $\begin{array}{l}9.10 \mathrm{E}-07 \\
\end{array}$ & & \\
\hline 2 & & $\begin{array}{l}2.51 \mathrm{E}-06 \\
6.45 \mathrm{E}-01\end{array}$ & $\begin{array}{l}8.84 \mathrm{E}-06 \\
5.40 \mathrm{E}-01\end{array}$ & $\begin{array}{l}7.07 \mathrm{E}-02 \\
5.40 \mathrm{E}-01\end{array}$ & $\begin{array}{l}1.83 \mathrm{E}-02 \\
5.11 \mathrm{E}-01\end{array}$ & $\begin{array}{l}8.90 \mathrm{E}-02 \\
5.26 \mathrm{E}-01\end{array}$ & $\begin{array}{l}5.16 \mathrm{E}-06 \\
8.48 \mathrm{E}-02\end{array}$ & & & & $\begin{array}{l}3.51 \mathrm{E}-05 \\
5.40 \mathrm{E}-01\end{array}$ & $\begin{array}{l}5.90 \mathrm{E}-06 \\
5.40 \mathrm{E}-01\end{array}$ & $\begin{array}{l}1.70 \mathrm{E}-05 \\
5.40 \mathrm{E}-01\end{array}$ & $\begin{array}{l}2.73 \mathrm{E}-02 \\
1.00 \mathrm{E}+00\end{array}$ & & & & $\begin{array}{lll}7 & 1.26 \mathrm{E}-06 \\
0 & 1.00 \mathrm{E}+00\end{array}$ & & & & & & & $\begin{array}{l}0.00 \mathrm{E}+00 \\
5.88 \mathrm{E}-01\end{array}$ & & \\
\hline & & $1.62 \mathrm{E}-06$ & $4.77 \mathrm{E}-06$ & $3.82 \mathrm{E}-02$ & $9.34 \mathrm{E}-03$ & $4.68 \mathrm{E}-02$ & $4.38 \mathrm{E}-07$ & & & & $1.90 \mathrm{E}-0 \mathrm{~S}$ & $3.18 \mathrm{E}-06$ & $9.18 \mathrm{E}-06$ & & $1.70 \mathrm{E}-03$ & & & & & & & & & & $\begin{array}{l}.0 .0 \mathrm{E}-11 \\
0.00 \mathrm{E}+00\end{array}$ & & \\
\hline 3 & & $6.98 \mathrm{E}-06$ & $3.92 \mathrm{E}-06$ & 1.5 & $8.27 \mathrm{E}-03$ & $1.69 \mathrm{E}-01$ & $4.46 \mathrm{E}-06$ & $6.19 \mathrm{E}-04$ & & & $9 \mathrm{E}-05$ & $8.65 \mathrm{E}-06$ & $3.67 \mathrm{E}-06$ & & & & & 89. & $7 \quad 8.13 \mathrm{E}-03$ & & & $2.35 \mathrm{E}-05$ & $0.00 \mathrm{E}+00$ & & $0.00 \mathrm{E}+00$ & & \\
\hline & & $\begin{array}{l}6.03 \mathrm{E}-0.1 \\
4200-06\end{array}$ & $\begin{array}{l}4.68 \mathrm{E}-01 \\
1.84-0.6\end{array}$ & $\begin{array}{l}4.68 \mathrm{E}-01 \\
7.10-022\end{array}$ & $\begin{array}{l}4.31 \mathrm{E}-01 \\
3.56 \mathrm{E}-03\end{array}$ & $\begin{array}{l}4.50 \mathrm{E}-01 \\
761 \mathrm{E}-02\end{array}$ & $\begin{array}{l}4.82 \mathrm{E}-02 \\
2.15 \mathrm{E}-07\end{array}$ & $\begin{array}{l}7.977-022 \\
4938-05\end{array}$ & & & $\begin{array}{l}4.68 \mathrm{E}-01 \\
1.37 \mathrm{E}-05\end{array}$ & $\begin{array}{l}4.68 \mathrm{E}-0.1 \\
4.05-06\end{array}$ & $\begin{array}{l}4.68 \mathrm{E}-01 \\
1.72 \mathrm{E}-0.6\end{array}$ & & & $\begin{array}{ll}0 & 1.00 \mathrm{E}+00 \\
3 & 1.28 \mathrm{E}-05\end{array}$ & $\begin{array}{llll}0 & 0 & 1.4 \\
5 & 7\end{array}$ & $\begin{array}{ll}0 \\
0 \\
8 & 1.00 \mathrm{E}+00\end{array}$ & & & & & $\begin{array}{l}1.00 \mathrm{E}+00 \\
0.00 \mathrm{~F}+00\end{array}$ & & $\begin{array}{l}5.31 \mathrm{E}-01 \\
0.00 \mathrm{E}+00\end{array}$ & & \\
\hline 4 & & $\begin{array}{l}\frac{4.200-E-6}{7.68 \mathrm{E}-06} \\
7\end{array}$ & $\frac{1.84-0.06}{3.83 \mathrm{E}-06}$ & $\frac{7.100-02}{1.87 \mathrm{E}-01}$ & $\frac{3.56 \mathrm{E}-03}{6.54 \mathrm{E}-03}$ & $\frac{7.61 \mathrm{E}-02}{2.10 \mathrm{E}-01}$ & $\frac{2.15 \mathrm{E}-01}{7.86 \mathrm{E}-06}$ & 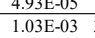 & $3.80 \mathrm{E}-06$ & & $\frac{1.135 \mathrm{E}-03}{6.58 \mathrm{E}-05}$ & 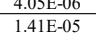 & $\frac{1.12 \mathrm{E} E-06}{4.13 \mathrm{E}-06}$ & 8.2 & 9. & -05 & -08 & E-07 & E-08 & 5 & $1.43 \mathrm{E}-02$ & $\begin{array}{l}2.25 \mathrm{E}-1.3 \\
2.4 \mathrm{E}-03\end{array}$ & $\frac{E}{E-007}$ & $3.26 \mathrm{E}-05$ & 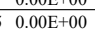 & & \\
\hline & & $5.89 \mathrm{E}-01$ & 4.45E-01 & $4.45 \mathrm{E}-01$ & $4.05 \mathrm{E}-01$ & $4.26 \mathrm{E}-01$ & $3.94 \mathrm{E}-02$ & $6.93 \mathrm{E}-02$ & & & $4.45 \mathrm{E}-01$ & & $4.45 \mathrm{E}-01$ & $1.00 \mathrm{E}+00$ & 1.0 & $\begin{array}{lll}0 & 1.00 E+00\end{array}$ & 01. & 01. & & & & & & & -01 & & \\
\hline & & $4.53 \mathrm{E}-06$ & $1.71 \mathrm{E}-06$ & $8.34 \mathrm{E}-02$ & $2.65 \mathrm{E}-03$ & $\begin{array}{l}8.94 \mathrm{E}-02 \\
8\end{array}$ & $\begin{array}{l}3.10 \mathrm{E}-07 \\
30-2\end{array}$ & $7.13 \mathrm{E}-05$ & $3.92 \mathrm{E}-07$ & & $2.93 \mathrm{E}-05$ & $6.30 \mathrm{E}-06$ & $1.84 \mathrm{E}-06$ & $1.14 \mathrm{E}-01$ & $9.20 \mathrm{E}-04$ & $\begin{array}{l}4.62 \mathrm{E}-05 \\
\end{array}$ & -08 & $\mathrm{E}-07$ & -08 & & -03 & $1.26 \mathrm{E}-03$ & $4.81 \mathrm{E}-07$ & -05 & $0.00 \mathrm{E}+00$ & & \\
\hline 5 & & $8.41 \mathrm{E}-06$ & $3.60 \mathrm{E}-06$ & $2.04 \mathrm{E}-01$ & $6.99 \mathrm{E}-03$ & $2.29 \mathrm{E}-01$ & 5.47E-06 & $1.14 \mathrm{E}-03$ & & & 59E-05 & $1.00 \mathrm{E}-05$ & $2.82 \mathrm{E}-06$ & & & & & & & & & & 05 & & & & \\
\hline & & $\begin{array}{l}5.84 \mathrm{E}-11 \\
4.92-06\end{array}$ & $\begin{array}{l}4.37 \mathrm{E}-01 \\
1.57-06\end{array}$ & 4.37Е-01 & $3.95 \mathrm{E}-01$ & $4.16 \mathrm{E}-01$ & & & $\begin{array}{l}9.91 \mathrm{E}-22 \\
5.09 \mathrm{E}-07\end{array}$ & & $\begin{array}{l}4.37 \mathrm{EE}-01 \\
2.00 \mathrm{-05}\end{array}$ & $\begin{array}{l}\begin{array}{r}3.37 \mathrm{E}-1 \\
4.38 \mathrm{E}-06\end{array} \\
4\end{array}$ & $\begin{array}{l}4.373 \mathrm{E}-01 \\
1.23 \mathrm{E}-06\end{array}$ & & & & & & 001 & & & $5.06 \mathrm{E}-01$ & $1.00 \mathrm{E}+00$ & & $\begin{array}{l}-01 \\
-00\end{array}$ & & \\
\hline 6 & & 06 & $3.30 \mathrm{E}-\mathrm{C}$ & $\frac{8.89}{2.18}$ & $\frac{1.10 \mathrm{E}}{7.32 \mathrm{E}}$ & $\frac{3.530-22}{2.45 \mathrm{E}-01}$ & $1.491 \mathrm{E}-05$ & $\frac{1.48-E S}{7.31 E-04}$ & $3.65 \mathrm{E}-04$ & $5.36 \mathrm{E}-04$ & $\frac{2.000-03}{1.18 \mathrm{E}-04}$ & $\begin{array}{l}\frac{4.388-06}{2.72 E-05} \\
2.05\end{array}$ & $\frac{1.23 \mathrm{E}-06}{7.07 \mathrm{E}-06}$ & $\frac{1.2}{1.4}$ & 1. & $\frac{1.87 \mathrm{E}-05}{3.18 \mathrm{E}-05}$ & $\begin{array}{l}-08 \\
-08\end{array}$ & $\frac{89}{89}$ & E- & & $\mathrm{EE-03}$ & $\begin{array}{l}\frac{2.944-\mathrm{E} / 7}{1.98 \mathrm{E}-03} \\
\end{array}$ & $\begin{array}{l}3.20 \mathrm{E}=05 \\
3.63 \mathrm{E}-05\end{array}$ & 05 & $\begin{array}{l}\mathrm{E}-00 \\
\mathrm{E}-03\end{array}$ & & \\
\hline & & $5.80 \mathrm{E}-01$ & 4.291 & & $3.86 \mathrm{E}-01$ & $4.09 \mathrm{E}-01$ & & & $9.60 \mathrm{E}-02$ & 6.2 & $4.29 \mathrm{E}-01$ & $4.29 \mathrm{E}-01$ & & $1.00 E+00$ & & $01.00 \mathrm{E}+00$ & $\begin{array}{ll}0 & 1.00 \mathrm{E}+00\end{array}$ & $\begin{array}{ll}0 & 1.00 \mathrm{E}+00\end{array}$ & & & & & $1.00 \mathrm{E}+00$ & & & & \\
\hline & & $5.45 \mathrm{E}-06$ & $\begin{array}{l}1.42 \mathrm{E}-06 \\
.30-2\end{array}$ & $\frac{9.35 \mathrm{E}-02}{.38-02}$ & $\frac{2.83 \mathrm{E}-03}{7.5-30}$ & $\begin{array}{l}1.00 \mathrm{E}-01 \\
1.07-0.0\end{array}$ & $\begin{array}{l}4.78 E-07 \\
.78-790\end{array}$ & $4.59 \mathrm{E}-05$ & $3.50 \mathrm{E}-05$ & & $5.07 \mathrm{E}-05$ & $\begin{array}{l}1.17 \mathrm{E}-05 \\
0.78-5 .\end{array}$ & $\begin{array}{l}3.03 \mathrm{E}-06 \\
.03-0.0\end{array}$ & $1.43 \mathrm{E}-01$ & $1.10 \mathrm{E}-03$ & $2.18 E-05$ & $5 \quad 4.82 \mathrm{E}-08$ & $\begin{array}{l}89.17 \mathrm{E}-07 \\
8.83-07\end{array}$ & $E-06$ & & & $9.90 \mathrm{E}-04$ & $\begin{array}{l}3.63 \mathrm{E}-05 \\
331-0 .\end{array}$ & $=06$ & $\begin{array}{l}2.04 \mathrm{E}-03 \\
\end{array}$ & & \\
\hline 7 & & $1.04 \mathrm{E}-05$ & $3.00 \mathrm{E}-06$ & $2.18 \mathrm{E}-01$ & $7.45 \mathrm{E}-03$ & $2.47 \mathrm{E}-01$ & $1.78 \mathrm{E}-05$ & $6.42 \mathrm{E}-04$ & $6.00 \mathrm{E}-04$ & $6.13 \mathrm{E}-04$ & $1.48 \mathrm{E}-04$ & $3.78 \mathrm{E}-05$ & $\begin{array}{l}9.04 \mathrm{E}-06 \\
\end{array}$ & $1.43 E-01$ & $1.12 \mathrm{E}-03$ & $32.41 \mathrm{E}-05$ & 5 4.44E-08 & $8 \quad 8.30 \mathrm{E}-07$ & 7 9.48E-06 & 03 & $9.29 \mathrm{E}-03$ & $1.74 \mathrm{E}-03$ & $5.41 \mathrm{E}-05$ & $1.42 E-05$ & $4.67 E-03$ & & \\
\hline & & $\begin{array}{l}5.80 \mathrm{E}-11 \\
6.00 \mathrm{E}-06\end{array}$ & $\begin{array}{l}4.29 \mathrm{E}-01 \\
1.29-06\end{array}$ & 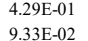 & $\begin{array}{l}3.86 \mathrm{E}-01 \\
2.87 \mathrm{E}-03\end{array}$ & $\begin{array}{l}4.08 \mathrm{E}-01 \\
1.010-01\end{array}$ & $\begin{array}{l}3.38 \mathrm{E}-02 \\
6.01-07\end{array}$ & $\begin{array}{l}6.25 \mathrm{E}-02 \\
4.01 \mathrm{E}-05\end{array}$ & $\begin{array}{l}9.57-\mathrm{E}-02 \\
5.74-05\end{array}$ & $\begin{array}{l}6.25 \mathrm{E}-22 \\
3.8 \mathrm{E}-05 \\
\end{array}$ & $\begin{array}{l}4.29 \mathrm{E}-01 \\
636-05\end{array}$ & $\begin{array}{l}4.29 \mathrm{E}-01 \\
\end{array}$ & $\begin{array}{l}4.29 \mathrm{E}-01 \\
3.37 \mathrm{E}-0.6\end{array}$ & $\begin{array}{l}1.00 \mathrm{E}+00 \\
1.43 \mathrm{E}-0.0\end{array}$ & 0 & +00 & 100 & +00 & & & & -01 & $\begin{array}{l}1.00 \mathrm{E}+00 \\
5.090\end{array}$ & E-01 & $5.00 E-01$ & & \\
\hline 8 & & $\frac{6.000-60}{1.04 E-05}$ & $\begin{array}{l}1.29=-106 \\
3.03 \mathrm{E}-06\end{array}$ & $\frac{9.35-0-22}{2.22 \mathrm{E}-01}$ & $\begin{array}{l}2.87 \mathrm{E}-03 \\
8.09 \mathrm{E}-03\end{array}$ & $\frac{1.010-01}{2.53 \mathrm{E}-01}$ & $\frac{6.010-07}{1.76 \mathrm{E}-05}$ & $\begin{array}{l}\frac{4.01 E-05}{7.24 E-04} \\
7\end{array}$ & $\begin{array}{l}5.744-55 \\
5.77 \mathrm{E}-04\end{array}$ & $\begin{array}{l}3.83 \mathrm{~B}-\mathrm{E}-5 \\
6.73 \mathrm{E}-04\end{array}$ & $\frac{6.366-05}{1.46 E-04}$ & $\begin{array}{l}\frac{1.162-\mathrm{E}-5}{3.66 \mathrm{E}-05} \\
\end{array}$ & $\begin{array}{l}\frac{3.87-06}{9.45 \mathrm{E}-06} \\
\end{array}$ & 1.4 & & & & & & & & & & .05 & & & \\
\hline & & $5.79 \mathrm{E}-01$ & $4.26 \mathrm{E}-01$ & $4.26 \mathrm{E}-01$ & $3.83 \mathrm{E}-01$ & $4.05 \mathrm{E}-01$ & $3.29 \mathrm{E}-02$ & $6.15 \mathrm{E}-02$ & $9.46 \mathrm{E}-02$ & $6.15 \mathrm{E}-02$ & $4.26 \mathrm{E}-01$ & $4.26 \mathrm{E}-01$ & $4.26 \mathrm{E}-01$ & $1.00 \mathrm{E}+00$ & 1.00 & $\begin{array}{lll}0 & 1.00 \mathrm{E}+00\end{array}$ & 01.0 & $+\infty$ & 001 & 00 & 01 & -01 & $1.00 \mathrm{E}+00$ & $\begin{array}{c}-01 \\
-01\end{array}$ & $4.98 \mathrm{E}-01$ & 14 & \\
\hline & & 5.991 & $\begin{array}{l}1.29 \mathrm{E}-06 \\
3.40 \mathrm{~F}-1\end{array}$ & $9.45 \mathrm{E}$ & $\begin{array}{l}3.10 \mathrm{E}-03 \\
7.0 \mathrm{E}\end{array}$ & $\begin{array}{l}1.03 \mathrm{E}-01 \\
2.65 \mathrm{~F}\end{array}$ & & & $\begin{array}{r}5.46 \mathrm{E}-05 \\
431-04\end{array}$ & 4.131 & & & & & & & & & & & & & & & & & \\
\hline 9 & & $\begin{array}{l}9.1 \\
5.7\end{array}$ & $\begin{array}{l}3.492-06 \\
4.22-01\end{array}$ & $\begin{array}{l}2.37 \\
4.22\end{array}$ & $\begin{array}{l}7.26 \mathrm{E}-03 \\
3.78 \mathrm{E}-01\end{array}$ & $\begin{array}{l}2.65 \mathrm{E}-01 \\
4.00 \mathrm{E}-01\end{array}$ & & & & & & & & & & & & & & & & & & & & & \\
\hline & & $\begin{array}{l}5.766 \mathrm{E}-11 \\
5.25 \mathrm{E}-06\end{array}$ & 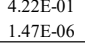 & $\begin{array}{l}4.222-\mathrm{E} 1 \\
9.99 \mathrm{E}-02\end{array}$ & $\begin{array}{l}\begin{array}{l}3.788 \mathrm{E}-1 \\
2.74 \mathrm{E}-03\end{array} \\
\end{array}$ & $\begin{array}{l}4.000 \mathrm{E}-01 \\
1.06 \mathrm{E}-01\end{array}$ & $\begin{array}{l}3.16 \mathrm{E}-22 \\
6.00 \mathrm{E}-07\end{array}$ & $\begin{array}{l}5.988-02 \\
4.10 \mathrm{E}-05 \\
\end{array}$ & $\begin{array}{l}9.28 \mathrm{E}-22 \\
4.00 \mathrm{E}-05\end{array}$ & $\begin{array}{l}5.988-02 \\
3.35 \mathrm{E}-05 \\
\end{array}$ & 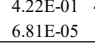 & $\begin{array}{l}\begin{array}{l}2.222 \mathrm{E}-1 \\
1.41 \mathrm{E}-05\end{array} \\
\end{array}$ & 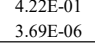 & $\begin{array}{l}1.00 \mathrm{E} E-00 \\
1.62 \mathrm{E}-01\end{array}$ & $\begin{array}{l}0.1 .00 \mathrm{E}+00 \\
1.13 \mathrm{E}-03\end{array}$ & 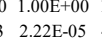 & 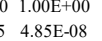 & $\begin{array}{ll}0 & 1.00 \mathrm{E}+00 \\
8 & 1.02 \mathrm{E}-06\end{array}$ & $\mathrm{E}-006$ & & $\begin{array}{l}01 \\
0.03\end{array}$ & $\begin{array}{l}-01 \\
04\end{array}$ & $\begin{array}{l}1.00 \mathrm{E} E-00 \\
4.35 \mathrm{E}-05\end{array}$ & $\begin{array}{l}5.525 \mathrm{E}-01 \\
9.27 \mathrm{E}-06\end{array}$ & $\begin{array}{l}4.95 \mathrm{E}-01 \\
2.15 \mathrm{E}-03\end{array}$ & $\begin{array}{l}-01 \\
-08\end{array}$ & \\
\hline 10 & & $9.08 \mathrm{E}-06$ & $3.41 \mathrm{E}-06$ & $2.17 \mathrm{E}-01$ & $7.13 \mathrm{E}-03$ & $2.44 \mathrm{E}-01$ & $1.01 \mathrm{E}-05$ & $8.64 \mathrm{E}-04$ & $2.21 \mathrm{E}-04$ & & $8.49 \mathrm{E}-05$ & $1.90 \mathrm{E}-05$ & $4.97 \mathrm{E}-06$ & $1.42 \mathrm{E}-01$ & \begin{tabular}{|l|l|}
$1.07 \mathrm{E}-03$ \\
\end{tabular} & $2.10 \mathrm{E}-05$ & -08 & $\begin{array}{ll}8 & 9.45 \mathrm{E}-07\end{array}$ & & & & & & & & & \\
\hline & & $5.81 \mathrm{E}-01$ & $4.30 \mathrm{E}-01$ & $4.30 \mathrm{E}-01$ & $3.87 \mathrm{E}-01$ & $4.09 \mathrm{E}-01$ & $3.42 \mathrm{E}-02$ & $6.30 \mathrm{E}-02$ & $9.63 \mathrm{E}-02$ & $6.30 \mathrm{E}-02$ & $4.30 \mathrm{E}-01$ & $4.30 \mathrm{E}-01$ & $4.30 \mathrm{E}-01$ & $1.00 \mathrm{E}+00$ & $1.00 \mathrm{E}+00$ & & $01.00 \mathrm{E}+00$ & & & & & & & & & & \\
\hline & & & & & & & & & & & & & & & & & & & & & & & & & & & \\
\hline 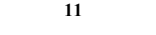 & & & 33E-06 & 2.15 & 7.27 & $2.42 !$ & & & 1.3 & 4 & & & 06 & & & & & & & & & & & & & & \\
\hline & & $5.81 \mathrm{E}$ & 4.31 & 4.311 & 3.88 & $4.10 \mathrm{E}-01$ & 3.44 & 0. & $9.66 \mathrm{E}-02$ & 6 & $4.31 \mathrm{E}-01$ & $4.31 \mathrm{E}-01$ & $4.31 \mathrm{E}-01$ & $1.00 \mathrm{E}+00$ & & & & & & & & & & & $5.02 \mathrm{E}-01$ & & \\
\hline & & & & & & & & & & & & & & & & & & & & & & & & & & & \\
\hline 12 & & & $3.69 \mathrm{E}-06$ & 2.191 & & $2.47 \mathrm{E}-01$ & & & 1.2 & & 15 & & & & & & & & & & & & & & $\begin{array}{l}8-03 \\
-03\end{array}$ & & \\
\hline & & $\begin{array}{l}5.80 \mathrm{E}-11 \\
4.89 \mathrm{E}-06\end{array}$ & 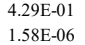 & 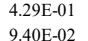 & $\begin{array}{l}3.86 \mathrm{E}-01 \\
2.80 \mathrm{E}-03\end{array}$ & $\begin{array}{l}4.088 \mathrm{E}-01 \\
1.010-0.1\end{array}$ & $\begin{array}{l}3.38 \mathrm{E}-02 \\
3.52 \mathrm{-}-07\end{array}$ & $\begin{array}{l}6.25 \mathrm{E}-02 \\
6.20 \mathrm{E}-\mathrm{s}\end{array}$ & $\begin{array}{l}9.58 \mathrm{E}-02 \\
1.23-505\end{array}$ & $\begin{array}{l}6.25 \mathrm{E}-02 \\
1.99-05\end{array}$ & 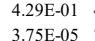 & $\begin{array}{r}4.29 \mathrm{E}-01 \\
7.71060\end{array}$ & $\begin{array}{l}4.29 \mathrm{E}-01 \\
2.21 \mathrm{~F}\end{array}$ & $\begin{array}{l}1.00 \mathrm{E}+00 \\
14 \mathrm{~F}=0 .\end{array}$ & & & $\begin{array}{ll}0 & 1.00 E+00 \\
5 & 5325\end{array}$ & $\begin{array}{lll}0 & 1.00 \mathrm{E}+00 \\
8 & 030\end{array}$ & & & & 5.0 & $1.00 \mathrm{E}+00$ & $5.56 \mathrm{E}-01$ & -01 & & \\
\hline 13 & & $\begin{array}{l}\frac{4.895-0.06}{8.700-06} \\
\end{array}$ & $\frac{1.58-0.06}{3.58 \mathrm{E}-06}$ & $\begin{array}{l}\frac{9.400 \mathrm{E}-22}{2.20 \mathrm{E}-01} \\
\end{array}$ & $\begin{array}{l}2.800-03 \\
7.19 \mathrm{E}-03\end{array}$ & $\begin{array}{l}\frac{1.010 \mathrm{E}-01}{2.48 \mathrm{E}-01} \\
\end{array}$ & $\begin{array}{l}3.52 \mathrm{E}-77 \\
8.74 \mathrm{E}-06\end{array}$ & $\frac{6.200-05}{1.01 E-03}$ & $\begin{array}{l}\frac{1.23-\mathrm{E}-5}{1.26 \mathrm{E}-04} \\
\end{array}$ & $\frac{1.999-05}{3.16 \mathrm{E}-04}$ & $\begin{array}{l}3.755-55 \\
7.35 E-05\end{array}$ & $\frac{7.711 \mathrm{E}-66}{1.56 \mathrm{E}-05}$ & $\begin{array}{l}2.212 \mathrm{E}-06 \\
4.27 \mathrm{E}-06\end{array}$ & $\mid \begin{array}{l}1.145 \mathrm{E}-01 \\
1.46 \mathrm{E}-01\end{array}$ & \begin{tabular}{|l|l|l|l|l|}
$1.09 \mathrm{E}-03$ \\
\end{tabular} & $\begin{array}{l}31.96 \mathrm{E}-05 \\
32.04 \mathrm{E}-05\end{array}$ & $\begin{array}{l}5 \quad 5.32 \mathrm{E}-08 \\
55.10 \mathrm{E}-08\end{array}$ & $\begin{array}{ll}8 & 1.03 \mathrm{E}-06 \\
8 & 9.99 \mathrm{E}-07\end{array}$ & & & $\begin{array}{l}8.000-\mathrm{E}-3 \\
1.46 \mathrm{E}-02\end{array}$ & $\begin{array}{l}\frac{1.35 \mathrm{E} \mathrm{E}-3}{2.75-03} \\
2.5\end{array}$ & $\frac{1.43 \mathrm{E} \mathrm{E}-05}{1.35-05}$ & $\left\{\begin{array}{l}1.50 \mathrm{EE}-05 \\
2.05 \mathrm{E}-05\end{array}\right.$ & $\left\{\begin{array}{l}1.21 \mathrm{E}-03 \\
2.241 \mathrm{E}-03\end{array}\right.$ & & \\
\hline & & $5.80 \mathrm{E}-01$ & $4.28 \mathrm{E}-01$ & $4.28 \mathrm{E}-01$ & $3.85 \mathrm{E}-01$ & $4.07 \mathrm{E}-01$ & $3.37 \mathrm{E}-02$ & $6.24 \mathrm{E}-02$ & $9.56 \mathrm{E}-02$ & $6.24 \mathrm{E}-02$ & $4.28 \mathrm{E}-01$ & $4.28 \mathrm{E}-01$ & $4.28 \mathrm{E}-01$ & $1.00 \mathrm{E}+00$ & $1.00 E+00$ & $0 \quad 1.00 \mathrm{E}+00$ & 01.0 & & & & -01 & $5.00 \mathrm{E}-01$ & $1.00 \mathrm{E}+00$ & $5.56 \mathrm{E}-01$ & $5.00 \mathrm{E}-01$ & 15.0 & \\
\hline & acti & 6 & $\begin{array}{l}1.53 \mathrm{E}-06 \\
356 \mathrm{~F}\end{array}$ & $\frac{9.431}{2027}$ & $\begin{array}{l}2.77 \mathrm{E}-03 \\
7.16 \mathrm{E}\end{array}$ & $\frac{1.01 \mathrm{E}-01}{2.50 \mathrm{C}}$ & $\begin{array}{l}2.94 \mathrm{E}-07 \\
8.07 \mathrm{E}-1\end{array}$ & & $1.20 \mathrm{E}-05$ & & & $6.66 \mathrm{E}-06$ & $\begin{array}{l}1.83 \mathrm{E}-06 \\
30 \mathrm{O}\end{array}$ & $\begin{array}{l}1.46 \mathrm{E}-01 \\
1.4 \mathrm{C}-0.0\end{array}$ & & & & & & & & & & & & & \\
\hline 14 & & & $\begin{array}{l}3.566 \mathrm{E}-06 \\
428-01\end{array}$ & $\begin{array}{l}2.22 E-\mathrm{I} \\
422 \mathrm{E}-\mathrm{-}\end{array}$ & $\begin{array}{l}7.161 \\
3.851\end{array}$ & $\begin{array}{l}2.50 \mathrm{E}-01 \\
4.07-0.1\end{array}$ & $\begin{array}{l}8.071 . \\
3.35\end{array}$ & $\begin{array}{l}1.001 \\
6.211\end{array}$ & $\begin{array}{l}1.21 \mathrm{E}-04 \\
9.53 \mathrm{E}-22\end{array}$ & $\begin{array}{l}3.05 \mathrm{E}-04 \\
6.21 \mathrm{E}-02\end{array}$ & 15 & $\begin{array}{l}1.448-05 \\
4.28-501\end{array}$ & $\begin{array}{l}3.90 \mathrm{E}-06 \\
428 \mathrm{E}-0 .\end{array}$ & $\begin{array}{l}1.47 \mathrm{E}-01 \\
1.00 \mathrm{E}+00\end{array}$ & & & & & & & & & & & 01 & & \\
\hline & & & 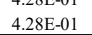 & 4.2.05- & S. & & & & & & & & & & & & & & & & & & & & & & \\
\hline 15 & & & 3.48 & 2.20 & 7.73 & 2.49 & & & & & & & & & & & & & & & & & & & & & \\
\hline & & 5.8 & 4.28 & 4.28 & 3.85 & $4.07 \mathrm{E}-01$ & 3.36 & 6.22 & 9.54 & 6.22 & & & 4.28 & & & & & & & & & & & & & & \\
\hline 16 & & $\begin{array}{l}\frac{5.19 \mathrm{E}-06}{8.71 \mathrm{E}-06} \\
\end{array}$ & $\begin{array}{l}\frac{1.499 \mathrm{E}-06}{3.58-06} \\
3\end{array}$ & $\frac{9.422 \mathrm{E}-02}{2.22-01}$ & $\begin{array}{l}2.98 \mathrm{E}-03 \\
7.54 \mathrm{E}-03\end{array}$ & $\frac{1.01 \mathrm{E}-01}{2.50 \mathrm{E}-01}$ & $\begin{array}{l}\frac{2.56-\mathrm{E}-07}{7.68 \mathrm{E}-06} \\
7\end{array}$ & $\frac{6.322-\mathrm{E}-5}{1.03 \mathrm{E}-03}$ & $\begin{array}{l}\frac{1.23 \mathrm{E}-0.5}{1.04 \mathrm{E}-04} \\
1\end{array}$ & $\begin{array}{l}2.044-5-5 \\
2.48 E-04\end{array}$ & $\begin{array}{l}2.744-5-5 \\
60.48 E-05 \\
\end{array}$ & $\frac{5.97 \mathrm{E}-06}{1.36 \mathrm{E}-05}$ & $\begin{array}{l}1.77 \mathrm{E}-06 \\
3.90 \mathrm{E}-06\end{array}$ & $\frac{1.4}{1.4}$ & & & & & & & & & & & & & \\
\hline & & . & $4.28 \mathrm{E}$ & & 3.84 & $4.07 \mathrm{E}-01$ & 3.34 & 6.2 & 9.52 & $6.21 \mathrm{E}-02$ & 4.28 & $4.28 \mathrm{E}-01$ & $4.28 \mathrm{E}-01$ & & & & & & & & & & & & & & \\
\hline & & $505 \mathrm{E}$ & 1.531 & 9.50! & & $1.02 \mathrm{E}-01$ & & & $9.89 \mathrm{E}-06$ & & & & & & & & & & & & & & & & & & \\
\hline 17 & & & 3. & 2.19 & 7.5 & & & & & & & & & & & & & & & & & & & & & & \\
\hline & & & 4.2 & $\begin{array}{l}4.29 \\
030\end{array}$ & 3.86 & 4.08 & & & 9.5 & & & & 4. & & & & & & & & & & & & & & \\
\hline 18 & & $8.90 \mathrm{E}-06$ & $3.50 \mathrm{E}-06$ & $\frac{9.39 \mathrm{~F}}{2.20 \mathrm{E}}$ & $\begin{array}{l}2.93 \\
7.53 \\
\end{array}$ & 2.48 & $6.09 \mathrm{E}-06$ & 1.1 & $5.34 \mathrm{E}$ & 3.99 & & 1.11 & 3.12 & & & & & & & & & & & & & & \\
\hline & & 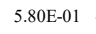 & $4.28 \mathrm{E}$ & & & & & & & & & & & & & & & & & & & & & & & & \\
\hline & & & & & & & & & & & & & & & & & & & & & & & & & & & \\
\hline 19 & & & & & & $\begin{array}{l}2.47 \\
408\end{array}$ & & & & & & & & & & & & & & & & & & & & & \\
\hline & & $\begin{array}{c}5.80 \mathrm{E}-0.11 \\
503-06\end{array}$ & $\begin{array}{l}4.29 \mathrm{E}-01 \\
154-06\end{array}$ & 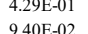 & $\begin{array}{l}3.86 \\
2.96\end{array}$ & 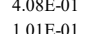 & $\begin{array}{l}3.38 \\
2.36\end{array}$ & 6.2. & 9.58 & 6.2 & 4.2 & 4.29 & 4.26 & 1.06 & & & & & & & & & & & & & \\
\hline 20 & & & $\begin{array}{l}3.54 \\
3.33\end{array}$ & $\frac{9.40}{2.21}$ & & & & & & & & & & & & & & & & & & & & & & & \\
\hline & & & 4.281 & 4.281 & 3.85 & 4.07 & & 6.22 & & & & & 4.28 & & & & & & & & & & & & & & \\
\hline & & & 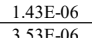 & & $\frac{2.9}{7.5}$ & $\frac{1.0}{25}$ & $\frac{1.2 .}{54}$ & & . & 2.9 & & & & & & & & & & & & & & & & & \\
\hline 21 & & & & & & & & & & & & & & & & & & & & & & & & & & & \\
\hline & & 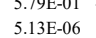 & $\begin{array}{c}.2711 \\
.1511\end{array}$ & $\begin{array}{l}4.271 \\
9.521\end{array}$ & $\begin{array}{l}3.84 \mathrm{E}-01 \\
2.90 \mathrm{E}-03\end{array}$ & $\begin{array}{l}\begin{array}{l}0.066-1 \\
1.02-01\end{array} \\
1\end{array}$ & $\begin{array}{l}3.331 \\
1.811\end{array}$ & $\begin{array}{l}6.202-02 \\
7.622-05\end{array}$ & $\begin{array}{l}9.51 \mathrm{~F} \\
2.89 \mathrm{E}\end{array}$ & & $\begin{array}{l}1 \\
5.4 \\
5\end{array}$ & $\begin{array}{l}4.27 \\
4.16\end{array}$ & $\begin{array}{l}4.27 \mathrm{EE}-01 \\
1.18 \mathrm{E}-06\end{array}$ & $\begin{array}{l}1.00 \\
1.4\end{array}$ & & & & & & & & & & & & & \\
\hline 22 & & & & & & & & & & & & & & & & & & & & & & & & & & & \\
\hline & & $5.79 \mathrm{E}-01$ & $4.27 \mathrm{I}$ & 4.27 & 3.84 & 4.06 & & & & & & & & & & & & & & & & & & & & & \\
\hline & & 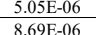 & & $\frac{9.51}{2.21}$ & & $\frac{1.0}{2.4}$ & & & & & & & & & & & & & & & & & & & & & \\
\hline & & & & $\begin{array}{l}2.21 \\
4.28\end{array}$ & & & & & & & 4. & & & & & & & & & & & & & & & & \\
\hline & & & & & & & & & & & & & & & & & & & & & & & & & & & \\
\hline 24 & & & & & & & & & & & & & & & & & & & & & & & & & & & \\
\hline & & & & & & & & & & & & & & & & & & & & & & & & & & & \\
\hline 20 & & $8.89 \mathrm{E}-06$ & $3.51 \mathrm{E}-06$ & $\frac{9.54 \mathrm{E}-22}{2.23 \mathrm{E}-01}$ & $\frac{2.82}{7.48}$ & 2.51 & .51 & & & & & & & & & & & & & & & & & & & & \\
\hline & & & 4277 & & & 4.06 & 3.33 & & & & & & & & & & & & & & & & & & & & \\
\hline & activ & & & & & & & & & & & & & & & & & & & & & & & & & & \\
\hline 26 & & & & & & & & & & & & & & & & & & & & & & & & & & & \\
\hline & & & 6 & $\begin{array}{l}4.26 \\
9.65\end{array}$ & 3.83 & 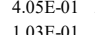 & 3.3 & & $\begin{array}{l}9.47 \\
2.72\end{array}$ & & & & 4.26 & & & & & & & & & & & & & & \\
\hline 27 & & & & & & & & & & & & & & & & & & & & & & & & & & & \\
\hline & & & & & & & & & & & & & & & & & & & & & & & & & & & \\
\hline & & & & & & & & & & & & & & & & & & & & & $1.02 E-02$ & 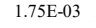 & . & & & & \\
\hline
\end{tabular}




\section{Activity-activity diagrams}

Figure E.6.33. Activity-activity diagrams for the basalt-seawater experiment showing mineral stability fields for the BSW1 experiment $\left(400^{\circ} \mathrm{C} / 488\right.$ bar $)$ and the $\mathrm{BSW} 2$ experiment $\left(350^{\circ} \mathrm{C} / 488\right.$ bar) showing minera stability fields in the $\mathrm{SiO}_{2}-\mathrm{Al}_{2} \mathrm{O}_{3}-\mathrm{CaO}-\mathrm{H}_{2} \mathrm{O}$ and in the $\mathrm{CaO}-\mathrm{Na}_{2} \mathrm{O}-\mathrm{Al}_{2} \mathrm{O}_{3}-\mathrm{H}_{2} \mathrm{O}$. Yellow circles show position of the output fluid composition from $\mathrm{SW} 1$ and $\mathrm{SW} 2$ at 377 and $342^{\circ} \mathrm{C} / 488$ bar, respectively. $\mathrm{Blue}$ arrows indicate fluid-path chemistry, in relation to different flow rate. In $\mathrm{BSW}$, black crosses show position of effluent samples collected at $1.0 \mathrm{ml}$ hr flow rate. Green crosses show position of effluent samples collected at $1.5 \mathrm{ml}$ (not visible on graphs). Orange crosses show position of efluent samples collected at $10 \mathrm{ml}$ hr ${ }^{2}$. Violet crosses show position of effluent samples collected at $7.5 \mathrm{milh}{ }^{-}$, while blue crosses show position of effluent samples collected at $5 \mathrm{ml}^{-}$. $\mathrm{h}$ BSW2, black crosses show position of effluent samples collected at $1.0 \mathrm{ml}^{-1} \mathrm{hr}^{-1}$ flow rate. Orange crosses show position of effluent samples collected at $10 \mathrm{ml}$ hr ${ }^{-1}$
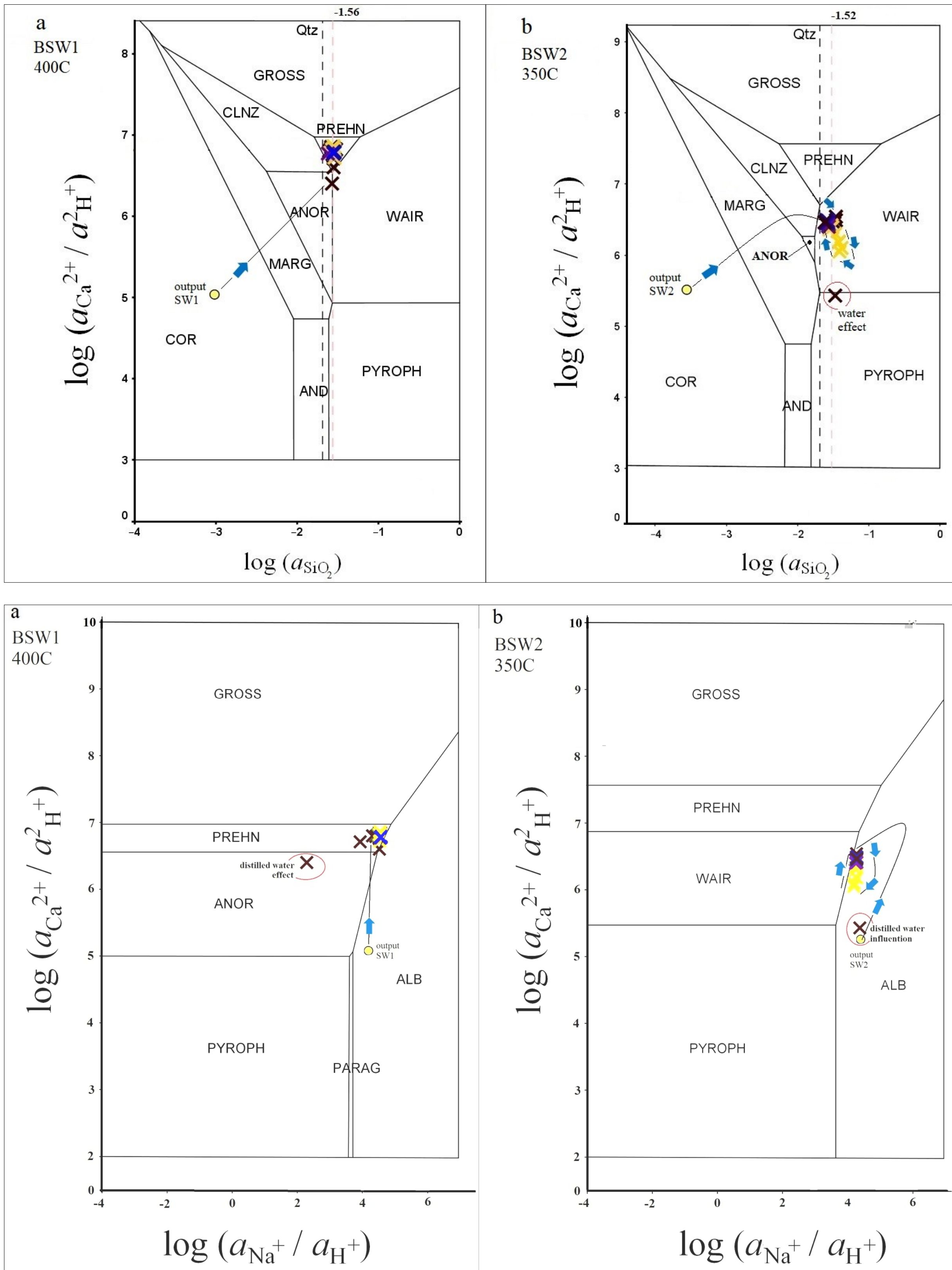
Figure E.6.34. Activity-activity diagrams showing mineral stability fields for the $\mathrm{BSW} 1\left(400^{\circ} \mathrm{C} / 488 \mathrm{bar}\right)$ and $\mathrm{BSW} 2\left(350^{\circ} \mathrm{C} / 488\right.$ bar $)$ in the $\mathrm{MgO}-\mathrm{FeO}_{-}-\mathrm{Al}_{2} \mathrm{O}_{3}-\mathrm{H}_{2} \mathrm{O}$ and in the $\mathrm{CaO}-\mathrm{FeO}-\mathrm{Al}_{2} \mathrm{O}_{3}-\mathrm{H}_{2} \mathrm{O}$ system. Yellow circles show position of the output fluid composition from SW1 and SW2 at 377 and $342^{\circ} \mathrm{C} / 488$ bar, respectively. Arrows indicate fluid-path chemistry, in relation to different flow rate. For the BSW1 experiment, black crosses show position of effluent samples collected at $1.0 \mathrm{ml} \mathrm{hr}^{-1}$ flow rate. Green crosses show position of effluent samples collected at $1.5 \mathrm{ml}$ hr-1. Orange crosses show position of effluent samples collected at $10 \mathrm{ml} \mathrm{hr}^{-1}$. Violet crosses show position of effluent samples collected at $7.5 \mathrm{ml} \mathrm{hr}^{-1}$ while blue crosses show position of effluent samples collected at $5 \mathrm{ml} \mathrm{hr}^{-1}$. For the BSW2 experiment black crosses show position of effluent samples collected at $1.0 \mathrm{ml} \mathrm{hr}^{-1}$ flow rate. Orange crosses show position of effluent samples collected at $10 \mathrm{ml} \mathrm{hr}^{-1}$. Violet crosses show position of effluent samples collected at $5 \mathrm{ml} \mathrm{hr}^{-1}$ while blue crosses show position of effluent samples collected at $2.5 \mathrm{ml} \mathrm{hr}^{-1}$

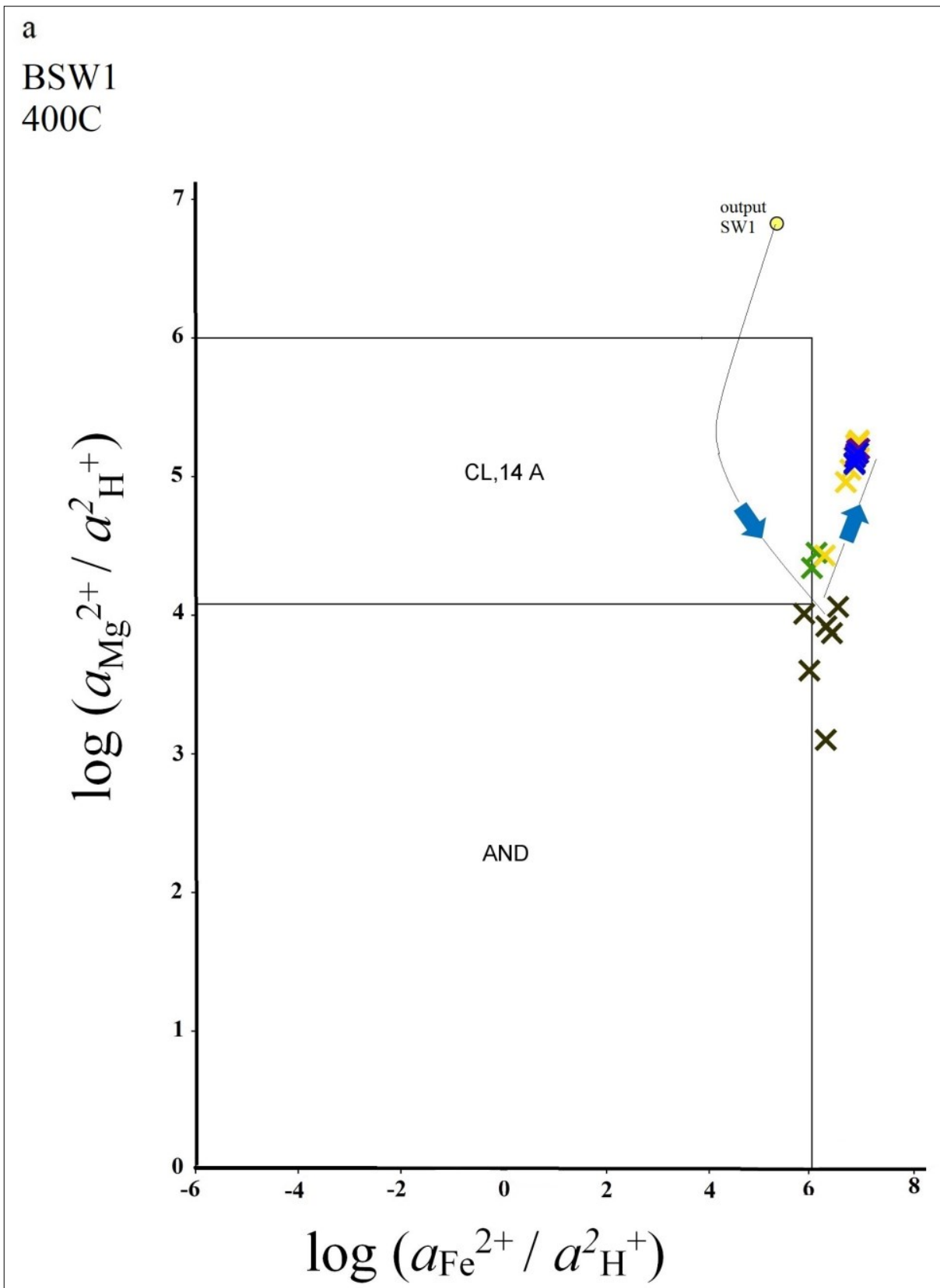

b

BSW2

350C

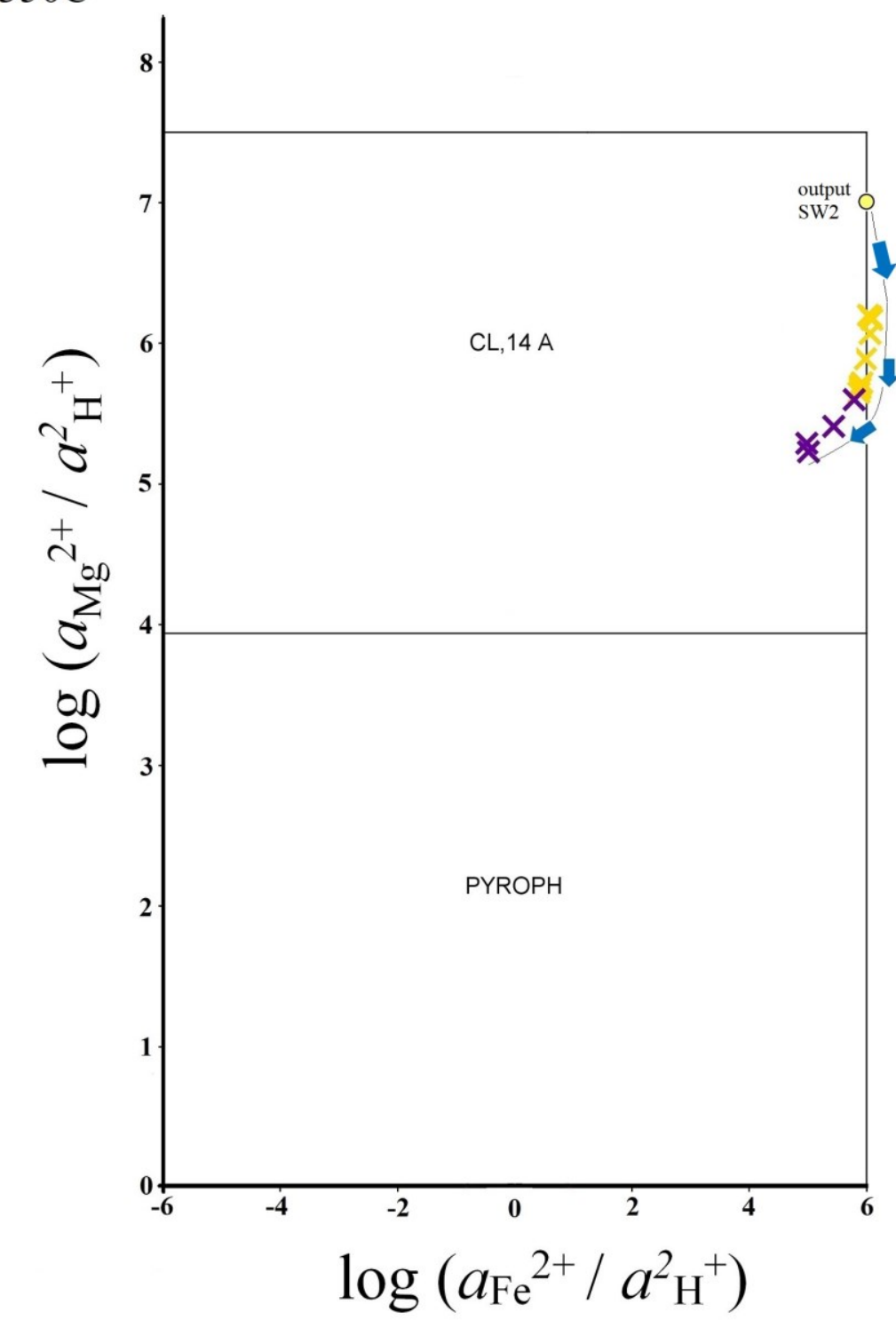

c

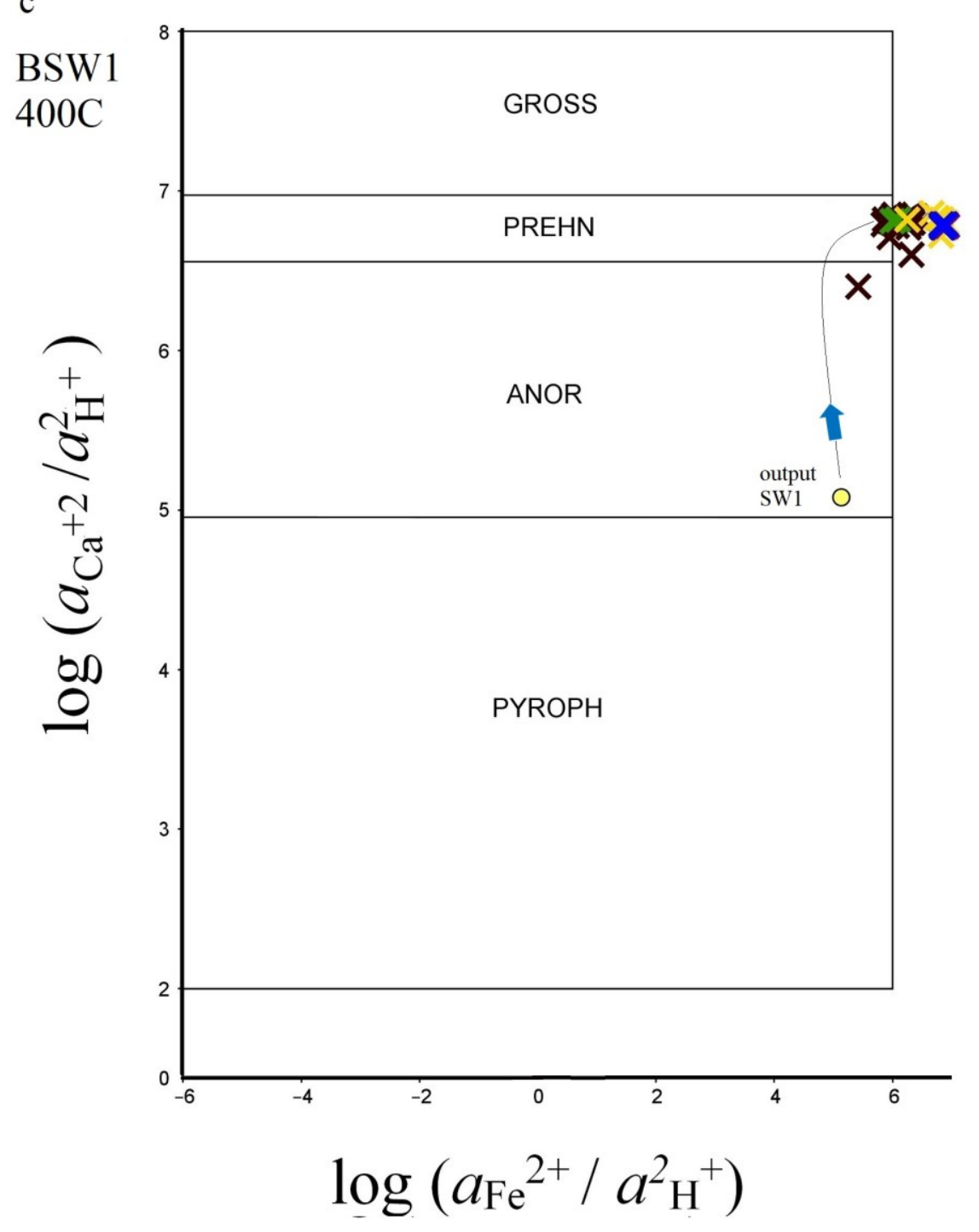

d

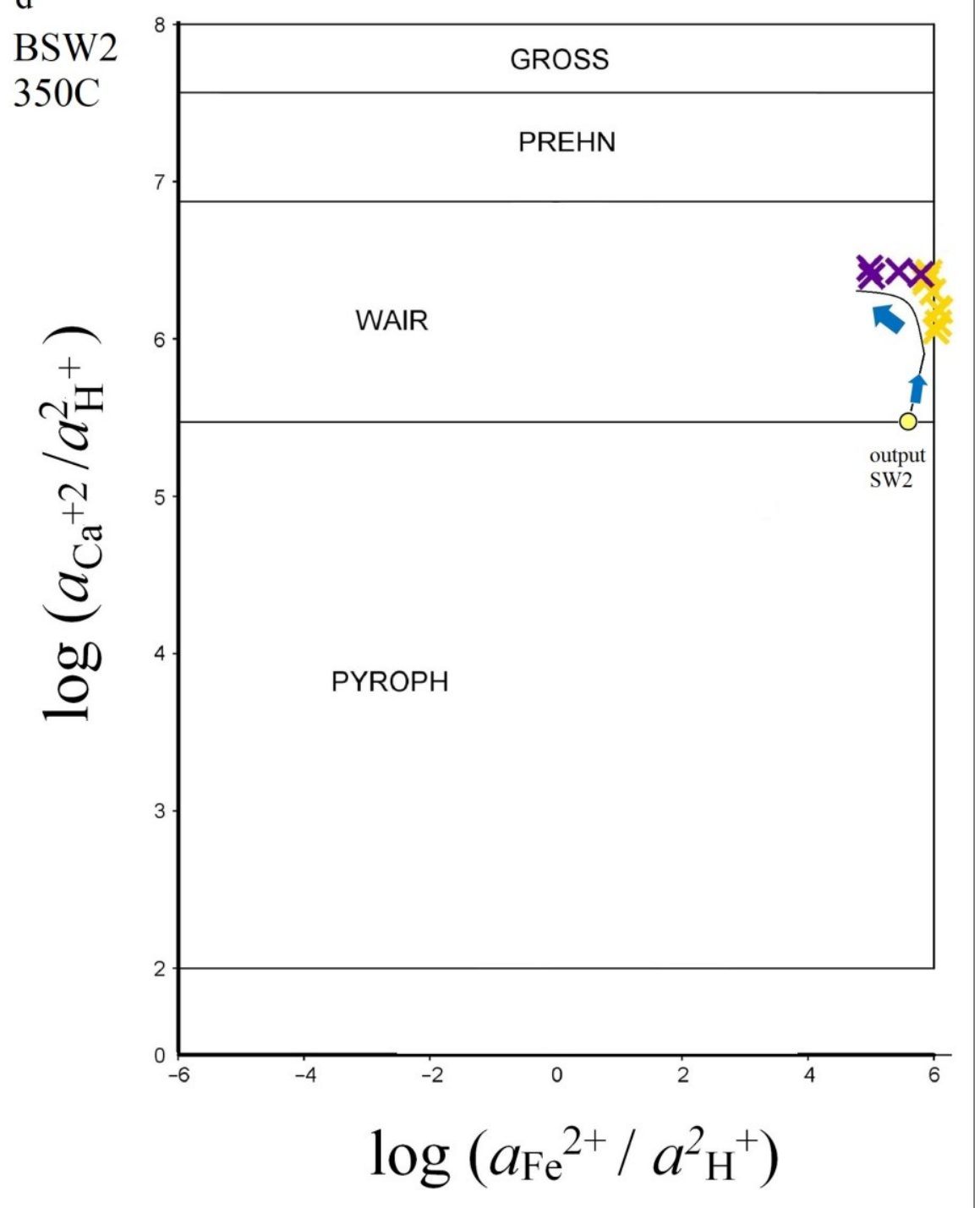


Figure E.6.35. Activity-activity diagrams showing mineral stability fields for the $\mathrm{BSW} 1\left(400^{\circ} \mathrm{C} / 488 \mathrm{bar}\right)$ and $\mathrm{BSW} 2\left(350^{\circ} \mathrm{C} / 488\right.$ bar $)$ in the $\mathrm{K}_{2} \mathrm{O}-\mathrm{SiO}_{2} \mathrm{Al}_{2} \mathrm{O}_{3}-\mathrm{H}_{2} \mathrm{O}$ system. $\mathrm{Yellow}$ circles show position of the output fluid composition from SW1 and SW2 at 377 and $342^{\circ} \mathrm{C} / 488$ bar, repectively. Arrows indicate fluid-path chemistry, in relation to different flow rate. For the BSW1 experiment, black crosses show position of effluent samples collected at $1.0 \mathrm{ml} \mathrm{hr}^{-1}$ flow rate. Green crosses show position of effluent samples collected at $1.5 \mathrm{ml} \mathrm{hr}^{-1}$. Orange crosses show position of effluent samples collected at $10 \mathrm{ml} \mathrm{hr}^{-1}$. Violet crosses show position of effluent samples collected at $7.5 \mathrm{ml} \mathrm{hr}^{-1}$ while blue crosses show position of effluent samples collected at $5 \mathrm{ml} \mathrm{hr}^{-1}$. For the BSW2 experiment, black crosses show position of effluent samples collected at 1.0

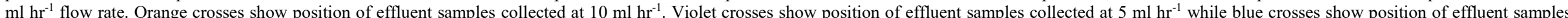
collected at $2.5 \mathrm{ml} \mathrm{hr}^{-1}$
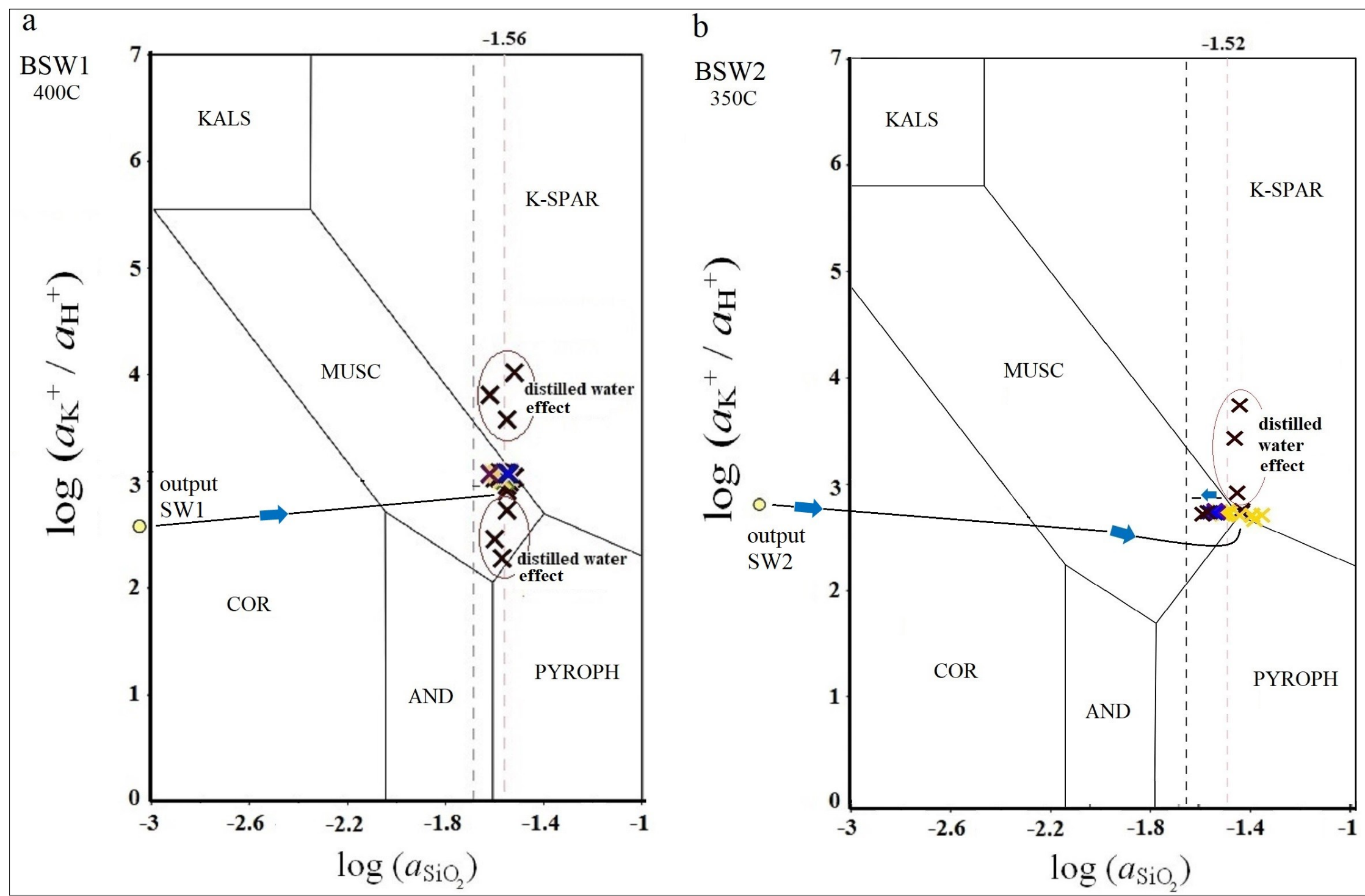
Figure E.6.36. Activity-activity diagrams showing mineral stability fields for the $\mathrm{BSW} 1\left(400^{\circ} \mathrm{C} / 488 \mathrm{bar}\right)$ and $\mathrm{BSW} 2\left(350^{\circ} \mathrm{C} / 488\right.$ bar $)$ in the $\mathrm{MgO}-\mathrm{Ca}_{2} \mathrm{O}-\mathrm{SiO}_{2}-\mathrm{Al}_{2} \mathrm{O}_{3}-\mathrm{H}_{2} \mathrm{O}$ system. $\mathrm{Yellow}$ circles show position of the output fluid position of effluent samples collected at $1.0 \mathrm{ml} \mathrm{hr}^{-1}$ flow rate Green crosses show position of effluent samples collected at $1.5 \mathrm{ml} \mathrm{hr}^{-1}$. Orange crosses show position of effluent samples collected at $10 \mathrm{ml}^{\mathrm{hr}} \mathrm{hr}^{-1}$ Viole crosses show position of effluent samples collected at $7.5 \mathrm{ml} \mathrm{hr}^{-1}$ while blue crosses show position of effluent samples collected at $5 \mathrm{ml} \mathrm{hr}^{-1}$. For the BSW2 experiment, black crosses show position of effluent samples collected at $1.0 \mathrm{ml} \mathrm{hr}^{-1}$ flow rate. Orange crosses show position of effluent samples collected at $10 \mathrm{ml} \mathrm{hr}^{-1}$. Violet crosses show position of effluent samples collected at $5 \mathrm{ml} \mathrm{hr}^{-1}$ while blue crosses show position of effluent samples collected at $2.5 \mathrm{ml} \mathrm{hr}^{-1}$
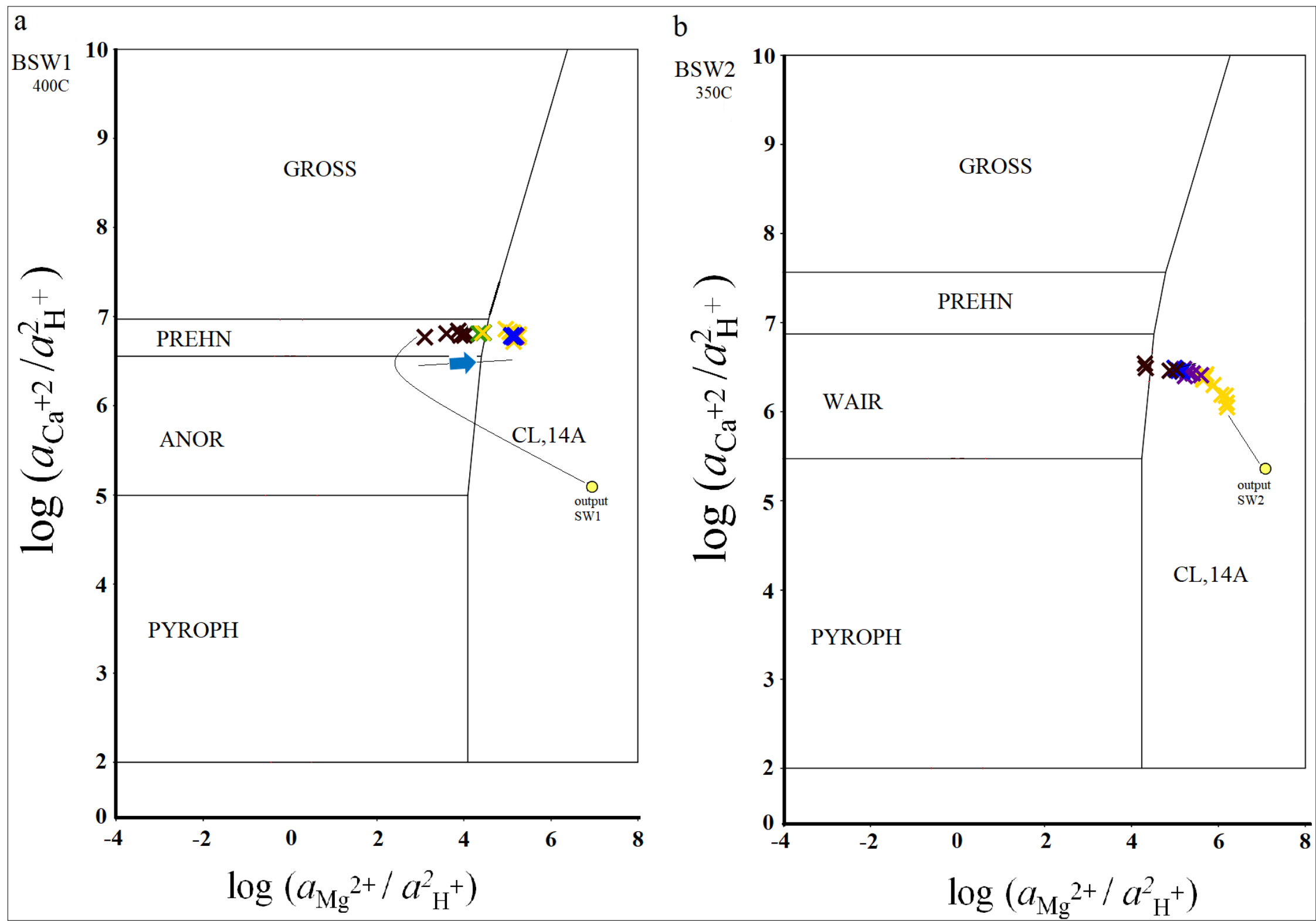
$\mathrm{Na} /$ K geothermometers

Table E.6.31. Values of the estimate temperatures for the BSW1 calculated with the geothermometers equations by Fournier (1979), Truesdell (1976), Fournier and Truesdell (1973), Santoyo and Díaz-González (2009), Arnorsson (1983), Tonani (1980), Nieva and Nieva (1987) and Giggenbach (1988)

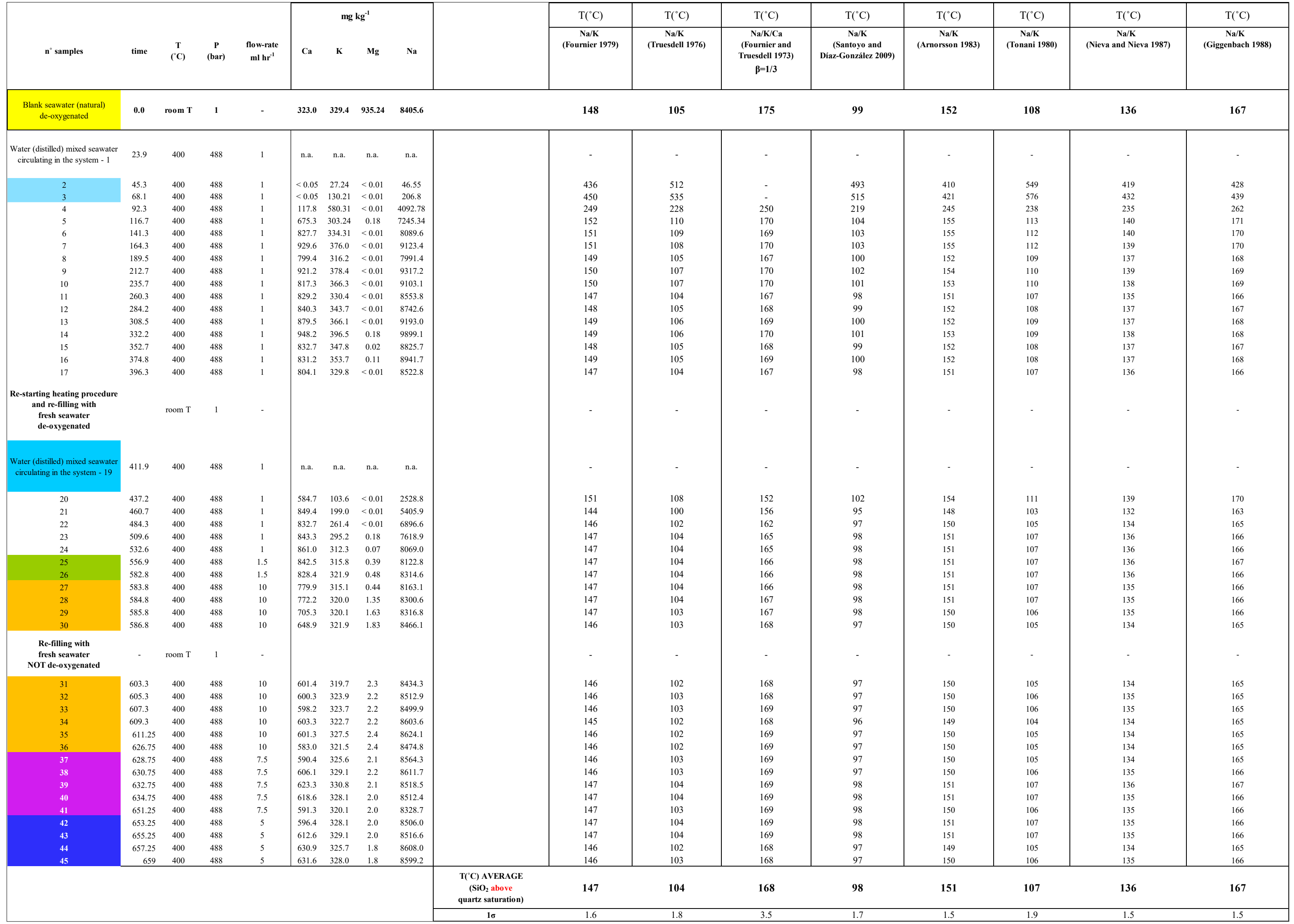



Appendices Doctoral Thesis: “Basalt - fluid interactions at subcritical and supercritical conditions: An experimental study"
University of Victoria Wellington and GNS Science, Wairake, New Zealand
by Mauro Passarella

Table E.6.32. Values of the estimate temperatures for the BSW2 calculated with the geothermometers equations by Fournier (1979), Truesdell (1976), Fournier and Truesdell (1973), Santoyo and Díaz-González (2009), Arnorsson (1983), Tonani (1980), Nieva and Nieva (1987) and Giggenbach (1988)

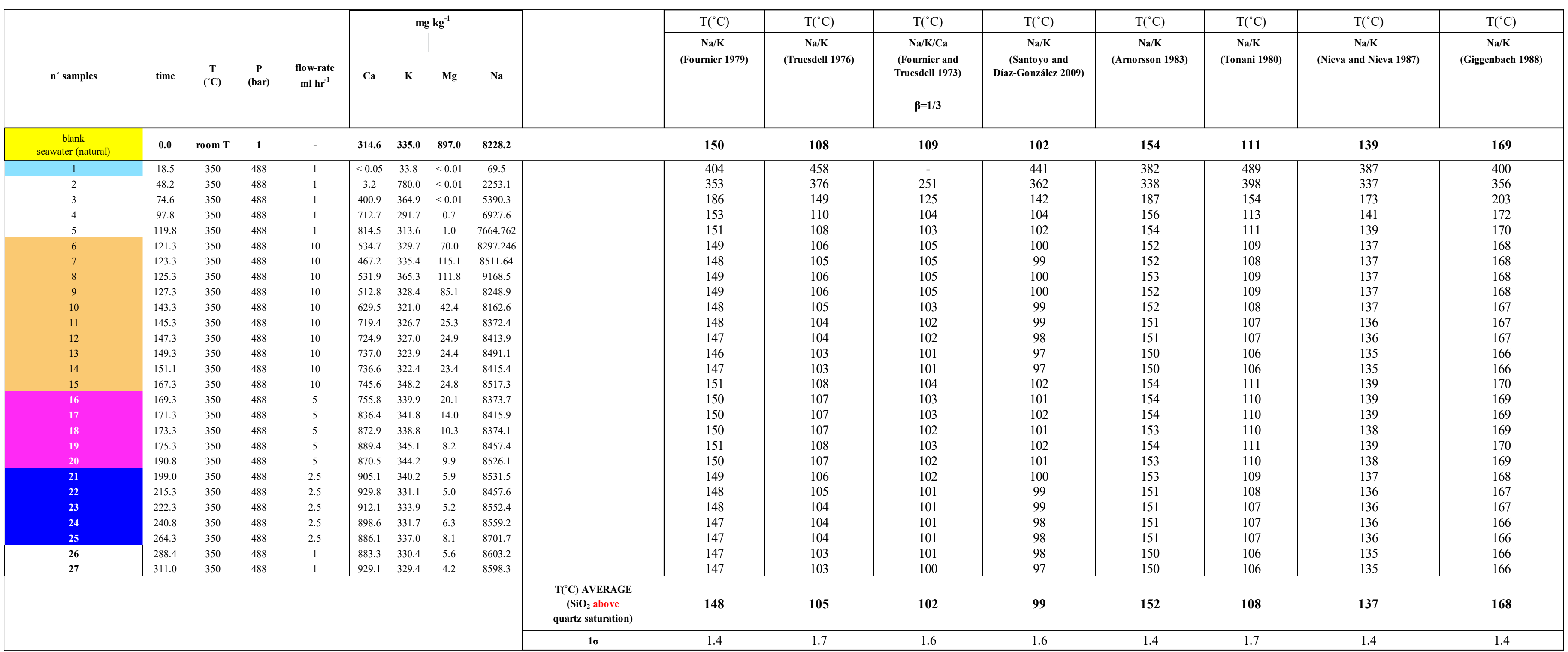


Table E.6.33. Geothermometers equations utilized for the calculation of the estimate temperature values reported in Table E.6.31-32

\begin{tabular}{|c|c|}
\hline $\mathrm{Na} / \mathrm{K}$ : Fournier (1979) & $T\left({ }^{\circ} \mathrm{C}\right)=\frac{1217}{1.438+\log \left(\frac{N a}{K}\right)}-273,15\left({ }^{\circ} K\right)$ \\
\hline $\mathrm{Na} / \mathrm{K}$ : Truesdell (1976) & $T\left({ }^{\circ} \mathrm{C}\right)=\frac{855,6}{0.8573+\log \left(\frac{N a}{K}\right)}-273,15\left({ }^{\circ} \mathrm{K}\right)$ \\
\hline $\begin{array}{l}\mathrm{Na} / \mathrm{K} \text { : Santoyo and } \\
\quad \text { Gonzalez (2009) }\end{array}$ & $T\left({ }^{\circ} \mathrm{C}\right)=\frac{876.3( \pm 26.26)}{0.8775( \pm 0.0508)+\log \left(\frac{N a}{K}\right)}-273,15\left(^{\circ} \mathrm{K}\right)$ \\
\hline $\mathrm{Na} / \mathrm{K}$ : Arnorsson (1983) & $T\left({ }^{\circ} \mathrm{C}\right)=\frac{1319}{1.699+\log \left(\frac{N a}{K}\right)}-273,15\left({ }^{\circ} \mathrm{K}\right)$ \\
\hline $\mathrm{Na} / \mathrm{K}$ : Tonani (1980) & $T\left({ }^{\circ} \mathrm{C}\right)=\frac{883}{0.78+\log \left(\frac{N a}{K}\right)}-273,15\left(^{\circ} K\right)$ \\
\hline $\begin{array}{l}\mathrm{Na} / \mathrm{K}: \text { Nieva } \\
\quad \text { and Nieva (1987) }\end{array}$ & $T\left({ }^{\circ} \mathrm{C}\right)=\frac{1178}{1.483+\log \left(\frac{N a}{K}\right)}-273,15\left({ }^{\circ} \mathrm{K}\right)$ \\
\hline $\mathrm{Na} / \mathrm{K}$ : Giggenbach (1988) & $T\left({ }^{\circ} \mathrm{C}\right)=\frac{1390}{1.75+\log \left(\frac{N a}{K}\right)}-273,15\left(^{\circ} \mathrm{K}\right)$ \\
\hline $\begin{array}{l}\mathrm{Na} / \mathrm{K} / \mathrm{Ca}: \text { Fournier } \\
\quad \text { and Truesdall (1973) }\end{array}$ & $T\left({ }^{\circ} \mathrm{C}\right)=\frac{1647}{\log \left(\frac{N a}{K}\right)+\beta[\log (\sqrt{C a} / N a)+2.06]+2.47}-273,15\left({ }^{\circ} \mathrm{K}\right)$ \\
\hline
\end{tabular}

